


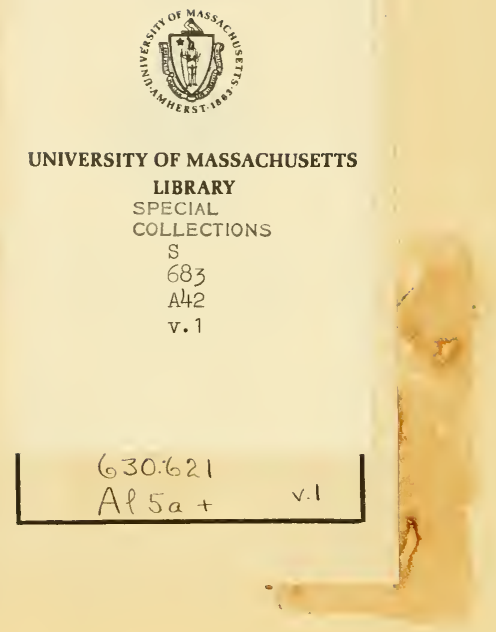




$$
\text { - }
$$ \\ .}





DIGEST

( ) $\mathrm{F}^{3}$

AGRICULTURAL IMPLEMENTS

PATENTED IX THE (XITED STATES

FROM

A. D. 1789 TO JULY 1881.

[ LT.MITET TO 100 COPIES.]

OOMPILED AND ARRANGED EY

J A M E S T. A L L E N,

UNITED STATES PATENT OFFICE,

WASHIN(iTON. I). (
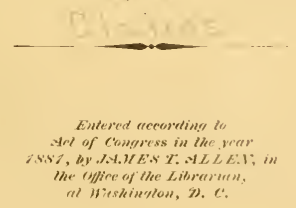


$$
\begin{aligned}
& 0.3010=1 \\
& 7-5 x+2 \times 1
\end{aligned}
$$




$$
\text { ETTIVAIORS. }
$$

Clark, (. MI.

(iuctail, 1).

Mlater, 1),

Melton, R. M.

Morris, K, F., $\mathbb{N}$ lireen, R. I.

Shares, 1), 11 .,

Slemmons, II. $(i$,

sinith, . I. C.

Wright, 1.. ‥, CT1.TITA TUR:DISK.

Baylist, F...

linamer, $\mathrm{F}$.

Hramer, F., \& Barlger, (). W.

Corbin, J. S.

Crane, $\vec{F}$.

Crane, E.

Cravath, II. I. I I. M.

Johnson, M.

ohnsut, X.,

1.a 1 ) ow, $C_{\text {. }}$,

Norton, R. 1).

Randall, S. Ci,

kandall, S.. (i,

[ nderwood, ]. K., CIITIVATORS-TARAI.1.F..

Eichholtz, II.,

()wen, Ci,

l'attee. J. 11.

l'ratt, E.,

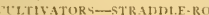

Norton, $($. P

Sims, Z. B.

Harris, ]. CTITIVATOR-TEFIIT.

H.ynch, E.. P., \& Wright, E. A.,

Matteson, 1). (., \& Williamson, 1. I'.,

Koger, i). 13.

kowell, 1. S. \& I.,

tiayre, C. H. \& Klinch, $($;.

Workman, IV., Hicheock, J.

CULINATORS-WIIEET. OR SULKY'.

Allisoll, A. H.

Armutrong, J. Jr.,

liertrand, Г. F., \& simes, $\mathrm{P}$., $\quad 672$

13loorl, A. R., II athaway, A. \& Beach, V. K,

Boyd, 1. C.,

lirinton, I. H.,

('anfield, . .

Dryten, II. A., d: C. E.,

Dumdas, 1 .,

Filtwood, R.. s l'itcher, K. L..

l'orles, 1.,

Hall, (...., \& H) E.,

Ileaton, 11. 1.

Kinyon, .1.,

Kissell, E. II., \& .I. I..

Mellill, T. II:

Ie()uiston, T.

Noble, I). I.,

Packard, L.

Rajer, IV. I.,

Rhamy, I. H.,

Koblins, K. 13.,

Sehrreder, J.,

smith, 1. R.,

Sinuth, II. B.,

Stafford, 1). S.

Tinkham, 3.,

( nthank, I).

IVtir, II, S., Ir.,

Weir, W. s.. Jr.

IV godward, I. A. \& S., S., d

Il.son, $\mathrm{T}$.,

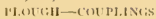

Underwosi, r. I.,

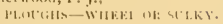

Baster, R.

Benmon, I', S.,

Brinckerhoft, C. R.,

Burton, X. F.

fisaclay, II. 1..

Cirusiley, II. Ci.,

Davenport, F. S.,

I) avison, 6 ; . 1.

Fruhling, IS..

II all, I, I.

Hall, T. j.,

IIilelreth, (i. W.

Ilill, F.A.,

James, IV. I.,

Iatteson, J). C.

Keady, II. IB,

slusier, 13.,

Volkman, 13.,

712

933

1008

1054

964

976

1119

1013

998

1022

1134

964

10.35

967

111

1194

1025

960

976

1023

I 000

HODELS SATED HWOLLI FKO.H THL: FIKE OF 1977.

Culver, H.,

bale, II. $H^{\prime}$,

Heaton, 11. 1.

Henery, A. P.

Neff, J. Jr.,

P'otter, J. 11.

1033

786

611

172

114

9421

MODELS TAKE I FROM TIL I)ERRIS OF TIIE FIKI 01877 .

CELTIVATURS.

Agnew, A., d Morrison, II.

Arnoli, 11. B., \& lirimm, J.,

Arrington, W. I.,

Barnett, J. A.,

Beaeh, C., \& Brown, T.

lielden, I1. M.

Belden, (:,

Bell, IV. C.

Benner, 1). (i.,

Black, i. (i.,

Bloodworth, E. Il.

Briggs, H. C.,

Brooks, IV.

Burns, I.

Cain, II., \& Stelfox, II

Cameron, 1. I .,

Chase, J. IV.,

Chase, 1. II.

Clark, i.

Clifton, L..

Clifton, W. C.

Copeland, ]..

Cox, B. S.,

Cox, B. . .

Craig, A. I.,

Crabtree, J. II.

Davis, J. 13.,

Heweene, $(x, 11$.

Dickion, I. II.,

Ioyle, L. II.

Eherly, 1).

Elliot, R.

Erwood, J. C.,

Fish, R. I.

Fleming, 1. $\mathrm{s}$.

Flory, C.,

Folly, I. IV.

612 Foshee, II. J.,

635 Freeman, E. 1.., (iible, J.,

J]art, (i, D.,

Holnes, 11 .

If, F., 5 .

Johnson, M.

Jonson, II. 1).

keezer, I,

Kinox, i. . 1 .

I.aird, 11.,

Lohler, A. li..

Mahon, I. B..

Neikle, $Y$.,

Melton, R. M.

Miehenor, A. 1)., d Steigmeyer, J. H.

Mires, 1.

Ililroy, J. II:

Moorehead, I. 13, \& Ponl, T. A. \& $\mathrm{i}, \mathrm{G}$.

Nauman, $\mathrm{k}$.

Nauman, E.

Oneal, C. 11 .

Oxer, II. J.

Parcell, P. B.

Parinh, G. IV.

l'erkins, E. H. 121

lool, T. II.

Potts, J.

Keams, B. F.

Rebman, J.

Reloman, I.

Remy, 13. II. \& N. T.

Richardson, IV

Rigell, M.

Rodgers, T. B.,

Routt, A. I'.

Sawyer, K.,

Severy, S.,

Slater, D. S.

Simith, II: D.

sinyder, J.,

speer, J. A., Jr.,

Stanton, R. Si.

Strowger, W. I).,

Thurston, F. C $i$.

Tolle, M.,

Toombs, \&. A.,

Yanhorn, R. P.,

Van Horne, R. P.

Van Horne, R. P.,

Wagner, J. R.,

Waite, T:

IValton, IV.,

Walton, S.,

Weaver, II.,

IVebler, N. $;$.

Whate, C. L., CVLTIVATURS-DISK.

Bramer, $\mathrm{l}$.

Bussell, F. T.

Coleman, L.

Hoyt, B. ('.,

Hoyt, R. C.,

Johnson, MI.,

La bow, C.,

Masten, J.,

Pond, J. F.,

sichlosser, I., CILTIVATORS-PARAI.I.EL.

Avery, R. H.,

Bennett, W. II., \&. Haight, II. K., 356

Junkins, J. C. 351

Louden, it:

Mcl)ill, T. W,

Poling, $\mathrm{T}$.

Pratt, $\mathrm{E}$.

Reeves, A. 1: 
Sle. , 1. 1 .

Summer, J. a Trumble J. CUATISATUR-RUTARY

Collom, I. 11

(ot) J. J].

Cooper, (i. W.,

Inecelie, M..,

Fenley, $\mathrm{G}, \mathrm{WT}$,

Fitzgerak, J. C.

Foye, II. II.,

Freeborn, WV.,

Ilewitt, S.,

Hopkins, (i. E.,

Jones, J. G.,

ivcDonald, T. E.,

Moody, L.,

Nusbum, A. B. C.

I'latt, JI. M.,

Smith, N. S., COLTIVATORS-STRADDLE-ROW:

Geisunger, J. I. d Williams, D. H. $s$,

Guthrie, 1.,

Matteny, R. G. \& Barnes, 1. R., 466

Sims, Z. B.,

stoll, M.,

Thomas, J. S. CELTIVATOR TEETH.

Buckingham, C. P.,

Colt, J. R.

Custer, G.,

Dryden, IV. A. \& Turnbull, J.M.

Iryden, WV. A.,

Elwood, R.,

Esterly, G. WV. \& Van De Water,

$$
\text { J., }
$$

Ford, W. P. \& T. H.

Forsyth, F, K.,

French, H. F.,

Freeman, E. L.,

Ilamilton, T. F.,

Hammon, T. W.

Ilanis, J.

Hooker, H. T.

Hullbert, W. II,

Hyer, B. S.

Kelly, W. H.

I amborn, L.

Lawbaugh, G, W.

Leonard, E.

Little, J, R.

Lynch, E. P. \& Wright, E. A. Lynch, E, P. \& Wright, E. A.,

Luppen, L.,

Maynard, $G$.,

Mattheson, I. C, \& Williamson, T. P.,

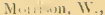

(hlell, R. I'.,

I'armile, E. d Curkentall, (i.,

Iicrpont, J.,

Pierpont, J. \& Tutle, S. . . .,

Roser., I) B.

Kogers, 1). B.

sayre, C. H.,

Sayre, C. H.,

smith, G. H.,

snyder,. ..,

Stockdale, J.,

Van Bracklin, B.,

Whate, M. R.

Wood, I.,

CULTIYATORS-WHEEL OR SULKY

Adams, J.,

Alexander, I. T. D.,

Barnett, M \& Wood, E. 694

Bashaw, J. N.,

Bird, J. C.

Bluser, N. G.,

Brinser, A. C.

Carlson, A. F.

Carlson, A. F, Shupes, C. d Cameron, W.

Carrington, S. E. ¿ E. H.,

(ox, R. C.,

Crowtluers, J.,

Guthrie, T. D., Jr.,

llewitt, P.,

Hluffman, O.,

Ives, E.,

Johnson, J. P.,

Jones, J.,

Lynch, E. P.,

Nahon, 1. B.

Mahon, 1. B.,

NcCorkell, R.

Peabody, S. G.

Reynerson, J. II.

Reynersion, I. 11.

Roberts, C. S.,

Sexton, J. B.,

Shaw, I.,

Stool, if.,

Wilkinson, G., PI.UGGS-COUPLINGS

Carr, N, \& J., Jr.,

Coons, S. P.,

Crossly, S.,

Jryden, W. A.,

Platt. W. H.,

Vamluvanee, I., \& Smith, II,
Vansickle, G. W., d NcConau. ghey, C., ILULiRS, - WHEIL OR SUIKY.

Beer-, E. A.

Iielden, C:,

Bullitt, II. N.,

Purlingame, A. II.,

Burlingame, A. H.,

Chapman, L.,

1)erwent, E., Jr.,

Diclie, IV..

Du bois, $\mathrm{N}$.

Fisher, s.,

Florance, J. L.

Fowler, A. A.,

Groves, G. A.,

Ilarris, J.,

Harrison, I. D.,

Hildreth, G. W',

Hiil, F. A.,

Hoyt, B. C.

Hunt, L.,

Kingston \& Gore,

Lathrop, L. B.,

Legg, J. T.,

Mlanuel, 1). A.

Nanuel, I), A.,

Meyer:, ('.,

Moore, (i.,

Murphy, M.,

Richard son, W. M.,

Russell, E. IV.

Rush, R. W., d E. W.,

Seibert, (;. d J.,

Slusser, B.,

Smalley, 1. A. \& J. H.,

Sparks, ().,

Stone, J.,

Vanarsdale, WV. 1.,

Watkins, J. T.,

Watt, G.,

Wolf, L.,

Woodworth, S. F.,

1092

$113 \mathrm{I}$

1129

1099

1099

1093

973

1140

1139

1074

1012

1088

966

[III

$105^{8}$

1040

966

ICO5

1007

1069

1109

II CO

1101

I035

1131

I110

II 7

974

1023

1092

974

1089

I 125

1022

994

$97 \mathrm{~S}$

1110

Worrell, J. \& Rynernon. J. H., 1056

Worrell, J.,

1112

Alden, MI., EXTENSIONS.

Cramer, J. P.,

Hall, T. J.

Hyde, W. S.,

Lechenthaler, G.,

Iic Ouiston, T.,

Melton, R. M.,

Kogers, D. B.,

Shares, D. W.,

939 Slemons, M. K.,

May 10, 1859

June 5,1857

May 1,1855

June 2I, I 893

July 25,1854

Oct, I8, 1859

Nay 31,1859

Nov. $1,1=45$

Aug. 1, 1854

()et. 9,1860

Mar. 20, I 855 
Adam, W. K.

Ailams, I.

Allams, II. A.

Alinis, J.

ddams, J. I.

Sllams, S. 11

Alams, $\therefore$ T.

Addison, IV. T.

Aderholt, E. A.

Annew, $\lambda$. and Morrison,

$$
\text { II: }
$$

Aiken, Ci, C

Aiken, (i. C.

Aiken,. . W.

lirey, R. $C$

Iker, I.

Albertson, $C$.

Alclen, II.

Aldrith. W:

Alexander, R. WI

Alexander, J. E.

Alexander, I. T. I).

Allen, I) R

Allen, S. L.

Allen, IV. K.

Alley, J. A.

Allis, A. Q.

Allivon, A. H.

Allison, A. H.

Allison, A. H.

Allison, A. H.

Alloways, J.

Allatou, F. H.

Altick, W:

Alvord, $C$.

Alvord, $c$ :

Ahord, C.

Ament. W. D.

Ament, W. D.

Amonett, A.A.

Anderson, A. P. and Edwards, B.

Anderson, A,

Andrew's, IV. I.

Andrews, IV. J.

Andrews, J. H.

Andrews, J. H.

Andrew, W. IV.

Insley, J and $(;$. iv.

Anthoine. L.

Anthony, S. E

Anyan, 13

Anyan, B.

Areber, D., Jr.

Argerhright, 1).

Arinstroing, J., Jr.

Armetrong, J., Jr.

Armstrong, J Jr.

Armutrong, $J$. and 6 .

Armstrong, J. and G. 1096353

Armstrong, $(i$, and Niur-

$$
\text { cheron, D. L. }
$$

Arndt, $T$.

Arnoli, (). J.

Amoldt, H. 13, and Grinum.

$$
\text { J. }
$$

Arrington, W. J.

Arthur, 1. B.

Arvin, I. N.

Aany, A. Y. and Wood, J. W.

Atchison, IV, J.

Atwater, J. B.

Atwood, C.

Atwood, C.
Plati Curim

So 23

$412 \quad 120$

$750 \quad 218$

$751 \quad 218$

Sig 233

$981 \quad 322$

$1115 \quad 358$

$85+\quad 243$

16345

3० 7

$512 \quad 150$

$513 \quad 150$

$\begin{array}{rr}7 & 2 \\ 1083 & 350\end{array}$

IS6 52

$1087 \quad 351$

194

S27 235

355 I10

$1165 \quad 372$

$599 \quad 173$

$174 \quad 4^{8}$

I 108356

$703 \quad 203$

IOI5 333

$674 \quad 194$

R.) $675 \quad 194$

$692 \quad 200$

712200

$1054 \quad 344$

$1048 \quad 342$

$\begin{array}{lll}50 & 13\end{array}$

$\begin{array}{ll}386 & 123\end{array}$

$521 \quad 15 \mathrm{I}$

719208

$\begin{array}{ll}749 & 217\end{array}$

$632 \quad 182$

$643 \quad \mathbf{1} 85$

$1140 \quad 364$

662191

$667 \quad 192$

$64 \quad 18$

$394 \quad \mathbf{I} 25$

$102533^{6}$

I049 342

4 SI $1+1$

$126 \quad 35$

$8+4 \quad 2+0$

$25^{8} \quad 75$

$\begin{array}{ll}705 & 204\end{array}$

$\begin{array}{ll}729 & 211\end{array}$

$840 \quad 239$

$\begin{array}{ll}852 & 243\end{array}$

$649 \quad 187$

(R.) $650 \mathrm{I} 87$

$\begin{array}{ll}676 & 195\end{array}$

$\begin{array}{ll}729 & 211\end{array}$

$\begin{array}{ll}1071 & 347 \\ 1096 & 353\end{array}$

37

$677 \quad 196$

$\begin{array}{ll}78 & 22\end{array}$

$122 \quad 34$

$\begin{array}{ll}78 & 22\end{array}$

663191

$266 \quad 77$

$271 \quad 79$

${ }_{3} \mathrm{~S}_{3} \quad 122$

$9 \mathrm{SS} \quad 324$

$992 \quad 325$
89
89
Atword, C.

Austin, I.

Iustin, J.

lustin, R. (i, s

Atutin, R. (i. S.

Austin, If 4 , S .

Avery K. 11.

Avery. R. 11.

Avery, 1

Avery, ir. C. $^{2}$

lore l and $100933^{1}$

bachman, J. I. $\quad$ SSo 253

biaclyer, N. $381 \quad 121$

Badlam, E. $\quad 384 \quad \mathbf{1 2 2}$

Bailey, I. II 1100

Bailey, I. and Marshall,

(i. $\quad 1147 \quad 366$

Bailey, $\mathrm{s}$.

$855 \quad 244$

Bailey, J. H. S74 250

Baird, E. A, and Gale,

$$
\text { A. T. }
$$

hiort, E. E.

B..ker, J. B

Baker, II:

Baker, I). C.

Baker, T. II

Baker, IV. T.

Baker, A.S, and landon,

$$
\text { IV. } \mathrm{H} \text {. }
$$

Baker, 11. II

Bakewell, C. N

Baktwin, I'. (),

Baldwin, 1.

Ball, T. J. and Poste, J.

Ball, II. M.

Ballagh, A. H.

Baltimore, J. T

liancroft, II

li.nk.. J.

liankinon, II.

I3amniran, I. C.

Bannigan, J. C.

Bannigan. J. C.

Barber, 1.

Barluer, 1., Jr.

Barber, 1.

Barcafar, $G$

Jarelay, T. W. and Sellar, R.

B..rclel, J.A.

Barker, i.

Barley, J. $1 \mathrm{H}$.

Barley, I. II.

barnes, $\mathrm{N}$.

Barnes, $H$.

Barnes, IV. C

Barnes, IV. $f_{\text {. }}$.

Barnett, I. A.

Barnett, It and Wood, F. 694

Barney, F.

liarnhart, $\mathrm{P}$.

Barnwell, A. S.

Barr, N. I.

I'arr, O, and cox, F, F

liarr, $\mathrm{O}$

Barrier, F. II

Barringer, J. II.

Barsalow, $\mathrm{H}$.

Bartlett, 1. W.

Barton, C. T.

Barton, 1. B.

Barton, I. B.

Bashaw, I. N

Batcheller, A. F.

Batcheller, A. $\mathrm{F}$.

bateman, $\mathrm{F}$.

Bates, IV. E.

Batson, I. W. and 1 . $\begin{array}{rr}359 & 111 \\ \operatorname{IOS}_{5} & 350\end{array}$

133

I $33 \quad 36$

I40 39

$737 \quad 213$

$7+2 \quad 215$

$708 \quad 229$

$974 \quad 35$

1016333

$122 \quad 34$

$140 \quad 38$

$\begin{array}{rr}9 & 2 \\ 66 & 10\end{array}$

$1082 \quad 350$

606201

I1 2

163

$636 \quad 18_{3}$

$826 \quad 235$

$830 \quad 236$

$53 \mathrm{~S} \quad 155$

605201

$63 \mathrm{I} 18 \mathrm{I}$

842240

$821 \quad 234$

$12 \mathbf{I}+3^{88}$

$645 \quad$ is 6

$796 \quad 22 S$

$665 \quad$ I9I

6.90 199

$53 \quad 15$

S39 239

Sis 242

604201

$6=8 \quad 180$

$6+15$

I $2 \mathrm{~S} \quad 36$

$660 \quad \mathrm{I00}$

$1172 \quad 374$

$77 \quad 22$

1001328

$673 \quad 194$

$1000 \quad 328$

$178 \quad 49$

639 ISt

$647 \quad$ I 86

809231

$405 \quad 128$

S12 232

10153

640 I 81
$20 \quad 4$

Battell, W

Batten, J. P.

Baum, C. C

Baumann, J. N.

Baxter, R.

Baylis, E 
Bever, J. T.

Bickelshymer, L.

Billings, R. F.

Billings, D. S

Bingham, J. and Pond, O. M.

Jird, J. C.

Bird, C

Birdsell, J.

Birdsall, F. M.

Bishop, C.

Black, G. G.

Black, $T$.

Black, A. M.

Black, A. II.

Black, J. F, and W. L.

Black, J. F, and W. L.

Blackistone, Z. D.

Blackistone, Z. D.

Blackstone, W.

Blackwood, J.

Blake, J. W.

Blanchard, J.

Blanchard, A. D.

Blauser, N. G.

Blauser, N, G

Bleecker, W. E.

Bleecker, WV. E.

Blodgett, W. W'. and smits, J. H.

Bloedel, H.

Blomsten; B. C

Blood, A. R., Hathaway, A and Beach, V K.

loodworth, E. H.

Blue, D. G.

Bodley, J. W.

Bohan, J.

Boles, A.

Bolis, V.

Bond, I. 1.

Bondeli, A.

Booker, J. W

Borchert, $\mathrm{H}$.

Borchert, H.

Borden, $T$.

Borland, A. J.

Borland, A. J.

Bossinger, J. W.

Bott, W. H.

Boughton, E.

Bourne, E.

Bouton, A.

Bowen, H. W.

Bowen, $\therefore$. B. and Abbot, A. ii.

Bower, J.

Bowers, H.

Bowman, D. W.

Bowman, L. D.

Bowman, R. J.

Boyce, W. J. and Haines, G. W.

Boyd, J. C.

Boyd, J. C.

Boyd, J. G.

Boys, H.

Bradley, G.

Bradley, G.

Bradley, $G$;

Bradley, C. I).

Bradley, B. C:

Bradley, B. C.

Bradley, B. C.

Bradley, B. C.
Plate Claim

$51 \quad 14$

$387 \quad 123$

$538 \quad 155$

$582 \quad 169$

1083350

$\begin{array}{ll}682 & 197\end{array}$

$\begin{array}{ll}747 & 217\end{array}$

$507 \quad 149$

661 190

133

$\begin{array}{ll}465 & 137\end{array}$

$609 \quad 175$

662190

$975 \quad 320$

$1176 \quad 376$

$139 \quad 38$
139

$139 \quad 38$

$1082 \quad 350$

106! 345

$126 \quad 35$

$364 \quad 76$

$1174 \quad 375$

752218

$\begin{array}{ll}791 & 227\end{array}$

$398 \quad 126$

$404 \quad 127$

$867 \quad 2.48$

$864 \quad 246$

$123 \quad 35$

$706 \quad 204$
707

$\begin{array}{rr}707 & 204 \\ 16 & 3\end{array}$

$45 \quad 12$

$288 \quad 87$

$739 \quad 214$

$99 \quad 29$

11433

I056 344

$254 \quad 74$

$\begin{array}{ll}615 & 177\end{array}$

$1200 \quad 383$

$1211 \quad 387$

$\begin{array}{rr}1 & 1 \\ 1061 & 345\end{array}$

I068 346

$\begin{array}{ll}931 & 297\end{array}$

IOI 30

$\begin{array}{ll}583 & 169\end{array}$

$395 \quad 126$

$470 \quad 138$

397 I 26

1067346

I07 31

$603 \quad 174$

$126 \quad 35$

$1123 \quad 360$

1216388

I042 341

$57 \quad 16$

$699 \quad 202$

(R.) $\begin{array}{rr}699 & 2 \mathrm{O} 2 \\ 700 & 203\end{array}$

$10+6 \quad 342$

$\begin{array}{ll}682 & 197\end{array}$

\begin{tabular}{ll}
$775 \quad 223$ \\
\hline
\end{tabular}

$\begin{array}{ll}792 & 227\end{array}$

$825 \quad 235$

$849 \quad 242$

$870 \quad 249$

939298

$\begin{array}{ll}1135 & 363\end{array}$

$1187 \quad 379$
Bradley, B. C. and Hague, C. A.

Bradley, B. C. and Hague, C. H.

Bradley, B. C.

Bramer, F.

Bramer, F.

Liramer, F. and Badger, O. IV.

Bramer, F,

Bramer, F.

Bramer, F.

Bramer, F

Bramer, F.

Bramer, $\mathrm{F}$, and Crowley, G. G.

Brannan, P.

Brannan, P.

Brate, B. F

Breeden, C. C. and Wheeler, O. T.

Breneman, M.

Bressler, G. IV.

lirewer, $J$.

Brewer, J.

Brewer, J.

Brewer, J.

Brewster, N. T. and Neher, A. D.

Briggs, E.

Briggs, E.

Briggs, H. C.

Briggs, H. C.

Briggs. H. C.

Brimingham, G. B

Brinckerhoff, C. R.

Brinley, T, E, C.

Brinley, T. E. C.

Brinley, T. E C.

Brinser, A. C

Brinton, I. H.

Bristol, H, ( $\mathrm{R}$.

Brittain, J. T.

Brittain, P. F.

Broadwell, WV. B.

Brock, S. WV

Brodnax, D. W. Sr.

Bronson, G. W.

Brooks, R. MI.

Brooks, IV.

Brooks, B. E

Brotton, R.

Brower, G, S., G. W., and

$$
\text { E. A. }
$$

Browne, R. T

Brown, G. IV

Brown, W. P.

Brown, W. P.

Brown, I.

Brown, W. P.

Brown, G. W.

Brown, F. E.

Brown, G. 1).

Brown, W. P.

Brown, W. P.

Brown, W. P.

Brown, I. M.

Brown, W. P.

Brown, W. P.

Brown, W. P.

Brown, H.

Brown, J. C. and Slimpert, G. H

Plate Claim

I I $52 \quad 367$

I $88 \quad 380$

$1198 \quad 382$

$264 \quad 76$

$270 \quad 78$

$270 \quad 78$

$270 \quad 78$

$27 \mathrm{e} \quad 78$

$271 \quad 79$

$276 \quad 81$

$277 \quad 81$

$277 \quad 81$

${ }_{28} 8_{1} 8_{3}$

$\begin{array}{ll}285 & 85\end{array}$

$942 \quad 299$

$868 \quad 249$

$\begin{array}{ll}786 & 226\end{array}$

$413 \quad 130$

$\begin{array}{ll}472 & 139\end{array}$

$\begin{array}{ll}727 & 210\end{array}$

$249 \quad 72$

$640 \quad 1 S_{4}$

$644 \quad 185$

$\begin{array}{ll}985 & 323\end{array}$

$835 \quad 23^{8}$

$\begin{array}{ll}31 & 7\end{array}$

$\begin{array}{ll}142 & 39\end{array}$

16345

$\begin{array}{ll}475 & \text { I } 39\end{array}$

$726 \quad 210$

$536 \quad 155$

$963 \quad 317$

(R.) $964 \quad 317$

$\begin{array}{rr}33 & 34 \\ 122 & 34\end{array}$

$1097 \quad 353$

$\begin{array}{lll}736 & 213\end{array}$

$\begin{array}{ll}719 & 208\end{array}$

$720 \quad 209$

$679 \quad 196$

$125 \quad 35$

686198

$468 \quad$ I 38

$935 \quad 298$

$408 \quad 128$

$760 \quad 220$

$24 \quad 6$

$\begin{array}{ll}134 & 37\end{array}$

$\begin{array}{ll}606 & 201\end{array}$

$604 \quad 174$

So6 23I

$\mathrm{S}_{42} 24 \mathrm{O}$

$188 \quad 52$

360 II I

$462 \quad 137$

$546 \quad 157$

$597 \quad 172$

$606 \quad 175$

$765 \quad 221$

$\begin{array}{ll}776 & 224\end{array}$

843240

862246

861246

941290

9 it 300

$9+3300$

$\begin{array}{lll}963 & 317\end{array}$

Brown, $C$ and Gerth, I 1021334 


\begin{tabular}{|c|c|c|c|c|c|c|c|c|}
\hline & Plate & Claim & & P'lati' & Claim & Colver, A. I & Plate & Claim \\
\hline Campbell, J. & 1027 & 336 & Chapman, $1 .$. & $\begin{array}{l}1057 \\
1063\end{array}$ & $\begin{array}{l}3+4 \\
345\end{array}$ & $\begin{array}{c}\text { Colver, A. } 13 . \\
\text { Priest, J. }\end{array}$ & 783 & \\
\hline $\begin{array}{l}\text { Canaday, II. II. } \\
\text { Canaday, H. II. }\end{array}$ & 852 & $\begin{array}{l}243 \\
363\end{array}$ & $\begin{array}{l}\text { Chapman, } \mathrm{L} \text {. } \\
\text { Chapman, } \mathrm{l} \text {. }\end{array}$ & $\begin{array}{l}1003 \\
1065\end{array}$ & $\begin{array}{l}345 \\
346\end{array}$ & Colver, A. B. & 810 & $\begin{array}{l}225 \\
232\end{array}$ \\
\hline $\begin{array}{l}\text { Canaday, H. II. } \\
\text { Canaday, II. H. }\end{array}$ & $\begin{array}{l}1137 \\
1142\end{array}$ & $\begin{array}{l}363 \\
364\end{array}$ & $\begin{array}{l}\text { Chapman, } 1 . \text {. } \\
\text { Chajman, } 1 .\end{array}$ & $\begin{array}{l}1005 \\
1084\end{array}$ & $\begin{array}{l}340 \\
35^{\circ}\end{array}$ & Colvin, II. H, and John. & & 232 \\
\hline $\begin{array}{l}\text { Canaday, II. H. } \\
\text { Canaday, II. H. }\end{array}$ & $\begin{array}{l}1142 \\
1171\end{array}$ & $\begin{array}{l}364 \\
374\end{array}$ & $\begin{array}{l}\text { Chajman, l. } \\
\text { Chapman, L. }\end{array}$ & 1129 & $36 \mathrm{r}$ & son, 1. R. & I I 3 I & \\
\hline $\begin{array}{l}\text { Canaday, II. H. } \\
\text { Canaday, H. H. }\end{array}$ & $\begin{array}{l}1171 \\
1207\end{array}$ & 374 & & I I 32 & 362 & Cone, $\mathrm{F} . \mathrm{C}$. & $\begin{array}{r}1131 \\
392\end{array}$ & 362 \\
\hline & 1207 & 385 & $\begin{array}{l}\text { ipman, l. } \\
\text { pman, } 1 . .\end{array}$ & 1195 & 382 & Cone, T. S. and Potter, & 392 & 125 \\
\hline $\begin{array}{l}\text { Canfield, } \lambda \text {. } \\
\text { Canfielel, } \lambda .\end{array}$ & 71 & 20 & $\begin{array}{l}\text { Chapman, l.. } \\
\text { Chapman, I. }\end{array}$ & 1143 & 365 & $\begin{array}{c}\text { Cone, } 1.5 \text {. and rotter, } \\
\text { H. S. }\end{array}$ & 602 & \\
\hline $\begin{array}{l}\text { nfield, } . \text {. } \\
\text { nfield, J. }\end{array}$ & $\begin{array}{r}71 \\
628\end{array}$ & 20 & $\begin{array}{l}\text { Chapman, I.. } \\
\text { Chappell, I. H. and }\end{array}$ & & & $\begin{array}{c}\text { H. S. } \\
\text { Conley, I. I }\end{array}$ & 602 & 174 \\
\hline $\begin{array}{l}\text { Canfield, J. } \\
\text { Canfleld, J. Hess, C. }\end{array}$ & $\begin{array}{l}628 \\
656\end{array}$ & ISI & $\begin{array}{l}\text { Chappell, I. H. and } \\
\text { Montgomery, J. }\end{array}$ & 718 & 208 & & 764 & 221 \\
\hline $\begin{array}{l}\text { Canfleld, J. Hess, C. } \\
\text { Canfield, .A. }\end{array}$ & $\begin{array}{l}656 \\
687\end{array}$ & I 89 & $\begin{array}{l}\text { Montgomery, J. } \\
\text { Chappell, I. H. }\end{array}$ & 774 & 223 & nelly, A & 94 & 28 \\
\hline $\begin{array}{l}\text { Canfield, A. } \\
\text { Canfield, A. }\end{array}$ & $\begin{array}{l}687 \\
801\end{array}$ & 198 & $\begin{array}{l}\text { Chappell, 1. H } \\
\text { Charles, F. G. }\end{array}$ & $\begin{array}{r}7 / 4 \\
1066\end{array}$ & $\begin{array}{l}223 \\
346\end{array}$ & Connely, J. & 677 & 195 \\
\hline $\begin{array}{l}\text { Canfield, } A . \\
\text { " R.) }\end{array}$ & $\begin{array}{r}801 \\
1802\end{array}$ & 230 & Charles, F. G. & 20 & & Connely, J. W. & 691 & 199 \\
\hline Canfield, A. (R.) & $\begin{array}{r}1802 \\
829\end{array}$ & 230 & Charten, J. & 29 & 7 & Conner, L. IV. and R. G. & 762 & 221 \\
\hline $\begin{array}{l}\text { Canfield, A. } \\
\text { Canfield, } \mathrm{A} \text {. }\end{array}$ & $\begin{array}{l}829 \\
854\end{array}$ & 236 & Chase, J. IV. & 157 & 43 & Conner, L. H. & 884 & 254 \\
\hline $\begin{array}{l}\text { Canfield, } \mathrm{A} . \\
\text { Cantelon, R. }\end{array}$ & $\begin{array}{r}854 \\
65\end{array}$ & 244 & Chase, J. W. & I 62 & $\begin{array}{r}45 \\
288\end{array}$ & Connor, W. J. & 1062 & 345 \\
\hline $\begin{array}{l}\text { Cantelon, R. } \\
\text { Canterbury, A }\end{array}$ & $\begin{array}{r}65 \\
267\end{array}$ & is & Cheasehro, J. E. & 998 & 328 & Conolly, G. IV. & $4^{8}$ & 13 \\
\hline $\begin{array}{l}\text { Canterbury, A } \\
\text { Capp, T. F. }\end{array}$ & 267 & 77 & Cheatham, W. T. & I 66 & 46 & Conover, S. B. & 679 & 196 \\
\hline $\begin{array}{l}\text { Capp, T. F. } \\
\text { Carey, A. }\end{array}$ & 764 & 221 & veth, J. & 395 & 126 & rath, $\mathrm{P}$. & 1040 & 340 \\
\hline , A. & 591 & 171 & $\mathrm{n}, \mathrm{E}$ & 536 & $\mathbf{1 5 5}$ & tant, I. & 8 & 2 \\
\hline Cargo, $\mathrm{H}$ & 797 & 229 & ldren, E. & 667 & 192 & Conway, C. R. & 1133 & 362 \\
\hline Carbart, P. S. & 44 & II & Children, E. & 676 & 195 & Cook, J. & 339 & 105 \\
\hline Carhart, P. Si. & 49 & 13 & Children, E. & 805 & 230 & Cook, A. M. & 623 & 179 \\
\hline Carlow, J. H. & 759 & 220 & Christman, R. D. & 165 & 46 & Cook, G W. & 708 & 205 \\
\hline Carlson, A.F. & 772 & 223 & Christ pher, J. G. & 27 & 6 & $\mathrm{n}, \mathrm{J} . \mathrm{H}$ & 407 & 128 \\
\hline Carlson, A. F., Shippse, C. & & & Chubb, A. I. & 745 & 216 & Coonrod, P. & 615 & 177 \\
\hline and Camr & 800 & 229 & Churchill, D. and & & & onrod. P. & 696 & 201 \\
\hline Carnagy, A. I & 534 & 154 & Brewer, S. C. & 648 & I 86 & Coons, S. P. & 940 & 299 \\
\hline Carns, J. C. & I IOI & 354 & Churchill, D. & 697 & 202 & per, N. B & 44 & I I \\
\hline Carr. N. Jr. and J. & 468 & $13^{8}$ & Clapp, H. W. & 743 & 215 & Cooper, G. W. & 68 & 19 \\
\hline Carr, D. F. & 731 & 212 & Clark, C. & 30 & 7 & Cooper, G. W. & 68 & 19 \\
\hline $\mathrm{H}$ & 746 & 216 & Clark, C. A. & 35 & 9 & per, C. J. & 173 & 48 \\
\hline Carr, H. & 746 & 217 & Clark, C. M. & 128 & 36 & per, A. & 348 & 108 \\
\hline Carr, H. & 746 & 217 & 64 & 129 & 36 & per, G. W. & 390 & 124 \\
\hline Carr, N. Jr. and J. & 933 & 297 & Clark, C. M. & 145 & 40 & Copeland, J. & $5 I$ & 14 \\
\hline Carr, H. C. & 1049 & 342 & Clark, IV. & 354 & 109 & opeland, 1 . & $I_{3}$ & 33 \\
\hline Carrington, S. E. and & & & Clark, P. & 507 & 149 & eland, J. & 151 & 42 \\
\hline C. $\mathrm{H}$ & 588 & 170 & Clark, M. M. & 620 & 178 & Coppage, W. & 864 & 247 \\
\hline Carson, $\mathrm{H}$. & 543 & 156 & Clark, IV. F. & 675 & 195 & Corbin, J. S. & 275 & 80 \\
\hline Carson, R. & 342 & 106 & Clark, R. M. & 1205 & $3^{85}$ & 64 & 275 & 80 \\
\hline Carter, N. C. & 34 & 8 & Clarridge, J. & 57 & 16 & Corbin, J. S. & 288 & 86 \\
\hline Carter, W. H. & 148 & 41 & on, I. G. & 351 & I08 & Corbin, J. S. & 288 & 86 \\
\hline Carter, G. D. & 354 & 109 & ton, J. & II 59 & 369 & eth, R. & 1062 & 345 \\
\hline Carter, C. I). & 359 & III & yton, J. & 1176 & $37^{6}$ & Coreth, R. & I08! & 349 \\
\hline Carter, C. H. & 489 & 142 & Cleaveland, G. D. & 134 & 37 & eth, R. & I 106 & $35^{6}$ \\
\hline Carter, C. L. & Sio & 231 & Clees, J. & 1032 & $33^{8}$ & Cormick, T. R. & 597 & 172 \\
\hline Carter, C. I. & 826 & 235 & Clements, A. P. and & & & nick, T. R. & 616 & 177 \\
\hline Carter, C. D. & 867 & 248 & Nealey, J. C. & 107 & $3 I$ & nell, T. J. & 992 & 325 \\
\hline Carter, G. R. & $\mathrm{IO}_{3} 6$ & 339 & Clements, WV. & 809 & 231 & rnell, 'T. J. & 997 & 327 \\
\hline Carver, H. E. & 1137 & 363 & , J. H. & 86 & 25 & , C. IV. & 986 & 323 \\
\hline Casaday, IV. I. & I I I & 359 & 1 . & 88 & 26 & I. & 793 & 228 \\
\hline " 4 (R.) & 1119 & 359 & Clifton, W. C. & 115 & 33 & Coston, W. M. & $79^{8}$ & 229 \\
\hline Case, J. & 621 & 179 & $\mathrm{~S}$ & I & I & Coston, W. M. & 813 & 232 \\
\hline Case, J. & 658 & I go & S. & 2 & I & Cottun, J. & 1224 & 390 \\
\hline Case, J. & 761 & 220 & B. M. & 95 & 28 & Conlter, IV. F., Trabue, & & \\
\hline Case, J. & 967 & 318 & Clover, C. C. & 856 & 244 & G. F. and Lowrey, & & \\
\hline Case, P. L. & 1190 & 380 & loyd, H. C. & 109 & 32 & W. A. & 717 & 208 \\
\hline Cass, A. B. & 607 & 175 & Cluckner, J. & 106 & 31 & Coulter, IV. F & & \\
\hline Cass, A. B. & 631 & $\begin{array}{l}182 \\
180\end{array}$ & Coats, S. & & 2 & Lanery, J. A. & 726 & 210 \\
\hline Castor, L. H. & $\begin{array}{r}627 \\
59\end{array}$ & $\begin{array}{r}180 \\
16\end{array}$ & Cochrane, J. & I 068 & 346 & Covell, A. T. & 1008 & 331 \\
\hline $\begin{array}{l}\text { Caswell, L. J. } \\
\text { Cates, N. A. }\end{array}$ & $\begin{array}{l}59 \\
72\end{array}$ & 21 & Cochran, B. C., T. W. & & & van, S. & 617 & 178 \\
\hline $\begin{array}{l}\text { es, N. A. } \\
\text { o, W. W. }\end{array}$ & 132 & 36 & and J. M. & $68_{3}$ & 197 & Cowing, $\mathrm{H}$. & 710 & 205 \\
\hline Cauthorn, 1. N. & 346 & 107 & Coe, $\mathrm{O}$ & 243 & 69 & Cox, M. C. & IOI & 30 \\
\hline Cavett, R. S. & $34^{8}$ & 108 & gin, S. L. & 189 & 53 & Cox, B. S. & 104 & 31 \\
\hline Caylor, I. & 142 & 39 & Colborn, L. H. & $3^{84}$ & 122 & Cox, B. S. & I34 & 37 \\
\hline Caywood, II, and J. & 725 & 210 & Colburn, D. W. & 679 & 196 & Cox, J. and Throp, J. A. & 601 & 174 \\
\hline Chace, E. A. & 1004 & 329 & Cole, N. C. & 157 & 43 & Cox, J. and Throp, J. A. & 628 & 181 \\
\hline Chamberlain, H. W. & $8 \mathrm{~S}_{4}$ & 254 & $\begin{array}{l}\text { Cole, J. H. } \\
\text { Cole, H. }\end{array}$ & 828 & 236 & Cox, S. H. and Pence, IV. & & \\
\hline berlin, W. H. & 388 & 123 & $\begin{array}{l}\text { Cole, H. } \\
\text { Cole, I. H. }\end{array}$ & 868 & 249 & H. & 698 & 202 \\
\hline berlin, T. B. & I I 55 & $3^{68}$ & $\begin{array}{l}\text { Cole, J. H. } \\
\text { Coleman, I. }\end{array}$ & 1045 & 342 & Cox, B. C. & $\mathrm{S} 12$ & 232 \\
\hline bers, C. F. & Iog9 & 354 & $\begin{array}{l}\text { Coleman, L. } \\
\text { Coleman, J. H. }\end{array}$ & 247 & 71 & $\mathrm{x}, \mathrm{J}$. and $\mathrm{S}$. & 1044 & 341 \\
\hline jers, $\mathrm{C}$. F. & I I 33 & 362 & $\begin{array}{l}\text { Coleman, J. H. } \\
\text { Collins, J. W. and Wil. }\end{array}$ & 723 & 209 & Coyle, H. J. & 123 & 35 \\
\hline Chandler, H. C: & 76 & 22 & $\begin{array}{l}\text { Collins, J. W, and Wil- } \\
\text { kinson, R. Y. }\end{array}$ & & & Crabtree, I. M. & 161 & +4 \\
\hline Chandler, M. and & & & kinson, R. Y. & $3^{81}$ & I 2 I & Craft, R. i). & 476 & 140 \\
\hline Nichiels, J. B. & 472 & 139 & $\mathrm{I}$ & 605 & I 74 & Craig, R. & 26 & 6 \\
\hline Chapman, J. & 181 & 50 & olt, J. R. & 540 & 156 & A. J. & $8 \mathbf{I}$ & 24 \\
\hline $\mathrm{n}, \mathrm{J}$. & 646 & I 86 & Colton, G. D. & 969 & 319 & Crain, O. A. & I $\$ 2$ & 50 \\
\hline Chapman, L. & 1037 & 339 & Colton, G. D. & 970 & 319 & Cramer, J. P. & 510 & 149 \\
\hline
\end{tabular}




\begin{tabular}{|c|c|c|c|c|c|c|c|c|}
\hline & Pate & Claim & & Plate & Claim & & Plate & Claim \\
\hline Crane, E. & 248 & 71 & Darling, M. anel Gray, H. & $8_{1}$ & 24 & Domalison, J. W., Sheets, & & \\
\hline a $\quad 4$ & 248 & 71 & Darnell, 10. E. & 290 & 88 & D. and Niller, A. C. & 996 & 327 \\
\hline Crane, E. & 248 & $7 \mathbf{I}$ & Fart, $A$. & 155 & +3 & Donaldson, $\mathrm{l}$. & 1012 & $33^{2}$ \\
\hline " & 249 & 71 & I) avenport, F. P. & 119 & 34 & Donely, T. and Cressler, & & \\
\hline Crane, B. J. & 1071 & 347 & Davenport, F. S. & 979 & 321 & J. B. & 701 & 203 \\
\hline (ravath, M. A. and I. M. & 247 & 70 & Davenport, F.S. & 998 & 327 & Dooley, J. & 97 & 29 \\
\hline * " $\quad$ * (K.) & 247 & 70 & 44 & 998 & 327 & Doolittle, G. W. & 667 & 192 \\
\hline Cravath, II. A. & 968 & 318 & Davenport, F. S. & 1133 & $3^{62}$ & Hoolittle, F. & 698 & 202 \\
\hline Cretek, C. C. & 474 & 139 & Davenport, F. ti. & 1211 & 387 & Dorman, J. M. & 95 & 28 \\
\hline Cremer, $\mathrm{F}$. & I055 & 344 & Davey, J. H. & 708 & 205 & Forsey, E. I. & 54 & I5 \\
\hline Crenshaw, M. & 379 & 121 & Davidson, I. M. & 93 & 28 & Dorsey. W. D. & 593 & 171 \\
\hline Criswell, R., Jr. & 6 & I & Davidson, W. J. & $18_{4}$ & $3 \mathbf{I}$ & Dorsey, IV. D. & 615 & 177 \\
\hline Croll, G. & +86 & 142 & Daviclion, WV. J. & 188 & 52 & Doss, IV. C. & 20 & 4 \\
\hline Cropp, F. M. & 850 & 242 & Davies, E., Jr. & 689 & 199 & Doud, I. II. & 790 & 227 \\
\hline Cross, B. H. & 178 & 49 & Davis, I. B. & 75 & 22 & Doud, J. IV. & 1014 & 332 \\
\hline Crossley, S. & 937 & $29 \mathrm{~S}$ & Davis, J. & 627 & I So & Douthit, s. I. & $1+6$ & 4I \\
\hline Crossley, WV. C;. & 1012 & 332 & Davis, D. M. & 628 & $1 S_{1}$ & Douthit, J. H. & 1002 & 329 \\
\hline " & 1013 & 332 & Davis. J. R. & 620 & $17 S$ & Doyle, I.. H. & $4 I$ & 10 \\
\hline Crossley, W. G. & 1064 & 345 & is, L. J. & 797 & 229 & 1)oyle, I. H. & 45 & 12 \\
\hline Crothers, F. R. & 979 & 321 & Davis, L.., Jr. & 857 & 244 & Drake, S. E. & 1150 & 367 \\
\hline Crothers, F. H. & ${ }_{10} 8$ & 339 & Davison, G. A. & $102 \mathrm{I}$ & 334 & Dryden, IV. A. and Turn- & & \\
\hline Crothers, F. R. & $\log 2$ & 352 & " " 4 (R.) & 1022 & 334 & bull, J. M. & 524 & 152 \\
\hline Crow, $C$. & 103 & 30 & Daviron, J. N. and Spen- & & & Iryden, II. A. & 528 & 153 \\
\hline Crowley, $\mathrm{i}, \mathrm{G}$. & 284 & 85 & cer, N. Jr. & 1028 & 337 & I ryden, W. A. & 599 & 173 \\
\hline Crowther, J. & 704 & 204 & Davison, A. & 1033 & 338 & Dryden, $\mathrm{WV}$. A. and C. E. & 685 & I97 \\
\hline Crump, T.J. & 1140 & $3^{64}$ & Datwson, W. I. & 393 & 125 & " 6 " $4(\mathrm{R})$. & 685 & I 98 \\
\hline Crutcher, $\mathrm{S}$. & 347 & 107 & son, $\mathrm{C} . \mathrm{H}$. & 970 & 319 & Dryden, IV, A. & 934 & 297 \\
\hline Cruttenden, A. E. & 1031 & 338 & Way, S. & 716 & 207 & Iryden, W. A. & 932 & 297 \\
\hline Culver, $H$. & 1033 & 338 & Day, W. & 725 & 210 & Duane, I. B. & 970 & 319 \\
\hline Cummings, $1 \mathrm{~T}, \mathrm{H}$. and & & & Deal, J. J. & 183 & 51 & Hu Bois, N. & 1093 & 352 \\
\hline Childs, H I. & 732 & 212 & Deal, I. J. & 185 & 52 & Duclos, V. C. & 1028 & 337 \\
\hline Cummings, W. H. & 779 & 224 & Deal, J. J. & 192 & 54 & finer, $\mathrm{W}$. & 75 & 22 \\
\hline Cummings, W. H. & 1218 & 389 & Dean, D. & 520 & 151 & gdale, J. K. & 43 & I I \\
\hline Cummins, S. A. & 480 & I 4 I & Debolt. C: & 466 & 137 & Dulaney. N. & SSI & 253 \\
\hline Cummins, 11. B. & 1066 & 346 & Decelle, M. & 397 & 126 & Dundas, I. & 588 & 170 \\
\hline Cummins, A. G. and & & & n, F. W. & 850 & 242 & " & 589 & 170 \\
\hline J. R. & 1083 & 350 & D'Hast, E. F. & 600 & 199 & Tumlap, J. R. & 487 & $1+2$ \\
\hline Cummins, J. R. & 1136 & 363 & Deighton, K., Jr. & 50 & 13 & I) mmavant, J. U. and & & \\
\hline Cummins, J. R: & 1176 & 376 & Demarce, $A$. and Vree- & & & Hamjson, W. A. & 155 & 43 \\
\hline Cunningham, J. & $5^{88}$ & 170 & land, $\mathrm{T}$. & 164 & 45 & Eurant. A. P. & $6=6$ & I So \\
\hline Cunningham, A. & 1044 & $34 I$ & Denham, 1 . & 647 & I $\$ 6$ & Durant, A. P. and Buck- & & \\
\hline Curkendall, $\mathrm{C}$. & I 28 & 361 & Dennett, D. & $5^{2}$ & 14 & ley, I). N. & 983 & 322 \\
\hline Currier, A. & 190 & 53 & nis, $\mathrm{O} . \mathrm{H}$. & 20 & 4 & Durant, A. P. & $9 S_{9}$ & 324 \\
\hline Currie, J. & 1154 & 368 & Dennis, F. IV. & 705 & 204 & on, J. L.., Jr. & 25 & 6 \\
\hline Curry, I. I. & 837 & 239 & more, $\mathrm{J}$ & 248 & 71 & al, $\mathrm{C}, \mathrm{R}$. & 1044 & 342 \\
\hline (entis, H. W. & 53 & 14 & n. $C$ & 657 & IS̀g & ight, s.. & 468 & 138 \\
\hline Curtiss, M. S. & 1010 & 331 & Derwent, E., Jr. & 1099 & 354 & Sht, s. & 471 & $13^{8}$ \\
\hline Curtiss. MI. S. & 1074 & $34^{8}$ & De Turk, J. I). & 519 & I5I & 1)wight, (i, II. & 721 & 209 \\
\hline Curtiss, M. S. & 1079 & 349 & Dever. E. M. and Pratt, & & & Fwight, $A, H$ and Chan- & & \\
\hline $\begin{array}{l}\text { Curtiss, M. S. } \\
\text { Curtiss, M. S. and E. W. }\end{array}$ & 1100 & 354 & I. C. & 626 & ISO & bers, IV. B. & 748 & 217 \\
\hline $\begin{array}{l}\text { Curtiss, M. S. and E. W. } \\
\text { Curtiss, M. S. }\end{array}$ & $\begin{array}{l}1123 \\
1148\end{array}$ & $\begin{array}{l}360 \\
366\end{array}$ & Deweere, (i. IV. & 80 & 23 & Dysert, IV: & 5 & I \\
\hline $\begin{array}{l}\text { Curtiss, H. S. } \\
\text { Cinster, I. }\end{array}$ & $2+6$ & 70 & Dewey, IV. E. & 836 & $\begin{array}{l}238 \\
138\end{array}$ & zert, W: & 461 & 137 \\
\hline Custer, J. & 246 & 70 & $\begin{array}{l}\text { Beyo, C. B. } \\
\text { Dick, C I. and Woehl, }\end{array}$ & 470 & 138 & Early, 1). S. & 87 & 26 \\
\hline Custer, G. & $5 \mathrm{I} 4$ & 150 & $\begin{array}{l}\text { Dick, (. L. and Woehl, } \\
\text { MI. }\end{array}$ & 1215 & 385 & Farly, D. S. & 93 & 28 \\
\hline 1) aggett, D. P. & $5^{8} 7$ & 170 & & 544 & 157 & Earlywine, N. & 131 & $3^{6}$ \\
\hline Dahl, G. J. & 1017 & 333 & Dickey, W. H. & $\begin{array}{l}544 \\
544\end{array}$ & $\begin{array}{l}157 \\
157\end{array}$ & Exsthurn, $\mathrm{C}$ & 20 & 4 \\
\hline Dahlbom, s. & 831 & 237 & lickey, W. H. & $\begin{array}{l}544 \\
343\end{array}$ & $\begin{array}{l}157 \\
157\end{array}$ & Easterday, E. S. & 704 & 204 \\
\hline Dailey, A. A. & 1050 & 343 & Jickey, IV. H. & - 343 & 157 & , C. I. & 1006 & 330 \\
\hline Inle, W. 1'. & 786 & 226 & Dickie, IV: & I 099 & 3.54 & an, J. S. & 507 & 149 \\
\hline 1)ale, IV. I?. & 799 & 229 & Dickson, A. A. & 24 & 5 & E.C. & 1113 & 357 \\
\hline Dile, W: I'. & SoS & 231 & Dickson, J. 11 & 85 & 25 & , E. C. & I 116 & 358 \\
\hline Daley, 1. & 529 & 153 & Dickerson, L. W. & 794 & 228 & agh. H. H. & 1007 & 330 \\
\hline Dalton, H. N. & 245 & 69 & Dierdorft, J. & 863 & 246 & Eberhart. J. WV. & II 59 & 369 \\
\hline Dalton, H. N. & 997 & 327 & 1)ietz, WV. I. & I 86 & $5^{2}$ & Eherley, D. & 15 & 3 \\
\hline Walton, 11. N. & 1041 & 340 & Dikeman, 1. R, and & & & Eberty, D. B. & 768 & 222 \\
\hline 1)amron, W. H., Massey, & & & Hewlett, J. J. & $3^{82}$ & 122 & y, D. B. & 792 & 227 \\
\hline K. H. and Whitman, & & & Dillon. $\mathrm{T}$. & 88 & 26 & I. J. H. & 990 & 325 \\
\hline & 698 & 202 & O. P. & 996 & 327 & Eckles, H. P. & 390 & 124 \\
\hline I)ana, ( : H. & 10 & 2 & S. O. P. & $\mathrm{IOO}_{3}$ & 329 & Eddelman, D. & 529 & 153 \\
\hline il, & 664 & I 9 I & , S. & 1165 & 372 & Eddleman, J. P. & 1046 & 342 \\
\hline Is, T. T. & 287 & 85 & $\mathrm{I}$ & 630 & ISI & Edgell, J. B., Alex- & & \\
\hline els, T. T. & $85 \mathrm{I}$ & $2+3$ & Dodye, T. H. & $3 \mathbf{I}$ & 8 & ander, J. W. and E. $\lambda$. & . 997 & 327 \\
\hline Inmels, C. I. & 415 & 130 & Dodge, R. I). & 607 & 175 & wards, 1 . & 6 & 1 \\
\hline Daniels, H. I. & I 150 & 367 & Dodge, R. L, and Walk- & & & Edwards, W. H. & 716 & 207 \\
\hline Daniels, E. S. & 1178 & 376 & er, E. M. & 999 & 328 & kdwards, 1$)$ & 785 & 226 \\
\hline Is, II. L. & 1220 & $3 \mathrm{Sg}$ & ing, L. & 1010 & 331 & Edwards, C. A. & 104.3 & $34 \mathrm{I}$ \\
\hline 1)anner, $\mathrm{J}$. & 469 & $13 \mathrm{~S}$ & Domschke, C. & 1148 & $3^{66}$ & Edwards, IS. I. & $113^{8}$ & $3^{6} 3$ \\
\hline
\end{tabular}


Fichl , le, .11

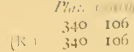

(k.) its 10:

Fistrind, li, and Cir=-

$$
\text { sel, if, } 1 \text { '. }
$$

Flilur, I. II.

Elilred, 1.

Elilired, 1).

Fllett, T. E.

Flli, $\mathrm{R}$.

Ellintt, T. C.

Elliott, IJ. A.

Flliott, il. I.

Elliv, T. I.

Ellis, J. I.

Ellis, 1 ;. . .

Elli-un, 1.

Elliston, C. T.

Flliston, C. T.

Ellwood, K.

Ellwourl, R, and l'itcher, R. 1.

Fillword, R. and Pitcher, R. 1 .

Fllword, R, and Pitcher,

$$
\text { R. } 1 \text {. }
$$

$$
\text { (R.) }
$$

Illw surd, R.

Elmer, N.

Emmert, E.

Emmert, l:

Emmenis, IV. and Wells, 1). A.

Emrick, I.

ind-ley, I. and Fletcher. E.

E.wo $\mathrm{k}, 1$

Erickion. (;. A.

Ernot, I. II

Eruxt, J. (;.

Erwuod, J. C.

Excudicr, $C$

E-hl:man, A

Fohleman. I.

Essington, $\dot{C}$.

Esterly, G. IV. and Van 1)e Water, I.

Eiserly, ixon.

Este, C. F.

Enicer, ().

Etter $>$ P.

Eustace, M., Kenman, I. and T.

Eutice, E. A.

E:an-, J. (i.

Evans, 1), Z.

Evan?, W

Eierest. 1). ()

Evick, C...

Evlar, T. F.

lis: 111, T. B.

Fanin: . I. and Legler,

Fanning, S. A.

Fargo, C. A

Firmer, IV. H.

Farn-worth, F.

Farruw, . 1.

Fath, I. C;

Fauliner, J. J.

laweet, $f_{i}$.

Fawke, I. W:

Fity, D, II.

Fay, J.

Fiy, I.

Felker, V.

18251
$1 \mathrm{ckt}$. Y

Felum. 11, 11.

Fenley, $\mathrm{C}, \mathrm{W}$ :

Femer, R. R.
Ferguxnn, J.

Jergation, $\$$. 1

Fergusen, s. $\mathrm{T}$.

Fermalt, I.

Fiell, (i, li.

Field, B, l.

Filkins, J. 1), and toe

Fink, J.

Finley, I. R.

Fish, T. P.

Fish, R. A.

Fislier, 1. 13.

Finer, $\mathrm{S}$.

Fisler, W. D.

Fisher, S.

Fislier, $:$

Fistuer, 1). S

Wisher, I. J3.

Fisher, I. B.

Finher. J. I;

Fitch, (). F,

Fitzrerold, I. C.

Flinn, .I.,

Horance, J. 1.

Forle: . . 13,

I9 4

533 I 54

$584 \quad 160$

$66 \quad 19$

666 I93

I $52 \quad 4^{2}$

1219389

360 III

$53 \mathrm{I} \quad \mathrm{I} 5 \mathrm{t}$

I 123360

$546 \quad$ I 58

693200

$593 \quad 172$

I $126 \quad 360$

$769 \quad 222$
10.7

1007346

$1036 \quad 339$

$1 \div 9 \quad 41$

$749 \quad 217$

I015 333

$876 \quad 251$

I70 47

$937 \quad 209$

$63+\quad 182$

1007346

I104 355

I $120 \quad 359$

$975 \quad 320$ I'ty, W. H.

Fithian, L. S

Flanshurgh, P, H.

Fleming, I. S.

Fleming, I. 11

Flumingr, I. W.

Fleming, $S, \mathbb{W}$.

Flumiken, T Y. and 1l:all, A.

Fletcher, I. J. and Sursa, 1. 11

Flisher, 1. (i, and bates,

$$
\text { E. II. }
$$

Flory, $c$.

Flosi, I.

Flym, I.

Forlow, S., 13.

Forbes, I.

IHi , wim

ois 323

(14) 209

$407 \quad 125$

II $10 \quad 356$

$744 \quad 216$

I I $51 \quad 367$

$122539 \mathrm{I}$

$648 \quad 156$

$378 \quad 121$

618 I 68

$964 \quad 317$

42 II

49 I 3

$54 \quad 15$

14340

$\begin{array}{ll}598 & 172\end{array}$

$659 \quad \mathbf{I} 90$

$739 \quad 214$

$973 \quad 319$

1005330

1156368

$1159 \quad 369$

$1164 \quad 372$

$50+172$

${ }_{3} \mathrm{~S}_{3} \quad 122$

$3^{8} 5 \quad 122$

$1046 \quad 342$

$123 \quad 35$

I $86 \quad 5^{2}$

$192 \quad 54$

1208356

$856 \quad 244$

I $\mathrm{S}_{4} \quad 378$

1019334

St 23

$11+0 \quad 365$

$7-1 \quad 21$

$1110 \quad 357$

$537 \quad 155$

$\times 2 \quad 24$

$932 \mathrm{~S}$

S60 249

(R.) 869249

Forst, (

$511 \quad 149$

$542 \quad 156$

I3I 36

$398 \quad \mathbf{2} 26$

14

$510 \quad 149$

I $164 \quad 372$

I I 44375

I 5944

$2 \mathrm{SI}_{3}$

$386 \quad 123$

1012332

$1162 \quad 371$

I $200 \quad 383$

$659 \quad 190$

$516 \quad 150$

Fontin, I. I.

Fountain, J. 1 I. $\mathrm{Ml}$.

Fowier, A. A.

Fox, I.

Foye, IV. II.

Foye, W. H.

Franyoton, [ ]I.

Francisco, H

francinco, 11.

Frauli. I.

Frank, j.

Frank, J. H

Frank, $c$.

Fration terger, J. T.

rankdar, li,

Franklin, 1). 1).

Frantz. IV.

Fraser, F. J.

Fraser, F. J.

friser, N. Wr. and Mic J.ellinn, . I. J.

Fraser, Ji. I.

Jirnzee, I. I

Freetroin, W

Frecland, 1'. F.

Freeman, E. L.

Freeman, E. I.

Freeman, E. L.

Freeman, W. 11

l'reeman, A.

Freeman, H. M., Lowe, J. and Stevens, J. F. $1075 \quad 348$

Freem n, M. I II73 375

Freeman, H. II. I159 369

French, H. F. $\quad 524 \quad 152$

French, J. C. 670 193

French, I. C. $727 \quad 210$

French, M. and J. C. $\quad 756219$

Fribers. $1.518 \quad 151$

Friberg, A. $\quad 532 \quad 154$

Friluerg, $A . \quad 936 \quad 298$

Fricly, I.

Frubling, IT.

$57 \quad 16$

I1 $34 \quad 362$

Frye, J.

Frye, 1.

Frye, I.

Fuller. 1).

(R.) $\quad 1134 \quad 363$

$905 \quad 317$

$965 \quad 317$

$968 \quad 318$

Fuller, II, and Boyil, T. 1 .

$755 \quad 219$

Fuller, 11, and Boyd, 1. I.

Funk, W. I.

lumk, 1). M.

Furaia, IV

linmas, B. and C.

Furnav, IV:

Furst, $\mathrm{C}$ :

Gile, A. H.

Giale, A. 11

Gale, A. I.

Gillagher, IV.

Galt, T: A and Tracy, (i. Si.

fanong, 1. MI. 


\begin{tabular}{|c|c|c|c|c|c|c|c|c|}
\hline \multirow{2}{*}{\multicolumn{3}{|c|}{ Geringer. I. B. and Plue ithe }} & & \multicolumn{2}{|c|}{ Plake $C$ (a)m } & \multirow[b]{2}{*}{ Jal, (. M, and D, E. } & \multicolumn{2}{|c|}{ Plate Claim } \\
\hline & & & & 39 & IO & & 592 & 171 \\
\hline IVilliams, D. H. S. & 467 & $13^{S}$ & Gonlee, O. II: & 150 & 42 & " $"$ " $\quad$ " $\quad$ (R.) & 592 & 171 \\
\hline Gentzrch, H. J. Sr. & 177 & 49 & Gos-lee, O. W. & 189 & 53 & Hall, J. A. & 669 & 192 \\
\hline George, I. & I 75 & 49 & Goss, F. & IO4 & 31 & Ilall, T. I. & 738 & 214 \\
\hline George. i. K. & 799 & 229 & Gowen. W. & IIS & 34 & Hall, T. I. & 964 & 317 \\
\hline reppert, A. & $\mathrm{S}_{52}$ & 243 & Gracey, J. B. & $\mathrm{S}_{73}$ & 250 & 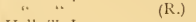 & 964 & 317 \\
\hline Gerber, I. & 528 & 153 & Graham, E. MI. & $1+1$ & 39 & Hall, ". J. & 1035 & $33^{8}$ \\
\hline Gerber, I. & 526 & 153 & Grahan, I. I. and WVal. & & & 6 $\quad 4$ & 1035 & 338 \\
\hline Gerber, I. and Brown, 11 . & 763 & 221 & lace, \$. J. & 350 & 108 & Hall, O. 1). & I I 37 & 363 \\
\hline Gesley, S. & $8_{45}$ & 241 & Graham, J. L. & 484 & 14 I & Hnmaker, I. & I 147 & 366 \\
\hline Gienley, S. & I 201 & $38_{3}$ & Graham, H. J. & 694 & 201 & Hamilton, I. H. & 113 & 33 \\
\hline Gibles, I. & I5 & 3 & ham, J. L. & 752 & 218 & Hamilton, T. F. & 530 & 153 \\
\hline (ibson, W. O. & 58 & 16 & Gratram, NI. G. & $S_{44}$ & 240 & Iamilion, A. & 825 & 235 \\
\hline $\begin{array}{l}\text { Gibon, R. F, and Cow- } \\
\text { den, S. MI. }\end{array}$ & 360 & I I I & $\begin{array}{l}\text { Graham, S. } \\
\text { Gramberry, A. R. and El- }\end{array}$ & 3023 & 335 & $\begin{array}{l}\text { Hammans, } G \text {, } \\
\text { Hammitt, J. M. and } \mathrm{Mi} \text {. }\end{array}$ & 863 & 246 \\
\hline Cibson, H. H. & $78 I$ & 224 & liott, $J$. & 535 & 1,55 & ler, H. T. & 1000 & $32 S$ \\
\hline ord. J. & 59 & 16 & & 413 & 130 & Hammond, W. & $66 I$ & 190 \\
\hline rel, G. L. & ISI & $5 \circ$ & , K. P. & 177 & 49 & mond, $\mathrm{A}$. & 985 & 323 \\
\hline Gifforel, G. T. & 655 & 191 & t, B. A. & $6.4 \mathrm{~S}$ & 186 & Hammond, A & $99 \mathrm{I}$ & 325 \\
\hline Gillert, I. R. and IVes. & $\cdot$ & & an, $C$. & 879 & 252 & Hammon. T. IV. & 515 & 150 \\
\hline ton, s. R. & 33 & 8 & $\mathrm{~s}, \mathrm{~J} . \mathrm{II}$ & 359 & II I & Hammon, H. B. & 513 & I 50 \\
\hline Gilbert, 1. B. & 723 & 209 & es, R. R. & 1007 & 330 & Hammon, T. IV. & 637 & I ${ }_{3}$ \\
\hline Gilbert, Г. M. & $9 s_{4}$ & 322 & , T. and sommer, $J$. & $7 \dot{S}$ & 23 & Hammon, A. 1'., Lincoln, & & \\
\hline Gilbert, I. R. & 1090 & 351 & H. I. & 156 & 43 & I. H., S., and Ham- & & \\
\hline Gilbert, 1. R. & 1100 & 354 & , H. II. & 162 & 45 & mon, $\mathrm{T} . \mathrm{W}$ & 671 & 193 \\
\hline Gilbert, I. R. & $I_{1} 3 \mathrm{I}$ & 362 & B. F. & 262 & 76 & Jammontree, J. F. & 1136 & 363 \\
\hline Gilbert, 1. R. & I 178 & 376 & IV. W. & 512 & 150 & R. & 1100 & 354 \\
\hline ert, I. R. & $\mathrm{IIS}_{4}$ & 379 & I. A. & 605 & 175 & I. T. R. & 78 & 23 \\
\hline ert, I. R. & 1206 & $3^{5}$ & $\mathrm{MI}$ & 794 & 228 & Hand, J. R. & 728 & 211 \\
\hline Gilchrist, H. H. & $\mathrm{S}_{14}$ & 232 & O. C: & $\mathrm{S}_{17}$ & 233 & Haney, R. and Estes, & & \\
\hline Gill, J. G. B. & -23 & 209 & 1. B. & 1079 & 349 & I. Si. & 736 & $2 I_{3}$ \\
\hline Gillerpie, G. WV. C. & $5 \mathrm{~S}_{2}$ & 169 & I. B. & IoK5 & $35^{\circ}$ & Haniver, N. E. and & & \\
\hline Gillham, S. I. and $f_{x}$, M. & 1009 & $33^{i}$ & field, I. T. & I ISS & 380 & loailey, 15,1$)$ & $7 \mathrm{c7}$ & 204 \\
\hline Gillham, S. J. Taylor, NI. & & & G. W. & 1172 & $37+$ & 1 largrave, W. (). & $69 \$$ & 202 \\
\hline C. and Stolle, J. W. & 1059 & $34+$ & Y. E. S. & $9^{S}$ & 29 & grave, $C$. & $86 I$ & 245 \\
\hline Gilliard, H. & 25 & 6 & th. IV. H. & 778 & 224 & Igrave. C. & $\$ 60$ & $2+5$ \\
\hline Gillies, E. Si. & 642 & 384 & es, I. IV: & 1122 & 359 & $n g . T$. & 526 & 153 \\
\hline ( Filliland, D. C. & 43 & II & Iaiv, II. S. & 1076 & $3+8$ & in, W. F. & IOI 7 & 333 \\
\hline Gilliland, A. 1. and B. F. & 990 & 325 & old, I. MI. & 685 & 198 & $\operatorname{lng}, \mathrm{T}$. & 760 & 220 \\
\hline Gilman, $1 \mathrm{~T}$. & 754 & 219 & old. A. II. & 714 & 207 & Hardy, J. & 973 & 319 \\
\hline J. S. & 652 & 187 & er, $\mathrm{F}$ & 1217 & $38 \mathrm{~S}$ & ion, A. A. & 717 & 208 \\
\hline (iilpatric, J. & 64 & I8 & hmann. A. & 94 & 28 & $\mathrm{r}, \mathrm{C} . \mathrm{A}$. & & 123 \\
\hline Given, J. H., Hutsompil- & & & Grons, I. & 606 & 175 & er, I. & 638 & 183 \\
\hline ler, $H$, and Gilbert, $C$. & 637 & $\mathrm{IS}_{3}$ & Gross, J and Tunison, J. C & . 695 & $20 I$ & $e_{2}, \mathrm{~J}$ & 638 & 184 \\
\hline Gilass, J. H. & I059 & 345 & Ground, R. B. & 1078 & 349 & er, J. . H. & $75 \mathrm{~S}$ & 220 \\
\hline Glasscock, 11 & 1199 & $3 \mathrm{S2}$ & A. F. & 59 & 37 & ier, $H$ & III & 32 \\
\hline Gleeson, D. H & 1043 & 341 & M. & 1095 & 353 & iss, 1$)$ & 55 & 15 \\
\hline (ilidden, J. & 161 & 44 & Q, G. A. & 1074 & $3 \div 8$ & Harris, I. & 522 & $15^{2}$ \\
\hline (ilidden, J. F. and & & & h. . I. I. & 743 & 215 & ". $\quad \therefore$ & 522 & 152 \\
\hline Vaughan, P. W. & 11.4 & 365 & ce, $\mathrm{T}$. & I 17 & 33 & a. & 523 & 152 \\
\hline Glidden, J. F. and & & & k. Si. & 635 & 183 & Harris, J. & 537 & I 55 \\
\hline Taughan, P. W. & I 158 & 369 & n, I. and Sit. C. & 599 & 173 & Harris, I. O. and slew- & & \\
\hline addard. C. F. & 1209 & $3^{86}$ & Gum, I. and St. C. & 603 & 174 & der, $\mathrm{W}, \mathrm{F}$. & 464 & 137 \\
\hline odfrey, J. S: & 249 & 72 & Giuptail, D. & 73 & 21 & Harris, E. H. and Cleg- & & \\
\hline ladfrey, I. s. & 254 & 74 & " & 73 & $2 \mathrm{I}$ & horn, J. & $5^{81}$ & 169 \\
\hline J. S. & 255 & 74 & Gustin, J. M. & 790 & 227 & Harris, Y.P. & 754 & 219 \\
\hline $\mathrm{I}: \mathrm{S}$ & 257 & 74 & rie, I. & 477 & $1+0$ & iv, N. J. & 766 & 221 \\
\hline Godfrey, I. S. & 257 & 74 & athrie, T. I)., Jr. & $8_{39}$ & 239 & is, R. S. & 858 & 245 \\
\hline Godfrey, J. S. & 257 & 74 & J. C. & ISI & 50 & ris, J. & 1012 & 332 \\
\hline , M. I3. & 109 & 32 & , B. F, and J. $\mathrm{V}$. & 714 & 207 & is, I. & 1053 & 343 \\
\hline S. MI. & 600 & 173 & $n n u_{j}, C . S$. & 63 & 18 & ris, M. WV. & 1070 & 347 \\
\hline 1, I. A. & 187 & 52 & 1 & 624 & 180 & $5, \mathrm{Ml}$ & 1157 & 369 \\
\hline ith, s. & 595 & 172 & $\mathrm{I}$ & 974 & 320 & is, S. MI. & $11 \div 5$ & $3^{65}$ \\
\hline Gollthait, E. & 963 & 3 I 7 & aege, J. & 977 & 320 & ris, M. & I I 79 & 377 \\
\hline H. & 1210 & 386 & aege, I. & 977 & 320 & rison, 1 . & & 1 \\
\hline $1,0 . \mathrm{E}$ & I $21 S$ & $3 \mathrm{Sg}$ & C, C. $A$. & $\mathrm{SS}_{3}$ & 254 & rison, J. 1$)$ & $\operatorname{Ios} I$ & $35^{\circ}$ \\
\hline Goodrich, A. I. & $\mathrm{So} 3$ & 230 & ue, $C .$. & I 149 & 367 & ison, J. 1). & 1088 & 351 \\
\hline J. II. and & & & $C, A$ & 944 & 300 & son. T. T. & 1185 & 379 \\
\hline odiard, 1$)$ & $11+4$ & 365 & gue, $(\ldots)$. & 1224 & 391 & ison, T. T. & 1208 & 386 \\
\hline$n, C, N$ & 185 & 51 & ight, $G, C$ : & 1787 & $35 \mathrm{I}$ & Harrold, H. & 1095 & 353 \\
\hline lon, A. & 65 & 18 & Haines, (;. W' & 1067 & 346 & IIarryman, N. S. & 604 & 174 \\
\hline lon. M. & 249 & 72 & Hallourt, W. G. & $78_{3}$ & 225 & Hart, R. and Nicholson, & & \\
\hline E. & In 43 & 341 & A. & 999 & 328 & M. $\mathrm{P}$ & I 186 & 379 \\
\hline II. 1 . & 532 & $\mathbf{I} 54$ & 1. J. & 32 & $\mathrm{~S}$ & Jart, (;. 1). & 473 & I 39 \\
\hline tiorham, II. 1. & 770 & 222 & Hall, 4 . & 51 & I4 & rove, II. & 534 & 554 \\
\hline Gorham, MI. L. & Sos & 229 & Hall, I. M. & 379 & 121 & Hartman, C. B. & 941 & 299 \\
\hline Gorham, II. $1 .$. & 805 & 231 & Hall, i... I. & $4 \mathrm{~S}_{3}$ & $\mathbf{I}+\mathbf{I}$ & Harvey, II: & 709 & 205 \\
\hline (iorham, E. 1). & 811 & 232 & IJall, 1). E. & 556 & 170 & Harwell, I: & $2 S$ & \\
\hline
\end{tabular}


Hishorist, F

Hasionork. H:

IIasidII, I.

Ilaskin, II, and Ilart, 1). 13 .

II. slup, IV

Ilasuenplug, (; I: and liaruhart, 6 :

II anslock, II. IV

Hach, 1 i. I).

Ilatfield, (;. IV.

Han hey, I., I).

Havertiek, $\mathbf{L}$.

llawkes, X.

Hawkins, 1.. F.

Hawley, A. IV.

Hawley. J. M.

Ilaworih, IT. H.

Hay, IV: and Freeman, T. $B$.

Ilayes, (i. J.

Haj nes, I.

lleaton, C. W. S.

Ilciton, $\mathrm{C}, \mathrm{IV}, \mathrm{S}$.

Heaton, II. I.

Ileaton, C. IV. S.

Heaton, C. IV. S.

Heerman, $\mathrm{T}$.

Hefit, C

Jetlin. A. J.

Hefin, A. T

Ileiges, J. .I

Ileisey, \&. 1 .

Helem, I.

I lemme, IV.

Hench, S. $\mathrm{X}$

Henderson, J. T.

Henderson, I. T

Henery, A. I'.

Henigst, IV.

Ilenry, s.

Henry, R. II.

Henry, W5.

Henry, IV:

Henry, W:

Henton, I.

Henton, I.

Heprinstall, T. S.

Hétinstall. T. s.

llerbert, I'.

Herman, I. B.

Herman, J. B.

Iermb: $\mathrm{I}$.

Ilemion, J. T.

Herr, I. B.

Herick, $\mathbf{i}, \mathrm{H}$

Hess, C.

Hevilbom, E II.

Ilewett, C. P.

Ilewett, C: P

I lewctt, I?

liewett, II. 1.

Hewit, S.

lick', $\Gamma$

lliggins, K. s.

Ilixgin $\mathrm{I}$.

Iligins, W. F. anil Per-

$$
\text { ry, J. }
$$

liiggins, R. S

Higgins, R. Si.

Higley, 11

IIilidreth, $\mathbf{C}$. II:

Hildreth, I'.

IIildreth, G. IV

ililesabeck, F. I.

Hill, P. I'.
Jivile Cintll

$107 \mathrm{~S} \quad 349$

$\cos _{2} \quad 350$

63 is'

$654 \quad 107$

I070 347

th I3 Ilill, 1... I.

106 iI Ilinchley, J. B.

753218

$6 \mathrm{I} \quad 17$

$637 \quad \mathrm{I}_{3}$

$144 \quad 40$

58 I 16

$595 \quad 172$

163

69 I9

603174

$10593+4$

726210

$+10 \quad 129$

${ }^{3} \mathrm{~S} 9$

$47 \quad 12$

$611 \quad 176$

R.) 611176

$612 \quad 170$

$614 \quad 177$

I9 4

$70120_{3}$

$6 \mathrm{SI} \quad 197$

713206

I $36 \quad 38$

7020

$347 \quad 107$

I 215388

$83 \mathrm{~S} \quad 239$

$405 \quad 12 \mathrm{~S}$

$484 \quad 141$

$172 \quad 48$

$278 \quad 83$

$636 \quad$ IS3

$\begin{array}{ll}722 & 209\end{array}$

I I 2 I 359

$\begin{array}{ll}121 & 359\end{array}$

II $39 \quad 364$

055 I 88

$734 \quad 212$

971319

$972 \quad 319$

$1010 \quad 340$

668 I 92

Iogs 357

$461 \quad 137$

7 OI 203

$58 \quad 16$

6020

$1016 \quad 333$

$403 \quad 127$

$537 \quad$ I 55

$535 \quad 155$

$768 \quad 222$

I $155 \quad 368$

$3^{82} \quad 122$

$92 \quad 27$

$804 \quad 230$

843240

IOI9 334

I 64371

1216358

I I

$40 \quad 10$

$657 \quad 189$

966318

(K.) $967 \quad 318$

$9+2 \quad 299$

I $49 \quad 42$

IIill. I. 1.

II:H. I. II.

Ilill, I. . I.

Ilill, I. I.

IIill I $\mathrm{I}$

I Indmarsh, J.

linkle, s. J. 1). $\mathrm{S}$.

Ilisurt, 13, $\mathrm{F}$,

Iloaglund, C

Iloake, S

Ilolinan, R. Ci.

IItudges, L. II.

IIoffeditz, I.C

Hoffeclits i. C.

Iloff heim, si. Sichmidt, I.

Hogle, s. S.

Iluke, I. I.

Holdredge, XI.

Uolonte, R.

Ifolladay, I. II.

Hulladay, I. M.

I Julland, I. II.

Ifollinger, I.

Inollinger, J.

IIolloway, L.

Holloway, 1. J.

IIolman, C

Holmes, J. C.

Holt, R. C

IJolt D. E. IV.

II onrighoune, L.

Honey, I. s.

llood, I. 1.

Hooker, H. T

Hnover, IV. L'.

Huover, II

Hopkins, W. A.

Hupkins, $\mathrm{C}$. F.

Hopper, IV. 1 .

Hopper, IV. I Ilancy, I

Horning, $\mathrm{S}$. $\mathrm{G}$

Houck, I

Houston, T. I.

Hownd, R. (

Huwe, H.

Howe, 11.

Howe, 11

Howe, II

Howell. M. II.

Hoyman, 11. ș.

Hoyt, F, C.

Hoyt, 13. C :
Ilinds, I. and Cice, I

IIinman, J and Freach,

IIoffman, I. and I Limebeck, 11. IV.

Hoffineyer, A. B, and

Hoisington, S. 1 .

IJullingsworth, J.

Holly, S. B. and Jones.

1lolmes, IV. C:

Holtz, B. and Enoch,

Humrighouse, 1 .

Hoover, T. I. and Henderson, I. T.

Horn, C. 1... Jr., and

Howes, K. X.. I Horr. IV. 1. and Welister, I. 13, I093 353

(A. I.) $\begin{array}{rr}241 & 69 \\ 242 & 69 \\ 258 & 75\end{array}$

IIost, B, C.

Hoyt, A. W.

IIublard, WV. P.

IIubbard, IV. P. and Robinson, J. IV. $\quad \mathrm{S}_{34} \quad 238$

Hublard, 13. R. 1049343

Huber, S. $\quad 95 \quad 29$

Hudson, I. IV. $\quad \mathrm{S}_{72} 250$

Huff, E. . . 33 \&

Huff, E. S. $\quad 96 \quad 28$

Huff, J. $\quad 723209$

Hutiman, $0 . \quad 829 \quad 236$

Hughes, $A$.
Hughes, ; . R. and Wall,

J E. $\quad 412 \quad 120$

Hughes, H. IV, IOI4 333

Hughes, 1). IV. $\quad$ 1079 349

Hughes, D. IV. II69 374

Huie, H. R. $\quad 977 \quad 320$

Huie. H. R. $\quad 1027 \quad 336$

Huic, H. R. IO41 $34^{\circ}$

Huie, I. MI. and Card, E, I063 345

Hullinger, M. H. $622 \quad 179$

Hullinger, M. II. 655 I 89

Hume, J. M. $473 \quad 139$

Humphrey, A. N. 1076348

Hunt, N. I.

Hunt, H.

Hunt, $\mathrm{I}$.

Hunt, A.

IIunt, $A$.

Hum, G. IV.

Hunt, G. IV

Hunt, $; \mathrm{H}^{\circ}$.

Hunt, I..

Hunt, L.

Hunt, F. IS.

Hunt, F, I3.

Hunter, S. C.

Hunter, IV and D, M

Hunter, J. B. 993326

Hunter, J. B. 1 . 1042341

Hunter, I. I3. $1102 \quad 355$

Hunter, E. T. II27 360

Hunter, E. T. I I 68 373

Hurlbert, IV. H. $\quad 522 \quad 152$

Hutchinson, G. E. 26t 75

Hutchinson. G. L. 65I IS7

Hutchinson, S. $995 \quad 326$

Hyde, II S.

Hyde, 11: 1:

Hyer, B, s.

llyers, B. S.

Ide, N

Imel, J.

Ingalls, $\mathrm{A}$.

Ingersoll. (', P.

Ingham, 1. and $J$.

Ingle, J. W, and Wright, R. IV.

ingraham, II

lngraham, II.

ingraham, $\mathrm{H}$.

Jingraham, 11.

Isaacs, IV, H, and Ban. 


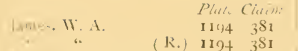

Taun *, J. II., Tucker, H. und Terry, T. I. $1077 \quad 3+9$

Jais, IV. D.

Jay. I. B.

Tefiesion, T. E.

Jefleron, T. E.

Jefferion, T. E.

Jeffersun, T. F

Jeffer-on, T. E.

Jefferson, T. E.

Jefierson, T. E.

Jefferson, T. E.

Jeffries, IV. 1.

Jenkin- I. ( .

Jenkins, J. C.

Jenkins, I'. R

Jeune, C. H.

Jenne, C. II.

Jenne, C. MI.

Jennings, J., Jr.

Jennings, $\mathbf{B}$.

Jessop, J. IV.

Jensup, G.

Jewell, F. C.

Jobe, T.

Johaneson. I.

fuhnson, IV. I.

Juhnron, M.

Johnson, 11 .

Johnson, J.

Johnson, I. G.

fohnson, NI.

fohmoon, R. A.

Juhnson. R. A.

Johnoun, R. A.

Johnoon, 11. MI.

Johnson. M.

Inlinarin, N.

Julinun, M.

Johnson, MI.

Johnson, MI.

Johnson, M.

Jubnson, MI

Johnson, F.

Johnson, C. R.

Johnson, J. I'.

Johnoon, X. S

Johnson, M.

Johnson, II.

Johnson, J. H.

Johnson, P. ix.

Iohnston, B.

Tohnston, J. S. and John-

son, C... . $\quad S_{43} 240$

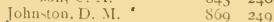

Jone-, I. II. and H. P. $\quad 91 \quad 27$

Jones, A.

Jones, I. B.

jones, I. $\mathrm{f}$.

fones, 11. and Jard,

jones, $\mathrm{S}$.

Jone- T. J.

Iones. I. H.

Iones, I.

loner, II.

lones, J. H.

forilan, W. II

Tortan, I1. 1?.

linclan, II. P

$[1,1,1, \mathrm{~N}, \mathrm{~T}$.

774

$396 \quad$ I 26
Julkins, XI. I).

Judsin, A. C.

Jay, E. IV

Kamerer, IE. I

kizy, J.

Keasor, J. L.

Keasor, 1, I.

Keck, P.H.

Keck, A.

Keezer, 1.

Keith, i.

Keller, 1. H. B.

Kelly, L. W.

Kelly, IV. H.

Kelly, W. H.

Relly, L. M

Kiendall T. IT.

Kendall, F. B.

Kiendig, D,

Kemmedy, A. H.

Kennedy, I.

Kenney. I.. J.

Kent, E. 11.

Kerchner, D. Monuer.

Kerschner, T. A.

Kessler, 13. J.

Kessler, J.

Kewin, C.

Keys, I. and the Mier. J. R.

Kiddoo, IV

Killam, II. and Valleav. G.

Kimball, (;

Kincairl. I. D.

king, 1, B.

Kin, .1. I.

King, T. M.

King, IV. H. 1.

king, (). I.

King, G.S.

Kinghorn, T: and R.

Kingston, S. I. and Gore,

\section{Kinkel, C.}

Kinsey, $\mathrm{C}$.

Kinyon, $A$.

Kirk, W. A. I

Kirknnan, J.

Kirkpatrick, s.

Kirkpatriek, S.

Kisell, F. M. and U, L. $1163 \quad 371$

Kisiell, J. M. and M. L. S22 234

(K,) $822 \quad 23+$

Kissell, F. M. and M. L. $8_{35} 238$

Kleffel, IV. $130 \quad 36$

kinap?, J. G. and Libly,

Kneedler, I, J).

Kinecdler. I. A.

Kinepper, E.

Kniglit, (;.

Knight, E. H.

Knuchle, J.

Knowiton, W. A

Kriowlton, W. A. and Rutledge, $A$.

Inox, s. A

Knox, J. M.

Kuehn, J

Krauser, J. anil C.

Kribs, P.

Krick, 1. S.

Krieble, 11. K.

Kring, (i. W.

Krogh, C. and I'. C.

S54 243

I1 2

$\begin{array}{ll}787 & 226\end{array}$

$683 \quad 197$

$4 i .2 \quad 1.37$

23
$17+\quad+5$

$\begin{array}{ll}17+ & 4 \\ 138 & 35\end{array}$

$\because 22 \quad 200$

$$
\text { T. S. and F. V. }
$$

Plati Claim

1136263 Kroner, \$. A

IO+I $3+0$ Kuchn, IV.

Kungler, ()

Io2S $33^{6}$ Kugler, ().

IOI 332 Kurtz, I.

liynett, II, B.

Kynet, H. P.

Kynet, H. 1'

1.acey, J.

Lacey, I.

Jiacey, 1.

I. acey, I.

I. acy, J. $(i$.

I $28 \quad 36$

l.andenberger, F. D. $\quad 156 \quad 43$

La Dow, C. $\quad 272 \quad 79$

1.a Dow, C.

(R.) $-72 \quad 79$

La Dow, C. $\quad 2 S_{2} 8_{4}$

Laffecty, J. WT. and Brown, C. B.

Lavil, $\mathrm{H}$.

I.ake, H. I.

1. mar, II. B.

1. $. \mathrm{mm} \mathrm{l}, \mathrm{A}$.

I.an.born, I.

Lampton, I. J.

Iandes, I. MI.

Landes, II.

Landin, T. R.

I.andphere, P. F.

Lime. D. H

Iane, I.

Iane. IV. B. aul Coltor,

I.ane, I.

Lane, J.

I ante, J.

Lane, I. Is.

1. ing fort, S. P. and stiouil. Wr. N.

Ianham, W. M.

I.anham, IV. N.

Lapham, s.

Laraway, R. K. and J.

large, $G .621 \quad 179$

Larribee, J. T. IT. $\quad 773 \quad 223$

i.athim, $\mathrm{A}$.

Iathrop, C: G.

I.athrop, L. B.

I aughlin, J. I.,

Jaughlin, I. J.

Jawbaugh, G. W', and IYilliams, I

1.awhaugh, $\mathrm{G}$. IV.

Ianrence, I.. L. and Thomas, G. S

Jeach, E. E.

Jeler, 1.

J.e Boyteaux, I. H. and Ashton, C. A.

$\begin{array}{rrr}\text { Ashton, C. A. } & 986 & 323 \\ \text { Jeclitenthaler, } \mathrm{C} . & +62 & 137\end{array}$

$\begin{array}{rr}773 & 223 \\ 1209 & 386\end{array}$

$65 \quad 15$

1005330

1127561

122.1391

$41 \quad 10$

$525 \quad 152$

So7 231

806231

$596 \quad 173$

l.ee, T.

1.ee, 1.

l.ee, J.

l.ee, $\mathrm{J}$.

Leeper, R. A. and Kid-

$\begin{array}{rr}+62 & 137 \\ 55 & 15\end{array}$

$167 \quad 46$

$2+269$

24269

967318

$967 \quad 318$ ter, Z. B

Leen, I. 1.

$601 \quad 173$

J.efelier. J. and schults, C. IV.

I.effler, F, C

1.effler, F. C.

J.efler, A. B.

Legg, J. T.
$601 \quad 173$

$168 \quad 46$

$260 \quad 75$

643 IS5

379

1007330
$8+62.11$ 
1.eilly, J. C.

Leidy, I. C:

1.eigh, A.

1.eland, . 1.

leonard. A.

I.eanard, A.

L.eonard, $\mathrm{F}$.

Leonard, F. A

Leslie, F. M.

Leslie, WV.

L.etz, J. I'.

Levee, E,

Lewellin. II.

1.ewis, A. I.

Lewis, VI.

Lewis, J. F.

Lewis, I

Lewis, I. B. and Ldall J. E.

Jew is, I. II:

Lewis, J. W:

Likes, II.

lindgren, A.

Lindly, J. I.

lindren, $C$

Little, I. R.

little, J. R.

Little, J. R.

I.ittlefield, C. H.

Litzenberg, B. F.

Litzenberg, B. F.

Livezey, I. B.

L.obdell, C.

Lobdell, C

Locke, D.

L.ockie, J. H.

Lockwood, S. .I.

Logan, J. B.

Long, $\mathrm{P}$.

Long, 1 .

Long. J. M.

Lony, 1.

Looker, W.

Lord, 1, and Woodman, $:$

Londen, IV.

Lowrie, W. E.

Lowth, M. F, and llowe. T. I.

$\begin{array}{lll} & 1025 & 33^{6} \\ \text { (R.) } & 1025 & 33^{6}\end{array}$

$\begin{array}{ll}1025 & 336 \\ 1036 & 339\end{array}$

$\begin{array}{rl}1037 & 337\end{array}$

$1059 \quad 344$

$11953 \mathrm{~S}$

$73+\quad 212$

$634 \quad 18_{3}$

$\begin{array}{lll}527 & 153\end{array}$

$527 \quad 153$

$727 \quad 210$

$1002 \quad 329$

119.381

$1217 \quad 388$

$30 \quad 7$

S9 26

$\begin{array}{ll}92 & 27\end{array}$

$+14 \quad 130$

10130

$991 \quad 325$

$1029 \quad 337$

$\begin{array}{ll}4+1 & 39\end{array}$

$\begin{array}{lll}587 & 170\end{array}$

$834 \quad 238$

1002229

$726 \quad 210$

$\begin{array}{ll}61 & 17\end{array}$

353109

$184 \quad 51$

$519 \quad 151$

Lowth, V. F and Howe, T. I.

Lowth, II. F and Porter. O, H.

$521 \quad 151$

$529 \quad 153$

1.owth, M. F and Howe, T. J.

Low, I.

Lucis, J. B.

1.udlow, J. . H. and Pruitt, S. C

Lueth. I.

Lufkin, C. If.

1.und, G. H.

Luney, $\mathrm{S}$.

Luppen, 1 .

Luppen, 1.

1.uppen, I.

1.uppen, $\mathrm{L}$.

Luppen, L.

Luppton, A.

I. ux, J.

Lyman, W., Jr.

Lynch, J. D.

Lynch, G. F.

1.ynch, E. P. and Wright, E. A.

$880 \quad 196$

$756 \quad 219$

$794 \quad 228$

$35^{8} 110$

$934 \quad 297$

Sos 231

7 So 22.4

$796 \quad 228$

II 533

$\begin{array}{ll}527 & 153\end{array}$

$527 \quad 153$

$936 \quad 298$

$936 \quad 298$

$188 \quad 52$

$\begin{array}{ll}799 & 229\end{array}$

$43 \quad 11$

$149 \quad 42$

$390 \quad 124$

$538 \quad 155$

Lynch, E. P. and Wright,

\section{Plate ('mim
$540 \quad 156$}

I.snch, F. I'. and Raff, I1. $R$.

lench, E I?

Lynch. E. P'.

Niabbett, T., Ji:

IIctllinter, $T, T$, and Mcl)onald, W. W:

MeBride, I.

UcCall, $\mathrm{l}$. R.
McCall, F. R.

$\begin{array}{ll}737 & 213\end{array}$

$73 \mathrm{~S} \quad 214$

939299

IOS 32

NicCatty, 13, F., Orr, I. IV. and R. J.

ICCaughan, C. A.

IIcClean, J. B, and Nayer, C.A

McCleave, H, P.

IIcClen, J. J.

Mlcclintick, I.. D.

IcCollester, 13. F

McConaughey, T. B.

NcConnell, J. R.

IIcConnell, I. K

IIcConnelI, I. R.

McCool, W.

Alc Cool, W. C.

Mic Corkell, R.

IcCorkell, R.

VcCormick. I. B. and liaker, il. R.

IcCurmich, IV.

Ifcormick, J. R.

IcCormick, J. R.

McCormick. T. R.

McCoy, WI. J.

IcCrocken, W.

IIcCray, T. H.

Iic Creight, 1 .

VIcCurley, A.

VicDermott, A. S.

IIcDermott, A. S.

IIcDill, T, IV

II IDill, T. W.

McDonald, T. E.

IICDonald, J. $\mathrm{k}$.

McDonell, A. S.

McEwen. E. S, and Adams, O, R.

McEwin, E.

IIcriee, C.

Incliee, T., D. W., and IV. J.

Ifcilew, P.

MeGrew, $C$.

If Ilvain. I.

Mcliay, N.

Nckinley, R.

Ilckinny, $\mathrm{S}$. P.

IIclemnan, J. K.

MicMahan, M. $\mathrm{s}$.

UIclleekin, F. M.

IcNabl, D.

IcNair, T. F.

Ir Neeley, D, and Cady, C. I.

VeNitt, II

MeNorton, I. T.

IcPike, I. M..

NicQuiston, T.

UcSherry, D. F

McTarmahan, $\mathrm{F}$.

Macy, I, and Watkins, J. $\mathrm{C}$.

Nlagruder, C. B.

Mahon, 1. 1?

Nahon, I. B.

Mahnu, I. B.

Mahon, I. B.

$\begin{array}{rrr}70 I S & 334 \\ 7 & 763 & 221\end{array}$

Vallon, J. 277 8I

Aallon, $j$, and Vion Phui, M. Ir.

$530 \quad 154$

Nallon, J.

Miangas, $\mathrm{J}$.

Janley, iv

Namly, F, B

Manly, F. B,

Mann, H.

Mann, $\mathrm{H}$.

Manny, A. I.

Nanny, A. II

Manny, A M

Manny, J. P.

Manuel, G. W.

Manuel, G. IV.

Manuel, D. A.

Manuel. D. A

Warkee, I. and Spicer, IV. E.

Markel, J.

Markham, D. A. S. and Eldrid, D.

Markham, A. S.

Markham, A. S.

Miarkbam, A. S

Markillie, T. R.

Markillie, T, R.

Mark?, G. M.

Marr, I.

M.nrsh, and, C.

Jarnh, 2nd, C.

Manh, and, C.

Marsh, I.

Marsh, W. W. and McIn-

$$
\text { tyre, } H \text {. }
$$

Marsh, W. W

Mar-hall, J. D.

Martin, A. T. Jr.

Martin, 1.

Martin, A.

Martin, $\mathrm{s}$.

Martin, T. J.

Nason, J.

Mason, R. E.

Mason, IV

Vason, W:

Jason, W.

Ilason, H. WV

$715 \quad 207$

$875 \quad 251$

$164 \quad 45$

943300

943300

143

184

$\begin{array}{ll}770 & 222\end{array}$

$\begin{array}{ll}770 & 222\end{array}$

$788 \quad 226$

I020 334

$1077 \quad 349$

$1069 \quad 346$

I I09 356

$350 \quad$ IOS

$602 \quad 17 t$

$\begin{array}{ll}589 & 170\end{array}$

$616 \quad 177$

653188

$69320 \mathrm{I}$

$972 \quad 319$

$980 \quad 321$

$\begin{array}{ll}871 & 2.49\end{array}$

1080 349

$135 \quad 37$

I $36 \quad 37$

I $33 \quad 37$

$690 \quad 199$

$\begin{array}{ll}777 \quad 224 \\ 170 & 374\end{array}$ 


\begin{tabular}{|c|c|c|c|c|c|c|c|c|}
\hline Mceher, A. & $\begin{array}{l}P \text { Pute } \\
280\end{array}$ & $\begin{array}{c}\text { Claim } \\
83\end{array}$ & Moore, I. (i. & $\begin{array}{l}\text { Plate } \\
1033\end{array}$ & $\begin{array}{c}\text { Cluim } \\
338\end{array}$ & Nevill, G. IV'. & Plate & Claim \\
\hline Meeks, is. & 796 & 228 & Neore, $\mathrm{G}$. & 1101 & 354 & Nevins, IV. & $\begin{array}{r}24+ \\
45\end{array}$ & II \\
\hline Mezquier, C. F. & 678 & $\mathbf{1} 96$ & Noore, $\mathrm{G}$. & 1107 & $35^{6}$ & Newlin, WV. & 1052 & 343 \\
\hline Nelurry, $A$. & Sig & 2.33 & Iloore, G. & 1112 & 357 & Newlin, W. & 1084 & 350 \\
\hline Meharry, W. J. & I 190 & 380 & Noore, I. H. & 1184 & 378 & Newlin, IV. & 1190 & 380 \\
\hline Meilile, T. & 127 & 35 & Moorehead J. B., Pool, & & & Newlin. E. & 686 & 198 \\
\hline Neikle, T. & 857 & 244 & T. A. and $G, G$ & 42 & 10 & Newman, W: B, and Wil- & & \\
\hline Meikle, T. & 1167 & 373 & Morgan, B. S. & 23 & 5 & kinson, T. J. & 1124 & $3^{60}$ \\
\hline Mcikle, $\Gamma$. & 1218 & $38 y$ & Morgan, $1 . B$. & $\mathbf{1 8 6}$ & 52 & Newman, IV. 13 . & II 35 & 363 \\
\hline Meloy, E. and Stanley, & & & Morgan, B. S. & 587 & 170 & Newson, G. S. & 395 & 126 \\
\hline A. K. & 1054 & 343 & Morgan, W. $\mathrm{V}$, and & & & Newton, R. & 1085 & 350 \\
\hline Meiton K. M. & 21 & 4 & Hackman, T. W. & 1208 & 386 & Newton, E. IV. & 1182 & 378 \\
\hline 6 & 21 & + & Norrel, $\Lambda$. H. & 378 & 121 & Nichol, T. N. & 1104 & 355 \\
\hline " $"$ & $2 I$ & 5 & Morris, E. F. and Green, & & & Nichols, 11.11. & 56 & 15 \\
\hline Melvin, M. A. & 1066 & $34^{6}$ & k. J. & 73 & 21 & Nichols, W: T: & 411 & 129 \\
\hline Mendenhall, C. & 881 & 253 & " $\quad$ " $\quad$ (R.) & 73 & 21 & Nichols, H. IV. & 273 & 79 \\
\hline Nerkel, $P$. & 999 & 328 & Morris, I3. F, and & & & Nicholson, J. IV. & 91 & 27 \\
\hline Nerrill, A. & 1070 & 347 & Austin, E. $H$. & 175 & 49 & Niece, R. K. & 177 & 49 \\
\hline Mesenger, N. and & & & Morris, J. R. & 397 & 126 & Niederauer, C. & $S 78$ & 252 \\
\hline Erwin, J. & 170 & 47 & Norrimon, J. E. & 53 & 14 & Nirhwitz, $\mathrm{F}$. & 253 & 73 \\
\hline Messenger, $\mathrm{N}$. & 467 & 137 & Murrison, $W$. & 514 & 150 & Noble, IV. & 251 & 72 \\
\hline Mettler, W. & 626 & 1 So & Morrison, J. E. & $33^{8}$ & 105 & Noble, D. I. & 656 & 189 \\
\hline Mettler. W. & 840 & 239 & Norrow, 1. J. & 100 & 29 & * $\quad$ " & 656 & 189 \\
\hline Neyer, 1 . & 45 & II & Morse, J. MI. & 692 & 200 & Noble, 10. J. & 606 & 192 \\
\hline Neyer, J. & 85 & 25 & Morsman, J. A. & 1221 & 389 & Notan, J. S. & 124 & 35 \\
\hline Michener, A. I). and & & & Morter, G. W and Berry, & & & Norling, A. and C. A. & 863 & 246 \\
\hline Steigmeyer, J. W. & 96 & $2 \mathrm{~S}$ & E. & 90 & 27 & Jorman, D. & 777 & $22+$ \\
\hline Michketion, XI. & 1039 & 340 & Nosely, 1 . & 119 & 34 & Nurton, C. P. & 478 & 140 \\
\hline Miers, I. & 37 & 9 & Mourning, F. G. & 342 & 106 & 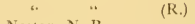 & 479 & 140 \\
\hline Mlillart, J. & 90 & 27 & Mowrey, C. & $11+6$ & 366 & Norton, N. B. & 1027 & $33^{6}$ \\
\hline Miller, I. & 110 & 32 & Mowrey, C. & 1146 & 366 & Norton, R. D. & 280 & $\mathrm{~S}_{3}$ \\
\hline Miller, I. & 159 & 44 & How rey, $C$. & 1217 & 389 & " $"$ " & 289 & $\mathrm{~S}_{3}$ \\
\hline Miller, I1. & 525 & 152 & Muir, W. & 92 & 27 & Nurton, C, P. & 674 & 194 \\
\hline Miller, R. M. & 346 & 107 & Mlumford, J. and Wilson, & & & Notman, W. & 106 & $3^{\text {I }}$ \\
\hline Miller, $(;, 1)$. & 629 & 181 & I. W & 602 & 174 & Nusbaum, A. B. C. & $39+$ & 125 \\
\hline Miller, W. D. & 795 & 228 & Munger, W. P. & 804 & 230 & Nutting, I. F. & 987 & $32+4$ \\
\hline Miller, 1. and Kaller, H. & $9 \mathrm{Si}$ & 322 & Munson. A. K. & 1190 & 385 & (Olell, K. I', Jr. & 535 & 155 \\
\hline Miller, IV: Is. & I I96 & 382 & Munz, J. F, & 1195 & $3 S_{1}$ & () dell, A. T. & $5 \times 1$ & 109 \\
\hline Niil!s, I. & 640 & $1 S_{4}$ & Murphey, $\mathrm{T}$. & 26 & 6 & Uehrlein, C: & i 59 & 44 \\
\hline Mills, J. & $7 \mathrm{~S}_{5}$ & 226 & Murphy; J. & 69 & 20 & ()gborn, H. and Taylor, & & \\
\hline Mills, J. R. & 621 & 179 & Miurphy, $\mathrm{I}$ & 1035 & $33^{8}$ & G. & $5 \$ 5$ & 170 \\
\hline Mills, S. G. & 652 & 187 & Ninrey $\mathrm{IV} . \mathrm{H}$. & 775 & 223 & ()gburn, H. & 595 & 172 \\
\hline Milne, J. (1). & 152 & 42 & Alurry, $\mathrm{J}$ & 1056 & 344 & oliendorph, H1. and J. & $108 y$ & 351 \\
\hline Mlilroy, I. II. & 77 & 22 & Muschert, B. F. & $1+2$ & 39 & ()'der, II: 11 & 621 & 179 \\
\hline Milroy, I. W. & 389 & 123 & Mussetter, 1. S. & $\mathrm{SS}_{3}$ & 253 & OHA, A. W: & 245 & 70 \\
\hline Milroy, I. IV. & 400 & 127 & Mustard, J. E. & $8_{50}$ & 242 & (Oler, I. & 1057 & 344 \\
\hline Niner, $f_{i} .(i$. & 526 & 153 & Mlyers, J. & I I & 2 & Olmuted, H. A. & 1203 & 384 \\
\hline Miner, T. H. and & & & Myers, Т. H. & 172 & +8 & () luon, $O$ & 861 & 245 \\
\hline Heavenridge, $x$. & 655 & $\mathbf{I} 89$ & Myer, I). & 384 & 122 & ()ne:t, C. IV. & 167 & 46 \\
\hline Ninnich, $\mathrm{F}$. & +70 & 138 & Myers, A. H. & 766 & 221 & () p. H. & $110 \bar{s}$ & 356 \\
\hline Minter. J. R. & 127 & $3^{6}$ & Myers, $c$ : & $1 \circ 8_{3}$ & 350 & ()rlando, I. & Si1 & 232 \\
\hline Minuse, 11 & IOIO & 331 & Myer, C: & 1100 & 354 & Orr, I. and Mlartin, H. H. & 1027 & 336 \\
\hline Mlisner, $F$, and $I ' A$. & 464 & I 37 & Nyer, C. & 1166 & 373 & Orr, W. T. & 1143 & 365 \\
\hline Mitchell, I. & 539 & 156 & Myers, $C$. & 1215 & 388 & () sborn, B. F. & 935 & 298 \\
\hline Mitchell, \&. H. & 636 & 183 & Nash, C. & 851 & 243 & () sborn, J. I). & 630 & 181 \\
\hline Nitchell, S. 11. & 619 & 178 & Nation, R. & 980 & 321 & Osborn, $\mathrm{O}$ & 1032 & 338 \\
\hline Nlitchell, S. H. & 750 & 218 & Nauman, E. & 156 & 43 & Osborn, 0 & 1106 & 356 \\
\hline Mitchell, J. M. & 858 & 244 & Nauman, E. & 163 & 45 & Ustrom, H. WV. & 72 & 21 \\
\hline Nomany, (). F. & 251 & 72 & Neal, H. IV. & 1020 & 334 & ()strom, H. IV. & 750 & 218 \\
\hline Monaghan, $P$. & 25 & 6 & Neal, H. $\mathrm{H}$. & 1039 & $34^{\circ}$ & Otwell, I. M. & I 79 & 50 \\
\hline Muntgomery. T. J. and & & & Neal, H. W. & 1071 & 347 & Ough, WV. & 1076 & 348 \\
\hline G. WI. & 158 & 44 & Needham, 13. F. and & & & Over-hiner, G. J. & 1090 & 352 \\
\hline Mooty, I. B. & 110 & 32 & 1.. W. & 942 & 299 & ()wen, G. & 337 & 105 \\
\hline Hoody, S. A. & 246 & 70 & Necdham, F. M. & 832 & 237 & " & 337 & 105 \\
\hline Moorly, 1 .. & 392 & 125 & Neff, J., Ir. & 79 & 23 & if 64 & 337 & 105 \\
\hline Noody, I. Bi. & 523 & 152 & Neff, J., Jr. & 114 & 33 & Owen, J. 11. & $5+1$ & $15 \overline{6}$ \\
\hline Mouily, W. A. & 687 & 198 & Neff, J., Jr. & 594 & 172 & Owen, D. C: & 545 & 157 \\
\hline Moon, II: Si. & $8+7$ & 242 & Neff, & $\operatorname{ros} 5$ & 350 & Owen, G. WI. & 481 & $14 \mathbf{I}$ \\
\hline Mooit, IV, s. & 865 & 247 & Neff, J. 13. & 1192 & 381 & Ow en, $f_{i}$. & $3+3$ & 106 \\
\hline Mluore, E. B. & 150 & 43 & Neff, J. B. & 1193 & $3 \mathrm{SI}_{\mathrm{I}}$ & Owen, C. N & 1066 & $34^{6}$ \\
\hline Moore, I. & 275 & 80 & Neff, f, B. & $120_{3}$ & $3 \delta_{4}$ & Gwen, C. N. & 1073 & 347 \\
\hline Moore, M. II. and Satter- & & & Neidich, J. and ( iirvin. & & & (), er, W. I. & 62 & 17 \\
\hline white, A. & 467 & 137 & & $3^{6}$ & 9 & I'ackard, $i$. & 590 & 171 \\
\hline Noore, 1. B. & 665 & I 91 & Neisler, 0.3. & 772 & 223 & * " & 590 & 171 \\
\hline Moore, $i$. & 687 & 198 & Nellin, A. J. & 191 & 53 & Packer, H. & 816 & 233 \\
\hline Noore, $\mathrm{C}$. & 776 & 223 & Nelson, K. & 4 & I & P'adon, I. S. & 608 & 175 \\
\hline Hoore, $\mathrm{C}$. & 859 & $2+5$ & Nelion, IV. & 1016 & 333 & Padon, J. Si. & 977 & 320 \\
\hline Whore, 1. & IOII & 332 & Netherland, J. 13. & 26 & 6 & Padon, J. ৯. & 987 & 324 \\
\hline
\end{tabular}


Page, (i.

Page, J. G.

Paine, C. J

Palcer, J.

Palmer, $\mathrm{N}$

Palmer, N.

Palmer, $\mathrm{N}$

Palmer, I. A

Palmer, I. A

Palmer, 1. A

Palmer, I). IV

Palm, J. H

Pangborn, C. . . and Beers, G. WV.

Paradis, J. B.

Parcell, P. B.

Parish, G. W:

Parker, J. A. J. WV.

Parker, 11 .

Parks, R. B, and J. R

Parks, R. B. and J. R.

Parlin, WV. H.

Parlin, W. H.

Parmele, E and curkendall, $\mathrm{G}$.

Parmele, E. and Patterson, R. . .

Parr, S., E.

Parrish, IV

Parrish, IV.

if, and J. (i. $1064 \quad 346$

Parsons, J., Jr.

Parsons, G. W. and Finney, W. S.

Parsons, G. A

Pattee, J. H.

Pattee, J. H.

Pattee, J. H.

Pattee, H. H.

Pattee, H. H.

Pattee, D.

Pattee, D.

Patterson, J.

Patterson, E. C.

Patterson, 1. M.

Patterson, T.

Patterson, $C$. and Abraham, H. L.

Pattillo, R. II

Patton, R. F.

Pattyson, P.

Paul, D. H

Paxson, C. E.

Payne, R. L.

Payne, J. T.

Payne, J. M.

Payne, J. M.

Payne, J. M.

Payne, J. M.

Payton, J. H.

Peaboday, S. G.

Peaboday, $\therefore$. G.

Peak, E.

Pearl, I. C.

Pearl, J. C.

Peck, S.

Peck, E.

Pedrick, R. R.

Peeler, J.

Peirce, J. H.

Pelsor, P. D, and $\mathrm{H}, \mathrm{C}$.

Pelton, L. D, and Barrow, I.

Pence, J. W:

Pendley, w.

Pendley, W. and Moss, A.
Plate Claim

Pendley, Wr, and Moss, A.
Pennock, S.

Peppler, T.

Percy, W. C

Perez, F.

Perkins, E. H. and $\$$. I).

Perkins, $\mathrm{H}, \mathrm{H}$.

Perkins, H. H.

Perrigo, A. S.

Perry, G.

Perry, A. (i.

Perry, (i.

Perry, F. 1

Perry, F, L.

Perry, F. I.

Perry, G. W

Perry, H. I.

Perry. H. 1.

Peters, $\mathrm{S}$.

Peterson, G. WV.

I'ettengill, C, B

l'eugh, S. B.

Pfiel, J. C.

Pfiel, J, C.

Phifer, E.

I'hifer, E

l'hifer, E.

Philler, IV. WV

Philp, J. W.

Phillips, J.

Phillips, E.

Pickering, 1. P.

Pierce, W

Pierce, J.

Pierce, J.

Pierpont, J. and liuttle,

Pierpont, $J$.

Pierpont, J.

Pierpont, I.

Pierpont, J.

Pierpont, J.

Pigg, H. L.

Pike, E. W

Pirkle, W. J.

Pitkin, J. H.

Pitts, I. K.

Pitts, II. M.

Plate, H. M.

Ilatt, W. H

Poetz, J.

Poetz, J.

I'ollard, J. L.

Poling, $\mathrm{T}$.

Pomeroy, H. A. f; and Hudson, R. F.

Pomeroy, S. G.

Pomeroy, S. G.

Pond, I. F.

Pond, J. F.

Pond, O. M.

Pond, $O$. M.

Poole, T. W.

Poole, J. F

Pool, J.

Porter, M., Jenkins, C.

$$
\text { E. and G. F. }
$$

Porter, J. F, and Norton, A.

Porter, F. $1022 \quad 335$

L. $1045 \quad 342$

Porter, J. E.

Potter, E. M

Potter, H. J.

Potter, H. S.

Patter, J. O.

Potts, J.
$877 \quad 252$

$1142 \quad 364$

$1053 \quad 343$

I3I 36

$144 \quad 40$

$167 \quad 46$

$\begin{array}{lll}787 & 226\end{array}$

$820 \quad 234$

$526 \quad 153$

17348

$\begin{array}{ll}658 & 189\end{array}$

$\begin{array}{rr}96 & 28 \\ 101 & 30\end{array}$

$124 \quad 35$

$161 \quad 45$

$1004 \quad 329$

IOI I 332

$\begin{array}{ll}1211 & 387\end{array}$

18250

$\begin{array}{ll}76 & 22\end{array}$

$\begin{array}{lll}982 & 322\end{array}$

$1006 \quad 330$

$64 \mathrm{I} \quad \mathrm{IS}_{4}$

$6 \$ 1 \quad 196$

$707 \quad 205$

$670 \quad 193$

$109 \quad 32$

$407 \quad 128$

$117 \quad 33$

$537 \quad 155$

$834 \quad 238$

$\begin{array}{ll}981 & 322\end{array}$

$982 \quad 322$

$\begin{array}{lll}528 & 153\end{array}$

$\begin{array}{ll}525 & 152\end{array}$

$932 \quad 297$

$157 \quad 43$

$866 \quad 248$

$1153 \quad 368$

$\begin{array}{ll}776 & 223\end{array}$

$74 \quad 2 \mathrm{I}$

$183 \quad 5^{1}$

$403 \quad 127$

938298

$062 \quad 345$

$380 \quad 121$

939298

$\begin{array}{ll}170 & 47\end{array}$

$\begin{array}{ll}171 & 48\end{array}$

$\begin{array}{ll}79^{8} & 229\end{array}$

$346 \quad 107$

$\begin{array}{lll}38 \mathrm{I} & 12 \mathrm{I}\end{array}$

$867 \quad 248$

I220 398

24570

$258 \quad 75$

$763 \quad 221$

$\begin{array}{ll}786 & 226\end{array}$

183

$8_{32} \quad 237$

$258 \quad 75$

$931 \quad 297$

I140 364

$\begin{array}{rr}157 & 43 \\ 921 / 2 & 300\end{array}$

$664 \quad 191$

IO52 343

$\begin{array}{ll}62 & 17\end{array}$

Potts, T. I. and Viont, P. C:

Poundstone, C. V

Powell, J.

Powell. E. R.

Bowell, E. 1),

Powell, T.

Powell, 1. W:

Pratt, E:

Pratt, 1. C.

Pratt, 1. C.

Prawl, P. and Wemple, F. $\mathrm{H}$.

Preston, $\mathrm{H}$

Price, W.

Price, W.

Price, J. A.

\begin{tabular}{ll}
$157 \quad 44$ \\
\hline
\end{tabular}

I'rice, J. ? $669 \quad 192$

I'rice, $\mathrm{G}, \mathrm{W}, \quad 674 \quad \mathbf{I} 94$

Price, J. $1045 \quad 34^{2}$

$\begin{array}{llll}\text { Price, J. } & 1172 & 374\end{array}$

Price, G. P. I169 373

Price, C. G, and Merritt, J. . II.

$1168 \quad 373$

Prosser, T. T., Darling, is. C. and K. A. $632 \quad 182$

Prout, H. $\mathrm{N}$.

$147 \quad 4 \mathrm{I}$

Prout, H. N. $\quad 176 \quad 49$

Prout, H. N. $\quad 814 \quad 232$

Prugh, G. W. and Beard, IV. H.

Puiliam, E. P.

$\begin{array}{ll}654 & 188\end{array}$

Purcell, J. L.

Purdy, S.

1108356

Pusey, F. W:

$1051 \quad 343$

Pusey, W. W.

Pyle, 1. N.

Pyle, I. N.

Quarton, WV. B.

Quick, W. B.

Quick, W. B.

$\begin{array}{ll}822 & 234\end{array}$

$848 \quad 242$

1118358

Juick, IV, B.

Quirin, G. and Berkel,

Rabb, J. W.

Ralston, A.

Ralston, I. B, and Har-

$$
\text { vey, is. }
$$

Ralston, J. B.

Ralston, J. B.

Ralston, D. W

Rand, N. A.

Randall, S. G.

Randall, S. G.

Randall, $\&$ G 
Relman. I

Reck, II:

Redfictel, R. B.

Resllinger. II.

Reed. M.

Reed, S.

keed, I. I.

Keed. .े. I

keet, T. M

Rerese, F.

Reene, E.

Rereve, II, F, A, B, Iut

$$
\text { 11. } \mathrm{T} \text {. }
$$

Keeves, A. B.

Recres, H. E.

Recves, H1. E.

kichard. I.

Keid, C. i.

Reiner, J. K.

liemy, B. IV.

Remy, B. IV and $\mathrm{x}$ "

$\begin{array}{llll}\text { Reny, 13. W, and N. T. } & 119 & 34\end{array}$

Kemv. N. T. $855 \quad 244$

kenfro, R. A. 1143365

Repp, I.

Reurs, I. 1.

Reyneron. I. 11 and Worrtil. J

Revnerson, J. H.

Reyneron, J. H.

Keynolds, F. F

Keynold. E. D. and

$$
\text { O. B. }
$$

$\begin{array}{rr}1143 & 305 \\ 64 & \text { I } 8\end{array}$

I $207 \quad 385$

$1047 \quad 342$

$678 \quad 196$

$705 \quad 204$

9924

Keymolely, P. F and I. $\quad{ }^{1} 3^{6} \quad 3^{8}$

Reynolds, E. D. and U. B. $796 \quad 228$

Reynolds, S. G.

Reynold ‘, E. D. and

$$
\text { O. T. }
$$

Rhamy, I. 11 .

$$
\begin{array}{rr}
1126 & 360 \\
872 & 250
\end{array}
$$

Rhinehart, IV, N and (R.) $873 \quad 250$

$$
\text { Felker, } \mathrm{H} .
$$

$61 \quad 17$

Rhinehart, IV, C. and Craston, $R$.

Khondes, A. A. and Tash, W.

Khodes, Ci, II:

liver. T. and Hitcheock,

L. R.

kice, J. H

lice, I. II

Rice. IV. B.

Kich, J. C

Rich, $\mathrm{C}$. and Xei-ler. C. L.

Kichard, 1.

Kichard-, J. .M.

kichartson. IV

kichard-on, IV. C. B.

Richardion, C. R. ant Behel, J.

Kicbardsun, I.

Richardson, L. W

kichartion, II

Richardion, T. and McInnis, XI.

Richardion, II: ML.

Richter, WT

Kickerd, J. C.

Riddle, IV. I

Riddle, W. N.

kider, J. J.

kigby, $A$.

kigell, $M$. and lvey. W. D.

kigell, M. $469 \quad I_{3} 8$

$484 \quad 141$

$654 \quad 188$

$1038 \quad 339$

$60 \quad 17$

$700 \quad 203$

$\mathrm{IS}_{5} 51$

7220

$408 \quad$ I $2 \mathrm{~S}$

$788 \quad 226$

834238

IOSo 349

III 357

$1120 \quad 359$

II 31

72

$\begin{array}{ll}703 & 203\end{array}$

$824 \quad 235$

I1 $36 \quad 363$

$629 \quad 181$

$160 \quad 44$

$\begin{array}{ll}31 & 8 \\ 32 & 8\end{array}$
7421
Riggs, II, 5

Riggs, D. C

Righter, J

Riney, T I.

Risley, ( . M and Roger

C. B.

Ritson, F.

Rivers, IV. H:

Roach, L.

Robbin-, R. B.

Roblins, R. B.

Robbins, R. B.

Robbins, R. B.

Kobbins, K. B,

Rolbin:, R. B.

Kobbins, R. B.

Rubbins. I. H. and $\backslash . \quad 1064 \quad 346$

Robents, I. C. $154 \quad 43$

Roberts, M. 1.

Roberts, T. B.

Roberts, E. 13.

Roberts, A. A, and l havis.

$$
13 .
$$

Koberts, $C$ :

Roherts, C

Rohert, $\mathrm{C}$

Roberts, $\mathrm{C}$

Roberts,

Robert?, C

Robert-, $\mathrm{C}^{\circ}$. S

Roleits. . II

Roliertion, 11. 11

Rohertion, E.

Robertwon, S. M. and Hamilton, A. A

Robertron, $\mathrm{IV}^{r}$. II.

Robertson, 11. H. and Carr, C. G.

Robertion, II: J. and

$$
\text { Kinght, } P \text {. }
$$

Robeitron, W. I.

Rubinson, L.

Rolinson, I.

Rolimion, J. H

Robinson, IV. K

Robimman. I. F;

Robinvon, J. (i.

Robson, I.

Ruby, Mi.

Rockafellow, s.

kockafellow, s.

Rockwood, 1.. ().

Rodelus, , C. S.

Kuden, A.

kodger, $\mathrm{C}$

kodgers, IF.

Rogers, IV. A

Rogers, H. 1.

Rogers, T. B.

Rogers, 1). 13$$
\text { is .. }
$$

Rogers, I). B.

Rogers, L.

Rogers, D. B.

Rogers. IV. T

Rogers, J. C.

Rogers, II. C

Rolirer, A. P.. C. F, and Blose, J. H

Romann, A. and Pet erka, J.

Ronat, M. E.

Roney, H.

Rood, E.
Palc Claim

399 Ruot, F. 1'.

Root, J.

Root, B. M.

Claim

$\begin{array}{ll}58_{2} & 169\end{array}$

753218

866248

Root. J. $\quad$ IO3I 337

Roquemore, P. H. I $\quad$ I53 42

Rose, J. J. $\quad 736 \quad 213$

Rose, H. II. $760 \quad 220$

Rosencranz, A. C. $\quad$ IISg 380

Ross, H. S. 107 3I

Ross, A. IV. $\quad 59$ I6

Rousc, T. $409 \quad 129$

Routt, A. P. $66 \quad$ I9

Routt, A. P. $\quad$ S4 25

Rowell, I. S. and J. $516 \quad 150$

(R.) $517 \quad 150$

Rowell, G. D. 536 I 55

Rowell, G. D. $\quad 540 \quad 156$

Rowell, I. s. and I. $\mathrm{S}_{2} \quad 24$

Romell, (;,D). I20 34

Rowell, M. M. $\quad 165 \quad 46$

Rowell, J. \$. $\quad 545 \quad$ I57

Rowel, E. $\mathrm{G}_{*}, \mathrm{~A}, \mathrm{D}$. Rice, J. R. and secley,

$\rightarrow \mathrm{ll}$

kowland, J. E.

Roy, F. $\quad 1+3 \quad 39$

Ruddick, II. A. II $20 \quad 359$

$\begin{array}{lll}\text { Rue, J. } & 463 & 137\end{array}$

$\begin{array}{lll}\text { Rue, I. } & 775 & 223\end{array}$

Ruffner, $S$. SOI 220

Rumsey, I. B. $\quad$ I.6 4 I

Runk, J.1.. $\quad 978 \quad 321$

Runk, I. I. $\quad 979 \quad 32 \mathrm{I}$

Runk, J. I., Brown, J. II. and Morgan, E. Ml. $992 \quad 325$

Rumstetler, A. and Win$\begin{array}{lll}\text { deck, A. } & 77 & 22\end{array}$

Rush, R. D, and E. IV. III 358

Russell, E. W. and J. N. $\quad 823 \quad 234$

Russell, P.S. \$56 244

Russell, E. IT. $\quad 1110 \quad 357$

$\begin{array}{lll}\text { Rutledge, A. SI6 } & 233\end{array}$

Ryer, W. H. $1212 \quad 387$

Sabin, S. A. $\quad 739 \quad 214$

Sachse, I. IO76 348

Sackett, C. F. $\quad 414$ 130

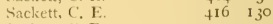

Sackett, C. E. $\quad 417$ 131

Sackett, C. E. $\quad 417$ I3I

Sackutt, C. E. $\quad 4$ I 131

sackett, C. E. $\quad 420 \quad 132$

Sackett, C. E. $\quad 42$ I I 32

Sackett, C. E. 424 133

St. John, G. B. and [interwood, J. K.

St. John, G. B.

St. John, G. B.

St. John, G. B.

St. John, $\mathrm{G}$. B.

St. John, W. II:

St. John, W. IV

Simpron, ().

Sandelin, N. F.

Sandelin, N. F.

Sanders, H.

Sanders, J. R.

Sanders, 1 . and Nich.

- aolds, L. C

Sanders, A.

Sandiford, $\mathrm{E}$.

Satterlee, MI.

Sattison, J.

Sattley, II.

Sattley, M.

Sattley, M.

Sattley, M.

Sattley, II. 
Savage, W', (i.

Savill, I.

Sawin, 1;. II:

saw yer, $\mathrm{K}$.

Sawyer, A. and IBarnes. H.

Siawyers, I. II.

Sawyer, F. II.

Sayre, C. II

Sinre, C.II

Siyte, C. H, and Klinck,

(i.

sayre, C. H

ticarbrough, I. L.

Schanck, (i, H.

Scheiblein, J. and Ileitz. man, I.

Schenck, (i, IV

tichermerhorn, J. and Forter, k.

scheumack, S. S.

sicllag, E.

Schlesser, J.

Schmeiser. H. J.

.chofield, S. C.

Sichrader, A.

Sichroeder, J.

$$
\text { " } "
$$$$
\text { " }
$$$$
\text { “ (R.) } 5
$$

Plute (Taim

641 Ist

$65+1 \mathrm{ISS}$

$71 \quad 20$

173

$605 \quad 175$

$613 \quad 177$

$633 \mathbf{1} 82$

143

$510 \quad 149$

$509 \quad 149$

$\begin{array}{ll}509 & 149\end{array}$

513150

15944

6 is 178

719208

$813 \quad 232$

$377 \quad 121$

$\begin{array}{ll}1103 & 355\end{array}$

${ }_{11} \mathrm{~S}_{3} \quad 378$

$259 \quad 75$

I $34 \quad 362$

$\begin{array}{lll}740 & 214\end{array}$

$813 \quad 232$

691200

(R.) 691200

Schoeffel, J. and Dell, W. $69 \mathrm{I} 200$

Sichuchard, J.

Schultz, I. 1), and Adams, R.

Sichwanger, $\mathrm{C}$.

tichwart/, II.

Sicofield, B. B.

Sienlrook, C. J. and Heine, if.

Search, C. F

Sears, I) A.

Sears, D, A.

Selbring, T. C.

ieeley, $\mathrm{S}$. F

reeley, S. F.

Seely, II.

Seger, E. S, and Ormis. ton, I. C :

Seibel, J.

Seibert, $C_{i}$, and $J$.

Seibert, $G$, and T.

Seibert, $t i$, and $I$.

Sieitz, I'.

Severy, S.

Seward, E.

hexton, I. B.

Sexton, I. Ii.

Siexton, J. B.

Sexton, E.

Seymour, W. H. and L. $597 \quad 172$

Shabley, C.

Shatters, II. R.

Shank, S. B.

Shank, S. B.

Shares, D. W.

Shares, D. W:

Shaw, A.

Shaw, T. II.

Shaw, J. L.

Shaw, H. F and i: F. $191 \quad 53$

Shaw; J.

Shaw, A.

Sheller, S. C.

Shepard, J.

Sherman, D. B.

sherrill, I.

sherrill, J.

$\begin{array}{ll}670 & 193\end{array}$

$\begin{array}{lll}984 & 323\end{array}$

$97+\quad 320$

$1035 \quad 339$

$\begin{array}{ll}713 & 207\end{array}$

$\begin{array}{ll}289 & 87\end{array}$

$148 \quad 41$

$518 \quad 151$

$700 \quad 203$
728

$\begin{array}{lll}728 & 211\end{array}$

$\begin{array}{lll}757 & 219\end{array}$

$1004 \quad 320$

${ }_{3} 84 \quad 122$

I21 34

$475 \quad 140$

$123 \quad 35$

10 2

123

133

$102 \quad 30$

$\begin{array}{rr}486 & 142 \\ 191 & 53\end{array}$

$280 \quad 83$

$\begin{array}{ll}585 & 169\end{array}$

$732 \quad 212$

$127 \quad 36$

$1037 \quad 339$

$\begin{array}{ll}410 & 129\end{array}$

$\begin{array}{ll}782 & 225\end{array}$

$\mathrm{S}_{36} \quad 23 \mathrm{~S}$
Sherneneil, 1.
Sherill, I

sherwoul, 1.

sherwood, T. N

Sherw ood, A. T.

shipelds, f. .ll

Shields, X. .

shielils. 1\%. II.

short, $\mathrm{T}$.

short. T.

Shrigley, I. I).

shull, N. I.

Shupe, E.

Siegrordner, $\mathrm{C}$.

Simons, A. D.

Simpson, J.

Simpson, M. $P$.

Simpson, M. P. and Ell.acott, J. I'.

Sim, 2. Is.

Sims, Z. B.

Sims, Z. B.

sintz, C.

Sisson, W. A.

Sisson, J, E.

Sivertsen, B. E.

skaggs, N. J.

Skaggs, N. J. and True, L. IV.

skiff, $\mathrm{M}$. $\mathrm{H}$.

Skillings, $H$

Skinner, H. II.

Skinner, I. B.

Skinner, S. T.

skinner, J. B.

Skinner, J. L.

Skinner, I. 1 .

Skinner, I. B.

Skinner, J. B.

skinner, H. II.

Slater, (1). S.

Slaughter, $D$.

Slaughter, W. J.

Slemmons, H. G.

I:ale $c$ inim

$1169 \quad 374$

$392 \quad 125$

$632 \quad 182$

652 ISS

$780 \quad 224$

$\begin{array}{ll}70 & 20\end{array}$

$112 \quad 32$

I.48 4 I

$634 \quad 183$

$982 \quad 322$

$287 \quad 86$

21

$\begin{array}{ll}1165 & 372\end{array}$

808231

$102 \quad 30$

$3+4 \quad 107$

$\begin{array}{ll}789 & 227\end{array}$

$\begin{array}{ll}99 & 29\end{array}$

$477 \quad 140$

(R.) $477 \quad 140$

$4 \times 2 \quad 1+1$

$\begin{array}{ll}754 & 218\end{array}$

686198

$\begin{array}{ll}792 & 227\end{array}$

$393 \quad 125$

$168 \quad 47$

$\begin{array}{ll}798 & 229\end{array}$

$709 \quad 205$

619175

$413 \quad 130$

11533

$652 \quad 188$

$699 \quad 202$

$744 \quad 216$

$\begin{array}{ll}747 & 217\end{array}$

$\begin{array}{ll}778 & 224\end{array}$

$986 \quad 323$

941325

$1079 \quad 349$

So 23

$92 \quad 28$

1115358

$34 \quad 8$

".

(R.) 34

ifer, R. H.

Sloan, S.

Slocum, J.

Slocumb,. . W and Phillipu, E.

Sloss, L. I.

Sloss, I. I.

868248

Slosson, E.

Slusser, G.

Slusser, B.

$$
"
$$

Slusser, B.

Small, B. B.

Small, B. B.

smalley, J.

imalley, I) A and J. H] 589 i7

simith, A.

Simith, $A$.

smith, A.

Smith, A.

Smith, A.

Simith, A. and T. S.

smith, $\Lambda$. and Waton, W. P.

Smith, A. C.

Smith, A, C:

R.) 1023

1039340

$488 \quad 142$

$184 \quad 51$

589 i71

$\begin{array}{ll}1092 & 352 \\ 1029 & 337\end{array}$

$337 \quad 105$

$\begin{array}{ll}463 & 137\end{array}$

$143 \quad 40$

$942 \quad 999$

$965 \quad 317$

$1024 \quad 335$

$145 \quad 40$

Smith, 1 .

$\begin{array}{rrr}125 & 35 \\ 125 & 35 \\ 1166 & 372\end{array}$

Simith, 1. 1 .

Sinitl, $F, l$

Smith, F. I.

smith, F. I'

Simith, F. P.

smith, lien.

Simith, C. I1

sinith, 6.11

Simith, (i. H.

Simith, t: H.

simith, II. I3.

Smith, II 13.

Smith, II. B.

smith, II. B.

Smith, H, B.

Smith, H. C

Smith, I. R.

Smith, I.

smith, J.

Simith, J. A.

Smith, J. B. 
Litaman, I. K.

Stanm, i:

Sitanchfield, 1)

sitanchfield, 1)

Standish, P. H.

Standish, P. H.

Stanley, A. R. and Ensign, 11. 11

Stanley, F.

Sitansburg, A. F, and T. M. 473 I 39

Sitanton, I. P.

Stanton, S. R.

Stanton, S. R.

Stark, A.

Starritt, J. 1).

Stary, E.

Stauffacher, A.

Sitaver, G. IV.

Staver, G, IV.

Sitartzmau, W. H

Sitearns C. C

Stearns, J, I.

Steinegger, $\mathbf{i}$.

steller, C. E.

Stenton, R. Si.

Stephens, A. I.

Srephens, $\mathrm{C}$.

Stephens, J.

Sterling, 11 .

Stevens, C. B.

Stevens, C: B.

Stevens, C. M.

Stevers, I. C

Stevelis, I.

Sterens, L. ().

Stewart, IV. 1.

fitevenson, i.

Stevenson, $\mathrm{G}$.

Stiber, i.

Stillwell, A. F

Stimmell, J.

stockdale, J.

Stocking, A. I.

stockstill, S. I. and

Kurtz, H. D.

Stockton, G. IV

Sitodiard, I. C.

Stoll, M.

Stoll M.

Stoll, M.

Stone, I. C

Stone, I).

Stone, I.

Stone, I.

stone, $U$.

Stoner, A. I

storm, $\mathrm{G}$.

Storrs, C. E., Keys, W. E and Jones, I). W'.

Stossburg, F. II.

Stout, 1.

stout, I, and $S$.

Situat, s.

Stover, D. $C$.

Stover, I). (

Stover, A. I.

Stover, D.

Stover, I. (

Siover, D. (

Sitowe, I. (i.

Stowe, J. (i.

Strait, k. F.

struchland, I.

siritby, W

Strong, IV. H

Stroud, A. I. WI.

Stroud, G. F

Stroud, J. C.
Plate Claim

$464 \quad 137$

39 IO

$\mathrm{IS7}^{52}$

$\begin{array}{ll}389 & 124\end{array}$

$1024 \quad 335$

$1025 \quad 336$

$\begin{array}{rr}71 & 20 \\ 849 & 242\end{array}$

874250

$667 \quad 192$

$401 \quad 127$

$55 \quad 15$

869249

8472.4

853243

$\begin{array}{rr}85 & 26\end{array}$

$616 \quad 177$

I030 337

I016 333

$474 \quad 139$

15
$392 \quad 125$

IS2 5 I

$100 \quad 29$

I $094 \quad 352$

1096353

$1078 \quad 349$

$54^{6} \quad 157$

1684

$381 \quad 121$

668 192

$\begin{array}{ll}722 & 209\end{array}$

$272 \quad 79$

$275 \quad 8 I$

$131 \quad 36$

$56 \quad 15$

853243

$5091+9$

$54 \quad 15$

I077 349

$682 \quad 197$

3) 121

$\$ 6 \quad 25$

479140

$779 \quad 224$

$409 \quad 129$

950 321

1089 351

980 322

$706 \quad 204$

$391 \quad 124$

837238

$76 \quad 22$

$160 \quad 44$

$40 \quad 10$

$619 \quad 178$

$996 \quad 327$

$520 \quad$ I5 I

$934 \quad 297$

655188

663 I9I

$75 ; \quad 219$

$826 \quad 235$

$\begin{array}{ll}776 & 223\end{array}$

$7 \mathrm{~S}_{2} \quad 225$

$254 \quad 74$

$39 \quad 9$

$793 \quad 228$

I2I 34

$533 \quad \mathbf{1 5 4}$

$\begin{array}{ll}713 & 207\end{array}$
653 I 88
Stroud, Wr, T).

Strowger, II. II.

Stryker, I.

stuart, H. C.

stubblefield, 19. A. and luse, W. H.

Studer, $\mathrm{P}$

Stukey, I. S.

Sturgis, W. B.

Summer, I.

summers, J. and Trimble, I.

Summers, R. B. and Dement, $\mathrm{S}$.

Summers, L. MI and Wilson, M.

sursa, J. IV.

Sursa, J. W.

Sinrsa, J. 11.

Sursa, I. W.

Sutherland, I. A.

Sutherlen, W. B.

Siuter, I.

Suydam, J. H.

Svenson, B. J.

Swallow, I. E.

Swaney, J. S.

Sweeny, II. P.

Siveut, H.

Sweet, Z. T.

Swickard, J. IV

Siwickard, J. W'

Tabor, 11. 1)

Tabor, B. D.

Taliaferro, C. IV.

Taliaferro, C. W.

Tally, T, J.

Tanner, 1), C:

Taplin, H. T.

Tappan, G. S.

Tarkington, Ml. S.

Tarnutzer, I. P.

Tartt, $P^{2}$. S. and Wilson, G. F.

Tate, J. E.

Tavean, A. 1.

Taylor, I. IV.

Taytor, $\mathrm{C}, \mathrm{F}$

Taylor, K. T

Taylor, A. C.

Taylor, WV

Taylor, IV, A. and Graves, IV. W.

Taylor, S. H.

Teagle, T. I

Teasdale, II, M.

Teller, D. C.

Terrell, H. 1)

Terril, E.

Terry, J. P

Terry, 'T. D., Case, A

$$
\text { and I arkin. } C \text {. }
$$

Tewell, L. S.

Tharp, C. and G. P.

Thayer, R. and

$$
\text { Mcclelland, I. }
$$

Thede, $\mathrm{C}$

Thirlwell, I.

Thomas, J. H. and Mast,

$$
\text { P. } \mathrm{P} \text {. }
$$

Thomas, I. H., Mast, P $P$. and 1 Tarding, $T$,

Thomas, J. I1. and Mlast, l'. '?.

Thomas, J. H. and J. WV.

Thomas, J. W

Thomas, J. S

Thomas, J. K.

$\begin{array}{rrl}\text { Plate Clum } & \\ 529 & 153 & \text { Thomas, J. R. } \\ 46 & 12 & \text { Thomar, J. C. B. } \\ 12 & 3 & \text { Thompson, A. } \\ 1191 & 380 & \text { Thumpson, J. } \\ 341 & 106 & \text { Thompson, J. J. } \\ 831 & 237 & \text { Thompson, J. J. and Col- } \\ 653 & \text { I } 88 & \text { lier, V. F. } \\ 829 & 236 & \text { Thompson, W. L. } \\ 15 & 3 & \text { Thompson, A. } \\ 357 & 110 & \text { Thompson, I. P. } \\ & & \text { Thompson, J. N. and } \\ 997 & 327 & \text { Thomady, W. }\end{array}$

Plate Claim

I I 733

357 I 10

$385 \quad 122$

396 I 26

$486 \quad 142$

4 So I 41

475 I 39

$785 \quad 224$

$\begin{array}{ll}777 & 224\end{array}$

$819 \quad 233$

$997 \quad 327$

$1188 \quad 380$

$1005 \quad 329$

$10463+2$

I050 34,3

I055 344

I 105355

IOI9 334

$966 \quad 317$

$1053 \quad 343$

$\begin{array}{ll}133 & 37\end{array}$

$1052 \quad 343$

I.8 44

I $078 \quad 340$

$689 \quad 199$

I030 337

$\begin{array}{ll}785 & 226\end{array}$

$876 \quad 251$

I 47 4I

$794 \quad 228$

$609 \quad 176$

662191

$420 \quad 132$

$821 \quad 234$

$393 \quad 125$

1216388

$353 \quad 100$

$\begin{array}{lll}3 \mathrm{~S} 7 & 123\end{array}$

I $70 \quad 47$

$66 \quad 19$

$255 \quad 74$

389

$79 \quad 23$

$87 \quad 26$

$125 \quad 35$

$138 \quad 38$

$465 \quad 137$

$1214 \quad 387$

16546

$49 \quad 13$

654 I 88

$176 \quad 49$

$84 \quad 24$

17348

$\begin{array}{ll}1081 & 349\end{array}$

I 2 I 34 
Turner. T:

Turner, J. and smith.

$$
\text { T. } \mathrm{i} \text {. }
$$

Turner, J. B.

Turner, J. B

Tuctin. 1 .

Tuthill, T. J.

Tuttle L. G.

Tuttle, S. D. and Gans,

$$
\text { I. } \mathrm{H} \text {. }
$$

Tyson, J. W:

Tweedy, I.

Uehling, $T$.

Uhl, C.. A.

Underwood, A.

Underwood, J. K.

Underwood, J. K.

Underwood, I. K. and it, John, G, B.

Underwood, F. J.

Unthank, D.

Unthank, $\mathrm{D}$.

Urban, J.

Utter, MI. L.

Utter, I.

Iail, A.

Vanarsdell, W. A.

San Bracklin, P. C.

Van Bracklin, B.

Van Brunt, G. W.

Van Brunt, W. A, and Davis, S. E.

Van Buren, I.

Van Camp, IV. WV.

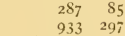

933297

(R.) 933297

$86+\quad 247$

(R.) 804247

$883 \quad 254$

$1086 \quad 351$

$841 \quad 239$

$862 \quad 246$

$1024 \quad 335$

1125360

$46 \quad 12$

$524 \quad 152$

$521 \quad 152$

$542 \quad 156$

$877 \quad 252$

818233

Vandegrift, T. F. and W. 803230

Vandegrift, T. F. and W. S12 232

Van De Mark, C.

Van Gorder, I. L.

$1220 \quad 389$

$\begin{array}{lll}1048 & 34^{2}\end{array}$

$10613+5$

$1087 \quad 351$

Van fiorder, (i. IV.

Vangundy, E. W.

Van Horne, R. P.

Van Horne, R. P.

Van Horne, R. P.

Van Horn, J.

Vanluvanee, $J$. and Sinith, H.

Van Neter, $\mathrm{H}$

Van Sickle, G. W' and IcConaughy, $\mathrm{C}$.

Van Sickle, G. WI, and IlcConaughy, C.

Van Winkle, G.

Vairin, A. L. P.

Vaughn, J. and Chamness, $\mathrm{E}$

Veber, IV. F.

Verharen, F. T.

Viars, J. A.

Vick, IV. H

Vickery. D. F.

Volkmann, B.

$$
\text { ". " }
$$

Von Phul, H., Ir. and Mallon, J.

Von Phul, H., Ir, and Mallon, J.

Von Phul, H., Jr. and Mallon, J.

Vowles, I.

Vowles, I.

Vowles, J.

Wade, T. I.
Watdell, I.

Wadsworth, W.

Wadsworth, H.

Waffle, C. I.

Waggoner, G.

Wagner, J. R.

Wagner, D. S.

Wagner, J., Jr.

Waite, $\Gamma$ :

Walker, W. T

Walker, 1.. B.

Walker, E. and Weed, A. NI.

Walke E. and Piatt, J. J.

Walker, E, and l'iatt, J. J.

Walker, L.

Walker, A.

Walker, $\mathrm{k}$.

Wall. J. B.

Wallis, T. R.

Walter, I. A, and Bushman, E.

Walton, E. W.

Walton, W.

Walton, S.

Walton, E. IV

Walton, E. W.

Ward, B. F

Ward, II. N

Ward, W. C.

Ward, P. J.

Warner, J.

Warner, $C$

Warren, T. P.

Warren, G. W:

Warren, (i, H.

Warren, G. H.

Warren, G. H.

Warwick, J.

Warwick, J.

Warwick, J and $\mathrm{A}$ T.

IVaterman, L. B. $\quad 606 \quad 175$

WVaterman, l. R. $\quad 110 \quad 176$

Waterman, I. B, 6271 So

Wathins, IV

Watkins, IV. M

Watkins, J. T.

Watson, W. T.

Watson, C. H.

Watson, C.H.

Watson, WI. M.

Wation, W. II.

Watson, W. M.

Watiles, 1I. J.

Wattles, II. I.

Vattles, H. I.

Wattles, I1. J.

Watt, G.

Way, S.

VIay, s.

Weaver, W.

Weaver, T.

Webb, T. IV.

Webb, T. W.

Webber, N. (;.

Weber, R

Weber, H., Ir.

Webster, II. H

Wehster, H.

Webster, 1. T.

Webster, 1. T.

Weems, T. I' S.

Weir, WV. S. Jr.

Weir, WV. S.

Weir, W. \&. Jr.

$\begin{array}{rr}\text { Plate craim } \\ 124 & 35 \\ 383 & 122 \\ 734 & 212 \\ 110 & 32 \\ 783 & 225 \\ 110 & 32 \\ 845 & 241 \\ 859 & 245 \\ 89 & 26 \\ 1+1 & 39 \\ 646 & 186\end{array}$

$\begin{array}{ll}737 & 213\end{array}$

$741 \quad 215$

$\begin{array}{rr}764 & 22 \mathrm{I} \\ 1024 & 335\end{array}$

$1072 \quad 347$

$\begin{array}{rr}274 & 80 \\ 827 & 235\end{array}$

$116 \quad 33$

$\begin{array}{ll}\mathrm{S}_{3} & 24 \\ 83 & 24\end{array}$

$158 \quad 44$

1047342

104302

$17 \mathrm{I} \quad 48$

$356 \quad 110$

$845 \quad 241$

$345 \quad 107$

$663 \quad 191$

$1197 \quad 382$

$1222 \quad 390$

1222390

1222390

$\begin{array}{ll}105 & 31 \\ 126 & 35\end{array}$

$1022 \quad 335$

$60 \quad 17$

$345 \quad 107$

$532 \quad 154$

$348 \quad 108$

$350 \quad 108$

$992 \quad 325$

$728 \quad 211$

$\begin{array}{ll}735 & 213\end{array}$

$744 \quad 216$

IOIO 33 1

$994 \quad 326$

$\begin{array}{ll}717 & 208\end{array}$

$1014 \quad 332$

I55 43

$1095 \quad 352$

$471 \quad 138$

$1030 \quad 337$

$108 \quad 32$

I $66 \quad 46$

$1222 \cdot 390$

$645 \quad 185$

$983 \quad 322$

$1045 \quad 342$

$1060 \quad 345$

$846 \quad 241$

$\begin{array}{ll}931 & 297\end{array}$

939299

$603 \quad 174$

Weir, W. . Ir.

Plate Cluim

Weir, W. S. Jr.

Weir. WI, S.

Welch, S. G.

Welch,. .

Welch, S. F.

Weld, $\mathrm{H}$.

Welden, F, N.

Wellman, D. L.

Wells, II.

Wells, W. J.

Wells, C.C.

Wells, C.

Wells, P. F.

Wells, J. T.

Welsh, J. C

Welti, I.

Wertenherger, 1.

Wertenberger, L. and Amiss, G. W.

R. $6 r_{2} \quad 176$

$\begin{array}{lll}635 & 183\end{array}$

Werts $\mathrm{N}$

West, IV. B.

West, B. J.

West, K. and Paul, H. F.

West, P. I.

Wharton, G.

Wharton, $\mathrm{G}$.

Whaite, C. L.

Wheat, II. K.

Wheeler, F, P.

White, M. F.

White, E. J.

Whitehall, N.

Whiteball, N.

Whitehall, N.

Whiteball, N.

Whitehead, J.

Whiteside, J. and Crabill, H. F.

Whitlock, C.

Whitman, L. M.

Whitney, S. M.

Whitney, S. M

IVhitney, J. M.

Whitney, J. II.

Whitney, J. R.

Whitney, W. H. and

$$
\text { Noble, C. T. }
$$

(k.) 635 18

$1138 \quad 363$

$623 \quad 179$

$1044 \quad 341$

$\begin{array}{ll}1128 & 361\end{array}$

$481 \quad 141$

$762 \quad 220$

$847 \quad 241$

225

$732 \quad 212$ 
Willıan- A.

Williameon, S. I).

Willerton, IV:

villmot, iV.

Wikon, F. ().

Wilson, F, K.

Wilson, J. 1. ant Morruw, R. $\dot{G}$.

Wilson, M.

Wilson, W. I

Wilson, J. C.

Wilson, J.

Wilson, $\mathrm{X}$.

IVilson, J. A.

Wilson, W. C

WVilson, $\mathrm{R}$.

Wilson, G. H.

Winfield, H. and Flynn, IV. P.

Wingo, B. W

Wing, I.

Winter, E. C.

Witter, B.

Witt, J. IV.

Wolcott, G. E

Wolfe, A. K.

Wolfe, T.

IVolf, I.

Wolf, L.

Wolpert, J.

Wood, NS.

Wood, I.

\begin{tabular}{|c|c|}
\hline & \\
\hline & $\begin{array}{l}\text { I } \\
100\end{array}$ \\
\hline & 226 \\
\hline 588 & 170 \\
\hline 26 & \\
\hline$s_{3}$ & 24 \\
\hline 174 & 49 \\
\hline 474 & 139 \\
\hline & 171 \\
\hline & 172 \\
\hline & 197 \\
\hline 733 & 212 \\
\hline & 216 \\
\hline 69 & 222 \\
\hline 983 & 322 \\
\hline 1138 & $3^{6} 3$ \\
\hline $4^{8} 5$ & $\mathrm{I}_{4} \mathrm{I}$ \\
\hline & 40 \\
\hline $68_{3}$ & I97 \\
\hline 407 & 128 \\
\hline $1_{3} 8$ & $3^{8}$ \\
\hline 1221 & 390 \\
\hline if 2 & 378 \\
\hline 832 & 237 \\
\hline 989 & 324 \\
\hline 706 & 204 \\
\hline $97 \mathrm{~S}$ & 321 \\
\hline 107 & 31 \\
\hline & 128 \\
\hline & 154 \\
\hline
\end{tabular}

Wood, J. F.

Woud, L. .

Wood, J. A.

Wuorls, A., Wells, D. and Jates, I.

Woods, C. J. and Phillips, J. A.

IVoods, s. E. and Whe. well, A. II

Woodward, J. A., S. S. and Mason, T

Wood ward, J. A., S. S. and Mlason, $\mathrm{T}$.

Woodworth, S., F.

Wooldridge, s. H.

Workman, IV, and Ilitchoock, J.

" " " (R.)

Worrell, J. and Rynerson, J. H.

Worrell, I. and kynerson, J. IH.

Worrell, J. and Rynerson, J. H.

Worrell, J. and Rynerson, J. H

Worrell, i.

Worrell, J.

Worrell, J.

Worthen, $\mathrm{S}$. A

Wottring, R.

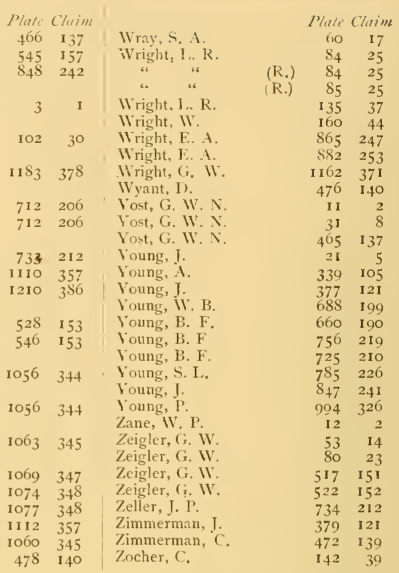


Adams, W: R.

Aileiloult, $\mathrm{E}$ -

I'at: $(\mathrm{l} / \mathrm{n})$

Annew A. S Ilerrison, W. Aiken, $\therefore$. W:

Aker, I.

Alclen. $\lambda$.

Allen, 1). R.

Allen, S. 1 ..

Allstoti, 1'. II.

Andrews. W. I.

Ansley, J. \& G. W.

Arnilt, 1 .

Arnoldt, H. B. \& Girmm, J. 78

Arrington, IV. J.

Arthur, 1. 13.

Austin, R. G. S.

Baker, 1. 13.

liaker, il.

baker, D. C.

Baldwin, P. O.

Baldw in, I.

Ball, T. I. \& Poste, J.

l3all, W. II

Bancroft, WV.

Banks, J.

Barnes, $x$.

Barnes, $H$

Barnett, J. A.

Barnhart, 1 '.

Barnwell, A. S.

Barrier, F. M.

Barr, II. I.

Barton, C.T.

B.teman, $F$.

Batson, J. W. \& L.

Beach, $C$. Brown, $T$.

Beale, $\mathrm{T}$.

Bean, J. C.

Beard, C. A. \& Evans, E. E.

Beard, A.

Beeching, $\mathrm{C}$.

Belden, H. M.

Belden, C.

Bell, W. C.

Bell, $\therefore$. R.

Belt, A. C.

Bemendefer, H. F. \& Smith, $G$.

Fenerlict, I. A.

Benedict, 11

Benedict, 1. A

Benedict, I. A.

Benner, I). (;.

liennett, G. T

Benton, I. B.

Bethea, J. C.

Hever, J. T.

Bishop, C.

Black, G. G.

Blackistone, Z. D.

Blackistone, 2. 1).

Blake, J. W.

Blomsten, B. C.

Bloodworth, E. H.

Blue, D. ( $i$.

Boles, A.

Bolis, $\mathrm{V}$.

Borden, $T$.

Bott, W. II.

Bower, J.

Bowman, D. W

Boyd, J. C.

Briggs, E.

Briggs, E.

Briggs, H. C.

Brinly, T. E. C.

Brinly, T. E. C
Brittain. J. T.

Brook, R. II

l3rooks, IV

Brown, (;. W:

Brown, W. I?.

Bum, W: T.

Burbank, R. 1 .

liurke. J. II

Burns. J,

Bushnell, IV

Busenger, $\mathrm{A}$.

Iuskett, I. I.

Cain, S. II. \& Stelfox, W.

Cameron, J. F.

Cimplell, $\mathrm{A}$.

Canfield, A.

Canfield, A.

Cantelon, R.

Carhart, P.S.

Carhart, $\mathrm{l}^{2}$. S

Carter, N. C.

Carter, IV. H

Caswell, I.. I.

Cate, N. A.

Cato, W. W.

Caylor, J.

Chandler, 11. C

Chapman, J.

Charlton, j.

Chase, J. WT.

Chase, J. W.

(heatham, IV. T.

Christman, R. D.

Christopher, J. Ci.

Clark, C.

Clark. C. A.

Clark, C. I].

" " " (R)

Clark, C. M.

Clarridge, $\mathrm{J}$.

Cleaveland, G. D.

Clements, A. I'. \& Nealey,

$$
\text { J. C. }
$$

Clifton J. H.

Clifton, L

Clifton, W. C.

Clime, $\mathrm{S}$.

6819 Clime, S.

9628 Close. B. M.

98 29 Cloyd, H. (C.

11733 Cluckner, J.

17448 Coats, $S$,

Io5 3I Coggin, .t. L.

Cole, N. C.

Connelly, A.

Conolly, i. W:

Constant, 1

Cooper, N. B.

Cooper, G. II:

Cooper, G. IV:

Cooper, C. J.

Copeland, ].

Copeland, I.

Copeland, I

Cox, M. C.

Cox, B. S,

Cox, B. S.

Coyle, H. I

Crabtree, J. . M.

Craig, R.

Craig, A. J.

Crain, $\mathrm{O}$. A

Criswell, R., Ir.

Cross, B. Il.

Crow, C.

Currier, A.
Burton, W. I.

Curtis, H. W:

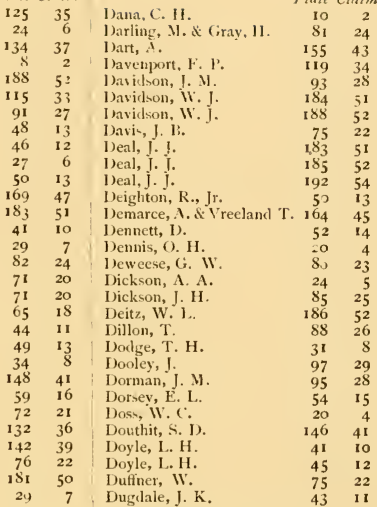

Dunnavant, J. U. \& Hampson, W. A.

Dutton, J. L., Jr.

Dysert, W.

Early, D. :

Early, D. S.

Earlywine, N.

Eastburn, C

Eberly I.

Edwards, I

Eldred, A.

Elliot, R.

Emrick, I.

Emmert, E.

Endsley, J. Fletcher E

Erickson, G. A. $\quad 47$

Ernst, J. W.

Erwood, I. C.

Escudier, C.

Essington, G.

Estes, C. E.

Etnier, (),

Eustace, M., and Kennan, J. \& $\mathrm{T}$.

Farmer, W. H.

Faulkner, J. J.

Fink, I.

Finley, J R.

Fish, T. P.

Fish, k. A.

Fleming, J. S.

Fleming, J. W:

Fleming, J. W.

Flisher, 1. G. \& Bates, E.

$M$.

Flory, C.

Forbes, \$. B.

Forbes, \&. B.

Ford, C.

Foreman, G. G.

Forshee, II. J.

Foster, A. G. IV.

Frampton, J. H.

Frank, J.

Frantz, W.

Freeman E. L.

Fridy, J.

Gardiner. T. E.

43

34

52

54

13

4

4
23

5

25

28

4 I

12

I I

\section{in}


Garland, T. H.

Garnett, J. II.

Gaston, H. A.

Geiges, $P$.

Gent $\angle s c h$, H. J., Sr.

George, J.

Gilsion, W. 0.

(iilbs, J.

Gifford, J.

Gifford, G. L.

Gilbert, I. R. \& Weston, S. R.

Gilliland, D. C.

Gilpatrie, J.

Gijiclen, $\mathrm{J}$

Goff, .11. B.

(iogrel, J. A.

Goodwyn, G. WV.

Gordon, $A$.

Goslee, O. WV.

Goslee, $U$. W.

Goslee, U. W.

Goss, F.

Gowen, WV.

Graham, E. M.

Grant, K. P.

Gregory, E. S.

Green, H. D.

Green, H. D.

Green, T. \& Sommer, J.

Grolmmann, A.

Grove, A. F.

Guice, T.

Gimptail, D.

" "(R.)

Guy, J. C.

Gwinnup, C. S.

IJall, J. ...

IIall, $\mathrm{s}$.

Hamilton, J. II.

Hand, J. R?.

Harwell, v.

Harrier, $\mathrm{H}$.

Harris, I).

Harrison, A.

Haskell, J.

Hassempflug, (i. F. \& Barnhart, $G$.

Hasslock, H. WV.

Hatlietd, G. W.

Haverstick, 1 .

Hawkes, N.

Ilawley, A. W.

Hawley, I. M.

I eaton, C. WV. S

Heaton, C. W. S.

Heerman, $\mathrm{T}$.

Hei res, J. M.

Heisey, S. L.

Jenery, A. P.

Herr, J. B.

Herrick, i. $\mathbf{H}$.

Hicks, T.

Higley, $\mathrm{H}$.

Hilidreth, $\vec{G}_{\text {, }}$ W

Hill, P. P.

Hinman, J. S French, D. S. $\begin{array}{r}\mathbf{1} 49 \\ 30\end{array}$

Hobson, R. (i.

Hoffiman, A. \& Limebeck, H. IV.

Holciredge, M

Holladay, J. is.

Hood, J. I.

Hollinger, $J$.

Hollinger, J.

Holmes, W. C.

Holmes, J. C.
Plate Claim

$150 \quad 42$

8324

$18+52$

I $77 \quad 49$

$175 \quad 49$

5) 16

153

5916

33

8

$25 \quad 6$

$43 \quad 11$

$64 \quad 18$

I61 44

10932

$187 \quad 52$

$185 \quad 51$

65 I 8

3910

5042

$89 \quad 53$

0431

I 34

$\begin{array}{ll}41 & 39\end{array}$

$177 \quad 49$

$98 \quad 29$

156 43

6245

$\begin{array}{ll}78 & 23 \\ 9 & 28\end{array}$

$9+\quad 25$

$\begin{array}{ll}59 & 17\end{array}$

$17 \quad 33$

7321

7321

$\begin{array}{ll}81 & 50 \\ 63 & \text { is }\end{array}$

328

$\begin{array}{ll}51 & 14\end{array}$

I3 33

\begin{tabular}{ll}
78 & 23 \\
\hline &
\end{tabular}

II 32

$55 \quad 15$

$63 \quad 18$

$4^{8} \quad 13$

I 66 3I

$\begin{array}{ll}61 & 17\end{array}$

$144 \quad 43$

$16 \quad 3$

$\begin{array}{lr}69 & 19\end{array}$

$3^{8} \quad 9$

$47 \quad 12$

$\begin{array}{lr}19 & 4 \\ 36 & 38\end{array}$

$70 \quad 20$

$72 \quad 4^{8}$

$59 \quad 16$

0920

$92 \quad 27$

11

10

$\begin{array}{rr}49 & 42 \\ 30 & 7\end{array}$

$\begin{array}{ll}37 & 7 \\ 38\end{array}$

$42 \quad 10$

$8_{5} \quad 51$

$151 \quad 42$

$97 \quad 28$

$55 \quad 15$

$67 \quad 19$

$\begin{array}{lr}19 & 4 \\ 03 & 30\end{array}$
Holt, R. C.

Homrighonse, L.

Honver, W. U.

Hopkins, IV. A.

Houlek, J.

Huber, s.

Huff, E. S.

Huff, E. S.

Hughes, A.

Hunt, M. J.

Hunter, S. C

Hunter, W. and D. M.

Hyde, W. S.

Ingraham, $\mathrm{H}$.

Ingraham, $\mathrm{H}$.

lngraham, $\mathrm{H}$

Isgrigg, N. I..

Jackson, ... WV.

Jackson, J. R.

Jenkins, J. C.

Jennings, J. Jr.,

Jessup, G.

John`on, W. D.

Johnion, M.

Johnson, M.

Johnson, R. A.

Johnson, R. A.

Johnson, R. A.

Jones, J. 1]. and H. P,

Jones, $\mathrm{A}$.

Kamerer, E. A.

Keel, P. I1.

Keezer, J.

Kelly, L. W.

Kelly, W. H.

Kennedy, A. II.

King, A. B.

King, M. D.

King, T. .1.

Kinghorn, T and $\mathrm{R}$.

Kleffel, IV.

Kuapp, J. G. \& Liblby, S.

Kinepper, E

Knoule, J,

Knox, S. A.

Kribs, $\mathrm{P}$

Krick, J. S.

Krieble, H. K.

Krogh, C. and P. C.

Kroner, S. A.

Lacy, J. G.

Ladenberger, F. D.

Laircl, H.

Lake, H. J.

Lamb, A.

Landes, $\mathrm{H}$.

Landes, J. .I

Landon, $\Gamma$. R.

Lang, J. B.

Lathrop, C. G.

Lawbaugh, G. W. \& Wiiliams, J.

Lee, Z. II

Lee, $\mathrm{S}$. F,

Lees, J. A.

Lefler, A. B.

Leland, A.

Leonard, A.

Leonard, A.

Leslie, F. MI

Lewellin, .I

Lewis, A. J.

Lewis, W,

Lewis, J. F.

livezey, ]. B.

loblell, $\mathrm{C}$.
Pirte Claim

$\log 32$

I 832

$\begin{array}{ll}90 & 27\end{array}$

$17 \quad 3$

$\begin{array}{rr}16 & 3 \\ 9 & 29\end{array}$

338

c6 28

$28 \quad 7$

$189 \quad 53$

I O 29

102

$4^{8} \quad 13$

6920

10531

$62 \quad 17$

\begin{tabular}{ll}
$169 \quad 47$ \\
\hline
\end{tabular}

16346

17950

$134 \quad 37$

235

17549

$187 \quad 52$

$188 \quad 52$

$190 \quad 53$

$91 \quad 27$

$173 \quad 4^{5}$

$100 \quad 30$

$\begin{array}{rr}9 & 2 \\ 41 & 10\end{array}$

173

$43 \quad 11$

$20 \quad 34$

$\begin{array}{ll}67 & 19 \\ 32 & 36\end{array}$

$\begin{array}{ll}41 & 39\end{array}$

297

3. $3^{6}$

$104 \quad 31$

$95 \quad 28$

21

23

$\begin{array}{ll}74 & 58 \\ & \end{array}$

$138 \quad 38$

$135 \quad 37$

$\begin{array}{ll}74 & 21 \\ 25 & 36\end{array}$

$56 \quad 43$

$\begin{array}{ll}56 & 43 \\ \text { os } & 32\end{array}$

359

$\begin{array}{ll}52 & 14 \\ 94 & 28\end{array}$

$\begin{array}{ll}94 & 32\end{array}$

$\begin{array}{ll}12 & 32 \\ 66 & 46\end{array}$

$33 \quad 37$

45

$55 \quad 15$

67
168
16

$37 \quad 9$

$\begin{array}{rr}7 & 1 \\ 1: 1 & 32\end{array}$

$140 \quad 39$

$190 \quad 53$

$139 \quad 38$

$95 \quad 28$

$144 \quad 40$

$190 \quad 53$

$\begin{array}{ll}30 & 7 \\ \text { S9 } & 26\end{array}$

Lobdell, C.

Loeki , J. II. 
Nellis, 1.1

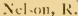

Netherlani, J. B.

Vicuin: II:

Nichols, IV, I).

Xichol-on, J. W:

P'le'c Chim

Niece, R. K

Nolan, I. S.

Xitman, IV.

()elurlein, (:

() meal, ( $\mathrm{C}$.

() strom, II. II:

() well, ]. . II.

()xer, IV. I.

l'arcell, l: l3.

Parrinh, (i. W:

Parsons, J., Jr.

Jarom, $C$, WW and Finney

$$
\text { II. } \mathrm{s} \text {. }
$$

Parsons, (i. A.

I'atter, i).

l'..tun, R. F.

l'axion, (.. E.

Iavue, k. I.

l'celer, ].

I'ercy, IV. C.

Percz, F.

Perkin, E. I1, and S. I). 14

Perry, F, L.

P'ery, F. I.

feiry, F. I.

Perry (i. IV.

I'erry A. G.

Pettengill, (: . B.

Peterwon, (i. W:

Philp, I. II.

Phillips, E.

Pierpont, I.

like, E. iv.

Pir'ile, W. J.

Poetz, I.

Poet? I.

Poole, T. II:

Pott $\div, \mathrm{J}$

Potter, E. M.

Price, II:

J'rice, $\mathrm{W}$.

Pric, I. A.

Prout, H. N.

Prout, J1. X:

Pyle, J, N.

Pyle, I. N.

Ralon, A.

Rayle, $\mathrm{S}$ :

Read, W. I?.

Ream, 13. F

Rebman, J.

Rebman, I.

Reed, $\mathrm{S}$.

Reese, $\mathrm{l}$.

Reiner, J. K.

Repp, I

Reynolds, F. F.

Reynolds, E. D. and (). B. 136 38

Khinehart, IV. X. and Fel. ker, $\mathrm{H}$.

Rhoades, A A and Tash,

$$
\text { W. }
$$

Rhodes, G. W.

Rice, $\mathrm{T}$. and Jlitchcock, L. R.

Richard, I.

Richards, J. M.

$\mathrm{R}$ chardson, WV

Kich, I. C.

Kichter, II:

$\begin{array}{rr}\text { 'lat } & \text { Clrim } \\ 191 & 53 \\ 4 & 1 \\ 26 & 6 \\ 45 & 11 \\ 53 & 15 \\ 91 & 27 \\ 177 & 49 \\ 124 & 35 \\ 166 & 31 \\ 159 & 44 \\ 167 & 46 \\ 72 & 21 \\ 179 & 50 \\ 62 & 17 \\ 114 & 33 \\ 165 & 46 \\ 4 & 1\end{array}$

$121 \quad 34$

16445

$97 \quad 29$

$42 \quad 11$

$112 \quad 32$

$22 \quad 5$

14440

167
06

10130

$124 \quad 35$

I 6145

17348

$\begin{array}{ll}76 & 22\end{array}$

$82 \quad 50$

$109 \quad 32$

$\begin{array}{ll}17 & 33 \\ 17 & 43\end{array}$

7421

$183 \quad 51$

$\begin{array}{ll}70 & 47\end{array}$

17145

$\begin{array}{rr}62 & 17\end{array}$

$154 \quad 43$

$38 \quad 7$

$147 \quad 41$

$76 \quad 49$

24
120

113

79
116

I. 3

$83 \quad 21$

$36 \quad 37$

$56 \quad 15$

I9 34

29
38

$74 \quad 21$

11

$18_{5} \quad 51$

7220

$60 \quad 17$
I $57 \quad 44$
Rishy, A.

Plutighe

Rigell, II. d lvey, II. 1), 31 , 44

kigell, M.

Rig, II, S.

Rivley, C. II, Rogrers, C

li. Wivers, W. I.

Roberts, 1 , r:

Kobson, I.

Roden, A.

Rodger, C:

Rodger, II.

koger, II. A.

Rogers, M. 1.

Risters, 1.11

Roney, $1 \mathrm{l}$.

Ro juemore, P. B.

Ross, A. II

Ross, H. S.

Routt, S. P.

Rontt, A. P.

Koy, F.

Rowell, J. s. \& J.

kowell, E. (i., A. D), Rice, J. R. \& Seely, S. $\mathbf{M}$.

Rowell, (i. 1).

kowell, M. .I.

Rumsey, J. I.

Runuteler, A. Wincleck, A

Sattion, J.

Sawin, (i. WV.

Sawyer, R.

Sayre, C. 11.

Scarbrough, J. I.

Schwanger, $\mathrm{C}$

Schwart $<$, II.

Szely, S. F.

Seely, $\rightarrow$. 1 .

Severy, $\mathrm{S}$

Shalters, is. R.

shank, S. B.

shares, D. W.

Shares, I), W.

". " " $\mathrm{R}$.

Shaw, A.

Shaw, J. 1.

Sheller, S. C

Shields, F. M

shields, N. .

shields, F. II.

Shull, N. I.

Simpson, J.

Sims, Z, B.

Shagge, N. J.

Skimner, H. II.

Slater, 1). S.

slaughter, I).

Stemmons, VI. G.

$$
\begin{array}{llll}
4 & 4 & \text { " } & \text { (R.) } \\
4 & 6 & 4 & \text { R. }
\end{array}
$$

Slocum, J.

small, li, B.

Sinith, IV. II.

Smith, J. S.

smith, W.

Sinith, (i. IJ.

simth, A. C.

Simith, W. I).

Simith, A. C.

Simith, A.

Smith, J.

smith, II.

Snow, M.

Sinyder, J.

Snyder, 11.

corlerlund, l'. solun, I. W

Sorley, E. M.

spaukting, $\mathrm{S}, \mathrm{T}$.

speer, J. A. Jr.

Springsteen, $\mathrm{A}$. B

spurgin, W.

sifuire, W. A.

Stamm, F.

Stanchficid, J).

Stanchfiekd, 1).

Stanton, J. P.

Starr, E.

Startzm u, W. H.

Stenton, K. S.

Stephens, I.

Stephens, C.

Stevens, J. C.

titiber, $\mathrm{C}$.

Stillwell, A. F.

Stocking, A. 1).

Stoll, y]

Storm, C. E., Keyes, W' E. d Jones, 1). IV.

Stosisberg, F. W.

Stout, I.

Strieby, W.

Stroud, I. I. IV.

strowger, W. I).

Stryker, I.

Summer. J.

svenion, B. J.

Swaney, J. S

Tabor, B. 1).

Tart, l'. S. \& Wilson,

$$
\text { G. F. }
$$

Tate, J. E

Taylor, J. W.

Taylor, C. F.

Taylor, R. T

Taylor, A. C.

Taylor, W.

Teagle, T. I.

Teacdale, H. M.

Terrell, H. D.

Terril, E.

Terry, J. P.

Tewell, L. S.

Thayer, R. \& McClelland,

$$
\mathrm{J} \text {. }
$$

Thomas, T. R.

Thomas, J. R.

Thorley, T.

Thurston, F, G.

Tiblits, J. J.

Tichenor, E. S.

Tolle, $\mathrm{v}$.

Tolley, $\mathrm{F}$. W.

Tolley, F. II

Tolley, F. W.

Tolhurst, G. IV.

Toombs, s. A.

Traver, A. J.

Traweek, K. C

Trumbo, E.

Turner, $T$.

Tuttle, 1.. G.

Tweedy, I.

Van Brocklin, P. C.

Vanhorn, R. J'.

Van Horne, R. 1

Vas Horne, I

Van Horne, R. P.

Veal, F.

Veher, W. F.

Vick, W. II.

Vickery, D. F.

Von Phul, II, Jr, and Mal. lon, I.

Piate (\% i)

$17244^{8}$

$54 \quad 15$ 


\begin{tabular}{|c|c|c|c|c|c|c|c|c|}
\hline \multirow{2}{*}{\multicolumn{3}{|c|}{$\begin{array}{l}\text { Plate Claim } \\
\text { Von Phul, H. Jr. and Mal- }\end{array}$}} & \multicolumn{3}{|c|}{ Plate Claim } & \multicolumn{3}{|c|}{ Plaie } \\
\hline & & & Wells, H. & 22 & & Wilson, J. L. \& Morrow, R. & & \\
\hline lon, $\mathrm{J}$ & 145 & 40 & Whaite, C. L. & 112 & $3^{2}$ & G. & 174 & 49 \\
\hline Waddell, J. & 124 & 35 & Whiteside, J. \& Crabill, H. & & & Wingo, B. W. & 145 & 42 \\
\hline Waffle, C. L. & 110 & 32 & F. & 24 & 5 & Witter, B. & 138 & $3^{8}$ \\
\hline Wagner, J. R. & 110 & 32 & Whitlock, C. & 116 & 33 & Wolpert, J. & 107 & $3^{1}$ \\
\hline Waite, $\mathrm{T}$. & 89 & 26 & Whitman, L. M. & Io & 2 & Wray, L.. A. & 60 & 17 \\
\hline Walker, W. T. & $14 i$ & 39 & y, S. M. & 60 & 17 & Wright, L. R. & 84 & 25 \\
\hline Walter, J. A. and Bushman, & & & $\mathrm{T}$ & 4 & I & " " " " * & 84 & 25 \\
\hline E. & II 6 & 33 & & 93 & 29 & " " " " " & 85 & 25 \\
\hline Walton, E. W. & $8_{3}$ & 24 & WVi & 103 & 30 & Wright, L. R. & 135 & 37 \\
\hline W. & 93 & 24 & , E. E. & 138 & $3^{8}$ & Wright, WV. & 160 & 44 \\
\hline $\mathrm{S}$ & $15^{8}$ & 44 & Wiard E. & 163 & 45 & Woods, A. Wells, D. \& & & \\
\hline B. F. & 104 & $3 \mathbf{i}$ & Wilcox, A. & 67 & 19 & Bates, T. & 3 & 5 \\
\hline Ward, M. N. & 171 & 48 & Wilhelm, J. & 47 & 12 & Woods, C. J. \& Philli[s, J. & 102 & \\
\hline $\begin{array}{l}\text { Warner, J. } \\
\text { Warren, T. P. }\end{array}$ & $\begin{array}{r}7 \\
68\end{array}$ & 2 & Wilkins, A. W. \& Eskridge, & & & Yost, G. W. N. & $\begin{array}{r}102 \\
11\end{array}$ & \\
\hline $\begin{array}{l}\text { War } \\
\text { Wat }\end{array}$ & $\begin{array}{r}08 \\
105\end{array}$ & $\begin{array}{l}19 \\
31\end{array}$ & S. T. & 102 & 30 & Yost, G. W. N. & 31 & \\
\hline Watkins, W. M. & 126 & 35 & Williams, J. M. & 29 & 7 & Young. J. & 21 & \\
\hline W. T. & 63 & 17 & Williams, B. \& Morgan, C. & & & Zane, W. P. & 12 & 2 \\
\hline Veaver, W. & 155 & 43 & C. & 176 & 49 & Zeigler, G. WV. & 53 & 14 \\
\hline Webber, N. G. & 108 & 32 & & 6 & 26 & Ziegler, G. WV. & 8o & \\
\hline Weber, R. & 166 & 46 & Wilson, F. R. & 83 & 24 & Zocher, C. & 142 & 39 \\
\hline
\end{tabular}




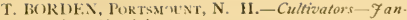
uary 1,3, is 3o. (No claim.)

II. HGiLET, CANAAN, CunN.-Cultizators.-December I1, 18,32. (No claim.)

1. REICHARD, GILFOR D, PA.-Cuitivators. - December 16,1833 .

Claim. - I do not claim as my invention the individual parts of the machine as I have described them, but the general arrangement and combination of the whole, which gives to it that character by which it is distinguished from other forms of cultivaturs or harrows.

SAMUEL CLIME, PLINSTEAD, I'A. - Cultivntors - Fuly 17,1835 . (No claim)

J. II G.ARNETT, EssEx, VA.-Cultizators.-February $3,18_{3} 6$.

Claim.- The form and fixing of the cast iron No. 3, as shown and described.

S. CLIME, NEW BRitain, PA.-Cultivators.--October 15,1836 (No claim.)

i. 1. Sill L1, Bexstlem, PA.-Cultivalors-Avember 26, 38 \% (No Claim.)

No 1,543.-I. KNOIILE, BAKFrsi'ille, M1), - Cullivators.-Afrils, is 40 .

Clain, - The using of several mold boards of cast iron of the ordinary construction of such mold boards, but without land sides, and the so arranging said mold boards as that the point of either of those in the rear shall follow that which precedes it, within the width of its furrow slice, in the manner and for the purpose herein set forth.

No. 1.779.- X. BARNES, EAstmaMrTos, N. V.-Cultivators-September 10,1840 .

Claim,- The described combination of the share, teeth and frame for dressing crops planted in rows, as herein set forth.

No, 2,526.-W. A. ROGiFRS, Si MMERSWH.LE, AlA.Cultivators.-April $1,18_{42}$

Claim - The manner of arranging the back and side rows of teeth, in comhination with the frame and beam as described, for cultivating cotton.

No. 2,647-4. WO'DS, D. WELI.S AND I. BATES, ApAMs, N. Y.-Cultizators-Day 28,1842 .

Claim.-We do not claim and we hereby disclaim any pretensions to an improvenent in the corn cultivator frames, brsing our claim upon the combination of three teeth of the aforementioned de-cription, to be used with the corn cultivator.

No. 2,650.-JOHN MASON, HADDUNFELl, N. J.Cultivalors.-Mav $28, \mathrm{IS}_{42}$.

Claim.-The hands are ertirely a new invention, and their operation is as descrilsed in the specification, and for as much as they may be usefully applied to other instruments. I wish all secured.

No, 2,792,-M. J. HUNT, CiNcinNati, OHo.-Cultivacors. - Seplen:ber $30,18+2$.

Claim - The employment of two sliding bars carrying two cultivator teeth: or two mold hoards, which may be shifted and set in the monner and for the purpone set forth.

No. 2,879.-J. PARSONS, JR., DUblin, IND,-Cultivators.-Decembe's 1 2, $18+2$.

Claim.-The combination of the slotted cross piece and hook-braces, and sliding clips with the forward connecting cross piece of the shafts rendering the aforesaid combined plows convertible into agricultural implements of various descriptions, for various purposes, as before described.

No, 3,356.-T WIARD, EAsT Avon, N. Y.-Cultivators.- Vovember 24,1843 .

Claim - The combination of a pole or shafts with a frame and gang of plows in the manner described, in such a way as that they will have an up and down motion, while ail lateral motion is prevented, in the pole or shafts, independent of the plows.

No, 3,406,-R. NEL.SON, WEest PoINT, IND.-Cultivators.- Fanwary 15,1844

Claim. - The manner in which $I$ have combined and arranged the bars $\mathrm{B}$, and lever $\mathrm{E}$, so as to effect the contraction and expansion of the cultirator, and in combination with the above, the iron comb $\mathrm{F}$.

No, 4,170.-A. HARRISON, Bussfield, Mich.-Cultivators. - Siprember $2,18+5$.
Claim.- The manuer of securing the cultivator beam to one of the cruss pieces of the handles or standards, (upon which it turns,) in combination with the manner of fastening and securing the same to each other, and regulating the angle of inclination of the handles an + cultivating points, and the position of the bem, by mean of the adjusting braces and nuts, constructed and operating substantiall, in the manner and for the purpose herein set forth, and repre sented in the different moditications of my new and im proved shovel-pointed cultivator.

No. 4,I71,-A. RALSTON, WEiT MnnLzTON, PA.Cultizators.-Sepeember $2, \mathrm{~J}_{4} 5$.

Claim.-1.- The attachment to the rear of the plow of the ad ustable hinged shoe, guiding cutter attached thereto, and arjusting lrace; all combined and operating substan tially in the manner and for the purpose herein set forth.

2 - The attachment to the plow standards and sliafts of the lateral adjusting braces, substantially in the manner and for the purpose herein set forth.

No. 4,320.-A. Eld RE.D, Oppenheimer, N. V.-Cul tizators. - December 20, 1845

Claim-1-1-Joining the sockets that receive the standards of the plows to the frame, as herein descrilued, to ad mit of adjunting in a vertical as well as horizontal direction, as specified.

2. - The method of adjunting the front double tooth by means of the enlarged nortice and wedges, in combination with the journal projections on the standards as described.

No. 4.725.-W. IYSERT, GetTYsherg, PA.-Cultiza tors.-Ausust 28,1846 .

Claim.-1.-The movable and jointed frame for cultivators, constructed and arranged substantially in the manner and for the purpose set forth.

2. - In combination with the shovels of cultivators, the point having a shank thereon, for the purposes above set forth.

No. $4,762,-$ I. EDWW.IRDS, OR.ANGE CO. INI)-Cultinators.-September $\mathbf{1 9}, \mathbf{1} 846$.

Claim-The manner of combining the hooks and eyes and clevis, as above described, by which the sides of the plow may be elevated and raised out of the ground, so a to conform to the inequalities and irregularities in the corn rows, without disturbing the other parts of the machine, and without the necessity of raising the entire plow.

No. 5.639 -D. PATTEE, Ypsilanti, Mich.-Cultizators.-Fune $20,18_{4} 8$.

Claim.-The manner of attaching and regulating the front sheath, and in combination therewith the manner of regulating the depth of cultıvation, as above set forth.

No. 5,755.-R. CRISWELI, JR., Chaneersiurg, PA.Cultizators. - September 5, 1848 .

Claim.-Giving the sides of a cultivating shovel point, the one a forward and the other a rearward curve, substantially for the purpose herein set forth and of the form represented in the accompanying drawing.

No. 5,859.-G. BEECHINt;, Augusta, N. Y.-Cultiva tors.-October $17,18.48$.

Claim.-1. - The construction of the quadrangular teeth for cultivators, as described and represented.

2.- The construction of the $\mathrm{U}$ shaped iron brace hav. ing a clevis formed on its front, and two vertical tran iverse grooves on its sides, as combined with the parallel timbers $\mathrm{A}, \mathrm{A}$, of the frame and adjustive standards $c^{\prime}, c^{\prime}$.

3.- The extra handles F, F, for raising the cultivator in turning at the end of the furrow or going over stones, as described.

5,998. - A. LELAND, MILTON, PA.-Cultivator, - Fan uary, 2, 1849

Claim. - The construction of the removable land sides with wings, substantially as represented, in combination with shares made without either bos-es, loops or other projections upon the sides that would interfere with their being turned bottom side up, and attached to the shanks in that position, or obstruct their action when thus upturned; the land sides and shares so constructed being connected together by one or more screw loolts, or by other analagous means. 
No. 6,007.-W. RICHTER, WILliamsbukg, IND. - Cultivators. - Fanwary 9, 1849.

Claim.- The corn fender $\mathrm{C}$, in combination with the cul tivator teeth $\mathrm{A} \mathrm{A}$, and the plow acting in the manner and for the purpose set forth.

No. 6,167.-I. WARNER, REAdING, PA. - Cultivators. - March $13,1849$.

Claim.-1.-Connecting the teeth of cultivators to the frames thereof, by attaching them to blocks adapted to slide in the frame, and provided with screws for regulating their position relatively to one another, and to the draft beam, substantially as described, and in combination with the foregoing.

2.-Connecting the teeth by means of a hinge or other turning joint, and provided with the jointed screw brace, the said joints and screw braces being attached to the sliding blocks to which the teeth are attached, as described.

No. 6,204.-S. W. AIKIN, SPRING HIL.L, TENN.-Culivators.-March 20, 1849 .

Claim.- 1.- The grooved board ( fig. 4 ) fitted to the scraper and bolted to the beam for the purpose of protecting the plants from falling clods of earth.

2.- The arrangement of teeth in one beam $B$, of the cultivator, and constructing them of different lengths for the purpose set forth.

No. 6,501.-S. COATS, LAFAYETEE, Wis, -- Cultivators. - Fune 5,1849 .

Claim. - The auxiliary cultivator teeth $\mathbf{H}$, in the outer ends of the drag $F$, as described and represented.

No, 6,511.-GE(). W BROWN, TYLERVILI.F, IL.1.Cultivators.- - Fune 5,1849 .

Claim. - The morle of adjusting the position of the shovels $D$, so as to throw the earth from or towards the rows of corn, or to the right and left at pleasure, by means of the before described combination of the levers $\mathrm{L}$, links $\mathrm{N}$, and, adjustive bars I, with the parallel slotted bars $B$, and oblique hinged bars $Q$, as describerl.

No. 7,463.-C. KODGER, Montpelier, Vr.-Cultivators.-Fune 25,1850 .

Claim. - The combination of the bar $a$, with the weel cutter $b$, in the manner and for the purpose set lorth and represented.

No, 8,483 .-I. CONSTANT, Buffalo, HFar T Grove, ILl.-Cultivators.-November 4, 1851 .

Claim. - The immediate jointed plows in combination with the main cultivating plows as described, for enabling the plowman to plow nearer to, or farther from, the rows at will.

No. 8,850 .-T. J. BALL and J. POSTE, PittsFiel.i, Mich.-Cultivators.-April 6, 1852.

Claim. - The construction of the long metallic inclined blades $e, \varepsilon, c$, on the after part of the machine, for cutting the sods and lumps and pulverizing the ground, as set forth.

No. 9, 314.-C. BISHUP, NORWALK, OHIO.-Cultivators.-October $12,1852$.

Claim. - The manner herein described of constructing the mold hoards $\mathrm{D}$, and combining them with the blade $\mathbf{E}$, in the manner substantially as herein specified.

No. 9,754.-PHILIP H. KECK, MoRgantown, VA.Cultivators.-May 31,1853 .

Claim. - The combination of the balancing pivot $\mathrm{P}$, with a cultivator constructed as above described, for aiding in turning the same.

No. 9,796,-E. L. FREEMAN, ANN ARBoR, MICH.Cultivators. - 7 une $2 \mathrm{I}, 1853$

Claim,-The precise construction of the tooth, and placed in the position as set forth, the vertical part and the horizontal part each having a backward slant.

No. 9.798.-W. S. HVDE, TOWNSEND, OHIO,-Ciultivators.-Fune 21,1853 .

Claim. - The cultivator herein described with adjustable supplementary wings, so constructed as to cultivate the soil near the roots of the plants superficially, and deeper at a distancé therefrom, the wings being adjustable to any required angle with the bottom of furrow so as to give any desired degree of inclination to the sides of the ridges or hills, and to change their inclination from time to time to adapt them to the varying stages of the growth of the plant.
No. 10,123.-L. M. WHITMAN, WeEdsPorT, N. Y. Cultivators.-October. 11,1853 .

Claim.-The employment of the long inclined spring wings $c, c$, secured at their front ends to the share and main standard, and turning upon the pin $\mathrm{E}^{\prime}$, in combination with the mechanical contrivances herein shown, for expunding and contracting the wings, or setting them more perpendic ular and nearer together, for the purpose of throwing more pulverized soil against or up to the hills, or setting them less inclined to the horizontal plane, and farther apart, for the purpose of allowing the pulverized soil, weeds, \&c., to pass over them into the broad open spaces in the center, the wings, in either case, cutting up the weeds and pulverizing the soil, as fully set forth in the specification.

No. 11,361 - C. H. DANA, WEST LEeANON, N. H.Cultivators.-Fuly $25,18_{54}$.

Claim.-Constructing each of the outermost teeth $\mathrm{G}$, with a horizontal blade projecting more or less outwardly from its slank, and with an upright portion $G$, hent up at the extremity of said outwardly projecting blade, the elge of said upright portion being parallel, or thereahouts, with the longitudinal direction of the cultivator, for the purpose of cutting up the weeds close to the rows of corn or other plants, and at the same time drawing the weeds away from the rows, and also serving to guide the attendant in directing the cultivator, so as not to injure the plants by too near an approach to them, substantially as herein described.

No. $11,460 .-D$. W. SHARES, HAMDEN, CONN.-Culti z'ators.-August I, 1854 .

Claim.-Providing the expranding and contracting hoeing wings $\mathrm{B}$, on either side, with cultivator teeth $\mathrm{C}$, pro,ecting downwards on the inside of the hoeing wing or scra, er?, as and for the purposes specified

No. 11,528. - J. MVERS, Powhatan PoINT, OHIO.Cultivators.-August 15, 1854 .

Claim. - The triangular wings upon the turned up portion of teeth $\mathrm{C}$, with their l.nd silles so inclined as to have a tendency from the plant when the implement is moving forward, constructed and arranged substintiılly as herein. before set forth, for pulverizing the e.urth and otherwise facilitating the cultivation of cotton.

No. 11,924.-W. B.ANCROFT, WHITEFORD, OHI,Cultivators.-Notember 14, 1854 ,

I am aware that a trangular knife like mine $\mathrm{h}$ s been used hefore.

Claim.- The method of makin $r$ the knife adjustable upon the frame $a$, by means of standard $c$, and hinged staudards $f$ and $g$, as set forth.

No. 1 2,536.-S. A. KNOX, Wurcester, MAss., assignor to Ruggles, Nourse, Mason \& Co,-Cultivators.Harrh 13,1855 .

Claim.-Arranging the curved knife, or pointed tooth $\mathrm{K}$, at or near the front end of the beam of the $h$ irse hoe, while the main or double hoe $\mathrm{C}$, is disposed at or near the rear end of the beam, and so as to enable the said tooth to be used in the manner and for the purposes as stated; it being employed in a common plow simply for cutting the sod or opening it for the reception of the nose of the plow.

No. 12,571.-G. W. N. YOST, PURT GIIISON, Miss.Cultivators. March 20, 1855 .

Claim. - The combination of the ad ustable scraper E, with the har and point $\mathrm{D}$, as described, for the purpose of bearing off the row and wrapping up the middle; also, for scraping off the row, and rolling the scrapings over into the furrow opened by the plow, substantially as set forth.

No 12,609 . - R. P. VANHORN, JACKson TOWN, OHIO. -Cullivators.-March 27, 1855.

Claim.--The peculiar elongated rhombus-shaped, w rought iron frame and arrangement of teeth, the front angle bearing a light steel cutter tooth, and the rear angle a large shovel tooth, in the manner and purposes set forth.

No, 12,611.-W. P. ZANE, Wooulich, N. J.-Cultivators.-March 27, 1855 .

Claim...-The vine-hooks, $f, g, g$, arranged in such a manner in relation to the cultivating teeth $h, h, h$, that the said hooks will remove the vines out of the way of the said cultivating teeth, and allow them to operate upon the soil without injury to the vines, substantially as set forth. 
No. $12,7+4-1$. STRYKliR, SIX MII.K Ruv, N. JCiultizuators.-Ifirit 17,1 \$ 55 .

( laim. - The applieation or use of front and rear support on supporters, which not only anwer all the purpesen of wheels, hut regulate and govern the action of the exulter in the sround; constructed and arranged sulstantially in the man. ner and for the purpone herein set forth.

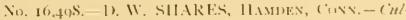
tirutors.- - Jonuer' $27,1.857$.

(laim. The contruction and arrangement of the series of teeth 11 , on the side bars $13, B^{\prime}$, in rel tion to the sait ban and to each other, in the manner and for the purpose specitied.

Xi, 1,150,-1), W. SIIIRES, IIAMHEX, CONN.Culticuturs-Januarl 27, 1857; re-issned Warth 12, 1861

Clain-1 - I series of coulter teeth $\mathrm{H}$, formed ubatantia ly as specified, and arranged diagonally to the line of motion, so as to form a harrow that looseus, mollifies and harrows the suil as described.

2 - The tooth $(i$, at the front end of the ecnter bar, formed with two divergent wings, in combination with a series of harrow teeth II, on the diagronal har [i, I', as set forth.

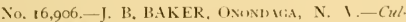
inaters,-March 31, is57.

Claim - The are or fender $\mathbf{E}^{\prime}$, in combination with the adjusting bar $\mathrm{E}$, whereby the stalks are laid asicle, and the said bar rendered much more durable, the whole constructed as set forth.

Ni). 17,594-M. T()I.LE, Newport, Kr.-Cultizutors. - June 16,1857 .

Claim.-The bracket $c$, in combination with the plow heam $d$, constructed, arranged and operated in the manner substantially as and for the purpuses set forth.

No. 17.777.-G. (i. BL.ICK, CFossinvil.1., ()HIO,-Ciul tiźtor.-July 14,1857 .

Claim.-In double plows with two beams joined at the clevis, and made to be ad usted to $r . w$ i of crops of different widths, is the rod /, arranged between the beam and provided with a eross bar T. upon which the be ims can vilirate when the plow - are a ljuted as described.

No, 17,797,-H1 MANN, SAN FraNeIsco, CAl.,-Cultizutur.- July 1 i , 1857 .

Claim.-The arrangement of shanks $g, g$, with rack-bar $f, f$, and se mental plate; $h, h$, in the manner and for the purposes herein set forth.

No, 18,073.-C. H. SAVRE, UTICA, N. Y.-Cultizators. - tusust, $25,1 \times 57$.

Claim.-1 combined horse hoe and double mold-board plow constructed, arranged and operated, cubtantially as set forth

No, I8,330-W. I. FORSHEE, INDIANAPIIS, IND,Cultizators.-Oitobir 6.1857

Claim.- The combination anl arrangement of the bar B, the wheels $\mathrm{C}$, the bar $\mathrm{H}$, and levers $\mathrm{G}, \mathrm{C}, \mathrm{G}, \mathrm{G}$, when eonstrueled and operated substantially as set forth.

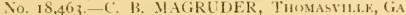
- Ciultizators.-Octoher $20,1857$.

Claim.-The polygonal plate $\mathrm{D}$, in combination with the $\operatorname{arm} C$, and beam $\mathcal{A}$, in the manner and for the purpones sct forth.

Vo. 18,714-J. SLVI.MIER, RALE1:ill, VA.-Cultizators. - Vinember 24, 1857 .

Claim.-The use of the hinged wings $D, D$, which are adjusted by rack and pinion, when arranged to move in and out over a station.sy curved supporting and guide rod E, which has two springs $\mathrm{F}, \mathrm{F}$, coiled around it in combination with a stationary circular notched plate J, pivoted tilting lever $\mathrm{K}$, and spring $\mathrm{L}$, which are arranged as shown, sul, stantially as and for the purpose set furth.

No. 18.739--J. GIBBS, NEWARK, OH10.-Cultinators. - December $\mathrm{I}, 1857$

Claim. - A cultivator constructed as herein described, viz: having it frame $A$, made of wrought-iron in the form shown, with metallic lipped plates i, made to slide lingitud inally on the frame, the share $c$, of the form shown, attached to the plates $\mathrm{i}$, by bolts $\mathrm{m}$, and capable of being aclju-ted and reverned, all as sjeeified.
No. I $8,825-$ K. S. SIENTON, NEW Jokk, N. I. Cinllicuters. - Diender 8,1857 .

(laim.-Unitm - two or more plows by an intermediate share, in the muner and for the purpones set forth: said share commencing at or near the point of the pluw A, and extending lackward in the direction of the sole of the land side of s id plow, and receding obliquely at or alout the angle uf the share of said plow, until it meet the share of plow $1 \mathrm{i}$, all substantially in the manner set ferth.

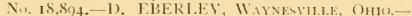
Shers Plear-Derember 22, $1 \mathrm{~S}_{57}$

(laim.- Gecuring the shares $\mathrm{E}, \mathrm{E}$. to the lieam A, by having the upl er end of their bars I), fitted in the bar (., the bar 11, also prosing through the loops or eyes $F$, of the har $\left(i\right.$, and secnred therein liy kes's $i^{2}$, the bar $(i$, being secured to the b-am A as shown, and the whole arranged as and for the purpose set forth.

No, 18,900,-A. W. H.AWl.EV, MII.AN, (1HI0,-CidtiF'aters.-Ditumber 22, 1857

(laim.-The movable fender K, ad'ustable arm J, and movalule lorace $\mathrm{B}$, with the peculiar shaped share $\mathrm{E}$, when arranged as set fouth, and for the purpose of protecling the plants from injury, as specified, and for ehanging the share and fender to the right or left of the frame, in the manner and for the purpose substantiatly as specifierl.

Ni1, 19,24S,-I. H()U('K, (1.INTIN, JN1), - Cultizators. - Februtury 2, 1858 .

Clain. - The arrangement of the triangular mold board $C$, and its adjustable standard $B^{4}$, with relation to beam $A$, tandards $\mathrm{B}, \mathrm{B}^{2}, \mathrm{~B}^{3}$, handles $\mathrm{H}, \mathrm{H}$, and shorels $\mathrm{S}, \mathrm{S}$, in the manner and for the purpose sel forlh

No, 19,401.-E. H. BL()()WURTII, TILOMASTUN, GA. - Cultizators - February 16, IS58.

(laim.-The combination of beam $Z$, and it handles (), with the dou' le feet 1,1 , and braces $C, 1$, the whole being arran ed in the manner and for the purpose set forth.

No. 19,742.-J. BANKS, IADEVILLE, ALA.-Cultizettors.- Werrith 30,1858 .

(iaim.- The construction, arrangement and eombination of the body of the implement and its movable teeth, as decribed, whereby it is readily adapted to properly receive in turn the several icraper employed for performing the various modes of cultivation specified.

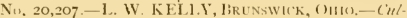
ticutiors. -Wey II, 1858 .

(laim.-The combination and arrangenent of the teeth beams B, B, with their attachin : and adjusting bars E, E, and $G$ G, and the scraper- $.1, M$, with their attaching and adjusting bar- $\mathrm{L}$ and $\left(i^{\prime},\left(i^{\prime}\right.\right.$, with each other, and with the central beam A, substantially in the $m$ mner and for the uurposes set forth.

No. $20,260 .-J$. ENISLEV and E. FIETCIIER, AB-

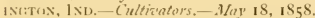

('aim.- I he arranging of thanks 1 , $\mathrm{E}, \mathrm{F}$, and shovels $G, G^{\prime}, G^{\prime \prime}$, with saddle $1, I$, and heam $I$, when construet. ed in the manner and for the purnoses shown.

No, 20,712,-W. A. HOPKJNS, VICKSITRG, MISS.(iultinutors - Func 29, 1858 ,

Claim, - The arrangement of the beam $\Lambda$, transverse beam $\mathrm{B}$, handle $($, holt -1$)$, shares $\mathrm{F}$, standard $\mathrm{F}$, ans $\mathrm{l}$ stays G, when the several parts are constructed and united as de. scribetl, and not otherwise.

No. 21,170-R. SAWIER, assignor to W. G, BROWVN, MoNyouth, ILL.-Cultizaters-1usust 10, IS5S.

Claim,- - Hy improved weeding and hilling plow, constructerl substantially as described, viz: with a coulter $B$, a root cutter 1 , adjustable casters $(;, C$, and turning shares $\mathrm{L}, \mathrm{L}$, applied to adjustable handle and a plow beam, and made to operate substantially as specified.

No. 21,625.-T. IV. POULE, Brunswick, OHit)-Cultistutors.-Siptember. 28,1858 .

Claim.-The combination and arrangement of the hinged arms $\mathrm{B}, \mathrm{B}, \mathrm{B}, \mathrm{B}$, and fixed concentric guards $\mathrm{D}, \mathrm{D}, \mathrm{D}$, in the manner specified.

No. 22,316.-T. TURNER, M IRYSIHI.E, (OHu.-Cultirators.-December I4, 1858

Claim.-The combination of the pulverizing mold-board $F$, and hilling mold-hoard $G$, constructed as show'n, and attached respectively to the longitudinally and laterally 
adjustable beans $\mathrm{A}, \mathrm{B}$, the whole leing arranged substantially as and for the purpose set forth.

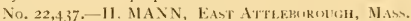
- Cullizutars.-Dicimber $28,1858$.

Claim.-1. The application of each wheel arhor to it wheel and the frame $\mathrm{A}$, substantially as described, viz: so that the whicel may turn on the arbor, and the latter extend into slots; and having fatenings, as explained, whereby not only the wheel may be adjustable with reference to the cutters, but the arbor and is screw nuts may be empluyed to strengthen the frame, in the manner set forth.

2. The descrilued arrangement of each of the slots of the wheel arbor with respect to the scraper of the periphery of the wheel, wherely the wheel, at whatever attitude it may he placed while its arbor is in the slots, will be at one uniform or proper scraping listance from the scraper.

The application or arrangement of the slide liar of the cutter $(i$, so as to operate not only as a scraper to the wheel hut as a-upporter of the cutter post or rod.

No. 22,520-LiE()]R(E W. TOH.HURST, LIVIK-

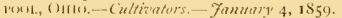

1 support the lower part of the looth by the braces (. C", aid braces are secured to the frame at the front enl, the lack end to the tooth about two thirds the way down. After placinis the tooth at the desirecl point it is secured liy means of the hooks $\mathrm{E}$ and quadrant $\mathrm{F}$.

Clain. - The arrangement of the flanged quadrants 1 ,

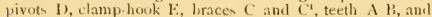
rigid frame $G$, in the manner and for the purposes set forth and described.

No. 22,860-GFORG ESSINGTON, PLAMFIFI, ()HIO.-Cullialor-Fibruary S, 1 S50.

The invention consist in the arrangement of mould. boaris and centre liece in the combin tion with the tandard point and shares.

Claim. - The arrangement of the mold-board, T T, centre-piece $P$, in combination with the coulter or stanlard 11 point I, and shares I I, the whole hem con-tructed subst.m tially as described and for the pur ove set forth.

No, 23,170.-THEODORE HEERMAN, SUMAR, TENN-Cultizators-Warch 8, 1859.

This invention convist in making the hindmost teeth A A much smaller or of less wilth than the front tooth B. and intermediate teeth $C \mathrm{C}$, and arranging the same so that they $\tan I$ out beyond the side edge, of the front tooth, and in beyond the inner side elgen of the intermediate teeth.

C'laim-1. The screw tapped shoulder or flange $c$, and screw sbank b, of the cultivator teeth A BC, in combination "I ith the screw nut $d$, having a series of auxiliary screws $f$, in the manuer nud fur the furpose deccribed.

2. In combunation with the above the specified arrangement of larie and small cultivator teeth $\mathrm{A} \mathrm{BC}$, for the purpones descrilied.

No. $23,580 .-$ W. C. HOLMET, BARNESVILLF, (XA.Ploces.-April 12, 1859.

The interior limb of each beam $a a$, is lent upat rigl:t angles inwardly, b forming an adjustable brace by being at tached; $d$ is a hook to be attached when it is wished to change the double into a single stock; $f$ is an attached seed ctropper, of which $y$ is a block through which the axle passes.

(laim-1. The arrangement of the double beams a $a$, hook $d$, cross adjustable braces $b$ ant $c$, shonks $k$, and braces $m$, the whole being constructed in the manner described for the purpose specified.

2. In combination with the above, the seed-rropper f constiucted for operation conjointly, as aet forth.

No. 23,886.-MII.TON AI.IDEN, AUBukN, N. Y.Cultiviators.-Way to, 1859.

This invention consists in connecting the thills, which are made of one piece with the handles, with the frame by means of braces, in such a manner that the thills pass over the growing crops, and that the sime are in a horizontal position, or nearly so, when attached to a horse, and the frame is so arranged that the shares can be adjunted in the same, according to the width of the different rows, and that a larger or imaller number of shares can be secured in the same.
Claim.-The described arrangement and comlination of the adjustable shares $B$, the frame $A$, and the raised thills $C$, which are made out of one piece with the handles $\boldsymbol{b}$.

No, 23,006.-W11.LIAM (. DOSS, LAVACA, Trxas. - Cultizators.-Miry 10, 1859.

This invention consists of a triangular frame with five shares or ploughs and a scraper; three of said five shares have mould board attached by means of serew', and should be uxed for hilling plants and keeping the ridge up as desired.

Claim.-The arrangement of the triangular frame A A B, of shares J K, with mould board that may be taken off at pleasure, scraper $\mathrm{N}$, and cultivators $\mathrm{l}$. $\mathrm{M}$.

No, 24,013.-OLIVER H. IUENNIS, MLTONA, IIL. - Cultizators.-Mas 17, 1859 .

Thi improvement consist in so connecting the side beam $\rightarrow B$ with the handles $C$ C, and arrming both the bandles and side be $1 m$ in connection with the central beam $A$, that the position of the side beams and the consequent breadth of cultivation shall be directly under the control of the bolder of the implement, to be instambaneously raised by him at pleasure.

Claim.- The arrangement and combination of the hinged handles $C \mathrm{C}$, hinged side beam $-13 \mathrm{l}$, and connecting liars 1111 , in relation to the central beam $\mathrm{A}$, sulmtantially in the manner and for the purpose specitied.

No. 24,059.-JOIIN IV. BATSON and 1.EONARD

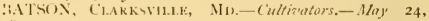
1859 .

11 is a concave po $n t$ apricel in a similar maner to the showel $\mathrm{E}^{4}$, this point following in the rear and lightly to one of the side furrow marle loy the point $\mathrm{F}$; it in unnecenary that a cutter should be applied to it. It is marle with the four point $o o^{1}, o^{2}, o^{3}$, each of $w h \mathrm{ch}$ may be uved in turn for en ering the grouni as the other hecomc dull and worn.

Clim.-The arrangcment of the rever-ible concave shovel point il reversibite shovel point $\mathrm{F}$ and it cutter $\mathrm{G}$, with beim A and st indark ( and 1), the whole being constructed and appled in the manner described, for the purpore specified.

No. $24,203 \cdot-C E L F S T I N$ EASTHUKN, Couniv, Ky.-Cultintors.-Mor 31, 1859.

1 firt une the $m$ chine as in seed coverer. In this operation the wheel $F$ is indispensably nectsary, the rake 11 is taken off, it be ng of no use in seed covering. When 1 have used my m thine as a seed c iverer, 1 remove the wheel F by drawing out the knees $G$, and altach the rake 11 , for the purpose of takin, the clo.ls or trash of any kind that may lixlge alsout the young plants. The rake in supyorted eight inches above the grwund by the spring, and works on a sp tce of ci shteen inclies horizontally, makung it convenient to strike anywhere necessary. The rake is takes off loy remosing the block J.

Claim.-The arrangement of the ploughs 1 , wheel $F$, block J, spring $\mathrm{I}^{1}$, and rake 11 , as set forth and rlescribed, for the purpose specified.

No, 24,227-KEUBEN M. MELT()N, CRMILRS. Vilit, VA-Cultizitors.-Way 31, IS59.

Claim, - - - the combination of the arjustable links with the adjustable slide, arrauged subatantially an dencribed, for the purpose of ad usting the distance buteen the ploughs.

2.- In combintion with the curved plough beam, the coulter constructed and arran;ed substantially as described, whereby the draft of the side ploughs is reg. ulated, by sliding the coulter on the beam, anil firm support given to the coulter in passing through compact soil.

No. 4,875.-REUBEN A. MELTiN, CritilersVtt.L.F, VA.-Cultivators.-Patent No. 24,227, Hay 31, I 859 - Re-issued tpril 16, 1872 .

Claim.-I. The adjuntable links $h$, and ad ustable sludes , constructed substantially as described, and arranged to operate with and for the purpose of adju-ting the distance between the plow-lseams, as set forth.

2. The coulter D, constructed surstantially as described, wih shovel or plows $\mathrm{F}$, when hoth coulter and shovels are independently ant freely ad ustable up or down the curved beams, so as to run deep or shallow, or at different depthi, as set forth. 


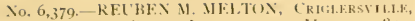

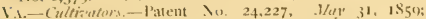
reissue No, 4,575, dated Ipril 16, is72; reissucd Afril

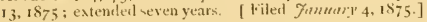

Brief.-The beams are adjustable literally by meins of links, and hy slides keved to the beams, which are curved and receive adjustitle plow. A coulter of novel form is alt iched to the center heam, and serves to stealy the plow, and hold them to their work.

Claim. - I. The al ustable links / and adju-t ble vlides $e$, constructed sulstantially as dencrilied, and arranged to operate with, and for the purpose of ad usting the dislance letween. the plow heams, as set forth.

2. The shovel $\mathrm{F}$, freely arljustable to any point up or down on the curver beams, so an to run deep or shallow. or at different depths, as set forth.

3. The esulter attachment D, constructed substantially as described, and adjustable up or down the curved beams, for the purpose speeified.

4. The coulter atachment D and shovels $\mathbf{F}$, operating in combintion with the curved heam, substantially as and for the purpose upecifietl.

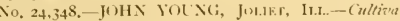
tars.- Funt 7, 1859 .

This inventi $n$ consist $;$ in the combination of the serew ex tension $\mathrm{A}$. On the lo: $\mathrm{m}$ of the stantiard B, with the oblinue slotted easting $\mathrm{C}, \mathrm{C}$, attached to the front sicle of the crous bar 1$)$ of the lream $\mathrm{E}$; alco, in the combination of the st 2 tion ory vertically perf rated bur ( $i$, with the ad ustable rake or harrow $\mathrm{H}$, arranged on a cult vat $r$, wherehy he harrow teeth can be cleared of all whitruction hy raising the rake or harrow, so hat its teeth rise through the vertical perfurat ons in the transwerse bar.

Claim,-1.-The combination of the serew extemsion $A$, on the lottom of the staudari B, with the oblique slotted castings C, C, attuched to the front side of the cross har II. of the heam E, subst intially as anil for the purposes set forth.

2.-The combination of the stationary verlically perfor. ated bar $\mathrm{G}$, with the arliustatle rake or harrow $\mathrm{H}$, arr.ungert on a cultivator, substanti.lly as and for the purpose set forih.

No, 24,486-DANES P'EFI.JR, TALIAHASSkF, FiA. - Ciultizators - Fumi $21,1859$.

( laim.-The arrangement of the bars $D$ ) and $E$, beam $A$, handles $\mathrm{F} \mathrm{I}$, and stanlarel $(C$, the bar $\mathrm{E}$ forming a br'ce, a colter, and a landicle, and bar, I) being provided with an inclined or tapering point, on which any style of blale may be secured, the two bars heinir pivoted together at $x$, and the whole operating sulstantially in the manner and for the purpose speeitied.

No. 24.507.-FR.INKI.IN VEA1., HALIETTSIILE, TFXAs.-Cultisuters- $\mathcal{F u m e}^{21}, 1.859$.

Claim.-Arranging the dovetailed projections $i$, at equal distances from the cutting edges of the shear, in coml ination with the lot $; j$ and reces-es $k$, in the arms and for the purpose of securing the shares to the arms, aud to renler them revenible, substontially as deveribed.

No. 24.514--HENRY WELIS, WALNUT fiROVF, 1.1..-C'ultiratirs - $7 u n e^{\prime} 21,1859$.

Chaim,-The arrangement of the share $\mathrm{F}$, mould boards $G(i$, rods $11 \mathrm{H}$, and 11 , the lntter having the parts $d d$ formed on them, the said parts passing respectively through the bar $C$ and beam $A$, this making a very frm structure, in the manner and for the purpuse set forth.

No. 24,580.- WILLTAM I. RIVERS. STMPTER DISTRICT, S. C.-Cultizators.-Fune $28, \mathrm{t} \$ 50$.

This plough is to enable the planter to thoroughly pulverize the land, breaking up the clods of earih, a the same time tearing out grasses of all kinds, being more especially adapted to the joint grass, with which some cotton lands are infested, and at the same time makin the drill in which the cotton is t, be planted.

Claim-The handles 1 , helves 2 , beam 3 , foot bar 10 plough 20 , harrow 45 , roller frame 6,7 , and roller 8 , when the whole are arranged for joint operation, as described and for the purpose set forth.
No. 24,644 -PIJIIIP KRIBS, JHFFKSON FIR IER, PA. Cultirutors. Fuly 5, 1859

In the driwings, $\mathrm{A}$ is in the centre and If $\mathrm{l}$, the site bass, which are franted into the front bar $c^{\prime}$, with their ends fastened to zether by the bolt I, the whole making a stroni frame, to which the other p:rts of the cultivator are fantened.

Claim. - I he arrangenent of the bar A B C , met.l frame (i, hamlles II, hanks $E^{\prime}$, teeth $\mathrm{E}$, bar $\mathrm{I}$, and hafi $\mathrm{F}$, as dencribet. for the pury ones et furih.

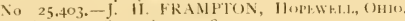
- Cultizature - Sitromber $13,1850$.

This insention comsists in a novel way of attaching the shares to the plough, wherelsy they may be readily ad justesl nearer to icther ir further apart, or hi her, or lower, as the nature of the work may require.

Claim - The adjustable share unndards $\mathrm{C}$; ; attuched to the parallel acljustable hars 1) 1), which are secured to the beam A by the bar $1: \mathrm{E}$, the whole being combined and arranged subuntially a and for the jur one set forth.

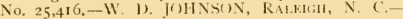
Culiziators.-.September 13, 1859 .

This invention consist in a peculiar mole of constructing the frame of the implement, wherelsy, in combination with double shares, the same may be reaclily adipted for the cultivation of variou crops.

Claim.- The hars A A, curved so as to form handles at one end, and havinis horizmutal ohlique posit ons to form the body of the frame, the draft bar C, and guicle or retaining bur 1 , the front encliof the bar $1 \mathrm{~A}$, hein $;$ connected or secured together by the collar or loop $\mathrm{B}$, in combination "ith the double-criper F, subs:antially as de-cribed ani for the purp.me set fint rih

No. 25,754.-13. S. IIORGAN, DH.III, Jowi.Cultizutors.-Octutier 1I. IS59.

By throwing the bial lever $f$ in the direction of the ar row $\mathbf{I}$, the levers hh $i$, are turned so an to come to a more wi right or vertical position. and the frame $\mathrm{A}$ is rained; when the hand lever $f$ is thrown in the direction of arrow 2, the frame $A$ is lowered. The raisin $;$ as well as the lowering of the frame is done pir.llel to the grount

Clim. - The arrangement and combinatien of the side wings 1) and wheels II II I of a eultivator, with the lever th hi bar $d$, ro is $e$, and h ind lever $f$, sulstimtially as and for the purlose specifiel.

No 26,121 -ISA IC N. P'ILE, JFATTR, IND,-

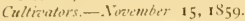

This invention consists in an improved mode of ad justing the wings of the cultivator, and also the central beam so that the wings may le st read out or contricted.

Claim.- The arran rement and combina' $i$ of the eurved pivoted wing rods $\mathrm{A} A$, curvel arljusiahle central rorl ( $^{\text {; }}$ looper socket, F, vertical movable stanil.rels J, rods $\mathrm{M}$ l races $\mathrm{L}$, and handle, $\mathrm{E}$, a and for the purpose shown and deveribed.

No. 26,?I6.-J. WIHTESIIDE and II. F. CRAHILI.

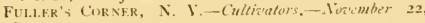
1859 .

This invention consists in arrangin the eurved shovel beams in such a manner that they can be used with their cuncave ides facint each other, and also reversed, bringing their convex silles towards each other, where by the cultivator may be adapted to different kind. of work. It consists also in ccmbining with said hing ed and curved shovel beam a crosabar with a gauging wheel in such a manner that, by shifting said bar, the w Ith of the shovel bears in adjunted, and that the depth to which the shovels cut is govened by said gauging wheel.

Claim,-1.-The arrangement and combination of the hinged ( urved shovel beams \& A, crossbar 1), and gauging whed $F$, substantially an and for the purpose set forth.

2.-The curved draft beam $\mathrm{B}$, arranged as deseribed, in combination with the crosubar $\mathrm{D}$, handles $\mathrm{G}$, and rod $h$, subsantially in the manner and for the purpose specified.

No, 26,259.-A. A. DICKSON, ANDIRSON, S. C.Ploughs. - Norember 29, I859.

This invention consist of an improved mode of constructing the plough, whereby the same is rendered simple and capable of being adapted to various kinds of work.

Claim. - The arrangement of the peculiar shaped bar D, 
with the shares $\mathbf{E}$ F and $(i$, beam $A$, and handles $\mathrm{C} C$, sulstantially as describer for the purpose set forth.

No. 26,563.-KH())(MM M. WROOKS, GReenvili.,

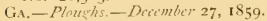

A in the plow hose or scraper; which is so arranged that it can he turned and sharpened by its operatinn in ploughing: $\mathrm{B}$ is the turning wing or share, secured to the plough beam / by clamps $U$ and screw bolt $C$; $\mathrm{D}$ is a piece of iron attached to the plow foot and extending back to protect the rod $\mathrm{F}$ from damage: $\mathrm{E}$ E are the nuts and washers on the end of rod F, hy which the plow hoe A is confined.

Claim - The arranuement of beam J, screw foot F, notch

, plow hoe $A$, opening $\mathrm{P}$ moutd hoards $O$, openings $W$. nuts E E, holes I I I, con-trutted as described for the purpose set forth.

No. $26,58 \mathrm{I}$-HENRY GIIJIARD, JoUNT Ilork, W1s.-Cultizators,-December 27, I859.

This invention consints of a circle fastened perm.nently to the bean, and provided with holes for the bolts which hold the jointel bars carrying the cultivator teeth, which bars are hinged to the beam in the centre of the circle, so that they can be vibrited and arr unged to stand forward opposite to or behind the centre of the circle.

Claim.-The arrangement of the permanent circle $G_{i}$ and jointed bars J J, when the whole is constructed for joint operations, as set forth.

No, 26,606,-P'EIER MONAGIIAN, CAMAK, GiA. - Cultituturs.-Dircmbir 27, 1859 .

Clam. - In combination with the hinged frame if a cutton cnltivator, the suring 11 , which is secured to the tongue of said cultivator for the purpoise of automatically raining the rear end of the machine, when the same is released by the operator, substanti.lly in the manner described.

No. 26,6I8.- MURGiAN L. ROG FERS, SPRING, PA. - Cultitutors.-Diecmber 27, 1859 .

The blides are attached to the plow frame as follows: Two bolts 7 and 8 pass through the blades and frame, and also through a flat lrar of iron 9, and the plough blades by the screw bolts are held firmly in their places; hy this arrangement the blades are rainet or lowered. or turned out as desired.

Claim.-The arrangement of the hooked and clouble cur ved central bar $\mathrm{C} \mathrm{N}$, curved slotted arm $\mathrm{F}$, wheel $\mathrm{G}$, handles

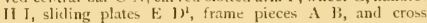
piece D, sub tantially as and for the purpose shown and described.

No, 26,976,-JOSEll L, IUUTTON, JR., Cherky LAKF, FI.ORID, - Ploushs. - Fanuary 31, 1860.

This invention consists in the arrangement of de. vices forming a plough, which cau be alterecl to cut deep or shallow furrow:s, and the handles of which can be eavily adjusted.

Claim.- The arrangement of the beam $A$, notched ad. justing bar 1 , handles 1 , crosi-bar; $C$, hooked tiple $H$, and wedge $F$, with the notched heel $C$, and notched and stotter toe $\mathbf{b}$, the white of the part- heing constructel for joint adju-tment is set forth

No, 27.14H.-THOMAS MURPHEY, CINCINNAT, Ohio.-Cultizinters.-Febreary 14, 1860 .

$A$ is the beam provided with the clevis $B$, by which it is drawn. It is mortised to the standard C, and hoth have connection with the hracing st indard D, to which the handles $\mathrm{E}$ are connected. F is a common shovel plough share connected to the standard $\mathrm{C}$ and braced to the beam $\mathrm{A}$ by $\mathrm{G}$. $\mathrm{H} \mathrm{H}^{1}$ are staples through which the adjusting rods of the mould boards and cultivator framer respectively pas for fastening.

Claim.-The described arrangement of the plough frame A C D E F, detachable mouldhoards $K$, and detachable cultivator frames $\mathrm{N}()$, the whole being constructed and operating in the manner and for the several purposes vet forth.

No. 27,376-JIMPSEY B. NETIIERLAND, LoUtSvilL.E, G.A.-Cultizators.-March 6, 1860 .

The lower extremities of the standards $\mathrm{B} \quad \mathrm{C}$ bave points entering recesses of corresponding size and shape in the rear sides of the sh wels or ploughs which are attached to them. The upper extremities of the standards are provided with two or more bolt holes, for the purpume of adjustin t their povition according to the character of the work to be done.

Claim.- The arrangement of the peculiarly sliaped branched standards B C, constructed as described, in combination with blarles or shovels, constructed as described, and attached to the stamlard in the mamer specified.

No, $27,402 .-F$. O. IVILSON, Mount Olive, N. C -Cultinators.-Wharch, 6, 1860.

As the two side plough loosen the earth at the root of the corn or cotion, and destroy the weeds or frass, the double mould turn plough advances and fills up the furrows createrl and leaves a shallow furrus in the centre of the two row's.

Claim.-The double mould turn plough $\mathrm{F}$, and the side turn ploughs $11 \mathrm{H}$, in combination with the beam $\mathrm{A}$, middle stock $E$, cross frame $D$, and side stocks $(\mathbf{G}$ G, when said leam $\mathrm{A}$ and middle stock $\mathrm{E}$ shall be bracel and supported by the stay $C$, and the other part: constructed aml arranged sulustantially as and for the purpose specified.

No, 27,406,-ROBERT CRAIG, STATE I INE CITY, INI, assignor to himself and J. D. LUDIC()W, of said STATE LiNe Citv.-Cultizators.-Warch 6, I860.

This invention connists in the empluyment of bevel keys, interposed between the feet of the implement and the shares, for the purpose of adiusting the latter in oblique ponitions to the right or left, to as to throw the earth outward from he implement or inward toward its centre, as circumatances may require.

Claim. - The employment or we of the curved bevel keys $\mathrm{F}$, interposed between the shares and their feet, and se cured by the same bolts d which attach the shares to the feet, as and for the purpose specified.

No. 27,614-WM. BLSHNEIL, EAsTON, l'kNN(iultizators- Warch 27,1860 .

$A$ is a beam, to the back part of which a plough $a$ in attached; B 13 are two beams, having similar ploughs b b attached to their lack enck. These beams are connected by the joint se' to the end of the bars C C, which pass loosely through the beam, and are pivoted to it at about their centres. The hars are allowed to turn in the heam, the mortises through which they pass be. ing sufficiently long to allow it. In the outer part of the beam $A$, a pulley, $D$, is fitted horizontally. This pulley has a twothed periphery, and a chain, E, passes around its outer side, the ends of the said chain being attached to the front ends of the beams B B.

Claim.- The arrangement of the central beam A, movable bars B; B, pivoted connecting bars C C, adjustable chain wheel, I), chain E, and ploughs, $l$, as and for the pur pose shown and described.

No. 27,659.-HARK SNUW, AUBCRN, MIss-COR. ton ciultizators. - Jurch 27, 1860

This invention consivts in attaching two scraping mould boards, $l$, to the front part of the body of the plough in such manner that one shall travel on each side of the row to scrape the ridge and throw the scrapings into the centre of the furrow, where they will be covered by the earth thrown upon them lsy the rear part of the scraping mould boards; two hilling mould boards, $c$, are secured to the rear of the frame, and are so arranged as to cut deeper than the scraping mould boards and to throw the earth inwards upon the plantsafter the ridge has been scraped; shield plates or fenders, $r$, are secured to the rea end of the plough beam and project downwards on each side of the row.

Claim.-The combination of the scraping mould boards $d$, hilling mould-board $e$, and fenders $g$, when arranged and operating, substantially as described.

No. 27, 776.-IOIIN G. CHRISTOPHER, BYRON, Ile-Cultivators.-April 10, I860.

Claim-In combination with the ploughs $C$ C D , the adjustable bat $p$, provided with the roller $t$, and arranged to permit of the adjustment, as shown, for the purpose set forth.

No. 27,962,-G. T. BENNETT, Maust Ol.IE, N. C. Corn and Cotton Cullitiators.-April 24, 1860 .

Claim. - The curved beam B as constructed, in combination with the straight beam $\mathrm{A}$, side beam $c$, braces $d$ and $c$, side and double turn-ploughs $\mathrm{F}$ and $\mathrm{G}$, and cotton-scraper 
$\mathrm{D}$, the whole being arranged in relation to each other substantially as and for the purpose set forth.

No, 28,4 S7-AI.I.F. HU HIIES, (iRATIOT, OHIO.Cultiotins Plourth. - Yay 29, IS60.

The object of this invention is to comnect the shanks carry ing the shovels to the frame or beams of the cultivator in such a manner that the shovels may be raised or depressed, and in fixing the shovels in the shanks and carrying them rigidly to the beams by sector bars having pins passing through them and through the heams.

Claim.-The shosel-cultivator described, capable of both a lateral and a vertical adjustment, when made in the manner and by the combined arrangement described and represented.

No. 28,523.-R, P. VAN IIORNE, (iRATIOT, ()Ho. - Cultizenters, - J/ay 29, 1 S60.

This invention consists in a novel arrangement of tooth-bars attached to a plate, the latter being connected to a bar provided with adjustable wheels, whereby the desired end is obtained.

Claim.-1.-The arrangement of the plate A, draught-bar $B$, tooth or share-bars $K$, and truck or wheel-bar $\mathrm{D}$, substantially as and for the purpose set forth.

2.- In connection with the plate A, draught-bar B, share-bar $\mathrm{K}$, and truck or wheel-har $\mathrm{D}$, the transverse lar $\mathrm{Ml}$, provided with teeth or shares N, substantially as and for purpose specified.

No.28,576,-VINES HARWELl, Wal.ker County, G.A.-Cultizators.-June 5, 1860.

This invention relates to a new and improved arrangement and construction of the different parts of a cultivator, whereby it may be readily adapted either for one or two horses, and when for one, either with or without shafts.

Clain.--The peculiar arrangement and combination of the removable shafts $\mathrm{C}$. centre beam $\mathrm{A}$, and guide $\mathrm{G}$, with a cultivator; the whole being constructed and operated in the manner, and for the purposes set forth.

No, 28,601,-WHITMAN PRICE, WAYNE COUNTY, N. C.-Ploushs.-June 5, I 860 .

This invention consists in the construction of the mould board and bar, and attaching the same to a circular beam.

Claim.-The arrangement of A, the circular beam B, the standards, $C$, the shovels, $\mathrm{D}$, the main beam, $e$, the handles, $a$, the screw on the upper end of the standards, and $b$, the screw nut, combined, and operating as described, and for the purposes set forth.

No. 28,831.-JOSHUA F. CAMERON, Livine: stun County, Mo.-Cultivators,-June 26, I\$60.

This plough consists of a main helve, A, through main beam $\mathrm{B}$, to which is attached the heel-bar, $\mathrm{C}$, and braces, D E, so constructed, that any form of share, right or left, can be fastened on the main helve by means of a screw through the socket into the helve upon which the share is fastened; and by unscrewing or moving the front brace and changing the hind bolt in the hind brace, the beam can be raised or lowered to any pitch; and by means of holes in the different helves, the bar and braces, and heam B, can he hoisted or lowered at the will of the operator.

Claim.-The described arrangement and combination of the rotary coulters $Z Z$, beam $B$, bar $C$, helves A F \& H I $\mathrm{K}$ and $\mathrm{L}$, cross bars if $\mathrm{N}$, and braces $\mathrm{D}$ EOP Q R S T $\mathrm{U} \mathrm{V}$, in the manner and for the purposes set forth.

No. 28,833.-JAMES CHARLTON, AllegheNY, PA.-Cultivators, Jume 26, 1860.

Claim.- The arrangement of the flanged bar $e$, bent so as to form the segment of a circle, and furnished with slots and $i$, the bar point or mould board and scraper being at tached to said flanged bar, arranged, constructed, and operated as described, and for the purpose set forth.

No. 28,870.-THOMAS KINGIIORN and ROBERT KINGHORN, Mokgan, OHo.-Cultivators.-June 26, 1860.

$A$, shows the central draft beam, the front end of which is curved up, as at $\mathrm{A}^{1}$, and is supported at its front end by a castor wheel, E, whose standard, F, passes up through the clevis, $G$, and the end of the draft beam, A; the clevis is fastened to the standard F by a set screw, whereby the end A can be sustained on the wheel E, at any desired height, while the clevis and wheel can freely turn to follow in the direction of the team, although the team curus abruptly.

('laim.-The combination of the adjustable side pieces $\mathrm{B}$ B, with their teeth $\mathrm{I}$, and adjusting rear supports 1) D, with the central beam $\mathrm{A}$, hooks, $c$, and castor wheel $\mathrm{E}$, arranged to operate in relation to each other substantially as and for the purposes set forth.

No. $28,929 .-J O H I N$ M. WIILIAMMS, Gikenvil.te, Gis.-Cultrivators.-June 26, 1860.

Claim.-The arrangement of the beam $\mathrm{A}$, the two collat eral beams $\mathrm{B}$ B, the graduated bars $a$ a, the handles M M, the supports F F, and the bar D, when the said har is se cured to the main beam and rests upon the collateral beams, and when the several beams are provided with vertical and horizontal mortises for receiving the bars and shanks, as is fully set forth, and for the purpose specified.

No. 28,968.-COUNCII, CLARK, ANDERSONIILL, GA.-Cultizators.-July 3, 1860.

A brace, convivting of two straight and parallel end and an arched connecting part $c^{-1}$, is fastened to the plough beam $d$, by means of the bults $c i$, passing through both end of the brace. The upper end of the plough shank $a$ is al. so secured to the rear end of the plough beam by the bolt $e$, while the lower part of the shank $a$, is bolted to the brace at $e^{1}$

Claim-The arrangement of the arched brace $i c c^{t}$, in comlination with the plous heam $d$, standard $a$, and run. ner $j$, in the manner and for the purposes set forth.

No. 29,043.-ALI.EN AGNEW, CHESTER Co., and WILLIAM MORRISON, CHADD'S FORD, PA.-Ciultiz'ators, - July 10, 1860 .

This invention consists mainly in the shape of the teeth and the manner of hanging them to the frame, so that the soil will freely rise up and fall behind them without clogging; and so that the teeth may be let down on the frame or it branches as they are worn away by use.

Claim.-A cultivator composed of a stem and branches and teeth projecting from the ends thereof, and secured and made adjustable thereon, as set forth, the whole being constructed and arranged substantially in the manner and for the purjoses described and represented.

No. 29,087-J(JEEPH B. LIVEZEY, Clarksboro, N. J. - Cultizators. - July 10, 1860,

This invention consists in the arrangement and combination of a sliding head with the side wings, operated with a handlever and fastened to both wings in front, together with two pivoted links, which connect the rear parts of said wings to the beam in such a manner that the said wings on being expanded or contracted, receive, at the time, a longitudinal sliding motion.

Claim.- The arrangement of the sliding cross head D, pivoted links $\mathrm{E}$, and hand-lever $\mathrm{F}$, in combination with the side wings $C$ and beam $A$, constructed and operated sub stantially as and for the purpose specified.

No. 29,127.-JOSEPH HINMAN, WATERTOWN, MAss, and D. S. FRENCH, MARIETTA, (iA., assignors to themselves and NATHAN KING MIDDLESEX, MASS. - Cotton Cult vators. - July 10, 1860.

This invention consists in the use of a series of rumners or plates provided with cutters, or shares, and attached to a suit able framing a requisite distance apart, and in such a way that a certain degree of vertical adjustment will be allowed them, and the plants thinned out by the cutters by drawing the implement transeversely over the drills in which the plants are growing.

Claim.-1.- The employment or use of a series of plates $\mathrm{B}$, provided with cutters $\mathrm{C}$, and attached to a frame $\mathrm{A}$, substantially as shown, for the purpose set forth.

2.-Attaching the cutters $\mathrm{C}$ to the plates $\mathrm{B}$, by means of tangs $h$, secured by set-screws in semi-circular bars $g$, on the plates directly over slots $f$, therein, as and for the purpose specified.

No. 29,136.-EPIIRAIM BRIGGS, MEDINA, OHIO. - Cultivators,-July 17, 1860 .

Clain.-The arrangement of the main beam $\mathrm{A}$ and the side beams or wings $\mathrm{C} \mathrm{C}$, the posts D D D D, the shovels E E E E, bars F F F F, bolts $G G G G G G$, changeable 
braces $11 \mathrm{H}$, handles $1 \mathrm{l}$, and round $\mathrm{K}$, in the manner and for the purpose set forth.

No. 29,147.-THOMAS H. DODGE, WASHINGTON, 1). C.-Cotton Ciultivators.-July 17, 1860 .

As this machine is drawn forward by the beam $A$ the plough share attached to E turns the earth towards the plants, while the guard or shield $F$ prevents it from falling on and covering up the same. The coulter $\mathrm{H}$, which runs in advance of the shield $\mathrm{F}$ and the plough scrapes the top of the earth away from the plants, thus cutting up the weeds while the plotgh which follows turns back the earth towards the plants.

Claim.-1,-In combination with a plough or cultivatur, the self-adjusting rotary shield $F$, arranged to protect the young plants, as described, and as shown in Fig. 1 .

2.- In combination with the plough or cultivator, the self-adjusting guard coulter $\mathrm{H}$ and rotary shield $\mathrm{F}$, as and for the purposes set forth.

No, 29,I96.-MARK RIGILL, and W. D. IVEV, Dawson, GA.-Cotton Cultizators.-July 17, 1860.

A guard wheel $G$ is attached to a brace or plate $\mathrm{H}$ on a fulcruin $d$, the brace or plate $\mathrm{H}$ being pivoted at the end $c$, while its other end is perforated with the holes $f f$, whereby it can be adjusted to set the wheel Gup or down, by means of the butt $g$, which passes through the beam $A$ and one of the holes $f$ in the plate $\mathrm{H}$.

Claim.- The arrangement of the guard wheel $G$, plate $H$, adjusting rod $\mathrm{F}$, with the beam $\mathrm{A}$, and standard $\mathrm{E}$, as and for the purposes set forth.

No. 29,211 - ; . W. N. VOST, of Yellow SPRINGs, ()Ho,-Cotton Culti ators.-July 17, 1860.

Claim. - The combination and arrangement of the body of the implement and its movable ploughs B, scraper E, and andard, $G$, constructed as described, whereby it is readily adapted to receive, in turn, the several ploughs and $s_{c r a}$ er, in order $t$ s perfor $m$ the various modes of cultiva tion specified.

No. 29.368. - EZKA ENIIERT, FRANKLIN GROYE, It.L. - Cultionturs. -July 31, 1860.

This invention consists in the combination, with an ordi nary shovel plongh or cultivator, of a wheel, rotating on the side of the plough, and provided with hoes on its edye, for the purpose of preventing the plough from covering the growing plants as it is drawn forwart, and also for the purpose of giving steadiness to the plough and enabling the attendant to guide it more readily, and, at the same time. for the purpose of digging up and pulverizing the soil around the roots of the growing plants.

Claim.-The combination, with an ordinary shovel plough or cultivator $\mathrm{A}$, of the rotary wheel $\mathrm{F}$, furnishes with hoes b, and operating in the namner and for the purpose specified.

No. 29,590.-JOHN S. HALL, WEST MANChFstFR, PA.-Ploughs.-Auyust 14, 1860.

This invention consists in uniting the standard of a plough to the beam by means of a ratchet and flanged plates, which admit of several adjustments that are very advantageous in implements of this kind.

Claim.-Uniting a plough standard to a plough beam by means of ratchet and flanged plates arranged on the sides of the beam and standarl, so as to admit of folding up, substantially as described.

No. 29,618.-MARK RIGELL, DAWson, GA.Cultivators.-August, 14, 1860.

The stocks $\mathrm{B} \mathrm{B}$ are pivoted or hinged to the beams $\mathrm{A}$, so that, by means of the rods $F$ and the nuts $e$, they can be set at different angles with the beans A. The shackle 6 performs the office of a self-adjusting connection to the beams $\mathrm{A}$, that of a draft piece to the machine, and also that of a safety draft spring, to prevent sudden strains on the machine.

Claim.- The combination of the spring shackle $G$, and adjusting bar E, with the beams $\mathrm{A} \mathrm{A}$, and stocks $\mathrm{B} \mathrm{B}$, arranged and operating in relation to each other, as and for the purpose set forth.

No. 29,789.-ENOCH S, HUFF, ZaNesvilete, OHIO - Cultizators.-August 28,1860 .

The arms e e are perforated with numerous holes, which pass across $a$ hole in the beam $b$, and as these arms are shifted by turnugg them around the fir pivot $i$, they are secured in place by the key $k$. The arms $c c^{1}$, are also pivoted to cross beams $h h^{1}$, which beams are also pivoter to the main beam $b$. By virtue of the two pivoted connections with the main frame $b$, the beams $c c$ and ploughs may be shifted into a great variety of positions in relation to the centre beam $b$.

Claim.-The combination of the segmental arcs $e e$, plough beams $b<c^{1}$, and pivoted cross beams $h h^{2}$, sulstantially in the manner and for the purposes set forth.

No. 29,876.-JAMIES R. GILBERT, Starkvili.e, and STEPIEN R WESTON, DAWson, GA.-Cultizators.-September 4, I860.

Claim. - The arrangement of the handles, beams, hinged standarcls, and hinged curved and notched braces, by which we are enabled to change the plough from a double beam adjustable cultivator plough to two single beam ploughs, ubstantially in the manner described.

No $30,119-T$. E. C. BRINI.Y. Lousvill.E, KY.Cultizators.-September 25, 1860 .

Claim. - The combination and arrangement of the plough beam $\mathrm{A}$, provided with removable feet or standards 1) C F, and the two pairs of adi,ustable rings or arms $\mathrm{H}$ II $\mathrm{N} \mathrm{N}$, provided respectively with the shares $\mathrm{J}$, and teeth $\mathrm{L}$, as and for the purpones set forth.

No, 30,295.-N. C. CARTER, UNiov City, IN11.Cultivators.-October 9,1860 .

This invention consists of a peculiar device for the purpose of regulating the distance hetween the cultivator teeth, for the purpose of enabling the saune instrument, or implement, to be used succesively on different crops where the distance between the drills is various,

Claim.-The arrangement of rods $c c$, rorls $c \epsilon$, with the leoped heads $e^{t} e^{1}$, ant terminal screw bolt $d^{1}$, in connection with rods $g$ and $h$, and screw link $i$, all constructed and operated in the manner as and for the purpose set forth.

No, 30,357.-MATIIEW G. SLEMMONS, CAIIZ, OHI0.-Ploughs.-October 9, 1860.

Claim.-The arrangement of the two curved shoulder beams $\mathrm{A} A$ a, clevis $\mathrm{B}$, transverse bar $\mathrm{D} m$, slotted, adjustable, forked handles $\mathrm{E}$ E $b$, and notched and inortised shovels $\mathrm{C} \mathrm{C}$, in the manner and for the purpose described.

No. 3,514-MATHEW G. SLEMMONS, CAm1\%, OHI?. -Place-October 9, 1860, No. 30,357; reissued fune 22, 1860.

Claim.-1. Two converging heams A A, each one of which has a shovel-nandard, ' $N^{\prime}$, formed by bending its rear end, substantially as described.

2. The converging heams $A \mathrm{~A}$, connected together, and constructed with curved shovel-standards, $\mathrm{A}^{\prime} \mathrm{A}^{\prime}$, upon them, substantially as described.

3. The union of the front enis of plow-leams, which have their rear ends bent to form shovel standards, by means of a clevis, or device, by which the team is hitched to the implement, substantially as described.

4. The converging plow-beams A A, having shovelstandards $\mathrm{A}^{\prime} \mathrm{A}^{\prime}$ formed on them, in combination with handles F F, and handle-supporting braces $\mathrm{E}$ E, substantially as described.

5. In combination with the foregoing, also, the manner sulsstantially as described, of adjusting the handles F F, and securing them to the beams at any desired angle.

6. Constructing of one piece of metal, a plow-beam $\mathrm{A}$ and a curved shovel standard $\mathrm{A}^{\prime}$, with a shoulder $d$, formed on the latter, substantially as described.

No, 6,131.-Plows.-MATHEW G. SLEMUONS, IowA City, Low a, assignor to Leggett \& Leggert. - No. 30,357 , October 9, I860; reissue No. 3.514, June 22, 1869 ; reissue November 10, IS74; extended seven years. [Filed October I 2, I874.]

Brief - The curved diverging beams unite at the front rigidly, and receive shovels at their rear ends. The handles are adjustable upon the beams.

Claim.-1. Two diverging beams, A A, that have their rear ends bent to form shovel standards, the said beams be. ing fastened rigilly together, substantially as described, at and springing from the point of attachment for the draft.

2. Two rliveruing benms, A A, that have their rear ends bent to form shovel-standards, and their front ends fastened rigidly together and merged into a device. substantially as described, whereby the plow may he attached to the draft. 
i. The combination, subst untially as described, wit's the two plaw-beams $A \mathrm{~A}$, of the bandles $\mathrm{F} F$ and adjustable handle supporting braces E 1 :

No, 30,7I, 1.TTIER B, IBLNTUN, PRNN VAN,

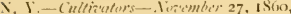

(laim. - The arrangement of the tooth $C$, shares and land sicle 1 , frame 1 , and har $F$ : the whole being contructed as ilescribed. for the purpose set forth.

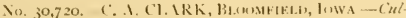

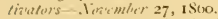

This invention comsist in the arrongement of the crank, axle, gange, or propelling wheeh, lever, rear shares, forward bares, longitudinal bars, perforated transverse bar: and handle-

Claim.- The arrangement of the crank axle $\mathrm{D}$, gauge or propelling wheeh $F^{*} \mathrm{~F}^{\mathrm{l}}$, lever $\left(i\right.$, rear shares $l^{\mathrm{T}} h^{\mathrm{l}} h^{\mathrm{l}}$, forward shares $h h$, longitudinal bar $A$ a $b i d$, transverse perforated lars $i c$, and handles $m m^{1}$, all in the manner and for the purposes described.

No. 30,737.-117RAM J. LAKE, Conolest, N. Y.cultizitors- linembir 27, 1860 .

Claim.-In combination with a cultivator, the swiveling of the thill thereto, so that they may assume a horizontal position when the cultivator is working on a billside, for the purpose of relievin the horse from the pressure or gous ing of the thills on his sides, and enable the operator to better guide and direct the cultivator as set forth and dencribed.

No. 30,741.-WIIJIAN J NACOS, CARTHRSTH.L. (iA.-C'ulliaterors.- Viatember 27, 1860 .

Claim, - The arraniement of the reversible beam $A$, stock 13, with it liraces $\mathrm{E} C$, ploughs $\mathrm{F}$, cutter $K$, landside ; standard $b$, handles 1 , and sprints 11 , uubstantially as and for the pur wes set forth.

No. 30,751.-J()IIN NEIIICII and ELIM R. GIRVIN,

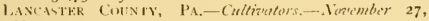
1860.

Claim. - The gauge or guile roul $\mathrm{K}$, with the sliding and binding plates 11 , set or binding screw 1 , in combination wilh the shovels F, and their projecting screw ends $f$, secured on said plates by the nut $h$ for adjustment, when made substantially in the manner and for the purpose specified.

No, 30,767-JOSEPH SLOCLIJ, SYRACLSE, N. V Cullizating llerrouss. - Ninesmber 27, 1860.

Claim.- A cultivating harrow composed of the two frames C 1), furnished with suitable teeth or plough, the side pieces of which frames are hinged at their ench, and can be spread or contracted at their rear ends, and which are united l,y a centre beam A \& 3 , compused partially of wood and partially of an arched iron bar, and supported on a pair of wheels; the whole being arranged to operate in the manner and for the purpose vet forth and represented.

No. 30,796,-HIRAM M. BELDEN, FARMINiTU, OHo.-Cultinaturs.-Dícimber 4, 1860 .

Claim.- The frame A composed of a single iron har, trent in the form as and for the purpose set forth.

No, 30,926-ISAAC MIERS, CLAY 1.1CK, OHIO, - Chltivutors.-Deiember IS, 1860 .

Claim - The arrangement of the longicuctinally adjustable side beams $\mathrm{C}$ I), straps $a a^{1} b^{1} b$, and ad usting plate $d$, with the centre herm $B$, plou hs E F G, ad ustable handles $h / h$, and standards $y \%$, all a shown and lescribed, for the purposes set forth.

No. 31,132.-W. 11 . SMITH, WY.ANET, II.L-Cultiara. tors. - Fomwary 15, I $\$ 61$

This invention convists in so piroting and bracing the rear stocks, or standarch carrying the hovels to the cultivator frame, and attaching said stocks to the handles of the cultivator, that the rear shovels may be moved laterally while the cultivator is being drawn through the field, and thu made to work up elose to rows of plants which are irregularly laid out.

Claim.-The brace ro $1 \mathrm{~s} g, g$, pivoted pieces $h h$, notchecl plates $k k$, and arms $m m$, in combination with the pivoted shovel stocks $\mathbf{E}$ E, anl handles $\mathrm{G}$ G, all arrange l and operating sulntantially ar and for the purposes set forth.
No, 31.178 - ANDREW 1, I.KRTER, CANTON, IND, - Cultizators-Janiary 22, 1861

The reversible shares are bolted at their centres to the respective stanlards, the lower parts of which are curved to correspond with the form of the said thires and strengthen the same to their extremitie. The upperend of the thare is held between the beam and a washer, conlined by a nut and bolt, by which the standard is attached to the beam.

Claim. . The describer combin tion of the bent be:m It, reversible shares $\mathbf{E} \mathbf{E}^{\prime}$ and standarels 1 ) $1 \boldsymbol{y}^{\prime}$, with the brace C and waber $F$, the said parts being constructed, arranged, and connected in the manner and for the purposes de. cribed.

No. 31,367-CIIARIAS BEACII and TIIOMSS

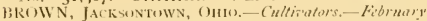
I 2, IS6I.

The shovels are slightly coneave on the face, and may lo attached to the beam by serews and bolt', so an to be removalile at pleasure.

Claim. - The arrangement of the concave shovel $c$, shield or guard ", beam A, with its curved neck $x$, the curved standards if $\mathrm{M}$, and the handles $\mathrm{N} \mathrm{N}$, the whole leing constructed as and for the purjoses set forth.

No, 3I,400,-WILJIAM PRICE, MoUNT ()IIVy, N. C. - Cultizators-Feluruary 12, I861.

This invention comints in the arrangement of the sev. eral devices,

Claim.-The arrangement of the heam A, side frames $A^{\prime}$ handles $\mathrm{B}^{\prime} \mathrm{B}^{\prime}$, shovels $\mathrm{C}$, standards $n$, rake-head $\mathrm{A}^{2}$, and teeth $b$, pin $c$, and yoke $d$, the whole being constructed, combined, and operating as and for the purpose set forth.

No. $31,416 .-J$. W. TAVLOK, ASHI.ANI, VA. - Cultiza tors.-Fibruary i 2, is6t.

This invention comists of a cultivator that can be opener and cloved at pleasure, and set to any width of furrow required.

Clam.-The arrangement of the parallel stays c, draw bar $d$, with its hinge $f$, cultivator frame $\mathrm{X}$, and harrow frame $y$, the whole being constructed as and for the purpose described.

No. 31,635-C. IV. S. IIE.ITON, SAl.s., I1.L.-Cultiantors.- Marith 12, 1861 .

This invention consists in constructing the end and side pieces with mortises or blots in such a manner that the shovels may be arranged in various positions and removed a greater or less distance from the main beam. The standards and braces are also mule adju-table as to height ant de ree of inclination.

Clim.-The arrangement of the slotted adjuatable crosspieces B' B', revervibfe aljustable luraces $F F^{\prime \prime}$, and adjust able standards $\mathrm{D} \mathrm{D}^{\prime}$, with the curved main beam $\mathrm{A}$, deflectin rod $\mathrm{I}$, and eross-pieces $\mathrm{C} C$, in the manner and for the purposes shown and described.

No. 31,683.-IVM. STRIEli, WAgontown, PA.-Cul.

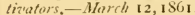

This inventiom consist in a main beam having two teeth and two hinged vanes or shares rendered adjustable by mems of hooked rods and a perforated plate in combr. nation with side lreams having teeth, and so connected to the main bean as to be acljusted laterally as well as vertic lly, in order that the relative position of the teeth and vanes may be altered every time the mehine is drawn over the same track, thus effectully turning up, breaking and spreading the soil.

Claim.-The heam $\mathrm{A}$, it $;$ teeth $i$ and $f$, and its hinged shares or vanes $h h^{\prime}$, the latter being rendered adjustable by the hooked rods $i$ and perforated plate $j$, and their teeth $m$ and ", when the said berms are so connected to the beam $A$ as to he adjusted laterally as well as vertically by means of the devices described or their equivalents, and when the whole of the ahove mentioned parts are arr.inged as and for the purpose set forth.

No, 31,742.-WILLIAM S. RIGGS, IIUHTSTOWN, N. J.-Cultivators.-Wharch 19, IS61.

The forward ploughs are so connected to the frame that they can be moved sideways and their inclination to the planted row changed, for the purpose of either simply loos. 
ening the ground or casting up a furrow, as may lie de sired.

Clain.-The arrangement, substantially as set forth, of the standards B $\mathrm{B}^{\prime}$, and shares $a$ and frame $\mathrm{A}$, the whole operating as and for the purposes set forth and described.

No. 31,753.-FREDERICK STAMM, LANGASTER, PA. - Cultinuters.-Warch 19, 1 S6I.

The side heams are connected to the rear end of the draught beam by hinges, and are adjusted to required width lyy means of arc-shaped stays in front.

Claim. - The arrangement of the draught beam B, side leam $A$, stays 1 , hinge $C$, and curved shovel $E$, with its he.d $Z$, the whole being constructed, operated, and operating in the manner and for the purjose set forth.

No. 31, $884-$ - (). W. GOSI.EE, Gl.Astenbury, Conn.Cullivators.-April 2, I861.

The object of this invention is to ohtain a machine which can be used either as a cultivator or hoe. This is effected by inserting the teeth, which are constructed with dovetail shanks, in mortises in the frame, and retaining them by a key-block. They can thus be readily removed and changed from one side to the other, reversing the sides of the right and left teeth in the frame-work, either throwing the earth outward or uy' to the hill. The adjustable ground wheel on the end of the frame regulates the depth to which the teeth enter the soil.

Claim.-The arrangement of the frame a $f$, arms $i$, hand. les $b$, braces $c$, plates $s$, clevis $d$, axle $c$, anl cultivator teeth I 23 , the whole being constructed in the manner and for the purpose described.

No. 31,917.- WM. F. VEFER, BuWLING GREK, ()Ho. - Cultivators.-April 2, IS6I.

The frame consist of two curved side-pieces, which are connected together at their front ends by a loolt, and attached to the crosu-beams $c d$. These crosubeams are placed together in pairs, a narrow space being left between for the invertion of the shanks or standards of the shares, the standards being slotted for the reception of keys, which hold them firmly. By this means the shares can lie easily adjusted to any desired position. The handles are connected together by a cross-bar, and attached to the frames by uprighis. The shares are connected by rods to the front part of the frame.

Claim.- The arrangement of frame A, bandles B B, slotted standard $\mathrm{C}$, shares $\mathrm{C}^{\prime}$, wedger $i$, rods $\mathrm{D} \mathrm{D} \mathrm{D} k$, and slotted crosi-be ums $i d g$, the whole being constructed in the manner and for the purposes shown and explained.

Nis. 32,010.-JAMES A. SIEER, JR. MANchester, PA., assignor to WILL.IAM J. KANE, of same place.-Cultio'a. tors.-April 9, 1 S6I.

Attached to the draught beam and stundard is a second curved beam, provided with luys, to which a scraper may be attached. The several attachments of the second beam aud scraper, are made by bolts passing through slots and secured by nuts, by which means the point of the draughtbeam and the scraper may be raised and lowered.

Claim.- The arrangement of the draught-beam $a$, second beam $c$, scraper $d$, and sloss 123 and $x$, when constructed substantially as described, for the purpose set forth.

No. 32,092.-IS.A. STOUT, TREMCNT, ILL.-Cultivators. - April 16, 1861

The stocks of the front cultivators or ploughs are attached to the handles that serve to guide the cultivator, and the handles are pivoted to a cruss.bar in such a manner that the operator, while guiding the cultivator, may vary the di-tance laterally between the furrows formed by the ploughs, as desired.

Claim.-Attaching the front cultivator teeth to the guid ing handles of the plough, when arranged substantially as described,

No. 32,366,-GiEORGE IV. IIIL.DRETII, LOCKPORT, N. Y.-Cultioutors.-May 21, I\$61.

The cultivator is made to expand and contract by means of horizontal slide irons lapping upon each other, with a loolt passing through slots to hold them at any desired point; connected to the ends of these horizontal irons are two ad. ditional slotted irons, crossing each other upwarls, and se- cured in any desired position to a post on the centre bar, for the purpose of giving additional strength to the machine when adjunted to various widths.

Claim.- The double slide irons $\mathrm{F} \mathrm{F'}$, or their equivalents, with the horizontal slide irons, when used to form a triangular contracting or expanding Iruss for strengthening the cul. tivator, as herein set forth.

No. 32,468.-S. M. CAIN, and IV SilELF()X, Austin, Trxas.-Cullivators.- Jun' 4, $186 \mathrm{r}$.

The parts of the plough are so constructed that it can be made to plough a row of any given width from three to five feet ; it can be made to plongh on each side of a row of corn or cotton; also, the diamond ploughs can be made to run on each site of a row so as to hill it up, the horse walking on the top of the row.

Claim. - The arrangement of diamond ploughs $f f$, the crencent coulter $k$, sweep $g$, wing hinges $m m$, wing $b \quad b$, slides $c$ and $d$, beam $a$, and handles $h$, as describel, for the purposes set forth.

No. 32,567.-JO11N KEEZER, Chil.сотнr, OHu. - Cultizators.- Funi 18, 1861.

The teeth $f f$, are constructed each with a long shank fitting in adiustable fastenings, so that they can be firmly held at any distance apart. Attached to the main beams are stay rods $i$, which pass through shanks of the cultivator teeth $f$. Connected with the frunt frame are stays E F, carrying a swivel, to which the whiffletree is attached; by means of a crew and nuts the swivel is rendered adjustable as to height, for the purpone of varying the depth of the cultivators in the ground.

Claim.-1.-Adjusting the distance hetween the teeth $f f$, or those uset in their stead, by means of the adjustable fantenings $h h$ and $g y$, and stay rods $i t$, when used in combi nation with the gallow frames $B$ and $C$, and stay rods $a$, constructed and arranged substantially as and for the purpose set forth.

2. - In combination with the foregoing, the stays $F$ and $E$, swivel $G$, screw $b$, and nut $c$, when arranged in relation to each other, and operated in the manner and for the purpose described.

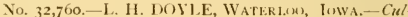
tivators.-July 9,1861

The central triangular-shaped spade is attached to the beam, as usual; in the rear of this are sockets and holts, from which two curved arms extend laterally nearly to the ground, and have at their ends shares placed obliquely ; alove the shares is a horizontal cross bar, provided with slots and bolts, by which the shares can be placed at the right distance apart to throw the soil upon the rows of plants on either side.

Claim.- The sockets D I', at the back of the beam A, with the feet or standards $\mathbf{E} \mathbf{E}$ fittel therein shown, in connection with the bar $\mathrm{F}$ and braces $h h$, arranged to brace the feet or standards E E, and at the same time connect the same to the har $F$ at the distance apart desired, substautially as and for the purpose set forth.

No. 33,044. G. W. LAIVBAUGII, and JOHN WIL, 1.IAMS, SHAvestid.Le, OHIO.-Cultizators.-August 13,1861 .

Claim. - The special arrangement of the side pieces A B, hinge $D$, arms $C^{\prime} C^{\prime}$ and $H I$, and handles $J K$, and shovels $\mathrm{PO}$, the whole being constructed and operating as and for the purpose set forth.

No, 33,208-I, B, MOORIIEAD, T. A, and G, G, POOL, Bili.lefontaine, OHu-C'ultivators.-September 3, 1861.

Upon each side of the heam are sockets for receiving the shank $;$ of cultivator teeth, the heads of the said shanks being formed with a square notch for receiving a square key. Another nutched piece, driven in one side of the key, favtens the whole in the sockets, which arrangement admits of the ready detachment of the teeth when necessary.

Claim.-A rranging the shanks $c r$ with a square notch $\ell$, in combination with the square key $f$, notched piece $g$, socket $d$, and adjustable handles B B, arranged in the man ner anil for the purposes described.

No. 33,740.-A. HOFFMAN and 1I. W. LIMEBECK, IJALF1DAY, ILL.-Cultivators.-Nin'ember 19, IS61.

The seed-box is operated by means of a rod actuated by a cam on the haft of the driving wheel. A scries of teeth 
are secured in the fromt part of the machine, and at the rear is a detachable curved harrow. I'loughs are arranged upon the inner and outer longitudinal beams

Claim...The seed box $\mathrm{C}$, cam wheel $k$, lever $f$, harrow $c$, teeth $b b b$, and ploughs $q$ q and $w$ w, when all are con structed and arranged substantially in the manuer and for the purpove set forth.

No. 33.793-C. E. l'A.SON, SALEM, OII1,-Corn Ploushs.- linember 26, 1361 .

This implement is designed for cultivating between the rows of corn. The parts are so constructed as to admit of an adjustnient by which the implement is brought under complete control of the operator, and adapted to follow and cultivate opposite sides of two straight or crooked rows with facility at one operation.

Claim.-The fenders B B, hinged forked bars C C, hinged handles $\mathrm{D} \mathrm{D}$, with the guard $\mathrm{F}$ and draught beam $\hat{A}$, when combined, arranged, and operating in the manner described

No. 33.985.-JEREMIAH FINK, BALIJWINSIILI.E, V. V-Cullinators.-December 24, $186 \mathrm{I}$.

To each side of the beam of a shovel plough is attached an angular brace, to which additional fine teeth may be secured, and their positions shifted on the lrace as may be lesired, by which means it is designed to combine a shovel plough with a small tooth cultivator in one machine, to be used as reyuired.

Claim.-Comlnining with the beam A, of a shovel plough, the triangular or double brace wings $\mathrm{E} \mathbf{E}$, sulistantially as and for the purpose specified.

No. 33,988.-1). C. GILLILAND, Brownsvili.e, OHO, - Cultiatators.-December 24, IS61.

To the draught-beam is rigidly attichet a plate, to which are pivoted beams, so that their rear ends can he expanded or contracted at pleasure. Secured to the rear ends of these beams are removable shanks carrying shares or cultivator teeth, which admit of being readily detached, and mould boarcls and a rake may be subilituted.

Claim. - The combination of the draft-beam $A$, hinged beams $B$ and $C$, removable shanks $a b c$, and attachable shares 11, shovel. I, and rake J, all constructed, arranged, and employed in the manner and for the purpose shown and explamed.

No. 34,578. - W. 11. KELLY, ONUNDAlia CUUNTY, N, Y. - Cultivutors.-March 4, 1862 .

The shares are so attached to the rear of the main centre beam by means of a clasp and nut and screw, as to be readily adjusted forward and lackward, and so that their rings may be mule to face either side or outwards and inwarcls.

Claim. - The combination of the central beam, made as described, with the shares 5 and shanks $a$, when constructed and operating as set forth, and attached to the beam by means of clasps and bolts, as shown in figs. 7, 7.

No. 35,223.- ]. K. DUGDALE, RICHMIND, IND.Cultivators-May $\mathrm{I}_{3}, 1862$.

This invention consists in the employment of two or more vertically sliding frames provided with cultivator teeth, knives or drill teeth, \&c., and attachel to the front prart of a frame mounted on a wheel or wheels. The sliding frames are raised and lowered to adjust the cultivator, \&c., to the proper depth by means of a pinion wheel working in a rack on the frame, and connected by a rod to a prerforated plate attached to the rear end of the frame. The rod is held in position by means of a pin passing into the holes of the plate and secured by a spring.

Claim - The arrangement and combination of the adjust. ing apparatus composed of the perforated plate $G$, pin and spring $I$, rod $F$, with pinion $E$, working in rack $c$, substantially as described and for the purposes set forth.

Also, the combination of the device or guides $L^{\prime}$ with the frames $\mathrm{B}$ and $\mathrm{C}$, as and for the purpose set forth.

No. 35,422.-WILLIAM LYM + N, JR., MALONE, N. Y. assignor to Himself and S. M. WEAL, of the same place.Cultivators.-Mliry 27, 1862.

In the rear of the plough are attached two long pieces or hoes made adjustable to suit furrows of different widths by means of arms and bolts. Two short hoes are also provided with similar adjusiments, and serve to remove the earth and weeds from the hill, while the long hoes restnre the earth to the hill in such quantities as may be tesirable.

Claim,-The combination with the plongh $A$, and hean I), of the long hoes B B, with their adjuting arms $d d$, and short hoes $C^{C} \mathrm{C}$, with their adjusting arms $f f$, said parts being constructed and arranged to operate in relation to each other, substintially as shown and described.

No, 35,505-P. S, CARH.ART, COLLAMER, N, Y.Cullizutors.-June' 10, 1862 .

This invention consists in attaching the draught pole to the front bar of the frame, in such a manner that the lat ter will be supported hy the draught pole when in use. The rear end of the pole is attached to the back bar of the frame by means of a rack, to which is fitted a toothed lever, hy means of which the rear end of the tongue may be raised or lowered, and thus regulate the depth of penetra tion of the teeth in the ground.

Claim.-The means, substantially as shown and described, for regulating the depth of the penetration of the teeth $B$ of the implement in the ground, to wit, the attaching of the draught pole $\mathrm{C}$ to the front bar $a$ of the frame by a bolt $d$, and having its back end connected to the back bar $a$ of ihe frame by a rack-plate E, lever F provided with a toothed segment $i$, and an adiustable pin $j$, which fits in notches in the plate $\mathbf{E}$, to operate as set forth

No. 35,961,-JACOB V.AN HORN, PlaANfield, I I.l.Cultivalors.-Juily 22, IS62.

The standards are formed as shown in the engraving, and are provided with wings near their lower ends, which may he readily removerl or retained for certain operations. The standards are secured to longitudinal lars, which are made adjustable so as to regulate their distance apart.

Claim. - The combination of the peculiarly constructed tandards $\&$ with the removable wings $a$, the regulatin oars $\mathrm{B} \mathrm{B}^{\prime}$, and braces $\mathrm{F}$, all arranged and operating as and for the purposes described.

No. 36,139.-N. B. COOPER, Gratis, OHIO,-Cultizu tors.-Alusust 12,1862 .

The standards to which the shovels are attached are secured to a slotted beam $\mathrm{A}$ in such a manner as to admit of their being moved in the same. The beam $A$ is connected at one end to a rod $B$ provided with holes at its front end fitting upon a pin, by means of which the slotted beam can be adjusted to rows of different widths.

Claim.-The arrangement of the slotted beam A, adjusta ble rod $\mathrm{B}$, and beam $\mathrm{C}$, for the purpose and in the manner herein set forth and described.

No. 36,180,-E. S. TICHENOR, JACKsonvilie, N. V - Cultizulors-Ausust 1 2, 1862

The front standard of this implement is attached to the plough beam by means of a hinge joint, and upon the side: of this standard, springs attached to the side beams are made to bear, for the purpose of guiding or steadying the same.

Claim.-The combination of the springs $c c$ or their equivalents, with the hinged tooth of a cultivator, substantially as above described for the purpose set forth.

No. 36,909.-JOSEPH MEVER, LINDEN HAL.1., PA.Culivator Ploughs. - Vinember 11, 1862.

This invention relates to the particular arrangement of parts for the purpose of adapting the cultivator plough to a variety of agricultural purposes, by which it may be adjusted both as to height and depth, as well as to width and draught.

Claim.-The cultivator plough, constructed, arranged, made capable of adjustment as to height, depth, width and draught, and operating in the manner and for the purpose herein set forth.

No. 37,005.-WILLIAM NEVINS, IRVING, N. Y.Cultivators. - November 25, 1862.

Upon the sides of the central beam are placed wings provided with teeth on their under surface and secured at their forward ends by hinges, and at the rear by over-lapping bars rendered adjustable by means of holes and a bolt. On the upper surface of the wings is a brace attached at each end by a bolt passing through one of a series of holes in the wings, by which means the latter may be set to any desired angle to pass between the rows of plants.

Claim.-The rigid angular wings $C C$ connected with the 
beam A, and made aljustable by means of the brace lar 1), eye bolts $d d$, and adjusting holes $f f$, or their equivalent devices, the whole arranged, combined, and operating sub. stantially as and for the purposes herein set forth.

No. 37,089.-I. H. DOVLE, WATERloo, Iowa.-Cultizutors.-December 9, 1862.

To the curved beam bar is attached at each side a laterally projecting bar, to which are bolted two angle bars, the latter being also attached to the plough standards in such a manner as to admit of their being secured at a greater or less distance apart, and also to admit of the shares being raised or lowered as desired.

Claim.-The combination with the beam bar $\mathrm{A}$ and standards $\mathbf{E}$ E of the adjusting bars $b d$, in the mamer here in shown and described.

No, 37,271.-D). G. BLUE, Winflel. , IowA.-Cultivators. - January 6, 1863 .

In this invention the forward plough-stocks are madelonger than the rear ones, and the draught so applied as to relieve the horses from the weight of the front of the plough. By the employment of removable shield, roller, and plough. stock, in the centre of the implement, it is adapted for use, either as an ordinary cultivator or a corn plough.

Claim,- $\mathbf{r}$ - The rear posts, when made shorter than the front ones, in combination with the use of an adjustable draught connection, substantially as and for the purposes set forth.

2.-The combination of the guage rumners $d d$ with the front posts, substantially as and for the purposes stated.

3.- The combination with the frames of the removable shield box $G_{2}$, plough $1 \mathrm{I}$, and roller 1 , substantially as set forth.

No, $37,988 .-P$. C. VAN BROCKLIN, Buffalo, N. Y.-Cultizators.-Warih 24, 1863.

The triangular frame of this cultivator is supported upon a wheel at each corner; the forward wheels being pivoted in arms projecting downwardly from the frame, and the socket of the rear caster wheel pivoted so as to be vibrated back and forth by the lever, with connecting rod- to lower the frame at all corners simultaneously.

Claim.-Cultivators having a triangular frame with a wheel at each corner, supporting a caster wheel at the apex of the frame, in a socket or journal box which is hung upon a bolt or pin, in such a manner that it may turn or swing freely upon said bolt, in combination with a swivel lever shaft which connects with the wheel and extends upwardly for a handle, and operates as a swivel upon which the whee turns freely, and which is connected with the forward wheels by means of rods, taking hold of the arms I, below the frame, so that all of the wheels may be raised or lower ed simultaneously by the driver, substantially as and for the purposes described.

No. 38,o66.- With.tAM G. STrotvGER, Oswego, N. Y.-Subsoiling Implement.-March 31, I 863.

This machine has two rows of chisel teeth diverging from the forward end and set in a metal plate with handles for the operator.

Claim.- An implement for subsoiling, ditching, \&c., com posed of a solid metal plate $\mathrm{A}$ and teeth $\mathrm{B}$, the latter being fitted in the former, substantially as shown, and the plate provided with handles $\mathrm{C} C$, and a clevis $\mathrm{B}$, all being constructed and arranged as herein set forth.

No. 38,593.-ISAAC B. MAHON, MARION, OHIo.Cultizators.-May 19, 1863 .

The improvement is in the beams and handles, which are mate of flat bars of the shape and construction indicated in the claim and illustration.

Claim,- The construction and arrangement of the bars $\mathrm{A} A$ and $\mathrm{B}$ placed vertically edgewise and welded together at their front ends, and braced by a thin cross-bar $\mathrm{C}$ placed vertically edgewise, in combination with the forked handle braces $G G$, each formed in one piece, in the manner and for the purposes herein specified.

No. 39,337- JUllN BURNS, FrankLIN, WARREN County, OHн, - Cullizators.- July, 28, 1863.

The handles of this cultivator are supported near their rear by rods passing downwards to the beams, and in front are attached to a prow-shaped clevis or continuation of the middle leam.

Claim.-The attachment of the handles $G$, at their forward end, to the upper end of the perforated prow-shaped clevis $\mathrm{E}$, which is formed on and made a part of the central beam $\mathrm{A}$, in the manner described, in combination with the stay rods $\mathrm{H}$ and beams $\mathrm{A} B \mathrm{~B}$, when arranged in the man ner and for the purpose specified.

No. 39,528.-CHARLES IV. S. HEATON, SAIEM, Marion County, Ill.., assignor to Jabez J. Peggutt.Cultivators.-August i I, 1863 .

This improvement consists of devices for throwing the direct strain upon the plough beams and relieving the jar caused by collision with obstructions; the forward ends of the beams are attached to a slotted cross.bar which is stayed by angle rods from the tongue, the draught rods having a vertical play by the motion of the clevis pin in an upright slot in the tongue. The lateral adjustment of the plough beams is by means of slots in the cross-beams, to which the former are clamped by set screws.

Claim.-1. - The arrangement in a cultivator of the brace rods $h h$, and stay rod $k$, in such manner that the longitudinal strain upon the implement shall be thrown upon the side beams $\mathrm{B} B$, and front beam $C$, when the implement is unobstructed by stones, \&c., but when the implement is obutructed by stones, $\& c_{*}$, the sudden jar due upon the tongue A shall be relieved by the oblong slot $c$, and finally be sustained by the stay rod $k$, all substantially in the manner set forth.

2.- The arrangement, in a cultivator, of the automatically shifting brace rods $h h$, pin $d$, and vertical slot $c$, in the manner and for the purposes described.

3. - The arrangement of the inclined stay $\operatorname{rod} k$, heam $C$, and :ongue $\mathbf{A}$, substantially as and for the purpose set forth.

4.-A cultivator combining in its construction the tongue $A$, side beams B B, upper and under slotted cross-beams C C', V-shaped adjustable braces or stocks $\mathrm{E} \mathrm{E}^{\prime}$, brace rods $h i$, and stay rod $k$, the several parts being constructed and arranged as described.

No. 39,7 24.-G. A. ERICKSON, SWEED BEND, WEISTER COUNTY, IUWA.-Cultizators-Siptimber 1, 1863.

The cultivator has two rows of shares and is supported on wheels. In the rear portion of the hinder bar is a reciprocating rod with harrow teeth, which is driven by a pinion and link from teeth on the driving wheel.

Claim.-The described combination of a vibrating harrow $\mathrm{E}$ with a cultivator, the whole being constructed and arranged to operate in the manner and for the purpose herein specified.

No. 4I,562.-J()SEPH W1 I.HEL.M, MuscatiNe, \}owA. -Cultivators.-February 9, 1864.

This invention relates to that class of cultivators which are constructed with two wings hinged together and designed to cultivate both sides of a row at one and the same time, and the improvement consists in an arrangement of devices by which the distance between the wings can be rearlily increased or diminished according to the width of the furrows.

Claim.-Having the arms $a$ - jointed at the centre, and combined with the clevis $c$, in the manner and for the purpose herein shown and described.

Also, the arrangement of the spring latch $g$, with the beam $A$ and arms $D D$, in the manner and for the purpose herein shown and described.

No. 42,737 - - SAMUEL A. TOOMBS, assignor to himself and SAMUEL M. PURSE, Ashley, Missouri.Cultivators.-May $10,1864$.

This invention consists of a curved bar, the ends of which form the rear part, and are connected by a curved cross-bar. Longitudinal bars are pivoted to the front of the curved bar, and are provided with standards that carry at their lower ends cultivator teeth, the rear ends of the bars serving as handles to govern the cultivator.

Claim.-A cultivator frame constructed of the curved bar $A$, united at its rear by the curved cross-bar $b$, and provided with the stationary standards and cultivator teeth $a$, and pivoted standards for handles $d$, the whole constructed and arranged substantially as herein set forth. 


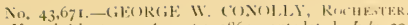

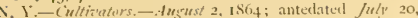
1564 .

This invention convists in a combination of an ad ustable arm, carrying at its rear end a scoop shaped cultivatur share arranged vertically, with vertical sharp edged shares, which latter are for the purpose of preventing a lateral movement of the cultivator as it is drawn forward, while the former or main share moves the earth sillewise towards the plant.

Claim. - The combination of the adjustable plough l' with the guides $\mathbf{~ I ~} \mathbf{~ I}$, said guides being constructed and arrang ed in the manner and for the purpose substantially as de scribed.

No, 45,019. - IOIIN MI. JURKE, DANVII.L, N, Y'Culticators - Vorember 15, IS64.

This invention consists in fastening the wings of the cen tral plough by wooden pins to projections on the unter vide of the plough. The upper surface of the shank of the cul tivator tooth in the rear is curved out, leaving sharp edges, which bite firmly into the wood of the be:m, so that it can be firmly secured by a single nut.

Claim.-1.-The shovel E, having a narrow central fin and staples $e$ e formed on its inner or uncler surface, in the manner described and for the purpose set forth.

2.-The teeth J, with cutting hooks $i$ and concave ends $t$, in the manner and for the purpose described.

3. - I he arrangement of the shovel $\mathrm{E} ; f$, wings $\mathrm{G} ; \mathrm{C}$, sitle beams $\mathrm{B} B$, handles D D cross beam $\mathrm{C}$, main beam $A$, and teeth $\mathrm{I} i \mathrm{f}$, the whole constructing an improved cultivator, substantially as and for the purpose set forth.

No. 45,612.-11ANF(IRI INGRAIIAII, NAPLE?, N. Y - Cultitators.--Decembr\% 27, 1864 .

In this invention the frame is T-shaped, carrying two teeth in front and one in the rear. The shaft are fastened directly upon the encl of the front bar, and are raiset and lowered by a cast-iron flange-shaped wedge.

Claim.- I - The construction and application of a castiron flange-shaped wedge, for the adjustment of the thills, snbstantially as in the manner and for the purpose herein described.

2. - The construction of a T-shaped frame, in combination with the adjustable thills, as herein arranged, substantially in the manner and for the purpose herein set forth.

No. 47,105.-GEORGE F. IIASSENPFLUG, and GEORGE BARNHART, fiRFEN TUWNSHIP, OHO,-Ciul tivators-April $4,1865$.

In this invention the frame is of a horse-shoe shape, and of one piece of bent timber. The plongh standards are ad. justable, and swing lack up'n hinges when the wooden jin is broken by any obstacle. The handles are also adjustable.

Claim.-The frame $a c$, when constructed as described, in-combination with the plough standards $b b b b$, the same being attacherl as specified.

$$
\text { No. } 47,534 \text { - J IMES R. FINLET, DELPH, IND - Cul- }
$$
tivater Plough.-Nay, 2, 1865.

In this invention the ploughs are double, and the shares and monldhoards are made of one piece of steel plate. the monldboards are symmetrical in form, oblate, and curvilinear.

Claim.-The equal or symmetrical mouldboard when said parts form a continuation of the share, and have the peculiar form and configuration, as set forth and describecl.

No. 47,536.-C. FOND, FOREST CiTY, ILI.,-Shot't Plough - - Way 2, 1865 .

This invention consivts in connecting to the frame of the ploughs by means of hinges, shaft:, to which is connected at one end an adjustable bar provided with holes and made adjustable by bolt fastened rigidly to the handles of the shafts, having on their ends nut for the purpose of adjustment.

Claim.-1. - The morle of making an even-draught twohorse shovel plough as herein deicribed; with the shafts $F$ attached to the frame by the hinges $m$ and $n$, and connecteil by the coupling bar $\mathrm{H}$, which arrangement, while it holds the shovels evenly, enables the operator to change the face of the shovels at will, and thereby guide the plough.

2.- The false cutteri $K$, in connection with the lraces $I$, made to slide in the gronve in the head piece 1 , and se. cured by the clamps 1 , as hercin set forth, in -uch manner, that the operator, lyy loosing the clamps J, may change the width between the shovels by sliding the topy of the braces in the growe.

3.-The ring-headed bolt () for holding the donble trees on the plough, sulntantially as herein set forth, in such manner that when the plough is thrown on its side they will halance, remaining parallel to the neck yoke.

No, $+7,615$, PETERS. CARIIART, COLLAMER, N. Y. - Cirltizators. - Mav 9, 1865 .

This invention consists in comnecting a plate to the shares of a cultivator, and attached to a rod at one end, and at the other to a lever, for the purpose of adjusting the depth of pentration of the shares into the ground.

Claim.-The adjustable pivoted soles or plate $\mathrm{L}$, attached to two or more of the share $B$ of the cultivator, and arrangeal with levers $F$, or their e.fuivalents, suhstantially as and for the purpone specified.

No. $48,324 .-11$. M. TE.ISD.A1.E, D.ANSIILI.E, N. Y.Cultirators.-June 20, 1865.

In this invention wings extend obliquely up from the front plough to the beams just aloove the rear plongh. A removable plough, with a continuation of the conlter $u_{1}$ on it, slide on with a groove and is secured by serews.

Claim.-1.- The arrangement of the mclined wings $E^{\prime}$ $\mathrm{E}^{\prime}$, with the double plough $\mathrm{E}$ and the beams $\mathrm{D} \mathrm{D}$, in the manner and for the purpore lescribed.

2.- The construction of the point represented in Figs. 4 and 5 , in combination with the part $\mathrm{E} b \mathrm{~d}$, subatantially as for the purpuse herein described.

No 48,783 -P.ARKER II. ALL.STOTT, JEFFERSON VIL.J.E, JND. - Cultiz'ators. - Fuly IS, 1865

This invention con-i-ts in the arrangement of the connecting bars, bolts, screws and slots for changing the angle be tween the hares and beams.

Claim.-The relative arrangement of the shares an beam and the comtruction and arrangement of the connect ing rods, bars, bolts, and screw and taps, so far as they assist in effecting the purpose and object of changing at will the angle between the shares and beams and thereby altering the draught of the tiller.

No, 49,III.-HANFORD INGRAHAM, NAIIES, N. Y.-Cultizators.-Ausust I, 1865.

In this invention the shafts are firmly attached at their rear encls to the cross-piece of the frame. The arms are elevated and depresued at will upon standards on the front cross-piece. Shafts are secured at any height by a set screw, working in the slotted tandard.

Claim. - The transver-e beams A anl, and centre for ward beam $a$, in connection with the knee-braces $\mathrm{C}$, as constructed and arranged, substantially in the manner and for the purpose set forth.

No. 49,3 S 9 .--RICHARD DEIGIITON, Jr , FAIRWEATHER, ILi..-Ploughs, - Auszust 15, i\$65.

This invention convists in making the frame for a double plough in the form of a triangle, and extending the handles to form a brace for the standard, also in the form of a triangle.

Claim. - The plough frame constructed of the two beam $A$ and $A^{\prime}$, the cross piece $B$, the posts $D$ and $D^{\prime}$, and han dles C C ; substantially as and for the purpose set forth.

No, 50,093.-WILliAll J. BLRTON, Turtie, Wr - Cultisators. - Septenber 26, I865.

In this invention a straight frame carrying teeth to cultivate two or three row, runs at each end njon two bows or shoes affixed near the outside teeth; thus doing away with wheels entirely.

Claim,-The bows C C-this broadly-the whole arranged as and for the purpose described and set forth. No, 50,403.-R. THAYER aml J. MC CLELAND, Pittsigurg, PA-Cultizators.-Octobir 10, 1865.

The novelty of this invention consists in the combination and arrangement of the several parts of the cultivator for the purnose of obtaining strength and durability.

Claim.-The herein described arrangement and combina tion of the beam $\mathrm{A}$, standarls $\mathrm{B}^{\prime} \mathrm{B}^{\prime}$, handles $\mathrm{C}^{\prime} \mathrm{C}^{\prime}$, braces I) ${ }^{\prime}$, and bolts $a d h i$, as and for the parpose specified. 
No. 50,930.-.TARKEY HALL, RUSSELIVHLL, KY. - Cultizators. - Vovember 14, 1865.

The side beams in this cultivator are adjustable laterally, and in rear of the cultivator teeth is fixed an adjustable har. row. The tongue is pointed, and by lifting up the handles the harrow is raised, and by depressing the handles the ploughs are raised, the ploughs and harrow respectively forming a fulcrum for the handles, which act as levers of the first and seconil order.

Claim. - The combination in a cultivator of laterally ad. justable plonghs, with a longitudinally adjustable harrow, having a rigil attachment to the rear of the frame, when constructed, arranged, and operating substantially in the manner and for the purpose set forth.

No. 51,286,-JOHN T. BEVER, BeTHEL, IlL,-Cultirators.-Dicember 5, 1865

The frame of this machine is of a triangular shape, and hinged at each corner, so that hy removing a pin at one of the inner corners the triangle can be reversed or doubled arouml, so as to reverse the position of the shares. Thus, by a simple movement the rigid teeth can be reversed.

Claim,-I, The inverting triangle frame A A A, constructed with free working joints or holts $b b b b$, or their equivalents, for the purpose of reversing the order of the turning plonghs $f f f f$, substantially as and for the purpose set forth.

2.- The double look or clevis $d d$, with cross-bar or flanges $k k$, or their equivalent, for the purposes herein specified.

3.- The handles $c c$, in combination with the inverting triangle frame $\mathrm{A} A \mathrm{~A}$, as and for the purposes herein set forth.

No. 51.428.-JOHN COPEI,AND, Quasqueton, Iowa. - Cultizators.-December, 12, 1865.

This invention consists in the attachment to cultivator beams of levers crossing each other and working on the pin that connects them together, and made adjustable by means of a perforated har secured to one of the levers and passing through a slot in the other, the perforations in the bar receiving a pin to allow of its expansion and contraction as required.

Claim.- The two cross levers $\mathrm{H} \mathrm{H}$, connected by a pin a and applied to the plough beams $\mathrm{B} \mathrm{B}$, to operate in the manner substantially as and for the purpose herein set forth.

Also the combination of the levers $\mathrm{H} \mathrm{H}$, perforated bar $\mathrm{J}$, lever $K$, and pin $g$, arranged to operate in the manner and for the purp se specified.

No. 51,567.-DANIEL, DENNETT, Buxton, Maine. - Culturators.-Decimber $19,1865$.

This invention consists in a method of bracing the plough standards to each other and to the beam. The front it indards are extended up to form handles.

Claim, - The plough standards, constructed as herein described, in combination with the beam fastened by the cruss-piece to the front standards, and with the braces or ties that confine the rear standards to the front standards, substantially as herein specified.

No. 51,817.-RICIIARD ELLIOT, Plainfield, N. J. - Comlined Ploush and Scraper.- Fanuary 2, I866.

Attached to the plough beam are a share, a scraper, and an oblique grading bar for levelling.

Claim.- The scraper composed of the bar $\mathrm{E}$ and botton F applied to or combined with a plough, to operate substantially as and for the purpose set forth.

Also, the bar $G$, in combination with the plough, substantiaily as and for the purpose specified.

No. 52,421.-Al.FORL LAMB, SKANEATEles, N. Y.Cultivators.-February 6, 1866 .

This invention consists of a triangular frame composed of iron rods and cruss-timbers. The braces coming from the rear beam are united to the front standards; the shafts are at tached to the beam by a swivel, and by means of a guage it may be so adjusted as to regulate the depth of the cut.

Claim -1.-The arrangement for attaching the shafts to the beam by means of the swivel $F$ and guage $G$, for regulating the depth of the cut as set forth.

2.- The arrangement of the frame E D C and standards
A B H, with the frame $\mathrm{K}$ and handles, all constructed and combined, substantialiy as and for the purposes set forth.

No. 52,515.-CHARLES BELDEN, Miblleburg, Оноо.-Cultivators.-Febrnary 14, 1866.

In this invention the handles are bolted to the sides of the beam. This beam is made of a bar of iron, double and ber.t round at the front end, through which a bolt passes for attaching the device to the end of the beam. The bar is turned at the front end and doubled closely together, excepting from where it is bent outward, and extends along so as to form a slotted opening. In this this opening is fitted and secured a curved standard, being secured by the bolt that connects the handles to the beam; this standard curves down on the inside of the double plough in front. The point is made of such metal as hardened steel, so as to he a self-sharpener.

Claim - $\mathrm{I}$ - The frame $\mathrm{B} F$, in combination with the changeable and reversible blades $\mathrm{H} \mathrm{K}$, when constructed and arranged as and for the purpose set forth.

2.- The herein-described cultivator with changeable and rcversible blades $\mathrm{H} \mathrm{K}$, when constructed and arranged as and for the purposes set forth.

No. 53,212.-GEORGE W. ZEIGLER, TiFFIN, Оню. - Cultivators.-March 13, t866.

This invention consists in the construction of a shovel plongh, with a movable cross arm or plate, and so arranging the same that the shovels can all be moved either to the right or left of the beam in oblique directions to the line of dratight; and also in the application of spring braces to the pivoted shovels and standards.

Claim,-1.-Constructing the shovel plough with a movable cross arm or plate $\mathrm{C}$, and so arranging the same that the shovels can all be moved either to the right or left of the heam in oblique directions to the line of draught, substantially as specified.

2.-The application of spring braces $k$ to the pivoted shovels and their standards, substantially as described.

3.- The construction of the shovel-holding plate $\mathrm{C}$, with lugs $c c$, to receive the out-side shovel standards, and also with a flat upper surface having notches in it to receive spurs which project from the bottom surface of the flanged casting $\mathrm{B}$, substantially as described.

4. - The construction of the central standard $g^{\prime}$ with a pin $e$, so that the plates $\mathrm{C} \mathrm{B}$ can be secured to the beam $\mathrm{A}$, in the act of securing the central shovel to the plough, substantially as described.

5. - The combination of the flanged casting $B$ with the shovel holder $\mathrm{C}$, these two parts being constructed substan tially as described.

6.- The construction of the shovels with detachable points t, substantially as described.

7.-Providing for adjusting all the shovels about a central axis simultaneously, when these shovels are attached to standards that can he adjusted and secured in position independently of each other, substantially as described.

No. 54, 122.-H. W. CURTIS, WorCestre, Mass.Cultivators.-April 24, i\$66.

The wings which follow the central share are expanded or contracted by segmental racks and a pinion.

Claim.-The wings E E, connected at the rear of the plough or share $\mathrm{D}$ by means of joints, in combination with the segment racks $G G$, and the pinion $H$, for adjusting the wings $\mathrm{E} \mathrm{E}$, all arranged to operate in the manner substantially as and for the purpose herein set forth.

No. 54,I9I,-JAMES E. MORRISON, WASHINGTON, D. C.-Cultivators.-April 24, 1866 .

The cultivator beams have flexible connections to enable the standards to preserve their verticality and adjust themselves to hillsides.

Claim.-1.-A cultivator having double plough heams $\mathrm{U} \mathrm{U}$, hooks 00 , clevis $p$, standards $x$, and cross-bars $y, y$, constructed, combined, and arranged substantially as herein specified.

2 - In combination with double plough beams united at their front ends as described, the standards $x x$, and cross bars $\mathrm{V} \mathrm{V}$, constructed and operated substantially as and for the purposes set forth.

3.- The entire cultivator with its varius devices, con 
structed, combined, and arranged substantially as and for the purposes herein mentioned.

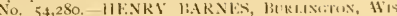
- Cultizulors.-. Man I, is66.

The stundards of the three shares are adjustably connected by clevi-es and stay roils to the cross-pieces of the frome to which the thills are attached.

Claim. - The combination and arrangement of the thill A, standards (; H, cross-piecen ( 1 ), rods $\mathrm{L}, \mathrm{M}$, and con necting bar (1), constructed and employed in the monuer and for the purposes specitied.

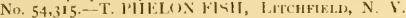
- Horse Hoc:-Way 1, 1866.

The side ploughs are adjusted towards and from the median line to vary the witth of tilth.

Claim.-In combination with a central plongh carried by and adjustable in the bean, the side ploughe carried by and made adjustable on a divided frame, which is also carried loy and made adjustuble on the beam, subutantially as and for the purpose herein describert.

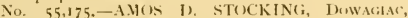
Mich. - Cultizators, - . 1/ay 20, IS66.

The rear caster wheel supports the cultivator ; the plough standards are supported by stay rods and by transverse pins in themselves and in the frame, and are raised by the partial rotation of the hoard to which they are attached by chains.

Claim.-I.-The application of a swivel wheel a to the rear end of a frame of a cultivator, which is constructed substantially in the manner described.

2.-Keeping the shwel standards E in proper position during their passage through the snil ly means of the trans. verse rods $h^{\prime}$ and notches $i$, combined $w$ ith the forward braces $k$, substantially as de-cribed.

3.- The pivetel bourd $\mathrm{G}$, or its equivalent, arranged trans venely across the cultivalor frame and connected to the shovel standards E, substantially as described.

No. 55,256 - EIIVARI) I. I)(OR.SEY, UNIUN, IND.Cultizators,-Fun: 5, iS66.

The devices cited tefer to the attaching and adjusting the main shares, and in addition to these an axle in the rear is provided with shares which, when reversed, form harrow leeth.

Claim.-1.- The rod E, arranged and used as and for the purpose set forth.

2. - The reversible and adjuxable ploughs and rakes M and $\mathrm{N}$, secured to the axle $\mathrm{K}$, said axle being attached to the upright $\mathrm{B}$ by means of an adjustable plate $\mathrm{H}$, arranged and used as and for the purpoie set forth.

3.- The block $\mathrm{R}$ with the ploughs $\mathrm{P}$, arranged in the manner subvantially as herein specified

4. - The guides $w$, arranged and used as and for the pur poses herein set forth.

5.-The plough-beam $A$, with the guide wheel $F$, upright 13 , and shovel 11 , in combination with the axte $k$, wheels L L, shovels $m n$, and bluck R, when used as and for the purposes specilied.

No, 56,286. - E. M. SORLEV, NEENAH, IVIs.-Culliz'ators. - Fuly 10, I866.

The bars of the frame are capable of adjustment to as. sume various shapes. The sides are connected by a pivot ed brace and connecting rods, and the teeth present a convex edge to the soil.

Claim,-1.- The jointed adjustable cross bar B, with arms $b b$, in combination with the shifting braces $c c i c$ and the side frame $\mathbf{A}$, convtructed and arranged substantially as and for the purposes herein described.

2.- The construction and arrangement of the shifting screw headed and sabre shaped harrow teeth or cultivators with hollow backs, in combination with the frame $A$ and the adjustable centre cross bar 13 , with it draught arm、 $b b$, applied and operated as herein stated.

No. 56,28S, - ESEN STARR, Royal ()AK, Mich.Cultivators.- 7 ulv 10, 1566.

The rear standards are laterally adjustable on the curved transverse brace-har, and the front stundard is adjuntable as to its raking angle.

Claim. - 1.- The curved or segment bar B, at the rear end of the beam $A$, in combination with the curved stand. ard J J, provided with upper hent end $a^{*}$ to abut or fit snugly against the rear sicle of the said har 13, and to which they are recured by bedts, substantially as forwn and described.

2. - The standard $F$, bent or curved as hown, and se-

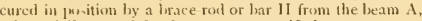
sulstantially as ami for the purpose specifiecl.

No), 56, 555,-1).INIEL, IITKRIS, ('ANAIN, MAINE.Horse Ilet:- July 24, i 866.

The thare has a midelle portion inclining forward and siden having an angular inclination; it is followed by wings which have a lateral arljustment by means of segmenis stipported by the reat of the berm.

Claim. - The share $C$, constructed or formed with sides a $a$, inclined buth transversely and longitudinally, and also formed with a central longitudinally inclined surface l, having a horizontal position in its transverse section, in combination with the adjustable mould-loards E E. pivoted to the rear of the share $C$, and retaines in position ly the clamp $F$, and bar $e c$, all arranged substantially in the manner and for the purposes set forth.

Nis. $57,3+1 .-Z$. W' LEE, BLAK:1.Y, GA.-Plough.duyzest 21,1566 .

The flanger of the lrackets are attached by shackles and wedges to the central beam; the olliciuity of the standards is determined by braces clamped to the brackets in which they are pivoted.

Claim.- The comlination of the shank $\mathrm{E}$, loracket $\mathrm{F}$, piv oted arm I, shackle $\mathrm{K}$ ancl wed re $\mathrm{L}$, all arranged and operatiug sulstintially as and for the purposes herein explained.

No. 57,719--JACOB IIOI.LINGER, NHLLRSBURG, (OH10.-Cultizators. - Septenipir 4, 1866.

The shares are attached to an expansalile triangular frame ant the hantles secured to the central longitudinal heam.

Claim.-The herein described construction of cultivators, comsisting of the beam A, curved hars B B, braces D, shares $C B^{\prime} B^{\prime}$, and handles $E$, several parlis being constructed arranged and operating as and for the purpose set forth.

No. $57,7+7$ - THOS. B. MCCONALGilleV, NEWARK, 1)EL.-Cultizators. - Septembur 4, 1866 . Antedated Au just $28, \mathbf{r} 866$.

A guard plate on an arm piroted to the sides of the cultivator intervenes between the young corn and the outer share on that side to keep clod from the plant.

Claim,- The applications of a guard or guards to a cul. tivator, sul-tantially in the manner as and for the purpose herein set forth.

Also, the pivoting the bar F to which the plate or guard $G$ is att iched between plates $\mathrm{E} E$ secured to the cultivator near its front end and provided with a rest $b$, substantially as discribed.

No. 57.792.-ADUISON F. SHIILWELL, FAYETTE, Iows.-Cultivators.-Siplember 4,1866

Forward of the rear plough are two lateral shares which are attached by a lirace frame to the beam, and are adjustable as to presentation and relative distance by the vibration of the jointed stantards and the pivoted share.

(laim. - The bar E, beam A, and cross-bars $\mathrm{G}$, in combination with the bars I, projections b, spurs $f$, shares J and brace-rols $K$, all arranged to operate as and for the purposes set forth.

No. 57,952,-W. D. NICIIOTA, CHICA(s), ILL.-Cult tivators.-Septimber 11, I866.

The side beams of the plough are hinged to the middle beam, and are maintained at their lateral adjustment by slot ted braces and a set screw, the forward end of the scrapers traversing in a slot of the centre beam.

(laim.-1.-Connecting the inould boards or ploughs A $\mathrm{A}$, with a hinge joint, substantially as described.

2.- The slot $s$, or its equivalent, in combination with the mould loards or ploughs, substantially as described.

No, 58,776.- JACOB K. REINER, LINE LEXINGION, 1'A.-Cultivators.-Oitober 2, 1866.

A lateral adjustment of the beams is made by a movement of stretchers in converging slide bars.

Claim. - The bar $\mathrm{G}^{\mathrm{G}} \mathrm{G}^{\prime}$, having the handles $\mathrm{H}$ il attached and connected by the screw J, provided with the nut $K$, in combination with the bars $\mathrm{FF}$; attached to the inner sides of the beams A A, and passing through eyes $a$, at the end of a bar $\mathrm{L}$, secured to the under side of the front har $\mathrm{G}$, with 
the clamp bar M, attacbed to the under side of the rear bar $f^{\prime}$, all arranged subutantially as, and for the purpose set forth.

No. 58,578.-TH(IMAS BE.ALE, New MILford, Il.I. - Cultizators. - October 9, 1866.

By means of the lever, the share and the scraper are re ciprocated, and the earth stirred and billed against the plants

Claim.-The bars A A having the har B pivoted to them, with the sparle or shovel $C$ attached to the front end of the latter, in combination with the bar $\mathrm{E}$ connected to the bar $\mathrm{F}$, which is pivoted to $\mathrm{A} A$ and connected to the pivoted bar $B$ through the medium of the rod $b$ and guide bar D. and the scraper and hilling device $G$ pivoted to the front ends of the bars A A, and operated from one of the pendants $c$ by the rod $H$, substantially as and for the purpose set fortb.

No. 58,58 I. -JESAE C. BOT 1), Mir.roy, IN1).-Plowshs. - Octobir 9, I 866.

The side beam - are pivoted to the fore-bar and adjusted laterally at the rear by slotted plates and set-screw.

Claim.-The beams $\mathrm{A} A$ in combination with the upright sbovels and bandles, when connected to the beam $\mathrm{C}$ by means of the swivels $11 \mathrm{H}$, and attached to the beam B by slotted bars F F and set-screw $t$, arranged substantially as pecified.

No. 58,597--JOHN CLARRIDGE, PANCHASTBURg, (OHio.-Double Shou'el Ploush-October 9, I866.

The plough has a lateral adjustment by slide racks and slide bar, and is beld to any adjustment by tooth blocks and wedges,

Claim - The combination and arrangement of the arms 1. and $\mathrm{M}$, the toothed blocks $\mathrm{N}$ and $\mathrm{P}$, and the wedges or keys $O$ and $R$, with the beams $B$ and $A$, the plough-head $G$, and the handle I, substantially as herein described, and for the purpose set forth.

No. 58,Soj.-J()IIN FRII)V, West Donetin. Tuws. SHII, I'ENN.-Cultizalors.-October 16, 1866.

The pivot frame at the front of the beams has journal bearing for a wheel; lateral adjustment of the outside beam. is accomplished by means of houked loits by which they are attacbed to a bar at their rear.

( laim.-The construction of the adjusting bar 1), fixed in its centre to the central heam 2, and provided with a series of holes $\mathrm{G}$, for the hook bolts $\mathrm{E}$, supporting and embracing the side beams I and 3 in combination with the pivots $\mathrm{A}$, when supported between the plates $\mathrm{P}$ and $p$, in the manner and for the purpose shown and specified.

No. 5S,8I9.-NATHAN HAWKES, APPLEION, MAINE. - Combined Cultizalor and Ditiher.-Uctober 16, is66.

This implement is for hoeing, subsoiling or shallower ploughing, or the planting of potatoes or grain. A twofaced mould loard is followed by wings or shares attached or following in the rear. Bars trailing in the rear, mellow the ground. A toothed disk, adjustable as to depth, has sicle pins to work the slides at the bottom of the seed hoppers. A draw bar is pivoted in the beam, which for deep ploughing is carried up a rack at the fore end of the beam, and held to any one of the adjusting notches by a wedge.

Claim.-All the various parts, constructions, combinations and arrangements hereinbefore described, for planting, boe ing, digging, and ditching, except so far as the mould boards $\mathrm{A}$, the beam $\mathrm{B} \mathrm{B}$, and the handles $\mathrm{C} C$, Fig. I, are like those of the common mould bourd plough.

No. 58973.-PETER BARNHART, Chtlicotie, OHto. - Carn Plough.-October 23, 1866.

The standards are pivoted at their upper ends, and have arms running from thence horizontally, adjusted by means of pius in the beam. An adjustable fender is pivoted to the beam to keep clods from the young corn.

Claim.-The adjustable fender $\mathrm{F}$ and beam $\mathrm{A}$ in comlination with the st undards B B, for purposes and substantially as described.

No. 59,003--WILLIAII O. GiJ3SON, ChIRLESTON, S. C.-Cultivator Plough.-October 23, 1 S66.

An angular share has its landside to the corn, and a plongh connected to the same frame follows, throwing the earth toward the corn.
Claim. - The two parallel treams A A, connected by two cross bar, $a$ and proviled with the gauge wheel $C$, in combination with the bar $d$, provided with the coulter projection $e^{2}$, and horizontal blade or knife $D$, and connected to the beam $\mathrm{A}$ by the standards $c e$ and the plough $\mathrm{E}$, attached to the heam $A^{\prime}$, all being arranged sulstantially as and for the purpose set forth.

No. 59,OI 3.-J()HN B. IIERR, WEST LAMPETRE ToWNSHIP, PENN.-Cultizators.-Oclober 23, 1866.

Attached to the tongue are two transverse beams carrying teeth adjustable laterally, in slots.

Claim.- The combination and arrangement of the parallel shovel beams A B, mited by the tongue $\mathrm{C}$, handles $\mathrm{H}$, and braces D, when constructed and operating in the manner and for the purpose yecified.

No. 59,269.-AMOS W. KUSS, NorthFifln, Mass. - Cullizators.-October 30, 1866.

The wheels and their arms are each adjustable, the latter on the frame, the sbares also on their vertical hars. Inclined hoe blades are pivoted to a central share so as to admit of a spreading adjustment, and curved hoe bars connect to the ends of these blades, adjustable at botb ends. A knife plate has a draught hook screwed to its shank. Slotted bars pivoted in the side beams are provided for lateral adjustment.

Claim, - I, - The combination of the adjustable wheels $\mathrm{E}$, and adjustable supporting arms 1), with each other, and with the front and rear ends of the central be in $B$, subiantially as herein shown and described.

2.- The teeth $F$, and adjustable uprights $G$, in combination with the cultivator heam $\mathrm{A}$ I $\mathrm{C}$, substantially as herein shown and descrilsed.

3.- The long hoes II, in combination with the central tooth $\mathrm{F}^{\prime}$, and the rear sicle teeth of the cultivator, substantially as lierein thown and clescribed.

4.- The combination of the adjustable curved hoes I with the rear ends of the long hoes 11 , substantially as luerein shown and described.

5.- The combination of the rear governori or adjusting rods $J$ with the curved hoes 1 , and the rear ends of the side beams 1 , C, substantially as herein shown anil described.

6.-The combination of the central adju-table governor $\mathrm{K}$ with the central beam 1), sulustantially as herein shown and described.

7.- The comlination of the gu urd knife L anil draught hook II with each sther, with the forward end of the central beam B, and with the frunt central tooth $\mathrm{F}$, substantially as berein shown and descrilues.

S. - The combination of the slotted adjusting bars $\mathrm{N}$, bolt $n^{\prime}$, and nut $n^{2}$, with each other, and witb the beams A $1 ; \mathrm{C}$, substantially as herein hown and described.

9.-A combinel horse cultivator and how constructed and arranged substantially as herein shown and described.

No, 59,358.-1.VMAN I. CASWELL, Scort THWNSitr, IND.-Cullivators. - Vowmber 6, 1866 .

Links and brace rods connect the side beams to the middle beam to allow the longitudinal adjustment of the frame to arrange the sliare in plough or cultivator fashion. The obliquity of the standards is regulated by angular braces, and a slight rotation effects the hed of the earth from the shares. Claim.-I.-The application of the turning armatures $F$ F F F F F to the cultivator, to change the $\mathrm{p}$ sitions of the side shovels, so as to form a shovel plough or a cultivator. The application of the braces $\mathrm{G}$ G to sustain the side beams and sisle shovels in their proper positions.

2.-The application of the braces $\mathbf{E} \mathbf{E} \mathbf{E}$ to the shovel standarils, to elevate and depress the shovel point and turn the sod or sward; the application of the curve to the extension mould plates; the mortise in the ends of the shovel standaris, and the flattening the points of the shovel

No. 59,5 4.- IOIIN GlFlORD, WATERTWW, N. V. - Horse lloe. - Novimber 13, 1S66.

The adjust tble wings in the rear of the share are attached at their forward ends to the standard, and at the rear are adjusted by slotted plates proceeding from the handles and beam respectively.

Claim.-The reversible wings 1 , attached to and following the share and adjustably supported from the frame A B, substant:ally as described and represented. 


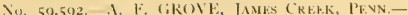
(iultizitors. - Virember 13. I866.

The sicle locams have longitudinal movement by which either plough may be put in the lead.

(laim. - The slicling or adjustable plough or shovel heams C C, applied to the main beam A of the implement, and arranged in comection with suitable levers, or their equivalents, to operate substantially as and for the purpose set forth.

Vo. $60,422,-B A R B A R V S$. RICII, PENFIEID, N. Y aclministratrix of the estate of I. C. RICIJ, deceased.-C'ut listalurs.-Ditimber 11, 1866 .

The shares have longitudinal adjustment on iron strips, and these strips have lateral adjustment at the rear by an expansible cart metal frame to which the handles are attached.

Claim,-1.-The standard frame C, provided withlugs $i^{\prime}$ at the top, and the parts $h / h l n$ at the bottom, when combined with exponding arms $\mathbf{E}$ E of a flexible metallic culfivator, the whole operating sulsstantially as and for the pur pose specified.

2.- The gange wheel stirrups, composed of two counterparts $r r$, and provided with the projections $t$, when combined with the flat sicle of $a$, of the cultivator frame, a herein set forth.

No, 6o, - WII.I.IAM T. WATSi)N, Notrinciham, MD.-Cultizators-Dicimber II, 1866.

The teeth are curved forward, and are inserted in me tallic plates in the rails.

Claim.-1.- The tecth $\mathrm{C}$ of a cultivator when constructed as set forth.

2.- The combination of the frame $A$, teeth $C$, and metallic sockets $D$, when said several parts are respectively constructed, and the whole arranued substantially as set forth.

No. 60,982,-SAMUEL A. WRAY, GRFenFIELD, IN1),Cultizator Ploughts.-Jimuary $\mathbf{I}, \mathbf{1} 867$.

The beams are attached together by a flexille plate, and have a slottecl adj istment plate near the rear end.

Claim - The combination of the beams $B$ and $B^{\prime}$, edastic plate $\mathrm{D}$, and hinge joint $\mathbf{E}$, with a device for retaining the beams in position, substantially in the manner set forth. No. 61,294 -SII. IS M. WHITNET, GALSHURGH, l LL. - Cultizators.-Jimuary I5, 1867.

The standards are secured by eyebolts and sockets to the beams, and are braced loy eyeholts to angle pieces, fastened to advance point on the beam The plough is steered by a caster wheel at the rear.

Claim,- - The securing of the standard $D$ to the lream A through the medium of the sockets B and screw bolts C, provided with eyes $a$, all constructed and arranged sub. stantially in the manner as and for the purpose set forih.

2.- The braces $\mathrm{E}$, applied to the beam, and standards, substantially in the manner as and for the purpose specified.

3.- The cater or gauge wheel $\mathrm{H}$, applied substantially in the manner as and for the purpose set forth

No, 61,705-JANES C. BETHEA, BIAKEIY, GA.Cotton Cultizators.-Febuary 5, 1867.

The shares are attached by rings and wedges to the stand ards and braces, and the latter similarly fastened to the beams. The braces are thus rendered adjustable at either end.

Claim.-1. - The mode, substantially as described, of fastening together the standard brace and share by a shackle and weclge.

2.- The mode of adjusting the pivoted standard by slip. ping forward the shackle and the upper end of the brace upon the beam.

3. - The relative lateral adjustment of the lieam by mens of the bolts with their collars, washers, and set nuts, substantially as represented.

No. $61,760 .-W$. N. RHINEHART and II. FELKER, Mraml CITY, OHto, assignor to themselves and O. P. RUSSELL. Cimn Cultiaters.-February 5, 1867.

The left side of the front plough and the right side of the second plough are turned forward in projecting flanges. The former, which runs nenrer to the corn, turns the eartl from the plants, and the latier fends off the cloris but throws the mellow earth to the plants.

Claim. - The ploughs C (', when constructed sulstantial ly as described, and their arrangement with reference to the plough 1 ) and frame, in the manner and for the purpose specitied.

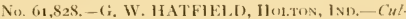
tirator Ploughs - Fiburury 5, 1867 .

Claim -1.-The loop li, clips C, and keys or wedge n, all arranged to secure the front ends of the beams $A$ together substantially as and for the purpose herein set forth.

2. - The beams A $A$. handles $1: \mathrm{E}$, brace $\mathrm{K}$, helsl together by the clips F F, and key $\mathrm{i}$, when all are combined and arranged as herein set forth

Ni), 61,943,-IVORY LORD and SEWELL W()()I) MAN, SAC(s, Mr.-Cultizaters.-Fibruary 12, 1867

The shank or standaril of the share is forked vertically, and the arms are traversed by rods which project laterally from the frame and on which the outer standards have side adjustment by set nuts.

Claim.-1.- The shank $s$, as shown in all the fignres of the drawings, elongated and perforated as described, and the brace $b$, connected therewith.

2.--The attachment of the teeth by the rods or arms at a distance from the wood, an shown in Figs, $I$ and 4 , and secured in place by nuts and keys, as described.

3.-The mode of widening or narrowing the machine by sliding the teeth on the arms rrh h, in Fig. 4 , and the combination of all, forming the cultivator as represented and described.

No. 62.060.--W. J. OXFR, WHI.1AMSPORT, IND.-Cu/. tirutors.-Fibruary 12, 1867

The frame is made of four piecen-a draft piece carrying the forward share, two bent side bars, to which the rear shares are attached, and a transverse brace har.

Claim. - in improved iron cultivator frame, formed by the combination of the bars $\Delta \mathrm{C}$ and $\mathrm{F}$, with enclr other; when saicl bars are constructed and arranged substantially as herein shown and described.

No. 62,223. -JONAS POTTS, BRHDGEPURT, W. VA.- Cultizators.-February $19,1867$.

To each beam is attached a share standard. By the tase of all, or the removal of parts, the beams in the case of sicle ploughs, and the standard in the case of the middle ploughs, the implement is convertible into a treble, double or single shovel plough.

Claim.-1.-A cultivator, provided with movahle uprights $\mathrm{D} D^{1} \mathrm{D}^{2}$, and their arms $d d^{1} d^{2}$. to enable it to the changerl to a double or single shovel pluugh, subutantially as and for the purposes described.

2.- The yoke $\mathrm{C}$, provided with a plate $\mathrm{C}$, having hooks $f$ fastened to it, to hold and support the arms $d^{\prime} d^{2}$, sulstantially as described.

3.-The plough beam $A$, provided with the projection $a$, and tapering at its end, substantially as and for the purpose set forth.

4. - The combination of the plough beam A, projection $a$, yoke $\mathrm{C}$, plates $\mathrm{C}^{1}$, hooks $f$, uprights I $^{\mathrm{D}^{1}} \mathrm{D}^{2}$, with their arms $d d^{\prime} d^{4}$, substantially as and for the purposes described.

No 62,272,-S. W. JACKSON, BALDVHLE, OHЮ.Shovel Ploughs.-February 19, 1867.

The standards are laterally adjustable by set nuts in screw bars that connect them to the beam. The braces are pivoted in the beam, and standards, and the handles vertically adjustable at their forward ends.

Claim. - The counter braces $\mathrm{G}$, adjustable screw rods or arms I), provided with nuts J, in combination with the standards $\mathrm{B} C$ and adjustable handles $\mathrm{E}$, arranged in the manner and for the purpose set forth.

No, 62,302,-LEWIS G, TUTTLE, NORTH HAVEN, Conn.-Cultizators.-February 19, I867.

The plough beams are expamible laterally to vary the width of tilth; the shafts are adjustable vertically to vary the depth of furrow; the handles are adjustable vertically to suit the operator.

Claim.- The combination of the shafts $G$ and $H$, when made vertically adjustable, with the beams $C$ and $D$, when 
made horizontally adjustable, and the whole is constructed and arranged substantially as herein described,

No. 62,326.-C'IIARLES S. GWINNUT', MILROY, IND. - Cultiaturs. - Felmury 26, is67.

The handles are pivoted at their forward ends to the frame and are regulated as to height by adjustment on their supporting post. The standards are adjustable laterally to vary the width of the tilth by means of slotted hars, segment bars, and adjustable draw rods.

Claim.-I.-The stanchion $d$, constructed and operating as and for the purpose herein set forth.

2.-The standards $\mathrm{E}$ in combination with plate $\mathrm{G}$, rods $\mathrm{I}$, plates $m$ and $n$, and curved plate $T$, the whole constructed, arranged, and operating in the manner and for the purpose herein specified.

No. 62,329.-JAIRUS HASKELL, LISBON, ME.-Cultivators.-Fibruary 26, 1867.

The frame traveries on three wheels, whove holders are vertically adjustable so as to regulate the depth of the furrow cut by the ploughs, which are adjustable laterally as to relative distance.

Claim.-1.-The combination of the three wheels $l i j k$, having their gauges $i$, pivots $m$, and clamps $n$, with the elongated teeth M N P, when the same are arranged in positions relative to each other on a cultivator frame of the described form, in the manner and for the purposes set forth.

2.-The combination of the splice beams II I, with the two rear wheels $j$ and $k$, attached and adjustable as set forth, when the two beams H I are connected with the beams $\mathrm{BC}$, in the manner and for the purposes set forth.

No. 62,385.-DAN1El, R. AI.LEN, CuMBERLANI), ME. - Cultirators.-Fibrumy 26, I867.

Claim.-1.-The relative arrangement and position of the teeth $c$ and $d$, viz., upon their respective cross-bars $a$ and $b$, converging at their lower ends, in the manner and for the purposes described.

2.-The combination and arrangement of the slots and holes in the cross har, the shoulder, flange, and lip on the teeth, with the bolt and nut, for the purpose of securing the teeth.

3.- In combination with the houlder, lip, and flange on the teeth, the additional slot-and boles in the third cross bar, for the purpose of remering the tecth $e^{2}$ and fadjustable as described.

4.- The combination of the slots $p$ and $\ell$, bolts $r$ and $u$, and nuts, with the slides secured to the mold boards $s$, for the purpose of reudering the mold board adjustable, as described.

5.- In combination with the diverging upper ends of the teeth $c$ and $d$, the scooped parts $m m$ of the beam $A$, in the manner and for the purposes set forth.

6.- The combination and arrangement of the scorer $z$, constructed as described, with the hooks $v$ and pin $x$.

7.- In combination with the subject of the first and fifth claims, the rounded top I of the teeth prijecting above the frame of the cultivator, as and for the purposes specified.

8.- The concave shape to the upper part of the forward edue of the tooth 3 . when the said tooth is attached as described, for the purposes specified.

No. 62,386.-WLLLIAM J. ANDREWS, CutMBiA, TENN.-Cultiantors-Fibuury' 26, 1867.

The broad-edged shares are attached to the frame at the desired obliquity to the line of Jraft, and are succeeded by harrow teeth attached to the same frame.

Claim.-The combined plows and harrows G H applied to the stmdards F F, substantially as and for the purpose specified.

No. 62,405.- IOHN GILPATRIC, BIDDEFURD, MECultizators.-Februtry 26, I 867 .

The triangular frame has transverie bars having pointed projections at their ends, to which the shares are attached.

Claim. - The iron cross bars B, provided with tongues a $a$, and the cast-iton teeth $\mathrm{C}$, when constructed and arranged as herein set forth and for the purpose specified.

No. 62,808.-A. S. BARNWELI, SAVANNAH, GA.Cultitutors. - Warch 12, 1867.

A tranverse bar is attached under the beam, extending on each ide and carrying two adjustable standarcls and shares. A central standard and double share follow in the rear, working the balk between the furrows just made.

Clain.-The two adjustable shares $\mathrm{G}$ G, in combination with the fixed double share $D$, applied to the beam $A$. and arranged to operate in the manner substantially as and for the purpose set foith.

No. 62,97 I.-LEVI REPP, TIFFIN, OHIo.-Cultizators.

- Mardh 19, 1867.

The three-beam cultivator is expansible laterally, the central portion having a hinged rear section with a shovel thereon. Pivoted clevises connect the points of the side beams to the central. The handle supports rise from the central beam.

Claim.-1.-The construction of the central beam A of a three beam cultivator with a jointed extension $A^{\prime}$, having a shovel applied to it, and also a spring 5 for keeping it down and staying it laterally, substantially as dencribed.

2.-Pivoting the front ends of the three beams A B B to $\mathrm{U}$-shaped clevis plates $a a$, substantially as described.

3.- The construction of the shovels $m$, with narrow and wide wings, and so that they can be reversed at pleasure, substantially as described.

4. - In combination with the forwarl pivot connections of the three beams A B B the lateral extension braces $\mathrm{CC}$, and stilt standards $\mathrm{E}$, connected to beam $\mathrm{A}$, in front of the joint $d$ by a bolt $e$, substantially as described.

No. $6_{3}, 430 .-T H E O D() R E$ B. ROGEKS, WeTHERSFiEl.n, ConN.-Cultiontors.- - April 2, 1867.

The cutter is obliquely set, and is secured by posts to the frame; the depth is regulated by bearer:

Claim.-The frame $\mathrm{A}$, arm $\mathrm{B}$, posts $\mathrm{D}$, in combination with the blade $\mathrm{E}$ and bearers $\mathrm{F}$, substantially as and for the purpose described.

No. 63.534.-C. G. LATHROP, SAN JusE, CAl..Heed Cutters.-April 2, 1867 .

The $\mathrm{V}$-shaped horizont al cutter has hooks on the ends of its wings, and is secured $t$, a standlurd beneath the plough beam which is supported on wheels.

Claim.-1.-A weed cutter made and operating subutantially as berein shown and described.

2.-The V-shaped horizontal cutter 1, provided with knives $K$, at its ends, subutantially as and for the purposes herein shown and described.

3.-The circular revolving coulter $G$, arranged in front of the plough leam in combination with the cutters $I$ and $K$, all made and operating substantially as herein shown and described.

4.- The adjustable draft attachment $\mathrm{E}$ and $\mathrm{F}$, in combination with the cutters $(\mathbf{I}$ and $\mathbf{K}$, as set forth.

5.-A weed cutter so con-tructed that either the knives or the wheels on which the whole device is supported can be adjusted up and down so that the cutters can be brought more or less into the ground.

No. 63,610.-RAINSFORD CANTELON, IINTGOMER Y, ALA.-Ploushs.-April 9, 1867.

The vertical circular frame has perforations for attaching the plough shank and beam in front, and the handles and adjusting arm hehind. To the arm and shank are attached perforated curved bars, to which cultivator or harrow teeth can he bolted.

Claim.-The rim wheel A, constructed in the manner berein represented, or in any other manner substantially the same, when used with the necessary devices for forming a plough, as herein specified.

No. 63,717.-ALEXANDER GORDON, RochesTER, N. Y, assignor to H. D. GORDON, same place.-Cultitu tors.-April 9. 1867

The middle plough has adjustable wings; the rear ploughs, one on each side, are pivoted to the cross-bar and are later ally adjustable by brace bars which connect them crosswise to ezch other.

Claim.-1. - The adjustable or swinging clamps $a$ in combination with the nould board $B$, for the purpose of holding the wings $w$, substantially as shown and for the pur poses specified.

2. - The skeleton metallic cross-bar or tie C, constructed as shown and described, and arranged in comnection with the shovel and teeth or hoe standards, for the purposes set forth. 
3. The diagonal guide or extension bars \& in combina tion with the teeth hars $\mathrm{D}$, as shown and descritred.

No, 63,830-WII.L.I.I.I M. B.AI.I., MukRIS FUWN, INU. - civlizators. April 16, 1567 .

The midkle shovel standard is attached to a central heam the others are curved right and left, and stayed by rods. The handles rest upon a vertical post on the rear portion of the beam.

Claim.-1.- The arm s, provided with ‘crew threasl and nuts $t$, as described, in combination with bar $c$, for the f ur pose herein specified.

2. - The arm s, provided with serew thread aut nut 1 , 1:e bar e, handle $d$, standards ( $C^{\circ}$ C, bracen b b b and beam A when the whole are combinet, arranged and operating in the manner and for the purpone sulstantially as hercin set forth.

No. 64,086.-1)ITER ETNIER, MOUNT UNIOx, PA.Cultizators-April 23,1867 .

The rudter blade is attached to the rear end of the centre beam, and is allusted by a lever loeld in position by a rack above. The handles are attached to the cruss beams, and united by a cross-bar behind,

Claim. - The combination of the guide blade or rudder 1), placed on the rear of the projecting centre lieam b, and the handles $\mathrm{C} C$ attached to the cross heam $a b$, arranged and operating substantially ar and for the jurpose herein descrilsed

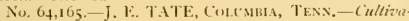
fors.-April 23,1867

The forward teeth and the scrapers are adjustable to leave a wiler ur narrower row. The clevis hook is on one side to enable the horse to walk beside the row. The coverer is a transverse bar of wood concave beneath

Claim.-1,- The adjustable scrapers $\mathrm{F}$ constructed as herein shown and dercribed, in combination with the bars ( $;$ and frame $A$ of the cultivator, substantially as and for the purpose set forth.

2.- The colton coverer $\mathrm{L}$, constructed as herein shown and described, in combination with the har $\mathrm{F}$ and frame $\mathrm{A}$ of the cultivator, substantially as and for the purpose set forth.

No. 64.370-1 INSELL P. ROUTT, LIHETY MIILS, VA.-Cultivators - April 30,1867 .

The adjustable and reversible share is secured by loop and liey upon the curved sheath whose point enters a hole in the back of the shovel to steady it.

Claim.-The changeable, reversil,le, and adjustable share secured by loops $G$ and heys or wedges $\xi$ upon the curved sheaths or shanks $\mathrm{C}$, whose points enter the holes or notches in the shovel or plourh to secure and steady it in any posi tion in which it may be adjusted, substantially as set forth

No. 64,429.-AliRAHAW P, KING; CAMDE, ()нIо,Cultinutors. - May' 7,1867 .

The two ouler cultivator, are coupled to the two inner one; by horizontal pieces, ard have laterally-projecting independently-att iched blade:

Claim. - 1. The arrangement of the two ouler cultivator, FA S J F'"' $\mathrm{A}^{\prime \prime \prime} \mathrm{S}^{\prime \prime \prime} \mathrm{J}^{\prime}$, and the two inner and smaller ones $\mathrm{K}^{\prime} \mathrm{A}^{\prime} \mathrm{S}^{\prime} \mathrm{K} \mathrm{F}^{\prime \prime} \mathrm{A}^{\prime \prime} \mathrm{S}^{\prime \prime} \mathrm{K}$ ', so coupled to rether by the pieces C M I and their described accessories as to lee held rigicl, or to swing from side to side, or to be separated into two distinct double share cultivators, in the manner described.

2.-The arrangement on the inner or landside, and in rear of a cultivitor shure of one or more independently. attached laterally-projecting blales or cutter $T$, substantially as and for the purpose stateil.

No, 61,868.-JACOB HoLlinger, Millershurg, OHlo.-Cultinaturs.-May $21,18^{\prime} 7$.

The salient bend of the curved beam serve as points of attachment for the st indards which are adjustable on the beam and braces.

(laim,-The curved heam $A$, as arranged in combination with the adju-table standards B and braces E II, for the purpose and in the manner substantially as set forth.

No, 64,927.- MLBERT WII.COX, MARUGKEFA, WWA. - Shovel Plourhs.-Miry 21, 1867

The extra side shovel is atached and secured by a curved supporting lar and brace, and the equilibrium of the draft is maintained by the extra curve and size of the nigh thovel.
Claim.-The attachment of the third shovel A, by means of the curved-supporting lar $B$ to the bean $C$ of the main plough, ako the manner of equalizing the draft of said plough, by making the left hand standard of the main plough more curved and the hovel on the same a size larger, in the manner and for the purpose above set forth.

Ni. 64.967 -T. EI.ZARE (IARIINER, BRYANTUWN,

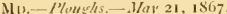

The two gang ploughs on each sicle bar of the frame throw the furrow into a ridge; drags and rollers follow the ploughs.

Claim.-A gang plongh, constructed and operating in the manner substantially as shown and described.

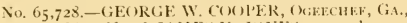
assignor to himelf and JAMIES V. JONES, same place.Horse Hoes.- Jwne 11 , is67.

Claim.-1.-A plougher hore hoe of four separate sec tions, viz: base $\mathrm{A}$, centre plate l', and thares $(\mathrm{C}$, construc ted and arranged substantially as dencribed and for the pur pose specified.

2.- The shoulders a a formed in the opposite sides of the plate 13, substantially an described and for the purpose specified.

3.- The metallic sole $\mathrm{I}$ secured to the bave plate $\mathrm{A}$, for regulating the depth of furrow, substantially as described.

No, 65,847.-THOMAS P. WARREN, N⿴RFH.K, VA. assignor to WVARREN \& W(O()I)II()USE, same place.Combined Cotton Ploush and Siraper.-Jumi is, is67.

Side scrapers and sharen are attached to the sole har in rear of the broad share to adlapt the machine to different phases of corn or cotton cultivation.

Claim.-1, - The standard 1; having the broad flange $x$, the siots $b b$, and the ar $u=$, sub-tantially as and for the purpose dencrilsed.

2.-The combination of the standard li, and the flanged supjorting attachment $C$, sub-tantially as and for the purpose specified.

3.- The scraper guide $\mathrm{K}$ attached to the landside in the manner and for the purpose alove shown.

No. 65,877.-GEORGE IV. C()I'ER, ()EECHE, GA. assignor to himself and JAMES V. J()NES, HER NIIIN, Gi. - Rice Cultizators.-June 18, 1867 .

The plough beams are adjustable laterally to the rear of the frame. The plough are attached to standarts having brace bars running from their lower ends, and are followed by curved teeth.

Cluim.-1.-The combination and arrangement of the braces $\mathrm{F} \mathrm{F} \mathrm{F} \mathrm{F}^{\prime}$, the lream $\mathrm{A}$ \& $\mathrm{B}^{\prime}$, and the braces $G \mathrm{G}$, substantially as and for the purpose described.

2.- The methot alove described of fastening the teeth $\mathrm{E}$ E E to the heams by two bolts, situated oblipuely to the grain of the wood, substantially is and for the jurpose ipcified.

3.- The indining and bencling of the cultivator teeth $\mathrm{E}$ E outward and backward upon the point of attachment to the beams A B B', substantially as and for the purpose described.

No. 66,284--HENRI F. IENENDEFER and (iEO.

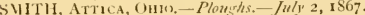

The notched bar and spring catch allow oscillation of the plough standards

Claim.-1.- The bar D, spring catch $c$, and spring $g$ when used for shifting the standards, - ulstantially as yecified.

2.-The arrangrement of the beam $A$, bars $d f$, standards, $\mathrm{B} \mathrm{B}^{\prime} \mathrm{B}^{\prime}$, with their ploughs and the roller $b$, when constructed, arranged, and used in the manner subutantially as set forth.

No. 66,335.-JAMES M. HAWIEV, IIUTON, IND. Plus lis.- $7 u$ ly 2,1867 .

The plourh stamdards have side bends by which they are attached to the plough beam when used in double-shove form. When three shovel are userl these standards are attached (1) side hrackets and an additional plough added. The scraper may be attached to the frame by standarls.

Claim.-1.-The standards $\mathrm{H}$ and E, constructed sul. stantially as herein described, in comlination with the shovel $K$ and $G$ and beam $A$, in the manner and for the purpose set forth.

2- The combination of the handles $B$ and forked and 
Jutfed connecting bar $($ with the beam $\Lambda$, substantially as herein shown and described and for the purpose set forth

3.- The combination of the bent bars or frame M with the beam $A$ and standard 11 , substantally as herein hown and de-cribed and for the purpose set forth.

4.- The combination with the scraper plate $P$ with the forwart standarts 11 , substantially an herein shown and de scribet and for the purpose set forth.

No. 66,310.-STEPHEN H. HERRICK, GRINNEI.L, Iowa. - Culliziators.- Fulv 2, 1867

The metallic standards are turned forward in a horizon tal direction and pivoted to the rear end of the beam The fore end of these longitudinal bars meet in a vertical screw which passes through the beam and is adjusted by set puts.

Claim.-The frame $B$, turned $m$ p and threaded at its forward end, and connected to and regulated at the rear end of the beam by the bult 1), as and for the purpose set fonth.

No.66,495.-HANFORD 1NGRAHAM, N.IILE, N. I - Culliñators.-Julv 9, IS67.

The borse is harnessed to the thills, and hitched to a hook attached to the central plough. The side ploughs are adjustable laterally.

Claim.-I. - The arrangement of the standards and cross bars with the moully or shares, as constructed, in combina tion with the thills, substantially in the manner and for the purpoves as herein descrilsed.

2.-The adjustment of the shares to the required angle by means of adjustable plates with flanges, substantially in the manner and for the purposes herein described.

3.- The arljustable claspe in combination with cross-bar $\mathrm{E}$, the thills, rods, standards, and hares, substantially in the manner and for the purposes as herein described.

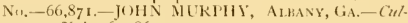

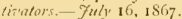

The beam are laterally ad,unted on the transverse bolts, to which they are secured by nutr. The plough standart. art attacherl to the beams and securesl with braces above and below. An adiuntable wheel in front regulates the draft. A hlacle with an extension arm is attached for hol low plowing on cotton l.muls.

Clum.-1.-The construction of the frame $\mathrm{A}, \mathrm{B}$, and $\mathrm{C}$. in combination with the plough leams $F$, secured thereto substantially as and for the purpose described.

2. - The plough $\mathrm{S}$, with its arm (2, substantially as and for the purpose sirecifiel.

No, 66,595.-F. MARION SIIIET.DS, MArov, MIS. - Cillon Ploushs or Ciultizalors. - Fuly 16, 1867.

The triangular, convex, side-plated hoes are attached ly stockito a horizontal beam, to whose tongue a team is attached.

('laim.-1.- The hoes 1$) d d^{\prime}$, when constructed in the manner and for the purpose herein described and repre sented.

2.- The combination of the hoes D D D, beam A hanks or stocks E E, draft tongue or beam 13, and handles $C C$, all arranged substantially in the manner and for the purpore set forth.

3. - In comlination with the above the fenders F F, appliet in the manner and for the purpose set forth.

No. 67,430.- $\$$ AMUEL L. HEISEl, WEST DUNEGAI. I'A.-Cullizators.-Anzast 6, 1867

The tongue is pivoted with the hammer lunt, and when the butt of the tonsue in raised by the lever out of the reces: of the semi-circular slicle plate it will swing about onequarter round befure turning the cultivator.

Claim.-The arrangement of the sliding plate B with it graide $c$, recess $b$, in combination with the lever $D$, and springs $\$$, $x$, all arranged and operating substantially in the maner and for the purpose specified.

No,-67,522.-JOHN FRANK, WEBSER CITy, UUWA. - Cultinuturs.-August 6, IS67.

The outer legs turning in their loands are adjusted by the transferrence of the hooks from one staple to the other to present the shovel towards or from the plants.

(laim.-A cultivator or shovel plough, having the leg $A$, staple B, strap C, staples D D, hook E, and staple F, arran ged, combined, constructed, and operating substantially as described.
No. 67,595-S. F. SHFLEV, SILVANIA, ()HL,-Ciult tors and Ploushs.-August 6, 1867

The line of draft in regulated by the sliding link in $\mathrm{com}$. bination with the share and wings, which are adapted to constitute it a cultivator or billing plough.

( laim,- The juinted draft rod 1, adjustable link (; heam A standard $C$, with oblong slot $d$, brace $\mathrm{D}$, handles $\mathrm{B}$, share $\mathrm{E}$, wings $\mathrm{F}$, cross rod $c$, and brace rods $a^{*}$, combined, arranged and operated substantially as described for the purpose specified.

No. $67,8+3 .-A N D R F W$ CANFIELD, LYoNs, IowA.Corn Ploushis.-Aurust 20, 1867.

The two side beams are jointed to backward projections from the central beam, to which the single-tree is connected, and are adjustable trantyerely ujon lateral stays of the beams and handles.

Claim.-The adjustable beams A A, with joint at B, and the open link $\mathrm{C}$, also the slotted bar $\mathrm{D}$, with the clamps $\mathrm{E}$ E, when constructed, arranged and operating subitantially as and for the purposes above set forth and described.

No. 67,84.--ANIIREW CANFIEI,D, LYoNs, Jow .-Corn Ploushs.-August 20, 1867.

The side heams are so hinged by the double bolted clev. ises, to the central frame as to lue adjustable laterally or removable therefrom.

Claim.-1.-The touble bolted clevis B, lar the purpose descrilued.

2.-The adjustable stay lar 1), for the purpose abose described.

3.- The combination and arrargement of a one horse corn plourh that may he readily changed to any, required width, also changed to any number of shovels, from one to three, making a single, clouble, or three shovel plough.

No. 67.917.-GE()RtiE W. SAWIN, NAsHuA, N. 11.Horse' Hoes.-August 20, 1867.

The frame is extensible at the rear end, its side beams being pivoted in front; and it has a detachalile rake hingel to the rear.

Claim.-1.- The combination as well as the arrangement of the rake I with the blades $\mathrm{D} \mathrm{I}^{\prime} \mathrm{A}$ and $\mathrm{A}^{\prime}$, made substantially as described and for the purpome set forth.

2.- The combination and arrangement of the gathering in blades $A A^{\prime}$ with the blades 1$)$ and $D^{\prime}$, made substantially as described and for the purpose set forth.

3.- The combmation of the movalble blade $B$, with the adjustable bars ('and C', made substantially as described and for the purpose set forth.

No. 68,392.- JAMKS P. ST INTON, PEDRICKTOWN, N. J.-Polato Ploughs. - September 3, I 867.

Sitle plough turn the earth and the double mould board plough turns the potatoes out. The side plou sh beams are connected by bars to the central beam, and the bar are inclined, more or less, for lateral adjustment.

Claim. - $\mathbf{t}$ - The employment of a hand lever for shifting laterally the side ploughs, substantially as described.

2.-Such lever combined with devices for locking the same in different positions.

3.- Such lever combined with a slide commected with the side plongh beams.

4. - Such lever combined with a side spring, operating as a self acting locking rlevice.

No. 68,670.-JOHN R. TIIOMAS, MIFFintown, PA. Corn Ploushs. Siph'mbir to, 1867.

The pivoted standards folk up under the frame when the plough is moved from place to place.

Claim.-1. - The plough points $d d$, having the form above described, substantially as and for the purpose specified.

2.- The method of adjusting the direction of the ploughs, above descrilsed, by means of the bolts $G \quad G$, the braces $F$ $\mathrm{F}$, and the hotes $i i^{i}$, passing in different directions through the side beam $13 \mathrm{~B}$, sulmantially as and for the purpose described.

3.-The washers 1111 , substantially as and for the purpone specified.

No.68,901.- WILI.IAN RICIIARD.AON, HuoksTuWN W1. - Plozsths. - September 17, IS67.

The rear plough standards slide vertically in boxes which slide laterally along a transverse rear bar of the frame. 
Claim. 1.- The buxes $1 \%$, sulmantially as and for the purpose tlescribed.

2 -The graduated heam i, for the purpose speci lied.

3.-The graduated plough shank or plough stanilards 6 ; $C^{\prime}$, for the purpose specified.

4. The arrangement of the removable plough $\mathrm{E}$ with the act ustable and removalik plough $\quad i(i$, sub-tautially as and for the purpose specitied.

5.- The combination of the plough shanks $f^{\prime}\left(i^{\prime}\right.$, the

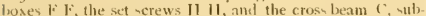
stantially as and for the purpose specified.

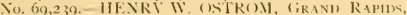

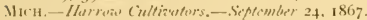

The teeth are secured tis the rear emd of the ban that are hun: upou a frame supported by wheels in front. The teeth rise and fall with the inequalities of the ground and are adjusted by the levers above.

Claim. - The combination of the frame A mounted on guide wheels $\mathrm{B}$ B, the bar a a suspended on the crosi-rod $b$, the movable cross bar $d$, and the crom laar $m$, attached to the handles $k k$, arranged and operating as and for the purpuse specified

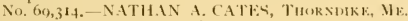

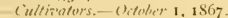

The coulter guites the front of the machine and stirs the sround, while the scraper clear the yace between the furrows mate ly the ploughs, which throw the earth outwarls to form a rilge that is umo thed by their overlying wings.

Claim.-1. - The combination of the central leam, carry. ing the arljustable roller, the coulter an I the scraper, with the l.tterally adjustable beans, carrying the ridging and moothing ploughs, the combination being and operating substantially as ilescrilsed for the purposes net forth.

2.-The combination with the scrapers of the Paterally adjuntable ploughs all constructet and arranged for joint operation, as described.

3.- The laterally adjustable furrow turning and ridge smouthing ploughs, constructed and operating as described.

4.-The combination wib the central beam and coulter of the clevis bracket and arlju-table yoke carrying the leading roller, all constructed, arranged, and operating as described.

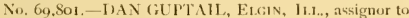
himself and H. N. MOSEl.K., same place.-C'uttivators. - Oclobir 15, 1S67.

The teeth of the cultivator are pliable and are supported in the rear by pendent bars, which limit their backward motion.

Claim.-The elastic or spring-shovel 1;, in combination with werlge or key L, substantially as anl for the purpone set forth.

No, 9,087.-DAN (;UPTA11, F.L.1N, Ir.1.., assignor, by mesne assigmments, to CHARLE. I.A IX) (original number 69,Sor. - Cultizators.-Oitober 15, 1867 . Re-issued Filumary 17, 1SSo. [Filed Dicimbir 13, 1S79.]

Claim - 1. The combination, uhstantially as hereinlefore set forth, of the frame and spring shosel which support it and are adjuntable relatively thereto, wherelsy the dej th of cut and extent of vibration of the shovels miy lie regulated.

2.-A $\mathrm{V}$-shmed frame having spring-shovels monnted thereon.

3.- The combintion, sulstantially as herein before set forth, of the pivoted frame-lars, spring-shovel mounted thereou, ani mechanism, subatanially such as described, for adjusting the bars relatively to each other.

4.- The combination, sulutantially as hereinbefore set forth, of the frame and ranks of spring thovels supporting the frane, the shovels in each rank being arranged one in advance of the other.

5.-The combination, substantially as hereinbefore set forth, of the frame, the spring shovels mounted thereon and arranged one in advance of the other, and support for resisting rearyard strains upon the shovels.

6.- The combination, substantially as bereinbefore set forth, of the frame, the spring-shovels having houks upon their upper ends, and wedges or locking devices for securing the shosels in place.

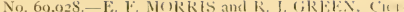

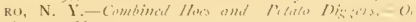
whit I $5,1867$.

The double-mouldboard plough is associated with bovel ploughis on taterally adjustable beams.

Claim.- The swinging beam $13, a n d$ wings or shares $F$ connected with rieling links $f f$, in commetion with

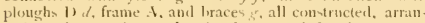
geel, and eprerating as herein shown and for the purpose set forth.

No, 7,157-F, F. NGRRIS and R. I, GiREl:N, CIG ko, N. V., asuigners, by mesne assignusents, to T. R. P() R

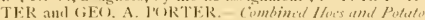

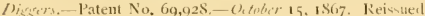
Junt 6, IS76. [Filed -1pril IS, 1876.]

Expansible heams carrying plouglu, and expansible inner wings linked to the beams.

Claim.-The expanding side beams li, bearing the ploughs $I) d$, and the expranding wings $F$, jointed to the shovel-plough $\mathrm{E}$, in combination with the main leam A, con structed, arranged, and operating subutantially as herein shown, and for the purposes described.

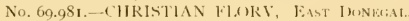

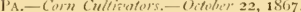

The metallic beam are pivoted to the tongue at their fore ends, and are adjustable befween vertical lxols in cros beams.

Claim.-The specified arrangenent of the pole $A$, thovel beams $\mathrm{E} \mathrm{F}$, straight cross-bars [) D, with the screw loolis $d$, notched and terninal, traight edged shovels $s$, all con structed and combined in the mamer and for the purpone yecified and shown.

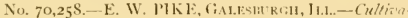
tors.-Oitwer 29, $1 \mathrm{~S} 67$

limprovement on W. II. Smith's patent, January 15,1861. The pivoted shovel 4 tondards are laterally aljusted in the lotted bows attached to the beams. The landles are at justed and secured by hooked bolts. The standards are st cured with rods nearly on the line of draft.

Claim.- I. - The combination of the plate $S$, jaws $R$, and coiled spring $U$, with the pivoted catch block $P$, anil standarl F, substantially as herein shown and described for the purpose set forth

2.-The hinged plate $\mathbb{W}$, and springs $\mathrm{X}$, in combination with the cross beam $\mathrm{B}$, and tandards $\mathrm{F}$, unlutantially as herein shown and descrilsed and for the purpose set forth.

3.- The combination of the lrace bar 11 with the benm $A$ and crous beam ( $;$, subsantially as herein shown and describerl and for the purpose set forth.

No. 70,472.-T. RICE and 1.UKE R. IITTCIIC) Caneatrea, N. Y:-Horse Hoes. - Tirember 5, IS67; ante dated Oitober 13, 1867 .

The handles are connected together hy a pivoted har and bent springs to allow oscillation to regulate the space worked.

Claim. - The combination of the curved perforated braces and hoe, as shown in Figs. I and 2, for the purjose of cul tivating garden and field crops in the best and most desirable manner.

No. 70,57 S.-S. A. KR()NER, New lintTAIN, PA.- Cullizators- Norember 5, 1867 .

The sections of the movable frame are attached by holtand metallic plates. The draft is regulated by the point of attachment of the frame on the heam. The handles are pivoterl in the middle so as to rotate and work from either end. The long clevis is attiched to the hook on the pivot bolt of the handle.

Claim.-1.-The Irestle 11 , in combination with the bandles $B$ and be:m A, for the purpose of bifting the handles, in the manner and for the purpone specified.

2.-The movable sides $C_{\text {and }} C^{\prime}$, in combination with the plate; $D$ and $F$, the slide $E$, and pin $G$, in the manner and for the purpose set forth.

3.-The arrangenent of the thares $K$. in combination with the movable sides $\mathrm{C}$ and $\mathrm{C}^{\prime}$, plates $\mathrm{F}$ and $\mathrm{D}$, slide $\mathrm{F}$, trentle $H$, and clevis 1 , in the manner and for the purpose set forth. 
No. 70,785-ALFRED C. BELT, Goresville, VA.Cultizators.- Viezember 12, 1867.

The culivator tecth are ranged in revened positions, hav ing their mould boards presented to opposite sides. The mould boards are perforated to pulverize and sift the soil. The coulter is adjusted to the reversed position of the land side.

Clain,-1.-The reversed arrangement of the alternate teeth of the cultivator, as described.

2. - The cultivator teeth arranged in reversed positions, as described, in combination with the adjustable coulter.

3.-The grooved or recessed beam, in combination with the Hanged teeth secured thereto, as described.

4-The forwarcl tooth, provided with the perforated sifter mold board, in combination with a following touth having the reverned arrangement described, for the purpose set forth.

No.-70,972,-JUNAT11AN B. DAV1S, UCKAY, Онเо. - Ploushis, - Vorember 19, 1867.

The frame is of iron, and the sides are binged together so as to admit of single vertical muvement, or of a side inclination of the whole frame.

( lain.-1, - Forming the beams A B, standards E, brace bar, ( $;$, and handles II, and adjustably connecting them to each other, snlstantially in the form and manner berein shown and de-eribed and for the purpose set forth,

2.- The combination of the jointed or pivoted bars $\mathrm{C}$ and I with the beams $\mathrm{A}$ and $\mathrm{B}$ and handles $\mathrm{H}$, substantially in the manner herein shown and described and for the purpose set forth.

No. 71,152,-IOIIN IV ERNST, HEIDEIGERG, PA.Adjustuble Cullizators.- Non'ember 19, 1867.

The four cutside bars are binged together, and the frame adjusted in which by a diagonal draft har, which bas movement between the fromt hars. The front bars have harrow teetb and the rear bar, have cultivator teeth.

Claim.- The diamond-shaped cultivator joined and adjust ed as berein described, when combined with the teeth, shovels, and regulating clevis, for the purposes set forth.

No. 72,004. - IVM. UUFFNER, PETERSHURCi, INU, Cultizators.-December 10, 1867 .

The shaft is aljusted ly varying the elevation of the wheel; its hinged supporter are acusted by the hind lever in the rear.

Claim.-The cultivator, composed of the elements A 1 $B^{\prime}$ C D E F H I J $N$ and the device for regulating the depth of the shovels, composed of the elements G KI II $\mathrm{P}$, all constructed and arranged as set fortb.

No. 72,227.-CHARI.ES B. PETTENGII.L, IJERRON, MF.., assignor to FREEMAN C. MERRILI, I'ARIS, NE.Cultivalors, - Detember in, 1867 .

The side lar are binged in front and expansible. The fore end of the frame has a curved heam giving support to a wheel. A longitudinal ground bar rmo backward from the front plougb.

Claim.-1.-The circular draw beam $A$, having the whee straps $a^{3}$, draft bars $a^{2}$, socket $a^{3}$, and ears $a^{4}$, cast solid there with, substantially as herein shown and described.

2.- The combination of the bent adjusting rod $F$ with the front tooth $\mathrm{E}$ and with the central bean $\mathrm{C}$ of the culti vator frame, subitintially as berein hown and described and for the purpose set forth.

3 - The combination of the ring bolt 1 , curved adjuating bars $\mathrm{H}$, and beams $\mathrm{C}$ and $\mathrm{D}$ with each other, subutantially as berein shown and described and for the purpose set forth

4.-The comlination of the hent adjusting rods $F$, circula draw beam $\mathrm{A}$, and teeth $\mathrm{E} \mathrm{K}$ l, of different length with eacb other with the beams $C$ and $D$ of the cultivator frame, substantially as herein shown amd described and for the pur pose set forth.

No. 72,560 - CHAR1.ES F. STORRS, W. E. KEVES, and DAVIl, W. JoNES, Grandili.1.5, Mich.-Cultizators.-Dicember 24, 1867 .

The shares have "jumping " cutters attached to their up per side to enable them tor ride over roots in plowing new ground.

Claim.-1,-The scoop-shaped plough - D, for cultivators, substantially as and for the purpose shown and described.

2. A scorop-shaped cultivatur plough $D$, secured to and forming part of a coulter or cutting edge C' substantially as and for the purpose shown and describerl.

3.-Tbe ploughs 1 , in combination with the V-shaped frame, substantially as and for the purpose shown and described.

No. 73,087,-WILlIA.M FRANT\%, PINUA, ()нIо.Cultizators. - January 7, 1868 .

Claim. - The combination of the standards $\mathrm{D} 1 \mathrm{y}^{\prime}$, and shovel plougbs $\mathrm{E} \mathrm{E}^{\prime}$, adjustably attached to cross beams $\mathrm{C}$ $\mathrm{C}^{\prime}$, and the adjustable rake $\mathrm{F}$, arranged to operate substantially as set fortb.

No, 73,231.-HIRAM C. CHANDLER, ERIE TOWNSHip, IND, - Shovel Ploushs.- Fumuary 14, is68.

The two fore standards are removable and are adjustable vertically by slotted brace rods, and laterally by the wedge block, wbicb in inserted between the standards and leneath the beam.

Claim.-1.- The notched beam D, for the purpose of ad. justing the handles to the desired height by a bolt passing through them and the notch.

2. - The double-slotted wedge $\mathrm{F}$ and methor of applica tion at the point $G$ under the beam between the standaris B H, to adjust them as to width, and the slotted rods E E securing a forward or backward movement of the standards B $B$ and the shovels attacher thereto, and fastened to the leam in the slots by a bolt or other similar device.

No. 73,945,-F. N. BARRIER, SIEVENSIN, AT.A.Cultizutors, - February 4, 1868 .

Claim.-The construction, arrangement, and combination of the central beam A with its shovel of plounh, the side beams $\mathrm{C} \mathrm{C}^{\prime}$, with their shovels or ploughs, the $\mathrm{U}$ or archshaped brackets E E, and braces $a c$, all as and for the purpose described.

No. 73.988.-JAMES W. MII.RON, G.ALVESTUN, INICorn and Cotton Cultivators.-Feliruary 4, 1808

The outer shares are attached to las which are pivoted to the fore end of the heam and connected hy toggle lever: to a notched hand lever by which they are transvernely adl. justed

Claim.-The movable arms 1) D, toggle jointed lever E, he. $\mathrm{m} C$, notched lever $\mathrm{F}$, rod $\mathrm{G}$, key $g$, circular frame $A$, and self-arljusting hoe shovels B B B B B, the whole as constructed and arranged, substantially in the mamer and for the purpose as herein set forth.

No. 74,005-ANIIREW RUNSTETIER and Al BERT WINDECK, PForis, ILL. Cotton Plowghs and Cultizators.-Fibrainy 4 , $186 \mathrm{~S}$.

The fore ends of the side plough beams are connected by universal joints to the frame to which the tongue is attached. The side beams are connected to rether and to a centra removalue bean liy trinsvere bars which allow later.l adjustment.

Claim.-The construction, combination, and arrangement of the frame pieces A B C, the iron gauge pieces $\mathrm{D}$ E F, hook and ring, and removahle shovel $\mathrm{M}$, aratcached to the beam or piece $B$, all as shown and for the purposes deseribed.

No 74,031.-11. B. ARNOLI)T and JOIIN GRIMII,

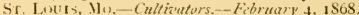

The baniles are pivoted to the beam, and slide on a seg mental bar upon the rear end of the beam. An adjustable additional draw bar is provided for deep ploughing.

Claim.-1 - The weed cutter C, when combined with a cultivator A B, as and for the purpome berein shown and deserilied.

2.-The movable arm $A^{\prime}$, when combined with the plough lieam $A$, as described, and for the purpoie set forth. 3.- The plough handles $A^{3}$, and the curved rack $A^{4}$, for the purposes berein set forth and described.

No. 74,032.-ISAIAH 13. ARTIILR, SIIUNSHX R6, PA. - Conen Plonerle and Cultizatos:-Fidruary to is68.

The central bandle is fixed, lut the other handle is hinged at the fore end and attached to one of two sicle post: to allow the operator to walk upon either side. The cross bars have slots traversed by bolts passing through the lieams loy wbich the beams may be adjusted, and secured firmly Ly engaging corrugation, on the burs and beams.

Claim.-1. - The combination of the fixed centr.3 handle E with the shifting adlustable hanlle $\mathrm{E}$ :', when used in a 
corn plongh and cultivator, ubstantially as and for the pur pose sprecified.

2. The wire guard $C$, when constructed in the form shown, hinged at it rear end, and alfowed to rine and fall at its forward end, and, when held in po-ition by rods $c^{\prime} c^{\prime}$ at its forward end, preventing the two gu rde from changing their parallel position to exch other, subsentially in the manner and for the purposes set forth.

3.- The corrugatel plates $c<$, when used in combination with the sicle beams $A^{2} A^{3}$, having corrugated ends, subst $m$. tially as and for the purposes indicated.

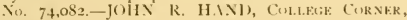
()H10, assignor to himself and JOIINSON ()RR, same place. (ultiraturs - Feliruary 4,1 S 8 .

The fore end of the heam laps over the rear end of the tongue, and is pivoted thereto. The rear end of the tongue carries a rectangular strap-ring in which the beam has vertical ad,ustment lyy a screw The tandards are secured to cross-bars, the lower pair of which are adjuntable in a frame at the rear end of the be $u$. The stanilardiare adjustable laterally upon the bars.

Claim,-1.-The dran tht pole If, capalide of atjustment upon the beam $A$, by mians of the clevis () and screw $]^{3}$.

2,-In combination with the element of claim firs, the shares $\left(i G^{\prime} K K^{\prime}\right.$, and handles $R R^{\prime}$, adjustable in the manner set forth.

No. 74.344.-THOMAS GREEN and JACO! SOMI UEK, MHTAMURA, JLL.-Cultiontors.—Fibuty' 11 , IS 1 S.

The ends of the singletree are connected by chains to the sides of the cultivator, and will assist in turning the lat ter.

Claim.-The combination of the adiustable pivoted draught rot ( 'and acljustable drau ht chain $\mathrm{E}$ with the

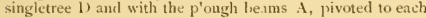
other at their forward encls, subtantially as herein shown and described, and for the purpose set forth.

No. 74,441 -JOSEPII SNYI)ER, Rock LICK, IV. VA - Civltivaters.-Fibruary 11,1868

Claim.-The cultivator, constructed with the curved main beam $\mathrm{A}$ and curvel supplemental beam $\mathrm{B}$, shares $c d$, handles $\mathrm{C}$, and braces $f, g$, and $m$, the whole arranged substantially as and for the purpose specified.

No. 74.721,-B.F.RE.M, AIB, ()HIO,-Shon' Plonghs and Cultizators.-Fibruary IS, 1868 .

The side leams are connected to the central beam by a transverse bar, and are either or both removable.

Claim. - The gauge beam E, constructed substantially a describe, In combination with the beams $\mathrm{A}$ and $a$, guidebar $\mathrm{G}$, shovels or ploughs $\mathrm{C}^{\mathrm{C}}$ ', or any of them, and coulter D, substantially as an.l for the purpores set forth

Vo. 74.775 -C. F. TAYLOR, VASSAL'BORO, M E.-Cultiziators.-Feliruary 25, 1868

The bar of the A-shaped frame is connected with the apex by a centre piece and the flaring shovels thrown inward.

Claim.-The $\mathrm{A}$-shaped cultivator $\mathrm{A}$ with its centre piece $a$ and cross piece $a^{\prime}$, in combination with the teeth $b$, ro arranged as to throw the earth inward, as and for the purpose described.

No. 75,185.-JUIIN NEFF, Jr., Pultney, N, Y.-Cultizutors - March 3,1868 .

The draw bar and the handles are adjustable sit as to work the plough with either side coinciding with the line of draught. The fore end of the draw bar is supported on a spring.

Claim,-1,-The dr ught ro I B, when made and applied and supported by a spring, an specified.

2.-The method of fastening and ad usting the handles by means of the support $\mathrm{E}$, as set forth.

3.- The teeth F, G, II, I and I, when constructed and arranged substantially as specified; also, the furrow board, when made and ajplied to the teeth substantially as set forth.

No. 75,211.-DAVID S. SLATER, PoYNET I, WIS.Cultiziaters.-Warch 3, 1868 .

The frame is constructed of iron, and has a central and two later.ally adjusted side ploughs. The sule ploughs are so clipped to the standarils that they may be set sideways, more or lcsi, to throw the soil in the required direction.
Claim.- I cultivator constsing of the central bar $A$, h.wing the adjustal,le handles $C$ and the rigid share ()$^{\prime}$ at tached thereto, in combination with the laterally acljustable ide bars 13 , having the adjustable shares $\theta$ secured thereto, and afl arranged to operate sulstantially as shown and de serilied.

No, 75,718 . - W. R. ADAMS, IXDEPENDINC, Mo.Corn Cullizators, - 14arch 24, 1868

The beams are connected to a draw plate in front and to a hinged cross bar at the rear. The outer plough have adjustable commection to the traw plate, and their standardis are connected by an aljustable cross liar which is hingeil to them by ring bolts.

(laim.-1.-The semi-circular-shaped plate $a$, sulstantially as described and for the purposes set forth.

2.-The cross piece D, as describel, and for the purpose set forth.

3.- The adjustable slides $E$, substantially as described, and for the jurpose set forth.

4.- The combination of these three ploughs, the plate $a$, the cross piece $\mathrm{D}$, and the slide $\mathrm{E}$, sulstantially as described and for the purpose set forth.

No. 76,412.-G. IV. I)EWEESE, Lin, OнI,-Cultivators.-1prit 7,1868 .

The end of the handles have each a cross har having a series of adju-ting bult holes by which, in combination with a pivot bolt, the handles are vertically adjusted.

Claim. - The adjustable arms $C$ and handles $a$ combined with the dranght beams of a cultivator, sulstantially as and for the purpose set forth.

No. 76,687.-GEORGE W. ZEIGILE, MAUNEe, OHIO -Land Tillers._. April 14, IS68.

The plough; or cultivators are adjustably connected to the beam, ant the beam may be so adjusted in relation to the draught attachments and handles as to plough a wider or narrower furrow.

Claim.-1.-Providing a single leam A, carrying a gang of ploughs or shovels, with a draught rot $\mathrm{D}$, which is pivoted at or near the middle of the length of said beam. and supporteci at or near its front end by means of a laterallyvibrating beam L, substantially as described.

2.- Supporting the fromt end of a draught rod D, which is pivoted to the eye $h$ of the intermediate stock $\mathrm{B}$, by mean of a hterally and vertically-adjustable segmental clevis $\mathrm{N}$, applied to the beam L, substantially as described.

3.- The adjustable casting $G$, provided with the standard and ad ustable standards / / for sustaining the handles I, and allowing these handles to he secured at iheir front end by means of a clamping bolt $j$, substantially as described.

4.- Providing for adjusting the handles $J$ of a singlebeam plough in line with a dranght rud $\mathrm{D}$, by means of devices $\mathrm{G}$ and $\mathrm{L}$, which are arranged to operate substantially as described.

5.-A metallic standard tock and holder B, constructed with a curved front edge $b$, a wwelled corrugated surface head $\epsilon_{\text {. and a slot } g}$, substantially as decribed.

6. - The wooden shovel carrying standard $\mathrm{C}$ applied to a stock $\mathrm{B}$, substantially as described.

7.-The construction of the clevis $\mathrm{N}$ of a segment form, with a notched flange $t$, and also with perforations throngh it for receiving the draught rod $\mathrm{D}$, substantially as deveribed.

8 - A single-beam gang plough which is provided with laterally-adjustalle shovel standards B C, laterally-adjustable hindles $\mathrm{J}$, a vertically and laterally-adjustable clevis $\mathrm{N}$, a laterally-adjustable arm or beam $L$, all arranged substantially as described.

No. 76,736.-I. G. FLISHER and E. M. BATES

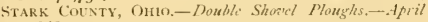
14,1868 .

The sole is hinged at the toe and its screw threaded rear end turned up and passed through an eye in which it is adjusted by nuts.

Claim.-1.- The adjustable sole I E, constructed and arr.nged substantially as and for the purpose set forth.

2.- In combination with the adjustable sole D E, the slide $g$, and nuts $f h$, arranged and operating sulstantially as and for the purpose described.

3.-The eutters or knives at a wen usert in combmation 
with the novel a, substantially as and for the purpose decribed.

No. 77,176.-MARTIN DARLING and IIALA GRAI Marithon, N. Y.-Cultizaters and Potato Diggrets Combined.-April 28,1868

The earth is thrown outward from each side of the potato row, and the potatoes raised by the inclined rake.

Claim - The frame A $a$, oblique cultivator rake B $b$, laterally-adjustable plough $\mathrm{C} \mathrm{C}$ and adjustable supporting wheels and standards $f$, all combined, constructed, and arranged as herein shown, and for the purpose set forth.

No, 77,260--ANDREW I. CR.AIG, AsHMORE, II.I.Double Sheritl Plowshtis.-April 28, 1868 .

The handles and plough standards are pivoted to the beam, and the latter terminate at their rear in perforated segments, which permit the vertical adjustment of handles and standards.

Claim.-1.-Adjustably attaching the plongh standards 1) to the rear ends of the he ims $A$, by mean of the vertical cross heads $a^{\prime}$ formed upon the said rear end of the said beam?, substantially as herein shown and described, and for the purpose set forth.

2.- Adiustably connecting the handles $\mathrm{F}$ to the beams A and plough standards $D$, by means of the uprights $G$, constructed and arranged substantially in the manner herein shown and described, and for the purpose set forth.

No. 77.474.-SIVION B. FORBES, NEW CUALER LAND, IV. VA.-Double Shorel Cullizators.-May 5, 1868

The sole bar is pivoted to the standard, and its rear end is comnected to the standard lyy an adjustable brace. The share is doulsle winged, and the double mould board is removalile.

Clain.-1.-The combination of the sole I), double winged point $\mathrm{E}$, and the doulle mould loard $\mathrm{F}$, with each other, substantially as herein shown and described, and for the purpose set forth.

2.-The combination of the adjustalile brace $\mathrm{G}$ with the curved rear part of the beam $A$ and with the sole $\mathrm{D}$, sub stantially as herein shown and described, and for the pur perse set forth.

No. 78,oSo.-IIENRY A. GASTON, STOCKTON, CA1..Cultizuters:-May 19, 1868 .

When a "bit" or cultivator tooth needs to be turned end for end, the key is driven ont and the hit slipped forward.

Claim.-In combination with an inclined reversible bi for a cultivator, the method of securing such bit to its stanclard, substantially as set forih.

2.-The combination of the series of bits (so applied to their vertical it indards) with the cultivator frame or carriage, subutantially as described.

Wo. $78,4^{24}$ - ALEX. CAIIPBELL, OXFORD, IND,Com Cultizators. Imi 2, 1868 .

The standards are secured in mortises in the frames at any desired angle, by mean of wedges and stay rods, so as to admit of their being changed and adiwted as required.

Claim. The attaching of the upper encls of the stanclarcl 1 is to the frame A, ly pivoting the former in mortises $b$ in the latter, in connection with the rods $d$ and the adjust able bar : attached to the draught pole, all arranged sulstantially ar and for the purprose set forth.

Vo. $78,4 S_{4}-$ J. S. ROWELLL and IRA ROWELI, BEA VER DAM, WIs, - Elezator for Cultizator Bars.- Fuae 2, 1868 .

Two roller stancls or learings are arranged on the top of the frame over the cylinder rod and under the hopper, extending upwarl and to the rear to receive the ent of a roller which is provided with suitable sheaven to receive the chain which elevate the bars.

Chim -1.-The roller stands or bearings, constructed and arrangert as and for the purpose set forth.

2.-The sheaves D 1', provided with the inclinerl eatch $d$ and luop $r$, in combinat on with the ratchet $b$.

3.- l'ivoting the jaw, as described, out of line with the trone in the sheave, so as to form an antomatic locking and unlocking device, as set forth.

4.-The combination of the sheaves $\mathrm{D} \mathrm{D}^{\prime}$, hearings $\mathrm{B} \mathrm{B}^{\prime}$. and roller $\mathrm{C}$, as arranged, and operating in the manner and for the purposes set forth.
No. 78,626.-WILLIAII WALTUN, EASt PALESTINE, Онго-Cultizuturs,-June 2, 1868.

Designed for adapting the hoes to various widths of furrow and preventing contact between the bandles and the plants.

Claim.-Attaching the handles D directly to the wings B, and providing an adjustable brace in the curved bars $\mathrm{H}$, in the manner and for the purpose substantially as herein set forth.

No. 7 S 774.-EI.ISHA WIARD WALTON, STOCKTON, CAL, assignor to himself and WILLIAM H. DERRICK, same place,-Horse Hoes. - Fune 9, I 868

A brace between the handles enables either handle to he set in line with the beam. The shares are made with two sharp edges, so as to be reversible and self-sharpening, and are provided with a point having a mortise for the reception of the lower ends of the standards.

Claim. - 1. - The regulating brace $m$, constructed sul stantially as and for the purpose above show'n.

2.- The standard $\mathrm{E}$ E of a horse hoe, constructed sub tantially as above describerl.

3.- The reversible hoe point $D$, with its slot or mortine $\mathrm{X}$, constructed and operated substantially as above shown.

4.- The reversible shares $\mathrm{A}$, and also their two sharp. cutting edges, constructed and operated substantially as above shown.

5.- The mould-hoard $\mathrm{B}$, in combination with the share $\mathrm{A}$, substantially as above shown

6.- The wedge 1, with its screw and nut, constructed and used substantially as ancl for the purpose above describ. ed.

7.-A horse hoe, with or withont the muld-board B, constructed and operating substantially as ahove described.

No. 79,001.-SAUIUEL REE1), Risine: SUN, MD.-Cultizators.-- Fun: 16,1868

The pointed or rudder teeth may he readily inclined to one or the other side by means of the long lever.

Claim - 1. The combination of the forked drausht bar $\mathrm{I}$, curved notched bar $\mathrm{I}$, and sliding catch $\mathrm{K}$, or their substantial equivalent, with each other and with the frame A of the cultivator, substantially as herein shown and described, and for the purpose set forth.

2. The pointed or rudder teeth $\mathrm{C}$, removably attached to the pivoted shanks D, for the purpose of pivoting the said teeth to the frame $\mathrm{A}$, sulsstantially as herein shown and described.

3.- The combination of tie long lever F, short slotted levers $\mathrm{E}$, piroted shanks $\mathrm{D}$, and pointed or rudder teeth $C$, with ench other and with the cultivator frame $A$, substantially as herein shown and described, and for the purpose set forth.

4-The comlination of the lever catch $\mathrm{G}$, with the long lever $\mathrm{F}$, and with the curved and notched rack $\mathrm{H}$, attached to the cultivator frume A, substantially as herein shown and described, and for the purpose set forth.

No, 79,042-k. R. W11.SON, Corusmes, OHn.-Hav. ruas - June 16, I868.

Designed as an improvement on a patent of the same in-

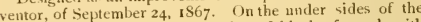
inner and outer rails are a series of blocks formed with grooves in which are secured metal plates that constitute the harrow teeth.

Claim.-The arrangement of the outer rails $A \quad A$ and inner rails $\mathrm{B} \mathrm{B}$, and the grooved teeth-holding blocks $\mathrm{K} \mathrm{K}$, pivoted in the manner described, and the perforated bars D $\mathrm{D}$, when the several parts are constructed and operated sulstantially as specified.

No. 79,161.-EI.BERT TERRII, CiLD WATER, MICH. - Cultizators.-June 23, 1868 .

The handles, by which the implement is guided, serve as hanks for the outer cultivator blades, wlich are held in their normal working position by the lateral pressure of the their normal working position which may he vibrated laterally springs upon the handle, which may he vibrated laterally or inner cultivator blades.

Claim.-1.- The arrangement herein described, for con necting the hamiles $\mathrm{C} \mathrm{C}$ and cultivator blades $\mathrm{F} F$ with the beam $\mathrm{A}$ and stationary cultivator point $\mathrm{E} \mathrm{F}$, so that the 


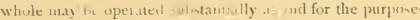
licrein set forth.

2. - The round piccen D D, with their shoulders $i$ i ans springs $f f$, in combination with the handles $C \mathrm{C}$, for con trolling the action of the nutsile cultivators, as herein speci fied.

Vo. So,015.-1. P. ROUTT, LHERTY IIILIS, VA.-Cal Vivalurs.-July 14, $1 \mathrm{SoS}$.

$I$ device attached to the plough standarch for the purpose of eradicating weeds and gras between the rows.

Claim-1.-The instrument, consisting essentially of the standard M, loop $s$, point $m$, and blades $n n$, having shar front cutting edges, when the several parts thereof are constructed and arrangerl as alore described, and for the purprose set forth.

2.-The combination of said instrument with the plough stundard B B and wedge 11 , snbstantially as described.

No, SI, 054-LEWIS R. IVRIGHT, TROY, N, Y.Ciultiatutors and Ploughts Combined.-Augrest $\mathbf{1 1}, \mathbf{1 8 6 8 .}$

All the part may he aggregated to form the compound implement-plotsh and cultivator-but the teeth and stand ards are readily detachable, in order that the plough may be used alone, and ricic z'ersa.

Claim. - 1.-The double mould board $\mathrm{B}$ and $\mathrm{C}$, so hinged aard connected together that the main part of said mould $\mathrm{B}$ may be elevated or depressed at will, according to the height of furrou desired to cut, substantially as fully hereinbefore described and set forth.

2.-The hinging of the sections of the mould hoard $\mathrm{C}$ and $\mathrm{C}^{\prime}$ to the centre standard $\mathrm{E}^{\prime}$, whereby a lateral motion may he given to the mould boards $B$ and $B^{\prime}$, to regulate the wislth of furrow to be cut, subtantially in the manner and for the purposes more fully hereintefore described and set forth.

3.- The slotted arms, or their equivalents, D D, in com bination with the mould boards $B$ and $\mathrm{B}^{\prime}$; substantially in the manner and for the purposes herein described and set furth.

4.- The upright or tooth shoe $\mathrm{E}$ in combination with the brace $\mathrm{F}$, or its equivalent, all cast in one solid piece, substantially in the manner and for the purposes herein fully described and set forth.

5.- The curved reversible tooth $\mathrm{H}$, in combination with the tooth shoe $E$ and brace $F$, each being constructed and operated substantially in the manner and for the purpose: hereinbefore described and set forth.

No. 5,532.-LEWIS R. WRIGHT, SCHENECTAIT, N. Y.-Cultivators and Plourhs Comblined-Catent No. \$1,054,-Dated Ausust 11, 1868. Re issued, Ausust 12, I873. [Application filed, 1/ny 21, 1873.]

Claim, - 1 - The donble monld board $B$ and $C$, so hinged and connected together that the main part of said mould board $\mathrm{B}$ may be elevated or depressed at will, according to the height of furrow desired to be cut, substantially as hereinbefore described and set forth.

2,- The hinging of the sections of the mould board $\mathrm{C}$ and $\mathrm{C}^{\prime}$ to the centre standard $\mathrm{E}^{\prime}$, whereby a latersl motion may be given to the mould boards $\mathrm{B}$ and $\mathrm{B}^{\prime}$ to regulate the width of furrow to be cut, substantially in the manner and for the purposes more fully hereinhefore described and set forth.

3.- The slotted arms or their equivalents D D, in combination with the mould boards $\mathrm{B}$ and $\mathrm{B}^{\prime}$, substantially in the mamner as and for the purpuses herein described and set forth.

4.- The curved reversible tooth $H$, with concave sides, the front surface of which is nearly flat, as and for the purposes set forth.

No. 6,836.-1.EWTS R. WRIGHT, HuDson, N. Y.. assignor by mesne assignments, to GIFFORD, JOHNSON \&. CO.-Cultizutors and Ploushs Combined.-No. 81,054. - Dated Aurrust I1, 1868 -Re-issue, No. 5,532 - Dated August 12, 1873.-Re-issuel, January 4, 1876.-[Filed, Norember $9,1575$.

Claim.-I.-The double mould board $\mathrm{B}$ and $\mathrm{C}$, hinged and connected torether, so that the main part of the said mould board B may be eleyated or depressed at will, according to the height of furrow desired to be cut, substantially as hereinhefore described and set firth.

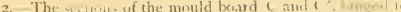
the centre stantard $\mathrm{I}^{\prime}$, whereloy a lateral motixn was be given to the movid buarkls $13 \mathrm{~W}^{\prime}$, to regulate the wilth of furrow to be cut, substantially in the manner and for the purposes more fully hereinbefore described and set forth.

3.-The slotted arms or their equivalents D 1), in com. bination with the monld boards B and B', substantially in the mamer as and for the purposes herein described and set forth.

4.- The cuitivator tooth made with nearly straight edges and V-shaped ent, sharpened upon the under side, curved in a vertical plane, and with the face flat, or nearly flat, transversely, substantially as and for the purposes specified.

No. 81,148.-T. H. DICKSON, ALFORD, IND - Plows hes. - Auszist 18,1868

The ends of the plate are bent up and slotted, and secured to the beam by bolts, so that it may be adjusted to change the depth of penetration of the clod-cutting knives.

Claim.-The adjustable plate $\mathrm{C}$, and the curved knives $\mathrm{D}$ $\mathrm{D}$, when used in combination with a shovel or other plough, $\mathrm{B}$, and its beam $\mathrm{A}$, the several parts being constructed and arranged substantially as and for the purjose herein set forth.

No S1,189.-JACOB MEYER, BIOOM TOWNSHIP, Он10,-Shonel Ploughs - August is, r868.

The outer plough standards vibrate upon pivots so that the movable plonghs may be placed nearer to or further from the central stationary plough, the desired relative position being maintained by means of the spring catches, and the rigid, notched bar.

Claim.- The upright centre bar A, provided with the notched cross-bar $\mathrm{L}$, in combination with the springs $d d$, and the lugse e, substantially as and for the purposes herein set forth.

No, $81,807-D$. MCNEELEY and C. T. CADT, SPUR GEON, 1ND.-Cultizators.-Sipfimber I, 1 S68.

The rear plough stanclard is fixed to the draught beam, and the forward standards to the cross beam supported thereby, the wheel having its bearings below in plates press ing against the beam, and supporting the shaft in their ears, the parts being strengthened by braces. A detachable rake is also fastened behind and to the rear standard.

Claim,-1,-The combination of the draft bean $\mathrm{A}$, with plates J J, slots and set-screws $s s^{\prime}$, and wheel D, substantially as described.

2,- The arrangement of the beam $\mathrm{A}$, handles $\mathrm{B} \mathrm{B}$, wheel D), ploughs E E E, standards $\mathrm{C} \mathrm{C}^{1} \mathrm{C}^{2}$, cross-beam $\mathrm{L}$, braces $\mathrm{K} O{ }^{\prime} \mathrm{\prime}^{\prime \prime}$, and attachable and detachable rake $\mathrm{F}$, substantially as shown and described.

No. 82,043-MICHAEL STOLL, CONFSTOGA TOW sIrI, assignor to himself, BENJAMIN SNAVELY and ANTHONY ISKE, LANCASTER, PA.-Potato Plonshs.September 8,1868

The shovels are so arranged that when in one position the soil is thrown outward, and when reversed the soil is thrown inward

Clain.-The arrangement and construction of my hovel 1, 2 and 3 , with their respectuve beams, slots, screw bolts $b$, and counter-sunk segment $G$, and adjustable bearings $E$, in combination, with or without the separate centre piece A, Fig. 2, all made in the manner and for the purpose specified.

No. 82, 089.-JOSEPH H. CL1FTON, NFWCASTLE, PA. - Cultizators.-Siptember 15, 1868.

The knives and spikes break up the soil, and the large wooden teeth on the cross-bar form drills.

Claim.-1.- The board A, provided with the knives $a$, \&.c., and teeth $b$, as and for the purpose set forth.

2.- The board $\mathrm{A}$, in combination with the bar $c$ and teeth , as and for the purpose set forth.

No, 82,180,-THONIAS THORLEY, SOTTHFIEI.11, MICH. - Cultivators. - Septembir 15, IS68.

The dranght is attached to the widest part of the ma chine. Braces or "levers" are attached to the forward end of the hinged plough berm, and to a rod in a slotted plate, to admit of the plough being adjusted to a greater or les: width.

('laim.-1.-The quadrant 1, provided with flanges ], 
when attached, and operating substantially as and for the purposes herein described.

2.- The levers $\mathrm{K}$, the bolt and hand nut $\mathrm{L}$ and the plate $\mathrm{N}$, provided with the slot $\mathrm{M}$, when arranged and operating substantially as, and for the purposes herein shown.

3.- The combination of the beam A, the vertical standard $\mathrm{C}$, the teeth $\mathrm{D}$ and $\mathrm{H}$, the handles $\mathrm{E}$, and arms $\mathrm{F}$, the standards $G$, the quadrant $I$, the flanges $J$, the levers $K$, the holt and hand nut $\mathrm{L}$, the slot $\mathrm{M}$, and plate $\mathrm{N}$, when constructed, arranged, and operating substantially as and for the purposes herein set forth, described and shown.

No. 82,753.-WILLIAM RODGERS, LINNVILLE, IND. -Cultizators.-October 6, I868.

The rake is hung on the end of the beam, behind and under which is the steadying wheel, and a rod, attached near its centre, with its top passing through the end of the beam, is adjusted by means of a screw on top, the rake being also braced by rods movably pivoted at its ends, projecting toward the main beam, thus allowing it motion, its teeth being slightly inclined inwardly.

Claim.-The rake $K$, supported and braced as described by the vertical and lateral rods, and having itself vertical teeth, in combination with the cultivator, provided with the steadying wheel $\mathrm{H}$, all constructed and arranged as and for the purpose set forth.

No. 82,814.-DANIEL S. EARLY, HMMMelstown, PA. -Cultivators.-October 6, 1868 .

A central beam has pivoted to it two side beams which fit in clasps attached to a cross-bar which slides over the central beam, thus regulating the width of the rows, and is held in position by a bolt passing through it and one of a series of holes in the beam.

Claim.-1.-The sliding bar E, in combination with the central beam $A$, the hinged side beams $D^{\prime} D^{\prime}$, and the fast ening $f$, substantially as described and for the purpose specified.

2.- The arrangement of the beams $\mathrm{A}, \mathrm{D} \mathrm{D}^{\prime}$, slide $\mathrm{E}$, clevis $\mathrm{F}$, wheel $\mathrm{B}$, handles $\mathrm{C} \mathrm{C}$, and plows or teeth $\mathrm{P} P \mathrm{P}$, in the manner shown and described.

No, 82,858.-DANIEL MATER, BELLMORE, IND.Ploughs.-October 6, 1868 .

The coulter is attached to a lapped langer which regulates the distance the coulter shall run from the shovel. The standards to which the shovels are secured are braced by rods extending from the beam and secured to the stand. ards by clamps.

Claim.-1.-The arrangement of the transversely adjustable coulter or cutter $\mathrm{F}$, with reference to the beam of the plough and shovel C, sulsstantially as shown and described.

2.- In combination with the beam and standards, the brace rods $H$, clamps $I$, and nuts $I^{\prime}$, arranged substantially as and for the purpose set forth.

No. 3,488.-DANIEL MATER, BELLMORE, IND.Ploushs.-Patented October 6, I868, No. 82,858 ; reissued Fune 8,1869 .

Claim.-1.- The arrangement of the transversely-adjus table shield $\mathrm{F}$, with reference to the beam of the plough and shovel $\mathrm{C}$, substantially as shown and described.

2.- In combination with the beam and standards, the brace-rods $\mathrm{H}$, clamps $\mathrm{I}$, and nuts $\mathrm{I}^{\prime}$, substantially as and for the purpose set forth.

3. - The construction of the shovel $\mathrm{C}^{\prime}$ with its guides or studs for retaining the same in position, in connection with the staple for securing it to the standard.

4.-The arrangement of the bolts $b \quad b \quad b$, at equal distances apart, in combination with the rear standard and brace, as set forth for the purpose described.

No. $83,340,-$ R. T. TAYLOR, EvERTON, 1ND, - Shiclds for Corn Planters.-Oitober 20, 1868.

An adjustable shield allows the corn to be plowed as close as desired without injuring or covering it up.

Claim.-1.-The adjustable shield B, constructed and attached to the plow in the manner described, and operated by means of the slotted arms on the stay $c$, and the lever D, substantially as and for the purposes herein set forth.

2.-The ratcli bar 5 , in combination with the bent spring $h$, for the purpose of holding the lever $\mathrm{D}$ at any point desired, thereby adjusting the shield $\mathbf{B}$, substantially as and for the purposes herein set forth.
No. 83,564.-WILLIAM H. STARTZMAN, BIG LICK, VA.-Cultivators.-Octoler 27, 1868 .

The stay rods or the adjusting keepers of the pivoted shanks are attached to the respective ends of the oblique bar.

Claim.-The arrangement of the standards B B, oblique bar $C$, rack bar $I$, and keeper $E$, with nuts $g$ and ploughs $D$, all as herein set forth.

No. 83,719.-DON CARLOS MATTERSON, and TRUMAN PANE WIILIAMSON, STOCKTON, CAI.Horse Hocs.-November 3,1868 .

The cutter is secured in the ends of curved bars, which are pivoted to the beam and held by adjustable braces, by means of which latter a greater or less "rake" may be given to the cutter.

Claim. - The combination of the reversible double-edged cutter D, the pivoted hars C C and adjustable braces E, with a beam $A$, substantially as described

No, 83,931,-LEANDER CLIFTON, BARRY, ILL,Cultizators. - Vozember Io, I868.

A safety spring clevis, which acts automatically, is formed on the forward part of the body. The handles may be adjusted to suit persons of different height and size.

Claim.-1.- The safety detaching device for a cultivator plough consisting of the curved piece $B$ and spring piece $H$, substantially as and for the purposes described.

2.- The cultivator constructed of the iron bow $\mathrm{A} \mathrm{A}^{\prime}$, curved piece $B$, spring piece $H$, ring $I$, pieces $F F^{\prime}$, standards $\mathrm{C} \mathrm{C}^{\prime}$, having bent and stotted ends $a a^{\prime}$, rod $\mathrm{D}$, nuts $b c$, brace $\mathrm{K}$, and ploughs $\mathrm{G}_{\mathrm{G}^{\prime}}$, all combined, arranged, and operating as and for the purposes described.

No. 84,094.-THOMAS DIILON, HIGHLAND, OHIO. - Corn Ploughs.-Nowember I 7, 1868.

The plough blade is adapted to any kind of a plough, single or double shovel, sulky plough, or subsoiler.

Claim.-1.-The tenoned plough beam E, pivoted in the beam $\mathrm{A}$, apd provided with a bent arm, $\mathrm{F}$, by which it is adjusted at any height desired, substantially as herein set forth.

2.-The curved plongh blade II, provided with an ear or lug, I, for the purpose of attaching it to the plough beam $\mathrm{E}$, substantially as herein set forth.

No. 84,238,-ThOMAS WAITE, Plymouth, OHIo.Cultizators,-Noz'mber I7, I868.

The shares can be adjusted for plonghing furrows of different widths.

Claim.- The side heams C, when provided with slots D, for the insertion and adjustment of the standards E, in combination with the beam $\mathrm{A}$, for the purpose set forth.

No. 84,338.-THEOPHII.US ARNDT, MOUNT JoY, PA., assignor to himself and E. L. FLOWERS, same place. - Cultizators.-November 24, 1868.

The plough-beams extend backward through slots in the bolts which pass downward through the curved slotted bar, and through binding clips and nuts at the under side thereof. This mode of attachment, in connection with that at the forward end of the beams, admits of the ready lateral adjustment of the beams together with the shovels.

Claim.-1.- The ring or ring plate $\mathrm{D}$, in combination with the central or main beam A of the cultivator, and with the hooked forward ends of the side or adjustable beams $\mathrm{E}$, suhstantially as herein shown and described, and for the purpose set forth.

2 - The combination of the curved and slotted bar $\mathrm{H}$, slotted bolts I, clips J, and nuts K, with the central beam $A$, and with the adjustable side beams E, sulstantially as herein shown and described, and for the purpose set forth.

No. 84,499,-CALVIN LOBDELL, FurT HILL, ILL.Cultizators and Secders.-December I, 1868 .

An adjustable leveler is arranged to run between the shovels of an adjustable cultivator, so as to smooth the sur. face of the soil, and gauge the depth of the shovels in the ground.

Claim.-1.-The leveler K K L, arranged to operate substantially as and for the purpose herein specified.

2.- The combination of the leveler $\mathrm{K} K \mathrm{~K}$, arm 1 , wings $\mathrm{B}$, rods $\mathrm{M} \mathrm{G}$, and curved plate $\mathrm{R}$, the whole being 
constructed and arran red substantially as aud for the purpone set forth

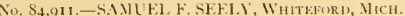
- (iultizators,-December 15, 1868; antedated Deicmbir 11, 1868 . An improvement on his patent of fugust 6,1867 .

A slotted arm attached to the cross rorl, which secures the handles together, slides in a mortise on the end of the plough heam, and is held by a cam lever. The plough stand. ard is attached to the plough beam in such a manner as to readily change the direction of the plonghs.

Claim.-1.- The tenon B', the cam lever C', the slotted $\operatorname{arm} \mathrm{F}$, in connection with the cross rol $\mathrm{E}$, when operating substantially as and for the purposes set furth.

2.- The share (), wings $P$, and braces $R$, in connection with the standard 1, when operating substantially as and for the purposes herein described.

3.- The adjustability of the standard 1, for the purpose described, in combination with the share $\mathrm{O}$, wings $\mathrm{P}$, and tenoned beam $A$, substantially as set forth.

4.- The combination of the beam $A$, the tenons $B^{\prime}$ and $\mathrm{B}^{\prime \prime}$, the cam levers $\mathrm{C}^{\prime}$ and $\mathrm{C}^{\prime \prime}$, the handles $\mathrm{D}$, the cross $\operatorname{rod} \mathrm{E}$, the slotted $\operatorname{arm} \mathrm{F}$, the slot $\mathrm{G}$ in the same, the slotted slide $\mathrm{H}$, the standard $\mathrm{I}$, the bolt and nut $\mathrm{I}$, the eye and ring $\mathrm{K}$, the draught rod $\mathrm{L}$, the hook $\mathrm{N}$, the bolt $\mathrm{N}$, the share $O$, the wings $P$, aud the braces $R$, when arrangell, constructed, and operating substantially as and for the purposes herein shown, set forth, and described.

No. 34,946,-W. UPTON HOOYER, DAYSVILLF, KY. -Ploughs.-December $15,1868$.

The two side ploughs admit of a reversal of position so as to turn the furrows to the right or left, and the implement is designed to be used for plonghing, planting, and cultivating.

Claim.-The combination of the three turn ploughs $f$, when arranged in relation to each other, and for adjustment, in the manner shown and dexcribed.

No. 85,467.-JOSEPH MILLARI, WINSI, IND, Cultizators.-Dicenter 29, 1868 .

The side bars are connected at their front ends to the center bar by springs, and their rear ends are moved toward or from the center bar by means of connecting rods operated by a lever adjustably pivoted in a forked standard.

Claim.- The arrangement of the side bars B B, rods D

$D$ and $E$, standard F, bar $\mathrm{G}$, lever $\mathrm{H}$, and bent notched bar I, all as shown and described.

No. $85,469 .-G$. W. MORTER AND EIMWARD BERRV, Haktvili.f, OHo.-Adjustable Shomel Ploughs. - December 29, 1868 .

Claim.-1.-The second heam E, pivoted to the main beam A by parallel har,$G$ G $G G$, and having attached to it the standard $F$, with brace rod $\mathrm{N}$, substantially in the manner and for the purpose specified.

2.- The rod 1, with bent front end and plate $K$, with one or more holes therein when used in combination with the beams $A$ and $E$, pivo:ed to each other by the bars $G G$, substantially in the manner and for the purpose specified.

3.-The double.shovel plough herein described, consinting of the beam A, handles B B, cross bar C, standard 1), second beam E, parallel bars $G$ G, rod I, plate $\mathrm{K}$, standard $\mathrm{F}$, braces $\mathrm{ON}$, and shovels $\mathrm{M} \mathrm{M}$, the several parts being constructed and combined substantially as and for the purpose specified.

4.- So constructing a shovel plough as that it may be charged from a double-shovel plough to a single-shovel plough, without any change of parts, except thc change of the two shovels for a single-shovel, substantially in the manner herein specified.

5.- So constructing an interchangeable double or singleshovel plough, as that, when used as a double-shovel plough, the distance between the two shovels may be changed as desired, the reveral parts being so arranged as that the only change of parts required in a change from a donble to a single-shovel plou, h shall he change of the two shovels fir a single-shovel, substantially in the manner herein specified.

No. 85,862,-CVRU' SCHWANGER, Mounr Jor TownshiP, PA.-Cultivators.-January 12, I\$69.

Claim.-1.-The contruction and arrangement of the slotted clamps $C$ for the curved plate $V$, when made to stradtle the beam, 1, 2, 3, 4, and 5, adjustable by a rexu. lowlt, 1., in the manuer and for the purpose specifict and shown.

2.- In combination with the stirrup E and cross.plate b, the pole $\mathrm{F}$, with its notch $\epsilon$, and shoulder $f$, when constructerl and applied in the manner and for the purpose specified.

No. 86,069.-JOEL H. JONES and IIENRY P. JONES, HER NDON, G.i.-Plonghs.- Finum? 19, 1869.

('laim.-1.- The brace $\mathrm{D}$, having the elongation $\mathrm{D}^{\prime}$ and the holes at its upper end, when attached to the plough. standard and beam, so as to be adjustable, in the manner and for the purposes set forth

2.-The harrows $\mathrm{H} \mathrm{H}$, projecting from each side of the heam $\mathrm{A}$, when constructed with the bent teeth, wooden plate $h^{\prime}$, and iron plate $h$, aud both fastened to the plough. beam by a single bolt $\mathrm{J}$, so that they swing loosely on the bolt, and can be lifted, to clean their teeth, unbstantially as above described.

3.- The arched brace E, having the holes in its upper end, when arranged in connection with the plough-beam and the two handles, in the manner and for the purposes set forth.

4. The arrangement of the forkesl standard $\mathrm{C}$, beam $\mathrm{A}$ arched hrace $\mathrm{E}$, and handles $\mathrm{G} G$, the latter being clamped between the tops of the standard $C$, and being adjusted upon the brace $\mathrm{E}$, as described, when the form of the handles $\mathrm{G}$ $G$, from the bolt $c^{\prime}$ to the bolt $c$, and from the latter to their upper end, is substantially as described and shown.

5.- The standard C, when curved as shown in fig. 1, bifurcated from its point upward, provided with lateral holes $a$, for fastening a mold board, and attached to the beam $A$ and the handles $G \mathrm{G}$, in the manner herein described and shown.

No. 86, 185 -JAMES SCOT T SMITH, HEIENA, ARK -Cultivators for Dirtung Cotton.- Fanuary 26, 1869 .

Claim.-Ploughs $\mathrm{A}$ and $\mathrm{B}$, beam $\mathrm{C}$ and $\mathrm{D}$, hirge $\mathrm{F}$ dividing plate $\mathrm{E}$, and thumb-screw $\mathrm{G}$, all constructed, arranged, and combined, as shown and described.

No. 86,502,-ROBERT I. BURBANK, BOSToN, MAss, - Cultivators.-February' 2, 1869.

Claim.-1.-The construction and arrangement of the removable and changeable plough.beams $\mathrm{B}$ and $\mathrm{B}^{\prime}$, and the center-beam A, whereby the former may be applied or attached to the latter, at either end or side thereof, and changed from one side of the center-beam to the other, so as to turn or plough the furrows outward or inward, without removing the ploughs from their beams, all substantially as and for the purpose described.

2.- The conbination with the removable and changeable plough-beams B and B', as shown and described, of ploughs $\mathrm{C}$, forming a double series, for the purpose and substantially as described.

No. 86,577 - - JAMES W. NICHOLSON, INDIANAPUI,IS, InD,-Combined Single and Donble-Shovel Plinushs.February 2, 1869.

Claim.-The convertible double or single shovel plough. having the several parts of which it is composed constructed and arranged substantially in the manner and for the pur pose herein set forth.

No. \$6.759.-THOMAS HICK, PECATONITA, 11.1.Cultizators-February 9, 1869 .

Clain.-1.-The sliding clamps $f$, in combination with the standards G, bars $F$, and set-screws $f$, as and for the purpose described.

2.- The cultivator above described, convisting sulstantially of the frame $\mathrm{A} \mathrm{A} \mathrm{A} \mathrm{A}^{\prime} \mathrm{A}^{\prime}$, bars $\mathrm{F} \mathrm{F}$, wheels $c^{\prime \prime}, \mathrm{H} \mathrm{H}$, witl their attachments, clamps $f$, and standards $G$, arranged and operated as and for the purpose set forth.

No. 87,060.-WILLIAM MUIR, WAUCONDA, Ir...- Horse Hoes.-February 16, 1869.

Claim. - The vertical standards $D$, transverse beam $C$, and pins $c$, in combination with the rods $\mathrm{E}$, slotted ruds $\mathrm{F}^{\prime}$, and and pin $f^{\prime \prime}$, constructed and operating substantially as anil for the purpose described.

No. 87,347-CALVIN LOBDELL, FurT HILL, ILL.- Horse Hoes.-March 2, 1869.

Claim.-The hiller S S, attached to the leveler, as and for the purpose set forth. 
No. 87,373.-DAIID SLAUGHTER, WEST HEMPFIFID TOWNSHIP, PA.-Cultinators.-Mitrch 2, 1869.

Claim.-The construction of the central hovel or scraper $Q$ with its side wings $\mathrm{R} \quad \mathrm{R}^{\prime}$, hook-ends $r$, in combination with the connecting-straps $\mathrm{P}$, the slide beams B $\mathrm{B}^{\prime}$, together with the wing-stay or guide $Z$, arranged and opernting substantially in the manner and for the purpose set forth.

No. 87.400.-DANIEL S. EARLY, HuMMELSTOWN, P'A.-Culiz'ators.-Afirch 2, 1869 .

Claim. - The tongue $e$, in combination with the clevis $h$, as and for the purpose set forth.

2,- The tooth A, in combination with the socket $d$, in the manner and for the purpose explained.

3.- The tooth A, provided with the recesses $a$ a and head , substantially as described.

4. - The tooth A, provided with the recesses $a$ and head $\prime^{\prime}$, in combination with the conjoined slots $b b^{\prime}$ and key $c$ substantially as described.

No. 87,9I4-JOHN M. DAVIDSON, PULASkI, PA.Potate and Corn Cultiantors, - Mareh I6, I869.

Claim -Frome A, bars b b', plates C $C$, rods $C^{\prime} C^{\prime}$, auljustable leg; B B, and drag-bar ( $i$, all constructed, combined, and arranged to operate as herein set forth.

No. 88,025.-SIMEON B. FURBES, STFuBFNYh,LE, OHIo.-Cultizator-Ploushs.-Marrh 23, I860.

Claim,-I.-In a cultivator-plough, a half shovel at, with one or more side cutters $s$, attached to a beam, or standard, $b$, along the line of its inner or vertical edge, sub stantially as hereinbefore set forth.

2.-A cultivating apparatus, having two or more half shovels $a$, connected with adjustable beams and handles, and with one or more cultivator teeth $c$, constructed substan tially as above set forth.

No, 88,034-ANTHONY GROHMANN, SOUTH SAFINAW, Mich, - Cultitators.-Wizrch $23,1869$.

Claim.-The implement described, baving the sickleback cutters $\mathrm{J}$, in combination with the adjustable beam $=\mathrm{C}$ and $F$, and centre-beam $A$, as described, for the purpose set forth.

No. S8,045.-HENRY LANDES, BATH, PA.-Cultina lors.-W/arih 23, 1869 .

Claim.-1.- The arrangement of the beam A, hars D D, standard $\mathrm{G}$, bar $\mathrm{H}$, handles $\mathrm{F} F$, wheel $\mathrm{C}$, bar $\mathrm{E}$, levers $d$, plate $b$, and hoes 11 , all constructed substantially as set forth.

2.- The hoes I I, when constructerl as clescribed, and ar ranged, two on each side beam and one on the centre beam, ubstanlially as set forth.

No. 88,136.-ALEX.ANJER CONNEILY. MILAN, 1Ni). - Cultiziators.-Worch 23, 1860.

Claim. - T ne curved testh $(\mathrm{H} H \mathrm{H}$ I K, secured to the rearwardly curved head, or cross bar $F$, the said teeth having an outwardly-diminishing length, as represented and described.

No. $88,2 S_{3}$. A. I. TRATER, LISBIRN, PA.-Ploughs. - Warch 23, 1869

Claim,- The levers E E and spiral springs F F, as con. structed and arranged forward of the shafts or standards D $\mathrm{D}$, substantially in the manner and for the purpose as herein shown and described.

No. 88,723.-EII KNEPPEK, CoItumt's, OHIO.Showed Ploushs.-April 6, 1869 .

Claim.- I. - The two slit hars I I, and rollers $\mathrm{K} \mathrm{K} \mathrm{K}$, in combination with the beams B B and $\mathrm{C}$, constructed and arranged as described.

2.-The spring $\mathbf{H ~ H}$, fastened between the middle heam $\mathrm{C}$ and onter beams B B, which bring the outer shovels always back to their normal distance from the middle shovel, when contracted as herein described

No. 89,565.-IANES M DORMUN, CLIIBORNE P'AR isH, LA.-Ploughs.-Way 4, I869.

Claim. The peculiarly formed plough shares $\mathrm{F} \mathrm{F}^{\text {? }}$, in combination with the articulating and adjusting braces $\mathrm{E}$. ${ }^{\prime}$ when said plough-shares and said braces are constructed and operate as herein described.

No. 91,031-A1.FRED IOHN LEWIS, PItTsbukgh, PA.-Cultizutor Plouglis.-F̈unc 8, i860.

Claim.-I.-The slides L, in combination with the shov ets I ' and $11^{2}$, vbstantially as described.
2.- The slides $\mathrm{D}$, with the rods $\mathrm{E}$ and $\mathrm{F}$, pins $\mathrm{G}$ and $\mathrm{H}$, in combination with the stilts $\mathrm{B}$ and $\mathrm{B}^{1}$, substantially as set forth.

3.- The knife $\mathrm{B}^{3}$, rod $\mathrm{B}^{4}$, in combination with the beam A, substantially as set forth.

4.- The shovel C, when attached to the beam A, by means of clamps $\mathrm{C}^{2}$ and $\mathrm{C}^{3}$, substantially as set forth.

5.- The combination of the above named devices in the construction of a shovel plough, whereby the shovels can be set at any position, by means of the slides and rods, substantially as described anil set forth.

No. 91,212.-B M. ClOSE, West CAMDEN, N. Y.Cultivators.-Fune 15, 1869 .

Claim-1.-The combination, with the cultivator-frame, of the thills, pivoted to the same, substantially in the manner described, so as to be capable of swinging or turning upon their pivot from side to side, independently of the cultivator, for the purposes set forth.

2.-The combination, with the pivoted thills and cultiva tor-frame, of the segment and its loop or guide, attached respectively to said thills and frame, and arranged to operate in connection therewith. substantially as and for the purposes shown and set forth.

3.-The combination, with the frame of the cultivator, of the thills, the hinged pivot or rod, on which the same turns, and the segment, and its loop or guide, under such an arrangement that the said thill may be cripable both of rock ing and of being turned or swung from side to side, substantially as shown and set forth.

No. 91,303.-I. A. BENED]CT, WEST S'PRINGFIFID, PA.-Cultinaters.-Fune $15,1869$.

Claim - The combination, with the plough A, of the plates $\mathrm{D}$, when arranged as specified.

No, 91,471 . - A. D. IIJCHENER and J. W. STEIG. MEVER, AtTICA, OHIO,-Corn Ploughs.-June 15, 1869.

Claim.-1.-Adjusting the movable side-beams of a plough, by means of the handles, substantially as herein set forth.

2.- The combination of the adjustable side-beam D, plate $G$, ears $b b$, and handle $\boldsymbol{H}$, all substantially as and for the purposes herein set forth.

3.- The arrangement on the under side of the handle $\mathrm{H}$ of the pawl $c$, spring $d$, rod $e$, and thumb-piece $f$, all substantially as and for the purposes set forth.

4.- The combination of the centre-beam A, sile beams D I, plates F, and $G$, and handles $H \mathrm{H}$, all constructed and arranged to operate substantially as and for the purposes herein set forth.

No. 9r,847--E. S. HUFF, ZaNesville, OHto,-Plowgh Cultiñators. - Fnne 29, 1869.

Claim. - The employment of the metal plate A, con-truct ed with the bars or projections $c \varsigma$, supplied with the pivot ed arms $b b$, in combination with the handles of a cultivator, and arranged substantially as and for the purpose set forth.

No. 91.963.-F. L. PERRY, CANANDATGUA, N. Y.Cultizintors.-June 29, 1869.

Claim.-1.- The attaching of the teeth $\mathrm{E}$ to the beams $A$, by having the front prongs $c$ of the teeth pass through the front ends of plates $d$, and the rear prongs $f$ fitted in the rear parts of the plates, in combination with the arms $g$ of the plates, the arms of each pair of plates being fitted together, and all constructed and arranged substuntially as shown and described, to admit of the Iurning or adjusting of the teeth as the beams A A are expanded or coniracted, as set forth.

2.- The adjusting of the clevis-plates $k k$, by mean of the bolt $m$, fitted in any of a series of holes, $l$, in sairl plates. in connection with the spring-catch $\mathrm{G}$, all constructed and arranged to admit of the adjustment of the gauge-wheel $C$, substantially as and for the purpose set forth.

No. 92,448.-J. L. HOOD, F1,Y) Cor'NTy, CiA., arsignor to himself, I. F. WARTIN, and J. S. BLACK.-DowbleFooted Plousth Stocks. - July 13 , IS69.

Claim,-1,-The within described plough-stock, consisting of the draught-beam $\mathrm{A}$, the side-beams $\mathrm{C}$, and $\mathrm{C}^{\prime}$, the bolts $c c$, and blocks D D, \&c., the plough-feet E E, and support-rods G G, all constructed and arranged substantially as and for the purpose shown.

2. - The side-beams $C^{\prime}$ and $C^{\prime}$, in combination with the 
bolts r, and c, and blocks 1) 1), de., substantially as and for the purpose specitied.

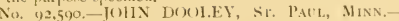

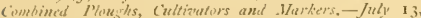
1800.

('laim.-1.- In adjustable plough, cultivator, and mark$e r$, having cultivators s, plough share $n$, and marker 13 , constructed and arranged substantially as and for the purposes specified.

2.-In combination with an adjustable plough and culti vator, mut and screw H, when workiny in the slotted stand ard, as described, and the perforated rods $i$, arranged and operating substantially as and for the purpones specified.

No, 92,641,-R. F. PATT()N, ()tiNe), OHн,-Corn aml cislen cultimtors. - July 13. ISog.

Claim,-1.- The draught-beam A, provicled with lugs or eyes $a a$, dc., loth in front and in rear, in combination with the cross bar $B$, substantially as and for the purpose shown.

2.- The cultivator or harrow-bars $\mathrm{C} \mathrm{C}$ and $\mathrm{E}$ E, when so constructed as to permit of their being pivoted at their centre to the crosi-bar $B$, and attached at either end to the eyes or lugs $a a$, de., upon the draught-heam A, substantially as shown and for the purpose specified.

3.- The handles F F, brace $f$, quadrant $G$, and set screw $x$, all combined and arranged substantially as and for the purpose shown.

4.-The within described agricultural implement, con sisting of the draught beam A, provided with the eyes or lugs $a$, dic., cruss-bar B, harrow or cultivator bars $C$ C and $\mathrm{E} \mathrm{E}$, handles $\mathrm{F} \mathrm{F}$, brace $f$, quadrant $(i$, and set screw in, all constructed and arranged substantially as and for the purpose shown anc described.

No. 93,017.-WALTER S.I1TH, BoONvII. IND.Culvivators. $-7 u l{ }^{\prime} 27$, I $\mathrm{S} 60$

Claim. - The frame $\mathrm{B}$, the wheels $\mathrm{C} \mathrm{L}$, the gauge $\mathrm{H}$, the gauge-lever I and gauge-spring $J$, the slicles $F$, the regulators $\mathrm{i}$, and the set-screws $\mathrm{U}$, and their application $t o$, and co.oper.tion with the ploughs, handles, and clevis.

No. 93.042.-HIRAII BENEDICT, DETRuIT, MICH., assisnor to himself and ALI.EN CHANEV, same place.Cultivators and Harrows Combinal.-July 27, 1869 ; -antedated $/ u / y, 16$, I $\$ 60$.

Claim.-1. - The center bar A, the side bars D, and other bars $G$, when pivoted together and arranged relative to each other, as shown, for the purpose of expanding the implement.

2. The harrow teeth M, in connection with the bars $D$ and $G_{1}$ and the cultivator-teeth $K$ and $L$, when arranged substantially as and for the purpose herein set forth, described, and shown.

No, 93,203.-SAHUEl, HU1BER, 1)ANVILLE, PA. Combinil Plowghs and Cultitutors.-Ansust 3, 1869.

Claim -1.-The plate 1 , 1 rovided with several sets of holes, for the adjustahle attachment of the plough-standards, substantially as herein shown and dencribed, and for the purpose set forth.

2.- The combination of the adju-table plough-utandards $F$ with the plate $\mathrm{B}$, substantially as herein shown and de scribed, and for the purpose set forth.

3.-The ploughs $\mathbf{E}$, constructed as lescribed, in combina. tion with the adjustable standards $F$ and plate B, substantially as and for the purpose set forth.

4.- The combination of the double mouid-bond plough 1 with the adjustable standard $\mathrm{F}$ and plate $\mathrm{B}$, substantially as herein shown and described, and for the purpose set forth.

5.- The combination of the fingers J with the mcu'd-boards of the donble mould-board plough 1 , adjustable standards $F$ and plate 13 , substintially as herein shown and described, and for the purpose set forth.

No. 93,507-EDWARI) WIARD, L,OUISVILLE, KY., assignor to B. F. AVERY, same place.-Expanding Doub-

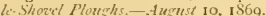

Claim.-I.-Adjustably connecting the plough-standards to the plough-beam, ly means of sockets, formed in the upper ends of said standards, and the hollow spindles E, substantially as herein shown and described, and for the purpose set forth.

2.-The plough-standard- 1 . made of a thin plate, with a thauge upon both sides of its forward edge, substantially a herein shown and described, and for the purponesel forth.

3.- The slotted brace-rod. $F$ and posts or arms $G$, in combination with the standards $C$ and beam A, whether said braces be placed in front or rear of said standards, substan. tially as herein shown and descrilsed, and for the purpose set forth.

4.- In improved expanding double-shovel plough, formed by the combination of the ploughs 1 , standards $C$, hollow spindles $\mathrm{F}$, brace-bars $\mathrm{F}$, post or arms $\mathrm{G}$, bean $\mathrm{A}$, ane handles $B$, with each other, substantially as herein shown and described, and for the purpose set forth.

No. 93.530.-E. S. GREG()RY, Lockport, N. Y.Cittivitora-Aurust 10, 1869 .

Claim-The slotted metal plate D, constructed as de scribed, in combination with the clamp-screw $f$, and bars ir, arranged to operate stubstantially in the manner and for the purjose specified.

No. 93,543.-B. F. McCARTY, J. W. ORR, and R. J ORR, FIORENCE, (is.-Combination Plowshs.-Austest In, IS6og.

Claim - The combination of beams A D F, spreader: I I, bolts $\mathrm{N} m$, plough-standards $\mathrm{E}$ G $\mathrm{O}$, bolt $r$, braces $\mathrm{H} 11$ standards $C$ and handles B B, all constructed to operate to rether, subatantially in the manner and for the purpose set forth.

No. 94.133.-FREEMAN F. REINOI.DS, BETHANY, (iA.-Cultizators.-August 24, I 869.

Claim - The combination of the movable means I J, with the pivoted cross-hars $\mathrm{K} \mathrm{L}$, the fixed beam A, the curved plate M, anil the adjusting-bolt $m$, adapted to be set in different holes in the curved plate, when the several parts referred to are constructed to operate together substantially in the manner and for the purpose described.

No. 94,351.-ZACHARINH B. SIMS, BoNHAM, TEXAs - cotton Plowghs. - tustist 3I, 1860.

Claim. - The reversible ploughs $b b^{\prime}$, in combination witl the ploughs $c, d$, for breaking up the soil and laying off seet. furrows, a $>$ and for the purpose set forth.

No. 94,554.-ABRA II BOI.ES, KINDER, IND.-Ploughs. - Siptimber 7, 1869.

Claim,-1.- Hinging the beveled forward ends of the plough-beams A to each other by means of the eye or hingeplates $\mathrm{B}$, and clevis C D, substantially as herein shown aucl described, and for the purpose set forth.

2.-Adjustably connecting the rear parts of the plough beams $A$ to each other by the adjustable over-lapping hinged bars $G$, uprights $H$, and overlapping adjustable hinged bars 1, substantially as herein shown and described, and for the purpose set forth.

3. - The combination of the springs $\mathrm{K}$ and projections $\mathrm{L}$ with the plough-beams $A$ and adjustable overlapping hinged bars $G$, substantially as herein shown and described, and for the purpose set forth.

No. 94,663.-JAMESSTEPHENS, Aciency CITY, IoIV.A -Plour hs.-September 7, 1860.

Claim. - 1. - In combination with the frame, constructed as described, two sbovels, arranged as specified, the righthand one being removable, and so twisted as to throw all the dirt to the right or left as may be desired.

No. 94,751.-IVII.LIA II HUNTER and DANIEL. II. HUNTER, MEADTille, PA.-Soil Tillers.-Siptember 14 1869.

Claim.-The construction of the head-piece $\mathrm{C}$, with the beveled edge at $s$, in combination with the tines or teeth, constructed as described, for the purposes set forth.

No. 95,035--ISAAC J. MORROW, EVERTON, IND.Cinlizutors.-Siptember 21, I860.

Claim. The adiustable standard $G$, so constructed that the plough $\mathrm{H}$ may always work at a higher level than the plough $\mathrm{C}$ of the rear standard $\mathrm{B}$, in combination with the beam $A$ and rear standard $B$, substantially as herein shown and described, and for the purpose set forth

2. - The adjustable pivoted lever $K$ and fender $J$, in com bination with the adjustable standard $G$, bea $n$, and rear standard B, substantially as herein shown and described, and for the purpose set forth. 
No, 9 OIO,-E A. KAMERER, GREENTUWN, ОHo, - Shoriel Ploughs - October 19, 1869.

Claim.-1.-A shovel plough, provided with one side and two movable shovels, when so constructed as that the movable shovels may be readily turned, so as to assume any required angle with the plough beam, and may be set at any desired distance from said beam, and, also, so that said movable shovels may be readily moved into, or nearly into line with said fixed shovel, substantially as is herein set forth.

2.-The arm M, rigidly attached to the shovel-standard $\mathrm{i}$, and held by a bolt, $\mathrm{P}$, working in a slot, $a$, in the plough. leam $A$, when said arm serves both to bold the shovel. standard $\mathrm{G}$ at the required clistance from the plough-beam $\Lambda$, and, also, to regulate the angular position of said standard, with respect to said plough-beam, substantially as is herein specified.

3.-Pivoting the standards $(i$, of the side-shovels $L$, of a shovel plough to the side beams $F$, by means of a hingepivot joint, $\mathrm{H} 1 \mathrm{~K}$, and brace $\mathrm{W}$, having a loose joint, $f$, with the standard $G$, subst intially as is herein specified.

96,126.-JAMES H. LOCKIE, HuMPHREY, N. V.Cultizators.-Oitober 26, 1869.- -antedated Oitober 16 , 1869 .

Clain, - The combination, with the central beam $\mathrm{A}$, of the onter beams B B, when the same are constructed, as described, and comected by the three armed piece C, substantially as described, for the purpose specified.

No. 96,344.-FRANCIS L. PERRI, CANANDaltilta, N. Y.-Cultizators. - November 2, 1869.

Claim.-r. - The arrangement of a series of cultivating teeth, in front of and in combination with the horizontal knife or cutter S, which follows the teeth.

2.-Arranging the points of the teeth, which run in ad vance of the horizontal cutter, lower than the cutter, to protect the cutter from stones and other obstructions.

3.-Curving the ends of the horizontal cutter, as shown and described, so as not to cut too deep near the rows of plants cultivated.

4.- Making the horizontal cutter adjustable higher or lower on the frame, substantially as described.

5.-In combination with the stirring teeth and horizontal cutter, the hilling-shares, arranged in rear of the horizontal cutter, substantially as described.

6.-The combined clevis and guage-wheel stand or plate, arranged to vibrate in the end of the beam, and provided with a notched segment and spring latch, so that the work man can release, adjust, and lock the clevis and gauge. wheel in the position required while the cultivator is at work or in motion.

No. 96,399.-MICHAEL C. C()X, BENNETTSVIHIE, S C - Ploughs.-Nerembir 2, 1869.

Claim,- The convertible plough, harrow, guano and seed sower and planter, having frame E, block $(i$, ploughs and harrows, Figs. $3,4,5,6,7,8$, and 9 , funnel $\mathrm{C}$, and box D, with bolts, openings, and straps, as described, constructed and arranged substantially as specified.

No. 96,667.-WILliaM H. BOTT, Vork, PA.-CornPloughs.-Noiember 9, 1869 .

Claim,-1.-The curved standard $O$, when constructed with the lateral spread, and with the series of holes 000 on each sicle, and employed in connection with the guides $\mathrm{N}$ $\mathrm{N}$, and beam $\mathrm{A}$, substantially as and for the purposes set forth.

2.-The arrangement of the two wheels $\mathrm{R} R$, and curved standards $S \mathrm{~S}$, in connection with the crosi-beam $\mathrm{B}$, longitudinal beam A, drag-bars I I, ploughs $G$ G, cross-bar II, and bandles E E, substantially as and for the purpose de scribed.

No. 96,757.-CALVIN J. WOODS and JoSEPH A. PHILI,IPS, Centreville, INn,-Plough and Cultizator. Comb- - November 9, 1869 .

Claim. - The plough herein described, having beams and ploughs $\mathrm{A}, \mathrm{B}$, and $\mathrm{C}$, bolt $a$, set-screws $d$. handles $H$, and sliding frame $\mathrm{F}$, constructed ard arranged as specified.

No. 96,979--JAMES SIMPSON, CURDOVA, I1.L.-Cultivators. - Newis mber 16, I869.

Claim.-1.-The combination of the adjustahle ploughs $d$ and $c$, and the shovel $c$, with the beam $a$ and handles $b$, all arranged as described.

2.-The detachable shovel $c$, and the adjustable stem $/$, constructed and applied to the beam as berein set forth.

3.- The reversible brace-rod $h^{3}$, in combination with re cessed and detachable blocks $j^{3}$, arranged to operate as described.

No, 97,319,-ALEXANDER SHAW, MoNmovTH, I1L. -Cultizators. - November 30, 1869. - antedated Norember 22, 1869 .

Claim.- The cutter $C$, with series of holes $c c c$, for regulating the depth, when comhined with the mould-boards $A$, point $B$, handles $\mathrm{I}$, bow $\mathrm{I}$, and the plate $\mathrm{D}$, substantially as described, and for the purpose set forth.

No. $97,465 .-A$. W. WILKINS and S. T. ESKRIDGE, - Rome, GA.-Expanding-Ploughs.-November 30, 1869.

Claim.-1.-Adjustably supporting the lower ends of the plough-standards $\mathrm{C}$, by means of the brace-rods $\mathrm{E}$, nuts $e^{\prime}$, rods or bolts $\mathrm{F}$, nuts $f^{\prime}$, and brackets $\mathrm{G}$, said parts being constructed, arrangert, and operating subitantially as herein shown and described, and for the purposes set forth.

2. - The combination of the rods and nuts $v d^{\prime}$, rods and nuts $\mathrm{E} c^{\prime}$, rods and nuts $\mathrm{F} f^{\prime}$, and brackets $\mathrm{G}$, with each other and with the beam A and standards C of the plough, substantially as herein shown and described, and for the purpose set forth.

No 97609.-CHARLES CROW, CovingTON, IND., assignor to himself and IVILLIAMSON D. KERK, same place.-Ploughs.-Diember 7, 1869 .

Claim.-1,-A plough, provided with two adjustable mould board, which may be moved nearer to or farther from each other, which may be used either as a ditcher or plough, substantially as set forth.

2.-The movable land side $\mathrm{L}$, when used in the manner and for the purpose described.

3.- The mould boards $\mathrm{H}$, cutter $\mathrm{M}$, braces $\mathrm{K}, \mathrm{N}$ and $\mathrm{O}$, beam $\mathrm{A}$, plates $a$, screws $c$, and sheath $\mathrm{D}$, when combined to form a plough, substantially as specified.

No. 97,921.-JOHN C. HOLMES, Wromini, PA.Corn Cultivators.-December 14, 1869.

Claim.-1.-The heams A A, constructed as described, each consisting of two bars $a n$, connected together at a suitable distance apart, and provide $l$ at one end with ears $b \quad b$, by means of which the beams are joined together, substantially as shown and describer.

2.-The combination of the beams A A with ears $b \quad b$, clevis B with ears $C c$, curved bars $C \mathrm{C}$, and bar $\mathrm{G}$ with ears $f f$, all constructed as described and for the purposes set forth.

3.- The reversible handles E E, connected by means of the $\operatorname{rod} \mathrm{F}$, and provided with the rods I) I), substantially as and for the purposes herein set forth.

4.- The combination of the beams $\mathrm{A} \mathrm{A}$ with the loops $d$ $d$, clevis $\mathrm{B}$, curved bars $\mathrm{C} C$, bar $\mathrm{G}$, reversible handles $\mathrm{E} \mathrm{E}$, and rods i) $\mathrm{D}$ and $\mathrm{F}$, all constructed and arranged substantially as and for the purposes herein set forth.

5.--The reversible ploughs $\mathrm{H} \mathrm{II}$, secured to the beams A $A$, by means of the shanks I 1 , and plates $h k$, substantially as shown and described.

6.-The plate $h$, provided with projections $i i$, and passed over the plough shank I, substantially as and for the purposes herein set forth.

7. - The combination and arrangement of the beams A A, clevis $\mathrm{B}$, bar $\mathrm{C}$ C and $\mathrm{G}$, revenible handles $\mathrm{E} \mathrm{E}$, and ploughs $\mathrm{H} \mathrm{H}$, all cunstructed and connected substantially as and for the purposes herein set forth.

No. $98,202,-S$. T. SPAUl. DING, NiNRTH COHOCTON, N. Y.-Cultizators.-December, 21, 1869.

Claim.-The combination, arrangement, and construction of the central beam $a$, cross bars $b b$, and side beams $c c$, the doubly adjustable clevis, and the adjustable single and double teeth $d d g$, the whole operating together as described.

No. 98,2I4-EDWARD WIARD, LuUISviLle, KY. assignor to B. F. AVERY, same place--Expanding Triple Shovel Ploughs.-Dice'mber 21, I869.

Claim.-1.- The bars or frame C, constructed and secured to the plough beam, substantially as herein shown and described, and for the purpose set forth. 
2.-Adjustably connecting the $r$ car plough-standards Gi to the rear ends of the bars or frame $\mathrm{C}$, by the tube E and long holt $\mathrm{D}$, whether made in one piece or seprarate, and the washers $F^{\prime}$ and set screw's $g^{\prime}$, sulstantially as herein shown and described, and for the purpose set forth.

3.-Adjustably securing the forward standard $\mathbf{L}$ to the forward end of the bars or frame $\mathrm{C}$, by means of the wash ers $\mathrm{N}$ and bolt $\mathrm{M}$, substantially as herein shown and described, and for the purpose set forth.

4.- The notched washers F N, constructed substantially as herein shown and described, when used for securing the plough standards in place, as and for the purpose set forth.

5.-The combination of the slotted and grooved washer $K$, eye-bolts $I$, and slotted arms $I$, with the brace-rods II and bars or frame C, substantially as herein shown and described, and for the purpose set forth.

No. 98,251.-FRA.TK GOSi, WEXFur 1), PA.-ShovelPlonghs, - Decomber $\mathbf{2 8 , 1 8 6 0 .}$

Claim,-1.-The combination, in a cultivating plough, of a beam $A$, standard $\mathrm{B}$, sole-bar $\mathrm{F}$, upright arm $\mathrm{H}$, and tie-bolt $(i$, constructed and arranged as herein described, and for the purposes set forth.

2.- The sole-bar F, as constructed, of the form represented and dencribed.

3. - The shovel or share E, constructed with the flaring dovetail-attaching socket e, sulstantially as represented and described.

4.- The combinasion, in a cultuvating plough, of a frame A, B, F, G, H, handles C, clevis D, shovel or share E, wings or scrapers $1 \mathrm{I}$, device $\mathrm{J} \mathrm{J} \mathrm{K}$ for adjusting the wings or scrapers, an adjustable gauge-wheel L. $l$, and means $a \mathrm{n}$; for holding the gauge-wheel, constructed and arranged as herein represented and described, for the purposes shown.

No. 98,471.-BOWNAN S. COX, PAulsborovgh, N. I.-Cullizators.-Fanuary 4,1870 . Antedated De. center 22, 1860.

Claim.-1.-In a cultivator, the fender F and tooth D, constructed and arranged substantially as and for the purpose set forth.

2. - Constructing the beam $\mathrm{C}$ with a portion bent, to contain a long tooth $\mathrm{D}$, and prevent the vines from falling forward, substantially as set forth.

3.-Constructing the rear ends of the oblique frame-bars, as described, in combination with suitable bolt and serew, to connect and regulate the same.

4. - In combination with oblique bars, as described, constructing and arranging the shank $\mathrm{G}$, as and for the purpose set forth.

5.- Constructing and arranging the standards $\mathrm{H}^{\prime} \mathrm{H}^{\prime}$, as specified in combination with the oblique bars, as set forth.

No, 98,650,-B. F. WARD, INDIAN SPRiNGs, Gi.Cullizaters.- Fanuary 4, 1870 .

Claim. - I. - The bow or frame D, cross-har E, teeth $-F$ adjustable cross-bar $G$, and stay or brace II, with each other, and with the standard C of the frame A B C, substantially as herein shown and described, and for the purpones set forth.

2.- The combination of the pivoted bars 1 , adjustable bars J, and cross-bar $K$, with the frame or low $D$, cross-bar $\mathrm{E}$, teeth $\mathrm{F}$, adjustable crons-bar $\mathrm{G}$, and standard $\mathrm{C}$, substan tially as herein shown and deseribed, and for the purpose set forth.

No. 99,208.-JOSEPII G. KNAPP, MADISON, and SAIIUEL 1). LIBBY, BLuoning Grove, Wrs.-Cultì' tors.- January 25, 1870 .

Claim_-1 - The form of the side knives, made of steel, iron, or both combined, as described, and for the purposes hereinbefore set forth.

2.- The setting the knives, in the manner and for the purposes substantially as hereinbefore set forth.

3.- The iron or other metallic chair, substantially as and for the use and purposes hereinbefore set forth.

4. - The combination of the broad, straight knife in front, with the side knives, all made and set substantially as described, with the metallic chairs on the side-beams, as described, also, the same combination of similar knives set in beams by means of mortises, or otherwise, substantially as and for the purposes hereinbefore set forth.
No, 99,236, -ANTIIONY A. RIIOADES and H11.E.

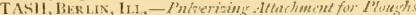
- Funuary 25,1870 .

Claim.-1.- The detachable blades 1), constructed and secured to the supporting bar C, substantially in the man ner herein hown and described, and for the purpose set forth.

2.- The combination of the detachable blades $\mathrm{D}$, adjust able supporting bar $\mathrm{C}$, and adjustable brace-bar $\mathrm{I}$. with each other, said parts being constructed and connected with an ordinary plough-frame, substantially as herein showa and described, and for the purpose set forth.

No. 99,377.-WILLIAM WATKINS, JH.IET, IL..Subsoil Ploushs.-February 1, 1870.

Claim. - The combination and arrangement of the share $A$, braces $C$, crooked bar $B$, shin $D$, brace $I$, beam $E$, block F, and bandles P P, as and for the purposes set forth.

No. 99,625-DANIEL (i. BENNER, Holmesvil.te, Oно,_Cultizators.-February 8, 1870

Claim.- The combination and arrangement of the main centre beam $a$, side beams $d$, braces $m m$, and handles $r r$ if $s h$, the parts being constructed and operated substantially as set forth.

No. 100,040.-NATHAN L. ISGRIGG, MOORE's HILL, IND.-Cultizators,-Fibruary 22, $187 \mathrm{O}$.

Claim.-1.-The nut $f$ upon the brace rod $E$, serving with the nut $f^{\prime \prime}$, the double purpose of securing the share to the standard and both to the brace, as set fortb.

2.-The combination and arrangement of the beam $A$, standard C, brace F, nuts $f^{\prime} f^{\prime \prime}$, and slotted share I J K, substantially as and for the purpose described.

No. 100,277.-JOHN C. ERWOOI, VERNoN, IND.Corn Cultivators.-Alarch 1, 1870.

Claim.-The combination of an adjusable mould board, A, with a triple toothed cultivator, for the purpose and in the manner substantially as shown.

No. 100,655.-WALTER NOTMAN, DEERFIEI.D, OHIO.-Cultivators.-March 8, 1870 .

Claim. - 1.-The arrangement and construction of the beams A A, clevis $K$, brace $D$, double cross bar $\mathrm{I}^{\prime}$, and handles B B, substantially as described.

2.- The peculiar construction and combination of the mould-boards E E, share F, and braces $\mathrm{C}_{\text {; }} \mathrm{H} \mathrm{I}$, substantially as and for the purpose set forth.

No. 100,984.-JOSEPH CLUCKNER, ARcAm, IND. - Dirt-Gauge for Ploughs.-Barch 22, 1870.

Claim,- The gauge D F, guard-loop or keeper F, and adjusting-ring $\mathrm{G}$, in combination with each other and with the plough-beam or frame, said parts being constructed and operating substantially as herein shown and dexcriberl, and for the purpose set forth.

No, 101,010-HERMANN W. HASSLOCK, NASHville, TENv.-Horse-Hoes.-March 22, 1870

Claim - The combination of the cross-bar E, standards F, hoes or knives G, nuts H I, braces J, wheel D, and adjustable standard $\mathrm{C}$, with each other and with the ploughbeam $\mathrm{A}$ and handles $\mathrm{B}$, substantially as herein shown and described, and for the purpose set forth.

No. 101,200,-JOHN WOLPERT, LOUISVIL.I., KY,Combined Ploughs and Cultitators. - March 22, 1870.

Claim.-The combination of the swiveling bars $\mathrm{C} \mathrm{C}$, clips D, side beams B $\mathrm{B}^{\prime}$, and brace $\mathrm{E}$, all arranged to operate substantially as and for the purpose set forth.

No, 101,076.-IACOB BOWER, DAYTON, OHIO,Cultivalors.-April 19, 1870 .

Claim. - The combination of the cultivator-teeth shanks B, shovels $\mathrm{C}$, and frame $\mathrm{A}$, the parts being constructed, arranged and operating in the manner and for the purpose substantially as described

No. 102,015.-HERVY S. ROSS, Millvil.Le, (HIO.Cultiatars.-April 19, 1870 .

Claim.-The construction, combination, and arrangement of the frame A A B C D $d$, the standard attachment devices $y z y^{\prime} z^{\prime}$, and the teeth or flukes $\mathrm{F} \mathrm{F}$, all as herein represented and described, for the purposes set forth

No. 102,223.-ALBION P. CLEMENTS and JOHN C.

NEAL.EY, Monroe, ME.-Cultizators.April 26, I $\$ 70$.

Claim.-The combination of the cultivator proper, the 
front $x$ ljusting- $\$$ lind 5 , and the adjustable guiding and smoothing-roller $\mathrm{E}$, all constructed and arranged to operate substantially as described and shown.

No. 102,543.-LOUIS HONIRIGHOUS, BALTIAORE, OHн.-Cultivator Ploushs.-Wan 3, IS70.

Claim,-1.-In combination with the frame A B C of a doulble-shovel cultivator, constructed to cultivate simultaneously both sides of a row of corn, the two adjustable rotary fenders $\mathrm{N} N$, so combined and arranged with reference to each other and to the main shovels $b \%$, as to inclose and shield hoth sides of the plants, substantially as herein set forth.

2.- The extra and auxiliary detachable shovels J and M, when so combined with a cultivator as that one of said shovels, M, shall be placed to work in the rear, and the other, $\mathrm{J}$, in front of the main shovels $b \quad b$ of the implement, substantially as and for the purpose herein set forth.

No. 102,841.-TRUMAN MABBETT, SR., VINELAND, N. J.-Cultivators.-May ro, is7o.

Clain. - The combination with a cultivator of an adjustable cutting-bar or skimmer, B, substantially for the purpose shown and described.

No. 102,993.-NATHAN G. IVEBBER, EAST SIRINGFIELD, PA. - Cultiatators. - Nuy 10, I870.

Claim - The arrangement of the fixed bow $(i$, the ad justable shovels $\mathrm{K}$, the hinged folding handles $\mathrm{I}$, and the locking and bracing yoke J, as herein shown and described, and for the purpose specified.

No. 103,476.-HUGH L.A1RD, MechaNiCsBUki, P.A.Culticutors.-Hav 24, I87o.

Claim.-.I-The means employed for rendering relatively adjustable the side-beams $\mathrm{A}_{\text {and }} \mathrm{A}^{\prime}$, consisting of the arched braces $\mathrm{C}$ and $\mathrm{D}$ and bolts $d$ and $i$, in combination with the pivoted cross-bar B, substantially as and for the purpose specified.

2.-The means employed for adapting the tongue to the various widths of the cultivator-frame consisting of the coupling-irons $F$, provided with the bolts $f$, in combination with the slotted cross-bar $\mathrm{H}$, suhstantially as shown and described.

3.-The scrapers $\mathrm{K}$ and $\mathrm{K}^{\prime}$, secured upon and combined with the hereinbefore-described cultivator, substantially as and for the purpose set forth.

No. 103.982, - HENRY C. CLOYD, WEST ALEXANDRIA, Онго,-Plousths.-Junt 7, I 870 .

Claim, - 1,- The arrangement of the shanks C C, rods $f f$, and nut $i$, with the plough beams $\mathrm{A} A$, and handles E E, connected by the boxes $h h$, through the stotted ends of the handles, all constructed substantially as set forth.

2.- The arran rement of the beans $\mathrm{A} \mathrm{A}$, clevis $\mathrm{B}$, shanks $\mathrm{C} \mathrm{C}$, ploughs $\mathrm{D} \mathrm{D}$, handles $\mathrm{E} \mathrm{E}$, guides $a q$ and $d \dot{t}$, rods $f$ $f$, nuts $i i$, and boxes $h / i$, all constructed substantially as and for the purposes herein set forth.

No. I04,154--RUFU'S C. HOLT, Morehouse PARish, LA.-Cotton-Choppers. - Fune I4, I87o.

Claim.-The arrangement of the adjustable standards F $F^{\prime} F^{\prime \prime} F^{\prime \prime \prime} F^{\prime \prime \prime \prime}$, brace-rods $H$, cutters $G G^{\prime} G^{\prime \prime} G^{\prime \prime \prime}$ G'l', frames A B C, hounds I, tongue 1 , handles $\mathrm{K}$, and wheels $\mathrm{D} \mathrm{V}^{\prime}$, when these several parts are constructed, united, and operate as herein described, for the purpose set forth.

No. I04,729.-MARCELLUS B. GOFF, DELAVAN, WIs.-Corn-Plouglis.-June 28, iS 7o.

Claim,- The guide-iron E, having a standard, provided with flange $a$ and elongated slot $b$, and having a base or runner made with a rounded front, $f$, substantially as described.

No. IO4,763.-JOHN IVESLEY PHILP, HuMBOLd, TENN-Cultizutors.-Jume 28,1870 .

Clain. - The arrangement of the frame A D, the arm $\mathrm{E}$, set-screws $g$, keepers F, draft-bar B, laandles $H h^{\prime} \mathrm{I}$, cultivator-teeth $\mathrm{K}$, harrow-teeth $\mathrm{J}$, and crossed or inclined teeth, all constructed substantially as shown and described.

No. 105,358.-JOSEPH B. MOODV, LOUISVIl.LF, KY. - Cultizaters. - Fuly 12, 1870.

Claim, - 1.-The arrangement of the bars $\mathrm{G} H z$ and $m$, arms $\mathrm{D}$, handles $\mathrm{B}$, beam $\mathrm{A}$, and ploughs $\mathrm{R}$, when the several parts are constructed as and for the purpose specified.

2.- In a cultivator, the arrangement of the plates $\mathrm{P}$ and $d$, and clew $\therefore$, when constructed a - tum $u$ and described. No. I05,745.-CHARLES L. WAFFLE, SHARON CENTRE, OHio,-Cultivators.- $7 u l y$ 26, 1870.

Claim.-1.- The arrangement on one side of the standard $\mathrm{A}$ of two parallel staples, $\mathrm{E} \mathrm{E}$, the lower one slightly further forward than the upper, to form a rest for the ploughstandard, and to enable the same to be adjusted by wedges vertically or horizontally, as set forth.

2.- The arrangement of the projecting points of fingers $\mathrm{H}$ below the edges of the shovels or shares of a cultivator, to pulverize the soil in advance, as set forth.

No. I05,S28. - ISAAC MHLLE, WORTH, Mich.-Cultizators. - Fulv 26, 1870 .

Claim. - The arrangement of the frame A B C D, hooks $a$, tongue $\mathrm{E}$, wheek $\mathrm{G} \mathrm{G}$, bars $b b$, pins $d$, teeth $I I \mathrm{H}$, braces $1 \mathrm{I}$, and handles J J, all constructed and operating substantially as and for the purposecherein set forth.

No. 106,004.-JACOB R. IVAGIER, MANADA Hili. PA.-Combined Harrowos, Cultizutors, Wheelbarronus, and Sleds.-Awyzt 2, IS70.

Claim.-1.- The arrangement in a harrow of handles $B$ $B$, the cultivator-teeth $c c$, and the swinging, elevating, or clearing-har 'B', substantially in the manner and for the purpose described.

2.-The gravitating swinging har $\mathrm{B}^{\prime}$, applied to a combined harrow and cultivator, in the manner and for the purpose described.

3.-The arrangement of the sliding bar $\mathrm{C}$, cultivator teeth $c$, hooks $h$, and forked props or arms $f$ upon the harrow, in the manner and for the purpose substantially as described.

4.- The arrangement of the harrow, having handles B, the wheelbarrow-wheel $D$, and the sleigh-runners $G G$, the several parts being constructed and arranged and operated substantially in the manner described.

No. 106,235.-IAMES B. T1BBlTS, Portiand, Mich. assignor to himself and JOSEPH STEBBINS, same place. - Cultivators.-August 9, IS7o.

Claim.-1,-The combination of the hinges L M, with the ploughs $\mathrm{K}$ and standards $\mathrm{E}$, substantially as herein shown and described, and for the the purpose set forth.

2.- The combination, with the heam $\mathrm{A}$ and standards $\mathrm{E}$, of the hinged ploughs $\mathrm{K}$, hars or rods $\mathrm{N}$, and pivoted adjustable lever $\mathrm{O}$, all arranged to operate as specified.

Vo, IO6,693.-HENRY HARRIER, 1NDIANAPOLIS, IvD.-Corn-Ploughts.-Ausust 23,1870

Claim. - The combination and arrangement of the beams $C \mathrm{C}$ and $\mathrm{A}$, the stocks $\mathrm{D} D$ and $\mathrm{B}$, pivoted handles $\mathrm{F} \mathrm{F}$, bar $\mathrm{G}$, and plates E E, substantially as and for the purpose hereinbefore specified.

No. 106,702.-AUGUSTUS' LEONARD, NEWELL'S RuN, Unto,-I'otato-Plons hs. - A urgust 23, 1870

Claim.-The plough descrihed, consisting of the beams $A A^{\prime} A^{\prime}$, rigidly secured at the front ends, connecting beam $\mathrm{B}$, arms $c c^{\prime}$, and handles $d d^{\prime}$, when all the parts are con structed and arranged as described, for the purpose set forth. No. 105,733.-NELSON S, SHIELDS, ROCKFORD, ILI. - Cultivators-Ausust 23,1870

Claim.- The springs B B, with bar $b$, when constructed specifically as described, and employed to connect the evener $\mathrm{C}$ directly to the beams A A of the cultivator, as described

No, I06,837-JACOB M. LANDEs, SOUdERs, PA.Combined Ploughs and Cultiantors. - fusust 30, 1870.

Claim.-The reversible ploughs J K, standards I D, draft-har $F$, and heams A G G, all constructed and relatively arranged, as and for the purpose described.

No. I06,956,-REUBFN 1. PAYNE, RACEVILLE, VA. - Cultivators.-August 30, 1870.

Claim.-The arrangement of the interchangeahle scrapers $A$, with harrows $E$ and centre piece $H$, and with the right and left-hand teeth B, substantially in the manner and for the purposes set forth.

2.- The teeth B, constructed substantially as set forth.

No. IO7,142.-CHARLES L. WHAITE, WAIERLy, PA,-Cultizentors-September 6, IS7O.

Claim, - The arrangement, in a cultivator formed of wrought iron, of the double curved central plough-beam B, split clevis $\mathrm{C}$, braces $m$, horizontal brace $K$, bandles $\mathrm{H}$, 
bent brace i, thomb-nut and sctew t, and rectional side plourh-heams 1 , horimontally jointed lyy twivine the adja cent ends of the sections at i, all com-tructed as vet forth.

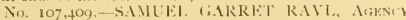

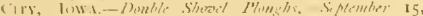
IS70.

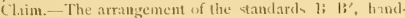
les $($, Iraces $b$, stirrups $a$ and $d$, the bolt $c$, and hook bolt $\therefore$ when constructed as described and hown, and for the purpose of adjunting s,id standarch.

2.-The plough ahove described, consisting of the leam A, the stanclaris $13 \mathrm{~B}^{\prime}$, the hamblles (; the clocl-fender 1 ) the shovels $\mathrm{E}$ and $\mathrm{F}$, the stirrupe $a$ and $d$, bolt $c$, and hookboll c, when constructed and arranged as described and shown, and an and for the purposes set forth.

No. 107.+16.-GEORGE H. SHITIl, THE Mories, low:- Cullizuturs-Siphember 13.1870

Claim. - The beam $\mathrm{A}$, the handlew $\mathrm{B} \mathrm{B}$, lraces $a$ a $a \mathrm{a}$, and loop b, arranged as described, and for the purpore set furth.

No. 107.456.-IRA COPELANI), NuRTH BrHYF WATrR, Miss.-Horse-Hoes - September 20. IS7o.

Cham-1-The comlination of the clevis $k$ with the lunvings $11 \mathrm{II}^{\prime}$, the notched segments I' M, and the key

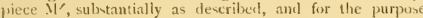
$\rightarrow-\mathrm{t}$ forth.

2.- In a horse-hoe, the bars $1 \mathrm{~A}^{\prime}$, when bent and arrangreal, in comlsination with the clasps $\mathrm{E} \mathrm{E}^{\prime}$, and cross-bar $\mathrm{F}$, substantially as described, and for the purpose set forth.

3.- The combination of the loop-bolt ' $N$ ' with the bar C C" the crons-bar F, and the pointer $Q$, sulutintially a described, and for the purpose set forth.

4.- The combination of the loop-bolt $\mathrm{N}^{\prime}$ with the cross bar $k$ and handle-hracket $\mathrm{K} K$ ', -ubstantially an dencribed, and for the purpose set forth.

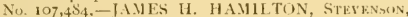
ALA.-Cinltizaters.-Siptember 20, 1870

Claim, - An improved cultivatur, formed by the cumbina tion of the three parallel heams A B C. pivoted cross-hars

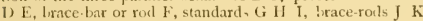
l. an. I I] N O, brace-har $P$, and brace and gauge-rod $Q$, with ench other, substantially as herein thown an clescribed, and for the purpose set forth.

No. 107,526.-Joll. NEFF. JR. Pultey, N. Y'Cultivators.-Siptimlict 20, 1870 .

Claim.-The arrangement, in a cultivator, of the beam $A$, the bars $\mathrm{F}$ and $\mathrm{F}$, the teeth $\mathrm{B}, \mathrm{C}, \mathrm{D}$, and $\mathrm{E}$, cutters $\mathrm{G}$, liandle; II, purts $a, b, c$, and $c^{\prime}$, all con-tructed to operate as slescribed.

NO, 107,754.-VICTOR BULIS, ST, MARY'S PARISH,

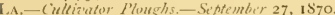

Claim.- The boe-ploughs $\mathrm{A}$, when mounted on a diagonal front lar of a frame, B, the said frane being provided with a cutier-blade, $\mathrm{C}$, in combination with the frame, convisting of the longitutinal bars $\mathrm{D}^{\prime} \mathrm{D}^{\prime}$, a sufficient numler of crosshar, and the sandad, E E', when said frame is provided with the adjusting elliptical rumern $G G^{\prime}$, and these latters are operated liy a yoke frame, $\mathrm{H}$, and a lever, $\mathrm{J}$, and all the parts are constructed, arranged, and operated subutantially an ilescribed, for the purpose set forth.

No. 10\$,047-PEIER 13. PARCEIL, ASHMORK, III.

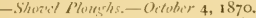

Claim, - The arrangement of the beams $\mathrm{A} \mathrm{A}^{\prime}$, hook $\mathrm{B}$, screw-rod C, handles $D^{\prime} \mathrm{L}^{\prime}$, round $\mathrm{E}$, braces $\mathrm{C}$ ( $\mathrm{i}^{\prime}$, plough $11 \mathrm{II}{ }^{\prime}$, bolt $a a^{\prime}$, nut $h b$, bolts $t^{\prime} e^{\prime}$ and $h h^{\prime}$, and set. screw's $f f$, all constructe.l substantially as and for the pur pore herein set forth.

No. IOS,230,-WIIIIAM C. CLIITON, E1.K RIIFK Towsshrp, low 1,-CornPloughs, - Octoher $11,1870$.

Claim. - The particular arrangement of the fiveshovels A, I, ( , I), and $\mathrm{E}$ in an iron corn-plough located as clescrilred, with the adju thble slotted bar $F$, when constructed and arranged sub-tantially as for the purpose above set forth.

No. 108,273.-LUPIE LLP'PEN, PEKIN, 11.1.-Shoz'? Ploughs. - Oifolier 11, 1870

Clam.-The arranirement, with reference to each other, of the plough-beams $\mathrm{A}$ A, sockets $\mathrm{C} \mathrm{C}^{\prime}$, drawbar $\mathrm{W}$, and bolt $\mathrm{E}$, subiantially as and for the purpose set forth.

Vi) 10\$, 398.-HENRV M. SKINNER, RurkFRun,

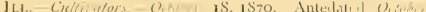
12, 1 15 70 .

Chim. - The machine described, having the longitudiual entre beam 1, transverse end heam - 13 13, supporting whech. ( ' $C$ ", hinged side levers $\mathrm{E}, \mathrm{E}$, and teeth $\mathrm{I}$, when combined and arranged as described, for the purpose set forth.

No. 108,44.-WILLIAM TIIOMIS BUNX, IIUM-

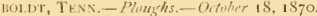

Claim.-The arrangement of the draft-beam $f$ with the plough-beams a $a$, the latter heing composed of the sections $b$ and $i$, which are comnected by the coupling $d$, and so arranged that the length of the beam $a$ may be variet at pleasure, for the purpose of placing the shank / either alureast or in rear of the shank $h^{\prime}$, the shanks $h h^{\prime}$, and the adjustable slat $k$, when all these parts are contructed and arranged to operate as described.

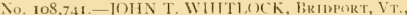
administrator of CVRUS WIITIL)(K, deceased.-Ilors Ihocs.-Ortuler 25, 1870

Claim.-The heam $\mathrm{A}$, with projection $\approx$ a, aliuntable legs: 1) 1 , plough-point 1 ), hirged to the sole-pice $(.$, and the pirated wings E E, braces d $d$, and bolt e, all constructed and arranged substantially as set forth

Nis, 108,834 -ELIJAII G, R()WVIII, NLFONZO)D. ROWELL, IANES R. RICE, and SUITII M. SEEI.ES.

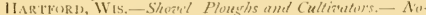
(rmbir 1, 1 \$ 70.

Claim. - A shovel plough and cultivator, constructed with centre frame A, handles If li, stem-post (C) side frames i) 1), cross-bar $\mathrm{E}$, teeth $\mathrm{F}$, and plough-share $(;$, arranged substantially as describerl.

No, 108,857. - JOIIN A. WAI.TER and EIJ BLSIl-

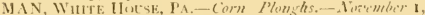
I. 7 7O

('lain..-The standards $(1)$, articulated on as to fold backward, and provided with the draft-rod (), whereloy they are secured in the vertically-inclined or folded position, arranged with the heam $A$, standard $\mathrm{B}$, handlen $\mathrm{F}$, as shown and descritred.

No, rog.247.-JOHIN REBMAN, BINKLEY'S BRHMA, P..-Cultivators.-Nirember 15, 1870.

Claim.--The arrangement, in a cultivator, of a fulcrumpully, $\mathrm{P}$, al instable hearings $\mathrm{F}$, acljustable lrace $\mathrm{G}$, central shovel-arm A, curved bar D, clip E, and hook-bolts i ' $'$, all constructed to operate as described.

No, 109.558,-IOHN R. THOMAS, MIFLIN, PA.Cotion. Cultiataters and Ploushs.- linimber 22, 1870

Claim. - The standarels $\mathrm{E}$ and $\mathrm{F}$, having one straight and one beveled side, substantially as and for the purpose specified.

No. I09,893.-TILOMAS (IUTCE, MUTXT ANDREW, A.A.-Cirten Plousths.-December 6, 1870.

Claim,- The ploughs $a a^{\prime}$, and double winged ploughs C C, each constructed and both sets relatively arranged in the particular manner shown and described, whereby they are adapted to cut a furrow with a vertical side, and to scrape along each side of the cotton-plant row or ridge, and clean the furrow of loose dirt.

No I09.934-EI.WOOD PHILIJPS, CPNTREILIF 1N1-Corn. Plonshs - Decomber 6, 1570 .

Claim.-A one-horse cultivator, having a horizontally. curved beam, to admit of the horse and slriver walking on the same side of the row of corm, the heam near its rear end being bifurcated downward, and on the extremities of which are pivoted the standaris of the shovels, for the purpose of giving to the latter a lateral motion in the arc of a circle, suhatantially as herein set forth.

No 109,990 -ISAAC A. BENEIHCT, IVFAT SI'RING.

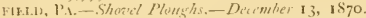

Claim.-The combination, with a pair of wings, D D, of arms $\mathrm{E}$ E pivoted to the foot of lorace I' turuing upwardly in an arc slot upon the top bolts $\mathrm{F} F$, and slotted at $G$ i: to allow the bolts II II to slisle thereon, to lift, expand, and contract saicl wings, all as deccrilied.

No. 110,682 -JACOH SATTISON, RIILFY TOWNHHP, OHI.-Cultirators.-Fanuary 3,1871 .

Claim, 1.-The adjustable slotted links or standaris $H$, pivoted to the crosu-beam $G$, in combination with the shares 
or wings 1 , substantially an described, and for the purpose specified.

2. - The adjustable slotted links $\mathrm{H}$ when pivoted to the vertically-adjustable cross-beam $G$, adjustable slotted links $F$ when pivoted to the sandard $C$, in combination with the shares $\mathrm{E}$, in the manner as described, and for the purpose specified.

3.- The arrangement of the shares E, adjustable slotted links $F$ or standards $H$, cross-beam $G$, beam $A$, and share 1 , in the manner as described, and for the purpose set forth.

No. II1,250.-WILLIAM BENJAMIN REAI), GAL LATIN, TENN.-Ciltizators - January $24,187 \mathrm{I}$.

Claim.-A cultivator, consisting of the reversible frame $A$, constructed as described, having the pivoted standards $g$ and adjustable braces $i$ and the adjustable handles $\mathrm{B}$ connected thereto, all as herem described.

No, 111,793.-ROBERT PATEN VAN HORNE, GRA тит, ()н10.-Double Shozul-Ploughs.-February I4, 1871 .

Claim.- In combination with the main beam $A$, branch beam $\mathrm{B}$, ploughs $\mathrm{H} \mathrm{H}$, hook $\mathrm{D}$, handles $\mathrm{I} I$, adjustable braces $\mathrm{L}, \mathrm{L}$, stretchers $\mathrm{K} \mathrm{N}$, and clamping-holts $\mathrm{E} F$, arranged relatively one to the other, the removable ploughbeam $\mathrm{P}$ provided with the shovel $\mathrm{O}$, coustructed as described for the purpose specified.

III,925-WILLIAM GOWAN, BARTIFTT, TENN.Cultivator-Ploushs-February 21, 1871.

Claim.-The plough $F$, having the snake-head point, narrow neck, and the long mould-board, gradually widening upward from said neck, as shown and described.

No, 112,130.-FRANK PHILIP DAENPORT, CARTHAGE, IL..., assignor to himself, JOHN WV. CHERRV, and THOMAS LOGA N. - Neadono Cultizators.-February 28,1871

Claim. - The combination of the bars E E E, cutting-fins F F F with the shear C, and the land-side bar D, beam and handles of the cultivator, operating substantially as set forth.

No. 112,481 .-DANIEL JOSELY OSARK, ARKaNSAS, -Cutton-Choppirs and Grain-Cultivators.-Wlarch 7, 187 I.

Chim-1.-The arrangement with each set of three chop. per-blocks A A, of the scoops $a a$, blarles $b b$, and plough $d$, subtantially as shown and described.

2 - The arrangement of the actjustable bars I J, runner $\mathrm{K}$, standards 1. L, and adjustable tongue N, substantially as shown and described.

No. 113,09 S.-HAMILTUN RONEV, I IY TUN, ()HIO. - Ploushs.-Warch 28, 1571.

Claim.-In a sod-plough, the arrangement of the frame $\mathrm{A} \mathrm{B} C$ and auxiliary frame $\mathrm{D} \mathrm{E} \mathrm{F}$ in relation to each other and to the roller $H$, cutters $a b$, seat $J$, beam $I$, share $G$, and rods $s$, substantially as described.

No. 113,206.-BE.XJA.MIN W. RE.MV and NO.AH T. REMV, BRookville, 1ND,-Corn-Plowghs,-Warch 28, 1871 .

Claim.-The combination of the beam A, shanks B C, ploughs $\mathrm{E}$, handles $\mathrm{G}$, braces $\mathrm{E} H$, and double-tree $I$, all constructed and arranged substantially as and for the purpores herein set forth.

No. 113,306.-ALBERT 11. KENNEDT; Oberi.1N, Онго.-Cultizators.- April 4, 1871 .

Claim.-The combination of the rod $\mathrm{F}$ with the slides 11 and the braces $6 \mathrm{G}$, substantially as and for the purposes hercinbefore set forth.

No. 113,934 -GUILF()RD D. ROWELL, MENOMOMEE Fal.L, Wis.-Horse and Hoe Cultizators.-April 18, 1871 .

Claim - A horse hoe and cultivator, arranged as follows: horse hoe M with wings $\mathrm{N} \mathrm{N}$, hoe-beam C, cultivator teeth $K$, plough-share L. in rear of frame $A$, serrated nuts $O$ on the tooth-stocks, and joints $\mathrm{D}$ in rear of share $\mathrm{L}$, and frame A, substantially as described.

No. $113,960,-$ CHARLESA. BEAKD and EZRA E. EVANS, ZaNesville, OHIo,-Ploughs.-April is, 1871 . Claim.-A plough, consisting of the beam A, arms $\mathrm{C} C$ and $\mathrm{E} E$, braces e $c e e$, and mould boards $\mathrm{B}, \mathrm{D}$ and $\mathrm{F}$, all constructed and arranged substantially as and for the purpose set forth.
No, 114,040 - ISAAC N. PVLE, PLFASANT MILLS, INI.-Cultizators.-April 25 I871.

Claim.-The bracket $\mathrm{K}$, having the form and applied to the beams A, as shown, and the fender J and spring $\mathrm{L}$ ar ranged therewith as specified, whereby the shank of said fender has a double bearing, and a vertical play in the bracket, for the purpose set forth.

No. 114,221 . - ARCHIBALD l. W. STROUD, MUNFORD, ALA.-Ploughs. - April 25, 1871.-Antedated April 19,1871

Claim.-The side-beams D 1), with their feet E E, ploughs $\mathrm{H}$ or $\mathrm{I}$, and braces $\mathrm{G} G$. when attached to the centre beam $\mathrm{A}$ by means of three bolts, $a a$, at equal distances apart, so that the side beams may be placed one in advance of the other or side by side, as may be desired, and the distance of sail side beans from the centre beam is regulated by the slotted washers $b b$, all as herein set forth.

No. 114,611,-HOSES R. SHALTERS, AILIANCE, Оніо,-Ploughs.-1/ay 9, 1871 .

Claim.-The arrangement of the plough beam A, provided with the seat $a^{\prime \prime \prime}$ having a corrugated upper surface, the cross-bar $a^{\prime}$, provided with the enlaryement or body a $a^{\prime \prime}$ having a corrugated lower side, and the screw bolt $a^{4}$, when the cross-har is placed upon the beam, the two corrugated surfaces being in contact, as specified.

No. 114,726,- LEONARD S. TEWE1.I, EI.BINSVILI.F, PA.-Cultiator-Pluse-hs.-May 9, 1871 .

Claim.- The curved beams C C and standards D D, with the handles $\mathrm{G}: \mathrm{G}$ attached to the standards and to the side beams, in combination with the straps $13 \mathrm{~B}$ and centre-beam A, constructed and operated as shown and described.

No, 114.964.-GEURGE W. PARSONS and WIL. LIAM S. FINNEV, HAKRISBCRi, PA.-Cultivators and Shovel Ploughs.-May 16, 1871.

Claim - 1.-The device for securing the front ends of the side-beams, consisting of angular ribs $c c$, in combination with grooves $b b$, in beams $B$ ' $B^{\prime}$, bult $a$, with a heveled head and triangular washer, W, substantially as described.

2.- The clevis $\mathrm{C}$, provided with the angular ribs $c c$ and square-shouldered recesses $\mathrm{R} R$, in combination with beams $\mathrm{A}^{\mathrm{B}} \mathrm{B}^{\prime}$ and standards II, substantially as described.

No. I 16,147 - THOMAS E. C. BRINLY, LOUSVII.F, Ki.-Cultizators.-Jwne' 20, 1871 .

Cluim.-The herein-described shaft-cultivator, composed of a rectangular frame, the elongated side-beams of which form the shafts $\mathrm{A} \mathrm{A}$, and carry at the rear the handles $\mathrm{B}$ $\mathrm{B}$, fixed central besm 1 tied to the side beams by triangular stıy $\mathrm{D}^{2}$, laterally-adjustable beams $\mathrm{E}$ and $\mathrm{F}$, slotted iron standards II, which are provided with adjustable shovels (i and ad ustably connected to their respective beams D E F, by braces 1 , and the gauge-wheel $\mathrm{K}$, hung in a frame $\mathrm{L}$, which is suspencled from the side beams of the main frame, and raised or lowered by means of a brace, M, passing through the beam $\mathrm{D}$, all the parts being constructed and arranged substantially as set forth.

No. 1 16,355.-AllFREI) RODEN, MUMFoRv, ALA.Ploughs.- Fune 27, 1871

Claim.- The combination, with a plough, H, of independent block $\mathrm{G}$, standard-plate $\mathrm{F}$, and side brace 1 , to hold the shovel $\mathrm{H}$ firmly in the position required.

No. $117,034,-$ PHINEAS ORLANDO BALDIVIN, SPRING L.AKE, Mich.-Cultizators.-Fuly 18, I87t.

Claim.-1.- The arrangement of the spring C, provided with bolt $i$, with the beam $B$, provided with the post $m$, and the tongue $D$, when each of said parts is constructed to operate suhstantially as and for the purposes set forth.

2.- In combination with the beams $\mathbf{B} \mathbf{K}$, the sectional extension guides $\mathrm{G}$, lever $\mathrm{F}$, and the extension of the spring E provided with latch-bolts $g$ and $g^{\prime}$, unbstantially as and for the purposes set forth.

No. 117,961 - IVILLIAMI J. ARRINGTON, l, I1s. VII.1.E, Gi.-Cultivators.-Auyzist 15, 1871 .

Claim.-The circular perforated plates $\mathrm{E}$ and $\mathrm{F}$, the two sets of pivoted perforated hars $\mathbf{H}, \mathbf{J}, \mathbf{J}$, and $\mathbf{K}$, the side beams B C, and ploughs, all constructed and arranged in the manner shown and described, whereby said side beams may be adjusted simultaneously or independently of each other without changing the relation of parallelism between the ploughs and the central or fixed heam $\mathrm{A}$, as specified. 


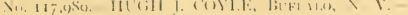

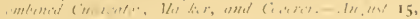
$\mathrm{IS}_{7} \mathrm{t}$.

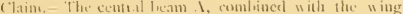

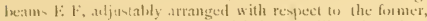
as ileveriberl, for the purpase of heing realily artapteal to serve the purpose of a coverer, marker, or culicator-frame,

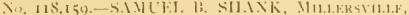

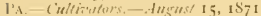

('aum. Hhe cultivating tevices $\mathrm{K}$ and $\mathrm{P}$, shown in Fig. 3. in combination with the frame, consisting of the onter side pieces . A . I and inuer beams 13 B, all pivoted to the front har F, and marle oblinuely adjustable by means of the curved sots in the bar $F$., nul fited to receive cither set of cultivatiner derices, as shown.

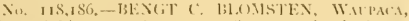

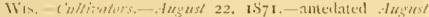
S, $15>1$.

flaim. The culturator clescrilsed, provided with the clas: tic site brams formed of a in te metallic bar bent as de seriberl, and central beam united to the side leams by the connections deserilied, each beam having stanclards provided with a longituditally-adjusting brace-rod, the parts heing conulined and arranged as anil for the purpose set forth.

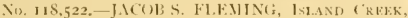

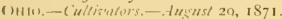

Claim.- The coulter $F$ formed sulid upon the forward end of the centre beam $A$ of the cultivator by henting the said forward end downward, substantially as herein shown and descritud, and for the purpone set forth.

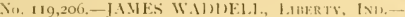
(inlizators. - Siplomber 19, IS7s.

Claim- The within-deseribed adjustable cultivatu-frome, to which the plongh-sbanks are attached, consining of the four beam $E E^{\prime} E^{\prime} E^{\prime}$, the two slotted crom-licams $\Lambda^{\prime}$ and A secured by the headed bolt $l, ~ l, '$, the connecting loar:

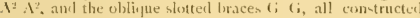
to) operate sub-tantially as and fer the purposes herein set forth.

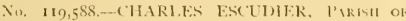

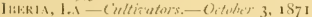

tham.-The arrangement, in a cultivator, of the main frame $"$, bearing-wheel and frame $s$, stambal plates $d$, shoe

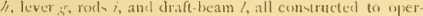
ate ar clencribed.

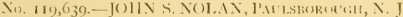

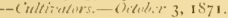

Ctam.-1,- The ollong and eight-sided bovel, l', adap. ted (o be revered or changed in position so an to allapt the implement for use as a harrow or cultivatur, as yecificd.

2. - The imprisid agricultural implement formed of the centml leam $\lambda$, hinged adjuntalble side beams $l$, and acl ju-timg devices $11 \mathrm{~J}$ i J F. the oblong reverible toth I moviled with self sharpening teeth 0 . the vine lifter 1 , I anil $X \mathbf{X}$, all consructed anil arranged as shown sul te seribed to aperate as specihed.

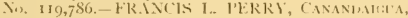
X. V.-Cultituters.-Oteber IO, IS7 1 .

(laim,-1,- lieveling the ents of the side har II 11 at different angles, and arranging them to be reversed to make the cultivator w icle or narrow, stambiantially as descrilied

2. The outriggers $I N$ attached to the cultivater, substantially as clexcriled, ant provided with rigid or ypringtceth male of $r$ and or ov l wire, for the purpone stot forth.

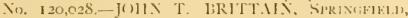

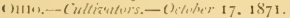

Clam.-1. - The frame of the cultivator, when comstructed of flat tire-iron, in hercin descriferl, ly combintion of the handles ( with the hent fromt and sicle lxeams A by means of the holiv, and the hinges 1), and again with the side beams A hy means of the connecting bar $E$, the bout bars 11, and the adjusiment $\mathrm{F}$, sulustantially as and for the purjoses hereinhefore set forth.

2.-The herein-described construction of the two solic land-side rear plough- I from a single square plate of met al without any warte of mattrial, so as to make each plough adjustable and reversible right or left, formed from a right anglexl triangle without casting or forgios. in combination

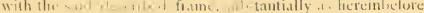
sil forth

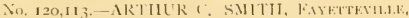
N. C.- Cullituturs. Oitober $17,1 \mathrm{~S} 7 \mathrm{1}$.

('laim. - The combination of the land-marker 1."' adap. ted to slide alono the pivoted arm 1 , and rendered adjustable hy means of the arms $\mathrm{N} N \mathrm{~N}$ and adjusting plate " with the stirrup $K$, cord $m$, and post 1 ', all arranged and prerating as deneribed.

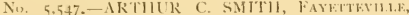

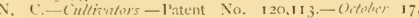

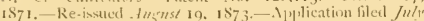
I2. 1873 .

I coton-seraper combinet with a cultivator.

('laim.-1.-In combination with the plough-heams I) D anl their handles $\mathbf{E}^{\prime} \mathrm{E}^{\prime}$, comnected by rod I with sleeve $i$, the diagonal braces $h^{2} h^{2}$, passing from the rear end of the plourh-lieams to and through the haudle of the plough on the other sicle, and adjusted by nuis $h^{3} h^{3}$, substantially as aut for the purposes herein set forth.

2. The combination of the land-marker $\mathrm{I}$ ", adapted $t$, slide along the pivoted nrm L, and rendered adjustable by means of the ams $\mathrm{N}$ and adjusting-plate $n$, with the stirrup $K$, cord $m$, and post 1 , all arranged and operating as described.

No. 120,794-AI.FXINIER C. TAVIUR, NORTI

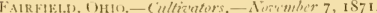

Claim. - The arrangement, upon the standard $\mathrm{C}$, of the share $D$, hinged and adjutable wings $\mathrm{F}$. adjutable and re versilule wings $(i$, and stay-rod 11 , as and for the purpome set forth.

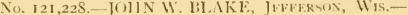

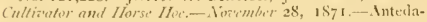
ted Visturlier 17, $187 \mathrm{I}$.

Claim,-1.-In a cultivator, the contral adjustalse standaral $a$, pivoted to the beam $\Lambda$, and comnceted to the clevis lash by mean of the draft-rod 1), wherely the pivot of the standard is relieved of strain, substantially as described, for the purpane specified.

2.- The brace or plate $\mathrm{E}$, in combination with the shovels and standiards, to re-enforce the points of the stovels, as hurein shown and describerl.

3.- The combined braces and hamblles $M$ M sliding loosdy woon the cross-head 13 , in combination with the pivoted adjustable central standari $a$, as herein shown ant clescribed. for the purpose specified.

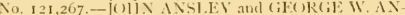

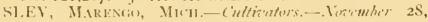
1871

Claim.-The plank pl-torm I carrying the pole l: and cultivatinr-teeth $n$ e $a$, \&c., or etuivalent phoughs, in combintion with the runners $C\left(C^{*}\right.$, with or withut trackingwheel, connecting fulesum-bar 1 , and hanlle-levers $\mathbf{E}$ E., comstructed, connected, and operatcal sulumatially in the manner and for the unes set forth.

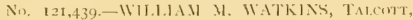

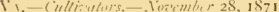

Claim 1.-The combination of the shank $F$, wing $f$. and point 11, when sid puts are comstructed and aranged subintially as and fur the purposes herein sut forth.

2.-The within-described cultivator, consisting of the frame $1 \mathrm{~A}, \mathrm{~N}, \mathrm{~J}, \mathrm{C}$, and 1) 1), metallic rockets at a, shanks E. F., wings $f$; with fluges / /, and gronved points II II, al] constricted and arranged substantially as set forth.

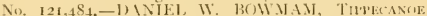

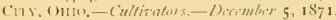

('loim.-In combinatson with a single bovel-plough, A Bi $C^{\prime}$, the s.contary bean and shovel $F^{\prime} \mathrm{F}^{\prime}$, when pivoterl fo the main beam at $f$ mul adjustably connected therewith at the rear end by mean of the liuk $(i$ and perforated or lutted plate or bracket $\mathrm{H}$, substantially in the manner set forth.

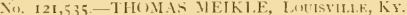

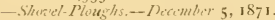

Clam - The combination of the beams $A$ and $B$ of $a$ double-shovel plough, tie-bolt $E^{\prime}$, and brace $E$, when the latter is constructed at each end with projections or flanges $c *$ for embracing the edges of the lueams, subutantially as and for the purpore set forth. 
Air, 123,128.-MITCII.IEL YHIIIRT\%, CFNTER N. H.-Cultizintors- - Fumbary $30,1_{872}$.

(laim,-The eombnation and arrangement of the slotted bar . 1, the long pivoted bars B I carrying the teeth b b, the short bar C C pivoted to the bars I B and to the adjustable yoke $\mathrm{D}$, and carrying the adjustable hoeing teeth $\mathrm{F}$, the whole constructed and operating sulutantially as described and specified

No. $123,+10,-J O I I N$ R. MINTER, UXIONII, I.E, S. C. - Cultionaturs-Fibrutry 6, I872.

Claim.- The scraper 1 , gauges 11 , and wings 6 , combined, as descrilsed, with cross-bar E, and the whole applied [is the standard of a cultivator, as and $f(x$ the parpone lescribed.

No. 123,583--SAMLEL C. SHELLER, LEWTSBUR;, PA., as ignor to ALFRED S. SllELILR, same place.Cullieatiss_-Fihuary 13, 1872 .

Claim. - The cutter $i^{-1} c^{2}$ and shovels D with their bent shanks, all connected to a single beam, B, in combination with notched, slotted, and adjustable stay plates $\mathrm{G}$, adjus 1 bly linged brace-rods E $\&$, turning bar $\mathrm{I}$, all jointly operaing ubstuntially in the manner and for the purpose spectied.

No, 123.717.-FRANCIS M. MCIEEKIN, PUTNaM

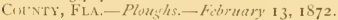

Claim.-The improved shovel-beam G, having the forward and rear diazonal legs $y^{1}, w^{1}$ together formed from a single bar of metal, bent to the form shown and described, in combination with the adjustable shovel $\mathrm{F}^{2}$, secured and reutered adjurtable by means of the bolt $g^{2}$ and nut $h$, sul. stantially in the manner described.

No. 124,316-MARION J. BARR, CEXTREVILLE, INL. - Ciltizators.- Whrih 5,1872 .

Claim.-The combined subsoiler and surface-plough E, having the bu.hed or shouldered print $d$, neck $d /$, and heveled surface plate $d^{2}$, constructed substantially as and for the purpose specified.

No. 125,057--IOSEPH G. L.ACl, E.t.RlEK1, WIS.,-

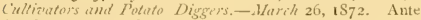
lated Awrih 13,1872 .

Claim.-I,-In a cultivator and potato-digger, the ndjustable slicle $\mathrm{C}$, with shovel $h^{\prime}$, and adjustable mould-board $\mathrm{l}$, ubst untially as and for the purpose set forth.

2.-The herein-described cultivator, consisting of the Iraft-beam A, senicircular beam B, rake II, plate (", and the adjustalle slides $C$, provided with the mould-boards $F$, vilistantially and for the purpore specified.

No. 125,936 - CokNELILS A. (LARK, SEWARI), Nin, - Cultirulors.-Afril 23,1872

(laim.- 1 . - The standard $c$, pivoted to arm $f$ so that it can move upward and outward, combined with wheel I) and wires $i$ to regulate the pitch of mouid-logard, all as set forth.

2.-The outwardly-inclined and loosely-pivoted arm $j$ and wheel F, combined with and arranged with respect to the whare $\mathrm{E}$ to remove recumlient grass or weeds, as set forth.

No. 4,948.-C()RNELIUS II. (CLARK, SEWAKD, NED

-Prairie Ploughs.-P.itent No. 125,936.-Znui is, iS72. Ke-istued, . Af,il $23,18_{72}$.

Claim.-1.-The stud.url pivoted to armi $f$, so that it can move upward and ontwarl, combined with wheel D and wires $i$ to regulate the pirch of mould-lmard, all as set forth.

2.-The oatwarlly inclined and loosly pivoted arm $j$ and wheel $\mathrm{F}$, combined with and arranged with respect to the share $\mathrm{E}$, to reinove recumbent grass or weeds, as set forth. 3.- The turn-puish, formed of flat-bottomed and threeiiled share of $h i s$, and wires $i j$, constructed and arranged shown ir. the drawing and set forth in the description.

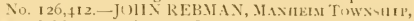

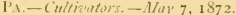

Claim.-In a cultivator, I claim the combination of the levices used, consinting of the detachalle truck A B C, beam 1,2 and 3 , central plate E, scraper $\mathbf{K}$, and projecting-plates $L$, all arranged and made adjustable in the manner and for the purpose specified.

No. 126,658.-WILLAM II. VICK, HuLLY Si'RINGS, Miss.-Cultitators.-Mar' 14,1872 .

Claim.-The stocks $\mathrm{H} \mathrm{H}$, in in combinatin with the beams

B I, said stocks being adapted to receive the mould-boards 1. 1. or to serve a braces to the vih-snil or foot-coulter standard $\mathbf{K} \mathbf{K}$, tur fontially a and for the pup e herein s. Trecified.

No. 126,815.-WILL1AM KLEFFEL, M.AFE CRER, Nes, - Cintinintors.-Mary $1+1+1 \mathrm{~S}_{72}$.

Clain, - 1.-The combination of harrow $F$, with the cultivator handles $\mathrm{E}$ by mean of the lever-handles $d d$, and vertical levers $h / h$, and chain or its equivalent for attaching it to the fram 2 of cultivator, su' -tantially as set forth.

2.- The combination of harrow $F$, lever-handlen $d d$, vertical levers $h / h$, cultivator-handles $\mathrm{E}_{4}$, sliding rings $\sigma_{1}$ and aljustable vertical bar $n$, all arranged to rperate sulsataitially as set forth.

3.- The truck $\mathrm{II}$, having its axle provided with the swivelguide $s$, and chain $\beta$ with rins $q$ on its end, in combination with the tongue $A$ having boles $t$ and bolt $r$, the whole arranged to operate as shown and set forth.

No. 126,991.-ASA BENNETT SPRINGSTEEN,

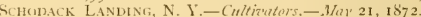

Claim.-The combination, with a surface-scraper, E, of a lever, $F$, provided with the rot-extractor $j i$, and arranged in the rear of said scraper, as descritsed.

No, $127,+69$.-NATIIAN EARLIWTNE, CENFKEVILIR, IowA., assignor to himself and (HARLES A.

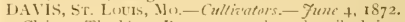

Claim.-The hinge 1 , con-tructed as deseribed, in combination with hars $\mathrm{A}$, lockin thas $a^{1} a^{2}$, standard $\mathrm{I}^{\prime}$, roller plough-frame E, when arrangerl to operate as and for the purpose set forth.

No, 127,508,-IVILLIA.U C. PERCS, B.IYT SiRA, L. A.-Cultirators.-Junc 4, is 72.

Claim,-The tapering plough $\mathrm{H}$, curved upon the arc of a circle, and having an opening formed in its mielelle parts leaving the plough simply a rim or frame, sulstantially an heren shown and described, and for the purpose set forth.

No. 127,658.-GEORGE STIBEK, Cog.NS STATHN, I'A. - Cultirators - 7 une 4,1872 .

Claim.- In combination with a cultivator constructed substantially as herein descrihed, the shaft 4 II II, whiffletree 1 , and the bar J, pivoted to a stamblart on the centre leam of the cultivator, all $<$ ubstantially ar an I for the purpose herein set forth.

No. 12S,O32.-GIO)ER G. F()RMIAN, STHKTHN, (i.. - Plumishs.-Jirni is, 1872 .

Claim. - The combination of the cross-bar f with the onter or end plongh-standards and the cross-bar E, pivoted to the beam $F$ and provided with an adjusting device, II, 2s shown and descrilued, to operate as specified.

Ni), 128,360-WII.L.AM WAI.KER CAT(), Hik ForD, Vi. - Cultizaters- Funi 25, I872.

Claim-1. The lifting-bir $\mathrm{m}$, construt ted and alapted to luc uned in combination with the plough, sulstuntially a described. for the purpuse set forth

2.- The allustable notched wings " $\|^{\prime}$, in combination with the removable plates $/$ an I the plough-standard, having sockets $\varepsilon$ adapted to receive an 1 hold the plates, when cosutructerl in the manner and for the purpones herein set forth.

No. 12S,73t-WIRUUIS 1), KIN(;, KING'S FERRI, N. Y.-Ciultinators.-July 9, 1872.

Claim.-In combination with the quadrilateral frame $A$ carrying the cultivator hoes, teeth, or ploughs 1 , a pair of thills $C$, and a pair of handles I), both pivoted centrally to said frame, as at $b$, and arjuatable thereon, respectively by the arc-pieces $c$ and supportic $c$, snbstantially as described and represented.

No. I2S,827.-FREIUERICK IV. TOIEY, COXSI'KIY, X. Y., assignor to himelf and R()IEET Y. D. (OI.LIEK. same place.-C'ultitators.-July 9, 1872 .

Two wheels pivoted to the front part of the franze in such a manner that the frame can be tilted forward bo as to rest entirely upon the wheels for the convenience of transportation.

Claim,-The arrangement of the arms I and wheels J, in connection with the frame $\mathrm{A}$, tongue $\mathrm{F}$, semicircular slotted plates $\left(i, y^{\prime}\right.$, and bolt II, sulstantially as herein shown and described, and for the purpose set forth.

No. 129,oS1.- WILSON BAKER, Minuter, TENN.Cotton Cullizators. - Fuly 16,1872 .

A cultivator for scraping and chopping out cutton. (inm- 


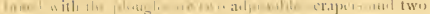

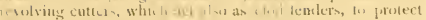
the young plants.

clam, - The combna ws, in a stadtle-row cultivator, of a har shear plough, $A, 1$, on each sicle, the seraper $C$. 1), next thereto, and the inner revolviner cutter, ats descrihed, atud for the purpose of cnabling it to operate an set forth.

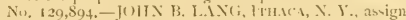
or of one-half of lis right to J. A. REYN()I.I) s, sme place - Cirllizulers. - July 30, 1872 .

- Has a central beam, wibh une shovet aml two adjuvable vide shovels.

('laim.-1.-The frame $i$, when secureal to the ent of the beam a, in combination with the adjustable stanilards $/ h$, and braces $f \cdot h^{\prime}$, substantially as shown

2.-The combinution of the rearward extension of the beam $"$, for the shovithole $c$, th the $V$-shaped frame $i$ of the sairl frome $i$, and of the handles $b b^{\prime}$, making the braced and mutual-supporting frame-work of the heam, frame. and handles, ax set furth.

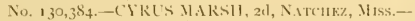

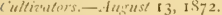

A combination of pivoted handles, having a peculiarly formed sccurmg-ron, with the main frame of the cultivator.

Claim.-1,-The machine described provided with the main frame $I$ \& $a$, the removable side bean $C$, having wheels and shovels att xched, as described, and pivoted landles $B \mathrm{l}$;, provided with the V-shaped iron $"$, alt consiructerl and operating substantially as described.

2.- The pivoted handles $B$ l, provided with the $Y$ : -haped irons b, with right-angle flange. in combination with the main frame, as described, the iron being so arranged that it may be realily adjusted and be bell loy: single pin or screw.

Xi), 130,765 .-BEN(;T JOHAN SIENGON, IIANOR

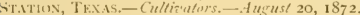

The parts are strengthened by the form and structure of the handles and brace.

Claim - The combination of the beam A, crosthar C.

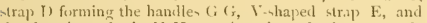
the shovel-itundards $\mathrm{H} \mathrm{H}$, passing through the straps 1 ) and E and crosibax C all cubitantially as set forth.

Xir. I 31,150.-CiEORGE 1). ('IEVELAN1), FIINT, IN1)-Cultiontors.-Siptember IO, I872.

When it is lecired to cultivate but two furrows at a tine, the from and rear standards are detached from the outside of the plates $E$ anil their ends inserted between the plates and the beam, thus bringing them nearer 1 gether, while the eentral one is swung hack out of the way.

Chin.-The eomlination of the bean $C$, pivoted and ad ustable standarils $\mathrm{A}$, in combination with the lient plates 1 i, when the sard parts are so arranged that the standards can be ariju-ted to cultivate two or three furrows at a time, substantially as set forth.

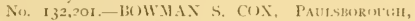
V. J.- Cullizatere-Oitubi 15,1872

This cultivator has a centrally fixed beam, to which are pivoted two obli gue beams, to which the cultivator-teeth are attached. By means of a lever, placel in convenient reach of the operatur, the hinged beam can be moved nearer to $\mathrm{cr}$ fuither from the eentral one, as may be devired

Claim,-The cultivator having the central benm $A$, holdin s the plinte $a$, transerse bor $\mathrm{E}^{\prime}$, and standart $\mathrm{F} \%$; the oblipge beam ( hinged at their forward ends to the beam $A$, and connected to the bir $\mathrm{E}^{\prime}$ by pivoted arm ' $e^{\prime}$; the adijustalle fender $E$ pivoted to the tooth $B$, and connected at their rear ends to the bean $C_{\text {, and }}$ the operative devices for acljusting the beams and fender, all substantially as and fir the purpose ypecified.

No. 132,764.-GI1.BERT JESSLT, SHORTsVILI.F, X. V.-Cultizators- - Viatembir 5, 1872 .

$A$ heam is pivoted to the forward end of diverging side pieces of a cultivator-frame, the heam extending forward and carrying a bearing-wheel. The rear end of the beam is elevated or depressed and held in place by a touthed segment, thus regulating the depth of the cultivation.

Claim.-The pivoted lar $B$ provided with a bearing.

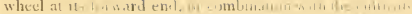

frame and segment $D_{\text {, in }}$ and for the purpose ypecifict.

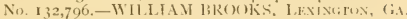
- Cullisuters. - Norimlier 5, 1572 .

The wing or scraper is pivoted lomely upon the bolt so that the scraper may accommodate itself to the inequalitie: of the ground.

Claim.-The combination, with an ordinary shovel-plough, A is C, of the sectional laterally-projecting curved wings 1 $\mathrm{E}$, hung upon the fastening-bolt $\mathrm{F}$, and aslapted to be uned in the manner set forth.

No, 133,387.-WIIIIAM 1). SMITH, HOMERVILI.E. (is.-Cillinators.- livember 26, 1872.

1 zigng har, centre piece, and side brace, ail of wronght. irm, furm the frame, which is provided with iron handles. The cultivator-tecth and shanks are each of one piece ant secured one to each longituclinal angle of the frame.

Claim.-An improved cultivator formed by the combina. tium of the zigzag lar $A$, made in one or more parts or pieces, the draft-har B, handles C, braces D, and plouglis $E$ with each other, substantially as herein shown and described, and for the purposes set forth.

No. 133.467-CVRUS MARSH, 2d, NATchez, Miss. - Cullizalors.- Vovember 26, 1872.

The wheels are very narrow so as to cut into the ground, in order to guicle the machine and keep it steady.

Claim.-The machine described, eon-isting of the central beam $\mathrm{A}$, with its removable shovel-plough, wheels a $a$, elbow irons $a^{1} a^{1}$ eross-heam B, bars C C, side beams D D, with their shares, and the handles E, all combined and arranged as described, for the purnose set forth.

No, 133,614.-LEWIS R. WRIGHT, TROY, N. V.Cullizators and Ploushs.-December 3, 1872.

The standard is seeured to the mould-loard by rivet, the whole secured by a nut. By slicling the standard upward or downward through the eyelolt $f$ the mould-boarl is raised or lowered.

Claim.-1.-The curved atandard $a$, top bar $d$, inclined brace $f$, all of one piece of metal, and the carverl tooth $b$. secured by the bolt $c$, all secured to the under side of the frame by the bolt ani not passing through the top har d and the beam $f$, as shown and describel.

2.-In combination with the frame-beam $\rho \rho \rho, I$ elaim the hinged wings $h h$, shares $s^{r}$, pivots $i$, movable rods ? $l$, and eve-bolts $b k$, all constructed and arranged to operate sulstantially as set forth.

Niv 133,865 -CASTER KRQGill and PETER $G$

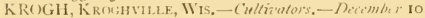
I 872 .

A single shovel plough has a reries of hoes adjustalsly arromged in the rear of the shovel.

Claim.-In comlination with a vingle shovel-plough, hocs which are hung in rear of the shovel upon a rod, 11, pasing through the handles and the standard, adjustably connected in pairs by slotted or notched lars, and fa-tened to the beam by tie-rocls. suliatantially as specified.

No, 134,050.-CVRL' JARCH, NATCHK, Mlss,-Cotcon-Simpers.-December $17,1872$.

levices for guiding the machine, consisting of sharp frontwheck, pisoted and havin a lever extencling backward to the hantiles of that the wheels may be turned in either direction, in combination with heel-plates, attached to the rear of the ploughs.

Claim.-1.-In a machine of substmtially the described con-truction, the combination of shrp guicling-wheels in front with guiding heel-plates in rear, sulstantially as deserilsed.

2.- The combination, in a single machine, of guiding and clevating mechanism, subatantially as deseribed, the frame, amul a pair of scraper-blades having heel plates attached thereto, all unhstantially as descrilued, for the purpese set forth.

No, 134,099.-FRANCIS REESE, WILSONTILIF, ALA.

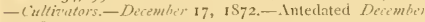
14,1872 .

Claim.-The combination, in a cultivator, of beam $\mathrm{A}$, gaugreable cross-bars C C, gaugeable bars B B, shouldered arms D D, shouldered berl-plate $\mathrm{E}$ bearing the cutter $\mathrm{F}$ and shovel $G_{i}$, and fenders 11 II attached to fender-block $\mathrm{I}$, 


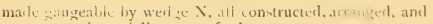
operaime vulintantially as set forth.

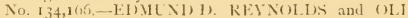

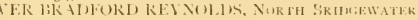
MAss.-Cultítators,-Dirmb.r. 2.4, 1872, - Intedated Dcunlur 10,1572

The blades are maxle of thin sheet steel cut and bent at nearly right angles. Flexible wire tecth project rearwarlly

Claim,-1.-The gang of hoe blades, ench formed with the blade and its standard both intined in the tirections as hown and dencribed.

2.- In combination with the hou-blates, the spring rake teeth fastened to the hoe-sandard, ant inclining downwarl, and diver in $t$ therefrom, substantially as shown an lescribed.

3.- In combination with the hoc-blader, constructed and arranged as described, the mould-board s, subatantially as shown and described.

No. 134,665.-JOIIN II IIEIGES, ŸURK, 1'A-Culti rators.-Jamury 7,1873 .

I cultivator havin a curved mould-hoard pivoted to the rear end of either outside beam, and capable of lseing aljust esl to act in commection with either of the cultivator-teeth.

Claim. - The curved mould-boards I), having flangen $d$ at the upjer rear end, pivoted to the rear conds of beams is 1 , and so arranged that the points of said mould-buard may be bronght against the sides of the central tooth or turner! to any desired position, substantially as specified.

No. 1 34,670.-R1CHARD G; II(JBSi), ИULKA,

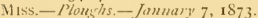

The heams of the cultivator are parallel to each other, and are adjusted by means of Irolts ani nuts. The shorter beam in secured against backward strain by means of a springlirace, attached by a hinge-joint to its forward end, and by a bolt to the main beam.

Claim.-The beam, A B, when comected by the hinged and slotted spring-lance $C$, in combination with the screw.

lolts E E, all constructed, arranged, and ujeratel as set forth.

No. 135,301.-JOHN TWEELI, VEKNUN, lND.-Cory

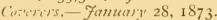

I clod mover of a trianmular or $\mathrm{V}$-shape, loosely attached to the rear part of a culivatur plough so as to adjust itself to the shape of the ridire and removes clods or other ols. structions that might prevent corn from coming up

(laim.-1.-The clad-mover 1 , in combination witb the semi-circular or archeil mould buard 11 and ploughs $($; , sul. stantially as berein shown and descrihed, and for the purperse set forth.

2.- The combination of the long staples I, rod $k$, and guide or keeper 1 , with the clocl mover I, remic roul ir or arched mould hoard 11 , and beam $A$, substantially as herein shown and dencribed, and for the purpores set forth.

No. $135,41+-1 R A$ E.IRICK, VRRxix, MICH,-Corm inltiontors.-Firzary 4. 1873.

The stondards and beam of adjustable and reversible cul. tivator shovels are secured by means of a round cross bar, a staple, and eyebolt, which may be easily loosened for jurpores of adjustment.

Claim.-The described method of securing the standards anl beams tingether by means of the croms bar 1 , evelult $k$, and staple I, as and for the purpose net forth.

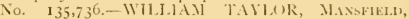
Miss.-Cullinaters.-Fibruary 11, 1573.

The expanding wings are connected by means of rids to a block sliding in the beam.

Clum. - The lilock I, arranged in a longitudinal slot of the heam $A$, the lars $\mathrm{I}$, connected therewith at the noner side and pivoted to the midkle portion of the wins $H$, the lever $\mathrm{N}$, amb plate (), all as show'n and described.

No. 135, S72,-13ENJA.MIN WITTFR, SHFkril.1's

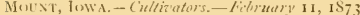

Claim. - The beam $\mathrm{E}$ with round tenon at its lower eml, shoulder $x$, and groove $y$, in combination with the concaved block f with ears $s=$, the shovel $i$, strap $h$, and bolts $i \quad i$, all rubutantially as and for the purposes herein set forth.

No. I 36, 249.-HOSEA K. KRIElBE, 1.ANDSIBA.E, PA. - Cirliciators.-Fibruary 25, 1873.

A straddle row cultivator, for a single horse. The inmer thianrular frame, baving handles, in pivoted th, the onter frome, so that it may lic armer (1) eather sicle ln operation three hoes pass between two ruws, while tne hue passes betwcen the next two rows.

Claim.-1. - The combination of the frames A and $D$, comstructed and arranged as shown, the said frames lating pivoted or hingerl together in front $x$ as to permit the immer frame to be swung from sirle to sicle, as and for the purpuse set forth,

2.-Tle cultivator, consisting of the tringrular main frame A holding the plates $a$, cross guicles $a^{2}$ with holes $a^{2}$ and standard " $q^{4}$ and shovel $\mathcal{C}$, and the pivoted frame 1) having shovel $\mathrm{E}^{2}$ and handles $\mathrm{E}^{\mathrm{I}}$, sulstantially an specified.

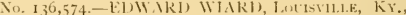

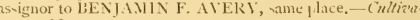
tors.-10y 4,1573 .

A cultivator with means of adjustment to carry one, two or three shovels, and to change their relative ponitions upon the beam, and their distance therefrum, by means of posts of lifferent lengths, through which pass screw bolts, as show.

(laim. - The cultivator, with the described means for arljustment to carry one, two, or three shovel, and to change the same to different positions, as shown in the drawing.

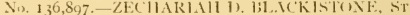

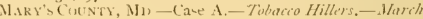
I8 1873 .

A leveler, having a flat surface and central projecting ril for smoothing the ground and keejing the machine in a di. rect line.-A hiller, having flanges on each sicle for drawing in the earth to form hills.

Claim,-1.-A leveler, E, when provided with a rib, $b$, on it murler side, for the purpose set forth.

2.-A hiller, $F$, when provided with side ribs $i$, constrnct ed sulistantially as described, and for the purpose set forth.

3.-A hiller. $\mathbf{F}$, when providect with side rils $i$, and a marking rib h, substantially as ilescrilsed, and for the pur posen set forth.

4.-A hiller, $F$, when prosided with sicle ribs $i$, marking rib $/$, and rearward projecting pieces, subntantially as de scriled, and for the jurjume set forih.

5.- The combination of a liller, $\mathrm{F}$, with a rumner, A, each being constructed sutumantially as alescrilied, for the purpone yrecified.

6 - The combination of the leveler $\mathrm{E}$ and hiller $\mathrm{F} w$ ith runner, $A$, all being constructed substantially as descrilual, and for the purposes set forth.

7. The combination of two or more runners, when each is provided with a leveler, $E$. and hiller F, and with a vinule pait of handles, $f$, to guicle the whole, subutantially an descrihed, for the purpose set forth.

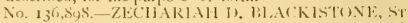

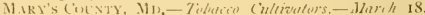
1873 .

The weetling blackes are attached to spring-arms, anil may be rased or lewercel by mein of levers and conneting chains.

Claim - 1, - I rumer A, when provides with a pair of cultivating implements, 1 , in front, and a pair of adju-table cuttimg or weeding blater, $m$, conatruted and arranged a descriluel, for the purpose sut forth.

2.-The weeding blates m, when connected to the runuer 1 ly means of a curved spring-arm, $n$, for the purpose set forth.

3.- In combination with the weeders $m$ and curved sprins arm $n$, the lever $s$ and connecting rod or chain ", for the purpore set forth.

i., 137,221-VYK()N I.EWTI.IIN, BERtiE, N. Y.

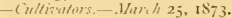

1 jointed heal armed with teeth for the purpune of raking throurh the rows of corn, and thu freeing them from weeds and dirt; arranged for att achment to a common col tivator.

Claim.-The cross beam $C$, with jointed heats $C^{\prime} C^{\prime}$, the learing $\mathrm{D}$ 1), tirrups $d t$, lirace lars E $E$ ', and loop $\Sigma^{\prime}$ when combined anil arranged with an orlinary cultivator, in the mamer and for the purpone specified.

No. 137,649.-1(1)REN\% BAI.DW1X, StoNe MIL.s, N. S.-Cultimators.-April 8, $1 S_{73}$. Application filed Votembir 23,1872

A frame provitled at the sides with lrolts mad to receive 
lotted arms of interchangeable hatrow and cultivator, and to render them adjustable; to the forward part of the frame is secured a hoe-blade favtened to the frame by rigid arms, in rear of the loe-blade is a hole into which a hook on the harrow or cultivator in inserted; in front of the hoe- blade is secured a caster-wheel for adlusting the depth of the hoe. hlade.

Claim.-The combinat on of the frame and its blade $c$ and adjustable wheet $\mathrm{E}$, when fitted for the interchangalle plough and harrow substantially as specified.

No. 137,782.-AUGUSTES I.EONARD, NEwril's RuN. OHIо.-Cultizaturs. - April 15, 1873. Application filed Ausust 30, 1872 .

The said beams are rigidly attached in front to the central beam, depending upon their elanticity for the lateral move. ment in rear to alljust them to a grenter or less width. Thi movement is controlled by the handles pivoted to hars sliding through a mortise in the central beam and held in any desired position by a retaining-pin

Claim.-1, - The combination of the central beam, the side beams, the sliding bars, and the pivoted handles, the handles being connected to the sliding hars at their front ends, substantilly as clescribed.

2.- The machine described consisting of the central beam $A$ and the side beams B, united thereto as described, the handles $\mathrm{C} \mathrm{C}$, standards $c c$, tie-bars $c^{\prime}$, sliding bars D D with holes, as described, and the securing-pin in the central beam, as set sorth.

No. $138, \mathrm{~S}_{3} 8$ - -DEWITT CI.INTON BARKER, Fultox, X. Y.-Cultizaturs.-Vin 13, 1873. Application hiled March 24, 1873 .

A corrugated brice-bar, by mean of which the distance between the ploughs can be regulated, and which allows the pluugh-standards to be turned so an to throw the earth to or from the plants.

Claim.-I.-The corrugated br.tce-bar $G$, contructed and arranged in combination with the stocks $\mathrm{D} \mathrm{D}$, sulhstantially as and for the purpose herein specified.

2.- The combination of the adjustable and reversible hinged wings E, E, constructed and arranged substantially an specified, with the shovel-stocks D I) and brace-bar G, s.lbst utially as and for the purpose herein specified.

3.- The herein described culcivator composed essentially of the central beam A, shovel-stocks C and D D, adjustzble wings E E, corrugated brace-har $\mathrm{G}$, and heveled-edge shovels H if I, constructed and arranged substantially as herein specified.

No. 138,964 - WIILIAII T. WALKER, FoNTENoY MiLLS, GA.-Cultiotors.-1Kor I3, is73. Application filed Murch 22, 1873

The side beams are pivoted at the center in such manner that the ploughman by the handles can increase or diminis the width of the space cultivated while the machine is in motion. Springs attached rigidly to the center beam serve to restore the frame to its u-ual shape.

Claim,- The springs $\mathrm{H} \mathrm{H}$ secured to the fixed central beam $\mathrm{A}$, and connected at their free ends with the pivoted and handled side beams C C by means of staples or other equlvalent guides, as shown and described, to operate as specified.

No. 139,001.-EVN1)ER M.GRAHA Y, VERNoN, I.A.Cultizutors. - Mity 20, 1873. Application filed May I6, IS72.

A frame adapted to receive interchangeable cultivating devices, so that the implement may be used in cultivating different crops.

Claim.-1.- The combination of the frame A B, wheels 1), axles $x$ hooks $I$ rod $I$, and rack or frame $E$, adapted to receive ploughs $\mathbf{H}$ or other cultivating devices, substantially as shown and describerl.

2. - The combination of the bars $\mathrm{E}^{2} \mathrm{E}^{3}$, bolls and nuts $23456789 \mathrm{ro}$, and blocks F with the frame A 13, utb. stintially as shown and described

3.- The grooves $y$ in the frame A $\mathrm{B}$, in combination with the notehes $b$ in the rack or frame $k$, substantially as and for the purpose described and set forth.

No. 139,065.-THOMAS M. KING, MUREREFS BOROUGH, TENN.-Whrrozes.-Way 20, 1873. Application filed Fanuary 6, 1873 .

Two harrows, the frame of each being formed of a straight bar and a remicircular lar, and attached to a beam by trolt so is to be aljustable at various angles to each other.

('laim. - The improved harrow, consisting of the two like parts, each formed of a utraight har, D, perforated semicircular har F, central brace.bar ( $i$, and teeth $E$, attached to the beam A by two adjusting loults, $f$, as shown and de scribed, whereby they may he set at various angles to each other horizontally, and adjusted so as to leave a wide or narrow space between them at their front ends, as specified.

No, 1 38,320 - - PHILIP LONG, Pr.NN TownshIP, near Junction Railroad Station, County of I.ANCASTER, PENN., assigner of one half his right to JOHN M. l'lllI.PS, same place.-Cultizators.-Wuy 27, 1873 . Application filed Fanuary 25,1873

The side beams of the cultivator are piroted at the front by a plate-hinge, which adds strength to the beam. The large number of teeth or shovels are narrow and pointed, set upon long standarts for the purpose of deeply pulveriz. ing the entire soil through which it passed.

Claim.-The above-dencribed three-beam cultivator, with long standards passing through inserted bush plates, and narrow pointed shovels: the frame adjustable as to width at the front ly means of the peculiar hinge and plate, with the curved slotted-bar and set-screws at the rear, all combined and arranged subatantially as set forth,

No. 139.750 -CHARI.ES ZOCIIER, AUGUSA, GA. -Cirton Culizators - Fun: 10, 1873 . Application filed Warch 29, 1873 .

A series of notches or offsets, inclined bachward and upward, are formed upon the sweep so that it may clexr it self of trash.

Claim.-The sweep B, having its cutting-edge notched and the portion of said edge between the oftset $b^{1}$ inctined, as specified, for the purpose of enalling the sweep to clear itself of obstructions, as set forth.

No, 140,724-BENIAMIN F. MUSCIIERT, MORRISIIt.L, 1.A.-Cultizators.-July 8, 1873. Application filed December 7,1872

The cultivator has a fixed center shovel and two side hovels adjustable as to width by having their standards placed movably upon two cross rods or hars with screwends and adjusting-nuts, the whole held firmly in position by rigid braces.

Claim. - The combination, with the rods $\mathrm{F} \mathrm{F'}$ and their adjusting-nuts and standaris, of the rigid braces $b^{\prime} b^{\prime}$, and the beam $\mathrm{D}$, as specitied.

No. 140,885 .- JACOB (AVLOK, FAIRV1EW, assignor of one-half his right to CHARI.ES E. JONES, REDKES, IND.-Cultizutors,- July 15, 1873.-Application filed Oitober 12,1872 .

Interposing a transversely-recessed block having its outer faces plated with metal between the cultivator-shank and the beam to render easy adjustment of the shank, in connection with the adjustable brace provided with an eye, to which the brice is secured.

Claim,-In a cultivator, the combination of the transverselv-recessed block 1 , having its outer face plated with smooth metal, the laterally-adjustable shovel-heam E, provided with the eye $e$ and the adjustable perforated loraces $F$, substantially as shown and described.

No 141, 199-EPHRAIM BRIG(iS, CI.EVRAAND, OHIO.

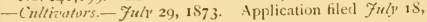
1872 .

Furrows are thrown up on both rows at same time.

Claim.-The combination, in a cultivator, of a centre beam and two pivoted arljustable side beams with reversible shovel carried on tenoned wooden tandards secured to the beams by double grooved metallic suckets, all arranged as descrilied, and for the purpose set lorth.

No. 141,464-FREDERIC ROV. PARISH of ST. BERN AR1), 1.A.-Cultianturs.-furzest 5, 1873.-Application filerl April 5,1873 .

Two pair of scrapers are secured to the frame by which the earth from each side is thrown into the trench and a ridge formed, which is made uniform and pressed by a following plough and roller, the latter being adjustable in height. By means of a bent axle and lever the covering devices are raised from the ground at will.

Claim.-1.- The combination of the frame $A$ with the 
mould hord $\mathrm{E}$ E, regulator or leseler $\mathrm{F}$, to sether with its vertically-adjustahle frame $\mathrm{F}^{\prime}$, its roller $\mathrm{F}^{\prime \prime}$, standaris and vertical screw's $G$ G G G, substantially as described and shown, and for the purpose set forth.

2.- The combination of the wheels and axle $B^{\prime}$, lever $\mathrm{C}^{\prime}$, hasclle $\mathrm{H}$, runner II $\mathrm{H}^{\prime}$, screws I I, oncillating cross piece 1 with fore-wheek $\mathrm{B} \mathrm{F}$, with their mountings, all constructed and operating together substantially as described and shown, and for the purposes set forth.

No. 141,707.- KUFUS A. FisH, Worcester, Mass. -Cultizators.-Ausust 12, 1873.-Application filed fanwar $y$, 3,1873 .

The teeth are secured to the frame by means of metallic socket bolted to the side of the beams, the teeth being beld in the sockets by keys and pins. The beams are adjuted in regard to width by means of notched segments and held in place by a tapering pin passing through flanges.

Claim. - I - In combination with the cultivator frame, the independennt metallic socket $\mathrm{C}$, tooth I), and wedge for holding the tooth in said socket, as set forth.

2.-The socket $\mathrm{C}$ and pin or key $\mathrm{F}$, in combination with the tooth $\mathrm{D}$, formed with a slot to engage said key, and the wedge, or it equivalent, substantially as shown and set forth.

3.- The combination, with the notched expanding hars, of the holder $G$ and pin 13 , substantially as shown and set forth,

No, I42,655.-ALBERT SMITH, PROVIDENCE TownsHur, PA.-Combined Shoird-Ploughs and Cultivators.September 9, 1873.-Application filed Harth 17, 1873.

The combination of devices wherehy a cultivator can in a moment and without removing bolt $=$ or screws be changed to a shovel-plough.

Claim.-A cultivator with main centre-beam and standard, carrying a main shovel, with two side beams, each carrying a smaller shovel, the side beams adjustahle in width, as shown, and attached in front, so as to be removed by unhooking alone, making a complete single shovel-plough, the whole contructed and arranged as shown and described.

No, 143,019.- IIILLIS LEWIS, OXFuRD, N. C.-Culitauturs. - Siptember 23, 1873.-Application filed April 3, 1873 .

A centre heam, with diverging side heams, supplied with curved harrow-teeth, followed by flat shares, one in each beam. A remicircular blade is placed behind the shares, whose length is as wide as the rear end of the machine. A rake in attached by links to the rear end of the beams, for removing wceds.

Claim. The combination of the cultivator-teeth I) I', semicircular blade $\mathrm{C}$, and rake $\mathrm{E}$, as described.

Nu. 143,350,-FELIPE PEREZ, HAVANA, CUBA,-C'ultizutors.-Seftember 30, I873. Application filed Alusust 4,1873 .

Two pairs of side bars, farthest apart at the centre, and con verging at each end, carry in front a series of cutting-blader. Behind them is a horizontal blade or scraper, extending acros the entire width of the frame, followed by harrow-teeth.

Claim.-A cultivator composel of a forward supporting roller, $\mathrm{E}$, of the cutting-blades $\mathrm{F}$ F, horizontal transverse blad $\mathrm{H}$, and pointed teeth IJ, to operate on light soil, substantially as herein shown and described.

No. 14+8,6.-I.EVI HAVERSTICK, MANor, PA.('ullizators.-. Vuacmber $25,1873 .-$ Application filed . April 23. 1873

The irregular-shaped beams are jointed by one overlapping the other. The pivoted shovel-standards are slotted at the upper end, and held in position by a hooked brace, which engages a ratchet-wheel. The strain of a fixed obstruction causes the wheel to turn and releases the shovel-standard.

Claim.-The beams B B', held on a common centre-pin or pivot-bolt, $A$, in combination with the shovels $C$, rateliet II, and sliz)-brace or pawl L, all arranged and operating sul stantially in the manner and for the purpose described.

No. 14+4,933.-HENRI VON PIIUL, JR., and JAMES MALION, Holly W(я)D, LA-Combinced Stubliti-Shazers and Scrapirs.-Nonember 25, 1S73.-Application tiled . An5 ust 16,1873 .

A curved, vertical cutter, designed to split the row s of sugarcane stubble, is mounted upon a frame with rumer: The cutter is followed hy a pair of oblique horizontal knives behind which is a triangular scraper, the last two being adjustable as to height by means of bas and cranks operated by a lever.

Claim.-1.- The combination of the knives $G$, sliding angular bars $\mathrm{H}$, connecting-bars $\mathrm{I}$, crank-arms J, shaft $\mathrm{K}$, lever $\mathrm{L}$, and catch-bar $\mathrm{M}$, with each other and with the frame $A$ $\mathrm{D}$, sulustantially as herein shown and described.

2.- The combination of the scraper $\mathrm{R}$, bar $\mathrm{Q}$, and lever $\mathrm{P}$ with the shaft $K$, having crank-arms $U$, the lever $L$, knives $G$, and bar $H$, all as shown and dexcribed, whereby the two cutting devices may be simultaneously raised and lowered by operating said levers, as set forth.

3.- The combination of the cutter $T$ with the knives $G_{\text {, }}$ scraper $k$, and frame $\mathrm{A}$ ), sulstantially as herein shown and described.

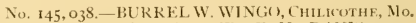
assignor of one-half his right to JESSE H. DAVIS, same place.-Cultinators.- Vine'mber 25, 1873.-Application filed June 28, I873.

The tandards extend above the beam to which they are pivoted. They are adjusted by a pin, which passes through them and through holes in a semi-elliptical plate which is secured to and rives above the beam.

Claim.-The plough herein described, having the adjuntable standards $\mathrm{B} B$ pivoted one on each side of the beam $A$, and the bent brace $C$ secured at one end to the standard $B$ and at the other end to the semi-elliptical plate $D$, and plough-beam $\mathrm{A}$, as and for the purpose specified.

No, 145,627.-CORNEIIUS II. CIARK, SHWARD, NEI,. -Ploushs. - Décember 16, 1873. - Application filed Schem:let 27,1873 .

To a widened portion of the beam-standards, rising from a horizontal portion, are attached a cutting-share-being fixel to the front hy rivets, clamps, and keys-and a sod-turner extending to the rear from the base-plate. The sicle-cutting portions are inclined or flaring.

Claim.-The standard portion C, having attached thereto the share C', with inclined sides, and the mould-1,oard-turner $G$ extending slightly over the rear edge of share $C^{\prime}$, combined substantially as shown, and for the purpose specified.

No. I45,691-ARTHILR C. SMITH, FAVETTETHi.l., N. C.-Cithizators.-Decimbir 16, 1873.-Application filed September 15, 1873.

Diagonal braces, having swiveled screw-joints, connect each beam with the others, and also with the upper pant of the handles,

Claim, - I. - In an implement consisting of two or more ploughs, the comlination of the diagonal braces D i), connecting the front part of the beams with the upper parts of opposite handles, and the diagonal braces $\mathrm{G} ; \mathrm{G}$, connecting the upper and lower parti of opposite handles, substantially an herein set forth.

2. - In an implement cominting of two or more plonghs, the combination of the tiagonal liraces $\mathrm{f}) \mathrm{L}$, connecting the front parts of the beams with the upper parts of opposite handles, and the diagronal braces $\mathrm{J} J$, connecting the front and rear ends of opposite plough-heams, sulstantially an herein set forth.

3.- In an implement consiting of two or more ploughs, the combination of the diagonal brace- $\mathrm{D} \mathrm{L}$, connecting the front parts of the beams with the upper parts of opposite hand$\mathrm{F}_{\mathrm{r}}$, the diagonal braces $\mathrm{G} G$, connecting the upper and lower parts of opposite handles, and the diagonal braces J J, connecting the front and rear end of opjosite beams, all substantially as herein set forth.

No. 1+6,216.-IIENRY VUN PHUI, JR, and JAMES IIAJLON, HoLLY Woun, near BATIN Rutie, I A.-Sir a)-Came Cultivaturs. - January 6, 1574.-Application filed Septimber 20, 1873 .

A long har or land-sile runs parallel with the line of clraft. Its front is made sharp, and there in linged to it a broader plank or monle-board having it edge beveled and shod with iron for a scraper. A curved lever and links expaut or contract the rear end of the machine.

Claim.-The combination of loarl $A$ and land-side C, hinged together, and having levers $\mathrm{D}$ and studs $\mathrm{F} \mathrm{F}^{2}$, with pivoted bar $\mathrm{F}^{\mathrm{t}}$ and lever $\mathrm{E}$, capable of being fastened at different points of adjustment on a stud, $F^{3}$, as and for the purpose set forth. 
No. I46,848.-FREI)ER] K (i. TIlRUSTON, NE:I

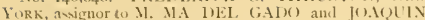
1.1.k.1, same place.-Furrene-Serapers.-Finutury 27, 1874 - Application filed .4ustws/ 23,1873

The scraper-blade has ohlique ends narrowing towards the rear, where the blade is sharply cut away, to gather the soil and allow it to fall over the centre.

Claim.-In a furrow-scraper, the plate $A$ provided with lateral vertical flanges $a^{1} h^{1}$ converging to the cut away central portion of said plate, as and for the purpose set forth.

No. 146,952,-JES.SE B. RUAISEY, WASHINGTUN, 1). C -Cultitators.- Fanum 27, IS 74 .-Application filed Dicimber 31,1873 .

The handles are hinged to the rear of the cultivator-frame, and shovels attached to them, which may be turned in or out at pleasure. The tooth or plough is reversible, and has a narrow flange on one side, meeting the opposite portion or monld-board at an angle.

Claim.-1-The combination of the cultivator-frame A B, bars 1 ) D, braces E E, and handles $\mathrm{G} G$, hinged to the rear ends of the beams A, substantially as and for the purposes herein set forth.

2.-The reversible concave plough or tooth I, provided with the angular narrow sicle flange $f$, substantially as shown and described, and for the purposes herein set forth.

3.- The combination of the frame A B, teeth C, bars D $\mathrm{D}$, braces $\mathrm{E} \mathrm{E}$, hinged handles $\mathrm{G} \mathrm{G}$, and the ploughs attached thereto, substantially as and for the purposes herein set forth.

No. 147,068.-CALEB M. RISLEY, WलmBt RY, N. J., and CLAJTON B. ROGERS, PhILAderphia, PA, - Cultivators. - Fibruary 3, 1874 .-Application filed Hay 18, 1872 .

The lateral adjustment of the drag-bars is effected by curved laar, extending inwardly through slots in the lraces which join the handles to the middle bar, a wedge or key securing them in the slots at any lesired width.

Claim.-The two sliding back bars $\mathrm{H} \mathrm{H}$, the slotted stays $\mathrm{I}$, and wedge-key $\mathrm{K}$, in combination with the bars A B C, and handles of the frame of the cultivator, the said parts being constructed and arranged as and for the purposes hereinbefore set forth and described.

No. 147, 6r6.-SAMUEL DAVIS DOUTHIT, Boyusvil.LE, KY.-Cultizutors.-February 17, 1874.-Application filed December 6, 1873 .

A series of teeth are arranged obliquely upon the beam in front of the shovel-plough, which carries a wing or scraper for throwing the fine earth up to the plants after the weeds and clods have been thrown away from the plants by the reversely inclined teeth.

Claim.-In combination with the teeth $a$, beam $A$, and shovel $\mathrm{D}$, the wing $\mathrm{E}$, attached to the shovel $\mathrm{D}$ at an angle the reverse of that formed by the teeth $a$, substantially as described.

No. 148,262.-BYRON D. TABOR, WILSON, N. Y. assignor to himself and C. D. TABOR, same place.-Cultiz'ators.-Harch 3, I874.-Application filed Janwary 29, $1 S_{74}$.

Upon a rod connecting the rear ends of the frame-bars or thills the broad curved bearings of the plough-standards are pivoted adjustably, a brace-lever extending forward to a slotted hanger, also laterally adjustable.

Claim.-1.-The plough-shank E, formed with the broad hook $m$ at its upper end, in combination with the shaft $h$, eye-screw $i$, and nut $y$, substantially as and for the purposes herein set forth.

2.-In a cultivator, the clamp $H$ constnicted as shown, with bearings $I, 2,3$ and 4 , on all four sides of the cross-bar $\mathrm{B}$, preventing any forward or backward movement, but al lowing it to move laterally on the bar, substantially as herein set forth.

No. 148,845.-HORACE N. PROUT, WestField, MAss.-Ilocin: Attachments.-Wureh 24, 1874.-Application filed Fibruary 19, 1873

The main plate or land-side runs upon its edge. The front end is beveled to form a sharp point. To it are attached a horizontal knife, and a curved wing or cutter, to operate between the plants and the track of a cultivator. The whole is connected to the cultivator-lseam liy a curved tandard. ('aim.-1.- The hoeing attachment to a cultivator above lescribed, consisting of the land-side $\mathrm{A}$, with angular points $X^{\prime}$, provisled with the wing-spring $B$, and curved horizontal cutter $C$, in combination with the standard 1 , whereby the whole is attached to a plough or cultivator, as and for the purpose described.

2.-The wing-spring $\mathrm{B}$, constructed as described, and attached to the land-side $\mathrm{A}$, or secured directly to a cultivatorheam or mould-board of a plough, as and for the purpose set forth.

No. 149,090.-WILLIAM C. BELL, ORANGE COURT Ilouss., VA.-Cultizatins-Plouchs,-March 31, 1874.Application filed famuary 17,1874

An oblique reversible point is slipped upon the standard, where it is held in position by a shovel, which bears upon it upper surface. The shovel is secured to the standard by a lug on the back, one bolt, and an angle-washer.

Claim.-1.- The combination, with the standard A, having toe-point and heel-notch, of the point $\mathrm{B}$, having slot as shown, and a shovel, $\mathrm{C}$, secured to standarcl, as set forth.

2.-The shovel $\mathrm{C}$, having lug $c^{-1}$, and the right-angled bar or washer $\mathrm{E}$, and the bolt $\mathrm{D}$, in combination with the standard $\mathrm{A}$, as shown and described.

No. 149,181.-TOSEPH A. BARNETT, CIAYSVILle, OH10,-Corn-Ploughs.-Narch 31, 1874.-Application filed Fibruary 4,1874

The side beams are hinged to the cross-bar and pass through a keeper bolted to the centre beam, in which they may be freely drawn together by the handles, and are thrown out again by the springs. A rear drag-bar carrying a plough is attached to the centre heam.

Claim.-The combination of the centre beam A, with bean $A^{1}$ attrched to it, arms E E, frame $H$, hinged side beams $A^{2}$, handles $G$, and springs $d$, all constructed substantially as and for the purposes herein set forth.

No. 149,719.-WALLACE H. CARTER, WatervilLE. ME.-Clay-Cutters. - April I 4, I 874.-Application fled October 30,1873 .

Upon a right-angled cutter-frame, attached at its ends to a runner-frame, an adjustable and reversible knife and mouldboards are applied.

Claim.- I, - The sled A, frame C, mould-boards D, and reversible cutter $\mathrm{E}$, the several parts being arranged and combined in the manner and for the purpose set forth.

2.- The inclined metallic frame C, fitted by its ends to and upon the inside faces of the runners, as described, and combined therewith, and with the movable and reversible clay-cutter $\mathrm{E}$, as and for the purpose set forth.

No. 150,719.-SOLOMON SEVERY, WALPOLE, MAss. assignor of one-half his right to LAWSON D. GRAV, same place.-Cultizators.-Way' 12, I 874 -Application filed Fcbматл' 12, 1874 .

Claim.-In a cultivator, the beams A C D E F, hinged together at their rear ends and spreading towards the front, acljustable by the bars $b c e f$, and provided with the curved teeth $\mathrm{G}$, attached directly to the front ends of the beams, in the manner and for the purpose specified.

No, I51,549.-FRANCIS M. SHIELDS, HASHUQUA, Miss, assignor to himself and JOHN C. HOLMES, same place.-Ploush-Supporters.-June 2, I874.-Application filed October 18, 1873 .

Claim.-The wedge-shaped plough-iron support $A$, having flange $\mathrm{E}$ on its upper face, hollowed out and provided with points $G$ on the lower, and having central slot $H$, as and for the purpose specified.

No, 152,623.-WILIIAN H. FARMER, ROME, GA.Cultizators.-Junc 3o, 1874.-Application filed Junc 9, 1874 .

Three beams, each carrying a shovel, are hinged at their forward ends. The rear ends of the outer ones can be expanded and held in place by set braces. On one side of the mildle beam is an extra hook, into which the beam on that si le can be secured, and the set brace removed accordingly and placed at the rear.

Claim.-The combination of the beams II $\mathrm{B}$ and the beam $\mathrm{E}$, adjustable from the hook $b$ to the hook $e$, with the adjusting brace or swinging plate $\mathrm{F}$, substantially as shown and describer. 
No. 153,127- -W II. SPLRGIN, Brownsville, MoCombined cultizators and Harrots.-July 14, 1S74. [Filed Junt is, 1874.$]$

The hinged side beams have jointed spring-bar connect ions, which allow a rocking motion, and may be guided in or out by the handles.

Claim. - 1. - The combination of the side beams $\mathrm{C} \mathrm{C}$, cen tre beam A, eye-bolts $a$, loops or straps $b$, and jointed perforated spring arms D D, substantially as and for the purposes herein set forth.

2.-The combination of the beams $\mathrm{A}$ and $\mathrm{C} C$, spring arms I) I), ploughs $\mathrm{G}$ G, and spring cutters $\mathrm{H} \mathrm{II,} \mathrm{all} \mathrm{constructed}$ substantially as and for the purposes herein set forth.

No. 153,168 -PETER l'. HILL, CRESTON, ILL-Cullizators.-July I2, 1874 . [Filed Fibruary 29, 1872.]

The frame consists of a tongue, and cross bars, to which the adjustable standards are attached. The depth to which the shares penetrate the soil is regulated by adjustable shoes or runners upon each side, and provision is made for the substitution of a "gopher blade," in place of the shares.

Claim.-The combination of the standards B B, frame A, leds C C, gopher.lays D D, and spindles or hubse, to which cultivator plough beams may be attached when desired, subtantially as specified.

No, 153,586 . - I. D. LYNCH, INDEPENDENCE, MISS.cultivators.-July 28, 1874.-[Filed May 16, 1874.]

In addition to the adjustable swinging beams of a parallel cultivator, a fixed plough standard is attached to the rear of the draft-tongue.

Claim. - The central plough $b$ of a gang of ploughs, rigidly but removably attached to a draft pole, $\mathrm{A}$, in combination with ploughs $g g$, of whith the beams D D are pivoted to a transverse cross bar, $B$, which is rigidly secured to the rear end of the draft pole A, which beams D D are laterally adjustable for different widths of rows, and which are connected together at or near their rear ends, substantially as and for the purposes specified.

No. 153,942.-O. W. COSI.EE, Buekingham, CoNN.Cultizitors and Ridgers.-Aurzst 11, 1874.-[Filed May $21,1974$.

The draft may be applied to the other end of the adjustable cultivators bars, and a coverer and scrapers substituted for the teeth, forming a ridger and potato coverer.

Claim.- The combination of the scrapers $d$ ', double share teeth $d$ and wheel and draft regulator $c$ with the cultivator frame $a$, having hinged adjustable side bars and reversible handles, to adapt it to carry the scrapers $c$ and curved horicontal plate $g$ of a coverer and ridger, substantially as shown and described.

No. I 56,847-THOS. H. GARI.ANI, WEST CLEVE I..NI, OHIo.-Cullizalors.- Notrmber 17, 1874.-[Filed Siptembir 21,1874 .]

The beam, the handles, side hars, and braces, are constructed of one piece of metal, and adapted for various interchangeable cultivator.

Claim.- The triangular frame A, constructed in the shape described and shown, the handles $\mathrm{E}$, and braces $a, a$, the whole made of one piece of metal, and adapted to carry a shovel plough having adjustable wings, or various forms of cultivator blades, with horizontal cutters and rakes, substanas and for the purpose set forth.

No. 157,196.-JAS, COPELAND, Bloumingdate, Oнto.-Corn Concrers and Cultivators.-Woamber 24. 1S74.- [Filed October 10, 1874 .]

The bars may be adjusted in width by their spring, and a shovel carrying standard replacing the wheel standard when used as a cultivator.

Claim. - The combination of the beams A A with curved flexible front ends, and the draw beam $B$, having a notched recess, with the spring braces ( 1 ), the perforated cross bar $\mathrm{E}$, and the standard $\mathrm{F}$, having a wedge shaped seat at its upper end, forming an adjustable cultivator, adapted to receive a wheel when used as a coverer, or shovels of various shapes when used as a cultivator or shovel plough, substantially as shown and described.

No. 157,398,-JAMES M. HOLLADAY, TWYMAN's STuRE, VA.-Cultinators.-December 1, 1874 .- [Filed Octobir 19, 1874 . ]

Adjustable standards with right angled shanks, work. ing between frame bars, and held by break-pins.

Claim.-1.- The standards B, bent at right angles at their upper ends, in combination with the frame A of double bars $a b$, and the break-pins $c$, substantially as shown and described.

2.-In combination, the hook $\mathrm{F}$, having its rear portion bifurcated, bent in the shape of an arc, and provided with adjusting holes, the brace and draft bar $E$, and the front standard, all having a common bolt, $d^{\prime \prime}$, substantially as described.

No. 159,331-MOSES JOHNSON, THRFF RIVER', Mich.-Cultiators. - February 2, 1875 - - [Filed famary 8,1875 .

A cultivator-tooth is cut from a metal plate, and shaped to present a mould-hoard form with a cutting or coulter edge. The main frame, made of a single metal bar, has removable wings, the front of the whole being of diamond shape.

Claim,-1.-A cultivator tooth, having the inclined coulter $n$, the concave mould-board $m$, with its oblique cutting edge, and the sloping rear edges $p p^{\prime}$, forming the acute angle or notch $\mathrm{X}$, substantially as described.

2.- The draft frame A, made of one piece of metal, consisting of the parallel bari $a$, meeting in front and doubled to form the draft beam $b$, in combination with the detachable wings $B$ and inner bars $c c$, substantially as and for the purpose set forth.

No. 159,523 - JOHN O. MILNE, MINNEAPoLIS, MINN. -Cultizators-Fibruary 9, IS75.-[Filed Vovmber 7. 1874.]

The adjustable beams are moved by arms attached to a gear-wheel, and turned by a pivoted lever having a geared segment.

Claim, - In combination with the hinged beams $C C^{\prime \prime}$ the lever $d$, having toothed segment $x$, gear-wheel $m$, levers $n$ $n^{\prime}$, and connecting bars 00 , as described, and for the purpose specified.

No. I 59,658 ,- M. EUST ACE, HighField, DRUMCONDRA, and JAS. KENNAN and T. KENNAN, DUBLIN, IREI.AND.-Wachines for Thinnins or Spacing Crops.February 9, 1875. - [Filed December 6, 1873.]

A series of longitudinal slotted bars carrying a rumner or guide at each end, and a hoe with side cutter in the centre. Two cross-bars adjustably connect the whole, bein, fastened firmly to two, and loosely to the others. The machine in driven across the rows, and the curved guides allow the hoes to strike the ridge of plants, and then raise them to deposit the earth and plant in the furrow. The guides may be adjusted as to length and the hoes as to heiglit.

Claim.-1.- The combination of two guide-frames, Il and IV, fixed to transverse bars B B, with other frames, I, III, and $\mathrm{V}$, connected to the transverse hars by guides I and springs, chains or links $K$, so as to be capable of independent vertical motion, substantially as herein described in reference to Figs. 5, 6, and 7 of the drawings.

2.-The gruides $\mathrm{A}^{1} \mathrm{~A}^{2}$, formed of metal bars, and secured so that they can be adjusted in length and position. to suit drills of different widths, substantially as described with reference to Figs, 1 and 5 of the drawings.

3.- The combination of a straight guide, $A^{2}$, with a curved guide $\mathrm{A}^{1}$, and hoe-blade $\mathrm{F}$. placed either behind or in front of $A^{1}$, substantially as described with reference to Fig. 14 of the drawings.

No. 160,353-PETER D. ROOUEMORE, PANOLA Colnty, TEx.-Cultizatmr.-March 2, 1875.-[Filed Vorvenber 9, 1874.]

Standards pivoted to handles, allowing change of pitcl by slots in the beam; the centre standards removable.

Claim. - The combination of beam A, having diagonal slots $s s$, adjusting-braces $d$, adjusting cross-rods and nuts $b$ $c$, and standards $a$, pivoted to the handles, all arranged and operating substantially as set forth.

No. I 60,545--JOS. ROBSON, OSceola, Wis.-WeedCullers and Hillers.-March 9, 1875.-[Filed May 7, I 874 .]

The standard has arms extending backward and hinged to the rear end of beam. This gives vertical adjustment to the point, and holds the bars which govern the expansion of the cutting and hilling wings. 
Clanm-1, - The adjustable standard (', with rear ward Iy-projecting arma C" (", which are hinged to the rear end of the beam $(i$, and have a socket to receive the adjusters $I$. in combination with the triangular weed-cutter $\mathrm{A}$ and hor izontal knives 11, sulstantially as and for the purposes de scribed.

2- The combination of the standard $\mathrm{C}$, having arms $\mathrm{C}^{*}$ weed-cuter A, hnives 11, having adjusters I, ani mouldboard E, substantially as described and shown, and for the purposes set forth.

No, 161,157-I.EONAR1) (. ROBBIRTS, GORUAM,

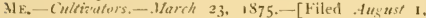
1874 .

The frame consists of three beams, pivoted together at the rear ends, and mare laterally adjustable in front, the front end of each outside heam being provided with guage-wbeels, independently adjustable. The cultivator-teeth are secured to the outer beams.

Claim.-The outer beans, pivoted at the rear ends and made laterally adjustable in front, in combination with an adjustable gauge.wheel on each, as shown and described.

No. 161,455.-F. W. TOLLEV, CoXSACKIF, N. Y.Cultuators.-Ward 30, 1875. - [Filed Famury 4, 1875.]

The entire frame curns upwarel and forward to he tranported upon the wheels.

Claim.-1.-4 cultivator-frame consisting of curved bars A, long rods $\mathrm{B}$, with end screw receiving nuts, and tubular washer: $\mathrm{C}$, all substantially as shown and described.

2.- The combination, with frame and pivoted tongue. adjustable in sotted guides $\mathrm{F}$, of the pivoted draft hook $K$, having link $\mathrm{I}_{\text {, }}$ adapted to couple witb the hook $\mathrm{II}$ or $\mathrm{N}$, in the manner and for the purpose specified.

No, 163,523.-EI.1AS M. POTTFR, RITHERFORU

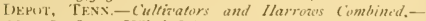
Hay 18, 1875. - [Filed Felineary 33, 1875.]

A rectangular frame consisting of three beams, each car rying a cultivator tooth, with handles secured to the outer ones. To the middle beam, at its rear end, in attached a triangular harrow, which has a limited vibration to the right and left.

Clain.-In combination with the plough stock A the triangular harrow, loovely connected by means of the pin $i$, and limited in lateral vibration by the steady piss $e^{x} e^{x}$, sul $x$ stantially as describet.

No. 163.921 - AI.BER' LART, RoCKVILLF, CoNv,(iultivators.-Fune 1, 1875.-[Filed April 17, 1875.]

The frame consists of a central beam to the upper side of which the handles are attachet. A cultivator-tooth is ad justably secured to the front end, and a wing standard a tittle in the rear, to the upper end of which is secured a spring, extending rearwardly, terminating in a bifurcation. which supports a bearing-wheel. Stationary wings are at. tached to the wing-standard, and ad,ustable wings are attached to pivoted arms upon each side of the centre beam.

Claim.-The combination, with spring-adjusting wheel, of stationary wing $\mathrm{I} I$ and adjustable wing $1 \mathrm{~J}$, as and for the purpone specitied.

No, $165,55^{2}$-JAMES U, DUNNAVANT and W. A. HAMFSON, BYHALIA, Wiss.-Cultizators.-Fuly 13. 1875. - [Filed Warch 15, 1875.]

A light triangular frame strengthened by flanges, and secured to the front end of the centre beam by longitudinal plates and cross-bands.

Claim.-The flanged metal frame C D E, with its connecting-bands $a$, adapted to allow of the adjustment of the side beains, all constructed and arranged as set forth

No. 166,044.-WII.LIAM WEAVER, GREXIVICH, N Y:-C'ultizators. July 27, 1875.-[Filed Mur 15, 1875.]

An angular-sbaped cultivator with alternate devices, to adapt it for use as a cultivator, hiller, or potato-digger.

claim.-1.-The angular bar A A, slotted in their front sections, in combination with the angular draft-bar $B$ and standard D, forming a cultivator of nearly diamond shape, and adapted to receive alternate cultivating devices, as shown and described.

2. - The combination of an angular slotted frame A A, draft-bar B, slotted handle-socket, (), standards D F H, and ploughs C G E, all arranged subatantially as and for the purpose specified.
Nu, I66,290.-EDWARI) NAUMAN, LN(WNTOWN, OHlo, ¿ultizators.-Iusues! 3, 1875. - [Filed Jume 19. [875.]

A swiveled canter-wheel adjusted by a lever and notched bas:

Claim.-The combination, with the cultivator-beam $\mathbf{A}$, carrying shovels as described, of the gauge-wheel F, having an extended shank or tenon, the lever $G$, and notched round $/ h^{1}$, joining the handles $H$, all as shown and describ. ed, to operate as specified.

No. 170,549.-HERMAN D, GREEN, ITHACA, Y. V. asignor to FREEMAN, VALFNTINE \& (iREFN, same

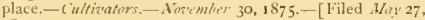
1875

Claim,-1. - The beam $a$, cast in one piece, and consist ing of the extensions or parts $a^{\prime}, b, e$, and $y$, as shown and described.

2.- The beam $a$, constructed as shown and described, in combination with the cross-bars $f$ and $h$, standards $i j$, and bandles $k k^{\prime}$, arranged substantially as and for the purpose set forth.

3.- In a sbovel-cultivator, the beam $a^{\prime} b$ and arm $t$, cast in one structure, in combination with the front shovel-plough. and the two rear hoes and their standards $i$, the arm $e^{\prime}$ sup porting said rear standards near their top, as set forth.

No, 170,882 , ENOS R. M(x)RE, BELL'S MILIS, AI.A. -Culrizators.-December 7, 1875.-[Filed Angust 20, 1875 .]

Harrow-frame in front of ploughs, with slotted bar to al low the whole to be closed or expanded.

Claim.-The combination of the main beam A, station ary slotted cross-beam $B$, adjustable cross-beam $C$, the slotted beams D D, carrying the plough feet and shares, ani the adjustable barrow-bar;, all subtantially as and for the purposes herein set forth.

No. 17t,391.-FREDK I), LADENBERGER, (ILF BECt.AH, WIs.-Harroze Attachments for Cultizater Ploughtis.-December 21, 1875. - [Filed September 17, 1875.]

In the rear of an opening or shovel plough are hinged two diverging beams, that are made adiustable by a curved brace-bar. These beams each carry first a share, which throw the soil outward. The rear ends of the beams carry harrow teeth which level down the furrow made by the plough.

Claim-A combined implement, consisting of the shovel or breaking plough $\mathrm{A}$, side ploughs $\mathrm{B}$, and harrow $\mathrm{C}$, the beams of the ploughs $B$ and $C$, being rigidly bolted together and made adjustable in width by a curved bar D, and connected to the breaking-plough $\mathrm{A}$ by means of eyeholts $a$ and brace-rods $b$, all constructed as and for the pur pose specified.

No. 171,420 . IOSHLA PIERPONT, BUSHNELL, I1.1. - Cultiñators.-Decemlic7 21, 1875. - [Filed linember 6 1875.]

An adjusting-plate upon a cultivator-standars, for holding the lirace at various lengths.

Claim.-1.- The block $(i$, constructed, as described, with lugs $\%$, series of holes ${ }^{\prime}{ }^{\prime}$, and prongs $/ 4$, sulsstantially as and for the purpose specified.

2.-The bleck ( $i$, baving prong $h$ and lugs $s$, with $a$ series of holen $g^{\prime}$. combined for operation with the brace $\mathbf{E}$, pin $\tau^{\prime}$, randards $\mathrm{B}$, and plough-heams A, substantially aand for the purpose specified.

No. 171,503.-JOSEPH W. (IIASE, MIDILEPORT,

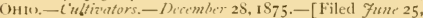
1S75.]

A clamp in two part, to aljust the width of the cultivator by sliding upon the beams, and permits vertical adjument by a step-block.

('Taim - The clamp o, composed of the upper plate $c$, having the mortised lugs $u{ }^{\prime \prime} 2 c^{\prime}$, and the lower plate $\Omega^{\prime}$, having the central mortised lug $x$, in combination with the gib $g$, the set-screw $\tau^{\prime}$, and the plough-beams, as and for the purposes set forth.

No, 172,869 . - NELSON C. COI.E, BEAVER DAM, WIS -Cultizators.-February 1, tS76. [Filed August 4, 1875.]

Devices for coupling together the drag-bars of seeders or wheel-cultivator, to form an orlinary cultivating implement. 
Claim,-1n a cultivator, the loops or clasps B E, the rods $D$ and $F$, wedges $F G$, and draft-hooks $H \mathrm{H}$, in combination with the tooth-bar $\mathrm{A} A$, as and for the purposes described and ret forth.

No, 173,238.- JAMES A. PRJCE, IIOUETON, TEXAS,Cultivators.-Fehrwary 8, I876. [Filed Oitober 8, 1875.] Claim.-A cultivator provided with rear adjustable side beams D E, one placed in advance of the other, on opposite sides of the main beam, pivoted in front and curved backwardly therefrom, as and for the purpose specified.

No. 173.425.-WILIIAM A. SQUIER, GORHAM, N. Y. Cultizators.-February 15, 1876. [Filed Nonember 4, 1875.]

Devices for connecting the parts, wherehy the thills are pivoted at their centres and vibrate vertically.

Claim.-In a cultivator, the loops L L', provided with the perforations $p$, the elbows $e$, and extensions $x$, in combination with the vibrating thills $T$, handles $H$, and crossbars $C^{\prime} C^{\prime}$, arranged for the purposes substantially as set forth.

No. 173.554 -THOMAS J. MONTGOMERJ and GEO. W. MONTGUMERY, WINCHESTER, TENN.-Cirltizators. - February 15, 1876. [Filed September 17, 1875.]

An extensible rear support or runner for a shovel-plough.

Claim. - The combination of the outwardly, downwardly, and forwardly curved standard $\mathrm{B}$, the extension-braces $\mathrm{D} d$, and the flanged har $\mathbf{E} e^{\prime}$, all constructed and arranged as and for the purpose specified.

No. 175,200.-JUHN S. SWANEY, MARENGo, Iowa. -Root-culting Ploughs.-March 21, i876. [Filed fanwarp 15, 1876 .]

Claim.-In a root-entting or transplanting plongh, the combination with two diverging beams, of the side cntters B B, inclined base cutter C, inclined plate E, and wedgeshaped sole D, substantially as herein shown and des. cribed.

No. 175,216.-SILAS WALTUN, MoORESTOWN, N. J. -Cultizators.-March 21, 1876. [Filed Fibruary 5, 1876.]

The curved standard and its combination with the curved beam.

Clain.-I,-The standard S, curved downwardly, and outwardly and terminating in a vertically-inclined stem or blade holder, arranged as described, for the purpose set forth.

2.- The standard S, curved downwardly and outwardly, and terminating in an inclined blade-holder, in combination with the reversible blade $b$, cut awity at $i$, as and for the purpuse described.

3.- The combination, with the main beam A, having an offset at its reat end, of the curved standard $\rightarrow$, for the purpose of centering the blade in such a manner as to allow obstructions to pass over the top of the same, substantially as described.

No, 175,251--1.EWIS MILI.ER, RHHMOND, IND.Corn.Ploughs.-Warch 28, 1876. [Filed Fanunry 24, 1876.]

'The standard brackets, in two parts, united by disks, one having a slot and the other a stucl. Handle-fastenings clasp the round beam, giving lateral acljustment.

Claim.-1.-The arrangement and combination of the arm $\mathrm{D}$ D, circular plates $\mathrm{E}$, slot $\mathrm{E}^{\prime}$, and arms $\mathrm{W}^{\prime} \mathrm{L}^{\prime}$, in the manner and for the purpose set forth.

2.- The clutche $\mathrm{OO}$, braces $\mathrm{C} \mathrm{C}$, and handles $\mathrm{B} \mathrm{B}$, in combination with the beam $\mathrm{A}$, as herein set forth.

No, 176,072.-JUHN L. SCARBROUGH, FAYETTEviLI.F, ALA. - Combined Ploushs and Harrowes - dpril 11 , 1876. [Filed December 13, 1875.]

Clain.-In a combined plough and cultivator, the adjustable hinged harrow-beam $\mathrm{B}$, with its teeth $\mathrm{E} E$, perforated adjustable arc $\mathrm{C}$, and beam $\mathrm{A}$, in combination with the ad. justable hinged and slotted standard $G$, plough-point $F$, and adjustable abutment $K$, substantially as set forth and described.

No. 176,240.-CASPER OEHRLEIN, ST. PAUl, MiNN. -Cultinators.-April 18, 1876. [Filed November 19 , I875.]

A plough as shown, capable of carrying interchangeable parts, to adape it to various nses.

Claim.-The combination, with plough-beam $A$ and standard $\mathrm{B}$, of the shoe $\mathrm{C}$, with flat sole and curved sides rising to an edge, and having a triangular point, I, curved plate $J$, and eyes $b^{\prime}$, the whole adapted to use as a furrowopener, or to receive a pair of extensible mould-boards, M, or rakes $\mathrm{K}$, all constructed as herein shown and described.

No. 176,466 -ABRAHAM G. W. FOSTER, NEWMAN, (iA.-Cultivators and Subsoilers,-April 25, 1876. [Filed December $\mathbf{1}, 1875$.]

The bar carrying the standards is pivoted under the plough-beam, to he swung around at any angle. Standards and bar are adjusted and held by serrated plates.

Claim. - The cross-bar $s$, swiveled to the plough-beam by the bolt $l$, and the ratchet-plates $h i$, in combination with standards 2 , having serrated top notched plate 0 , and bolt 4 , whereby said cross-bar is adjusted in line with the beam for a subsoiler, or at an angle with it for a cultivator, as described.

No. 176,704,-F. W. STOSSBERG, PoND, Mo.-Cultivators - April 25, 1876 . [Filed Fibruary 19, 1876.]

The construction of cultivator-frame and $e^{-m b i n a t i o n}$ with the guards.

Clain,-The perforated adjustable cross-bars $\mathrm{H} \mathrm{H}$, with screws on their outer end 4 , in combination with the standards $\mathrm{J}$, adjuntable forward and backward in a vertical plane, braces $\mathrm{K} \mathrm{K}$, nuts $h h$, pin $f$, and guard-rods I $L$ attached to the cross bars $\mathrm{H} \mathrm{H}$ at their rear ends, and adjustable therewith, substantially as described and for the purpose set forth.

No. 177,007 -A. RIGBJ, UpPer StIllwater, Me.Cultivators.-May 2, 1876 . [Filed March 11, 1876.]

A harrow attached to an adjustahle beam-cultivator.

Claim.-The combination, with the adjustable side beams of a gang-plough, of the hooked rorls $h h$, harrow $G$, with elongated staple $i$, chain $k$, and round $m$, with its hook, subst.ntially as and for the purposes herein set forth.

No. 178,826.-WILLIAN WRIGHT, LOCKPORT, N. J - Cinltirators._- Fune 13, 1876. [Filed November 20. 1875.]

The teeth made in two parts, having a beveled socket and tenon, and a web upon each, that receives a rertical bolt in the rear cavity.

Claim.-The cultivator tooth 1 , constructed as described, in combination with the tapered tenon $h$ on the standari, the web $d$, and the bolt J, substantially as described.

No. I 78,846 . JOSEPH GLIDDEN, LIBERTY, ME.Cinltizators.-Fune 20, 1876. [Filed February 7, 1876.]

A centre beam carries two ploughs, the forward one narrow and the rear one wide. (On either side is pivoted a plough-standard capable of lateral adjustment. A pair of handles are supported from a central standard from the main beans.

Claim. - The described improved cultivator, composed of the handles C, bar D, support-piece $d$, heel and toe spades F. F, differing in widths, an described, and the lateral adjustable spades A A, having their stocks pivoted to a rockshaft, B, and furnished with support-rods $b$ b and perforated curved braces $f f$, all heing arranged and applied substantially as specified.

No. 178,9 I2,-JOHN M. CRABTREE, WELI.INGTUN, () Hо.-Cultizators.-Fun 20, 1876. [Filed February 21,1876 .]

There are two sets of shares and two mould-hoards, which extend the whole length of the machine in diverging lines. The shares are adjustable both horizontally and vertically. The forward end of the centre beam is mounted upon an adjustable pilot-wheel.

Claim.-In cultivators, the vertically and horizontally adjustable mould-boards $\mathrm{N} \mathrm{N}$, in combination with the vertically and horizontally adjustable shares $\mathrm{J} J$ and adjustable pilot-wheel Q, substantially as and for the purpore set forth.

No. $179,220 .-$ GEO. W. RHODES, ETNA, N. Y.-Cul tivators. - Fune 27,1876 . - [Filed fune 1+ 1876.]

By detaching the brace from the pin on the lever, the resistance of the front teeth, operating in connection with the draft of the team, will cause the cultivator to tilt forward upon the wheels.

Claim.-In a cultivator, the arrangement of the different parts, consisting of the frame $\mathrm{A} \mathrm{B}$, the tongue $\mathrm{F}$, having the roller $H$, the wheels $K$, lever $\mathrm{D}$, and notched brace $\mathrm{E}$, con- 
structed aud operatiug sulestantially as descrituel, and for the purpose set forth.

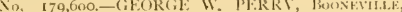
Miss. - Ploushs. - $7 u / 1,4,1376 .-[$ Filed . April $15,1876$.

The frame consists of a centre beam, to which the tongue is attached, two side heams and two cross heams. These beams and cross pieces are pivoted together in such a man ner that, by pusling one forward and the other tackward, the distance hetween them is increased or diminislied. The outside beams carry each a share. An adjustable headblock, carrying another share, is sccured to the under side of the middle beam, and which can be removed at plensure.

Claim.- I - In combination with the heam $\mathrm{A}$, the detach able and longitudinally-adjustable bar $1 \%$, provided with a mortise, the foot $\mathrm{E}$, provided with a tenon fitted into said mortise, and said bar and foot, secured to the frame A by the clips $n$, as and for the purposes herein set forth.

2.-The side beams B B, perforated and pivoted bars C ( , and graduated plate () , in combination with the beam A and the longitudinally adjustable bar $D$, and its foot $E$, all substantially as and for the purposes herein set forth:

No. 180,396.-DANIEI. F. VICKERV, ()xFoR1), Al.A. assignor to himself, $G$. F. MATTISON, and A. 11.

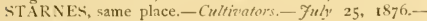
[Filed . Hoy 8, 1876.]

A beam is provided with a slotted cross bar, which is bolted to its rear end, and secured at any desired angle by curied slotted braces. The central portion of the beam is also slotted, to allow of greater adjustment.

Claim. - The improved cultivator, furmed of the slotted beam A, curved braces E F, pivoted cross bar I, and share standards $C$ C, said parts heing sloted in the manner shown and described, and the clamp holts $c d h$. all combined and arranged as specified.

No. I80,999-HERMAN D. (IREEN, ITHACA, N. Y - Cultizators. - Ausust 15, I876-[Filed April 15, 1876.

Claim. - I - The metallic top piece $b$, between the stand ards $u$ and handles $c$, and having cust as part of, and ex tending from it, wings or flanges, to which the handles are bolted, and the standards pivoted laterally, directly unlerneath the handles, substantially as set forth

2.-The line piece $e$, fitted to the base of the standards and held fast to it hy the brace rod $g$ and bolt $f$, and having hoes $d$ adjustable to it by bolts, subatantially as set forth

3.- The hoe piece $i$, cross bar $h$, ancl standard $a$, held rogether about the rear end of the brace $s$, subutantially as set forth.

4.- The top joint piece $l$, and hoe piece $\ell$, made ar described, in combination with the standards $a$, handles $i$ braces $g h$, and hoes $d$, as set forth.

No. 18I,041.-JOSEPH W, CIIASE, MImI.FMRT, OHIO.-Ciultizators.-August 15, 1876.- [Filed Murch 8. 1876$.

The frame is made of iron, and consists of three lvars, curved at the rear end to receive the shares. The outer hars are pivoted to the centre har, and are adiustable out ward and vertically.

Clain. - The combination of the beams $a d$, handles $r$, guide $e, 1$, links $y$, bolt $i$, plates $h$, set screw 3 , and a fasten ing device for connecting the end of the links to the heam $d$ substantially as specified.

No. ISI,746.-R. C. TRAWEEK, BLANCO, Trx.I'loughs.-August 29, 1876.-[Filed fune 26, 1876.]

The two cross-bars holding the braces and the standards pivot upon the heam, anil the standards and braces pivot upon the cross-bars. When the latter are adjusted, the shovel-standards are autumatically kept square with the line of draft.

Claim. - The combination of the cross-bars $\mathrm{C}($; , pivoted at their centers to the beam $\mathrm{A}$, the standards $\mathrm{D}$, pivoted at their upper ends to the cross-bar $C$. the braces $F$ pivoted at their forward ends to the cross-bar $G$, the adjustable chain $I$, and the adjustable hook-plate I, with each other and with the plough-beam A, substantially as herein shown anc described.

No. I82,128,-EDW ARD JAL IIAN, BRIDGEPORT, ()н10.-Cultivators.- September 12, 1876.- - Filed June I 2, 1876.
A thur central beam embraced by a U-shaped bend in a crosisod for adjusting the beams.

C. laim. - The combination of short bent central beam $F$, rod $\left(i g^{2}\right.$, and braces $J \mathrm{~J}$, with beams and handles, as aud for the purpose specified.

No. IS2,347.-HORACE C. BRIGGS. Wrst AUBURN MF - Cultizators.-Siptember 19. 1876.-[Filed fune 26, I 876.$]$

The frane adjustable in width, and the turgue and it braces adjutable to any width

Claim.-I.-The combination of curved uprights $c$, having perforated flanges $c^{\prime}$, the bent pusts $\boldsymbol{F}$, braces $H$, crossbars D G, and plough-lreams B, provided with notched brackets R, substantially as herein shown and described.

2 - The curved uprights $\mathrm{C}$, with perforated flanges ${ }^{\prime}$ rigidly secured to the front ends of plough-beams $B$, and adjustably secured to crost-bar $\mathrm{D}$, in combination with the hooks $J$ and tongue $I$, as and for the purpose specified.

No. $182,399 .-E$. A. Al)ERHOLT, OXFORD, AI.A.Cultivators.-Scplember 19. 1876.- [ Hiled April 15, I876.]

A cultivator with a main beam, to which is attached, by a bifurcated brace, two adjustahle side heams.

Claim.-I. - The beam $A$ and $C \mathrm{C}$, in combination with the bow $\mathrm{D}$ and the bars $\mathrm{E}$ E, with graduated holes for holding and spreading the fromt of the side beams, as is herein set forth.

2. - The bar $\left(; F\right.$ and $\left(i^{\prime}\left(G^{\prime}\right.\right.$, in combination with the heams $C($, the handles, and the har $\mathrm{E} \mathrm{E}$, and bow I), as and for the purpose set forth.

No, I83,09o,-EDIVARI) IVIARI), LotisviLLE, Kr. assignor to B. F. AVERY, same place.-Cultivators.-Oitober I0, IS76.-[Filed April 17, I876.]

A single straight iron beam supports the handles. Upon one side, near the rear end, is mounted an arm, secured by holts, for the reception of the plough-itandard. About the middle of the beam, and upon the opposite side, is mounted another arm, to receive the forward standard.

Claim.-1.- The combination in the double-shovel plough, of the single iron-beam, the two shovels, and the braced and stayed brackets, all constructed and arranged as and for the purpose set forth.

2.-The plough-shovel bracket $F$, constructed with the abutting side plate, the tubular stay, flanged plate, and diagmal brace, in the manner and for the purpose described.

3.- The lever-bracket, as described made with an open loop, to receive the plough-beam edgewise, and with a passage thruugh its looued portion, to permit the insertion through it and the beam of a wooden pin, substantially as deacribed.

No $183,147-4$ DEMARCE and TEUNIS VREE1.ANi), FAIRFIELD, I (IWA.-Combined Cultiñators and

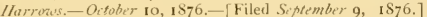

A frame hinged centrally by connecting-lars, operating with vertically adjustable runner.

Claum.- I. - The beam A, having teeth, as described, and connected to each other by the hinged bars $B B^{\prime}$, anil arranged to operate with the runner, $G$, substantially as described, and for the purpose specified.

2.-The beams $\mathrm{A}$, having teeth, as described, handles $\mathrm{E}$, chain F, draft-hook $C$, and convecterl to each other by the binged bars $\mathrm{B}^{\prime} \mathrm{B}^{\prime}$, and arranged to operate with the rumners (;, substantially as and for the purpose specified.

No. $18_{3}, 18_{3}-W I J .1 .1 A M$ MANI.FY, MINIEN, I.A.(iultivators.-Oitober 10, 1876 .-[Filed Fulv 29, 1876.]

Curved standards arranged to curve outward and carry each a shovel, or to curve inward and both support one shovel.

Claim.-The combination of beam 1$)$ with bent standards E $\mathrm{E}$ and hovel $\mathcal{G}$, wherehy said standards may he adjusted far apart or clone together by simply transposing them, substantially as and for the purpose set forth.

No, IS3,202,-GARLANI) A. I'ARSONS, J JOVFR, ARK. - Cultivitors.-Oitober 10, 1876. - Filed Fuly 31, I876. Devices for adjusting and bracing the cultivator-beams.

A cultivator-frame consisting of the central, intermediate, and outside plough-beams A B C, the beam B having the cross-bars $G$ passing through beam $A$, and the beam $C$ having cross-bars $\mathrm{E} F$ passing through both beams $\mathrm{A} \mathrm{B}$, sub stantially as and for the purpose specified. 
Vi, IS3,868-MARK II ROIVELL, Ocisomowoc, WIs.-Cultirators.-Oitober 31, 1876. [Filed Fumi 22, 1876$.

A single beam supports upon pivoted hangers a series of share-bars, so coupled that an immovable obstacle will turn all the shares backward, to prevent injury to the parts. By removing a part of the cultivator teeth a horse-hoe is formed.

Claim. - A cultivator constructed with frame A, standards 11 , teeth $D$, eari $F$, swirging on bolts $G$, connected with rods 1, all in combination, substantially as described.

No. 184,658 . -GEORGE W. PARISH, SAIANNAH, GiA.-Rier-Cultizators.-Virember 21, I876. [Filed Aws. I $9,1876$.

Claim, - 1,- The cultivator-teeth I, having horizontal blades $a$, vertical cutting-edges $b$, brace $c$, and shanks rounded and adapted to form the pirot for tbeir carryingframe, substantially as and for the purpose described.

2. - The combination, with the frame $\mathrm{E}$. composed of loosely-jointed parallel bars, of the cultivator-teeth $\mathrm{D}$, having sbanks rounded at the top, and provided with nuts to form the front pivots of said frame, and having a rearwardly-inclined brace, $c$, extending to the rear pivuts of the frame, and secured thereto by tbe same bolt $d$ that forms the pivot for the frame, and secures the adjusting-har, sub. st intially as described.

No. 184,674 -THOMAS I. TEAGILE, INDEPFNDENCE, MAss. - Cultinators.- Vonember 21, 3876. [Filed July' 3. 1875.$]$

Claim-In a cultivator, the combination, with the ad. justable side beams $C$ C and the upper and lower trans. verses connecting-bars $C_{i} J$, of the upper and lower front transverie bars $b \quad b$ and the central draft-beam A, extended in rear to rest on the lower or transverse bar $\mathrm{l}$, connecting said side beams, substantially as specified.

No. 184,838 , - ROBERT I), CHRISTMAN, JoIIstun County, N. C.-Gang-Ploughs.- lin'timbir 28, 1876. [Filed $F_{11} /{ }^{2}, 29,1875$.]

Clain.- In combination with the frame A or similar frame, the bolts $m$, the plate $\mathrm{D}$, with the frame or stirrup $(i$, made with the land-side in one piece, or adlapted to receive a land-side in a separale piece, and with wing $f$ for the attachment of the point $h$, all constructed and arranged subutantially as shown and described.

No. 185,039 - THOMAS T. MCALLISTFR and VII

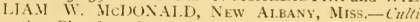
varing Plough.s.-December 5, 1876. [Filed Fibruary 5, 1876.]

Claim-In a cultivator the combination, with the beams $A$ and colters $\mathbf{F}$, of the fallow-blocks $1 \mathrm{I}$, having the form specified, and arranged horizontally, as shown and described, to operate as specified.

No. I85,211. WIILLAM T. CIIFATHAM, RIENZI, Miss.-Plonghe,-Decimber 12, 1876. [Filed October 14.1876 .7

The standards raised or lowered in loops; the construc tion of the parts; an attachment for clrawing off clods left upon the plants.

Claim.-1.- The plough standards B, arranged to slide in loops of the bars I) E against a spring, $\mathrm{H}$, as shown and described.

2.- The combination, with beam A and plough-standards $\mathrm{B}$, of the spacing-bar $\mathrm{I}$ and braces $\mathrm{E}$, correspondingly adjustable, as and for the purpose set forth.

3.-The bandle-bars $F$, attached to the upper part of braces $\mathrm{E}$, and provided with an end hook, that connects with the loops of bar. D, as and for the purpose specified. 4.- The knocker $O \mathrm{P}$, arranged under, and at the rear ol beam A, as shown and described, to drag the clocls off the corn-row.

No. 1 \$ 5,55 I, - TIIOMAS R. LANDON, SI.ADESTILI.E. N. C.-Cintividors.-Dicember s9, 1876 . [Filed August $2 \mathrm{I}, 1876$.

Claim. - The angular standard-bars F H, slotted in their vertical arms, in combination witb the braces $I$, having slotted horizontal upper arms, and with the slotted adjustable cross-bar $\mathrm{E}$ and beam $\mathrm{A}$, substantially as herein shown and described.

No. 186,281.-ROBERT WEBER, NEW ULY, TEX,-
Plowsh-Stocks.- Fammary 16, 3S77. [Filed October 14, 1876$.

The form of the sockets for securing the standards, and devices for changing, to adapt the frame to various cultivating implements.

Claim.-1,...The keeper 1, provided with a square socket in its forward part, and a round socket in its rear part, in combination with the beam $\$$, for securing a standard to said beam, substantially as herein shown and described.

2.-The combination, witb the beam A, of the U-bars $\mathrm{N}$ and keepers $\mathrm{P}$, the latter provided $\mathrm{W}$ ith square forward and round rear sockets, as shown and described, so that standards may be fastened thereto by screws and wedges, in the manner specified.

No. 186,611 .-E. H. PERKINS and S. D. PERKINS Visalia, CAL.-Cultizators.- Fanuary 23,1877 . [Hiled June 6,1876 .

The beam is supported upon two standards, to the lower end of which is secured a slotted sole-piece, forming also a point. The forward section of this is horizontally slotted, and in whicb are pivoted two thin steel plates or blades, which overlap at their forward ends. A sliding brace moves fore and aft between the wings upon the sole, and is secured by a set-screw. By this means the wings are adjusted.

Claim.-1.- A pair of cutter-wings, D D, made to overlap each other within a slot of foot $C$, as and for the purpose set forth.

2. - The slotted adjustable bar $\mathrm{E}$, having cross-hend $e^{\prime}$, in combination with wings $\mathrm{D}$, having rotches $d^{\prime}$, as and for the purpose specified.

No, $187,190-11$. SNVDER, CoNwAY, IICH-Ilor Fork-Hooks, -February 6, 1877. FFiled December 19 IS76.1

Claim.- The horse fork-bouk, consisting of the curved books $a$, united to form the shank draft-hook $b$, and com bined with the centrally rearward-projecting handle or lever $d$, and its rigid bar $c$, upon the back curve of the tines, for use as described.

No. $187,470 .-$ S. F. I.E. New Siotlani, N V:Cinltiziators. Firmary 20, 1877 . [Filed fanmary 3, 1876.]

A syuare frame laving in front adjustable arms, project. ing forward, and carrying caster-wheels and rear adjustable arnis witl fixed wheels.

(laim.- In combination with the cultivator-frame A, the rear wheels I monnted on pivoted arms $C$, provided with slotted arms $d$ and set-screw's $n$, and the caster-wbeels $D^{\prime}$ mounted on the adjustable arms $F$, substantially as and for the purpose set forth.

No. 187,665 -CHARI.ES W. ONEAL, SHOP SPRINi, Trxx.-Plongh-Couplinss for Domble Shotels.-February 20, 1877 . [Filed Oitaber 14, 1876.]

Claim.-The plough having the long straight rudderbeam $\mathrm{B}$, in line with the draft, and the short laterally-bent beam $A$, having its clevis and rear ends parallel with the beam $\mathrm{B}$, the handles $\mathrm{F}$ connected to the parallel portions of said beams, the links $K K^{\prime}$, and the clevis-pin $\ell$, whereby the clevis ends of the straight and bent beams are pivoted together, substantially as specified.

No. I87,238.-J. A. LEES, PhIJ.ADEI.PHIA, PA.-U'edDestroyers. - April 3, 1877 . [Filed February 28, 2877.

A weed-destroyer combining clearing teeth and blader with sharpened side edgen, for cutting weeds and grass even with the surface of the ground.

Claim.-The teeth $\mathrm{B}$ and cutter $\mathrm{C}$, in combination with the central beam E and pivoted side beams [), and with the pivoted rear beams $G$, straps $F$, and rods $d$, substantially as and for tbe purpose set fortb.

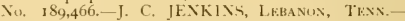
Ploughs.-April 10, 1877. [riled Fibruary 26, 1877.]

Cultivator-beams loosely shackled together. A shield to protect the forward connecting-joint.

Claim.-1.-The beams of a double-shovel plough pivoted at their forward ends, said joint being protected Jy a bridge, substantially as and for the purpose set forth.

2.-The combination of the plough-beams A B, bars C $F$, and bridge $D$, substantially as and for the purpose set forth. 


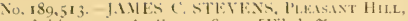
1.A.-Cultivators.-Afril 10, 1\$77. [Filed fanuary 22, [877.]

Construction of the frame for adjustment, and to adapt it for interchangeable working devices.

(laim.-The combined cultivator amt eed cureres herein deveribed, componsed of the main be:an 1), the angular beam (, adjutable on the main beam, the stotted standards $1 \mathrm{~B}$, the adjustable cross-bars $\mathrm{F}$ if M, and the laterally-adjustable handles $K \mathrm{~K}^{\prime}$, adapted to carry the covering devices () P' () or cultivator-teeth and viovels, substantially as shown and described.

No. I00,092.-X. I. SKAGGis, TALlfidia, A1.A.Plousth-Storks. - Ipril 24, 1877. [Filed Marih 24, 1S77.]

[laim.- The combination of pivoted standard $F$ with brace-har I and curved pivoted bar $\mathbf{H}$, having a series of holes near its upper end, substantilly as and for the purpose set forth.

Yo, 190,230-A. BUSE.NCIER, I!II. BRorK IJEPOT,

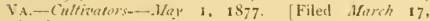
1877.

A shovel-plough having three beams, to be used in combination, or separatel and used as single-shovel ploughs, each be $\mathrm{m}$ being provided with a set of handles.

Claim.-The plough-beam A, constructed as described, and provided with the handles $\mathrm{B}$, in combination with the plough-beam J, provided with the eve L, perforated plate 11 , of plough-beam $\mathrm{I}$, and upright $\mathrm{K}^{\prime}$, hinged to the heam $\mathrm{J}$ at $\mathrm{K}^{-3}$ whereby the cultivator may be trawsformed inta a clouble-shovel plough with a single pair of handles, ant the upright $K^{\prime}$ folded down on its plou sh-beam out of the way, subtantially as described.

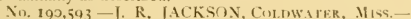
Plowsths._. Hay S, 1877. [Filed Harth 31, 1877.]

A double-shovel plongh con-tructed with devicen to place both shovels parallel with each other, or to place one before the other, as may be deemed best.

Claim. - The combination, with beam $\mathrm{A}^{\prime}$, handle $\mathrm{E}^{\prime}$, and fixed standard $\mathrm{F}^{\prime}$, of beam $\mathrm{A}$ having perforations $a a^{1} a^{2} a^{5}$. brace $\mathrm{I}$, standard $\mathrm{F}$, having perforations $f f^{\prime}$, and handle $\mathrm{E}$, having perforations $e c^{\prime}$, substantially as and for the purpose set forth.

No. I91,458,-TH(OMAS F. MCXAIR, WORTHVII. (iA.-Ciultitators-May 29, $\$ 877$. [Filed April 28, 1877 .

The plough-standard, are interchangeable from front to rear, and can be turned up and held out of the way on a line with the beam.

Claim.-1.-The combination, with the beam $A$ and pivoted braces I 1 , perforated at their rear ends, of the slotied interchangeable plough-feet i: $\mathrm{G}$, comnected to the beam by the lolt $d$, and capable of being foldted on a line svith the beam and there recured, subut.mtially as and for the purposes herein ret forth.

2.- The plotigh-foot $\mathrm{G}^{1}$, pivoted to the rear extremity of the beam $\mathrm{A}$, and capable of hein $;$ thrown upwarl when not in use, as set forth.

No: 191,990.-NELSON MESSENtiEK and JAMES ERWII, NEWARK, IL..-Cultizators.-Juin 12, 1877. [Filed Sipiember 29, 1876.]

The shovel-standards are braced botk to the frame and to each other. The draft is pendent from the double-tree.

Claim.-The combination, with the pole A, stationary cross-bar B, and pivoted double-tree $\mathrm{E}$, of the $\mathrm{V}$-shaped brace $($, draft-rod $\mathrm{K}$, link $\mathrm{L}$, rod or chain $\mathrm{V}$, and hook or clevis $\mathrm{N}$, all constructed and arranged subatantially as and for the purposes herein set forth.

No. 192,020.-PEMBK()KE S. TARTT and (iEORG

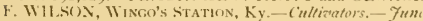
12, 1877 . [Filed Vinember $13,1876$.

Standards with cutting-edges, and horizontal shovels with sharp edges on ald vides; devices for fastening thovel and plough-feet.

Claim.-1-A cultivator constructed with st indards $a$, sharpened on their front edges, and provicled with horizontal flat feet $b b$, combined with shovels $\mathrm{B}$ B, slightly convex transversely, and with edges on a horizontal plane, as and for the purpose set forth.

2.- The shovels $\mathrm{B} B$, of the form described and shown, with sharp rear edges $i c$, as and for the purpose set forth.
3. The horicontal flat feet $1 \mathrm{i}$ having depresstons on cells in the upper surface, with tapped screw-holes in said cells, combined with the shovels $13 \mathrm{~B}$, having yrojectim on the under side to fit said depressions, and cell on the upper sicle to receive the Horn liearls of the lookling-bolts wherely buth upper and uneler surfaces are smoth and unolstractecl, and the buits $c$, are relieved of all shearing strains.

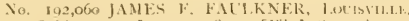
Ki:-Cultizators,-June 19, 1877. [Filed Seftember.,30, 1876 .

A thort beam adju-table forward and hack upon the other, and details of construction to adapt the frame for various cultivating implements.

Claim.-1.-The main beam A, having the curved rear $\operatorname{arm} \mathrm{B}$ and two sets of perforations, the one in rear of the other, in combination with the branch beam $\mathrm{C}$, having a single set of perforations, whereby the branch beam is adjustable longitudinally, and the whole adapted to receive either a turn-plough, cultivator-shovels, or clocl-cutter, sulsstantially as and for the purpose described.

2.-The combination of the main beam A, having a curved standard, B the longitudinally-adjustalite branch beam $C$, having a like standarl, $B^{1}$, the harrow-beam $m$, provided with spaced teeth /, having their shanks at right angles to their cutting-blades, and the curverl arms $\%$, corresponding to the curvature of the tandards $B \mathrm{~B}^{\prime}$, substantially as specified, and for the purpove set forth.

No. 192,387.-J(1HX POETZ, SilAktape, Mixi-

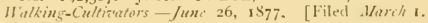
s 877.$]$

The thills are rigid and secured to twn cross-bars in front. The cultivator-beams are pivoted upon the front bar and play bosely upon the rear bar, except the two central beams, which are rigidly fastened thereto.

Claim - 1. - The cumbination of the crosu-bar $\mathrm{A}$ and $\mathrm{B}$, the rigid beams $\mathrm{C}$, and adju-table beam $\mathrm{C}^{1} \mathrm{C}^{2}$, provided with the shovels $\mathrm{E}$, the rigid thill $\mathrm{I}$, rigid handles I, and wheels J, as shown and described.

2 - In combination with the oblique outside shovels $\mathrm{E}$ attached to the swinging beams, the braces $\mathrm{F}$ and clamping device $\mathrm{G}$, as shown.

3. - In a cultivator, the combination of the two crossbars, A $B$, having thills $L$ attached, two parallel rigid beams. C, attached to the cross-bars, conneeted by a bar, a, and provided with rigid handles $I$ and outside swingin? beam $\mathrm{C}^{2} \mathrm{C}^{2}$, pivoted to the bar $\mathrm{A}$, and held by the slotted bars 1 ) and bolts $c$, as shown.

No. 194,009.-D. STAN(11FIEI.I), DAIENPRRT,

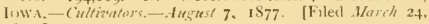
1877.]

A wheel cultivator in which the handles and the central beam are marle of a single piece of iron or steel, the side hars also of a single piece lrent back upon it relf, and clamped together at the teeth. The lever $\$$, attached to the rear wheel, is derigned to regulate the direction of the culivator.

Claim. -1.-The combination, with the main beam A of a cultivatior having the angular operating handle $\mathrm{B} \mathrm{B} \mathrm{B}^{1} \mathrm{~B}^{2}$, of the vertically adjustable caster-wheel $(i$, the lever $S$, extending from said caster-wheel beyond the cross-har of the handle and the spring $T$, bincling the latter on the crombar, substintially as specified.

2-The combination, with a cultivator having a front traveler-wheel, C, of a verically-adjustable and horizontallyvibratory stecring-wheel, $G$, stubtantially as ypecified.

3.- The combination. witls a cultivator having a front transporting-wheel, C, and the triangularly-extended beam having a notched cross-bar $\mathrm{B}^{2}$. of the vertically-adju-table and vilsating wheel $(;$, it operating-lever $s$, and a spring binting the said lever against the said bar, substantially as specified.

4-The combination, with the beam A having a triangular operating-handle, $\mathrm{B} \mathrm{B}^{1} \mathrm{~B}^{2}$, and the laterally-adjustal 1 : beam $\mathrm{C}^{\prime}$ pivoted to said beam $\mathrm{A}$, of the curved plate $\mathrm{E}$, having slots $i$ and perforated offset $p$, the threaded bolts $f^{2}$ secured to said beams $C^{\prime}$, the clamp-nuts $q q^{\prime}$, the shank o' of the caster-wheel $G$, the operating-lever $S$, and spring $T$, substantially as specified. 
5.- The plough-beam $A$ and handle $B B^{1} B^{2}$, formed of a single piece of metal, substantially as specified,

6.- The combination, with the main beam of a cultivator having a front transporting-wheel, $\mathrm{C}$, of the single-tree D, pivoted to said beam, and having its lever-arms extendıng to the front at eacb side of said wheel, substantially as specified.

No, 194,108.-J. POETZ, ShAKOPEE, MinN,-Cultiza. tors.-August 14, I877. [Filed Afril 16, 1877.]

Fixed centre-beams, on which is mounted a rotating plate. Two or more outer swinging beams on each side are connected, by rods, to the plate at different distances from it pivot-point, so that the beams shall be at equal distances from each other, whether spread or contracted.

Claim, - The combination, in a cultivator, of one or more stationary central beams, a plurality of laterally-swinging beams on each side of said central beams, a plate or arm pivoted upon the central beams, and a series of independent arms extending from the individual beams inward to the opposite side of the plate, and pivoted thereto at different distances from its centre, in the manner shown and descrihed, whereby the beams are moved different distances and uniform spaces maintained between them at all times.

No. 194,504.-11. N. JVARD, CEDAR RAPIDS, IOWA., assignor of one-lialf his right to D. J. BUCKLEX,-Cultivators, Weeders and Warkers.-Ausust 21, 1877.-[Filed July I1, 1877 .]

Claim, 1.- In combination with the beam A, having the shorter and side beams $\mathrm{A}^{\prime} \mathrm{A}^{\prime}$ connected thereto, as shown, the marking-hoes $b^{\prime}$ adapted to be set at any desired angle horizontally on standards $b$, substantially as described.

2.- In a cultivator, the hoes $b^{\prime \prime}$, adjustable horizontally by means of beams $A^{\prime}$ and spread-irons $C$, and also on the standards $b$ by means of arms $g$, straps $h$, and lever $j$, substantially as set forth.

3.- - In the within-described device, the combination of the side-beams $A^{\prime}$ with main beam $A$ by means of strap $B$, adjustable lengthwise on said beam, and, by means of spread-irons C, adjustable parallel or at an angle therewith, substantially as described.

4. - In combination with the frame A B A A, constructed and adapted to operate as clescribed, the triangular sodcutter $a a a$, and hoes $b^{\prime \prime} b^{\prime \prime}$ and $b^{\prime} b^{\prime}$, forming thereby a weeding device, substantially as herein set forth.

No. 194,713.-T. H. MISERS, Pleasant, Dale, IV. VA. assignor to J. W. PAINTER and J. S. VEACII, Strasburg, VA.-Shood-Ploughs and Cultizators.Aurrest 2S, 1877.-[Filed May 4, 1877.]

The spliced and removable centre-standard, the removable side-bars, secured by a hinged latch and hooks, provicling for the use of from one to five shovels.

Claim.-.1.-The combination of the beam B, the stock C, the removable standard D, fitted to the end of the stock $\mathrm{C}$ by an oblique joint gained for the reception of the beamtenon, and secured by the side plates $\mathrm{A} A$, bolts $d d$, and brace-rod $\mathrm{E}$, as and for the purposes set forth.

2.- The combination of the removable lateral stocks or standards $\mathrm{F}^{1} \mathrm{~F}^{2}$, the stationary tenons $\mathrm{G} G$, and the hinged latches 1 , formed with pins $i$, as and for the purposes describel.

No. 195,125-ALVANES P. HENERY, MALTA, OHuo.-Cultivators.-Siptember I I, I877. [Filed July 14, I 877

Claim,-1.-In a cultivator, the pivoted clamp H, with side arms $\mathrm{I}$, in combination with the centre beam $\mathrm{A}$ and diverging side beams $G \mathrm{G}$, operated substantially as and for the purpose set forth.

2.-In combination with the beams $A$ and $G \mathrm{G}$ and the connecting-links a $d$, the pivoted clamp II, with side arms I I, and lever J, substantially as and for the purposes herein set forth.

No. 195,459.-JOHN W. SOHN, Hamiton, ()H10.Cultivators. - September 26, I877. [Filed June 4, 1S77.]

A centre harrow-frame with gravitating wings, the latter prevented by blocks from descending to a level position. The wings carry curved cutting-blades and harrow-teeth.

Claim.-I.-The concavo-convex cutting and elevatin blades $\mathrm{D}$, arranged obliquely, in combination with the self- adjusting wings $\mathrm{B}$, provided with teeth, substantially as and for the purpose specified.

2.-In a cultivator having self-adjusting wings, the combination of cultivating-teeth, obliquely arranged elevators, and stops $d$, or their equivalents, as and for the purpose specified.

No. 196,670.-ASA JONES, SNow HiL., N. C., assignor of one-balf his right to JOHN H. DAIL, same place.-Cultizators.-October 30,1877 . [Filed September 8,1877 .

Claim.-The combination, with the plough-beam $A$, of the adjustable board $D$, slotted at each end at $\ell$, and in the centre at $b$, with the adjusting-ploughs $\mathrm{G} \mathrm{E}$, fastened thereto by means of the bolts $f h$, and operating in the manner as set forth.

No. 197,100.-CHARLES J. COOPER, CXFORD, Al.A.-Double-Winged Cultizators-Nowember 13,1877 .

[Filed Aug7est 13, 1877 .

A pair of standards carrying shovels and scraper-wings are united at the top in a screw-shank, the halves being separate, and held together by the nut.

Claim,-The feet $\mathrm{D}$, provided with ploughs $\mathrm{G}$ and wings $\mathrm{G}^{\prime}$, and forming half-round threaded tenons $a a$, in combiDation with the mortised beam $A$ and and nut $b$, as set forth.

No. I97,IS4-JOSEPH P. TERRY, LAKE CITY, Fi.A.-Cultivators.-Nowithber 13, is77. [Filed Scptember 7,1877 .

Claim.-The curved plough-standards having the rightangular $\operatorname{arm} c$, the lip $f$, and the flange $s$, in combination with the beams having lateral notches or slots, as shown and described.

No, 197,660.-ALVY G. PERRY, HICKORY FI.AT, Miss,-Ploughs.-Notember 27, I877. [Filed February $24,1876$.

Claim.-In combination with the ploughshares and the standardst the detachable and interchangeable mold-boards, whereby the plough is adapted to turn right or left furrows, substantially as described.

No, 197,867.-IRWIN S KRICK, CONNEAUTUIILE, PA.-Cultizators.-Dicember 4, 1877 . [Filed August 25, 1877.7

Claim,-I,-The combination, with the adjustable handles D D and the vertical rod $G$, of the sleeve $E$, having tubular sockets $\mathrm{E}^{\prime}$, hrade-rods $c$, and clip $f$, for the purpose hereinbefore set forth.

2.-The combination, with the beam A, gange-wheel $C$, and breaking-tooth $\mathrm{I}$, set at an angle of the plough $\mathrm{M}$, provided with hinged wings $\mathrm{N}^{\prime}$, yoke $\mathrm{N}$, with bolts $k$, and the hinged adiustable spreaders $O$ and thumb bolts $m$, substantially as described,

No. 199,017.-ISAAC A. BENEDICT, JVFST SPRINGFIEI.D, PA.-Cultizators. - Fanuary 8, 1878.-[Filed October $25,1877$.

To an ordinary shovel-plough side shares are attached by means of adjustable braces, with a cross-bar between the side beams, so that by adjusting this cross-bar backward or forward the side shares are brought nenrer together, and set at a greater distance apart.

The combination, with end-slotted and adjustable standards $\mathrm{H} \mathrm{H}$, of the connecting bar $\mathrm{J}$, clamps $\mathbf{K}$, and rods $\mathbf{L}$, the latter being vertically adjustable on standard $A$, as and for the purpose specified.

No, 200,68I.-SAMUE1, L. AlLEN, PHil.adelphiA, PA.-Cultivators.-February 26, I 878.-[Filed December 8, I 877.$]$

A scraper-blede with both ends sharp-the point of one end downward, and the other upward. secured to a curved and pivoted standiard with segmental cross-head, which may be turned to cause the scraper to throw in or out. Device for a clevis, removable when turned backward.

Claim.-1.-The within-described reversible blade J, curved throughout its length, having an inclined end, $m$, and a curved end, $m^{\prime}$, the latter merging into the lower edge $n$ of the blade, and forming with the upper edge $n^{\prime}$ a point, $p$, and both ends $m$ ' $n^{\prime}$ being sharpened, as specified.

2.-The combination of the frame of the machine and a furrowing-blade with a pivoted frame, G, as described, whereby, without changing the point of connection of said 
device, the blade may bereversed, so as to cause it to throw either from or toward the row as specifiet.

3.-The combination of the T-head $f$, having openings nearer the rear edge than the front, as described, with the elevis $\mathrm{g}$, having an opening $i$, as set forth.

No. 202,972,-J. S, WII.SON and R. G. MORROW, Calmoun, Ga.-Ploughs-April 30, 1878 . Filed Fibruary 16,1878 .

Claim.-In combination with an ordinary plow-beam, the side beam $\mathrm{F}$, formed with the angular lip $e$ at its forward end, and arranged for adjustment laternlly and forward and back, the bolts $a b$, and notches $x$, formed in the top of the main plow-beam, sulstantially as and for the purposes herein set forth.

No.-203.048.-M. JOHNSON, LickPORT, N. Y.Cultivators.-April 30, 1878 . Filed fanuary 17, 1878 ,

Claim.-1,- The beam A, bent connecting-bars $a$, constructed to turn in sockets $C^{\prime}$, and the plates $b, b$, in combination with the wings $\mathrm{B}, \mathrm{B}$, adjustable by braces $\mathrm{D}$, and pins g, substantially as shown, and for the purpose described.

2.- The adjustable braces D, secured by pins $\mathrm{g}$, in connection with plate $y$, to beam $\mathrm{A}$, in combination with connecting bent bars $a a$, constructed to turn in sockets $C^{\prime}$, the plate $b$, and wings $B$, substantially as shown and specified.

No,-205,630,-I, GEORGE SPRINGFIELD, Mo-Cultivators.- Fuly 2,1878 Filed April $9,1 \times 78$.

Claim.-1.-The combination, with plow-beam A, handles $\mathrm{D}$, and clamping-plates $\mathrm{C} \mathrm{C}^{\prime}$, of an eyebolt, $c$, arranged as described, to simultaneously secure the forward ends of the handles and bind together the clamping-plates, substan stantially as described.

2.-The combination of the perfurated plow-beam A, the notched side beams or standards E E', the clamp-plate $\mathrm{C}$, having lugs $h$, the clamp plate $\mathrm{C}^{\prime}$, having tongues $\mathrm{y}$, the bolt $c$, handles $D$, and vertical bars $G$, attached to the handles above and the side standards below, substantially as described.

3.- A bar having its forward end notched to receive the lug of the clamp-plate, combined with the said clamp-plates $\mathrm{C}^{\prime}$ ' the vertical hars $\mathrm{G}$, and the handles $\mathrm{D}$, and extending rearwardly from the clamp-plates to support the handles, substantially as descrited.

No.-205,668.-B. F. MORRIS and E. H. AUSTIN, SCOTT's HiLl, TENN.-Cultivator and Seeders.-Fuly 2, 1878. Filed March I 6, i 878 .

Claim.-1.-The combination with a plow-standard having spaced loops $\epsilon^{\prime}$. and a ratcheted lirace having a rear tooth, $i$, of the adjustable subsoll plow $\mathbf{F}$, having a ratcheted shank $k$, and a wedge or key l, behind said shank, substantially as specified.

2.-The combination, with the beam $\mathrm{C}$, a ratcheted plowstandard $f$, having spaced loops $c^{\prime}$, and an adjustable subsoiler, E, having ratcheted shank $k$, of the slotted brace D, correspondingly ratcheted, and having a rear tooth $i$, adapted to engage the ratchets of the stand of said subsoiler, sub stantially as specified.

No. 206,505.-H. D. TEWELL, STANSville, GA.Scraper Attachment for Shovet-Plows-7uly 30, 1878 . Filed fune 14,1878

Claim.-The scraper having a flas middle portion and two side wings, which are inclined to the rearward, and provided with downwardly and rearwardly twisted upper corners, curved forward, as and for the purpose set forth.

No. 206,654.-B. WILLI AM: and C. C. MORGANPlons-7uly 30, 1878. Filed May 29, 1878 .

Claim.-I.-The foot D, made of bar-iron, with its end bent to straddle the beam, as seen at $a$, and having bolts $n n$. for holding them in position, and provided with a setscrew $e$, for securing and allowing of their adjustment on the beam substaniially as and for the purposes set forth.

2.-'T he revolving eccentrically pivoted plate $y$, in combination with a plow foot and shue, sutistantially as and for the purposes herein set forth.

No. 206,752.-P. SODERLUND, SWEDE POINT, IOWA. -Corn-Plows.-Angust 6, i878. Filed May 1 I, I877.

Claim-I.-In a corn-plow and cultivator, the swivel from, hifurcated, and perforated standard-beareis $g$ g, carrying the pivoted and adjustable standards 2 and 3 , in combi- nation with rigid branches $v v$ of the beam $a$, substantially as and for the purposes shown and described.

2.-The adjustable braces or stays $m$, linked key-bolts $n$, swiveled bearers, $o$, and fixed fastenings and adjusting devices $r$ in combination with a plow-beam and a plow-standard, substantially as and for the purposes shown and described.

3.-The rigid forked heam $a b b$, the certral, fron pivotal, and guiding standard I, the adjustable pivoted and swiveled standards 2 and 3 , each carrying an adjustable handle $h$, arranged and combined to operate substantially as and for the purposes shown and described.

No, 207,443.-H. N. PROUT, WESTFteld, MAss.Hoeing-Machines.-August 27, 1878 . Filed 7um 24, 1878 .

Claim-1,-The improved wing-springs or hoes $\mathrm{G}$, with inner and outer surfaces straight, vertically or crosswise, and of uniform thickness and elasticity, with the lower and front edge leveled to a cuttung edge, said hoe being wider in front than in rear, substantially as and for the purposes set forth.

2.-The adjustable plate $\mathrm{C}$, having the flanged socket and the lateral and longitudinal slots, substantially as shown and described.

3.-The adjustable flanged plate $\mathrm{C}$, constructed as dcscribed, in combination with standard $B$ and main supporting frame $a$ as and for the purpose set forth.

No. $207,767-R E U B E N$ K. NIECE, FRENCHTOWN, N. J.-Cultivators.-September $3,18_{7} 8$. Filed $7_{u l y} 27$, 1873 .

Claim.-1.-A cultivator-frame consiting of the side beams, $\mathrm{A}, \mathrm{B}$, with pusts $\mathrm{A}^{1} \mathrm{~A}^{2}$ and $\mathrm{B}^{1} \mathrm{~B}^{2}$, adjustable bars $\mathrm{C}^{1} \mathrm{C}^{2}$, adjustable rear beams, D D, and adjustable cross beam $\mathrm{F}$, substantially as set forth.

-2. - The combination of the beam A or B, beam D, eyebolt $d$, brace $f$, and rod $h$ with adjustable bolt $c$ in the bar $\mathrm{Cl}^{\mathrm{l}}$, for the purpose set forth.

No. 207,778 , - JUSEPH SMITH, ELYRIA, OHro.-Cultivators.-September 3, 1878 . Filed August 12, 1878 .

Claim. - In a cultivator, the combination of the frame $a$, handles $b$, slotted plate or frame $d^{\prime} d^{\prime}$, clamping screw rods or bolts $i$, and the bent arms $h$, for the attachment of different implements, substantially as shown and des ribed,

No. 207,960.-HENRY J. GENTZSCH, Sr., GHICAGo, ILL,-Plozws.-Septcmber Io, 1878. Filed $7 u t y$ 18, 1878 .

Claim.-The double share $\mathrm{A}$ and the $\mathrm{s}$ andard $\mathrm{C}$, supported on a rearward extension of such share, in combination with the mold-boards $\mathrm{H}$, pivoted to the share and adjustably connected to the said standard by the lapping perforated bars $\mathrm{K}$, secured in the casting $\mathrm{L}$, and the bracerods $\mathrm{M}$, attached at their upper ends to the slotted plate $\mathrm{N}$, vertically adjustable on the standard, constructed and arranged substantially as described and shown.

No. $208,084 .-K E N N E T H$ P. GRANT, SAN BUENAventura, CAL.-Weeder-September 17, 1878 . Filed Fune 17,1878 .

Claim,-In a weeder, the beam A, curved standard B, having $\mathrm{T}$-feet $\mathrm{C}$, and the inclined overlapping reversible blades $\mathrm{N}$, constructed and arranged substantially as shown and described.

No. 208,284--CLARK T. BARTON, TUscumbia, ALA. - Cnltivator-September 24, 1878. Filed March 19, 1878.

Claim - In a cultivator, the combination of short central beam $\mathrm{D}$, long side beam $\mathrm{B}$, short side beam $\mathrm{A}$, bolt $d^{\prime \prime}$, washers $d^{2}$, inclined cross-bar $\mathrm{E}$, and $\mathrm{U}$-boit $d^{\prime}$, substantially as shown and described.

No. 208,964--BENJ. H. CROSS, CABAnISS, GA.-Cultivators.-October 15, 1878. Filed Ausust 24, 1878 .

Claim.-A combined plow and cultivator having the bracket $\omega$, bent as described, and arranged between the two sides of the doubled and offsetted standard 3 upon the loolt $f_{1}$ and held at the outer end by a bolt, e, as shown and described.

No, 209,005-JOHN C. BEAN, Crossville, Ill. Cultivators - October 15, I878. Filed September 7, I878.

Claim - A cultivator-plow consisting of the hinged beams $a$, with tongue and groove, the removable crosspieces $h$, the removable cross clamping-bolts $i c$, the removable vertical brace $m$, the hinged braces $n n$, and the rigid frame-handles whereby the beams are closed together or 
aljusted to an, h-med wilth, anil mlapted for use with the plough, as de-cribed.

No, 209, 366.-ELJAS TRUMBO, RUTLAND, ILL.Cultiv.tors. - Ortober 29, I878 Filed August I, I878.

Claim. - The combination, with the side beams, $\mathrm{D}^{\prime}$, of a cultivator and the standard $C$, attached thereto, of the inderendent detachable curved irons $\mathbf{B}$, each having a perforated stem, $b$, at the top, bent at right angles to the body of the curced iron, and a share, A, with its forward edge circular and I raced to the independent iron $\mathrm{B}$, all constructed and arranged to operate as shown and described.

No, $209,48 t$ - JOHN JEN NINGS, JR., NATICK, MAss. -Cultivators.-October 29, 1878 . Filed $7_{u l y} 20,1876$

Claim.-The combination of the mould.board $C$ with the brush $\mathrm{F}^{\prime}$, attached to its end, suhstantially as and for the pur pone described.

No. 209823 - L.MeCLRI.EJ, MADison, ALA,-Comhined Harrous and Cultirators.-November 12, 1878 . lisled Aurwst 15,1878 .

Claim.-A harrow or cultivator frame consisting of the beam $\mathrm{A}$, tooth-bars $\mathrm{B} \mathrm{B}^{2}$, and adjustable spacing-hars $\mathrm{C} C$, the bar, on one side being longer than on the other, as shown and described, so that in cultivating on both sides of a row the line of draft may be thrown to one side, to prevent the horse or workman from tramping on the plants in the row.

No. 210,351.-LITTLETON M. OTWELL, RoswEL.L, Gi-Plowshs ant Cultivators.-November, 26, 1878 . Filed $7 u l y \quad 29 \quad 1878$

Claim-The combination, with the angular foot-plate $C$, having horizontally-slotted wings $c d$ of the laterally-adjustable blades $\mathrm{D} \mathrm{D}^{\prime}$, and the rake or harrow $\mathrm{F}$, set at an angle, and the body of which, $G$, is slotted vertically, to permit it sertical adjustment, all arranged and operating substantially as lierein described, and for the purposes shown and specified.

o. 210,548 ,-STEPHEN P. McKINNY, BARRETTSVH.L.F. GA.-assignor to Joshun Dooley and James M. Bond, same place, one-third to each.-Ploughs.-December 3. 1878 . Filed October 14,1878 .

C'laim. - In combination with the plough-beams $\mathrm{A} \mathrm{A}^{\prime}$ and pivoted standards $\mathrm{L} H$, the adjustahle braces $\mathrm{E} \mathrm{E}^{\prime}$, having hooked shoulders $f$, bolts $h$, and nuts $i$, whereby said hook. ed shoulders may be secured in the notches 5 of the standards, s) as to form additional supports or abutments for the shares or shovels affixed upon the standards, substantially in the manner and for the puroose set forth.

Nu. $213.7 \mathrm{IS}-\mathrm{MATTHEW}$ SMITH, WAXAHACHE, TEx.-Cultivalors-December so, 1878 Filed November 6.1878

Claim.-I. A cultivator havng a forked expansible beam A, one branch, $a^{1}$, of which is terminated with a curved hovel support, $a^{2}$, and the other branch, $a$, made straight ant without a shovel-zupport, and adapted to have a remosable shovel-support, $G$, attached to it, either forward of or abreast with the curred permanent shovel-support $a^{2}$, subtantially as and for the purpose set forth.

2. In combin.tion with a cultivator, $\mathrm{A}$, having a draft hook $a^{3}$, the gooseneck clevis plate I, having apertures $j^{1} j^{3}$, whercby it can be slipped upon the heam and confined to it ly a single bolt, unbstantially as and for the purpose set forth. 3. The combination of the adjusting clevis plate J, reversible eccentric clevi, hook $\mathrm{L}$, and hook $a^{3}$ of the cultivator beam, substantially as and for the purpose set forth.

4. The draft adjusting clevis plate $J$, having its shank, of goon nec's shape, provided with apertures $y^{1} y^{3}$, in com bination with the hooked end of the $\mathbf{V}$ shaped beam $\mathrm{A}$. the two branchas $a a^{1}$ of the beam, and the $\mathbf{T}$-bolt fastening K. substantially as set forth.

No. 210,884 -FREDERICK W. TULLEV, Coxs ie. X. Y... assignor of one-third his right to SAMUEL HTEl'HEXS, same place.-Cultivators.-December 17,1878 Filed $7_{1} / 1.24,1878$

Chim - I-The head-stock D, constructed in one piece, with the horicontal mortise $f$, lateral recesses $p$, vertical plate 0 front and rear side bearings, $r r^{\prime}$, and bolt -holes $v o^{\prime}$ and $s s^{\prime}$, as shown and described.

2,-The improved cultivator-blade having a uniform width alsout equal to one-third of its length, V shaped cutting-edge at each end with the point in the middle, and the whole in the form of about a third-pointed portion of a band making one spiral turn around and from end to end upon a cylinder having its diameter about one-fourth of its length, as shown and described.

3. - In a cultivator, the improved blade having $\mathrm{V}$ shaped cutting end edges and the particular spiral form and propor tions specified, in combination with the standard, and secureb thereto with all straight lines in the spiral working surface of the blade inclined upward, rearward and laterally, and with the lower middle point, $b$, and the upper side corner, $m$, in a vertical plane $y y$, coincident with that in which the blade is drawn forward in use, as shown and described.

No. 211,397.-JOHN C. GUY, FayetTeville, Ga.Cultivators. - Ganuary 14, 1879 . Filed October 28, 1878 .

Claim. - The removable and adjustable bifurcated standards $\mathrm{D}$, in combination with the adjustable braces $d$, provided with a $T$-shaped head, $f$, arranged to serve also as a stop for the shovel, and the retaining-pin $g$ on the opposite side of the standard, substantially as and for the purpose de scribed.

No. 2I 2,897.-JEREMIAH CHAPMAN, VIRGINIA City, Nev,-Reversible Gang-Ploughs,-March 4, 1879 Filed February 25,1878 .

Claim.-In a reversible gang-plough, the combination of the central beam, $\mathrm{C}$, and double cross-slats $h, m$, and $r$, with the reversible beams A B, constructed as shown and described, and parallel to the heam $\mathrm{C}$, as and for the purpose set forth.

No, 213,34I,-CHARI.ES McGREW, BLoomington, ILL.-Cultivators.-March 18, I879. Filed December II, 1878 .

Claim.-1.- The combination, in a cultivator, of the central beam provided with the curved or convex knife $\mathrm{E}$ and shovel $\mathrm{D}$, and the side heams provided with the rear curved or convex knives, $\mathrm{E}$, and rear shovels, and long diagona and lateral cutting-blades $\mathrm{F}$, the several parts arranged, relatively to each other, substantially as and for the purpose herein shown and described.

2.-In a cultivator, the combination, with side beams, B, of the diagonal and lateral cutting-blades F F, the central bean. $A$, and distributing-wheel $G$, arranged in rear of said blades, substantially as and for the purpose specified.

3.- The combination, in a cultivator, of the central beam provided with the curved or convex knife $\mathrm{E}$, shovel $\mathrm{D}$, and distributing-wheel $G$, and the side beams provided with the curved or convex knives E, rear shovels, D, and long diagonal and lateral cutting-blades F, substantially as herein shown and described.

No, 213,410-GEORGE L. GIFFORD, SAN ANTONIO, TEx.-Ploughs.-March 18, 1879. Filed October 22, 1878 .

Claim.-The slotted plough-beam A, having the curved perforated guide $B$ and vertical portion $C$, with branched arms and holes $c$, in combination with the slotted standard D and adjustable handles $b$, substantially as shown and described.

2. - As an improvement in ploughs, the frame composed of side bars $i$, end bars $j j^{\prime}$, and having quadrant-guides $\mathrm{B}^{\prime}$ $\mathrm{B}^{\prime}$ standards $l \quad l$, and pivoted stocks $d^{\prime} d^{\prime}$, in combination with guides $\mathrm{B}$, standards $\mathrm{C}$, and beam A, substantially as described.

No. 215,885 -OSRO A. CRAIN, Evanston, Ill.-Cultivators.-Nay 27, 1879. Filed April 21, 1879.

Claim.-1.- The slotted colter D, constructed substantially as and for the purpose set forth.

2.- The slotted colter $D$, in combination with the adjustable mold-boards $\mathrm{E}$, hinged to the colter in the manner specified.

3-- The colter $\mathrm{D}$ and adjustable mold-boards $\mathrm{E}$, in combination with the pivoted straps $F$, adjustable side pieces, B, and beam A, all arranged and operating in the manner set forth.

No, 216,449.-GEORGE W. PETERSON, OXFORD, Al.A.-Cultivators.-Fune 10, 1879. Filed March 20, 1879 .

Claim.-A cultivator having the bent loop-beams A B, perforated in front and having their faces flush with each other, and provided on their rear ends with flanges $a^{\prime} a^{\prime}$, adapted to receive one end of the adjustable pivoted elbowlink $b$, the other end of said link pivoted to the bent flanged braces $h h$, said braces engaging the upper ends of the han- 
dles $13^{\prime} 13$, and the lower ends of said handles being adjus ted to said beams $A$ B by means of the adjustable bolt $d$, sulustantially as specificd.

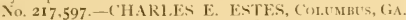

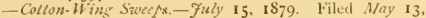
1879 .

Claim. - The combination of the standlard $\mathrm{A}$, having wings $a^{\prime}$ and point $C$, with the thin narrow blacles 13 , provided with transrere slots $b^{\prime}$, and bolted to the wings, so that their forward ends will be clamped between the said wings and the point, substantially as shown and described.

No.21S,407.-COLUMBUS STEPHENS,CAVE SPRING, GA.-Cultivators.-August 12, 1879 . Filed Vovember 5. I87S.

Claim, - As the improvement in cultivators hereinbefore deseribed, the combination, with the standards $\mathrm{D}$ and the beams $\mathrm{A}$, having one or more rows of indentations, as specified, of the braces $\mathrm{G}$, having their upper ends made hookshaped to embrace the beams, and the set-serews $1 \mathrm{H}$, passing through said braces opposite the row of indentations, all as and for the purpose set forth.

No, 2 I8, 482 - JAMES L, BUSKETT, ST, lous, Mo,Cultivators. -Aususl 12, 1879. Filed fune 28, 1879 .

Claim.-The fixed central beam, $A$, bearing a shovelplough at its rear end, and provided with eross-bars C C, bolted permanently to it, said bars being provided with recesses $\mathrm{E}$ E, in combination with two removable reversible beams, D D, carrying land-side shares near their forward ends, and capable of adjustment as a cultivator, ridger, or single-shovel plough as set forth.

No. 218,568 . - WILLIAM J. PIRKLE, CIMMINi, G -Ploughs.-August 12, 1879 . Filed Fanuary 14, 1879

Claim. - I - The combination of the adjustable side beams, $A \mathrm{~A}$, the sectional cross-bars $\mathrm{B}$, with hooks $b$, the self-adjusting clevis, composed of the doubled bars $\mathrm{L} L$, the bolt $p$, and link L,' substantially as and for the purpose herein set forth.

2.-The combination, with the plough-foot D, of the hinged side wings, $\mathrm{H} \mathrm{H}$, conneeted by the slotted bar $h$, the lever 1 , having inclines $x$, and the plate $i$, substantially as and for the purposes herein set forth.

No. 2 I9,227.-JOSIAH J. DEAL, MASSILLON, assignor to WILLIAM M. JOHNSTON, WILMOT, ОнIо,-Cultivators.-September 21879 . Filed Warch 3, 1879.

Claim-1.-In a cultivator, the handles D D, pivoted to the rear of the frame $\mathrm{A}$ at $d^{\prime \prime}$, in combination with the bent pivoted beams $\mathrm{C}$, said handles being adjustably connected to saicl beams at $c^{\prime}$, substantially as described.

2.-In combination with the frame $A$, the pivoted bent beams $C$, the pivoted handles $D$, and the wheel, $B$, journaled centrally to the front of the frame and adapted to be turned to either side by the movement of the handles, substantially as and for the purpose described.

No 219,745.-WILliAM E. LOWRIE, CleAr PORT, OHIO.-Ploughs or Cultivator.-September 16, 1879. Filed May 22, 1879 .

Claim.-1.- The combination, with the beams A and B, connected together by horizontal and vertical pivots $\mathrm{C} \mathrm{I}$, of the handles E F, connected independently to said beans, a: described.

2.- A double plough constructed with a main beam, $\mathrm{A}$, a secondary beam, $\mathrm{B}$, connected to the first by horizontal and vertical pivots $C$ and $D$, handles $E F$, attached independently to the said beams, and a clip-brace, $\mathrm{M}$, for fixing the beams rigidly together when desired, all substantially as herein set forth.

3.-The combination, with beams A B, connected by horizontal and vertical pivots $\mathrm{C} \mathrm{D}$, and handles E F, of the elipbrace $\mathrm{II}$ and triangular hinged brace $\mathrm{L}$, for rigidly securing the beams and handles, as described.

No. 220,352.-WILLIAMI J. DAVIDSON, BIG SPRING, VA.-Shovel Ploughs._October 7, 1879. Filed February 14,1879 .

Claim.-1.- The reversible standards B, carrying plough on one end, and curved at the other to form colters, as set forth.

2.-The combination, with the standard, consisting of a plain bar adjustable on the bars $a a^{\prime} a^{\prime}$, of the securingbolt and nut and gage $n$, adapted to be secured by the nut,

\section{as specified.}

3.- The combination, with the standard, of the bull tongue $d$ and the broader-pointed end blacle, $h$, constructed and adapted to be secured by the samic bolt, $m$, passing through both, and to be used together, or either separately, on the same standard, as specified.

4.- The combination, in a cultivator-shovel, of the shoe $g$ and the thin steel facing-plate $t$, adjustable on the shoe, conforming thereto, and projecting slightly beyond the edges of the same, substantially as set forth.

5.- The combination of the shoe and adjustable thin steel facing plate $t$, provided with ears $w$, adal ted to clamp the edges of the shoe, as specified.

No. 221,803.-PETER GERGES, SKIPPACK, PA.-Cultivators.-November, I8, I879. Filed August 14, I879.

Claim.-The combination, in a cultivator with single beam $\mathrm{A}$, of the standards $\mathrm{E} F$, carrying wide ploughs $\mathrm{L}$, and the standards $\mathrm{G} . \mathrm{H}$, carrying narrow ploughs $\mathrm{M}$, all of said standards being bolted to beam through blocks, and the said standards $\mathrm{G} H$ being seeurecl at difierent angles but by the same bolt, as shown and described.

Ni) 222,087.-B. B. SMlAL, Nurth Lubes, Me.Combined Horse-Hoes and Cultivators. - November 25, 1879 . Filed fuly 8,1879 .

Clam.-The tongue A, and end-slotted cross-bars B C D in combination with standards $F$, plows $G$, standards $H$, and hoes $I$, all constructed and arranged to operate as deseribed.

No. 222,367.-IAMES M. RICHARIS, BRCNDIDGE, ALA.-Cotton Scrapers.-December 9, 1879. Filed Sep. tember 24, I879.

Claim. - I. - The combination of beams $\mathrm{A}$ and $\mathrm{D}$ and intermediate block, $\mathrm{G}$, constructed to present bearings at different angles, and devices for clamping the block and beams together, substantially as described.

2.-The combination of beams $\mathrm{A}$ and $\mathrm{D}$, bloek $\mathrm{G}$, and connecting-bolts, hook $\mathrm{H}$, stay, and standards B, substan tially as set forth.

No. 222,783.-NIARTIN HOLDREDGE, KENT, OHIO. -Cultivators.-December 23, 1879. Filed August 5, 1879.

Claim. - In a cultivator, the combination, with the center beam having a standard and plough, of two side beams pivoted back of their front ends to a cross-bar, and each carrying two shovels and made adjustable, so that when the rear ploughs are moved outward the front ploughs, will move inward, and vice versa, substantially as shown and deseribed.

No. 222,\$93.-GEORGE W. GOODWY', PETERSBURG, $V_{A}$., assignor of one-half of his right to PASCAL DAVIE, same place.-Cultivators and Cultivator. Tecth.-December, 23. I879. Filed August 16, 1879.

Claim - I - A reversible cultivator tooth having praetically a straight landside and an enlarged shovel-shaperl and eurved furrow-side, the straight line of the land side and the curved line of the furrow-side intersecting to form the eultivating points, said tooth being concave from point to point and convex from the land side to the furrow side, substantially as and for the purpose specified.

2. - A reversible cultivator-tooth having a straight landside and an enlarged shovel-shaped and curved furrow-side, the straight line of the land-side and the curved line of the furrow-side meeting to form the share or ehisel-shaped cultivating points in contimuation of the straight land-side, said tooth being coneave from point to point and convex from land-side to furrow-side, substantially as described.

3.-A reversible cultivator-tooth having a straight landside provided with a cutting-share or mold-board formed at right angles thereto and an enlarged shovel-shaped and curved furrow-side, the straight line of the land-side and the curved line of the furrow-side intersecting to form the cultivating-points, said eultivator-tooth being concave from point to point and eonvex from the landside to the furrow-side, substantially as deseribed.

4.- A reversible eultivator-tooth having a straight landside with a cutting-share or mold-board formed at right angles thereto and an enlarged shoyel-shaped and curved furrow-side, the straight line of the land-side and the curved line of the furrow-side meeting to form the share or chiselshaped cultivating points $d d$, in continuation of said straight land-side, the cultivator-tooth being concave from point to 


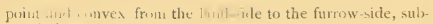
stantially otn slescribe.l.

5 -1 reveraible cultivat $u$ - 4 , oth having, practically a strifint land-sile and an enlarged shovel-shaped and curved furiow-sile, the straight line of the land side and the curved line of the furrow-side intersecting to form the cultivatingpoints, said tuoth heing concave from point to point and cunvex from the land-side to the furrow cide, and having its greatest convexity at the point of attitchment to the standiard nearer the land-sicle than the furrow-side, as sat forth.

6 - In a eultivator, the combination of the standards $\mathrm{E}$ $\mathrm{D}$, carrying the interchangeable and reversibl teeth describer with the standard $\mathrm{F}$, carrying the tooth $K$, arranged and operating togetber substantially as describe for the purpose specified.

No. 223.713.-JOSIAH J. DEAL, WitMry, Онto.Cultivators. - Famuary 20, I SSO. Filed September 19, 1879.

Claim.-1. - The combination of the longitudinally-rliding handles $\mathrm{D}^{\prime \prime}$, the steering-bar $\mathrm{D}$, having in one arm a pawi, $d$, rod $d^{\prime}$, the quadrant-plate $B$, and vertical shaft $I^{\prime}$, carrying the wheel $\mathbf{E}$, stbstantially an and for the purpose described.

2.- The eombination of the bent plough-bars A A, having eyes $a$ a formed therein, yaudrant-plates B and C, having pivots $a^{\prime} a^{\prime}$, on which the eyes $a$ a are turned, substantially as and for the purpose described.

3.- The combination of the shovel-bars $A$ and $A^{\prime \prime}$, the quadrant-plates B C. hanilles 1$)^{\prime \prime}$, yoke 1$)$, paw $d$, ver tical shaft $D^{\prime}$, and wheel $\mathbf{E}$, substantially as and for the pur. pose described.

No. 224,402.-WILLIAM L. DIETZ, SCHoHARIE, N. Y.-Broom.Cornand Cotton Serapers and Cultivators.February ro, rs8o. Filed Vovembir 13, 1879.

Claim.-I-In a scraper and cultivator, the combination, with the frame $\mathrm{A}$, of the frame $\mathrm{D} \mathrm{E} \mathrm{E}$, provided with the straps G H and the friction-roller I J, and the scraper-plates $\mathrm{K}$, substantially as herein shown and dercribed, so that the scraper-plates $\mathrm{K}$ may be moved haterally without moving the main frame A, as set forth.

2.- In a scraper and cultivator, the combination with the frame A, and the frame $D$ E F, that carries the scraper plates $\mathrm{K}$, of the handles $\mathrm{I}$ and the holts N P. substantially as herein shosvn and described, for moving the frame D E F and the scripers $K$ upon the frame $A$, as set forth.

No. 225.264.-ALFRED AKER, STRFAFU, IL1... assignor of one-half his right to JA MES $(;$. WIISON, same place.-Cullivators.-Harch 9, 1880 . Filed fanuary' 26, 1880

Claim.- The cultivator for cutting the roots of weeds, ulostantially as before specified, componed of a licam furmed with a curved standard, which standard is flattened out from the point a to the extreme end $a^{\prime}$ into a flat horizuntal sole, $C$, reaching about as far forward as the end of the beam, and flat knives or shares diverging from the extreme forward end of said sole.

No. 225,535.-JEWIS B. MORGAN, WEST LIBERTY, W. VA., assignor to JOHN E. WAVT, same place, and WILLIA.I RICE, JR., WEST ALFXANwER, PA., one third

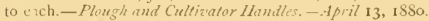
Filed Sipiem der 5, $1 \mathrm{~S}_{7} 9$.

Clim. - The eombination of the bandles $C$, cross bars D, spring $c$ itch $F$, the rod and lever $G 11$, the latter placed contiguous to the rear end of the handles, and the plough beam and notched arch $\Gamma$, as shown and dencribed.

No. $225,55 \%$ - I I IIES W. FI.EMING, ST. JOSEIH, Mo.. assignor of one-half. his right to FLORENCE H. S!UMPF, same place,-Combined Cultizators and Harvars.-4pril 20, 1880. Filed Wurch 6, 1 SSo.

Claim. - The triangular-shaped frame $A$, with teeth 6 and hovel $d$, and having connected $t$ ) it cross-beam $a$ and segmental guile-bars $e f$, in combination with the wings $B$ C, having teetl $s^{r}$ and ploughs or shovels $h$, said wings being connected to the beam $a$, as described, and for the purpose set furth.

No. 227,687.-JOHN A. GOGEL, TOLELO, OHIO.Cultizators. - Misy I8, 1880 . Filed Februnr 27, I880.

Claim.-The clamping plates $h$, composed of two halfsections embracing the rear end of the beam, having the pivot bolt $b^{1}$ and the curved vertical slots $b^{2}$, in combination with the round standards $f$ and clauping-bolts $b 4$, ubstantially as shown and described.

No. 228,S53.-RJCHARD G.S. AUSTIN, PINE BLUFF, AkK.-Cotton Cultivators- Inne 15, is8o. Filed May 4, IsSo.

Claim.-1.-In a straddle row cultivator, the combination, with the two semicircular wings $C$ and the tonguearches $\mathrm{A}$, of the pivoted arms or frames $\mathrm{D}$, adapted to slicle upon the curved bars of said wings and be held adjustably thereon by the plates $c$ and set screws $d$, connecting the frames $D$ to said wings, substantially as and for the purpose set forth.

2.- In a straddle row cultivator, the combination, with the tongue-arches A A, having inwardly projecting purtions $a$, of the semieireular wings $C$, earrying the pivoted standard arms or frames D, substantially as and for the purpose set forth.

No. 229,3IS.-RICHARD A. JOHNSON, NEWNAN, GA.-Cotton-Cultivators.-Fune 29, 1880 . Filed May 27, IS5.

( laim.- In combination with a plough or cultivator standard and a cultivator tooth or shovel, a combined guard and cutter eonsisting of the vertical-wing $f$, whith prevents the earth from being thrown upon the cotton, and the wing $I$, which serves as a scraper, substantially as shown and deseribed.

No. 229,484 -DANIEL STANCHFIELD, DAVEX PURT, Iowa. - Plought. - Fnene 29, 1880 . Filed November 18, 1879 .

Clains.-The combination, with the beams B, adjustable toward or from each other, and a plough section $\mathrm{D}$, having a shank, of side-mold-boards, E, each provided with an imlependent shank, said section $D$ and mold-board. E adanted to be secured as described to form a single wing plough, or detached to form cultivator-teeth, as speeified. No.231.701.-WTLLIAM J. DAVIDSON, B1G SPRING, VA.-Ploushis and Cultivators.-Ausust, 31 , 1SSo. Filed Feburary 7,1880 .

Claim.-1.-The combination of the plough beam $\mathrm{H}$, having the lateral arm $\mathrm{A}^{\prime}$, the $\mathrm{L}$-shaped bracket $\mathrm{B}$, secured adjustably to the arm $\Lambda^{\prime}$ and aclapted to be attached in different positions, and a standard, E, carried by the bracket 13, sulhstantially as herein set forth.

2.- The combination of a curved standart, E, turuing on a fixed pivot, $i$, and having a slot, $m$, the plough beam or bracket having a slot, $n$, crossing the slot $m$, and the adjustable bolt $t$, passing through both slot 4 , as berein specified, for the purpumes set forth.

No. 232,133.-RJCHARD A. JOHNSON, NiEwnaN, GA.-Cultivators and Scrapers.-September 14, IS80. Filed fuly 22, 1880 .

Clam,- In a cotton cultivator and scruper, the combination of the standard A, wing B, for protecting the young plant from the dirt, wing C, having the slot $\mathrm{D}$, the bolt. $G$, and shovel $\mathrm{I}$, the sloxt $\mathrm{D}$ in the wing ( being of such a shape that the wing can be adjusted into clifferent positions, substantially as shown.

No, 232,450-WILILAM P, BROWN. ZANESVILLE, Onin.-Ploishs._September 21, 1880 . Filed August 11, I 880 .

(laim.-I.-In a plough, the cumbination of the wooden portion $\mathrm{A}$ and iron portion. $\mathrm{B} \mathrm{B}$ of the plough-beam with the $\operatorname{rod} H$, bolts $G G^{\prime}$, and the revolving cups $K$, having flange, $L$ and steps $N$ and $O$, and interposed cross-bars $Q Q$, secured in place in said steps by nuts, substantially as and for the purposes set forth.

2.- In a plough, the combination of the portions A and B 13 of the berm, the bolt $G \mathrm{G}^{\prime}$, wedges $\mathrm{T}$, rod $\mathrm{H}$, handles I), cups K, bars ( ), and nuts and washeri K s, constructed and operating substantially as and for the purposes set forth.

3.-In a plongh, the cups $\mathfrak{K}$, having flanges $\mathrm{L}$, shoulders II, and stepe $\mathrm{N}$ and $(\mathrm{O}$, in combination with the cross-bars (). $\operatorname{rod} \mathrm{H}$, and beam $\mathrm{A}$ and $\mathrm{B} \mathrm{H}$, substantially as and for the purposes set forth.

No. 232,993.-ADJISON LUPTON, TROY GRove, assirnor to himself, MYRON A. HOLBROOK, MATTHEW BUIHER, and OJIVER CHADDOCK, LAMOIILE, JLL. - Cultivators.-October 5, 1880. Filed February i8, iS8u.

Claim.-The combination, with the frame $\mathrm{A} \mathrm{B} \mathrm{C,} \mathrm{of} \mathrm{the}$ 
plates 1), acnte-angles at wach curl, and prosulest with shanks 1 , twisted to incline them, the two out vite plates beine inwarlly inclined and the inside platen lxins atjustable to inclin. either inwardly or outwardly. wherely both sides of a row of plants may be serapeel or hilled, an the scribed.

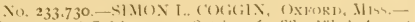

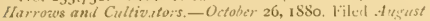
17,1880 .

Claim,-In a harrow or cultivator, the fromt blacles or scrapers 13, attached to the front teeth, and morle both longitudinally and vertically adjustable by mean of the slot 0 and set-screw $\&$, the rear serapers, $C$, arljustalsly attached to the rear teeth, and the intermediate teeth, $a$, all combined and arranget substantially an deseribed, and for the purpose specified.

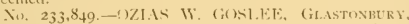

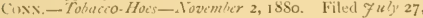
1850 .

Claim.-1.- The blades $(i$, attached to and supported by the tooth $F$, in combination with the tooth $\mathrm{E}$ and the bean $A$, said bi ules being adjustahle horizontally ly meani of the bolt and - tots $E^{\prime}$ subatintially as describid

2 - The combination of the blades $(i$, the supporting tooth F., the beam $A$, and the guicle $J$ in the rear of the tooth $E$, to form a cultivating device, sthetantially as described.

3.-The combination of the tooth $\mathrm{D}$, the supporting tonth $F$, with the blades $G$, and the guide or cutter $J$, with tho bean $A$ and the roller $C$, sulstantially as deveribel.

Vis. 235.097 - SIL.ASC. HUNTER, CIIARI.UTTK, N. C - Cultivators.December, 7, 1880. Filest May 6. 1880

Claim, - The forwardly-projecting diverging arm . I', ri ridIy comected with the beam 1 , in combination with teetl arranged, the forwarl one to work in close proximity with the row and to throw the soil outwarl or away therefrom, and the other in a reverse povition for throwing the soil in warl toward the row, as described.

No. 235,986.-SMITH R. BELL, PALEstinf, ARK.Cultizators.-Decembir, 28, ISSo. Fileal Sitptember 7, ISSo.

Claim,-In a cultivator, the combination of the beam $A$ angular standards $\mathrm{D}$, and shovels $\mathrm{O}$, the upper ends of the standaril being cut away, so that the st undards will diverge at their lower ends, and the shovels $O$ bein q bent buc'iward st their mifur cnds, wherely the ditt is presed inward toward the plants, substantially as shown any described.

No, 236,343,-IAIES F. LEWIS, RuckY HII.J. KV -Combined cultitaters and Scrapers.- Funuary 4 , IS81. Filed tuszust 23,1850 .

Claim.- The herein-described cultivator, consinting of the bea'm $\mathrm{A}$, the perforated plates B C, the laterally-adjuntablo beams I) Es tise hifurcated slotted stan lards $\left(i\right.$, braces $H^{\prime}$ and coalters H, the said beam E adanted to be adjunted hackwarl or forwaril to form a cultivator or scrajer, as de. scribed.

No, $23 \$, 132$-FREDERICK IT. LESLIE, CFI, FK Grove, G1.-Ciultizaters,-Fetruar 22, ISSI. Filei Warch 10, 1880 .

Claim.-The beam $\mathrm{A}$, standards $\mathrm{A}^{\prime}$ and shovels, the differentilly-slotted and differentially-arr.ın zed bars $\mathrm{F}$ and $\mathrm{E}$, the serrated slotted bars D I, the perforated beams C, the perforated tie-bar $\mathrm{R}$, and the comnecting bolts and nuts, the whole constructed, arranged, and combined to afford longituclinal, lateral, and differential adju-tment at will, as an-l for the purposes set foith.

No. 239,369.-AIKEN CURRIER, WIILABROtGH, astignor of one-half to CHARLES WV. WOFIDE()R1), E-

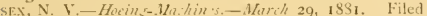
Octo's 7 , 1850 .

Claim - I - In a hoeing-m ichine, the comlination, with the frame hin zed centrally, of hoes secured adjustably to sail frume, the mans whereby they may set more or lesw obliquely, and the bands F P, adjustable with the thills and the handles, sulstantiaily as described.

2.- In a hoeing machine, the liands F l", passins, re spectively, above and below the frame, secured thereto $b_{y}$ bolts $G$, and having pivoted to their forward ends vertical slotted link: K, altached adjustably to thills, substantially as and for the purpose set forth.

3.- In a hoeing machine, the band: $F F^{\prime}$, secured to the frame, as herein, lescribel, and having pivoted to their ends vertical slotted linh , $K$ and 11 ', attaclied, respectively, to the the thills $\mathrm{H}$ and handles $\mathrm{H}$, and capable of adjustment, suhstantially as and for the purpeses set forth.

4.-The combination, with thills II, bands $\mathrm{F} F$, and hinged frame $\Lambda$, of bolts $G$, passing through the same, and having on their upper ends projections $f^{\prime}$, as and for the purpose set forth

No. 239.798. -RICHARD A. JOHNSON, NEWNAN, i.A. - witianters-April 5, IS81. Fileil February 12, 1881.

("laim. - In a cultivator, the combination of the standard A. the cultivator $\mathrm{B}$, the clamping bolt $\mathrm{C}$, and the two wings which have sots or opening mate through them for the clamping bolt to pass through, and angles upon the top edge of the wing to catch agrainst the under side of the shoulder on the standard, the parts being combined and arranged to operate substantially as shown and described.

No, 240.102, - IAMIES L. SHAIV, PRAIRIF. CENTRE. ItL.-Ciltivators. - April 12, 1881. Filled March 19, 1881.

Claim.- In a gopher-cultivator, the comlination, with the beams $\mathrm{F} \mathrm{F}$ and the arch 13 , of the blocks or slides D D. carrying the said beam, and secured adjustably upon the horizontal ends C C of the arch, substantially as shown and described.

No. 240,642-A NDREW BEARD, EAsUNIILA, ALA. -Double Ploushs.-April 26, 1881. Filed September 4, I S80.

Claim. -1,- The curved standard or dray-bar $\mathrm{H}$, formed of a double bar of iron and having a brace, I, inserted between the sides and acron the hond, whereby the standards are stiffened and braced in any position to which the swinging heam may be moved.

2. - The combination of the curved standarils H, the braces $J$, the swinging cross-bar 1 , plough-beam $A$, and braces $\mathrm{F}$, substantially as shown and deveribed.

Nis. 240.045-FR.ANK BATE.II.N. SPRING MILI.S, V. I, assignor of one-half to EIJI.ARI) S. BATEMAN, ame place.-Cultizators.-Way 3, i\$81. Filed Dor'emLit 22,1880 .

Claim. - 1- The combination of the bar $A$ of the frame, the presser plate $\mathrm{D}$, the $\mathbf{U}$-haped bar $d$, having openings in loth standards, and the ivolts for confuing the same, as specified.

2.-The combination of the side bar of the frame, the bent plate $\mathrm{E}$, bolted to said bar, the cutting-blade $\mathrm{F}$, having a stem, $n$, and the bolt $f$, adlapted to an opening in the laterally-projecting portion of the plate E. and having an eye, $s$, for the recuption of the said stem $n$ of the blade, as set forth.

Ni. 241,697-A.RON J. NEILLIS, PITTSBtroi, PA.-

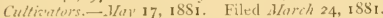

('laim. - I. - In a cultivator, the combination of longitudinal frame-bars, expansion bar, or spread-irons, pivoted at one end to one of said frame-bars and independently adjustable longitulinally at the opposite end upon another of saiul frame-bars, and cultivator shovels attached to the expansion bars, substantially as and for the purpose specified.

2.- In a cultivator, the combination of longitudinal framehas- expansion-bars, or spread-irons, pivoted at one end to one of said frame bars, and independently adjustable longitudinally at the opposite end upon another of said frame bars, ancl spring or vibratory shovels attached to the expansion bars or spread irons, substantially as and for the purpose spacified.

3.-In a cultivator, the combination of longitudinal frame bars, expansion bar or spread irons, pivoted at one end to one of said frame bars and acliustable fongitudinally at the oppowite end upon another of said frame bars, and a longituclival coupling bar or bars connecting the transverse expansion bars or spread nons, substantially as and for the purpose ipecitied.

4. - In a cultivator, the combination of a longitudinal center lar, adjustable longitudinal side bar, tranvverse expansion thar, or spread irons, pivoted at one end on the longitnclinal side bars and longitudinally adjustalle independently at the opposite end upon the center bar, cultivator sbovels attached to the expansion bars or spread irons, longitudinal coupling bars for connecting the transverse expansion bars, and an independently adjustable rudder tooth pivoted on the 
rear end of the longitudinal center bar, substantially as and for the purpose specified.

No, 24I,855.-JAMES W. FLEMING, AsPEN, Colo.Combined Cultivators and Harrows-.May 24, I88I. Filed March 28, 1881.

Claim.- The triangular frame A, connected to the cross beam $a$ and having the teeth $d$ and shovel or plough $c$, and at its rear end elongated slots $i$, in combination with the wings $\mathrm{B} \mathrm{C}$, connected to the beam $a$, said wings having connected hereto strap irons D, with holes $g$, and fastened to the frame by suitable bolts $h$ passing through said holes and throuhg the slots $i$, as and for the purpose set forth.
No. 242,279.-JOSIAH J. DEAL, WILMot, OH10, assignor of one fourth to WILLIAM M. JOHNSTON, same place. - Corn Cultivators.-May 31, 1881. Filed April 6, $188 \mathrm{r}$.

Claim.-In a cultivator without wheels, the frame A, having the double hack bar, $A^{\prime}$, in combination with the independent beams $\mathrm{B} \mathrm{B}^{\prime}$ and the adjustable handles C, whereby each plough beam can be swung separately while in action, substantially as and for the purpose described. 



\begin{tabular}{|c|c|c|c|c|c|c|c|c|c|c|}
\hline & \multicolumn{2}{|c|}{ Plate Claim } & \multicolumn{4}{|c|}{ I'la' Clerizu } & \multicolumn{4}{|c|}{ I'hre Chrim } \\
\hline Anthony, S. E. & $25^{8}$ & 75 & Ilenigst. W. & & 278 & 82 & Pond, J. F. & & 245 & $7)$ \\
\hline Asay, A. MI and Wood, & & & Hill, J. 1. & & 273 & s) & I'oncl, J. IF. & & $25 \mathrm{~s}$ & 75 \\
\hline & 266 & 77 & $1 \log \mathrm{k}$, S. S. & & 250 & 72 & I'ool. J. & & 258 & \\
\hline Atchison, W. J. & 271 & 79 & Ilomrighouse, 1. & & 256 & 74 & Quarton, W: 13. & & $24+$ & 69 \\
\hline Austin, J. & 280 & $8_{3}$ & Hoyt, B. C. & & $24 I$ & 69 & Kanclall, S. (i. & & $=43$ & 9 \\
\hline$\underset{\text { Bayliss, E. }}{\text { E. }}$ & $\begin{array}{l}264 \\
265\end{array}$ & $\begin{array}{l}76 \\
76\end{array}$ & " & 1. 1.) & 242 & 69 & Randall, S, (i, & & $\begin{array}{l}243 \\
263\end{array}$ & $\begin{array}{l}69 \\
76\end{array}$ \\
\hline Bean, s." & $\begin{array}{l}265 \\
268\end{array}$ & $\begin{array}{l}76 \\
77\end{array}$ & $\begin{array}{l}\text { lloyt, B. C. } \\
\text { Ilntchinson, G. F }\end{array}$ & & $\begin{array}{l}25^{i} \\
261\end{array}$ & 75 & Randall, S. (i. & & $\begin{array}{l}203 \\
263\end{array}$ & $\begin{array}{l}70 \\
76\end{array}$ \\
\hline Blanchard, J. & 264 & 76 & Ives, 11 . & & 236 & 85 & Randall, S. G. & & 267 & 77 \\
\hline ondeli, $\mathrm{A}$ & 254 & 74 & n, A. and I & Irwin, R. & 263 & 77 & Randall, S. Ci. & & 263 & 77 \\
\hline J. W. & 258 & 87 & n, T. E. & & 286 & 85 & Redfield, R. J3. & & 267 & 77 \\
\hline ramer, F. & 264 & 76 & II, T. E. & & 290 & 88 & Reynolds, S. G. & & 273 & \\
\hline Bramer, 1 & 270 & 78 & Johnson, H. .I. & & 241 & 69 & Ritun, E. & & 247 & 71 \\
\hline " " (R.) & 270 & 78 & $\mathrm{n}, \mathrm{M}$ & & 250 & 72 & Robeits, MI. 1.. & & 246 & \\
\hline Bramer, F. ¿ Badger, O.W. & 270 & 78 & $"$ & (R.) & 250 & $7^{2}$ & Kodeliush, , . S. & & 244 & \\
\hline Bramer, F." & $\begin{array}{l}270 \\
271\end{array}$ & $\begin{array}{l}78 \\
79\end{array}$ & Johnson, M. & & $\begin{array}{l}250 \\
251\end{array}$ & $\begin{array}{l}72 \\
72\end{array}$ & $\begin{array}{l}\text { St. John, G. B. and Un } \\
\text { wood, J. K. }\end{array}$ & ler- & $2 \mathrm{~S}_{4}$ & 85 \\
\hline $\mathrm{F}$. & 276 & 81 & 4 & (R.) & 252 & 73 & St. John, G. B. & & $2 \mathrm{CO}$ & 88 \\
\hline 1 & 277 & & “ & & 252 & 73 & Sanders, T, and Nichar & iolds, & & \\
\hline $\mathrm{F}$ & 277 & & " & (R.) & 252 & 73 & L. C. & & 274 & \\
\hline Bramer, $\mathrm{F}$ : & 281 & $8_{3}$ & Johnson, M. & & 253 & 73 & Satterlee, M. & & $24 I$ & 6.) \\
\hline $\begin{array}{c}\text { Bramer, } F \text {, and Crowley, } \\
\text { (i. G. }\end{array}$ & & & $\mathrm{n}, \mathrm{II}$. & & 255 & 74 & $\mathrm{~T}, \mathrm{~J}$ & & 259 & 75 \\
\hline Brewer, J. & $\begin{array}{l}285 \\
249\end{array}$ & $\begin{array}{l}85 \\
72\end{array}$ & n, M. & & $\begin{array}{l}260 \\
263\end{array}$ & & $\begin{array}{l}\text { oeftel, J. and Dell, } \\
\mathrm{P} \text {. }\end{array}$ & Wi. & $\begin{array}{l}255 \\
289\end{array}$ & \\
\hline W. M. & 251 & 72 & n, it. & & 265 & 77 & , il. F and G. F & & 280 & 83 \\
\hline I, E. T. & 256 & 74 & Johns un, 1 . & & 278 & $\mathrm{~S}_{2}$ & J. 1 & & 2. 7 & 6 \\
\hline I, E. T. & 261 & 75 & , G. R. & & 283 & $8_{4}$ & D. & & $2+3$ & 9 \\
\hline Bussell, E. T. & 261 & 75 & V. A. L. & & 245 & 70 & & & 276 & I \\
\hline Bussell, E. T. & 262 & 75 & La Dow, C. & & 272 & 79 & , $G$ & & 272 & 79 \\
\hline sury, A. & 267 & 77 & " $4 " 4$ & (R.) & 272 & 79 & (i. & & 275 & \\
\hline & 243 & 69 & 1.a Dow, C. & & 283 & $8_{4}$ & E. & & 254 & \\
\hline an, L. & 247 & 7 & $\mathrm{v}, \mathrm{C}$ & & 282 & & A. L. & & 255 & \\
\hline Corbin, J. A, & 275 & 80 & H. & & 278 & 8 & $\therefore$ and G. P. & & 260 & \\
\hline " " (R.) & 275 & 80 & & & 281 & 8 & P. & & 259 & \\
\hline Corbin, J. S. & $\begin{array}{l}258 \\
288\end{array}$ & $\begin{array}{l}86 \\
86\end{array}$ & & & 242 & & A. & & 259 & 69 \\
\hline , E. S. & $\begin{array}{l}288 \\
248\end{array}$ & $\begin{array}{l}86 \\
7 t\end{array}$ & $\begin{array}{l}\text { Lee, J. } \\
\text { Lefeber, J. an }\end{array}$ & chultz, & 242 & 69 & $\begin{array}{l}\text { Tracy, S. D. } \\
\text { Underwood, A. }\end{array}$ & & $\begin{array}{l}244 \\
267\end{array}$ & \\
\hline " " (R.) & 248 & 71 & G. IV. & & 260 & & Underwood, J. K. & & 269 & \\
\hline Crane, E. & 248 & 71 & Leonhard, F. A. & & 259 & 7 & " $"$ (R.) & & 269 & \\
\hline " " (R.) & 248 & 71 & Leslie, $\mathrm{W}$. & & 257 & 74 & Underwood, J. K. & & $27 \mathrm{t}$ & 7 \\
\hline Cravath, M. A. and 1. M. & 247 & 70 & McCormick, J. & B. and & & & Underwood, J. K. and & d St. & & \\
\hline " & 247 & 70 & Baker W. R. & & 243 & 69 & Juhn, Gi, B. & & 287 & \\
\hline Crowley, G. G. & 284 & 85 & Mallon, J. & & 277 & 81 & in, A. 1. P. & & 254 & 74 \\
\hline J. & & 70 & $\because \mathrm{Jr}$. & & $\begin{array}{l}271 \\
268\end{array}$ & 79 & B. & & 274 & \\
\hline J. $\mathrm{H}$. & $\begin{array}{l}246 \\
245\end{array}$ & $\begin{array}{l}70 \\
69\end{array}$ & A. & & $\begin{array}{l}268 \\
280\end{array}$ & $\begin{array}{l}77 \\
83\end{array}$ & $\begin{array}{l}\text { West, W. B. } \\
\text { West, B. J. }\end{array}$ & & $\begin{array}{l}253 \\
284\end{array}$ & \\
\hline & 287 & 85 & O. $\mathrm{F}$. & & $25 t$ & 72 & & & & \\
\hline T. E. & 290 & 88 & A. & & 246 & 70 & ENGLISH I'ATENTS S & SHOWI & ING & \\
\hline Den & $24^{8}$ & 71 & & & 275 & & CULTIVATC & ORS. & & \\
\hline & 242 & 6 & & & 244 & 69 & & & & \\
\hline $\begin{array}{l}\text { Fisher, J. B. } \\
\text { Foster, C. R. }\end{array}$ & $\begin{array}{l}276 \\
281\end{array}$ & $\begin{array}{l}81 \\
83\end{array}$ & , H. W. & & $\begin{array}{l}273 \\
253\end{array}$ & 79 & $\begin{array}{l}\text { No. } 3,687 . \text {-Abel, } \\
\text { " }, 862 \text {. Clark, }\end{array}$ & & 26, & \\
\hline $\begin{array}{l}\text { Foster, C. R. } \\
\text { Galt, T. A. and Tracy, }\end{array}$ & 201 & 83 & $\begin{array}{l}\text { Nishwitz, F. } \\
\text { Noble, W. }\end{array}$ & & $\begin{array}{l}253 \\
251\end{array}$ & $\begin{array}{l}73 \\
72\end{array}$ & “ 3,022.-Corbett, & Oct. & & \\
\hline & 289 & 87 & Norton, R. D. & & 280 & $\dot{s}_{3}$ & " $731 .-"$ & Mar. & & \\
\hline J. F. & $\begin{array}{l}262 \\
249\end{array}$ & $\begin{array}{l}76 \\
72\end{array}$ & $6 \quad 6$ & (R.) & 289 & 83 & " $3,135$. & Sept. & 7 & \\
\hline $\mathrm{J}$ & 254 & 74 & & & $\begin{array}{l}245 \\
241\end{array}$ & $\begin{array}{l}7 \\
6\end{array}$ & " $3,8,1$-Greig, & Oct. & 3,1 & 876 \\
\hline J. S. & 255 & 74 & & & 276 & 8 & " $3.9^{8} 4$ - Justice, & Oct. & 27 , & 1877 \\
\hline J. S. & $\begin{array}{l}257 \\
257\end{array}$ & & & & 279 & & “ 1,737.-Lake and & & & \\
\hline $\begin{array}{l}\text { Godfrey, J. S. } \\
\text { Goulfrey, J. S. }\end{array}$ & 257 & 74 & R. M. & & 279 & 82 & Thomas, & May & 26 , & 68 \\
\hline Gordon, MI. & 249 & 72 & Pence, J. W. & & $25^{6}$ & 74 & Lobb, & May & $\mathbf{I}$ & \\
\hline
\end{tabular}




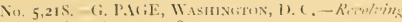
Mouldioneds.-Augut $7, \mathrm{I}_{4} 47$

Claim. - The employment of the friction rollers in com bination with the revolvirg mould boards subatiantially as specified for adjusting the heel of the mold hoard ont or in to regulate the furrow.

No, 9,879-VIILFOX SITTERLEE, 1, MISA, I1.1.Siced-Planters.-Ju'y 26, 1853 .

Claim, - The arrangement of the drill and covering wheels, or their equivalents, on flexible axles, so that they will rise and fall to accommodate themselves to undulating ground, whereby the grin is all the furrows is planted at an equal depth and equally covered.

No, 11,162,-H. H. JOIINSON, CARliste, PA.R'olury Cinltiontors. - Juni 27, IS 54.

Claim, - A system of sharpened disks or rotary coulters, a part of which are armed upon their peripheries with knives projecting laterally; said knives being set obliquely to the radius of the disks, as above described, the whole being combined and arranged in three several sets, so that the two set, armed with knives shall cut alternate sections of the soil, substantially as set forth.

No. 15,654 -B. C. HUYT, PuRT WasHinfton, Wis.Arroling . Would-boarts.-Siplember 2, 1856

Claim.-The ad ustahle rotary moull boards $\mathrm{K} \mathrm{K}$, com hined with the beam $D$, and frame $R$, the whole being arranged in the manner described.

No, IS 4 - B. C. HOYT, PORT W.ISHINGTuN, WIS.-

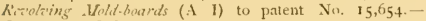
January 5,1858 .

Clain.- The adjustable axle 11 , with angular journals $C$ II', and adjusting arms I $I^{\prime}$, in comlina ion with the stirrup or standard D, tot ry molit-board $G$, and ground propelling or driving wheel $\mathrm{N}$, as and for the purpose set furth.

No. 17,1 4.-EZRA l:IINERT, FRANKLIN, GRONE, I1.t.-Sicid-Dril's. April $28,18_{5}^{8}$.

1 do not claim broadly the use of edge wheels in seedin machines; neither do 1 cla $m$ I roxdly the use of extention tubes; but 1 claim the arrangement and combination of the wheels $\mathrm{E}$, with the extension pieces $d$, in the manner and for the purposes sub-tantially as dercribed.

No, $18.69 \mathrm{~s}$ - J LEE, Gilleshurg, 11... - Whed Ploughs.-Hinember 2+. IS57.

Claim.-1. - The peculiar arran rement, consisting of friction wheels $d$, incline planes $f$, and lever $\mathbf{K}$, for adjusting the plough frame to any required position, substantially as set forth.

2.- The pec-liar arrangement, consisting of the flange or guart $c$, and pivoted axle $a a^{\prime}$, for allowing the turning of the front track to a position at right angles, or nearly so, to the hincl truck, so that the machine may turn a square conner w thout liability of lifting the plonghshares out of the grouni, substantially as set forth.

No. I8,S21-JUAL LEE, GILISBURG, II.L.-Sitd Flanters.-Decimber 8, is57.

Claim,-The hevel wheels D D', constructed, arranged and operated in the manner as set forth, when com:bined with the swivel tube $\mathrm{C}$, for the puipose set fort'i.

No. J9,489.-ORMAN COE, WASIINGTON, WIs.Rotary Harrotos,- Warch 2, 1858 .

Claim.-The combin tion, with the bars A o' a harrowframe of a series of revolving, circular, conical or concave, furked harrow teeth; said teeth being arranged obliquely to the line of draft, and operating unitedly, substantially as and for the purposes set forth.

No, 21,3:9.-J. B. MCCORMICK and W. R. BAKER, Buston MAss. - Sicting Withines.-Aurust 31, i 858 .

Claim. - The arran rement and combination of the rotating wheel G, with the stationary plates or shares, substantially as and for the purpose shown.

No, 21,375--J. D. SiMITH, LAvister, OHIO.-Sedins Machines.-Aurust $31,1858$.

1 do noi claim bruadly the employment of two wheels for opening the furrow, the seed being dropped between the wheels

Claim.-The arrangement and combination of the spout $K$, wheels $I f$, frame $H$, and trame $D$, as and for the purposes shown and descriled.
No. 25,443.-S, ， RANIAL1, NEW lBAANIREE,

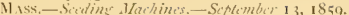

(laim. - The arrantement and combination of the series of plate wheels D D, seed boxes A, and horizontal bar B, subtantially as shown and slescribed, so that, as the bar 1 is drawn along, the plate wheels shall assume an oblique position, as set forth.

No. 3.464.-SILAS (;. R ANDAIL, NIW BRAINTREF, MAss,-Sieding Machines,-Septomber 13, 1859.-Xin, 25, 443; re-issued Hay 25, 1860 .

Claim.-1.-The harrowing plate-wheels I, revolving upon axles oblique to the line of draught, arranged in series, and inversely duplicated, substantially as shown and described, for the purposes specified.

2.- The arrangement and combination of the series of plate-wheels D D, seed-boxes A, and horizontal bar B, substantially as herein described and shown, so that as the bar 13 is drawn along, the plate-wheels shall assume an oblique position, as set forth.

No. 26,630.-SAMUEL D. TRACY, VER NON, N. Y.Secting Ciultirators. - December 27, 1859 .

Claim.-1.-Giving the zigzag or alternate opposite inclinations to the blades of the spur wheels $C^{\prime} \mathrm{C}$, in the manner and for the purpose herein set forth.

2.-The combination of the novable or adjustable cutters $\mathrm{D}$ D and their slotted supports $g .5$ with the zigzag spur wheels $\mathrm{C} \mathrm{C}$, in the manner and for the purposes herein specified.

3.-The arrangement of the seed box $\mathrm{H}$, in grooves, in the undericle of the hingerl seat $G$, so as to be adjustable beneath it, removable therefrom, or turning up therewith, substantially as herein described.

4.- The vibrating seed distributor I, con-tructed, operated, and operating substantially as and for the purpose herein specified.

No. 30,645.-GEORGE S. ROUDEBUSH, NATCHEZ,

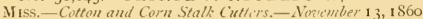

This invention consints in the employment of a biconical roller, provided with flanches and cutters, used in connec tion with stationary scrapers and a rotating cutting cylinder all the parts being placed in a suitable frame and arranged for joint operation.

Claim.-The biconical roller D, provided with the knives $\mathrm{E}$, in connection with the knife cylincler $\mathrm{H}$, and with or without the bars or scrapers $G$, all being placed in the frame A, essentially as and for the purposes set forth.

No. 31,OS9.-W. B. QUARTUN, CARlinville, IH..Serdins Machines.-Jamuary S, I86I

A number of wheels are placed side by side on a fixed shaft behind the seed-tubcs, each of which is capable of a motion independent of the cutters, and so constructed and placed on the shaft as to rive or fall and accommodate themselves to the inecualities of the surface of the ground independently of each other, while they will each form a deep and sloped furrow and corresponding ridge, and thus press the seed completely into the soil.

Claim. - The arrangement of the rods $\mathbf{E}^{\prime}$, cutters $\mathrm{D}$, axle $\mathrm{I}^{\prime}$, oscillating shaft $\mathrm{D}^{\prime \prime}$, rod $h$, lever $\mathrm{E}$, seed box $\mathrm{B}$, roller $J$, hub $c$, and linged pivoted lever $h$, all as shown and described, for the purposes set forth.

No, 32,078.-GEORGE W. NEVILL, BATH, ILL.Seed-Drills.-April 16, 1861

The wheels $C$ are made with beveled edges tipped with steel, to make indentures in the ground, into which the grain is dropped. The wheels $E$ are provided with spurs on their peripheries, and are so situated that a portion of their outer surface moven through openings in the hopper and agitates the grain, causing it to pass through openings, whence it falls into the conveyors. In the rear of the conveyors are shoes provided with plates at their sides which cover the grain, the heel of the shoe pressing the soil down upon the same.

Claim.-The wheels $\mathrm{C}$ and the wheels $\mathrm{E}$, being fixed upon shaft, hopper B, conveyors D, and shoes F, the whole arranged and operating as sct forth.

No. 33,072.-H. N. DAl.TON, JACKSONUIL.F, CAL.Sectins Machines.-Augus/ 20, 1861

The hounds of the draught-pole are pivoted to the sides of the main frame. The front transvere bar of the hound: 
is connected to the front end of the frame by a vertical adjusting screw which passeb through a rocking nut, and is fastened at its lower end to the back edge of a bearing plate bolted to the bottom of a cross-bar of the hounds, so that by means of the screw the rear end of the frame may be depressed, and the ploughs adjusted to any depth or raised entirely from the ground.

Claim.-The hounds I I pivoted at $i$ i to frame $A$, and mounted on the caster wheel $\mathrm{N}$, in combination with the bearing plate $k$, adjusting screw $\mathbf{K}$, and rocking nut $j$, all arranged in the manner and operating as described.

No. 33,103.-JUSEPH F. POND, Cr.eVELAND, OHIO.Sied-Planters.-Aurust 20, I 86I.

This invention consists in the construction of a dropping tube, to wbicb adjustable or reversible arms are attached: also, a bent bar, with stationary and reversible arms, upon which are disks or wheels placed oblicuely to the line of dranght, having cone-shaped bearings for equalizing the side draught and preventing friction on the axle, the cone being secured to the arm by a pin, and may be adjusted by shifting it to vary the width of the disks.

Claim.-1.- The two serrated or plain disks W W, oblique to the line of motion, upon stationary adjustable and reversible arms $a \quad a$, attached directly to the dropping tube $T$, and the stationary and adjustable arms attached to a piece $\mathrm{P} \mathrm{P}$, for the purpose of covering grain, cultivating and hoeing vegetables in different manners, as set forth.

2.-The application of the cone bearings $B$, and cap $d$ and pin $i$ in the hub $H$ and disk $W$, when placed or running obliquely to the line of motion, when applied to seedplanters, cultivating and hoeing machines, for the purpose of equalizing the side draught to obviate friction and secure a more easy action of the macbine or implement, as specified, for the purposes set fortb.

No. 36,724-A. IV. OLDS, Green OAK, Mich.Cultivators. - October. 2I, 1862 .

The cultivator is so constructed as to be supported in part by one or more bearing wheels, so arranged and adjusted that a forward movement of the vebicle will cause a positive rotation of the cultivatior. The form of the teeth is sbown in the engraving.

Claim.-1.-The adjustable axletree 1, bearing wheels $K$ and $K^{\prime}$, in combination with the cultivator frame A $B$ axis $C$, and pipe-box $E$, when these parts are arranged and operated as and for the purpose specified.

2.-The bell-shaped, round-shankerl tooth, constructed and operating as and for the purpose herein set forth.

No. 45.926.- IVILLIAM A. I. KIRK, HAMIToN, Oнго.- Sol Cutters.- Jintwary 17, I 865

Clain. - 1.- The arrangement of frame $A$, roller, $B$ and $\mathrm{C}$, and rod-cutting blade $\mathrm{E} e e^{\prime} e^{\prime \prime}$, substantially as set forth. 2.-The parts A B C D $\mathrm{D}^{\prime} e \iota^{\prime} e^{\prime \prime} \mathrm{F} \mathrm{GK}$ and $\mathrm{L}$, as herein arranged and combined.

No. 55,826-JOHN CUSTER, SANDUsky, Он1о.Cultivators.- Func 26, 1866.

This clod-crubhing roller has a series of cutters on its periphery whose intervals are occupied by hinged clearing plates which prevent the accumulation of soil.

Claim.-1 - The binged cleaners $\mathrm{H}$, in combination with the levers I, arranged to operate with the cutting rollers $\mathrm{D}$, in the manner and for the purpone herein specified.

2.-The combination of the cutting rollers D, hinged cleaners $H$, frame $A$, bar $K$, and chain $J$, arranged and operating as described.

No. 58,951.-\$1LAS A MOODY, SAv Francisco, CAL.-assignee to PHII.1P E. DIV1NE.-Sod Cutters.Octobs I6, I 865.-The revolving shaft, armed with disk cutters, has a cover and seat, which assist in forcing the disks in the ground.

Claim.-A series of circular blades or knives upon a shaft or axle arranged to rotate, as described, in combination with the cover $\mathrm{C}$ and seat upon the cover, substantially as described.

No. $62,367 .-M$. L. ROBERTS, SMithfield, CANADA.-Ploushs. - Fibruary 26, I867.

Claim.-1.- The friction wheel $G$, having its axis inclined at an angle of $90^{\circ}$ or thereabouts, one bearing being attached to the beam, and the other to the lreel of the mold board, so that the two faces of said wheel bear against the side and bottom of the furrow, with nearly equal force, in combination with the other parts of the plough, arranged and operating substantially as and for the purposes set forth.

2.-Constructing a plough without the land plite or -lide, when the same is provided with a friction roller or rollers, which track in the furrow angle, which is cut by the share, substantially as set forth.

3.- The combination of the inclined wheel $\mathrm{C}$, with the anti-friction mould board, composed of the series of rollers $e$ $c$, or their equivalent, arranged and operating substantially as set forth.

No. 63,224.-IOHN CUSTER, CORsicA, ОHIn.Roller for Pulverizing. Soil and Clods.-Warch 26, 1867.

Claim.-I.- The continuous single ring cutters $s s$, secured by projections $a$, in grooves $e c$, upon the periphery or the rollers D D, arranged as and for the purposes herein described.

2. - The cleaners or scrapers formed of a corrugated metal plate secured to the cross bar $F$, with the corrugation or volutes $c c$, placed between the cutters $s s$, in the manner and for the purpose herein clescribed.

No. 66,802.-M. A. and I. M. CRAVATH, BunomingToN, II.1.-Revolving Plowghs.-July I6, I867.-

Each plough is made of a single plate of steel, concavo-convex in shape, the edge sharpened with the bevel on the outer side. The ploughs are arranged in oblique series so as to clear each other's furrows and have an obliquity on their axes relatively to the line of draft, to give the width of the fur row slice.

Claim.-1.-The plough A, combined with the axle $a$, constructed as berein mentioned, as a new article of manufacture.

2 - The arms $i f g h$, or different shapes and lengths as shown for the purpose of combining and operating two or more ploughs.

3 -The combination of the slides F F, the hent lever G $\mathrm{G}$, the swivels $\mathrm{H} H$, the curved straps 1 , or any equivalent device, to operate the wheels $\mathbf{E} \mathbf{E}$, in the man ner set forth for the purpose herein mentioned.

No. 9,603.-MVRTILLUS A. CRAVATH, Binoming TON, IIL., and JAY S. CORBIN, GoUverNF.tR, N. Y.; said CORBIN assignee of said M. A. CRAVATH and of ELMIRA E. CRAVATH, Administratrix of ISAAC M. CRAVATH, deceased.-Revolving Ploughs.-No. 66,802, dated $\mathcal{F}_{\text {uly }}$ i6, 1867.-Re-issued March I 5, 1881.- [ Filed November 23, I 880.$]$

Claim.-1.- In a rotating disk-plough, a rotating concavo-convex plough constructed of a single plate of metal, arranget, substantially as described, to have its front edge cut the soil, and adapted to turn the soil to form a furrow.

2.- In a plough, a revolving concavo-convex cuttting-disk mounted upon and attached directly to the tongue or draftframe, substantially as described.

3.-The combination, with a draft-frame, of a revolving concavo-convex disk arranged, substantially as described, to cut the soil to form the furrow, and monnted on said frame olsliquely to the line of draft.

4.- The combination of a plough-frame, revolving diskplougbs below said frame, and a driver's seat adapted to have the driver's weight enforce a uniform cutting action of the disk.

5.-The combination of a draft-frame and a gang of two or more concavo-convex disk-ploughs, arranged with the concave sides toward the front and at an angle with the line of draft.

6.-The combination of a draft-tongue, rotating concavoconvex cutting-disks, rotating axles for said disks, adapted to hold the concave sides of the disk in the direction of the draft, and an intermediate frame which connects said axle to the tongue.

7.- In a revolving plough, the combination of a concavoconvex cutting-disk and a rotating axle which has one end mounted in the rear of the other to hold the concave side of the disks in the direction of the draft.

8.- - In a revolving plough, the combination, with the connecting frame, of the rotating concavo-convex cutting- 
disks, adiyted to suppor sid frame above the ground and to bave the cuncave sicles at an angle to the line of drait.

9.- In a revolving plough, the combination, with the supporting-frame, of a gang of rotating concavo convex cutting-lisks arranged in parallel planes, and adapted to have all the concave sides throw the sis in one direction.

10.- The combination, with the rotating ploughs $A$ and the axles $a$, of the arms if $5 h$, of different lengths, and each arranged to support the ends of two of said axles.

II. - The combination of the slides F F, the bent lever: G (i, the swivels $\mathbf{H ~ H}$. and the curved straps I I to operate the wheels E E, as set forth.

No. 67,634-L, COLEMAN, NEW ORI.FANS, LA., assignor to WHLLIS P. COLEUAN, same place,-HIt: roies.- fus rust 13,1857 .

The frame is supjorted on wheels, and is adjustable thereon. Two rot.tin shafts carry serrated disks. The rear disks are cleared by spring fingers projecting forwasd from a transverse bar.

Claim,-1 - The combination of the two series of re volving disks B B B and C C C, or their equivalent, when the same are constructed and arranged substantially as described for the purpose set forth.

2.- The two series of revolving disks B B B and C C C, in combination with the slicling-standards $\mathrm{K}$, lever $\mathrm{E}$, arm $\mathrm{P}$, rock shaft $\mathrm{N}$, handles $\mathrm{F}$ and frame $\mathrm{J}$, when these sever.al parts are constructed and arranged with respect to each other and to the clearers D D D, as described for the jurpose set forth.

No. 69,484 -EDWIN RITSON, MaLtaville, N Y. assignor to WILLIAN H. BUKTIS, same place.-Sictins Machine's.-October 1, iS67.

Claim.-1.- The combination of the rotary furrow opener E, and coverers I, attached respectively to the frame C D, t. Je former being connected by hinge, or joints $a$ to the front end of frame $\mathrm{A}$, and the latter connected by hinges or joints $b$ to the rear of the frames C, substantially as and for the purpose set forth.

2.- The combination of the furrow openers E, coverers I, and the seed-distributing device compused of the vibrating shoes L, and perforated bo.tom of the reed box, provided wih shdes $o$, all arranged substantially as and for the pur pose specified.

No, 71,589.-IAY DENSMORE, Hol.1.ky, N. Y., assignur to L. A. DENSWORE, and HIRAM CURTIS.Rotatins Touth Cultivators. - Deiember 3, 1867.

Clain. - 1.-A rotating cultivator tooth, consisting of any number of teeth, attiched to a hub or common centre, around which they are free to revolve, and set at an angle to the draft, substantially as described.

2.- The combination and arrangement with rotating cultivator tooth of the standard $S$, the pin $\mathrm{P}$, the bush $O$, the washer $i$, and the keys $l$ and $n$, substantially as set forth and described.

3.- The combination and arrangenent with a rotating tooth cultivator of the frame $\mathrm{B}$, the shaft $\mathrm{G}$, the cranks $\mathrm{F}$, the whe's A A, the lever $\mathrm{L}$, the pin 3 , the cross-bar $\mathrm{N}$, and the holes 4444444 , substantially as set forth and described.

4.- The combination and arrangement with a rotating tooth cultivator of the pole $\mathrm{I}$, the guides $\mathrm{K}$ and $\mathrm{I}$, the pin t, the holes 222222 , the driver's seat C, and the spring E, substantially as set forth, and described.

No 73,876.-ELISHA CRANE, ElkHART City, ILL.-Device for Sarifying the Soil Preparatory to Ploushins.-January 28, 1868.

A series of cu'tung disks are pivoted in standards attached to the inclined bars of a frame which is vertically ad ustable upon rollers.

Claim.-1.-Arranging in a suitable frame a series of gang of cutting blades or disks, when the same are so adjusted as to cut the soil in parallel channels, substantially as described and for the purpose specified.

2.- The lever $\mathrm{H}$ and curved arm $\mathrm{I}$, in combination with the windlass frame, when the same are arranged substantially as described and for the purpose specified.

No. 8,260.-ELISIIA CRANE, Elknart CiTY, II.L., assignor to CHAS. 1.A DOWV-Harrow-Cultizators.-Pat- ent 73.876 , dated fanum: 28, 1868 . Reisuted M/ay' 28, is 78 . [Filed I/ay 16 , is 78 .]

Claim - 1 - In a cultivator, the combination of a triangular frame with a leading cutting clisk at its apex and a series of following disks on each side thereof.

2.- In a cultivator, the combination, with a frame, of opposing gangs of revolving disks, overlapping each other

3.- In a cultivator, the combination, with a frame, of gangs of revolving disks, said gangs being set at opposite angles to each other, and confined by said frame to the same horizontal plane.

4.-In a cultivator, the combination of a frame and driver's seat with gangs of revolvin z disks, each gang heing arranged at an opposite angle to the other on sairl frame, the driver's weight enforcing a uniform cutting action on the disks of said gangs.

5.- In a cultivator, the combination of a frame with gangs of vertically-rotating disks, each wheel having its cultingedge adjustable relatively to the line of draft.

6.- - In combination with a cultivitor-frame, two gangs of disks attached thereto, said gangs extending rearwardly and ontwardly from the line of draft.

7.- In combination with a cultivator-frame, a revolving cutting-disk having its axle supported at two points, its support being provided with a clamping device for holding said axle in the desired position relatively to the line of draft.

8.-In a cultivator, the combination of two disk-gang bars, a central draft-bar, and a transverse brace-bar with a seat for the driver supported from three points by connections attached to the frame.

No. 76,404-ELISHA CRANE, EL.KHART, ILL.Sarrifying the Soil Preparatory to Ploughing. - April 7, I 868 .

Claim.-1-The truck frame B B where the same is provided witl a series of parallel rods or axles $\mathrm{B}^{\prime} \mathrm{B}^{\prime}$, when the same are provided with a series of cutting blades or disks $b b$, and the whole is constructed and arranged so as to operate substantially as described and for the purposes specified.

2.-The truck $B$ when the same is in combination with the uprights $a d$ and wheels $a^{\prime} a^{\prime}$ and the whole is so constructed as to o: erate substantially as described and for the purposes specified.

3. The truck $\mathrm{B}$, rods or axles $\mathrm{B}^{\prime}$, cutting blades or disks $b$ when the same is in combination with the windlass rollers $c \epsilon$, and its operating mechanism, and the whole is so constructed and arranged as to operate substantially as described and for the purpose specified.

4.-Arranging above the truck $B$ when the same is provided with parallel rods or axles $\mathrm{B}^{\prime} \mathrm{B}^{\prime}$, and cutting blades or disks $b$, of the platform $F$ and driver's seat $g$ when the whole is so constructed and arranged as to operate substantially as described and for the purposes specified.

No, 8,261,-ELISHA CRANE, ElKHART Citv, Ill., assignor to CHAS. LA DOW. Patent 76,404 , dated April 7, 1868 . Reissued May 28, 2878. [Filed May 15, $1 \mathrm{~S}_{7} 8$.]

Claim.-1.-The combination, with a cultivator-frame, of twn or more gangs of revolving disks, mounted on throughaxles, said axles being supported relatively to the frame at more than one point, and said gangs being arranged to prevent longitudinal rocking of said frame.

2.- The combination, in a cultivator, of disk-gangs, driver's seat, and frame with a pole pivoted to said frame, which pivotal connection allows the said pole to be raised or lowered without affecting the position of the driver's seat.

3.-In a cultivator, the combination of disk-gangs with a truck-'rame and main frame, said main frame being arranged to brace said trucli-frame against transwerse strain.

4. - In a cultivator, the combination, with a truck-frame, of disk-gangs and axles passing through said gangs, each axle being secured to the truck-frame and said truck-frame attached to the main frame at more than one point.

5. - In a cultivator, the combination, with a frame, of disk-gangs mounted on through-axles, and each axle arranged transversely to the line of draft and at different distances longitudinally from the front of the machine.

6.-In a cultivator the combination of a frame and disks 
arranged in gangs on through axles, so that a disk of one gang will overlap a disk of another.

7.- In a cultivator, the combination of two or more gangs of revolving cutting-disks, each gang turning with its axle and each axle journaled at two points to a truck-frame, said truck-frame being connected to said main frame at more than one point.

8.- In a cultivator, the combination of a frame with revolving cutting-disks arranged in gangs on through-axles, each axle being attached to said frame by bearings which confine the gangs to a uniform horizontal plane.

9.- In a cultivator, the combination of a main frame and truck frame with gangs of revolving disks mounted on through-axles, the axle of each gang being secured to the truck-frame at two points, and the truck-frame being attached at two or more points to the main frame, whereby the said gangs are braced against vertical and transverse strain.

Io.- In a cultivator, the combination of an axle having a square or equivalent shape in cross-section with a series of cutting-disks correspondingly perforated, so as to turn therewith.

No. 76,909.-MATTHEW GORDON, WASHINGTON, Iowi.-Combined Corn-Stalk Cutters, and Cultivators.Atril 21, 1868 .

The machine runs on two wheels and has a vertically adjustable frame which has a shaft on which are several toothed or bladed cylinders. These cylinders are removable and as many may be used at a time as necessary for the required width of tilth, the vertical adjustment determining the depth of tilth.

Claim,- The cylinders op $q$, with cutters and teeth or hoes arranged upon the shaft, and operated substantially as and for the purposes herein recited.

No. 77,184--JOSEPH S, GODFREY, LESLIE, MICH.Rerolving Mould Bourds.-April 28, 1868 .

The mould boards are circular tapering blocks, and are hung so as to turn with the friction of the earth npon them.

Claim.-The combination of the mould boards A A with the cutters B B, the shares C C, the shafts D D, and the frame E, when constructed substantially as described, for the purpose designed and set forth.

No. 82,793.-JOHN BREIVER, NEW Vienna, OHIO. -Combined Land Rollers and Clod Pulverizers.-Oitober 6, 1868 .

Claim.-The drums B B, provided with knives C C, in combination with the cultivator $\mathrm{E}$, when constructed and operating substantially as and for the purposes herein set forth.

No. S4,12r.-SIDNEY S. HOGLE, Berea, Ohio.Secting Machines and Cultivators Combined.-Nonember 17,1868 .

Claim.-I.-The revolving cultivators E, as arranged in combination with the jointed frame $\mathrm{A}$, for the purpose and in the manner substantially as set forth.

2.- The combination of the revolving cultivators $\mathrm{E}$ and rollers $\mathrm{B} \mathrm{B}^{\prime}$, in the manner as and for the purpose specified.

3.- The combination of the revolving cultivator $\mathrm{E}$ rollers $\mathrm{B} \mathrm{B}^{\prime}$, and seeding boxes, substantially as and for the pur pose specified.

4.- The special construction and arrangement of the drill box $\mathrm{A}^{\prime}$, when operated in the manner as and in combina tion with the cultivators $\mathrm{E}$ and rollers $\mathrm{B} \mathrm{B}^{\prime}$, for the pur pose described.

5.- The slotted standards $i$, revolving cutters or disk $F^{\prime}$, in combination with the box $\mathrm{D}$, in the manner as and for the purpose set forth.

No. 85,451.-NIOSES JOHNSON, THREE RIVERS, Mich.-Plowshs.-Derember 29, I868.

The ploughing is done by means of the sharp corrugated wheels revolving on pins in stirmps attached to the bean. The width of the furrow can be regulated by means of the hinged beams, which are held in position on the arm by pins.

Claim.-A plough, having wheels $\mathrm{A}$, beams D, stirrups $\mathrm{B}$, axles $\mathrm{C}$, and punctured arm $\mathrm{K}$, constructed, arranged, and operating substantially as described.

No. 9,031.-MOSES JOHNSON, LOCKPORT, N. Y. asvignor, by mesne assignments, to CHARLES LA DOW.
-Plous.hs.-No. 85,451, December 29, 1868.-Re-issued January 6, 1880.-[Filed November I1, 1879.]

Beams hinged together and carrying wheels for turning or cultivating the soil; also adjustable at different angles to the line of draft.

Claim.-I.- Wheel-gangs hinged together at their inner ends, so as to admit of their horizontal movement, substantially as hereinbefore set forth.

2.- The combination, substantially as hereinbefore set fortb, of wheel-gangs, their hinge which admits of their horizontal movement, and the draft-connection at or near the hinge.

3.-The combination, substantially as hereinhefore set forth, of wheel-gangs, an interposed hinge-connection, and mechanism, substantially as described, whereby the angle of the gangs relatively to each other may be varied.

4.- The combination, substantially as hereinbefore set forth, of disk-gangs, a hinge-connection, a cross-brace, and mechanism, substantially as described, for adjusting the gangs and holding them at regulated distances apart.

5.-The combination, substantially as hereinbefore set forth, of gang-beams, nechanism, substantially such as described, for adjusting their relation to the line of draft, the concavo-convex wheels or disk-cutters, and the adjustingclamp by which their angle relatively to the line of draft is adjusted.

No. 9,032.-MOSES JOHNSON, LOCKPORT, N. Y. assignor, by mesne assignments, to CHARILS LA DOW. -Ploughs.-85,451.-December 29, 1868.-Re-issued Janwary 6, 1850.-[Filed November I1, 1879.]

Transverse beam with concavo-convex wheels or cultivating-disks and draft-tongue.

Claim.-1.-The combination, substantially as hereinbefore set forth, of the tongue, the cross-beam connected therewith, the wheels which support said beam, and mechanism, substantially such as described, for adjusting the angle of the wheels relatively to the line of draft.

2.-The combination, substantially as hereinbefore set forth, of the tongue, the cross-hean connected therewith, the wheels which support said beam, mechanism, substantially such as described, for adjusting the angle of the wheels relatively to the line of draft, and a driver's seat mounted on the cross-beam.

No. 85,639.-IVILLIAM MARTILLOUS BUSH, Greensburg, InD.- Wachines for Pulverising Earth.Fanuary, 5, 1869

Claim.-1.-4 roller or pulverizer, constructed substantially as described and as shown in the drawings.

2 - In combination with the disks or sections $D$ and knives or cutters $\mathbf{E}$ of the pulverizers, the scrapers $\mathrm{H}$, arranged substantially as shown and described.

No. 90,770-OLIVER F. MOMANV, DowatiIAC, Mich.-Roller Grain. Drills,-Fune I, I869.

Claim.-1.-The con-truction and arrangement of the frame $\mathrm{A}$ and hopper $\mathrm{C}$, in combination with the wheels $\mathrm{B}$, sliding-frames $d$, and lever $\mathrm{W}$, as and for the purpose specified.

2.- In combination with frame A, wheels B, hopper C, and the frames $d$, the construction and arrangement of slides $f$ and $O$, the bars $i$ and 3 , levers $N$, and handle $r$, and the arrangement of the coverers $\mathrm{S}$, in combination with the pedestals T 1, driver's sent $\mathrm{X}$, all as and for the purpose specified.

No. 92,992.-WIL.SON NOBLE, New HAVEN, CoNN.Ploughs.-Fuly 27, 1869; antedated Fuly 3, 1869.

Claim.-The wheel $\mathrm{D}$, constructed with a corrugated surface, in combination with the ploughshare, substantially as and for the purpose set forth.

No. 93.307-MOSES IOHNSON, THREE RIVERS, Mich.-Potuto-Diggers and Cultivators Combined.-August 3, 1869 .

Claim. - I. - The disks E, when constructed, apulied, and operating as described, for the purposes specified.

2.- In combination with the disks $E$, the scrapers $d$, apron $(\mathrm{i}$, ploughs $\mathrm{H}$, and roller $\mathrm{C}$, constructed and arranged substantially as and for the purpose descrihed.

3.- In combination with the foregoing devices, the attachable-beam $\mathrm{K}$, cross-bar $\mathrm{N}$, disks $\mathrm{R}$, scrapers $h$, and 
vings of constructed und arranged vulsstantially as specified.

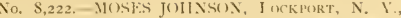
assignor, by mesne as ignments, to ("11AR1.ES I.A J)(II.Rolary Ciultizators.-93,307, dated August 3, IS69.-Kie issued May 7,1878 . - [Filed April 27,1878 .

Claim.-1.-In a cultivator, the combination of a concaro-convex cutting disk with a pendent seraper which enters the concavity of said disk.

2.- In a cultivator, the combination of a frame, pendent scrapers, axles, and concave cutting disks with adjusting mechanism, whereby the lateral distance between the scrapers and disks cau be either lessened or increased,

3.- In the cultivator, the combination of a revolving coneavo-convex disk with a support for said disk, having a pendent scraper attached thereto, and adapted to enter the concavity of said disk.

4.- In a cultivator, the combination of a supporting frame and a concava-convex disk with a pendent clearing device, which presents a cutting edge rearwardly for the purpose of shaving the earth from the clisk.

5.- In a cultivator, the combination of a revolving axle with a concavo-convex disk and clamping-nuts working on screw-threads, so as to follow said disk and tichten it in place.

6.-The combination, in a cultivator, of a draft-frame with two revolving axles attached thereto, and having concavo-convex diski mounted on and firmly clamperI to said axles by adjustable nuts.

7.- In a cultivator, the combination of a draft-tongue, cross-har, and revolving disks attachel to said bar, said disks being adjustable towarel or from each other, and ar ranged to straddle a row of plants and turn the e.rth either toward or from the row, as descritred.

No. 9, I68.-MUOSES IOHNSON, LOCKPORT, N. Y. assignor, by merne assignments, to CIJARLES LA IOIII.-Rotary Cultizators. -93,307, dated Aurust 3, 1 S79.-Re-issue No. 8,222, dated May 7, 1878 . - Reissued April 20, ISSO.-[Filed Nin'thle'r II, is 79 ]

Claim.-I.-The combinution, substantially as hereinbe ore set forth, of a draft-bir, a cross-beam connected therewith, cutting-disks secured upon the cross-heam and supporting the same above the ground, and handles by which the implement $\mathrm{m}$ iy be controlled.

2.-The combination, substantially as hereinbefore set forth, of a main frame, a draft-bar, cutting-disks arranged on opposite sides thereof and supporting the frame, and handles to vary the angle of the disks.

3.-The combination, substantially as hereinbefore set forth, of a cross-beam or frame, supporting stirrups or yokes in which the disks are mounted, and laterally-movable adjusting-clamps, which permit the lateral adjustment of the disks upon the frame or cross-beam.

4.- The combination, substantially as hereinbefore set forth, of a rotating concavo-convex cutting - disk with a pendent scraper adapted to enter and clean the concavity of said disk. 5.-The combination, sulstantially as hereinbefore sut forth, of a revolving concavo-convex disk, a support in which it is mounted, and a pendent scraper attached to said support and conforming to the concrivity of the disk.

6.-The combination, sub tantially as hereinbefore set forth, of a revolving cutting-disk mounted on a down-hang. ing support, a scraper for the disk, and adjusting mechanism, whereby the clistance between the disk and the scraper can be varied.

7.-The combination, sub tantially as hereinbefore set forth, of a draft frame, a down-hanging support, a concavoconvex cutting-divk revolving in bearings therein, and a pendent scraper provided with a cutting-edge in the rear to shave clogging matter from the disk.

8. - The combination, substantially as hereinbefore set forth, of a draft-frame, down-hanging support, and axle mounted thereon, a concavo. convex cutting disk movable laterally on the axle, and clamping nuts working on screw. threads on each side of the clisk to lock it in its adjusted position.

9.-The combination, substantially as hereinbefore set forth, of a draft-bar, a cross.lar, a cutting-disk, a support therefor, a scraper supported by one end only, and mechan- ism wherchy the disk and scraner may be simultaneously adjusted relatively to the line of draft.

No. 9,169.-MIUSES JU)INSUN, LOCKRORT, N. Y. assignor, by mesne assignments, to CHARLES LA Doll.-Rotary Cultizators.—93,307, dated August 3, 1569.-Reissue No, 8,222, dated May 7, 1878. -Reissued ipril 20, ISSo.-[Filed . Virember I I, 1S79.]

Claim.-1.-The combination, substantially as hereinlefore set forth, of a main frame, a draft-har, cutting-lisks mounted on the frame at an angle with the line of draft and supporting the frame above the ground, mechanism for adusting the angle of the disks, and a detent for locking the aljusting mechanism and the disks in their adjusted positi. $n$.

2.-The combination, substantially as hereinbefore set forth, of a main frame, a draft-bar, cutting-disks arranged on opponite sides of the draft-bar at an angle with the line of draft and supporting the frame, mechanism for varying the angle of the disks, and a detent for locking said machanism ani the disks in their adjusted position.

3.-The combination, substantially as hereinbefore set forth, of main frame, a słotted draft-lar connected therewith, cutting-disks, an adjusting-bar passing endwise through the slot in the draft-bar, and a pawl or dog, whereby the angle of the disk; may be varied and held relatively to the line of draft.

4.-The combination, substantially as hereinbefore set forth, of a draft-bar, a cross bar, cutting-disks arranged on opposite sides of the draft bar and sumporting the frame ahove the ground, a perforated har for varying the angle of the clisks, and a dog which enters the perforations in the bar for holding the disks at the angle to wlich they are set.

5.-A revolving concavo-convex disk-cutter, constructed, substantially as herein-before set forth, with a continuous unobstructed rim or cutting edge connected with its hub by spores.

6.-In a cultivator or other earth-turning implement, a revolving continuous unobstructed cutting rim or edge connected with its axle or hub by means of spokes.

No. 95,960.- IVILLIAM B. WEST, UTICA, Wis.Plouts/ls.-October $19, \mathbf{1} 869$.

Claim. - The combination, with a plough, of the antifriction-rollers F, shaped and arranged substantially as specified.

No, 96,007.- IIOSES JOHNSO)N, THREE RIVERS, Mich.-Pofuto-Diggers and Cultivaters-Oitober 19, 1869 . Claim, - I. - The concave wheels $\mathrm{K}$, with their hooks ir, staples $\mathrm{S}$, and scrapers $z$, screws $\mathrm{C}$, and nuts $n$, when constructed and arranged to operate substantially as specified. 2.-The shields $\mathrm{Y}$, in combination with the wheels $\mathrm{K}$ and beam $\mathrm{A}$.

3.- The potato-digger herein described, having adjustable concave wheels $K$, plongh $H$, staples $S$, shield $Y$, and caster $\mathrm{P}$, constructed and arranged to operate substantially as specified.

No. 97,680.- FREDERICK NISHIVITZ, BROOKLYN, N. Y-Harrozi-Cultivators.-December 7, IS6o.

Claim.- $t$ - The combination, in a harrow-cultivator, of a revolving disk, with a hollow boss, closed at its inner end, substantially as and for the purposes set forth.

2.-The combination, in a harrow-cultivator, of revolving disks, independently adjustable, rełatively to the line of draught, sulsstantially as set forth.

3.- The combination, with a harrow-cultivator frame, of a stud-1xle, a thimble, and a clamping-bolt, substantially as set forth.

4.- The combination, with a harrow-cultivator frame, of the recessed thimble, the clamping-bolt, and the stud-axle, as set forth, whereby the disk is carried at an angle, both to the line of draught and to the horizon.

5.-The combination, in a harrow-cultivator frame, of a revolving disk with a scraper, which keeps the disk on its axle, substantially as set forth.

6.- The combination, in a harrow-cultivator, of a loose disk, an adjustable axle, and an adjustable scraper, substantially as set forth.

7.- The combination, in a harrow-cultivator, of revolv. ing disks, arranged in two series or gangs, adjustable toward or from each other, subtantially as set forth. 
8. - The combination, in a harrow-cultivator, of an adju-table triangular frame, a leading disk, at the apex of the triangle, and a series of following disks, on each side of the triangle, substantially as set forth.

9. - The combination, in a harrow-cultivator, of an adjustable triangular frame, two series of revolving disks, and a seat for the driver, sulsstantially as set forth.

10.- The combination, in a harrow-cultivator frame, of a long arm, a short at m, pivoted to the long arm, and the cross-pieces, admitting of the adjustment relatively to the line of draught, substantially as set forth.

No, 98,017.-ALBERT BONDELI, PHILAIFLPHIA, Mo.-Ploushing Madhines.-December 21, 1860.

Claim.-1.- The spade-wheels A $\sigma^{\prime}$, one or more, constructed substantially as herein shown and described, and set at an angle with the vertical line, and with the line of draught, substantially as and for the purpose set forth.

2,- The combination of the circular revolving cutters $D$ with the spade-wheels $A a^{\prime}$ and frame C, substantially as herein shown and described, and for the purpone set forth. 3.-The combination of the adjustable caster-wheel E F $\mathrm{G}$ and adjustable hinged or jointed tongue $\mathrm{H}$, with the frame $C$, circular revolving cutters $\mathrm{D}$, and spade-wheels $\mathrm{A} a^{\prime}$. substantially as herein shown and described, and for the purpose set forth

4.-Arljustably connecting the truck-wheels I with the frame $\mathrm{C}$, to which the spade-wheels $\mathrm{A} a^{3}$ and the circular revolving cutters $\mathrm{D}$ are attached by the pivoted arms $\mathrm{I}$ and guide-slides $\mathbf{K}$, or equivalent devices, substantially as herein shown and described, and for the purposes set forth.

5.-The combination of the levers L, or equivalent devices, with the arms J, to which the axles of the truckwheels I are attached, and with the frame C, to which the spade-wheels $A a^{\prime}$ and circular revolving cutters $D$ are attached, substantially as herein shown and lescribet, and for the purposes set forth.

No. $9 \$, 120,-R a n s o m$ E. Strut, Galesburgh, $\mathrm{Mich}$ - Ploushs.-December 2I, $1 \mathrm{~S} 69$.

Claim.-1.- The slotted platform $a$, provided with a curved groove on its upper side, substantially as and for the purposes herein set forth.

2.-The box $b$ and cap $d$, con-tructed as described, and made adjustable upon the platform $a$, substantially in the manner and for the purposes herein set forth.

3.-The disk E, provided with shaft $c$ and rim $c$, substantially as and for the purposes herein set forth.

4.-The combination and arrangement of the plough. beam $\mathrm{A}$, landside $\mathrm{l}$, handles $\mathrm{C} \mathrm{C}$, braces $\mathrm{D} \mathrm{D}$, platform $a$, box $b$, wheel mould-board $E$, and scraper $f$, all constructed as described, and operating substantially in the manner and for the purposes herein set forth.

No. 98,647.-A. L. P. VAlRIN, Ripi.ey, Miss.- Itheded Harrowos.- - Fanuar' 4, 1870.

Claim.- In combination with the frame A, the disks $B$, arranged to rotate on the axle $\mathrm{B}$, bent at it centre, all constructed as shown and clescribed.

No. IO1,256.-JOSEPH S. GOHFREV, LesLiE, Micil., assignor to himself and SEARS M. LOVERIDGE, PIT TSBURG; I'A. - Ploushs. - Warch 29, 1870

Claim.-1.- In a plough or cultivator, a horizontal flange, $x^{\prime}$, to which to attach the box-plate of a revolving mould. board, substantially as described.

2. - Making in the flange or box-plate two or more slots, such that, forming a point at or near the forward edge of the revolving mould-hoards as a centre, such mould-boards can be adjusted to any desired angle or pitch, substantially as described.

3.-In combination with such mould-board and box-plate, a sand-tight box, as a bearing for the mould-board shaft, substantially as described.

4.-In combination with a revolving mould-board, a scraper $g$ attached to the box-plate, so as to be adjustable with it, substantially as described.

No. 101,522.-JOHN SCHROEFFEL and WILLIAM DELL, AlleghLNy City, PA.-Harrozes and Earth-Cut. ters.-April 5, 1870 .

Claim.-One or more series of cutting-wheels $d$, each series being mounted on a shaft in a frame, in combination with a rocking harrow, $h$, substantially as described.
No. IOI,540.-AUGUSTIN I. TAVEAL, CHAPTICO,

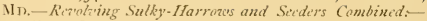
April 5,1870

Claim.-The construction and arrangement of the cylindrical harrow M, sockets $h$, teeth $g$, braces $r$, and socketrings $w$, constructed and operating as and for the purpose herein set forth and described.

No. 105,446,-JOSEPH S. GODFREY, LESLIE, MicH., assignor to himself and SEARS M. LOVERIDGE, PITTSBURG, PA.-Plouglis.- Fuly 19, 1870.

Claim.-The arrangement, substantially as described, of a concave-faced revolving disk mould-board, in connection with a plongh, whereby it shall be caused to rotate by action of the monld from the furrow, without coming in contact with the bottom of the furrow, and without the necessary use of other appliances to impart to it a rotary motion.

No. 105,460.-NOSES JOHNSON, ThreE Rivers, Mich.-Cultinators.-July 19, 1870.

Claim.-The cultivator herein described, having crossbar $\mathrm{C}$, staples $\mathrm{D}$, disk E, scrapers $a$ and $\mathrm{H}$, brace $\mathrm{K}$, drawbar $\mathrm{N}$, and auxiliary handle $\mathrm{P}$, when constructed and arranged to operate as and for the purposes specified, as an improvement upon my patent of August 3, 1860.

No, 106, 1 18.-ERA.TUS T. BUSSELL, INDIANAPOLIS, IND., assignor to himself and JOHN N. GREENE, same place, assignors for one-third their right to J. M. TIL.FORD, same place. - Cultizators or Harronis.-August 9, 1870.

Claim.-A cultivator or harrow, composed of the wavesided frame A, disks B B and C, the toggle $\mathrm{E}$, and handle $\mathrm{P}$, in connection with ratchet-bar $\mathrm{R}$, arranged, combined, and co-operating in the manner described, and for the purposes set forth.

No. 107,287 . JOHN W. PENCE, Cı.АYToN, OHјо.Earth-Pulverizers.-September 13, 1870.

Claim.-The arrangement of the boxes $G$, screw-rols $H$, and nuts 1 , with the shafts $\mathrm{E}$, cutters $\mathrm{F}$, and frame $\mathrm{A} C$, subtantially as shown and lescribed.

No. 107,777 -LOUIS HOMRIGHOUSE, BALTIMORE, Oilio.-Cultin'ators.-Sipt'mber 27, 1870.

Claim.-An enlarged bearing-wheel, $\mathrm{H}$, combined with the draft-beam A of a cultivator-plough, about midway of its length, to carry and support the machine, all substantially as herein described.

No. I08,712.- WILLIAM LESLIE, FORT MADISON, IowA.-Combined Stalk and Heid-Cuthrs and Land-RolLers.-Octobir 25, 1870 .-Ante-dated October 15, 1870.

Claim.-1.- The frame, formed of the side-beams A A, centre-beam $A^{\prime}$, bars $C$, cross-bars $B$, and platform $D$, all constructed and arranged substantially as shown and described.

2.-The runners I I and I', connected by the cross-bar J, in combination with the screw-rods $K K$, substantially as and for the purposes herein set forth.

3.- The arrangement with the frame constructed as herein described, and provided with the runners 1 I and I', bar $\mathrm{I}$, and screw-rods $\mathrm{K} \mathrm{K}$, rod $\mathrm{O}$ and coulters $\mathrm{M} \mathrm{M}$, all constructed to operate substantially as set forth.

4.- The arrangement, upon the rear part of the frame as constructed, of the two shafts $\mathrm{E}$ E, provided with circular cutters $G \mathrm{G}$, and box $H$, said shafts being removable, as set forth.

No. 112,333.-JOSEPH S. GODFREY, Leslie, Mich., assignor to himself and SEARS M. LOVERIDGE, PITTSBURG P'A.-Attachment for Revolving Mould-Boards for Ploughs.-March 7, 1871 .

Claim.- $\mathbf{t}$.- The arrangement of the standard $d$, shank $e^{\prime}$, and eye $c$ with the box $n$ and mould-board $m$, with suitable connections to the plough-beam, substantially as set forth.

2.- The arrangement of the hollow standard $d$ to admit the shank $c^{\prime}$, with eye $a$, shank $a^{\prime}$, and plough-beam $b$, substantially as described.

No, 113,760 ,-JOSEPH S. GODFREY, ROCHESTER, assignor to himself and SEARS M. LOVERIDGE, PITT:BURG, PA.-Revoling Mould-Boards for Ploughs.-April 18,1871 .

Claim.-A revolving, flat, plain-faced, circular disk mouldboard, arranged in connection with and with reference to the lower level of the point and shin-piece, substantially as described. 


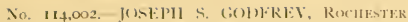

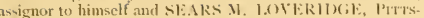

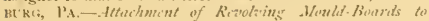
Plousths.-April $25,1571$.

Claim.-1. - I circular rotating scraper, combined with a revolving mould-board, substantially as described.

2.- I bent spinclle, capable of hoth lateral and rotary adjustment, as a earrier for a revolving mould-board, and in combination therewith, substantially as described.

3.-The saclule-piece, 5, in combination with the slotted post $d^{\prime}$ and fastening-eye ', as a means of adjusting vertically the spindle $a$ and mould-hoard $m$, sulstantially as described.

No. 114,088 . -SHERIIAN E. ANTHONY, STILI, WATER, N. Y.--Potato Disterss.-April 25, 1 S71.

Claim -1.-The combination of the tinet disk $t u$, shaft $h$, journal-bearings $i k$, bevel-pinion $n$, bevel-gear $\mathrm{E}$, axle $B$, and frame i $f$, when all said parts are arranged as shown and described.

2.-The disk $t$, provided with the teeth $u$, and combined with the shaft $h$ and frame $F$ in the $m$ inner described, and for the purpose of emabling the shaft $h$ to be set at angle with the side pieces of the frame.

No $11+707$-JOSEPH F. POND, C1.EVELAND, OU1, - Reroling-Disk-Harronos.-May 9, 1871.

Claim.-1.-The semicircular bar B, to which thills or pole may be att uched, in combination with the disk-bars $A$ $\mathrm{A}$ and bar $\mathrm{C}$, or its equivalent, to admit of the described atjustment, substantially as set forth.

2.-The disk $\mathrm{V}$, in combination with hub $\mathrm{P}$, box $\mathrm{R}$, and axle $\mathrm{U}$, when placed or running olliquely to the line of motion.

3.- In combination with disk $\mathrm{V}$, hub $\mathrm{P}$, hox R, axle $\mathrm{C}$, the vielding washer $c$, friction washer $b$, and p.cking, sul stantially as and for the purpose set forth.

No. I15,057--BENA1AH C. HOYT, ForT ATKINion,

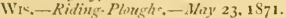

Claim. - 1, - The sinule pivoted lever D, slotted disk A, and wheel $G$, all combined as described, for the purpose specified.

2.-The bracket $\mathrm{K}$, hub $\mathrm{H}$, and shaft $\mathrm{B}$, all combined as described, for the purpose specified.

No. 116,745 - JOSIAH POOL. Rio Vista, CaL Rotary Sod-Cutters.-Fuly. 4, 1871 .

Claim.- In a cod.c tter provided with a series of rotating disks, the series of beams $\mathrm{A}$ having curved liearing surface, as and for the purpose described.

No. 117,485 - ADOLPHE TOURNIER, BARNYILLF, N. Y.-Garden-Tools for trimmins Sod.- $F_{u l y} 25,187 \mathrm{I}$.

Claim-The gardener's tool, compused of frame A with box $\mathrm{H}$ attached, shait $\mathrm{B}$ with cutter $\mathrm{F}$ and wirle-roller $\mathrm{O}$, an- 1 provided with the auxiliary rollers I I on arms $\mathrm{K} \mathrm{K}$, the whole to be used by hand for the purpose of trimminy the out -ide edges of sod, or of the lawn as spe. ified.

No. I18,749.-IOHN SCHLOSSER, PIoUA, ОНIO,Clod-Crushers.-September 5, I871.

Claim.-The combination and arrangement, in a clodcrusher, of the frame $\mathrm{A}$, tongue $\mathrm{B}$, hangers $\mathrm{C}$, cutters $\mathrm{E} \mathrm{E}^{\prime}$ shafts or axles $D^{\prime} D^{\prime}$, and arms $b b$, all as herein shown and deccribed, for the purpone specified.

No. 118,758 . - ISAAC P. TICE, New Vork, N. V -Plougrhs.-Scpimber 5, 1871. Antedated August 21, 1871

Claim,-1.-A series of parallel disks, $b$, having a ditance of from three to twelve inches from each other and projecting from the face of the roller about the same distance, more or less according to the nature of the soil and the work to be done, as and for the purpose specified.

2.-The scrapers D, when made to fit the yaces between the flanges $b$, and held in contact with the face of the roller by a spring, $d$, or equivalent, as specified,

3.-Theadjustability of the scraper D from $c$ to $c^{\prime}$, as and for the purpose specified.

No. I 1 8,951,-FRANK A. LEONHARD, Columbia, TENv.-Cotton-Choppers, Scrapers and Cultivators.-Siptember 12,1871 .

Claim.-1.-The arrangement of the rollers I and scraper $J$, in connection with the arms $F$, whereloy they are adapt ed to oscillate, as shown and described.

2.- The arrangement of the iwo sets of rollers I ani scraper J and the vilorating chopper $S$ in connection with the pivoted frame E, aw wown and described.

Ni). 120,446 . JAMES LEFERER \& GEORGE W. SIILLTS, CAMHRIDGE CITY, IND,- - Earth-Pulatritrs and Ilarrvats.-October 31, 187 1.-Antedated Octobir 21, 1871,

Claim.-1.-The two sets of star-wheels A B, having straight blades, with their broad ends spread out in planes at right angles to cach other, for the purpose specified.

2.-In combination with a set of star-wheel pulverizers, $A$, the rod $H$ and lever $I$, arranged on the frame, as and for the purpose specified.

No. I2I,02I, COLIN THARP AND (IEORGE P.

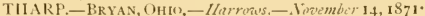

Claim.- I. - The teeth $\mathrm{D}^{1} \mathrm{D}^{2} \mathrm{D}^{2}$ attached to hars $\mathrm{D} \mathrm{D} \mathrm{D}$, in combination with the rocking-bars $\mathbf{E} \mathrm{E}^{\prime}$, connected together by suitable means, and operated by the mechanism $\mathrm{F}^{\prime}$, as and for the purpose described.

2.- The improved harrow herein described and shown, consisting of the platform A $a a$, knives $G^{\prime} G^{\prime}$, trucks $i i$, and the mechanism $\mathrm{E} \mathrm{E}^{\prime} \mathrm{F}^{\prime} \mathrm{F}^{\prime}$ for operating the bars D D D, all in combination sulmtantially as shown and described.

No, 124,585.-MOSES JOHNSON, THREE RIVERS, Mich.-Potato-Diggers.-Wark I?, IS72.

Claim.-I. - In a notato-dinger the combination of a plough with the pivoted converging lateral bars $\mathrm{E}$, and the inclined sejarating wheels $\mathrm{G}$ journaled therein, substantially as specified.

2.-The combination of the centre-heam A, plough C. lateral beam $\mathrm{E}$, draw-braces $\mathrm{D}$, rear arch $\mathrm{F}$, and inclined wheels $\mathrm{G}$, substantially as specified.

3.- The combination with the plough-heam $A$, of the lateral beams $\mathrm{E}$, and the oblique draw braces $\mathrm{D}$, pivoted at both ends, substantially as specified.

No, I25,681,-GEORGE F, HUTCHINSON, ClEvE. LAND, OH1O - Cultivators.-April 16,1872 .

Claim.-The pivoted plate E. having stots $i c$ and lugs $f f$, the plate $\mathrm{D}$, nuts and bolts $c c$, and casting $I \mathrm{I} i$, in combination wilh the tongue $\mathrm{G}$ and harrow frame $\mathrm{A} \mathrm{A} \mathrm{B} \mathrm{C}$, all substantially as herein described, for the purpose specified.

No. 127,677 .-ERASTUS T. BUSSELL, assignor to IVILIMIAII M. BUSSELI, INDIANAPOLIS, IND.-Disks for Asricultural Implements. - Funi 11, 1872.-Antedated Mar 25, 1872 .

Clin,-1.-The disk L, composed of the metallic hub $\mathrm{A}$ and the narrow metallic continuous rim $\mathrm{B}$, secured to the end of the light metallic spokes $\mathrm{C}$, at a lateral angle of from five to fifteen degrees to the line of the spokes $C$, and beveled from it: inner to its outer edge to form a cutting periphery, for the purpose hereinbefore set forth.

2.-The right-angled adjustable bracket D, having its horizontal face E serrated or roughened and provided with the stot $F$, and its perpendicular face $G$ provided with the axes 11 , in combinntion with a cultivator-disk having a cutting periphery, for the purpose hereinhefore set forth.

No, 128,588.-ERASTUS T. BUSSELL, assignor to WII.LIAM M. BUSSELI, INDIANAPOLIS, IND.-Ploushs. - $F_{11} / y^{\prime} 2,1872$. - Antedited $f_{u n e} 15,1872$.

Cluim, - 1, - A revolving disk, A, compesed of the metallic zone $\mathrm{C}$, connected with a huh by radial spokes, and prom vided with a series of ribs or flanges, $B$. each of which extend across the inner face of the zone $\mathrm{C}$ in the direction of a cycloidal curve, for the purpose hereinbefore set forth.

2.- The rudder-wheel $\mathrm{J}$ provided with the vertical flange $\mathrm{K}$ and supported in bearinas in the adjustable bifurcated bracket L, the traction-arm $\mathrm{MI}$, the vil rating lateral pressure- $r \mathrm{rm} \mathrm{N}$, and the tiller $\mathrm{O}$ provided with the rods $\mathrm{Q}$, all arranged relatively one to the other, in combination w th the plough-frame, as described.

No, 129,712-ERASTUS T, BUSSELL, INDLANAFOL.IS, IND.-Cultizators.-July' 23, 1872.-Antedated June 15,1872 .

Chim.-1,-A plain disk, A, and either a concavo-convex disk, $\mathrm{C}^{\prime}$ or a disk, $\mathrm{C}$, connected by a bar, $\mathrm{B}$, provided with a stud, D, having sockets $h i j$, substantially as and for the purpose hereinbefore specified.

2.- The handle $\mathrm{F}$, having shanks $\mathrm{E}$ and $\mathrm{G}$ and $\mathrm{a}$ sineguard, $N$, in combination with a plain disk, $\Lambda$, and either a concayo-convex disk, $\mathrm{C}^{\prime}$, or a disk $\mathrm{C}$, commected by a har, 
b, has ang \& -14 I, D, provided with richet if $i j$, an and for the purpose hereinlefore specified.

N., $130,125,-$ BENJAMIN F. GRFEN, SYRACUSE, N. V.-Putnti-Dimers- Iuyust 6, IS72.

Diggers constructed of circular forks, mounted on sleds or frame-work; the circtilar fork suspended obliquely to the line of motion, and rolate when brought in contact with the earth.

Claim.-The rotary forks, composed of a center piece and radial tines, in combination with a sled or frame and adjusting levers or shafts, arranget' to move the forks both laterally and vertically, all operating substantially as herein described.

No. 132,364.-MOSES IOHNSON, THREE RIVERS, Micu. - Asignor of one-half his share to EDIVIN LANTY, same place.-Potato-Dirgers.-Octolit 22, 1872.

The machine is in two sections, the forward wider than the rear one. The forward sharesturn a furrow outwardly from each side of the row into separiting-wheek, anil the rear portion, having a double share, turns the bills of potatoes bo:h way into like separating-wheels, which separate the pot toes from the snil.

Clain. - The putatc-ligger, constructed in two separate sections, $\mathrm{A} \mathrm{A}^{\prime}$, the former provided with the single-winged ploughs 1) and sifting wheels C, and latter provided with the double-winged ploug $h \mathrm{D}^{\prime}$ and siting-wheels $\mathrm{C}^{\prime}$, substantially as specified.

No. 137,026, - SII.AS G. RANDAI.L, ProvidFNCE, R. 1-Assignor to AMELIA A. RANDNLL, same place. -Secding Machine -MLay I8, 1873 .

Claim.-1.-The combination of the seed-box and the seed-controlling apparatu; with the axle-bars B and $\mathrm{B}^{\prime}$, each of which is providet with the series of plate-wheels and is pivoted to the $t$ up plate, substantially as described, by means of which the machine may be adjusted so as to cover the seed as it dropied with much or little earth, as may be required.

2.-In combination with a seeding-box and distrituting device operated by axles which are adjustable at varuu angles the universal-joint coupling link $F$, as and for the pur. poses specified.

No. 6,053.-SILAS G, R.INDALL, PROTIDENCE, R, I., Assignor to A. A. RAND.Al.1, same place-Sertins Hachines-137,026, May, IS, is73. Reissued Siftemtict 15, 1874.-[Filed Hay o, 1874.]

Claim.-1.- The combination with the main frame, of the independent disk.fr.mes, artanged in different vertical plane relatively to each other, and with their aljacent in. ner ends oretlapping, and lyong one behind the other, substantially as hereinbefore set for $h$.

2.- The combination of the main frome, the $1 \mathrm{w} t$ ) disk. frames connected therewith in different vertical planes, with their adjacent ends lying one behind the other, a series of disks arranget in $2 w 0$ independent sets, and an axle mount. ul on each disk-framc, an which axle ench disk of the set is I w - ely mounted, sub-t ntially as hereinbefore set forth.

3-The combinution substantially as set forth, of a uang of disks, a disk-frame in which they are mounted, and a main-frame, near the outer end of which the outer end of the disk-frame is pivoted, while its inner en i is connected with the central portion of the main frame.

4.-The combination substantially as hereinbefore set forth, of the min frame, the adjustable tongue and the dirk. frames, adjustable lon itudinally, as well as angularly, relatively to each other at their inner ends.

5.-The combination of the seed-controlling apparatus with one of the disk-gangs by mean; of a universal-joint comection, wherehy the seeling mechanism is driven by the disk-wheels.

6.- The combination of the disk-shaft, clisks mounted thereon, thimble, i.nterposed b-tween the disks and clampnuts, these members being constructed and operating, substanti 11 ly as set forth to hold the disks securely, and yet admit of their being readily removed and replaced.

7.- The combination of the disks and the forked piloted scrapers overlapping the disks.

No, I40,IS2,-FRANK BRAMER, LITHLE FALL, N. l.-Cimbined thicel-Harmas and Sirders. - Fone 2.4.

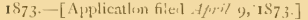

Concave disk-harrows have their adjustable frame; mado stelf-bracing to the main frame that carries the seed-box. The sced-slide is operated by a crank on one of the disks,

Claim.-1.--The main frame composed of the longiturl. inal hars $A$ and oblique transverse bars $\lambda^{1}$, in combintion with the adjustable gang-bars $\mathrm{C} \mathrm{C}^{\prime}$, arranged to brace the frame, substantially as and for the purpose set forth.

2.- The seed-distributer or agitatis of a combined seed. ing machine and wheel-harrow, connected with and operated by a crank on the shaft of one of the wheel-gangs through an adjustable pitman arranged at right angles to said shaft, substantially as and for the purposes set forth.

3.- The construction of the pitman-connection, of the seet-distributer and harrow-wheel shaft, and of the parts $11^{1} I^{2}$, to permit the adjuttment of its length and angle, as described.

4.- The spools or thimbles L provided with notched or perforated hubs, or hosses, or pins for securing the harrow. wheels and causing their uniform rotation, sulstantially as descrilied.

No. 144,433.-JEROMIE IHLANCHARD EAST SASINAW, MICH., assignor of one-half his right to $\mathrm{H}$. WAL

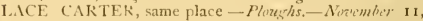
I873.- [ Application filed April 5, $18_{73}$.]

Clain.--The two sets of skeleton-wheels A B, formin the entire mold-board, and used in connection with the bar $D$, all construct ed and arranged as shown, and for the purpose specified.

No, 146,224.-EIJW1N BAYLISS, MAssILLON, (HI1n. -Whel-Harrows.-Januny 6,1874 . [Application filed Siplimbir 17, I873.]

The divk-gangs have both a horizontal and vertical movement, chains or stops limiting the vertical motion The disks are made adju-tably axially to counteract any imper. fection in shape and produce a true rotation.

Claim.-1. - The adjustable wheel or disk gangs D, united to the transverse frame bar A by a vertical pivot, and also ly a horizontal p vot, whereby the angle of said wheelgangs can be adjusted as descil ed, while at the same time they are free to conform to the uneven surface of the ground, independently of the main frame and of each other. all combined subutantially as described.

2.- The combination of the wheel-gings 1 , connected with the main frame $\mathrm{A}$ by vertical pivot, as described, with the tongue $\mathrm{C}$ and adjustahle draft-rods $\mathrm{F}$, substantially as and for the purpose set forth.

3. - The ad ustable whecl-gangs D, united to the framehar by a horizontal pivot, as described, in combin tion with chains a r stops for limiting the vibrations of said gangs on said horizontal pivot, as vet forth.

4.-The harrow disk $\mathrm{H}$, provided with the polygonal sockels, or an equivalent device, for permitting their adjustment, in combination with the ferrule $\mathbb{K}$, constructed substantially an and for the purpose described.

No. S, 147.-L1)WIN B.IVI.ISS, MAssil.uN, ()HIO.Which-llariones, -146,224, Jamuary 6, I87\%--Re-issned April 2, 1878.-[Filed Him/2 I8, iS78.]

Claim.-1.-The combination, substantially as hereinbefore set forth, of a main frame (or main transverse lar) and wheel or disk gang connected there-with by interposed swiveling hinge-connections, which pernit the gangs to vibrate frecly relatively to the main frume to conform to $\mathrm{um}$ even surfaces over which they piss.

2.-The combination, subiantially as hereinbefore set forth, of a $m$ in frume, (or main transverse bar,) a tongue connected therewith, wheel or disk gangs, unted with the main frame by interpored swiveling hinge-connections. and an adjustable connection between the tongne and wheel or disk gangs, whicreby the angle of the gangs relatively to the line of dr.ift may be vared without interfering with their vibrations on their hinge-connections.

3.- The contsination, sulstantially as hereinbefore set forth, of a main frame (or main transverse bar,) wheel or clisk gangs connected with the main frame by interposed swiveling hinge-connections, and chains or stops, for limiting the vibration of the gangs relatively to the main frame. 4.-The combination, substantially an hereinbefore set forth, of a main frume, (or main transverse bar, a tongue connected therewith, a driver' seat, wheel or disk gings 
connected with the main frame by interposed swiveling hinge-connections, and adjustable connections between the gangs and tongne, to adjust the angles of the disks relative ly to the line of draft, and to limit their vibrations relatively to the main frame.

5.-Harruw-disks provided with polygonal sockets, or an equivalent adjusting device, in combination with the spacing ferrule constructed with projections interlocking with the disk-sockets, substantially as shown, and for the purposes described.

6.-The combination, substantially as hereinbefore set forth, of gang-bars, hangers having bearings enlarged at one end to constitute lubricating-chambers, friction-washers inclosed in saitl lulsicating-chambers, and disk-gang spindles inclined to the line of draft, whereby wear of the sjindles is prevented and Jubrication insured.

No. 146,908.- IIOSES JOIINAON. THRFE. RIVERS, Mich,-Potato Diggers.- Yamuary 27, $1 S_{74}$. [Filed fanwary 10, 1874 .

The beam is made of iron, the rear part forming nearly three-quarters of a circle, with a lug fir securing the handles. The circle terminates in a straight arm projecting for ward and downward, at an angle of about twenty degrees, more or less, and to which the digging-share is attached. The share is pointed, elevated in the longitudinal centre line, and each wing provided with a separating-wheel with curved arms, and which are rotated by frictional contact with the ground.

Claim.-The potato-digger consisting of the draft-beam having the extensions $b$ and $d$, the angular ridged shovel $\mathrm{D}$, having the corner notches $\mathrm{E}$, the journal-arms $(i$, and the inclined sifting-wheels having the per pheral finger: $z$, all arranged substantially as suecified.

No. 151,192,-A. MERRITT ASAY and JOHN W. WOOD, PHILADEIPHA, PA, - Corn-Plentes and Fitilizer-Distributers.-May' 26, 1874 . [Filed December 30, I 873 .]

Claim.- The combination of the disk-wheels $c c$, adjustably mounted and arranged in their frames, as shown and described, the piroted bar () , and the furrow-opening plough $\mathrm{P}$, mounted just in advance of where the corn and fertilizer are drolped, as co-operating devices for placing the plantings projerly under the surface, substantially is set forth.

No. 153,311-ALEXANDER JACKSON and RICHARD IRWIN, Murtonsville, IND,-Liz'lirs, Pulterizers and Corn-Planters.-September 22, $1 \mathrm{~S}_{74}$. [Filed July $3,1874$.

Claim.-1.-The combination of leveling-beams $a$ a $a$ a $a$, arranged, as shown, to rest upon the ground, axles or shafts $b b$, and a series of cutting-wheels $c c$, sulsstantially as and for the purpose described.

2.- The combination of leveler and pulverizer $\mathrm{A}$, consisting of beams $a$ a $a a b$, shafts $b b$, and cutting-wheels $c c$, with the corn-planter E, flexibly attached thereto, substantially as shown and described.

No. 155,420.-ASA CANTEBURY, Grbson City, II.L. - Seed and Grain Drills.-September 29, 1874. [Filed $\left.F_{u l y}, 3,1874\right]$

Claim,- The combination, in a seeder, with sharp, deeply furrowing-wheels B, curved sponts D, to drill the grain, reversely-curved spouts D, to drill the grass-seed on the nearly-filled furrow, and small blunt wheels $B^{\prime}$ that press the pulverized soil to and shallowly over the grassseed, all constructed and arranged substantially as and for the purpose specified.

No. 155,975.-R. B. REDFIELD, HARRISVILI.E, OHIO. -Clod-Crushers.-Octoher 13, 1874. [Filed August 28, 1874.]

A gang of cutting-disks in front; several series of transverse oblique crushing bars; cutters fixed to the transverse bars.

Claim.-The combination of the revolving cutters I, st?tionary cutters F, and timbers A B C, arranged obliquely in relation to each other, in the manner substantially as described, and for the purpose specified.

No. 160,129-ANGELINE UNDER IVOOD, CARROLL Tox, ILI.-Land-Pulerizers.-February 23 , $1875 .-$ [Filed November 30,1874 .]
The pulverizing devices consist of a series of disks placed upon a shaft near togcther, and having cleaning-fingers between them. Two of these are mounted in rectangular frames, and placed end to end, each being journaled upon the end of a bent rod, which constitutes the hounds of the tongue.

Claim.-1.-In a land-pulverizing machine, the combination, with the pivoted oscillating frames $\Lambda \mathrm{A}$, having friction-rollers $\mathrm{H}$, of the bar $\mathrm{G}$, having bearing-plates $g^{\prime}$, as and for the purpose specified.

2.-The hent or V-shaped rods $J$, connected to the pole $\mathrm{I}$, and bar. $\mathbf{K}$ to form hounds or braces, and extended rearwardly through the castings I and front bar of the oscillating frames $A$ to form the pivots or journals thereof, as shown and described.

No. 161,060.-S. G. RANDALL, Greenf. N. Y.-Disk IIarrow-Cultivators,-March 23, 1875. [Filed February 26, 1875 .]

Two revolving shafts are secured to the under side of a frame, in a position oblique to the line of draft. Upon these shafts are secured a series of disks, with their faces looking inward and forward. A space is left hetween the inner disks of each series, and between and forward of these is placed a pair of disks, the faces of which look forward and outward. The soil is thrown ontward by the two inner disks, and inward by the others of the series.

Claim.-In a disk-cultivator, the combination, substantially as hereinbefore set forth, of a frame, two series of revolving disks arranged dingonally to the line of draft, with their axes inclined thereto, and leading disks interposed hetween the two series, and arranged to throw the earth in the opposite direction therefrom.

No, 163,527.-SILAS G. RANDALL, GREeNE, N. Y. -Disk-Harrows. - May iS, I875. [Filed March 17, I 875.]

The concave disks for each series are mounted upon a hollow shaft, which is hung upon short journals projecting inward from the hangers. A small rod with a head on one end, and a screw-nut or pin on the other, passes through both journals and the hollow shaft, to prevent the hangers from spreading.

Claim.- The combination of the hangers, having the lateral journals $a$, with the tuhular axle mounted on said journals, and the shaft $G$, passing through the axle and connecting the hangers together, substantially as and for the purpose described.

No. 165,108.-JOHN MASTERN, West AlexAndRIA, Онг.-Harrotes.-Junc 29, I S75. [Filed April 17, 1 S75.]

Claim.-I.-In combination with the outer coulters I and $I$ of each section, the cutters $\mathrm{OO}$, adapted to be secured at their ends to said coulters, and having their cutting-edges upon a line with the peripheries of the same, substantially as and for the purpose shown.

2.- In combination with the main frame of the harrow, the check row markers $\mathrm{N}$ and $\mathrm{N}$, pivoted to or upon the rear side of said frame, and capable of being brought into or removed from contact with the ground, substantantially as and for the purpose set forth.

No. 169,134.-SAMLEL BEAN, Clinton Valley, OH10.-Con-Stalk Cutters.-October 26, 1875. [Filed Wlarch $27,1875$.

Claim.-In a corn-stalk cutter, the series of serrated and flanged sleeves $\mathrm{J}$, and the flanged hubs $\mathrm{H}$, applied on each end of the axle $\mathrm{G}$, in combination with circular cutters $a$, secured substantially as described, and for the purpose set forth

No. 169,499--JOHN K. UNDERWOOD, SAUK CENTRE, MiNn.-Rotary Gang-Ploughs.-Ninember 2, 1875. [Filed July 31, I 875.]

Claim.-1.-The frame A C, having two sets of axles, D R, hook-bolts $\mathrm{U}$, standard $\mathrm{M}$, and keepers $\mathrm{K}$, adapted to receive rotary ploughs or cultivators, in the manner described.

2.- The combination, with rotary ploughs $\mathrm{H}$, of beams $\mathrm{I}$, pivoted upon the frame at $\mathrm{J}$, and swinging in keepers $\mathrm{K}$, the forked lever $\mathrm{L}$, the bars $\mathrm{O}$, standard $\mathrm{N}$, and pin $\mathrm{N}$, as and for the purpose specified. 
No. 7,865.-J. K. UNDERWOOD, ANOKA, MINN.Rotary Gang-Ploushs.-160,499, November 2, 1875.-Reissued August 28, 1877.-[Filed July 24, 1877.]

A pair of truck-wheels support, in an adjustable manner, a gang of disk-wheel ploughs having straight, smooth, flaring rims, standing at an angle of about forty-five degrees from a vertical plane. The rims are held by arms radiating obliquely from a central hub. A modification is shown and described in which the disks are adjustably mounted in pairs facing inward, thus making a straddle row cultivator.

Claim.-1.-In a rotary ploughing-machine, carried on truck-wheels, the rotary ploughing-wheels $\mathrm{H} \mathrm{H}$, with flaring rims, having sharp, smooth, and perfectly circular peripheries, mounted on truck-wheels, and working in planes diagonal to the line of draft, substantially as described.

2.-The rotary ploughing-wheels OO P P, arranged in pairs upon a frame mounted upon truck-wheels $\mathrm{B} \mathrm{B}$, and the wheels in each pair liverging from each other from the ground upward, substantially as shown and described.

3.- The combination of the frame A, truck-wheels B B, hook-bolts $\mathrm{U}$, lever $\mathrm{V}$, standard $\mathrm{M}$, and wheels OOPP, combined and arranged to operate substantially as described.

4.- The combination of the rotary ploughing-wheels $H$ pivoted beams $I$, keepers $K$, lever $L$, and standard $M$, all mounted on truck-wheels B B, and combined and arranged to operate substantially as described.

5.-In combination with the truck-wheels B B, frame $A$, and ploughing-wheels $\mathrm{H} \mathrm{H}$, set diagonally to the line of draft, the caster wheel $F$, with its fiange $f$, all arranged to operate substantially as described.

6.-The combination of the frame A C, having two sets of axles, D Q, hook-bolts U, standarl M, and keepers $\mathrm{K}$, adapted to receive rotary ploughs or cultivators, in the manner described.

7.-The combination, with rotary ploughs $\mathrm{H}$, of beams I, pivoted upon the frame at $\mathrm{J}$, and swinging in keepers $\mathrm{K}$, the forked lever $\mathrm{L}$, bars 0 , standard $\mathrm{M}$, and pin $\mathrm{N}$, as and for the purpose specified.

No. 171,092.-F. BRAMER, LITTLE FALLS, N. Y.Whiel-Harrows. -Dicember 14, I875.-[Filed Oitober 6, I875.]

A series of disks placed in gangs upon two shafts, each gang facing in opposite directions to prevent side draft. A series of cleaners attached to a single bar for each gang, and arranged to operate simultaneously by a lever.

Claim.- In combination with a gang or series of rotating harrow-disks, the clearers or scrapers united to a reciprocating bar, adapting them to be operated simultaneonsly by means of a lever, substantially as and for the purpose set forth.

No.-8, 299.-FRANK BR.AMER, LITTLE FAL.L, N. Y - Wheel-Harroats. - i71,092, December It, IS75.-Reissued fune 25, 1878, - [Filed June 10, 1878 .]

Claim.-1.-The combination, substantially as hereinbefore set forth, of a series or gang of harrow-disks having concave faces or sides with a series of scrapers or clearers adapted to be vibrated or moved close to or in contact with said concave sides and removed therefrom while the machine is in motion.

2.-The combination, substantially as hereinbefore set forth, of a series of rotating concavo-convex harrow. dinks, a series of pivoted, rocking, or adjustable clearer, or scrapers, connected together, and a lever pivoted on the gang-frame, whereby the scraper may be caused simultaneously to approach or recede from the concave faces of the disks.

3.- In combination with a gang or series of rotating harrow-disks, the clearers or scrapers united to a reciprocating bar, adapting them to be operated simultaneously by means of a lever, substantially as and for the purposes set forth.

4.-The combination, substantially as hereinbefore set forth, of a draft frame, a gang or series of rotating harrowdisks connected therewith, a series of scrapers united to a bar mounted upon the gang-bar or disk-frame and adapted to vibrate in contact with or close to the sides of the disks, and a lever pivoted upon said gang-bar, extending to within reach of the driver while in his seat on the machine, whereby the scrapers may simultaneonsly be caused to clear the sides of the disks, and then removed therefrom when the clisks are free and clear, to prevent clogging by accumulation upon the scrapers.

No. 174.767.-FRANK BRAMER, LitTLE FALLS, N. Y., and $O$. W. BADGER, WHITNEY's POINT, N. Y.; said BADGER assignor to said BRAMER.-Wheel-Harrones.March 14, 1876. - [Filed February 4, 1876.

Upon each side of the tongue is hinged a triangular frame, the forwarl beam of which carries a gang of disk-teeth, whose axis of rotation is placed oblique to the line of draft. A seat for the operator is mounted upon a spring-bar, whose ends rest in stirrups that are supported in brackets rising from the rear beam of the triangular frame.

Claim.-1.-The wheel-gang frames or planks, hinged by their inner ends to the intermediate pole or tongue, or a rigid extension thereof, substantially as described.

2.- The gang-wheel frames, hinged to the intermediate pole or pole-frame, in combination with the seat-support extending transversely over said pole or frame, and connected with the gang-frames at points outside of the centres of their transverse length, for the purpose and substantially as described.

3.- The transverse seat-support or bar connected with the gang-frames by means of the swinging compensating links or stirrups, substantially as described.

4.-The combination, with the hinged wheel-gang frames of the swivelling supports E, stirrups $f$, and transverse seatsupport or bar $G$, arranged and operating substantially as described.

5.- The combination of the hinged gang-frames $A A^{1}$, intermediate pole or pole-frame B, swiveling standards E, swinging stirrups $f$, and seat spring or bar $G$, all arranged and operating as described.

No. S,oSo,-FRANK BRAMER, LitTLE Fills, and ORRIN W. BADGER, WHITNEY'S POINT, N. Y., said BAIOGER assignor to said BRAMER.- Wheel-Harrozos. -174,767, March 14, 1876.- Re-issned February 12, 1878.- [Filed Finuary' 25, 1878.]

Claim.-1. - Wheel-rangs hinged by their inner ends to an intermediate pole or tongue, or to an extension thereof, substantially as hercinbefore set foith, whereby they are enabled freely to conform to the surface over which they travel.

2.-The combination, substantially as hereinlefore sct forth, of independent wheel-gangs with an intermediate pole or pole-frame, to which they are hinged at two points, whereby they are braced against transverse strains, as well as allowed freely to conform to undulations of the surface over which they travel.

3.- The combination, substantially as hereinbefore set forth, of wheel-gangs, an intermediate pole or pole-frame, to which their inner ends are directly linged, and a transverse seat-support connected with the outer ends of the gang-frames, whereby the weight of the driver keeps the gangs down to their work without interfering with their vibrations on their hinges.

4.-A transverse seat-support connected with independently-hinged wheel-gangs by means of swinging compensating links or stirrups, sulistantially as hereinbefore set forth, whereby the vertical movements of the gangs are limited.

5.-The combination, substantially as hereinbefore set forth, of hinged wheel-gangs, swiveling socket-pieces mounted on the gang-frames, and a transverse seat-support pivoted to stirrups in the socket pieces, whereby both the vertical movements and angular adjustments of the wheel-gangs are compensated.

6.- The wheel-harrow hereinbefore described, consisting of the combination of wheel-gangs hinged to an intermediate pole or pole-frame, swiveling socket-pieces mounted on the gang pieces, planks, or frames, swinging stirrups pivoted in said socket-pieces, and a transverse seat-support pivoted to the stirrups, substantially as hereinhefore set forth.

No. 177,668.-JOHN K. UNDERWOOD, SAUK CENTRE, MiNN.-Rotary. Ploughs.-May 23, is76.--[Filed Warch I $3,1876$.

The shape and arrangement of the frame, the hanging, and means for elevating the disk-ploughs.

Claim.-1.-In combination, in a rotary g.ng-plough, the bent horizontal arm E, rigidly attached at its forward end 
to the truck, the diagronal brace $F$ attached to the rear part of the arm I: and to the forward part of the implement, the bent vertical part of the said brace forming the plough-beam guards or keepers, and the pivoted and diagonally-arranged plough-beam, having its free end arranged in the said keepers, substantially as and for the purposes specified.

2.- The combination of the bent arm $\mathrm{E}$, pivoted ploughheam 1 , beam-guicle F, lever II, ratchet $G$, pawl $a$, piece $a^{\prime}$, connecting-cord $b$, and dish-shaped plough-wheels I J, set diagonally to the line of draft, all arranged substantially as described, in a rutary gang-plough, for the purpose set forth.

3.- The combination of the plough-beam I, having a broad or hat central part, the separale axles $c c$, elongated loops $d d$, nuts $c c$, and wheels $J \mathrm{~J}$, journaled adjustably on the single beam, all substantially as and for the purposes specified.

No. 179,122,-ASA T. MARTIN, JR,, BUTLER COUNTY, Iowa.-Ploush Shivlds and Cleanirs.- Yuni 27, 1876. -[Filed Aurust 13, 1875.]

A revolving fender, concave and with serrated edges, attached to an arm or slicle, which gravitates in the box clamp attached to the plough-beam.

Claim.-As a fender attachment for ploughs, the combination of the gravitating toothed wheel $A$, bub $B$, stud $b$, slide $\mathrm{C}$, and stirrup $\mathrm{D}$, with guides $d$, all constructed substantially as and for the purposes herein set forth.

No. 185,061 - W. J. ATCHISON, Z1ONSVI1.l.E, 1ND., assignor of one-half of his right to INO. J. ATCHISON, same place.-Revolving Harrowes and Cultizators.-Decembir $5,1876$. - [Filed Oitwer 27, 1876.]

A series of star-wheels are arranged in a frame, the arms of which interlock. On alternate sides of each arm, at varying distances, are projections, which penetrate and pulverize the soil.

Claim.-The star-wheel B having radiating arms $\mathrm{C}$ and the sharp angular projections a upon either side of the wheel or arms, as and for the purpose stt forth.

No. 185,209.-F. BRAMlER, Litti.e Falls, N. Y.Whed-Hurrows.-December 12, 1876.-[Filed fune 14, 1876.]

Claim.-In a wheel-harruw, the reversely-acting wheelgangs arranged one in rear of the ether, and in the same, or nearly the same, longitu linal plane, substanially as and for the purpose described.

No. 186,634.-GEO. STEVENSON, ZuNsville, IND. - Revolving Ciultivators-January 23, 1877.-[Filed $D_{i}$. cimher $11,1876$.

Claim.-In a revolving cultivator or earth-pulverizer the star-wheel $C$, having each of its arms provided with straight cutting-edge $a$, and inclined side cutter: D D, set at an angle of about forty-five degrees, and in circular form, substantially as and for the purnoses herein set forth.

No. 187,392-C. LA JoOW, Albany, N. Y.-Har rent-Cultizators.-February 13, 1877. - [Filed Derember I3, 1876 .]

A series of disk-wheels are mounted upon axles connected at their inner ends by a universal joint. The draft-bar: are connected to the axle by univerial joints. The wheelganns are adjustable relatively to the line of draft.

Claim.-1.-In a harrow-cultivator, the disk-gangs, connected at their inner ends by a universal joint, as herein described.

2.-The combination, in a harrow-cultivator, of two disk-shafts, connected at their inner ends by a universal joint, and adjustable relatively to the line of draft.

3.- The combination of lle draft-bar $G$, boxes $G^{\prime}$, braces $J$, pole $\mathrm{E}$, and seat $\mathrm{I}$, with the flexibly-jointed axles C C and wheels $\mathrm{A}$ of a harrow-cult vator, as and for the purfoses lerein set forth.

4.- The combination of the draft-burs $\mathrm{G} G$ and universal joints $G^{\prime} G^{\prime}$ with the axles $C$ C and the centre joint $D$ connecting the axles, and adjustably connected to the rear end of the pole, for the purposes herein set forth.

5.- The combination of the axles $\mathrm{C} C$, universal joints $G^{\prime} G^{\prime}$, braces $G G$, and univeral centre joint $D$, with the pivoted rod $b$, adjustably pivoted stirrup $H$, pole $E$, and nut $a$, substantially as and for the purposes herein set forth.

No, 8,159-CHARI.ES I.A IUU, Albany, N. Y.-
- Harrone-Cultizators._-187.392, February 13, 1877.Reissued April 9, 1878. - [Filed Warch 22, 1878].

Claim.-1.-In a harrow-cultivator, the disk-gangs having the inner ends of their axles flexibly connected together.

2.-In a harrow-cultivator, the disk-gangs jointed at their inner ends to allow both vertical and horizontal vibration.

3.- In a harrow-cultivator, the disk-gangs connected at their inner ends by universal joints, substantially as set forth.

4.-In a harrow-cultivator, the disk-gangs bearing directly against one another at their inner ends, for the purpose set forth.

5.-In a harrow-cultivator, the disk-gangs having their pivotal bearings directly upon their axles and at points between their ends, for the purpose of preventing bodily endwise swing of the gangs when vibrating, as set forth.

6.-In a harrow-cultivator, the disk-gangs doubly pivoted at points between their ends, and having their inner ends flexilhy connected, so that opposite ends of both gangs may have corresponding vertical and horizontal vibration, substantially as set forth.

7.- In a harrow-cultivator, the vibratory disk-gangs having the dra t devices connected directly to their axles.

8.--In a harrow-cultivator, having gangs of disks mounted on through-axles, a draft tongue connected, by lateral extensions or hounds, directly to said axles, and having vertical vibration independent thereon, substantially as described.

9.-The combination, in a harrow-cultivator, of the adjusting devices, the draft tongue and connections. and the adjustable disk-gangs, whereby the angles of the gangs may be adjusted at will for wide or narrow furrows without disconnecting any of the parts, as herein set forth.

10.- The combination, in a harrow-cuitivator, of the disk-gangs, an adjusting-rod, and a pivoted bracket or holder, by which said rod and the disk-gangs may be adjusted, for the purpose set forth.

11.- In a harrow-cultivator, the combination, with the adjustable disk-gangs, of a pair of bars rigidly secured to the draft-pole at their forward ends, and serving both as draw-liars and braces for the disk-gangs.

12.- The combination, in a harrow-cultivator, of the draft devices and vibratory disk-gangs with an intermediate holding-piece, for the purpose of rendering the connection of the gangs rigid at will.

13.- The combination of the draft-bars $G \mathrm{G}$ and universal joints, $G^{\prime} G^{\prime}$ with the axle $C$ C and the centre.joint $D$, connecting the axles, and adjustably connected to the rear end of the draft-frole, for the purposes herein set forth.

14. - The combination of the axles C C, universal joints $G^{\prime} G^{\prime}$, braces $G G$, and universal centre-joint $D$ with the pivited rod $/$, adjustably-pivoted stirrup, $H$, pole $E$, and nuts $a a$, substantially as set forth.

15. - The combination of the draft-bars $G$, boxes $G^{\prime}$, braces $\mathrm{I}$, pole $\mathrm{E}$, and seat I with the flexibly-jointed axles $\mathrm{C} C$ and wheels $\mathrm{A}$ of a harrow-cultivator.

No, 188,81 5.-H. WV. NICHULS, NORTHFIELD, IND,Cultivators.-Warch 27, 1877, [Filed January 20, 1877.]

Claim.-In a revolving cultivator-wheel, the combination of two alternating series of long and short teeth or spokes, substantially as and for the purposes herein set forth.

No, 190,104.-S. G. REYNOLDS, BRISTOL, R. 1.Ploushs.-May 15, I877. [Filed April 19, 1877.]

Two revolving disks for the mould-board and land-side of the plough. Cogs on the inner side of the circumference of the disks engage with each other. Tapering journals project inwardly, and work in tapering sockets, which compensate the wear.

Claim.-1.- In a plough having the two rotary disks, $h l$, the journals $o$ made to cross each other, the bearings being cast in one piece, substantially as described.

2.- The two rotary disks $h l$, having their journals $o$ arranged to cross each other, one journal being horizontal and the other inclined downward so as to cause the land-side to act in opposition to the mould-board, substantially as set forth.

3.-The concave-disk mould-board $h$, with conical journals $o$, and provided with $\operatorname{cog} s o^{\prime}$, in combination with convex land-side disk $l$, also provided with conical journal, and 
with cogs that engage with the cogged mould-board, substantially as set forth.

No. 191,054.-JOHN L. HILL, Clmax, Kas.-CornPlunters and Grint Drills-May 22, 1877 . [Filed Fibruary $26,187 \%$ ]

Claim.-The combination of the seed-boxes M, the slides $Q R$, the brushes $O$, and the springs $P$, with the recessed hubs of the concaved rotary cutters $\mathrm{K}$. and with the beans I J, substantially as herein shown and described.

No. 193,999--T. SANDERS and L. C. NICHAOLDS, Hamero, Iows.-Harrmos and Cultizutors. - August 7, I877. [Filed Juni: 15, 1877.]

The ploughs capable of lateral adjustment, are arranged upon a shaft journaled in the frame near the front end In the rear of the ploughs are two shafts, with star-wheels arranged alternately thereon, having bearings in the lower ends of levers pivoted to the sides of the frame, and having connection with a lever pivoted upon the frame, by means of which the harrow-wheels may be raised or lowered.

Claim.-1.- The plongh $G^{3}$, constructed as described, with the reversed hoof $e$, front cutting-edge $e^{1}$, and curved side flanges $\mathrm{E}^{2} \mathrm{E}^{2}$, substantially as herein set forth.

2.- The star-wheel herein described, constructed in two parts, each part consisting of an elongated hub, $\mathrm{J}$, clisk $\mathrm{J}^{1}$, and radial arms $\mathrm{J}^{2}$, and the two part. locked together by one or more lugs $h$ and corresponding recesses $i$, substantially as and for the purposes herein set forth.

3.- The combination of the two shafts $\mathrm{H} \mathrm{H}^{\prime}$, each with a series of star-wheels, as described, the pivoted levers I 1', connecting-rods $k k^{1} k^{2}$, shaft $\mathrm{K}$, with arms $\mathrm{K}^{1} \mathrm{~K}^{2}$, the lever $L$ and ratchet $L^{\prime}$, substantially as and for the purposes herein set forth.

4.-The combination of the frame $A$, adjustable up and down on the wheels D D, the adjustable ploughs $G^{3}$, laterally adjustable on the shait $G$, the adjustable shaft II $H^{\prime}$, with bisected star-wheels placed thereon, and the roller R, all constructed substantially as herein set forth.

No. 195,677--JOHN B, WALL, CARTHAge, Mo.Combined Harrozes, Seed-Planters and Rollers. - September 25, 1877. [Filed February 20, I877.]

Claim.-I.-The combination of the cutters VI, harrowframe $\mathrm{R}$, drills $\mathrm{X}$, and roller $h$, substantially as set forth.

2.- The frames $\mathrm{R}$, hinged to the axle $\mathrm{N}$, and provided with the beams $U$, in combination with the forks $W$, drills $\mathrm{X}$, and roller $h$, substantially as set forth.

No. 197,545.-JAY S. CORBIN, Gouvrerneur, N. Y. -Whel-Harrows. - November 27, 1877 . [Filed Nay 14, I 877.$]$

The disk gangs have separate pivotal bearings in hangers firmly bolted on the main frame, and are adjusted in the line of draft by a pawl and ratchet and rods from the inner ends of the gang-shafts.

Claim.-1.-The combination, with the main frane, of hangers, rigidly connected thereto, and independent diskgangs, vibrating upon the hangers, substantially as set forth.

2.-The combination, with the main frume, of hangers $B$ $\mathrm{B}$, rigidly attached thereto, and indepenclent disks-gangs, pivoted to the lower ends of said hangers, and vibrating in both horizontal and vertical planes, sub-tantially as set forth.

3.-In combination with the main frame and the diskgangs, the hangers $13 \mathrm{~B}$, provided with the enlarged pivot hearings or seats, and the thimble-hearings b b, provided with pivots, which are supported in said seats, substantially as set forth.

4.-The combination, with a gang of rotating harrowdisks, of a revolving scraper-bar, placed in a different plane from the disk-shaft, to permit the scrapers to enter the concave side of the disks, substantially as described.

5.-The combination, with a gang of rotating harrowdisks, of a lever, connected to the gangs for setting the same, at an angle with the line of draft, substantially as described.

6.- The combination, with a gang of rotating harrowdisks, of a lever for setting the same at an angle with the line of draft, and a rack and dog for holding the disks in position when set, substantially as described.

7.- In a wheel-harrow, the disks attached to an axle by means of an irregular hole through the centre of the disk, which permits it to touch the axle in but two points, and a tapering wedge, the two points and the wedge being equidistant, substantially as described.

8.- The combination, in a wheel-harrow, of independent disk-gangs, a lever $\mathrm{G}$, and connecting rods $\mathrm{F} \mathrm{F}$, one or both rods being provided with holes $f$, whereby the inner cnd of one disk-gang may be arranged in advance of the inner end of the other disk-gang, substantially as set forth.

9.- The combination, in a whecl-harrow, of the main frame $A$, hangers $B \mathrm{~B}$, thimbles $b b$, connecting-rods $\mathrm{F} \mathrm{F}$, lever $\mathrm{G}$, and scrapers $\mathrm{H} H$, substantially as described.

No. 8,675.-JAY S. GORBIN, GOUVERnkur, N. Y.Whed Harrowis,-197,545, Nivimber 27, 1877. Re-issued Fune 24, 1879.- [ Filed May 26, 1879.]

Claim.-1.- The combination, with the main frame, of hangers rigidly connected thereto, and independent cliskgaugs vibrating upon the hangers, substantially as set forth.

2.-The combination, with the main frame, of hangers 13 $\mathrm{B}$, rigidly attached thereto, and independent disk-gangs pivoted at the lower ends of said hangers and vibrating in bit th horizontal and vertical planes, substantially as set forth.

3.-In combination with the main frame and the diskgangs, the hanger $\mathrm{B}$ B, provided with the enlarged pivot bearings or seats, and the thimble-learings $b \quad b$, provided with pivots, which are supported in said seats, substantially as set forth

4.- The combination, with a gang of rotating harrowdisks, of a revolving scraper-bar, placed in a different plane from the lisk-shaft to permit the scrapers to enter the concave side of the disks, subitantially as described.

5.- The combination, in a whecl-harrow, of the following element-, viz: a draft-frame or a draft-plank projecting laterally from the tnngue, disk-gang pivoted to the draftframe or draft-plank, and a set-lever mounted on the tongue and connected with the disk-gangs letween the points at which said gangs are comecter with the draft-frame or draft-plank, substantially as set forth.

6.- The combination, sulistantilly as set forth, in a wheel-h rrow, of the following elements, viz: a tongue, a draft-frame or traft-plank projecting laterally from the tongue, disk-gangs pivoted to the draft-frame or traft-plank, a lever mounted on the tongue, and rods comsected with the levers and the metal bearings which support the inner ends of the disk-gangs.

7.- The combination, subst ntially as set forth, in a wheel-harrow, of the following elements, viz: a tongue, a draft-plank or draft frame projecting laterally from the tongue, disk-gangs pivoted to the elraft-plank or frame, a lever mounted on the tongue connected with the inner end of the disk-gan ss, and a rack and dog for bolding the disks in proper position when set.

8.-The combination, substantially as set forth, in a wheel-harrow, of the following elements, viz: a tongue, a frame-plink or draft-plank projecting laterally from the tongue, disk-zangs pivoted to the draft-frame or plank, a lever connected with the disk-yangs, for setting them at the rlesirecl angle to the draft-plank, and levers and scrapers supported upon and adjusted with the disk-gangs.

9.-In a wheel-harrow, the disks attached to an axle by means of an irregular bole through the centre of the disks, which permits it to touch the axle in but two points, and a tapering wedice, the two points and the wedge being equidistant, substantially as set forth.

10.- The combination, in a wheel-harrow, of independent disk-gangs, a lever, G, and comnecting-lods F F, one or both rods being providerl with holes $f$, wherely the inner end of one disk-gang may be arranged in advance of the inner end of the other disk-gang, sub-tantially as set forth.

I1. - The combination, in a wheel-harrow, of the main frame $A$, hangers $B$, thimbles $b$, connecting-rods $F \mathrm{~F}$, lever G, and scrapers H HI, substantially as described.

No. 200,327.-JOHN MOORE, SAlisbury, Mo.-Sod. Cutti's and Cotten-Choppirs.-Fidruary 12, 1878.-[Filed September 27, 1877 .

Claim - The combination of the frame A, with clevis B and handles $\mathrm{C} \mathrm{C}$, the rotatin $r$ wheel $a \mathrm{D} b$, the circular cutters $G$, and the sectional cutters $G^{\prime} G^{2}$, all constructed sulstantially as and for the purposes herein set forth. 
No, 200,355-GLOR(iE STEYENSON, ZWNSIIIIE,

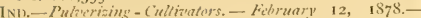
[ lited July 16, 1\$77.]

Claim. - The thimbles or tubes $b b$, in combination with the rods $a$ and the siar-wheels $I$, having huls $b$, and the frame, whereby the wheels may be adjusted to any desired distance apart in relation (1) each other, constructed and arranged substantially as and for the purpose set forth.

No. 201,562.-JAMES H. S.IITH, Moxteri.1.n, ARk Stalk-Pullits.-Wirch 19, i 878. - [Filed Ausust 29, is 77.]

A reel ojerates near the rear inner exlye of the disks to throw off the stalks. The broad sur ace guides direct the stalks between the disks. The rake serves to gather up the stalks.

Claim.-1.-In a st -lk-puller, the dish-shaped and corrugated wheels C C, crranged at an angle with the line of motion of the machine, for the purposes herein set forth.

2.- The combination of the wheels C C, arranged and operated as described, and the reel $\mathrm{D}$, substantially as and for the purposes herein set forth.

3.- The rake comprsed if the side bars $H \mathrm{H}$, pivoted as described, the cross-bar $\mathrm{I}$, with blocks $\mathrm{J}$, independentlypiroted bars $\mathrm{K} \mathrm{K}$, and the teeth L. I, in comllination with a stalk-pulling mechanism, all constructed substantially as and $f_{1} r$ the purposes herein set forth.

No, 201,765.-JAY BOSTWICK FISHER, DAVENPORT, Iow:- - Sulky-Ploughs.,-Whrch 26, 1878.-[Filed Filinuary 2, 1878 .]

Attached to the mould-board are two pairs of concave disks, to cover the joint between the furrow, and alsn to cover the seed ilrolped. A seedin r device and spur-wheel to oprerate its seed-slide are also attached to the mouldboard. A revolving coulter, with concave cut'in'r-'dges, i geared to a saw-cutter, and drives it at a higher speed. Varions special devices.

Claim.-1.-In combination with a plough having a mould-board constructed substantially as described, the concave revolvin mould-loards T, arranied to scrape snooth and fill up the crevice or joint between the furrows, substantially as set forth.

2.-In ecombination with a flough, N, constructed substantially as described, and with the revolvin:mould-boards $\mathrm{T}$, a seeding device, $\mathrm{U}, \mathrm{c}$ msisting of the rim'ess wheel $\mathrm{V}$, rod $V^{\prime}$, spring $v^{\prime}$, and seed-cup slides W W', constructed and operating substantially as an I for the purpose specified.

No, 204,713.-FRANK BRAMER, LITTLE FALI.S, N. Y.-Whiel-lfarrmis. - Funi II, 1878 .- [Filed May 23, 1878$.

Claim.-I.-A wheel-harrow cultivator consisting of the combination of a pole or tongue, a hirh main frame, wheelgangs supp uting the high frame throigh the merlium of rigid fixed standard interpose 1 between the gang-bars and main frame, and rods for bracing the wheel-rangs a rainst independent moiements and injurious strains.

2. - The combination, substantially as hereinbefore set forth, of the main fr ıme, the gang-bar, the interposed supporting-standlard, the brace-ro-1s, the slotted plate secures to the brace-rods, and the adjusting-screw or set-bolt on the gang-bar.

3.-The combination, substuntially as hercinlefore set forth, of the slotted $\mathrm{m}$ in frame or beam. the pivoted gangbars, and the doubly-slotted pl.tes, stid plates being connected $t o$ brace-rods by set-b ilts working in one set of slots, and to the gang-bars ly set bolts working in the other or curved slots, wherely the working angle of the disks rel.tively to the line of draft may be varied and the disks adjusted laterally relatively to said line of draft.

4.- The combination, subst nt ally as hereinhefore set forth, of a main frame, reversihle wheel or disk gangs, and mechanism for lickilig the gangs, wherehy each gang m.xy be turned end for end on its pivot and securely locked.

5.-A wheel-harrow provided with reversible disk-gangs, the disks or wheels havin 7 concavo-convex sides or faces, whereby either the conc ive or ennvex faces of the wheels mry be brought opposite each other, as set forth.

6.-A wheel-harrow provided with rever-ible disk-gangs, one on each side of an intermediate tongue or draft-frame, the gangs heing also capable of independent lateral adjust- ment relatively to the line of draft to vary the space between the inner ends of the gangs.

No. 205,498.-N. PALMER, NEW VORK, N. Y.-Rotary Mould-Board Ploughs.-Fuly 2, 1878. [Filed Dccember 20,1877 .]

The beam and share are of ordinary construction. The mould-board is disk-formed, supported hoth on the convex and concave sides, having a radius greater than the depth of the furrow. The land-side of a single plougl extends to some distance to the rear of the mould-board. Two ploughs or more may be arranged in a gang, and the beams connected by a spring-brace. When two or more ploughs are used, the advance ploughs have a short land-side to allow the turning of the furrow.

Claim.-1.-In a gang of disk mould-board ploughs, the extended land-side I) of the rear plough, in combination with the short land-side $\mathrm{D}^{\prime}$ of the advance plough, and connecting spring-brace $H$, as and for the purpose specified.

2.-The braces $\mathrm{F} \mathrm{F}^{\prime}$, in combination with the ploughbeam and disk mould-board, fitting closely to the eoneave surface, thus forming both a support and a cleaner, as shown and described.

3.- The supporting spring-brace, in combination with the advance plough, substantially as and for the purpose described.

No, 205,608, - FRANK BRAMER, LiTTLE FALIS, N Y.-What-Harrews. - Fuly 2, 1878 . [Filed May 23 , 1878.7

Claim-1-1-The combination, substantially as hereinbefore set forth, of the tongue, the wheel-gangs pivoted on opposite sides thereof, and eapahle of vibrating relatively thereto to conform to undulations in the surface over which they pass, and the stiffening-bar adapted to engage with the wheelgangs and tongue to render the machine rigid, and capable of being disengaged to render the machine flexible.

2.-The combination, subutantially as hereinbefore set forth, of the tongue and the gang-frames, hinged on opposite sides thereof, one gang-frame being hingerl in advance of the other.

3.-The combination, substantially as hereinbefore set forth, of pivoted gang-frames, arehed or inclined supports for the driver's seat, pivoted at their outer ends to the gangframes and at their inmer ends to the seat, and adjusting devices by which the inclination of the bars and the height of the seat may be varied.

4.-The combination, substantially as hereinbefore set forth, of the tongue or intermediate frame, gang-frames pivoted thereto, an arched or straddling seat-support pivoted upon the gang-frames and to the seat, bencath which the inner ends of the supporting-bars cross each other, and slotted plates provided with inclined surfaces, mounted on the supporting-bars and acting upon the under surface of the seat, or an extension thereof.

No. 206,185.-IAMES MALLON, BATTON ROUGE, LA. - Cultizators.- Fuly 23, 1 S78. [Filed December 22, 1877.]

The frame is rectangular, and is supported upon two wheels having adjustable crank-axles. The cultivator-beams are pivoted to a rock-bar supported upon the forward beam of the frame, and have both a vertical and horizontal motion. The cultivators are of the disk form, the outer edges being cut into sections, the concave sides facing inward, and adjustable on their own axes in the line of draft, so as to take in more or less land.

Claim.- The improved cultivator herein described, provicled with adjustable beams $L^{\prime} L^{\prime}$, each furnished with revolving cutters, the blades of which are curved, substantialy as described, and operated on an adjustable bearing, for the purpose set forth.

No. 206,2I8.-FRANK BRAMER, IITTIE FALLS, N V.-Whech-Harronus. - Fuly 23, 1878. [Filed Fuly 8, I878.]

Claim,-1.-Wheel-gangs pivoted to a wheel or carrying frame, and capable of swinging freely laterally, relatively thereto, substantially as hereinhefore set forth.

2.-The combination, substantially as hereinbefore set forth, of the wheel or carrying frame, the coupling-frame suspended therefrom, and the wheel-gangs mounted on the coupling-frame.

3.-The combination, substantially as hereinbefore set 
forth, of the wbeel or carrying frame, the tongue, the coupling-frame pivoted in front of and crossing the axle, and the wheel-gangs mounted on the rear of the coupling-frame, whereby the gangs can swing clear of the carrying-wheels.

4.-The combination, substantially as bereinbefore set forth, of the wheel or carrying frame, the coupling-frame pivoted thereto, and the wheel-gangs pivoted on the coup ling-frame, wbereby the gangs can swing vertically, laterally, and at an angle, as well as be adjusted relatively to the tongue.

5.- The combination, substantially as hereinbefore set forth, of the wheel or carrying frame, the coupling-frame, the wheel-gangs, and the lifting-levers on the carryingframe, wbereby the gangs may be lifted clear of the gromd.

Mo. 206,85o. - FELIX JOHNSON, PARIS, TEXAS.Plou his.-August 13, is78. [Filed Fuly 6, is 78 .]

The revolving mould-board has cogs upon its inner side, which gear with a pinion upon a vertical shaft carrying a hotizontal land-sicle roller. The pressure of the latter against the land imparts motion to the mould boarl. A frame upon the land-side of bean carries a toothed cutter upon a roller, which is also geared to, and assists to revolve the mould-board.

Claim.-1.- Tbe combination, in a plough, of a revolv ing mould-board, $f$, provided with $\operatorname{cogs} g$, the vertical sbaft $h$, having pinion $i$, the gear-wheel $o$, toothed cylinder $f$, and cutter-wbeel $t$, substantially as described.

2.- The combinatton of the roller $j$, vertical shaft $h$, having pinion $i$, and the revolving mould-buard $f$, having the teeth $g$ upon its inner side, substantially as set forth.

3.- The combination of vertically-adjustable cutter $t$, toothed cylinder $p$, long pinion $o$, shaft $r$, and frame $s$, substantially as shown.

No. 207,808.-WILL1AN HENIGST, CuLUMHUs, ()Ho -Cultiators.-Siptember 10, 1878.-[Filed Marih 30, I 878.$]$

Claim-1-1 - In a grain-plant cullivator, the cumbination of the wheeled frame $\mathrm{A}$ and a series of vertically-swinging independent frames. D, each frame D having a series of loosely-turning pointed cutter-wheels, F, and cultivator blades E, substantially as and for the purpose set forth.

2.- The combination, with the wheeled frame A, of the independent frames $\mathrm{D}$, having the wbeels $\mathrm{F}$ and blades $\mathrm{E}$, and the vertically-swinging arms $i^{1}$, carrying either shields or rakes, substantially as and for the purpose described.

3.-The combination of the cultivator-blader E, revolving pointed cutter-wheels $\mathrm{F}$, and the penduluous frame $\mathrm{D}$, carrying the blades $\mathrm{E}$ and wheels $\mathrm{F}$, subitantially as described.

4.-The combination of the seel-hopper II, frame A and frames D, having blades E, and wheels F, suhstantially as and for the purpose described.

5.- The combination of the seed-hopper $M$ and fertil zerhopper L, provided with the cone-wheels /, inclined spout $l^{1}$, and adjustable shaft $k$, the revolvin: pointed cutter wheels F, cultivator-blates E, and frumes D, substantially as and for the purpose described.

6.- The vertically-swingin shields $\mathrm{I}$, applied in poirs, in combination with the vertically-swinging frumes $D$, baving the blades $\mathrm{E}$ and wheels $\mathrm{F}$, substantially as and for the purpase described.

No. 208,246.-D.IVII) 11. LANE, ANokA, MINN.Rotary.Ploughs.-September 24, 1S78. - [Filed Fune I3, IS7S.]

Clum.-1.- - In a rotary ploughing implement carried on draft-wheels, the combination of a rotary ploughing-wheel, $\mathrm{K}$, having a concuvo-convex cutting-edge arranged next to the soil, and without the interposition between it and said wbeel of other pars, and for traveling on the bottom of the furrow, and baving its flaring concavity turned partly forward, the rotatively-adjustable and ohtusely-bent axle 1 , carrying the said plou shing-wheel, and having thereon the tapering collar $I$, and allapted at one end to receive a wrench, and the axle-box F, vertically adjustable with relation to the said draft-wheels, the said box being provided with a clamp for rendering the said axle either loose or rigid therein, substantially as and for the purposes specified.

2.- In combination, the caster-wheel $\mathrm{S}$, mounted on the rotary stock or carrier S', having thereon the rigid notched collar $h$, the pivoted lever $Q$, applied to the frame carrying the plough-disks, the bolt or slide $f$, carried lyy the sand lever, the fixed serrated plate $R$, the lever $U$, pivoted to the lever $Q$, and the fixed loop $\mathrm{V}$, substantially as and for the purposes specified.

3.- In combination, the supplemental frame $E^{\prime}$, providcd with an axle-box, $F^{\prime}$, and carrying a vibrating lever, $Q^{\prime}$, having on its lower ent the caster $S$, the removable halfaxle $\mathrm{P}$ and its draft-wbeel, the removable dish shaped ploughing-wbel $\mathrm{K}$, the removable axle-box $\mathrm{F}$ and its clamps, the removable obtusely-bent axle $\mathrm{J}$, and a locking device for engaging the lever $Q^{\prime}$, sutstantially as and for the purposes specified.

4.- The share $\mathrm{K}^{\prime}$, arranged behind a rotary concavo-convex or dish-shaped plougb-disk, and placed for eutting through and under the sod or land next to the furrow turned therefrom by the disk, substantially as and for the purposes specifier.

5.- A cutting blade or share mounted on a vercically-vibrating caster-stock or carrier, in combination with a rotary concavo-convex or dish-shaped plough-disk, the said share being arranged to cut under the sot or land before the sod or land so cut is turned by the said disk, sulsstantially as and for the purposes specified.

No, 209,508.-RUIBERT M. PITTILlo, CARTFRsvili.e, Ga.-Cotton-Sed Planters.-October 29, 1878 .[Filed August 26, 1878.]

No claims for the disks, described in the specification as coverers.

No, 211,638 . -NELSON PALMER, NEW YoRK, N. Y. -Rotary Mondl-Board Ploughs.-Fanuary 28, IS79.[Filed December ${ }_{3}, 1878$.]

A concave-disk plough, with a convex-centre, either fixed or removable. A removable conlter to fit over the sh.re and land-side, and ovcrlap and protect the joint between the share and disk.

Claim.-1.-In a machine or implement for turning the soil, the concave disk or mould-hoard $\mathrm{E}$, provided with a convex centre, $G$, upon its front or concave face, substantially as and for the purpose lierein shown and described

2.-The combination, with a concave disk or mouldhoard $\mathrm{E}$, of a removable convex-cenire, $\mathrm{G}$, substantially as and for the purpose herein shown an!l described.

3.-The combination, with the revolving disk or mouldboard and the plough-share and land-side provided with the bottom cntting-flanges $m m^{\prime}$, of the coulter $\mathrm{D}$, provided with the rearwardly-projecting angular flange $d$, and hottom cutting-flanges $n n^{\prime}$, forming forward continuations of the cutting-flanges $m m^{\prime}$, substantially as and for the purpose here:n sbown and described.

No. 213,242 . - NELSON PALMER, NEW YORK, N. Y. -Kolary Gang-Plonghs.-Warch 11, iS79.-[Filed Fanwary 6,1879 .]

An inner or second frame hinged at the front carries a series of concave disk-ploughs with convex centers. A third frame hinged at the rear carries shares, which work in front of and protect the edre of the diski. Eitber frame may be raised or worked independently of the other.

Claim.-1.-In an earth-turning machine, one or more shares immerliately preceding, but detached from and adjustable independently of one or more disks, substantially as shown and described.

2.- In an earth-turning machine, a series of concave disks, with convex centres on their front or earth-turning surfaces, attached to a separate frame and adjustable independently of shares or cutting" devices which immediately precede them, substantially as and for the purpose set forth.

3.- In an eartb-turning machine a series of shares or cutting-devices pivated or hinged to the front end of a frame, which is pivoted at its rear end to an adjustable disk-frame, by which series of adjusting devices the shares or cuttingdevices nay be elevated or depressed in a horizontal position, substantially as shown and described.

4.- - In an earth-turning machine, $a$ series of disks attached to an adjustable frame, and a series of shares or cutting. devices attached to a stparate adjustable frame, in combination with clevices for adjusting said frames at different degrees of elevation separately or togrether, or relatively to each otber, substantially as and for the purpose shown and described. 
5.- In an earth-turning machine, the principal frame, $C$, secondary frame, 1 , and the third frame, $(i$, in combinat on with the slotted bearings or guidcs $l$ and the gnides $l^{\prime}$, all constructed and operating substantially as set forih.

No. 214 , ISo.-RIC11.RD I). NORTON, NEW SHARGN, X. J.-Pulacricins Disk-Ifamones.-April \&, 1879 . [Filed January 16, 1879.]

Claim.-1.- The combination of the slotted button M with the flattened holding- ${ }^{3}$ ar $J$, and with the tongue $A$ and cross-har B of the harrow, substantially as herein shown and described.

2. - The combination of the cam-button $\mathrm{N}$ with the slotted button $\mathrm{M}$ and the fittened holding-bar $\mathrm{J}$, substantially as herein shown and deccribed.

No. 9,676.-RICIIARI) D. NORTON, HLiHT -TOWN, N. J.-Pulzcrisins Disk-Harrons.-214.180, April s, 1879.-Re-issued $A$ fril 19, 1881 - [Filed $1 / t y$ 1 17, 1SSo.]

Claim.-1.-The combination, in a wheel-harrow, of disk-gangs flexibly connec'ed at their inner ends to a bearing, 1, a main frame, and a draw - bar flexibly connected at its front end to the ma'n frame, and having its rear end inflexibly attached to the bearing $I$, subutantially as set forth.

2.- The combination, with the main frame, consisting of the tongue $\mathrm{A}$ and the cross-bar $\mathrm{B}$, of the holding or draw bar J, the slotted button $\mathrm{M}$, and the dirk-gangs, substantially as and for the purposes set forth.

3.- The combination of the cam-button $\mathrm{N}$ with the slotted buttun . II and the flattened holding-har J, subutantially as herein shown and described.

4.-The combination, substantially as set forth, of a main frame, disk.gangs flexibly connected at their inner ends, and also connected to the main frame, a lever, a bar connecting the lever and the flexible connection, and a button or guide-plate in whith said bar works.

No. 2I6.592,-JOHX ALSTIN, CHICAgo, ILL. Ploughs.- June 17, 1879 . [Filed Janumy $15,1878$.

Concave plonghing-divks with the cutting-edges made in sections, and placed at one end of an axle with bearings at both ends; a mold-bo.rd which both scrapes the disk and turns over the furrow; the irre sular frame hinged in front, and connected by a lifing lever to an arched carriage frame made rizid to the axle.

Claim.-1.- The rotary ploughing-dinks $\Lambda^{\prime} A^{\prime}$, one or more, consisting of the annular concavo-convex dish shaped or flaring working or cuttin s blades $G^{\prime} G^{\prime}$, made in sections, removably applied $t$ s the outer ends of radial arms or spokes, in combination with one or more axles arrangred at an angle to the line of draft, and journaled in a vertically-adjustable beam or frame mounted on draft wheels substantially a $i$ and for the purposes specifiel.

2.- The rotiry , loughing-disks $\mathrm{A}^{\prime} \mathrm{A}^{\prime}$, one or more, consisting of the annular concavo-convex dish-haped or flaring working or cutting blades $G^{\prime} G^{\prime}$, made in sections, removably applied to the outer ends of radial arms or spokes, in combination with and rigidly applied to a long axle, $E^{\prime}$, set diagonally to the line of draft, and having double bearings in a vertically-adjustable frame or beam mounted on draft-wheels, substantially as and for the purposes specified.

3.- The rolary plonghing-disks $\mathrm{A}^{\prime} \mathrm{A}^{\prime}$, one or more, consisting of the annul ir concavo-convex dish-haped or flaring workint or cut ing blades $G^{\prime} G^{\prime}$, made in sections, remosably applied to the outer ends of radial arms or spokes, and set diagonally to the line of draft, in combination with the mold-boards $\mathrm{H}^{\prime} \mathrm{H}^{\prime}$, having convex faces arranged in or nearly in, csutact with the concave faces of the said disks or blades, the said disks and mold-hoards being applied to a vertically-adjustable fr.me carried on draft-wheels, subutantially as and for the purposes specified.

4.-The combination, in a rotary plough mounted on dr.aft-wheels, of the frame $\mathrm{M}$, pivoted or hinged at its forward end to the forwasd part of the carriage and carrying the rotary ploughing-disk $\mathrm{A}^{\prime} \mathrm{A}^{\prime}$, one or more, mounted rigidly on the long axles $E^{\prime} E^{\prime}$, set diagonally to the line of draft and journaled in double bearings in the said frame, and the lifting devices connected to the frame $\mathrm{N}$, substantially as and for the purposes specified.

No. 216,878 . CHARI.ES A. MEEKl:R, GREEN's
FARus, ('oxs - Smoothing. Ilarrows-Jane 24, 1879.

[lïled Fibruary 27, 1879.]

Claim. - The combination of a front and rear set of rotary cutters, the latter closer together than the former, with an intermediate smoothing-board or scraper; D, arminged in the frame $A$, as shown and described, to bring the soil into a fine tilth for the reception of seeds or plants.

No. 220,255.-HF.NRY F. S1l AW, Bosson, MAss, and GEORGE F. SHAW, DedhaM, Mass.-Whel-Marrows. - Oclwher 7, 1879. [Filed June 9, 1879.]

Claim, - 1.-A harrow having all the disks or wheels ar rangerl on one straight shart on both sides of the central line of draft, and at an inclination to said shaft, as cleserided, so as to partially raise the soil, and adjuntable, so that they may throw the soil, wi h one adjustment, toward said central line, or, with another adjustment, outward from said line, substantially as hereinbefore set forth.

2.- In a harrow, a straight shaft having thereon disks or wheels on both sides of the central line of draft, placed at the angles therewith specified, and made adjustable, as and for the purpose specified, when said shaft is arranged at right angles to the pole or central line of draft, substantially as hereinhefore set forth.

3.- The comlination of one straight shaft $\mathrm{D}$, having the wheels or disks $\mathrm{E}$, and collars $\mathrm{G}$ and $\mathrm{H}$ arranged thereon, as specified, portion of gear J, gear 1 , and lever K, subtantially as hereinbefore described.

4.-In a wheel-harrow, springs $\mathrm{F}$, intervening between the shaft $D$ and cross-har $\mathrm{B}$, substantially as hereinbefore set forth.

No. 223,151.-JOSEPII LANE, CHICAGo, IIL., assignor of one-half of his right to SAMUEL STREET FULLER, StratFord, ONTARIO, CANADA,-Rolling Coulters. December 30, I879. [Filed October 24, 1879.]

Claim. - The combination, with a mould-hoard plough, of a rolling coulter made in dished form and arranged with its dished or concave side or the monld-board side of the plough, as de-cribed.

No. 224,009.-CHARLES R. FOSTER, CHICAGo, ILL. - Kotary Ging-Ploughs.-February 3, is8o. [Filed Ausust $2,1879$.

Claim.-1.- The crank-axle C, having upon one end the disk-plongh $\mathrm{B}$, and mounted at the other end diagonally upon the wheeled supporting frame $A$, in combination with the movable bearing. D, the crank-lever E, hand-lever $\mathrm{G}$, aad link-rods connecting the lever and axle, whereby the axle is made crpable of ad ustment in two directions to e ther raise and lower the disks or change their angle to the line of draft, substantially as described.

2.- The crank-axles $C$, mounted diagonally on the wheel-frame $A$, in combination with the disk ploughs $B$, mounted on the axle-cranks outside of the supporting-frame, the crank-lever E, hand-lever G, and link-rods connecting the levers and axle, whereby the disks are raised or lowered, substantially as clescribed.

No. 225,331.-FRANK 13RAMER, LITTI.E FAl.LS, N. Y.-Wheel-llarrows._-Warch 9, 1880.-[Filed December 29,1879 . ?

Claim - 1,-The combination, sub-tantially as hereinbefore set forth, of a licle having the capacity of muving freely in the line of draft, a bar or support upon which said slide moves, disk-gang har, a frame, pivot-connections between said frame and disk-gang burs ct or near the outer ends of said bars, and the pivot-connections between the slide and the inner ends of said bars, whereby the angle of the disks relatively to the line of draft may he varied.

2.- The combination, sub-tantially as hereinbefore set forth, of the tongue, the slide moving freely longitudinally thereon, mechanism. substantially such as described, for locking the slide in any desired position, disk-gang bars, a frame, pivot-connections between said frame and bars at or near the outer ends of the bars, and pivot-connecions between the slide and inner ends of said bars, wherelyy the disks may be adjusted as desired relatively to the line of draft and locked in position.

3.- The combination, substantially as hereinbefore set forth, of the tongue or draft-frame, the slide having the capacity of moving freely longitudinally thereon, the wheel or disk-gang bars or frames, their pivots or hinge-connections 
with the slide, the connecting-arms and their pivots or hinge-connections with the gang-bars or frames and tongue. No, 225,394-CliARLES LA DOW, AlbaNy, N. Y -Whed-Hirrows.-March 9, 1880. [Filed November 4, I 879 .]

Claim.-I.-The combination, substantially as hereinbefore set forth, of the main frame, the supplementary swinging frame, the disk-gangs mounted thereon, the lifting-levers and their detents on the main frame, and the slotted sectional link-rods having set-screws connecting the disk-gangs and levers, whereby the supplementary frame may be left free to rise vertically or may be held rigidly in any desired position.

2.-The combination, substantially as hereinbefore set forth, of the main wheel-frame, the supplementary swinging frame, the disk-gangs mounted thereon, lifting mechanism, substantially such as described, mounted on the main frame, and the driver's seat mounted on the laterally-swinging disk-frame to increase the pressure upon the disk-gangs. 3.-The combination, substantially as hereinbefore set forth, of the main frame, the supplementary frame, adjustable in width, the driver's seat, and the pivoted standards interposed between the seat and frame to compensate its adjustments.

4-The combination, subst.untially as hereinbefore set forth, of a disk-gang, its standaril, a sleeve in which it rocks, a crank plate or arm on the disk-gang standard, a rocking lever, a link connecting the crank arm and lever, and a stop to limit the movement of the lever.

5.-The combination, substantially as hereinbefore set forth, of the disk-gangs, their rocking standarcls, crank-arms, and links, with the rocking lever, whereby the disk-gangs move in harmony when changing their angle relatively to their line of draft.

6.-The combination, substantially as hereinbefore set forth, of the laterally-2djustable swinging frame-beams, the disk-gangs mounted in sets, each set on its respective beam, the rocking standards, their crank-arms, links, and rocking lever, the latter being connected by pivoted links to the side beams to compensate adjustments of their clistance apart.

7.-The combination, substantially as hereinbefore set forth, of the rocking dısk-gang standard, its crank arm or plate, the link connecting it with the rocking lever, and the adjustable connection between the crank-arm and link-rod, to enable the driver, while in his seat, to vary the angular relation between the disk-gangs and line of draft.

8.-The combination, substantially as hereinbefore set forth, of a disk-gang, its rocking standard, a foot-crank to rock the standard to vary the angle of the d sk gang rel.tive. ly to the line of draft, and an adjunting-cl.mp connecting the rocking st indard and foot-crank, to compensate adjunt ments in the wirth of the supporting-frame, and to main tain a proper relation to the driver's seat.

9.-The combination, substantially as hereinbefore set forth, of the disk-gang shaft or thimble and the adjustable sectional supporting-yoke to vary the inclin tion of the diskgang shaft horizontally and transversely to the line of draft.

10.- The combination, substantially as hereinhefore set forth, of the axially-turning rakes and the shields in which they are mounted.

II. - The combination, substantially as hereinbefore set forth, of the laterally-swinging frame with the disk-gangs, the shields, and the rakes, all carried thereby.

12.- The combination, substantially as hereinhefore se forth, of the min axle, the main frame mounted therein, the swinging frame pivoted to the man frame in front of the axle, the disk-gangs hung from the swinging frame in front of the axle, and the driver's seat on the swinging frame in the rear of the axle, whereby the weight of the driver counterbalances that of the disk-gangs.

No. 225,526.-GEORGE R. JOHNSON, RUSSELL, IowA, assignor to JOHN C. COOK, same place.-Corn Cultivators.-March 16, 1880. [Filed Fune 6, 1879.]

Claim.-The combination, with the tongue-yoke, of the pivoted seat-bar and its seat, provided with a guide-support adapted to move up and down on the vertical portions to the yoke E, chains, and a hooked cross tree or bar on the tongue, suhstantially as and for the purpose specified.
No. 226,233--CHARLES LA DOW, AlbANY, N. Y.Combined Seeders and Cultivators.-April 6, I8So. [Filed November 7, 1879.]

Claim,-1.- The combination, substantially as hereinbefore set forth, of a straddling main frame, a gang of diskcutters adjustable relatively to the line of drift beneath said frame, and guides mounted on the frame to counteract the lateral thrust of the gang.

2.-The combination, substantially as hereinbefore set forth, of a gang of disk-cutters adjustable relatively to the line of draft, a straddling main or draft frame, and guidewheels on the frame adjustable relatively to the line of draft.

3.- The combination, subsiantially as hereinbefore set forth, of a gang of disk-cutters, and a reversible draft or main frame.

4.- The combination, substantially as hereinbefore set forth, of a gang of disk-cutters, a reversible draft frame, and supporting-wheels mounted upon said frame, whereby the frame is maintained in a horizontal position while being reversed.

5.- The combination, substantially as hereinbefore set forth, of a gang of disk-cutlers arrangred to turn the earth in one direction, a reversible draft-frame, and mechanism for locking the frame in the same position relatively to the cutters during the forward as well is the reverse moventent of the machine, whereby the furrows are turned in a uniform direction.

6.-The combination, substantially as hereinbefore set forth, of a gang of revolving disk-cutters, a reversible draftframe, a circular track upon which said frame turns, and mechanism for varying the gang relatively to the line of draft.

7.-The combination, substantially as liereinbefore set forth, of a gang of disk-cutters, a reversible draft-frame, a circular track upon which saicl frame turns, movable stops adjustable upon the track and a detent adapted to engage with said stops to lock the draft-frame in any desired position relatively to the disk-gang

8.- The combination, substantially as hereinhefore set forth, of a gang of dish-cutters, a circular track supported above the disk-gang, a straddling main frame above said track, and grooved pulleys depending from the main frame and embracing the edges of the track, said pulleys constituting a draft-connection between the track and the frame.

9.-The combination substantially as hereinbefore set forth, of a straddling main or supporting frame, a seed-box supported beneath said frame, a disk-gang the shaft of which revolves in bearings depending from the seed-box, and mechanism, substantially such as described, for simult.1neously adjusting the angle of the seed-box and disk.gang relatively to the frame and to the line of $\mathrm{dr}_{\mathrm{a}} \mathrm{ft}$.

ro.- The combination, substantially as hereinbefore set forth, of a gang of disk-cutters, a seed-box, a series of seedwheels constituting a forced feed capable of working either way, mechanism for driving said wheels in either direction directly from the disk-yang sh ift, and a reversible frame, whereby the seed is distributed, during the forward movement of the machine as well as during its reverse movement without interference from the reversal of the frame.

11.-A gang or series of spoked or perforated disks mounted on a common axle, arranged to revolve together, substantially as described.

12.-The combination, substantially as hereinbefore set forth, of the disk-gang sheft, a series of spoked or perforated disks mounted loosely thereon, collars or spacing thimbles interposed between the disks, and clamping mechanism, whereby the spokes of the disks can be adjusted relatively to each other and the disks rigilly secured together on their shaft, with which they turn.

No. 226,691.-BENIAMIIN J. IVEST, NEW ORLEANS, LA.-Cultivators.-April 20, $188 \mathrm{o}$. [Filed Fuly 30, [879.]

Claim.-1.-In a rotary cultivator, the right-angled standards $E E^{\prime}$, the lower ends of which are turned and fitted with horizontal spidles $\mathrm{F} \mathrm{F}^{\prime}$, of the construction described, carrying revolving disks, substantially as described.

2.- In a rotiry cultivator, the combination, with the angled standards $\mathrm{E} \mathrm{E}$, horizontal spindles $\mathrm{F} \mathrm{F}^{\prime}$, and the 


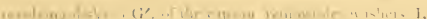

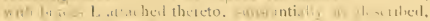
an f For the purpre ext forth.

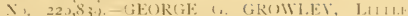

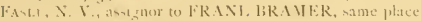

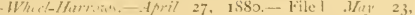
IS-S.

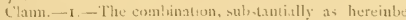

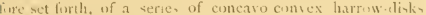
with a veries of serapers or clearers fixed upun a turning bar or rock haft, wherely the scrapers or clesters my be operatel to bring them close to or in contact with the concave vites of the lisks, or to remove them therefrom, by simply rocking the seraper har or shaft in its bearings.

$\mathbf{z}$,-The combination, ulmtantially as hercinbefore set forth, with a gang of rotating harrow-clisks, of a revolving, roching or turning scraper bar places! in a different plane from the disk shaft or axle to pernit the scrapers or clearers

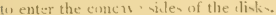

3.-The combination, ulatantially as hereinbefore set forth, of a gany har or heam, a gang of rutating harrow-diskis, the shaft or axie of which has it hearing in -upport on the ganz-bar, a turning or rocking las proviled with scrapars or clearer mounted on the gang-bar in a different plane from the ilisk shaft or axle, and a lever for controlling the scra1;is.

Vo. 227.070.-(iARLAND B. ST. JOIIN and IOHN K.

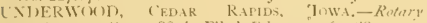

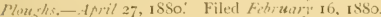

(laim,-1.-In combination with frame 1), as ileneribed, and rotary disks $\mathrm{F}$, the horizontal under revolving cutting disk, $\therefore$, substantially $i s$ and for the purposes set forth.

2.- The frame D, $\boldsymbol{Y}$-haped at the rear. having swinging -ide sruicle-wheel, J, at the forward ead, and carrying on the vide the disks $F$, combined with lever $\mathrm{K}$, ratchet $\mathrm{E}$, and arm $C$, and wheel $A$, substantially an described.

3.- In a plough, the combination of a forward out vertically-cutting diak with a horizontal-cutting share-blade liscateil behind said disk and adapted to cut under and to the bottom of the furrow, substantially as describet.

No. 227.724.-FRANK BRAIIER and GEORGE (i.

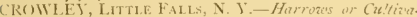
lors, - Mhiz Is, ISSo. Filed tpril 6, I83o.

Claim.-1.- The combination, substantially as hereinbefore set forth, of the main fram:, disk-gangs mounted upon the opposite sides of saicl frame, and mechanism for causing each disk-gang shaft to amume a different angle from the other relatively to the line of draft, at the will of the driver, without interrupting the operation of the machine.

2.- The combination, substantially as hereinbefore set forth, of the main frame, the rlink-gang, its vertical shaft, the soc'set therefor, the crank ant pitman, the rock-shaft. and a lever for operating the rock shaft whereby the angle of the disk-gang shaft relatively to the line of draft may be varied at pleasture.

3.- The combination, substantially as hereinbefore set forth, of the disk-gang.'its vertical shaft, the socket therefor. and the draft-rod, whereby the gang-shaft is promptly restored to its working angle by the draft of the team after having been turned to move the machine siclewice.

4.- The combination, substantially as hereinbefore set forth, of the disk-gang, it vertical, shaft, the socket therefor, the adju-table -lott d plate and :et-crew, the top or pin, and the houlder against which it abuts.

5.-The ocm'sination, subtanially os hereinhefore se: forth, of the disk-gang, its vertical shaft, the socket therefor, the adjustable slotted plate and set screw, the stop or pin, the shoulder against which it abuts and the draft-rod.

o.- The combination, ub-tantially: as herinbefore set forth, of the main frame, the horizontal arm secured thereto, mechanism, substantially such as described, for elevating or depressing the outer end of said arm, ant a disk-gang mounted thereon.

7.-The combination, substantially as hereinbefore set forth, of the main frame, the disk-gangs, their vertical shafts, the sockets therefor, levers for changing the angle of each gang, and draft-rods connected to the disk-gangs.

8 -The combination, sulsstantially as hereinhefore set

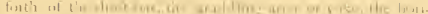
contal gпu -

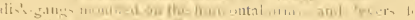

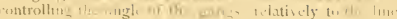
ir.aft.

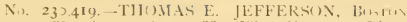

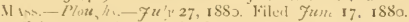

Claim.-1.-C cutum whe in or disks, or the equivalent thereof, an at B, of relatively large and imall diameters or ire, in embination with a plough, wherelyy the plougher soil in uniformly harrowed or cultivated, and alon the pren. are and friction on the lankide of the plough are avoided, sulutantially as set forth.

2.-In a plough, the furrow-vit barin whect $\mathrm{D}$, ap plied to an auxiliary frame $\mathrm{C}$, having a plough attached to it in combination with disks or wheeh, as at $\mathrm{B}$, applied to a main frame, A, whereby the frames are supportel on the furrowside by the disks or equivalent contrivanc s while plough ing and harrowinu are going on, and by the furrow-ide wheel when the said op:ration-cease and the plough a:ad disks are rained out of the soil, sulntantially as described.

3.- The combination of the seed-planting mechanism, as at $\mathrm{E} \mathrm{E}^{\prime}$. with the main frame, auxiliary frame, oblique disk w or wheel, as at $\mathrm{B}$, or an equivalent contrixance for relieving the plough from presure and friction on its landside, and also barrowing or cultivating the soil, and a plough for turning over the soil, substantially an de acribed.

No. $231.5^{82}$. -HENRY IVE-, BATAli, V. Y.-Cul.

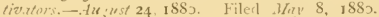

Claim, -I, - In a eultival or, the combination of two set rotating point-1 rot, tr te th, E. chutring rearwarilly, and curved pointel raik or tecth $K$, arranged at sutable distances apart on the wuter side of the vet if rotating teeth in planee parallel with the line of draft, wherely the ground iv opened or scarified without beins turned over on both sides of the same row of plant and between the rows or hills, arch (;, and the lrag-har, H 1 , substantially as set forth.

2. - The combination, with two seth of rotating teeth, E, of the esnnecting $\mathbf{U}$-haped bars $G$ and aras $H$, whereby the encls of the bar $G$ are connected with the frams of the machine, subatantially as set forth.

3.- The combination, with the rotating tecth E. $\mathbf{J}$-haped connecting bar $G$, and arms $\mathrm{H}$, of the sleeve 1 , supurting. the forward ends of the arms $\mathrm{H}$, and male laterally adjust able on the frame of the machine. vibstantially as set forth.

4.- The combination, with the $\boldsymbol{U}$-haped bir $\mathrm{G}$, provided with socket $r$, of the elbow shaper whors $f$, incerterl with their vertical portions adjustable in the sockets 5 , and carry. ing upon their horizontal portion the hubse, to which the teeth E are securesl, substantially as set forth.

5.-The combination, with the shaft $a$, of the wheels A. male laterally arjustable thereon, rotating teeth $\mathrm{E}$, mounter on arbor $f$, which are attached to latcrally-acliustable frames G $\mathrm{H}$, and cursed teeth $\mathrm{K}$, arramed between the seval sets of rotating teeth and secured to laterally-adjuntable arm. I, subtantially as set forth.

No, 233.455.-JOIIN K. (NDFRWUOH) and GARL.AND B. ST. IOHN, CEDAR KAITU, JUWA.-Re(a)Y Ploushs,-Oilobr 19, 1880. Filed Filum, I6, 1880.

Claim,-1.- The combination of the plough-frame A with the piroted caster standard $F$, finger $i$, and recesied guicling and locking arm $G$, suintantially an and for the purposes set forth.

2.-The combina $i$ on of frame $A$ an l plouth dirks C with the axle $\mathrm{E}$. pivoterl standare $\mathrm{F}$, and finger $i$, as described, and wheel $D$, substantially as and for the purposes set forth,

3.- In a shifting axle, substantially as described, the collar (), stem S, nut $n$, and slotted cap L, in combination with the conical chamber or bearing $K$, sub-tantially as and for the purpose set forth.

No. 233,999.-THEODORET. DANTEI.S, MURRISON, I1.l.. asignor to himself, MARTIN $V$. ALSTIN, and HENRY S. FERGUSUN, same place-Com-Planters.November 2, 1880. Filed $\mathcal{F}_{\boldsymbol{u}} / \mathrm{y}, \mathbf{2 4}, \mathbf{1 8 8 0}$.

Claim. - In a corn planter, the combinations of the frame $\mathrm{C}$, the seed boxes $\mathrm{A}$, the hangers $\mathrm{E}$, the disks $\mathrm{H}$, the bent axle $G$, the rods $J$, the bar $K$, the slotted arms $L$, the bolts 
$n$, and wheels $\mathrm{M}$, substantially as berein shown and described, and for the purpose set forth.

No. 235,029.-I. DILL SHRIGLEY, IUWA CITY, IOWA -Combintil Seed-Drills and Rolling Cu'ters. - November 30, 1889. Filed Siptembir 22, 188 o.

Claim.- I. - The combined seed drill and rolling cutter comprising the frame $\mathrm{A}$, hopper $\mathrm{B}$, shaft $\mathrm{C}$, drill tubes or teeth $b$, and the rolling cutters D, the points of the drill tubes being extended forward between and close to the sides of the cutters, and the discharge openings located above the points and on the posterior sides of the drill teeth substantially as deicribed.

2.- The curved drill tubes or teeth having flattened points, posterior grain orifices, and shields, substantially as set ferth.

No. 238654 - IAY S, CORBIX, GoUverNeUR, N. Y -Disk-Harrowe.-Wirch 8, 1881. Filed funt 12, 1883,

Claim.-1, - The combination of the following element viz: two or more gangs of disks, each having a separate axle, a draft frame and transverse frame, joined rigidly to gether and supported entirely upon the cutting disks, two or more swinging gang frames situated entirely in the rear of the transverse frame and connected thereto independently of each other, and bearings for the gang-axles respectively situated between the ends of the axles, and supported upon the swinging gang-frames, whereby said barings raise and fall with the axles relatively to the main transverse frame, substantially as set forth.

2.- In rotating disk harrow, the combination, sub-tantially as hereinbefore set forth, of the following element, viz: a transverse connecting frame, two or more axles, each carrying a series of cutting divks, automatically stringing frames for supporting the cutting disks, and the bars $\mathrm{E}^{3}$, rigitlly attached to the gang-frames and hinged at their front end directly to the transwerse framo.

3.- The combination of the following element, viz: a draft-tongue, a transverie fram. ri i lly connect al to a ail tongue, cutting disks arranged to support the entire weight of the transverse connecting frame, gang frames pivoted independently of each other directly to the transverse frame on horizontal lines transverse to the lines of draft. whereby both ends of each gang-axle automatically rise together and fall together, and said axles swing independently of each other, subitantially as set forth.

4.-The combination of the following elements, viz : rota ting cutting-disks, a transverse frame supported entirely upon the cutting disk, gang fromes hinged to the transverse frame on horizontal linestransverse to the lines of draft and arranged to rive and fall automatically, disk axles supported on the gang frames and arranged to have both end, of each axle rise together and fall together, and stops which limit the automatic movements of the gang frames, substantially as set forth.

5.-In a rotating dis' harrow, the combination, sub-tantially as hereinbzfore set forth, of the following elements, viz: a transvere connecting frame, two or more gang frames hinged directly to the transvere frame and arranged to freely swing antomatically thereon, rotating cutting disks carried by said gang frames and arranged to support the entire weight of the frame, and an intermediate e pualizing mechanism secured rigidly to the transverse frame and arranged to rest loosely upon the gang frames, whereby the weight of the frames is supported upon the cutting disks, and the gang frames are allowed to automatically conform to the surface of the ground.

6.-In a rotating dis' harrow, the combination, with a transwerse frame and two or more disk gangs arranged to automatically oscillate vertically, of the gang frames $\mathrm{E} \mathrm{E}^{\prime}$, which at their front ends are hingéd directly to the transverse frame, and which, while oscillating, retain the gang axles in sub-tantially borizontal lines, sub-tantially: as set forth.

7-In a rotating disk hanow, the combination, with a vertically oscillating gang of disks mounted on an axle, of an automatic adjusting mechanism, whereby the inclination of the gang axle to the line of draft is automatically altered by the vertical movement of the gangs, substantially as and for the purposes set forth.

8.-The combination of the following elements, viz: a main frame, a vertically swinging gang frame, hinged to the main frame, a sliding axle supported on the hinged gang frame, a sliding bearing and a pivoted bearing for the axle, both supported on said gang frame, and an adjusting mechanism, by which the position of said axle is adjusted both automatically and at the will of the operator, substantially as set forth.

9. - In a rotating disk harrow, the combination, with a gang frame and a disk axle, of a sliding bearing and an oscillating bearing for said axle supported on said gang frame, substantially as set forth.

IO.- In a rotating disk harrow, the combination of the following elementi, viz: a main frame, a gang frame pivoted to the main frame, a rocking mechanism hinged to the main frame, a gang axle arranged to rotate in a sliding bearing and in a piroted bearing, and a link connected to the gan? axle and attached eccentrically to the rocking mechanism.

11.- The combination, with the main frame and two or more disk gangs hinged thereto and mounted on slidint axles of the rocking bar 1 , connected to all of the disk axles, substantially as set forth.

12.-In a rotating disk harrow, the combination of the following elements, vis : a main frame, a gan frame pivotel to the main frame, a disk scraper rixilly attached to the gang frame, and a rotating cutting disi arranged to oscillate horizontally on the gang frame independently of the dis': scraper, and to be moved toward the scraper when the dis'is are to be cleaned, substantially as set forth.

13.- The combination of the following elements, vis: a main frame, a gang of two or more cutting din'st arranged to o-cillate vertically on the main frame, a gan frame having the arm $\mathrm{E} \mathrm{E}^{\prime}$, situated between the adjacent disk; and extending backward from the central line of $t^{\prime} \cdot 2$ disks $t>$ tireir rear ed res, the cross bar M. secured to tis r saren 1 . of said arm, E E', and the scrapen N, rigidly attachel to t'se crow- bar .11, subst antially an set fort'i.

14. - In a rotiting di $\ldots$ harow, the combination, with a rotating cutting disk and mechanism for adjusting the angle of said disk relative to the line of draft, of a scraper adapted to be brought into play by the angular adjustment of said disk.

15.-In a rotating disk harrow, the combination, with horizontally adjusting disk gangs and scrapers arranged to clean the disks, of mechanism operated by a single lever, whereby the, inclination of the gangs is altered, and whereby the scrapers are brought into operation, substantially as set forth.

16.- The combination, with a gang frame of a rotating cutting disk mounted on said frame, a disk axle arranged to slide on said frame, ancl a bearing for said axle pivoted to the frame in front of the axle, whereby the axle is caused to move endwise when it is oscillated about the pivot of said bearing, substantially as set forth.

No. 238,655 -JAY - CORBIN, GuUverseur, N. Y. -Disk-Harrouis.-Warch 8, 188 I. Filed fune i2, 1880 .

Claim.-1.-In a dis's harrow, the draft tongue, two opposed disk gang, and the braces $\mathrm{C} \mathrm{C}$, secured directly to the disk gangs and to the tongue, in combination with the transverse connecting frame, situated in front of the gang axles, and arranged to rust vertically upon the braces $\mathrm{C} \mathrm{C}$, in front of saicl axles, and connected to the tongue above the disks, substantially as set forth.

2.-In a disk harrow, the combination, with the tongue and two opposing disk gang, arranged to vilorate vertically independent of each other, of a transverse frame formed of a single connecting cuttine bar shaped to have the downwardly projecting arms $\mathbf{H}^{\prime} \mathbf{H}^{2}$ respectively connected to the outer bearings of the gangs and the intermediate part, $\mathrm{H}^{3}$, formed in one piece with arov $\mathrm{H}^{\prime} \mathrm{H}^{2}$. substantially as set forth.

3.- In a disk harrow, the combination, with the drafttongue and two opposed disk gangiarranged to vibrate independently of each other, of a transverse connecting bar, which is flexibly connected directly to the gangs by horizontal pivots and is rigilly connected to the tongue, substantially as set forth.

4.- The combination with the disk gangs, of a transverse connecting bar or fram hinred to the dis' frames below the 
axlen the the s.ms, - ubstantially as and for tire purpore, set forth.

5. The combination, with the transterse connecting frame, of the disi gangs arranged to oscillate horizontally on a pivot situated below the axle of the gang;, sulstantially :ts and for the purposes set forth.

6.-The combination, with the transverse connecting frame, of disk gangs arranged to oxcillate vertically on pwot which are situated bshow the asles of the disis, subatatially as set forth.

7.- In a cutting dis': harrow, the combination, substantially as herein set forth, of the following element, viz: a transverse connectiag frane, two or more oppoving disk gangs supported independently of each other on said trans. verse frame, and each provided with a separate through axle, and separate springs connected to the gang frames at point between the ends of said frames, to cause the gangs to oscillate in vertical lines.

8, - The combination of the main frame, a "dis's gang pivoted to the main frume at a puint bitween the ends of the gang, and a spring, which is arranged to oscillate the gang vertically, and is situated at the center of oscillation of the yang.

9.- The combination of the following elements, viz: the draft tongue, the main frame attached to the tongue trans versely, the dis's gangs pivoted horizontally to the transvere fiame, and the metallic bracss C, pasing loosely throush the transverse frame and connected both to the disk gangs and to the tongue in front of the transverse frame.

10.- The combination with the trausverse gang frame anl the disk gan , of device arran red, sub tantially as described, to adjust said frame vertically upon the ganzo, as set forth.

11.- The combination with a main frame and disk gangs connected to said frames by vertical pivots, of mechanism, sub-tantially as described, arranged to adju t the main frame on s.id vertical pivats as set forth.

12.-The combination of the following element, viz: the draft tongue, the main frame attached to the tongue transversely, the disk ganus pivoted to the main frame, the bsarings $\mathrm{L}$ for the gang axles, the lugs $\mathrm{L}^{2}$, attached to the $b$ arings $I$. in front of the axles, an $I$ the braces $C$, which pass loosely through the main frame and through the lug; $I^{2}$, and are bant upward to form the vertical pivots $C^{2}$ for the gan frames.

13. - In a disk harrow, the combin tion, with a rotating di k, of a scraper surrounding the axle and rotated therewith sub tantially as set forth.

14.- The combination, with a rotating disk, of a disk scraper which is supported at one end only, and bas it, fixed end at or near the center of the disk and it- free end at or near the circumfereuce of the dis's, subutantially as set forth.

15.- In a disk harrow, the combination of the following element, vis: a series of rotating disk, a series of scrapers support rl independently of each other and arranged to respectively engage with said disks, and a scraper operating mechani-m which engages with the scrapers to bring them into action, an:l which is entirely dinengazed from the scrapers when they are idle, substantially as set forth.

15.-The combination, with the rotating disks and the series of the scraper. $O$, of the sliding bar $F$ and arms $i i$, adapted to engage with said scrapers, substantially as and for the purpose; s.t forth.

17.-The combination, with the scraper, $O$ and mechanism arranged to stop the rotation of said scrapers, of the levers $G$, arranged to automatically permit the further rotation of said scrapers, substantially as set forth.

18. - In a disk barrow, the combination, with a rotating cutting disk, of a hollow hub which is beveled at both ends, to bave the planes of said ends oblique to the plane of tise divk and to the $a x i$, of rotation, subutantially a set forth.

19. - In a dis': harrow; the combination, with a through axle, of dis't hub, which are arranged in contact in a con tinuous series along the axle, and are heveled at their conti zuous ends, to have the planes of said end, obli jue to the axis of the hubs, substantially as set forth.

20.-In a di,k barrow, the combination, with a series of rotating disks and the through axle revolving continuously witb said diki, of a series of contiguous disk hubs, each having a disk rigidly secured to it unter face and each beveled at the end contiguou so the adjacent disk hub, subtantially as set forth

21. - The combination, with the rotating disk and a scra. per for said disk, of the hub $a^{\prime} a^{2}$, having the collar $a$ formed with the recess $a^{7}$, to receive the scraper, substantially as set forth.

22.-The combination, with the axle $B$, the connecting rod 1 , and the series of disks, of the inner disk hub, $A^{\prime}$, provided with the flange $a^{8}$, whereby said bub is adapted to be loosely attached to the connecting rod $\mathrm{D}$, substantially as set forth.

23- The combination, with the axle $\mathrm{B}$, the connecting rods I) $\mathrm{D}$, and the gangs of disks separate from each other at their inner ends, of hubs respectively mounted upon the gang axles and arranged to project inwardly from the innermost hub of cach gang, to provide a fastening for the connecting rods D D, substantially as set forth.

24. - The combination, with the disk and fixed stops $a^{3}$ of the ring $\mathrm{N}$, having the inclined faces $n^{2} n^{3}$ arranged to bear against the said steps, subitantially as and for the purpose set forth.

No. 239,219,-JAMLS W. BODLEY, NEW ORLeANS, LA.-Rotary Cultizators.-Warch 22, iSS1. Filed Fanuary 5,1880 .

Claim.-1.-In combination, the standard C, adjustably beld in the slotted beam B, and capable of rotary motion, the disks $D$, secured upon an axle formed by bending sucb standards $C$ at right angles, the parallel beam $A$, having the slots $i$, and connecting braces secured to the axle of the disk and adjustable in such slots

2.-The combination with the beams $\mathrm{A}$ and $\mathrm{B}$, provided with slots $c$ and $b$, of the standard $\mathrm{C} C$, constructed as herein shown, rotary ploughs 1 , and braces $I \mathrm{~K} \mathrm{~L}$, adjustably connected with the bams $A$ and $B$ by means of cranknut, $e^{\prime} e$ and $e^{\prime} e^{\prime}$, substantially as berein shown, and for the purpose set forth.

No. 249.993,-THOMAS A. GALT and GEORGE S. TRACY, STERLING, ILL.-Disk-Harrozes.-May 3 188I. Fïled furust 5, I 880 .

Claim.-I.-In a disk harrow composed of two gangs of disks baving their inner ends contiguous to or approaching each other, substantially as shown, the combination of the two lever. F F, fulcrumed on the tongue $\mathrm{A}$, and the rods $d d$, connecting said levers respectively to each gang of dinks, whereby, by means of the separate use of said levers, either gang of disks can be thrown back past the end of the the other to discharge intervening obatructions, and be returned to its position without affecting the position of the other gang of disks, substantially in the manner herein shown and described.

2.-The combination, with the concavo-convex disk D, of the revolving scraper $\mathrm{E}$, having a continuous unbroken surface on the side contiguous to the concave face of the disk, and arranged so as to be presented to the concave face of the disk and operate hetween the axle and the periphery thereof, and project slightly beyond said periph ery, subatantially as and for the purpose herein shown and dexcribsd.

3.- The combination, with the concavo-convex disk $\mathrm{D}$, beam $\mathrm{C}$, and pendant $\xi$, of the revolving scraper $\mathrm{E}$, baving a continuous unbroken surface on the side contiguous to the disk, and a unilateral jourual, $h$, mounted in said pendant, said scraper arranged so as to be presented to the concave face of the disk, and operate between the axle and the periphery thereof, and project slightly beyond said periphery, substantially as and for the purpose berein sbown and described.

No, 211,074.--PHILIP SE1TZ. BATON RovGE, assignor of one half to RICHARD W. BOLAND, NEW ORLEANS, LA. -Culiza rs.-May 3, I88I. Filed Angust 6, 188I.

Claim.-1.- In a cultivator, the combination, with the carriage A B C, the $\boldsymbol{U}$ shaped bar $\mathrm{F}$, and the draw rods $\mathrm{E}$, of the short bams I, the swiveled $\boldsymbol{U}$ shaped standards J, baving locking turn-tables or disks $\mathrm{N}$, the sets of rotating circular cutters or plough plates $\mathrm{L}$, the long beams $\mathrm{H}$, the swiveled $\mathbf{U}$ shaped standards $\mathrm{P}$, having locking turn-tables or disks $k$, and concavo-convex rotating disks or plough plates $Q$, as and for the purpose specified. 
2.-The combination, with the disk of the that $\mathrm{K}$, the swiveled $\mathbf{U}$ bar $\mathrm{J}$, the turn-table $\mathrm{N}$, having a number of holes for pins, and the beam 1 , as and for the purpose set forth.

No. 24I,086.-GARLAND B. ST. JOHN, CEDAR RAPIDS,

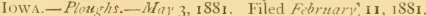

Claim.-I.-In a plough, the half-share and mould-board $C$, cut away at $c^{\prime}$ in front on a curved line, its forward end or point extending about to the center of the disk $C$, and combined with said disk, which is mounted by sleeve $\mathrm{E}$ on the inclined arm $\mathrm{F}$, extending from the plough-beam, substantially in the manner and for the purposes set forth,

2.-In a plough, the combination of the revolving concavo-convex disk with the half share and mould board arranged to work in unison, said disk cutting in advance of the mould board, substantially as described.

No. 242,115.-DAVID E. DARNELL.-MASONVILLE,
N. I.-Marking Out Sled for Asriculturat PurpostiMay 31. ISS1. Filed December 31, 1880.

Claim.-r.- The brackets $\mathrm{C}$, with rear disk-like portion$\mathrm{H}^{\prime}$, the disks $\mathrm{H}$ having cnps $\mathrm{G}$, the shares $\mathrm{E}$ having hub, on their inner faces, the axle-pins $S$ and vertical eyebolts $D$, combined as described, the disk and disk-like portions $\mathrm{H} \mathrm{H}^{\prime}$ being contiguous, and the disks being rotatable on the disk portions, and the cups $\mathrm{G}$ formed with said disks $\mathrm{H}$, all constructed and operating as and for the purpose set forth.

2.- The riding-sled with runners of $\mathbf{T}$-metal, the brackets $C$, with the rear knees of the rumners pasted through them, the disks H, shares E, pins J, and bults D, combined and operating as described, and forming an improvement in marking out sleds, as stated.

No. $2+3,676$. - THONAS E. JEFFERTON, BOSTON, Mlass-7une 28, 1881. See Plovghs-Wheel or Sulky. 

Alexander, R. WV.

Avery, R. H.

Avery, R. H.

Baird, E. A. and Gale,

$$
\text { A. T. }
$$

Bennett, IV. II. and Heirht, II. K.

Hrown, W. P.

Carson, R.

Carter, C. D.

Carter, C. D.

Cauthorn, I. N.

Cavett, R. S.

Clark, W.

Clawson, L. G.

Cook, J.

Cooper, A

Crutcher, S.

Eichholtz, MI.

" 4

Ely, B. M.

Evans, J. (;.

Gardner, J. M.

Gibson, R. F and Cowden, S. $\mathrm{Al}$.

Graham, J. I. and Wa]. Jace, ... J.

Graves, J. M:

Helem, $\mathrm{I}$.

Hooper, IV. 1.
Plate Claim

355110

$343 \quad 106$

$\begin{array}{ll}345 & 107\end{array}$

359111

$356 \quad 110$

$360 \quad 111$

$342 \quad 106$

$354 \quad 109$

359 III

$\begin{array}{ll}346 & 107\end{array}$

348108

$354 \quad 109$

$\begin{array}{ll}351 & 105\end{array}$

$339 \quad 105$

$34 \times 108$

$347 \quad 107$
34

34 ㅇ 106

(R.) 340106

(R.)

$341 \quad 106$

$340 \quad 106$

$360 \quad 111$

349108

360111

$350 \quad 108$

359111

$347 \quad 107$

349
Hooper, IV. L.

Hoyman, II. S.

Jenkins, J. C.

Joy, E. IV.

Kendall, T. W.

Lanham, IV. M.

Lanham, W: M.

Louden, IV.

Ludlow, J. M. and I'ruit, S. $C$

Mclill, T. W.

Meliee, C.

McNitt, M.

Markee, J. and Spicer, IV $\mathrm{E}$.

Miller, R. M.

Morrison, J. E.

Mourning, F. (i.

Owen, $G$.$$
\text { " } "
$$

Owen, G.

Parker, J. A. J. W:

Pattee, J. H.

Pattee, J. II.

Pattee, H. H.

lattee, H. II.

Pattee, J. 1 .

l'eck, E.

l'oling, T.

\begin{tabular}{cc} 
Plute Cluim \\
351 & 108 \\
358 & 110 \\
351 & 108 \\
354 & 109 \\
353 & 109 \\
341 & 106 \\
342 & 106 \\
353 & 109 \\
& \\
358 & 110 \\
356 & 110 \\
357 & 110 \\
352 & 108 \\
& \\
350 & 108 \\
346 & 107 \\
335 & 105 \\
342 & 106 \\
337 & 105 \\
337 & 105 \\
337 & 105 \\
343 & 106 \\
360 & 111 \\
344 & 107 \\
344 & 107 \\
346 & 107 \\
355 & 109 \\
355 & 109 \\
357 & 110 \\
339 & 105 \\
346 & 107 \\
\hline & \\
&
\end{tabular}

Prate, E. Plate Clain

Pratt, E.

$33^{8} \quad 105$

(R.) 338 IO

l'rice, T. J. and Hunt, A. $35^{2}$ Ing

Reck, W. 341106

Reeves, W. F., A. B. and M. T.

Reeves, A. B.

$353 \quad 109$

kobertson, WV. I1. 351 Io8

Roliert-, T. li, $\quad 344 \quad 107$

Simpson, M. P. $\quad 344 \quad 107$

slifer, R. H. 1 . 358 III

Sloss, L. L. $\quad 339 \quad 105$

Sloss, L. L. $\quad 342106$

slusser, $G$, $\quad 348108$

Smith, A. 337105

simith, $J$. 359 иा

Stubblefield, D. A. and

Luse, W. H.

Sunmers, J. and Trimble, 341 I 106

ग. $357 \quad 110$

Thomas, J. W. $\quad 349108$

Thomas, J. C. B. $\quad 357$ 110

Thrasher, T. L. $\quad 347 \quad 107$

Vangundy, E. W. $\quad 338 \quad 105$

Ward, IV.C.

Warner, C. $\quad 354 \quad 107$

Wat on, C. H. 345107

Watson, IV N. 345 108

Watson, W. N] 350 108

Williamson, $4 . \mathrm{D}, \quad 35^{2}-105$

Voung, A. $\quad 339$ 105 


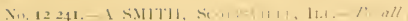

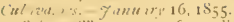

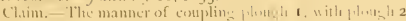

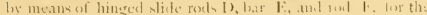

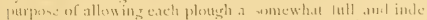
fondent $m$ tion. and ret bring the plough under the control

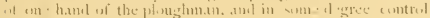
inth phowehro ar wet forth.

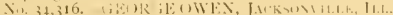

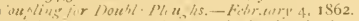

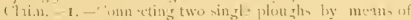

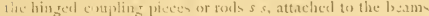
of aitl plengti in the rear of the atanilareh the reof, so asto

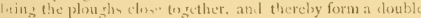
m. ntillowarl plough, in the monner and for the purpese de- It:ucil.

$\therefore-7$ T. combination of th: curred or bent piecen $t l$, and the viding joint of the bars ( and 1$)$, in the manner and for the purpone specitied.

3.-Connacting the compoum curved or lent bar $\left(^{\circ}\right.$ with the bar 1$), 1, y$ m. in of the chain $x$ or $i t-c$ puivalent for the purpuse set forth.

4. Th: combintisn of the front curved stretcher bar 13 , and joint:al bar $\left({ }^{\prime} \mid\right)$, for the purpose of comnecting two plonghr, ans set forth.

5. - Tane combination of tive front stright bar B, with

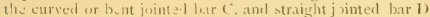
for the purpose of connectins two ploughr, as specified.

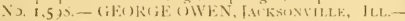

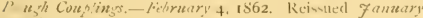
5. $156+$.

(Jam -1. - Connectinz two single ploush by mean of tite hingerl couplin : piecen or rochs s s attrehed to the heam at s.ixl plost she it tie rear of the standard thereof, so as to

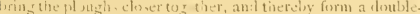

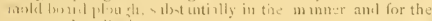
purpose dencrib-i.

2. - The combimation of the curved or bent piece or 1. cee $t /$ and the slidin: juint of the bar ( and $I)$, in the inzmer and for tixe purpose herein specifial.

3.- Comecting the compound carved or bent couplins itur ( with the upper coupline bir 1$)$, substantially in the in muer and for the purpow hercin set forth.

4.- The coulsimation of the front cursed in bent stretcher thar B and curved or bent couplinar bar ( ' for comnecting two ploustrs, substantially in the manner and for the purpone her in set forth.

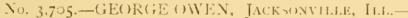

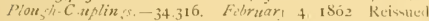

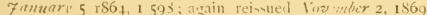

Chim. - I - cimpling twan or more plenghe, with rigid coupling, macle of nowl or iron, or partly of wost and partly of iron, and combeted with the plouglis by loose or hinge joints, subtantally as anl for the jurpose heroin vecitied.

2.- The combination of the curver or bent piece or pizes $t l$, and the ali ling joint ws the han ( am l), in the manner ant for the fur 0 : hercin yecilied.

3. - Connecting the compound curvel or bent compling lar ( with the npp-r co.pling lar $\mathrm{b}$, substantially in the manner and for the f.uppone h.rein set forti.

4.- The combination of the front curverl or bent stretcher bar $\mathrm{B}^{\prime}$, and curved or bent coupling bar $\mathcal{C}$, for connecting two ploughs, substantially in the manner and for the purpose berein et forth.

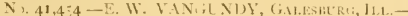
Cultivitor:-February 2, i 864 .

Claim. - The imorovel mann-r of e by $m=a n$. of the peculiar arrongements of the piveted yosed connecting bar, $E$ with thank f, workine in ab:l through the luttel or voen traitht bar $\mathrm{F}$, in comlanation with the draught beam. 1. , the whole operating substantially in the manner and for th purp, , lo erein set forth.

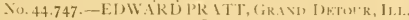
- Civ'tivatori. - O-tobir Is, 1864.

Claim.-The two plough bam- I . I, connected to rether at a proper distance apart by means of har 11 or 11 attached to the $\mathrm{A}$ by pivot bolt $a$, to admit of an inderendent lungi. tudinal movement of the boams $A$, the latter leing used

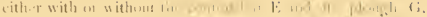

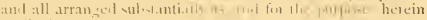
ret forth.

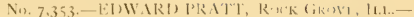

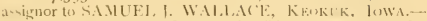
culizilors 44.747 O.tos r. 18 is64. Keissued Oitober 17. 1576 . Filed $7 u^{4}+12,1875$

Claim-1.-In culivators, a cromathar, 11, with clevaled center, havins at it enl, vertical pivot-1"', with upper and lower fxariurs I I' ther for, and interypaces P', comnecting two plonsh-frames, I I' as as to hold their ploughs upright and allow thom movement on the pives, suret.untially as set forth.

2. - The combination, in a walking stradtlle row cultiva tor, of two plongh beams, A A', each hearing a handle, K, with an clevated cromyoke, having at the tend pivots 1. ', and upper and lowur bearing, $1 I^{\prime}$, connecting the ploum heams, 50 as to hold their plough upright and allow either of them to be drawn freely in advance of the other as they are drawn forward, sulystantially as set forth.

3.- The elevated cross yote, hasing pivots $\mathrm{L}^{\prime \prime}$, and intersacen $P$ in its ends, in combination with two plough frames, $A A^{\prime}$. connected in the rear to hold them from crowding apart or together as they are drawn along in throwing furrow's to the center or apart, substantially as set forth.

4. - The cultivator, with two plow beams, A A', connected without forward tomute, and having the front plows $\mathrm{C} \mathrm{C} \mathrm{com-}$ lined with vertically adjuntable runners $M$, unbstantially as set forth.

No, 54.I9I-TAMES E. HORRISOX', WASHINGTON, D. C.-Cultizutors,-ipril 24, 1866.

Claim - 1 - A cultivator having double plough beams $\mathrm{U}$ U, hooke o, clevis $p$, standarels $x \cdot$, and cross bar Y. Y, comstructed, combined, and arranged suletantially as herein -pecified.

2.-In combination with touble plough beams united at tieir front enif, at, descrilsed, the tanclards $x$, and cross b.ar, Y $Y$, comatructed and operated substantially as and for the purpones set forth.

3 - The cntire cultivator with it sarious devices, cons structed, comlined, and arranged ulutantially as and for the purpores herein mentioned.

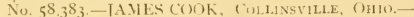
Culvour re-Otober 2, 1866

Claim - - - The intermediate frumes 1 and a al, constructet in the manner described, in comlsuation with the standards d anil d' beam I;, and drag bar, $/$, arranged, connected and ormatin in the manner and for the nurpose syecified.

2,- Thic upper frame $a a^{1}$, and yring connection $b$, in conalination with the plourh handles and notches or gains, to limit the oxtillating motion of the ploughs, in the manner and for the purpue sulutantially as sencribed

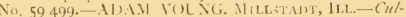

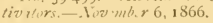

Cham-1.-The comvenction of the beam. $\mathrm{C} \mathrm{C}^{\prime}$ and tixcir combination with the socket, or the handle $\mathrm{B}^{\prime}$, as the care may be, for the purpore of forming the connection burween two corn plousls.

2. - The arljustable clampon D, for the purpose of uniting the two part of the lxam $\mathrm{C}$ and $(\%$, sulutantially as herein d-icribed and set forth.

3.-The brics $E^{\prime}$ and the stoples $c^{\prime}$, for the purpone of att rehing the handles $E$ to the other portions of the plough.

No. 68,247.-L. L. SLosis, near Sistu UNuN, KY.Double S/2:2v:1 Ploughs.-Aurust 27. I 867

Claim. - Comnecting the plough frames to each other by the three aljustable bars $11 \mathrm{E} \mathrm{F}$, not in the same horizontal plane, and pivoted or counected at end to plough frames by loulile jointerl, hinged or equisialent connections, so as to have loth a lateral and rertical novement, subutantially as herein thown and described and for the purpore set forth.

No, 70,111.-EZR.I I'ICK, (11t:AGo, I1.1.-Cu'tiva-

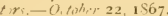

(laim.-1.-A frame work for carrying and drawing the plough of a stadille row cultivator, supported on rumer. substantially as describerl.

2.- The frame supported on runners, in combination with two gangs of ploughs, substantially as specified.

3. - The main frame, supported on runner, in combina- 


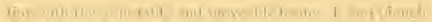

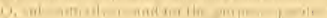

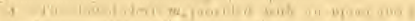

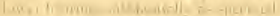

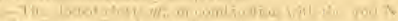
7)

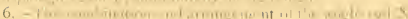

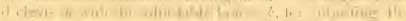

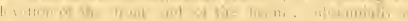
1. 11.21

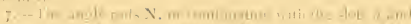

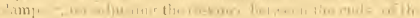

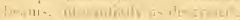

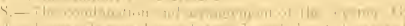

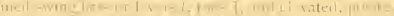

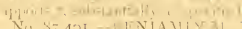

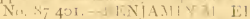

3.

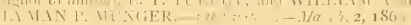

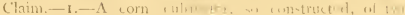

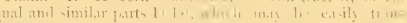

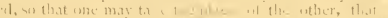

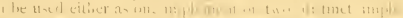

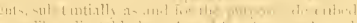

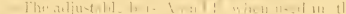

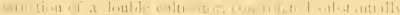

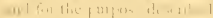

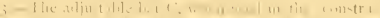

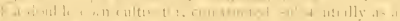

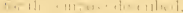

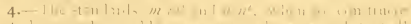

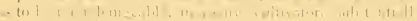

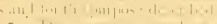

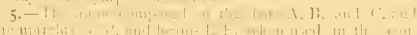

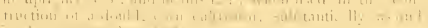

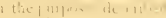

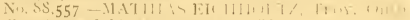

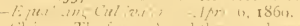

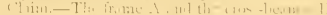

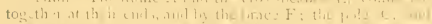

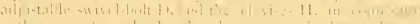

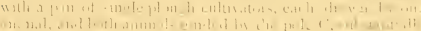

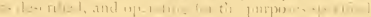

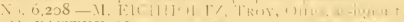

11 P.ITTEF, МI:

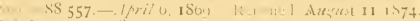

ink 1 \% $11+17.1874$.

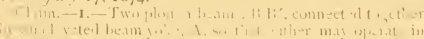

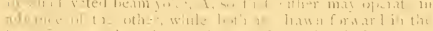

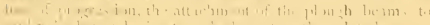

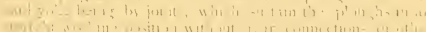

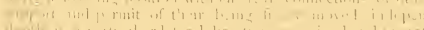

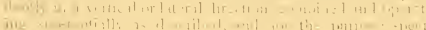

105

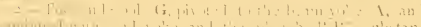

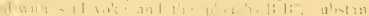

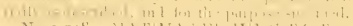

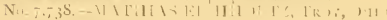

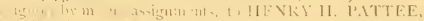

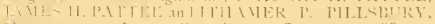

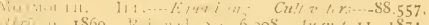

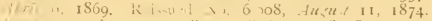

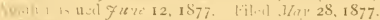

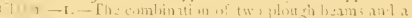

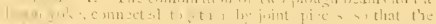

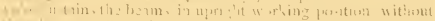

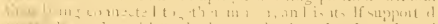

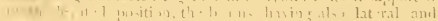

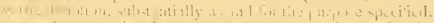

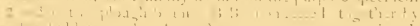

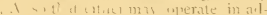

is 13 o ofrumil in the line

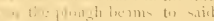

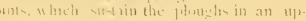

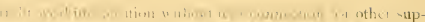

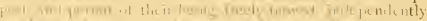

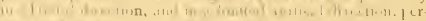

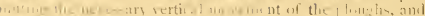

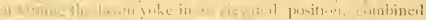
16) I.

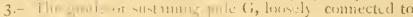

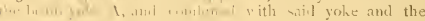

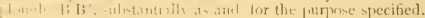

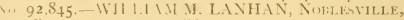
$\therefore-130 \%, 7 /-7 \pi / 1.20,1569$.

Lim.-1. - The r rms-piece IJ, formed of a metal plate,

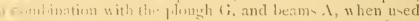

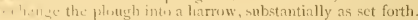

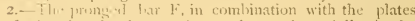
1. fir lamsing the fram. A together, subantially in the

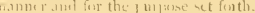

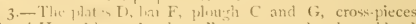
F and H, am lesce 1, when all are arraned and combined th. manner and fin the purpune set fonth.

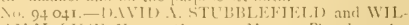

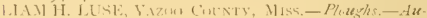
ü. 24, I 869 .

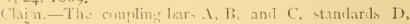

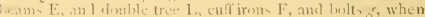
sh hale i, comlincal, artanged, and opurated ul tantially ant fin the ptorpuses set forth.

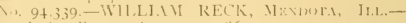

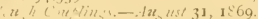

tiam.- i plough coupling, conviting of the twe reads $A$ . ane l wf the clamp (", which has two screws if ., sulatan-

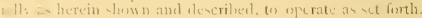

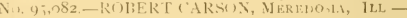
Woughs Sertenticr 21, 1860.

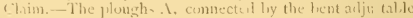

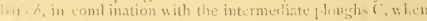
Thasesl as hercin deneriherl.

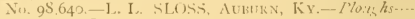
fomery 4.1870

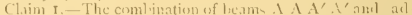

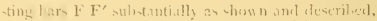

2. The coml inatim and atrangement of the lean $A$ A

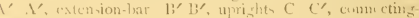

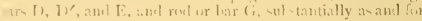
pinpore at finth.

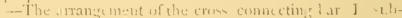
intially ar and for the purpuse $x$ ct finth.

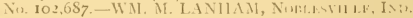
Piousti-. Way 3, 1870

(') i:as - In combination with the tonble plengh $A$, cras.

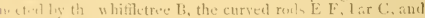

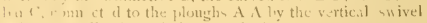
trits - U J), all substutially s set forth.

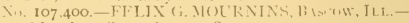
Cu n. I'lowh hs.-September I3, 1870

1 't im-The soulite set of plouglis, ar. of fortis, for culti. stime two-icles of a row of plant-, when macic and corranged

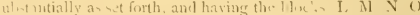
and I. $\mathrm{II}^{\prime} \mathrm{N}^{\prime}()^{\prime}, 2=, \mathrm{t}$ forth, an the two commectimg part. I nil K. for the prur whe deseribed.

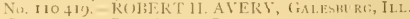
- Cullitators.-De ember $27,1870$.

('Thim - - - The comlination and arranmenent of the lesaterl complings $\mathrm{H}^{\prime}, \mathrm{K}$, and $\mathrm{M}$, and cennecting or link-

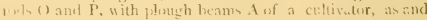
for the purpers-ulutantially as set forth.

2.- The dain $n \|$, whin comlined and arrinced t oper

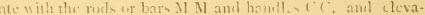

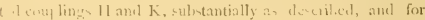
the puypore specificil.

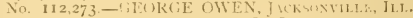

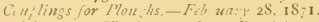

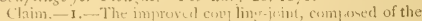
roller $k$, with its stem / and key $m$, aml the eyes I, L, all

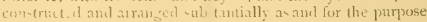
hervin sperified.

2 -The desulste cultisaturs or plonghs. provided with the canpling-hars $\mathrm{I}$ ) and $\mathrm{E}$, junted thereto lyy the couplings $\mathrm{F}$

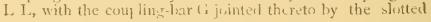




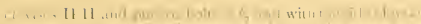

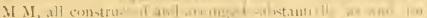

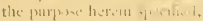

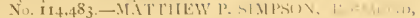

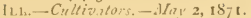

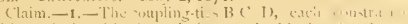

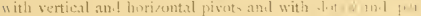

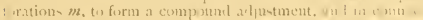

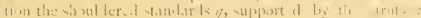

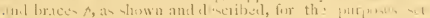
iurth.

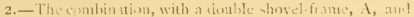

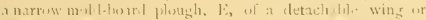

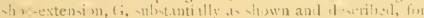

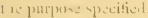

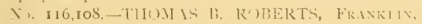
+ -Cultivatur:-7un:20, $188 \mathrm{t}$.

1 tim.- - s strullle-row cultivator havins three turn fit ez he on each of two beam-, the for m $m$ t $t$ wo arran red to tan in irom the row of plants, and the hin l:not one throwing

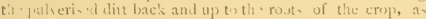
dextive. 1.

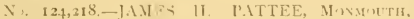
ILt, axiznor to him-2lf, llENRY H. PATTEL, amil

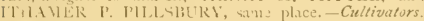
- M:r' $5,1 S 72$.

Clatu. - - The axle A, having plat is $B$ hinged to the whe a spindle-plat 's $\zeta$, so that the wheck are retained in the line of progresion when on: $\mathrm{i}$ - in arlvance of uther, as it firth.

2 The plat's Oand N, wastier T, bolt P, amil laar $\mathrm{T}$, parating in emplination, for the jurpose of hinging the ?:ams to tire as / , subatantially as at forth.

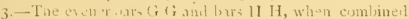

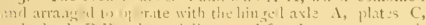
anl wheels E IE, sub tuntiall; as an I for the jurpos speciticil.

No. 6,0So-IA., H, P.ATTEF, MuNmotтH, HL.,

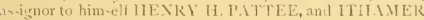
P. I'Il.L.SBURI: - culli:al is, - I24,21S, Jarch 5, IS72. Keisued $O$, ber 17,1874 . Fil d Fuly 22, 1874 .

'Tam.- The combination, in a walking straltlle-row cu'ti 1.2tur, of the followins iastrumentalitis, viz., two whecls, I)

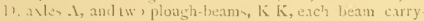
it. han lle and on or or ire sho: lor plougin, and indeleal leatly hinged to the ave, so $x$ to be retaine $]$ in work ist [s-ition withrut $r: x$ comection or supjort, ani

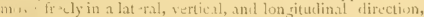
- wh ntially a an I for the purp-sespecificl,

2.-The axle A, hin rel to the wheel spindle or draft plates ii i) o that the wheel are retain il in the line of proveresw.m by the draft of the animak, when ome is in alvanee of

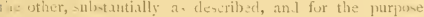
iverie 1 .

3. - In c smbination wirh wis. 10 , lraft plate $\mathrm{B}$, of rating 1 , support ant give lirection $t$, Lie whucl, sulsstmtially as and for the purpon - $p$ i i iel.

4.- The combination of the pl a i b:am, K K, axle $A$, an I wheels $D$ is, the latter lwing linged or pivoted to the avleto permit of one ind $m$ wing in alvance of the other, -ulistantially as describe 1, an I for the purpose specifie 1.

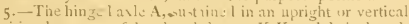

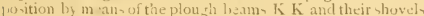
or ploughs ant the j.int pices which cosnect the beam, to the avle, substantially a an+l for the purpuse sed forth.

5.-The evener bar, i am.1 11 , comlined an.l arrangell to

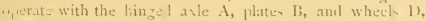
Uh, tuntially as an 1 for the pur,pose sise viel.

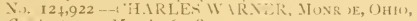
- Culivitor....March 25, 1872.

Clam.-Th e mbination of the a lju-table flexible coupling $b i f$ and E EK with the two pl u ris, substantially as and for the purposed specified.

No. 127,293--RUBERT I1. AVERT, Gilf.Est:ki.

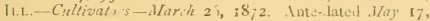
1872

Claim.-1.- The plates B, constructed, as shown, with a ree s, $b^{\prime}$ and rin: $b^{\circ}$, and arranged to operate with lange E,

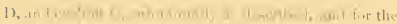

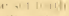

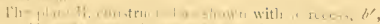

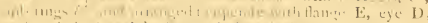

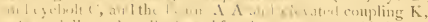

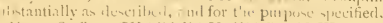

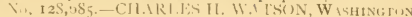

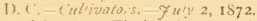

Clain.-1,- The biut beamin A A, as shown in Fig. 3, as ary for the purpone et forth

2. $7 \%$ beams A $\mathrm{A}$, when forming both beans and lomguc, whether, bent or strai rht, having an independent vertical aul lat-ral movement, leing bingeil or jointed at their forwaril cact $\rightarrow$ a-to maintain an upright position, for the purp we net forth.

3. Th: : beams a 1 , hinged or pivoted as as to have a free in lep 'n l-nt rertixal and latural movement apon the bar or yoke B, and supprestet in prsition without ivheels or frame, a) and for the purpose decerilied.

4.- The heams A A, hintel or pivoted to the bar or yoke 1 , and male arljustable upum the bar or yolie, as and for the purpo-especulie.l.

5.-The evener $C$, pivoteil to the bar or yoke at the extreme

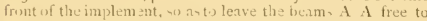
be oprat $\approx l$, su'stutially as and for the purpowe specifecl,

6.-The single tres is $D$, when made longitudinally adjustalile upon the bsam,$A$, for the purpone set forth

7.- The combination of the alju-talile evener $C$, adjust. ble single treen I) 1 , beam $A$ A, and chain $\mathbf{E}$ E, substantially a and for the purpune thereribed.

Ni, I 26, 11S,-R(Ilil:RT M. MILLER, SIRINGFIELD,

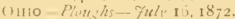

(tuim. - The arrang ament of arch $A$ with its ends $b$ b, crose clenis $c$, beam plith 4 , plotgh beame d, upright $c$, nuts

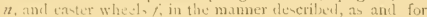
purpuse lac reimbefore st fortly.

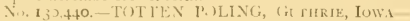
Cultivators- fus sust 13,1872

Claim-The bars $\mathrm{A}$, con-tructed sub-tantially as berein -hower and decribe l, and piroted to cath other at their in. ner enck to arlapt them to receive the plough beams and iraft, as and for the purpose set forth.

No. 134.732.-ISAAC N. CAUTif(iRN, Carthage,

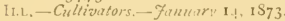

Clain-The ploa sit or cultivent or beami $\mathrm{E} \quad \mathrm{E}^{\prime}$ attached directly to pait 1 , whic's act. $2 \cdot\{.1$ - louble trec or evener, lyy hinge junt-arranzeil to give - frarate free lateral or lat-

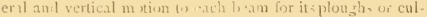
tivators and holit them $u_{j}$ ri ht in $\mathrm{un}_{2}$, uh,tutially as ret forth.

No, 135.148, - IAME-II. P.AT IEE, M NM: M TH, LLL.,

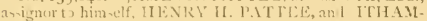

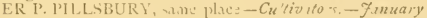
21. 1873

Claim.-1. - The lrac $\mathrm{K}$, at liutably attache l between

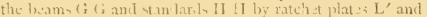

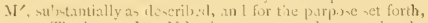
2.-The beam plate $\mathrm{N}$ howing a se rmental recos in the outer encl, in combination with the journal plate l, bolts $n$ and $R$, and yinalle 13 , sulutatially a-de-crilsed, an 1 for the purpove ype-ified.

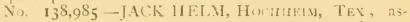
irnor to him elf, ami (IIARLE' TIMII, same place.-

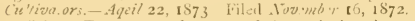

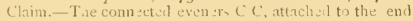
of tam plough framen by rinm 1), and to the siles of said gang phough by the jointel rol, F F, as and for the purpose deacribuxl

Nis. 141,954-THOS. L. TIIRASHER, PARIS, TEX.Plowsti Couplin.-Ausust 19, 1873. File I goly 5, 1873.

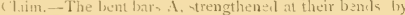
the evira foll $a^{\prime}$, provided at their lower und with swiveled dimping plates li and sel screws $\mathrm{C}$, and at their upper en 1 s "ith the "uen $a^{2}$, liden E, and notche- to recuive the key D, u'vemtially as herein shown and descriled.

No. 144,321.-SEBERT CRUTCHER, LITTLE MotY F, Ki.-Crllitat:rs-Nov:mber 4, 1873 . Filed Séptember 6 , 1873 .

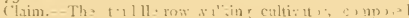


If the trane C D E, ant pluagin whone beams are st their [or w.13, wh connected by link joints to the bar $\mathrm{C}$ of the frame. wul whose land idic lars $H^{\prime}$ and $\mathrm{I}^{\prime}$ are pivoted to the fixed perclent arms $F$ and $G$ of the bar $E$ of the frame, substantially as and for the purposed specified.

No. 144, 740.-RICAARU S. CAVETT, BruIAS, TEx. 1873.

Claim.--The combination of beams A $A A^{\prime} A^{\prime}$ and

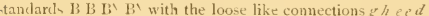
and $p n$, at and for the purpored clescribed.

No. 145,690. -GEU. SLUSSER, HILlsBurough, OH10, an-ignor of one half his right to C.S. BEI.1. and JA.MES 11. ANDERSON, same place--Cultivaters.-December 16 , 1873. Filed Aurnst $20,1873$.

Claim.-The combination, in a clouble shovel walking cultivator, of the beams $\mathrm{B}$ B, slotted at their front ends, the adjustable arched yoke $\mathrm{D}$, adjusting pins $\mathrm{E}$, and curved fixed runners $\mathrm{F}$, constructed, arranged, and operating as de cribed.

No. 145,848.-ANDREW COUPEK, MAcushi, JLL., a ignor of one-half his right to $\mathrm{IARTHA} \mathrm{E.} \mathrm{UPIJEGRAFF,}$ same plact-Cultiaciors.-Dicember 23, 1873 . Filed Oclolie, 6,1873

Claim.-1.-In a parallel cultivator, the frames A A carrying the wheel epindles $n$, the draft attachment $I$, and the plough beams $C$, all constructed and combined as shown, for the purpose set forth.

2.- The cumbination of the frame's $A$ A. draft attachment I, and center bar J), having arched arms, and connecting the frames by means of hinged joints i, substantially as shown ansl de:cribed, and for the purpose specified.

No. 151,733.-IVILL1AM M. IVATSON, TuNicA, II. - Culivato s- Fune 9, 1874 . Filed Filum, 21, 1874.

Claim. 1. In a traldle row cultivator, the neck yolsc $G$, with staple,, , in cumbination with the draft tongues D, having long staples $h$, substantially as and for the purpones sct forth.

2. The comlination, in a straddle row cultivator, with the imflependent sliding plough draft tongues, of a neck yot connected to said tongues, and arranged to prevent lateral weking of the same, substantially as vpecifirl.

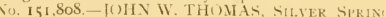

TEx:-Ploughs.-Fune 9, 1874. Fileal fonmary 5, 1874.

(laim. - The combination of the standards () with the bas or plates I X] and their roller K I, attacher] to the beams I mal rear tandards 1 of the plourgh, and vith the beam P if two thovel ploughy, stbstantially a- herein shown and the cribecl.

No. 153.893 -JEFFERS(N II. (iARHNEK, SILYH

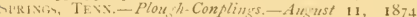
Fil:al fone 23, 1874

Claim. - I. - The double wivel joint compused of the flangerl and tuothed secve (; the futted collar I), witis it. kej-to $t$ ied journal pin $E$, and slottct journal box coupling tuck $F$, or their mechanical equivaleuts, all arrangerl as de cribed nud set forth

2.- The double swivel joint, as shown, in combination with standarl 13 and connecting ruds or bars 11 , all arrang ed as de:cribed, and for the purpone set forth

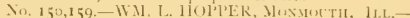
Cultivators._-Ortides: 20, 1874. Filed Aurus: 10, 1874

(laim.-The combination of the rigitaxle A, beanis J) 1 ), coupling $G(i$, draft plates $B$ B, and rumer $C(C$, the run$\|<\mathrm{r}$-jotirnaled in the $\mathrm{l}_{\mathrm{r}, \mathrm{ft}}$ plates, the draft plates pivoted to the axle, and the beam having free veltical and hateral motom, all operating as and the purpose specified.

No. 157,014-JESSE M.IRKEE and WM. E. SIICER.

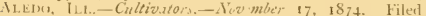
Sepsembir 12,1874 .

( laim-1.- The combination, with the plouth lrams I A, of the forked castings $\mathrm{E}^{\prime} \mathrm{E}^{\prime} \mathrm{E}^{\prime} \mathrm{E}^{\prime}$, arched asle 6 , with yimiles if, curved arm 1 , bolts $i$, swiveled runner 11 , and iraft hooks $h$, all substautially as set forth.

2.- In a cultivator, the metallic socket $J$, connected to the roul $m$, liaving a hook at its end, which clutches into a staple in the plough heam, as and for the purposes herein set forth.

No. 157.125.-IOHIN L. CIRAH.AM, CARTHACF, II.1..

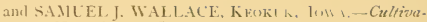
co:s.-Novembir 24, 1874. Filed Dicenber 1, 1873.

Claim -1. - The cloulle curved teeth ('. with flat horimatal lase, attached to the top of the cros har and projecting obliquely forwarl, and provided with rear braces attached to the under side of vaid hars, as set forth.

2.- The arched yoke $K$. with tuds hinged to the ploush beanis and lewit to the rear, or arranged to rest by bearings on one or loth beam back of the hinges, to support the arched celuter uright, sulstantially as set forth.

3.-In a straddle row cultivator, the combination of two ploush frames, each separately and automatically held up, with arched yoke $K$ and cunnecting joint to let them rock freely sidewire, substantially as ret forth

4.- The plough $\mathrm{E}$, swiveled to turn on a nearly vertical axis, with breaking pin or other holding means, subatantially as set forth.

5. The comlination of cultisating plungh $\mathrm{E}$, swiveled as lescribed, and with safuty holding device, with the revolving collar $\mathrm{E}^{2}$, subutantially as set forth.

No, 157,895- - WII. BEIH WATSO), TuxicA, IL.. - Cirltizators.-Derember 15, 1874 . Filert Sestember 26. 1874

Clam.-The tongues A A, jointed together at their forwaril end, and capable of a rearward or forward movement inclependently of each other, in combination with the runners E.E.ts the upper horizontal part of which are jointed, hy the clevin $F$, the flowh beam $C^{\circ} C^{\circ}$, by which the latter are capable of a forward or rearward movement with the tongues A A, a lateral movement to ward or from each other on the horizontal part of the runner, and alus a vertical movement on the ame, sul iantialIy as ilecribed.

No 162.577.-WM. 1I. ROBERTSON, BU1.A, Ir.1.., assignor of two-thirds hiv right to RUliUS FORI) and A. II CiLXN, ame place.-Cultizatus,-April 27,1875 . Tiled Fanum 5,1875

Claim.-The har II, curved, as shown, to form a runner, $h$, and an adju-ting bandle, $h$; aranged to operate with the plough beam C, eyebolt 1. axle 1, and wheek 1;, subuantially an clescribed, and for the purpose specitied.

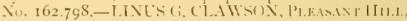

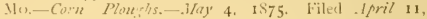
1874

Claim-Two frames I' 1 ', currying a gang of ploughs having their respective t of mold loar h tarned in opposice directiom, in combination with the connecting lum 1 , pivoted loonely to each, as wown and descrilsed, so that they inay by -imply turning, and withut any adju-tment, lue made to turn the sil to or from a rew of plants.

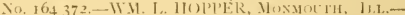

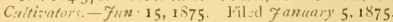

Claim,-1.The axle $A$, construct-al, as descilibel, of an elcvated whart celitral part, $a$, diver ins si le parts $a^{\prime}$, and horizontal parti $a^{\prime \prime}$, and has in the bar $a^{*}$, bolted thereto, subitantially as describul, and for the urpore specilied.

2.-A plough elevating and suntaining device for tongueless cultivator, con inting of a runner carrs ing rod, 6 , hinged to the plough beam, and to which is hinged a rod, H, hy which it may $\mathrm{L}$ ? fixel in operative position, unlstantially as dencribet, amel for the purus:-pecitied.

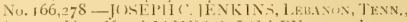

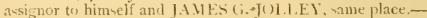
Cullivato-s_-Ausus/ 3, 1875. Filed A/ril 17, 1875

(Yaim.-The combination, with two cultivators or gang ploughs, of a metian eoupling, consisting of the blocks $\mathrm{K} K$, and pivoted low J, an and for the purpose ypecified.

No. 167.458 - H.IKTIN HCNITT, HowI STATION,

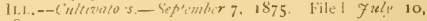
1875

Cham.-The combination, with the ratehet bar $F$ and the rock bar, $\mathrm{C}$, carrying te th $\mathrm{E}$, oi the combined handles and paw $1 \mathrm{~K}$, pivoted in support, 1 , and arran ted to operate in the mamer shown and described.

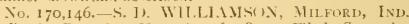
- Do:ble Plonghis-. Tivember 16, I875. Filed Septumber 18,1575

(laim.-1,-. The bar C. bolted to the axles $B$, and secured to the frame piece. A by means of the flanged plate 1 . 


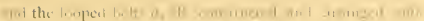

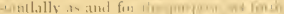
2.- - The - lue 1 the top. x a tim

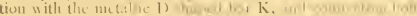

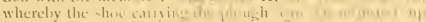

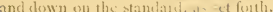

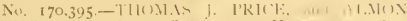

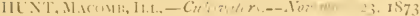
Fileit $7 \| 22,1575$.

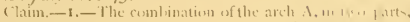
and swiveler in or near its center, with the drats lo inat. S

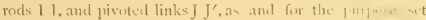
forth.

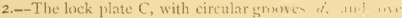

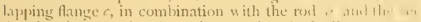

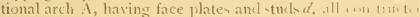
sub-tantially as slown and rlescribed.

No. 174.320-H. S. TARK1N(TTON, IN111N.11491.

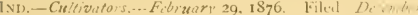
4. 1875

Claim.-I.-The independent arch supporting boxes R k . arranged with a grooved recem in each hals of the box, so .1 to clayp a collar, $m$, attacherl to the wrotght iron axle $13^{1}$ and alos provited with openings as alowe and below the collars $m$, in which operates the studs $8 w^{1} a x^{2}$ to form an independent support of the arch $\mathrm{B}^{1}$, as sheswa and described 2.-The coupling boxes $\mathrm{R}$, constructed to support the up right arch $\mathrm{B}^{1}$, in combination $w$ ith the flanged plates $\mathrm{N}$. hav ing vertical slots, and with gib slides $S$, provicled witls the bracelugs $T$, substantially as described and sluswn, for the purposes set forth.

3.- The horizontally pivoted draft bars $C$, having the projecting lugs $\mathrm{B}^{*}$ and wheel spindles $\mathrm{P}^{3}, \mathrm{r}, \mathrm{j}$ illy atticheil therets below and in front of the axle, and the ear ( 1 . in combination with the arched axle B, laving the flanget blocks $\mathrm{B}^{2}$, horizontally pivoted to said dr.uft har, sulntan tially as shown and described.

4.-The fender clamps U, provided with Aanger, to day the plough beam, a neck, unon which the shrs : arm $k$ ro tates, and a cored aperture, to receive the fenter har $\mathrm{H}, \mathrm{a}^{2}$ shown and described.

No. 174,684-THONAS W. KENTALJ. (KistuN,

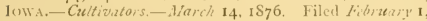
1876 .

Claim.-1.-The rumners E, arranged to support the axle of a tongueless cultixator, with the ploughs $D$ suspended therefron, in manner substantially as dencribed.

2.- The combination of the rimners E, ploughs D, hookrods $\mathrm{F}$, and axle $\mathrm{A}$ of a tongueless cultivator, mbetantially as and for the purpose specified.

3.- The combination of the axle.1. rmmers E, plough

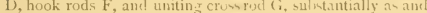
for the purpose specified

No, 175.256.-ALFRED B. REFYES, KNI:HT,THWN, IND.-Cultivators.-...Warch 28, 1876 . Filed March, ${ }_{3}$. 1874 .

Claim.-1.-The arched axle B, with ends of dis-imilar form, whereby one end is rigisl in the drac lar 1 . and the other is allowed to turn freely in the slray har $E^{\prime}$, - ul--tan tially as shown and descriled.

2.- The arched axle B, having a square horizontal curl, and the opposite end round and provichel with - lecve $p$, in combination with the curved and slotted suproting lar N, having ears $\mathrm{C}$, and adoptesl to carry either a wheel or rumer as and for the purposes set forth.

3.- The comlination of the hinged draw har $\%$, and the slotteal eurved bar $\mathrm{X}$, hinged to the ends of the arched axle B, as lierein descrilued.

4.- The clamp I, pixoted to the sandard and hold in its provition ly the latch $\mathrm{K}$ and pin $k$, in the manner and for the purpue lictein alescribed.

5.-1 hossel fratening composed of the eccentric I, titterl

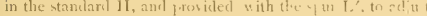
the shovels at different angles, as herein itecrilecel.

Xi. 177.258.-WILLIA.] LOLDEX, EARFIFI, lowA -Cultivat r. May 9, 1876. Filed Fibran 1 2, 1S76

Claim. The axle or heam sole of a stracklle row cultiva tor, constructed as rlescrilesl. with it archet central portion

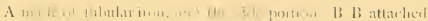

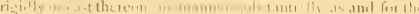

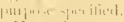

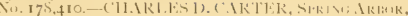

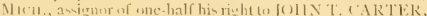

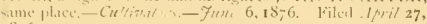
1 is 76

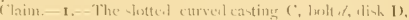

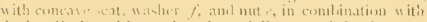

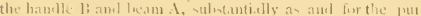
preco lat ris in ect forth.

2. In comblination with the two arme i $A$ of the culti-

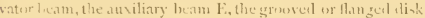

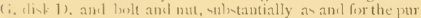
1. whe hatein set forth.

3. The combination, with a loovel ant tamelaril, of the

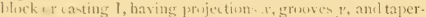
ime jus f. with triangular sot and set serew, sulmtantially as ancl for the purposes hercin set forth.

4-The esmlinstion of the plates $I$, having hethes $m$ for the cmeln of the arehed asle K, huls $\pi$, lolt f, and castings l', firstes between the onter enils of the flates, suimtantially shom 11

5.- The rigit whiffleteens, socket or other holding de ice K. cantiour $\mathrm{P}$, and plates ]., - vlbutantially as described.

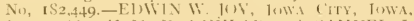

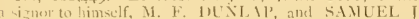
Filsi, same place.-Cullivitur.-Siplember 19, 1S76.Fil id $f_{u u^{\prime}, 1,1}, 186$.

Cluim.- The combination of wok 11 with the draft liars D, and with the whets A, working on independent aslow B, hinged to yoke E, sthotantially an-yecificel.

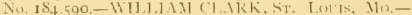

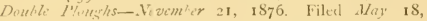
1876.

Claim, - 1-The combination, with a ploush beam, A, of the top and lotom plater D I), leitterl at flucir front emels, and formed with the eyes $d d$, the pivetul curved lar $G$ per. forated and notched as described, and pun is substantially as and for the purposes herein set forth.

2. - The cumbination of the sotterl compling har ff with armo $h h$ and cup 1 , the slotted coupling har $1 l^{\prime}$ with arms

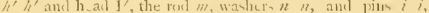
nlistantially as and for the purp see, herein set forth

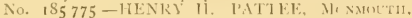

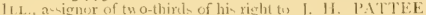
aml 1. I'. J'ILLSBURY, ame place,-Cultiontors - De entier 26, 1876 . Filed Sipiember 19, 187

Claim-1. - The combination, in it tomiruclers cultivator,

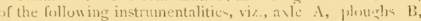
sluttecl shaft plates E, rumners $(i$, and bolt, 11 , suli-taustinlly as and for the purpose specified,

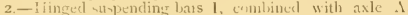
phough $\mathrm{B}$, wheels F, substantially as described, and for the purpore recitied.

3.-The combination, in a tongu-lese cultivator. of the

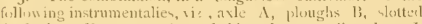
draft plate E. muners $G$, and hinger strpending lars $I$, -ul: tantially $x$ and for the purpose -pecifiet.

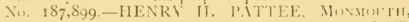
11.L., assignor of two-thirsh of hi, right to JA.4. II I'AT TlE and 1. 1'. 1'11. LABURY, name place-Culirators.Fidruat y, 27, 1877 . Filed Dicimbir 5,1876

Claim. The archeal axle wr tom yoke $A$ of $a$ itraddle nuw cultivater, constructed, an describied, of similarly curved hars a a of iron or sted, arranged sille by sicle in cluse proximity, and parallel, or nearly $\rightarrow n$, and having the sikle plates B B secured to and between the curved has $a$ a, in mamer subsuntially as and for the purose specified.

Nu. $187,9 S_{3}$. - WILLIAM F. RLEVES, I, B. REEVES

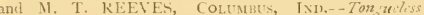
Plow:hs.-March 6, 1877. Fileal Oetober 10, 1876 .

Claim - - 1 - The findle $t$, formed with at crp, m, saik eap basin 5 an ammular recess, $s^{\prime}$, between it front colye and yimille (o received the enil of the huth $/$, and having a projectins ling, $y$, at the front, to enter a corresponding recen formenl in the front cap $k$, all constructed and arringed a shown and de cribed, for the purposes set forth.

2. The spindle $t$, formed with cap $m$, which is provided 


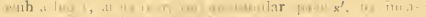

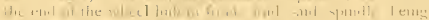

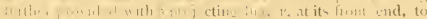

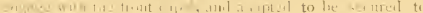

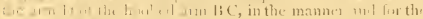

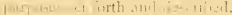

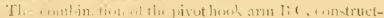

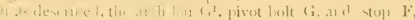

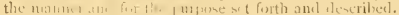

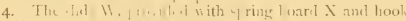

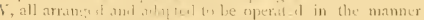

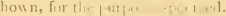

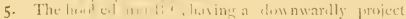

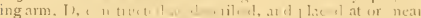

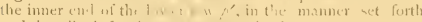

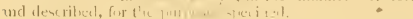

6. The two hali li... i 11, sometract al to clasp the

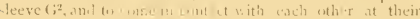

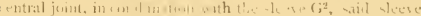

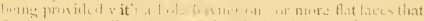

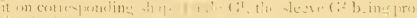
Whel wit's las or la

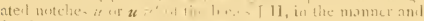

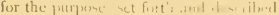

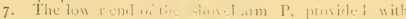

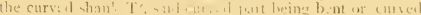

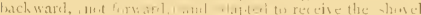

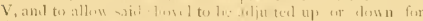
the purpo-e of $x$ - nlatur the pits h in the slusel, as at forth and lescribal.

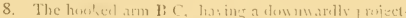
ing arm, 1). lexateil at of near the mer ent $p^{\prime}$. combin-al

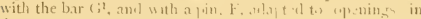

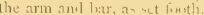

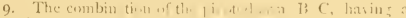

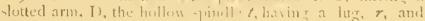

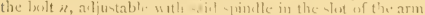

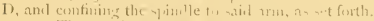

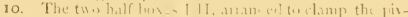

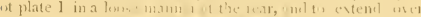

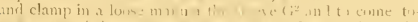

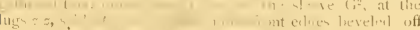

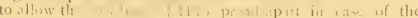

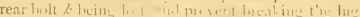

the nammet set forth an 1 if - ands al.

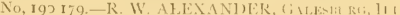

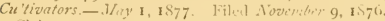

Claim - I. - I cultivator phw trane, male in twu put.

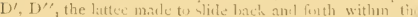

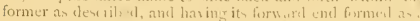

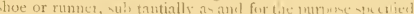

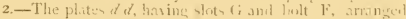

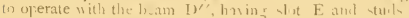

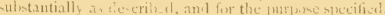

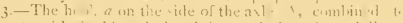

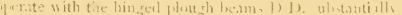

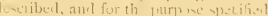

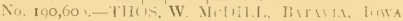

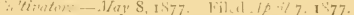

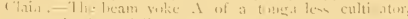

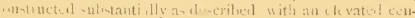

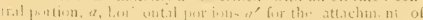
the plough beams, and scric al pustions as. to which the

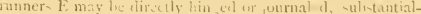

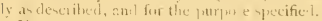

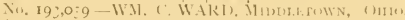

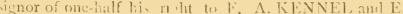

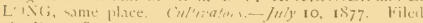
if $i$ i/ $23, \mathbf{I} \mathrm{S}_{77}$

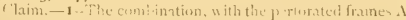

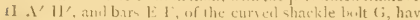

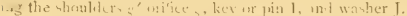

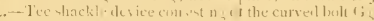

1, anil waxher I.

No. I03,362,- IV. II. I3EN NETT amil] I. R. 11E]G11T.

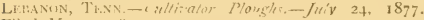
Fileel $M a y^{14}, 1577$

("aim,-1. - The combination of the mislille plough beam

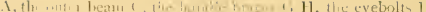

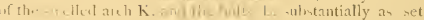
fouth.

2.- Ih comblinations of the mindle form A, the inner

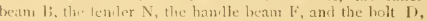

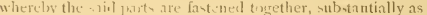
iet forth.

3.-The combuntion of the mirldle heams $\mathrm{A}$, inner beams 1;, handle-fucam, $F$, and trolts I passed throurh all of the aid parts, and extembled beyond the inner beam, wherehy a imble favenimur is stcured, and either the fender $\mathrm{N}$ or beam 1 e?n the med t plen-ure, nu'atantially as and for the purpone leverilues

4.-The beam $A$, hwine hosis $\mathrm{R}$, in sombination with the arehe lindble tree 8 , having flat bearin: s, and outer

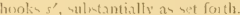

No, 103.532,-Cl1.15. MefiEE, Erwour, Kaxsas,-

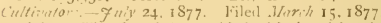

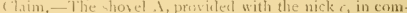
Jinarinn with the centrally arransed colter or blate E, as ant fin tise pumpone dercribed

Ni2, Ig1, I00,-T. C. 13. TIT()УAS, I'AJMYRA. Mo.-

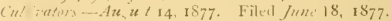

(') ain - - - The three armel couplins $\mathrm{C}$, the horizontal arm prosulc: $l$ with a transvere slot to receive a tuil upon the umo frar I), and allow the latter a parial rotatim, and thesestical protion, haxinf a lulue and set serew to permit itsalju-tment at cliferent hei he $u_{1}$ on the vertical part of a) le, as shem naul demcrilieit.

2.- The combinatiun of the three armed coupling $C$, avter 1: crims bar 1), mal set sercws $d^{\prime \prime}$, as and for the Hirpere specified.

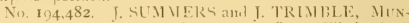
'TF, 1N5.-Cultitaor-Ausus 21, 1877. Filed April I $6,18 \% 7$

Clum.-1. The coml ination of the bar $\mathrm{I}$, the holt, $\mathrm{C}$ 1 . ond the eye $p^{2}$ with the forweted ends of the two leam

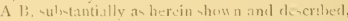

2-The arch. Formet is the twr aljustable lecut hars I I, and connectine lare or lini $K$, in combination wit's the for wart part of the twis pairs of lecam $A$ B $\triangle 1$, stostantially

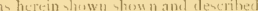

No. I95,042.-TAVES H. PATTEE, MoNar?TI, II.1..

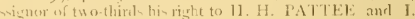

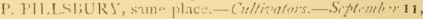
1877. Filed /une 30, 1877 .

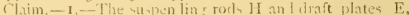

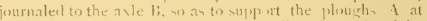
uniform, or nesrly unifor $\mathrm{m}$, heights, while esther sitle of the av... i astranced if receled indepentently, sulutantially as deretibed, and for the sumpore specified,

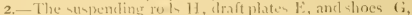

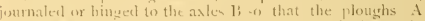
m.xy les $\rightarrow$ pended an the rod 11 , and vither end of the axle

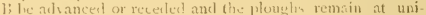
form, or nualy uni orm, bights, stistantially as ilexcribed, aml for the purpos $>p=c$ ilie.l.

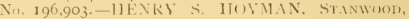

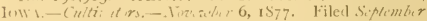
27,1877

Clan-.1-In a cultivator, the combination of the arched axle d, wich forallel amm $I^{\prime} I^{\prime}$ at each and, the frames

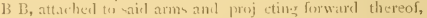
the spindlis / A. propecting from said fromes in front of the axle, and the wheth $C^{\prime}($, placed on said spinclles, sulmantially as and for the purpones herein set forth.

2. - In a cultivator, the comlination, with the arched axle

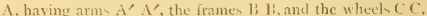
of the himed or swiveled frames $B^{\prime} b^{\prime}$, hasing youmles d d and the wheel, 1) I), substantially as atrl for the purpones hercin sct fort'!.

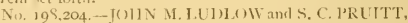

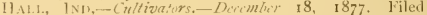
Si, stembir 17,1877

(laim.-1. - The combination of the parts $\mathrm{D} \mathrm{I}, \mathrm{E} \mathrm{E}, \mathrm{F}$ $F$, and $G$, forming the arch to a cultivator, and constructed and operated substintially ats specified.

2. The combination of the shaft H, the device C, constructerl of two part, as shown, and having two slots, in 


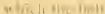

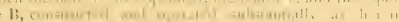

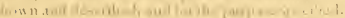

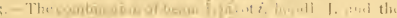

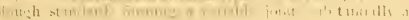
sin wherl.

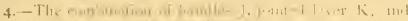

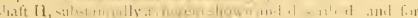
th: purpon $\ldots$.

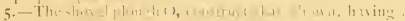

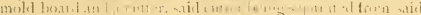

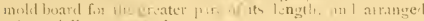
-ubatantially $a-4+1+1 \times 1$.

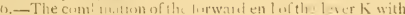

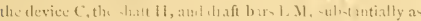

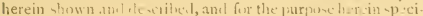
lie 1 .

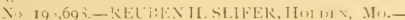

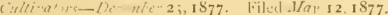

Claim.-1.- Ih combination of arch A, haviug horizon

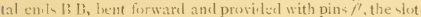

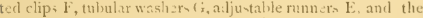
doulle beams $(1)$, hasins clamp bolts $c^{\prime}$, subtantially as trown and d ecribed.

2 - The combination of the bar I, having a shoe formed up on it-lower end and a notch in its forward edge, the conneeting lar or lin's J. the connecting bar I', having a hook

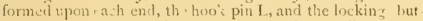
ton K, wth the inner plonr heams D, subut untially as her: in -how nam incerilsed.

No. 199972 -IEFIERQ')N II. GRAVES, BLmsom

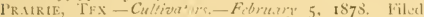
ฟi:

Claim, - The combination of bams $A$, bars $C_{7}$, having curved arm 1, and the proted angle burs $\mathrm{H}$, all connected an I arrangerd as and for the purpose specified.

No. 20:.763.-IO,iIAII SIIITH, (),WE : , ILL.COrn

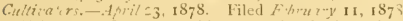

Claim.-I. - In a corn cultivator or sl mash, the mion of the right and left ploughs I $A^{\prime}$, wovid it with the perforatcil bar or plates $b$ b, detachably comnected together by heated scres bolts $d d^{\prime}$ and nuts $d^{\prime} d^{\prime}$, with the puir of ham Her B B and the lotterl central upright C, all detachably secured to the ploturhs $A A^{\prime}$, sulstantially an thown and deseribed, and for the purp, te set forth.

2. - The double bowet cipualiser F and clish or plate $h^{\prime}$, fivoted to and in combination with the ton rue of the cultivatur or plough, and confinel under the flange or plate $i$, and passessing a limited horizontal movement in the are of a circle, substantially as and for the purpose specified.

No, 204.883 - (IIIRI.ES 1). C.IRTER, ALIFAX, awi mor of me-half his riatht (1) I. T. (IRTER, SPRINe:

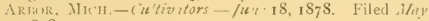
2. 1878

Claim.-1,-The combination of the axle $a$, plates $b$, rigidly secured thereto, plough beams, upright e, pasing lomely up throush the onter ends of the plates, and ilraft lars $f$, fastened to the npritht $e$, between the enils of the plates, whereby the front ench of the beam i may be raised upward to any desired degree, substantially as shown.

2. - The combination of the sleeve $\tau^{\prime}$, having the serrations $o$ upon its front edge, and a broove, $t$, in its lower front end, with the shovel block $z$, having the flange $\%$, projection $s$, and clamping serew $n$, wh)-tantially as specified.

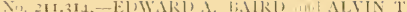

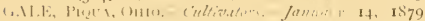
Fileal liv $v$ 'whe $23, \mathbf{1} 878$

Claim. - 1.-In combination with the hinge plate $d$, the

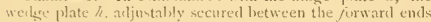
of the plew th leam, and having the sicle atjocent to the lumie plate heveled, subatantially as shown, and for the 1н11 10 se specified.

2. - The wh re $m$, pivoted between the clevis $\mathrm{D}$, and provile.l with a hinge joint at $o$, and sliding collar $\phi$, in combi$n$ ntion wit's the hin red plough hean $f$ and hooked arm $k$, sil t tmintly as set forth,

1. 3. - The arches 11 , pivot $\alpha$ in the braces $b b$, in combina ion winh the clevis D, comstitutimy bearings for the axles of a $t$, wheel cultivator, an herein shown, and for the purpose alerribxis.

4.- The swiveled arches 11 , adapted to turn in the arms k. provided with hoo'sel end h, in combination with shoes $m$ and clevises 1), or ecuivalent supp rting frame work for the arches of the carriages, sub tantially as shown and specifies.

No. 219.509.-TOSEPHI A. J. W. PARKER, WHITE1it.1. Trenx-Piou his.-Sipicmber 9, 1879. Filed $A u$ wast $\mathbf{1}, \mathbf{1} 879$

Claim.-The combination, with the adjustably connected plougin, of the whiffletrees arljustably secured to the clevises of $t^{\prime} y$ : $\rightarrow m$, flexibly connected at their adjacent ends, and p-usided with trace-hooks at each end, substantially in the manner and for the purpose set forth.

No. $219710 .-R I C H A R D F$. GIBSON and SYLVES. TER 17. COWDEN, TUscalorsa CoUNTY, ALA.Cultivators.-Siptimlir 16, 1879. Filed July 12, 1879.

Clain. - The combination, in a convertible cultivator, of the draft bur B and its supporting wheels, the draft bar B', the clevine, $C^{\prime} C^{\prime}$, the pluugh beams $A A^{\prime}$, the former having it forward end beveled, the plough beams $\mathrm{D} \mathrm{D}^{\prime}$, the adjuting bolts $d^{\prime}$, the handles $\mathrm{E}$, and their braces $e e^{\prime}$, all arranged, con tructed, and op rating subtantially as shown and described.

No. 220,571.-WILLIAM P. BROWN, ZANESVILLE, OH10,_Ciltivizors._October I4, IS79, Filed May 3, I 379 .

Claim. $-1-$ In a tongueless cultivator, the draft bar $A$, provicled with the arm $\mathrm{B}$ and the spindle $\mathrm{C}$, in combination with the wheel of a cultivator and the clevis F, as and for the purposes subiantially as set forth.

2.- In a tongrueless cultivator, the draw bar A, provided with the siot $\bar{D}$, or its equivalent, in combination with the axle E. provided with the horizont $\mathrm{sl}$ portion $c^{1}$, and the clevi. $F, 2$, and for the purposes set forth.

3. - In a cultivator, the cultivator beam $G$, provided with the arm $\mathrm{H}$, in combination with the clevis $\mathrm{F}$, the axle $d$, and the arm B, as and for the purposes substantially as set forth.

No. 237.376. - IAMES G. EVANS, MLACOM! 1LL. Cultiators.-Fibrutry 8, $183 \mathrm{r}$. Filed $7 u / v 6,1880$.

Claim.-1.-The combination, with the frame or rigidly comnected dra $;$ bars of a cultivator, of the hinged standard $\mathrm{B}$, provided with a handle, the pivoted lever $o$, the connections 8 $t$, the pivoted standard $\mathrm{B}^{\prime}$, and the jointed rods $i i$, subitantial. Iy as shown and deseribed.

2 - The combination of the hinged and bandled standard B. standard $\mathrm{B}^{\prime}$, and its connecting devices, rods $m n$, runner $\mathrm{D}$, arch $\mathrm{J}$, and frame $\mathrm{A}$, sub tantially as shown and described. 


Aclams,

Altic: W:

Andrew, IV. I.

Atwater, J. 1:

bistier, 8 .

Iiatlim, E.

hatcheller, A. F.

licristrewser, II

Ibruinger, C.

Bickle-hymer, L.

Bleecher, W. E.

Blee ker, W. E.

Plourne, E.

Bowen, H. W.

Breeden, C. C. and Wheeler, $0, \mathrm{~T}$

Iroatmax, 1). W., Sir.

liurch, 1. W.

Hussell, E. T.

Carwin, I. I.

(hamlerlin, IV. II.

Chenoweth, I.

Colb, rn, I. H.

Collin., I. W. and Wilkin son, R. Y.

Conc, F. C.

Coon, J. H.

Cooper, I: W.

Crenshaw, M.

Daniels, C. I.

I) $a w>o n$, W. J.

1 )ecelle, $\mathrm{M}$.

Jikeman, I. R, and llewlet!, I. J.

Eckles, 1H. P.

Elliott, J. C.

Elliston, C. T

Ernest, J. C .

Fenley, G. WV.

Ficlel, , , B.

Fithian, L. S.

Fitzgerald, J. C.

Fosgard, G. A

Foster, A. K. and B. H.

Foye, W. 11.

Foyc, IV. H.

Frechorn, W.

Fraser, E. J.

Frazee, L. F

Gatling, J.

Graner, J.

\begin{tabular}{|c|c|}
\hline I'urte & Claim \\
\hline 412 & 129 \\
\hline 386 & 123 \\
\hline 394 & 125 \\
\hline 33 & 122 \\
\hline $3^{81}$ & 121 \\
\hline 34 & 122 \\
\hline 405 & 128 \\
\hline 383 & 123 \\
\hline 390 & 124 \\
\hline $3^{8} 7$ & 123 \\
\hline $39^{8}$ & I 26 \\
\hline 40.4 & 127 \\
\hline 395 & 126 \\
\hline 397 & 126 \\
\hline 413 & 130 \\
\hline 408 & 128 \\
\hline 394 & 125 \\
\hline 387 & 123 \\
\hline 391 & 124 \\
\hline 388 & 123 \\
\hline 395 & 126 \\
\hline $3^{84}$ & 122 \\
\hline $3^{81}$ & I 2 I \\
\hline 392 & 125 \\
\hline 407 & 128 \\
\hline 390 & 124 \\
\hline 379 & $12 \mathrm{I}$ \\
\hline 415 & 130 \\
\hline 393 & 125 \\
\hline 397 & 126 \\
\hline $3^{82}$ & 122 \\
\hline 390 & 124 \\
\hline $40_{3}$ & 127 \\
\hline 401 & 127 \\
\hline $3 \mathrm{~S} 2$ & 122 \\
\hline 407 & 128 \\
\hline $37^{8}$ & 121 \\
\hline $3_{3} \delta_{3}$ & 122 \\
\hline $3^{8} 5$ & 122 \\
\hline 398 & 126 \\
\hline $3^{86}$ & 123 \\
\hline 406 & 128 \\
\hline 409 & 129 \\
\hline 412 & 129 \\
\hline $3^{85}$ & 122 \\
\hline 396 & 126 \\
\hline 377 & 121 \\
\hline 413 & 130 \\
\hline
\end{tabular}

IIall, J. .1.

Iarper, $(\therefore$. $A$.

Haynes, J.

llumleron, T. T:

Hessclb m, E. M.

IJewit, S.

Hoffineyer, A. B, and Sichnielt, $J$.

Hopkins, G. E.

Hughes, $G$, R. and Wall, J. F:

Hycle, W. B.

Johnson, I.

Johnson, J. 6 .

Jones, I. (i.

Jones, 11. and Vard, W. K. $404 \quad 128$

Judl, N. 'T'.

Kent, E. II.

Keriliner, $\mathrm{T}$. $\mathrm{A}$.

Locke, $\mathrm{D}$.

Lynch, G. F.

McCaughan, C. A

McClean, J. B, and Mayes, C. A

Mccracken, W.

MeCray, T. II.

McDonald, T. E.

Nic Donell, A. S.

McKinley, R.

Martin, in

Mathes, W. McC.

Milroy, I. W.

Vilroy, J. IW.

Mloody, $\mathrm{L}$.

Morrel, A. II

Morris, J. R.

Myers, D.

Nichols, IV, T.

Newsom, G. .. .

Nusbaum, A. 1. C

Pedrick, R. R.

Pelsor, P. D. and H. C.

Phillips, J.

Pitkin, J. II.

Platt, H. M

Pomeroy, H. A. G. and Hudion, R. F.

Poundstone, C. $\mathrm{N}$.

Randolph, J. 11. Jr.,

Richardson, W. C. B.

Roach, L.

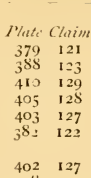

129

$412 \quad 129$

$399 \quad 126$

$3^{8} \mathrm{I}_{3} \quad \mathbf{2} 2$

$393 \quad \mathbf{I} 25$

$\begin{array}{ll}404 & 128 \\ 306 & 126\end{array}$

$391 \quad 124$

$409 \quad 129$

$414 \quad 130$

$390 \quad 124$

$386 \quad 123$

$399 \quad 126$

$386 \quad 123$

$423 \quad 132$

$391 \quad 124$

$401 \quad 127$

$401 \quad 127$

414130

$410 \quad 129$

$389 \quad 123$

$400 \quad 127$

$392 \quad 125$

$375 \quad 121$

$397 \quad$ I 26

$384 \quad$ I 22

411129

$395 \quad 126$

394 I 25

$419 \quad 13 I$

$411 \quad 129$

407 I 28

$403 \quad 127$

$380 \quad 121$

$381 \quad 121$

$400 \quad$ I 27

$400 \quad 127$

$408 \quad 128$

$380 \quad 121$
Ruberts, E. I.

Roure, $\mathbf{T}$.

Siackett, C. E.

Sackett, C. li.

Sackett, C. E.

siackett, C. F

Sackutt, C. E.

Siackett, C. E

Sackett, C. E.

Siackett, C. E.

Schermerhorn, J. and Porter, R.

Schuchard, J. R.

Schabley, C.

Sherman, I). B.

Sherwood, I.

Sivertsen, B. E.

Skillings, 11 .

Simith, N. S.

Soniat, $\mathrm{I}$.

Spancer, H. II.

Standish, P. H.

Starritt, J. 1).

Stephens, A. J.

Stevens, I.

Stoddard, J. C.

Stone, I. C.

Stoner, A. F.

Tally, T. J.

Taplin, H. T.

Tamutzer, I. I'.

Thompson, $A$.

Thonspson, J.

Tilley, J. R.

Tranter, J., Kinsey, J. and Carr, J. M.

Trouard, A.

Tuthill, T. J.

Uehling, T.

E. lon, J.

Wadsworth, IV.

Whitehead, J.

Winters, E. C.

Wood, N. S.

Young, J.

Zimmerman, J.
Plati Clim

$388 \quad 123$

4 C 129

$414 \quad 130$

$416 \quad 130$

$417 \quad 13 I$

$417 \quad 131$

$418 \quad 131$

$420 \quad 132$

$421 \quad 132$

$424 \quad 133$

$377 \quad 121$

$3^{87} \quad$ I 23

$38_{4} \quad 122$

$410 \quad 120$

$392 \quad 125$

$393 \quad 125$

413130

$380 \quad 121$

402 I 27

$423 \quad 132$

$389 \quad$ I 24

$401 \quad 127$

$392 \quad 125$

$381 \quad 121$

$380 \quad 121$

$409 \quad 129$

$391 \quad 124$

$420 \quad 132$

$393 \quad 125$

$\begin{array}{lll}387 & 123\end{array}$

$3^{85} \quad 122$

$396 \quad 126$

$412 \quad 129$

$396 \quad 126$

$400 \quad 127$

$377 \quad 121$

$389 \quad 124$

$405 \quad 128$

$\begin{array}{lll}38 & 122\end{array}$

$379 \quad 121$

$407 \quad 128$

$406 \quad 128$

$377 \quad 121$

379 I 2 I 
J. Gi,TLNG, NURFRleshorougI, N. C.-Rotury Cul tivito: -9 unt $19,18_{35}$.

Clain.-The manner in which I have combincd the operation of the wheel and hoes in the interior of the frame so as to protuce the application I have described ol giving motion to the said hoes.

No, 2,04\%,-J. F. 1 SCIIERMERIIORN, INDIANA and R. POTTLR, NEW YoRK-Rotary Cillivators.-April to, 18,1 .

C aim.-1.-Combining the large or cutter cylinder $\Lambda$, and the revolving shaft of spiders $I$, arranged as set forth, in an open frame so constructed as to allow of their applica tion to the purpose spesified as herein describrd.

2.-In combination with the foregoing, the hopper $L$ and operating cylinder $J$, the whole being constructed substantial ly as described.

3.--In combunation with the cylunder $A$, and shaft of spiders I, arranged as set forth, the mode of raising the frame and cylinders from the ground by means of the shoes $O$, and levers Q, the whole being combined, arranged and operating sulst intially in the manner described,

No. 5,665.-J. YOUNG; JEFFERS x, MAINE-Rotury Cutivitors.- July $_{11}, \mathrm{I}_{4} \mathrm{~S}$.

Claim - I - The combination substantinlly as berein set forth of the several series of spades or plough plates $e$ e with the cutter wheels A A

2.- The manner of operating the spades or plough plates by means of the arms $m$, and $n n$, projecting from each plough bar $\mathrm{D}$, th: stop $f$ de cending from the axletree, the elastic arms $r r$, radiating from the rings $d d$, sccured to the inner sides of the wheels and the pins $s s$, projecting from th: inner sides of the wheels substantially as herein set forth; not intending by this clam to limit myself to the exact number, proportion and arrangement of ploughs or spade plates as $h$ rein set forth and $r$.presented, but shall vary the same as 1 may deem expedient, whilst 1 attain the same end by substanti.lly the same means.

No. 6,091-T. J. TUTIIILL, Elmira, N. V.-Rotiry Cultioutors.-February 6, I 849 .

Chim.-The rotary cutters $\mathrm{K} \mathrm{K}$, and screw shaft I $J$, in combintion with the wheel and handle shafts, arranged in the m. unner and for the purpose herein described.

No. 10,624-G. L. FIELD, st. L.UUts, Ao.-C mb.n.d Plow: h: and flar) owe:-Barch 14, 1854 .

Claim. - 1. - The arrangement of the shicld plates I' and Q, on the shaft L, for the purpose set forth.

2.- The arrangrement of the rotary harrows li 13 , sustained aloove the ground and in the rear of the cultivating cylinder for bieaking and pulverizing the falling eath as set furth.

No, 12,690.-A. H. MURREI, MARLEx, TLXAS.Rotary Cultizators. - April to, 1855 .

Claim.-1.-The combination of the adjustable thinning point (or points) $m$, at the forward end of the cultivating prim (or points) ', at the rear cnd of the cultivator, substantially as herein set forth.

2.-Combining the rotating cutter $d$, with the lateraliy adjustable thinring point (or points) $m$, and the cultivatung point (or points) $r$, substantially in the manner and for the 1.urpose herein set forth

No. 14,533.-M. CRENSIIAW, SPRINGFIELD, TEXAS. - Rotary Cultivalors. - Marth 25, i 856.

I laim. - In combination with the series of cutting plates or dics the series reciprocating hoes, when the bo $\mathrm{s}$ are 50 arranged as to work in lines parallel with the cutteis or disk , and so inclined downward and rearward as to readily rise up over any obstruction without danger of clogging or choking, as set foith.

No. 15,453.-I. ZIMMERMAN, OsWEGo, ILL.-R'otary Culiviztors. -7u'y 29, 1856 .

Claim. - The revolving rake and cleaner, in combination with the series of elastic cutters $c$, and flat cutters $C$, as set forth.

No, 17,09I,-JOIIN M. IIALL, Warrenton, Gi.Rolary C.llivia.0.5-April 21,1857 .

Claim.-The combination with the wheel $P$, of the ad justable hoes $i$ constructed, arranged, and operating in the mann $r$ and for the purposes set forth.

No, 17,467.-JESSE WAITEIEAD, MANCHESTER, VA. - Rolary Culizutors.- Tun' 2, 1857 .
Claim.-In combination with the coulter $\mathrm{E}$, and mould brards $(i, w$ hich scrape off and smooth the sides of the fur. row, and scrve to guide and direct the machine along said furrow, the horizontal plate $\mathbf{F}$, which shoves off the top of the furrow and receives all the excess of earth, and the dis tributors Il, for scattcring the earth therefrom, so as not to leave it in ridges, the whole being combined and operating together, substantially in the manner and for the purpose set forth.

No. 19,652,-L. ROACH, Covtncton, Ky.-Roiary Cultieraiors.-March 16, 1558 .

Claim.-The described arrangement of spiral splines $G$, (to which the ploughs are attached) and adjustable arms if in combination with gravitating shaft $\mathrm{E}$ and guage wheels $\mathrm{L}$., as described and shown.

No, 20,659.-HENRY M. PLATT, DARIEN, Conn.Cultivators. - Func 22, 1858

Claim.-The arrangement of the screw shaped plough share $\mathrm{A}$, having wangs $\mathrm{E}$, with boxes II and $\mathrm{F}$, wheels $\mathrm{I}$, and roller $\mathrm{D}$, the whole being constructed and oparating conjuintly in the manner and for the purpose set forth.

No, 21,377.-NATHANIELS. SMITH, BUFFALO, N. Y.-Kotary Cultivators.-August 3i, is $5 \mathrm{~S}$.

I do not claim the flanged or broad cutting cytinder, nor placing a gang of hoes behind such cylinder the combination of the conb frame clearer with such cylinder.

Clain.-The use of the double joint piece D, to connect the gang ol hoes to the axle, when said joint piece extends beyond the axle, and subserves also the purpose of a foot lever to throw the hoes out of the ground, in the manner and for the purpose set forth.

No. 23,407.-J. C. STODDARD, WORChTER, MASS.Rotary Cultivaturs. - Wuri-h 29, ${ }_{1} \mathrm{~S}_{59}$.

Claim.-1.-The share $A$, and wings orblades $C$ arranged relatively with the wheel or whecls behind the share $\mathrm{A}$ and letween the wings or blades $C$, substantia ly as and for the purpose set forth.

2.- The adjustable rotating scrapers $J$, applied to the wings or blades $\mathrm{C}$, and arranged to operate as and for the purpose set fortl.

3. - The combination of the lateral adjustable hoes $m$, share $\mathrm{A}$, adjustable wings or blades $\mathrm{C}$, rotating scrapers $\mathrm{J}$, wheels II, one or more, arranged for joint operntion substan tially as and for the purpose set forth.

No. 28,687-II. A. G. PONER()S, PROVIDENCE, R. I., and R. F. IIUDSON, HARTFuRb, CONN.-1'loush. 7 thl 12,1860

Claim.-The combin d arrangement of the rotary screw .haped ploughs $C$, on shaits 11 II II, arranged paraltel wit each other and with the path of motion of the machine, with the oscillating frame I), when the whole is constructed and operates asdescribed for the purpose set forth.

No. 30,72I.-I. W. COLLI IS and R. Y. WII.KINSON

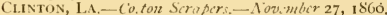

Claim. $-1,-1$ he arrangenient of the hoe wheet $E$ and shaft $D$ with the y.elding har $F$ and spring $K$, for the pur pose of automatically raising the hoe whet after it bas been de presed by the operator, substantially in the manner de acibcel.

2.-In combination with a spring or yielding rolary hoe wheel for thinning cutton, the adjustable and non yielding mould ploughs secured to the rear supports of the machine, for the purpose of thinning and moulding cotton at one operation, sulstantially in the manner described.

No. 30,771.- L. STEVENS, DovER, KY.-Cultitato:s. -Nov mber 27, 1860 .

Clain. - The arrangenent of the hars B B, connected with the b am $A$ by the clamps $G$, in conuection with the ad justable feet or standards F F and bars J J, at1ached to the bars $\mathrm{B}$ L, and having the ploughs and sciapers respectively secured to them, the handtes $C^{\prime} C$ leing attached to the bars $B$ and landsides $b b$, and all arranged as and for the purpose set forth.

No. $34,473 .-$ N. BADGER, SHeliyville, Kr.-Dig g. 15 . Wach nes.-M, bruary 25. I 862.

(laim.-I. - The com ination of the oscillating guid? I, arms $d$, and crank $G$, with cylinder $F$, as anl for the purpose shown and described.

2.-Also, the combination with the parts of the pulverizing rolle is N P, as shown and described. 
No. $35,087-$ J. R. DIKE.M.AN and J. J. 11 EWT.ETT,

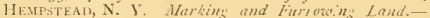
lfril 29, 1862

Claim. - The combination of a reel or revolving marier with shares or teeth J attached, or applied to a frame mount. ed on wheels, and arranged to operate substautially as and for the purpove set forth.

No. 3S, IC9. -SILAS HEWITT, SEXECA FAI.LS, N. I' - Ciol Crushers - fpril $7, \mathbf{1} \mathrm{S6}_{3}$

Claim.- The adjustalile clearers E, arranged as shown, in combination with the toothed cylimler $\mathrm{D}$, for the purpose precified.

No, 39,3 $\mathrm{S} 9$-JOHN G. ERNsT, JoRk, PA.-Clod Cizthe's. - tursust 4, 1863 .

Clam.-The combination and arrangement of the stationary teeth $\mathrm{B}^{\prime} \mathrm{B}^{\prime}$ and $\mathrm{B} \mathrm{B}$, secured to frame work $\mathrm{A} A$, shaft 4 aud C, wheels or cutters E E E E, and wheels or cutter: if $d d d$, when constructed and operating as and for the purpose described.

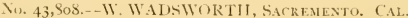
- Tillius the So:l-August 9, 1864.

(lam.-1.- The employment or une of a series of tincs or teetls d attached to a suitable rock shaft D, and having an oblique or inclined position relatively with the surface of the soil to be operater upon, so that as saicl tecth or times are propelled or cirawn along in the sill the latur will be forked up, while weeds, straw, and similar trash will pass over the teeth or tines to the rear of the machine, substantially as hercin set forth.

2.- The combination of the teeth or tincs $d$, rotary tonth ed drum $G$, and roller $C_{\text {; }}$ all arranged substantially as and for the purpose specified.

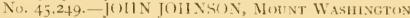

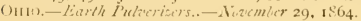

Claim. - ln the construction of the implement harein de scribed, the combination and arrangement of the frime $A$, pulverizer $C$, furnislied with open tectl l, eurverl in the manner describet, traction wheels $b$, gearing $c d c^{*} f$, and adju'table caster wheel 1), substantially as and for the purjoses herein specified.

No. 46.768.-JO11X B. A7 IV.ITER, CHWAGo, li..Plous hs.-Mar, ile 14, 1865

Clam-1.-The combination of one or more rotating augars with one or more turn plongh and an adjustable winging frame 1;, sulstantially as dencrilicel.

2.- - hac employment of rotating augurs upon a frame I, that carrics the plough $I \mathrm{~N}^{\prime}$, and which is hinged at its renr arched cnis to the rear sumpurting axle 1), and strpended ncar it fromt cnd from the beam C, subatantially as described.

3.- Irranging the augers in a line with and over the points of the ploughs when $\mathrm{b}$ th augers and plowers are sustained beneath and loy a vibrating frame, sulstantially as dencribeit.

No. 47,005-LE.MUEL, S. FITIII.1N, R.IHWAY, N J.-Ro ary IMlo:zhis - Warih $2 \mathrm{~S}, 1865$

Clam.-1.-I traction wheel or drum which is provided with bevelleal slat or har, extending obli-fucly acrus it, and operating sulstamtially a decribed.

2. - Tiecuring the slats of a ground propeller to the radial spokes of three or more wheels, which are constructed and traced sabstantially as described.

3.-The employment of metal face plates $c e$ in combi nation with the bevelled and obli juely arranged slat $s$, stb. Q. antially as descrihesl.

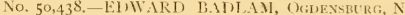

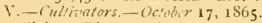

Clam.-The combining and arranging of the cutter wheels C C , on shart $\mathrm{B}$, with the cultivalor teeth as arranged on bar $F$ F, with the drill tecth $G G$, seed boxes $I$ and $O$, and roller $\mathrm{P}$, and conducting tube; 11 11, with the cuadran. gular frame $\mathrm{A}$, and wheels if $\mathrm{N1}$, all combined and arranged in the mamer and for the purpose herein sit forth.

No. 51.757-CIIARLES SIIA1:E1.EV, ВRเянI.Y, N. Y.-Pul rising an l Forroivins Derics-Dicember 25, 1865 .

Claim.-1.-The furrow openers or shares 7 , attached to a frame mounted on wheels in comlination with reciprocating

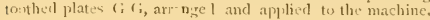

to operate in the matuer substantially is and for the purpores lecrin set forth.

2. - The attaching of the plates $G ; G$ to the mathine by mean of arms E, two or more fitted on a bar F, and arranged substantially as shown, to admit of the raising and lowering of said plates as described.

3.-The operating of the plates $G$ G from, the driving wheels through the medium of crank shats and pinions 1 $I$, and comecting ruds $f$, the shaft $I$ having their bearings in sliding or adjustable rods or shafts $\mathrm{H} \mathrm{H}$, connected to a lever $k$, by which the plates $G$ \& may be readily rendered aperative or inoperative as desired.

No. 52,496.-1)AVIl, MIXERS, assignor to himself and

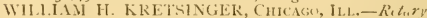
I'oushs, - Fil ruary 6, 1863.

Claim.-The emjloyment of a series of rings in comt ination with the revolvine cylinder $l$, and shovels $a$, arranged and operating subtantially as and for the purposes hercin shown and described.

No. 53.577.-LEVT H. C(ILBORN, CHICAGo, lLt.-

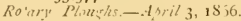

Claim.-1.- Giving the helical or screw ploush blades of a rotary plough, in aulition to their serew form, an axditional curvature from the periphery toward the cent.r. bagiming at or near the ent tring ed ere, and gratually increasing tow ird the leaving edge, the sam: being a development of the monlal boaril of the common plourh aroumal an axis of revolution.

2.-Attaching to a rotary plough blate, st any suitable place thercon, a horizontally projectirg cutt $x$, in orster to give a horizontal slicing und arcut to the furrow, sub tantially as set forth.

3.-Naking rot ury plough blales adju-tabl = on their propelling shaft, so that tirey may le sat to cut furrow of different widtls by attaching two, three, or more blacter to the shaft, as set forth.

4.- Connecting the plows hilukes to the plough aloaft, so that their lelivery end -hall project in the rear of the bhaft. and te left free and unshotructid, subtantially as described.

5.-Connecting the plough shaft to the axle of the driving wheels by a lome jommal if, so at $t o$ allow the plough $t a$ viluat : in oreler t, prom small stones and other light olstruc. tions, sulst.m ially as set forth.

(i). 5,319.-ANDREIV TILOAISON, OITIMWA.

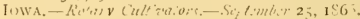

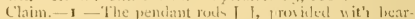
ings for the exlinder $G$, sai.l bearings b ing puided in sht: in the frane $\mathrm{k}$, for the purpuses and substantiolly as hercin shown and deweriber.

2.- The retolving cylinder in eumlstantion with the pendent rod, I I amd crowned lraxas 11 11, siletantially as and for the puip me hercon shown.

3.- The frome k, providet with the futs which grite the hearing of t'ic pendent ruds J I and braces, sulutantally as hercin shown,

Nu. 58.513 - J. JR.lsER, EkII. P'A., asimor to

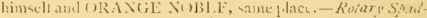
in: Whilin :-Oco.2\% 2, 1866 .

Claim,-1.- The sorweth-faced cylinder $\mathrm{C}$, set with row of tectio or stale m, and hung on the fr se shaft a $n$, in com

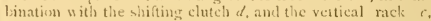
and pinion b. for raisintan 1 lowering the cylimber, constructed and operated subatantially as and for the purjose herein lescribed.

2.- The rotating pulverifing arms $\beta$, in combination with the syaling cyliter $C$, ant comect d therewith by the gear

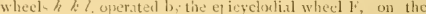
chine of the cylimicr con-tructed and operated sulstantially as nul for the purpones harein ypeiticil.

3.- The -pring scraper $r$, and the friction roller or bearcr E, in combination $\|$ ith t've - prating cylinder $C^{\prime}$, eonstrncted and operated substantially at atal for the purgose hercin described.

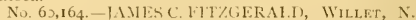

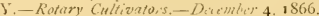

C'aias.-I. - The arrangenent of the spirally and inclined arm pulvericer $H$, re-ting in the cecentric bearings $k$, when said patti are combinet with a vestically adju-table faame $(i$, 
- msented from the main frame and coneentric with the axk as set forth.

2. - In combination with the frames $\mathrm{f}$ and $\mathrm{C}$, the draught chains $\mathrm{M}$, and the gange arms $\mathrm{N}$, operating subet.ntially as and for the purpose specitied.

No. $60,625-1$. K. and B. II. FosTER, HAI.I.FTSULL.

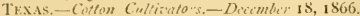

Clain.-1. - The share $\mathbf{E}$, composet of two parts $d d$, arranged in V form, with a space $c$ between their front encl and atticheel to a standard fund to front end of the handles If 1 , in the manner shown and tescribed, or in an ecutivalent was, to admit of being adjusted at a greater or lessclistance apart at their front ends, substantially as shown aud describerl.

2. The reciprocating eutter $\mathrm{L}$, opernted from the wheel 1) through the medium of the screw's $i$ and the rock har I, provided with the arms of $f^{\prime}$, in combination with the share 11. substantially as and for the purpose specified.

3. The fitting or securing of the screws $i$, to the wheel 1) by means of the concentric anuular grooves $c^{\circ} c^{\prime}$ in the sick of the rim $b$ of said whecl to receive the nuts $a$ of the screws $i$, whereby the screws may be reaclily applied to and de tached from the wheel and secured at an equal di-tanee apart, substantially ar descrilued.

No. 61,545-CHARLES A. MeCAUGIIAN, Mascan,

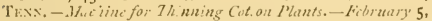
$\mathrm{IS} 07$.

Clain.-The double scraper F, attached to surpended frame $l i$, combined with the double transverse cutter $s$, oprated by the swinging frame $h$, for the purpose of thiming cotton plant in a row at one operation, constructed and oper. ting sub-tantially as hercin dencribed.

Ni, 6z,663,-W. M.CRACKEN, BAINiRIUGE, 1ND.Ciston ('ulliatatis. - Warelt 5. I 867 .

Claim.-1.-The scraper 1, in combination with the plough the former being placed at the rear of the latter and arr.uged relatively therewith, sulstantially as and for the purprose set forth.

2 -The comecting of the share $F$ to the mould-board $\mathbf{E}$ by mans of the clovetail arms $c$, cleats $d$, and keys $c$, subtantially as devcribed.

3 - The manner of attaching the wheel $\mathrm{C}$ to the beam, so that it may be adju-ted higlier or lower to resulate the depth of the penctration of the plough, as set forth.

4.- The combination of the hoe $O$, pivoted rod $\mathrm{L}^{\prime}$, pend ant arm $i$, sccurcel to the conlter bar, and can I., operating in the manner nnil for the purpose specificd.

No. 64,057-W!1.1A11 ALTICK, HiYros, OHlo-

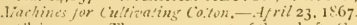

Claim-L-The arrangement of the haft $c$, with its clateh and bevel wheel, with the pinion $\mathrm{T}$, shaft $\mathrm{IV}$, and wheed $\mathrm{X}$, provaled with it adjustable loes, the several past being cern-tructed and used as and for the purpose specified.

2.- - dijusting the arms OO in the wheel $\mathrm{N}$, ly means of their grooves and the pins $b l$, sulhstantially as and for the purpose syecificel.

3.- The bar H, upm which the plunghe or cultixator tecth are secured, used in connection with the gromsed plates a $a$, rock shaft \&, with it arms and lever J, substantinlly as and for the purpose specifict,

No. $6 ; 262-J O H X$ P. TARNUTZER, FoNil IU LAC, Wis.-Cullivator.-Ipri! $30,1867$.

Claim.-1.-The shaft 1), with finion $y$ and pinion rack $r$, and capstan had $($; and movalle frame 13 .

2. - The rollers $\mathrm{F}$ if and shewe $S$, upon which a chain parses.

3.-The linges $h / 2$, upon which the frame $\mathrm{E}$ is liung.

4.-The wings zo zo.

5.- The movalule frame beam $\mathrm{B}$.

No. 645 S 3 -J. DAVIDSCIILLTZROIESONIA, PA. and REUbEN Al)AMS, same place, assignors to them-

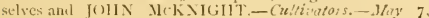
IS67

(laim,-1.-The arrangement of the frame A with it shaft, $f$, arms I I, bars $b b$, and springs $a \quad a$, with rakes $b$, when operated in the manner and for the purpose set forth.

2.- The elevation or depression of the frame with it = cul. tivatur by means of the bar sanillever $y$ attached to the thill $c$, in the manner substantially and for the purposes specilied.

No. 67.940--LEMUEL, 1HECKLLSIIYYIER, LAIVN IVokTH, KAN, assignor to himself and (iRAN1)ERSON T. 1)FKRING - Hurrents.-Aust 20, 1867

Claim.-1.-The harrow shoes $k^{2}$ or $k$, to which the teeth $h^{\prime}$ are attached, in combination with the comnecting hars $\mathrm{L}$, levers $\mathrm{I}$, comecting bars $\mathrm{N}$, and crank whecl (), by which motion is communicated from the grearing to the said shoes or shoe, sulstantially as herein shown and descrilied.

2.- The comlination of lever $G$ with the stationary frame $\mathrm{C}$, or tongue $\mathrm{D}$, and with the movalble frame $\mathrm{F}$, substantially in the mamer herein show 11 and described and for the purpose sct forth.

No. 684 ro,-E. T. BUSSELL, INIJANAIOLIS, IND, aS simas to himelf, W. H. (ANI)EE and JACOB EL 1)REDGE.-Rotary Pioush-Depemlier 3, 1〔67

Claim.-1 - Segment driving wheels $\$$, compassing les than half a circle, when n-ed in combination with pinions $p$, for the purpose of rotating each aurer mon its own axis at the proper point for most effectually breaking and pulverizin the earth, substantially as shown

2,- Supplementary yielding cogs $6 b$, when the same are attached to flat springs, as shown, and these, in connection with the segments $\&$, as and for the jumpore stated.

3.- Dist shield $f$, and itsadjunct $i$, when these are made and used substantially as shown and for the purpose speci fied.

4.-Cantor wheel $t^{2}$ and roller $m$, or their equivalents, when the same are used for graduating the depth of thi rotary plongh, and for transpusting the same from place to place.

No, 68,689--HENKV BEKKSTRESSER, OUAKRR

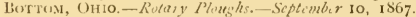

Claim.-1.-The ploughse $¿$, titted upon the periphery of the wheel E, constructed and arranged as shown and described, as and for the purpose spccifiect.

2.- The combination of the wheel $\mathrm{E} w$ ith the tilting frame $A$, the draft pole $\mathrm{F}$, and the lever $d$, arranged and operating substantially as and for the purposes set forth.

No. 73,I8I. C. A. HARPEK, WIEELING, INn,-Cultiv ters.-January 7,1868 .

Claim.-1.-The combination of the wheel $D^{\prime}$ with the cultivator frame A l3, substantially as herein shown and described, and for the purrose set forth.

2.- The cumbination of the spiral or serew plate II with the wheel $1 y^{\prime}$, and with the cultivator frame A 13 , substantially as shown and described, and for the purpose set fotth.

No. 74991.-W1ILLAM II. Cl1.MIB1KLIN, MrII IN.I, N. Y.-Futate Digracrs.-Wurch 3 , is 8

Claim,-1.-The wheel $(;$, formal with three curved prongs $g^{\prime}$, and removalily arranged upen the sheft $l *$, sub stantially in the manner herein shown and described and for the parjoses set forth.

2.- The combination of the pronged whech $(i$, shaft $F$, frame $\mathrm{B}$, gear whech $\mathrm{E}$ and 1 , axle $\Lambda$, drive whech $\mathrm{C}$, and tongue $I$, with each other, substantially as herein shown and described, and for the purpose set forth.

3.-The comlination of the tumgue 1 , seat $K$, bas $L$ I lever $\mathrm{N}$, and catel $\mathrm{N}$, with the frame $1 \mathrm{l}$ and axic $\lambda$, all $\mathrm{cm}$ structed, arrangerl, aud operating sulstantially as hercin set forth for the purpose specilical.

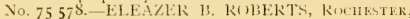
N. V-Cilticators,-Wareh 17, 1863.

Clam,-1.-The application, to cultivators, of rotary weed cutters hung on a vertical shaft, and operating substantially in the manner locein shown and described, and for the purposen set forth.

2.-The application, to cultivaters, of rotating hoes hung on a vertical shaft, and operating sulntantially in the man ner herein shown and described, and for the purpores et fortls.

3.- The arrangement of the arn $\mathrm{M}$, in nombination with the rotary hoe 1 , sulst:ntially in the manner and for the purposes herein hown and decrilisl.

No. 77,83 D.-JAMES IV. MII.ROV, G.ALTESTUN, INN

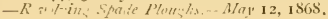


Cham,-1.-In a revolving spade plough, the hinged frame D, operating substantially as and for the purpuses set forth.

2.-The employment of one or more revolving ploughs or forks, arranged to operate substantially as described.

3.- The combination of the lower spade or forked whecls $\mathrm{K} R$, with the upper wheels $\mathrm{R}^{\prime} \mathrm{R}^{\prime}$ gearing therein, substantially in the mamnes and for the purp ose set forth.

4. - The combination of the frame $A$, roller 11 , [:aw] l, and cords $v z$, all arranged and operating substantially as and for the purpose specined.

No. $78,031 .-J O H N$ VAUGHN, MIAM Couxty, and ELI CHAMIESS, GRANT CoUNTY, IND.-Subsoil l'onsh-Wiry 19, 1868.

Claim.-1.-The construction and arrangement of the wheel $B$, strbantially in the manner and for the purpose as heruin set forth.

2.-The combination of the frame I and dashboard $d$ with the wheel 13 , substantially in the manner and for the ptrpose as herin set forth.

3.- The combination of the plough D with the wheel $B$, ulstintially in the manner and for the purpose as herein set forth.

4 - The comlination of the jack or cleancr $\mathrm{C}$ and frame I with the wheel $B$, sulntantially in the nunner and for the purpesi ai herein $s$ t forth.

No. $78,403,-\mathrm{PHIl}$ ANIER H. STANIJSH, VIARTINEZ, CAl.- Howntins the Cuthers for Rotary l'kustas.Hav 26, IS6S.

Clam.-1.-The revolving huls E E and the stupporter F $1 \%$, constructed and operating sulstantially as and for tix purpose decribed.

2. - I llexible or yielding arm, having the sy ring $G$, or its erguivalent, together with the rutary cutter, sulutantially as and for the purpose described.

No. 78.442 -IIARMCN 1'. ECKI.ES, CATsk11.L, N. Y.-Cimbin: l Cultimens and llers,-Juni 2, IS68.

Claim.-I.-The fans or padalles $f f$, when altached to thafts $\mathrm{K}$ K, and operated substantially as and for the pur pose ypecihed.

2. - The combination of the shafts $A$ ancl $K \mathrm{~K}$, gear wheels I I, and H II, nul frame S, when arrangerl sub.t:u tially as described, and for the purpose of opernting tine paddles or plates $f f$, as hervin specitied.

3.-The combination of the cultivator frame 1, with it teeth $\mathrm{MI}$ Ml, secured to the frame $\left({ }^{*}\right.$, as describat. with the shaft $K K$, frame $S$, and padtles $f f$, for the purp se of cultivatins or pulverizing the earth, and ricking or hilling the same, at one and the same time, as herein set furth.

Ni), So,6o4.-GEUR(;E W. $(7)$ PER, (MEECIIEF, G.

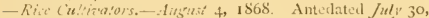
I 868 .

Claim,-1,- The cutter $D$ of a rice cultivator when arramel as describul, with upturned cutting sides $a$ a, sub-tiontially as ist forth

2. The curvel custeri E E, when arranged on the sides of the cultivator, so as to cut close to the plant, without injuring the same, an set forth.

3.-The revolving toothed hreakers II II, when arianged with beveled edges, and when male and operating substantially as herein shown and describul.

4.-The revolving breakers II II, when made as sct forth, in combination with the washer b, and cleaners $1 \mathrm{~T}$, all male and operating substantially as herein shown and described.

5.- Ilaking the arm $F$, in which the axles $G$ of the breakcrs has its bearing, atluntable on the bean $\mathrm{A}$, so that therelsy the height of the breakers can be adjusted, as set forth.

6. - A rice cultivator, consiating of the b-un or frame $A$, with the cutters 1) E E, and breaker. II I1, all made anil onsating sulstantially as herein shown and ilescribed.

No. So,643-iEURGE F. LVNCH, MILWNGE, Wis.-Rotary Cu'tivitors.-Au,zest $4,18,8$.

Claim-1.-The shape of the tooth and the manner of finding the curve of the same, to stit any sized head or cyl. inder, is herein recited.

2. Ilavin the heal loose on the axle, to prevent clog ging or choking, as herein clescribet, in cumbination with the attachin: the heads to the truck by straps, so as to permit each head or cylinder to act and move over obstructions independently.

No. 81.333.-COR NELIUS BERNINGER, MIFR, ILI.., assimor to himedf, WILLIA Fi FIEND, and GEORGi L. B.AILV, same place.-S.il Pulvirizers.-1njut 25 , 1868

(lim.-The harrow teeth $d$ and toothed cylinder $F$ provided with the wheels $f ; G$, when said parts are applicd or attached to a frame, E, suspended to a mounted framc, $A$, and all arranged substantially in the manner as and for the purpone set forth.

No. $83,45 \%$-FRANCIS L. CAGIVIN, JOLIET, IH.L.

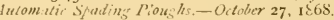

Clain.- I.-The spades $a$, when operating in the manner and by the devices described, so as to enter the ground on the cycloit line, as set forth.

2.- The maintaining of the parallel between the spades a. from the time of their entry into the ground until the heel of the spades come to a rest up arain-t the llum or dist: $b$, to any given point, either before or pa-t the hinge line, by means of the traction and weirht of the machine, causing them to turn on their hinse, as described.

3.- The backward turn of the spades afrom the cycloid entry line to their original position, as describud, ly means of the upright lever $c$, and spring $i$, as set forth, regulat id to stop at any given cycloil point hy means of the cleviec shown in Fig. 5, or its equivalent.

4.- - l'he spacles $a$, cunstructed with a crank and hinge, when att icherl, as set forth, to the periphery of the drum or disk b, in combination with the upright lever $c$ and Pring ?

5. - I rutary spader or plough, con tructed with spades $a$, hin resi (1) the dram or divk b, as slown in comlination with a frame, constructed and querating sub-tantially as set forth.

6. - The mode of leverase, subatantially as derctibel, to fore: the spoles into the rround, and to raise them out of the ground when derircd, as set forth.

7.-The combination of all the pats described, when arrungerl and operating as set forth.

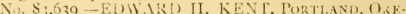

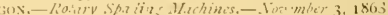

Clam. - The spacte bar. $E$, moving in slot, 1 ), operated by pawlo II and lever I,; alus, fa-tening the spade lass E, when ext :niled untward in the sists () of the cylimeler I. ly the latehes 1 , falling in and out behind the collurs $(i, w$ it' the grisure $M$, on the shaft $\mathbb{V}$, an.l the concentric segmelit I and bars $J$, and combination of the various part. as hercin de-cribed, and for the purposes set fouth.

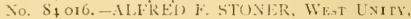

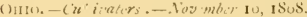

Claim - - - The sniked roller 13 , in cumbination with the spring, concase, or tooticel bar $\mathrm{N}$, arranged and operated sulsetiutially as set forth.

2. - The arrang anent of the liller $\mathrm{E}$, in comlsination with the share $C$ in tive fiont patt of the frame, am the pulveri:ing roller and concay $\rightarrow$ stahtutially as dencrib-cl.

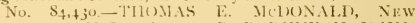

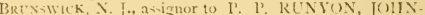
SON LESTER and (iE)R(:E I. IA NEWA same place.

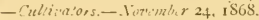

(laim -1. - I machins, having a series of cultivator te th arranga lon a rotary shaft, in combination wit t a swinging or hines from = pivotel in rear of the cultivatur, when the latter iv opsatcl by it progressing over and in contact with the grounil, suls, tantially as described.

2. - The employnent, in combination with the cultivator hinged frame, of the chains, or their eyuivalent, and a suitable moving and holding mechanism for ret.ining the ad. justable frane while the cultivator is at work, subsantially as and for the purposes sct forth.

3. - Irranging the tect't un exch hub, or each set of teeth, spirally, as and for the purposie specilied.

4.-Method, shown and described, of contructiner and combining the teeth and their retuining arm, and hubs

5.-A divided cultivator shaft, where by the machine is remelerel capalole of stracklling a row of plant, and cultivatin: each >ille, as herinbefore set ferth. 


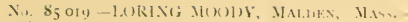

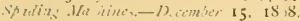

Claim.-1,-Hangin s, upon cranks, spades, wi-h handles pasing through the :sxle, which serves as their fulcrum, operatin s subst mtially as and for the purposes described.

2. - Conmeting the spade handles with the crank by means of the sockets and screws, in order to lengthen or shorten them at pleasure, subatantially as and for the parpoies described.

3.-The combination of the lever II with the axle, whereby the spades may leinclined at any angle with the earth, or thruwn ont of it, when desired, substantially as and for the purposes described.

4.-The combination of the lever I, the rotating bar $J$, the and arm K. with the crank C, for throwing the machins ont of or ints gear, at pleasure, substantially as and for the pur. poses described.

5.-The combination of the movable blocks II with the crankis ( and posts $\mathrm{N}$, substantially as and for the purposes described.

No. 87,721 -AIRAII.1M J. STEVENS, EL DORADO,

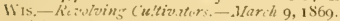

Claim,- The revolving clyinder E, adjustable -tan lards $a$, casters $c$, bent rods s, teeth $u$, wedges $r$ cross lar I), and drums $y$, combined and operating with the growved wheel hubs, and the bands or belts herein mentioned, snlstantially as specified.

No. SS, $36 \mathrm{~S}$, -FRANCIS C: CONE, SiN FR.NCISCO, CA1.._-Spating Warchin s._. Wurch 30, 1 S69,

Claim.-1.-The above described machine spade, when proviled with an ad ustaile arm, E, and a cutting edge, F, projectiug in frout of the blade $G$, substantially as set forth.

2. - The revolving flanges $B$, having the timgential slot 1), for letermining the angle of the spader, sub-tantially as herein described.

3.- The not the, or shoulders $a$, in the sisles of the slots I), for holding the spale, substantially as herein described. Nu. 92.756.-IXMAN SHERIV()I, SPRINGHELD, ILL. - Spadin, iliachines-Jul, 20, 1869.

('lain. - I.-A spadinir machine, constructed and arrang. ed witi the revolving cylinder A, stationary shaft $B$, frame C, (pretes 1), shink and toggles $a$, finger $b$, studs $c$, grooved whet 1 , studs $d$, slots $e e$, substantially as herein described, and for the purposes set forth.

2.-The stationary gruoved wheels E, constructed and arranged with the stuils $d$ and slotsec, substantially ar herein describerl, and for the purpose: set forth.

3.- $-T_{1}$ : combination of the spade: $\mathrm{I}$, shank and toggles $a$, wit the revolving cylinder $A$, arranged subatatially as hercin descrilied, asi for the purposes set fortl.

4. The combination of the shank anl togrles $a$, fingers $\therefore$ and stuls $c$, with the grooved wheel $\mathrm{E}$, studs $d$, and sint: , for the purpose of creating the semi-revolution of the spades I), suthtutially in the manner her in clescribed.

Xo. 92,834 -IAMES (i. JUHNSON, CAKTHMAL, ItL.

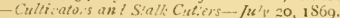

Claim.- The construction of the machine herein ilescrib e l, consinting of the combination outer frame $A$, hinged frame (C, roller L, cutter . .I . .I, and prongs () (), whereby I am enabled to furnish, in one machine, a corn stack cutter, which, by a slight interchange of parts, as set forth, may be used as a meaclow cultiv it or, substantially a specified.

No. 93,23S.-IBREDE E. SITERTSEN, I'TTSBT'RGH,

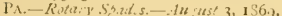

Claim. - In improved rotary spader, consinting of the sever.l p.rts specified, all combined, constructed, and arranged as described.

No. 9j,C05--IVILLIAM J. DAWSON, IROOkFIILD,

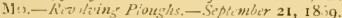

Clain.-1.- Inimpraved revolving plough, formed by the combination of the plough or shovel plates $K$, arms I, shaft I, pivoteil aclju-table frune $F$, horizontal frame $C$, axle 13, gear wheels L . Il, and wheels A, with each other, and arringed to operate as herein shown and described, and for the purpose sct folth.

2.-The conbination of the long bolt , $G$ and pivoted lever II with the adju-table frime $\mathrm{F}$ and stationary frame $\mathrm{C}$, sub. sta tially as herein shown and described, and for the pur. px: vet fonth.
Ni3. 95,394.-IIF.NRY T. T.II'I.IN, SUE 114 NEW MAR

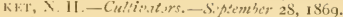

(laim. - 1. - The combined cultivator and harrow tecth Il $\mathrm{m}^{\prime}$. eonstructed subeantially as herein shown and described, and for the purpose et forth.

2.- The reversible teeth $\mathrm{Xl}$ and adjustable radial arms 1 . in combination with the revolving plate $k$, sulstantially as hercin shown and described, and for the prupose set forth.

3.- The combination of the tecth $\mathrm{M}$, adjustable arms $\mathrm{I}$, revolving plate $k$, shafts 11 and $F$, gear wheels $F$, and 1 , axle B, wheels $A$, and frame $C$, with each other, substan. tially as herein shown and described, and for the purpose set forth.

4.- The combination of the detachable circular cutter $\mathrm{N}$ $n^{\prime}$ with the shaft $\mathrm{H}$, plate $k$, adjustable arms L, and teeth M, sidustantially as herein shown and described, and for the purpose set forth.

5.- The combination of the bent lever $O$ and lever $C$ with the shaft $\mathrm{H}$, plate $k$, acljustable arms $\mathrm{L}$, and teeth $\mathrm{M}$, sul, stuntially as herein shown and described, and for the pur pose set fortls.

No. 95.956. - TIIEODOR UEHLING, LOGAN, NE BR ASK A. - Kutating Cu'tivaturs.-Octotw 19, 1869.

Claim.-1.-The cultivator A, constructed and operated substantially as described, for the purposes set forth.

2. - In combination with a rotating cultivator, the slide E, arranged and operated sulnstantially as shown and described, for the purposes specilied.

No. 97,870.-ISAAC W. BURCH, FAYETTF, Miss.Cotton (uwitiotirs.-Derembir 14,1869 .

Claim.-1.-A cotton cultivator, having adjurtable beams $E$, vibrating on joints $C$, in the front part of the frame, and adjustable, as to their distances apart, in the manner described.

2.-A cotton cultivators provided with a vibrating framc $\mathbf{I}$, and rotary cutters $\mathrm{N}$, arranged as described, to cut close to the plant, and cultivate on each side thereof, as set forth. 3.-A cotton cultivator, with a pair of plonghs F F, to work on both sides of the row, and arranged in front of the frame, combined with a series of oblique cutters $\mathrm{N} \mathrm{N}$, on the hinder part thereof, arranged to rotate on disks, at a less distance apart than the ploughs, and to cleam up clonc to the plant; all as shown and described.

4.- The combination, with the frame $A$, mounter on wheels $\mathrm{B}$, of the vibrating frame I and rotary olligue cutters $\mathrm{X}$, arranged for adjustment and for operation, substantially as specified.

No. 100,183.-A. 13. C. NUSBALM, SicrameNro, CA1.-Cultivators.-Fichany 22, $1 \mathrm{~S}_{70}$

Claim.- I. - The rotary cylinder or polyen H, having it seeth or shares attzched to it as shown and described, when said cyliucler or polygon is fitted within a swinging frame connected to the axle $A$, as described, and flriven or rotated from the driving wheel $\mathrm{C}$ through the medium of a chain, $1 \%$, fitted over pulleys F I, having concave perith. eriesprosided with transverse rilss, sub-t.untially as shown and descrilsed.

2.-The combination of the swinging frame $G$, cylincler or polygon $\mathrm{H}$, with spirally attached teeth, driving chain $\mathrm{F}^{\prime}$ working ever the pulley: F I, when all are constructed and applied to and ued in connection with a suitable frame mounted on whecls C C', one of which is used as a driver, substantially as herein shown and clescriberl.

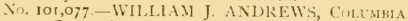

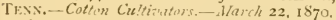

Claim.-1.-The combination of screw rod $\mathrm{G}$ with rock ing box E and shaft D, all operating subtantially as and for the purpose set forth.

2,- Th. auxiliary frame $\mathrm{M}$ attached to main frame $\mathrm{A}$, and arrimged to operate substuntially as and for the purpore dercribed.

3.-The auxiliary frame M. provided with scrapers N N and teeth () (), arranged to operate an and for the purpose sprecitied.

4.- The combination of shaft $A$, screw rod $(i$, boxes $C$ $E$, whed $J$ with it: adjustable hoes, frame $A$, and auxiliary frame $\mathrm{M}$, all arranged cubstantially as set forth. 
No. 101,710.-JAMES CHENOMETI, SHELI:YI1.LF, $\mathrm{S}$..-Retury Spades. - April 12, $1 \mathrm{~S}_{70}$.

Claim.-I, The wheel E, sparles G, lall and soc..ct joint $\left({ }^{\prime}\right.$, and slide $G^{\prime \prime}$, when combined and arranged as specified.

2.-In combination with the whecl $E$ and spades $G$, the rotating coulters $\mathrm{C}$, as specified.

3.- In combination with the element of the firt claim, the $\operatorname{cam} \mathrm{F}$, when operating as and for the purpose specified.

No. 106.195-GODFREY S. NEWSOM, NASHVILlE, Texv,-Sulisoil Pulacrigers.-Aust.s! 9, 1870.

Claim. - The arrangement, in a subsoil pulverizer, and on a rotating tool stock thereof, of a series of triamgular plough points, 1 , sharpened on two skles, and shank $\mathrm{K}$, drawn to an celge on thcir front sicles, all for the purprose of cutting and hreaking up without turning the soil.

No, 107,218, ELIIAII HOURNE, NIW 1BERIA, LA. - Noutsis, Planters ind Cultizator:- Siptember 13, I\$7o.

Claim,-1,-The detachalsle rutary plough stock 11, formed in two part, hinged together, and constructcel with tuluiar spokes, an descrilied.

2.-The arrangement of clouble spur whed D, pinion; $\mathrm{P}(\mathrm{i}$, secel droppor $\mathrm{W}$, and rotary ploughs $\mathrm{I}$, epstating as described.

No. 107,639-IAMES TRANTER, JOSLPII KIN

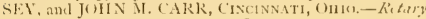

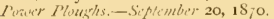

Claim.-1.-The revolving head or heads 1 I K, armod with the scries of movalile ploughs or share, $\mathrm{Ml} \mathrm{N}^{\prime}$, astaitut to operate apon the soil, in the manner sut forth.

2.-The described arrangement of one or more series of plotghs $\mathrm{M}$ or $\mathrm{N}^{\prime}$, rotating head I $\mathrm{J} K$, and fixed cam $\mathrm{N}$, wherehy the snid plongh are subjected, during the advance of the machine, to a continusus rotation, partly in and partly out of the ground.

3.- In the described combination, with the elcments of the clatue next preceding, the described arrangement of adjustable roller 0 , whereliy the penetration of the plough is controlled.

No, 109273 .-- WOHN TIIOMPSON, LUUISYILLF, KY

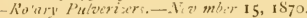

Clim. - The combination of the pulverizer E, the gear ing by which it is rotated, and the several devicen for adjusting and maintaining it in position, all constructed, arrangred, and operating substantially as herein descibed.

No 109.741.-NELSUN T. UUDI, WASHINGTON, D. C.-Rotiry Mough/s. - Nivemb r 29, 1870.

Claim.-1,- The frame F, pivoted centrally on the axle B having a series of rotary ploughs n.ounted upon a trausverse shaft at its rear end, and so arranged that by acljuving its front end, the ploughs can be raised or lowered at will, sub. stantially as described.

2.- The arrangement of a series of gangs of rotary ploughs substanti.ll is describz', whereby the ploughs of ench gang may be adju ted tucut at any recraired de th, inclependently of the vther gangs in the series, sothat, whilic one sicle of the machine is lower than the other, the whole series of ploughs may be adjusted to cut at a uniform depth, as set forth.

-The oscillating frame $\mathrm{F}$, having lever, $m$, with their pin $n$, and springs $i$ attached thercto, in combination with front frame or rearch $C$ having the screw $G$ and inclines $\rho$ thereon, and the sliding clutches $i$ and wheels I), with the clutches $h$, all arranged to operate as and for the purpose set furth.

Nr. 112.913.-LAWRENCE F. FRAZEE, JERSEY CiTY, N. J.-Ploughs.-Murch 21, 1871 .

Claim - The diggers J, the coulters $1 \mathrm{H}$, and the plough 1), arranged in relation to each other subatantially as described.

No. $113,19 j^{\circ}$-JOSEPH R, MORRIS, HOUSTON, TEX.1S. - Rotary Plous /is.-Mitrik 28, 1 \$ 7 I.

Clain.-A shaft having thereon a series of clisks, to the circumference of each of which are attached at an obtuse angle to the radiuses, spacles, operating as set forth.

No, 126.453-IIENRI II. JiHEN, I'K+NIDENE, R.
1.-C"rllitulo s.-Jine 4, 1872 . Antedited May 29, 1872 . Clam,-1.- The automatic cultivator, substantially as show $\mathrm{n}$ and decrilsed, or, in other work, the comlination of the locking frame $F$ and the guide har $d$. provided with operative mechanim in substance as explained, with the carriage $C$ and and it series of rotary tool shafts $G$, having mechanism for operating them essentially as set fotth; and

2. - 'n combination therewith, I claim one or more post: 13, arranged in maner and for the purpose as shown and explained.

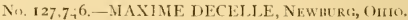

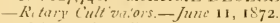

Claim.-The cylinder C, provided with flat and sharp tecth, alternately arrnged and mounted in the frame 1, having a series of teeth $k$, and hinfed, as shown, to the main frase; said frame lialoo carrying the traction diving wheet 1), and having coml ined with it the lever $g$ for raising or lowering the frame by a single morement, and the device $/ \mathrm{f}$ for supporting the frome when adjusted, all con-tructed, arranged, and operating suly, tantially as herein described.

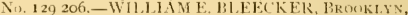
as-ignor of three-fouths of his right to $1 \mathrm{HENRV}$ 13I.EECK-

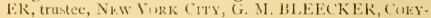

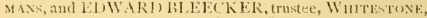

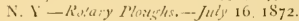

Clain.-1.- The combination of the cams $m / 2$ and $k$ with the plonghing tecth $/ \zeta$, piveted alternately on the two sides of the whecl i, as and for the purpoxs herminefore described, and operating in the maner set forth.

2.- The combuation of the levers $d$ and $d^{1}$ and the wheck $b$ and of with the laver $/$ and ploughing wheels $i$, as and for the purpmes hercinbefore sit fonh.

No. 131,16,-CiLlSTAVE A. HORS(IARI), HoUston, Tr.X,- Cinlisuters - Sipiemb.r. 10, 1872.

Claim,-1.-The rod or spikes attached at the ir imer ends to the ring $f$ and pas-ing through the rim of the whecl $c$, in comlination with the eceedtric $g$, focl $g^{\prime}$, and lever $h$, for projecting such ypikes when the cultivator is in use or withdrawing them at the sile in contact with the eath when going to or returning from the fiele!, as set forth.

2.- The revols inn cultisntur, made of a series of cliangeable and reverible spades or knives with share-shaped end, retain din position between rings, an! removable, sulstantially as specifled, so that the arrangement of the spades may be varied, ar ypecificel.

3.- The frames m, connecterl at their ut per ends to the frame $a$ and carrying at their lower ends the shat $o$ of the re voluing spades or kiives, in comlination with the geasing 10, 12 and 15, and 1 prating mechani-m for movin s said frames $m$ and raicing or depressing the stiul knives, sub-tantially as set fonth.

4.-The intermittent reciprocating : tirrer $t$, constructed and operated subtantially as and for the puposes $x$ t forth.

No. $13141 .-W I L I . I A M$ B. HYI)E, (O.IKLIND, C.II. Rotury Sid-Cutiers.-Sipiemter 17, I\$ 72.

Chim.-1 - In a sod-cutter, the two ratary cuttere G F, revolved in clone proximity to ench other aud in op osite direction, 11 yon a cummen centre by means of the shaft $\mathrm{L}$ and hollow shaft $\mathrm{l}$, in the mamer and for the purpose above specified

2 - The hollow shaft B with its rotary cutter 6 and berel wheel 1 ), on 1 the shaft $\mathrm{E}$ with it rotary cutter $\mathrm{F}$ and bevel wheel $[1$, in conldination with the transverse shaft $A$ carrying the level whech ()$^{\prime}$ and 1 , combined and arranged in a rotary sod cutter, substantially as and for the prorpose abuve dencritued.

No, $135.385 .-J .1 M H E S$ B. MCLEIN and CIIARLES A. MAlis, FRANk1.1N, KV-Combined conshri, culti-

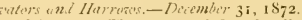

Claim.-1.- The cutter C C and rollers D D, arranged alternately and revolving inchendently of cach other upon a common shaft, $a$, in thic frane $\Lambda$, substantially as hercin set forth.

2.- The lever J, pivoted to the L shaped bar $d$ and combined with the har $b$, cutter: $(i$, and arms $H$, allowing the depth of the cutters to be regulated and operateal from the front or rear, sulutantially as and for the purpose descrilued. 


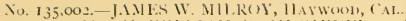

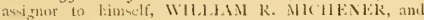

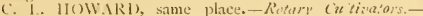
fazut: $y \geq 1,1 S_{73}$.

Claim. - The trame $A$ and axle B, wheck I) $\mathrm{D}^{\prime}$, and spindles $($ ' $($ ', in comlination wit's the independent revolv. ing ploughe or tecth I I on the anle, and arranged to bo rainet or lowered by lever $\mathrm{E}$, all substantially as and for the purpose hercin specilied.

(i) I35.174-ILCIIEE TROUARI), NEW ORI.RANS,

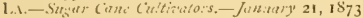

Cham. - The improved machine for grublling sugar cane stubble, the same consiating of frame $\left(i f^{\prime}\right.$, rumers I I, and the eylimed A proviled with the teeth $\mathrm{B}$, baving point constructed as deicribed, said cylind $r$ being mounted on the axle shaft ( jourualed in the pivoted lever: 1), which are adjusted at their free ends by the tandards $E$ and pins d, all as shown and described.

No. 135,66 \% -CH.IRLES N. POUNDSTONE, 1.TVO-

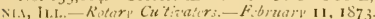

(lam.-1 - The wheel 1) having arms $i$ provided with sksts, in combination with tecth $\%$, so as to rencler the litter adjustable, substatially as and for the purpose set forth.

2. - The spindle $d$ with shoe $a$, povided with pivotal ril a and slot $L$, in combination with wheel $\int$ ), bolt 6 , and stem (c) subatantially as and for the purpose set forth.

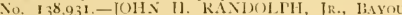
Gout.4, 1.1.-Whet-Cutivates.-Way 3, is73. Filed Fibruar, 8,1873 .

Claim.-1.- The combination of the gear wheels T X, shaft 11 , and bracket $\mathrm{V}$, with the propeller or screw blacles $I^{\prime} \% A^{\prime}$ and shait $E$ of the drive wheel 1), substantially a: herein shown and describst, ant for the purpone set forth.

2. - The combination of the keeper of long hearing ( and loop If $^{\prime}$ with the adjustable stindard 11 , shaft $E$ of the clrive wheel I), and bracket $V$ of the propeller shaft $\mathrm{W}$, sulsat.mtially as herein shown and dscribed, and for the purpose set forth.

No, I 39,0I3.-ROBERT MCKINLEY, IIYIN: PARK, N. Y.-Ritam Cultivat.rs.-W/ay 20, 1873 . Filed Februt: $y^{\prime}, 1873$.

(laim. - The hoe $a$, and its rock shaft and links, in com lintion with the rothting rake 1 , as and for the purpose set fort'i.

No. 142,094-CHARLES T. EILISTON, CHINTON,

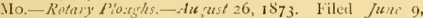
IS73.

( laim.-1.-The double set of picks, having a forced rotation, arranged relatively to each other in the rear of the coulters and in advance of the driving wheels, substantially as shown and described.

2. - The conbination of the frame el, pivoted upon the gearect shaft 2, with the pivoted frame $c$, the comecting rods 6 , and a suitable lever for raising and lowering the picks and coulters, suls:tantially as specified.

3. - The combination of the frame $d$, having the ratchet bars accured to it , rear and pivoted frame $c$, with pivoted frame $e /$ comecting rodk, and lever for tri-iug and lowering t'ie picks and coulters, substantially as shown.

No. 144,34 \%.-ILL.IN $\therefore$. HCI)(INELI, OsGoris:

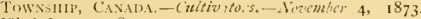
rill : / Juse io, 1873

Claim.-1.-1 cultivator having its frame A motunted centrally on two wheels, with an adju-table caster wheel, $\mathrm{N}$, suj proting it i rear encl, and having the rotating toothed cyl. inder J suspended in bearings from the rear end of said frame in combination with the fixed tecth, all constructed and arranged tu operat: subst antially as described.

2.- In coml ination with the frame $A$ having the cylinder J and t.eth arranged to mperate ni described, the adjustable weat $\mathrm{V}$, and the tongue hinged to the frame at or near its center, whereby more or less weiglat can be applied to the cyl inder, and the frame with it attachment; be left free to follow the undulations of the surface, as set forth.

No. 144419 - IOHIN D. STARRITT, CHI. ICo, li.

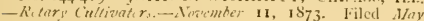
17,1873
Claim.-In a retary cultisat $r$, the rotary kuives $F$ structed and arranged sub,tantially as dercibed, and each hasius a free, inclependent, vertically vidding moxement with relation to the cther by rearon of the nutachment of cach to a corresponding rotary shaft by means of a univer al jrint, and by reason of the arrangement of the stems $(; ; i$ in the yokes $\mathrm{HI} \mathrm{H}$, sul st.mtially av and for the purpones ypecifiecl.

Ni. 145,I77-ANIJREAS B. IIUFFMEYER and

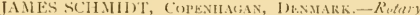

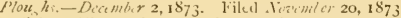

Clam.-The combination of the revolving cutters $\mathbb{E}$, re volving shares $A$, and stationary shictl or deflector $\mathrm{D}$, ath ar ranged and operating subtanti.lly as and for the purpose specified.

No. 145.737.-JOHN G. JONES, FALATUETH, MAss.Spading IIachin's.-December 23,1873 . Filed A/ril 7 1873 .

Chain.-1.-In a spaling machine, the combination of the vertically arranged spade $a$, pivoted to the crank $\mathrm{C}$, hav. ing balance wheel $b$, and operat d by the pinion wheel o t gearing in the driving or traction whecls $\mathrm{B}$ B, witb the braces $d$ and thimble $c$, all amonged and operating as hereiubefore sut forth.

2. - The combination of catches upon the insitic of the pinion wheels $p$, and of the spring bead linch $f$ ins s s, by the insertion or remoral of which the machine is put into ot out of gear, as hercinbefore et forth.

No. $147.992 .-$ LLCIEX SUNIAT, JEFFERSON PARISH, LA. - Cane Cultivato s. - Fibruary $24,18_{74}$. Filed Ausust 12,1873 .

Claim.-1.-The longitudinal shaft $K$, having hubs provided with spring teeth 5 , in combination with the branched hnuger $L$, journal boxes $\ell$, pini:n wheels $N$, and rotary shaft $\mathrm{E}^{\prime}$, substantially as and for the parpose described.

2. - The combination of the longitudinal toothed shaft: $K$, pinion wheels $\mathrm{N}$, rotary cultivators $\mathbf{E} \mathrm{F}$, bars $\mathbf{D}$, stanclarels H, yokes $G$, and beam $A$, sub tantially as and for the purpose described.

No. 148,063.-ERIX M. HESSELBOM, It.LAWARA, LA.-Cotton Cultivators.-March 3, 1874 . Filed Jun 7. 1873 .

Claim,-The combination, in a cultivator, of the land wheels $C \mathrm{C}$, the movable frames $H \mathrm{H}$, and cutters $\mathrm{N}$ N, as herein shown and for the purpose set forth.

No, 151,510-JUL1AN II. PITKIN, AKRON, OHIO,Ro ary Pliughs.-Jüe 2, 1874 . Filed April 24,1874

('am,-1.-The combination of the plough cylinder and plonghs revolving around the shaft or journals $a$, the crank or cams $\mathrm{C}$, turning with said sbaft or journals, and the jour nals $c$, on which the min wheck are supprerted and turn, eccentrically arranged on said cranks or cams, as and for the purpose described and represented.

2.-In combination with the pole or double tree, to which the team is hitched, and which is movable longitudinally in dependent of the main frame, and with the cranks or cams $C$, the chains and pulley wheels for applying the power of the team to the raising of the ploughs Irom the ground, subtan. ti $1 l y$ as clescribed.

No. 152,834 - J. C. ElLlotT, Simeson County, Ky -Culticater.-Ju'y 7, 1S74. Filed May 12, 1874 .

Claim.-The comilnation of parallel frames $A$, revolvin harrow's $13 d x$, connecting arch rods $a$, and casing $C$, all constructed and operating an and for the purpose specified.

No. 154.168.-W. E. BLEECKER, BRoKIYN, as signor of part his interest to H. BLLECKEK, Trutec NEW VORK CITY, GEORGE M. IHILECKER, (UEY MANs, and E. BLEECKLR, Trustee, WhITE-ToNe, N. Y -Rolary Ploughts.-Azszst 18, 1874 . Filed April iा 1873

Claim.-1.-The wheels $d d$ carrying the plonghing fork $c c$, in combination with levers $j j$ and catches $k$, the whole constructed and operating substuntially as hercin hefore set forth.

2.- The wheels $d d$, arranged as described, in combina. tion with the centre disk $a$, as and for the purposes described.

3. - The springs $f p$ in combination with the frame $i$, 
fingue $w$. and whesis if $d$, carrying ploughing forks $c i$, -uisuntally as herembefore set forth

No. $15+489-$ HEZEKIAH JUNES and WILIIAM K. IARD, ROKFIRI, III.-Ro'try Plinglss-Ausust 25. IS 74 . Filed May is, I8 84

(laim.-1.-The combination, in a revolving plough, of the hand bell crank lever I 1$)^{\prime \prime}$, guicle block $d^{\prime \prime \prime}$, and circular grooved guide ${ }^{\prime}$, with the revolving plough shaft C', carrying the ploughs E, eonstructed and operating as and for the jurpose describerl.

2.- The combination of the eross girt or knife bar $\mathrm{F}$ with knives $f$, links $F^{\prime}$, plough shaft $C^{\prime}$, carrying ploughs $\mathrm{E}$, and pivoted hand bell crank lever $\mathrm{D}$ in', constructed as and for the purpose described.

Ni. I 56,268.-A. F. B.ITCHELIER, FixchFoRD, Iow.1.-Corn Ploushs.-Oitober 27, 1874. Filed July IS, $1 \delta_{i 4}$.

Claim,-1.-The hearls G G, vertically adju-table on the hafts $F \mathrm{~F}$, in combination with rots $\mathrm{J} I$ and nuts $h h$, and yokes I) $\mathrm{D}$, as ant for the purposes described.

2.- Rods $J$, comected to handles $K$ and eomlined with vertically-adjustable heads $G$ and laterally-adjustable yokes I), as anil for the purposes described.

3. - Supputing bar $b$, in combination with yokes $D$ and thosel carrying heads $\mathrm{G}$, substantially as describet.

4.-The sent $\mathrm{I}$, on $\operatorname{rod} \mathrm{I}^{\prime}$, in combination with pendant $k$ and eveluglt $/ h^{\prime}$, suh-tantially as dercribed.

Ni. 157.893,-IIEVKI VON PIIUL, TR, and TAMES

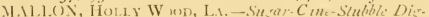
sers ant Cidtianters.-Ditmhit 15, $1 S_{74}$. Filed $f^{\prime} y^{\prime}$ $25, \mathrm{IS}_{74}$.

Clain,-I.-In a sugar-eane-tul,ile digger, the curved teeth $\mathrm{E}^{\prime}$, the disks $\mathrm{E}$, having enlarget notches or slots in their periphery, and the revolving shafts $\mathrm{D}$, said disks being arranged altermating in position on the shafts, as shown and described.

2.- The combination of the digging mechanism formed of the tecth $\mathrm{E}^{\prime}$, dinks $\mathrm{E}$, and sluaft 1 , the sliding blocks a, guides b, link $d$, crank shaft $c$, lever $f$, and emred nctched rack , as shown and discriled, whereby the sligger can be aclju-terl to and held at any desired height.

Xu. 158.374 - J.1.HES T. HENDEKSON, WoODHER,

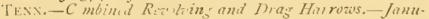
ary 5, $1 \$_{75}$. Filed Ditumbir 16,1874 .

Claim.-The combination, with a harrow, having a series of revolving cutters arranged upon a transwerse haft jour maled in the sile frames, of the stationary cutting blacles or harrow tecth, arranged upon a transtere shaft, and extend ing in a diagomal rearward direction from saicl shaft, and terminating between the revolving cutters, substantially as herein shown and descrilied.

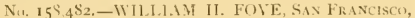

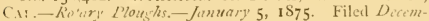
b. $\cdot 22,1874$.

Claim-1.-A rotary plough consisting of a series of concaro-convex cutting blakes arranged spirally around a snp portmg and driving shaft, substantially as described, for the jurpose specifict.

2.-The syiral cutting blacles adapted for adjustment upon the shait, for the purpose of regulating their cut, and the consequent width of the furrows, stubstantially as de scribecl.

3.- The combination of the asljustable collars and slotted welges with the concavo-convex eutting blades and the main supporting shaft, substantially as deseribed, for the purpose specified.

4.-I rotary plongh having two sets of concavo-convex blatles arranged spirally around the supporting shaft, so as to extend outward in opposite directions from the centre thereor toward the ends, sulstantially as deserilied, for the purpose specitict.

5.- The blades of a rotary plough, each macle with a spiral curve, and with a concavo-convex form trausversely, substantially as described, for the purpose specified.

Nis. $155,663 .-\mathrm{N}$. S. WVOOD, BunNE CInNTY, Mo.R:twlitin, Cultizators.-January 12, 1875 . Filed July 16. 1874

Chain.-1,-The combination of frames I I, eonnected ly yole 2, haff S 8, univer ally jointed hoe shaft-9 o, pis.

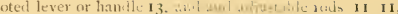
and for the purytone described.

2.-In coml ination with th: drivine wheels, frames, and arched comecling lar, the cenred shaft 8 \&, miverally jointed to the rotary shait, $8 \mathrm{~s}$, an and for the purpose de seribed.

No. 161,057.-JAS, P'illLLlPs, Thorstuws, INI,-

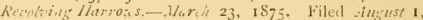
1574

Claim,-1,- The wheel $\mathrm{N}^{\prime}$ on vertically movable harrow that J, combined with flange $f$ and holding down wheel $e$, suljstantially as described.

2.-The combination of the wheel $\mathrm{N}^{\prime}$, providet with flange , the wheel $\varepsilon$, the grooved shaft J, provided with fixed collar $r^{\prime}$ and liding collax $r$, the rod $n$, anm $i$, and lever K, operating substantially as clescrilsed.

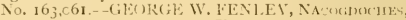

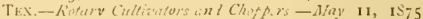
Fïled 1 Wati/i 6,1875

Chim.-1.-The combintion of the sliding luars II, the gear wheel $\mathrm{E} F \mathrm{~K} \mathrm{~L}$, and the plowgh that 11 with the frame If and the wheds $A$, subtantially as her.in sliown anil describud.

2.-The combination of the rack lar $I$ and rear wheels J with the frame i) and the slicling lari I1, that carry the gearing F K L and the plaugh shaft II, subtantially as herein show nand de-cribal.

No. 163.3:6.-E. C. WINTERS, CoLtat, JL1.-K'e-

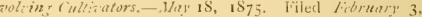
1 875

Claim.-In combination, the titting frame I, the coult.rs $K k$, carrical by and fram. the frame $\$$, the rasoling and spirally arranged spates $a^{\prime} a^{\prime}$, carriesl by the frame ?, the driving geating, and the adjunting mechanim, all metating together -ubatintially as cl-crilas, in the sam: implement.

No. I64 42S. - JAIES II. (CH)N, DRS JIHNis, LOWA.

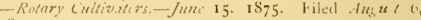
1874 .

Claim.-I.-The auxuliary frame $F$, carrying the cog wheels Xix, 1 and 3 , and the crank whecls $s$, in coml ina tion with the cor wheeh No. 2 an.l piuions stib tantially as describerl, to suspend and operate a series of spasles.

2.- The combination of the spate comping cae $\mathrm{F}$ with the crank whech $s$, substantially a clescribet, to alternately thru-1 down and raice up as serice of spatc.

3. - The sliting frame $(i$, carrying the scries of spates $k$, in combination with the suspended easc $\mathrm{F}$, subtantially ar describect.

4.-The frame or forked bars $n n$, when pivoterl to the fixed shaft $d a$, their upper and front end, and connected with fitmen or roe's 00 , extendinir from the ir lower and rear ends to the adjustable auxili isy frame $\mathbf{F}$, for the purpose of carrying rotary cutting cylinders and aljuting them relitive to the series of spaules 4 , substantially as and for the j.ur pones specificl.

5-The combination of the hand uhee 11 , finions $x$ shaft $x$, ausiliary frame $l$, and rack $\mu$, v $u l \cdot$ tantially as descrilued, anol for the purposes specitieal.

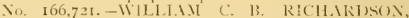

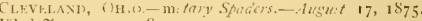

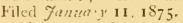

Claim.-1. - In coinl ination with the hinged spalen I J', the scriper, comsisting of the pirsted frame $M$ and hoes $a^{\prime}$. arranged to operate sulutantially as descrilud, and for the purpose specified,

2. - The shaker $K$, as arranged in relation $1 c$, and in comlamation with, the spactes $J^{\prime}$, as anel for the jurpore specilied.

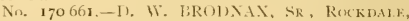

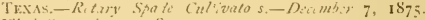
Filed Sipimbir $20, \mathrm{IS}_{75}$.

Claim.-1,-The comlination, with the frame I), with suppoting arches $\mathrm{E} \mathrm{F} \%$ of the compoumd lever $\mathrm{F}$ and yote 1, for raising the cultivator whed, as tescribed.

2.-The rotary ymale cultivatior composed of frame i), supporting arche; E E', jointel hinged liand lever $\mathrm{F}$, yoke 1. roik $\mathrm{H}$, and wheel $(i$, all comstruet al, arranged, and adajtul to operate as and for the porpows lescriberil. 


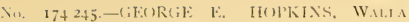

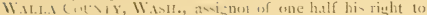

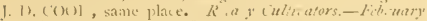
291870 . linel jus 7,1874 .

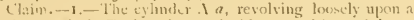
tationary shaft, E, lotted at cach sicle aromel its priphery, mul comstrice ol around each head with guides $A^{\prime}$, as and thr the fur uns described.

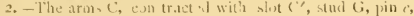

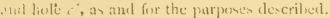

3.-The sup arm $[$ ), with roller tud ( $i$, as and for the puipus describerl.

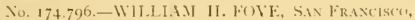

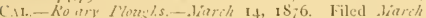
3. 1876 .

(loim.-The conbination of tive pirally curved steel cutting ant re-snforcinz strip or stiips $\mathcal{C}$, with the concavoconvex y iral cutters A of a rutury plough, subtantially a. d-cribed, for the purposes specified and set forth.

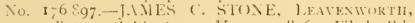

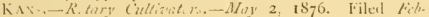
mat) 5 is 86

Claim.-The combination of a series of circular saws, I, and the sliaft $G$ with the whech, axlis, and frame of a 1) migh, stb-tantially is herein shown and clescrilecl.

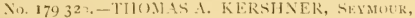

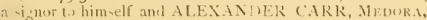

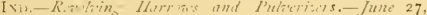
1. 7 6. lileal finum I $5,1 \leqslant 76$

Cham.-1.-The lecth II. male with curved forwarel cliec, concaved rear ediges, and broad leats pointed to the re, rwarel, in combin: tion "ith the cylincice (;, snbatan tially an hercin shown and deacribed.

2.- The combination, with axle $B$ and frame C, of the hinued frame $E$, and pendant hinges $F$, arranged substantiall; as and for the purpose speci ied.

Vi. 179427 - TIIONAS ROUSE, INIANAPOLIS, INI.

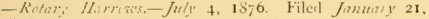
I 876 .

Chim-1.-In a motary harrow, the comlimation of the master wheels $V^{\prime}$, pinions $k^{1}$, shaft $R^{2}$, harrow heads $k R$, and harrow har 1 , arranged to be revolved in the adjutable boxes $R^{3}$. secured in the hangers $C^{-2} C^{2}{ }^{3}$ in the manner shown, for the purposes set foith and ilescribed.

2.-In combination with the adjutalle boxes $\mathrm{R}^{3}$ and hanger, C, the lifting rokk if D, provitled at their uper ent? with a rack which engasen with the pinion, E E that are opernte.l loy means of the lever a, in the manner shown for the purposes set forth and de-crilied.

So. 179.918.-JICOB HATNES, BASNFTTATH.I., W.

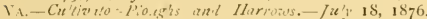
Filed 1, 1, 1,1875 .

(laim.-1 - The combination of the stationary rods I), the chains F, the comccting rod ( $;$, and the lever II, with the min frame If and with the frame $E$, thet carrics the plonths I J K I, sub-tantially as hercin shown and deseiitiol.

2.- The piroted frames $\mathrm{X}$, and spring-catch bar $\mathrm{I}$, in combination with the journals of drive-wheels $A$, frame $E$, ant $r$ t 2:ory ploug is $L, 4 m$ bstantially as and for the purpose s)-cificel

No, $181,870 .-D A V I D$ P. SHERIIAN, CASTLFTOS,

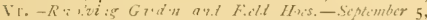
1876. Filesl Jul: 15,1876 .

ilaim.- A frame consi-ting of siclehoarcts A, front cod loard $\mathrm{B}$, rear top hoard $\mathrm{C}$, and handles $\mathrm{K}$, in combination wi h roller, rotary hoe, and wheel-axle substantially as and fir the purjo.es specified.

No.1S:, 59.-WILLIAM JCC. M.ATHES, CALDWI1. Tr., ant rnor of past of his right to THOMLS MI. HL N'T and WILI.IAM PHILIP, Sr., same place-Cmbine?

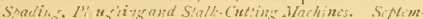
li, $5,1>76$. Filed July 5, IS76.

Clam.-1.-A serien of spadesarranged in a plane parall al with th: axis of the machine, and interposed spades 'in planes at ri ght angies thercto. all attached to a reciprocating cros, bar and operating as herein set forth.

2.- The comlination of the range of cpates $F()$ and the

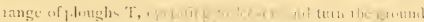

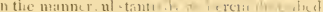

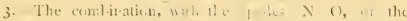

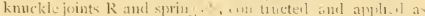

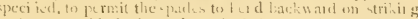

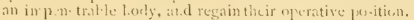

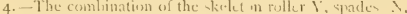
and pleugh $\mathrm{I}$, an and for the purpone s-t forth.

5.-The coml ination of the elutele wheel or $]$ inion $F$, for throwing the spacke in :tul out of ecenr, ame the lock IV as, for necuring the crant. shaft $f$ se as to retain the ypales in their clevated poition.

No, 181976 .-PETER D. PLLSOR and HENRY C.

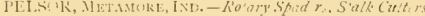

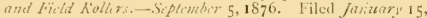
$1 \mathrm{~S}_{7} 6$.

Claim, - 1. - The roller A, presided with rows of alternat. ing slut $a^{1}$ in it face, and with correyponcling radial sot $a^{\text {? }}$ in its cnl, the sicle plates C, prosilled with circular grooves $c^{1}$ and eccentic branch grooves $c^{t}$ in their imner surfices, the cutter $(i$, and the cutterbars 11 , in combination with each cther, ubstantially as hercin shown and descrilsed.

2. - The combination, with roller having slots $a^{1} a^{2}$, the barn 11 . and the spades $\left(\mathrm{i}\right.$, of the side plates $C^{\circ} \mathrm{C}$, hasing eccentric srooves $c^{l}$, and the guide hlocks 1 , oferated by mechnion I K I, its and for the purpore specified.

3.- The slot $c^{-1}$ formed in the upper pat of the side p'ates and their notched capblocks P, $t$, enal, le the cutter bar- and cutter. Il to he withdrawn from the roller A, substatially as leercin sl:own and ilecuiled.

No. 187.759 . - WILLLAM T. NiCHOLA, CHICACw,

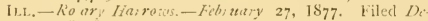
a mber $28, \mathrm{I} S-6$

Claim:-1.-The cross bar $e$, proviled with inclinedlugs o: arm $\iota^{\prime}$, in combination with the sirally wound metallic stips $F$, substantially as and for the purpose set forth.

2 , - The screw or piral rotary scarifiers $\mathrm{E}$, in combination with the jointed adjuvtable shaft C, substantially as and for the jurpose set forth.

3.- The rotary screw scarifiers $\mathrm{E}$, in combination with the jointed shaft $\mathrm{C}$, adljustable hanger $\mathrm{D}$, ancl tongue $\mathrm{B}$, substantially as and for the purpose set forth.

4.-T he com 1 , nttacherl to one end of a revolving scair fier, E, in combination with the sliding adju-table rock shaft $\mathrm{K}$ and -ecding sicle $/$, subatantially as and for the $\mathrm{j}$ mose stt forth.

Xंก. 190 7 6.-JOHN R. TILLEV, I)EMLRARA, RRITISH

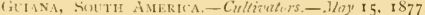
Filed oitebre 7,1876 .

(laim.-1.-The long cutting-kniven $\mathrm{K}$ and hubs $\mathrm{I}$, on shait $($, havims large chain-wheel $\mathrm{F}$, and made free ti risc and fall in sletted bearings, in combination with the small bearing-wbeels $A$ and axle 1 , having the small chain-whed I) and the endle ss chain $\mathrm{E}$, whereby the knives are given a slow rearwarl motiou he ile that caised by the forward pro. gress of the machine.

2. - The comlination of lever $\mathrm{N}$, rock-shaft $\mathrm{M}$, and slotted $\operatorname{arm}-1$. I, with the sliaft $(i$. that carries the ploughs, slicling bearing $H$, slotted brackict $I$, and the frnme C, substantialiy as her in thown and describerl, fir the jurpose specified.

No. 191,332,- WII. FREEIBORI. SAN Francisco,

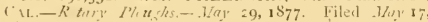
1875 .

Claim.-1-The horimntal shaft or hub $\mathrm{A}$, with its cir-

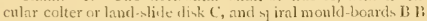
saicl spiral mould-horals l cing continuous, so as to form a rotary plough, stibstantially as descriled.

2.- The offet D), arrangred between and in combination with the spiral concaro-convex mould-lonrd and hub $A$, as and Fir the purpose described.

No. $194+36$. GEO. R. HUGHES Tand JOIN E. WALI.

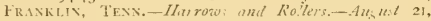
IS77. Filet Febrimy 24,1577 .

Claim.-The harrow-frame $\mathrm{A}$, provided with the sectional mollers $\mathrm{D}^{\prime} \mathrm{C}^{\prime}$ and cutter, $\mathrm{E} \mathrm{E}$, alternately arranged on their shafts between said roller, the axes of the rollers and cutter being parallel to cach other, sub-tantially as clescrilsed, anil for the purpowe at forth.

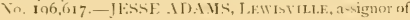


one-half his right to JOHN S. S.IEAR, WAVEI.AN1, INIr.So 7 Pulverizers. - Ockber 30, 1877. Filed March 21, is76.

( laim.-In a machine for pulverizing the soil, the combination of the frame $\mathrm{N}$, pivoted on the axle, the adjustable draft-pole $s$, and standards $Q(2)$, with cylinders $F$ and $G$, having tecth $H H$, and bars $J$, having knives $I I$, substat tially as herein sbown and described.

No. I9S,163.-H. SKILIINGS, HuTchINson, MiNn. - Rev hing I'lousho.-Dicomber i I, IS77.-Filed October 13. $1 \$_{77}$.

Claim.-The independently rotating wheels $\mathrm{D}$, having narrow and beveled rims, in comlination with loose bands $H$, arranged between the wheels, substantially as and for the purpose set forth.

No. $198339-$ C. C. BREEDEN and OWEN T. WHEELER, BEDForD, KY.-Rotary Cullivators.-De comber I8, 1877. Filed Nownber 6, is 77 .

Claim.-The combination of the sleeves $G$, the bent shaft $\mathrm{H}$, and the plough-wheels $\mathrm{I} J$ with the swinging bars $\mathrm{F}$, the loops $\mathrm{E}$, the axle $\mathrm{B}$, the lars or frame $\mathrm{C} \mathrm{D}$, and the diving gearing $\mathrm{K}$ L A, substantially as herein shown and de scribed.

No. 198,540.-JOIIN GRANER, NEW ()RI.EAN, LA. - lieviving Cultisators.-Dicumber 25, 1877 . Filed Angust 25, I 877

Claim.-1.- The frame D, having tongue E, arranged to be attached to cither end of the macbine, and the axle $b$, having bearing wheels $\mathrm{A}$ and gear-wheel 1 , in combination with the hinged frame $F$, shafts $G \mathrm{~m}$, gear wheels $i \mathrm{kl}$, chain $\mathrm{K}$, and crank-shaft $\mathrm{T}$, sulsatantially as described.

2.- The blades $x$, of the shape described, attacherl to the shaft $m$ in propeller form, and arranged to revolve in the direction of the line of draft, ancl made reversible to allow their points or opposite ends to enter the ground first, substantially as described.

No. 203,172 - IOUIS MARTIN, LyONs, N. Y.-M/achines for Extirminating Noxious Grasses.--1pril $3 \mathrm{O}, \mathrm{iS} 7 \mathrm{~S}$ Filed Januetry $2,1 \mathrm{~S}_{7} \mathrm{~S}$.

Claim-. I- In a machine for exterminating noxious grasses, the cylinder $\mathrm{D}$, constructed of rings or disks $x$, resting upon the shaft and clamped at the encls, the said rings or disks being bolted together in pairs, and securing the teeth $i$ between them, as shown and described, and for the purpose specified.

2.- The disks or rings $x x$, having plane abutting faces, clamped together in pairs by the bolts $z z$, ant provided with the sockets $y$, enlarged at their inner ends to receive and hold the corresponding shanks of the tecth $i$, as shown and described, and for the purpose spacified.

3.- The combination, with the cylinder $D$ and clearers $/ l$, of the platform I, and endless apron $\mathrm{K}$, the platform being attached to the springs $u z$ at the imer eme, and acliustable both at at the inner and outer ends by the levers L II, as shown and described, and for the purpose specificd.

No. 205,369.-D.NIEL LOCKE, CKLSTON, IL.LClod Crushers. - July 16, IS78. Filed June $24, \mathrm{IS}_{7} 8$.

Claim.- The combination of the frame $a$, toothed rollers $g$, driving wheels $i$, aljustable axles $h$, gears $i$ and $l$, and caster wheel $r$, substantially as set forth.

No. $2=6,974$ - CIIARI.ES E. SACKETT, MATILDA FurNACF, WAYXe TOWN'HIP, MIFFLIN COUNTY, P'L-

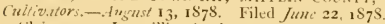

Claim.-I - In a tilling implement, the combination of a resolving cutter, a revolving sparle, and a sifting grate, sub. stautially as de icrilsed.

2. - In a tilling implement, the combination of a revoly ing cutter, a revolving spade, a sifting grate, and a hilling attachment, substantially as described.

3.- In a rotary tilling implement, the combination, with the revolving cutter and revolving spade, of the side frames $272 \mathrm{~S}$, forming benrings for their journals and boxes which inclose the driving train of gear wheels connecting the two shafts, and forming, with the handles 2930 , lever for con trolling the depth of the spade and cutter, and for lifting them from the earth either separately or jointly, substantiaily as shown and described.

4.- In a tilling implement, a revolving cutter, revolving sparle, whecls Io II, side frames 2728 and handles 2930 the comnecting har $17 \quad 1 S$, and ratchet segment 33 , com- lineel and arranged substantially as shown and describect, wherelyy said frames and haudles may act as levers of the first and sccond orders alternately in cortiolling the movements of the implement.

5.-In a tilling implement, sub-tantially as shown and described, the combination, with the revolving cutter and revolsing :pade, wheeis $10 \mathrm{II}$, side lever, and handle, of the draft bars 17 is, which move independently of the side frames or levers, and to which the dranghe shatl bo applied at one of the adjuxtable : ttaching holes, whereby the thrust of the revolving cutter into the eath is regulated, and the fulcrum of the wheels IO II may be vuried along said bars to raise the revolving cutter substantially as described.

6.-In a tilling implement, a revolving cutter and a revolving spade combined together for conjoint operation, the said part - being constructed and hung with relition to each other so that the spacles shall play within the spaces afforded between the cuiters, and the cutters shall run close to the axis of said spade, whereby the eath lifted by the spades shall be conlined thereon, sulstantially as de scribed.

No. 218,129 - - CHARLES J. I ANIELS, LEHANU, N.

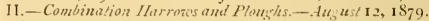

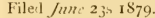

Claim. - I. - The rings $\mathbf{E}$, connected by lar $\mathrm{G}$, in comli. nation with the semi-circular ring $E$, cylinder I, having pinions $\mathrm{N}$, and whedi (; having cogged llang as 1 , sulintantially as ret forth.

2.--The platform 1 , suppurted on wheels $C$, in coml ination with rings 1 , semi-circular rings $E$, and toothed cyliuder I, substantially as set forth.

3.- The platform A, provided with har (2), having 1 ins ", combined with ratchet $k$, lever $s$, har $f_{r}$, lings $F$, having projection, 11, and semi-circular rings $\mathrm{E}$, having slot-c, substantially as set forth.

4.- In a rotary cultivator, the cylinder I, provided with teeth having the cutting blades () and the wedge-sliaped $f$ ortions $\mathrm{P}$, constructed and arranged as shown and dincritred, and for the purposes set forth

No.219,115-CCIARLESE.SACKETT, MATI.DA FTR-

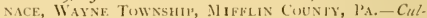
livatins Machins.-Siptemler 2, IS79. Filed March $\mathbf{1 7}$, I 879 .

(laim.-1-1u a tilling implement combining two or more revolving cutters and a rotary shifting grate or harrow, the interpusition between them of a ixed spade componed of plowing points projecting between said eutters and uniting back of them to form a common spade-surface, so inclined that the earth divided by the cutters shall be rained, passed rearward and dropped into the furrow so made, or upon pulverizing or sifting devicus, substantially as described and shown.

2. - In a tilling implement combining a fixed spade and a rotary sifting-grate, the combination therewith of two sicle plat «s, 12 I3. inclosing the sai I spade and si.ting-grate, and extending above and below the plane of their surlinces or centres a sufficient height and depth to contine the upeoming carth upon them, and to keep open the furom-s] ace below them for the redeposit of the earth atter preparstion by the ift ing-grate, subutantially as described and shown.

3.-In a tilling or pluting implemsut, the combination therewith of a rutary sifting-grate provicled with revolving toothed loars having a forced rotation, and for the pnipose of harrowing or preparing the earth raised $b_{j}$ the tilling clevices in one continuous operation, whether for the purpose of planting in the same operation or not, substantially as shown and described.

4.- In a tilling implement comlining a revolving cutter, a fixed spade, and a rutary siting-gate, the coml unaton therewith of an automatic l luting attachment of convenient device, whereby the earth may be plauted at the same time as tilled, and in one and the same continuous pjeration, sulsstantially as described and shown.

5. - In a tilling implement, the sent 56 and draft-bar 46 47 , in combination with the $T$ rocking lever 89 , ratchetpouts 3536 , frame 67 , with it - cultivating attachment- lever 43, and axie, arranged as described, to caltse the driver $\mathbf{s}$ weight tis asiot in forcing the implement into the easth, or to 
1.aise and sintain it alove the groual, subtantially as shown wit descrilset.

6.- In a tilling implement, the combination therewith of on arljustable triangular lifting and earrying arrangement composed of the "l roeking leven 8 9, supported on the anle 4 , the eultivating attaehment bar 67 , and ratchet-pusts 35 36 , wherclsy the carrying wheels and axle serving at a fulcrum, the power of the team, acting througl the 7 rocking levers at either enil, alternaiely serves to raise or sustain the implement from the earth at will, substantially as shown and described.

No, 219,116.-CIIAR1.ES E. SACKETT, M.ITILDA FekNACE, WAYNE. TOWNSH, MHFLIN COUNTY, PA. -

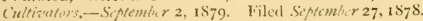

(laim.-1.-In a tilling implement, combining two or more revolving eutters, 51 revolving with a ecntral roller or axis, 52, the subelivision of that roller into, or the surround ing of that axis by, a number of smaller rollers, 2, rotating on iudependent axes 3 , and having sharpened eutting edges 4. that serve to cut up, erush, or disintegrate the weeds, stalks, or other field growth that may pass between said revolving euters, substantially as deseribed and shown.

2. - In a tilling implement, comlining a revolving spade, eomposed of one or more rotating blades, 53 , the combination therewith of a series of parallel bars, 5 their supporting wheel 6 and 7 , eccentric traek, and sicle plates, 8 and 9 , for projecting and withdrawing the spade-cleaners and forcibly ejecting the earth at each revolution, sulistantially as de seribed and shown.

3.- In a tilling implement having a revolving or fixed spade, the combination therewith of a sifting-grate of uneryual spaces, the rovolving toothed hars $\mathbf{1 2}$, with gear-train $\mathbf{1} 3$ and I4, the sisle frames, 11 and 15 , the latter provicled with an inclosed gear-box, the chain 21, and chain-wheels 20 and 31 , substantially as shown and deseribed.

4-In a tilling implement combining a revolving eutter, a revolving spade, and a sifting-grate, the combination therewith of an automatic seecl-drill, of a convenient device for planting the easth at the same time as tilling it, and in one continuous op ration, substantially as described and shown.

No. 220,176.-CHARLES E. SACKETT, MAIILDA

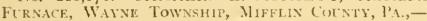
Cumbind Ploushs, Harrewi, and Drills.-Siftimbir' 30 , 1879. Filed $\mathrm{Nay}_{\mathbf{1}} \mathbf{4}, \mathbf{1} 879$.

Claim,-1,- In a tilling apparatus, the eombination, with a plough earried on a frame, of a wheel supponting said frame and alapted to move on the hottom of the furrow last made, and to receive and pulverize the earth from the furrows in process of making, as set forth.

2. - In a tilling apparatus, a revolving pulverizer, closed or partially closed on the furrow side, adapted to receive the earth from the land side, and provided with internal pulverizing apparatus adapted to pulverize the earth and to let it drop in the furrow behind the pulverizing-whecl, as set forth.

3.- In eombination with the revolving pulverizer having hars and teeth, as set forth, the shield 8 , fixed to the haft and operating in connection with the plough and the revolving wheel, as and for the purpose set forth.

4.-In combination with a tilling apparatus, consisting of a plough and a revolving pulverizer, receiving the earth from the plough, moving in the furrow last made, and leaving the pulverized earth therein, a seeding device, the parts operating together as set forth.

220,177.-CHARLES E. SACKETT, MATLDA FUR-

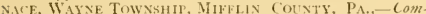

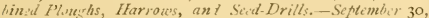
IS79. Filed Ausust 13, I 879

Clain.-1.-The eombination of a earriage-frame, of a frame carrying ploughing and harrowing deviees, and of the levers 23 , lifting-hars 26 , shaekle-hars 25 , lifting eranks 27 ar.d the shaft-erank, connecting-rod, and lever, as set forth.

2.- In combination with the lifting apparatus and the suspended frame, the springs 24 , arranged upon the bolts of the prineipal lever-bars 23 , and opernting with the eontrolling lever, to raise the frame, as set forth.

3.- The combination of a earriage-frame and combined plough and harrow-frame with the lifting-springs 24 , the principal levers 23 , lifting-bars 26 , the shackle-bars 25 , lift- ing-erank 527 , erank-hhaft 28 , angling, rank 29 , comnecting rod 30 , controlling-lever $3 \mathrm{f}$, and stop-frame 32 , substantially as shown and described.

4.- In a vertical wheel-harrow, the emmbination of trans verse removable bars and the perforated rims, whereby the spaces are marle arljustable in width, as set forth.

5.-A vertical whecl-harrow, 2 , in eombination with a pulverizing plate, 15, having hinged finger bars or cleaners 17 and spring 19, whereby obstructions which will not pulverize are passerl withont injury to the implement, sulutan. tially as shown and deseribed.

6.-The plough made laterally adjustable, in combination with the vertical wheet-harrow, the mould-board of the plc ugh being adapted to the imner periphery of the harrow, ns set forth.

7.-A vertical wheel-harrow, 2 , in combination with a plough, 4 , made fatt to a sliding beam, 5 , slicling upon rods, as 66 , and actuated by a serew, 7 , and erank-hanclle 8 , or sinilar deviee, all in connection with the common frame I 1 , whercby the amount of earth turned into the harrow may be regulated, substantially as deseribed and shown.

8. - The combination of a earriage of substantizlly the construction describec, of a supplemental frame suspencted on one side and earrying the plough and pulverizing-wheel, which operate in connection with each other, and of a seeddropping device mounted on the opposite side, the whole apparatus operating to plough, pulverice, and plant at one operation, as set forth.

No. 221,095.-RICHARI) B. PEIRICK, RICIMNN1, IND,-Plousiks.-Octotser 2S, 1879. Filed Harth 25, IS79.

Claim.-1. - The revolving plough $\mathbf{l}$, of tubular form, for encireling, operating upon, and rearwardly delivering the soil, substantially as described.

2. - In a machine-plough, the eombination of the eutter proper, $g^{\prime}$, having plain or irregular edge for severing the slice of soil, and the revolving tube 1 for inventing the same. 3.- In a machine-plough, a tube, $I$, and a cutter $s^{\prime \prime}$, the latter being provided with a lip, $\mathrm{R}$, projecting into the tube, as and for the purpose set forth.

4.- In s machine-plough, the lip $\mathrm{R}$, projecting rearwardly from the eutter $g$, and formed to prrsent an edgre, $r$, obliquely to the earrying part moving away therefrom, for the purpuse of facilitating the revolution of the tube, deereasing compression, and increasing breaking effeet.

5.- The tube 1 and cutter proper, 5 , the latter having a lip, $\mathrm{R}$, projecting into the former, said lip locing provided with a brush, $S$, radinting from the convex side of its rear edge, $r$, eombined and operating as described.

6. - The eombination of the eutter $g^{\prime}$, lip $\mathrm{R}$, and tube $\mathbf{l}$, having slots or escape-holes $i$, for the purpose set forth.

7.- In a maehine-plough, the fixed entter $G \xi^{\prime}$ and the revolving tuhe 1 , having gear-holes, $f^{\prime}$, in combination with shaft $\mathrm{F}$ and suitable gearing driven from the gromd-wheel $\mathrm{B}$, substantially as shown and described.

8.-The tuhe 1, having gear-holes $f^{\prime}$ and escape-holes $;$ guarded hy outside plates $\mathrm{T}$, unbstantially as set forth.

9.-The eombination of the tube 1 and the eutter $u^{\prime \prime}$ with lip $\mathrm{R}$ and guards $\mathrm{T}$

I0.-The combination of the revolving tube 1 , fixed cutter $\mathrm{G}$, collar $\mathrm{H}$, tie-rools $\mathrm{J}$, and rollers $\mathrm{K}$, suhstantially as shown and deseribed.

11, - In a machine-plough, the tube-shaft F, eollars (; and $\mathrm{H}$, and tie-rud, I, substantially as deseribed, and for the purpose of supporting the loracing and tube.

12.-In a machine-plongh, the drive-wheel B, gearing / $d$, cross-shaft 1 , bevels $\mathrm{E}$, tube-shaft $\mathrm{F}$. and gearing $f f^{\prime}$, for revolving the tube $I$, substantially as set forth.

13.- In a revolving plough, the ribs or guides $X$, or their equivalants, to provent any tendeney of the soil to ulicle -iclewise

14.-The combination of tubular plough I and frame $(; 11$ $J$, or its equivalent, and rollers $K$, provided with retaining flanges $k$, as and for the purpose set forth.

15. - In a revolving tubular plough, the tooth or breaker $\mathrm{W}$, substantially as described, and for the purpose set furth

16.- $\ln$ a revolving plough, the combination of tule 1 , rear collar, HI. and tooth or hreaker $\mathrm{W}$, substantially as shown and described. 
No, 222,603-CIIAKl.ES E. SACKETT, IIATIISA

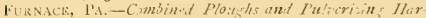
rens.-Dic:mler 16, IS79. Fïled Nivember 4, IS;9.

Claim.-I-In a tilling apparatus, the combination, with a wheel-harrow, of a plough located by its sicle and adapted to turn the furrow into said harrow, and of a second plough arranged in a line (but on a higher plaue) with the first, and forwarl of the harrow, as and for the purpose set forth.

2.-In a tilling apparatus, the forward plough, 11, made vertically adjustable, in combination with a revolving pul verizer made vertically adjustable, so that the latter may admit the parsage below it of any depth of cat or thicknes of field-growth removed by the former, sulsstantially as described and shown.

3.-In a tilling apparatus, the combination, with an ordi nary beam plungh, of a horizontal axle crossing the saic pluagh beam and supporting upon the furrow side a revoly. ing wheel-pulvericer adapted to move in the furrow lint made and to receive the earth from said plough, and upon the other end an arljustable gauge-wheel traveling upon the land, the two wlicels when adjusted in combination supjort iner, steadying, and erualizing the movement and cut of the plungh, sub-tantially as descrilsed and shown.

4-In a tilling apparatus, the combination, with an ordi nary lieam plough, of an axle connected to said plough and made vertically adjustable thereon, said axle carrying on one end a pulverisins-wheel adapted to nove in the furrow and receive earth from the ploughshare, and upon the other end an adjustable gauge-wheel traveling on the land, as set forth.

5.-In a tilling apparatus, the combination in gangs of a series of ordinary beam-ploughs aud resolving wheel-pulverizcrs adapted to move in their respective furrows and to receive and pulverize the earth from their respective ploughs, sulstantially as described and sown.

Nu. 229,200.-TIJ)UAS J. TALLY, RockPokT, THX., asignur to himelf and JOHN J. WELluFN.-Rotary Ploukthe-Junc 22, I 880. Filed April 22, 1SSo.

Claim.-1.- I rotary plough constructed substantially as hereinshown and described, consinting of the drive wheels $\Lambda$, having eog, $O$, the axle $B$, the swinging frames $J$, having guard boards ' 1 ' and guard tods (2, the cylinders L, carrying phughs $\mathrm{M}$, and the gear wheds $\mathrm{N}$, whereby the plough cylinder are rotated by the advance of the machine, as set finth.

2.- In a rotary plough, the combination, with the axle I anil the shafts $\mathrm{K}$, carrying the plough cylinclers $\mathrm{I}$, of the sin inging quadrantal fromes J, having guard board, P' and suard rods $Q$, substantially as herein shown and descriled, wherely the said plough cylinders are suspended from the said axle, as set forth.

3.- In a rotary plough, the combination, with the inner quadrantal frames, J, carrying the plough cylindess 1., of the fenders $R$, attached to said quadrantal plates and rocking with them upon the axle, substantially as herein shown and described.

No. 233 ,SOg-CHARLES E. SACKETT, MATILDA

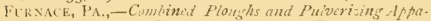
rutus. - Uctoher 26, 1883. Filed July 20, 18So.

Claim.-1.-The pulverizing-wheel adapted to operate in connection with a plough to receive the furrow-slice therefrom, said wheel having a cylindrical tread and frusto-conical furrow sitle, substantially as described.

2.- The combination, in a pulverizing-wheel, of the hub. casting $\mathrm{F}$, inclined radial bars $u$, rims $i^{\prime} v^{\prime}$, and transverse lars a', substantially as described and shown.

3.-In a combined ploughing and pulverizing apparalus in which the furrow-slice is turneal into the pulverizer, the combination of a pulverizing-wheel, a straight axle, and a landside-wheel of the same size as the pulvering-wheel, and adjustably attached to the axle, substantially as descrilied,

4-The combination of the axle, the arm $a$, fixed directly to said axle, the plough, and a suitable elevating-arm, sub. stantially as deseribed.

5.-The combination of the plough, the arm $a$, fixed directly to saicl axle, the axle, and the double arm $r r$, subutantially as shown and described.

6.-The combination, with the plough-arm $a$ and axle, of the slotted arms, , perforat-it hatulles, and connecting beith, as decreribed.

7.- The combination, in a combined plough and wheel pulverizer, of a straght axle and a landide-whet with the sement-casting $\mathrm{B}$, lever 0 , wheel-spindle $f$, and the described whel-pulveri:er, of the same diameter as the laudside wlecl, sub-tantially as described and shown.

Ni). 235.372.-TIIUMAS II. M.CRAY, TYRONZA, ARK.

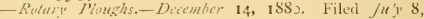
ISSO,

Claim.-In a rotary plouging machine, the combination of the steering wheel $J^{\prime \prime}$, intermediate gear and pinion wheels, II'I J', the double cogged rack bar $G^{\prime}$ and icller wheel $h^{\prime \prime}$, to sutain the rack lar, and the stirrup in which the shaft of the plough cylinder is sustained, all comstructed and arranged sulstantially as and for the purpone describel.

No. 236.671-MENRY II. SIENCER. MWNH CiTy,

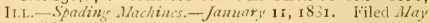
21,1880 .

Claim:-1.-A spading machine supporterl upon a wheel carriage, and consisting of a serich of spades held in guides and arranged ralially around an axle and caused to hine a rotary reciprocating motion around and from the axle, in comlination with a spring mechanim arranged between the axle and sra.les, wherehy the said movement will be retarted as the siates shall enter the ground and nccelerated as they are withdrawn from the earth, as shown and described.

2.- In a sparling machine, the combination of the sujporting wheels, the revolving axle, an independently revolving sleeve to fit around the axle, gnide disks attached to sat sleeve, supporting rotary reciprocating shovel, and the multiple gearing to cause the sleeve and its comsections $t$, revolve upon and in the direction with the axle and at an accelerated speed therewith, in the manner and for the pur. pose substantially as described.

3.-In a pradiug machinc, the combination of the suppoiting wheels $\forall \hat{h}$, the driving axle $A$, the hollow sleeve $1 I^{\prime}$, guide diisks $1 \mathrm{I}^{\prime}$, carrying rotary reciprucating spades $\mathrm{K}$, provided with cylindrical hulis that cuvelop the slecve II' and are comected therewith by a coiled spring, and a set screw in the one working in a segmental slot of the other, to limit their movement one upon the other and exert a yick. ing spring pressure upon the spades ns thicy cnter the ground, stubstantially as described.

4.-The combination, in spading machine, of the supporting whecls $\mathrm{B}$, axle $\mathrm{A}$, sleeve $11^{\prime}$, multiple gear to comnect the axle with the sleeve, muicle disks I I', sparles $K$. cccentric $L$, with grooved periphery $l^{\prime}$, secured to jeripheral rim $L^{\prime}$ loy set screws $l^{2}$, and vegment plates $K^{\prime}$, pivotel $t o$ studs $\mathrm{K}^{2}$, that slide in slot in the face of the peripheral rim, in the manner and for the purpose sulbtantially as described.

5.-In a sparling machise mounted upon a wheeled carriage, the guide clisks I l', supported uy on a sleeve or axle and carrying rotary reciprocating spades, in comlination with the eccentric 1 . adlu-tably connected to the frame of the machine by a bail, $\mathrm{L}^{2}$, to regulate the thrust of the spades into the rround or to raise them out of contact therewith al. together, substantially as and for the purpome deneriled.

No, 238,532,- JULIUS GCHUCIIARD, FREDFRICS-

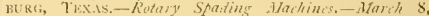
ISSi Filed Dercmbir 13, IS80.

Claim.-1.-In a motary spading machine, the combina tion of the supporting and clrauglit frame $\Lambda$, transverce axle $C$, the rotary spading drum I), mounted at one end of said axle, and the traction wheel II at the of prite end thercof, all as and for the purpose set forth.

2.- In a rotary spadiug machine, the combination of the supporting and draught frame $\mathrm{A}$, transwerse axle $\mathrm{C}$, the rotary spacling drum i), mounted at one end of said axle, the traction wheel $H$ at the oppo-ite end thereof, with the spading drum $G$, hinged frame $I$, cleaner $J$, mounted on axle $C$, and the cleaners $K$, all constructed and relatively arranged as herein shown and described, for the purpose set forth.

3.-In a rotary sading machine, the curved touth $\mathrm{E}$, having a square chisel point and a triangular cross section, the concave face being of uniform wistls, and the thickness of the tooth increasing from the point of the lase, as and for the purpose set forth. 


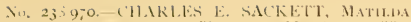

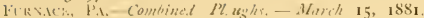
literl finumy 14. ISSt.

Clam, -1, - The combination of the pulverizing whecl, the lent axk, and the land wheel with the plongh flexibly su panded beneatle said bent axle and dischateriner into said whed, and with levices for preventing laternl movement of siil plough, whereby rertical movement of the plough and proper relation to the pulverising wheel are maintained, ubstantially as dencribed.

2.- The combination of the bent axle 13 , the tongue $\mathrm{C}$, the yoke braces ot $a$, fixed directly to sail axle and ailin ted for connection cither to the plough beam or to the tongue, as ret forth,

3. The combination of the plough beam, the yoke braces $a$ a, fixed clirectly to the axle, the axle 13 , the pivotal supports 5 , and the carrying frame composed of the jointed tongue (; the diagonal braces 33 , the re-enforcing braces 44 , and t:rminating preferably in the frame 66 to support 4. pivented to the axle through the smpport 55 , substantially as dercribed and shown.

4.- The cumbination, with the wheels, the bent axle, and the lraces a $a$, alapted for pirctal connection either to the plough leam or the tongue $C$, of the described lifting devices, and adapted to raine either the plough or cultivator tecth, as set forth.
5.- The combination of the whecl, the bent aske, the tongue $($, the hook $c$, the plough beam $\|$ ith pin $p$, ancl lifting levor, ubutantially as clescribed.

6.-The combination of the wheels, the bent axle I, the lever handles $h$, the tongue $C$, and the lraces $a$, saicl lever hamiles $/ /$ being pivoted upon the braces $\sigma$, as set forth. 7.-The combination of the tongue $\mathrm{C}$, the guide prats as, fixed to its rear extension, the lever handles h, pivoted upon the braces $a$, bent axle 13 , wheels, and the devices for tmin. ing the carth, substantially as described.

'8.--The tongue (', consisting of a fixed and movable part extended to the rear of the bent axle $B$ and pivoted thercon, in combination with the frame 66 , alayted to receive a seed box, and with braces $a \Omega$ and bent axle li, sul)stantially as described.

9. - The combination, with the tongue $\mathrm{C}$ and braces 33 , pivoted upon the bent axle B at its upper part, of the yolic iraces $a$, fixed to said axle near the wheels and adapted to be pivoted to the tongue $\mathrm{C}$ or to the plough beam, and also in combination with the eyebolts 15 , fixed to the rear of said axle and alapted to hold cultivator devices when desired, sulstantially as described.

I0.-The combination, with the plough and pulverizer wheel to receive the furrow, of the seed tubes $t$. loeated directly in rear of the said whecl, whereby the seed are dropped in the midts of the earth as it falls from the wheel, shistantially as deseribed. 


Andrew, IV WV.

Au-tin, K. G. S.

Austin, R. G. S.

Beaver, J. 'T.

Black, T.

Bouton, A.

Breneman, I.

Briergs, H. C.

Broadwell, W. B.

Brown, J.

Bullock, R.

Carr, N. Jr., and J.

Carter, C. 11.

Chandler, M, and Nickels, J. 13.

(raft, R. 1).

Creek, C. C.

(roll, (i.

Cummins, $\mathrm{S}, \mathrm{A}$.

l banner, J.

Debolt, $C$.

beyo, C. B.

Dunlap, J. R.

Jwight, $\mathrm{s}$.

Dwight, $\mathrm{s}$.

1)yzert, W

Ellis, T. J.

Eshleman, A.

Frankeberger, J. T.

Freeland, P. F.

Ganong, L. M,

Ganong, I.. II.

Gialir, IV.

Geisinger, J. B. and WVilliams, D. II. S.

Graham, J. L.

Guthrie, L.

llall, C. M.
Harris, J. O, and Slewder, W. $\mathrm{F}$.

llart, G. D.

Henderson, J. T.

Hernby, J.

Hoffeclitz, J. C.

Hoover, T. J. and Ifenderson, J. T.

Hume, J. Ml.

Ingersoll, C. P.

Jessop, J. W.

Johnston, B.

Krauser, J. and C.

Kugler, $O$.

Kusler, $O$.

Kugler, $O$.

Kurtz, J.

$\begin{array}{lll}\text { Lechtenthaler, G. } & 462 & 137\end{array}$

McEwen, E. St, and Arlams, O. R. $\begin{array}{lll}488 & 142\end{array}$

Mason, R. E.

Matheny, R. G. and Barnes, L. $R$.

Messenger, $\mathrm{N}$

Minnich, E.

Misner, F. and P. A

Moore, M. H. and Satterwhite, $\mathrm{A}$.

Norton, C. P.

" " "

(R.)

Palcer, J.

Powell, J.

Ravenscraft, H. C.

Reed, $\mathrm{M}$

$\begin{array}{ll}466 & 137\end{array}$

$\begin{array}{ll}467 & 137\end{array}$

470138

$\begin{array}{ll}464 & 137\end{array}$

$\begin{array}{ll}467 & 137\end{array}$

$\begin{array}{ll}478 & 140\end{array}$

$479 \quad 140$

$481 \quad 141$

$\begin{array}{lll}487 & 142\end{array}$

$476 \quad 140$

I.

Reynolds, P. B. and I. C. 479 140

Rice, K.
Rice, J. $\mathbf{H}$.

Righter, J.

Roby, M

Rue, J.

Shank, S. J.

Shaw, T. M.

Sims, Z. 13.

“" " "

(R.)

Simall, B. B.

Smith, A.

Smith, J. B.

Plati Claim

$484 \quad 141$

$\begin{array}{ll}462 & 137\end{array}$

$487 \quad 14^{2}$

$\begin{array}{ll}463 & 137\end{array}$

475140

$486 \quad 142$

$477 \quad 140$

477148

$\begin{array}{lll}482 & 141\end{array}$

488 142

$463 \quad 137$

$\begin{array}{ll}461 & 137\end{array}$

StabI, H. . Duffenbacher, J. 46I 137

Staman, J. K.

$\begin{array}{ll}464 & 137\end{array}$

Stansbury, A. F. and T. M. $573 \quad 139$

Steller, C. E. $\quad 474 \quad 139$

stoll, M.

$479 \quad 140$

Taylor, W. A. and Graves, W. W.

$\begin{array}{ll}465 & 137\end{array}$

Thirlwell, J. $\quad 463 \quad 137$

Thomas, J.S. $\quad 480140$

Thompson, J. J. and Collier, $\mathrm{V} . \mathrm{F}$.

Thompson, J. J.

Thompson, J. A.

Tower, A. C.

Tower, A. C.

Webb, T. U.

Weld, II.

Wilde, D.

Wilson, $\mathrm{N}$. $\quad 474 \quad 139$ $\mathrm{P}$.

$\begin{array}{ll}476 & 139\end{array}$

$480 \quad 141$

$486 \quad 142$

$482 \quad 141$

$484 \quad 141$

471138

$481 \quad 138$

$469 \quad 138$

Wood, J. F,

$48_{5} \quad 141$

Wottring, R.

Wyant, 1 ).

$\begin{array}{lll}466 & 137\end{array}$

Yost, G, W. N.

Zimmerman, C. 
P. ST.AHI and J. IDLFFENB.ICHIER, TAR!GT Tin

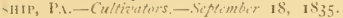

Claim.-1. - The sheers or mould luards which are ent cast in one piece and forming a coulter theer and mmulal board!).

2.-The high stamelands $\mathrm{C}, \mathrm{I}), \mathrm{F}, \mathrm{F},(\mathrm{i}$, and 11, which carry the plesigh beams of far above the corn or potatoen a n not to break it down, so long an it needs cultivating.

3.-Placing them in such a manner an to ploms ar culti vate hoth siles of a row of curn or potatoes at one and the same time, of gninz over the same; We dis not reatrict the number of heern or mould boards and standarels to three on each sick of the plough as their number muse be increaseal or climinishe las the distance between the row of corn or potatoes is increaserl or timinished.

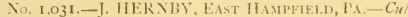

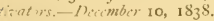

(laim.-The peculiar mamer of constructing, affixing and comecting the mould boards, so as to almit of their being shifted and turned so as to regulate the di-tance apart and the brearlth of the furrow as herein clescribed.

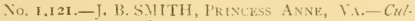
ivaters.-thril $15, \mathbf{1}_{3} 9$.

Claim.-The arrangement of the perforated beams in combination with the shifing and reser-bl-plons h- for throw ing the earth from or towarls the ruws of corn, recrulated to any width required, in the manner le ore described.

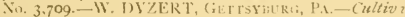
to.s - tusust 16, I:44

Claim.-The curvel iron brace, which connect the two sides together, in combination with sail -iiles amil the tongue, con-tructed and arramsul in the manner above specified.

No. 4.745,-J, an! C. KRAUSER, READINs, ['A.Cutivators -Sipientiber 5,1846 .

Claim.-I.-The knee or l race cat on the beam as ex plained.

2.- The longitwinal opening (), (), together with th metallic hoxes $\mathrm{H}, \mathrm{H}$, as set forth.

No.11.379.-G. LECHTEN HIIALER, LIMESTUNVIL. LE, PA. -Cultivitur: $-7 u / y \quad 25,1854$.

Claim. - The methoul hercin wown and dercrited of at. taching the shares $G$, to the beams $A$, Vic: having metal strips $\mathrm{F}$. perforated with holes $\mathrm{f}$, secured to the murlersides of the beams $\mathrm{A}$, and rockets formed of two lips g, s, made at the upper ends of the shares and perfor.t.d with hotes $h, h$, in which holes h, and in the holes $f$, in the plates $\mathrm{E}$, wooden pins $i j$, are passed, securing the liares to the beams as set forth.

No, I1.929,-I. BROWN, LAW: RMGE, ILl.,-Culti. va: r.-Novmbir 14,1854

claim. - The combination of the ansular chined frame $a a^{\prime}$ (having the two pieces $a, a^{\prime}$, uniterl at their forward ends into a tongue, ) with the lims tandaris $d, d^{\prime}, e^{\prime} c^{\prime}$, and short standards $h, h^{\prime}$, in the manner and for the purpose herein set forth.

No, I8,928.-I. RICiHTER, Ci.ARK、BtRG, VA.-CultiF'ators-Decimber 22, 1857 .

Claim.-The employment of the pinions $e$, and $\mathrm{f}$, when in combination with the screw shaft $/ i$, and teeth or ploughs $a$, $a$, substant ially in the manner and for the purpose set forth.

No, 24, 4II.-AZELSNITH, WestFielD, OHIw,-Cultivintors.-Junc 14, 1859 .

Claim.-The artiuting brace plates C C, frames B B, and cutters D D, when arranged as described, and in combination with the adju-tahle mould boards.

No. 24.4I8-JOSEPH THRILWELL, GALESI:URi; IL1.- Ciultivators.-June I4, I859.

Claim, - The arrangemont of the frame $A d$, the iron bows $\mathrm{B} \mathrm{B}$, the hinge bow $\mathrm{C}$, the tongue braces $\mathrm{D}$ D, and fitting chain $F$, when constructerl and used in combination for the purposes set forth.

No. 25,006.-TARLEY F. FREELAN1), NEWARK,

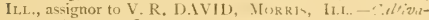
tors.-Ausust 9. 1859 .

Claim. - The arrangement of the tongue $\mathrm{A}$, cursed or segment bar $\mathrm{B}$, beams $\mathrm{E}$ E, with screw rod c, and pendents $d^{1}$, and shares F, attachel, subatantially as and for the purpose set forth.

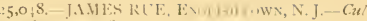

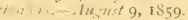

thum. The arrmgement of the smose itraft pole $f_{i}$

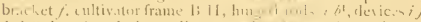

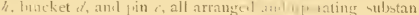

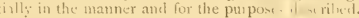

No, 26,695.-F. MISNER, and I\% A. MISNER, Fux, The (itivato - Januare 3, 1860

(lam.-The arrangement of the beam $h$, wings $m$, trans-

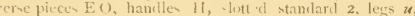
shovel K, castings C B, brace rouk h, for'ed strap G, forked rud $x$, stal transverse timb:r s, the whole being constructed and uned towether in the manner and for the purpose die cribed

No. $26.799 .-$. K. STANAN, MTFFLIX, (1)HW.CZl/i ators.- Jinueary 10, 1860 .

Claim. - In combination with the bows $A$ and $D$, arranged relatively as specified, ancl havion their lower ends cham fered as describet, the cultivating tecth or shares $\mathrm{P}$, and the connecting brace strap $\mathrm{Q}$, when the whole is constructed aucl arranged as before set forth, for the purposes specified.

No. 27,125.-J. O. IIAKRIS and W. F. SLEWIDER,

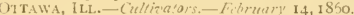

Claim-In comlination with a V shaperl atjustable and reversible frame, the adjustalsle and hinged plough stocks B, when constructed and arranged suhatantially in the manner and for the purpose dencribeil.

No. 29,537.-W. A. TAY7.OR and W. W. GRAVES, EORT Aimus, Miss.-Cultitators,-Augus/ 14, 1860.

Claim.-The arljustable heams E E, plough $d$ d, bracc rods $b^{1}$, and thic scrapers $\mathrm{G}(\mathrm{i}$, with their tandard braces 4 , and the brace rods 5 , all combined am arranerl in the manner herein set forth.

No. 29,759.-THOM.AS BLACK, PRINCEVII. II.L.Critivalors.-Au,ust 25,1860

Claim.-The arrangement of the ela-tic travere how bar C, a.lju-tahl. ruda c, buw bar $\mathrm{B}$, berms $\mathrm{A} \Lambda$, double trees $\mathbf{K}$, chain I, pulleys H J I. beam A, guards $G$ G, standards E, and hares i) $\mathrm{F}$, all as shown and ilencribed for the purpone set forth.

No. $29,8.49$-G. WV. N. VO S.T, YKLLOW SPRINGS,OHIO, anignor to himelf and JOHN F. WATSiN, EDWARDs

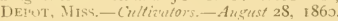

Claim.-The arrangement and combimation of the two heams $A$, crow braces $K$ and $L$. novable vhares $D$, and wheels $G$; the whole being contructed as anil for the purpures describerl.

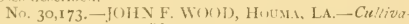
fors.-Siptizuth 25, 1860 .

Claim.- Th: arrangement of the hinged adjustable wing F, when ured in combiuntion with the asliustable frame i shovel, D), and rakes ( ; sulntantially in the manner and for the purjose set farth.

No, 30,302,-('IRLSLEDOLT, OTTAW, ILL-Culti. ז alors, - O tiber 9. IS60.

Claim.-The arrangement of the handles ( $C$, the joint $\mathrm{K} \mathrm{K}$, the lrackets $\mathrm{F}$, and the urright 1) $\mathrm{D}$, for the purpose set forth and as described.

No, 30,741,-R, G, II ATHENY and L, R. BARNES, IE KAl.1, Miss - Plorr-his.-. Vivemelier $27,1860$.

Claim. - The arranzement of the bar: $\mathrm{B}$ B, comnected with the beam A by the clamps $(\hat{r}$, in connection with the adjustalile feet or standard. F F and barn J J, attached to the bars $B$ B, ant having the plough and scrapers respectively secured to them, the handle, C ( $)$ ins attache 1 to the fars I) and land ides $b b$, and all arranged as and for the purpose set forth.

No. 30,745.-NEILSON MESSENGER, NF,WARK, ILL. Cultivators.-Novemb'r 27, 1860.

Claim.-The arrangement of the horicontal bour G G, with the pending feet or bars $\mathrm{H}$, having the share $\mathrm{I}$ attach ed in connection with the tamlarels $F$, beiner lined by the rocts $a$, and the har $G$, braced by the rods $\mathrm{D}$, an and for the purpose set forth.

No 30,74 S. - M. H. MOORE and ALEXANI)ER SAT TERIVHITE, Rome, (iA.-Criltivalurs.-Woriember $\mathbf{2 7}$, I 860.

(laim.- The arrangemenf of the lan D D D E E, beam $\Lambda$, and feet $F$, with the bars $G^{1}$ attached, the two latter part. 
being secured to the bars E E, as and for the purpose set forth.

No. 30,758. -HARRISONC. RAVENSCRAFT, KING Wou, VA.-Cultizators.-Nove'mber 27, 1860 ,

Claim.-The middle portion $\mathrm{A}$, in combination with the outer slicling rings $\mathrm{D}$ and $\mathrm{E}$, arranged and operating as above set forth.

No. 30,963.-JOHN B. GEISINGER and D. H. S. Williams, Montville, OHIO.-Cultivators.-Deiem. ber I 8,1800 .

Claim.- The arrangement of the curved slotted bar $\mathrm{C}$, curved slotted braces II II hinged to bar J, standards N N, shares Q Q, eye bolts S S, links R R, bars K, bolt L, beam $\mathrm{A}$, and handles $\mathrm{E}$, the whole being contructed substantially as described.

No. 31.305.-SOLOMON DWIGHT, BYRON, ILL.Cnltivators. - Fibruary 5, 1861 .

Claim.- The arrangement of the main frame $A$ and tongrue $\mathrm{B}$ of a single piece of timber, in combination with the retaining strap $C$, shaping block $D$, cross brace $H$, and standarcls $\mathrm{E}$, the whole arrangred and operating as specified and for the purpose set forth

No. 32, 58 .- NATHAN CARR, JR, and JOIIN CARR, MONMOLTH, ILL. - Cuitizalors.-July 23, IS61.

Claim,-1.-Making the frame in the form of a bow, in combination with supporting it by castor wheels H If, as shown and described.

2. - In combination with said bow $\mathrm{A}$ and castor wheels $\mathrm{H}$ $\mathrm{H}$, the hinged plough beams $\mathrm{C} \mathrm{C}$ and tongue $\mathrm{B}$, arranged in relation to each other, as shown and described.

No. 35.434 - - IV. B. BROADWELI. SPRINGFIELd, Il.L. -Corn-Ploushs. - June 3, I862.

Claim.-In combination with the bar $\mathrm{G}$ and clamps II H the fender or guard I, applied to the beams $\mathrm{A} A$ and bar $\mathrm{G}$, is and for the purpose specified.

No. 36,998 -C. B. INGERSOLL, MURRIS, ILL.—Culcizatirs. - linember 25.1862.

Claim.-The combination and arrangement of the draught pole, $\mathrm{D}$, the double-tree $\mathrm{A}$, the beams $\mathrm{E}$, the cross be.m $\mathrm{F}$ the standarels $(i$, the supports $C$, and the whiffletrees $B$, when all are constructed, arranged, and operating substantially as and for the purposes herein delineated and set forth.

No, 37,219,-JOSEPHUS DANNER, MILTON, ILL.Cultivators-December $23,1862$.

Claim.-The combinution and urrangement of the draught pole $\mathrm{A}$, the adjustable beams $\mathrm{B}$, the standards $\mathrm{C}$, and shares $c$, the support $D$, and the bar E, and the strap F, or it equivalent, all arranged and constructed substantiully as and for the purposes delineated and set forth.

No. 37.780.-P. B. and L. C. REYNOLDS, PropheTs Town, Whitesides CoUsTr, I.L., assignors to themselves and CLARK G. REY NOLDS, all of same place-Cultiva tors.-February 24, 1863

Claim.-1.-The arrangement upon adjustable beams B $\mathrm{C}$ of two or more pairs of perforated lever adjusting plates $\mathrm{H}$ $h i$, for the purpose of adjusting two or more pairs of shovel stocks $G^{1} G^{2} t t$, in the manner and for the purpose described.

2.- The arrangement of the bent sustaining bars F F, side beams B C, and slots $b$ is $s$, in the manner and for the purpose described.

3.-The arrangement of the frune A B C D E, swingle tree $\mathrm{I}$, draught rods $\mathrm{J} \mathrm{J}$, adjustable hanger, $\mathrm{KK}$, perforated lever adjusting plates if $\mathrm{H} 1 \mathrm{H}$, swivelling square or flat top standards $G^{1} G^{2}$, bent sustaining bars $F$ F, and slot $b c s$, the whole constructed and operating together in the manner and for the purposes described.

No. 38,337 - - ROBERT RICE, GEORGETOWN, VERMIL LION Countr, II.L.-Cultizators.-4pril $28,1863$.

Chim, -1.- The connecting of the front ends of the bars $a$ $a$ of he implement to the draught pole $B$, by means of the elastic plates $b \quad b$, in combination with the cross-bars $c c$ fitted to the clraught pole $\mathrm{B}$ and passing loosely through the bars $a a_{r}$ and with the braees $c e$ attached to the plough standards $\mathrm{C} \mathrm{C}$ and the cross bars $c c$, as herein set forth.

2.- The handles E E, attached at their front ends to the draught pole B, by means of screws or bolts $g$, in combination with the spring or elastic bar $i$, and the upright $\mathrm{D}$, on which the rod hears, substantially as and for the purpose herein specified
No. 45,549.-DANIEL WILDE, Washingtov, Iowa. Corn-Cultizators.-December 20, 1864

Claim.-1.-The lever $u$, resting on the front bar of the frame, and supported near the middle by the notched plates $w$, secured to the uprights $x$, ancl operating as and for the purposes herein recited,

2.- The arrangment of the rocking bar 5 , elevated bar $m$, in relation to the handles and the shovel stakes, for the purpose herein set forth.

3.-In connection with the arrangement of the rocking bar $g$, bar $m$, and the shovel stakes, the stirrups $q$, for the purpose herein named.

4.- The plate $j$ with its inclined and horizontal faces $k$ and 1. for the purpose herein set forth.

No. 46,376.-EIIAS MINNICH, Mckees's Half FAlLs, PENn.-Cullizators.-February 14, I865.

Claim.-The arrangement of the braces M M, connecting the plough shares to the tongue, with the teeth or rake $\mathrm{L}$, as arranged and combined with the angular-shaped frame $\mathrm{E}$, as herein described and for the purposes set forth.

No. 49,358.--JOHN T. BEVER, BETHEL ILl.--Cultivators.-June 27,1865 .

Claim.-I. - The lever handles I I containing uprights $d$ $d$, with cross bars $\mathrm{X} \mathrm{X}$, made in solid framing to vibrate upon pivot $\mathrm{P}$, in combination with beam or tongue $\mathrm{A}$, ancl clevis $\mathrm{N}$.

2.- - The arrangement of the elevating clevis $\mathrm{N}$, clevis guide $o$, cleats or notches $r r$, and corresponding notches $s$, as and for the purposes herein specified.

No. 50,217.-ANDREW BOUTON, NAPA, CAL.-Cul. tivators.-October 3, 1865.

Claim.- The right and left cultivators A A supported by the caster wheel $\mathrm{F}$ and adjustable wheels $\mathrm{B}$, and connected by transverse bars $G$, all arranged substantially as and for the purpose herein set forth.

No. 52.542.-CA],VIN B. DEVO, assignor to himself and EDGAR B. RINNER, MARENio, II.L.-Cultivators. - Fibruary $13,1866$.

Claim.--1. - The combination and arrangement of the triangular frame B B C, draught pole A, stanctards D, and braces E, constructed and operating as and for the purposes set forth.

2.--In combination with the said draught pole $\mathrm{A}$, triangular frame $\mathrm{BC}$, standards $\mathrm{D}$, and shovels $\mathrm{D}^{\prime}$. the arrangement of the inclined posts $\mathrm{F} \mathrm{F}$, provided with the pulleys $c c$, the pulleys $\mathrm{G}$, and cord or chain $\mathrm{I}$, operating substantially as and for the purposes specified,

3.- The arrangement of the toothed plates L $\mathrm{N}$, slot $m$, bolt $\mathrm{N}$, and $\mathrm{O}$, with the draught pole $\mathrm{A}$, cross bar $\mathrm{C}$, and inclined posts $\mathrm{F}$, sliding in the loops $a$, all arrangedand operating substantially as herein set forth and described.

No, 53,592.- SOLOMON DWIGHT, ROCKFORD, ILJ. Citlizators.-April $3,1866$.

Claim.-The combination of the rigid tongue, the curved side pieces, the adjustable rear and middle cross-beams, the adjutable handles, the swivelling ploughs, and the yielding spring corn guard, when constructed, arranged, and operating as described.

No. 55.185.-TIMOTHY U. IVEBB, SPRINGFIELD, ILL. --Cultivators.-May 29, 1866.

Claim.--1.- The construction of the frame, the timbers A $A$ and the cross bars or timber, B B B, so notched and halyed together on an angle that the face of the cross bars B will place the straight standards C C C $\mathrm{C}$ in the proper inclination for supporting and bracing the ploughs or cultivators, substantially as herein described.

2.-Making corresponding series of hole $c$ c through the cross bars B B B for the purpose of bolting and bracing the cultivator standards $\mathrm{C}$ ( $\mathrm{C} \mathrm{C}$, so that the cultivators may be changed to work eithar right or left and the spaces adjusted between them, as aud for the purposes herein set forth.

No. 56,173.-ROBERT BULIOCK, SOUTH MHLS, N. C.--Cultiziators.-July 10, 1866.

Claim.-The combination of the stock with the weeding shears, the iron rod braces, the eye-holes, and iron bolts, when these several parts are arranged, constructed, and adjusted substantially as described.

No. 57,698.-WILLIAM GEAHR, New HOLland, $\mathrm{PA}$ - - Cultivators. - September, 4,1866 .

Claim.-The independent, adjustable, and reversible 
beams 1) D, in combination with the upright $\mathrm{E} F$, when con nected with a suitable framework, sulstantially in the manner and for the purpose specitied.

No, 58,534.-CIIKISTIAN ZIMMMEKMAN, Cor. LINSVILI.E, (OHIT.-Plough/ls.-Oitober 2, 1866.

Claim.-I. - The manner of attaching the tounge to the plough by means of the perforated plates $a$ and and $b \quad b$, arranged and operating in the manner and for the purpose described.

2.-The combination of the protecting plate $r$, enclosing the landside of the plongh, with the mouldboard and land side made of one piece of motal, substantially as chencribed for the purpose specified.

3.- The linged draw bars of of with their adjusting nuts and screws, in combination with the adjusting frame com posed of screw rodse e and cross bir $g$ with their .uts and adjustable handles, arranged and operating in the manncr and for the purpose set forth.

No. 60,892.-T. C, HoFfentTZ, Mercersieri, PA. - Cultizaiors. - January 1, 1867.

Claim.-The arrangement shown and described, con sisting of the adjustable and pivoted spring standard C, removable shares I J, and adjustable handles E

No. 61.512.-MARTIN IIRENEMAN, EAST DUNBGAI TowNSHIP, PA., assignor to himself and SAMUEL LBY, ElizABETHToWN, PA.-Cu'tizators.-January 29, 1867.

Claim. - The special arrangement and construction of the frame A $A^{\prime}$ B ( 1 ), in combination with the reversible handles $F$, and holes 10121314 and 15 , arlapted for the reception and application of the axle and wheels L M. scraper $U \mathrm{P}$, all constructed and operating in the manner and for the purpose specified.

No. 62.181.-MOSES CHANDLER, CoRINTH, ME., and JOHN B. NICKELS, KENDUSKEAG, ME., assignors to $\mathrm{V}^{*}$. S. PALMER and J. B. NICKELS.-Horse Hoe's. - Fibruary 19. I867.

Claim.-1.-Adjustably attaching the wings or blacles 11 when formed as described, to the uprights G, substantially as and for the purpose set forth.

2.-The combination of teeth or cogs with the blades II and uprights $G$, substantially as herein shown and described, and for the purpose set forth.

3.-The combination of the piroted rake heads $K$ with the blades or wings 11 , substantially as herein shown and described, and for the purpose set forth.

4.- Securing the uprights $G$ to the caps $C$ and to the slotted cross bar B by means of angular bolts $\mathrm{E}$ and steady pins I, substantially as herein shown and described.

5.-The comlination of the stay braces $J$ with the uprights $\mathrm{G}$ and adjustable caps $\mathrm{C}$, substantially as herein shown and described.

6.-The combination of the adjustable slotted caps $\mathrm{C}$ and slotted cross-har 13, having bands D around thei slotted ends, with each other and $x$ ith the draft beam A, substantially as herein shown and described.

No. 62.898.-ALEXANIER F, and THOS. M STANSBURY, LEWISTOWN, ILL.-Cultivators.-Marih 12, 1867 .

Claim.-The slotted shoe or bearer $\mathrm{F}$, the double-trees $\mathrm{K}$ and $G$, the clevis bars $H$, draft rods $I$, and pendant staples $J$, all substantially as and for the uses and purposes hereinbefore set forth.

No. 63,384.-GEORGE 1), IIART, LYCOMING COUNTY, PA.-Culiziators.-Apitil 2, 1867 .

Claim. - The combination of the standards $\mathrm{A}$, attached to the plate $\mathrm{C}$ by hinge and standards $\mathrm{A}^{\prime}$, with its tenon at the upper end, as shown in Fig, I, with the blades or cutters B, the plates $\mathrm{C}$, when provided with the slots $g$ and the notche $h$ and the frame or support $O$, all constructed and arranger substantially as descrilied and set forth.

No, 64 878.-JAMES M. HUME, Colchester, ILI. assignor to himself and C.F. HOY'T, same place.-Cutti vators.-May $21, \mathbf{1} 867$.

Claim,-The arljustable beams B, arranged in combina tion with the frame $\mathrm{A}$, levers $\mathrm{K}$, links $\mathrm{L}$, bar $\mathrm{G}$, an $\mathrm{I}$ single tree $\mathrm{M}$, as and for the purpose sub-tantially as described.

No. 66,717.-Jolli KURTZ, Clinton Township, PA.-Corn Cultinators and Potato Ploughs.-Fuly I6, 1867 .
Claim.-1.-The slotted side pieces B B, with their top and bottom bars or plates $\mathrm{C} \mathrm{C}$, and arljustable uprights $\mathrm{E}$ E, as arranged and combined with the reversible ploughs 11 II, as herein described and for the purposes set forth.

2. - The slotted sicle picces 1; B, with their bars C C, for the purposes set forth.

No. 6\$,290.-CHARLES C. CREEK, LIBERTY, IND,Cultivaters.a-August 27, 1867 .

Claim.-1.-The provision, in a corn plough or cultivator of a shifter wheel 1), constructed and attached substantially as shown and descirlued.

2.-The I'lough irons $\mathrm{B} \mathrm{B}^{\prime}$, having the element $b b^{\prime} b^{\prime \prime}$, arranged as shown and described.

3.- The arrangement in a corn plough or cultivator of the adjinstable bar $G$, with its bolt and nuts $F f$, substantially as set forth for the purpose specified.

4.- In combination with the adjusting bar $\mathrm{i} F \mathrm{~F}$, the adjusting arrangement $\mathrm{W} Y y$ of the tongue on the beam,

5.- The frame R, consisting of the elements $S s t$, in combination with the racks $U \mathrm{U}$ and chains $\mathrm{V} \mathrm{V}$, admitting of a slight forward or retrograde movement in the ploughs B B' in respect to each other and the beam $\mathrm{H}$.

No. 68,678.-MARMADUKE WILSON, MARQUETTE, Wis. - Corn-Cultivators. - September 10, 1867 .

Claim.-I.-The levers If and I nsed in combination with the tungue $G_{\text {and }}$ cross-bars $\mathrm{B} \mathrm{B}^{\prime}$ of a cultivator frame, arranged and operating substantially as and for the purpose set forth.

2.-The combination of thestandards $\mathrm{C} C \mathrm{C}$ C with the frame $\mathrm{A} \mathrm{A} \mathrm{B} \mathrm{B} \mathrm{B}^{\prime}$ and braces $\mathrm{E}$ E, as and for the purpose set forth.

3.-The clevis $o$ attacherl to the cross-bar B, in combina. tion with the adjustable tongue $\mathrm{G}$ and levers $\mathrm{H} \mathrm{I}$, substantially as anil for the purpose set forth.

No, 72,107.-C. E. STELLER, CHICAGO, II.L-Cultivators.-Decimber 10, 1867

Claim.-I. - The hinged runners J WV, substantially as and for the purpose set forth.

2.- The slotted sides A A and B B, in combination with the shanks C D E, arranged to be set at different angles, and fastened by set screws $Z Z$, as described,

3.-The combination of the guicle bar $\mathrm{E}$, arranged to be raised and lowered, with rear standards $/ 1 \mathrm{H}$ and sides $\mathrm{A} \mathrm{A}$ $\mathrm{B} \mathrm{B}$, as described.

4.-The combination of standards $\mathrm{G} G \mathrm{G}$, hinged runners IV, and sides A A B B, as set forth.

5.- The shanks $U$ of shovel $T$, arranged to fit in a socket $V$, and bar $S$, in combination with standards $G G$ and cross har 1 , as and for the purpose set forth.

6. - The double evener L, arranged substantially as set forth

7.-The double evener $\mathrm{L}$, in combination with braces $\mathrm{OO}$ and $P \mathrm{P}$, with or without hraces $Y$, substantially as set forth.

No. 72,622.-J. T. FRANKEBERGER, HENSLY, IlL. - Cultivaters.-Deccmber 24, IS67.

Claim.-1.- The combination of the beams G G, when hinged at their front ends to the bar A, substantially in the manner set forth.

2.- The beams G G, when combined with the standards II, the handles $\mathrm{R}$, and hars $\mathrm{F}$ and $\mathrm{A}$, the whole constructed and operating substantially as herein described.

No, 83,111,-J. J. THOMPSON and V. F. COLLIER, RicHwoOd, OHio,-Cultizators-October $13,1868$.

Claim.- The combination in a quadruple plough or cultivator, of the inner movable beams $\mathrm{B}$ l3, staples $b \quad b$, rod $\mathrm{F}$, plates D D, outer stationary beams $B^{\prime} B^{\prime}$, tongue $A$, plate $I$, and handles L L, all applied in the manner and for the purpose set forth,

No. $84,165,-$ HORACE C. BRIGGS, WeST AUEURN, Mr.-Hoeins Machin:s. - Norember 17, 1868.

Claim.-1. - The combination of the cross bars A and B, longitudinal bars $C$, runners $D$, curved parts or pieces $G$, and ploughs or hoes I with each other, substantially as herein shown and described, and for the purpose set forth.

2. - The combination of the inwardly projecting adjustable hoes J with the rear ends of the runners D, substantially as herein shown and described, and for the purpose set forth.

3.- The dranght irons $H$, constructed as lesir $y l$, in com. linution with the curved parts $G$ of the runners $D$, substan- 


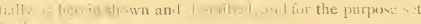

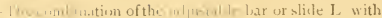

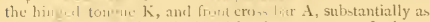
herein sum and describeal and for the jurpose set forth.

Ni. $85.387 .-$ I. W. IESSOP, HARVW'BURG, ()HO,ciulituters.-Decimber 29,1868 .

('aim. - The provision in a cultivator of the acliustalule wing heam $\mathrm{H}$, rovided with muld plonghs, cross heam 1 uni (c, anil standards J), alse provided with plourhs, when It sereral parts, herein nameal, are c mstructed, combines. iul arranged as herein set forth, for the purpose specilied. No. 85.968 , - SAMUEL I, SHANK, MINOK TOWN 1:1. 13.1.-Corn Cullivitors-Jinuar! 19, 186n.

laim. - The combination and arrangement of the protect hoards B B', cross pieces ( F, and piece -1 E, to which i. irarels $\mathrm{A} \mathrm{A}^{\prime}$ are connected by pivots $c$, when constructed alyplied substantially in the manner and for the purpone "tificel.

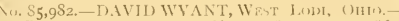

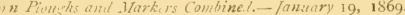

Claim.-1.-The arangement consisting of the beam A, crum support. B B, hamelles (C, shovel tanclarls I) I) foint traces $d c$, all comstructed and applied in the mamer and for the parp se herein decrilied.

2.--The arranwement of the marker $G$, hook s, staples $/ 4$, am A A, eroms sulpurt 1 ; 1 , shovel stamlark's I) $\mathrm{D}^{\prime}$ juin

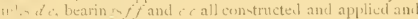
soting anhercin de-cribed and shown.

No. 8S,409.-JOHN l'MIVELl, SUllivan, IIL.-

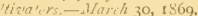

lim.-1.-The beam 13 , in combination with the lorim E ami Fo aljutable bolts C, links D, and frame A rein de crabs, for the purpres specilied.

In cumbination with the alwow, the bandles (i.

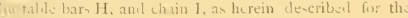
- vrecitied.

9I, ZIS.-R(IBERT D. CRAFT. LA PORT, IND. ultistors. - Jutze 22, 1869.

'taim.-The sile rails A A, erom piece, B B, C C, tongu

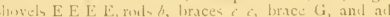
$\therefore$ respectively comstructed and arransed, ax wet forth. 94,350.ZACHARIAII B. SI IS, HeNIIAM, TEX ion Phu his-dugust $3 \mathrm{I}, 1809$

- Tim,-1. - The curred flange $a$, in emml ination with

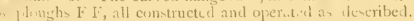
2. - The flanererl protector $d$, in combinatisn with the

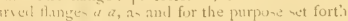

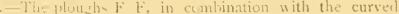

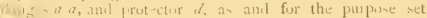
(ati.

4.- The pionsh torth I, in combination with the plourhe

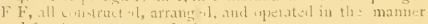
and for tir jimume ot forti.

No, 5.513,-LACHARIAII J. SIVS, BONIIAM, TR.X.

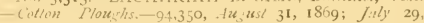
1873: filed Ipril 20, 1871 .

Claim-1.-The curvel flan ge $k \mathrm{k}$ emhinesl with the Jisugh- $G(i$, sul-tantially an lecerilicel.

2.- The removable curved flanses $\mathrm{K} K$ alanter to b: inltet or otherwin attached to the plud i. $G_{i}$ G; - cthotantilly: as set forth.

3. - The plough tooth 1 , in combination with the plonghs i, constructecl, arrm reil, nul oueratime substantially ar tea ribed.

4.- The flanged protectur $d$, in comination with the ursed flanges $k \mathrm{~K}$, an and for the purpose specifiel.

5. - Th $\geqslant$ ploughs $G(i$, in combination with the curved 1.12us $\mathrm{k} \mathrm{K}$ and protector . , operating as sct forth. 94,490.-IEWLA IUUTIRIE, WATERLAS, INU.

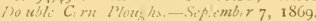

Claim.-1,-The heal bloci $\mathrm{H}$, as anl for the purposes (ut forth.

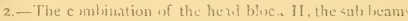
4). and the posts $\left({ }^{\circ}(\right.$, with the sheath $1 \mathrm{I}$, the raver ite floughs E E, and gnard, $C_{i}(i$, in the manner and for 1c purpo-es herein sineciticel.

3.- The combination of the past $\mathrm{C}$ C, sub beans (1) 1), 1i.t handles B 1, substantially as set forth.
95,044-JOILN J. RAY and JAMES R. YOUNG, Neil ORleavs, LA.-Cullierting Hocs.-Septembir 21, IS 190 .

Claim,-The blacles A, connected and supported by posts, braces and transverse beams, in the angular arrangement described, and provicled with weed cutters and wheels, all sulvtantially as specified.

1OI.468,-BENJAMIN JOIINSTON, NEW IBERIA, 1.A.-Finiching Cultivators.-April 5, 1870.

Claim.-An improved finishing cultivator, constructed, arranged and operating substantially as herein shown and described, and for the purpose set forth.

No. 101.695.-REUBEN WOTTRING, PROSPECT, OHIO.-Cultisalors. -April 5,1870 .

Claim.-1.-The side pieces A A, in combination with cross bars $\mathrm{B}$ and $C^{\prime}$ and intersectine rods $g$, when constructed and arringed as and for the purpose set forth.

2.-The side pieces $A$ A, cross bars $B$ and $C$, rods $\xi 5$, linged rods $m n$, link $f$, teeth $i i$, and shovels $e i$, all combined and arrangerl as and for the purpose described.

No, 105.326-LUTHER M. GANONG, lirIAR's Print, MIss,-Cotton Cultivators,-Jaly I 2, 1870 .

Claim.-1.- The har D, as comstructed, in combination with scrapers $\mathrm{E}$ E or ploughs $\mathrm{G} \mathrm{G}$, arranged in the manner and for the purpose set forth.

2.-A cnitivator, consisting of slotted beam $A$, handles B $B$, standard $\left(C\right.$, bar $D$ D $D^{\prime}$, scrapers E E, ploughs (i G, and thumb screws $a$, all constructed and arranged as shown and described.

No. 108.38. - ('TCER() P. NORTUN, Praikie City,

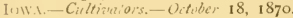

Claim.-The artangement of the runners $\mathrm{E}$, ploughs F II $\mathrm{K}$, ruds $\mathrm{ll}$, blocks $\mathrm{L}$. wedges $\mathrm{O}$, tongue $\mathrm{B}$, and jointed dunble tree frame A C D, as shown and described, for the purpose : ct foith.

No, 5,557-CIClERO I'. NORTON, PRAIRIE CITY, low: antignor to ITHAMAR P. PILLSBURY, NONin) TH, ILL.-Civltivator,-108.384.-Oitober 18, 1870. Reisued An, zust 26, 1873 Filed July 22, 1873.

Claim. - The main frame A B and runners E, arranged, relatively to each other, no that either side of the main frame to rether with it; rumurs, may be advanced, and either plough beam vertically or laterally oicillated witho ut disturbing the parallelism of the rumers with each other or with the line of progression, substantially as described, and for the urpose specincul.

No, 108.518.-VIOSES REED, LITTLE RUEK, ARK 4NsAs,-Cittin and Corn Cultivators.-October 18, 1879.

(Txim.-I.-Th combination of the arms $d$ and staples (; when arrugel in a cotton cultivator, subntantially as and for the purpe-e - vecified.

2.-The combination of the harrow $A$, sament $E$, set screw $y, a n]$ handle 11 , when constructel suls tantially as described, and for the purpose mentioned.

No. 109.812. - ABRAHAM ESIILEAHA, MIRTINS FILLE, PA, - Cultizuturs.-Dacimber 6, 1879.

Claim.- The arrangements of two sets of shovels $\$$, adjurtable oblique beam $B$, and cross-beams $A \Lambda$, when constructed and unerating as herein descriled, and for the purpoees set forth.

No. 113.109 - IICHAEL STOLL, CONESTAGA TOWNSHIP, P.A., anvignor to himelf and IACOB $(\mathrm{A}$. PETERS, same plact.-Cultivitors.-Barch 28.1871

Claim.-The construction and arrangement of the three curved adju-table shovel arms i 23 when on each side of the pole $\mathrm{A}$. so shortened from the centre that the two central pairs will be in the desired position for the seraper II, bolted to each pair, in combination with an advance shovel on the outer side of each, all combined and operating in the manner shown and for the purpose specifel.

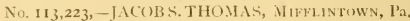
- Cullivintor. - Jurch 28,1871

Claim. - The crosu bar $d$, provided with a series of grooves or notches to receive the spring shanks $b$ b of the shovels $c c$, and with the traverie slot $e$ for the clamp bolt $f k$, all arranged as shown and lescribed, in connection with the beam $a$, whereby the shovels may be laterally adjusted lengthwise by moving the cross har and shanks of the beam, as set forth. 
No, 146.776. -JAMES J. TII(I)MPSON, ColuMnus, OHo.-Cullizators. - July 4,1871 .

Claim.-1,-The hoxe's g. composed of cells $y$ and flange $y^{2} y^{2} y^{2} y^{2}$, in combination with shovel standards, beams, and the contining holts 8 , substantially as dercriberl.

2.- The combination of the draft pole $A$, sidc leams B 1 ;

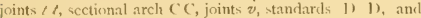
loosely connected brace E, all constructcd arrangecl, anc operating sulstantially in the mannerand for the purpose described.

3.- The combination of the removable diagonal braces $P$ $\mathrm{P}$, brace $\mathrm{E}$, hinged arch $\mathrm{C} C$, beam $\mathrm{A}$, and swinging side beams $B$ B, substantially as and for the purpose described.

No, $117,608,-S 1 M() \mathrm{N}$ A. CUMMINS, VIENNA, N. I. - Ploughtis.-August 1, 1871 .

Claim, - 1.-The arrangements of the slotted frame B, ad justable ploughs $\mathrm{A} \mathrm{A}$, adjustable colters $\mathrm{D} \mathrm{D}$, bars $e^{\prime} c^{\prime}$, guards $\mathrm{M} \mathrm{M}$, and har $e c$, sulstantially as and for the pur pose set forth.

2. - The adjustable bars $e e$ and curved guards M M, in combination with the slotted main frame $B$ and ploughs $A$ A, combined and operating substantially as set forth.

3.- The tongue $\mathbf{E}$, cross bar $\mathbf{F}$, and thill iron $f$, in com bination with the ploughs $\mathrm{A} A$, frame $\mathrm{B}$, and adjusting har $K \mathrm{~K}$, substantially as and for the purpose set forth.

4.- The tongue $\mathbf{E}$, cross bar $\mathbf{F}$, coupling $j$, and braces $h$ $h$, in combination with the plough $\mathrm{A} A$, main frame $\mathrm{B}$, and adjustable bars $\mathrm{K} \mathrm{K}$, substantially as and for the purpose specified.

No. II8,Ooo.-THOMAS J. ELI.IS, DECATEUR, ILL.Cullivators.-Aurust 15, 1871 .

Claim.-The shaft $\mathrm{F}$, knee $\mathrm{H}$, handles $h h$, standards 1 $I^{\prime}$, rods $\mathrm{K} \mathrm{K} \mathrm{K}^{\prime} \mathrm{K}^{\prime}$. braces $\mathrm{D} \mathrm{D} \mathrm{E} \mathrm{E}$, and hinges $b b^{\prime} b^{\prime} b^{\prime}$ in combination with the standards $\mathrm{C}^{\prime} \mathrm{C}^{\prime} \mathrm{C}^{\prime}$ and forked pole $A$, substantially as and for the purpose hercinbeforc set set forth.

No, 118,549.-GEORGE IV. OIVENS, FAIRfIELD, lows.-Cullizaters.-Ausns/ 27, 1871 .

Clain,- The arrangement of the cultivators $\Lambda \Lambda$, coupling

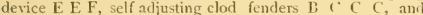
spring $\mathrm{D}$, as set forth and described.

No. II9,904.-HENY WELD, BLACK WALNUT, ILI. - Cultivators.-October 10, 1871 .

Claim.-The combination of the double tree $\mathrm{C}$, single tree $d$, the lever $c$, the $\mathbf{L}$ shaped adjusting plates $c$, and the ploughs $\mathrm{E}$, all mounted upon the beams $\mathrm{A}$ and arranged to operate as set forth.

No. 124,241.-WILLIA M W. ANDREW. LA PORTE, IND.-Antedated Feliruary 22, 1872 ,-Cultivitors. - Marih 5. 1872 .

Claim.-In combination with the central beam $A$, the draft attachment consisting of the bars $O O^{\prime}$, having central enlargement 0 , brace $T$, and the vertical adjustable pieces $P$, substantially as and for the purpose set forth

No, 128,497.-ROBERT E. MASON, NORWAY, ILL.Culivutors.-July 2,1872

Claim.-The combination of the shovel and gopher share D, made of one piece of metal, substantially as described.

No. 134,824.-AUGUSTUS C, TOWER, MendotA, IL.I.-Cultivators.-January 14, 1873.

Claim 1.- The series of knives $a$ a set at an angle, as de scribed, and adapted to work upon each side of the hill, substantially as described.

2.-The combination, in a cultivating machine, of the following elements-i.e.: A pair of beams adapted to operate upon each side of a row of corn, having a series of curved inclined knives set at an angle, as described, a pair of following smoothing heams and suitable means for connecting the two substantially as described.

3.- The combination, in a cultivating machine, of the following elements-i. e.: A pair of beams having knives $a n$, suhstantially as described, a pair of following smoothing beams, means for connecting said beams, and teeth adapted to pass the hill on each side and remove the clods, substantially as described

4.-In a machine of substantially the described construction, an adjustable rod, D, carrying adjustable harrow teeth arranged one in advance of the other, substantially as described.
No. 135 I65-ZACILARIMII IS, SIML, BONHAN, Trx. - Cullitators.-Jammry 2i, 1873 .

('lim. - The combination of the angular shaped iron bracen ( provided with the perforations $c$, the perforated beam $A$, the perforated cross head 13 , and reversible shovel 1., substantially as and for the purpose specified.

No, 136.590.-LLTHER II. GINONI. FRIAR'S Ponst, Mliss.-Cieliviztors.-March 4, 1873

Clam. - The combination of the plate $\mathbb{E}$ provided with grooves $e c$ and in the frames ( " provided with the beads $d^{n} d^{1}$, as and for the purpose described.

No. 137,609-CVRUS M. HALL, VArEs CITY, IL.1.Adjustabli Braic Couplings. - Iprit S, i 873 . Filed March 8,1873

Claim.-The combination of the brace rods A A bent, as describerl, to form the bails $a a$, and outwardly curved ends $b b$, the loose ring $\mathrm{D}$, and the bolt or swivel joints $\mathrm{C}$ C. to form an adjustable brace compling, as herein set forth.

No. 141,145-OLIVER KUGLER, RARITAN, assignon to himself, JAMES D. MCC AULFY, and JACOB VAV FLEET, ClINTON, and IOHN $\Lambda$. THOMMISON, RED. DINGToN. N. J.-Cultivators.-July 22, 1873. Filed Scp. tember 14, 1872

Concave scrapers are attacherl to runners, which converge in the rear. These are followed by shorter scrapers or shares. which throw the clean soil toward the row of plants.

Claim.-1.-The combination, with the gatherers L L, of arms M M, arranged as and for the pnrpose specified.

2. - The hook chain $\mathrm{K}$ on projecting end of bar I, ring 4 , rods $\mathrm{J} J$, and chains $k^{\prime} k^{\prime}$, contlined and arranged with a cultivator frame, as described, to form a flcxible draft.

No, 141,146. - Ol.IVER KUGLER, Thrfe BRIDGES, assignor to himself, JMES D. MCCAULEY and JACOB VAN FLEET, CLINTON, and JOHN A. TIIOMPSON, REDDinctun, N. J.-Cultivators,-July, 22, 1873. Filed June 24,1573 .

Claim.-1.-The combination of the runners $A \mathrm{~A}$, front and rear standards B B , cross hars $\mathrm{C} \mathrm{C}$, center draft heam $\mathrm{D}$, and handles $\mathrm{E} \mathrm{E}$ to constitute the cultivator frame, subtantially as herein set forth.

2.-The combination of the up and down adjustable bar H, with the keys and screw rodk, with laterally adjustable bar I, plow shanks J J, pivoted plows $K \mathrm{~K}$, slotted as described, and held by pins or screws $i i$, as and for the purposes herein set forth.

No. 145,862,-JOHN LINDSEY GRAHAM, CARTIAGF, InL..-Ploushs.-December 23, 1873. Filed January 27,1873 .

Claim.-I, - The tecth R R ${ }^{1} R^{2}$, constructed in the form shown, and attached to the frame by bolts $S S^{\prime}$, arranged as and for the purpose specified.

2. - The beam E, provided with the teeth $\mathrm{L}, \mathrm{L}^{\prime}$, and the frame $O$, provided with the teith $R R^{1} R^{2}$, all constructed and arranged for operation as anil for the purpose set forth.

No. 152,778.-A. C. TOWEK, NENIGTA, II.L-Cultivaturs.-Jult 7,1874 . Filed Fibruary 20,1874 ."

Claim.-1.- The combination of the adjustable clamping irons, the draft rods, and the beans $\mathrm{A}$.

2.-The knife bean A, knive $a$, chains $i$, clamping irons, the draft rods, and tongue, comlincel and arrangesubstantially as describerl.

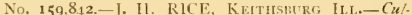
tizators.-Fibruary 16, 1875. Filed Dicimber 29, 1875 .

Claim.-The angular frames A B C, carryin r handles 1), in combination with the arched rorl $d$, having two bearings, $b$, upon each frame, and the pivoted bars $\mathbf{E}$ and draft device, all constructed as and for the purpose hercin specified.

No. $161,882 .-$ ], T. 11 ENDER.SON, WimmURY, TENN. - Cultivators.Afril 13, 1875. Filed Mareh 19, 1865.

Claim.-1.-The combination, in a cultivator composed of two flexible connected sections, if a series of pulverizing teeth$F$, a pair of scrapers, $G$, and a pair of hilling plows or cultivator shovels, M, substantrally as and for the purpose set forth.

-2. - The pivoted or adjustable scrapers $G$, hinged to the standards $\mathrm{I}$, in combination with the adjusting screw $K$, hinged to the arm L, substantially as and for the purpose described.

No. 168,074-HENRV IWINFIELD and WM, P 
FINN, PAxfetio, N. C.-ciulizators.-Septimier 21, 1875. Fileal Juni 5,1875 .

Claim.- In a cotton cultivator, the slotted bars $C^{\prime} C^{\prime}$, laterally adjustable on the leam $\mathrm{A}$, in combination with the tanclards D $(i$, with shovel $F$ adjustable in the slots of the bars C C', sulstantially as and for the purpose set forth.

No. 168,2,6, - J. A. TIIOMIPS()N, REAInNitiN, N. J, Cultivators.-Sifimbir 28, 1875. Filed Augum 20, 1875

Chim.- - - The combination with the runner frame A $\mathrm{BC}$, having the slotted wings $\mathrm{H}$, of the adjustable plough heams $(i, G$, provided with the sprin: straps $a$ and the loolt $b \quad b$. all subutantially as and for the purposes herein ct forth.

2.-In combination with a plow, I, having a round shank, $h$, the slotted heam $(i$, slotted plate $m$, with parallel flanges $n n$, set screw $f$, and break pin $i$, all constructed substantially as and for the purpone herein set forth.

No. 169.677.-GEORGE CROJ.L, TUNTOCANY, OHIO.Combined Cinltivaturs and Hurrows.- Novimber 9, 4875 . Filed Aurust 28,1875 .

Claim. - The combination of the beams $\mathrm{A}$, the slotted upright, $F$ and $G$, the pivoted draft hars $I I$, and the braces $K$. with each other, in subutantially the manner hcrein shown and describerl.

No. 170,778.-TIUOTIIY M. SH.IW, LEAANON, TENN. -Gang Pluzis.-Decimb; 7, 1875. Filed September 10. 1875 .

Claim.-The combination of the handles $B$ B and hars C, pivoted couplings $c^{\prime}$, coupling blocks $\mathrm{E}$, and vertical movable bar, I) D with the plough beams A, having the several bult holes specified, whereby the beams and handles may be adjusted to placethe ploughs opposite or in advance of one another, in the mammer set forth.

No. 175.985 - TUOMAS J. Ho ()':ER and IAMES T. 11 ENDERSiN, WumbURY, TENN-Ploughs.-April 11, 1876. Filed fimnary 14, 1876 .

Claim - In combination, with the beam $A$, handles $B$, and longituclinal har $\mathrm{D}$, the lient arms $\mathrm{C} \mathrm{C}$, brace $\mathrm{C}^{\prime}$, shovels $\mathrm{F}$. ani ploughi $G$, substantially as herein set forth.

No. IS 5.354 -OLIVER KUGI.ER, FI.EMINGTON, N.

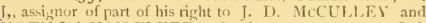
MI TIII)A VAN FLEET,-Culivalors,--July 25, 1876. Filed June 7, 1876.

Claim.-1.-The combination, with the beams G G and standare $B$, of the clevis $H$, secured to the standard, and having extenderl ends $a a$, forming sprinss, which are connected to the beams $G_{G}$, substantially ar and for the purposes here in set forth.

2.- The combination of the standards $B B^{\prime}$ the leams $G$ $\{i$, cornected to the sprinurs $a$ a of the clevis, and the cross bar I, provided with carved slot $x \quad x$, and the aeljusting imlts and nut $b d$, all sulstantially as and for the purpose licrein set forth.

Nin, IS1,654.-J. R DUNI.AP, SIIERMAN, II.1..-Com.

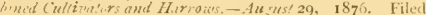
March $6,1876$.

Claim.-1.-The combination of the crank axles 1 ) and the rotary cutters $\mathrm{E}$ with the bar ( and the $V^{\mathrm{C}}$ harrow $\mathrm{A} \mathrm{B}$, -13hatatially as herein shown and dencribed.

2. - The combination of the cros bar $\mathrm{F}$ and the lever $\mathrm{G}$ with the crank axles D, the rotary cutter. E, the cross bar C, uxl the harrow A B, substantially as herein shown and de eriluerl,

3. - The combination of the liver $k$ and pivotcd har $I$. with the bar $\mathrm{C}$, the $\mathrm{V}$ harrow $\mathrm{A} \mathrm{l}$, and the ploughs I J, sub. tantially as herein shown and described.

4. - The combination of the pivoted bars If with the crose har $\mathcal{C}$, the V' larrow $A$, the lever $K$, ant the jivoted bar I, ub,tantially $x$, herein shown and dencribed.

5. - The combination of the cruss bar $\mathrm{N}$, having its middhe port raisel, and an oflset at the end of said raised middle part in comlination with the $V$ harrow \& $1 /$ and the levers ; 5. - 11 tantially as her in sown and deacribed.

Nio, $182.953 \cdot-$ JOIIN PALCER, EL DorADo, lowA.Cultivators, -0 itob.7 3, 1876 . Filecl Sepiember 14, 1876. Claim. - The combination, with the front and rear transerseline A B, central lari C letween the same, the shaft F. pasing transy recly through the said hars, and the pen- dent eye rod $\mathrm{K}$, having collars, as described, of the indepen dent adjustable plough beams $F$ and $G$, having the plates or ears J, provided with a series of elongated openings, J, substantially as shown and described, for the object specified.

No, 191,613. MALACH1AH ROBY, Kosciusko, IIss. - Combined Cotton Scrapers and Cultivators.-June 5, 1877 . Filed 4 pril $30,1877$.

Claim. - The combination of the cross bars B D, the side beams $C$ and their ploughs and standards, the bows and yokes $E$, the scrapers $F$ G, and the bands $H$ with each other and with the central beam $A$, substantially as herein shown and described.

No. 222,087,-BYRON B SMALI, North Lubec, ME. -Combinid Ilorse Hoes and Cultivators.-November 25 1879. Filed July 8, 1879.

Claim. - The tongue A and end slotted cross bars B C D, in combination with standards $F$, ploughs $G$, standards $\mathbf{H}$, and hoes $\mathrm{I}$, all constructed and arranged to operate as described.

No. 228,853.-RICIIARD G. S. AUSTIN, Pine BlufF, ARK.-Cotton Cultivators.-Jun: 15, 1880 . Filed May 4 1880

Claim.-1,-In a straddle row cultivator, the combination with the two semi-circular wings $C$ and the tongue arches $\mathrm{A}$, of the pivoted arms or frames $\mathrm{D}$, adapted to slide upon the curved bars of said wings and be beld adjustably thereon by the plates $c$, and set screws $d$, connecting the frames $D$ to said wings substantially as and for the purpose set forth.

2. - In a straddle row cultivator, the combination, with the tongue arches $\mathrm{A} \mathrm{A}$, having inwardly projecting portions $a$ of the semi-circular wings $C$, carrying the pivoted standard arms or frames D, substantially as and for the purpose set forth.

No. $236,970 .-$ RICHARI) G. S. AUSTIN, PINE BltEF, ARK.-Citlon Cultivators. Filed Aurust I 7, IS80.

Claim. - The combination, with the frame $A$, composed of semicircular wings $B$ and arches $C$, made in one piece, of the beam $\mathrm{D}$, handles $\mathrm{E} \mathrm{E}^{\prime}$, and the short beams $\mathrm{H}$, carrying standards $\mathrm{F}$, having teeth $\mathrm{G}$, and adjustably secured to satd frame by the clips $a$, substantially us described.

No. 237,523.-EZRA S. MLEWEN, LIsBox, and OLIVER R. ADAMS, MARSEJLLES, ILl.-Culivators. Filed June 24,1880 .

Claim.--1.-The plough standards G, adjustably attached to the main frame by the bent rods 1 , in combination with plotgh heams and suitable mechanism for attaching them to the main frame, which permits them to be adjusted laterally sulostantially as and for the purpose descriced.

2.- The plough standards $\mathrm{G}$, adjustalsly attached to the main frame by the bent rods $J$, in combination with the plough beains F, adjustably attached to the main frame by complings $f$, substantially as and for the purpose described.

3. - In a cultivator, a blade, in combination with a fixed coupling block having a concave seat at its outer end, and a shoe arched to correspond with the concavity of the coupling block, and adjustably attached thereto by means of a bolt and a slot following the curvature of the arch, and also adjustable on the blade by means by means of a pivotal bolt at one end and slot at the other, substantially as and for the purpose described.

4.-The blade $\mathrm{J}$ and the convex shoe $\mathrm{K}$, provided with the pivot bolt $k$ and slots $k^{2}$ and $t$, in combination with the coupling block $\mathrm{M}$, having the concave seat $m^{2}$, and with the standard $G$, substantially as and for the purposes described.

5.- The complings D D', shaped as described, and provided with the slots $d$ and perforation: $d^{\prime \prime}$, for the purpose of making the plough handles lateralty and vertically adjustable independently of each other.

No. 242,508,-CHARIES H. CARTER, StRANGER, TEX.-Ploughs.-June 7, 1881. Filed April 4, 1881.

Claim.- In a plough, the combination of the two beams $\mathbf{A}$, provicled with the two ploughs $B$, which have their mould hoards turned in opposite directions, the two outside beams, $G$, having the shovels secured to them, and which are made to run deeper and in the rear of the ploughs and to throw the dirt inward toward the plants, the two beams $A$ being adjustable between the two outer beams, substantially as shown and described. 




\begin{tabular}{|c|c|c|c|c|c|c|c|c|}
\hline & Plate & Claim & & Plati & Clitim & & Plate & Chaim \\
\hline Aiken, G. C. & $5^{13}$ & $15^{\circ}$ & Granberry, A. R. and El- & & & $\begin{array}{l}\text { Moodly, J. B. } \\
\text { Morrixun, WV. }\end{array}$ & $\begin{array}{l}523 \\
514\end{array}$ & $\begin{array}{l}152 \\
150\end{array}$ \\
\hline $\begin{array}{l}\text { Aiken, G. C. } \\
\text { Alvord, C. }\end{array}$ & $\begin{array}{l}515 \\
521\end{array}$ & $\begin{array}{l}150 \\
15 t\end{array}$ & $\begin{array}{l}\text { liott, J. } \\
\text { Green, W. W. }\end{array}$ & $\begin{aligned} 535 \\
512\end{aligned}$ & $\begin{array}{l}155 \\
150\end{array}$ & $\begin{array}{l}\text { Morrixun, IV. } \\
\text { Odell, R. P., Jr, }\end{array}$ & $\begin{array}{l}514 \\
535\end{array}$ & $\begin{array}{l}150 \\
1=5\end{array}$ \\
\hline Bannigan, J. C. & $53^{8}$ & 155 & IIamilton, T. F. & 530 & 153 & Owen, J. H. & 541 & 156 \\
\hline Beckwith, W. G. & 524 & 152 & Hammon, T. W. & 515 & 150 & Owen, 1). C. & 545 & 157 \\
\hline Beckwith, $\mathrm{S}$ & 525 & 153 & Hammon, H. B. & 513 & 150 & Parmele, E. and Curken & & \\
\hline Bertrand, F. T. & 543 & 157 & Harding, $\mathrm{T}$. & 526 & 153 & dall, $\mathrm{G}$. & 532 & 154 \\
\hline Billings, R. F. & $53^{8}$ & 155 & Jarris, J. & 522 & $15^{2}$ & Peck, S. & 541 & 156 \\
\hline Birdsell, J. & 507 & 149 & " " & 522 & 152 & Perry, G. & 526 & 153 \\
\hline Birmingham, G. B. & 536 & 155 & (R.) & 523 & 152 & I'ickering, I. P. & 537 & 155 \\
\hline n, W. P. & 546 & 157 & IIarris, J. & 537 & 155 & Pierpont, J. & 525 & 152 \\
\hline gham, C. P. & 539 & 156 & Hartgrove, W. & 534 & 154 & Pierpont, $J$. and & & \\
\hline Bucklin, M. & 511 & 149 & tt, C. P. & 537 & 155 & S 5 & 528 & 153 \\
\hline Burnett, R. A. & 547 & $15^{8}$ & Hewett, C. P. & 535 & 155 & Ready, W. B. & 520 & 151 \\
\hline II, S. S. & 533 & 154 & Hisert, B. F. & 518 & 151 & Kogers, I. B. & $5 \mathrm{c} 8$ & 149 \\
\hline ron, J. F. & 512 & 150 & editz, J. C. & 517 & 151 & "4 4 & 508 & 149 \\
\hline Igy, A. P. & 534 & 154 & Iloney, J. S. & $50 S$ & 149 & “ “ & $5 \subset 8$ & 149 \\
\hline , il. & 543 & 156 & Hooker, H. T. & 515 & $1 \div 0$ & Rogers, H. B., S. and L. & 511 & 149 \\
\hline , E. & 536 & 155 & Houston, T. J. & 535 & 155 & s, J. B. & 513 & 150 \\
\hline Clar & 507 & 149 & Hurlbert, IV. M. & $5^{22}$ & 152 & I. & 519 & 151 \\
\hline & $5 \div 0$ & 156 & S. & 523 & $15^{2}$ & Rowell, J. S. and I. & 516 & 150 \\
\hline , J. P. & 510 & 149 & $\mathrm{~m}, \mathrm{H}$. & 516 & 150 & $4 \quad 46$ & 517 & $15 \circ$ \\
\hline G. & $51_{4}$ & 150 & il. & 541 & 156 & Rowell, (i. D. & 536 & 155 \\
\hline 1. & 529 & 153 & IV. H. & 515 & 150 & ;. 11. & 540 & 156 \\
\hline & 520 & 151 & , F. B. & 544 & 157 & $\mathrm{~J} . \mathrm{s}$ & 545 & 157 \\
\hline , 1. 1). & 519 & 151 & Iton, W. A. & 543 & 157 & $\mathrm{H}$. & 512 & 150 \\
\hline $1 \mathrm{I}$ & 544 & 157 & Lafferty, J. W. and Brown, & & & C. II. & 510 & 149 \\
\hline H. & 5.4 & 157 & G. B. & 544 & 157 & Sayre, C. H and Klinck, ( . & 509 & 149 \\
\hline Dickey, IV. II. & 543 & 157 & , L. & 509 & 149 & " $\quad$ " (R.) & 509 & 149 \\
\hline Dryclen, W. I. and Turn & & & Lawbaugh, G. WV. & 525 & $15^{2}$ & Sayre, C. H. & 513 & 150 \\
\hline J. . I. & 524 & 152 & d, $\mathrm{E}$ & 536 & 155 & E & 518 & 151 \\
\hline W. A. & 528 & 153 & J. k. & 527 & 153 & 11. & 531 & 154 \\
\hline J. S. & 507 & 149 & , J. R. & 527 & 153 & & 530 & 154 \\
\hline I) & 529 & 153 & Louth, M. F, and Howe, & & & II. W. & 547 & $15^{8}$ \\
\hline od, R. L. & 540 & 156 & T. J. & 519 & 151 & C. II. & 546 & 157 \\
\hline y, G. W. and Van H) & & & Lowth, M. F. and Howe, & & & $\mathrm{e}, \mathrm{J}$. & 509 & 149 \\
\hline IVater, J. & 533 & 154 & T. J. & 521 & 151 & f). C. & 520 & 151 \\
\hline 2. & 531 & 154 & Lowth, YI. F, and Porter, & & & W. I. & 529 & 153 \\
\hline D. O. & 546 & 158 & & 529 & 153 & $1 \%$ & 533 & 154 \\
\hline , J. & 537 & 155 & en, L. & 527 & 153 & s, J. H. and J. W. & 534 & 154 \\
\hline IV. P. and T. H. & 511 & 149 & Luppen, L. & 527 & 153 & $\mathrm{~F} . \mathrm{W}$ & 533 & 154 \\
\hline H. & 542 & 156 & Lynch, E. P. and Wright, & & & & 541 & 156 \\
\hline , I. R. & 510 & 149 & E. A. & 538 & 155 & J. and Smith, T. P & 514 & 150 \\
\hline Fountain, J. I.. & 516 & 150 & " & 539 & 155 & Van Bricklin, Is. & $5^{24}$ & 152 \\
\hline $\begin{array}{c}\text { Fowler, J. and Bacon, F } \\
\text { V. }\end{array}$ & & & Lynch, L. P. and Wright, & & & Van Lrunt, (i, WV. & 521 & 152 \\
\hline 11 & 515 & 150 & McCal & 545 & 157 & S. E. & 542 & 156 \\
\hline 11 & 514 & 150 & , J. J. & 547 & $15^{8}$ & C. II. & 532 & 154 \\
\hline , E. L. & 510 & 149 & Mccollester, B. F. & 521 & 151 & t, R. and I'aul, II. F. & 519 & 151 \\
\hline E. I. & 523 & 152 & McSherry, 1). E. & 531 & 154 & & $53^{8}$ & 155 \\
\hline & 524 & 152 & Mallon, J. and Von Phul, & & & & 534 & 154 \\
\hline Fri & 518 & 151 & HI., Jr. & 530 & 154 & inson, J. E. & 539 & 156 \\
\hline & 532 & 154 & Matteson, D. C, and Wil- & & & & 531 & 154 \\
\hline C. $\mathrm{O}$. & 542 & 156 & liamson, T. P. & 517 & 151 & Woad L. S. & 545 & 157 \\
\hline Gaston, H. A. & 520 & 151 & (R.) & 518 & 151 & Workman, WI and llitch. & & \\
\hline Garnett, J. M. (A. J.) & 507 & 149 & Maynard, G. & 511 & 150 & & 528 & 153 \\
\hline & 528 & 153 & & 525 & 152 & * (R.) & $54^{6}$ & I 53 \\
\hline & 526 & 153 & Miner, J. G. & 526 & 153 & Zeigler, G. WV. & 517 & 151 \\
\hline Gorham, A. L. & 532 & 154 & Mitchell, J. & 539 & 156 & Zeigler, G. W'. & 522 & 152 \\
\hline
\end{tabular}


PEIER CI.ARK, AURORA, N. Y.-Cultivator Tecth.Ansust 20, $18_{35}$.

Claim. - The peculiar formation of the tooth without a flange, the mode of fastening it and giving it a forward direction suited to the graduated width of the harrow and the method of graduating the same.

I. S. E.ASTMIAN, BALtimore, MD.-Cultizalor Teith. - Fune 30,1836 .

Claim.-1.- The construction of the leg or shank and the manner of fastening it to the wood or frame.

2.- The manner of attaching the share to the leg by means of the straight groove and bolt as shown.

No, 14.-I. M. GiNRNET Г, EsSEX, VA.-c'ultiatalor Tecth.-October14, 1838 .-(A. I.) to patent of February $3,18_{3} 6$.

Claim.-The removable point on the double mould board plough of iron and the mode of attaching the two togethes.

No. 3,819.-J. BIRDSELL, Il AMORTUN, PA-Culizator Teeth.- lovimber $9,18_{44}$.

Claim.- The self sharpening convex cutter constructed, suhstantially as herein set forth in combination with the cul tivator tooth in the manner and for the purpose described.

No, 4,245-D. B. ROGERS, StafFuRD, I. Y.-Cultivator. Teith. - Now, mle'r I, 1845 .

Claim.-The shank of the tooth so formed of thin metal as to receive a wedge in its recess in the manner described for the purpose of firmly connecing it with the beam in all directions as set forth.

No. St5.-D. B. ROGERS, StafFord, N. Y.-Cultivitor Teeth.- Vorember 1, i 845 . Reissued September 20, 1859 .

(laim.-Making the shank or upper part of cultivator teeth of thin plate steel, $\mathrm{U}$ shaped, or curved round in front, substantially as hereinbefore described, for the purpose of securing the necessarv strength to permit the tooth to be made, enture hank and blade of a single piece of metal, and also of enabling the tooth to be secured in its place in the beam ly means of a wedge driven into the cavity of the shank, substantially as hereinbefore described.

No, 1,274.-DAVII) B. RO,iERS, AltegtlaNY, PA,Cultivator Teeth.- Vovember 1, 1845 . Reissued Sepiember 20, I 859, extended; again reissued Febru iry 11, 1862 .

Claim,-1.-Making cultivator teeth entire of thin plate steel, the shank or upper part being bent or curved round in front, substantially as described and for the purposes set forth, irrespective of the mode of attaching the tooth to the bearn.

2.-Attaching cultivator teeth to the cultivator frame by inserting the upper end of the shank (curved round in front for that purpose) into a suitable hole in the beam, and driving a key or wedge into the cavity of the tooth, thereby pressing the shank against the sides and front of the hole in the beam, and thus securing it in its place.

Yo. 6,336.-J. S. HONEY, IIARTFORD, CONN.Cultivator Teeth-Apili 17,1849

Clam.- The self sharpening four pointed plate for a cul tivator, with its iron bed, each of the four to he used successively, but when two have been used the plate is to be turned over, bottom side up. (that is, the raar made front,) in order to use the o:her two.

No. 7,220.-L. LA.MBORN, Kennett Sivare, PA. - Cultiziator Teeth. - March 26, iS50.

Claim.-The manner of zonstructing the cultivator tooth, substantially as described, by which a separate steel cutter is eml raced between the two halves of the touth, removable at pleasure, and by which wedges can be applied against the shoulder; of the tooth and the under side of the beam, for the purpose of changing the angle of inclination of the share, in order to increase or diminish the depth of culture, the torthturning on the bolt passing through the head of the same, and the beam, whilst unserting the wedges, the wings of the toot h being secured to the four sided changeable share, by means of screws and nuts or other equivalent means,

Yo. 12,332. -J, STOCKDALE, YPSil.ANTI, M I CH.(iultizator Feeth.- - Zanuary 30,1855 .

Claim.-The reversible cast iron plate, marked fig. 2, with the groove on the under side, marked $K$, round cast iron tay pin on the upper side (i. Also the application of the up of the cultivator tooth in th: groove aforesaid. Also the application of the wrought iron bolt or shank passing through the said plate as described.

No. 14.254--C. 1I. SAYRE and G KLINCK, UTtCA, N. Y.-Cultivator Teeth.-February 12, 1856.

Claim.-So constructing a cultivator tooth that, when macle of thin or sheet metal, a part thereof shall form a tubular shank B, whereby said tooth may be drawn up and securely attached to the frame sulstantially as described.

No. 3,477.-CIIARI.ES II. SAYRE, for himself, and THE RENINGTON AGRICULTURAL WORKS, UTicA, N. Y., as,ignees, by mesne assignments of CHARLES H. SAYRE and GEORGE KLINCK - C Cul. tivator Tecth.-14,254.-Febunary 12, 1856 . Reissued Fune, 1869 .

Claim.-1.- So constructing a cultivator tooth, that when made of thin or sheet metal, a part thereof will form a tubu lar shank B, whereby said tooth may be drawn up and securely attached tc the frame, substantially as described.

2.- Forming shoulders or braces $\mathrm{G}$ Irom sheet metal, by bending or swagging it, substantially as and for the purpos set forth.

3.-A cultivator tooth made from sheet metal in such a manner as to form braces $\mathrm{G}$ and tubular shank B, substantially as described.

4.-A cultivator tooth made of sheet metal, so as to form a tubu'ar shank, B, and 'orace $G$, in combuntion with the nut F screw thread $a$, and plate $\mathbf{A}$, substantially as and for the purpose described.

No. 16,364.-J. B. CRAMER assignor to H. CRAMER, SCHUYlerville, N. Y.-Cultizator Ticth.-Fanuary 6 , 1857 .

Claim.-As a new manufacture my improved cultivator tooth composed of a properly shaped sheet metal blade and shank $\mathrm{B}$, with an iron head $\mathrm{A}$ cast upon the shank and embracing its outer and inner surfaces in such manner that the said blade shank and head of the tooth will form but a single piece substantially as set forth

No. 17,925.-F. R. FORSYTHE, CAPE VINCENT, N. Y.-Cultiz'ator Tielt.-Autsust 4, 1857 .

Claim. - The new manufacture of cultivator teeth, consisting of a sheet steel blade, bent to the required form with a cast iron boss / cast thereon, substantially as specified.

No. 18,174--E. L. FREEMAN, assignor to himself, I, and G. LORD \& CO., Watertown, N. Y.-Culti:ator Teeth.,-Scptember 8, 1857 .

Claim.-1.-A lopped headed cultivator tooth A, (Fig. 2) made in the manner substantially as hereiu described.

2.-A brace, washer and stay pin (Fig. 3) in one pieca underneath the head substantially as described for the purposes set forth.

No. 18,47t.-C. H. SAYRE, UtICA, N. Y.-Cultizator Teith.-October 20, 1857 .

Claim.-The method described of securing cultivator teetb formed of shect metal to the frame, by means of a head or cap piece, constructed in the manner substantially as described.

No. 19,234.-N. BUCKLIN, Grafton, N. H. - Culti ator Ticth.-Fibruari $2, \mathrm{I}_{5} 8$

(laim.-A cultivator tooth having two shares, which rive with a curve so as to form semi-mould boards with their front edges terminating in a single perpendicular plane or cutter, and in combination of aid plane or cutter, exteniing forward with a straight cutting edge rising fron the points of the shares at an angle of about 32 and terminating at the top in a flange on each side connected with the tops of the semi-nould boards, fnr the purpose of fastening the tooth to the frame of the cultivator.

No. 19,584,-D. B., S. and L ROGERS, Pittsburg, PA.-Cultiza'or Teeth.-Diar.h 9, 1858 .

Claim. - The combination of teeth, braces, standards, spring clamp and gauge irons with the frame of a cultivator, the whole being con-tructed and arranged in the manner and for the purposes set forth.

DO. 22,946. - WILLIAM P. FORD and THEODORE: H. FORI), CONCORD, N. H.-Cultiviter 7eeth.-Februar' 15,1859 .

This invention consists in so forming the front edge of a cultiwator tooth that it shall tend to run into the ground to the required depth, and yet shall not be liable to be clogged, 
also, in lringing the top of the wings together at point so low down on the body of the toeth that the surface soil may close back over the path of the tooth and not leave a furrow.

Claim.- The described cultivator teeth, formed sulstan ti.llly as specitied.

No, 24,508,-G.ARDINEK MAYNAN1, 11.1日N, N. Y - Cultitutir-Teth.-June 28, 1859.

Claim.-The arrangement of the tooth A, stay C, and wrought irom -tem and brace $B$, when the stem is welded between the wings of the tooth and $m \cdot a l=$ to form a hrace, sul tantially as set forth, the whole being constructed and used in the mamner speciticd.

No. 26,297.-HENRY SAN1)ERS, ITICA, N. V.-rul fivitu- Tith - lovimbir 29, 1859.

Claim.- The flanches $a$, and semi-circular projection 13 on the tooth, and the flanches $c c$ and pin $e$ on the chair, and arrangerl in relation to each other in the manner substantially as clescribed and for the purpose set forth.

No. 27,092.-(iEORG,E C. AlkEN, NASHUA, N. II.Cultivator-Tith-Iibuary I4, 1860.

Claim. - The combination and arrangement of the fixed plate $B$, vertical coulter $A$, flanges or mould-hoards C C $C$. and cutter 1) I, substantially as set forth.

No. 27,347.-JOSHLA F. CA.IERON, LIVIXison,

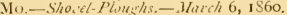

Claim - The arrangement of the beam A, standard A, shosel C, hinge screw $\mathrm{D}$, rods $\mathrm{E} \mathrm{E}$, and set-screws or pivots $\mathrm{F}$ F, as described, for the purposen set forth.

No. $27,363 .-$ W. IV. GREEN, CrHLsEA, IHL-Cultizu tor-Te'th.-11arih 6, 186 .

Clam.-1.- Having the wheels $c r$ of the implement at tached to vertical perforated bars $\xi s$, which pas loosely through the lack part of the frame $A$, in connection with the adjustable draught-pole $B$, the whole being arranged as and for the pnrpose set forth.

2. - Attaching the shares $\mathrm{D}$ to their standards $j$, by man of the socket $l$, plates $q$, and bolis $n$, the socket and plates being attached respectively to the shares and standards, and the lrolts passing through the socket, plates and standards, the bolts passing through transverse slots $m$, in the sockets and projections $r$, on the plates, the whole being arranged as and for the purpose set forth.

No. 27.797. - 1IEMAN B. HAMMGN, BRISTOLV11.I. (1)110.-C'nltivatur 7eeth.-April 10, 1860.

('laim.- - the employment of the grooved plate $\mathrm{C}$ in com hination with a frame $\mathrm{A}$ and reversiljle arm $\mathrm{B}$, luaving a projection $a$, as and for the purpone shown and described

No. 27.956.-GEORGE C. AlKEX, NAsHtA, X. H.(ultizator Terth. - April 24, IS60.

Claim.-The combination and arrangement of the socket $\mathrm{F}$, shoulder $\mathrm{B}^{1}$, and journal $\mathrm{B}^{2}$, with the plate $\mathrm{B}$, vertical coniter $\Lambda$, flanges or mould-boards (' $C$, and cutter $D 1$ ), substantially as set forth.

No, $28,198,-\mathrm{DAVIJ}$ B. ROGERS, Pittskurgh, l'A. - Cullizator Tirth.-Way S, 186 o.

(laim. - Attaching the Lolt by which the tooth is secured to the beam to the shank of the tooth, by wrapjing the bank around it, and passing a portion of the shank, together with the bolt, into the beam, in combination with the shoulder and stay point, formed ont of the npper end of the shank, subitantially in the manner described, for the pnrpone of at taching the tooth to the beam of a cultivator.

No, $28,785,-C H A R I E S$ H. SAYRE, UTICA, N V.Cullizator Tielh.-June 19, 1860.

Claim. - The shank $A$, as constructed, in combination with the loose top plate 1), for the purposes set forth.

No. $28.945 .-J 0 S 1 \mathrm{AH}$ TURNER and TIlt)MAS P. SMITH, SiNAPEE, N. H., assignors to themselves and EIMUNi) BURKE, NEWTORT, N. H.-Cultiralor Ticth. -Jun: 26,1 , 560 .

Claim.-1.- The coulter A, with the identation or recess $\mathrm{E}$, constructerl substantially as described.

2.- The conter $\mathrm{A}$, in combination with the concave wing $C$, with the curved point $C$, constructed and operated sub stintially as descrilect.

No. 32,077.- WILLIAM MORRISON, CHADI'S FORI, 1'A.-Cultivitor Teith.-1pril 16, I861.

(laim.- I cultivator tooth, having a sharp front edge, Haring vides, and a rliamond or arrow haped opening at its top, to receive a similarly shaperl shank, by which it is united (u) the cultivator frame, substantially as dencribed.

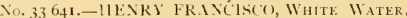

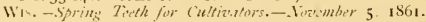

(laim.-1.- I spring cultivator tooth constructed and operating stibstantially in the manner and for the purpose described, in combination with a check lrace, substantially as described.

2.- So constructing the shonlder of a cultivator tooth that, when the working point of the tooth is arrested by any sudden obutrution, the strain uyon the tooth will be relieved liy the action of the shonlder, subut.untially as described.

No. 37,071.-GEOR(IE CLSTER, MUXROE, MICH. assignor to himielf, E. 13. ROC T, and J. J. STEVE.S, of the same place.-Cultiviler 7icth.-Dicimber 2, 1862.

Claim.-A an improved article of manufacture, a cultivator tooth provided with wing, and all constructed of a piece of rolled steel, in the mamer herein set forth.

No, 40,414.- WHLLIAM H. KEIIV, IrsANDER, X. J,-Ciultizetor Teeth.-Oitolicr 27, IS63.

Claim. - The tooth, or, as it is sometimes called, the point, of the form and shape and constructed essentially as described.

No. 40,935.-HENRY T. IIOOKER, SKANEATRLE4, N. V.-Cutiator Tielh-Dicembor 15, is63.

Claim.- The standard A, provided with the revisible share C, detachable moukl-boards, B B', and pulverizer D, the whole constructed, arranged, and operating in manner and for the purpose hercin set forth.

No. 45,671.-1H(O)AS IV. HA.IIMON, assignor to

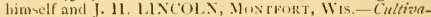
cor Terth-Dicembir 27, 1864.

Claim.-The employment or use in cultivators and grin drills of two parallel shaft B $\mathrm{l}$, comected by touthed seg. ments $C^{\prime} C$, or their equivalents and having the arms or standards 1$)$ of the teeth $E$ attached to them, to operate in the manner sub-tantially as and for the purpose herein set forth.

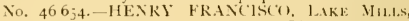
IIIs.-Tielh for Cuitivators. - March 7, 1865

Claim.-1.- The eccentric standard to a cultivator tooth, constructed and operated substantially as described.

2.-The slotted slide and set screw, arranged and operated in the manner and for the purpose described.

3.-The combination of the set and set-retaining device with the eccentrically hang hank of a cultivator-torth, substantially as and for the purpose clescribed.

No. 47008 .-IOSEPH FOIII.EK and F. M. IB. ICON. WITEKIown, Wis.-IIangins Cultivator 7eeth.-March 28, 1865 .

Claim. - Retaining the cultivator tooth by friction against a quadrant bearing substantially as specified, so that the said tootl can be in a vertical or in an inclined po ition and will yield to olnstacles without injury to the tooth, as specified.

No, 51,055-HANF()Rl) 1NGRAHAM, NALLE, N. Y.-Cullivalurs.-1irember 21, 1865.

Claim.-The shank $\mathrm{A}$, with circular or curved plate $n$, having a series of notches or cuts $a^{\prime}$ and slot $c$, whereby the same may be adjusted either laterally, angnlarly, or otherwse, by means of stationary pins $d$ or movable pin, or their equivalent, either with or withont a slot in the plate ar may be desired, substantially in the mamer and for the purpose herein set forth.

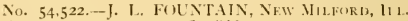
- Cultinatir Bilades. Miry 8, 1 S66.

Claim.-The offset 13, lot 1), and screw holt $\mathrm{E}$ in combi mation with the standard $C$ and blade $A$, arranged in the manner and for the purpones substantially as set forth.

No. 56,102,-JOHN $\rightarrow$, and IRA K()NELI, BEAYFR I) AM, Wis,-Cultitiator Tecth.-July 3, I\$66.

('lam. - The combination of the slotfed beam A, shank 13 , brace bar (; and bolt $\mathrm{I}$, when the parti are constructed and aranged to operate as and for the purposes herein specified.

No, 2,909.-IOHN'S. ROWELl, and IKA ROIIIII. lieAver DAM, Wis.-Cultizentor 7ieth. $-56,102$. Juls 3, I 866. Reissued Wurch 3 I, y 868.

Claim.-The combination of the slotted beam A, shank B, brace bar (; and bolt 1), when the parti are cm-tructed and arranget to nperate, an and for the purpone herein $y$ sci. tical. 


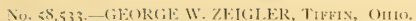

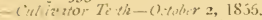

Claim-1.-Securing a shosel or eultivator tooth to it: frame by mean of a universal joint, in such manner that the shovel can be inclined either laterally or longitudinally with respect to its frame substantially as described.

2.-The concaro-convex shank $a$ formed on or secured to a shovel or tooth, sulsstantially as and for the purpose de seriibel.

3.--The combination of the shank $a$ concave plat $\mathrm{D}$, convex bolt head s, nut $c$, ant a shovel $\mathrm{C}$, or its equivalent, substantially as described.

Nis, 6),So3.-J. C. HOFFEDITZ, Mercersatra, PA.-

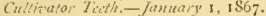

Clain.-The arranzement of the cultivator standard C, hanger 13, and wooden pin $c$, as described and represented.

Xis, 63.647.-DON C. MATTESON and T. P. WILI.IAMSON, STock ToN, CAL.-Cullivitor Teth-ipril 9 1867.

Claim-1. - The double pointed adjustable lit $\mathrm{A}$, and the beveled foot of the curved standard $C$, resting on the said bit, in combination with the double mould bourd or shovel $\mathrm{B}$, the same fitting over the standard and bit, substantially as dc scribed for the purpose speci ied.

2.-The oblong bladz or share D, in combination with the manner of fastening the te th torether by bolts passing throush the mould board bit or share, substantially as described.

No. 3,097.-DON C.IRLOS MATTESON and TRU-

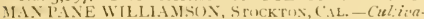
for Ticill-1pri! 9, is $57-33,6+7$. Reissted fu, ist 23 1868 .

Clain - I, - The double pointed adjustable bit A stached to the beveled foot of the curved staudard $\mathrm{C}$ substantially as and for the purpose specified.

2 - The oblong blarle or share $\mathrm{I}$, in combination witl the bit A, sub-tantially as clescribed, for the purpose specifiecl.

No. 64,657.-ANDREWV FRIBERG, MoL1NE, 1L1.Cultizito. Tisth-Mav 14, I 567 .

Claim-Securing the share to the stock by means of the bloc's $C$ anil stirrup c, when said parts are constructed and arrangerl sub tantially as herein shown and described.

No.67 457-EIIAS SEWARD, ILAMITON, OH1OPlou, ths-Ansust 6, 1867.

Cl.ii:n - Thic self-adjunting plough $\mathrm{F}$, made with the con vex sho: $C$, haviny the angular horizontal bane $d d e c$, and curved recedin $r$ shank $h$, as a new article of manufucture, constructed and operating in the manner and for the purpose subutantially as decribed.

No. 63, 40.-BENJAIIN F. HISERT, NoRTUNHIL.

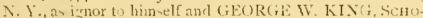

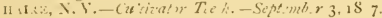

Clim, - A cultisatort soth or plow altached liy a vertical joint to the buan so as to swing liorizuntally, as and for the purposes sat forth.

Yo. C973t.-t. WEST and II. F. PAUL, Cuvorn,

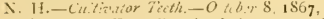

Claim.-1.-Ext.n.ling the fl nring part of the wings of a cultivat $r$ or harrow troth bie': bevond the rear edre of t'u boily of the tooth, and having the space butween the sai I winz open on top, to allow the suriace soil t , fall over 11. w'g or the wins int, the furruw made by the troth, whotintially as hersin sown and $d$ sccribed.

2.- Having the wines B B of the cultivator or harrow i oot's $r$ movable from the borly I of t'ze tooth, sub-tulially aanil for the purpone herein shown and described.

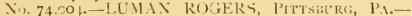

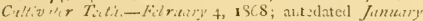
23. 1863 ,

('ai n.-I. - The rils $b$ on the bac's of cultivat or teeth or of blades lor slovel plougha, for the purpoie of athling strunsth to the blade, or for forming a means of attuching it to it, standard or frame.

2. - Attaching cultivator tew th or blales of shovel ploughs by means of a bolt inserted into a rib or projection on the back of th: to sth, which fits into a recess or groove in the stanlard or frame, substantitly ai and for the purposes dercibed.
No $75,+36,-11$ F. LollTil and \% J HolVF, OWAToNna, Mins. - iullitator. Tieth._Marth 10, $186 \mathrm{~S}$. Clnim,-The combination of the beam $A$, having the mortines $m n$, as clescrilsed, with the link $c$, wedge $w$, and hinged tooth $\mathrm{T}$, having the brace $\mathrm{B}$, substantially as and for the purposes set forth.

No. 75,667.-J. D. DE TURK, EXЕтек, PA.-Cizl-

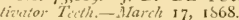

Claim.-The cap, represented in figs. 1, 2, 3, and 4, intended to be fastened to the cultivator beam, into which the tooth is to be inserted, and fastened by the iron hinge bolt $a$, figs, 1,2 , and 3 , and the wooden pin or key at letter $c$, figs. 2 and 3 , by the use of which the breaking of the tooth can be avoided.

No. 76,847.-D. C. STOYER, DAyTon, OHIo.-Cultiza:or Shevels. -Afril 14, $18 \leqslant 8$.

Claim,-1.-The bearing $C$, fitted between the shovel B and standard $A$, in combination with a slip joint fastening, substantially as and for the purposes described.

2.- The staple $a$, fastened to the shovel B, and the hooked bolt fastening $b b^{\prime}$, in combination with the rounded bearing portion $C$, interposed between the shovel $B$, and recessed standard $A$, substantially as described.

3.- So attiching the shovel Is to its standard $A$, that the shovel can be adjusted and set at different angles with respect to the line of draught without changing the axis of movement of said shovel out of its true line, substantially as tescribed.

No. 78 , 080.-HENRV A. GASTON, SitockToN, C.1L. - Cu'tivators.-Nay 19, is68.

Claim.-1.-In combination with an inclined reversilule bit for a cultivator, the methot of securing such bit to its standard, sulsstantially as set forth.

2.- The combination of the series of bits (so applied to their verlical standards) with the cultivator frame or carriage, substantially as described.

No. 79.45I-DANIEL DE.AN, BRIGHTON, Mich,Cultivaror Teth.-June' 30 , is 8 .

Claim.-The reversible cultivator tooth $A$, when contructed substantially as shown and for the purposes describer.

No. 83,503.- WILLIAM B. READY, SACRAMENTO, CAL.-Cultrwator T $T^{\prime}$ thi.-July 28,1868 ,

Claim-I. - The groove $c$ in stock $a$, as a seat for an ad justable point for a cultivator tonth.

2.- The movable tongued, pierced with holes or slots $i \quad i$ $i i$, forming an adju table $\mathrm{p}$ sint of a cultivator tooth.

3.-The combination of the grooved stock or support a with theadju talble ton rue $d$, for the purposes of a cultivator tuoth, sulstantially as alove dercriled.

Nก. 81,188. - B. F. IJCCULLESTER, CMIFORN1A, ML.

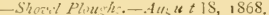

Claim. - The combination of the dunble pointed hovel plough $\mathrm{l}$ with the st ind ard $\mathrm{A}$, plate $\mathrm{C}$, laving lugs $c c$, block 1), holt. E E, and screw nut ic $c^{\prime}$, sub tantially as ani for the purpose ahove set fortl.

V.. $82423,-$ II. E, LOIVTH and T. J. IIOWE, OW

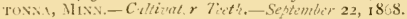

Clain-In combination with the mortised beam $A$ and the toot'i I', having the shank \& b', and pivoted on the bolt $c_{1}$ a tirrup shaped clamp E, having an oblong or semicircalar opening (), the si le $o$ of which, that bears against sliunk $b^{\prime}$, bein t stai ht, and sail clamp being confmed to the beam $A$, and tightenad or losened hy mean ; of a screw shank $r$ passing through a Intin tize sile of the beam, and a screw nut $n$. fitting upon it out,ide of the beam and screwing wonin the side of the be:m, or against a washer, sub-tantially as described.

No. 8,235,-CLARK ALVORD, CORTIAND, WIS,Dras Bar for Cult rators.-Olcuber 20, 18,8 .

Claim-1.- The compound drag bar, as above described and shown,

2,- The con truction of the cultivat $x$ tooth and fastening it to the rlrag bar by pasing the bolt through the angle as above described and how'in

3. - The movable clasp in combination with the drar hat as alowe de icribed and shown, and for the purpones ahove set forth. 
No. S6,26r.-GEORGE W. VAN BREUNT, IIORICWN, Wis,-Cultivalors.-January 26, IS69.

Claim.-1.-The notched and curved arm B', of a pivot ed cultivator tooth, in combination with the locking bolt 1 , substantially as and for the purposes set forth.

2.-The arrangement of the wedge $i$, rubler or other spring $o$, and parts $m m^{\prime}$ of the bolt 1 , when the said part are employed, substantially as and for the purposes set forth.

3.-The clamping plate $\mathrm{C}$, in combination with the two bolts $b b^{\prime}$ and the pivoted cultivator tooth, subatantially as and for the purposes set forth.

4.- The stop $e^{\prime}$ arranged upon the curved arm $B^{\prime}$, and operating in connection with the clamping plate $\mathrm{C}$ and bol $b^{\prime}$, substantially as and for the purpose shown and described.

No. 85,306.-WILL1AM M. HURLBERT, IVINONA, MINN.-Cultivator Tecth.-January 25, IS69.

Claim.-The combination of the slotted bar B and tooth $A$ with the plates $C$ and bolt $\mathrm{D}$, when said parts are constructed ami arranged as shown and describzd.

No, S6,794,-GEURGE W. ZlGLER, MAUMeE C1Ty, OH10,-Cu/iviztor Teeth.-Fibruary 9, 1560.

Claim.-1.-In a single beam cultivator, so adjusting the shovels, by making the front and rear bearings or offists of different lengths, that the tendency to lateral deviation of the rear end of the beam $A$, by the resistance of the earth upon the front shovel, substantially as described.

2.-A hollow thimble bearing, E, constructed with notches $s s^{\prime}$ in its end, adayted for receiving a shovel standarl, and admitting of the adjustment of such standard in different planes, substautially as ilescribed.

3.-The constrnction of the hollow thimble bearing, with a flange $a$, on one end, and notches $s$ in the opposite end, substantially as and for the purposes described.

4.- The notchecl thimble learing $\mathrm{B}$, in combination with an eye bolt (C, and shovel standard I), constructed substantially as descrited.

5.-A single beam cultivator, having its shovel standard contined to notched or grooved thimbles or offet-, of diflerent lengthe, Ly means of eye bolts, which also confine the said thimbles or offists to their beams, substantially as and for the purposes described.

Nu. S7.IOI. - IAMES IIARRIS, JANESVILLE, WIS.Cultivitors.-Pcbruary 23, 1869 .

Clain.-1.-The detached or independent circle iron C.

2.- The arrangement of the detached circle iron $\mathrm{C}$, with the tooth 13, whereby buth have a common bearing on the pisot pin $a$, substantially as descrilrecl.

3.- The combination of the twoth B, circle iron $\mathrm{C}$, and coupling device $b$, substantially as described.

4. - The arrangement of the woth 13 , independent circle iron $C$, setting device $\mathrm{E}$, and drag bar $\mathrm{A}$. sulustantially as and for the purpose described.

5.- The combination and arrangement of the tooth $B$, and independent circle iron $\mathrm{C}$, when jointed by the coupling device $b$, and having a common bearing, $a$, with the dray bar $A$ and setting device E, or pin l, sub-tantiallyas described.

6.- - Joining the drag hars to the draught rod by means of the elongated metallic hox I), wherely a broad, firm bearing is secured and washers butween the bars dispensed with, substantially as described.

No. 4.ST2.-JAJlES IJARRIS, JAXESVille, Wrs, Cultivn'o:3.-S7,101. February'23, iS69. Reissued March I 9,1872 .

Claim.-1,-A wooden drag har, provided with a me tallic bearing box, secured by means substantially as described, for the purpose set forth.

2.-A drag bar, provided with an orifice at one end, and elongated bearing box, and a securing bolt, for the purpose specitied.

3.-A dray bar, provided with an orifice and slot at one end, an elongated bearing box and securing bolt, for the purpose specified.

4.-The combination of the drag bar A, having an orifice and slot, as deseribed, with box $D$ having the flange, as and for the purpose set forth.

No. 4,813,-JAMES HARRIS, JANESTILLE, Wis.Cuttizaturs. 87,101, Febluiry 23, I\$69. Reissued Warch 19, 1872.

Claim.-1.-The detached or independent circle iron C.
2.-The arrangement of the detached circle iron $C$ with the twoth $\mathrm{B}$, wherehy both have common bearing on the pivot pin $a$, substantially as descríbed.

3.- The combination of the tooth $\mathrm{B}$, circle iron $\mathrm{C}$, and coupling device b, substantially as described.

4 - The arrangement of the tooth $\mathrm{B}$, independent circle iron C, sctting device E, and drag bar A, substantially as and for the purpose described.

No. S9 I 37--E. L. FREEMAN, Williamstown, N. Y.-Cutivitor Terth.-April 20, 1869 .

Claim. - The harrow or cultivator tooth berein described, when constructed as set forth.

Nis, 8, 409.-BENJAMIN S. HYERS, PEKIN, ILL.Cultita or - - April 27, i 869.

Claim.-I.-The loop N, when rigilly secured to the blade $\mathrm{A}$, in combination with the hook $\mathrm{C}$, substantially as and for the purposes herein shown and described.

2. - The plates $\mathrm{F}$ and $\mathrm{i}$, in combination with the loop $\mathrm{B}$ and hook $C$, as herein shown and described, and for the purposes set forth.

3.-The loop B, hook $\mathrm{C}$, and plates $\mathrm{F}$ and $\mathrm{C}_{i}$, in coml ination with the blade $A$, and leg 1 , when constructed and arranged substantially as hertin shown and described.

No. S9 422.-JUSEl'H I: MUUIN, PEMLROKE, Kx.Cu $\$ vito; - Ap:il 27, 1869 .

Claim. - The cultivator teth or plourhs G, constructed and attached to the frame $A$, substantially in the manner herein shown and dexcrib $\mathrm{d}$, and for the purnose set forth.

No. 92.910-BENJAJIIN VAN BRAE KLIN, LE RUY, N. Y.-Cutiower Tith.-July 20, 1869.

Claim.-A tooth, having its shank, A, provided with one or morespurs 2 , for the parpose of securing it in position, sub t intially as described.

No. 93, 95.-HENRI F, FRENCH, Boston, MAss,Cul'isuior Tirth. - Au, ust 17, 1869.

Claim. - The cultivatur tonth formed from a square bar, and pinted and curved at the point dingonally, as shown and described.

No. 94 725.-WILLIAMI A. IURTDEN and J. M.

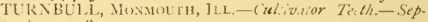
$4 m l_{1}, r 14,189$.

Claim,- I - The combination and arrangement of the shovel 1 , plate $C$, and cutt $2 \mathrm{E}$, substantially as described and for the purpose set forth.

2.-The combination of the slovel $\mathrm{F}$, and the cutter $\mathrm{E}$, in its rear, as and for the p.rpose describerl.

No. 9 , 383.-W. G. BLCKWITII, LUWNDESBOROETI,

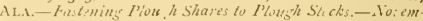
Ler. 2,186 .

Claim.-1.-The rectangular socket $\mathrm{B}$, when con-tructed as and for the jurpose set forth.

2.--The sodiet B, when furnished with projuction C, knob $g$. and wedge $d$, in combination with lough share 11 , the whole being connetred in the manncr described.

No, 97,2 13.-11ENKY MII,LEK, RoAIsIIH, VA., assinor to himelf, $\therefore$. P. H. M!LI.ER, J. G. 11. MIILLEK,

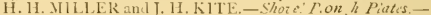
Niv miser $23,15 \%$.

Claim,-I, - The mold A, hrving a face concave lengthwire, and plane crosowise, and having seat - at its ends, sibstantially as and for the purposes: $t$ forth,

2.-The cumlination of the mold $A$, having seats at its encls, with the removable reversible points $A^{\prime} A^{\prime \prime}$, substantially in maner and for purpuse describst.

No. 99,7 2. J ISIILA PIIERPUNT, LA II.IRPE, ILI., assignor to limelf and Sil) NEV S. T T TLE, s.me place.

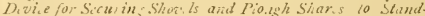
aris.-Fibruary S, I-jo.

Claim. - The iron or mital ring 1), with shank thread and nut, or their efunivalent, in eonnection and combination with the iron of metal thimble E. constructed and operated as and for the purpose herein describul.

No. ICO 298.-G. WV. I.AWBAUGII, GExeseo, Il.1.-

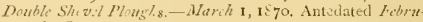
ary $26,1870$.

Claim,- The within describal plough stocl, consinting of the side beam $A$ and $A^{\prime}$, feet $C$ and $\mathcal{C}$, handles 11 and 11 , and braces $1, K$, and $\mathrm{L}$, all constructed and arranged subantially as an I for the purpose shown. 
2.-The devices employed for rendering the shovels ad justable, consisting of the block $\mathrm{E}$, bolts $e e^{\prime}$ and $\mathrm{F}$, and the wedge $i$, substantially as shown and specitied.

3.- The combination of the heam $\mathrm{A}$ and braces 1 and $\mathrm{L}$, substantially as and for the purpose shown.

4. - The fender $\mathrm{X}$, when connected to the plow by means of the flat adjustable spring support $\mathrm{M}$, as shown, and for the purpose specitied.

to. $100,713,-5 \mathrm{ANFORD}$ BECKWITI1, OsIKosI, Wis.-Cultivator. Teth.-March 16,1870 .

Claim.-I, - The cultivator tooth 13 , with a bracing dual head $i$, , arranged relatively to the washer $d$, bolt $c$, and cul tivator bar $A$, for the purposes set forth.

2 - The washer $d$, provided with groove $t^{\prime}$, when used in combination with tooth $\mathrm{B}$, bar $\mathrm{A}$, and bolt

No, IO2,150,-GEORGE PERRV, GRAXVILI.F, ILL.1)oirlie Shavel Plonghis.-April 19, 1870 .

Claim.-A cultivator tooth or shovel, consisting of the standard B, constructed with flanged arm B', and shovel A attached to said arm substantially as and for the purpose set forth.

No. 104,754-JAMEG G. MINER, NAsHVIlle, TENN. - Cinltizitor I'longhts.-Juni 2S, 1870

Claim. - I cultivator plough formed in one piece, with wings witcuing from front to rear to form an acute angle, and baving a stcel share, formed of a turned up ledge, con verging towarl the center and lying flat ip on the ground, wherely a very small frictional resistance is attained, the share is male a self sharpener and the entire space between the rows cut out at a single passage.

No, $105.570 .-T H($ IS SS HADIN(;, LA FAYETTE Ixin.-Shwiel Teell for Cutivators.-July 19. 1870.

Claim. - I drill or shovel tooth for cultivator:, Ne., pro vidcel with a clamping strap, C, rigidly attached to saicl tooth, and clamp bolt $\mathrm{E}$, outide of and behind the standard $\mathrm{A}$, subst metally as set forth.

No, $105,478$. - IULIUS (IERBER, ROKFORI, ILL. - Cullivatiri-Ausust I $6,1870$.

Claim.- The device described, consinting of the clevis $d$, with har $d^{3}$, and notched face $d^{2}$ angle iron $c$ with bolt an 1 set serew $e$, when combined and arranged as deseribad, and employed in connection with a cultivator beam and shovel stundare, as described.

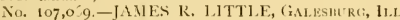
- Cultiv, to s, - Sipicmber 6, 1870.

Claim.- I.- The plate $\mathrm{B}$, constructed substantially as described, arringed with the shovels and sanclards of cultivator ploughs, for securing and adjusting the same, sulmtan ti.lly in the manner st forth.

2.-The construction and arrangement of plates 1 and $C$, b olt : $b^{\prime} b^{\prime}$ and $E$, head 1 , pivot bolt $\mathrm{J}$, and plug $\mathrm{S}$, sulstan tially as and for the purpose sp scified.

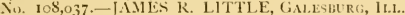
- Cullivators,-Octwber 4. I87o.

Claim.-Securing the standards $B$ to the beams $A$ by means of the eye bolt $C$ and adjustable double soclict $f ; 11$, substantially as describsd, and for the purpose set forth.

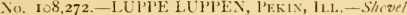
Plousis. - Octuber II, 1870 .

Claim. - The clamy her in describad for attaching shovels to the stanclard of a plough, composed of two brackets secured to the back of the shovel, and having recesses in their op p-ing faces, for the reception of the stamelard, which is clamped butween them by means of a bolt and nut, sub. strutially in the manner set forth.

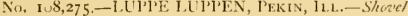
Piou; $/ 2 s .-O i l o$ ier II, IS7O.

claim.-I.-A slovel fastener, consi-ting of the hlock A, cap $\mathrm{l}$; , bolt $\mathrm{C}$, and tight 2 ning nut $\left(C^{\prime}\right.$, smbstantially as shown and described.

2.- In combination with the element in the preceding clause, the fillets $\mathrm{D}$, subutantially as and for the purposz sit forth.

No, IOS,47I.-TLLIUS GERBER, ROCKFORD, ILI. - Cultivators. Oitoier 18, 1870.

Claim.- A ring for bolding standards, when used in connection with a lwit and hesing l, lock, and so constructed as t) $b=$ capable of a turning mosement in the bolt, as describzd, for the purpose set forth.
No. I08,5I2.-JOSIIUA PIERPONT and SIDNEY S. TUTTI.E, LA IIARVE, IIL.-Fiastinings for Shozels for Cultivaters ant Pl(ushs.-Octobir is, 1870.

Claim.-The combination of the eye bolt $H$ and the wooden pin $\mathrm{E}$ with the standard $\mathrm{A}$ and the shovel holder $\mathrm{C}$, made and constructed substamially as and for the purposes hereinbefore set forth.

No. I IO,IO3.-WII.LLAM W()RKNAN, and JASON HITCHC(xK, Rupes, Wis,-Friclion Block for allachins Cultizalor and other Teeth.-Dicinber 13, 1870.

Claim. - The friction bloca 13 , formed with the wings b b' and the intermediate socket $f$, and shoulders or and $h$, in combination with a tooth sliank, C, substantially as clescribed.

No. 9,638,-IVILLIAM IVORKMAN, WEst DE PLRE, and JASON HITCHCUCK, RIros, Wis.; said HITCHCOCK asiznor to said WWORKM.1N. - Friction Block for attachins Cultivalor and other Tielh. - $1 \mathbf{1 0}, \mathbf{1 0}_{3}$, Deccmber $\mathbf{1}_{3}, \mathbf{1}_{7}$ O. Reissued April 5, $18 S_{1}$. Filed Nuvimber 22, 1880

Claim.-I.-As an improvement in connecting cultivator and other slip teeth to dras-bars, the block attached to the drag-bar and contined is its adjusted position by friction, said block being provided with means for supporting the tooth shank, substantially as described.

2.-- The combiuation with the clrag bar, of the block carrying the tooth shank and confined in its adjusted position on the drag-bar by friction, substantially as described.

3.-In combination with a drag-bar, the block attached to the drac-bar and provided with means for supiorting a tooth shank constructed sepurately from the block and arranged at one side thereof, substantiall y as described.

4.-A friction block attac hed to a dray-bar and adapted to be adjusted at different angles, in combination with a tooth shank comnected with the friction block and adapted to have a movement indepentent of the friction block sub. stantially as described.

5.- The friction block provided with the intermediate socket, $a$, and shoulders $c c^{\prime}$, in combination with a tonth or shovel having a shank fitted in said socket, substantially as described.

No, I Io,836.-IVIILIAM A. IHRVIDE, MonMouti, 11.L., asignor to himself and JO)11N M. TURNIBUL.L, same place,-Caltivators.-Junury Io, I87 1 .

Claim, - The cultivator shovel $A$, when constructed substanti lly as deseribed, with a diagonal twist or curved across it- lower part, for the purpose of offering a counter resist ance to the side pressure of the urdinary twisted shovels, sub. tautially as described and for the purpone pecified.

No. i 12,862 , - WHLL1A.1 1). SlRoU1), Oshkosh, Wis,-Cullivito/s.-March 21, 1871

Clain. - The wing $c$ and serew bolt $c$, in their relation to the tooth $a$, friction brace $d$, and $\operatorname{lag}$ bar $h$, as bcreinhefore net forth.

No. I I7,C92.-MICHAEI, F. 1,0)TII and ORLEAN

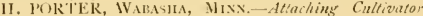
Teith to Bitmis.--July I8, 1871 .

Claim. - The brace $d$ of the cultivator tooth, provided with a series of holes for reception of a pin on which rest the free end of the plite spring $f$, whereby the inclination of the tooth to the beam may be varied without changing the tension of the spring as herein shown and described.

No, I $17,524,-1) A N I E 1$, EIH)ELMAN, MAbISON, IND.-Cuit.vitiors.-Ausu:t 1 , IS 1

Claim. - The interchangeable sidc hoes $c c$, provided with teats or projections, as clescribed, for adjuting the angle of their position, and with reversible blades or shear, when arranged in combination with the harrow tecth $a a^{\prime} a^{\prime \prime}$, in the manner and for the purpose herein set fortl

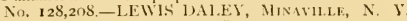
Cultivitor Tith. -..4u, u.t 22,1871 .

Claim.-The sted bottom facings $A$ A and overlaping wronght iron stock $\mathrm{C}$, constructed and applicel to the stand ard 1 , as and for the pusp se specified.

No. 118,362 -TIIOMAS [․ 11AMILTON, GENESEA, II.L.-Cultizalors and Shovel Plo.tshs.-Ausust 22, IS 1 . Claim.-I.-In a cultivator or shovel plough, an adjustable shovel block or attechmont, when provided with a ball 
and socket bearing and combined with the standard and shovel, substantially as and for the purpose specified.

2. The plate B provided with the semi-splerical socket, and the block E provided with the curved slots $c$ and bow $\mathrm{E}^{\prime}$, in combination with each other, the standard $A$, the shovel D, and the bolts F, substintially as and for the purpose shown and described.

No 120,789. SAMUEL SNIDER, TAYLURSVILLE, Ky., assignor to himself, A. I'. HARC()UkT and (i. H. ST()NE, same place.-Cullizaters.-November 7, IS71.

Chim.-The shovel $(i$, having a contral riclge, $d$, the sljeles lxing stoped and furnished with wings $H$ 11, while the upper portion of the shovel is rouncled in cross scction, and is graclually widened out above the point at which the wings diverse, as shown and dercrilied.

No. I2I,794.-IAMES IIALOON and IIENRT VON

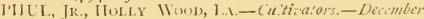
12,1871 .

Claim.-The comlination of the slotted plates II (), clutch $y$, flange $k$, and standard of shovel $(i$, as set forth.

No. I 22,240-1)AT(1) Z. EVANS, TOWN PUNT, MbCu'tirutors,-Dicember 26, 1871

Claim.-1.-A cultivator tonth consitting of a shank, 1, and cletachable blade 13, secured together and to the frame of a eultivator by a single bolt $\mathrm{F}$, sulstantially as herein descilised.

2,- - I cultivator tooth comiting of a shank . I, and an adjustable blasle $\mathrm{B}$, securesl to the sliank, so ns to be adjustable thercon, by a set screw $m$, or its equivaltut.

No. 1 22.729.-1)ANIEL E. HeKHERlit, DAvт, (1) Iu.-Cirin Frills.-fansury 16, 1872

Clam, - I- The combination of the reversilile hoe of tooth $C$ with shank 1 , provided with flangen d, for the purpose of holding it in position, substantially as herein deserileet.

2. - The shank $\Lambda$, provided with the flanges $d$ and slot $c$ in combination with the loe or shovel e, for the purpowe of acljusting the latter at describer

No, $125.494-G E O R G E$ IHOI'KINS SMITII, JWS

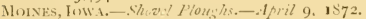

('laim.-The shovel plough share 1 , haviue central ril, $D$ and side ribs C' ('arranged thereon, as and for the purpose described.

No. I25 872.-JACK WOOD, WrinWFe, ALA.-Cultialors.-Afril $\mathrm{I} 6,1 \mathrm{~S}_{72}$

Chim.-The frot $b$, contructed with the perforctions on the unuer side to give the lateral arljustment, and the washer $f$, with the perforations on the lnack to give the circular adju-tment, connected to the arms or standards at and i-, end olerating substantially as recitecl.

No. 127.757 - ANIUREW FRIBERG, NGLINE, ILL. - Cultivalir,-Jume 15, 1872 .

(laim.-1.-1 shank for cultivators, composed of a plate of wrought metal duubled or fokled in the line of its lensth, so that it-cross section shall he of $\boldsymbol{U}$-lape, whercly it is adapited to clasp around the front of the cultivator beam, and to have a shovel attacheil thercto and adju-ted thercon substantially as descril ed.

2.-In combination with the atrove describerl shank, I claim the shovel (; arranged to be aljusted up or down thu reom, substantially as clescribed.

3.-1 also claim the ahove de-cribed shank B, f irrited to the heam $\lambda$, and locked in posilion ly a break pits, with a sherel $(C$, attached thereto, all censtiticted and arranged to operate sulxtantially as described.

No, 12S686.-(IIARLES 11. WATSON, WISHAG TON, I). C.-cutiviters-Jull 2, 1872 .

Claim.-1.-1 reversible cultivater or plough stendard. having a plesurh or a cultivator, or harrow to th upon one end, and a suitable rumer or slevice for rumning upon the ground upon the other end, sulutantially as and for the prorprove set forth.

2. - The standard $\mathbf{B}$, provided with the head a and finnge 7, as and for the purpose specified.

3. - The standarcl $\mathrm{B}$, having a suitab? e head, $a$, flange $i$, and in combinntion with b:am $\mathrm{A}$, the standard leing pircted to the beam and held in place by a pin at $c^{\circ}$, sulutantially as and for the purpone dercribed.
4.-The rever-ible standard B, when constructed substantially as specified, and for the purpose set forth.

No. 12 ).859.-EDIVIN PIRYELE, DAVENPORT, IUWL, and GEORGE CURKENDALL, MOLINE, ILL., assignor: to J)EERE \& $(\mathrm{O}$., MoLiNE, ILL.-Cultivators.July 23, I872

Claim.-1.-A an attachment to cultivators, we claim a tirring device, $\mathrm{E}$, having three or more prongs. arranged in the manner and for the purpose substantially as sel forth.

2.-The stirring device $\mathrm{E}$, having three or more prongs, arranted as described, in combination with and aclinstable up ancl down upon a curved heam or plough stanclard subtantinlly as and for the purpose specified.

3.-The stirring device E, constructed as described, in connection with the plough beam A and standard B having metal pivot (, and wooklen pin I), substantially as and for the purpose specified

Ni, I31,SIS-MIRUUTS I, (CORHAN, RUCKFORD, 11.L.-Cuit vators.-Octotier I, 1872

Claim, - The single friction plate $\mathrm{B}$, constructed as described, in combination with sandard I), clamp bolt $\mathrm{F}$, and bsam $K$, as and for the purpone set forth.

No, 1,1,86t-CIEORGE WI. ESTERLY and JOSEPH

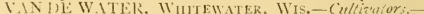
$O, b_{i}+1,1572$

Clam.-1.-The liftine lar $\mathrm{B}$, having the $\mathrm{r} x \mathrm{l}, \mathrm{F}$ attached, sairl roch pasing un through sk to or their equivalents in the dras bar, A, and connected by chains or cords to the rock haft $C$, whoreby the ctrags bars can all be rained toguther and ench $b=$ free to rise and fall ildependently, and the lifi. ing bar be helel in its place, stbatantially as described.

2.- The mortiect or hollow lilock (i, provicted with the curred sot and the shoullers or projections (), in combinatium and with the shank $1 \bar{i}$, lolt $r$, and drag bar $\Lambda$, all con-

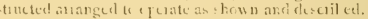

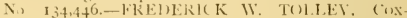

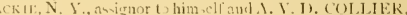

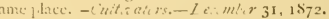

Claim.-The tandard 1: 1), haviner slots $f^{\prime} d^{\prime \prime}$ shaped to receive a bolt i', comsuncted as ret forth.

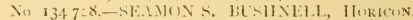

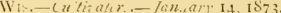

Cleibe- lien A, touth B, and stanard $C$, in coml ination with $\mathrm{se}$ screw $(i,-11)$ tantially a cluscrilucel.

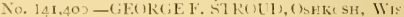

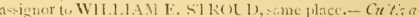

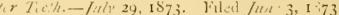

(laim.- The shank I provided with the kinchle D and pin 6 , anel the sletted and recested plate $(i$ prosiclul $\|$ ith projections $\mathrm{F} F$, in comblination with the chag $\mathrm{l}$ : $\mathrm{K} \mathrm{K}$ and spring f. culotantially as and for the prije-e locritil cicre ict forth.

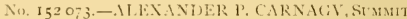

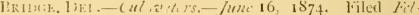
maa y $14 \quad 1874$

Clain.-Thic coml ination, in a cultivator, of toeth S, U shaperl in cros section, with the independent socket $T$, the wedge bolt, an the nut, as described, wherdy the tor.th $\mathrm{i}$, drawn firmly in to the socket, and hoth s-curch to the bum, in the manner specilied.

No. 152,7-6-JOIIN 1T. TIIOMAS and JOsilPI W.

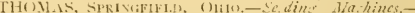

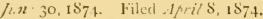

Claim. - in coml ination with the clag lar $\Lambda$, lifurcated

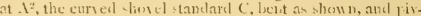
oted lyy at lof at D, and clamped lyy bolt E, sulwat.utially as thown and itertilied.

Aiv. 153.565-WII. II.IRTGROTE, OXFuTI, II Cultisulers-Julv $28,187 \div$. Filed Dicumbir 9,1871

Claim. - The coml ination vith the shovel $b$, haring ris islly secured to it rear portion the cencave convex plate $C$, of the slotted metallic stio: 1), comcitin $r$ of the spon shaped plate 4 , beit to correy (am! t t the concavity of the plate $C$ and it: upper part bent $t$, wrun liangend $d \dot{d}$, between which the lower end of the ploming beam in secured by means of the transverse pin $d^{7}$ and wooden $\mathbf{n}$ itch in $^{2} d^{2}$. sulv tantially as and for the purpose deseribed

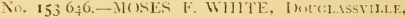

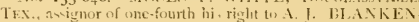




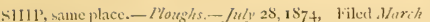
3I, 1874 .

(laim.-The combination of the foot 1 ) of the standard with the bar 1$)$ and the plate or share (; the same being secured by bolts $a$ a, arranged as shown and descrihed, for the purperse specitied.

No. $15+, 667-1$. R. GRANIBRRRV, and JOSEPII

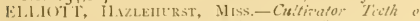

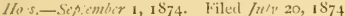

(laim. The blacle $A$, provided with the lip or tongue $C$ and rib 1 , and the removalide point 13 , attached to said ton crue hy means of bolt $a$, all as and for the purposes herein ict forth.

No. $158,0 \$ 1$-CORJTON P. HEWETT, KINGSTOX, His., ans nor to himself and HENRY V()LKMAN.

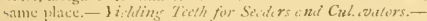
Dirmice 22, 1874 . Filed inzust 7,1874

Claim,-1.- The combination with the pisoted share of tooth BC I), and hinged rod or toggle I J K L M, of the corrugated or serrated plate $\mathrm{E}$ and $\mathrm{F}$, bolts (; and $\mathrm{P}$, and the spring $\mathrm{N}$, adapted to hear on it projection, (), from rod $\mathrm{J}$, substantially ats sut forth.

2. - The combination, with the pivoted share or tooth $B$ C 1), togrcle I J K L. . , and plate E F, of the yring N, hav in $y$ il free end bearing on an ailustable projection, (), for regulating the tension of the spring, substantially as specilied.

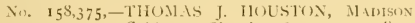

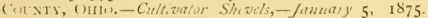
Filed ()

Claim.- The eultivator shovel shown and describerl, with the mpight I and foot part C'marle in a single piece, so as to form the carity $t^{\prime}$ treneath, having the angular siles $a$, is hereinbefore set fit ith.

No. $15 ₹, 512,-R O D N E Y$ P. ODELL, JR., P.RMA CH. TK1, antsuor of one-hall his right to $\mathrm{s}$. K. (O) ELL,

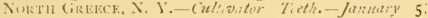
1575. Filed Drimler 3,1574 .

Claim. - A cultivator tooth, eonsisting of the wing $A$ and land-icle $\mathrm{B}$, formed in a single lice, the $w$ ing being mate in the form of an exuivalateral triangle, with the square corner and the land ide proviled with the upright curved point $f$ stamiling haek from the rear of the tooth, as hercan shown and decribed, and for the purpose specitied.

Niv, I5\$ go6.-EINWIN CHILDREN, I) NIMTH, [1]

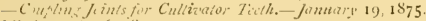
Filual (1, 10 ' 4 . 6 , is 74 .

Chim,-1he coupling joint herein de-crilecl, comsisting of the ca.ring $\mathrm{C}$, made with the concave custy 1 ), the catins $\mathrm{E}$, mate with the consex projection $\mathrm{F}$, the cye-holt (;, pissing through the nut 5 , and through or thwart fin 11 , pasing through the eye of aad bolt and resing on the moteles $h / h$, attached and connecting and in - coml inntion with the standard $A$ and shovel b; substantially as specified.

No. 160 444.-EZRA LEON.IKD, AKRoN, ()H:O-

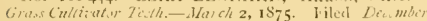
$16, \mathrm{I}_{74}$

Clami- - Is a new anticle of manufacture, the alowe decrilsed cultivatur tooth, consiting esentially of the shank C. the coulter $B$, and the two winged hare 11 , having the harp cutting edge 1 , curved to rum nearly parallel with the -ruiace uf the gromel, sulmtanially as st toudr.

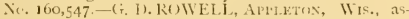
isuor to kollELL and Mokkis, same place,-Slip Tiedt

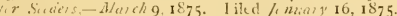

Clim, - 1. - The combination of lip tooth 15 , having brace (', with rectelect $\mathrm{cam}$ L, sulstantially as sat fortlo.

2.-The heam . 1, tooth B, having brace $\mathrm{C}$, and cam 1), having indicator figures $\mathrm{E}$, all in combination subst.ntially as rut finth.

No. 161.745.-G. J. I3RIMINGIAN, TRF. Ton, THN.

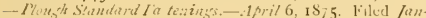
u1I) $23,15_{j 5}$.

Chaim. - In a -tandard-fat -ning for plourbs or cultivators a plate 1 , having a perforated tapered how formed on it, in combination with the plate $b$, having a socket postion, 1. formet on it to receive saicl los s, yb-tantially in the manner and for the purpones at forth.
No. I66.979-JuIN FLYNN, Monches, Wis.-Cull

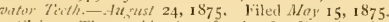

(laim.-The combination of spring I) F and whed $G$ with the piroted tooth $\mathrm{B}$, having the concavity $b^{2}$, lug $b^{1}$, and set screw 13 , as shown and described, to operate as specified.

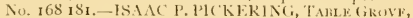
11.1.-Combind Cultivors ant Iharrazs.-Siplembir 28 , IS75. Filed tu, 115 1 $^{4}, 18_{75}$

Claim.- The combination of the head B, made in two parts or halves bolted together, an:l provided with $\mathrm{V}$ grooves ancl with recesses in thcir inner surfaces, and the reversilile square teeth $\mathrm{C}$, macle pointed at one end, ant provided with shovels $c^{\prime}$ at the ir other ends, with each other, substantially as herein shown and described.

No. 170,627.-JOHN HARRIS, MARquhtTE, Wis.-

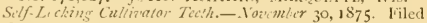
Ju' 10,1575 .

Clam. - The combination of the catch spring $\mathrm{C} c^{2}$, the reenforcing spring $\mathrm{D}$, the bent lever $\mathrm{E}$, and the bar or bars $\mathrm{F}$, with the beam $A$ and the pivoterl cultivator tooth 1 ; substantially as herein shown and describerl.

No. $171, ; 66,-$ COKYDON P. HEWETT KINGSTON Wis.- Hiciding Teell fir Sicedero and Cultivators.-Decinbr 28,1875 . Filed June 26,1875 .

Claim. - I, - The spring am $\mathrm{E}$ and toggle arm F, having a sliding pivoted connection, and adapted to be pivoted, respectively, to the beam plate and standarl, substantially as specifierl.

2.- The combination, with the foregoing described sliciing pivoted arms $\mathrm{E} \mathrm{F}$, of the screw bolt $c$ and double nuts, one abose and the other below the arm E, as and for the purpose set forth.

No. 172,373-J. C. HANN1G:N, DENLEITH, ILL.Cutivilos Tie'h.-Junuary 18, 1876 . Filed Ausust 30 , ${ }_{1}{ }^{7} 75$

Claim.-The combination of the standard $\mathrm{B}$ and its ball C with the socket I), constructed in two parts $d$ d, clamped together and secured upon the ball of the standard, the lower part of the socket carrying the shovel or plough share $\mathbf{E}$ subtantially as describer.

No. 173,873 - M. K. WHEAT, PARIs, Kr.-String Lo:ks for Pioushs.-Fibuary 22, 1876. Filed January 22, 187

Clam.-The spring lock bars D, provided with the shoulders $b^{\prime}$ at their upper ends, pivoted to the plough beam $A$ or the plough : tandard, and having the plough plate $C$ at tached to their lower end, sulstantially as herein hown and clescribed.

No. 175,649.-RUFUS F. BILLINGS, KINGSTON IV,s.

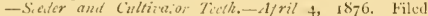
January 15, 1876.

(Claim.-1.- The lever C, pivoted at it cunter in the slot of heam $A$, and having its opposite ends engaged by the spring $D$ and the standard B, as shown and described.

2.-The combination of the pivoted bar $\mathrm{C}$, the rollers $\mathrm{F}$, the spring I), and the pivotel touth I, substantially as herein shown and descriled.

No. 175.721,-ELWARD P. LYNCII and EIGAR A. WRIGIIl, DATENPORT, Iow.-Culcitaturs.-April 4, 1\$76. Filed Fibrugiy 19, 1876 .

Claim,-Thesleeve D, having the slots $a b$, in combination with the block 1 , attached io the shovel, and provicled with the irregular shaped sket $r$, and the fult $C$, having a scitare neck $c$, ftting the slot $a$ in the sleeve, suly tantially a described. and for the ur ose st forth.

No. 7,250-ELWARI) I. I.VNeII ad E. A

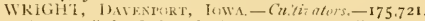

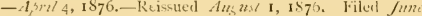
26. $18 ; 6$.

Claim.-1,-The shank D, having a slot b, formed thercin of p sit the front of the beam, sulstantially as and for the purjo,e set forth.

2-The shank [), provided with the slot $a$, in combination with the shovel $\mathrm{A}$, having the llock $\mathrm{B}$, provicled with the tramserse vot $x$ and the theaded bolt $C$, all e n-ntructerl to operate sub: antially as decribed.

3.- The block 15, secured tathe shorel $A$. and prosided with the slot $x$, of a width corresponcling to the square hank of the Theared bolt $C$, and having an enlargement at one 
end, in which said bolt can be turned, substantially as and for the purpose set forth.

4 - In combination with the block B, having the slot $x$, the bolt $\mathrm{C}$, provided with $\mathrm{T}$ shaped head $o$ and the square shank $e$, said parts being constructed to operate substantially as set forth.

No. 178,180 .- J. MITCHELL, Elma, N. Y.-Cultiza tor Tieth.-March 30, 1876. Filed February 25, 1876.

Claim.-A cultivator tooth, with a wing or wings, $a$, formed or cast thereon at right angles thereto, as and for the purpose specified.

No. 183,121.-C. P. BUCKINGHAM, CHICAGO, ILL.Cultivators.-October 10, 1876 . Filed $A u_{\text {sust }}$ 1 7, 1876 .

Claim.-The wrought metal sleeve or shank $B$, formed from a blank bent or folded into the shape described and shown, and provided with a lateral concavity $b^{\prime}$, in its front side, at the lower end thereof, adapted to receive the convex surface of the wrought metal shovel block $\mathrm{C}$, substantially as and for the purpose set forth.

No, 185,152 - IAS. E. WILKINSON, I ISBON, ILL.Ploughs.-December 5, 1876 . Filed Siptcmber 16, 1876.

Claim,-A slant plant for the shovels of corn ploughs or scrapers, consisting of an oblique elongated body portion D, having the advanced transversely slotted end bearings $e$, and extending from its middle portion upward the horizontally slotted cylindrical face bearing G, substantially as specified.

No. is8,001.-J. R. COI.T, LYNDONviL.LE, N. Y.-Cul tivator Tieth.-Mardh 6, 1S77. Filed Octuber 17, 1S76.

Claim.-A cultivator tooth having its blade $\mathrm{A}$ made in the form of an equilateral triangle. broalest at it; point and tap. ering back to the shank, and constrncted with a convex entting edge, as shown and described, and for the purpose specified.

No. $189,550 .-R$. L. EILWOOD, SrCAMORE, IIL - It taching Cultivator Shozels.-Afril 17,1877 . Filed Jan uary 24,1877

Claim.-1.-The block $A$, having its hack extended around the standard, and fitting against the standard, where the pressure is applied, and provided with the end holes $b$ and suitable rivet holes, substantially as specified.

2.-The combination of the block A, constructed as de scribed, with the clamp $B$ and screw $D$, arranged to clamp the standard against the back of the block and support it under the set screw, substantially as set forth.

No. 191,451-EDWARTIP. LYNCH and EDGAR A. WRIGIH, DAVENPORT, IOWA.-Culizators.-May 29, 1877. Filed Not'cmber 8, 1876 .

Claim.-The curved block $B$, having the transverse slot $x$ extended around to one side to permit the bolt $\mathrm{C}$ to be shoved forward to bring its round portion in the slot and allow it to be turned therein or shoverl out forward, subitantially as shown and described.

No, I 92,390.-GUI1,FORD D. ROWELL, APPLETON, WIS, as ignor to APJLETON MANUFACTURINC; CO. same place.-Ciultivator Tceth.-June 26, 1877 . Filed May 21,1877 .

Claim,- The friction plate $c$ having a socket in its lower edge through the entire thickness of the plate, which sockct is largest at its upper end, to receive the enlarged head of the tooth $b$, wherely the tooth and plate can only be separ ated by a sidewise movement, substantially as herein.

No. 193.735. - BVRON TOWN FoND DU LAC, WIS.Devicis for Bracing Cu'tivator Teth-July 31, 1877 . Filed July 2, 1877

Claim.-1.-The combination, with the beam $A$ and pivoted cultivator tooth 13 , of the double brace $\mathrm{D}^{\mathrm{D}} \mathrm{D}^{\prime}$, bolt and nut $F f$, and washers $G(i$, arranged upon opposite sides of the beam $\mathrm{A}$ and outside of the braces, substantially as and for the purposes specified.

2. - The combination of the heam $\mathrm{A}$, having the encircling grooves $\mathrm{E} \mathrm{E}^{\prime}$, washers $\mathrm{G} \mathrm{G}_{\mathrm{i}}$, having lugs or pins $c c$, holt and nut $\mathrm{F} f$, double brace $\mathrm{D} \mathrm{D}^{\prime}$, and pivoted eultivator tooth 1 , the several parts constructed and relatively arranged substas tially as herein shown and described.

No. 194.310.-SANFORD PECK, WALDRON, I11.Sifety Clamps and Hooks for Cultivators.-A A tugust 21,1877 . Filed July 17,1877 .

Claim.-The combination of the hook D and the spring clamp $A$, having the aljunting screw $a$, and attached to the beam $\mathrm{B}$ and the standard, in the manner and for the purpose set forth.

No. 194,331.-JOHN H. OWENS, Houston, lli.Cullivator Teeth.-August 28, 1877 . Filcd August 8, 1879.

Claim.-The herein-described cultivator blade, consisting of the mold board $A$ and diamond shaped blade $B$, cast in one piece, curved gradually the whole width from the point of blade to the extreme top of mold board, and also curved gradually transversely across the mold board, thereby facilitating the throwing of the soil to one side, equalizing the draft of cutting surface, and strengthening the blade as specified.

No. 197,638,-MOSES IOIINSON, THREE RIVFRS, MICH., assignor to the UNION MANUFACTURING COM1'ANY, same place.-Cullizator Ticth:-Novembir $\mathbf{2 7}$, 1877. Filed Octeber 26,1877 .

Claim.- The cultivator tooth herein described, composed of the wing or mold board $A$ and land-side B, having the flange or sole $a$, made of a single piece of metal, in combination with the point $C$, provided with the beveled shoulder $c$ and rounded seat $b$, as and for the purpose set fortb.

No, 198,372-C. O. GARDNER, SPRINGFIEI.D, OHIO, ascignor to I. P. M A.ST and CC. same place,-Cleltizator and Seeling Machin's,-Dicember 18, 1877. Filed Siptemeber $6, \quad$ I 877

Claim, - I. - The friction block A, provided with the side flanges and the stud $b$, in comlination with the bolt $G$ and the stanclard, perforated to fit upon the stud and bolt, as shown.

2 - The pivot block $\mathrm{A}$, having the side flanges, in combination with the standard suntained therein, in the mamner shown, without the an-istance of the flanges.

3.-The shovel-block B, cast in one piece with the shoulderi $s$, and the hey scat D, sulstantially as shown.

4.-In combination with the notched tandard $F$, the reverible shovel l, lock 13 , having the shoulders $g$ and the key $a$ inserted, as shown.

5.- In combination with a notehed : tandard, $F$, a hollow reversible shovel block adyted to fit upon the end of the standard, and a transverse tapering kev, $a$, passed through the block and seated in the notcly of the standard, substantially as shown.

6.-In combination with a notelied standard, a hollow shovel block adapted to fit thereon, and provided with a shoulder to alut against the end thereof, and a tipering transverse key bearing in the lilock and stindard, and scrving to hold the block firmly against the front and end of the standard, substantially as shown.

No. 199634--Sll.VANUS 11. FORD, BEAVRR 1)AM,

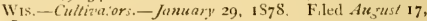
1877

Claim -1.-The combination with the beam or drag lna $A$ and tandard $E$, of the rocking clamm plates $C$ and C', sulvtantially as and for the purpose specificd.

2.-The combination, with the rocking clamp plates $C$ and $C^{\prime}$, of the lever $(i$ aud notched bracket $F$, substantially as and for the purpone pacitied.

No. 201,301-WII.1.ARI) A. VAN BRUNT and SPENCER F. INATIS, IIORICON, WIs.-Cutivitor Teeth.—Warch 12, 1878. Filed April 4, 1877 .

Claim.-A cultivator tooth diamond-shaped in ontline, the surface of its lower or penetrating postion male laterally conves or rounded, and formed with sharp elenving edges, and it: upper or scouring surface made transversely flat, subtantially as and for the purpose described.

Nis, 20 3.417.-IILGil] CARSON, PITTSIURG, PA., assignor to AI.EXA.VIHR SPELR S Si()N. same place. - Cuílionter Tiath.-Mar 7, 1878 . Filed April 8, 1878

Claim.-1.-A cultivator tonth whose shank is provided with a key or cross bar havin threaded transverse ends, which project through it sides and ars adlapted to engage with a nut or similar fastenin duice, substantially as set forth.

2. - The combination, with a cultivator frame, of a cultivator-tooth, the two secured together by the engagement of a nut or similar fastening device with a key or bar, which latter has threaded tranverse ends projecting through the sides of the tooth's hank, sulu tantially as set foith. 


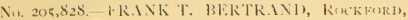
[1.1.-C'ullivalors.-July 9, 1878. lïlert Way 20, i\$7S.

Claim.-1.-The combination, with a bed-uble having a raived batring on one end for the adjustable attachment of th: aim of the standard-holder, and a projecting annular flange, on its opposite encl of a standard holder with an an nular flange waich fit, within the amnular flange on the bed plate while the forward end of the holder is connected with the bocl-plate by in break-pin, substantially as set forth.

2. - The combination, with a berl-plate having a raised hearing on one end for the reception of a break pin, of a stantaid holder provided with a series of holes in it forward enl, wherelsy the standard may be adjuntably secured to the lee?-plat - by means of a break-pin, sub-tantially as sct forth. 3.-The combination, with a hel-plate provided with a raised learing for the reception of a break-pin, and an annular flange on itsoppositz end, of a standard holkter provided with a serie, of holes in its forward end and an annul ir than ie on its rear end, sub tantially as set forth.

X.. $2,9,576$. - WILLIAM H. DI KEV, JACKsox,

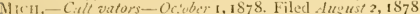
("aim - The reversible block 1 , having the longitudinal r.cess, 1), and attached to the standarel at two or more points in the sam wertical line, and the double point sl blade $C$, se cureal to the bloc: by two or more bolt, in the same virtical line, in comlimation with the standard $A$, having the recess $a$ to recite the block 1;, and stpporting the upper point of the hule, arran red and operating as speciticil.

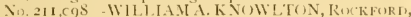

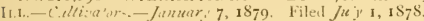
Cham, - I - Mre combination, with a hracket-plat proset. o. w wh thanges to embrace the drag-thar and a depending flan ze laving an arcshaped sot formed therein for adjusting the stantani, of a sucl grooved to reccive the shovel tam art, :nel provikel with a depencling arm, which latter iprevided with an open slot and an adjusting holt that ex

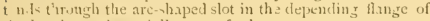
the loracket, suli-t nitially as sct forth.

2.-The combination, with the curved shovel-hack, of in clamping-lbloc': em tructed to fit again the curvel back and contracs one edue of the stanclard of a secont clamping.

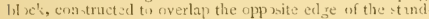
arel, ant an adju ting an I fastening bolt, substantially an sct ret forth.

ir. 214.373.-WILLIAM H. DICKEY, JUCK-r,

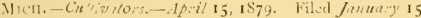
1 79 .

Claim. - Is a device for securing a cultivator llade or

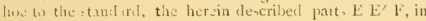
ce smbinati m with the holt $c^{1}$ and nut $e^{2}$

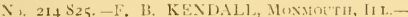

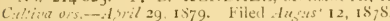

(laim.-The combintion, with the shovel $A$, of the fenter $C$, having the upwardly-projecting side $c$, wit's the rommleal front etlre $c$, and the buttom face $c^{\prime \prime}$, hent it rixht angles (o) the side $c$, embracing the lower face of th: showel and proviled with the open slots $e$ and the l:olt $d$, proviled with $n$ in, the whole constructed and arranged to opreat: in tir: munner and for the puriove set foith.

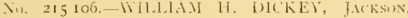

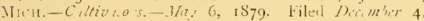
I $\mathrm{S}_{7} \mathrm{~S}$

Finim.-The stmelarl $A$, with its lower section, $a$, in clise I firwarel and poviterl with a cireular face, in combi-

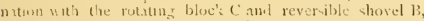
Wrerely the hovel may fre rotated upon the standard and it. upper point remain in close proximity to the upper s.etion of the thmlari, ulmantially as shown and describst.

Ni. 2:0 157.-JAC IE W. LAFFERTY and GEARG

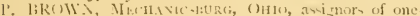
hilf of their ristt to Jolis C. B.tKER, ame place.-

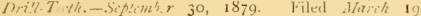
1879 .

Claim,-1,-In combisation with a sundarl having a tho:el han's pisoted thercto, a spring cla-1) scparate and

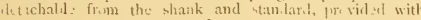
tuil or priections adapled to engare with the thank and sandard and lock them together, substantially as descrilsed.

2. - In combination with the standard $A$ and pivoted shank b, the spring bow $C$, atlapted to stratille the shank, and provided with projections which pass through the shank and engage with the standard, subtantially as described and shown.

3.-In combination with the standard and the pivoted shovet shank, the spring clasp provided with acljustable studs or pin pasing laterally through the shank into the stanilard.

4.-The combination of a standart, a shank or shove block pisoted thereto, and a locking pin urged through the hank into the standard by spring presure.

No. 223,752,-DAlEL C. (III'IEN, LA l'R.1IK1E, II.T. Coupline Jinn' for c'ullizator Tirh.-Jantery 20, 1883 Filed Oct. bir 17, i 579 .

Claim.-The improved coupling for loughs, comsisting of the cup-shaped cavity $C$ and the hollaw projection $\mathrm{E}$, in combination with the hemicpherical washer $F$ and bolt 6 , all constructed and arranged substantially as herein shown and described.

No, 225.531.-EIDWIN R, MCC N1,1, LOCKPORT, N. Y

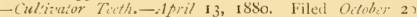
is 79

Chaim- A cultivator-tooth havmg the coulter A, by means of which the tooth in secured to the plough-ntandard, and obligutely projecting cutter-blade It, with cursed prongs $a$ a, subatantially as shown, and for the purpose described.

Nis. 232,850,-IOHN S. ROWEI, BEAVER D.IM,

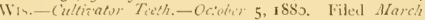
15, 188 .

Claim.-1.- The slotted beam A, the piroted slipping plate $B$, slotted to receive the bindiag-bolt 6 , and provited with the clamping bolt $\mathrm{C}$, and shoulders out vicle of the beam, combined with the adjustable or reversible tooth \&, rigilly but removably secured there, substantially an de-cribet.

2. - The slipping plate B, adapted to be pivoted at its front end by bolt $p$, provided with slut $\ell$, curved about the axis of bolt $t$, whereby the claming bolt b may pass through said plate, comlined with a hooking shoulder, l', and hook. beaded clamp-bolt $C$, whereby the slank $S$ may he firmly held, but may be arlju-ted longitudinally as to said shank.

3.-. I lipping-plate, $\mathrm{B}$, adapte.l to be located in a cleft in the betm $\Lambda$, provided with a hooking shoukler, $l$, offict

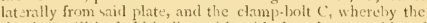
shank $S$ will he held in line with said plate, but capalile of adjutment up and down thercon, as shown in lig. 4 .

4.-The slipping plate B, constructed with laterally projecting flanges along it rear edlse, whereby the unued tooth $\mathrm{i}$, guarded while the machine is in operation.

5.-The slippin tote li, pivoted and clamped within a cleft in the heam A hy seinar it: bult, combined with a bolding houlder, $P$, and clamp bolt $C$ for the bank $\$$, out aile of the brim, an set forth.

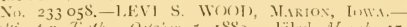

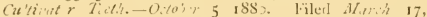
1880.

Claim.-1 cultivator tonth conntructed subatantially as shown and describal, con-inting of the contral -tundarel, 1 , having starpened forwaril edge, and the circular cutter l;, having its wing slightly thited nnI formed unon the end of the stamlari 1 , is set forth.

No. 236377 - C.ARK II STEVENS, BERLIX, Wh.

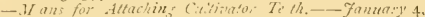

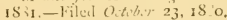

Claim,- In a sip-tooth for cultivatiors, the combinatom, with the beam $A$, brac'set arm C, and brace $E$, of the pivot bolt 1 , ratchet whed $H$, and prwl $K$, s at $s 1$ in the reces.; of the bracket arm, and hela in place by the suring l, contricterl ant operating sub tutially as and for the jurpose at forth.

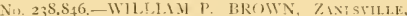

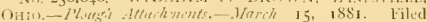
$\sin \mathrm{im}^{3}, \ldots 3, \mathrm{i} \leq \mathrm{S}$

( laim- - Ina plough att chnocnt, the plate \$, heving uypes win , F, and Iower win, $\mathrm{F}$, provided with cured his 
(i, and located upon opposite ste of a sucket, $C$, having set-screw $d$, in combination with the pointed shovel $A$, bolt $a$, nut $\div b$, and the rounded plough standard 1), con-tructed and operating substantially as and for the purposes set forth. No. 239.947.-DAVII O. EVEREST, KALAMAzor, Micu.-Cultivators.-April 12, 1881. Filed Octobir 25, 1879 .

Claim.-1.-In combination with a supporting frame $\mathrm{F}$, a spring having it two free ends adapterl to admit of an att.achment thereto of a ploughing or cultivating tooth or blade sulotantially as and for the purpose shown.

2. - In combination with the frame of a harrow, plongh, orcultivator, a spring attached between the free enls to said frame, the free ends of said spring alapted for the attachment thereto of a plough-blade or cultivating touth, substantially as and for the purpore shown.

3.- The curved spring $\mathrm{E}$, attached at a point batween its ends to a suitable frame in combination with the link 1), or its equivalent, and a plough blade or cultivator touth, sub. stantially as and for the purpose shown.

No, $2+0,159$ - -JOIIN J. McCLEX, ROsETI.T.E, II. . as ignor of one-balf to ALEXANIEK KREK; and JUIIN

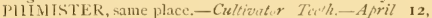
ISS I. Filed Dicimbir I $_{3}$, ISSO.

Claim.-1.-1 cultivator tooth in which a bull tongue or plate, 1 , forms one side thereof, and from which a wing, C, having an arm, $\mathrm{C}^{\prime}$, extends laterally and rearwardly, sub. stantially as ancl for the purpose specified.

2. - In combination with the buli tongue or plate $A$, the wing C, having an arm, C', and adjutably sccured to the plate $A$ by the welge-shaped block $G$ and bolts $d$ and $i$ substantially as and for the purpose specified.

No. 242,256. -ROBERT A. BURNETT, WASHINGToN (n)RT-Hoxs1, OHt), asignor of two-thirds to AHCSS FHHRNTON and TOSEPH 1). OGLE, same

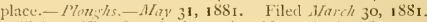

Claim.-The draught beam $\mathrm{A}$, with projection for stop $\operatorname{lng}$ and pivot, and stay $\mathrm{G}$, in combination with shovel bam $\mathrm{B}$, armi (; lever $\mathrm{l})$, and spring $\mathrm{F}$, substantially as and for the purpse set forth.

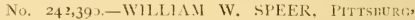
P.1.-Cull,vior Tith.,-May 31, 1881. Filed April 7, 1831 .

Claim.-The combination, with a cultivator tooth, having a tubular shank and an angular-shaped bearing and a fastening bolt extencling through said tubular or hollow shank, of two serratud clisks located on the tubular shank between the upper end of the cultivator tuoth and frame, one of sail disks proviled with a lug which extends into the frame, and the other with an angular-haped openins which lit, the angular bearing on the lower portion of the tubular shank, substantilly as set forth. 
Adams, II. I

Aelams, I.

Aclams, J. A.

Aelelisun, W. T

Allich, WI

Alesander, I. T. I).

Alley, J. A

Alliton, A. 11 .

Allison, .1. 11

Allison. 1. 11.

Alvoril, $C$.

Alvoril, C.

Ament, W. I).

Ament, W. 1).

Anderson, .1. J'. and Edwarch, B.

Anderson. $\mathrm{A}$.

Anthoine, L.

Anyan, B.

Anyan, li.

Archer, 1)., Jr.

Argerbright, 1).

Armstrong, I., Ir.

Armstrong, J., Jr.

Armstrong, J., Jr.

Arnold, (). J.

Arvin, J. N.

Auttin, I.

Avery, $\mathrm{f}$

Bachman, J. 1.

bailey, s.

Lailey, J. H.

Baker, I. II

Baker, II. T.

Baker, A. S. and Landon, W. H.

Baltimore, J. T.

Bankson, IV

Bannigan, J. C.

Banni gan, J. C.

Barber, 1.

Barber, 1. Jr.

Barber, 1 .

Barcafar, $(i$.

Barlel, J. A.

Barker, . I.

Earley, J. H.

Barley, I. H.

Darnes, IV. $G$ :

Barnes, IV (:

Barnett, M, and Wood, E.

Barney, F.

Bar, O, and Cox, F, F

Barsalow, H.

Barton, L. B

Ibarton, L. B.

Bashaw, J. N.

Batcheller, A, F.

Eatten, J. '?

Bates, IV. E.

Baumann, J. N.

Baum, C. C.

Bean, H. and Tyson, J. D. 693200

Bean, E. C. and Welden,

$$
\text { F. N. }
$$

Behel, J.

Behel, J.

Belmont, $\mathrm{H}$.

Bell, S. ancl Bronson, (;.

$$
\text { IV. }
$$

Bennett, A,

Benson, J., S. anct W

Bentley, $\mathrm{C}$ : A

Bergen, I.

Bergen, I.
Pint. Claim

$750 \quad 21 \mathrm{~S}$

$751 \quad 218$

Sig 233

$85+7 \quad 2.4$

$837 \quad 235$

$5179 \quad 173$

$703 \quad 203$

$674 \quad 194$

li) $605 \quad 19$

$692 \quad 207$

$\begin{array}{lll}712 & 206\end{array}$

719208

$\begin{array}{ll}7+9 & 217\end{array}$

6,32 IS2

$643 \quad 155$

662191

$667 \quad 192$

$814 \quad 240$

$705 \quad 204$

$729 \quad 211$

$840 \quad 239$

$852 \quad 2+3$

$729 \quad 211$

$049 \quad 187$

(R) $6 \% 0 \quad \mathrm{IS7}$

$676 \quad \mathbf{1} 95$

$677 \quad 196$

66319 i

$625 \quad 150$

$66 j \quad 191$

(8) 253

¿55 244

$874 \quad 250$

$\begin{array}{ll}737 & 213\end{array}$

$7+2 \quad 215$

$798 \quad 239$

696201

$636 \quad 183$

$826 \quad 235$

$830 \quad 236$

605201

$63 \mathrm{I} 1 \mathrm{Si}$

$\mathrm{S}_{42} \quad 24 \mathrm{O}$

S2I 23

$645 \quad 1 \$ 6$

$795 \quad 228$

665191

6yo 199

$848 \quad 242$

839239

694201

$628 \quad 150$

660190

$673 \quad 194$

$\begin{array}{lll}639 & 1 S_{4}\end{array}$

$647 \quad 186$

$809 \quad 23 \mathrm{I}$

$812 \quad 232$

$793 \quad 2=8$

$640 \quad 184$

$607 \quad 175$

$7+2 \quad 215$

$784 \quad 225$

$807 \quad 231$

$758 \quad 2 \mathrm{I} 9$

$730 \quad 211$

699202

$637 \quad \mathrm{I} 198$

$828 \quad 236$

$66+191$

$68 \mathrm{c} \quad 106$
Bertrand, T. F. and Sames,

Plate Clutul

I'. 650 1 190

Bertrand, 'T.F. and Sames, l', $672 \quad 193$

$\begin{array}{lllll}* & \text { " } & \text { (R.) } 672 \quad \mathrm{I} 93\end{array}$

Jiencler, $\mathrm{F} . \mathrm{P}$.

(R.) $672 \quad 194$

Billings, 1). s.

Bircl, J. C.

liird, $C$.

Birdsall, F, M.

Hinck, .1. M.

Black, A. II.

Blauser, N. G.

S28 235

$\begin{array}{lll}5 \mathrm{~S} 2 & 160\end{array}$

$\begin{array}{ll}682 & 197\end{array}$

$\begin{array}{lll}747 & 217\end{array}$

661100

$609 \quad 175$

662190

$752 \quad 218$

$\begin{array}{ll}791 & 227\end{array}$

Blodgett, W. W. and Smits, I. $\mathrm{H}$.

$\begin{array}{ll}867 & 248\end{array}$

Bloedel, 11.

Blod, A. R. Hathaway, A. and Beach, V. R.

Pilood, A. R. Hathaway, A,

Tinhan, J.

Booker, J. W

loughton, E

liowers, H.

Boyd, J. C.

Boys, II.

Bradley, C. D.

Tiratley, li. C.

Bradley, G.

Bradley, $\mathrm{f}$.

Bradley, 6 ;

Braboan, I'.

Brate, B, F.

Bressler, G, IV.

lirewer, I.

Brewer, J.

644 IS A. D.

Briggs, H. C.

lirinser, A.C.

Brinton, J. H.

Bristol, H. C.

Brittain, P. F.

Bronson, G. WW

IBruoks, J. E.

Brotton, R.

Browers, G. S., G. IV. and

$$
\text { E. A. }
$$

Browne, R. T.

Brown, G. W

Brow?, F. E

Brown, G. D.

brown, J. M.

Brown, IV. P.

Brown, W. P.

Hrown, W. P.

Bruner, M.. Jr.

Bryan, J.

Buchanan, S. A.

Buckley, R. C.

Bucknall, M. 11.

Fuckner, C. J

Buffington, M. C

Buffington, M, C.

Burdge, H. R.

Jirnham, J. and Lathrop,

$$
\text { IV. C. }
$$

Burnham, I

Buttler, N.

Butner. II.

Byerly, H. F.

Byer;, J. E.

Calkins, Geo.

Canaday, H, H.

Canficld, I.

Plute Cluim

$62818 \mathrm{i}$

Cantlck, J. and Her. C. $656 \quad 189$

Canficld, $A$ Sol 240

\begin{tabular}{l}
$829 \quad 236$ \\
\hline
\end{tabular}

Canfield, A. $\quad 854 \quad 244$

Capp, T. F. $\quad 764221$

Carey, A. $591 \quad 171$

Cargo, H. $\quad 797 \quad 229$

Carlow, J. II. $\quad 759220$

Cartion, A. F. $\quad 772 \quad 223$

Carlson, A. F., Shipps, C. and Camron, WV.

$\begin{array}{lll}731 & 212\end{array}$

Carr, II. $\quad 746-216$

Carr, 11. $\quad 746 \quad 217$

Carr. H. $\quad 746 \quad 217$

Carter, C. L. $\quad 810 \quad 23 \mathrm{I}$

Carter, C. . L. $\quad 826 \quad 235$

Carter, C. 1). $\quad 867 \quad 248$

Case, J. $621 \quad 179$

Case, I. $658 \quad 190$

Case, I. 761220

Cass, A. B. $607 \quad 175$

Cass, A. B. $\quad 63 \mathbf{I} \quad \mathbf{1} 82$

Cantor, J. H. 627 180

Cinywood, M. \& I. $\quad 725 \quad 210$

Chamberlain, H. W. $\quad 884254$

Chapman, J. $\quad 646$ I86

Chappell, 1. H. and Montgomery, J.

Charpell, 1. H.

Children, E. $\quad 667 \quad 192$

Children, E. $\quad 676 \quad 195$

Children, E. So5 230

Chubb, A. L. 745216

Churchill, D. and Brewer,

$$
\text { S. C. }
$$

Churchill, D.

(lapp, H. WV.

Clark, M. .1].

Clark, WV. F.

Clements, W.

Clover, C. C.

Cochran, B. C., T. W, and 
Cowing, $\mathrm{H}$.

Cox, I. and Throp, I. A. $628 \quad 181$ Cox, I. and Throp, J. A. 6or 17t Cox, S. H. and Pence, IV. H.

Cox, B. C.

Cropp, E. MT.

Crowther, J.

Cuningham, J.

Cummings, IV. II. and Childs, H. L.

Cummings, IV. II.

Curry, I. L.

Daggett, D. P.

DahIbom, S.

Dale, W. P.

Dale, W. P.

Dale, W. P.

Damron, W. II., Massey, k. H. and Whitman, I. $\mathrm{F}$.

Daniel, C

Daniels, T. T.

Davey. J. H.

Davies, E.. Jr.

Davis, I.

Davis, D. AI.

Davis, I. R

Ihavis, L. I.

Davis, I.., Ir.

Day, S.

Day, II:

Degen, F. II

D'Hast, E. F.

Denham, I.

Dennis, E. W.

Denton, C.

Dever, E. M. and Pratt,

$$
\text { I. C. }
$$

Dickerson, L. II.

Dierdorff, J.

Dodge, R. D

look, J.

Donely, $T$. and Cressler,

$$
\text { I. B. }
$$

Doolittle, $G$. W.

Doclittle, E

Dorsey, II. D.

Dorsey, II. D.

Dourl, I. W.

Dryden, W. A.

698202

$\mathrm{S}_{12} 232$

$850 \quad 242$

$704 \quad 204$

$588 \quad 170$

$732 \quad 212$

$779 \quad 224$

$837 \quad 239$

$587 \quad 170$

$\begin{array}{ll}8_{31} & 237\end{array}$

$756 \quad 226$

$799 \quad 229$

808231

$695 \quad 202$

664191

851243

$70 \mathrm{~S} 205$

$689 \quad 199$

$627 \quad 1$ So

$62 \mathrm{~S} \quad 181$

$620 \quad 178$

$797 \quad 219$

$\begin{array}{ll}857 \quad 244 & 4\end{array}$

$\begin{array}{ll}716 & 207\end{array}$

725210

$\mathrm{SjO} 242$

600190

$647 \quad 18 i$

705204

$657 \quad 189$

$626 \quad$ I So

$\mathrm{S}_{36} \quad 2, \mathrm{~S}$

$79+22 \mathrm{~S}$

863246

$607 \quad 175$

$630 \quad 131$

$701 \quad 203$

$667 \quad 192$

698202

$593 \quad 171$

$615 \quad 177$

$790 \quad 227$

$599 \quad 173$

Dryden, IV. A and C. E. $685 \quad 197$

Dulaney, N.

Dundas, I.

$$
\text { (R.) }
$$

(k.) 685 I 98

$881 \quad 253$

588170

5 s9 170

026185

Durant, A. T.

I)wight, S. H. and Chambers, W. I?

Easterday, E. S.

Eberly, D. B.

Eluerly, D. B.

Edw:ards, IV. II.

Edwards, D.

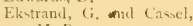
II. $P$.

Elder, J. M.

Ellett, T. E.

Ellic, I. L.

Ellwoorl, $k$ and P'itcher, R. I.

Ellwool, K. and Pitcher, $\begin{array}{lll}\text { R. L. } & 789 & 227\end{array}$

Ellwool, R. and Pitcher,

$$
\text { R. L. } 820 \quad 233
$$

(R.) $520 \quad 233$
Emoms Wh ata Clam 1). A

Eshleman. I

Esterly, Geo.

Etter, S. P.

Ewick, C. A.

Eylar, I. F.

Farnsworth, F. 749217

Fath, L. G.

Fawkes, J. II:

Ferguson, I.

Fermald, J.

Ficld, B. F.

Fisher, st.

Fisher, $S$.

Fisher, IV. D

Fitch, O. F

Flenniken, T. MI, and II III,

Forbes, J.

Fountain, I. I.

Frank, J.

Frank, J. H.

Franklim, D. D.

Fraser, N. II and Mcl.el. lan, A. J.

French, J. C.

French, J. C.

Fuller, D.

Furnas, IV

Furmas, B. and $C$.

Furnas, W.

Furst $C$

Ginse, II. I).

Garcliner, C. (). and Dow ney, W. C

(iardiner, (. ().

(iarter, R.

Giaskill, R. R.

Gaylord, (), I.

George, I. K.

Gejpert, $)$.

Cierber, I. and Brown, H. 763 221

Givaley, S.

Gibson, H. H.

(infford, G. T

(iilbert, 1. B.

Gilchrist, H. H.

Gillespie, $\mathrm{C}, \mathrm{IV}, \mathrm{C}$.

(iillies, E. S

(iill, I. G. B.

Gilman, IV.

Gilmore, J. Si.

Given. 1. H.. Hutrompiller, H. and (ilbert, $\mathrm{C}$.

Goff, S. Ml.

Goldsmith, S

Goodrich, A. I.

forham, M. I.

Gorham, N. L.

Gorham, M. L.

(iorham, E. I).

Gracey, J. B.

Graham, I. 1.

Graham, II. I.

Graham, N. C;

Grant, B. $\mathrm{A}$.

Grattion, C.

Green, 1. A.

Green, $\mathrm{M}$

Green, O C.

Griftith, IV. II.

Griswold, A. M.

friswold, A. II.
Gross, J.

Plate Claim

Gross, J. and Tunivon, J. C. $695 \quad 201$

Girubh, d.J. 743215

Gulick, S. $\quad 635 \quad$ I83

Gum, I. and St. C. $599 \quad 173$

Gum, J. and st. C. $\quad 603 \quad 174$

Gustin, J. M. $\quad 790 \quad 227$

Guthrie, T. I)., Jr., $\quad \$_{39} 239$

Guy, B. F. and J. V. 714207

IIaege, J. $\quad 624 \quad \mathbf{I 8 0}$

Hague, C. A. . $\quad 883 \quad 254$

Halburt, II. G. $\quad 783 \quad 225$

Hall, D. E. $\quad 586 \quad 170$

Hall, C. M. and D. E. $592 \quad 171$

" (R.) $592 \quad 171$

Hall, J. A. 669192

Hall, T. J. 73 S 214

Hamilton, A. $825 \quad 235$

llammans, i. $\quad 863246$

Hammond, IV. 661 190

Hammon, T. W. $\quad 637 \quad 183$

Hammon, A. P., Iincoln, I. H. and I., and Hammon, T. IV. $671 \quad 193$

Hand, J. R. $\quad 728 \quad 211$

Haney, R. and Estes, J. S. 736213

Hanover, M. E. and Bailey, D. D.

Hardgrave, $\mathrm{C}$.

$707 \quad 204$
861

$\begin{array}{lll}608 & 202\end{array}$

Hardgrave, C. $\quad 860245$

Harding, T. $\quad 760 \quad 220$

llarmon, A. A. $\quad 717208$

llarper, J. $\quad 638 \quad 183$

Harper, J. $\quad 638 \quad 184$

Harper, I. M. $758 \quad 220$

Harrs, $\mathrm{E}$. H. and Clegborn, J.

Harris, V. I'. $\quad 754 \quad 210$

Harris, N. J. $706 \quad 221$

Harris, I. S. \$58 2.45

Ilarvey, W. 7OS 205

H.rrman, N. S. $604 \quad 174$

I Iaskins, M. and Hat, 1 . I.

IIatch, E. I).

$\begin{array}{ll}684 & \mathbf{3 9 7}\end{array}$

$637 \quad 18$

Ilawoith, II. II. $\quad 603 \quad 174$

IIayes, $(i$.$) . 726.210$

Henton, HI. I. $611 \quad 176$

" " * (R.) 611176

II iton, C. IV.S. $\quad 612 \quad 176$

Ilenton, C. IV, S. $\quad 614 \quad 177$

Ilefit, C. $\quad 7012{ }_{3}$

Heflin, A. I. 6SI 197

Heflin, A. T. 7 I3 206

Hench, S. N. $838 \quad 239$

Henry, $\rightarrow$. $636 \quad 183$

Henry, R. II. 722209

Ilenton, I. $\quad 655 \quad 188$

Henton, I. $734 \quad 212$

Herman, J. H. $668 \quad 192$

Herndon, J. T. 701203

Hewitt, P. 708222

Higgins, K. S. 804230

Higgins, J. $\quad 8_{43} 240$

Hildreth, I'. $\quad 657 \quad \mathbf{1 8 9}$

Hill, J. H. $\quad 706204$

Hinckley, I. I. $\quad 783 \quad 225$

Hindmarsh, 1. $\quad 673 \quad 194$

Hinds, I. and (iee, J. $\quad 721209$

Hinkle, s. I. $\quad 839239$

Hoagland, $\mathrm{C}$. $\quad 705204$

Hoake, S. $\quad 593 \quad 171$

Hodges, L. H. S28 236

Hoffheins, L. 659190

Iloisington, S. B. 752 Is 
Itollaclay, I, M.

Ifolling-worth, I.

Holman, $C$.

Holt, [1, F..

IIolly, . $\mathrm{i}$. I3, and Jones, I.

Joltz, B. and Eniseh, II:

Hewer, H.

Horning, A. G.

llowarel, K C

Itowe, 11.

Ilowe, II.

IJowe, II.

Howe, 11

Howell, II. II.

Hubloard, W. I'.

Hubbarl, II. P. and Rob-

imen, I. W:
If uclion, J. W:
Uuff, J.

Inuti, J.

Huftionan, ().

Hullinger, M. H.

Hullinger, M. II.

II un, II. C.

Hunt, A.

Hunt, . A.

Ilunt, 1 .

Ilutchinson, (i. L.

Hyer, B. S.

Ide, N.

Imel, ].

Ingle, I. W., and Wright,

Ives, $\mathrm{k}$.

Jay, I. B.

jenkins, P. R.

Jenne, C. II

Jemne, C. M.

Jenne, C. M.

Jewell, F.C

Johe, $\mathrm{T}$.

Johaneson, I.

Johmson, J. P.

Johnson, X. $\mathrm{s}$.

Jolunson, M

Johnson, II.

John on, I. H.

Johnston, J. S . and Johnson,

$$
\text { C. A. }
$$

Johnston, I). M.

Jones, 1. B.

Jones, $\mathrm{S}$.

Jones, T. I.

Jones, 1. if.

Jones, I.

Jones, W.

Jones, J. H.

Jorlan, W. H.

Jordan, H. P.

Jordan. H. P.

Kieck, A.

Keller, J. H. B.

Kerschner, D., Monger, T

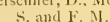

Kensler, J. F.

Kessler, I.

Kiddoo, iv,

King, W. 11. L.

King, (). J.

Kinyon, $\mathrm{A}$.

Kirkman, 1.

Sol 220

Kiscell, E. M. and M. L. $822 \quad 234$

$\begin{array}{lllll}\text { " " } & \text { (R.) } 822 & 234\end{array}$

Kissell, E. M. ant M. L. $835 \quad 238$

Knight, G.

Knight, F. H.
Kinou lten, W. A. and Rut ledge, 1 .

linox, J. II.

kiothn, J

Kring, (i. W:

liynet, II. Is.

Kinett, II, I?

Kynctt, II, P.

Lincey, I.

Lacey, 1.

Lacey, I.

Lacey, I.

L.amar, X. F.

1.apham, 5 .

Lampton, F. J.

I andphere, P. F.

Lane, IV, Ii and Colter, IV $\quad 677 \quad 195$

l.arge, 6 ;. $621 \quad 179$

L arrabee, J. T, W. $773 \quad 223$

Lawrence, I. L. and Thomas, $\mathrm{C}_{4} \mathrm{i} \quad 807 \quad 23 \mathrm{I}$

l.each, E. L. $\quad 806 \quad 231$

l.cher, 1. $596 \quad 172$

l.eeper, R. A. and Kidder, 2. 13

$601 \quad 173$

צ.eftler, $\mathrm{F}$. C.

l.eflier, $\mathrm{l}, \mathrm{C}$

Leidy, I. C.

leigh, 1 .

Lewis, J.

[indly, J. ].

lindiren. (

little, 1. R.

Long, $\mathrm{I}$.

Long, 1. M.

Looker, W.

Lowth, M. F and Ifowe,

$$
\text { I. J. }
$$

L.ow, I.

i,ucas, I. I.

L.ufkin, C. M

1.und, G. II

Luney,. .

I ux, J.

Lynch, E. I' and Raff, II $\mathrm{R}$.

Lynch, E. P.

McClintick, 1. D.

Iccorkell, $\mathrm{K}$.

McCorkell, R.

McCormick, W

IcC reight, A.

McI Dermott, A. S.

IIcl Dermolt, $A$. $S$.

McDill, T. W.

" " " " "

NeEwin, E.

IcGee, J., W. W. and W.

Acklew, I?

Acllvain, I.

Mckiay, N.

II. Naluh, D,

McNirtun, J. T.

NcQuiston, T.

(R.) $591 \quad 171$

Macy, I, and Watkins, J.

C. Mahon, I. B.

Mahon, I. B.
Mahen, I. F.

Mahon, I. B.

Mahon, I. I).

Maier, $\mathrm{I}$.

Mallon, J.

Mangas, $\mathrm{J}$.

Ianny, A. J.
Minny, A. M.

Inle Claim

$\begin{array}{lll}770 \quad 222 & 22\end{array}$

Manny, J. P. $\quad 785 \quad 226$

$\begin{array}{lll}\text { Markel, J. } & 602 & 174\end{array}$

Narkhom, [ , A, L. and EI-

Iricl, 1 . $\quad 589 \quad 170$

Narkhm, A.S. $\quad 616 \quad 177$

Markham, А. ธ. 653 is\$

Markham, A. S. 693201

Marks, (i. I. S. S71 249

Marsh, J. $690 \quad 199$

Marbl, IV. WV. and Mcln-

tyre, $11 . \quad 777224$

Martin, A. 685198

Martin, S. 781 225

Martin, T. J. $724 \quad 209$

Matchet, I. 1 , and Smith,

$$
\begin{array}{lll}
\text { P. IV. } & 792 \quad 227
\end{array}
$$

Mead, C. E. and Stevensin, $C$ : E.

Meeks, G.

Megquier, C. F

$616 \quad 177$

Meharry, A. 8 I9 233

Meikle, T. $\quad 857 \quad 244$

Mentenhall, C. $\quad 851 \quad 253$

Mettler, W'. $626 \quad 180$

Hettler, IV. $\quad \$ 40 \quad 239$

Miller, G, 1). 620 ISI

Viller, W. 11. $\quad 795 \quad 228$

Nills, I. $640 \quad 184$

Mills, J. $\quad 785 \quad 226$

Mills, I. R. $621 \quad 179$

Mills, S. (;. $\quad 652$ is7

Miner, T. H. and IIeavenridge, S. $\quad 655 \quad 189$

Mitchell, S. H. $\quad 636 \quad \mathrm{IS}_{3}$

Mitchell, $\rightarrow . \mathrm{H}, \quad 619178$

Nitchell, S. H. $\quad 750 \quad 21 \mathrm{~S}$

MitchelI, I. M. $\quad 858 \quad 244$

Moody, W. A, $\quad 687 \quad 198$

Noon, W. S. $\quad 847 \quad 242$

Moon, W. S. $\quad 865 \quad 247$

Moore, L. B. 665191

Noore, G. 687 198

Moore, G. $\quad 776 \quad 223$

Moore, G. $\quad \$ 59245$

Morgan, B. S. $\quad 5^{57} 170$

Mlorse, J. N. 692200

Mumford, J. and Wilson, $\begin{array}{lll}\text { J. W. } & 602 & 174\end{array}$

Munger, W. P. $\quad \mathrm{SO}_{4} 230$

Murrey, W. H. $\quad 775 \quad 223$

Munsetter, 1. S. $\quad 8_{3} \quad 253$

Mustard, J. E. $850 \quad 242$

Nyer, A. H. $766 \quad 221$

Nash, C. $\quad 851 \quad 243$

Needham, F. II. $\quad 832 \quad 237$

Neff, J. [r. $\quad 594 \quad 172$

Neisler, O. L. $\quad 772 \quad 223$

Nelon, E. 686198

Ncicletaner, C. - 878252

Nuble, 1). J. $\quad 656 \quad$ I89

" (R.) 656 Is

Noble, 1). I. 666192

Norlin: A. and C. A. $\$ 6332,6$

$\begin{array}{lll}\text { Norman, 1). } & 777 \quad 224\end{array}$

Norton, C. P. $\quad 674 \quad 194$

Odell, 1. T: $\quad 58 \mathrm{r} 169$

Oghorn, 11, and T:ylor, G. 586 170

Oghorn, II. $\quad 595 \quad$ I 72

olcler, il. H. $621 \quad 179$

Olson, (). $\quad 861245$

Orlando, J. SII 232

Qhorn, 1. D. 630 I8I

Ostrom, H. W. $750 \quad 218$

Packard, L. $\quad 590 \quad 171$

Packer, H. $\quad$ (R.) $590 \quad 17$ 


Padon, J. S.
Page, J. G.
Paine, C. J.
Palmer, I. A.
Palmer, I. A.
Palmer, I. A.
Palm, J. H.
Pangborn, C. S. and Beers,$$
\text { G. W. }
$$

Parker, H.

Parks, R. B. and J. R.

Parks, R. B. and J. R.

Parlin, IV. H.

Parmele, E. and Patterson, R. N.

Pattee, D.

Patterson, J.

Patterson, E. C.

Patterson, 1. M.

Paul, D. H.

layne, J. T.

Peaboday, S. G.

Peaboday, S. G.

Pearl, J. C.

Peirce, J. H.

Pelton, L. D. and Barrow,

$\begin{array}{lll}\text { J. } & 683 & 197\end{array}$

Pendley, W. $\quad 865 \quad 248$

Pendley, W. and Moss, A. S70 249

Pendley, W. and Moss, A. $877 \quad 252$

Perkins, H. H. 7 S7 $^{227}$

Perkins, H. 11 S2O 234

Perry, G. $658 \quad 189$

Phifer, F. $\quad 641 \quad 184$

Phifer, E. 681 196

Phifer, E. 707205

Philler, W. W. $670 \quad 193$

Pierce, W. $\quad 834 \quad 238$

Pierpont, J. $\quad 866 \quad 248$

Pigg, H. L. $\quad 776 \quad 223$

Pollard, J. I. $\quad 798 \quad 229$

Pomery, S, G. $\quad 867 \quad 248$

Pond, O. M. $\quad 763 \quad 221$

Pond, O. M. $\quad 786 \quad 226$

Poole, I. F. $\quad 832 \quad 237$

Potter, H. S. 664 I9I

Potts, T. J and Yont, P. C. . 638 I84

Powell, E. R. $\quad 757 \quad 219$

Powell, E. D. $\quad 874 \quad 250$

Preston, H. 709205

Price, J. $669 \quad 192$

Price, G. W. $\quad 67+\quad 194$

Prosser. T. T., I rarling,

M. C. and K. A. $632 \quad \mathbf{8 2}$

$\begin{array}{llll}\text { Prout, H. N. } & 814 & 232\end{array}$

Prugh, G. W. and Bearl, W. $H$.

Purdy, S.

Pusey, F. W.

Rabb, J. W.

Rand, N. A.

kankin. J. II.

Raper, IV. 1 .

Rate, E. F.

Rayl, S. G,

Raymond, 1). R.

Redlinger, $\mathrm{I}$.

Reed, J. J.

Reed, S. I.

Keed, T. M

Reese, E.

Reichard, J.

Reid, C. L.

Renny, B. WV.

$654 \quad$ I 88

$822 \quad 234$

$\mathrm{S}_{4} \mathrm{~S} \quad 242$

$795 \quad 228$

70S. 205

694201

745216

(R.) $745 \quad 216$

714207

$743 \quad 215$

$84+241$

$68_{4} \quad 197$

$671 \quad 193$

$709 \quad 205$

$755 \quad 219$

$766 \quad 221$

711206

$748 \quad 217$

$684 \quad 197$

Renny, B. W. and N. T. 8 I4 232

Renny, N. T.

Reynerson, J. H,
Reynerson, J. 11. Plate Clarim

Reynolds, I. D. and O. H. $796 \quad 228$

Rhasny, J. 11 .

872250

Rhinehart, W. C. and (ias. ton, $\mathrm{R}$.

(R.) 873250

R. 7 IS 208

Rhodes, W. and Porter, M. 639 is.

Rice, 1. H. 654 is8

Rich, C. and NeisIer, O. L. $70020_{3}$ Richardson, G. R. aud Be-

hel, J.

Richardson, J.

Rickerd, J. C

Ricldle, IV. N

Ricler, J. J.

Roblins, R. 13.

Robbins, R. B?.

Robbins, R. B.

Robbins, R. 13.

Robbins, R. 1:

Robbins, R. B.

Robluins, K. I3.

Roberts, $A$. A. and $\mathrm{Da}$

vis, B.

$788 \quad 226$

$834 \quad 238$

703203

$824 \quad 235$

$629 \quad \mathrm{I} S \mathrm{I}$

$725 \quad 210$

$743 \quad 215$

$762 \quad 220$

$\begin{array}{ll}790 & 227\end{array}$

(R.) $\begin{array}{ll}790 & 227 \\ 790 & 227\end{array}$

$\begin{array}{ll}83 & 237\end{array}$

Sto 245

$8 \mathrm{~S}_{2} \quad 253$

Roberts, C.

Roluerts, C.

Koberts, C.

Roberts, $\mathrm{C}$.

Roberts, $\mathrm{C}$.

Roberts, C.

Roberts, C. S.

Rolbertson, H. II. and Carr,

C. G. $\quad 597 \quad 172$

Robertson, II. J. and Knight. P.

Robertson, W. J.

Robinson, I.

Robinson, I.

Robinson, J. II.

Robinson, W. R.

Rockafellow, Si.

Roger, 1). B.

Rohrer, A. P., C. F. and bluse, J. II.

Romann, A. and Peterka, J.,

Root, I. I'.

Root, I.

Root, B. il.

Ruse, I. I.

Rose, II. II

Kowland, J. E.

Rue, J.

Kufiner, $\mathrm{s}$.

$586 \quad 170$

$609 \quad 175$

$610 \quad 176$

$610 \quad 176$

$633 \quad 1 S_{2}$

$633 \quad 182$

942 I 85

$670 \quad 193$

835238

$826 \quad 235$

585160

731212

$738 \quad 214$

$\begin{array}{ll}779 & 224\end{array}$

$617 \quad 178$

$582 \quad 169$

Russell, I', \&. $\quad 856 \quad 244$

Rutlelge, $\Lambda$.

Sabin, S. $\Lambda$.

St. John, (i. Is.

Sit. John, (i, li.

St. Juhn, (i. B.

St. John, W. W.

St. John, W. W:

Sandelin, N. F.

sandelin, N. F.

sanders, $A$.

Sandiford, K.

Sattley, M.

Sirvage, W. Ci.

Savill, J

$\begin{array}{ll}771 & 223\end{array}$

685198

$582 \quad 169$

753218

866248

$736 \quad 213$

$760 \quad 220$

68 I 197

$775 \quad 223$

833234

$\begin{array}{ll}956 & 244 \\ 816 & 233\end{array}$

$739 \quad 214$

$644 \quad 185$

$71920 S$

$748 \quad 217$

$648 \quad 186$

$671 \quad 193$

$\begin{array}{ll}773 & 223\end{array}$

$\begin{array}{ll}773 & 223\end{array}$

$857 \quad 244$

718208

761220

$641 \quad 184$

$654 \quad 158$

Sawyer, A. and Barnes H. $605 \quad 175$

Sawyers, 1. H.

Sawyer, E. II.

Schanck, C. II.

Scheblein, J. and Heitzman, $J$.

schenck, $G, 11$.

Schofield, S. C

Sichruler, $\mathrm{A}$.

Schroeder, J.

Plul' claim

$\begin{array}{lll}740 & 214\end{array}$

$813 \quad 232$

691200

(R.) 691200

Seabrook, C. J. and IIine $\mathrm{H}$.

Sebring, T. C.

Seely, IV.

Seger, E. S. and Ormis. ton, J.C.

Seibert, $G$, and $J$.

Sexton, I. 13.

Sexton, J. B.

Sexton, J. 13.

Shaw, I. $\quad 585 \quad 169$

Shaw, $A$

Sheriill, J.

sherrill, I.

Sherwood, I.

sherwood, T. N.

Sherwood, $\mathrm{A}$. T.

Sihort, $\mathrm{T}$.

Shupe, E.

Simons, A. I).

Simpson, M. P. and Ellacott, J. P

Sintz, $C$.

Sisson, W. A

Sisson, J. F.

Skagas, N. J. and True, L. W.

Skelly, I. II.

Skiff, M. 11.

skinner, J. J)

Skimner, S. T.

Skinner, J. B.

Skinner, J. B.

Skinner, J. 13,

Sloan, S.

Slocumb, S. W. and Phillips, E.

Simalley, I.

Smith, (ieo.

simith, I. K.

Smith, N. F.

Simith, 11. 1)

Sinuth, J. D.

Simith, 11. 1;

Simith, 1' W.

Smith, J, A.

Smith, I. E.

Smithion, F. I.

Sinook, IV.

Spain, 1.

spangler, J. W

spangler, J. W.

Sparks, A. I.

Spies, A. 15 .

sprague, $G$

Sprague, I'.

Springatead, R, II.

Stafford, 1). S. 


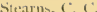

Sitevens, 1... ().

Stewart, W. 1.

Stimmell, 1.

Stuckton, $i ;$ IV:

Stoll, .1 .

Sitone, ().

Storm, $($ :

Sitout. 1. and 4

Sitover, A. I.

Stover, I), C.

Stover, 1). C.

Stover, D. C

stowe. I. G.

Stowe, J. (;.

Strickland, I.

Strong, Wi. H.

stroud, I, C

Studer, P.

Stukey, J. S.

Siturgis, II. 13.

Sweet, M.

Swickard, J. W:

Swickard, I. IV.

Tubor, B, I.

Taliaferro, C. IV

Taliaferro, C. W

Tanner, D. C

Teller, D. C.

Thede, C.

Thomas, J. H. and Mast,

$$
\text { P. P. }
$$

homas, J. H., Jast, P. P. and Harding, $\mathrm{T}$.

Thomas, J. H. and Mast, P. P.

Thomson, P. IV.

Thompson, IV. L.

Thompson, A.

Thompson, L. P.

Thornton, S. C.

Thornton, S. C.

Throp, J. A. and Cox, J. $613 \quad 177$

Tilden, II.

Tinkham, 13 .

$$
\text { "4 } 4
$$

ipton, L. K.

Tipton, L. K.

Tobias, J. C. and Bates, W. N.

Tomlinson, J. H.

Tompkins, it.

Tostevin, J. P.

\begin{tabular}{|c|c|}
\hline Mori. & (Fal) \\
\hline $6 \pm 6$ & 177 \\
\hline 668 & 162 \\
\hline 722 & 209 \\
\hline $8_{53}$ & 243 \\
\hline 682 & 197 \\
\hline 779 & 224 \\
\hline 706 & 204 \\
\hline$S_{37}$ & $23 \mathrm{~S}$ \\
\hline 619 & 178 \\
\hline C & ISS \\
\hline 663 & I91 \\
\hline & 219 \\
\hline 26 & 235 \\
\hline 76 & 223 \\
\hline & 225 \\
\hline 53 & 185 \\
\hline 7 & 228 \\
\hline 7 & 207 \\
\hline$S_{31}$ & 237 \\
\hline 653 & ISS \\
\hline 829 & 236 \\
\hline 689 & 199 \\
\hline $7^{85}$ & 226 \\
\hline$S_{7} 6$ & 251 \\
\hline 794 & 228 \\
\hline & 176 \\
\hline 662 & 191 \\
\hline$\delta_{21}$ & 235 \\
\hline 654 & 188 \\
\hline 787 & 226 \\
\hline
\end{tabular}

Tostevin, J. P.
$649 \quad 187$

$651 \quad 187$

$623 \quad 179$

$780 \quad 224$

$\begin{array}{ll}777 & 224\end{array}$

SI9 233

$\begin{array}{ll}716 & 207\end{array}$

$\begin{array}{ll}778 & 224 \\ 598 & 172\end{array}$

$\begin{array}{ll}598 & 172 \\ 598 & 172\end{array}$

$\begin{array}{ll}\text { (R.) } 598 & \text { I72 } \\ \text { (R.) } 599 & 173\end{array}$

$\begin{array}{ll}779 & 224\end{array}$

SSO 253

$724 \quad 200$

$769 \quad 222$

$767 \quad 222$
617

$617 \quad 178$

$646 \quad 186$
Totten, l'. R.

Tisw nuend, I.

Irais, 1). IT

'Tuiv, 1). W'

Trvis, A. J3.

livut, J. H.

Trowluidge, J. T.

True, 1. II:

Tucker, A. (i.

Turley, M.

Turner, J. 1 .

Turner, I. 13.

Tuttle, 5.1 , and Gans. J. I1.

Tyson, J. $\mathbf{~} \mathrm{T}$.

Uhl, C. A.

Unthank, j). .t "

Unthank, 1),

Utter, MI. 1.

Utter, 1.

Van Buren, $\mathrm{J}$.

Van Camp, IV: A.

Vandegrift, T. F. and W. $\mathrm{S}_{12} 23^{2}$

Vamlegrift, T. F. and W. $\mathrm{SO}_{3} 230$
Van Muter, H.

Van Meter, H

Verharen, F. T.

Viars, J. A.

Vowles, I.

Vowles, J.

Vowles, I

Wadsworth, II.

VVaggoner, $\mathrm{G}$.

Wauner, D. S.

Wagner, J. Ir.

Walker, L. B.

Walker, E. and Weed, $\Lambda$. M.

$\begin{array}{cc}\text { Pinte clrim } \\ 715 & 207 \\ 649 & 156 \\ 721 & 209 \\ 740 & 214 \\ 862 & 246 \\ 795 & 228 \\ 763 & 221 \\ 809 & 231 \\ 627 & 150 \\ 585 & 169 \\ 601 & 173 \\ 604 & 174 \\ 6\end{array}$

692200

$\begin{array}{ll}677 & 196 \\ 607 & 175\end{array}$

$\begin{array}{ll}864 & 247\end{array}$

(R.) $864 \quad 247$

$88_{3} 254$

$8+1 \quad 239$

862246

$877 \quad 252$

$\$ 53 \quad 243$

$768 \quad 222$

$592 \quad 171$

$602 \quad 174$

716208

$\begin{array}{ll}734 & 212\end{array}$

$7 \mathrm{~S}_{3} \quad 225$

$845 \quad 241$

859245

646 IS6

693201

Walker, E. and Piatt, J. J. 74 I 215

Walker, L.

Wallis, T. R.

Ward, P. J.

Warren, G. W.

Waterman, L. B.

Waterman, L. B.

Waterman, L. B.

Wattles, H. J.

Wattles, H. J.

Wattles, H. J.

Way, S.

Wehster, H. H.

Vleems, T. P. S.

Weir, W. S. Jr.

Weir, WV. S. Jr.

845241

$663 \quad 191$

$606 \quad 175$

$610 \quad 176$

627 ISo

$728 \quad 211$

$735 \quad 213$

$744 \quad 216$

717208

$645 \quad 185$

$846 \quad 241$

603174

$611 \quad 176$
Weir, W'. S., Jr.

Welch, Si. (i.

Wells, W. J.

Welden, l: N.

Wellman, 1). 1.

Viells, C. C :

Miells, C:

. 724209

Wells, I'. F. $\quad \begin{array}{lll}789 & 227\end{array}$

Velty, 1. $709 \quad 205$

Wertenberger, I.. $\quad 8_{23} \quad 235$

Wertenberger, 1. and Amiss, G. IV

Werts, N.

West, P. I.

Wheeler, E. P.

White, 1:. J.

Whitney. I. M.

Whitehall, $\mathrm{N}$.

Whitehall, $\mathrm{N}$.

Whitehall, N.

Whitchall, N.

Wiarel, E.

Widman, J.

IVilcox, E.

Wilkinon, I. Il. $731 \quad 21$

Willinson, G. $\quad 813 \quad 232$

Willerton, IV. $\quad \begin{array}{lll}676 & 195 \\ \text { Willi } & 786 & 226\end{array}$

Williams, $A . \quad 626 \quad 180$

Willmot, W. $\quad 588 \quad 170$

WVilson, IV. I. $590 \quad$ I 71

Wilson, J.C. $\quad 595 \quad 172$

Vilson. I. $684 \quad 197$

Wilson, N. $\quad 733 \quad 212$

Wilson, J.A. A. 7452 I6

Wilson. IV. C. $\quad 769 \quad 222$

Wing, I. $\quad 68_{3} \quad 197$

Wolfe, A. K. $\quad 832 \quad 237$

Wolf. 1. $706 \quad 204$

Woodward, J. A., S. S. and Mason, $\mathrm{T}$.

712206

(R.) $612 \quad 176$
Woodward, J " (R.) 712 206 and Mason, T.

Wright, E. A.

Wright, E. A.

Wood, I. A.

Young, W. B.

Voung, B. F.

Young, J.

Voung, B. F.

Young, B. F.

Soung, S. I.

Zeller, J. P.
$733 \quad 212$

$865 \quad 247$

$882 \quad 253$

$848 \quad 242$

$688 \quad 199$

$660 \quad$ J90

$847 \quad 241$

$756 \quad 219$

725210

$785 \quad 226$

$734 \quad 212$ 



No, 4,459- N.ITIIAN HDE, SHFi,kY, N. S.-Whicl Culliators.-April $18,18+6$.

Claim,- The arrangement of the teeth in two rows, in combination with a pair of wheels, the treads of which are in a line mid-way between the points of the two rows of teeth, substantially as described.

No. 5,075-I. PATTERSON, MEuxA, N. Y.-H\%ed Cultizutors.-Ifril 17,1847 .

Claim.- The arrangement of the cultivator tecth as herein set forth, when such arrangement is combined with a wheel cultivator. in which the position of the wheels with reference to the teeth is such as herein set forth.

No. 5,195-A. T. ODliLL, RoYaLroN, N. Y.-Whiel Cultizutors. $-\mathcal{F u l}_{1} 17,18_{47}$

Clain.-I.-The combination of two double-jointed linges, and wheel $a$, wing frames I, I, containing the side cultivators $\mathrm{R}$, with the central frame $a, l, c$, containing the thircl wheel $w$, and central cultivatur R, constructed, arranged and operated in such manner that undulatory land may be cullivated in uniform depths of furrow, without straining or breaking the frames, the cultivators being made to accommodate themselves to the hills and hollows, and other inequalities of the land, by means of the flexible central joints or hinges $m, n$, attached to the aforesaid central frime $a, b, c$

2, - Combining a third wheel w, with two side wheels $w$ ii, in a jointed flexible or folding cultivator frame, made in the manner above described or otherwise made substantially the same.

No 5,257.-E. H. HARRIS and J. CLEGHORN, Cass Co., GA.-H/hecl Cultizators.-Ausust 2I, I8+7.

Claim.-The combination of the handles with the axle and hoe frame as described, the handles and hoe frame being independently attached to the axle which forms the fulcrum, and the relative position of the handles and hoe frame being adjustable, the handles are converted into adjustable levers for elevating and depressing the hoes.

No, 5, 20,-D S BLLLIVGS, Conveaut, Pa-Whe? Cultizators.-Fibruary 1, 1848

Claim. - The elliptic curve on the outside of wheels and the use of a tooth or teeth on each curve opposite the hubs in the combination with the cultivator frame as described.

No. 6,037.-DAVID B. ROGERS, SENECA FALIS, N. Y.-Whitel Cultivators.- Fanuary $16,1849$.

Claim-1- The mode of raising and lowering the frame $a$, containing the cultivator teeth $m$, for the purpose of g:uging the machine for deep or shallow ploughing, or for moving it from place to place, without causing the teeth to touch the surface of the earth. by means of the beforedescribed combination and arrangement of the crank axletree $D$, coguret wheel $F$, cogged segment $H$, short axle $G$, lever 1 , and perforated holdins plate $\mathrm{L}$, employed in combination with the frame $A$, of cultivator teeth $\mathrm{V}$, and sustaining wheels $\mathrm{W}, \mathrm{W}$

2.-The combination and arrangement of the binding and sustaining plates $\mathrm{N}$, made as descrihed, in combination with the transverse beams as described, to which said plates are secured.

No. 8,348.-G; W. C. Gillespie, Burlingron, Iowa, - Whecl Cultizutors, -Sipt, o, 185r.

Claim.-Hanging one or both of the axles of the wheels to the carriages of cultivintor, gangs of ploughs, seed drills, \&.c., to the frame of the carriage, so as to vibrate the axle or axles, or suffer them to vibrate and keep them at right angles to the motion of the ploughs when moving in a direct line, and when turning the ploughs, to keep the axle or axles in the direction of the rudius of the circle, or nearly parallel with the radius of the circle, formed by the track of the wheel turning upon said axle, when the plonghs constituting the gang are placed diagonally one behind the other in succession, and the wheels to the carriage of the same are also placed diagonally, one behind the other.

No. 9,003,-F. P. ROOT, SWEEdEN, N. Y.-WherlCultivators.-Fune 8,1852 .

I am fully aware that there are other modes of raising and lowering the frame contining the teeth of cultivator: in use, particularly that patented to D. B. Rogers, Jan. 16, I 849, which consists mainly of a combination of a crank axletree extending across the centre of the frame, on the ends or cranks whereof are mounted the suntaining wheels. While 1 acknowledge the similarity of the lifting action of the cranks of the axletree to that of the pivoted segment levers used by me, and which I disclaim, yet I am not aware that Mr. Rogers is entitled to claim all means for effecting the same result, and I conceive that my improvements differ in material points from his, and which form the subject of my claim, mounting the carrying wheels upon axles $F$, only when said axles are made to project from pivoted segment-shape levers at each side of the frame, in the manner and for the purpose specified.

No 10,197.-SENECA LEPl1AM, SALEM, ОнIо,Whed.Cultizators. - Nivember 1.1853 .

Claim.-The combination and arrangements of the parts, consisting of the lever $\mathrm{M}$, and its attachment to the brace $k$, and the connection of the tongue $a$, to the lever by the staple $\mathrm{N}$; and this in its application to the purpose of changing the direction of this and other machines.

No. 10,467.-E. BOUGHTON, East Bloomrield, N. I.-Whicel-Cultivators.-Finuary 31,1854

I do not claim any part of the raising and depressing devices; nor da I clain the knife or the wheels separately.

Claim.-The combination of the knife with the wheels for the purpose of cutting up the ground and destroying thistles or any other weeds, plants or grass.

No. 12,163.-JOHN IMEL, LIBERTY, IND, - Whed Cultizators.- Janumry 2, 1855

Claim.- The curved and adjustable guard or fender, hinged as described, to a tongue supported upon running gear.

No. I 2,653.-F. L. S.IITHSON, MEckLenburg, VA, Whict-Cultiatators. - April 3, 1855 .

Claim.-The combination of the harrow teeth and cylinder sulsstantially in the manner and for the purpose set forth.

No. $13,191-N$. WHITEHALL, ROS RoY, IND.Whe'd-Cultivaturs.-July $3,1 S_{55}$

Disclaiming all the devices separately considered.

Claim. - The arrangement and connection of the handles $\mathrm{O}, \mathrm{O}$, arms $\mathrm{M}, \mathrm{M}$, plough-beams $\mathrm{C}, \mathrm{C}$, and seat $\mathrm{W}$, for the purpose of operating ploughs, in the manner and for the purpose set forth.

No. 14.715 . -GEORGE EstTERISY, HEART PRAIRIE,

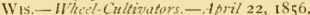

Claim.-The hanging of two or more ploughs to a sup porting beam or axle $\mathrm{H}$, by swivelling joints at each of the ends of their drag.bars G, G, so that said ploughs may be moved either way laterally without affecting the axle, and still maintain their parallelism, and thi; I claim whether the stock to which the ploughs are connected be adjustable in the drag-bars or the ploughs be adjustable in the stock or otherwise.

No I ,605.-H. D. GANSE, FreeholD, N. J.-WheelCultizators.-Aus. 26, 1856 .

Claim,- So constructing and arranging my cultivator by means of the clevis $x$, in the beams $\mathrm{M}$, and brace $n$, substantially as described, that in combination with the seat $w$ the ploughs may be guided by the driver's feet, in the manner set forth.

No. 15,819.- - L. ROBINSON, WeSt CAMrRIDGE, Miss.-Wheel-Cultivators.-Sipt. 3 o, 1856.

Claim. The arrangement consisting of the vertical cut ter $\mathrm{G}, \mathrm{G}, \mathrm{J}, \mathrm{K}, \mathrm{K}$, horizontal cutter $\mathrm{H}$, mould-boards $\mathrm{L}, \mathrm{L}$, and seed droppers $\mathrm{D}^{2}$, said parts being placed in the relation to each other shown, substantially as and for the pur pose herein set forth

No, !6,216.-1I. TURI.EY, G.ALFsBurg, III.-Wheel Cultivators.-Dic. 9, 1856

Claim. - The arrangement of the standard, mould-board and side cutter $\mathrm{K}$, with regarcl to each other, and to the other parts of the plough as that they will operate as herein set forth and explained.

No. 16,401.-J. SHAW, Richland, GA.—Wher-Cultiv'ators.-Jan. 13,1857 .

Claim.- In combination with the hoes E, E, having both a vertical and lateral adjustment, the shoes $\mathrm{H}, \mathrm{H}$, above them, and so adjustable on or with said hoes as to serve to 
throw the earth towards or from the plants, as may be required, the whole being for the purposes set forth.

No, 17,39I.-A. A. R(B)RT'S and B. DAVIS, IA GRANi:E, GA. - Whecl-Cultizators.-Nur $26,1 S_{57}$

Claim.- In combination with the frame A, A, and brake e, as described, the movable frame $B, B$, armed with hoes a, and h.urrow c, c, the teeth of said harrow being so arranged as to culivate between the bunches of cotton, and at the same time clear the standing cotton-plants from clods in the manner set furth.

No. 17,909.-H. OGBORN and G. TAYLOR, RICHMONI, INI, assignors to H. () shorn. - IJhed Cultizutors.July 2S, is 57 .

We do not claim the combination of a crank axletree extending across the centre of the frame, on the ends or cranks whereof are mounted the sustaining wheels, the same being for the purpose of raising an I lowering the frame of the cultivator as shown and lescribed in D. B. Rogers, patent Januiry 1849 .

Claim.-The combination of the plough beans $G, G$, with the eccentric axles $\mathrm{F}$, in the manner and for the purposes set forth.

No. I $8,530 .-\mathrm{N}$. WHITEH.ILL, Roß Roy, IND, asrignor to self and A. I. Whitehall, same place-Whed Citlivators. -0 t. 27,1857 .

Claim.-Providing a double cultivator, the middle of which is elevated to pass over the corn, with a compound evener suspended upon three points, and arranged as described for the purpose set forth.

No. I8,587.-DAVID E. HALL, ABINGDoN, ILL.Whed Cultivators.- Vie'. 10, 1857

Claim. - I, - The attachment of the shares $P$, to the hars 1 1, which have their back ends pivoted in the pendants H H, and their front ends fitted in the pendant slotted bar J J, which are attached to the sliding har $K$; the bar $\mathrm{K}$ being operated by the treadles $\mathrm{X}$, to give the lateral movement to the shares, and the bar 1 , used vertically by the treadles $\mathrm{N}$ to give them their vertical movement as described.

2. - The cutters (), pivoted to the bars 0 , and over the plates $R$, and connected to the rods $I$, the whole being arranged as shown for the pur-pose specified.

o. I $8,840,-D A V 11$ P. DAGGETT, PAI.MYRA, N. Y. - Whecl-Cultivators.-Dicember 15, 1857.

Claim.- The peculiar construction and arrangement of ol parts whereby the frame of the cultivators may be elevated or clepressed in relation to the surface of the soil, either parallel to the plane of the surface or inclined thereto forward or back at any desired angle by means of the lever beam $\mathrm{D}$, swivel wheel $\mathrm{I}$, swivel clevis $\mathrm{H}$, and adju-table wheels $\mathrm{C}$, combined, arranged and operating in the manner and for the purposes specified.

No. $21,128,-\mathrm{N}$. WI. FRASER and A. J. MC LELLAN. -LAPORTE, INm- Whit-Cullizators. August 10, 1858.

Claim.-The arrangement of the fender I), attached to the shovel standard $\mathrm{D}^{\mathrm{I}}$, the shovels $\mathrm{E}$, and the wheels $\mathrm{A}$, on the vertical shaft $a$, the whole being arranged for joint operation as described and set forth.

No. 21,428. - ISR IEl. LON(; TERRF. IIAUTE, IND.II Thed Cultizators.-Septimber 7, 1858.

Claim.-The employment of two frames A A, which are furnished with harrow teeth $c$, at their forward ends, and cultivator teeth $\mathrm{B}$, at their rear ends and connected by arch braces () 1), in combination with the propelling wheels $\mathbf{E}$, arranged on short crank axles; the tongue $\mathbf{G}$, arranged on top of the arch braces, and with the adjusting arrangements, substantially as and for the purposes set forth.

No, 21,600.-B. S. MOR(iAN, DEt.HI, IowA.-Ihe'el Cidtizaturs.-Octeler 5, 1858 .

Claim.-1.- The arrangement of the bar $\mathrm{E}$, with share stocks F, attached; the levers I, with links I, fitted in the triangular shaped openings $f$, in said levers, and attached to the coulter bars $\mathrm{K}$, which are connected to the levers $\mathrm{N}$, substantially as and for the purposes set forth.

2.- In combination with the above, the brace-rods $H$, attached to the share stockis $\mathrm{F}$, by means of springs $a$, and fitted in the recesses $b$, in the stocks, and arranged substantially as and for the purposes set forth.
No, 21, I 39-S, E. and C. II. CARRINGTON , WEV

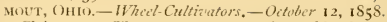

Claim.-1.-The arrangement and combination of the vicle wings $\mathrm{E} \mathrm{E}$, and bars $\mathrm{H} \mathrm{H}$, with each other and in re lation to the frame $A$, substantially in the manner and for the purpose specified.

2,-Also the mode of actuating and adjusting the hoes $K$. by means of the wheels 1$) \mathrm{D}$, stirrups $\mathrm{h}$ h, bar $\mathrm{L}$, lever $\mathrm{M}$, and plate $\mathrm{N}$, arranged in combination, and acting upon the handles $\mathrm{J}$, of the hoes substantially set forth.

No. 22,215.-W. WILI.MONT, WIIMINGTON, DEL.Whed-Cultizators. - Vorenter 30, is 58 .

Claim.-The arrangement and combination of the bars $G$, Gi, Gi2, bars $H$, adjustable weights I, chains I, bars $\mathrm{L}$ and handles $B$, as and for the purposes herein shown and described.

No. 22,630.-JESSE CUNNINGHAM, MARSHAI.1., Mo. - Cultizators. - Fanuary is, 1859.

I do not claim the reversible bar $I$, with a marker or wheel s attached, for such device has been previously used.

Claim.-Attaching the furrow shares $\mathrm{H}$ to a swinging frame formed of the shaft $\mathrm{E}$, bar $\mathrm{F}$, and arm b, placed in a mounted frame $A$, in combination with the buttons $C$ C, provided with step-like projections $d$ for regulating or adjusting the height or inclimation of said share-frame, and consequently the depth of the furrows, substantially as described.

No. 22,859.-JAMIES IUUDAS, LITTLE ROCK, ILl.Cultivutors.-Fibrunry 8, 1859.

Claim.- The arrangement of the half-shovels $w$ w, in connection with the lars $h h$ and $i$, to be moved to the right or left at pleasure of the operator.

No. 2,380.-JAMES IUNDAS, NimahA Countr, NE BRASKA.-Cultizators.-February 8, 1859 .- Re-issued $O_{c}$ loher 16,1866

Claim.-1.- The combination in a straddle-row cultivator of the following instrumentalities, viz: the two wheels, frame, and a series of ploughs arranged in two gangs with a central space between the gangs, so as to till the soil simultaneously at both sides of a single row of plants which the machine straddles; all of these operating in the combination substantially as set forth.

2.-The combination in a tradlle-row cultivator of the following instrumentalities, viz: the two wheels, frame, the series of plonghs arranged in two gangs as aforesaid, and seat for the driver, all of these operating in the combination substantially as set forth.

3.- The combination in a straddle-row cultivator of the following instrumentalities, viz: the two wheels, frame, the ceries of ploughs arranged in two gangs as aforesaid, and movable stocks, all operating in the combination so that while the wheels limit the penetration of the ploughs, the inner ploughs of the two gangs may be moved laterally to avoid the plants that are out of line in the row, sulustantially as set forth.

4. - The combination in a stradule row cuttivator of the following instrumentalities, vi 2 : the two wheels, frame, the series of ploughs arranged in two gangs as aforesaid, movable stocks, as aforesaid, and driver's seat; all operating it the combination substantially as set forth.

5.-The combination in a straddle-row cultivator of the following instrumentalities, viz: the two wheels, frame, the series of ploughs arranged in two gangs as aforesaid, driver's seat and a connection between the novable ploughs, all operating in the combination substantially as set forth.

6. - The combination in a straddle-row cultivator of the following instrumentalities, viz: the wheels, frame, series of ploughs arranged in two gangs as aforesaid, and mechanism to permit the ploughs to be raised relatively to the treads of the wheels, all constructed and operating in the combination substantially as set forth.

No. 23.135-JOHN M. WHITNEY, Bol.ToN, Mass.Cultivators. - Warch 1, 1859

Claim.-The arrangement of the teeth $a$, adjustable mould-boards, $\mathrm{D}$, frames $\mathrm{A} \mathrm{A}^{\prime}$, and cross.beam $\mathrm{B}$, with the branched swivel bar $\mathrm{L}$, and frame $\mathrm{H}$, the whole being constructed as and for the purpose described.

No, 23,182,-IDANIEL. MARKHAM, A. S. MARK 


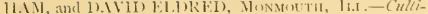
contors.-ulariti S, 1 \$5\%.

(lain.-The frame $\mathrm{A}$, formed of two parts $a$, connected by the traverse bars b, and provided with the slicling or acljustable frames ( $\mathrm{C}$, with the bars $\mathbb{E}$ and plosughs $F$ attach ed, sulotantially as and for the purpose set forth.

No, 23,402,-J()IIN SMIALIEI, BotND BRook, N. J. - Ciultitators. - Harch 20, 1859

I do not claim, broadly, hanging the main wheels of a cultivator to cranked axles for the purpose of deciding the depth to which the teeth shall penetrate the ground, as such a device has been heretofore used in cultivators

Nor do I claim a central lever for operating the cranked axle or the plough formed teeth, or any other part of the machine, separately.

Claim.-The frame, its adjustable pole, its teeth $m^{1} n^{1}$, and detaching teeth $\rho$, the cranked shaft $\mathrm{C}$, its central lever $E$, and driver's seat $G$, when the saicl seat is so situated as regards the handle that the driver can operate the latter without moving from the seat, and when all the parts are arranged in respect to ench other, sulwantially as set forth.

No, 24,071-NICHOIAS WHITEHALL, NEWTON, IND.-Cultivaters_-Wey 17,1859 .

Claim.-The combination of the stirrups 00 , with the notched handles $\mathrm{N} N$, eye bolts $\mathrm{D}$, and hooks $\mathrm{F} \mathrm{F}$, by which I am enabled to raise and secure the plough at any desired height, substantially as set forth.

No. 24,171.-W. I. WIL.SON, FRANKLIN, IND.-Ciultivators - Kay 24, 1850 .

Claim.-The arrangement of axles $A$ and $E$, whee's $B$, levers $\mathrm{C}, \mathrm{C}$, shanks $\mathrm{D} \mathrm{D}$, ploughs at $a$, cross piece $\mathrm{I}$, guides $\mathrm{F} \mathrm{F}$, and arms $d d$, for operating conjointly $\mathrm{m}$ a manner and for the purpose set forth.

No, 25,037-1.EONARD P.ACKARD, ( Al.eset'RG, II.I. - Cullizutors-Ausust 9, 1859

Claim.-The arrangement of the henms $\mathrm{P}$, the irons $\mathrm{Z} \mathrm{Z}^{1}$, and the projection $\mathrm{X}$, on the ends of the beams, the adjustable arms $\mathrm{S}$, braces $\mathrm{W}$, blades $\mathrm{T}$, lifting rods 1 , adjusting lar 3 , levers 5 , fulcrum 6 , and hinged pole $L$, as described, for the purpose set forth.

No. 4,774.-LEONARD PACKARD, GALESBRG, IL. Cultivators.-25,037.-August 9, 1859.-Reissued Fuly 18, 1871 .

Claim.-1.-The plates $a$ and longitudinally-slotted plates $b$, secured to the forward ends of the beams $D$, and pivoted by rids. $\mathrm{F}$ to the har $\mathrm{E}$ so as to permit of the ploughs being moved in a vertical or lateral direction by lever $(i$, as and for the purposes set forth.

2.- The interchangealle standards .I, adjustally secured to the heams $\mathrm{I}$, and braces $\mathrm{N}$, for the purpoves set forth.

3,- The combination of the pivoted beams $D$ and aljustable standards II with plates $a$ b, and rods $\mathrm{F}$, bar $\mathrm{E}$ and lever $(i$, subst ntially as and for the purpose set forth.

No. 25,764 --W1LLIAN SEELY, CHILLICOTHE, ILI, - Cultinators. Octeber is, 1850.

Claim.-The arrangement of the post D, arms E, cross $\operatorname{lar} \mathrm{F}$, lever $\mathrm{H}$, wheels $\mathrm{W}$, shovels $\mathrm{B}$ and $\mathrm{C}$, chains $\mathrm{R}$ and $\mathrm{Q}$, arms $\mathrm{U}$, cross bar $\mathrm{K}$, vertical lever $\mathrm{V}^{*}$ and $\mathrm{Y}^{2}$, roch $\mathrm{Z}$, whiffletree $\mathrm{X}$, and draft hook $\mathrm{A}^{2}$, the whole being constructed and cumbined in the manner and for the purp se described.

No. 25,843 - THOMAS MCQUTSTON, MORNing SUN, O1tro-Cultizaters.-October $18,1859$.

Claim.-The describerl arrangement of the elevated axle $\mathrm{I}$, beams $\mathrm{A} \mathrm{A}^{1}$, brackets $\mathrm{C} \mathrm{C}^{1}$, ancl rorls $\mathrm{B}, \mathrm{B}^{1}$, the whole being constructed in the manner and for the purposes set forth.

No. 4,383.-THON 1 . MCQUISTON, MORNIN: SUN, (jito,-Cultizators.-Oclolicr 18, I859.-Reissued May' 16,1871 .

Claim -1.-The combination, in a walking straddle-row cultiva:or, of the following instrument lities, viz: Two wheels $\mathrm{E}$, tongue $\mathrm{D}$, axle $\mathrm{B}$, and two plough-beams A A, each beam crrrying a handle and one or more shovels or ploughs, ansl independently connected or hinged ly brackets $\mathrm{C}$ to the axle, so as to permit of their being raised or lowered independently or moved laterally by the handle, as set forth.

2 - The comhination in a walling stradille-row cultivator, of the following inutrumentalities, viz: Two wheels E, tongue $\mathbf{1}$, axle $\mathbf{B}$, two plough-beams, hinged as aforesaid, ard rear connecting-hackles or links $\mathrm{F}$, all operating ou combination, suldatantially as and for the purpose set forth.

3 - The plates $\mathrm{H}$, interposed between the shares $\mathrm{f}$, and standards $a^{\prime}$ for the purpose set forth.

No, 27,106-ABNlR CAREY, Romk, G.A.-Cultizawar.-Fibruary 14, IS6o.

Claim,-The decribed arrangement of the ploughs $\mathrm{H}$, beams $(i$, and perforated rails $D$, the whole being combined and constructed in the manner and for the purposes set forth.

No, 27,174.-IOSEPH VOWELS, NEW IIUDSON, Mier. Cultiontors.-Fibuary 14,1860 .

Claim.-1.-In combination with the series of hoes or ploughs L I, the pair of front hoes or plonghs $\mathrm{N} \mathrm{N}$, constructed, arranged, and made adjustable in the manner and for the purpose herein described and represented.

2.-The peculiar construction, combination, ar.d arrangement of the frame, the pulleys, and the locking of the standards to the frame, substantially as described and for the purposes set forth.

No, 27,627 -CVRUS M. HALL and DAVID E. HAIL, UNIONTOWN, 1LL..Cullivators.-Marck 27, 1860. Claim, - The general arrangement and combination of the revolving conlter with knife-edged arms, the slovels $\mathrm{A}$ made with flukes or barbs, the beams B B, the cross bar $\mathrm{X}$, traps $S$, rollers $r r$, treadles $\mathrm{P} \mathrm{P}$, and the pin or pivot on which the beam B hangs, all connected as described and for the purpose set forth.

No. 5,601.-CVRUS M. HALI, and DAVID E. IIALL, UNIONTOWN, II...; said DAVID E. HALL assignor to said CYRUS NI. HALL. - Cultizators. - 27.627, March 27, I 860.-Reissued October I4, 1873. Application filed fanunry 5,1872

Claim -1.-In combination with the harbed share $\mathrm{A}$, the revolving cutting-wheel or shield $\mathrm{C}$, the periphery and arms of which have sharp cutting-edges, constıucted and arranged ubstantially as snown and described, for the purpose set forth.

2.-The combination of the hitch-bolt $\mathbf{K}$, the hars $m$ and $n$, the bolt, and the axle-tree $Y$, and a suitable device for holding and operating the same as co-acting devices for rendering the point ends of the beam adjustable, both literally and vertically independent of the motion of their rear ends and independent of each other, and for equalizing the draft of the machine, each constructed and all arranged substantially in the monner descrihed and set forth

3.- The combination of the slicling bar $x$, providerl with supports upon the rear face of the axle-tree $Y$ and the pendent posts I $\zeta$, as a device for communicating lateral motion to the ends of the plough-beams, and of allowing and guicling vertical motion thereof, independent of any motion of the front ends of the same, constructed and arranged substantially in the manner and for the purpose set forth.

4. - The combination of the front sliding bar $x$, the front cross-niece $\mathrm{F}^{\prime}$ the bars $m$ and $n$, hitch-bolt $\mathbf{K}$, bolt $e$, the levers $a$ a mounted and pixoted to the front ends of the teams, as shown by the link $l$, as co-acting devices for moving the front ends of the beams laterally, and of giving them vertical motion either to zether or independently of each other, and independently of the motion of the aft ends of the beams, each con-tructed and all arranged substantially in the manner and for the purpose described and set forth.

No. 27,632.-SAMUEL HOAKE, FREDERICK, MD.Cultizators-March 27, 1860. Antedated March 9, 1860.

Claim.-1.-The combination of the jointed shovel shaft $\mathrm{B}$, slutted shovels $\mathrm{T} \mathrm{T}^{1}$, drag bars $\mathrm{I}$ and $d$, shafts $\$$, straps $b$, spring detent $e$, and guides substantially as described.

2.- In combination with the foregoing I claim the adjust ment of wheels $\mathrm{W}$ on axle $\mathrm{A}$ by bolt $a$ and pins $i$, as specified.

No. 27,654--GEORGE SIITH, BALTIM)RE, OHI.Cultivators, March 27, IS60.

Claim. - The arrangement of the hinged tcet's F, shanks $\mathrm{G}$, ropes or chains $\mathrm{I}$, roller $\mathrm{J}$, and lever $\mathrm{K}$; the whole being arr.nged for joint operation as described, for the purposes set forth.

No. 27,703.-W. D. DORSEY, DECATUR, ILL.-Cultizutors.-April 3,1860 .

Claim.-1.-So combining the hinged heams C D of a 
cultivator with the treadles $\mathrm{HI}$, as that the driver on his seat may r.ise either of the two central cultivator hoes F, separately, or all the boes simultaneously, when constructed and arranged substantially in the manner and for the purposes described.

2.- In combination with the pairs of hoes so hung and operated, the shields L L, for protecting the young plants from the sods, earth, or soil turned up by the hoes, substantially as set forth.

No, 27,975.-JOSEPH F. EVI.AR, ScotT, Онг,Cultivators-April 24, I 860 .

Clain.-The described arrangement of the ploughs E F, frames $\mathrm{G}$, links $\mathrm{H}$, chains $\mathrm{I}$, standards $\mathrm{K}$, levers $\mathrm{L}$, chains or cords $d$, pulleys $\mathrm{M} \mathrm{N}$, and crank shaft $\mathrm{O} \mathrm{r}$, constructed and operating in the manner and for the purposes set forth.

No. 28,oi6.-IRULUS R. SNITH, Elain, Il.t.Cultivators.-A Aril 24, 1860 .

Claim.-The combination of the long standards $\mathrm{A} \mathrm{A}^{1}$, the check or guard pieces $\mathrm{E}$, the movable handles $\mathrm{N}$, the saddle $\mathrm{P}$ for the beim $\mathrm{B}$ to roll upon, the truss $\mathrm{G}$, consisting of the pieces of iron $S$, the standards $G G$, the rod $Y^{1}$ the stretcher $\mathrm{Y}$, the iron brace $\mathrm{K}$, and the joint $\mathrm{H}$, attached to the two wheeled carriage $O$, as described, and for the purpose specified.

No. 3,932.-IRULUS R. SIITH, ELgIN, ILl., assignor to J. GERBER, RoCKloRD, ILL.-Cillivators.-2S, OI6, April 24, 1860.-Reissued April 26, 1870.

Claim.-1.-An auxiliary frame carrying two or more shovel-standards upon each side, as shown, when said frame is hinged to the pole between the evener and neckyoke, as described for the purpose set forth.

2.-The combination of the main frame, consisting of the tongue, axle and beam $O$ with the auxiliary frame, consisting of the beam $B$, standards $A$, with its lifting devices, when the frumes are made separite an 1 distinct from each other, and are connected only by the joint II, as described, for the purpose set forth.

No, 28,I9I,-JOHN NEFF, JR., Pultney, Vt.-Cultivators.-May 8,1860 .

Claim.-The arrangement of the crank shaft $H$, the handles $I$, couplings $K$, springs $J$, supports $L$, cross piece $\mathrm{M}$, and screws P, constructed and operating as described, for the purpose set forth.

No. 28,8,3.-O. F. FITCII, MORrISTuwn, IND.Cultivators.-June 26, iS6o.

Claim.-The described combination and arrangement of braces and frames, arranged in the relations set forth, and made to serve the purposes described.

No. 29,027.-J. C. WIL.SON, Cedar Hill, Texas,Gang Ploughs.-Fuly 3, 1860.

Claim.-The arrangement of the plough frame upon the wagon frame, as and for the purpose described.

No. 29,094.-HARRISON OGIURN, GREENFORK, IND.-Cultivators. - Fuly to, i 8 fo.

Claim. - The arrangement of the spring bolts $\mathrm{K} \mathrm{K}$, the piece $\mathrm{H}$, staple $\mathrm{B}$, and movable seat $\mathbf{M}$, in combination with the ploughs $\mathrm{U} \mathrm{U}$ an $1 \mathrm{~V} \mathrm{~W}$, the whole bein $r$ arranged, constructed, and operated substantially as set forth.

No. 29,583. - SCHUYLER GOLDSMITH, WATAga, ILL.-Cultivators.-August i4, IS60.

Claim.-The combination and arrangement of the seat G, draft pole I, racks J K, and axle E, applied to the frame A, substantially as and for the purposes set forth.

No. 29,592,-LVMAN E. HAWKINS, SANGAMON, ILL.-Cultivators.-Aurust 14, IS60.

Claim.-The arrangement of the oblique stocks $\mathrm{J}^{2}$, ploughs $\mathrm{J}$, vertically inclined stocks $1^{1}$, ploughs $\mathrm{I}$, rcds $a b$, frame $\mathrm{A}$, axletree $\mathrm{B}$, wheels $\mathrm{C} C$, pole $\mathrm{D}$, lever $\mathbf{E}$, and sent $\mathrm{G}$, as and for the purpose shown and described.

No. 29,704.-LEWIS LElBER, SPRINGFIELD, ILL.Cultivators.-August 21, 1860.

Claim.-1.- The arrangement of the ploughs K L and the cultivator frame, substantially as and for the purposes set forth.

2.- The combination with a cultivator of the swingletree $\mathrm{U}$, the crossbar $\mathrm{W}$, at the top of an elevated draught pole, two vertical levers V V, and an arched yoke $\mathrm{Y}$, substantially as and for the purposes set fort'?.
No. 29,707-T. W. MCDILL, OQtaWKA, TLL.-Culi:z'aters.-. August 2 I, I 860 .

Claim.- The arrangement of the axle $A$, and bars $b b k k$, and cross-piece $c$, with the loose comnection of the draught pole $\mathrm{B}^{1}, \mathrm{t} t$ the machine, substantially as and for the purpores set forth.

No. 6,137.-THOMAs W. McDILI, Batavia, assignor of one-half his right to J. C. McDILL, MuNRok, InwA.Cultivators.-29,707, -tustust 2I, IS6o.-Reissued Kov. 17, 1874.-Extended seven years [Filed Oct. 2, 1874.

Claim,-1,- The axle A of a walking striddle-row cnltivator, constructed substantially as described, with an elevated central portion $a$, horizontal portions $a^{\prime}$, for attachment of the forward ends of the beims, and with spindles $a^{\prime \prime \prime}$ for the wheels substantially as set forth.

2.- The combination of the axle $\mathrm{A}$ with the beams $\mathrm{C} \mathrm{C}^{\prime}$, the latter attached to the horizontal portions $a$ of the axle, substantially as and for the purposes specified.

3.- The beams $C^{\prime} C^{\prime}$ pivoted to the axle $A$ and cross-bar D by spindles $i$, substantially as and for the purposes specified.

4.- The combination of the beams $\mathrm{C} \mathrm{C}$ and $\mathrm{C}^{\prime} \mathrm{C}^{\prime}$, axle $\mathrm{A}$, and bar $\mathrm{D}$ with the tongue $\mathrm{H}$ and bent arms $\mathrm{K}$, sulsstantially as and for the purposes specified.

No. 29,762.-GEORGE W. BROWN, Galesburgh, I1.L.-Cultioutors.-August 28, I860.

Claim.-1.-So combining the frame, wheels, and ploughs with the levers L M, as that the driver or operator, from his seat, may turn or cramp said frame, wheels, and ploughs, on the tongue, to cause the ploughs to follow the crooks in the rows of plants, substantially as described.

2.- So combining the seat and tongue with the frame, and with an axle set in advance of its supports in the wheels, as that the driver or operator in his seat, by shifting his weight, may raise, hold up, and lower the ploughs substantially as described.

3.- In combination with the ploughs, the convex cutters or shields N N, when constructed, arranged, and operating as set forth.

No. 30,000.-WILIAAM H. SEYMOUR and LOTHROP SEYMOUR, WEYMOUTH, OHI.-Cultivators.-Siptember II, IS60.

Claim.-The special arrangement of the swinging or adjustable frames $Q$ in combination with the hinged arms $\mathrm{II}$ $\mathrm{N}$ and adjustable teeth, when constructed and operating as described.

No. 30,589.-HENRY H. ROBERTSON and CVRUS G. CARR, Kingston, Mo,-Cultitators.-Nonember 6, IS6o.

Claim.-The arrangement for united operation, in a cul. tivator, of two or more ploughs $G$, or scrapers $N$, a series of cross-bars L L $\mathrm{L}^{1}$, a series of adjustable buttons J, perforated loops $\mathrm{E}$, and stop pins $\mathrm{I}$, substantially in the manner and for the purposes described.

No. 30,723.-TUILY R. CORNICK, CAP AU GRIS, Mo. - Ploushs.-November 27, I860.

Claim.-The combination and arrangement of the cross piece $w$, tongne $m$, axle $z$, wheels $x$, pieces $c$, cross-piece $w$, pieces $k$, cross-pieces $h$, helves $n$ and $\mathrm{P}$, chains $\mathrm{S}$, ploughs O Q Z Y, rod $v$, levers $c$ e f, and seat $l$, substantially as described, for the purposes set forth.

No, 30,727.-SAMUEL FISHER, IVEST WINDSOR, N. J.-Ploughs.-Nozember 27,1560 .

Claim.-The combination of the pivoted beams $\mathrm{G}$ with the pivoted ploughs supported hy a pin, when arranged to operate in the manner and for the purpose set forth; and this I claim whether the ploughs be made adjustable, and be raised or lowered, or held by the devices described, or by others accomplishing a similar object by substantially the same means.

No. 30,897.-BENJAMIN TINKHAM, CAMERoN, ILl. - Cullizutors.-Decimber II, I860.

Claim.-1.-The combination with the axle B and plates $c d$ of the beams E, plates $a b$, and pins or bolts $f$, substantially as and for the purposes set forth.

2.- In combination witl the above I claim the pins or supports $h$, with the hounds D, as and for the purpose described.

No. 4,231.-BENJAMIN TINKIIAM, CAMERon, as- 
vignor to 11.11 P(i) $30,597,1$ inmber 11, 1860 .-Keissted fanmary 10, 1871 .

Claim.-1.-The heams 1 , hinged or pivoted to the axke lyy a joint, substantially such as describcl, whereby the beams, with their shovels, have a frec vertical and lateral movement, and still be held in an upright position, as herc. in set forth.

2.-The rearwardly-projecting bars $\Gamma$, or their equivalents, for supporting the hinged beams above the gronnd, substantially as described.

3.-The combination of the axle $B$, rigid tongue $C$, braces or hars $\mathrm{D}$, and the hinged beams $\mathrm{E}$, all arranged to operate substantially as and for the purpose herein set forth.

No. 4,600.-BENJAMIN TINKHAM, CAMERoN, assignor to $\mathrm{HAPGOOD} \& \mathrm{CO}$, CHICAgo, II.L.-Citlizators. - 30,S97, December I1, 1860.-Reissue No. 4,321, fanwary 10, 1871.-Reissued Octobir 17, 1871.

Claim.- In a straddle row cultivator, the tongue $\mathrm{C}$ rigidly secured to axle $\mathrm{B}$, in combination with bars j) I rigidly secured to the axle, serving as braces to the tongue, and having their rear ends or two equivalent bars extended to the rear to support the plough-beams E E with their gangs of ploughs above the ground when required, substantially as set forth.

No. 30,966,-TOSEPH GUN and ST. (T.AIR GUM, MARseil.tes, IL.L.-Cultizators.-Deimber 18, 1860.

Claim.-The lever $\mathrm{E}$, in combination with the levers $\mathrm{L}$ $\mathrm{L}$, the open slot standards S S, and the slots on the lower side of the cross-piece $\mathrm{H}$, by which to control the central movement of the ploughs, when arranged as set forth, as is substantially described.

2.-The driver's seat D, in combination with the several elements of the preceding claim, when arranged as set forth and substantially as described,

No. 31,101.-I. T. D. ALEXANDER, MARYENnA, TExAS.-Cultizators.- Januar1 I 5, I86I

Claim.- The arrangement of the beams A .1, the bars B B and II H, as constructed, the shanks F F, the wheels D $\mathrm{D}$, and the slotted crank axles $\mathrm{E} \mathrm{E}$, the whole being arrang ed and connected in the manner and for the purpose spectied.

No. 31,112.- W. A. DRYDEN, NoNMOUTH, ILL.-Culliz'ators.- Jamuary I5, $186 \mathrm{I}$.

Claim.-1.-The arrangement of the lever $\mathrm{G}$ with the $\log f$, in combination with the stop $s$, on the upper surface of the beam $A$, and with the plate $\varepsilon$, at the under surface of the draught pole, constructed and operating as and for the purpose specified.

2.-The arrangement of the pin $j$, projecting from the beam $A$, in combination with a bole $k$, in the lever $G$, substantially as and for the purpose described.

No. 31, I33.-DANIEL S. STAFFORD, DECATUR, II.I. - Cultizators.- January 1 5, I861.

Claim.-1.-In combination with the driver's seat and a tongue pivoted to the main frame, the arc $d$, with its projections or braces $e \epsilon$, so that the driver may, from bis seat, cramp the main frame on the tongue, to cause it to follow the crooks in the row of plants, substantially as described.

2 -In combination with the seat and main frame, the construction and arrangement of the bent axle, for the purpose of allowing the driver to use the axle itself as a lever to raise or lower the frame upon itself, substantially as described.

3.- The long bent share blades or cutters $H$, for the purpose of cutting under and throwing the loosened soil towards the plants, when combined and arranged with a frame such as described and represented.

No. 5,827.-ELIZA S. CONKLIN, ExECuTRIX, MA CON COUNTY, and JOSEPH STAFFORD, KNOX COUNTY, It.., assignee of DANIEL S. STAFFORD, deceased.Cultivators.-3i,133, January 15, r86r.-Reissued April 7, 1874.-[Filed Sipiember 20, 1870.]

Claim.-1.-The combination, in a straddle-row cultivator, of frame $A$, wheels $B$, series of ploughs $(\dot{x}$, arranged in two gangs, with a central space between the gangs, and elevated or bent axle C, constructed substantially as descrihed, to permit the corn to pass under it, and to raise or lower the plough-frame, as set forth.
2.- The elevated pole $I$, segmental slides $c$ and $d$, and stirrups ${ }^{\prime}$, in combination with frame $a d$, as and for the purpose set forth.

3. - With the foregoing devices of second claim, the axle C and driver's seat $\mathrm{E}$, in combination, for the purposes set forth.

4. - The combination, in a stracklle-row cultivator, of the two wheels $B$, axle $C$, frame $A$, series of plonghs $G$, and supplementary wheels $J$, all operating in combination, for the purposes set forth.

5.- In a straddle-row cultivator, the share-blades $\mathrm{H}$, constructed as described, in combination with frame $A$, bent axle $C$, and wheels $B$, substantially as and for the purpose set forth.

No. 31,382,-SII.AS M. GOFF, EAST ADDISON, Vt.Cultivators.-February 12, 1861 .

Claim. - The arrangement of the adjustable shares $\mathrm{L}$, bar $M$, and frame $K$, with the frame $N$, segment bar 0 , roller $N^{\prime}$, frame $D$, share $E$, toothed shaft $F$, and hooks $J$, in the manner and for the purpose shown and described.

No, 31,393.-R. A. LEEPER and Z. B. KIDDER, SAN JosE, ILL.-Cultizators.-February $12,1861$.

Claim.-1. - The employment of the laterally swinging bars $I$ I and shares I in combination with the uprights $j^{\prime}$, beams L I, crank shafts $M$, rods $t k$, and lever $\mathrm{N}$, in the manner shown and described.

2.-The arrangement with the above-named parts of the arms $a a$, bars $b$, and slotted plates $D$, and frame $A$, seat $\mathrm{E}$, lever $\mathrm{F}$, heams $m \mathrm{~m}$, upright $j$, and standards $\mathrm{G}$, in the manner and for the purposes shown and described.

No, $1,996 .-$ R. A. LEEPER and Z. B. KIDDER, SAN JosE, ILL., assignors to DILLIS, KERN \& CO., ATLANTA, I1.L.-Cultizators.-February 12, 1861 .- Reissued June 13 1865.

Claim.-1.- Suspending the share standards I I upon pivots or bolts at their upper ends, substantially as and for the purposes shown and described.

2.- The combination and arrangement of the share standards I I, slotted supports $j j$, and beams $\mathrm{L} \mathrm{L}$, jointed at their front ends, as and for the purposes specified.

3. - The employment of the crank shaft $M$, provided with the arms $s$ and $r$, arranged and operating substantially as and for the purposes specified and described.

4. The combination of the oscillating standards I I, beams L L, crank shafts M M, provided with the arms $r$ s and rods $t$, arranged and operating as specified and lescribed.

5.- In combination with said standards I, beams L, connecting bar $\mathrm{K}$, crank shaft $\mathrm{M} r s$, and rod $t$, the rod $\mathrm{O}$ and and lever $\mathrm{N}$, arranged and operating as and for the purposes specified and shown.

6.- The combination and arrangement of the oscillating stanflards 11 , supports $j j$, cross-bar $k$, rods $l l$, and beams $m, m$, substantially as and for the purposes specified.

7-In combination with said oncillating standards I I, uprights $j ;$, cross-bars $k$, rods $l l$, and jeams $m m$, the employment of the fulcrum $h$ upon the cross-bar $g$, lever $F$, and rods $i$, all arranged and operating substantially as and for the purposes set forth.

8. - The arrangement of the spindles $a a$, bars $b \quad b$, and slotted plates $\mathrm{D}$ D, with the frame $\mathrm{A}$ and seat $\mathrm{E}$, all arrancer as and for the purposes shown and specified.

No. 31,682.-J. B. TURNER, JACKsonville, ILL.Cullizators. - Harch 12, $186 \mathbf{I}$.

Claim, - I.-The arrangement of the frame A, with the draught-pole $\mathrm{B}$, triangular frame $[$, and bar $($, substantially as shown, to admit of the independent hateral movement of the frame $A$, as set forth.

2.- The arrangement in the described connection with a cultivator of the double-tree $\mathrm{E}$ and stirrups $(; \mathrm{G}$, connected by chains $\mathbf{F}$, the stirrups being fitted loosely on the rod $\mathbf{H}$, at the front part of the frame $A$, to prevent the draught mechanism interfering in the least with the adjusting movement or frame $A$, and to render the line of draught perfectly adjustable.

3.- The combination of the hinged guard-frame $K$, chain $t$, and seat $I$, constructed, arranged, and operating in the mamner and for the purposes set forth.

4. - The combination of the curved bars $\mathrm{O}$ and $z$, and 
Miding collar l', comtructed and operating as described to adjust the height of the plongh: $K$ ".

5.-The employment or use of the adjustable culters or scraper. L L, applied to the frame A and in front of the rollers $\mathrm{M} \mathrm{M}$, for the purpose set forth.

6.-The arrangement of the driver's seat I, with the cultivator frames $\mathrm{J} J$ and guard-frame $\mathbb{K}$ attacherl, in connection with the adjustable bar $q$, as and for the purpose specified.

No. 31,702,-JOHN COX and J. A. THR()P, THREE Rivers, Mich, - Cultizators, - Marich io, 1861

Claim.-1.-The combination with the oblique side bar $\mathrm{A} A$ and swinging shovel-tocks of feet - $\mathrm{F}^{\prime \prime} \mathrm{J}^{\prime \prime}$ of V-shaped frame of three-sided metallic blocks G G, the blocks being constructed with their inner face to be parallel with the line of draught and in contact with the upper end of the shovel-stocks, and their outer face parallel with the oblique bars, each block being let in the sides of the hars and confined by a single bolt H, substantially as and for the purposes set forth.

2. - The combination with the oblique side bars A $A$ of metallic ears I I, wooden pins L I, swiveling connecting links $K K$, shovel-stocks $F^{\prime} F^{\prime}$, and pivoted screw-bolt H II, substantially as and for the purposes set forth.

3.- The arrangement of the V-shaped frame A A B, crank-רxle C, supportiıg wheels $C^{\prime}$ ' ', arch-shaped bar $\mathrm{E}$, adjusting lever $\mathrm{F} f$, three-sided blocks $G$ G, shovelstocks $\mathrm{F}^{\prime} \mathrm{F}^{\prime}$, screw-bolt; $\mathrm{H} \mathrm{II}$, metallic ear; I I, swiveling connecting links $\mathrm{K} K$, and wooden pins $\mathrm{L} L$, substantially as and for the purposes set forth,

No. 31,725.-JOHN MARKEL, Muntickli.I, ILL.Ciultivators. March 19, 1861 .

Claim.-1.-The combination of devices G b H $h \mathrm{I}$, for permanently or temporarily adjusting the working width of the cultivator shovels, constructed, operated, and operating in the manner substantially as set forth.

2.-In combination with the ahove, the reversille dished wheels $\mathrm{C}$, as fully described for the purpose set forth

No, 32,301,-JOSEPH VolvLES, NEw Hudos, MicH.-Cultivators - Miny 21, 1861

Claim.-The arrangement of the inclined braces C C F E standardi D D G $G$, handles II IH, and frame $A$, as shown and described, wherelyy the several parts are made to brace and support each other, and a very firm and desirable implement oltained.

No. 32,13.-T. SCOTT (\%) and H. S. POTTER,

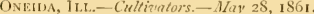

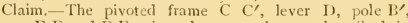
beams $\mathrm{E}$ E and $\mathrm{F} F$, pivoted to a rod $a$, as described, in combination with adjustable pivoted brackets J J J, and pivoted shovel stocks ( $;$; $G^{\prime} G^{\prime}$, all arranged as shown and described.

No. 32,431 -JOSIAH MUMFORD and J. W. WIL SON, CLARKSBURG, ()HIO.-Cultirators.-Miry 2S, i S61

Claim.-Sio hanging the pairs of ploughs that run on each side of the rows of plants to the frame and to each other so that they may have both a vertical and horizontal ad ustment, as well as a rocking movement, on their shaft $\mathrm{H}$, but when so rocked, one plongh of the pair shall not be throw' int s or out of the ground more than its fellow, as described and represented.

No. $32,4+2$, IVILIIAM S. WEIR, IR., MonmourH, J.1.-Cultinutors.-Way 28,1861

Claim.-1.-The combination of a spring catch $\mathrm{P}$ and catch-plate $Q$, with the plough-frame I and seat-frame, substantially as and for the purposes set forth.

2.- The combination with the seat-frame and plough frame of catch-plate $(Q$, spring catch $\mathrm{P}$, and adjusting hlocks $d d$, constructed and arranged to operate in relation to each other as and for the purposes set forth.

3.-Pivoting or hinging the plough-frame I to the front of the sent-frame, and in front of the seat-frame and in front of the axle of the man supporting-wheels, in combination with and providing said frame I with two sets of ploughs I J K K, arranged to operate in relation to each other as and for the purposes set forth.

No. 32,560.-JOSEPH GUM, and ST. CI.AIR GUM, MARSELles, IlL-Cultivators-7nni I8, 1861 .

Claim.- The combination of the lever $l$, the levers l" $l$, to control the vertical and lateral movements of the cultivator while in use, with the upright hooked metallic rod $r$, by use of which to adjust the cultivators from the ground, for removing the machine from place to place when the machine is not used in cultivation, subutantially as described.

No. 33,1 29.-HENRV BOWEKS, NEW Hudson, Mich. Cultizutors.-4ugust 27,1861 .

Claim.- The bolster $\mathrm{D}$ the king bolt $\mathrm{E}$, axle A, neap C, heams $\mathrm{FF}^{\prime} \mathrm{V}$, hinges $\mathrm{H} \mathrm{II}^{\prime}$, standards or arms $\mathrm{K}$, braces $\mathrm{N}$, ploughs or hoes $\mathrm{L} \mathrm{L}^{\prime}$, and handles $\mathrm{P}$, the whole being contructed, combined, arranged, and operating as and for the purposes described.

No. 33,176.--WADE 11. HAWORTH, Tonawanda, 11.L.-Cultizators.-August 27, 1861 .

Claim.-I.-The connecting rod E, and crank-shaft $\mathrm{D} d$, employed in the manner explained, to turn the wheels $C$, on a vertical axis by the deflection of the tonme, as and for the purpose set forth.

2.- The combination of the beams $\mathrm{K} \mathrm{K}$, levers L M and $n$, rods $\mathrm{N} n l^{\prime}$ and $\mathrm{O}$, and suspending chains $l$, arranged and operating substantially as and for the purposen explained, in connection with a four-wheeled cultivator.

No. 33,235.-RIIEV BROTTON, OSKALOOSA, IOWA. - Cultiziators-Septimbir 10, 1861.

Claim.- The expanding toothed frames $G$ G, constructerl substantially as shown, conniccted to the mouthed bar $A$ through the medium of the levers $\mathrm{K} \mathbf{K}$, and attached to the elevating levers $J \mathrm{~J}$ by means of rods e e $f s$, all combined and arranged for joint operation, as and for the purpose set forth.

No. 33,834-W11KENSON FURNAS, ONONWA, JowA. -Ploughs.-December 3, 1861 .

Claim - The arranirement of the pulley bars $\mathrm{N} \mathrm{N}$, pulleys $\mathrm{M} e$, treadles $\mathbf{P}$, levers $\mathbf{J} \mathbf{J}$, cords $c c$, bars $\mathbf{F}$ F, and racks $\mathrm{K} K$, with the swinging and rising plough standards $G_{i} G_{1}$ and the driver's se it $O$, all as shown and described.

No. $33,860,-1$. B. TURNER, JACKSONVILle, le...Cultivators, - December 3, IS6r.

Clain 1.- In combination with a main frame, supported on and carried by a drum $\mathrm{B}$, on one side serving as a roller and a wheel $\mathrm{C}$, on the opposite side a hinged plough frame $\mathrm{I}$, controlled by said main frame substantially as described.

2. - The combination of the pivoted levers E P, with a horizontally hingad tongue $O$, so that the driver, from bis seat, may change the line of draft and the direction of the machine, substantially as set forth.

3.- The angularly shaped brace $n$, for holding the mouldhourd or the brace at it upper portion, when it also admits of having the unobutruted space between the monld-boald and the brace, as at $h$, for the purpose as described.

4.-Fastening the monld-boards to the plough frame by means of the cross braces $i j$, brace $n$, and staple $m$, with its key, in the manner and for the purpose described.

5.- The removatle extension piece $t$, in combination with the mould-boird, for the purpose clescribed.

No. 34,362,-N. S. HARRYMAN, FRANKFURT, IND.Cultivators.-February 11, 1862.

Claim.- The combination of the several parts, constructed and operating as described, to wit: The bar $\mathrm{G}$ pivoted to the top of the rear standards, the frame $\mathrm{F}$ and standards $\mathrm{F}$ E, with the draught frame, all substantially as shown.

No. 34,406.-JAMES COLLINS, FARMINGTON, ILL.Cultizitors-Fibuary 18,1862 .

Clain - 1-The combination of the perpendicular draught rods $f f^{\prime}$ depending from the transverse bar $a a^{\prime}$ and braces $h h$, extending back from the lower part of the said dranght rods to the axle-tree, all construeted and arranged as described and for the purposes stated.

2.- The combination of the clevis $y$ and draught rods $f f$, when convtructed and operating as and for the purposes set forth.

3.-The crank levers $k k^{\prime}$ and adjusting nuts $x$, constructed and arranged in connection with a corn plough on wheel in the manner and for the purposes set forth.

4.-The combination of the cross-bar $a a^{\prime}$, draught-rods $f l^{\prime}$, braces $h h h^{\prime}$, clevis $g$, adjusting levers $k k^{\prime}$ and $p p^{\prime}$, curved axle-tree $c c^{\prime}$, and seat $m$, all substantially as and for the purposes set forth. 
No, 34.528. INIDRJII S.IWYTK AND HENRY

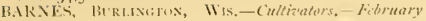
25. 1 (S) 2 .

Clain.-The arrangement of the pendulous suspended frame (; attached draught pole $F$, shates $E$, rock $I$ ), and chains $I^{\prime} D^{\prime}$, with the segments $K K$, rock shaft 1 , and lever $I$, in the minner shown and described.

No, 34.630,-1.1. (iREEN, HKNkv, 1t.1.-Cultivators.Wurch 11, 1862.

Claim. These four features combined in onc machine in the manner described: the first feature consisting in the main frame, the bowed and cranked axle. and driver's seat, arranged in respect to each other as descriled; the second, convisting in the arrangement of the tongue ( $;$, the lever 11 , and the driver's seat $I$, in relation to each other, as set forth; the third, consisting in making the main frame in two parts, arranging and elevating the driver's seat $J$ and the frame $E$ E L L and $\mathrm{V}$ thereon, and the bow of the axle therein, as set forth; the fourth feature consists of the bars 00 , the frame E E L I, and N, the swivet I, and the main frame, arranged in relation to each other as set forth.

No, 34,732.-F. E. BROMN, Huiнtsтown, N. J.Cullitaturs, - Warth 25, 1862 .

Claim.-1.-The combination of the adjustable slides F, plates $G$, stotted pendants $E$, and crnecting rod If, with each other and with the standard $I$, in the manner shown and described.

2.- The arranjement of the pendant-4lotted bars E. J, slides $\mathrm{F}$ K, plates $\mathrm{G}$ I, rods $\mathrm{H}$ II, standards I N, and arms $i o$, with each other and with the arms $q$, links $j$, arms $s$, shafts $l$, and lever $O$, an and for the purpone show' scrilsed.

No. 34,828,-JOIIN GROSS, MANILLA, IND.C Cultiinters-April 1, 1862 .

Chim.-The lever frame B, with lever $C$ and adjutable point 1 , when operated in connection with the frame $A$, with the guide bar F, and rullers I I, by means of the stand.rds E, the whole being arr.unged and operated as set forth.

No. 35,272,-E. J. WHITE, LockE, N. V.-PloughsMay $13,1862$.

Claim.-The ploughs If $(2$, when attached to vertical sliding standards $\mathrm{L}, \mathrm{K}$, which pass loosty through the mounted frame or platform $\mathrm{A}$, and are connected to adjusting levers $\mathrm{K} \mathrm{S}$, in combination with the vertically adjuntable coulters $\mathrm{P}^{\prime} \mathrm{T}$ and guage wheel $\mathrm{X}$, all arranged for joint operation, as and for the purpose set forth.

No. 35.282.-L. B WATERMAN, ChICAGo, II.L., assignor $t$, himself and J IIES S. B.AN(i., of the same place,-Cultizators, - Mlay' 13, 1862.

(laim.-The arrangement of the adjustable seit 1 ), in combination with the duble-tree $(\mathbf{i}$, draught-rod $\mathbf{K} \mathbf{K}$, and graduating bur $I$, when operated and attached to the framework for the uses and purposes described, as sulstantially set forth.

No, 35,669.-A. B. CASS, Nescativf, Iow.:-Cultizators.-June 24,1862 .

Clain- The pivoted share standards $a^{*} a^{*}$ and stiding share standards $g$ s, connected to the jointed adjustable lever $\mathrm{E}$, in combination with the seat $\mathrm{H}$ and lever $\mathrm{F}$, connected to a lever $\mathrm{E}^{\prime}$ and the seat support 1, all arranged as and for the purpose specified.

No, 35.673--R. D. IOODGE, ADEL, IowA.-Cultizators.- 7 une 24, 1862 .

Claim. - The arrangement of the sturrups $b$, connecting the front ends of the beams $G\left(i^{\prime}\right.$, in combination with the treadles $e$, hand-levers $k$, and guide-bars $m$, alt constructed and operating in the manner and for the purpose shown and described.

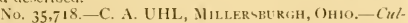
tivators.- Fune 24,1862 .

Claim.-1.-The arrangement of the lever $L$, rods $m$, beam I, and ploughs $\mathrm{E}$, as described, for the purpose of lifting the ploughs from the earth as described.

2.- The guides $F$, for regulating the depth of the fur rows, in combination with the pins inserted in the holes $f$, in the said guide-bands F, substantially as described and hown.
No, 35,085.-I. N. B.IUMANN, MUSATINE, IOWA.Cultivators.-Fuly 29, 1862

Claim, I I The attaching of the double tree $I$, to the cross-bar 1 of the standards $G$ G when used in combination with the chain if It passing under adjustable pulleys $\mathrm{N}$ $\mathrm{N}$, and a whifiletree $\mathrm{P}$ connected to each chain, substantially as and for the purpone set forth,

2.- The guard or clod crmsher, consisting of the adjustable bars R R provided with parallel rock ", and attached to the bar 1), which is also adjustable and secured to the crosu-bar K, as set forth.

No. 36,019.-J. S. PADON, Stmafrajel.d, Il.L.-Cultišrtors. - July 29, 1862

Claim.-The arrangement of the adjustable frames C, and beams $F$ and $G$, in respect to each and under the main frame $\mathrm{B}$, when constructed and operated in the manner described and shown.

No. 36,158,-1. B. JONEL, XeniA, ()Ho.-Cultizators. - Iuxust 12,1862

Claim -1.- The laterally moving or adjus!able plough frame 1), when operated as shown, to wit: by means of the tooth segment $\mathbf{E}$ E on the rock shaft $\mathbf{F}$, gearing into the racks $d d$ on the frame $\mathrm{D}$, and the latter fitted in the mounted frame $A$, as and for the purpose set forth.

2.- The manner of attaching the plungh standards $\mathrm{H}$ to the frame $\mathrm{D}$, to wit: by placing the standards in guirles $i$, attached to pendants I secured to the frame D, and securing the standards at any desired height by means of the catches J, an and for the purpose specinied.

No. 36,609.-R. R, GASKILL, Wyanf, ILL.-Cullivators. -Octolier $7, \mathbf{1} 862$.

Claim.-1.-The plough bars F F, secured to the front cross-bar $h$ of the frame $A$ by means of the double hinges or universal joints $a^{*} a^{*}$, in combination with the rods $\mathrm{G}$ $\mathrm{G}$, fitted in the bearings $\mathrm{H}$ connected to the b.ars $\mathrm{F} \mathrm{F}$, and arringed with the adjustable bearings $\mathrm{J}^{\prime}$, as shown to operate as and for the purpose specified.

2.- The adjustable or movable seat $($, when arranged as shown, and used in combination with the bars $F$ F, rods G $G$, and levers $J$ or $K$, as and for the purpose set forth.

3.- The swinging or ad ustable draught pole $\mathrm{D}$, arranged as shown with the holding lever $\mathrm{E}$, in combination with the lirakes formed of the levers $O$, rod $Q$, and cranks $R$, with the shoes $S$ attached, all arranged to operate as and for the purpose set forth.

No. 36,785 , - W. H. JORI AN, ROSEVILIE, IND.-Cullizators, October 28 , i 862 .

Claim, - The ploughs $\mathrm{J}^{\prime}$, when arranged so as to be simultaneously raised and lowered hy the turning of the bars 1 G, connected by a rod or bar $I$, as shown, in connection with the laterally adjustable frame $\mathrm{A}$, connected with the axle $\mathrm{E}$, and all arranged as and for the purpose set forth.

No. 36,859.-CVRUS ROBERTS, THREE RIVERS, Ilicu,-Cultizators, - Viarember 4, 1862 .

Claim,-1,- Mounting the front feet in a frame having both a lateral and a vertical movement when arranged and operating substantially in the muner and for the purpose described.

2.- The combination of the front and rear lifing frames, to which the rempective rows of teeth are attached, with a hand lever, substantially in the manner described for the purpose set forth.

3.- The combination of the stay chains with the frame and feet, when arranged in relation to the juints of the lifting frames, in the manner and for the purpose specified.

4.-The combination of the tongue, driver's seat, and front and rear lifting frames, when arranged in relation to the wheels, substantially as herein described, for the purpose of halancing the machine, as set forth.

No. $36,889 .-1$. M. BI.ACK, Auburn, IL...-Cultirators.-Notember II, IS62.

Claim.-The rock-shaft D, with the plough bars or Leams $\mathrm{E} \mathrm{E}$ attached to it, as shown, and connected at their hack end by the cross-bar $\mathrm{F}$, in combination with the arm $\mathrm{G}$ and the lever I, the latter being provided with the arm J fitted between cleats or projections $d d$ on bar $F$, all arranged substantially as and for the purpose herein set forth. 
No, 36,022-1 W TALIAFERRO, KeIthshurg, IL1.-Cultizators. - Vote'mber i1, 1862.

Claim.-1.- The plough beams $G$, connected at their front ends by universal joints $d$ to pendant supports $I$ at the front part of the frame $\mathrm{A}$, and provided at their back ends with journals $c$, which are fitted in pendant guides $H$ at the back ends of the frame $A$, in combination with the uprights li $\mathrm{j}$, bar $\mathbf{L}$, and rock-shaft $\mathbf{M}$, with treadle or foot-piece $\mathbf{N}$ attached, all arranged as and for the purpose set forth.

2.- The rotary shield or guard formed of the two wheels $Q Q$, provided with radial teeth or rods $m$, and attached to the bar P, which is connected to the draught pole B by the links $l l$, substantially as and for the purpose set forth.

No. 36,945--J. L. ELLIS, ConcoRD, H.L.-Cultizators.- Nozember IS, 1852.

Claim.-The rock shafts ( $\mathrm{C}$, uprights D D, connected at their upper ends by the bar $\mathbf{E}$ and the lever I, said parts being applied to the main frame $A$, provisled with curved transverse bars $\mathrm{B} \mathrm{B}^{\prime}$, in combination with the supplemental frame composed of the parallel bars $\mathrm{L} \mathrm{L}$ and curved trans. verse bars $K \mathrm{~K}$, with the driver's seat J attached, the supplemental frame being mounted on wheels connected to the main frame, and all arranged to operate as and for the purpose set forth.

No. $36,948,-B$ and C. FURNAS, (JNonwa, lowa.Cultivators.-Nonembir I8, IS52.

Claim.-1.- The bars $\mathrm{H} \mathrm{H}^{\prime}$, connected at their front ends to the pendants F F, and provided at their back ends with the driver's seat I, in combination with the bars MI M connected at their back ends with the cross-piece $\mathrm{N}$, and attached to the plongh-beams $G \mathrm{G}$ by the cords or chains $k k$, all arranged substantially as and for the purpose herein set forth.

2.-The treadles $\mathbf{K} \mathbf{K}$, when attached to the ploughleams $G G$, and connected to the cords or bar $L$ by the cords or chains $l$, as and for the purpose herein set forth.

3.-The uprights $O O$ attached to the plongh-beams $G \mathrm{G}$ fitted in the guides $m m$, of the bar $\mathrm{L}$, and connected by the bar P, substantially as and for the purpose specified.

No. 37,009.-CYRUS ROBERTS, THREE RIVERS, Mich.-Cultivators.- Vin'e'mber 25, 1862 .

Claim.-1.-The combination of a foot lever, hand lever and crank axle with a driver's seat, when arranged for joint operation, subatantially in the manner described for the purpose set forth.

2. - The combination of the hind feet $\mathrm{K}$ with the removable projecting arms $\mathrm{K}^{\prime}$, when arranged and operating substantially as and for the purposes described.

No. 36,0I0,-CYRUS KOBERTS, THREE RIVERS, MICH.-Cultizators.- Vinember 25, 1862 .

Claim,-1,-Nounting the feet in a frame having a lateral sliding movement, substantially as described, in combination with stay chains attachad at one end to the feet and at the other to a fixed point on the main (rame, as set forth for the purpose of keeping the feet always in the same plane relative to the frame or to the path of the machine, notwithstanding said lateral movements.

2.-The combination of the rod $G^{\prime}$, sliding frame $g$, and lever $g^{3}$, when arranged and operiting substantially as and for the purpose described.

No. $37,(119 .-1$. B. WATERM.AN, CHIC 160 , ILL.Cultizators.- Vove'mber 25, 1862.

Claim.-1.-The peculiar arrangement of the beams $\mathrm{J} \mathrm{K}$.II and the bar $\mathrm{L}$, in combination with the upper framework, when operating substantially as described and for the purposes specified.

2.- The arrangement of the lever I, the chain $h$, and the pulley $\mathrm{H}$, when the same are used in connection or combination with the grooved axle attachment $\mathrm{E}$ and the slide $\mathrm{F}$, the whole being arranged and operating as and for the purposes set forth.

3.- The adjustable bow $\mathrm{G}$, when arranged with the bar $\mathrm{I}$, as and for the purposes set forth and delineaterl.

No. 37,166,-H. I. HEATON, PEOR1A, ILL.Cultivators.-December 16, 1862.

Claim.- The arrangement of the sliding bars $\mathrm{C} \mathrm{C}^{\prime}$, draught-pole $\mathrm{D}$, bar $\mathrm{E}$, and lever $\mathrm{F}$, in connection with the frames $\mathrm{J} J$, having the ploughs $\mathrm{P}$ attached, all arranged as and for the purpose herein set forth.
No. 7,944--HENRY I. HEATON, SiDNEy, IOWA, assignor to WM. A. KNUWLTUN.-Cultizators,-37,166. - December 16, 1862.-Reissued Norember 13, is77. [Filed fun? 25, 1877.]

Claim.-1.- The arrangement of the sliding bars $\mathrm{C}^{\prime} \mathrm{C}$ ', draught-pole $\mathrm{D}$, bar $\mathrm{E}$, and lever $\mathrm{F}$, in connection with the frames $\mathrm{J} J$, having the ploughs $\mathrm{P}$ attached, all arranged as and for the purpoie hereinbefore set forth.

2.-The combination, with a double-tree pivoted in rear of the supporting-axle of the cultivator, of pendants located in advance of said axle, and rigid draught rods directly connecting the outer ends of the double-tree with the lower ends of said pendants, substantially as described.

No.37,251.-WILliAM S. WEIR, JR., Monmouth, I1.L. - Cultizators.-December 23, 1862 .

Claim. -1.-The combination and arrangement of the frame $\mathrm{B}$, tongue $\mathrm{A}$, and wheels $\mathrm{C} C$, substantially as set forth.

2.- The combination with the posts $\mathrm{B}^{\prime} \mathrm{B}^{\prime}$ and ploughbeams of the loops $a$ and draught-adjuting devices $b b$, substantialiy set forth.

No. 4,6Ió.-Willia.I S. WEIR, Jk., Monmourh, 1LL.-Cultivators.-37,25 I.-Dicember 23, I862.-Reissued Octoher 24,1871 .

Claim.- 1 .- The combination, in a walking straddle-row cultivator, of the following instrumentalities, viz: Two wheels $\mathrm{C} \mathrm{C}$, tongue $\mathrm{A}$, axle $\mathrm{B}$, and two plough-beams $\mathrm{F} \mathrm{F}$, independently hinged to the axle by means of joint-pieces $\mathrm{K} \mathrm{K}$, so constructed as that the plough-beams, with their gangs of ploughs, may be moved independently anit freely in a lateral or vertical direction, and be retained, during the operation of the ploughs, in an upright position, without the aid of other connection or support, substantially as and for the purpuse set forth.

2.- The cumbination, in a walking straddle-row cultivator, of the following instrumentalities, viz: Two wheels $\mathrm{C} C$, tongue $\mathrm{A}$, axle $\mathrm{B}$, and two plough-beams $\mathrm{F} \mathrm{F}$, hinged as aforesaid, with a bar D, or equivalent device, projected in rear of the axle, by means of which the plough-beams, with their gangs of ploughs, can be suspended clear above the ground, when not in use, substantially as set forth.

3.-The joint-pieces $\mathrm{K} \mathrm{K}$, constructed as described, with perforated places $b b$, and holts $c$ and $e$, in combination with the plough-beams $F$ and uprights $B^{\prime}$ of the axle, for the purposes set forth.

No. 37,309.-DANIEL S. STAFFORD, DECATUR, MACoN, Cir, 11.t._-Cultizators. Finuary 6, 1863.

Claim. - I. - The suspended and dually-connected arrangement of single ploughs in combination with each other and with a wheeled carriage so as to operate substantially as described.

2.-In combination with the suspenrled and counected arrangement of ploughs in pairs, so constructing and arranging the carrying frame thereof that it may be inclined by the driver so as to operate substantially as specified.

No. 37,474-CHARIES IV. S. HEATON, BELLEVILLE, ST. ClatR Co., ll.L., assignor to JABEZ 1. PlGGOTT and H. RENTCHI.ER, of same place.-Cultivators.- Fanuary 20, 1863.

Claim.-1.-A cultivator frome, folding and expanding vertically on the plan of a parallel rule, substantially as and for the purposen descrilied.

2.- The combination of the slotted beams B B, slotted links $O O$, and vertically folding and expanding parallel rule frame, substantially as and for the purposes described.

3.- The combination of the elevated cultivator frame A $\mathrm{A}^{1} \mathrm{~A}^{2} \mathrm{~A}^{3}$, clutch pulley $\mathrm{H}$, or it: equivalent, propelling wheels $\mathrm{E}$, cross shaft $\mathrm{F}$, and pendant cultivator lieams $Q^{\prime}$, suhstantially as and for the purposes set forth.

4.-The combination of the ratchet wheel, lever pawl and hrake with the pendant cultivator beams, substantially as and for the purposes set forth.

5.- The combination of the lever $\mathrm{M}$, with the pawl, brake, ratchet wheel, and pendant cultivator beams, substantially as and for the purpose set forth.

6.- The combination of the swinging lever $\mathrm{P}$ and pen- 
dant cultivator heams in a machine operated substantially as herein deserilsed.

7.- Guards or poles 6 , in combination with a back yoke 8 , as set forth, or the eyuivalent thereof.

s.-The poles 6 , when applied and used for the purpose set forth.

9.-The back yoke 8, when applied and used as and for the purpose set forth.

10.-In a cultivator for cultivating growing crops, and which employs pendant heams ()$^{\prime}$, and a vertically expanding and folding parallel rule frame, the combination therewith of the adjustable stanlard 3 and adjustable brace 4 . made in two pieces and with a loose joint, substanti.lly in the manner and for the purpose described.

11. - The arrangement together on the same machine of the ratchet wheel $\mathrm{K}$, the brake $\mathrm{N}$, and foot and hand levers M L I, and P all combined as shown and described.

No. 37,532.-JOH. A. THROP and JOIIN COX. THRFF RIVERs, St. JosepH Co., Ilich.-Cultizators.Famuary, 27, IS63.

Clain.-1.-The arrangement of the shovel legs on pivots, in combination with a laterally adjustable frame, or its eauivalent, swivelling connecting or stay rods and yield. ing connections or wooden pins, substantially in the manner and for the purposes described.

2.- The flexible or jointed frame $\mathbf{H}$, or its equivalent, in combination with the swivelling stay rods $h$, legs $1 \mathrm{I}$, crossbars $\mathrm{A}^{\prime} \mathrm{A}^{\prime \prime} \mathrm{A}^{\prime \prime}$, and the cultivator $\mathrm{A}$; all constructed substantially in the manner and for the purpose lescribed.

3.- Adapting the cultivator to the double use of "seaming" and "hilling" by the combination of a stiff frame, a jointed, pivoted frame $\mathrm{H}$, and adjustable steps or pins $a a$, substantially as set forth.

4.- The jointed frame $H$, in combination with a rigid frame, when the frame $\mathrm{H}$ is pivoted at its front ends and sapported by a guide at its rear end, substantially as described.

5.-The arrangement of the stay rods $h$ and the legs I I, in combination with a frame $\mathrm{H}$, which lums on a different fulcriz from those on which the stay rods turn, substantially as set forth

No. 37,775--E. II. SAWYERS, West GROVE, DAvis Co., IowA.-Cultivators.-February 24, 1863.

Claim. - The main frame $C$, guide rod $G$, melallic support $\mathrm{J}$, lever II I, rods a $a$, plough frame $\mathrm{F}$, and spindle $j$, the whole combined and arranged to operate in the manner and for the purpose specified.

No, 38,171-AIFRED LEIGH, Cinton STation, HiNTERDox Co., N. J.-Cultivators.-April 14, 1863.

Claim.- The arrangement of the frame A with wheels $3 \mathrm{~B}^{\prime}$, adjusting levers $\mathrm{C}$, furrowing shares $\mathrm{E}$, hinged cultivator teeth $F$, and swivel bar $G$, with marker $H$, all constructed and operating in the manner and for the purpose herein shown and described,

No. 38,261-CHARLES W. S. HEITON, BEIILVII.LE, ST. Clair Co., ILI.., assignor to JABEZ J. PIGGOTT and HENRY RENTCHLER. of same place.Cultinators.-April 2 I, $1 \mathrm{~S}_{3}$.

Claim.-I. - The truss-frame A, constructed in the manner described, in combination with short axles and vertical ontside hangers $i$, as and for the purpose set forth.

2.- The guard-hiace E, arranged and operating substantially as described.

3 -The combination of the long tongues or poles $\mathrm{K}^{\prime} \mathrm{K}^{\prime}$, neck yoke $\mathrm{I}$, reach $\mathrm{L}$, and brace $\mathrm{N}$, substantially as and for the purpose set forth.

4. - The combination of the adjustable seat $O$, reach $L$, long tongues $\mathrm{K}^{\prime} \mathrm{K}^{\prime}$, neck yoke $\mathrm{II}$, and brace $\mathrm{N}$, substantially in the manner described.

5.-A shovel beam formed of two parts $\mathrm{B}^{\prime} \mathrm{B}^{\prime}$, which make an angle, in combination witl a slotted standards, which is adjustable, substantially as and for the purposes set forth.

6.-The combination of the jury-brace $/$, which is adjustable, with the donble beam B B', and slotted standards, subitantially as and for the purpose set forth.

7.-The arrangement of the foot levers $n$, curved bars $p p$, notched cross-piece $\%$, roller $m$, and cords or chains $o$, substantially as and for the purpose set forth

8.-The arrangement of the slotted adjusting pieces $c$, pendant share-beams, and clraught device I, with single swingle-trees and frame $A$, and ontside hangers $i$, , in the manner and for the purpose described.

9.-The combination of the slotted picces $C$, brace rod E, frame $\mathrm{A}$, and pendant share-beams, substantially as and for the purpose set forth.

No. ${ }_{3}^{3} 8,295$ - - WILLIAM D. DORSEY, Decatur, Macon Co, ILL.-Cultizutors - L pril $28,1863$.

Claim.- The arrangement, in the manner herein shown and described, of the two adjustable share frames I I and the operating foot levers L L with each other and with the bars E E, the pole A, and the driver's seat C, all as set forth.

No. 38,651--J. W. BOOKER, Fairmount, VermilLION Co., ILL.-Cultivators.- May 26, I863.

Claim.-The plough-heams E E connected to the main frame $A$, as shown, in combinanion with the uprights I I, provided with the stirrups $K K$, the handles $G \mathrm{G}$ attached to the plough-beams, and the curved rods L L, al] arranged for joint operation as and for the purpose herein set forth.

No. 38,884 .-PHILIP COONROD, KeIThseurg, MerCER Co., ILL.-Cultizutors.-Juni 16, 1863. Antedated Itut 2, 1863

Claim,-1.-The combination of the stationary frame D, and the rising and falling frame $\mathrm{E}$, when the latter is provided with the laterally-adjustable ploughs $\mathrm{F}$ and guards $\mathrm{M}$, :rranged with the bars or levers $j j$, operated through the medium of the foot lever $J$ or hand lever $I$, as herein set forth.

2.-The lever $u$, connected with the frame $\mathrm{F}$, through the medium of the shaft L, crank $s^{\prime}$, and link $s$, but this only when used in connection with the laterally-adjustable ploughs $\mathrm{F}$, and the means employed for operating as berein described.

No, 39,276.-TULLY R. CORMICK, CAP-AU-GRIS, Lincoln Co., Mo.-Cultivators.-July 21, 1863.

Claim.-I.- The combination of the plough shanks and handles $G \mathrm{G}$, dranght chains $\mathrm{L} \mathrm{L}$, universal joints $\mathrm{M}$, connecting rod $H$, and adjusting nuts $h$, constructed, arranged, and operating substantially as and for the purposes set forth.

2.-The combination of the elevating levers $1 \mathrm{I}$, draught chains J J, and binged plough-shanks F F, constructed, arranged, and operating substantially as and for the purposes specified.

No. 39,412.-A. S. MARKHAM, MoNMoUTH, IVARREN cousty, lLL.-Cultivators.-Ausust 4,1863 .

Claim-1 - The frame A, having a draught-pole B attached to it, in connection with the rollers $\mathrm{C}$, fitted in the lower part of said frame $\mathrm{A}$, and the plough beams $\mathrm{D}$ attached to the frame $\mathrm{A}$, and connected at their back parts by the bar G, substantially as and for the purpose specified.

2.- The particular manner of connecting the plough beam - $D$ to the frame $A$, to wit: by having the front ends of the beams slotted longitudinally with pins or bolts $y$ passing through the slots into bars 1 , which are fitted loosely on shafts $e$, substantially as and for the purpose set forth

3.- The draught bars J, attached to the front ends of the plough beams $D$ by bolts $j$, and connected at their upper ends to the frame A by chains $l$, and having hooks $k$ secured to them, all arranged as shown, wherely the dranght may be regulated, and the beams $\mathrm{D}$ adjusted longitudinally as may be required.

No. 39,428.-C. C. STEARNS, Homer, Champaign, COUNTY, ILL,-Cultizators,-4ugust 4, 1863.

Claim.- The rising and falling bars $\mathrm{F}$, having ploughs II att.ached to them, in connection with the guides $G$, provider with the catches $\mathrm{L}$, the above parts bein arranged as shown, with the bars D D attached to the axle $\mathrm{A}$ and cross-bar E, as and for the purpose set forth.

No. 39,450.-C. E. MEADE and G. E. STEVENSON, DENMARK, LEE COUNTY, IowA, assignor to C. E MIEADE, aforesaid-Cultivators.-Ausust 4, 1863.

Claim. - The slide bar $\mathrm{G}$ attached to the axle A, substantially as shown, and provided with the pendants H H, 
in combination with the lever I, plough-frames $\mathrm{J} J$, shield or guard L, and treadles $\mathrm{K} \mathrm{K}$, all arranged to operate as and for the purpose herein set forth.

No. 39,553.-SAMUEL COWAN, BLOOMFIELD, DAVIS CuUnTy, lowa. - Cultivators.-August I 8, 1863.

Claim.-1.-In combination with the adjustable and hinged cultivator stocks, herein described, the levers $K$, rods $\mathrm{NO}$, and treadles $\mathrm{M}$, substantially in the manner and for the purpose set forth.

2.- In combination with the adjustable and hinged cultivator stocks, herein described, the lever $\mathrm{H}$ and transverse bar $\mathrm{G}$, for the purpose of shifting said cultivators sidewise, suhstantially in the manner and for the purposes set forth.

No, 39,597--JAMES P. TOSTEVIN, RACINE, Wis.Cultizutors. - Ausust I $8, \mathbf{i} 863$.

Claim.-The combination and arrangement of brices $\mathrm{H}$ hooks I, nuts I, and staples I, operating substantially in the manner and for the purposes set forth.

No, 39,686, -N. E. SMITH, SPRINGinale, CFDAR County, lowa.-Cultivators.-Austust 25, 1863.

Claim.- The draught pole $B$, pivoted to the front har $A$ of the machune as shown at $a$, with its back end resting on the back bar $\mathrm{A}^{\prime}$, and having the driver's seat $\mathrm{D}$ attached to it, substantially as and for the purpose herein set forth.

No. 39,703.-SAMUEL ROCKAFELIOW, MUSCATINE, IowA., assignor to Ifimself and JOSHUA W. HOOPS, of same plince.-Cultivators.-Ausust 25, 1863.

Claim.-1.- The combination of the cords $c c$ with the draught pole $\mathrm{E}$, pivoted at its rear end to the cross-bar $\mathrm{A}^{\prime}$, and the foot levers $1 \mathrm{I}$, arranged, constructed and operating as and for the purposes herein delineated and set forth.

2.- The combination of the levers $\mathbf{F}$ and the rods $\mathrm{H}$ with the curved handle $\mathrm{G}$, when constructed, arranged and operating as herein set forth and clescribed.

3.- The combination and arrangement of the beams D $\mathrm{D}$, adjustable at their front ends, with the rods $\mathrm{H}$, the levers $F$, and curved handle $G$, as and for the purposes herein set forth and shown.

No. 39,760.-1I. B. SMITH, Eureka, Woomford Counry, IlL.-Cidtivators.-Siptember. 1, IS63.

Claim.-1.-The pivoting of the plough handles $\mathrm{N} \mathrm{N}$, to rods $\mathrm{II}$, fitted vertically and loosely in shafts $\mathrm{L}$, which are allowed $t)$ turn in the ir bearings in pendants $g^{\prime}$, attached to a shaft $f$, which is also allowed to turn in its bearings, all being arranged as shown to admit of the adjustment of the ploughs $\mathrm{O}$, as and for the purpose set forth.

2.-The ploughs $\mathrm{J}$, and rake share $\mathrm{E}$, attached to separate or independent shafts $\mathrm{H}$ II C, which are fitted loosely between pendants $d$, connected to a shaft $\mathrm{B}$, that turns loosely in its bearings in the frame $\mathrm{A}$ of the mochine, as and for the purpose set forth.

3.- In combination with the ploughs $O O \mathrm{~J} J$ and rake share $\mathrm{E}$, arranged as shown, the adjunting chains $\mathrm{F}$ G K and $A^{\prime} P$, applied in the manner as and for the purpose specified.

No. 7,377.-HOEL, B. SMITH, Buck IIEAD, GA., assignor to STEPHEN A. GOODWIN and DAVID J. POWERS, CHICAGO, and R ILPH ENERSON and WM. A. TALCOTT, ROCKFORD, JLL.-Cultitutors-39,760, September I, I863.- Reissued October 3I, IS76. [Filed June 6. Is76.

Claim.-1.-The combination, substantially as herein, before set forth, of the wheels, the open skeleton draft frame, and the ploughs capable of lateral oscillation with respect to the path of the wheels while the machine is operating.

2.-The combination, substantially as hereinbefore set forth, of the wheels, the open skeleton draft-frame, the ploughs capable of lateral oscillation with respect to the path of the wheels while the mochine is operating, and a seat in rear of the open space, whereby the operator has an opportunity to observe and readily adapt the ploughs to the irregularities of the plants in the rows.

3.-The combination, substantially as hereinbefore set forth, of the wheels, the open skeleton-frame, and the laterally-adjustable ploughs suspended therefrom.

No. 39,837 . G. H. SCHANCK, Libertyville, Lake County, ILL.-Cultizators-Sippimber S, IS63.

Claim.-Extending the hinged frame $g$ back, and locating the driver's seat $s$ thereon, in relation to the foot-board $f$, handle $m$, and spring $n$, as described; whereby the driver can drop the cultivator ploughs with his hands, and at the same time press them into the ground, or regulate their dip with his weight.

No. 40,095--BENJAMIN F. FIELD, SHEBOYGAN FALLs, WIS, - Cultivators. - September 29, 1 S6 3.

Claim.-1.-The arm of drag-bar $G$, when constructed as descrihed.

2.-The combination of the arm G, the cultivator E F, the independent rolling shield $\mathrm{K}$, and the arm $\mathrm{L}$.

3. - The combination of the crank $R$, the pulleys $t$ and $s$, the shaft $\mathrm{P}$, and the cords or chains $r$ and $p$, for the purpose of elevating the cultivators and shields.

4.- Making the wheels of a cultivator adjustable on their shaft or axle by means of the collars $n n$ and set screws $o$, substantially as set forti.

No. 40,367.-RICHARD H. SPRINGSTEAD, CONstantine, St. Joseph County, MiCh.-Cultivators.-Oc. tolier 20, 1863.

Claim.-1.- The arrangement of the lever $\mathrm{C}$, sliding bar $\mathrm{F}$, its attached teeth $\mathrm{H}$, and their hinged bar $\mathrm{E}$, with the hinged bar 1 , its attached teeth, lever $h i$, and standard $\mathrm{J}$, all in the manner herein shown and described.

2.- The arrangement with the hinged bars $\mathbf{E} \mathbf{I}$, axle $\mathbf{C}$, and wheels B, of the guards $b c$, all operating together in the manner herein shown and described.

No, 40,766, - SANIUEI H. MJTCHELL, E1. PASo, WOODHRD CiUnty, ILL.-Cullizators,-December 1, 1863.

Claim. - The arrangement and combination of transversely adjustable swivel hars $c$, hinged plough beams $D$, notched bars $\mathrm{H} \mathrm{H}$, doubletree $\mathrm{I}$, and bar $\mathrm{J}$, and connecting rods $h$, and axle $A$, provided with a number of holes $b b$, intended to receive the swivel bars $c c$, to which the beams D D are attached by means of pivots $d$, the swivel bars $c c$, adinstable in the holes in the axle so that the beams can be brought closer together or forther apart, according to the width of the furrows; all constructed and operating in the manner and for the purpose thown and described.

No, 40,776,-ISAAC and STEPHEN STOUT, TREMonv, Tazeweli County, 1Ll.-Cultizators.-December 1, 1863.

Claim.-I.-The combination and arrangement of a front and rear frame in a cultivator, when constructed in the manner and for the purpose described.

2.-The combination and arrangement in the rear frame of the cultivator of a driver's seat made adjustable, and a standing support for the driver, a lever catch bar, studs for the supporting wheels, and a projecting connection $f$, all ojerating substantially in the manner and for the purpose described.

3.-The combination and arrangement in the main or front frame of the cultivator, of the hinged lever, the central support for the middle plough handles and their braces, a lever-catch to regulate the depth of ploughing, and an adjusting device to change the line of clraught, all operating substantially in the manner and for the purposes set forth

No. 40,859.-MILES H. SKIFF, CORNWALI. BRIDGE, Lischfiet.D CuUnty, CunN.-Cultizators.-December 8, I 863.

Claim.-The combination of the carriage F, that carries the cultivator teeth or ploughs, with the axle $A$, and with the main frame $C$ carried on said axle, so that the driver from his seat may, at pleasure, move said carriage laterally or tip it up or let it down, and fasten it down, substantially in the manner and for the purpose herein described and represented.

No. 40,909.-MARCUS M. CL.IRK, IndUSTRY, MC Donough County, JLL.-Cultizators.-December 15, is 3

Claim.-The vertically-adjustable stimups $f$ and hinged plough beams $\mathrm{F}$, in combination with the frame $\mathrm{A}$, running on wheels $\mathrm{B}$, which can be turned in either direction by a hand lever $\mathrm{D}$; all constructed and operating in the manner and for the purpose herein shown and describel.

No, 40,915--JOHN R. DAVIS, BLOOMFIELD, DAvis County, Juiva.-Cultizators.-December 15, 1863.

Claim,-In combination with the pivoted cultivator 
frames I I J' $\mathrm{K}$ l, also the hooked foot levers $\mathrm{V} \mathrm{X}^{\prime} n^{\prime}$, rocks $l$, ani staplen $Q$, all construcied, arran sed, and oper. ating as specified, so that either or buth the frames may be realily raised by the feet of the driver, and retained, by hooking the treadles into the staple 0 , as explaned.

No. 40,959.-A. J. SPARKS, WYIXET, BIREAL (i),

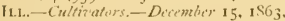

Cham.-1.-The two lever $f\left(i,{ }^{\prime}\right.$ connected together by a joint formed of the slotted plate,$r$, and segment rod $i$, and attached to the plough beams II II, sulostantially as shown to admit of a ready lateral movement of the same as well as the ready elevating of the ploughs above the surface of the earth, as set forth.

2.- The suspending of the plough beams II 11 trom the frame $A$ by means of the upright bars I J, and incline bars $A s$, provided with rollers $s a$, at their upper ends, which work on suitable ways or guicles, substantially as set forth.

3.-The hooks. II on the plough beams II, in connection with the pendent hook projections $\mathrm{N}$ on the frame $\mathrm{A}$, when said parts are used in combination with laterally moving plough beams, for the purpose specified.

No. 40,973,-ERASTUS WII.COX, Derhi, Det.AWARE Co. Lowa.-Cultizutors.-Decmber 15, 1863.

Claim.-The combination and arrangement of the frame A A B B, bars D D, and adjutable standards F F, wheels $\mathrm{H} \mathrm{H}$, inclined bar $\mathrm{I} I$ and $\mathrm{J} J$, tands $\mathrm{N} \mathrm{N}$ and $\mathrm{T} T$, bars $\mathrm{L}$ and $\mathrm{II}$, handles $\mathrm{J}^{\prime} \mathrm{J}^{\prime}$, shovel stocks $Q$ and $\mathrm{V}$, with culti vating shovels $\mathrm{S}$ and $\mathrm{X}$, the whole constructed as clescribed

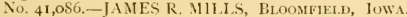
- Cultievators.-January 5, IS64.

Claim.-1.- In combination with the pivoted frame $\mathrm{K} \mathrm{K}$ II $\mathrm{R}$ and drag beams II I' $\mathrm{I}^{\prime}$, constructed and arranged as specified, the post $\mathrm{N}$ and lever $\mathrm{F}$, constructed and applied in the manner described to adapt the cultivator frames to be moved laterally, or either or both of them raised by mean of a single lever, as explained.

2.-The movable bar $\mathrm{O}$, when employed in combination with the post $\mathrm{N}$, reversible lever $\mathrm{P}$, and reversible beams $\mathrm{H}$ $\mathrm{H}^{\prime}$, in the manner described, for the purpose of adapting the machine for furrowing the ground so as to prevent the settling of water around the roots of plants in wet weather.

No. 41,159.-GEORGE LARGE, ROSEMOND, ILL.Cultivators.-Janutiry 5, IS64

Claim.-The foot levers $\mathrm{F}$, in combination with the tie $\mathrm{G}$, the bars II, the bars P, the cross-pieces J and I, and the metal plates $m$, the whole constructed and arranged in the manner and for the purpose set forth.

No. 41,3S9.-WILLIA.l 11. OLDER, PACKWAUKE, Wis.-Cultizators,-January 26, I864. Antedated Janu ary 20,1864 .

Claim.- The arrangement of the standards F F, the treadles $K^{\prime} K^{\prime} \mathrm{M}$, as shown and described, to wit : the standards being fitted in the the bar $\mathrm{E}$, with the bolts $d$, passing through longitudinal oblong slot; $c$, therein, and the treadles connected to the standards by means of the cords, belts or chains $f^{\prime} f^{\prime \prime}$, all arranged to operate as set forth.

No. 41,423.-JARVIS CA.SE, L.AFAYETTE, IND,-Culti andors. -Fidirwary $2,1864$.

Claim.-I.-The combination of the pivoted stocks I) $\mathrm{D}^{\prime}$ with the arms $\mathrm{O}$ and pivoted laar $\mathrm{N}$, operated by the stirrups $\mathrm{K}$ and lever $\mathrm{M}$, or by either of the same, substantially as set forth.

2.-Placing the treadle $P Q$ and stocks $D D^{\prime}$ forward of the elriver's sent, the same being arranged and operated suls stantially in the minner and for the purposes specified.

3.-The hingred stock-liolder $1 \mathrm{H}$, for holding the stocks $\mathrm{E}$ and allowing the latter to rise in relation to the frame, sub stantially as described.

No. 41,435.-IIARTIN H. HULI.INGER, GRANVILLE, 1t.t.-Ciultizators.-February 2, I864.

Claim.-1.- The peculiar arrangement of the shanks $G$; united by the double-jointed brace $\mathrm{M}$, and provided with rollers $\mathrm{T}$ working in the slot $x$, substantially in the manner and for the purposes set forth.

2.- The double-jointed brace M for connecting the shanks $G$, thereby enabling the driver to keep the ploughs in place when the shanks $G$ are five feet or more in length, substantially as set forth.

3.- The combination of the rollers $\mathrm{T}$ and windlass $\mathrm{D}$, the former operated by the driver's feet and the latter by his hands, substantially in the manner and for the purposes set forth.

4.-The arms $\mathrm{L}$ and shaft $\mathrm{S}$, for making the driver's seat adjustable, as specified

No. 41,523.-PATRICK MCGILW, DES MUINES, IoW A. - Cultizators,-Fibrunry 9, 1864.

Claim.-1.-The two plough standards II H fitted in the metal plates $G$ and connected to the front part of the frame A by har $K$, in connection with the handle I attached to the bars $n \mathrm{~J}$, which are fitted to the standards $\mathrm{H}$, as shown, t) operate as described

2.-The plough standards L L, connected to the front part of the frame A by the bars $\mathrm{N}$, and fitted between the guides $s$ and secured between them by the plates $u$ and bars $u^{\prime} \ell$, in connection with bar $o$ attached to the bars $\mathrm{N}$ by the rods $u$, and connected to the levers by the rod $R$, all arranged to operate as set forth.

No. 4 1.550.-P. W. T11OMSON, TRURO, ItL.-Cultiz'ators.-Fibuary 9, 1864

Claim.- The combination and arrangement of the plough heams $\mathrm{E} \mathrm{E}$, pivoterl at $x \cdot x$, the standards $\mathrm{N} \mathrm{N}$, the cross bar $\mathrm{F}$, provided with the bands $a$, and the lever $\mathrm{L}$, all constructed and operating substantially as and in the manner set forth.

No. 41,555.-SAMUEL G. IVEICII, ATHENS, I1.LCultizators.-Fetruary 9, 1864

Claim.-The bar F, having the rraught pole $\mathrm{G}$ attached, supported by the castor wheels I I, and connected to the frame A by levers D D, the back ends of which are connected to the bar $\mathrm{F}$, having a lever $\mathrm{H}$ secured to it, and all arranged so as to admit of the raising and lowering of the ploughs and the lateral adjustment of the draught pole relatively with the body or main portion of the machine as set forth.

No. 41,569.-ARION M. CLARK, assignor to himself, ARTEMIS B. VANT, and HORACE COOK, CHCAgo, 1Lt..-Cultizators.-February 9, 1864.

Claim.-1.-The combination and arrangement of the evener $\mathrm{B}$, the bent levers $a a$, and the draught rods $c c$, with draught pole $\mathrm{A}$ and axle $\mathrm{H}$, all arranged and operating substantially as and for the purposes herein delineated and set forth.

2.- The combination and arrangement of the U-shaped strap $d$, the anti-friction roller $f$, and the staple $c$, with the adjustable bars $F$ and the levers $I$, constructed with a curved end, substantially as and for the purposes herein shown and specified.

No, 41,614.-WILKENSON FURNAS, ONONWA, lows.-Cultizintors.-Fitruary 16, IS64.

Claim. - The arrangement of the treadles I I, frame $b$, beams $D$, ancl guards $G$, with the frame $A$, levers 11 , and serrated bars $m$, all constructed and operating together in the manner herein shown and described

No. 41,677--C. J. BUCKNER, PAxTon, ILt.-Culliviators.-Fibruary 23, 1864

Claim.- The combination of the horizontal connecting plate $a$, pendant slotted plates $b \quad b$ and $f f$, beams $g$ g, rods $i$, bracing foot bars $\mathrm{G} G$, and transverse bars $\mathrm{K} K$, all as herein shown and described.

No, 41,709.-JOHN L.ACEV, Chicago, I1.L.-Cultizators.-Fibrumy 23,1864 .

Claim-1.-The arrangement of the pivoted bolis or pins $c$ and $d$, and the holes $a$ and $b$, the movable beams $A^{\prime}$, and $G$, stirrup $I$, and bars $H$, for regulating and adjusting the draught of the ploughs.

2.-The combination of the lever $\mathrm{R}$, the rest or stop $e$, connecting bar $\mathrm{S}$, bow $\mathrm{T}$, pivotal holts $c$ and $d$, with the movable beams $\mathrm{A}^{\prime}$ and $\mathrm{G}$.

3. - The combination of the bars $H$, stirrup $I$, and chain $\mathrm{M}$, with the movable beams $\mathrm{A}^{\prime}$ and $\mathrm{G}$.

4.- Hinging the rear ends of the movable beams $\mathrm{A}^{\prime}$ between the front and rear ploughs by the pin $c$, so as to move such front and rear ploughs in opposite directions, alt being constructed and operating substantially as set forth and specified.

No, 41,743.-J()HN LACY, assignor to himself, CON. 
RAD FURST, and DAVID BRADI.EY, CHICAGO, I1.L.Cultizators.-February 23, 1864.

Claim.-The combination and arrangement of the movable adjustable frame $B$, pivoted lever $D$, segment pinion $C$, and rack $h$, with pulley $a, \operatorname{rod} b$, and foot levers $k k$. the whole constructed and operating in the manner and for the purposes herein set forth.

No. 41,769.-JACOB HAEGE, SHILoH, ILL.-C'ultivators.-.Warch 1, 1864 .

Claim.- The plough beams I I, fitted in the stays $\mathrm{K}$, and upon the rods $J$, in combination with the springs $L^{\prime}$, and curved plates $\mathbf{M}$, all arranged and for the purpose specified.

No. 41 , Sg9.-JOHN AUTTIN, ROCKFORD, ILL.-Cultivators.-Warch 15,1864 .

Claim.-1.-The combination of the shifting driver's seat $\mathrm{U}^{\prime}$ with the main frame $\mathrm{A}$ and laterally shifting plougbs $\mathrm{K}$, in the manner described, for the purpose of enabling the driver to balance the machine and control both the vertical and the lateral movements of the plonghs as set forth.

2. - The combination of the main frame $A$ and compound lever frume F G with the plonghs EK, when the several parts are arranged and operate as described, for the purposes set forth.

3.- The combination of the adjustable driver's seat, the foot levers $\mathrm{N}$, and the laterally ad ustable ploughs $\mathrm{K}$, when severally arranged (relatively to the main frame A) and operating in the manner and for the purpose described.

No. 42,532.-SETMOUR SLOAN, KeWANEe, 1LI.Cultizutors.-April 5, IS64.

Clain.-The combination of the beams B B C C, connecting hars D L' E F G, levers $c c$, treadles $H$, and bent levers II', all constructed, arranged, and operating in the manner and for the purposes herein specified.

No. 42,513.-S. W. SLOCUMB and E. PHILIPS, FULTON CITY, ILL_-Cultizators.-April 26,1864 .

Claim.-1.- The stirrups $h h$, arranged as herein described, and employed to enable the operator to move the inner plonghs laterally and independently by the direct application of his feet, as specified.

2. - In combination with the loosely shackled standards $F$ $F^{\prime} F^{\prime \prime} F^{\prime}$, constructed and arranged as herein described, the chains $a a^{\prime} a^{*} a^{\prime *} b b^{\prime}$, eye-bolts $H^{\prime} H^{*} H^{\prime \prime}$, and thumb-nuts $a^{2}$, as and for the pmrpose set forth.

No. 42,514.-J. D. S.HITH, PEORIA, ILL.-Cultizutors. April 26,1864 .

Claim.-1.-The combination of the carriage swinging frame $b b$, driver's seat $A$, hinged shovel carrying frame $d$, vibrating sbovel standards $y$, , (connected to rock-shafts,) stop-pins $p p$, adjusting chain $n$ when the frame $d$ with the shovels is entirely forward of the axle of the frame $b b$, and the standards of the shovels are connected together at their upper extended ends by an adjustable bar $h$, and operated by the single pivoted handle C from the driver's seat; all in the manner and for the purpose herein described.

2.- The arrangement of the rear wheeled frame $b b$, front cultivator frame $d$, seat $A$, shovels $g$, rock-shafts $g^{\prime} g^{\prime}$, bar $h$, lever $\mathrm{C}$, stop-pins $p \rho$, chain $n$, tongue $\mathrm{B}$, and oblique laterally adjustable guards D D, all for united use in a machine adapted for cultivating growing crops, as set forth.

3.- The arrangement of the chain comnection $n$, stop-pins $f P$, in combination with the hinged forward shovel frame and the rear wheeled frame, when the said frames are constructed and operated in the manner herein described, and all adapted for the purpose set forth.

No. 42,646.-E. NI. DEVER, and HRA C. PRATT, PEORIA. ILL.-Ciultivators.--May IO, I 864 .

Claim.-1.- The rotary guards a a mounted upon the stock $\mathrm{P}$ and employed in combination with inner cultivators $k k$, in the manner and for the purposes described.

2.-The foot lever $V$ fulcrumed upon the axle and extending forward bencath the bar $m$ and backward into convenient proximity with the seat $F$, as and for the object specified.

No. 42,932 . - A. P. DURANT, AtLANTA, ILl.-Cultizators.-May $3 \mathrm{1}, 1864$.

Claim.-The two sbare frames $\mathrm{E} . \mathrm{E}^{\prime}$, when constructed, combined, and arranged in respect to each other, and the axletree $\mathrm{A}$, as described, and when raised and lowered by the forward and backward motion of the draught power applied to the doubletree $\mathrm{R}$, substantially as shown and described.

No. 43,123.-WILLIAM METTLER, FRANKFORT, ILI. - Cultivators.- Fune 14, 1864 .

Claim.- I. - The teeth G G, laterally movable bodily with out angular change, in combination with fixed teeth $\mathrm{F} \mathrm{F}$, sitnated further bebind and outward than the said movable teeth, arranged and operating substantially as and for the purpose herein specified.

2.-The combination of the guide posts $n$, with the adjusting screws $P$ P, as herein set forth.

3.- The combination of the hinged or jointed controlling braces $\mathrm{R} \mathrm{R}$ with the guide posts $n n$, and elevating devices L M N, substantially as and for the purpose herein specified.

No. 43,249.-ALMON WhlliAMS, Berea, Ohro.Cultivators.-June 21, 1864 .

Claim. - The adjustable reach $\mathrm{F}$, the slotted hinged frames $\mathrm{G} \mathrm{H}$, and $\mathrm{M} \mathrm{N}$, in combination with the teeth or cultivator and slotted hinges $J$, in the manner and for the purpose set forth.

No. 43,268 - L. B. WATERMAN, assignor to himself, E. IV. SIMONDS, and P. A. FISCHER, CHICAGO, ILL.Cultizators, - Fune 21, 1864 .

Claim.-1.-The braces $\mathrm{T} T$ ane jointed hars $\mathrm{T}^{1} \mathrm{~T}^{2}$, in combination with the pendent shovels $\mathrm{N}$, when arranged and operating as set forth.

2.-The auxiliary wheeled supports $R$ at the rear of pendent shovel frames $\mathrm{II}$, in combination witb the main supporting wheels $\mathrm{C} \mathrm{C}$, substantially as and for the purpose set forth.

3.- The combination of the half rolling beams $f$ with the pendent frames $\mathrm{HI}$ and auxiliary supporting wheels $\mathrm{R}$, substantially as and for the purpose set forth.

4.- The combination of the jointed brace $T T^{1} T^{2}$, pendent shovel frames $\mathbf{~}$, half rolling beams $f$, and foot lever and hand levers $O \mathrm{P}$, substantially as and for the purpose set forth.

No. 43,288.-1. IH. CASTOR, EDDINGTON, 1L1.-CornPloughs. - Tune 28, IS6.4.

Claim,-1.-Moving the standards $i$ i of the ploughs I laterally by means of the hail-shaped bar J, bent levers $\mathrm{K} \mathrm{K}$, and treadles L L, all arranged substantially as herein set forth.

2.-The combination of the hars C C, frame D, driver's seat $\mathrm{E}$, rock shaft $\mathrm{F}$, links $d d$, and levers $\mathrm{G} c$, all constructed, arranged, and employed, substantially as described, for raising the ploughs when required.

No. 43,395.-JOIIN DAVIS, Alleciheny City, PENN.-Cultivators.-7uly 5, 1864 .

Claim. - The arrangement of the pieces $c$ and $c^{\prime}$, uprights $f$ and $f^{\prime}$, and bars $g$, with teeth $h$, the whole leing constructed, arranged, and operating substantially in the manner herein described and for the purpose set forth.

No. 43,4 1.-ALFRED G. TUCKER, RICHVIEW, IL...-Cultizatcrs.-July 5, 1864 .

Claim. - 1. - The beams E E', suspended by means of links $m m^{\prime}$ and arms $n n^{\prime}$ from rock shafts $0 \mathrm{O}^{\prime}$, in combination with the vertically adju-table reversible ploughs $G$ ' $i$ ', and hand lever $H$, constructed and operaring in the manner and for the purpose sulstantially as hcrein set forth.

2.- The sockets $i i^{\prime}$ and set screws $j j$, in combination with the standards $F F^{\prime}$ and ploughs $G^{\prime} G^{\prime}$, constructed and operating in the manner and for the purposes substantially as set forth.

3.- The screw-rods $g$, and nuts $g^{\prime}$, in combination with the separate laterally adjustable section of the frame $\Lambda$, constructed and operating as and for the purpose specified.

4.- The screw-rods $k k^{\prime}$, with suitable nuts, in combination with the laterally adjustable plough-beams $E E^{\prime}$, constructed and operating as and for the purpose specified.

No. 43,470,--FRANK BARNEY, BLOOMNGTON, ILL. - Cultivators. - Fuly 12, IS64.

Claim.-The hand lever $H$, with its swivel fulcrum $K$, in 
comnection with the crank shaft $\mathrm{G}$, hinged rear standard $\mathrm{F}$, and swivel front standards $\mathbf{E}$, all constructed and operating in the manner and for the purpose substamially as licrin specified.

No. 43,635-JANIES CANFIELI), SABULA, IUWA.inltizators. - Jull 26, is64

Claim.-The combination and arrangement of the axle E E, the bow I), plough bean II F, cross-pieces R, and bow I, the removable har J, dranght pole A, bar B, standards (C, pivot $x$, ancl seat (), all constructed, arranged, and operating subatantially as and for the purposes specified.

No, 43,836. - IOHIN $\mathrm{COX}$ and JOHN A. THROP, THREE RIVFes, ilien.-Cidtizitors.-Ausust 16, 1864.

Claim.-1.- So constructing the axle $C$ that it c:mtitutes a rocking lever support for the frame A and driver's sent $G^{\prime}$, and a means by which said frame can be raived or depressed, sulstantially as herein descrilied.

2.-The com! in tion of the lever $\mathrm{D}$, or its equivalent, with an axle, the points of support of which for the driver's seat and shovel frame are arranired on opposite sides of the fulcrum, or axis of motion of said axle, substantially as de-cribed.

3.- Arranging the ilriver's seat and frame of the machine upon a supporting axle in such manner that the weight of one can be made to counierbalance the weight of the other whether the point of rest of the driver's seat he on the opposite side of the fulcrum from that mon which the frame rests, or direcily over the fulcrum, or at any point hetween the fulcrum and the frame, substantially in the manner set forth.

4.- The connecting or stay rod $\mathrm{F}$, or its equivalent, in combination with the driver's seat, sustained sulstantially as described.

5.- The combination of a piroted lever $\mathrm{H}$, loop $j$, slide J, guide rod $\mathrm{J}^{\prime}$, shovel stand.arts $a^{2} a^{2}$, pivoted stay rods $a^{3} a^{3}$, and woolen pins $n n$, all constructed and arranged substantially as described.

No. 43,901.-D. M. DAV1S, ascignor to himself and W. L. F. JONEs, Ismury, ItL.-Cultizators.-1urust 23 , 1864

Claim.-The combination and arrangement of the lever 1 , the rod $r$, the vi' rating lever $\mathrm{C}$, the rot $r^{\prime}$, and the plough beam $\mathrm{E}$, when constructed and operating substantially as herein delineated and described.

No. 44.729.-C. M. JENNE, YuUNG AMerica, Jll.Cultizators.-Octoler is, is64.

Claim.-The securing of the plough I to the device by beving its standards 11 attaclsed to a bar $G$, which is connected to the inner beanis of each pair ly pivots $d$ substantially as and for the pur ose specitied.

No. 45,066.-GEORGE I), MJLLER, LONNGTON, ILL - Cultivators. - Nurember 15, 186

Claim. - 1.-The swivel frame $\mathrm{D} \mathrm{D} \mathrm{D}^{1} \mathrm{D}^{2}$, in combina tion with the segmental pulley $\mathrm{E}$, bar or lever $\mathrm{E}^{\prime}$, foot piece $e c$, cords 11 , and 1 ulley 1 , the whole being arr.nged to operate substantially as and for the purposes herein set forth

2.-The manner herein described of employing the roller R, so that it may be adjusted simtitaneonsly with the ploughs, by menns of the lever $\mathrm{O}$.

No. 45,177.-J. J. RIDER, Wiltun Junetion, IowA. - Cultivators.- Vintember 22, IS64.

Claim.-1.-The treadle levers, $11 \mathrm{M}$, the adjustable roller $\mathrm{K}$, and the chain s ur cords $\mathrm{I}$. $\mathrm{L}$, when so conbined with each other and with the frame of a cultivator plough as to sustain the weight of the plough and plough beams, and enable them to le quickly and revilily elevated from the ground by the clriver, substantially in the manner and for the purposes here: $n$ set forth.

2.- The cord $p$, pulleys o o o 0 , angular lever $\mathbf{W}$, spring bolt $l$, are-shaped cross-beam S, and sockets $m m$, when combined with each other and with the frame of a cultivator plough, for the purpose of enbling the driver to adjust the direction of the draught, substantially in the manner herein set forth.

No. 45,231.-J()HN DOAK, KFIthitra, In.L-Cultivator Plowshs.-Nive'mber 29,1864

Claim,-Connecting to rether the beams $\mathrm{G}$, II $\mathrm{b}$ : means of flexible connections or hinge $\left(i^{\prime}\right.$, for the purpose of al lowing the beams. $\mathrm{Il}$ to receive a lateral movement from the tirrups $c$ independently, of the beams $(;$, while both the henms (f Il may be moved veltically simultaneously by means of the arm $S$, sulut intillly as set forth.

No. 45,264,-JAMES 1). (ISBORN, GISHEN, 1ND.Cultizators.-1inember 20, I864.

Claim - 1, - The two-part axle $\mathbf{E} \mathbf{E}^{\prime}$, as employed in combintion with the levers $G^{\prime} G^{\prime}$, racks $F F^{2}$, and wheels 1) 1 ', the whole hein: constructed and arranged in the manner and for the purpose specified.

2.- The tongue $K$, in combination with the heam $B$, rol. ler I', arm I, rod $H$, lever $G$, and caster wheel $L$, all arranged and opesating in the manner described, to convert the implement from a stiff to a loosc-tongued machine.

3.- In combination with a cultivator, constructed as herein descrilied, the slirle $Q$, arranged and employed substantially as and for the purpose specified.

No. 45,503.-A. KINYOON, AMuroy, Il1..-Corn Culticators - December. 20, 180.4

Claim.-1.-The tubular shaft $G$, having the plough beam I 1 attached to it by straps $T$, in connection with rod $\mathrm{R}$ fitted loosely in said shaft, and connected ly pendants $\mathrm{H}$ with the beams I I, and connected ly a strap or cord with a pulley $\mathrm{V}$, all arranged substantially as shown, to admit of the aljustment of the ploughs, as set forth.

2.-The altaching of the front ends of the plough beams I I to the part $b b$ of the draught pole through the medium of the swinging bent birs $O \mathrm{O}$, connected by a draught equalizer composed of the rods $Q Q$, ehains $j j$, rod $l$, and pulley or pins $k$, all arranged substantially as and for the purpose set forth.

3.- The securing of the standards I to the benms I by means of the eyes $d$, screw rods $c$, and nuts $f$, to admit of the arluting of the ploughs $L$, as set forth.

4.-Contructing the draudit pole of two parts $b \quad b$ arranged in V-form and attached to the axle $A$, as shown, when saicl prile, thus cunstructed, is usecl in connection with the plough beams I I, arranged with the mechanism described for adjusting them vertically or laterally, as specified.

No. 4.495.-ALONZO KINYON, AmBoy, ILL.Corn-Cultivutors.-45,503, December 20, I864.-Reissued Fuly 25, 1871

Claim.-1.-The rounded standar' J, having a shovel, $I$, attached thereto, and secured to the frame or heam of a cu'tivator by means of an eye-bolt, substantially as described, wher by the shovel may be ndjusterl, as set forth.

2. - In combination with the fore roing, the brace-rod $\mathrm{K}$. arranised to operate as set forth.

3.- The tubular shaft $G$, provided with the lever $U$, and connceted by the strots $T$, to the beams $I$, whereby the shovels may be elev ted at will, as set forth.

4.-The sliding-rod $\mathrm{R}$, provided with the rigid arms $p$ and $\mathrm{H}$, the latter being connected loosely to the beams $\mathrm{I}$, and the former by straps \%, to a pulley, V, having a footlever, $I^{*}$, atiached, all arranged to operate as set forth, whereby the beams, with their stantards and shovels, may be moved laternlly at will, as set forth.

No. 45.615.-JOHN KIRKMAN, PEORIA, ILL-Cultivators.-Deicmber $27, \mathbf{1} 864$

Claim.-1.-The spring E E s, and thumh-screw $o$, employed in combination with the levers $B$ B, to retain the ploughs in either a working or an elevated position, and secure the same against liability to injury by contact with immr vable bodies, as set forth.

2. - A machine constructed in the manner herein described, supporting the neck yoke $y$ and the end of the tongue by means of bows C, or their equivalents fiting upon or over the top or upper part of the horse's neck, substantially as and for the purpose set foith.

No. 45,687.-IRA BARliER, JR., LA PORTE, IND.Cultizators.-January 3, 1865.

Claim.-1.- The pivots $c$, pivoted with the pronged or forked ends, and arranged as shown in relation to the beam $c$ and frame $\mathrm{O}^{\prime}$, in combination with plough beams $\mathrm{L}$, operating as and for the purposes herein shown and set forih.

2.- Suspending the rear ends of the plough beams L by the chains $d$, in combination with the piv ted front end of 
said heams, for the purpose of enabling the operator to give the shovels the lateral motion, substantially as and for the purposes herein specified.

No. 45,700.-A. B. CASS, Chicago, Ill.-Cultivators. - Jamuary $3, \mathbf{1} 865$.

Claim. - I. - The combination of the adjustable lever A, bar $a$, levers $b$, and ploughs $M$, arranged and operating substantially as and for the purposes set forth and shown.

2.-Attaching the scrapers J to the axle, by one or more arms $K$, subntantially as and for the purposes shown and set forth.

3. - The combination of the adjustable lever $A$ with the rod $L$, provided with the arms $l$ or their equivalent, and the chains $h$ operating as and for the purposes shown and specified

4 -The employment of one or more rollers $H$ to facilitate the lateral motion of the lever $A$, operating substan tially as shown and lescribed.

5.- The employment of the roller I in combination with the lever A, arranged and operating substantially as and for the purposes herein shown and specified.

No. 45,730.-DANIEL McNAB, Moscow, Miсн.Cultivators.- Fanuary $3, \mathbf{1} 865$.

Claim.-Constructing a cultivator or drill tooth with an upper curved portion, which curved part shall have a bearing against some rigid portion of the machine when it is in motion, so that the form of such curved portion of the tooth, and the position of the tooth, shall determine the amount of resistance which it may overcome without it being raised from the ground.

No. 45,750.-T. T. PROSTER and H. C. DARLING, CHeAgr, Ir.l., and K. A. DARLING, Fond DU L.AC, Wis.-Cultizator for Gans Ploushs.-January 3, 1865

Claim.-I.-Guiding and regulating the movement of the tongue I) by means of the pulley $\mathrm{H}$, chain $\mathrm{F}$, eye bolts $G$, attached to the sicle frame $A$ and levers $H$, substantially as described.

2.-Connecting the pair of draught arms B B, without regard to the number of pairs used, to the forward main cross-bar of the frame A lyy means of the double-nutted screw bolt L L, and which forms, with the plates MI M, a hinge or other joint, so that while the said bars shall have a free vertical motion, they may be adjusted laterally without being detatched or removed from the said cross-bar.

3.-Constructing a cultivator or gang plough so that the interval between the shank $\mathrm{N} \mathrm{N}$, which supports the ploughshares, may be increased or diminished, $\mathrm{u}$ ithout removing the shaft barx $\mathrm{B} \mathrm{B}$, or their connections from the main cross-bar of the frame $A$, when each pair of shaft hars are capable of lateral adjustment, inde endent of the other pair or pairs.

4. - The combination of lever $\mathrm{T}$, rods and poles $\mathrm{U} U$, operating the ratchet wheel $S$ upon the roller $O$, for ele vating simultaneously the several ploughs of the gang or gangs, substantially as set forth.

No. 45,758.-LVMAN SHERIWOOD, MARINE, Ill.,-Cultizafors.- Jamuary 3, IS65.

Claim.-I. - The arrangement of the frame $A A^{\prime} A^{\prime}$, with its teeth or ploughs $c c$, in combination with the rol lers B B, all being constructed and arranged to operate substantially as and for the purposes set forth.

2.-The arrangement of the pole $\mathrm{E}$ with reference to the frame $A$ and standard $f$, substantially as and for the purposes set forth.

No. 45.782.-THOMAS WILES and JAMES MCGINNIS, MUsCative, Iowa.-Cultizators.-January 3, IS65.

Claim.- The combination of the rising and falling or vertically-adjustable ploughs $O$, with the rising and falling and laterally adjustable ploughs 1 , when the latter are pivoted to shafts $\mathrm{D}$ D, and connecterl to the shaft $\mathrm{P}$, so as to rise simultaneously with the ploughs $\mathrm{V}$, on the turning of the shaft $\mathrm{P}$, as and for the purpose herein set forth.

No. 45,So7.-IV. D. AMENT, Muscatine, IowA.Cultizators.-January $\mathbf{1 0}, \mathbf{1} 865$.

Claim. - In combination with the standards D D, adapted to he operated by treadles so as to move the ploughs vertically and laterally, I claim the adjustable blocks $G$, resting upon the plates $\mathrm{E}$, and employed to vary or regu- late the depth to which the ploughs penetrate the ground, in the manuer herein explained.

No. 45,833.-ADAM KECK, Montgomerx, ILL.Culticutors, - January 10, IS65.

Claim.-1.- The attaching of the axles $\mathrm{C}$ of the wheels $\mathrm{B}$ to plates $\mathrm{D}$, secured to castings $\mathrm{E}$ at the under side of the framing $\mathrm{A}$ by means of botts a passing through oblong slots $c$ in the castings, substantially as shown and described, to admit of the wheels $B$ being adjusted further forward or backward, to keep the machine in a proper equipoised state, as set forth.

2.-The plough beams $G \mathrm{G}$, provided at their front ends with upright bars $g$ connected by joints $h$ to the castings $\mathrm{E}$, and provided at their back ends with upright bars $H$, having each a notch $i$ to receive a catch 1 , all arranged substantially as and for the purpose set forth.

3.-The springs $\mathrm{K}$ on the back part of the framing $\mathrm{A}$, in combination with the upright bars $H$ of the plough beams $G G$, as and for the purpose specified.

4.-The attaching of the plough beams I, I. hy means of the upright $\mathrm{M}$ and joints $j$ to the pivoted plate $\mathrm{N}$ arranged on the framing $A$, substantially as shown, to admit of the working or moving of the ploughs Q, as set forth.

No, 45,860,-CVRUS ROBERTS, THREE RIVERS, MicH - Cultizators.- Fanuary 10, 1865.

Claim,-1,-The combination of the main frame, the shifting plough frame, the lifting lever, and the shifting machine arm $O P$, with the driver's seat, when arranged for joint operation as described.

2.- The hifting foot lever $R$, constructed and arranged to operate as and for the purposes described.

3.- The combination of the shifting frame, the ploughs, and the corn guard with the main frame when constructed and arranged in operating as described for the purposes set forth.

No. 45,86I-CYRUS ROBERTS, THREE RIVERS, Mich-Ciulizintors.- Fanuary 10, I\$65.

Claim.-1.-The combination of the double-ended shovels with their stocks, by means of the reversible swiveling brackets $c$, and bolts $c$, in the manner described, for the purpose of reversing the shovels when worn or injured, and of turning them sidewise to throw the earth more or less towards or from the plants as desired.

2.- The combination of the shovel stocks and shifting frame by means of the brackets $J$, bolts $j^{3}$, and clips $j^{4}$, as described, for purposes set forth.

3.-The combination of the shovels, the auxiliary or shifting frame, and the main frame, when constructed and arranged as decribed, for the purposes set forth.

4. - The combination of the plough stocks and shifting frame by means of the brackets J, blots $j$, and set screw $j$, as and for the puposes described.

No. 45,866.-E. H. SAIV YERS, ORLFANS, JowA.Cultizators. - Fanuary $\mathbf{1 0}, 1865$.

Claim.-I, - In combination with the levers 1.' and shaft $\mathrm{L}$, the oblong slot $i$, formed and employed in the manner and for the purpose sjecified.

2.-The described arrangement of the adjustable cultivator frame $\left.1 l^{\prime} I^{2}\right]^{3}$, the brace rods $h$, angular shaft $M l$ and draught rod $\mathbf{N}$, the whole being employed in the manner and for the purposes set for: $h$.

No. 45,934,-ELIAS C. PATTERSON, CHICAgo, ILI. - Cultizators.-Jamuary 17, 1865.

Claim.-1,- The curved levers A, B, C, I), constructed and operating substantially as described.

2. - The combination of the curved and straight levers, comstructed and operating substantially as described.

3.- The combination of the curved and straight levers with the ploughs, constructed and operating sulstantially as clescribed.

6.-The peculiar form and arrangement of the middle rear ploughs, in connection and combination with the two outside rear ploughs, all constructed and operating substantially as described.

No. 45,987.-J. W. FAWKES, DECATUR, TLL,-Cultivators.-Janwary 24, I865.

Claim.-I.- The frame E applied to the draught-pole C, as shown, in connection with the foot-levers $H \mathrm{G}$, arranged 
with the frame, to admit of the hatter being operated as and for the purpose specified.

2.- The pivoted plough standards J connected to segments $\mathrm{I}$ ly hars $\mathrm{L}$ and links $\mathrm{I}$, in connection with the wooden pins $l$ in the segments, all arranged substantially a and for the purpose set forth.

3.-Providing the segments $\mathrm{Ml}$ with handles $\mathrm{N}$ in connec tion with straps $\mathrm{O}$ on the frame $\mathrm{E}_{2}$ as and for the purpose set forth.

No. $46,116 .-$ CHRISTOPHER IIDREN, AURURA, ILI..-Cultivaters.- January 31, I865.

Claim.-The rising and falling bar $\mathrm{E}$, operated by the levers L L', and having the plough standard I I permanently attached to it, as shown, in combination with the adjustable plough-standards F F, attached to said bar as described, and operated by the crank shafts $k$, all arranged substantially as and for the purpose set forth.

No. 46,274-THOMAS SHORT, FAIRMOUNT, ILL.Cultizaters and Harrones. - February 7, i 865.

Claim.-1.-The frames D D, provided with shovels E, and teeth $\mathrm{F}$, the clevises $a d$, and screws or bolts $a^{\prime}$, in combination with the adjusting frame $G H$, the latter permitting the cultivator frames to be operated simultaneously or irdependently, and adapting said frames when used as a harrow to be brought together at their rear ends, as herein specified.

2.-The combination of the treadles I, loops J, and connecting rods or wires $i$, for adjusting the frames $\mathrm{D} D$, substantially as explained.

No. 46,285.-WILliAM S. WEIR, JR.. Monmouth, IL.L. - Com Ploughs.-February 7, i 665 .

Claim.- The curved rods $M$ attached to the back end of the bars $d d$, and bent in the form of hooks $k$, at their lower ends, in connection with the lever $o$ attached to the back end of the draught pole $C$, all being arranged and applied substantially as and for the purposes specified

No. 4,489.-WILLIAM S. WEIR, JR., MUNMOUTH, Ii.t.-Culticators.-46,385, February 7, 1865 .- Reissued Fuly 25,1871

Claim-I, - The cross-bar $F$, when pivoted to the draught pole of a walking straddle-row cultivator in rear of the axle or truck-frame, and connected with the clrausht in manner substantially as and for the purpose set forth.

2.-The plates $h h$ secured to the forward endis of the plough-beams, and blocks $g s$, and journals $f$, constructed and operating substantially as clescribed, for the purpose of hinging or pivoting the plough-beams to the axle by brackets $\mathrm{I}$, or their equivalent, as set forth.

3.- The pivoted rods II having the hooked ends $k$, in combination with the bars $d d$, levers $\mathrm{O}$, and draught-pole $\mathrm{C}$, substantially as and for the purpose set forth.

No. 46,349.-SA.MUEL GULICK, KLINE'S GRove, PExx.—C Cultrintors.-February I4, 1865 .

Claim.-1. - The frame D fitted on the axle A, and con nected hy chains or cords $\mathrm{E} E$ to fast pulleys $\mathrm{F} \mathrm{F}$, on a shaft (i, which has its bearings on uprights $\mathrm{C} \mathrm{C}$, attached to the axle, and which serves as guides for frame $I^{\prime}$, all being arranged as shown with a lever and notched bar, or their equivalents, wherehy said frame may be raised and lowered bodily and secured at any desired height for the purpose specified.

2. - The pivoted bars Q Q when applied to and used in combination with the adjustable frame $\mathrm{D}$, substantially as and for the purpose set forth.

No. 46,355- - SAMUEL HENRV, CHENOA, ILL.C Cul tivators.-February 14, 1865

Claim.-The arrangement of the levers J J, connected by straps $h$ to the pivoted frame $\mathrm{F} \mathrm{G}$, and by pendants $\mathrm{K} \mathrm{K}$ to the plough beans L L, which are hinged to the axle, the said frame $\mathrm{F} \mathrm{G}$ being further capable of lateral deflection by pressure of the feet of the driver, substantially as and for the purposes described.

No, 46,378.-SA MUEL H. MITCHELL, EL PASO, JLL. - Gans Ploughs and Cultivators. - Filruary 14, 1865.

Claim.-The split and expanded draught-pole C, in connection with the axle $\mathrm{A}$ and bar $\mathrm{E}$ and $\mathrm{O}$ and rods $h$, all arranged as and for the purpose herein set forth.

No. 46,383.-IRA A. PALMER, Muxmouth, ILL.Cultivators.-February 14, I865.
Claim.-1,-The draught equalizer composed of the rods D D, provided with arms $d d^{\prime}$ at their upper and lower ends, and placed at right angles to each other, with the lower arms projecting at right angles from the machine, with the upper arms $d$ connected by a rod E, and the whiffletrees at tached to the lower arms $d^{\prime}$, substantially as and for the purpose set forth.

2.-Connecting the plough beams $\mathrm{E}$ to the bars $c$ of the main frame $\mathrm{A}$, through the medium of the hars $k$, which work on adjustable pins or rods $l$, in plates $m$, attached to the bars $c$, and the pins $j$, which pass through plates $i$, at tached to the plough beams and through the bars $k$, all being arranged substantially as and for the purpose specified.

3.- The particular manner of constructing the main frame $A$, to wit, of the side bars $a a$ arranged in $\mathrm{V}$-form, connect ed at their upper ends by cross-bars $b b$, and mounted on wheels B, substantially as herein set forth.

Mo. 46,537--WM. BANKSON, MOUNT PleAsant, IowA.-Cultizators.-Filintary 28, 1865.

Claim.-The frame F F, the lever $L$, the suspension of the ploughs 3 and 4 on har $\mathrm{X}$ and the moving of them with the lever $\mathrm{N}$, when constructed substantially as described and for the purpose set forth.

No. 46,657--J. H. GIVEN, H. HUT.SONPII,LER and CHAS. GILBERT, DEs MoINEs, IowA.-Cultizators.Narch 7,1865 .

Claim.- The frame D pivoted or attached to the draught pole $\mathrm{A}$, as shown in connection with the jointed set bar $\mathrm{O}$, angle plates $p$, and the plates $r$, all arranged to admit of the ready elevation of the ploughs, as set forth.

2.- The uprights $\mathrm{H} \mathrm{H}$, connected at their upper parts to the lever J, and connected at their lower parts to the plough standards F F, and pivoted to the frame $d$, substantially as shown and described, to admit of the lateral movement of the ploughs $\mathrm{G}$, as described.

No. 46,666,-LORENZO D. HAUGHEY, ATLANTA, I1.T.-.Cultivators.-Warch 7, 1865

Claim.-1-The pivoting of the axle $\mathrm{A}$ to the draughtpole $\mathrm{D}$ to admit of the lateral movement or adjustment of the ploughs, as set forth.

2. - The semicircular frame $\mathrm{C}$ attached to the front side of the axle, in connection with the friction-roller $\mathrm{F}$ and bolt or $\operatorname{rod} G$, attached to the draught-pole $D$, substantially as and for the purpose specified.

No, 46,675-JOHN W. INGLE and R. W. WRIGHT, Livingst' N, IL.L.Cultizators,-March 7, 1865

Claim,- The frame $\mathrm{D}$, attached to the axle $A$ by a pivoted bolt $a$, and provided with pivoted plough standards $\mathrm{H}$, connected by rods $k$, the segment bars $\mathrm{J} \mathrm{K}$, and lever L $\mathrm{L}$, in combination with the levers $\mathrm{G}(\mathrm{G}$, attached to the frame $\mathrm{D}$, and dranght-pole $\mathrm{C}$, all arranged to operate substantially as and for the purpose set forth.

No. 46,752,-T. IV. HAMIMION, assignor to himself, JOSEPH H. LINCOLN, S. LINCOLN, and A. P. HANI MON, NoXTForD, Wis, - Corn Plouglls.-Warch 7, is65.

Claim.-I.-The two semicircular frames B C, applied to the drau ht pole $\mathrm{D}$, in the manner substantially as show to form the main frame of the machine.

2.- The axle $\mathrm{A}$, connected to the draught-pole $\mathrm{D}$, by the pivot bolt $a^{\prime}$, in the manner as shown, or in any equivalent way, to operate as herein described.

3.- The toothed segments C C, arranged as shown in combination with the shaft $\mathrm{F}$, and bar $\mathrm{H}$, for the purpose of moving or adjusting the axle $\mathrm{A}$, as set forth.

4.- The attaching of the ploughs $T$ to the standards $S$ by means of the stems $h$, fitted in bearings $i$, the former heing provided with nuts $j$, and all arranged substantially as described.

5.-The method of adjusting and holding the frame $k$, by means of the toothed segment $\mathrm{N}$, segment bar $\mathrm{M}$, and lever $Q$, all arranged substantially as set forth.

No. 47,0I6.-JOHN HARI'ER, SALEM, IOWA.-Corn Cultizators.-March 28, 1865.

Claim.-1.- The frame F F, adjustable on the segmental guide rods $\mathrm{C} C$, as specified.

2.-The manner in which the front shovels are attached to the bar $\mathrm{B}$, turning them to or from the corn as may be required, in combination with the lever $\mathrm{L}$, substantially as and for the purposes set forth. 
No. 47,O17.-JOHN HARPER, HILLSBOROUGH, IOWA. - Cirltintizlors. - March $28,1865$.

Clain.- The slotted shovel standards $\mathrm{P}$, in combination with the lever 1 , rope $O \mathrm{~S}$, and stirrup $\mathrm{V}$, the several parts being constructed, arranged, and operating as and for the purpose set forth.

No, 47,055--I. H. THOMAS and P. P. MAST, SPRINCFIELD, OHIO-Cultivators.-Warch 28, 1865.

Claim.-1.-Swinging the suspenders 1 I from the top of the standards $G G$, for the purpose set forth.

2.- The combination of plates $\mathrm{H} \mathrm{H}$, suspenders $\mathrm{I}$, and standards $G G$, as described and for the purposes set forth.

3.- So pivoting the rock-haft $O$, from which the beams $\mathrm{E}$ are suspended as that, when the handle $a$ is turned up and thrown forward, it shall remain in that position, and thus keep the plough suspended without the use of any catch or other device, substantially as set forth.

4.- The adjustable stop $k$, in combination with the adjustable stretcher $\mathrm{K}$ and suspenders I l, substantially as set forth.

5.- The shaft and journals $j j$, in combination with the braces $f$ and drag bass F F, whereby the supplemental tooth may be readily attached, maintained in position, and allowed to swing backward when the wooden pin $c$ is broken, substantially as described and set forth.

No. 48,332,-T. J. POTTS and P. C. YOST, HAMILTON, ILL.-Cultizators.-Apral 18, 1865.

Claim.-The lever L, fitted in the slotted bar M, and cunnected at its rear to a cross-bar I attached to the standards $e$ at the rear of each beam, the front end of said lever being fitted between the prongs $h h$ of a foot lever $\mathrm{N}$, and all arranged to operate in the manner substantially as and for the purpose set forth.

No. 47,380 - - L. B. BARTON, NetaMora, ILl.-Cultiz'ators. - April 25, 1865 .

Claim,-The hinged or jointed frame $\mathbf{E}$ placed within the main frame $\mathrm{A}$, as shown, in combination with the laterally swinging shovel or plough standards $g g$, levers $\mathrm{J} \mathrm{J}$, with stirrups $\mathrm{K} \mathrm{K}$ attached, and the curved or bow shaped bar $\mathrm{M}$, all arranged to operate substantially as and for the purpose herein set forth.

No. 47,568 . - WILLIAM RHODES and M. PORTER, Lovington, ILL.-Cultizators.- May 2, IS65.

Claim.-1.- The roller F mounted upon the tongue E and adapted to move simultaneously therewith, so as to change the line of draught, in the manner and for the purpose berein set forth.

2.- The slot $c$, whereby the dranght may be shifted at will from the tongue $\mathrm{E}$ to the roller $\mathrm{F}$, in the manner and for the purpose dencribed.

No. 47,641.-JANES HOLLINGSWORTH, CHICAGO, ILL.-Cullivators.-Nizy 9, 1865.

Claim.-I.-The use of a spring shovel beam, which will admit of a lateral swinging movement of the shovels, substantially as described.

2.- Constructing cultivator shovel beams of wood and metal, substantially as described.

3.-The rock shaft E provided with loose arms $c d$ and lever $\mathrm{E}$, for enabling the attendant to elevate the shovel beams singly or together, at pleasure, sulstantially as decribed.

No. 47,655-JOSEI'II MILLS, READING, 1LL.-Cultiz'alors.-Way' 9, 1865

Claim.-1.-The vertically adjustable and jointed posts D D, and the vertically adjustable, jointed and swinging posts $\mathrm{E} \mathrm{E}$, in combination with the rods $\mathrm{K}$, for the purpose of guidin; and adjusting the shovels, substantialiy as described.

2. - The rotating axle $\mathrm{B}$ in comhination with the jointed posts D D E E, substantially as described.

3.- The double screw rod $\mathrm{F}$ and swinging nuts $\mathrm{G}$ in combination with the swinging posts $\mathrm{E}$ E, sulustantially as described.

4. - The standard M in combination with the posts D D $\mathrm{E} \mathrm{E}$ and the axle upon which they are mounted, substantially as described and for the purpose set forth.

No, 47,693. - WILLIAJ] E. BATES, Elmore, ILL.Cullizalors.-Mar 16, 1865.
Claim.-The swinging levers $Q Q$ connected substantially as tescribed, with the forward and rear shovel stanclards, which are pivoted in such relation to the frame and laterally-moving mechanism that the two shovels thus connected are caused, by the action of the treadle, to approach to or recede from the corn in concert, as described and represented.

No. 47,699,-JAMES BREWER, Aleany, N. Y.Cultiziators, - May 16,1865 .

Claim.-1.- Securing the central pair of cultivator standards to the plough beams by means of swivel hinges for the purpose of admitting them to be moved in a vertical as well as in a lateral direction, substantially as and for the purpose specified.

2.-In combination with the laterally movable standards $O$, adjustable stirrups $r$, substantially as and for the purpose specified.

3.-In combination with the laterally movable standards $O$, the extension pieced $p$ and knee stirrups $s$, for the pur pose of enabling the ploughman to operate the plough by hand or foot, substantially as and for the purpose specified.

No. 47.904.-EDWARD PHIFER, TRENTON, N. J., assignor to himself and JA $11 E S$ M. GROVER, LAWR FNCFVILLE, N. J.-Cultivators.-May 23, I865.

Claim.-1.- The combination in a cultivator of longitudinal frame pieces, adjustable at both ends to cultivate any wilth of row, with an axle on wheels adjustable to any width of furrow, substantially as and for the purpose described.

2.-The combination of an adjustable frame, with one adjustment for the tooth, with a separate adjustment for the shank, when both are flexible when changing the position of the cultivator tooth, and rigid when the tooth is at work, substantially as and for the purpose described.

3. - The combination in the cultivator of one or more rigidly held teeth or ploughs, with an adjustable mechanism, substantially as described, whereby the driver can control at pleasure the operation of the teeth, singly or in series, as set forth.

No. 48,066.-SAMUEL G. HORNING, Mount CARRuLI, ILL. - Cultizators. - Fune 6, IS65

Claim. - The combination of axle $B$, the har $E$, the beams $s s$, chains $t$, the beams $\mathrm{C} \mathrm{C}$, and braces $O$ and $\mathrm{I}$, the whole constructed and arranged as and for the purpose substantially as herein set forth.

No. 48,068.-HENRY HOWE, DARLINGTON, WIS.Cullizators.- Fune 6, I\$65.

Claim.-1-The oblique bars E E, connected to the draught pole 1 , and to the short parts $a$ a of the axle A, in connection with the bars I I, and driver's seat L, substantially as and for the purpose set forth.

2.- The plough frames F F, connected to the bars E E I $I$, and shaft $K$, substantially as shown, and to admit of being operated as described.

No. 48,102 .- WilliaM G. SAVAGE, Clinton, Ii.l. - Cultizutors.-June 6, I865.

Claim.-I. - The arrangement of the plongh standards $\mathrm{G} \mathrm{G}$, shafts $\mathrm{F} \mathrm{F}$, and lever $\mathrm{H} \mathrm{H}$, placed within the frame $\mathrm{C}$, which is pivoted within the mounted frame A, substantially as and for the purpose herein set forth.

2.- The connecting of the frame $\mathrm{C}$ to treadles $\mathrm{I} I$, in the manner substantially as and for the purpose described.

3.-The combination of the two frames $\mathrm{A} \mathrm{C}$ with the plough standards, treadles, and levers, all arranged to operate in the manner substantially as and for the purpose set forth.

No. 48,271.-EDWARD S. GILliES, AlbaNy, Wis.Cultivators.-Fune 20, 1865 .

Claim,- The attaching of harrows and ploughs, either or hoth, to the frame of a cultivator by means of pendant rods $\mathrm{E}$ provided with springs $\mathrm{F}$, and connecting the heads of the larrows and ploughs to springs $\mathbf{I}$ attached to shafts $\mathrm{J}$ at the front part of frame $A$, in the manner substantially as and for the purpose set forth

No. 48,281 . B. HOLTZ and WILIIAN ENOCH, SPRINGFIELD, OHIO.-Cultivators.-Fumi 20, 1865 .

Claim.-1,-Conmecting the drag bars $\mathrm{E} \mathrm{E}$ to a single 
point on the main frame by the draught rols $(; C$, substantially as descrilsed.

2.- In combination with the draught rock (i G, the traveller rod $a$, sulsstantially as described.

3.- Imparting a lateral motion to the rear end of the plough beams by mean of the two single levers or rods $O$ and $\mathrm{K}$, arranged and oper.ting as devcribed.

4.- l'ivoting the lever $\mathbf{K}$ upon the self-adjusting pivot I in the manner shown, for the purpone of permitting said lever to be moved hoth vertically and laterally, and thus performing the operation of moving the ploughs without the use of more than one lever, $k$, and with but a single pivot for said lever.

5.-Connecting the dray bars in front by the stretcher $F$. provided with pivot screw's and set screw's, as de-cribed.

6. - The combination and arrangement of rods $\mathrm{G}$, the drag bars $\mathrm{F}$, posts $H$, foot rests $\mathrm{J}$, levers $\mathrm{K}$ and $O$, ring $k$, and joint $L$. I, as shown and described.

No, 48,445 .-CVRLS ROBERTS, THREE RIVERS, Micil.-Cultivators.-7une 27, 1865

Claim.-I. - The combination of the plough beams with the flaps and stay rods, substantially as described, for the purpose set forth.

2.- The combination of the frame, the movable driver's seat, and the ploughs, sulsstantially as and for the purpose described.

3.-The combination of the adjustable drives's seat and hand lever with the adjustable link rod $s$, as and for the purpose described.

4.-The combination of the frame, the driver's seat, and the ploughs with the rear flap and stay rods, substantially as described, whereby the driver can exert his whole weight in raising the ploughs, as set forth.

5.- The combination of the frame and driver's seat with the shifting ploughs and elbow levers, when arranged and operating as described.

6.-The combination of the plough beam and stay rod with the hinged socket and wooden pin, when arranged and operating as described, for the purpose set forth.

No. 48,627-JOHN LACEV, assignor to CONRAD FURST and DA III) BRA1)LEY, CHICAGO, IH, - (idlt vators. $-J$ uly 4,1865 .

Claim.-1.-Connecting the movable parts of a mounted cultivator with the wheels and axle by the horizontal swing. ing bars or rods I, substantially as shown and descrithed.

2.- I'ivoting the seat lever $K$ to the axle by means of the post $\mathrm{Y}$, or its equivalent, and to the movable parts of a cultivatur, so as to adjust the weight of such movable part and cause the reaction of the force applied to move them to operate in the same direction as the direct force, all being substantially arranged and constructed as and for the purposes set forth and specified.

No. 48,817 - C. II. JENNE, ILL. Young AMERICA Cultiz'aters.-July is, is65.

Claim -1.- The axle A arranged or applied to the draught pole $C$, substantially as shown, to admit of a forward and backward play thereon, for the purpose set forth.

2.- In combination with the above, the rods D D attach. ed to the draught pole $\mathrm{C}$, and passing through the axle $\mathrm{A}$, with springs $a$ on their rear ends, to operate substantially as and for the purpose herein set forth.

3.-The stirrup $\mathrm{H}$ applied to the draught pole $\mathrm{C}$, in combination with the bars 11 , rods $f$, links 5 , and axle $A$, all arranged substantially as and for the purpose specified.

4.-The rods XI II attached to the plough heams J J and connected by links $\mathrm{N} N$ with the adjutable plates $(0)$ on the draught pole C, substantially as and for the purpose set forth.

5.- The bar $\mathrm{E}$ connected by a hinge or joint $b$ with the rear of the draught pole $\mathrm{C}$, in combination with the rod $\mathrm{F}$ and adjustable plate $(i$, for the purpose specified.

No. 48,884 - -W. D. A.IENT, MuscatiNe, IOWA.-Cul tivators. - July 25, I $\$ 65$.

Claim.-The adjustable metallic plate $G$ formed or cast in one piece, with the bearings I, substantially as described

No. 48,959.-FREDERICK C. LEFFIER, HIGHLAND TowNSH1P, IowA.-Cultivators.-July 25, 1865.

Claim.- The draught bars $\mathrm{L}$, attached to the rear bar $\mathrm{E}$ by pirot $:$ and upright $=f$, and secured to the upright bars $A$ by a rod (i, substantially as and for the purpose set forth. No. 49,008. - (iAR1.AN1) B. ST. JOHIN, KAt.AMAZno, Mich. - Cultizators._-July 25, 1865 .

(laim.-The two plough heams A A connected together as shown, in commection with the handles $(;)$; pivoted to the beams, and having the wheets $I$ attached to them, and the serment racks $\mathbf{J}$ and catches $\mathrm{K}$, all arranged substantially as and for the purpome herein set forth.

No. 49,075.-IANIES BREWER, A1.BANY, T1..-Cultiz'ators.-Ansust 1.1865

Claim.-1.-The eombination of the corn guards R, the stirrups and the swivelling standards $S$, with the frame, when arranged and operating as described.

2. - The combination of the swivelling front ploughs and the frame, with the adjustable sliding collars, the drag chains, the lifting chains, the tension screws and the tilting lever when contructed, arranged, and operating as described.

3.- The combination of the plough standards and frame with the adjustable bracket $(\mathrm{O}$, and swivetling or crank hinge $\mathrm{P}$, when constructed, arranged, and operating as descrihed, for the purpose of varying the angle of the plough to the furrow, while allowing the ploughs both vertical and latern! play, as set forth.

4. - The combination of the triangular frame, the adjustable driver's seat, the lifting lever, the outer ploughs, the adjustable inner ploughs, the shields, the stirrups, and the lifting chains, when arranged and operating substantially in the manner and for the purpose described.

No, 49,512,- $i$, EKSTRAND and A. P. CA.SSEL, WATAGA, In.L.-Cultizators.-Aurust 22, 1865.

Claim.-The adjustable bar $G$ having the plongh beams I I L I connected to it by the bairs P R and the bars $\mathrm{R}$, comnected at their upper ends by a bar $\mathrm{S}$, alt being arranged and applied to a mounted framing, to operate in the manner substantially as and for the purpose set forth

No. 49,540.-EZRA MCEWEN, New LisBon, TLL.Cultizators.-Aurust 22, 1865 .

Claim.-1.- The combination and arrangement of the draught pole $\mathrm{E}$, the plough beams $a a$, the cross-bar /, provided with the slots $b b$, cross.bar $c$, beams $d d$, shares $m n$, and handles, as and for the purposes specified.

2. - The combination and arrangement of the plough beams $a a$, crossubar $l$, slotted as shown, handles $h$, connecting strips $c e$, and shares $m n$, as shown in Fig. 3, substantially as shown and set forth.

No. 49,547--JOHNG. PAGE, ROCKFuRd, JLL.-Cultirators-4ugust 22 I865.

Claim.-1.-In combination with a cultivating machine for cullivat ing two rows, the employment of the two shaft poles $\mathrm{D} \mathrm{D}$, arranged ant oper ting substantially as and for the purpores herein specified and shown.

2.- In combination with a cultivator, arranged so as to cultivate two rows at once, the arrangement of two semicircles $\mathrm{M} \mathrm{M}$, the connecting bar $\mathrm{N}$, or its equivalent, and the front share standards $\mathrm{J}^{\prime}$, operating substantially as and for the purposes specified.

3.-The arrangement of the latch $\mathrm{R}$ with the rod $m$ and are $\mathrm{E}$, as and for the purposes shown and set forth.

4.-The arrangement of the lever / with the latch $R$ and rod $m$, operating to release the forward ploughs when they are raised from the ground, substantially as shown.

5.- The arrangement of the long nec, yoke $D^{\prime}$ with the two poles $\mathrm{D}$, as and for the purposes specified.

No, $49,667-\mathrm{H}, \mathrm{H}$. IVEBSTER, CIAREMONT, N. H,Cultivators. - Austest 29, 1865.

Claim.-1.-The shifis $\mathrm{A}$, chains $\mathrm{C}$ and $\mathrm{D}$, and cultivator $\mathrm{B}$, combined and arranged substantialiy as described and for the purposes specified.

2.-The spring $m$, lever $n$, and slotted st mdard $\mathbf{L}$, when used for the purpose herein set forth, substantially as described.

No. 49,715-GEORGE CALKINS, El PASO, ILL.Cultinators. - Scptember 5, 1865 .

Claim.-1.- The combination and arrangement of the plough beams $\mathrm{D}$, levers $\mathrm{F}$, supports $\mathrm{K}$, levers $\mathrm{E}$, provicled with the rods $\mathrm{L}$, the cross-piece $\mathrm{H}$, and frame $O$, when constructed and operating substantially as and for the purposes set forth.

2.-The comlsination and arrangement of the plough- 
beam levers $\mathrm{E}$ and $\mathrm{F}$, provided with their fulcrums as described; cross-piece $\mathrm{H}$, frame $\mathrm{O}$, and the levers $\mathrm{M}$ and $\mathrm{N}$, when constructed substantially as and for the purposes described.

No. 49,845.-J. A. BARDEL, FREEPORT, 11.1.-Cultivators.-September 12, IS6-

Claim-1. - The plough beams F F, attached to the front part of the frame $C$ by universal joints $a$, in combination with the laterally-swinging extension bar $\mathrm{D}$ and levers $\boldsymbol{H}$ $\mathrm{H}^{\prime}$, all arranged to operate substantially as and for the purpose set forth.

2.- The treadles 1 , in combination with the plough beams and extension bar $\mathrm{D}$, as and for the purpose specified.

No. 49,856.-JASPER CHAPMAN, LINN Co., lowA. - Corn Cultivators. - September 12, 1865.

Claim.-1.- The double bars $d$, constructed and operating as and for the purpose set forth.

2.- The combination of the lever $\mathbf{L}$, the plate $k$, and the beams $h h$, in the manner and for the purpose herein specified.

No. 49,938.-LONDUS B. WALKER, ChICAGo, ILl. - Cultizuators.-September 12, 1865.

Claim.-1.-The combination and arrangement of the vibrating bars $\mathrm{C} \mathrm{C}$ with the bars $\mathrm{D} \mathrm{D}$, which draw the cul. tivating teeth.

2.-In combination with the vibrating bars $c c$, the levers $\mathrm{W} \mathrm{W}$ and links $\mathrm{Z} Z$, arranged to operate them, substantially as descriled for the purpose set forth.

3.- Making the foot levers $\mathrm{W} \mathrm{W}$ with three arms, and hanging them so that the driver, by applying his foot to either of the upper arms, can work the levers and vibrate the bars $\mathrm{C} \mathrm{C}$ in either direction.

4-Making the axle or pivots of the wheels bollow, in combination with the rock shaft and levers working through them, to raise the cultivating teeth.

No. 50,OI8.-IBRAHAN J. MIINNT, Freeport, ILL. - Cultivators. - September 19, 1865.

Claim.-1.- The employment of the lever E, the bar 6, and the yoke $F$, or its equivalent, for the purpose of giving direction to the machine from the seat, as is herein fully set forth.

2.-Attaching the plough beams to the hounds or sidepieces A A in such a manner that said beams can be brought closer together or separated by moving them forward or backward, as is herein represented.

3.- The combination of the triangular frame with the devices for changing the direction of the machine, as and for the purpose specified.

4.- The combination of the levers $\mathrm{G}$ and $\mathrm{H} \mathrm{H}$ with the plough beams, as and for the purpose herein specified.

No. 50,052,-J. P. TOSTEVIN, RACiNE, Wis.-Cultivators - September $19,1865$.

Claim,-1.-The combination and arrangement of the tongue $A$, when extending back and joined to the crosspiece C, substantially as shown, the bolts J, J, the set screw $\mathbf{K}$, and frame B, when contructed and operating substantially as and for the purposes set forth.

2.-The combination and arrangement of the cross piece C, providled with the slot $a$, the T-bolt $H$, plutugh standard $\mathrm{E}$, provided with the slot $b$, base $\mathrm{F}$, and $\operatorname{rod} \mathrm{D}$, when operating substantially as described.

3.- The combination and arrangement of the cogged sectors $\mathrm{N}$ and $\mathrm{O}$ with the wheel and frame of the cultivator, when operating substantially as herein specified.

4.- The combination and arrangement of the lever $\mathrm{L}$, slide rod $\mathrm{U}$, notched standard $\mathrm{R}$, shaft $\mathrm{X}$, and sector $\mathrm{N}$, when constructed and operating subutantially as and for the purposes herein set forth.

No. 50,141.-W. H. L. KING, Princeton, Iowa.Cultivators.-Siptember 26, 1865.

Claim.-1.-The plough beams E E attached to the frame $A$, by means of the univeral joints $F$, in combination with the uprights $\mathrm{G} G$, and slide $H$, and foot levers $\mathrm{J} \mathrm{J}$, all arranged to operate in the manner snbstantially as and for the purpose set forth.

2.- The pivoted frame $Q$ connected to the shaft $\mathbf{M}$, substantially as shown, when used in comnection with the plough beams $\mathrm{E} E$ connected to the shaft $\mathrm{M}$, and all arranged substantially as and for the purpose specified.

No. 50,229.- I $\mathrm{AAAC}$ DUNHAM, LANESFIELD, KANSAS. - Cultivators.-October 3, IS65.

Claim.-The arrangement and combination of the several parts, substantially as described, in their relation to the frame and running gear, whereby the machine is adapted to the different kinds of work, as explained.

No, 50,257.-ROBERT MCCORKLE, Philadelphia, P'ENN -Cultiziators. - October 3, I\$65.

Claim.-1. The metal pieces $\mathrm{F}$, provided with the horizontal flange $a$, recessed to receive and hold the bolt $c$, and having the lugs or projections $b$, for the purpose of attaching the dray bars $\mathrm{D}$ to the slotted bar $\mathrm{A}$, and adjusting the same therein, as set forth.

2.-The plates $\mathrm{G}$ and $\mathrm{H}$, constructed and arranged to operate in combination with the drag bars 1 , as and for the purposes set forth.

3.- The plate 1 , in combination with the elbow levers $\mathrm{L}$, and plates $G$, for the purpose of moving the ploughs I I, as berein described.

4.- The rubber disk, or its equivalent, in combination with the standard $n$, and head $\mathrm{R}$, of the drag bar, when constructed and arranged to operate as and for the purpose set forth.

No. 50,439.-L. B. BARTON, MeTAMOR.1, ILl.-Cultivators.-October $17,1865$.

Claim.-1.-The combination and arrangement of the lever $h$, beam $D$, and double-tree P, as shown in Fig. 4.

2.-The lever $h$, in combination with the double-tree P, ro $1 c$, and be $\mathrm{m} \mathrm{D}$, the latter having its front end pivoted to the main frame, and all the parts arranged to operate as and for the purpose herein set forth.

3.-The harrows $l$, in combination with the central swinging ploughs, as shown and described.

4. - The combination and arrangement of the standard L, lever $\mathrm{O}$, and cross-bar $\mathrm{B}$, as and for the purpose set forth.

No, 50,453.-D.N1EL CHURCHLL and S. C. BREWER, IONIA, IL1.-Cultizators.-October 17, 1865.

Claim.-I.-The combination and arrangement of the draught rods $G$, the har $F$, clevis $a$, and slotted pendant $H$, as and for the purpose set forth.

2 - The combination of the plough beam $\mathrm{E}$, clevis $a$, and slotted pendant $\mathrm{H}$, when arranged to operate as shown and described

No. 51,031.-JOHN FERNALD, FRANKFORT, IND.Cultivators.-Non'mber 21, 1865

Claim.-I. - The movable seat M, connected to the levers $\mathrm{K} \mathrm{K}$, in the manner and for the purpose described.

2.-The donble-plated perforated rolling shields $\mathrm{V} \mathrm{V}$, when used in the manner and for the purpose described.

No, 51,096.-IV. W. ST. JOHN, ST, Lours, Mo.Cultizators.-Noz'cmber $21,1865$.

Claim-I.- Jounting the be.rm $\mathrm{A}$ on the wheel stand 1', the two parts being connected together by means of the bolt $a$, or its equivalent, so as to form a swivel joint, for the purpose of allowing the wheel B to be turned to either side to assist in the guidance of the ploughs $F$.

2. - The combination of the wheel stands $\mathrm{B}^{\prime}$, and frame $A A^{\prime} A^{\prime \prime}$, and frame $C D D^{\prime}$, with the swinging frame $\mathrm{E} \mathrm{E}^{\prime}$ and plough beams $\mathrm{F}$, as and for the purpose set forth.

No. 51,306.-B, A. GRANT, Mount Pleasant, Iowa. Cultivators.-Dicmber 5, IS65.

Claim.-1.-The combination and arrangement of the plough beams J, the arms $\mathbf{K}$, the cross bar $\mathbf{L}$, vertical-rods $\mathrm{M}$, and loops $m$, operating as and for the purposes specified.

2.-The combination of the plough beam $\mathrm{I} \mathrm{J}$, clasps $a$, arms $K$, cross-bar $L$, uprights $I$, loops $m$, uprights $P$, rod $\mathrm{N}$, arms $n$, all arranged and operating as and for the purposes specified.

No. 51,365.-JAMES T(IWNSENI), HEAD OF SASSAFRAS, MD.-Cultivators.-December 5, IS65.

Claim.-1.-The arrangement and combination of the lifting bar $G$, lever $K$, with the beams $F$, made adjustable up and down, and also capable of being run laterally by the stirrups, substantially in the manner and for the purposes set forth. 
2. - The use of the hinged bar ( ), carrying the shank: 1 ' and markers $R$, the bar being provided with adjusting serews $\checkmark$, and operated by the lever $\$$, sub t.ntially as described.

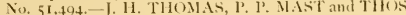

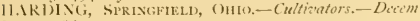
ber 12,1865 .

Claim.-1.-The independent short axles 1:, provided with the projection $\mathrm{F}$, and sccured to the main axle $\mathrm{B}$, in the manner shown and described.

2.- The combination of axles $\mathrm{E}$, rods $i$, and lever $\mathbf{1}$, as shown and described.

3.- The lever $(i$, in combination with the lever I, rods $c$, and axies $\mathrm{E}$, arranged and operating as set forth.

No, 51,680,-JAMES AR.ISTRONG JR., ELMIRA, II.I.. - Cultinators.-Decimbir 26, 1765.

(laim.-1,-The shovel-carrying frame 1$)$ D, with the driver's seat $D^{\prime}$, secured to its rear end, said frame being pivoted by its forward ends to two levers, which are secured rigidly to the carriage axle $\mathrm{B}$, and are provided with foot stirrups $m m$, substantially in the manner and for the purpose described.

2.- The movahle-stepped block $c$, appliert to the axle B of a cultivator carriage, for adjusting the shovel frame of the cultivator, substantially in the manner and for the purpose herein described.

3.-The longitudinal lateralty rocking rocts $c c$, in combination with the pivoted cap $d$, applied in a cultivator, substautially in the manner and for the purpose herein described.

4.-The compound pivot joint $c i$, for connecting the shovel standards $\mathrm{G} \&$ i to their supporting frame, and allowing the lateral vibration of the standards, as welt as permitting the desired adjustment of the same, either to the right or left, substantialty in the manner describect.

5.-Constructing the shovels $S$, with an embracing extension $t$, which is pivoted to the standard in the manner described and represented, for the purpose set forth.

6.- The combination of the shovel frame D I) C' with the tevers $C G$, vibrating tandards $G G$, curved levers 1 l, and treadle; $\mathrm{H} \mathrm{H}$, substantially as described.

No. 3,348.-JAMES ARMSTRONG, JR, ELMRA, II.L. -Cultivintors.-51,680. - Deicmber 26, 1865. - Reissued Whrch $30,1 \mathrm{~S} 69$

Claim.-1,-Two longitudinal beams or levers C C, extending both in front and in rear of the axle B of a cuttiva. tor, and secured rigidly upon said axle, at any required dis tance on each side of its centre, said beams or levers being pivoted or hinged, at their forward ends, to the shovel-carrying frame $\mathrm{D} D$, substantialty as described.

2.-The beams or levers $\mathrm{C}$ C, applied to the axie of a cultivator, and extending both in front and in rear of saicl axte, so that when their ends are depressed, the shovel-carrying frame is raised, substantially as described.

3.- Rigidly securing the draught-pole $\mathrm{E}$ to the transverse brace $\mathrm{C}^{\prime}$ and front brace $b$, of a shovet-carrying frame of a carriage cultivator, when such frame is hinged at it front end, and it, together with the rear end of the draught pole, and with said braces, rises boctily, as the cultivator teeth are elevated, substantially as described.

4.- Pivoting the inner shovel-tandards $G_{i} G$ to a transverse brace $C^{\prime}$ of a shovel-carrying frame, which is hinged at its front end, and has the draught pole attached to it, substantially as described.

5.-A carriage-cultivator, combining in its organization two pairs of longitudinal beams, hinged or pivoted together at their front ends, or levers D D, C C, and a driver's seat, located on extensions which are above the axle in rear of the axte of the transporting-wheets, and in rear of the ploughs or shovel, substantiatly as described.

6.- The shovel-carrying frame I) $\mathrm{D}$, with the driver's seat $\mathrm{D}^{\prime}$ secured to its rear end, said frame being pivoted by its forward end to two levers, which are secured rigilly to the carriage-axte $\mathrm{B}$, and are provided with foot-stirrups $m$ $m$, substantially in the manner and for the purpose de scribed.

7.-The movable stepped-block $c$, applied to the axie B of a cultivator-carriagc, for adjusting the shovet-frame of the cultivator, substantialty in the manner herein descrilsed.

8 ,- The tongitudinaliy laterally-rocking rods $e c$, in com- bination with the pivoted cap $d$, applied in a cultivator, substantialty in the manner and for the purpose herein described.

9.- The compound pivot-joint $e i$, for connecting the shovel-standards $\mathrm{G} G \mathrm{G}$ to their supporting-frame, and altowing the tateral vibration of the stanclards, as well as permitting the desired adjustment of the same, either to the right or left, substantially in the manner described.

10.-Constructing the shovels $s$ with an embracing-extension /, which is pivoted to the standard, in the manner described and represented, for the purpose set forth.

II. - The combination of the shovel-frame $\mathrm{D} \mathrm{D} \mathrm{C}$ with the levers C C, vibrating-standards G Gi, curved levers I I, and treadles $\mathrm{H} \mathrm{H}$, substantially as described

No, 51,682,-C. C. BAUM, OXFOR1, IOWA.-Cultivator Ploughs.-Dicember 26, 1865.

Claim.-The combination of the bars C, vertical shafts D, cranks $b$, comnecting rod $\mathrm{E}$, lever $\mathrm{F}$, heads $\mathrm{J}$, and axles $\mathrm{K}$, as and for the purposes set forth.

No. 51,721--WILLIAM H. HOWELL, EWINGSV1LLE, N. I.-Cultinators.-Dicember $26, \mathbf{1} 865$.

Ctaim.-1.-The frame, consisting of the diagonal stotted bars $\mathrm{A} A$, tongue $\mathrm{B}$, and axle $\mathrm{D}$, arranged as shown and described.

2.-The elbow lever b, connected to the plough by the rod $c$, or its equivalent, in combination with the handle $a$, and bar $f$, provided with the hook $c$, when arranged to operate as and for the purpose set forth.

3.- The combination and arrangement of slotted bars $\mathrm{A}$, pendants $\mathrm{E}$, drag bars $\mathrm{F}$, and bar $\mathrm{C}$, as shown and described.

No. 52,49.-G. 1. HUTCHINSON, WhITE RoCK, ILL. - Cultivitors.-January 16, I866.

Claim.-1. - The rock shaft $h^{\prime}$, arms $h$, and standards $b^{\prime}$ in combination with the axle-trees $\mathrm{B}$ and adjustable braces $b c$, when arranged as and for the purpose set forth.

2.-The arrangement of the lever $\mathrm{P}$ and adjustabie tongue $\mathrm{D}$ in combination with the frame $\mathrm{A}$ and axletrees $\mathrm{B}$ when hinged together, as and for the purpose described.

No. 52,053.-BEN JAMIN F. KESSLER, WILMINGTUN, ILI.-Cultivators.-7anuary $16, \mathbf{1} 866$.

Claim.-Elevating and sustaining the beans $\mathrm{E}$ by means of the chains $m$, drums $\mathrm{L}$, roller $\mathrm{K}$, wheel $\mathrm{J}$, cord $b$, and slide $m$, when all arranged and operated substantially as described.

No. 52,003.-J H. THOMAS and J'. P. MAST, SPRINGFIELD, OHIO-Cultivators.- - Ұanuary I6, is66.

Claim. - I. - Pivoting and bracing the shield bars $\mathrm{C}$ to the beams $B$, in such a muner that the shietds will retain their relative position to the shovels when they are being moved taterally, and at the sime time be permitted to play $\mathrm{np}$ and down independently of exch other, and of the shovets, as and for the purpose set forth.

2.- The metal pieces 0 , constructed as shown, and arranged to operate in connection with the bars $C$, as herein set forth.

3.- The metal stirrup $O$, constructed as shown, and arranged to operate in connection with the swinging bar $b$, and bean $B$, as set forth.

4. - The pulleys $e$, secured to the standards E, in combination with the rock shaft 1 , chins $S$, and beams $B$, arranged as shown and described.

5.-The angle irons 1 , constructed as shown, and arranged to operate in connection with the axte $G$, stanctards $E$, and rock shaft 1 , as and for the purpose herein set forth

No. 52,159.- JAMES S, GiLMORE, MILLERSBURG, IL1.-Cultivator Ploushs.-January 23, I866.

Claim. - I. - The arrangement of the plough shanks $\mathrm{F} \mathrm{F}^{2}$ $\mathrm{F}^{3}$, square shafts $\mathrm{D} \mathrm{H}$, adjustable clevises or arms $\mathrm{E} \mathrm{H}^{\prime}$, chains $I^{\prime} 1^{\prime}, \cos$ wheels $\mathrm{K} L$, and tever $L^{\prime}$, as and for the purpose described.

2,-The arrangement of the shaft $\mathrm{O}$, curved bar $\mathrm{P}$, stirrups $Q Q$, vertical arm $R$, bar $S$, uprights $S^{\prime} S^{\prime}$, curved bars $V V$, and pins $t t$, as and for the purpose specified.

3.-The reversible lever $\mathrm{W}$, in combination with the shatt $O$, and set screws $z \%$, as described.

No. 52,I84.-STEPHEN G. MILLS, DES MOINES, IowA.-Cultivators.- Fanuary 23, 1866 .

Claim.-The arrangement of the double-shovel plough beams F, standards 1 , guides $J$, pair of chains $\mathbf{E}$, wheels $\mathrm{L}$, 
bridge $\mathrm{M}$, bar $\mathrm{O}$, lever $\mathrm{N}$, and shifting seat $\mathrm{R}$, substantially as descrilied and represented.

No, 52,213,-THOMAS N. SHERIVOOD, DUNLAPSVII.1.E, IND.-Cultizators.-January 23, $1 \$ 66$.

Claim.-1.- The lever $\mathbf{N}$, placed on the rear part of the

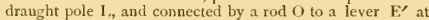
the rear of the bar $\mathrm{E}$, in combination with a staple $\mathrm{M}$ attached to bar $\mathrm{E}$. passing through the draught pole to receive the front end of lever $\mathrm{M}$, and the connecting of the rear end of the draught pole to the bar $\mathrm{E}$ by a hook $e$, substantially as and for the purpose herein set forth.

2.- The rollers $\mathrm{K} \mathrm{K}$, when applied to the device in front of the ploughs, substantially as and for the purpose set forth.

3.- The combination of the adjustable plough beams $\mathrm{B}$ B C C, rollers $\mathrm{K} \mathrm{K}$, wheels $\mathrm{P} \mathrm{P}$, and draught pole $\mathrm{L}$, all arranged to operate in the manner substantially as and for the purpose set forth.

No. 52,217.-JAMES B. SKINNER, ROCKFORD, ILL. - Cultivators.- Junuary 23, 1866.

Claim.-1.- The frame of a cultivator so constructed of two longitudinal pieces as to have its front constitute the tougue, while its rear extends bebind the axle to support the driver's seat and ploughs, substantially as set forth.

2.- Uniting the frame to the axle by levers arranged as described, in combination with the mechanism, substantially as described, for rendering the frame rigid when raised to its greatest height, for the purpose set forth.

3.-The combination of the standards with the frame, the bent levers, and the foot levers, when arranged and operating substantially as and for the purpose set forth.

4. - The combination of the standards with the frame so that they shall be raised and lowered with it, and be capable of a sidewise and pivotal movement, and these with the mechanism, substantially as described, for locking the standards rigidly when adjusted for the purpose set forth.

5.- In combination with the stand irds 3 and 4 , the crossbar I, ratchet bar $\mathrm{M}$, and the catch plate $i$, and the catch hooks 13 and 14 , arranged and operating as and for the purpose set forth.

6.-The combination of the adjustable mould boards $R$, with the standards and ploughs, substantially in the manner and for the purpose set forth.

7.-The combination of the doubletree $\mathrm{N}$ with the main trame and with the levers $\mathrm{P}$ and $\mathrm{P}$, arranged and operating substantially as described, for the purpose set forth.

No. 52,222.-LAFAVETTF STRICKLAND, TALLEYRAND, Iowa.-Cultivator Ploushs.- Fanuary $23,1 \mathrm{~S} 66$.

Claim. - I. - The upright bars $H^{\prime}$ attached to the plough frames E E and connected at their upper ends to handles $K$, the front ends of which, as well as the front ends of the plough frames, are connected to the framing D by staple joints, subitintially as and for the purpose specified.

2. - The adjustable plates $\mathrm{N}$, secured to the inner surfaces of the bars $H^{\prime}$ in connection with the eyes or guides $f$, arranged as shown, to regulate the depth of the penetration of the ploughs in the earth, as set forth.

3.- The shoulders $i$, attıched to the rear sides of the bars $\mathrm{H}^{\prime}$, in connection with the spring catches $j$ on the framing $\mathrm{D}$, for the purpose of holding, when required, the ploughs above the surface of the earth, substantially as set forth.

N. 52,348,-CHARI.ES C. WELLS, LYoNs, IOWA.Cultivators.-Fanuary $30,1866$.

Claim.-1.- So constructing and arranging the hounds $\mathrm{C}$ $C$, front cross-beam $z^{\prime}$, and rear beam $v^{\prime}$, in combination with the axle A, that the same may be adjusted by the movable bolts and holes, sulistantially in the manner and for the purpose herein set forth.

2.-Constructing and arranging the standards $\mathrm{D}^{1} \mathrm{D}^{2}$, in connection with the hounds, so that the may be shifted from the straight bolts $f f$ to the elbow ones $e c$, substantially in the manner and for the purpose herein set forth.

3.- The application of the stirrups F F to the rear of the standards $D^{1} D^{2}$, substantially in the manner and for the purpose herein set forth.

4.-The combination of the lever $\mathrm{E}$ with the stirrups $\mathrm{F}$ $\mathrm{F}$ and standards $\mathrm{D}^{1} \mathrm{D}^{2}$, for raising the latter in conjunction with the feet, substantially in the manner and for the purpose as herein set forth.
5.- The arrangement of the rear cross-beam $v^{\prime \prime}$, in combination with the stirrups and standards, so that the latter may be moved in a lateral direction independent of each other, substantially in the manner and for the purpose herein set fortl.

No. 52,429.-A. S. MARKHA.I, BushNELL, ILL.Cultivators.-February 6, 1866 .

Claim.-The securing of the pendants $\mathrm{J}$ on the rod $\mathrm{K}$ by means of bolts $i$ passing through any of a series of holes in plates $\mathrm{N} \mathrm{N}$ attached to the draught pole, substantially as shown and described.

No, 52,462,-JOSEPH S. STUCKER, SUgAR GROVE, OH10.-Corn Cultivators.-February 6, 1866.

Clain.-The combination and arrangement of the ploughs or cultivators, cross-bar, axle, and frame, when made adjustable, as and for the purposes set forth.

No. 52,606.-1. HARRISON RICE, SPRINGFIELD, Oнго.-Cultivators.-February I $3,1866$.

Claim.-I.-The combination of the three-sided double frame $a a a a$, and $a^{\prime} a^{\prime}$, with the removable seat $g$, and adjustable axle bearings, in the manner described, for the purpose specified.

2.- The combination of the main frame with the vertical frame $d$, windlass $c$, chains $f$, and joints $c c$, arranged and operating conjointly, in the manner substantially as described, for the purpose specitied.

No. 52,743.-GEORGE W. PRUGH and WILLIAM H. BEARU, ARMINGTON, ILL.-Cultivators.-Februnry 20, 1866

Claim.-1.-Combining and uniting in one machine the shaft J, fitted with a lever and pulley, and connected to the cultivator beams N N and S S for the purpose of raising and lowering them, and the bell cranks P P and stirrups $t i$, connected to the top of the two inside cultivator staffs $\mathrm{V} \mathrm{V}$, for the purpose of moving them laterally, substantially as described.

2.-Connecting and arranging the cultivator beams N S and $\mathrm{N} \mathrm{S}^{\prime}$, in relation to each other, substantially as set forth.

3.-The adjustable connection between the front ends of the cultivator beams $\mathrm{N} \mathrm{N}^{\prime}$ and the hangers $\mathrm{E} \mathrm{E}$, when said hangers and beams are arranged in respect to each other and to the cross-tie $\mathrm{Z}$ and the main frame A B C, substan. tially as set forth.

No. 52,754.-JOHN SAVILL, Monmouth, IlL.-Cultivators.-February $20,1866$.

Claim - I.-The bent axle A, provided with arms $a a$, in combination with the brackets $\mathrm{C} C$, containing the wheels $\mathrm{D}$ and fitted on the arms $a$, substantially as and for the purpose set forth.

2.-Connecting the front ends of the plough beams E F, to the upper ends of the brackets $\mathrm{C} C$, by pivot-bolt $b$, arranged with circle-plates $c$, substantially as and for the purpose specified.

3.- The evener, $r$ dranght-regulator composed of the splinter bars $1 \mathrm{I} \mathrm{K}$, connected by the rods $\mathrm{J}$, and arranged substantially as described.

No. 52,770.-D. C. TEller, Terre Haute, 1ND.Cultivators.-February 20, 1866 .

Claim, - The arrangement of the vibrating beams $R$, in combination with the spring sliding draw bars $F$ and crooked arms $m$ with the stop $U$, substantially as specified for the purpose set forth.

No. 52,905.-ANDREW J. STOVER, SANDYvili.e, IowA.-Cultivators.-February 27, 1866.

Claim.-The oblique bars D D, connected to the draught pole $\mathrm{C}$, and having standards $\mathrm{I}$ and shares $\mathrm{I}$ attaclied as shown, in combination with the plough beams G G connected to the bars D D, and arranged to admit of being tumed to give a lateral movement to the shares $\mathbf{L}$, substantially as and for the purpose set forth.

No. 52,998.-ISAIAH HENTON, SHelnYville, Ill. Cultivators.-March 6, 1866.

Claim.- The combination and arrangement of the carriage frame $\mathrm{A}$, the vibrating frame $\mathrm{B}$, pivoted to $\mathrm{A}$, the beams $k$, hangers $i$, standards $n$, and the hand lever $o$, with the sheaves $q$, and cords or chains $r$, substantially as herein specified and for the purpose described. 
No. 53,303,--M. II. HUI.I.INGER, GRANSHIL, II.I. - Cultizitors.-. Harch 20, 1866 .

Claim-I-The combination and arrangement of the curved bar $O$ and the rollers $T$, operating substantially as and for the purposes specified.

2. - The combination and arrangement of the beams II and 1 , the posts $\mathrm{I}$, the standards $\mathrm{L}$, curved bar $O$, and rollers $\mathrm{T} T$, substantially as specified and shown.

3.-In combination with the above the employment of the bent levers $P$, the chains $c$, and stirrups $Q$, as and for the purposes shown and described.

No. 53.322.-THOMAS H. MINER and SAMUEL IIEAVENRIDGE, GKEENFIELD IND, - C'ultizator Ploughs. .- Yarch 20, 1866.

Claim.-I.-The sliding plates D D, with the plough standards $\mathrm{F}$ passing through them, and the plates connected to the crank I of a sh.ift J, by rods e $e$, said shaft having a cross bar $K$ at its rear end provided with stirrups $L$, and all arranged to operate in the manner substantially as shown, to give a lateral movement to the ploughs.

2.-The connecting of the plough standards $F$ to cranks $\mathrm{s}$, on the plates D $\mathrm{D}$, by rods $f$, the cranks having levers $\mathrm{N}$ attached, and all arranged substantially as shown, to admit of the raising of the ploughs.

No. 53.326.-D. J. NOBLE, New Boston, ILL.-Cultivators.-Warch 20, 1866.

Claim.-The springs $\mathbf{F}$, applied to the pivoted plough standards $b$, substantially as and for the purpose set forth.

No. 2,683.-D. J. NOBLE, New Boston, It.t.-Ciltia'ators.-Wharch 20, 1866. Reissued July 16, 1867.

Claim.--1.-The combination of the adjustable plough beams $\mathrm{E}$ with a stationary frame $\mathrm{A}$ and a device wherehy said beams may be locked rigidly at any desired height, substantially as and for the purposes specified.

2.- The levers $\mathrm{H} \mathrm{H}$, pivoted to the frame $\mathrm{A}$ and arranged relatively with the plough frame $\mathrm{E}$, as heren specified, in combination with the notched plates $1 \mathrm{I}$, when all are constructed and operate substantially as and for the purposes set forth.

No 53,328.-LEWIS M. PATTERSON, JORDAN'S Grove, Ill.-Gang Ploughs.-Warch 20, 1866

Claim.-1.- The combination of the two frames F H, one, F, being attached by a pivot bolt or screw to the pivoted bolster $\mathrm{C}$, and the other, $\mathrm{H}$, altached to the front end of $\mathrm{F}$ by a hinge or joint, and having a lever, $\mathrm{J}$, connected to it, substantially as shown, for the purpose of keeping the frame $\mathbf{H}$, and consequently the ploughs, in an elevated or working position, substantially as set forth.

2. - The bolster $\mathrm{C}$ pivoted to the axle $\mathrm{A}$, in combination with the frames $\mathrm{F} \mathrm{H}$ and the lever $\mathrm{N}$, or its equivalent, all arranged to operate in the manner suinstantially as and for the purpose herein set forth.

No, 53,108-JAMES CANFIELD, WASHINGTON, IowA, and CHARLES HESS, LYONs, IOWA.-Cultivators. - Warch 27, 1866 .

Claim,-1.-The combination and arrangement of the inner beams F F, the slotted hangers II H, pivoted to the cross-bar $\mathrm{C}$, and the regulating har I, operating as and for the purposes described.

2.-The combination and arrangement of the plough beams $\mathrm{E} \mathrm{F}$, the bangers $\mathrm{G} H$, the levers $\mathrm{L} L$, cross-bar $\mathrm{C}$, chains $a b$, arranged and operating as and for the purposes described.

No. 53,445.-PAUL HILDRETH; BeloIt, Wis.Cultizators.-. Warck 27, 1866.

Claim,-The adjustable cultivator bars F F, the bed pieces II $\mathrm{H}$, the adjustable brackets IV W, the movable gauges $e c$, and the scrapers $q q$, when constructed substantially as herein set forth and described, for the purpose specified.

Vo. 53,446.-CHARLES HOLMAN, CAMERON, ILL.Cultivators.-Warch 27, 1866 .

Claim. - The buttons $\mathrm{H}^{\prime} \mathrm{H}^{\prime}$, secured to the upper ends of the rods $\mathrm{G} \mathrm{G}$, in combination with the bar $\mathrm{J}$, provided with the recesses $h h$, and the springs $g$, on the rods $G$, all arranged substantially as and for the purpose specified.
No. 53,525-CIIARLIS DENTON, PEKIN, ILL, as signor to himself, SAMUEL, E. BARBER, and SAMUEI F.IIAIVLEY, DECATUR, II...-Cultizators and Seeding Wachines. - Warch 27, 1866.

Claim.-1.-The plough framing, consisting of the two oblique bars $c c$, connected together as shown, and connected to the bars D D of the main frame by means of the joints $b$, for the purpose of raising the ploughs out of the ground when desired.

2.- The pivoted draught pole $\mathrm{O}$ in combination with the pivoted plough standards $\mathrm{K} K$, arranged substantially as and for the purpose specified

3.- The main frame, consisting of the bar $\mathbf{C}$, with slide bars D I attached, when used in combination with the plough frame composed of the oblique bars $c c$, and all arranged substantially as described.

No. 53,663.-C. S. PANGiBORN and GEORGE W. IEERS, ONARGO, ILL.C-Cultizators.-April 3, 1866

Claim.-The combination of the treadles L. L, plough beams $\mathrm{G} G$, swivel sockets II $H$, arms J J, treadles $O O$, and frame D, corstructed and arranged to operate in the manner as and for the purpose herein specified.

No. 53,837.-JOHN I.ACFY, CHicAso, II.L._Cultivators, - April 10, 1866

Claim.- 1.-Attaching the shovels to beams having an independent vertical movement, and so connected to the movable frame $\mathrm{L} \mathrm{H}$, that by moving the latter siclewise all the ploughs are moved with it, saicl movalle frame being pivoted at $h$, substantially as and for the purpose set forth.

2.-Interposing the conical rollers $a$ between the fixed and movable frames, to enable the latter to be more easily uperated, as shown and described.

No. 53,867.-GEORGE PERRY, IIUscatine, Iowa.Cultizutors.-April 10, 1866

Claim, - 1.- The ad iustable beams C C, in combination with the slotted cross bar $\mathrm{A}$, and the slotted braces and notched latches M M, substantially as and for the purposes set forth.

2.-The foot levers $\mathrm{G} G$, in combination with the supplementary frame, substantially as and for the purposes set forth.

3.- The buttons $\mathrm{O} O$, attached to the frame D D, and rigidly securing the supplementary frame either up or down when desired, substantially as and for the purposes set forth.

4.- The levers $\mathrm{H} \mathrm{H}$, and the parallel bar I, in combination with the hinged standards of the interior shovels and oscillating beams $\mathrm{C} \mathrm{C}$, the latter being also adjustably attached, substantially in the manuer and for the purpose set forth.

5. - The mode of attaching the standards of the interior ploughs by the jaws L L to the beams C C , substantially as and for the purposes set forth.

6.-A hinged shovel altached to the stundard by a wooden pin, substantially in the manner and for the purpose set forth.

No, 53,911.-EDWARD P. WHEELER, Nebraska City, NEB.-Cultivators.-April 10, 1866.

Claim.-I.-The arrangement of the levers F, pivoted standards $\mathrm{L}$, and plough beams $\mathrm{D}$, as described.

2.-Pivoting the lever $\mathbf{F}$ and standards $\mathrm{L}$ to the plough beams, by means of the longitudinally arranged pins or rods $f$, as and for the purposes shown and set forth.

3.-Providing said levers, when arranged with the standards L, as set forth, with the knee rests $l$, as and for the purposes specified.

4.- The combination of the binged beams D, standard $\mathrm{L}$, levers $\mathrm{F}$, and hook $d$, arranged as described and shown. 5. - In combination with the beams $\mathrm{D}$ and standards $\mathrm{L}$, the arrangement of the adjustable standard $\mathrm{P}$ and crossbars $Q R$, as described.

6. - The combination of the cross-marking bar $T$, provided with shovels $\mathrm{V}$, with the drags $\mathrm{J}$, for the purposes set forth.

7.- The combination and arrangement of the standards $\mathrm{L}$ P, the levers $\mathrm{F}$, beams $\mathrm{D}$, cross-bar $\mathrm{II}$, and brace $\mathrm{I}$ when arranged so as to render said standards L rigisl, for the purpose of ploughing in grain, as show'n and specified. 
No. 53,947.-JARVIS C.ASE, SPRINGFIELD, OHIO.Cultivators.-April $17,1866$.

Claim.-1.-Suspending the plough beams from the rock shaft $\mathrm{F}$, mounted on the posts $\mathrm{H}$, substantially as shown and described.

2.- The lock bar or brace $c$, arranged to operate in connection with the shaft $\mathrm{F}$, as and for the purpose set forth.

3.- The standards I, connected by the chain L, and provided with the foot rests $s$, as shown and described.

4.-Attaching the shields $O$ by means of the bent arms $n$ and staples $t$, as set forth.

No. 54,099.-THEOPHILUS F. BERTRAND and PETER SAMES, ROCKFORD, ILL.-Cultivators.-April 24,1866 .

Claim.-1.-The combination of the ploughs, draught rods, and elbow levers $\mathrm{O}$, with the frame and driver's seat, when constructed, arranged, and of erating as described.

2.-The combination of the standard, braces, eye-bolt, and grooved block, when constructed and arranged as described, to vary the angle of the plough to the crop, as set forth.

3.- The combination of the standard eye-bolt $j$, loop $m$, and draught rorl $\mathrm{M}$, constructed and arranged as described, to secure centre draught when ploughing at an angle to the crop.

No. 54,139.-I. L. FOUNTAIN, New Milford, ILI. -Combined Seeders and Cultizators.-April 24, 1866

Claim.-1.- The arrangement of hanging the cultivator to the hounds $\mathrm{C}$ at $\mathrm{Q}$, and by links $p$ the levers $\mathrm{S} r$, in combination with the hounds, axte, and cultivator frame, as and for the purposes set forth.

2.-The adjustable arms D, cross-brace F, and pieces $\mathrm{E}$ $\mathrm{E}$, for extending and contracting the frame, in combination with the seeding apparatus, lever $\mathrm{L}$, and seat $\mathrm{O}$, arranged as and for the purpose described.

No, 54,160.-SAlIUEl, HOFFHEINS, HAMILTON

Townshir, Penn,-Cultivators.-April 24, 1866.

Claim.-The combination of the devices for raising the shovels from the ground, and consisting of the levers G G, foot boards $\mathrm{H} \mathrm{H}$, and rocking seat $\mathrm{I}$, operating substantially as described and represented.

No. 54,317.-WILLIAM D. FISHER, Freeport, ILI. - Cultivators.-May I, 1866.

Claim.-The arrangement and combination of the drops $\mathrm{C}$, equalizer $\mathrm{E}$, adjustable frame $\mathrm{A}$, regulating lever $\mathrm{G}$, and fenders $J$, when arranged as herein described, and for the purposes set forth.

No. 54,637 - BENJAIIN F. YOUNG, Toulon, ILI. - Cultivators.-May 8, 1866

Claim.-1.-The inside frame B and the mode of connecting it with the frame $\mathrm{A}$, constructed and operated substantially as described.

2.- The iron lever $F$ hung upon a pivot by which the front shovels are swung to the right or left.

3.-The adjustable wooden wedges I, together with the crooked iron necks D, by which the front shovels are adjusted so as to throw the dirt to or from the corn.

4.- The side or guage $\mathrm{P}$, by which is adjusted the depth the shovels enter the ground.

No. 54,659.-ORLANDO BARR and FRANKLIN F. COX, BrLoit, WIs,-Cultizators.-AFav 15, 1866.

Claim.-The rod $\mathrm{B}^{\prime} \mathrm{B}^{\prime}$, as shown in Fig, $\mathbf{I}$, the head blocks $\mathrm{B} \mathrm{B}$, sliding upon the said rod $\mathrm{B}^{\prime} \mathrm{B}^{\prime}$, connected with the gear $b b$, and foot lever and section pinion $D$, the sliding rods $\mathrm{A} A$ attached to the beams $\mathrm{A}^{\prime} \mathrm{A}^{\prime}$, and the device and arrangement of the draught rods $g g$, and chains $e^{\prime}$ $e$, when constructed substantially as and for the purpone herein set forth and described.

No. 54,751.-WILL1A.I IICCORMICK, Muscatine, lows.-Cultizators.-Way 15, 1866.

Claim. - I. - The cast iron standards Z, provided at their upper ends with lips $i$, to fit over the upper and lower edges of the plough heams 1 , in order to avoid the use of the braces to retain the standards in position, substantially as set forth.

2.- The arrangement of the plough heams I, as shown, to wit : the rear ends being provided with rods $\mathrm{J}$, to fit into staples or guides $K$, at the lower parts of uprights $G$, at the rear of the frame $A$, and their front ends connected by chains $R$ to uprights $G$, which are attached by universal joints $g$ to the front part of the frame $A$, the uprights $G$ passing down between rollers $\mathbf{M}$, and the front bent parts $a^{*}$ of one of the clevises $\mathrm{L}$ of each beam, substantially as and for and for the purpose specified.

3.- The attaching of the doubletree $Q$ to the front ends of the beams I, when said beams are connected to the bar $I^{*}$, through the medium of the uprights $O$, in the manner substantially as set forth.

4.- The arrangement of the treadles $\mathrm{T} T$, with the beams I I, and levers W, substantially as and for the purpose specified.

No. 54,763.-EDWIN PARMELE and R. N. PAT. TERSON, DAVENPORT, IOWA.-Cultivators.-May 15 1866 .

Claim.-1.-Applying shovel standards to a carriage in such manner that that they are allowed to rise or fall bodily or independently of each other, and also of being moved laterally tugether by the feet of the attendant, substantially as described.

2.- The slotted shovel standards D D, in combination with the treadles $r r$, and the driver's seat, substantially as descrilied.

3.-Connecting the standards D D to the roller e, in such manner that their lower ends can be swung forward and upward in combination with contrivances for allowing said shovel standards to be adjusted laterally, and also moved up and down in a direction with their length, substantially as described.

4.- - So constructing the two treadles $r r$, that each one serves as a lever, and also as a means by which both standards can be moved simultaneously either to the right or to the left, substanially as described.

No, 54,842,-FRANCIS M. BIRDSALL, MARTINSviLle, OHis-Furrowing Machines.-May 22, 1866. Antedated Mizy 16, 1866

Claim.-The plough frames $e$, lonritudinal strips $e^{\prime}$, and levers $d$, in combination with ploughs $g$, frame $A$, and sliding straps $h$, constructed as ahove descrilicd and for the purposes set forth.

No, $54,854,-$ H. F. BVERLY, Clinton, ILL, assignor to ISRAEL CAMPBELL.-Cultivators.-Mity 22, I 866.

Claim.-1.- The sliding holts $k k$, slots $i i$, and pendants $b b$, combined and operated substantially as and for the purpose specified.

2.- The roller L, lever $f$, and chain $M$ and $h$, combined and operated substantially as and for the purpose set forth.

No, 55,093.- WILLLAM HAMIIOND, MARshaLI. Micn,-Wheel-Cultizators and Gang Ploughs.-May 29, 1866 .

Claim.-The employment, independently, or in connection with each other, of the bent axle, bearing levers $\mathrm{L}$, in combination with the fulcrum pins $F$, and adjustable stopkauge plates $\mathrm{G}$, connected and arranged relatively to and with the frame and wheels of a cultivator, or gang plough, substantially as and for the purpose herein specified.

No. 55.381.-H. B. SMITH, EurekA, IlL.-Cultivators. - June $5, \mathbf{I} 866$.

Claim.-1.-The construction of the frame $\mathrm{A}$ in the manner substantially as herein shown and described, to admit of said frame being expanded and contracted laterally to adjust the ploughs nearer together or further apart, as may be required, and admit of a direct application of the draught of each animal to the device, as set furth.

2. - In combination with the frame A thus constructed, the pivoted beams $\mathrm{C} \mathrm{C}$, arranired or applied substantially as and for the purpose set forth.

3.- The connecting of the plough beams $\mathrm{G} \mathrm{G}$ to the beams $C$, by means of the universal joints $\mathrm{H}^{*}$, constructed substantially as shown and described, to admit of the vertical, lateral, aud rolling motion of the ploughs, as set forth.

4.-The combination of the adjustable frame A, pivoted beams $\mathrm{C} \mathrm{C}$, plough beams $\mathrm{G} \mathrm{G}$, all arranged to operate in the manner substantially as and for the purpose set forth.

No, 55,993,-A. M. BLACK, AUrurn, ILL.-Cultioators.-July 3, I 866 .

Claim.-1.-The pole $a$ having a cross-bar A rigidly 
secured thereto, and a framework composed of the plough beams B B, with cross-pieces b b' pivoled tis the ends of said cross-bar A, substantially in the manner and for the purpose specified.

2.- The cross-har A, plough beams and frame $\mathrm{B} \mathrm{B}$ b $\mathrm{b}^{\prime}$, the arjustable prop $C$, and lever $H$, all arranged and operating in the manner and for the purpose set forth.

3.-The hook and eye-bolts, which project from the inside of the plough leams $\mathrm{B}, \mathrm{B}$, and fasten the standards $m m$, to beans $\mathrm{B} \mathrm{B}$, the connecting rod $g$, eye and rod fastening in cross-piece $b$.

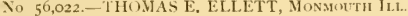
- Cultivators.-July 3, 1866.

Claim.-1. The combination of wheel A, bar P, and axles $G G$, with the ends at right angles, for the purpose and substantially as described.

2.- The attachment of tongue with side movement, substantially as described.

3.- The bars $H$ H for supporting axle-boxcs $F$ and clevis () , substantially as and for the purpose described.

4.- The rod 2 , for the purpose described.

5. - The combination of the axle $G$, bars $H \mathrm{H}$, wheel $A$ and tongue, in a manner to produce side movement, for the purpose and substantially as descrilied

No. 56,122,-C. IV. TAlIAFERRO, Keithsiurg, Ilt. -Corn Cultivators.-July $3, \mathrm{I} 866$.

Claim.-1. The particular m.nner of constructing the frame of the machine, to wit, of two parallel bars $A$, connected by semi-circular metallic hars $\mathrm{B}$, with the axles $\mathrm{E}$ fitted between or having their bearings in said bars, substantially as shown and for the purpose set forth.

2.-The connecting of the plough heams $\mathbf{F ~} \mathbf{F}$ to the axles $\mathrm{E}$, by having the latter formed with slots $a$, to receive clevices $a^{*}$ at the front ends of the be $1 \mathrm{~ms}$, with pins passing throu th the axles and clevices, substantially as and for the purpose specified.

No. 56,157.-ANDREW P. ANDERSON and BVRON EDWARDS, PRixceton, ILL.-Cultizators.-July Io, I 866 .

Claim, - The beams I) D, in comlination with the plough standards $H \mathrm{H}$, and the plough standards $\mathrm{E}$, substantially as and for the purnose set forth.

No. 56,289.-D. C. STOVER, LANAKK, 1LL.-Cultionators.-Fuly 10, 1866 .

Claim,-The arrangement of the uprights $c c$ and bar $d$ with the pendant bars I I and plough beans D D L L .

No. 56,295.-G. W. WARREN, II ACoMr, ILI-Cultiv'ators.-Fuly $10,1866$.

Claim,-1.- The inner frame, pivoted at its rear end to the main frame, having the two rear ploughs attached permanently thereto, and having the pivoted bars $\mathrm{T}$ secured to it in the manner shown.

2.- The long standards I, having the front shovels attached thereto secured to the pisoted hars. $T$ underneath the axle and frame, and arranced as set forth.

3.-The screws $c$, arranged to adjust the depth of the pluaghs, in the manner shown and described.

No. 56,341--ISAAC AVERY, OrTAWA, Ili-Cultizators.-7uly 17, 1866.

Claim.-1. - The attaching of the plough beams $A^{*}$ to pendants $a^{*}$, of the cross-bar $\mathrm{C}$, by means of universal joints $\mathrm{D} \mathrm{D}^{\prime}$, substantially as and for the purpose specified.

2.- The combination of the plongh heams $\mathrm{A}^{*}$, universal joints $\mathrm{LD}^{\prime}$, doubletree or evener $\mathrm{C}$, trace chains $\mathrm{F}$, and pulleys $e^{*}$, all arranged to operate in the manner substantially as and for the purpose herein set forth.

No. 56,511.-TOHN N. ARVIN, VAIPARAISO, IND,Cultizators:-July 24, 1866.

Claim, - The arrangement of the joints $b$, miversal joint: $\mathrm{H}$, links $\mathrm{O}$, arms $\mathrm{P}$, and chains $\mathrm{J}$ in combination with the curved plongh beams G $\mathrm{M}$ and shaft E, operating in the manner and for the purpose herein specified.

No. 57,484-CHARLES D.NIEL, LAMONTE, Mo.Cultivators.-August 28, 1866.

Claim.-1.-The jointed handled and vilurating cultivators $h \mathrm{~h}$ in combination with the plough beams $c c$, the axle $\mathrm{B}$, and hounds $a$, constructed and operated substantially as and for the purposes herein described.

2.-The suspended plough beam; $c c$, in combination with the hounds $a d$, and the stirrups $d d$, constructed and orerated substantially as and for the purposes set forth.

3.- The arrangement of the ollitiue hanging hounds $a a$, in connection with the centre beam $\mathrm{A}$, the plongh-beams $c$, the side braces $e c$, and the axle $B$, constructed and applied substantially as and for the purposes herein specified.

4.-The arrangement of the swinging seat $C$ on the centre leam $\mathrm{A}$, in combination with the vilbrating cultivators $h h$, and their jointed handles $m m$, applied in connection therewith, substantially as and for the purposes herein described.

No. 57,563-H. S. POTTER, FAirfield, IOWA-Corn Cultivators.-Aurust 28, 1866.

Claim, - 1. - The frame A, with the driver's seat B, placed on its rear end, and connected at its front end to the hounds $D$ of the draught pole in front of the axle $E$, substantially as and for the purpose set forth.

2.- The frame I, in combination with the plough beams $\mathrm{L}$ L, connected by swivel joints to the rod $\mathrm{K}$, above the axle $\mathrm{E}$, arranged in connection with the frame $\mathrm{A}$, to operate substantially as and for the purpose specified.

3.- The lever $Q$, attached to the front part of the frame $A$, and applied to or arranged in connection with the frame $J$, and the loop $l$, with roller $m$, substantially as and for the purpose set forth.

4- The connecting of the plough standards G M to the frame $\mathrm{A}$ and beams $\mathrm{L}$, by means of the pivoted bars $b g$, provided with wheels $c h$, substantially as and for the purpose specified.

No. 57,619.-JACOB BERGEN, PLAIN TownshtP, OHIO, assignor to himself and PETER KAUFMAN.Cultizators-Awrust 28, 1866

Claim. - 1. - The peculiar arrangement of the bent axle II GFGH, in connection with the frame $A$ and the wheels G, substantially in the manner and for the purpose specified.

2.-The peculiar arrangement of the back braces $\mathrm{E}$ and frame $\mathrm{A}$, in the manner and for the purpose specified.

No, 57,660.-T. H. BARLEY, LongWood, Mo.-Cultivators.-September 4, 1866 .

Claim, - 1. - The iron bars D D attached to the plough beams $\mathrm{A} \mathrm{A}$, to support the crosapiece $\mathrm{E}$ a suitable distance above the plough beams, in connection with the plough standards F F pivoted to the cross-piece, sub-tantially as and for the purpose set forth.

2.-The curved handles $\mathrm{K} K$, pivoted to the adjustable bar $\mathrm{f}$, and connected to the bars $\mathrm{F}$, which are pivoted in the b.ir $\mathrm{H}$ and secured to the plough standards F F, substantially as and for the purpose set forth.

No, 57,700.-GEORGE T. GIFFORD, Monmouth, 1L1.-Cultizuators.-Siptember 4, 1866

Claim. -1 - The arrangement of the frames $B$ and $A$, and movable pivot L L, for balancing, sulistantially as described.

2. - The combination of the lever $\mathrm{F}$, cross-bars $\mathrm{E}$ and $\mathrm{C}$, and ploughs G G, with the inside frame, for the purposes set forth, and substantially as descrihed.

3.-The arrangement of frames B B and A A, by which the weignt of driver supports or tends to lift ploughs, substantially as described.

4.- The slide S, operating in the axles as described, and for the purpose set forth.

No. 57,752.-L. B. MOORE, JANESvil.Le, Wis.-Corn Cultivators.-September 4, I866.

Claim.-The construction of a corn cultivator by the combination and arrangement of the various parts, substantially as they are described in the foregoing specification, or their mechanical equivalents, when used to produce the sid antomatic reciprocating motion of the said levers $j j$ and shovels $\mathrm{X}$ X, as specified.

No. 57,856.-M. H. BUCKNALL, DARIEN, Wis.Cuttivators.-September II, 1866.

Claim.-1.- The lever frames B B, attached at their front ends by joints $a$ a to the front end of the frame $A$, in combination with the segment guides $\mathrm{C} \mathrm{C}$ and the stop pins $d$, or their equivalents, substantially as and for the purpose herein set forth.

2.-The combination of the teeth $\mathrm{J}$, standards $\mathrm{I}$, rivets $o$, 
shoulder $k$, screw nut $l$, braces $m$, and frame $A$, substantially as described for the purpose specified.

No. 57,858.-JOHN BURNHAM and WJLIAAM C. LATHROP, LA SAI.LE, ILL.-Cultivators.-September 11 , 1866.

Claim.-I. - The attaching of the plough frames $G$ to an upright mounted frame A by means of joints $d$ and bars F, arranged as shown to form a universal joint connection to admit of the vertical and lateral movement of the ploughs, substantially as described.

2.-The connecting of the two plough frames $G G$ by means of a yoke $\mathrm{H}^{*}$, having its ends pivoted to bars $I^{*} I^{*}$ which are secured horizontally on the frames $G G$ by pivots $\epsilon$, to admit of the frames $\mathrm{G}$ rising and falling independently of each other, as set forth.

3. - The duplex double tree arrangement, composed of the two double trees D E, attached to the draught pole C and connected by the rods $a$, substantially as described.

No. 57,906.-HENRT HOOVER, HEMLO, ILL.- Cullivators.-September 11, 1866.

Claim,-1.-The arrangement and combination of the central beam $O$, shovel standards $D^{\prime}$, shovel $O^{\prime}$, with the central roller $F$ and shaft 5 , when constructed substantially as and for the purpose specified.

2.- The segment guides $J$, having the grooves $S$, in combination with the inner beams $G$, rollers and shovel stand. ards $\mathrm{D}^{\prime \prime}$, shovels $\mathrm{Q}^{\prime \prime}$, cams $\mathrm{L}$ and shaft 5 , substantially as described and set forth.

No. 58,082 , $\$$ AMUEL P. ETTER, SCOTLAND, TENN. - Cultivators.-Siptember 18, 1866.

Claim.-1.- The compound levers $R$ and $Q$, connected to the plough beams by the braces or rods $U \mathrm{U}$, when con structed and operated for the purposes and substantially as described.

2.- The compround levers $R$ and $Q$, rods $U$, and plough beams $\mathrm{H} \mathrm{H}$, in combination with the pendants $\mathrm{G} G$; and pendant guides $J$ J, substantially as and for the purposes shown and described.

No. 58,125.-D. J. NOBLE, NEw Buston, ILL.-Con Cultivators. - Seprember 18, 1866.

Claim - The adjustable foot pieces L L connected to the plough standards I I, and arranged with brace $\mathrm{K}$, in combinntion with the mode of attaching said standards to the frames $\mathrm{C}$ and $\mathrm{F}$, substantially as and for the purpose herein specified.

No. 58,147.-ANDREIV STARK, TOPEKA, KANSAS.Cultuzators.-Septimber 18. 1866.

Claim.-The pivoted bars $\mathrm{L}$ L having the driver's seat $\mathrm{N}$ attached to them, in combination with the plough beams $\mathrm{H} \mathrm{H}$, connected at their front ends to the front part of the frame of the machine, and the plough beams and bars connected by chains $h$, or their equivalents, substantially as and for the purpose specified.

No. 58,188.-ALEXANDER ANDERSON, LoNiun, CANADA West.-Cultivators.-Siptember I8, I866.

Claim.-1.-The mode of su-pending the cultivator frame beneath the axle by means of the chains $G G$, rods $R$ $R$, and levers $J \mathrm{~K} \mathrm{~K}$, so arranged, as described, to give $i$ the necessary lateral and vertical play.

2.-The slotted extension axles $\mathrm{F}^{\prime} \mathrm{F}^{\prime}$, counterpart central portion F, and bolts S S, constructed and operating as described and represented.

No. 58,380.-FDWIN CHILDREN, LIBERTY, WIS.Cultivators.-October 2, 1866.

Claim.-The pivoted draught pole D, in combination with the pivoted bars $H$, lever $G$, and the plough beams L I, connected to the bar I, which is pivoted to the bars $\mathrm{H}$ $\mathrm{H}$, all arranged substantially as and for the purpose set forth.

No. $58,3^{89}$.-GEORGE W. DOOLITTI.E, LiNCOLN, JLL.-Cultivators.-October 2, 1866.

Claim.-1.-The form of the plough mould as berein described, for the purposes specified.

2.-The arrangement and combination of the guiding mechanism herein described.

3.-The iron axle $\mathrm{S}$, and the supporting brace $\mathrm{N}$, constructed and operating as herein described.

4.- The combination of all the parts, operating substantially in the manner herein described.
No. 58,693--L. O. STEVENS, PEKIN, ILL.-Corn Cultizator:-Ototer 9, I S66

Claim.-1.-The frame D, arms $\mathrm{N} \mathrm{N}$, and beams A A, combined and operating substantially as described for the purpose specified.

2. - The curved or arched bars M M, in connection with the frames $K \mathrm{~K}$ for supporting the shaft $\mathrm{L}$, substantially as and for the purpose specified.

No. 59,012.-J. B. HERMAN, MoUnT VERnon, Iowa. - Cultivators.-October 23, 1866

Claim.-I.-The arms R, applied to the machine, substantially as shown, in combination with the hinged bar J, chains $Q$, and plough beams $\mathrm{L}$, all arranged substantially as and for the purpose specified.

2.-The curving of the rear parts of the plough beams $\mathbf{L}$. in combination with the inner laterally-adjustable plough beams I, subutantially as and for the purpose set forth.

No. 59,022.-R. C. HOWARD, LENA, ILL.-Corn Ploushs,-October 23, 1 S66.

Claim.-The guide rods 0 , in combination with the lever $a^{\prime \prime}$, and beams $\mathbf{F}$, substantially as described, for the pur pose specified.

No. 59,215.-JOEL A. HALL, Columbes, OHso.-CotLon Cultizators,-October 30, 1866.

Claim.-1.- The combination of the curved hlades or scrapers with the ploughs $\mathrm{B}^{2}$, substantially in the manner herein shown and described, so as to plough the furrow, cut the weeds, and throw the earth upon the roots of the plants, all as set forth.

2. - The combination of the toggle levers I with the plongh beams, substantially as herein shown and described.

3.- The crmbination of the guide, with the toggle levers $\mathrm{I}$, substantially as herein shown and described.

4.- The combination of the walking beam and tre illes, with the toggle levers, substantially as shown and described.

No 59,231 -WILLIAM K1DDOO, KeIthSBURg, ILL. Cultivators.-Oitober $30,1866$.

Claim. - 1.- The plough beam $F$, in combination with the lever $G$, or equivalent neans, for raising and lowering the plough beam without changing its horizontality.

2.- The combination of the plough beam $\mathrm{F}$, lever $\mathrm{G}$, cord $\mathrm{E}$, and link L, substantially as and for the purpone set forth.

3.- The combination of the plough beam $\mathrm{F}$ and draught bar $K$, substantially as and for the purpose set forth.

4.- The combination of the plough beam F, dran ht rod $K$, and guide rod $S$, for the purpose of retaining the said beam in proper horizontal position.

5.-The adjustable suspended frame $\mathbf{N}$, provided with the lever $\mathrm{P}$ and link $\mathrm{Q}$, or their equivalents, for the purpose set forth.

6.-The shield $\mathrm{U}$, suspended by the rods $\mathrm{V}$, so that the ploughs may he raised or lowered without affecting the height of the shields.

7.- The levers $G$ and $P$, and their attachments, substantially as described, so as to enable the attendant to adjust the ploughs vertically or horizontally without leaving his seat.

No. 59,232.-GEORGE KNIGHT, Bone, IowA.Sulky Ploughs.-October 30, 1866.

Claim.-1.-The attaching of the front end of the plough heam $\mathrm{H}$ to the pendent bar $\mathrm{E}$, through the medium of an adjustable plate $F$, substantially as and for the purpose set forth.

2.-The suspending of the plough beam $H$, from the axle $\mathrm{C}$, by means of the cords or chains $c c$, and the retaining or holding of the plough beam so as to prevent it from moving laterally by means of a chain or cord $d$, substantially as set forth.

No. 59,262.-JACKSON TRICE, GREENFIELD, IND.Ploughs.-Oitober 30, 1866.

Claim.-I. - The arrangement of the plough frame $K$, and springs $Q \mathrm{R}$, for regulating its motions, substantially as described.

2.- The pivoted tongue I) and latches $\mathrm{G} \mathrm{H}$, operating substantially as described.

3.-The foot levers J J, in comhination with the tongue 
$1)$ and latches (i II, operating substantially as described. No, 50,279,-k. S. SF(ilik and J. ('. (IRNISTUN,

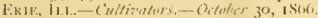

('laim. - The application to a corn plengh or cultivatur of the crotch beams, and strap, revolving hinge, and piuman rod, iron crinks, ratchet circle, and spring catch lever, attached to the beams by the pitman rod and hinge, to raise and lower the beams and shovels, and the blade hinges to attach the inside shovel standards to the beams; the brace fool stirrup to guide the invide shovels, and the crutch-bearing stat, as herein described, reference being had to the drawings herewith submitted.

No. 59,381,-JAMEA C. FRENCI1, MUNMoUTH, 11.L.ciultizuters.-Virembler 6, 1866 .

Claim.-1. - The combination of the frame piece $\mathrm{A} \mathrm{A}^{\prime}$, swivels $\mathrm{E} \mathrm{E}$, and clrag lours $\mathrm{F} F$, said parts being reupec. tively constructed and the whole arranged for use sulsstantially as set forth.

2.-The combination and arrangement of the tongue $\mathrm{B}$, frame A $I^{\prime}$, plate $C$, rods $C^{\prime}$, and bars ('”, substantially as devcribed.

No. 59,454-C - S. RoleRTS, Lvons, IowA.-Cuttizaters. - Virember 6, 1866 .

Claim.-1.-The drag hars $\mathrm{G}$ and $\mathrm{G}^{\prime}$, arch $\mathrm{E}$ and lirace L, when reypectively constructed and arranged for use, sulust intially as set foith.

$\therefore$ - The combination of the drag lari G, stirrups $F$, axle B, lever 1 , and rorls I' subutantially as and for the purpone set forth.

3.- The curved braces $D$, when ad ustably atıached to the frumework of a cultivator, substantially in the manner and for the purpose set forth.

4.-The combination of the shovel plougls $\mathrm{H}$, and mouldboard ploughs 11', when the inncr shovel ploughs are made adjustable and arranged subutantially as set forth.

Xo. 59,643.--W. W: PllILLER, Port Byron, ILL.Cultiatuturs. - Vore'mber 13, 1866.

Claim, -1.-The pivoted draught pole C, provided at its rear end with a curved or segment liar $\mathrm{D}$, having friction rollers or wheels cinserted within it, and working or resting upon a semicircular way or track $\mathrm{E}$ on the frame $\mathrm{A}$, substantially as and for the purpose set forth.

2. - The bar or lever ") attached to the rear end of the draught pole $C$, substantially in the manner as and for the purpose set forth.

No. 59,654--JOIIN J. REED, PuI.O, ILL.-Sulky

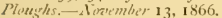

Claim,-1. - The walking beam ( $i$ piroted to the rear end of the tongue or pole $\mathrm{F}$, in combination with the stirrups $i c$ yoke $\mathrm{I}$, and plough standards $\mathrm{K} \mathrm{K}$, substantially as herein shown and decrihed, and for the purposes set forth.

2 - The pivoted pendent hars $c^{2} c^{2}$, and hars $\mathrm{R} R$, in combination with the frame $C$, substantially as shown and described and for the purposen set forth.

3.-The projecting bar I) D in combination with the frame, substantially as herein shown and described.

No, 59:7 20.-H. C. HUNT, AMrszy, ILL., assignor to himelf and C. 1). VALGHAN, same place-Cultiztrlors.-November 13,1865 .

Claim.-1,-The combination of the circular frame A and rectangular frame $C$. when constructed and arranged sulistantially as and for the purposes specified.

2.-Comtructing the two beams of a sinsle piece of wrought iron ur wood, bent in the form of the letter $U$ or any equivalent form, provided with the draw loops, as and for the purpoves shown.

3.-The employment of the cams $\mathrm{P}$, arranged with respect to the plough beams and frome of a cultivator, substantially as and for the furposes specified.

4.- The employment of the rollers $h h$, when arranged with the cams $\mathrm{P}$ and beams $\mathrm{D}$, and operating as and for the purposen described.

5.- The crank shaft ?, arranged and operating with the cams D, substantially as specified and shown.

6.- The employment of a transomed spindle, constructed and operating as herein shown and set forth.

7.- In combination with said transomed spindles, the ar- rangement of the arn $J$ extending parallel with each other forward, so that the connecting bar $k$ will not obstruct the vicw of the operatur, as and for the purposes descriled.

s.- The enployment of the hook $\approx$. or their equivalent, for the purposes specified, in the monner described.

No, 60,5 S9.-W1L1.IAM W. ST. JOIIN, ST. IAw1s, Mo.-Combined Gans Plowess and Cinltizators.-Decimber IS, IS66; antedated Diecmler 2, IS66.

Claim.-1.- The combina ion of the frame A C C D D D, with the beams $\mathrm{N}^{1}$ and $\mathrm{F}$, the drauglit-rorls $\mathrm{N}$, and either the cultivator or ploughs $\mathrm{F}^{\prime}$, and their attachments, or the gang-ploughs $\mathrm{Nl}^{+}$, and their altachments, sulstantially adescribed.

2.-The comlination of the whecl stands $B^{1}$, with the frame $A$ ( $\left(C^{\prime}\right.$ I) $D^{1}$, in such a manner as to admit of lateral regulat ry movement, substantially as and for the purpose set forth.

3.-The combination and arrangement of the lever $\mathrm{M}^{3}$, with the beams $\mathrm{N}^{i}$ and chord or cha'n $m^{4}$, substantially as set forth.

4. The empluyment of the guidint bars $\mathrm{N}^{*}$, when constructed and used as and for the purpose set forth.

5. - The a tachment of the clraught rod II for the plough beam $\mathrm{Nl}^{1}$ to the pole $\mathrm{P}$, substantially ar deseribecl.

No. 60,722,-A. P. HAMMON, J. H. LINCOLN, S IINCOIN, and T. W. HAMMION, MUNIFOKT, WISCultizators.- Fanuary s, 1867.

Claim.-1.-The pivoting of the dranght pole $\mathrm{D}$ to the frame $\Lambda$, and the connecting of the rear end of the former to treadles 11 , substantially as and for the purpose set forth.

2.- The connecting of the plough tandards of the two beams $\mathrm{J} J$, in the manner shown, or in any equivalent way, so that when the ploughs of one beam are moved or shoved backward, those of the opposite beam will be moved forward, and zice acrsa, for the purpose specified.

No. 60,916.-TIIEOI'HILUS F. BERTRAND and PETER SAMES, ROCKFURD, ILL, - Cultizators- Fanuลrา 1, 1867.

Claim.-1.- The combination, substantially as described, of the tongue with the axle, arranged as set forth for the purpose specified.

2.- The combination with the trongue of the single crosspiece $\mathbf{E}$, so arranged as that it shall serve as a brace for the segment and a fulcrum for the levers that control the aux. iliary frame.

3.- The combination of two spring bolts with two supporting levers and two ratchets and with the axle arranged and operating substantially as and for the purpose set forth.

4-The combination of the rigid frame with the auxiliary frame, when the former is lunged to the latter, substantially in the manner and for the purpose described.

5.-The combination of the auxiliary frame with the tongue when the former is hinged to the latter, substantially as and for the purpose set forth.

6.- The combination of an adjustable support for the driver's fect with the auxiliary frame, substantially as and for the purpose set forth.

7.- The swiveled eye-lolt or double block constructed, arranged and operating substantially as and for the purpose set forth.

8.-The combination of the eye-bolt and standarl with the beam of the auxiliary frame, substantially as and for the purpose set forth.

No. 4.30\%.-THE()1']11LUS BERTRAND and PETER SAMES, ROCKFIRD, li. .-Cintizators. -60,916, fanuany I, IS67.--Reissned Warch 28, IS71.

Claim.-1.-The combination, substantially as described, of the tongue $\mathrm{I}$ with the axle $\mathrm{C}$, arranged in the manner and for the purpose descrilsed.

2.-The cross-piece $\mathbf{E}$, attached to the tongue D, substantially in the manner and for the purpose described and shown.

3.- The tandards $c$ and $c$, having pulleys $x$ and $x^{*}$, when arranged upon and attached to the axle $\mathrm{C}$, in combination with chains and rods 7 and 8 , and the hinged inclined auxiliary frame $\mathrm{H}$ and $\mathrm{H}^{\prime}$, arranged to operate substantially as shown and described.

4.- The curved notched bars $d$ ', secured at their upper ends to the standards $c$ and $c$ by rods 5 and 6 , and to the 
cross-piece $\mathbf{E}$ by rods 3 and 4 , in the manner and for the purpose set forth.

5.- The combination of two supporting-levers $F$ aul $F$ with the spring-bolts and curved notched bar $d$ and $d^{\prime}$, with the hinged inclined auxiliary frame $\mathrm{H} \mathrm{H}^{\prime}$, when con structed and arranged to operate in the manner shown.

6.-The adjustable foot-rest $\mathrm{M}$, notched standards $\mathrm{L}$, and holding wedge 9 , when constructed and arranged to operate together in the manner and for the purpose described.

7.-Adjusting the anxiliary frame $H^{H}$ ' with the plough standards, to different widths by means of the arched coupling-bar $K$, and screw staple-clamps $h$, as described and shown.

8.-The screw eye-bolt $P$ and socket-plate or block $Q$, in combination with bed-plate $R$, constructed and arranged to operate as shown.

9.- The standard $\mathrm{O}$, screw-eye bolt $\mathrm{P}$, socket-plate or block $Q$, and bed-plate $R$, in combination with beams $H$ and $\mathrm{H}^{\prime}$, substantially as shown and described.

10.- The safty-pin $i$, in combination with the standards $\mathrm{O}$, screw eye-bolt $\mathrm{P}$, rings $l$, brace-rod $k$, and auxiliary frame $H$ and $H^{\prime}$, in the manner and for the purpose de scribed.

I1.- The combination of the rigil frame, consisting of the tongue $D$ and axle $C$, the hinged auxiliary frame $H$ and H', carrying the ploughs, and their means of adjusting the same laterally, consisting of the arched bar $k$ and screwstaples $h$, with the foot-supports $\mathrm{M} \mathrm{M}$ and the lifting and holding devices supported upon the tongue and axle, in the manner and for the purpose shown and described.

No. $4,58 \mathbf{r}$-THEOPHILUS F. BERTRANI and PETER SAMES, RockFord, ILL.-Cultizalors.-60,916, Jamuary 1, 1S67.-Reissue 4,309, 1/arch 28, 187r.-Keisued Octobitr $10,1871$.

Claim.-I.-The cross-piece $\mathbf{E}$, attached to tongue $\mathbf{D}$ and bracket $a$, substantially in the manner and for the pnrpose described and shown.

2.-The standards $c$ and $c$, having pulleys $x$ and $x^{\prime}$, when arranged upon and attached to the axle $\mathrm{C}$, in combination with the chains and rods 7 and $S$, and the hinged inclined auxiliary frame $H$ and $H^{\prime}$, arranged to operate substantially as shown and described.

3.- The curved notched bars $d d^{\prime \prime}$, secured at their npper ends to the standards $c$ and $c^{\prime}$ by rods 5 and 6 , and to the cross-piece $\mathrm{E}$ by rods 3 and 4 , in the manner and for the purpose set forth.

4.- - The combination of two supporting levers $F$ and $F^{\prime}$, with their spring.bolts and curved notched bars $d$ and $d^{\prime}$, with the hinged inclined auxiliary frame $H$ and $H^{\prime}$, when constructed and arranged to operate in the manner shown.

5.- The adjust.ible foot-rest $M$, notched standards $\mathbf{L}$, and holding-wedge 9 , when constructed and arranged to operatc together in the manner and for the purpose described.

6.- - Adjusting the auxiliary frame $H$ and $H^{\prime}$, with the plough standards, to different widths, by means of the arched coupling-bar $K$ and screw staple clamps $/ t$, as described and shown.

7.- The chains or rods 7 and 8 , when their pendant ends are connected to bearings or supports that project outside of and are not affected by the adjustment of the beams $H$ and $\mathrm{H}^{\prime}$, as described and shown.

S.-The screw-eyebolts P, and socket-plate or block $Q$, in combination with bed-plate $R$, constructed and arranged to operate as shown.

9.-The standard $O$, screw-eyebolt $P$, socket-plate or block $Q$, and bed-plate $R$. in combination with beams $H$ and $H^{\prime}$, substantially as shown and described.

10. - The safety-pin $i$, in combination with the stand.rds $O$, screw-eycholt $\mathrm{P}$, rings $l$, brace-rod $k$, and auxiliary frame $H$ and $H^{\prime}$, in the manner and for the purpose described.

11. - The combination of the rigid frame, consisting of the tongue D and axte $C$, the hinged auxiliary frame $I I$ ard $H^{\prime}$ carrying the plonghs, and their means of adjusting the same laterally, consisting of the arched bar $K$ and screwstaples $h$, with the foot-supporters $M$ and $M$, and the lifting and holding devices supported upon the tongue and axle, in the manner and for the purfose shown and described.
No. 61,040.-HENRY BARSALOW, SAINT ANNE, ILL.-Cultizators.- Fimuary 8, IS67.

Claim-1- - The leams $;$; attached to the front of the frame $\mathrm{A}$ by an adjustable universal joint connection, and suspended by chains near their rear ends to travelling rolleri $i$ on the raised cross bar $b$ of frame $A$, substantially as and for the purpose set forth.

2.-The combination of the mounted frame A, plongh or shear beams G G, and detachable seat E, stirrups and foot piece $E^{\prime}$, all arranged substantially as and for the purpose specified.

No. 61,091.-R. B. PARKS and J. R. PARKS, NEPONSET, ILI.-Cultizators.- Fanuary 8, 1867

Claim,-1, - The angular hars $H$ piroted to bar I, and conmected with the treadles $\mathbf{J}$ by links $e$, in combination with the beam ${ }^{*} \mathrm{D}$, and operating substantially as described, for the purpose specified.

2. - The pivoted bars L, in combination with the ploughs $\mathrm{K}$, and standords $\mathrm{E} \mathrm{E}^{\prime}$, and set screw $g$, substantially as described for the purpose specified.

No. 61,195.-JOHN HINDMARSH, IIENRY, ILL.Corn Ploughs. - Ganutry 15, 1867.

Claim, -1.-The lever $\mathbf{N}$, in combination with the standard $U^{*}$, for sustaining the plough in an elevated position when required,

2.- The rods $O($ ), plough heams $G G$, cross-har $P$, and crew $Q$, combined and operating as described.

3.- The combination of the pluugh beams $G G$, standards L L, lever $\mathrm{N}$, and lrace rods $j$, all arranged and applied to a mounted frame $\mathrm{A}$, to operate in the maner subutantiall as and for the purpose specifid.

No, 61,450.-C I'. NORTON, ROSEville, It.1.-Cultiz'ators.-Fanuary 22, 1867

Claim,-1.- The pole B, arch C, and supporting wheels D D, constructed and arranged substantially as and for the purpose herein set forth.

2.- The pole $\mathrm{B} b$, fig. $\mathbf{I}$, sliding box $f$, loop $\mathbf{F}$, and set screw $k$, in connection with the plough beam $A$, all arranged and operated as and for the purpose described.

No. 61.566.-GEORGE WV. PRICE, BLoOMINGTON, IL1..-Gang Plough/25 and Cultizators,-Fanuary 29, 1867.

Claim.- The comhination of the vibrating beams G G and the iraces I I, connecting them with the dranght pole $\mathrm{E}$, the outside ploushs $\mathrm{K} \mathrm{K}$, connected by the sheaths $b, b$ and the rods $d d$ with the beams $G G$, and the inside ploughs $L 1$. connected by the swivel couplings $g g$ to the standards $s s$, and the rods $e e$ to the braces I I , arranged and operating substantially as and for the purposes herein describet.

2.-Forming the shovels or shares $\mathrm{K}$ K L L, in such a manner that if a line were drawn in its oblique section, as shown in fir. 3 of the drawings, the same would stand at an angle of about $22^{\circ}$ from the standard: $b \quad b c c$, to which the shovels or shares : re attached, and said ploughs having such a bevel that the point of the cutting edge when throwing inwardly shall be uron the inside of a line continned in the direction of the length of the standarls is b e e, and sail point when throwing outwarlly shall be upon the outsice of said line for the purpose of preventing any lateral pres-ure, sulstantially as herein set forth.

No. 61,622.- IACOB KESSILER, YORK COUNTY, PA.Cultivators.-January 29, 1867.

Claim, - The arrangement of the teeth $\mathrm{G} G$, as constructed with the loar E E, rods D and $a$, and the frame of the machine, as and for the purposes specified.

No, 61,619.-A. H. Al.LISON, ChARLGTTESTILl. IN1).-Cultizators.-January 29, 1867.

Clam.-1.-The plough beams D I), suspended to the curved guide-rods $f f$, and connected with the stirrups or levers $5 g$, for ohtaining lateral movement in combination therewith and with the vertically sliding cross-heads F F, the levers $H \mathrm{H}$, and the springs $m m$, con-tructed, arranged, and operating substantially as and for the purposes herein described.

2.- The arrangement of the rotary perforated clod guards $n n$, combined with the ploughs $b b$ and beams D D, constructed and operating as herein set forth.

No. 9,085.-ASA H. Al.LISON, MiLlville, IND., as signor to Fagle Manufacturing Company.-Cultivators.- 


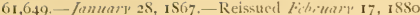

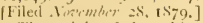

The weight of the cultivator-beams is wholly or partially sustaned by sprungy.

Claim. - 1. - The plough-beam: D 1), suspended from the curved guide-rods $f f$, and connected with the stirrups or levers $x^{x}$, for olutaining lateral morement, in comlsination with the vertically-sliding cross-heads $1 F$, lever 1111 , and springs $m \mathrm{~m}$, sulsst untially as and for the purp ses describerl.

2.- The combinution of a wheeled frame and vertically. swin ring drag-bars jo nted at their forward ends to the frame at a fixed height, and springs interposed between and h.wing connection with lo: h the frame and the heams, and exerting an upward strain upon the latter when the machine is in action.

3.-A cultivator wherein the attendant is mechanically assisted in raising the shovels from the ground, the same emlracing the combination of a whecled frame, vertically. swinging beans, and lifting springs adapted and arranged to lift the free ends of the beams withont assistance above their operative position, substantially as described.

4.-The combination is a straddle-row cultivator, of a wheeled frame, two inde endent vertically and laterally swin zing beams, and sprin ts adyted and arranged to exert an upward strain on the beans and permit them to move both vertically and laterally while subject to the springaction, substantially as described.

5. - In a wheeled cultivator, drag-bars cap ble of a vertical movement at the rear ends only, in combin ition with springs exerting a lifting strain on said ends, whereby the springs are caused to govern or assist in governing the position of the beams and shovels, substantially as described.

6.- - In a wheeled cultivator, the c mbination of verticallymoving beams, springs acting upward thereon, and means, substantially as described, for holding the beams down, so that the springs will automatically lift the beams and shovels out of action when released, as set forth.

7.- In a cultirator, the combiratien of a wheeled frame, rertically-swingin \& beams ointed thereto, and surings arranged to receive the wei ht of and sustain the be rm, when the latter are elevated out of action, substantially as described.

8.-In a wheeled cultivator, the combination of beams adapted to swing vertically at the rear ends, springs exerting an upward s rain on said benms, and handles under the direct control of the attendant, operating upon and enabling him to control the heams, substantially as described.

No. 61,674,-IS.A.IC B: MAHON, DeXkIRK, ()HIO.Cultizators.-January 29, 1867 .

Claim, - I. - The sliding frame G fitted on the rod F at the rear of the axle $A$, in combination with the ploughbeams I I, connected at their front ends by universal joints $d d$ to arms e, secured to the lower end of the bar J, and provided with curved stand.ards $\mathrm{H}$, whicb work in guicles $c$, attacbed to frame $G$, substantially as and for the purpose specified.

2. - The plou_h-beam $\mathrm{N} \mathrm{N}$, connected by pivot boits to the lower ends of the har $J$, and provided with curved standards $r$, which work in guifles $s$, formed at one end of the bolts $n$, which secure the arms B to the axle A

3.- The shaft $O$, provided with the segments $P$ to which the plough-beams I I N N are connected by chains $\mathrm{Q}$, and also provided with a segment $\mathrm{P}$, to which a hand-lever $\mathrm{R}$ is connected by a chain $S$, all arranged for the purpose of raising and lowering the ploughs, substantially as set forth.

4. - The whiffletree bars $\mathrm{V} \mathrm{V}$, having their lower ends pivoted to the lower ends of the bar J, and their upper ends connected with the doubletree $\mathrm{U}$, substantially an and for the purpose specified.

5.- The securing of the ploughs $M$ to the beams I 1 by means of the socket $/$ at the rear sides of the ploughs, the loose sockets $a^{*}$ and the s.rew bolts $z^{\prime}$ which pass through the oblon $z$ slots $*$ in the heams 11 , substantially as and for the purpoies set forth.

No. 61,805.-IV. F. Cl,ARK, HaramaN'S MILLS, N. Y. - Cultivators.-Febraray 5, I867.

Claim.-1.-The plank A, grooved al its under side to receive the hars $\mathrm{B} \mathrm{B}^{\prime}$, which have the teeth standards $\mathrm{C}^{C^{\prime}}$ attiched, as shown, in combintion with the lever- F F, having the wheels I I attached to the plank A, pivoted be tween their front end and the driver's seat $H$, secured to a cross-hir $G$; attached to the rear ends of the levers, all ar$r$ :agerl substantially as and for the purposes herein set forth.

2.-The perforated segments I $K$, attached respectively to the levers $\mathrm{F} \mathrm{F}$ and plank $\mathrm{A}$, subsiantially as and for the рuтр sse specified.

No. 61,836.-THOMIS JOBE, ClarKSTILL, OHO.Cultizators,-Febramy 5, 1867 .

Chim.--The arrangement of the plough-beams $G$ and levers 11 , applied to the frame of the device, in combination with the adjusable bar $a$, at the rear of the axle $B$, all arranged to operate substantially in the manner as and for the purpiove set forth.

No, 61,906.-CHAR1.ES WII.I.ARD, NEwTON, PA.Cultinator.-Fidruary 5, 1867.

Claim.-1. - The combination of the adjustahle arched couplings $\mathrm{N}$ and $\mathrm{O}$, with the frames $\mathrm{A}$ and $\mathrm{B}$, and rigid ploughs and rigid tongue, all constructed, arranged, and operating substantially as and for the purpose set forth.

2. - The combination of the plate $\mathrm{R}$, carrying cultivatorteeth or ploughs with the frumes and with the $\operatorname{rod} \mathrm{U}$, when atranged to operate substantially in the manner and for the purpose set forth.

No. 62,001.-E. CHIIDREN, LANCASTER, W15,-Cultizators.-Fibrutry 12, 1867 .

Claim - $\mathbf{r}$.- The friction ruller $;$, inscrted in the pivoted draft-pole $\mathrm{C}$, in combination with the har II attached to the pivoted arms $\eta_{i} \xi$, all arranged to operate in the manner as for the purpose herein set forth.

2.-The links I and T-shaped levers I applied to the plough-beams and frame $A$, to operate in the manner substantially as and for the purpose set forth.

3.- The securing of the ploughs $\mathrm{K}$ to the standards $\mathrm{L}$ by means of the staples 11 , hats, $r$ and the keys $t$, all arranged subntantially as and for the purpose herein set forth.

No. 62,109.-JAMES ARMSTRONG, JR., ELMIRA, IL.L.-Cultiators.-Febrany 19, 1867 .- Improvement on his patent December 26,1865 .

Claim.-1.-Providing a shovel-carrying frame D, which is pivoted to levers C, so as to operate substantially as described, with an auxiliary adjusting lever $G$, or its equivalent. whereby the driver can regulate the depth of the shovels at pleasure, whether the machine be in motion or at rest, substantially as set forth.

2.- Pivoting a lever $(\dot{x}$, which has an eccentric bearing 5 upon one end, to the iraft-tongue of frame D, and providing such lever with a locking device for holding it in any desired position, snbstantially as descrihed.

3.- Supporting an adiustable shovel-carrying frame D upon the axle $A$, by means of the levers $C$ and an adjusting device $G, r f h$, subwantially as describet.

4. - The use in a $c$ Itivator of an eccentric lever $g, s$, for the purpose de-cribed.

No. 62,185.-J. W. CONNELY, Charleston, IH...Cultizaters.-February 19, 1867 .

Claim.- 1.-The machine, in combination with a cultivator of the several parts as arranged and described.

2.- The arms $O$, made either of wood or iron, and manner and place of attachment to bar or doubletree on forward end of hounds of frame, as described and shown

3.- The flexible connecting beams F F, with arms $\mathrm{OO}$, either by bolts, pins, or clevis, as shown and describer.

4.- The bar $B$, arms $O O$, beams $F F$, and stocks $T T$, as constructed and shown and described.

No. 62,344.-W. B. L.ANE and W. COI.TOR, ORgAN SPRING, IND.-Cultizaters. - Fotereary 26 , I 867.

Claim.-I,-Combining with a two wheel carriage, a shovel carrying frame which is adapted for carrying five shovels $a, b b$ and $d$, and which is composed of vertically vilorating beams $\mathrm{H} \mathrm{H} \mathrm{I} \mathrm{I,} \mathrm{connected} \mathrm{togrether} \mathrm{by} \mathrm{transverse}$ braces $\mathrm{J}$, so as to be laterally adjustable, substantially as described.

2.- Arranging a vertically and laterally adjustable shovel frame, which is constructed as described, upon a two wheel carriage, in such manner that the shovels will be located beneath, and in a vertical line, or nearly so, with the axle. . substantially as described. 
No. 62,387 .-OMAR J. ARNOLD, Mount IDA, WIs. -Cultivators.-February 26, 1867.

Claim,-1.-The axle C, inclined downward from it: centre outward in both directions, in connection with the extended draught pole $A$ and brace rods $b b$, substantially as and for the purpose set forth

2.- The beams $\mathrm{D}^{\prime} \mathrm{D}^{\prime}$, extending in front of the joints $d$ and connected by a cross bar $\mathrm{F}$, subntantially as and for the purpose set forth.

3.- The lever $G$, provided with the pin or $\operatorname{rod} f$, in combination with the beams $\mathrm{D}^{\prime} \mathrm{D}^{\prime}$ and cross bar $\mathrm{F}$, all arranged substantially as and for the purpose specified.

No. 62,511.-J. W. TYSON, LOWER Providence, PA. Cultivators.-Fiburuary 26, 1867

Claim.-In combination with the adjustable cultivator frame, the use of the chains $n$ and $o$ when arranged to operate as and for the purpose set forth.

No. 62,868 .-C. F. IIEGQU1ER, EUREKA, 11.L.-Cultivators.-Warch 12,1867 .

Claim.-The plough standards F F, pivoted at their upper ends in metal straps $c$, which encompass loosely the shaft $G$ in the frame $A$, so that said standards and the ploughs A attached may he moved vertically and laterally in combination with the plough standards I I, pivoted to the outer sides of the frame $A$, the levers $k k$, to which the plough standards are connected, and the rods $\mathrm{N}$ attached to the plough standarcls, all being arranged to operate in the manner substantially as and for the purpose set forth.

No. 63,050.-HENRI HOWE, ONEONTA, N. Y., assignor to himelf and E. R. FORD, same place.-Cultia'ators.-Warch $\mathbf{1 9}, \mathbf{1} 867$

Clain.-1.-The pendants D and the manner of securnng them to the plough beams and frames, substantially as and for the purpose shown and described.

2.- The bars $\mathrm{E}$, in comlination with the plough beams E and pendants D, substantially as and for the purpose herein shown and described.

3.- The comlination with the tongue $F$ and driver's seat $\mathrm{G}$ of the plough beams $\mathrm{E}$, swivel braces $c$, and doubletree $1 \mathrm{H}$, substantially as and for the purpose herein shown and described.

4.- The slotted $t$ inzue $F$, made substantially as and for the purpose herein shown and described.

5.- The lever, I and chains $h$, for the purpose of raising the ploughs out of the ground and retaining them in that position, substantially as herein shown and described.

6.- The upright side frames $\mathrm{B}$, as arranged and connected with the horizontal cross-bars $C$ and $C^{\prime}$, substantially as and for the purpose herein shown and described.

No. 63,260.-H. B. KVNETT, LisBun, IowA.-Gang Plousths,-March 26, 1567

Claim.-The combination of the slotted cross piece E, side pieces $S$, bolts $f$, pendants $c$, adjustable clevises $d$, and beams $F$, substantially as described, $f \cdot r$ the purpone specified.

No. 63,426.-JAMES H. REVNERSON, PLFASANT PLAIN, IowA.-Culticutors.-April 2, 1867 .

Claim.-1.-The manner of shifting the ploughs and beams either in or out by means of the sl tted rods, and curved slotted hars of iron at D D D D, and the upright bar with holes, together with the movable cross timber and slide at $\mathrm{E}$, also the manner of fastening the shovels to the beams by means of blocks of wuod at $\mathrm{H} \mathrm{H} \mathrm{H} \mathrm{H}$.

2.- As an improvement the general construction and combination of the machine aside from the wheels, axle, and tongue.

No. 63,447-P. L. WEST, BATH, ILL-Cultirators,April 2, 1857. Antedated March 19, I867.

Claim.-1.- The construction and arrangement herein shown and described of the ploughs D D, their attachment links $d^{2}$, and their draught rods $d$.

2.-The device $\mathrm{C}$, a $\mathrm{C}^{3} \mathrm{C}^{2} \mathrm{C}^{3}$ and $c^{\prime}$, for giving the ploughs $\mathrm{D}$ the requisite latera! motion.

3.- The combination and construction of the posts $d^{1}$ and props $d^{4}$, substantially as described and set forth.

4-The construction and arrangement of the ploughs $D^{1}$, and the curved bars $D^{3}$, also the device $d^{5}, d^{6} d^{7}$ for raising the said plonghs up out of the ground, substantially as described and set forth.
No. 63,473.-DANIEL W. COLBURN, LOAMI, ILL.Sulky Ploughis.-April 2, 1867

Claim.- The combination and arrangement of the beams $\mathrm{E}$, chains $\mathrm{D}$, roller $\mathrm{C}$, arm $\mathrm{K}$, notched bar $\mathrm{J}$, and standard $\mathrm{I}$, substantially as described, for the purpose specified.

No. 63,476 , -S. B. CONOVER, NEW YoRk, N. Y.Combined Cultitators and Planters.-April 2, 1867.

Claim.-1.- The combination with the main frame $A$, supplemental frame $\mathrm{D}$, and fixed ratchet bar $\mathrm{F}$ of the operating lever $E$, bell crank levers $b$, horizontal connecting rods $c$, and upright connecting rods $d$, substantially as herein set forth, for the purpose specified.

2.- The sliding rods or braces $i$, attached to the supplemental frame I), passing up through suitable holes or slots, either vertically or on an incline, in combination with the main frame $\mathrm{A}$ and operating parts above recited, substantially as herein set forth, for the purpose specified.

No, 63,698.-H. C. BRISTOL, RavenNa, OHIo.-Cultivators.-April 9, $\mathbf{1} 867$.

Claim.-1.- The movable frames C, provided with the adjustable standard $G$ and shares $H$, as arranged and connected in combination with the levers $\mathrm{D}$, draft chains $\mathrm{P}$, and carriage, for the purpose and in the manner set forth.

2.-The jointed standard I, provided with the shovel I and guide stay $K$, in combination with the standards $G$, shares $\mathrm{H}$, and carriage, as and for the purpose described.

No. 64,061-JACOB BERGEN, CANTON, OHIO-Cultirators.-April $23, \mathbf{1} 867$.

Claim.- The arrangement of the crank axles D D with the levers $\mathrm{I}$, spring $d$, and guides $\mathrm{I}$ and $\mathrm{J}$, substantially as and for the purpose specified.

No. 6+119.-MICHAEL F. LOIVTH and THOMAS J. HOWE, OWATONNa, MINN.-Cultizators,-April 23, 1867

Claim.-1-The combination with the quadrant $J$ of the adjustable segment $\mathrm{N}$, for the purpose of changing the position of the lever N, substantially as and for the object specified.

2.-The combination of the quadrants $J$ J', segments M, shaft $\mathrm{K}$, and lever $\mathrm{N}$, with the chains or flexible connections 1 , connecting bar $\mathrm{H}$ and shovel beams 1 , all arranged and operating in the manner and for the purpose specified.

No. 64,376.-GEURGE SPRAGUE, SPRING; Hill, Kansas.-Corn Cultizators.-April $30,1867$.

Claim.-The combination of the root cutters F F, the shovels $d d$, and the plough beams E E, arranged and connected for adjustment and operation, substantially as and for the purposes herein described.

No. 64,542-EDMOND H. KNIGHT, UNADILI.A, II Iсн.-Cultizalors.-May 7, I867.

Claim.-I,-The beams $G$, having plough and shovel standard $1 \mathrm{H}$, pivoted to them in combination with the frames $\mathrm{F} \mathrm{F}$, the beains and frames being secured to the axle $\mathrm{A}$, and used in connection with hand levers $\mathrm{K}$, foot levers $\mathrm{S} S$, and catches $\mathrm{R} \mathrm{V}$, all arranged to operate substantially in the manner and for the purpose set forth.

2.- The springs $\mathrm{H}^{*}$ connected with the beams $\mathrm{G}$, and attached to the frames $F$, substantially as and for the purpose specified,

No, 64,563.-EDWARD PHIFER, TRENTON, N. J.Cultizators.-May 7,1867

Claim.-1.-A cultivator frame composed of a series of timbers shorter than the diameter of the wheels and arranged parallel to the tongue, substantially as described.

2.-The combination substantially in the manner described of a tongue laterally adjustable on the axle with a series of frame timbers of a length less than the diameter of the wheels, arranged parallel to the tongue and adjustable laterally on the main axle.

3.- The combination, substantially as described, of the tongue and short parallel, frame timbers with a series of slotted adjusting plates attached to the front of the frame timbers and secured to the tongue.

4.- The combination, substantially in the manner described, of the parallel frame pieces arranged for adjustment in pairs with the slotted down hangers, front lifting rods and drag bars, for the purpose of adjusting the front ends of the drag bars.

5.-The combination of the frame pieces, down hangers, 
drag bars, lifting rods, hand levers, and sector rack, when arranged, substantially as described, for the purpose of enabling the driver to control each pair of ploughs by a single lever.

6. - The arrangement of the sector rack, hand lever, and spring detent as described, whereby the catch act both as a detent for the lever and as a guide to keep it parallel with the sector rack.

No. 64.576.-JUIIX E. R()WL.IND, II.IGERSTOW, .It.-Ciltizators.-1/ay 7, 1867 .

Claim.-The ahove-descrited cultivator, the beams C, levers $\mathrm{X}$, and : tirrup lever $\mathrm{M}$, being all arranged and com bined subitantially in the manner and for the purposes set forth.

No, 64,658.-A. J. HEFLIN, MoxmotTh, ILI. - Cultizeators. - Jary 7, 1867

Claim.-1,-Forming the shovels I with wints, the outer wing of each shovel being curved or turned up, substantially as herein shown and described and for the purpose set forth.

2-The combination of the pivoted bar $\mathrm{D}$ with the beam $G i$ and rertical bar $a^{\prime}$ of the frame A, substantially in the m.mner shown and descrihed and for the purpose se forth.

No. 64,721.-G. W. STOCTON, OQUAKA, ILL.-Cultiarators.-1/ar It, IS67.

Claim. - The swivel rods $G$, in combination with the joint or piroted clevises $c$, the iraught-evening device $K$, and bent bars L, arranged and operating substantially as described and for the purpose specified

No. 65.158.-HIRAM BOYs, RusHVILIf, IND, - Cultiz'ators,-Way 28, 1867 .

Clain.-I. - The frame $A$, as constructed with adjustable tail piece $a$, arms $b$, with swivels for connecting the shovel beams and rollers $\mathrm{E}$, with chains for attaching the shove bars, when combined, arranged and operating in the manner and for the pur :oses herein specified.

2.- The beams D D, shovel hars $f f^{\prime}$, and shields $c c$ connected by the adjustable bars $m m$, in the manner and for the purposes set forth

No. 65.719.-10SEPH C. BIRD, RISING SiN, MD.Cultivators - Fune II, I867.

Claim.-1.-The arrangement of the share frame E, supported from the lever H II' and pivoted frame $I$, in such a manner as to lift vertically or independantly, as de scribed.

2.-The trapezoid-shaped cultivator frame, concisting of the portions $a \quad a \quad b \quad b \quad c \quad c$, arranged substantially as described.

3.-The share $e$, formed double without a weld, pinched in at the centre to embrace the standard $F$, and with flaring end, in combination with the stirrup brace, sulbstantially as represented in fig. 4 :

No. $65,875,-$ B. C., T. W., and I. M. COCHRAN PANA, ILL.-Cittizators.-Funi 18, i867.

Claim.-I.-The metallic frame $D$, with seat $E$, plates i $a$, plough frames $G \mathrm{G}$, and plunghs $i i$, all constructed, arranged, and operating in the manner and for the purposes herein specified.

2.- The shovel frames $\mathrm{G} \mathrm{G}$, arranged with rods $\mathrm{H}^{\mathrm{H}} \mathrm{H}^{\prime}$ and $m$, for shifting the loops $b b$ and levers F F, for elevating the shovels in the manner as set furth.

No. 65,918.-JOSEPH KOEHN, CANTON, OHIO.Cultivators. - Fune I 8, I 867 .

Claim.-1.-The frame $A$, with diagonal bars $A^{\prime} A^{\prime}$, for connecting the hovels D 1), when constructed in the man ner and used fur the purpose set forth.

2. - The arrangement of the lever $c$, spring $t$, pin $z$, in combination with the axle $b$, rack $s$, for the purpose specified.

No. 65,938.-LORENZO D. PELTON and JOSEPH BARROW, HARRISOx, (HO, assignors to themselves and ALEXIS GREEN. same place.-Cultizutors.-Junc 18 , 1867.

Claim. - I - A mode of construction wherehy the wheels and secondary beam B may be detached, and by means of auxiliary bolt holes $c$ in the handles $\mathrm{C}$, and in the sheath at $\epsilon^{\prime}$, the handles lowered to a convenient height to be managed by an operator on foot.
2.- In combination with the elements of the clause immediately preceding, the provision of the descrihed mechanism for lifting the ploughs from the ground, either temporarily to pass an of stacle J J', or more permanently to allow of moving the implement on a road or otherwise $\mathrm{F} \mathrm{F}^{\prime} \mathrm{H} \mathrm{h}^{h}$ and $\mathrm{I}$, and the position of the seat, which enables the driver to control thcse levers and manage the plough handle.

66,200,-ISRAEL, WING, EARIVII.1., JowA,-Sulky Ploughts.-Juni: 25, I 867 .

Claim.-I. - The combination of the inclined tongues $C$ with each other, with the double tree I) and axle B, sub. stantially in the manner herein shown and described and for the purpose set forth.

2.- The combination of the plough standards $\mathrm{G}$ and $\mathrm{H}$, bars $\mathrm{I}$ and chains $\mathrm{K}$ with each other and with the tongues C , substantially in the manner herein shown and described and for the purpose set forth.

No, 66,253,-NATHIAS REDLINGER, FRFFPORT, lil..-Corn Ploughs.-July 2, 1867

Claim.-The arrangement of the lever $\mathrm{A}$ with its roller $\mathrm{E}$, connected to the beams $\mathrm{G}$ and the treadle $\mathrm{C}$, as arranged with the ploughs $B$, when combined with the beams $G$, as herein described, and for the purpose set forth.

No. 66,491-MARSHALL HASKINS and D. B. HART, MENTOR, OHIn,-Cultitutors.-Fuly 9, IS67.

Claim.-1.-The use and employment, specially, of cultivator shovels or ploughs $\mathrm{M}$, provided with perforations or open intertices made transversely across the blade, or in any direction that will serve the purpose contemplated, as herein set forth.

2.- The use and employment of the blinds $\mathrm{N}$, provided with slots and with jogs $\mathrm{O} O$, in combination with the above described perforated shovels or ploughs M, and operating substantially as and for the purpose specified.

3.- The use and employment of said described perforated shovels II, with and without the said described blinds $\mathrm{N}$ N, in combination with the slotted right-angled beam $\mathrm{H}$, crosstie I, rods $\mathrm{G} G$, grooved clevis $\mathrm{E}$, beam $\mathrm{F}$, plough standards $\mathrm{P}^{\mathrm{1}}$, swivel braces $\mathrm{Q}$, brace $\mathrm{Q}^{1}$, slotted bands $\mathrm{P}^{4}$ and $\mathrm{P}^{\mathrm{b}}$, and bolts $\mathrm{P}^{2}$, all arranged, combined, and operating as and for the purpose described

4.- The graduated standards $\mathrm{J}$, plough handles $\mathrm{K}$, rod R, and joints in beam $F$, combined and operating as and for the purpose described.

No. 66,627.-B. W. REMI. BronKVILle, IND.--Combined Seeders and Cultizators - July 9, I 867

Claim.-1.- The main frame, composed of the vertical arched iron bars C D, and the horizontal frame F, also made of iron bars, and the whole combined with the short axles B B, by which it is supported in the carrying wheels, substantially as and for the purpose described.

2.-In combination with the main frame composed of iron bars or straps and supported as clescribed, the pivoted bars $\mathrm{H} \mathrm{l}$, to which a cultivator or seeding mechanism, substantially such as described, may be attached, as and for the purpose set forth.

No. 67,093--JACOB WIL.SON, SOMERFOR1, OHIO.Cultinators.-Fuly 23, 1867 .

Claim.-1.-The combiuation and arrangement of the doubletree $\mathrm{D}$, rods $\epsilon$, levers $\mathrm{E}$, and whiffletrees $\mathrm{H}$, with the frame A, mounted on wheels, substantially in the manner and for the purpose set forth.

2.- The two ploughs I I, connected together by the cross arms $h$, and connected at their front ends by bolts to the pendants $\mathrm{G} G$, with the pendant guiden $O$, passing through loops $q$, at the outer sides of the beams I, sulstantially as and for the purpose specified.

3.- The attaching of the plough standards $\mathrm{II} \mathrm{II} \mathrm{to} \mathrm{the}$ cross arms $h$ of the plough beams I J, by means of the swivel bolts $i$, in comnection with the straps $\mathrm{P}$ passing over the fixed pulleys $Q$, and the stirrups $h$, all arranged to operate in the manner as and for the purpose specified.

4. - The raising and lowering of the plough beams I J through the medium of the levers $o$, semi-circular bars $n$, and straps $m$, arranged substantially as shown and described.

No, $67,173,-W$. A and C. E. DRVIEN, MoNMouth, IL...-Cultizators.-July 30, 1867.

Claim.-1-The frame $a$, in connection with the ex 
tended braces $b \quad b$, substantially as described and for the purpose set forth.

2.- The slotted axle, in combination with frame $a$, and seat pieces $h h$, for the purpose set forth and substantially as described.

3.- The sliding seat piece $k$, in combination with pieces $h h$, for the purpose set forth.

4.- The vertical adjustment of seat as described.

5.-The arrangement of pieces, $y y z u$ and $x$, for giv ing circular motion, substantially as described.

6.-The slotted fulcrum, in combination with the frame $a$ a, for the purpose set forth and substantially as described.

No. 4,252.-WILLIAM A. DRYDEN and CJRUS E. DRVIDEN, assignor to AUGUSTUS ADAHS, SAND WiCH, ILL,-Cultivators.-67,173, July 3o, 1867.-Reissued Fibruary 7, IS7 1 .

Claim.-1.- The frame of a wheeled cultivator, adjustable longitudinally upon it axle or other support, for the purpose specified.

2.- In a wheeled cultivator, a driver seat adapted to be thrown into position to form a riding cultivator, and to be turned up or moved out of the way of the driver when walking, for the purpose specified.

3. - The adjustable seat bar $J$, in combination with the pivoted side bars 1 , for the f urpose specitied.

4 -The driver's seat of a cultivator, adapted for vertical adjustment, with relation to the frame, by the means substantially as described, for the purpose specified.

5.-The combination of the cultivator-frame with the bifurcated tongue or extended braces, for the purpose specified.

N\%. 67,295.-A. M. GRISWOLD, MOMENCE, IL.LCultizators. - July 30, IS67.

Claim -1,-The ad ustable rods 00 and the adjustable brace rod $j j$, for the purposes srecified.

2.-The joints $i i$, when combined with the rods $o o$ and $i j$ and plongh-bearin: beams $E$. $\mathrm{E}$, sulsstantially as and for the purposes set forth.

3.- The cams $m m$, when combined with the braces $n n$, the rods $s$, and bar $r$, and operating in the manner and for the purposes described.

No. $67+4+1$ - ALBURTIS MARTIN, OUUAWKa, ILL, assignor to himself and J. R. MARTIN-Corn Cultizutors.-August 6, iS67. Antedated fuly 27, 1867 .

Clim.-1.-The plou th frame C, when supported hy the rollers $m$ and $n$, an $I$ the arrangement with reference to the frame $A$, axle $B$, and the plough beams $D$ and $E$, in the manner substantially as described and for the purpose specified.

2.-The semi-circular $\operatorname{cog}$ wheel I, shaft $\mathrm{Y}$, lever $\mathrm{K}$, crank I, and bar $\mathrm{P}$, in combination with the cog bar 11 attached to the frame $\mathrm{C}$, substantially as described, and for the purpose specified.

3.- The connecting piece $t$, in combination with the straps attached to the post $F$ and the beam $\mathrm{D}$, substantially as and for the purpose set forth.

No. 67,9:9.-F. F. BRITTAIN, GeNesEo, ILL.-Corn Cultizutors.-August 20, 1867.

Claim.-The marking device, $\mathrm{c}$ msisting of the hars $h h$, beam $G$, and standards $1 I$, in combinition with the frame A of a corn plough substantially as set forth.

No. 68,104--EDWARD NEWLON, Moniouth, ILl. - Cultizators.- furust 27, 1867 .

Claim.- The vertical adjustment of heams $y y$, in combi nation with the frame, constructel as described and for the purpose set forth, in connection with the mole of attaching the draught.

No, $78,11_{4}-\mathrm{ANTON}$ ROMANN and JOHN PE

TERKA, Wiltun, IowA.-Combined Ploughs and Cultivators.-August 27,1867 .

Claim,- The form and construction of the cultivator and harrow combined, when arranged, adjusted, and operated with the bolt $\mathrm{F}$, beam $\mathrm{C}$, and axle $\mathbf{I}$, as attached to the frame or bars $\mathrm{G}$, with the regulutin $\mathrm{t}$ wheels $\mathrm{L}$, as herein described and for the purposas set forth.

No. 68,124---W. A. SISSON, SHEFFIELD, It.L.-II7iedCultivators.-August 27, 1867

Claim. - I. - A wheel cultivator, constructed so that the draught power shall be applied direct to the shovel frame, and the driver's seat mounted upon the carriage frame, which is attached to the shovel frame at its forward end by a loose connection, which permits said carriage frame to rise and fall with the undulations of the ground in any direction without affecting the operation of the shovel frame.

2. - The friction rollers $x x$ at the forward ends of the carriage frame, in combination with the loops $\mathrm{H} \mathrm{H}$, substantially as and for the purpove set forth.

3.- The perforated plates $\mathrm{P} P$, in combination with the legs $k k$ of the driver's seat, fitted so as to be inserted into said perforations for the purpose of adjustment, as set forth.

4 - The handles $\mathrm{O} O$ at the sides of the shovel frame to enable the driver to raise said frame and free the shovels from the ground.

No. 68,165.-ANDRFW CANFIELD, Lyons City, IowA.-Corn Cultizators.-Ausust 27, 1867 .

Claim.-1.-The adjustable extension guard to regulate the amount of earth applied to young corn.

2.-The raising levers $\mathrm{G} G$, in combination with the double stirrups $a$, for the purpose above set forth.

3.- The principle of raising and lowering a seat, by means of a joint, in the support of the seat when used substintially as and for the purposes above set forth.

No. 68,525.-W. A. MOODY, Montezuma, JuWA.Cultivators.-September 3,1867 .

Claim. - The fitting of the front ends of the plough beams $G G$ on pendent rorls $F$, and connecting the leams by chains $\mathrm{N}$ to eccentrics $\mathrm{L}$ on a shaft $\mathrm{K}$, the beams being connected by a bow-shaped rod or bar $\mathrm{H}$, all arranged to operate in the manner substintially as and for the purpose set forth.

No, 68.519-IOSEPH BENSON, SAYUEL, BENSON, and WILLIAM BENSON, LEBANON, PA.-Cultizators.-September 3,1867 .

Claim.-1.-The use of the blocks $\xi g$, more or less in number, and the blocks $z z$, more or less in number, arranged upon the rods $i$, and so combined with the standards $f$ as to allow the arrangement of either standards or blocks on either side of the bars $s s$ when desired, and for the purposes specified.

2.- The guides $h h$, when arranged, combined and used substantially in the manner described and for the purposes set forth.

No. 68,643-GILPIN MOORE, MOLINE, ILL, assignor to JOHN DEERE, C. H. DEERE, S. H. VELIE, and G. WI. VINTON, same place,-Cultizintors.-Siplember Io, 1867.

Claim.-1.-The axles B, constructed substantially as herein shown and described, for the attachment of the ploughs and wheels of a cultivator, as set forth.

2.-The double-acting clevis or device for attaching the plou rhs to the axle, said device consisting of the plates $n c$ and $m$, and bolt $o$, all constructed and arranged to operate substantially as described.

3.-The plate $h$ when constructed and used in connection with the standard $G$ and brace $d$, substantially as described.

4.- The cultivator, havin: its several parts constructed and arranged for joint operation, substantially in the manner and for the purpoie herein set forth.

No. 6S,648.-WM. H. PARL3N, CANTOX, ILL. Corn Cultizators. - Siptember $\mathbf{1 0}, \mathbf{1 8 6 7}$

Claim.-1.-The strong, durable and economical frame of attichment between the tongue and axle or wheels, as secured by the simple bars $\mathrm{A}$, in manner and form as shown, or in any similar form, upon the same principle.

2.-The extension hooks $k k$ in the beam holder $C$, substantially as above described, and as in drawing shown, or any similar hook in similar connections, and for the uses herein descrilhed.

No. 68,662,-PERRV W. SMITH, ABINGDON, ILI..Cultivators.-Siptember 10, 1867.

Claim. -1. - The combin.tion of frame pieces A A, bars D D D D, knuckles E, and adjusting hars $O O$, substan. tially as described and for the purpose set forth.

2.- The vertical adjustment devices, bars $O O$, and 
knuckles E E E E E vilisantially as described and for the purpose set forth

3.-The metallic upriglits D) I) D 1), arranged as de cribel and for the purpose set forth.

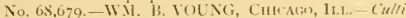
Eutors. - Siplember 10, 1867 .

Cham.-1.- The combination in a straddle-1ow culliva tor of the main frame, split tongue, jointed plough beams, ant wheels

2.-The combination of wheels and jointed plough beams in a straclclle-row cultivalor, the beam on each side having its joint or point of attachment out of the line of motion of its set of ploughs.

3.- The combination in a straddle-row cultivator of wheels, doubletrees, whiffletrees, jointed plongh heams, and frame when the plough beams are jointed forward of the whiflletrees.

No. $68,784-1 R . A$ A. PAI.MER, MENMUUTH, 11.1.Cultinators.-Siptcmber I0, I 667 .

Claim.-1.- The construction of the frame A I) C B, subst.untially as described and for the purpose set forth.

2.- The adjustable hook $\approx$, as arranged and for the pur pose descrilied.

3.- The jaws P P, knuckle r" $p^{\prime \prime}$, adiutable pin a' $l^{\prime \prime}$. and plates $T$, constructe. 1 an:l arranged as deseribed and for the purpose set forth.

No. 68, SO$_{3}$.- MIORDECAI SIVEET, RICHLAND, IND. - Ciultivutors. - Sintember 10, 1867.

Claim.-The arrangement of the shanks $K$ with the shaft $\mathrm{F}$ with it, arms, handle and connecting rods, and with the levers II MI, sub-tantially as and for tne purpose set forth.

No. $68,8+8$. ElLiOTT DAliES, JR, CARThatie, ItL._Cultivators.-Siptember 17, 1SG7.

Claim. - I.- The lever $\$$, in combination with the sliding cross head II, mounted on sile pieces ( $\mathrm{C}^{\prime}$ ', and bearing pieces $(1) O^{\prime}$, connected by stay rods $\mathrm{P} \mathrm{P}^{\prime}$ to $\mathrm{m}$.in axle $\mathrm{A}$, and bearing the two inside ploughs $\mathrm{R}$ R', all substantially as specified.

2,- The stat omary lack ploughs $\mathrm{F} \mathrm{F}^{\prime}$, connected to the

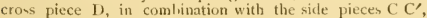
the sliding cross head $\mathrm{N}$, with its ploughs R R', the wheels I' $\mathrm{I}^{\prime}$, seat $\mathrm{K}$, and the tongue $1 \mathrm{H}$, hinged to end's of pieces C' $\mathrm{C}^{\prime}$, all substantially as specified.

No. $68,910 .-E L 1 Z A$ STAFFORD, DHCATUR, IL1.. administratrix of the est te of D.S. STAFFORD, de ceased; assirnor as administratrix to herself, SULLIVAN BUKGFSS and JOSEPH STAFF()RD.-Cultivators.Septembir 17, I867. Antedated Aurust 20, 1867.

Clain,- The pivoted curved plough standards H, connected by the chains J, substantially as and for the purpose specitiesl.

Ni. 69,003.-ISAAC b. MAHON, WUNKIRK, OHO, Cullizutors - Sipcember 17, 1867

Claim.-1. - Constructing the metallic frame of the machine in two parts $\mathrm{C}^{\prime} \mathrm{C}^{\prime}$, connected together and braced, in the manner substantially as shown and described.

2.- Suspending the frame to the axle $\mathrm{A}$, by clips $\mathrm{D}$, ar ranged in connection with the braces $\mathrm{E}$ and the pendants to which the outer plough beams are attached, all being ar ranged substantially as and for the purpose specified

3.- The doubletree $\mathrm{C}$, pivoted to the draft pole $\mathrm{T}$, in connection with the whiffetrees $\mathrm{V} V$, pivoted to the frame of the machine and connected to the ends of the double tree by l'nku, all arranged sub-tantially as set forth.

4. - The attaching of the inner plough beams $I J$ to the front of the frame by mean of universal joints $c c$, sulsstantially as described.

5.-The fender bars L L, connected with the inner plough beams J J, and universal joint s $c \epsilon$, and arranged in the manner shown so that the fenders $M$ may be set at any desired height and at a greater or less distance from the ploughs and have an independent up and down motion and at the same time retain their relative position with the ploughs, substantially as shown and described.

6.-The open or skeleton fenders $\mathrm{M}$, when auplied to the fender bars L L so as to admit of being adjusted further forward or backward on said bars, substantially as and for the purpose specified.
7.-The pulleys or vegment an the - thitt 1 , connected hy chains d to the plongh leams J J K K, in combination with the lever $S$, connected ly a chain $n$, with a pulley 0 , on shaft 1, all being arranged sulstantially as and for the purpose specified.

S. - The guicles $(i, i$, on the shaft $F$, in connection with the upright $\mathrm{N}$, pawing through said guides and the stirrups (), attached to sairl uprights, all arranged to operate sulstantia ly as descriled.

9.- The fixed guides $\mathrm{R}$, attached to the frame of the machine, with the uprights $\mathrm{O}$, of the outer heams $\mathrm{K}$, passing through the same, subatantially as and for the purpose set forth.

No. 60,07I - M. C. BUFFINGTON, LA IIARPE, JI...Corn Ploushs.-Seftember 24, I\$67.

Claim. - I. - The bent axle A, with the wheel arms C and dranght pole B altached, as shown, in connection with the pulleys $d t c^{\prime}$ and draught chain or cord $E$, all combined and arranged to operate in the manner substantially as and for the purpone set forth.

2.- The atraching of the plough beams $\mathrm{F}$ to the axle $\mathrm{A}$ by means of the tules $h$ ir, the latter being fitted on rods $f$ attached to the part $c$ of the axle, and the former secured by pins $j$ between plates $i i$, at the front ends of the plough beams.

3.- The brace rods or hars $k$, connected with the ends of the rods $f$ and rear end of the elraught pole 13 , sulstantially as and for the purpose specified.

4.-The combination of the axle $A$, dratught jole $B$, brace rods or bars $k$, and the universal joints which connect the plough beams with the axle, all being arr.unged sulistantially as and for the purpose specified.

No, 69,081-E. F. I'HAST, SWAN (REEK, IlL-Culciuntors - Siftemlise 24, 1867 .

Claim.-I.- The frame A B G F, beams D D D D, cross piece 11 , rods o os 5 , connecting bar $r^{\prime \prime}$, and lever "' ${ }^{\prime \prime \prime}$, constructed as described and for the purpose set forth.

2.-The levers $u^{\prime \prime} u^{\prime \prime}$, in combination with the main frame and beams $\mathrm{D}$, substantially as described and for the purpose set forth.

3. - The cross-piece $\mathrm{M}$, in combination with the rods so $o$ and heams D, substantially as described and for the purpose set forth.

No, 69,109-JOHN MARSIl, SENECA, ILL-Com Ploushs.-Siprimlert 24, 1867

Claim - 1- The slotted timbers F F. with their boles I I I $\mathrm{I}$, and their trunnions $G G$, sulsstantially as and for the purpose describet in the foreroing specification.

2.- The iron straps or loops $\mathrm{H} \mathrm{H}$, at the encls of the plough heams $\mathbf{E} \mathbf{E}$, in combination with the frame $A$, substantially as and for the purpose described.

3.-The shovels $\mathrm{K} \mathrm{K} \mathrm{K} \mathrm{K,} \mathrm{with} \mathrm{their} \mathrm{upwardly} \mathrm{project-}$ ing tail ends, substantially as and for the purpose described in the foregoing specification.

No. 69.162.-I. H. BARLEY, Srdas.1A, Mo-Cultizators, - Sistimbir 24, 1867

Claim,-1.-The combination and arrangement of the loop or bent hook $I$, bent lever I, comnecting rod or chain $K$, and lever pawl $L$, with each other, and with the frames $\mathrm{D}$ and $\mathrm{E}$ of the cultivator, substantially as herein how and dencribed and for the purpose set forth.

2.- The combination of the rack $M$ with the standard of the frame $\mathbf{E}$, and with the lever pawl $\mathbf{L}$, to operate in connection with the loop or hent hook J and bent lever I, suhstantially as herein shown and described and for the purpose set forth.

3.- The comb nation of the piroted seat hars $\mathrm{N}$, and adjustable holfers (), with the side bars of the cnltivator frame $\mathrm{C}$, sulstintially an herein shown and described and for the purroze set forth.

4-The shield $F$ constructed with flanges $f^{1}$ and wings $f^{2}$, and connected to the frames $E$ and $D$ by the har $G$ and chains $H$. substantially as berein shown and described and for the purpose set forth.

No. 69,186,-J. IV. CONNELY, Charleston, ILL.Cullizators. - Siptemlerer 24, 1867 .

Claim-1.-The slotted adjustable crank spindles B in combination with the axle $\mathrm{A}$ and wheels $\mathrm{C}$, substantially 
as herein shown and deviberl and for the purpose set forth.

2.- L'voting the forwarcl ends of the beam $K$ to the longituclual bars $\mathrm{D}$ by nueans of tent or elhow bolts $\mathrm{S}$, ulistantially an herein shown and described.

3. - Pivoting the forwarl ends of the beams $K$ to the tongue $G$ by means of the bent or ellow botts $[$, substan tially as herein shown and described.

4.- Pivuting the forward ends of the beams $k$ to the front cross-bar $\mathrm{E}$ by means of ellow or bent swinging bolts $T$, substantially as herein shown and deseribed.

5.- I'ivoting the forward ends of the beams $K$ to the front crosu-bar $\mathrm{E}$, by means of the strap or band $\mathrm{X}$ passing around the said cross-bar $\mathbf{E}$, and secured to the ends of the said beams $K$, substantially as herein shown and clescrilied.

No. 69,255.-IOIIN SCHR(EDER, KI(K.IP(), II.1.Cultivators.-Siptember 24, 1867 .

Claim.-1.- The manner herein shown and described of securing the plongh beams to the frame A, by means of pendants $G$ and a movable crosi-lar $F$, the latter leing pivoted to the tongue $D$, substuntially as set forth.

2.-The alrove in combination with the swinging draught bars $\mathrm{N}$, made as described.

No. $7,496,-$ I. SCHROEDER, KurkAyoo, assignor to $H$. H. PATIEE, MuNmetr, Ir.L.-Cultizators.-69.255.Siptcmbir 24, 1S67.-Rei-sued February 6, 1877. [Filed Jonumy 16, 1877 .]

Claim.-1.- Two plongh heams 1; 3, connected together by an elevated beam-yoke, $A$, so that either may operate in advance of the other, while both are drawn forward in the line of progression lyy draught-animals attached to each side of the machine, so that each animal draws in a manner its adjacent plough, the altachment of the plough beams to said yoke being by joint: which permit of moving the beams freely and indepentently in a lateral direction, combined and operating substantially as described, and for the purpose specificd.

2. - Two plough heams, B B, connected together by an elevated beam-yoke $A$, so that either may operate in alvance of the other, while both are drawn forwarl in the line of progression by diraught-animals attached to each side of the machine, so that $\mathrm{e}$ ich animal draws in a manner its adjacent plough, the altachment of the plough beams to said yoke being by joints which sustin the ploughs in an upright working postion without rear connections or other support, and permit of their leing moved or oscillated freely in a lateral direction, combined and operating substantially as described, and for the purpose specified.

3.- The two plough berms, B B, connected together by an elevated beam-yoke, A, so that either may operate in advance of the other, while both are drawn forward in the line of progression by draught-animals attached to each side of the machine, so that each aninal draws in a manner its adjacent plough, the attachment of the plough beams to said yoke being by joints, which sustain the plough in an upright working position without rear connections or other support, and permit of their being moved or oscillated freely in a lateral or vertical direction, combined and operating stibstantially as described, and for the purpose specified.

4.- The draught-bars $f f$, connected to the upper and lower portions of the arched heam yoke $\mathrm{A}$, and arranged to operate with said leam yoke and with the two plough beams B B, connected thereto, substantially as clescribed, and for the purpose specified.

5. - The draught-bars $f f$, hinged to the beam yoke $A$, and combined to operate with said beam yoke and plough beams B B, substantially as descrilucd, and for the purpose specified.

No. 7,497.-J. SCHR(EDER, KICKAPOO, assignor to H. H. PATTEE, MonmotTh, II.L.-Cultizators.-69,255. -Septembir 24, 1867 -Reissued Fibruary 6, $18_{77}$. [Filed Jamaary 16, 1S77.]

Claim.- I. - The frame $H$, supported on wheels $I$, and combined to operate with the pivoted heam yoke $A$ and beams $\mathrm{B}$ B as a support, sulistantially as descritued, and for the purpose specified.

2.- The guide-pole I, frame II, and wheets I I, arranged to operate with the benm yoke A, pivoted to the frame $\mathrm{H}$, and having plough beam if li linged thereto, substantially an described, and for the purpose specified.

No. 69,442.-C. Il, JENNE, YouNG AMERICA, ILL.Cultiators.-Octobir 1, 1867.

Claim.-1.-The arrangement with reference to the seat u of the heam $i$, working upon universal joints, and provided with suitable shares and handles, substantially as and for the purpone specified.

2. - The share stocks $n$ pivoted to the beams $i$, and furnished with stems $x$, extending through the slotted guides $c$, substantially as ancl for the purpose specified.

3.-The wedges $g$ in combination with the inclined bars $f$, rods $h$, and beams $i$, wherehy the said bcams with the shares attached thereto may be raised or lowered, substantially as herein set forth.

4.- The wedges $d$ in combination with the oblique bars

in such manner that the position of the said bars may be changed to adiust the position of the beams, substantially as herein set forth.

No. 69,468.-J. MAIISON MORSE, SiNIWICH, ILL. - Ciultiantors.-October 1, 1867.

Claim.-The combination of the cart and frame B C D E F G H, constructed and arranged subutantially as descrihed, with an orlinary corn cultivator, as and for the purpose herein set forth.

No. 69,725.-S. T). TUTTLE and J. II. G.INS, EaTuN, OHuc.-Cultieators.-Oitober 8, $1867^{\circ}$.

Claim.-1.- The sliding or adjumble doubletree $K$ applied to the draft pole $(i$, substantially as shown and described, and connected to the plough beams $\mathrm{E}$ on the axle $C$, all being arranged to operate substantially in the manner as and for the purpose ret forth.

2.-The pivoting of the draft pole $G$ to the main frame $A$, in comnection with the pivoted socket $H$ and the footpiece I, all arranged to operate substantially as and for the purpose specified.

3 - The arm or lever $\mathrm{N}$ provided with the foot-piece $\boldsymbol{U}$, and the toothed segment bar $P$, on the front crom-piece of the frame $\mathrm{A}$, the arm or lever $\mathrm{N}$ heing attached to a plough leam E, and all arranged substantially as and for the purpose set forth.

4.- The rake $S$ connected to the arms $V$, fitted on the axle $C$, and having the springs $W \times$ attached to them, substantially as shown and described.

5.- The application and arrangement of the rope $\mathrm{I}$, as shown and described, for the purpose of raising the rake when required.

6. - The combination of the sliding donthletree $K$, plough beams $\mathrm{E}$ on the axle $\mathrm{C}$, and the pivoted or laterally adjustable draft pole $G$, all arranged to operate in the manner substantially as and for the purpose set forth.

No. 69,743.-A. H. Al.I.ISON, CHARLoTIESV1I.1.E, IND. - Cultivitors.-Octeder 15, 1867.

Claim.-1 - The axles $d$, in combination with ties C C, when constructed and arranged as and for the purpose herein set forth.

2. - The beams I $\mathrm{D}$, the blocks $\mathrm{H} \mathrm{H}$, the rod $m$, the rods $g g$, and the disks $h$, the whole constructed and operating substantially as herein specified.

No. $69750 .-H$. BEAN, Scuurikn1., PA., and J. D. TYSON, I UWWER PRoNIDENCR, PA.-Cultiz'alors,-October I5, 1867 .

Claim.- I. - The comlination with the main frame A of the levers 1 ) and brace rod $d$, arranged to operate as shown and described.

2.- The sliding Irar 1 , provided with the cord $F$ and chains $l$, or their equivalents, when arranged to operate as and for the purposes set forth.

No. $70,328 .-$ C. A. EWICK, Rushumi.F, INn.-Caltiralurs.-Oitober 29, 1867.

Claim.-1.- The arrangement of the frames A A', connecter together as specified and provided with the cranks $c i s g$, in the manner and for the purpose set forth.

2.-The shovel heams $\mathrm{D} \mathrm{D}^{\prime} \mathrm{D} \mathrm{D}^{\prime}$ connected to the cranks $c$ and $g$ and secured in position by the springs $G G^{\prime}$ and chains $r, r$ to the frame $A$, as specified. 


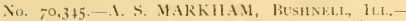

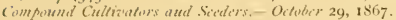

Claim.-In connection with the frame of a whecled cultivator the pentants E E, leams I, with the plotigh shanks J J, chains or cords 1 ., and levers $\mathrm{P}$, with the har. , rods a $a$, and whiffletrees 66 , arranged and used as and for the purpose specified.

Vo, $70,38_{1}$ - ELISUIA WALKER and A. M. WEED, LA PORTF, IND.-Cultizators.-October $29,1867$.

Claim,-1,-The mode of counterbalancing the weight of the tongt:e ly that of the driver by the means of the seat $\mathrm{K}$, resting upon the bar $\mathrm{K}^{\prime}$, adjustably secured to the tongue and supnorted upon the axle, substantially as set forth.

2.- The combination of the tongue $\mathrm{D}$, doubletree $\mathrm{F}$, with socl:ets $F$, and heams $G$, respectively constructed and ar. ranged suistantially as set forth.

No. 70.530,-IILGH J. GRAHAM, MoxMoth, II.t. - Cultivators- Virimber 5,1867 .

(laim.-1,-The stotted bar (), in combination with the handles $\mathrm{F}$ F and upright bar $\mathrm{V} \mathrm{r}$, substantially as tescriberl an ! for the purpose set forth.

2.- The curved iron $\mathrm{F}$, in combination with the notehed har $\mathrm{N}$, clutch $\mathrm{W}$, lirace $\mathrm{Q}$ and sliding seat $\mathrm{D}$, arranged as set forth and for the purpose claimed.

3.- The movable bar $\mathrm{X}$, in comlination with the handles for the purpose described and sulstant ally as arranged.

4.- The elutch or slide $\mathrm{W}$ and notehed bar V, substant ially as described and combined for the purpose set forth.

5.-The hinge $C$ in combination with the curve $T$ for the puipose of giving vertical and lateral movement and for vertical adjusment.

No, 70,615,-JOIIN II. RANkIN, Versallles, Mo.

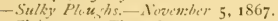

Claim.-1.-The cultuvators $\mathrm{C}$, construcled as ahove teseribed and for the purpose set forth.

2. - The cultivators $\mathrm{C}$, serew $l$, nut $l^{\prime}$, eords $\ell$, drums $f$, on axle $g$ and handle $h$, in combination with the frame $A$ all arranged as above described, and for the purpose set forth.

3.-The ploughs D, constructed as above described and for the purpose specified.

4.-The eultivator $C$, plonghs D, adjusting bars b, rail d, screws $l$, nuts $l^{\prime}$, cords $c^{\prime}$, drums $f$ on axle $g$, and handle $h$, in comb nation with the frame $\mathrm{A}$, as above described and for the purpose set forth.

No. 70,779.- MURGAN BARNETT and ELI WOOD

HARDINSIURG, N1),-Cultiators, - Nontmber 12, 1867 .

Claim.-1. - T he plough frames formed by the combina

tion of the beans $\mathrm{G}$, standards $\mathrm{E}$, and arljustable brace bars I, with each other, substantially in the manner berein shown and deser.bed and for the purpose set forth.

2.- l'ivoting the beams $(;$ upon the forward sicle of the axle $C$, by means of the rods or holts $J$, and elips $K$, sub stantially as herein shown and deserbed and for the purpose set forth.

3.- The combination of the locking keys $\mathrm{P}$ with the rorward ends of the beams $\mathrm{G}$, and with the rods or bolts $J$, substantrally as herein shown and deseribed and for the pnrpose set furth.

4. - 'The combination of the guide frames M with the beams $\mathrm{G}$, and rods or bolts $\mathrm{J}$ and $\mathrm{X}$, sub-tantially as herein shown and described and for the purpose set forth.

5.- The combination of the levers 1 , with the beams $G$ and guide frames .I, subvantially as herein shown and described and for the purpose set forth.

6.-The combination of the graduated stop-lever 0 with the beams $\mathrm{G}$ and guide frames $\mathbf{M}$, substantially as herein shown and deseribed and for the purpose set forth.

No. 71,623,-I. P. JOIINSON, MlAcoN, II.L-Cultizators.-Decimlier 3, 1857

Claim,-1. - The attachment of the lorked plough beams $F$ F to pendants $b$ b by means of lnose joints $c$ and the employment, in combination therewith, of the stindards $G$ $G$ and diagonal brace $G^{\prime}\left(G^{\prime}\right.$, steps $s g^{r}$, and diver's seat $D$. arranged and operating substantially as descriłed.

2.- In combination with plough beams $F$, which are attached by loose connections at their forward ends, and sus. tained in position by diagonal braces $G^{\prime} G^{\prime}$ and standards $G$ $G$, the employment of strpending chaiss and stirrups for enabling the clriver to raise and lower the ploughs, substantially as descrilied.

No, 71,834 -.IRA BARBER, 1.A PuKTE, IND,-Culti.

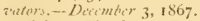

Claim.-The beams B B, the chain $C$, and the pivoted liat har $\mathrm{D}$, the double-curved shovel $\mathrm{F}$ and the slotted bar I I, as substantially arranged, comnected, and set forth in the annexed and foregring specification.

No, 72,0:7.-JOIIN CROSS and JOIIN C. TUNISON, 1)ecatur, H1...-Ciullizators.-December 10, 1867 .

Claim,-1.-The arrangement and combined action of the two frames, so that when any permanent obstruction comes against any of the ploughs, the frames will disconnect, and the back frame ride or move up on the front one, and thus avoid breakage, substantially as deseribect.

2.-A frietional spring hook upon the tongne or tongue frame, for catching and holding upon a cross bar of the "rear frame," so that the two frames will not disconnect until the pressure upon the plough or ploughs exceeds that for which the hook has been adjusted, substantially as descrilied,

No. 72,297-DENRV HOWE, ONEWNA, N. Y.-Cultirulor:-Dicimber 17,1867 .

Claim,-1,-Extending the rear end of the eentral beam Clack, to receive and support the rear or central plough stanilar i 1), substantially as herein shown and described.

2.- The gauge wheel frame I, constructed substantially as herein shown and described, and pivoted to the eentral heam $\mathrm{C}$, or to some other support at the central part of the eultivator frame, as and for the purpose herein set forth.

3. - The combination of the lever lateh $\mathrm{N}$ with the beam C and gatige wheel frame J, substantially as herein shown and descrilied and for the purpose set forth

4.- Pivoting or hinging the tandards $\mathrm{D}$ and $\mathrm{F}$ to the cultivator frame hy means of the brace ears $d^{\prime}$ and $f^{\prime}$, substantially in the manner herein shown and describerl and for the purpose set forth.

No. 72,456.-PHIL.IP COONROD, KeIthsBurs, ILL. - Double cittivator Ploughs,-December 24, 1867.

Claim.-The cultivator, consicting of two separate gangs of ploughs G G, each gang constructed of curved iron bars $5 \mathrm{~s}$, as described, and adjusted by means of clevis $\mathrm{H}$ and box $\mathrm{C}$, both constructed aud operating substantially as herein set forth, in eombination with axletree $A$, constructed as deseriberl, hoxes D D, and draught rod E, substantially as set forth.

No. 72,598.-JOSEPH E. BROOKS, (GoODING'S GROVE, IL1.-Cultiantors.-Decimber 24, iS67. Antedated De: c'mber 19. 1S67

Claim.-I - The arrangement of rods $\mathrm{L}$ with the frame of the machine and the plough beams E E, substantially in the manner and for the purposes set forth.

2.- The arrangement of the draught cord $b$, sheaves $a a$, and pivoted hangers $\mathrm{C} \mathrm{C}$, so as to operate substantially as and for the purposes descrihed.

3.-The combination and arrangement of the plough beams $\mathrm{E}$, rods $d$ e, lever $\mathrm{L}$, cord $\mathrm{K}$, rod $\mathrm{J}$, and lever 1 , sub stantially as and for the purposes specified.

4.-The combination of the suspeniled plough beams E, rods $\mathrm{U}$, and levers $\mathrm{W}$, arranged and operating $\mathrm{a}$ and for the purpose shown and set forth.

5.- The peculiar arrangement of and node of attaching the bow $\mathrm{V}$ to the rear part of the plough beans, herein shown and specified.

No. 72,7 So,-J. T. BAITIMORE, Marble Rock, IowA.-Cultizators.-December 31, 1567 .

(laim.-1.-The combination of the beams G, pivoted at their front ends to the arms $\mathrm{E}$ of the frame $\mathrm{C}$, and passing through the slotted arms $\mathrm{F}$, with the beams $\mathrm{H}$ pivoted to their inner iides, sulsstantially as described.

2.- The combination of the elhow levers $\mathrm{L}$, cross bars $\mathrm{N}$ and $\mathrm{K}$, with the standards $\mathrm{l}$, connected to the beams, arranged for operating the shovels, substantially as deseribed.

No. 72,835 .- R. GARTER, GRANI RAPIDS, NiCH.Cultizators:-Deember 31, 1867.

Claim.-1.-The arrangement of the wheels $\mathrm{E} \mathrm{E}$, hung on the inside of the frame heams A A, with an adjustable cast-iron slide $b$ working in uprights $c c$, having serrated or toothed faces for fastening it at any height, with correspond- 


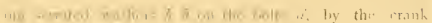

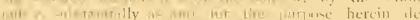
active

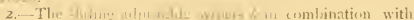

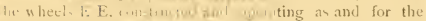

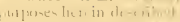

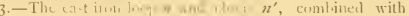

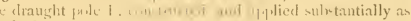
I fouth.

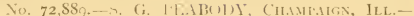

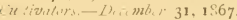

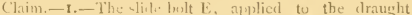
iasle 1 , and arranges in relation with the croms har $\mathrm{C}$, to operate in the mamur -ub-tiantially as and for the purpone at forth.

2.-The arrangement of the front lar D with the tomdarils $F$ of the enster where $(i "$, wnd the arms $g$ of tis cros lar C. -ul-tatially as aul for the purpose set finth.

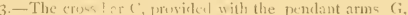
3 enmlination with the lingh licams H II' and adjusta1.1. frame I, all arranecil subutantially as and for the pur in se vrecificel.

4.-The -tay en lira e liar- $j j$, in esmnection with the lars C I) and the-tamburl- F of the ciater wheel $G$, all ironged sul atartially in the manter an and for the purpose if fosth.

5.-The bracing of the hanelles I f' by means of the hais $\mathrm{K}$, subutinti illy as set forth

6.-The lacis:g of the draw loult 1 , at the rear of the if aght pole, subatutially as and for the purpose speci ical.

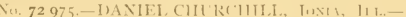
Culli, nuls, - Jumury 7, 1868 .

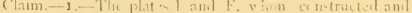

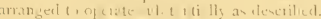

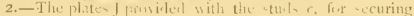
snel holding the feram to the main frame, and hat ing alor the lot lor aljustans thens, as ut furth.

3. - The combination of the bent renk $T$ and cromeracl

H, pivoted to the in. in frame, ame arrongerl to opperate a dencrilien!.

No. 73,081-WII.LLIN II. I) A.WK()N, K()BERT II

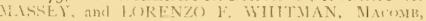

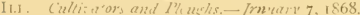

Claim.-I.- The combination of the wheel at with the wrist $e$, fi fing thases $e^{\prime}$, and 'rambenm $a^{\prime}$, ar aul for the

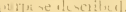

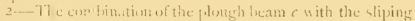

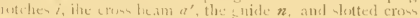

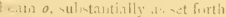

3-The combination of the plotush benm $c$ with the

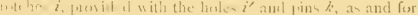
Hic purpane sot fo rh.

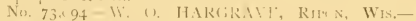

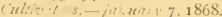

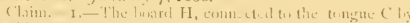
th. himes Il', sothat the strill tech san lee clesateat by the

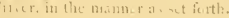

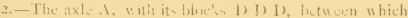

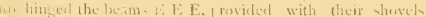

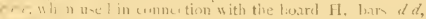

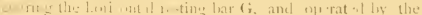

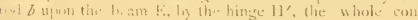
totet:el am! the I in the manner stmantially as yeei1. 1 .

Ner. 73.166. $\rightarrow$ II. Cix and 15. 11. 1'LNCL, MAT

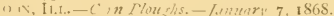

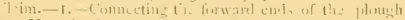
im $\mathrm{H}$ tes the frame $\imath^{\circ}$ liy uess of the clevin I, cun

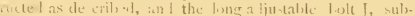

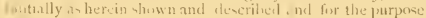
I firth.

2. - The combination of the 1 se + t) and tooties pawl P wh the shaft $\mathrm{N}$. grooved eerment. M, chain L. on 1 beam. $I$, is connection with tise clutines I and leme boits J, for raising the plough vettically from the sround, suls-tantially averein shaw ambitscribeil.

3.-The combination $\mathrm{an} I$ arraremont of the plough $V$, having cutter $v^{\prime}$ attached to them, ans turning the dirt from the hills, flutghs W running at a lower level than the plough $V$. and turning the dirt toward the hills, standards $\mathrm{R}$ and $\mathrm{T}$ and beam. II with each other, substantially as herein hown and described, and for the purpose set forth.

No, 73,172,-EDITIN DOOLITTLE, PAWNEF, ILL.Cultizutors-Jamzary 7. 1868 .

Claim.-I.-The hinged slicley M, friction wheels $\mathrm{N}$, and bent bar $F$, with each other and the plough beams I, and with the beams or bars D, stibstantially as herein shown and described, and for ihe purpose set forth.

2.-Incombination with the above, the knees or bars $O$, cross bar $P$, and lever $R$, all arranged and operating in the manner and for the purpone set forth.

3.- The comlination of the adjustable connecting and brace bars IV, upright $\mathrm{V}$, and plough beams I, when arranged to operate in the manner herein described and reiprenented.

No. 73.217.-TOSEPH IVIDMAN, PAxoLA, ILL. Cullowhers.-Janumy 7,1868.

(laim.-1.- The detachalle seat lars E E, secured to the main frame A of the machine, substantially in the manner as and for the purpose set forth.

2. - The attaching of the front ends of the plough beams ( $i$ G to the pendauts I I by means of univenal joints II when thi attachment is used in connection with the pivoted armo $\mathrm{O}(\mathrm{y}$, connecting har $\mathrm{P}$, sand lever $\mathrm{O}$, for giving a lateral motion to the plutghs, sulstantially as described.

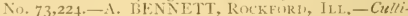
rators.-Jumary 14, 1869. Antedated Jamuary 4 IS68.

Claim.-1.-The hitching iron $a$ in combination with the plough leam ( C, and the front cross beam D, ar r.m. I anil operating sub tal.ti.lly as and for the purposes her. in ilrecribed.

2,-The chain /h, with the-tirup $m$, at onc end, con nected with the plomsh beam $C^{*} C^{*}$ at the osher eisd, and law-ins over the rear cros hean $\mathrm{E}$, to raise the beams and

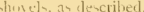

. The upright hand leverie e, hinged or pivoted io the

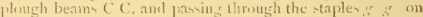
tiecruss lrean $\mathbf{E}$, to which they are secured by pins $k \cdot k$, arranged and opurated as and for the purpose decrilienl.

4.-The movalse furt piece or uteps $f$, on the levers $c e$, hellt in place liy notches in the ides of the levers tis and for the parpune specified.

5.- The adjuntable lraces of and st itted bolts $r \quad r$ aranged in relution with the heans $C$ and standard $d$, to regulate the pitch of the shovels, is herein shown and lescrilied.

Vo, 73,264-STEPHEN T. SKINNER, TWKSIN

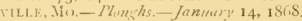

Claim.-1-My forwarl urirth frame $\mathrm{F}$, with wing bar G and Rat chains 11 11. for the Use and purpose as specilicel atnd herein set forth.

2.-The attaching of my pule to the centre, or near the left ide is my machiuc, for the $u=$ and purpose as specilied and herein set forth.

3.- My tiiple whiffletree, with the triple link $x$, as represented in Fig. 111, for the use and purpess as specilied and herein ret foith.

4.-My crank axles, as mals, attached, and opreraicd on my macline, for the use and purpone as yecilied and horein hei forth.

5.- My "efmpound regulating shalt" $\mathrm{X}$, with the rerolving roclictr $j ;$, suing lever $K$. and circle L, for the use and purpumes as specifical and herein iully set forth.

6.- The combination of my cran's axlen, compound reg. ulatims sh: it $\mathrm{X}$, and spring lever, for the use and pur pore as anceiticel and herein set forth.

7.-My domble crank shaft $M$, with lever $\mathrm{N}$ and ling $\mathcal{Y} \mathrm{Y}$, for the use and purpose as specified and here in set forth.

No. 73,291.-JESSEE C. BON7), MILRoY, INI,, assignor to himreif, C.P. WII SON, and L. I. K()IBL.ET.-Culi zaters,-Jumuary It, 1868 . 
('aim,--The arrangement of the beams 1) with their attachment directly to the axle $\mathrm{A}$, lyy means of shiftingclevtses, with handle 11 , har I, and has $F$ and $(i$, the several parts being constructed and operating substantially as and for the purpose specitied.

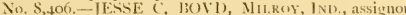
to himself, C. P. WHLSON, and L. L. BU131.1:T. - cultiz'ators. -73,291. - January 14, 1868. - Reissued Siptember 10. 1878 . [Filed April 10, 1878 ]

(laim.-1.-In a cultivator, the combination of the handle $\mathrm{M}$, the cross-bar $\mathrm{K}$, and the rest $d^{2}$ with the ploughs, beams, and standards, for the purpose of holding them up from their ordinary positions, substantially as herein shown and specified.

2.- In a cultivator, the combination of the pole $\mathrm{C}$, axle 13, plough beams F F, ad ustable attachments $\mathrm{G}$ G , standards 1 , cross bars $K \mathrm{~L}$, and handle $\mathrm{I}$, substantially as herein shown and described, and for the purposes specified.

No, 73,392,-JANlES B. SEXTON, IEI.LA, IOWA, as signor to himself and JOHN L. ANDREW, sime place.(iwltivators.-January 14,1868 .

Claim. - 1.- The adjustable iron bars (;, constructed sulistantially as herein shown and described, and adjustably attached to the end bars $a^{2}$ of the frame $A$, as and for the purposes set forth.

2.- The beams $H$, constructed substantially as herein shown and described: that is to say, curved outward at their forward ends and strengthened at their rear ends by the cross-lars J, as and for the purposes set furth.

3.- The curved adjustal,le bar or yoke L, curved edgewise, and adjustably holted to the cross-bars J, substantially as herein shown and described, and for the purpose set forth.

No. 73,547.-CHARLES RICH and OSC.AR 1.. NEISLEK, PoUghkeEPSIE, N. Y.-Combin'd Cultizators and Harrows.-January $2 \mathbf{1}, \mathbf{1} 868$.

Claim, - I. - The adjustable bars $\mathrm{K}^{\prime} \mathrm{K}^{\prime}$, when arranged on the sides of the hill, and when provided with handles $j j$, connected at their upper ends so that the teeth can be accommodated to irregularities in the hill, or can be connected for broadcast harrowing or tilling, substantially as herein shown and described.

2.-The device for cornecting the harrow frame $\mathrm{C}$ with the axle $\mathrm{A}$ and driver's seat $\mathrm{l}$, consisting of the bars $\mathrm{E}$ and $F$ on the axle, of the links ( $i$, levers $\mathrm{H}$ and $J$, and connecting rods $h$ and $i$, all made and operating substantially as and for the purpose herein shown and described.

3.-The alrove, in combination with the notched har $\mathrm{Ml}$, when made as and for the purpose described.

4.- Securing the dranght bars $\mathrm{N}$ to the rear of the har row holders $\mathrm{K}$, substantizlly as and for the purpose herein shown and described.

5.- The hollow cultivator tooth $\mathrm{P}$, when arranged so that it can be fitted to and easily removed from a harrow tooth L, substantially as and for the purpose herein shown and described.

No. 73,699.-THADDEUS DONELY and I. B. CRESSLER, SuLtrHAMPTin, PA.-Adjustable Shozid Ploushs.- Fanuary 28, 1868 .

Claim.-1.-The combination of lever L with subordinate levers $/$, and their attachments, pawls and springs, when operating upon the sleeves $S \mathrm{~S}$, substantially as described

2.- The combination of lever 1 , with sleeves $S$ S and shafts $s^{1}$, to move laterally, substantially as described.

3.- The arrangement of levers $\mathrm{T}^{2} \mathrm{~T}^{1}$, and $t$, in connection with the tongue, substantially as described.

4.-The use of a central plough, F, detachably arranged, in connection with the side ploughs, substantially as described.

5.- The combination of lever $\mathrm{L}$ and its attachments, forming a combined lever, with vertical and horizontal motions, coincident when necessary and convenient, together with the adjustable devices $T^{2} T^{1}$, and $t$, all operating together, substantially as and for the purpose specified.

No. 73,805 - JOHN T. HERNDON, BANCROFT, MO. - Cultivators.-Janwary $28,1868$.
Claim.-1.-The combination and arrangement of the beam IEJ, connected by chain U to pulleys $V$, on the shaft W, substantially as and for the purpose set forth.

2.-The comnecting of the inner beams J I by the bar $h$, and the attaching of the uprightis $5 g$ on said beams to the arms $Q$, by the bars $\mathrm{N}$, arms $\mathrm{O}$, and shafts $\mathrm{P}$, for the purpose of giving a lateral movement to the shares or shovels L, substantially as and for the purpose specified.

No, 73,891.-CHRISTOFER HEFFT, TAZEWELL Countr, Hi..-Cultinators.-January $28, \mathbf{1} 868$.

Claim,-1.-The combination and arrangement of the diagonal frame $A$ and cross bar $C$; pivoted to the main frame, and having the standards $h$ and $u$ attached thereto, as shown, with the levers $c$, all as shown and described.

2.- In combination with the above, the detachable handle $\mathrm{F}$ and lever $\mathrm{H}$, arranged to operate as and for the purposes set forth.

No. 73.979.-NATHAN S. JUIINSON, MAQUOKETA, IowA.-Corn Cultizutors.-February 4, 1868 ; antedated February 1, 1868

Claim.-1.-The combination of the two axle bars B B and the four upright standards A A A A, and cross beam S and bolts $\mathrm{E}$.

2.- The combination of the seat board and seat lever 1 with the levers L L, shovel beams I I), and the movable pivot or standard $\mathrm{C}$, substantially as and for the purpose herein specified.

No. 74,044- JOHN BURNHAM LA SALIE, ILI., assignor to himself and D.AVID I. IIUUGH, same place.Cultizators.-Fibruary $4, \mathbf{1} 868$.

Claim.-I,-In combination with the elevated axle-tree $A^{2}$, hounds $B$, pivoted draught pole $C$, and lever $C$ ', having a movable fulcrum, the pivoted beam $D$ having the plough beams secured to its extremities, or to pendants applied thereto, said beam being comnected by means of a chain to the draught pole, substantially as described.

2.-In combination with a pivoted beam $\mathrm{D}$, arranged and operated as described, and provided with pendants upon its ends, the plates $d^{\prime} d^{\prime}$ having the plough beams attached to them, substantially as described.

3.-The flexible draught comnection $h$, secured to swinging pendants $\mathrm{G} G$ at its ends, and passed around the axletree $\mathrm{A}^{z}$ longitudinally, substantially as described.

4.-The removable driver's seat $H$, applied to the carriage, and supported thereon, substantially as described, in combination with levers $\mathrm{P}$, sumpension chains $j$, beams $\mathrm{E}$, and pivoted cross beam D, substantially as described.

5.- The attachment of the plough blades or shovels $\mathrm{J}$ to their standards, by means of loops $m$ and clamping eyes or hooked bolts $n$, substantially as described.

No. 74,138.-JOHN C, RICKERD, LEWISVILLE, IND. - Cultivators.-Fibruary 4, 1868.

Claim.-1.-The double hinge, consinting of the screw bolt $f$, bases $g$, flanges $h k l$, lips $i j$, and pins $m$, to hinge the cultivator beams to the main frame, all constructed and arranged substantially as described.

2.-The hinged seat 1 , supported by means of curved rods, and provided with foot rests f, sulbstantially as and for the purposes set forth.

3.- The combination of the frame $A$, hooks $n$, rods $a^{2}$, and foot rests $f$, substantially as and for the purposes set forth.

No. 74,267.-J. A. ALI.EY, Clifty, IND.-Combincd Ploughs and Rollers.-Fehmeary 11, IS68.

Claim.-i.-The combination and arrangement of the short rollers $\mathrm{C}$, frame $\mathrm{A}$, rigid plough standards $\mathbf{I}$, and pivoted plough standards $\mathrm{J}$, with each other, substantially as herein shown and described and for the purpose set forth.

2.-Operating the pivoted plough standards $\mathrm{J}$ to guide the ploughs, by means of a lever $O$, pivoted to the upper end of one of the said standards, and to a support P, attached to the frame $A$, substantially as herein shown and described.

No. 74,678.-JOHN FRANK, Werster City, Iowa. - Cullinitors.-February 18, 1868.

Claim.-1.-The adjustable blocks C, constructed and operating substantially as described.

2.-The cultivator as it stands, with it 4 various parts and 
devices combined, arranged, and operating substantially as and for the purposes herein specified.

No. 74,754--ELIAS S. EASTERDAY, NoKomis, ILL. - Sulky Cultizators.-February 25, I 868 .

Claim.-1.-Extending the plough beams D forward to form the tongue of the machine, substantially as herein shown and described and for the purpose set forth.

2.-The iron frames (), adjustably secured to each other, and sliding laterally upon a rod or equivalent slide attached to the axle $\mathrm{B}$, in combination with the plough beams $\mathrm{D}$, substantially as herein shown and described and for the purposes set forth.

3.-The combination of the foot levers $Q$ with the plough beams $D$, and with the slotted irons or frames 0 , substantially as herein shown and described and for the purpose set forth.

4-Adjustably securing the ploughs $M$ to the standarck $\mathrm{K}$ by means of sockets $\mathrm{N}$, substantially in the manner berein shown and describer and for the purpose set forth.

5.- The combination of the pivoted levers $\mathrm{E}$, chain $\mathrm{F}$, and pulley $G$, with the plough beams $\mathrm{D}$ and with the har: $c^{1}$, connecting the forward ends of the bars $C$, substantially as herein shown and described and for the purpose set forth.

No. 75,127.-JOHN CROWTHER, UXFORD MICH.Cultivators.-Masech 3, IS68.

Claim.-Raising and lowering the frame $A$ by means of levers $\mathrm{D}$ and $\mathrm{H}$, and burs $\mathrm{C}, \mathrm{F}$, and $\mathrm{I}$, and shaft $\mathrm{J}$, suhstautially as herein specified.

No. 75,647.-J. H. REINerson, Pieasant Plans, IowA.-Cultivators.-March 17, 1868 .

Claim. - I. - The horizontal bar 1 , vertical bar $H$, rock shaft $K$, having arms $f$, arm $h$, lever $L$, and chain $b$, in combination with the plough beams $\mathrm{F} \mathrm{G}$, all arranged and operating as described, whereby the depression of the lever $L$ raises the outer beams $G$, through the medium of the arms $h f$ and chain $g$, and the inner beams $F$, through the medium of the vertical bars $H$ and horizontal bar 1 , as and for the purpose herein set forth.

2.- The vertical h.rrs II and horizontal bar I, in combination with the plough heams. F ( $;$ and lever $\mathrm{L}$, as herein described, for the purpose specified.

3.- The horizontal bars $\mathrm{H}$, attached to the inner beams $F$, when the lower ends of said bars are provided with the projecting foot rests $d$, arranged and operating as described, for the purpose specified.

No. 75,826.-BENJAMiN ANYAN, Fitchville, OH10.-Ciultivators.- March 24, 1868.

Claim.-1.-The supplemental hounds $b \quad b$, with the draught pole $G$ attached, and both said parts attached to the hounds proper D D, as shown, when said parts are applied to or used in connection with the front running gear of an ordinary farm wagon, for the purpose specified.

2. - The attaching of the standards I I of the front shovels $H$ to the supplemental hounds $b b$, and the attach. ing of the standards $K$ of the rear shovels $J J^{\prime}$ to the bars L L connected to the hounds roper D D, substantially as and for the purpose set forth.

No. 75,911.-CHRISTOPHER HOAGLANI), IFLEVAN, ILL.-Cullivators.-March 24, I 868.

Claim.-I.-The combination of the jointed plough standards $\mathrm{C}^{\mathrm{C}}$ ', plates $d$, links $\mathrm{K}$, scrapers $r$, and connect. ing links $l k$, as herein described, for the purpose specified.

2.-The links $/ k$, or other equivalent device, for connecting the front and rear standards, for the purpose of operatung the latter sumultaneously with the former, substantially as shown and described

3.- The plates $d$, with their holts $f$, or other equivalent device, for forming a hinge between the standards $\mathrm{C} \mathrm{C}^{\prime}$ and ploughs $\mathrm{P} \mathrm{P}^{\prime}$, substantantially as shown and described.

4.-The spring catch $O$, or its equivalent, for holding the standards forward, substantially as and for the purpose shown and described.

5.- The rod $\mathrm{L}$, for vibrating the standards $\mathrm{C}$ laterally, substantually as shown and described.

6.-The arms $\mathrm{N}$, for operating the rod L, substantially as shown and described.
7.- The rod I, with its hend $\mathrm{J}$, or other equivalent device, substantially as and for the purposes shown and described.

8. - The laterally vilurating standards $\mathrm{C}$, in combination with the $\operatorname{rod} \mathrm{L}$ and bend $\mathrm{J}$, substantially as and for the purposes shown and described.

9.- The plough.cleaner $r$, or other equivalent device, attached and working substantially as shown and described.

No. 76,411.-ELIJAH W. DENNIS, PEORIA, IlL.Cultizators.-April 7, 1868. Antedated March 25, 1868.

Claim.-1.- The arrangement of the levers 11 and cort $\approx$ with spring $h$ on the pole $M$, substantially as and for the purpose specified.

2.- The arrangement of the levers, handles H H with the cord $x$ and the pole $M$, substantially as and for the purpose specified.

3.- The arrangement of the plates $s$ and $t$, as constructed, with the shovel $y$ and bolt $w$, for securing the shovel to the beam, substantially as and for the purpose set forth.

No. 76,964--JOSEPH WOLF, Jov NG AMERICA, ILL. - Corn Ploughs.-April 2 I, I868.

Claim.-1.-Connecting the forward ends of the heams $\mathrm{C} C$ to the axle $\mathrm{A}$, by means of metallic loops, so that the said ends can be shifted, while the rear ends can be adjusted, substantially as and for the purpose set forth.

2.- The arrangement of the axle $\mathrm{A}$ with the heams $\mathrm{C} C$, which are loose at their rear ends, and with the tongue $F$, as and for the purpase set forth,

3.- The arrangement of the draught bars $\mathrm{H} \mathrm{H}$ with the axle $A$ and tongue $F$, as and for the purpose set forth.

No. 78,243 .-ORRIN STONE, Ionia, Mich.--Cultizators.-Miny 26, 1868 .

Claim.-The combination of the fixed and the yielding frames, when united together by flexihle connections, and the under or yielding one is made capable of being raised and carried hy the fixed one, in the manner and for the purpose herein described and represented.

No 79,119.-JUSTIN H. HILL, Clinton, Ilı.-Chltivators.-Fune 23,1868 .

Claim.-I,-The frames $\mathrm{A}$ and $\mathrm{C}$, and the lever F, combined and operating subitantially as set forth.

2.-The shovel handles $G$, arms $H$, and connecting bar I, arranged substantially as described, in combination with the frame $C$ and its adjuncts, substantially as and for the purpose set forth.

No. 79,304.-A. R. BLOOD, A. HATHAWAY, and V. R. BEAC11, INDEPENIENCE, IoWA.-Caltivators.June 30,1868 .

Claim.-I.-The levers I I, strips $a$, har L, and pivoted frame $I$, when all are arranged and operating substantially in the manner and for the purpose set forth.

2. - The set serew $\mathrm{H}$, seed slide $b^{\prime}$, levers $\mathrm{J} \mathrm{J}$, strips $a \quad a$, bar L. H, pivoted frame I, all combined and arranged as and for the purpose described.

No. 3,945-A. R. BLOOD, ALEXANDER HATHAWAY, and V. R. BEACH, INDEPENDENCE, IUWA.Cultivators. -79,304, June 30, 1868.-Reissued Muy 3, 1870 .

Claim.-I. - The levers J J, strips a a, bar L, and pivoted frame 1 , when all are arranged and operating substantially in the manner and for the purposes set forth.

2.-The set-screw II, seed-slide $b^{\prime}$, levers J J, strips $a a$, bar $L$, and pivoted frame $I$, all combined and arranged as and for the purpose described.

3.- The arrangement within the slotted bar $F$ of the shank $\mathrm{K}$, provided with tooth $\mathrm{G}$, when constructed as described, and the upper end of the shank, provided wath two or more holes $g g$, and held by a wooden pin passing through either of said holes, and hoth ends of said pin resting upon the top of the har F, substantially as and for the purposes herein set forth.

4.- The combination and arrangement of the frame $A$, seed-lox E, with rod $j$, and mechanism for operating the same, seed-slide $b^{\prime}$, set-screw $\mathrm{H}$, levers $\mathrm{J} \mathrm{J}$, strips $a \quad a$, bar $\mathrm{L}$, frame 1 , cultivator-bars F F, shanks $\mathrm{K} K$, and teeth $G$ $\mathrm{G}$, all constructed as described, and operating substantially in the manner and for the purposes herein set forth.

No. 79.344.-MAJOR E. HANOVER and DAVID D. 


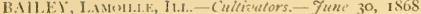

Claim.-1. The frame C, constructed and arranged substantially as hercin shown and described, in combination with the axle 13, as and for the purpose set forth.

2.-The combination aud arrangement of the pivoted oblique beams $\mathrm{I}$, connecting bars $\mathrm{U}$, levers $\mathrm{V}$, and connect ing rods W, with each wher, and with the frame (' ancl hounds D, substantially as herein shown and described, and for the purpose set forth.

3.- The combination and arrangement of the hounds D, frame $\mathcal{C}$, lever hooks or catches $\mathbf{E}$, coiled or equivalent spring $F$, and operating rod $(i$, with each other, substantially as herin shown and described, and for the purpase set forth.

4.- The combination of the angular or bent brace bars $T$ with the pivoted plough beams $\mathrm{P}$, axle $\mathrm{B}$, and frame $\mathrm{C}$, substantially as herein shown and described, and for the purpose set forth.

5.- The bent levers $A^{\prime}$. pivoted at their angle points to the axle $\mathrm{B}$, in combination with the connecting rod $\mathrm{B}^{\prime}$ in rear of the axle $\mathrm{B}$, draught rods $\mathrm{C}^{\prime}$, horizontal bar $\mathrm{E}^{\prime}$, hounds $\mathrm{D}$, and slotted vertical arms $\mathrm{D}^{\prime}$, all operating as described for the purpose specified.

Nis. 79,387.-EDWARD l'IIIFER, TRENTON, N. J.Cultitizlers.-June 30, IS68.

Claim.-I.- The skeleton frame E G, constructed as described.

2.- The combination, substantially as described, with a tongue pivoted by a king bolt to the axle of a rock shaft, arranged parallel with the axle, to which it is connected by sectors.

3.- The combination, subutantantially as described, with the tongue pivoted to the main axle by a king bolt, of a transversely-blotted plate bolted to the skeleton frame, whereby the tongue can tum laterally without moving the frame.

4.- The combination, sulsstantially as described, with a tongue pivoted to the main axle, of the rock shaft or skeleton frame, the treadles I, and the driver's seat, for the purpose of steering the machine, as set forth.

5.-The combination, substantially as described, of the tongue and driver's seat with the detent lever C' and the slotted plate e, whereby the driver can release the tongue or hold it rigidly as required.

6.-The crank arms $(i$, constructed and arranged for joint operation, as descrilsed.

7.-The combination, with the crank arms of the drag bars and removable sleeves $h h^{1}$, for the purpose set forth.

8.-The combination, with the crank arms and sleeves, of the adjustable coupling arms $G^{\prime}$, for the purpose se forth.

9.- The combination, with the sleeves $h h^{1}$, of the looped drag bars $\mathrm{H}$, and adjusting clamps $\mathrm{I}$, for the purpose set forth.

Io.- The combination, with the skeleton frame E and adjustable drag bars 11 , of the adjustable link bar: $\mathrm{L}$ and slotted cross bars $\mathrm{M}$ on the lifting levers, for the purpose set forth.

11.-The combination, with the tongue of the whifletrees, connected directly with the cranks G, as and for the purposes set forth.

12.- The combination, with the tongue pivoted to the axle by a king bolt, of a skeleton frame carrying ploughs adiustable in pairs, with the wheel: also adjustable on the axle, subitantially as describerl.

No. 79,450.-JOHN H. DAVEY, R@CKForD, ILI.Cultivators.-June $30,1868$.

Claim.-The frames B and C, the standards D D, pins E, the chains F F, the lever $K$, the chain $K^{\prime}$, all constructerl, combined, and operating substantially in the manner and for the purposes set forth.

No. 79,570.- IVILlla.l HARVFY, Volga City, Iowa.-Sulky Cultizators.-Yuly 7, 1868.

Claim.-1.- The combined arrangement of the shovels F F', supporting chains $1 I^{\prime}$, perforated straps $J J^{\prime}$, and wooden pins $j$, the rock bar $K k^{3}$, elevating chains $L^{\prime} L^{\prime}$, and treadle $\mathrm{Ml} \mathrm{m}^{\prime}$, and the dodging chains $\mathrm{O}$, and treadles
$\mathrm{N}$, all as represented and dexribed, for the purpose set forth.

2.-The hooks P P' employet, in combination with the inner shovels F F, to adjust said slovels relatively to the row, substantially as and for the purpose specified.

No. 79,598 . -N. A. RAND, WiNsLow, ILL.-Cultiza. cors.-Fuly 7, 1 S6S.

Claim.-The arrangement of the pivoted hars $\mathrm{C} \mathrm{C}$ (that connect with the cultivator beams I) D) and the movable seat bar $K$, between the axle and the frame piece 1 , whereby the operator can shift the shovels by the action of his feet, the several parts being constructed to operate substantially as set forth.

No, 79,956,-GEORGE IV. COOK, MACON, IHL.('ultizators. - July 14, 1868

An arrangement whereby the attendant may ride or walk while operating the shovels and managing the team.

Claim.- The connecting of the standards F F of the plough heams E E, by cross-hars $c c$, as shown, in combination with the crank shafts 1 , chain $d$, pulleys $f$, and treadies $\mathrm{H} \mathrm{H}$, all arranged ant applied to mounted frame A, $\neg$ listantially as and for the purpose set forth.

No.. So,094--J. H. SKF.LlY, ARoMA, l11.., assignor to himself and J. C. DANFORTH, same place.-Cullivalors. - July 21, 1868 .

Claim. - I. - The beam C, in combination with the pivot rod $\mathrm{E}$, brace $\mathrm{F}$, and $\operatorname{arm} \mathrm{D}$, the latter being arranged to swing with the beam $\mathrm{C}$, and to travel on the track $\mathrm{N}$ by means of the roller $\mathrm{M}$, substantially as shown and set forth.

2.-The combination of the heam $\mathrm{C}$, chain $c$, arm D, and the elbow lever $H \quad 1$, the latter being pivoted to the arm, and having a projecting $n \vdots b$ for locking against its top, substantially as and for the purpose set forth.

No. So,102,-ISAAC WELTY, OLNEY, Ill..-Sulky Cultivators.-7uly 21, 1868 .

Claim.-1.- In combination with the cuter shovels or ploughs $\mathrm{H} \mathrm{J}$, the lateral braces $\mathrm{H}^{\prime}$, rendered acljustable by means of the slots $h^{3}$ and bolts $h^{2}$, in the manner shown and described, for the purpose set forth.

2.-The combined arrangement, with the inner shovels G $1 \mathrm{~S}$, of the perforations $e^{\prime} c^{\prime}$, for the reception of their attaching eye bolts 5 , the pulleys $n " n$, for the reception of their elevating ropes or chains $K$, and the perforated bars $\mathrm{T} U \mathrm{U}$, as and for the purpose specified.

No.So.221.-SAHUEL J. REED, CAMDEN, OHO.Sulky Ploushs.-July 21, 1568.

Claim. -1 - The beam A, pole $A^{\prime}$, caster wheels B B, arms $b b$, cross bar $b^{\prime}$, lever $C$, and foot piece $C$, the whole being combined and arranged substantially as described.

2.- The plough beams E E, constiucted and arranged as described, in combination with lever $\mathrm{F}, \operatorname{crank} f$, and guides $f^{\prime}$, as and for the purpose set forth.

No. So,502.-HIRAM PRESTON, ORFORDVILle, Wis,-Cultizators.-July 28 , i 868 .

Claim.-I.-The adjustable V-shaped part $>$ C, in combination with the rocking shaft $B$, when constructed and operated subatantially as described and set forth.

2.- The lever $h$, provided with the springs $i$, and the $\operatorname{arm} \mathrm{E}$, in cunjunction with the parts $\mathrm{C}$, and ratchet $k$, for the purpose of controlling the parts $C$, sulistantially as described.

No. 80,556.-ROHEKT MCCORKELL, PhIlADelphia, PA.-Cultizators.-August 4, I868. Antedated July $\mathbf{5}_{5}$, 1868

Claim,-I.-The lever $H$, rack $L$, and connecting rod $\mathrm{N}$, in combination with the plates $\mathbf{E}$, for the purpose set forth.

2.- The lever $c$, in combination with the drag bars C, standard $n$, and rubber spring $r$.

3.- The mode of attaching and securing the head $b$ of the drag bar $\mathrm{C}$, for the purpose of adjusting the angle of the ploughs.

4.- The mode of attaching and securing the standard $x$ to the bar $y$, as and for the purpose set forth.

No. So,795--HENRY COWlNG, New ORleANS, LA. - Asricultural Machines.-Ausust 4, 1868 .

Claim.-1.- The application and combination of the 
double block system of equalizing draught, as above set forth.

2.-The application and combination of the single block system, in combination with the donble block system.

3.-The guadruple whiffletree.

4.-The application and combination of the cross-bar $1^{2}$ with the tongue, for the purposes specified.

5 -The slotted slide-bar $\theta$ for the whiffletrees to slide upon, as set forth.

6.-The joint in the tongue, as and for the purpose set forth.

7.-The rotary grooved cylinder, as and for the purposes specified.

8.- The adjustabie thumb screw $l$, in combination with a slide valve for regulating the quantity of grain sown.

9.-The application of a steering apparatus to agricul_ tural machines, composed of the wheels I, cross-bar $K$, sheaves $i i^{\prime}$, standards $J^{\prime}$, rope or chain J, stirrups $j j$, crossbar $l$, and the levers $L$ and $L^{\prime}$.

10. - The standards $\mathrm{I}^{\prime}$ and the adjustable cross-beam $\mathrm{K}$.

II. - The standards $D^{1} D^{2}$ of the canopy, the cross. bar provided with screws $d d$, for the purposes set forth.

12.- The curved standards $e^{3}$ and box straps $c^{4}$, for the purposes specified.

13.- The semi-circular rack-lever $E$, and handle and stop-lever spring $f$, for the purposes herein set forth.

14. - The tripping lever $p$ and cord or chain $p^{\prime}$, for the purpose herein set forth.

15.-The application of horse or other power that may be employed to draw the machine, for raising the ploughs and instruments out of, and from the ground, as set forth.

16.-The application and combination of a scraper and presser to a gang of ploughs, for the purposes herein set forth. fied.

17. - The cross-bars $\mathrm{A}^{3} \mathrm{~A}^{4}$, for the purpose herein speci-

18.-The construction of an axle, so that the wheels can be moved further apart or nearer together, to suit the widths of rows, as above specified.

19,-In combination with a gang of ploughs, the digging wheel $\mathrm{K}$.

20.- The digging wheel, in combination with the arrangement for raising and lowering it, as set forth.

21. - The three-toothed harrow $G$, or its equivalent, as and for the purpose set forth.

22.-Making the shares and coulter in one piece, as and for the purposes above specified.

23. - The application and combination of a canopy to a gang of ploughs or harvesting machines, for the purposes above specified.

24.--The manner of making canopies with an expansive cord, as and for the purpose above specified.

25.-The tube on which the main wheels revolve, for the purposes herein specified.

26. - The curved plough standards and the springs, for the purpose above specified.

27. - The constructing of a plough so that in raking a root or stone it will be thrown out and forced immediately back, as above specified.

28.- The nest of cups in the cylinder, for the purpose herein set forth.

29.-The combination, as seen in Figs. I and 2, for the purpose of planting or sowing, as above specified.

30.-The application and combination of the cross-bar $\mathrm{H}^{\prime}$ with the tongue 11 , Fig. 3 , for the purposes herein set forth.

3I.- The combination, as seen in Figs. 4 and 5, and the particular shape of the third plough with the incline for raising up the soil before turning over, as above set forth.

32.-The mole plough, in combination with the beams seen in Fig $\mathbf{I 5}$, wheel-raising apparatus, quadruple trees and their arrangement, for the purpose herein specified.

33.- The opening of the mould at different depths, and taking off the front monlds and using their standarls only, and using them all at once or separately, as above set forth.

34.-The application and combination, as seen in Fig. 8, with its modifications, for the purposes herein set forth.

35.-The application and combination, as seen in Figs. Io and $\mathbf{x}$, of the gangs of ploughs, and the tines in the cen tre, or before or behind the ploughs, as above set forth.

36. - The stubble lowerer $Q$, and the arrangement herein set forth, for opening a deep furrow and turning the stubble into it, and the arrangement and combination of the ploughs, as seen in Fig. 12, or their equivalent, as set forth.

37.- The arrangement and combination, as seen in Fig. 13, for covering the caves, as set forth.

38.-The single-hinged arm, for the purpose herein set forth.

30. - The arrangement for ditching, as set foith, and under-draining by the nould plough, as set forth.

No. 8 ז, 108 . - JACOB REICHARD, F.ivetteville, PA. - Cultizators.-August I8, IS68.

Claim.-An improved caltivator, arranged, constructed, and operating substantially in the manner as shown and described, and for the purpose set forth.

No. 81,660.-ALEXANDER MCCREIGHT, TRANQUility, OHIO.-Corn Ploughs.-Siptember 1, 1868.

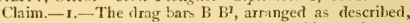
when operated by means of a fixed and movable attachment, substantially in the manner set forth.

2.-Operating drag bars by means of levers having movable fulcrum, substantially as described.

3.- The drag bars $\mathrm{B} \mathrm{B}^{1}$, as described, as in combination with Jevers $D$ and cross bar $C$, substantially as and for the purpose set forth.

No. 82,060.-A. H. ALLISOON, CHARlot TESville, IND. - Cultivators.-Siptember 15, 1868.

Claim.-I.- The yoke $C$, secured to the under side of the tongue, and provided with the adjusting blocks $g .5$, in in combination with the beams $G G$, uprights $f f$, provided with adjuting holes, dnuble tree $c$, arms $c^{\prime} c^{\prime}$, and braces, connecting the ends of the yoke with the main frame, all constructed, arranged, and operated in the manner and for the purpose set forth.

2. - The beams $G \mathrm{G}$, hinged to the adjusting blocks $\xi \xi$, and provided with the shanks $i$ i and braces $h h$, in combination with the bails J J and foot pieces Z Z, all constructed, arranged, and operated as set forth.

No, 82,191- T. A. WOOINWARD, S. S. WOODWARD, and THOM AS MASON, SANDWICH, ILL.-Cultizators.September 15, 1868 .

Claim. - I. - The revenible axle joints $H \mathbf{H}$, pivoted to the frame A B, and arranged to balance the same, substantially as set forth.

2.-The combination of the ahove-described axle joints with the frame A B and folling seat $L$, as and for the purpose berein decribed.

3.--The handles 1 ) D, pivoted to the standards E E, and made adjustable to or from each other by means of the slotted plates F F and set screws I I, as described and shown.

No. 3.541.-T. A. WOODIVARD, S. S. WOODWVARD, and THOMAS MASON, SANDWICH, It..-Cultivators.September 15, 1868.-S2,191.-Reissued 7uly 6, IS69.

Claim.-1.-Broadly, the reversible arms $\mathbf{K}$, hinged to to the frame A B, and arranged to balance the same, snbstantially as set forth.

2.- The combination of the above-described reversible arms $K$, with the frame $A B$ and folding seat $L$, as and for the purpose herein described.

3.- The handles D D, pivoted to the standards E E, and made adjustable to or from each other, by means of the slotted plates F F and set screws I I, as described and shown.

No, 82,406,-ARCHABALD T. HEFLIN, MoNsoutur, ILL.-Cultivators.-September 22, I 868.

Claim.-1.-A two-wheeled elevated draft frame, with a draft pole, $C$, secured upon the cross beam $B^{\prime}$ of said frame $A$, swivelling double-tree $C^{\prime}$, applied to the draft pole, and connected to links $b b$, in combination with levers $c$ and scraper-carrying beams D D, all combined, arranged, and operating substantially as described.

2.-The attaching hooks J J, applied to links $b$, which are connected to the double-trees $C^{\prime \prime}$ and to levers $c c$, said 


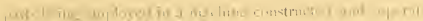

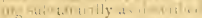

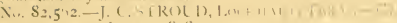

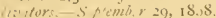

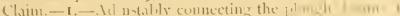

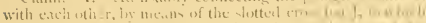

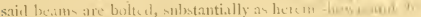
ecrib at ant in the jurpore set forth.

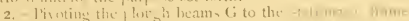

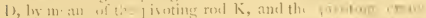

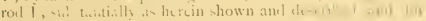

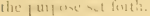

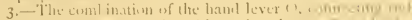

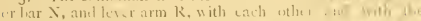

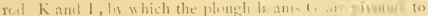

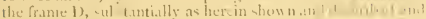

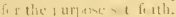

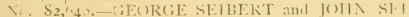

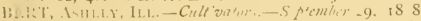

Clai 1- - line comlination of the frame, the whects,

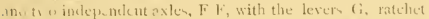

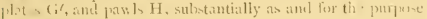
at forth.

2. - The combination of the chiver's seat $\mathrm{k}$, braces 1 , aml unt rior lecams (") ("), so arram exi thit the latter may lo unes cel lat rally hy tixe action of the alri:-1; substantially in the maner set forth.

3.- The wml inati of of ihe past lant aforegail with the

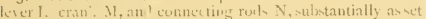
inth.

4.- The combintion of the frame $B$, the oncillating l, toma (") ("), arl fiction rolle: 1), arranged to operate sul $\rightarrow$ tanti. Ily as cherriled.

5-The comlination of the connecting reh $\mathrm{N} \mathrm{N}$, the $\mathrm{x}$ cilliting loam $\mathrm{C}^{\prime \prime} \mathrm{C}^{\prime \prime}$, and the eye bolts $\mathrm{N}^{\prime}$, for reculating

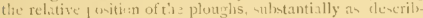
ed.

6.-Tl e arranrement of the tongue $\mathrm{A}$, lince rod . $\left.\right|^{1}$, ard tud screw $A^{2}$, substantially as and for the purpore set finth.

No, 82.938.-B. F. GUY and ]. V. (FUY, M Mome, I1 L. - Cullivaro-Plo, his-Oclo h, i $3,18.8$.

(laim. - r. - In c smlination with plesgh thu hung in a fiame, the sping bars and comecting chains or corde, at and fin the purpose set forth.

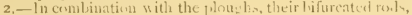

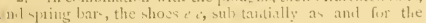
purpuse deacrilient.

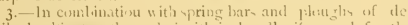

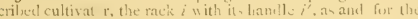
purpase ste suiber.

4-The cultiwat ir lough, when constructed of the creral

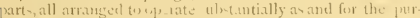
inse $t$ foull.

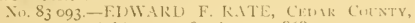

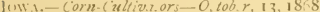

Claim,-The levers $A$ and $J$, roller $F$, and regnlating har [), when con tracted and arranged substantially as and for the purposes hurcin y ecilied.

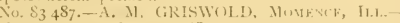
Cultivators.-Oitober $27,1 \times 68$

Claim.-1.- The tuck D, the slides I', one or l oth, when arranged with rel tion to the rod b and leam. L, aud tu ap. erate as and for the purp ones set fouth.

2.- The cxtra shovel $A$, when arranged upon the leams $\mathrm{f}$, ulstuntially as d-scrilued and set forth.

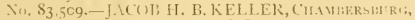
l's -Cultion zlo.3-Cotiber 27, 1868.

('aim,-1.-The pisoted stamblare (i, arranesed in con mection with the roils ?, India-ruble r yring I, and hoan. E, all arrauged in the manner sulstantially an and for the purj we s t forti

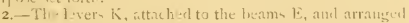
in relation with the elriver's seat 1), - nl tanti I?, 3 . 31 il for the purpose specified.

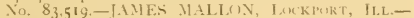

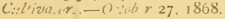

(laim.-1. The hamdles E, brace () in coml ination with

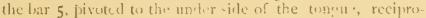

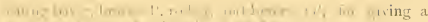

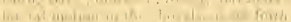

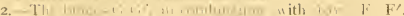

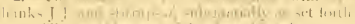

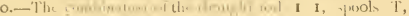

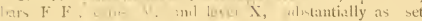
lirth.

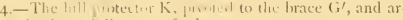

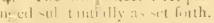

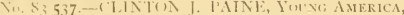
-i d limelf aH IIENTRl CRESWELL, WAREEN 1.1-C.rn-Plow - Oitolier 27, 1868 .

1. in -1.- The enroel draught lar B, runnine from in-ile of the eentre of the sheels forward and 11. $n: 1.1$, whetantially as and for the purposes herein set $\ln (1$,

- The arangement of the cursed plough beams F F, mar I. I th the curved trausht lar $\mathrm{B}$, as and for the purI wim a firth.

s. - The lar E, ruming from the outside of the centre of the 1 . in , l-, and across the top, as and for the purposes hereiin teit li.till

4. He comlination of the forked ents a $a$ of the 14. him , f.... lines, sulstantially as and for the purposes herein 11 it

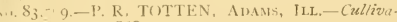
$-\left(0,1 t_{c}^{\prime}, 27,1858\right.$

Clam,-1.- The bow-shaped lever $\mathrm{K}$, in connection with 1! lie wil. I, comblined and arranged sulstantially an and fin the jur re speciliet?

2.- The connecting of the lenms $f ;(i$ of the inner ploughs

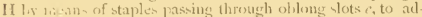
mit if the l.teral mosement of siil flerighs, substantially as et forth.

Nu. 83.675.-STERIING(:. TIIT)RNTON, MLCOMK,

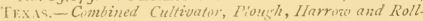
$r-$ Vivimbir 1,1858

Chim,-r-The combination and arrangement of the fixed frame $($, movalble frame $\mathrm{E}$, parallel ruler joints $d d d d$, lever $(\vec{j}$, rod $s$ rack $H$, and pring catch fever $g$, the whole leing contructed to operate in the manner and for the purfuncis at forth.

2. The joint plates $d d$, when comstructerl in the tri. ansular slape describul and sloswn, and provided with molch or in the ir under vlace, and thed in connection with the fin $\tau^{-1}$, and eries of hole $v^{2} v^{2} v^{2}$ in the fixed frame, for th: furpace of arlju-ting the depth to which the plotighe, dic., $\operatorname{can}$ wor:

3.- The ivot $a$, in comlination with the lugs $a^{1} a^{2}$ and livitis and $e^{\prime}$. pasing through the rear end of the rraught whe, the wh whe leing comstructul to operate in the manner unul in the larjore specifict.

4.- The the of the stanilarls L L, in comlination with the - prings / / and midtlle heams J I, for the purpose and operatinur in the manner described,

5,-The rocking frame $\mathrm{M}$, when pixoted to the drag i ar or arm $\mathrm{R}$ R, as described, and provithd with the lever $s$ and aljuting bar $r^{2}$, loy which the whole frame can be raisctur depremed at pleasure, in combination wigh the Haning desice $u$, when made to operate subtantially as de retiled.

6. - The descrilied methot of attacling the tooth or fluturh $K$ to the frame of the machine, numely, the employ. ment of a bifurcated -tandard, su comstructed as to brace the truch laterally; and, if necessary, provided also with braces (1) brace it longituclinally $w$ ith the machine, sulutantfally as liwwn and specified.

No. 83.83S.-SAMLEL DAY, DELEVAN, T1.L.-Cultiva: r. $-N$ v. mber 10, 1 S68.

Claim.- In a con cultivizur the morle of guilding the machine and shovel ly mean of the crank $D$ and connections, with the lever 0 , an and for the purpores above deeril eel.

Nis, 83,94.-WIV. H, EDWARDS, MU1.1NE, ILL.Joiuts and Couplings for Cultizators. . Vowember 10 , IS6S.

('inim.-1.-The joint and coupling for cultivator, consiving of the side plates $\mathrm{G}$, the clasping plates $g$, and verti- 
cal rod $H$, all constructed and arranged substantially as herein described, and for the purpose set forth.

2.- The method of connecting the vertical rod $H$ to the frame of the cultivator, by means of the eye bolt 1 and plate $\mathrm{I}$, or their equivalents, substantially as herein described, for vertically and laterally adjusting the shovel beams, as set forth.

No. 84,029.-JOSEPH VOWELS, Milford, MiCH.Cultizators. - Vore'mler 10, 1868 .

Claim.-I,- The mould-board 1, constructed substantially as shown and deseribed.

2.- The combination of the mould-b ard $\mathbf{L}$ with a cultivator.

3-- The construction of the wedge $\mathbf{N}$, and its arrangement with reference to the tongue of a eultivator, or for any equivalent purpose, substantially as shown and deseribed.

4.- The arrangement of the hangers $\mathrm{H} \mathrm{H}$ wilh their teeth $\mathrm{M}$ M, with reference to the wheels of the machine, substantially as shown and described.

5.-The arrangement of the sub-tongue $F$, frame $E$, sector $\mathrm{D}$, lever $\mathrm{C}$, hangers $\mathrm{II}$ and $\mathbf{K}$, and braces 1 , subrtantially as thown and described.

No, $84,184 .-A B R . M$ A. HAR ION, OLNEY, II.I.Cultizaiors. - lotember 17, I868

Claim.-I. - The ploughs $\mathrm{H} \mathrm{H}$, attached by clevines to the front bar of the diagonally-braced open frame A B D E $\mathrm{F}$, and connected by a cross-bar 1, which admits their adjustment as to relative distance, and causes them to swing by a parallel motiun as they are deflected laterally, subitantially as described.

2.- In combination with the said ploughs, thus atcached and connected, the sliding foot bar $\mathrm{K}$, arranged as described, and adapted to hold them in elevated position, for the pur. poses described.

No. 84.413,-WM. F. COUT,TER. G. F. TRABUE, and $\mathrm{W}$. A. LOIVERY, HARDINSBERG, IND,-Cultizaters. - Novimber 24, I 868 .

Claim.-I. - The V-shaped brace pendants S S, adjust. able beams $G G$, stiff pendants $H 11$, and staple guides $p p$. arranged together in a cultivator, substontially as herein deseribed.

2.-The hooked spring goose necks $\mathrm{F}$, applied to axle $\mathrm{B}$, and adapted to serve for holding up the shovel-carrying beams out of action, substantially as described.

No. 84,149.-SETH WAY, LA PuRTE, IND.-Cultizators.- Non'tiombir 24, I868.

Claim.-I.- The swivelling joint 28, secured to the tongue of the carriage, sulstantially as and for the purpose described.

2.-The construction of the lever $\mathbf{1}$, and its combination with the plough beams, subutantially as shown and de. seribed.

3 - The arrangement of the tirrups 4 , with reference to the two diverning portions of the plough heams, substantially as and for the purpose descrilied.

4. The socket 3, and its combination with the axle 7 and tongue A, substantially as shown and described.

No. S $_{4} 575 .-\mathrm{S}$. G. PEABODV, ChAMPAIGN, 1LL.Cultivators.-December 1, IS6S.

Claim.--1.- An arrangement of mechanism by means of which the direction of the wheels $\mathrm{F}$ may be changed by the lateral movement of the plough beams $H$, substantially as herein shown and described, and for tbe purpose set forth.

2.-The combination of the bushes or tubes $C$, swivelled shaft or axle E, gcar wheels or segments of gear wheels $K$, and swiveled shart $G$, with each other, and with the wheel $F$, cross-bar $B$, and plough beams $H$, substantially as herein shown and described, and for the purpose set forth.

No. 84,583 - A. B SPIES, SiTERI.ING, It.I., assignor to JUHN K. JoURNEV, same place.-Cultizators. -Dccen bir. I, 1858 .

Claim.-1.-Connecting the frame $\mathrm{E}$ to the axle $\mathrm{A}$ by means of the roller $\mathrm{I}$, link $\mathrm{H}$, yoke $\mathrm{J}$, and clevis $e$, all arranged as and for the purpose set forth.

2,- The lever $K$. applied to the frame $\mathrm{E}$ and axle $\Lambda$, in the manner substantially as and for the purpose set forth.

3.- The curved bar $\mathrm{L}$, attached to the axle $\mathrm{A}$, swivel pulley $\mathrm{M}$, clevis $e$, rope or chain $\mathrm{N}$, and bar $\mathrm{O}$, all combined and arranged to operate in the manner substantially as and for the purpose set forth.

No. $84,611-1 S A A C$ H. CHAPPELL and JAMES MONTGOMERY, DECATUR, ILL.Cultivators.-Decembes $\mathbf{1}, \mathbf{1} 868$.

Claim.-1.-A cultivator, the draught pole and plough frame of which are pivoted on the seat har, substantially as and for the purpose set forth.

2.- The attachment of the draught pole to the seat bar hy means of the pin $a$ pivoted in slot $c$ and nut $d$, substantially as and for the purposes set forth.

No. 84,649.-ROGER SANDIF()RD, JOLIE'T, JLL.Cultizators. - Dicember 1, 1868 .

Claim.-1.-The segmental oscillating coupling-clevis, shown in Figs. 1 and 2 , consinting of the parts $a d n$, and the part $o$, shown in Fis. 3 , when applied to a cultivator in the manner and for the purposes set forth.

2,- The metal cross piece $A$, in combination with the post or frame $c$ and supporting arms B B, constructed and arranged in the manner described.

No. $84,763,-W$. C. RHINEHART and ROBERT GASTON, Oskaboosa, Iowa-Corn Ploushs. - Derember $8,18.38$.

Claim.- The inclined fenders $b \quad b$, for protecting the reins of the driver from the action of the wheels, in combination with the inclined frame B, substantially as set forth.

No 84.776.-GARL.AND B. ST. JOHN, BROOKLYN, Mich.-Cultivators.-Dicember 8,1868

Claim, - The securing of the standard $\mathrm{G}$ between the two heams $\mathrm{C} C$, by means of the bolt $m$, arms $n n$, and braces $11 \mathrm{H}$, all arranged subutantially as and for the purpose set forth.

No, 84.910 -TOHN SECHEIIBIEIN and JOHN HEITZMAN, PHiLADELIHIA, PA.-Hand-Culdizitors.Derember 15, I 868 .

Claim - I- The coulters $i$, floughs $f$, and transverse plate $\mathbf{E}$, when combined and arranged as shown and de scribed.

2.-The frame A. stilts $B$, transverse plate $C$, standards D I), pin $c$, wheels $C$, elearer $F$, coulters $c$, and the ploughs $f$, when combined and arranged as shown and described.

No. 84.43I-CIARK AIVORD, WESTFORI), WIS,Cultiators,Decembor i 5, 1868

Claim.-1.-Clamping the teeth to the side of the drag bars by means of the independent plate $\theta$, and the two screw loolts, when the several parts are constructed and arranged to operate in the manner described.

2.-The arrangement of the slotted cross bar J, drag bar: $[1$, headed bolts $b$, fixed to the drag bars and extending through the slots of the beam $J$, and springs $i j$, substantially as shown and described.

3.-The employment of cleaning bars $r r$, arranged in relation to the teeth, substontially as described, an ${ }^{r}$ operating to clean the teeth, when the latter are raised o when the bars are depressed, as herein set forth.

4.-The combination of the cleaning bars $r r$, beam $\mathrm{N}$, spring $s$, and hinge $n$, when employed on a cultuvator, for the purpose specified.

5. - The combination of the frame $C$, rocking with the axle, as described, with the draught pole E. pivoted to the front beam of the frame, the plough beams I I, the cleaning bars $r r$, and the springs $s$, substantially as and for the purposes herein described.

6. - In combination with the rocking beams $\mathrm{F}$ and $\mathrm{N}$, cleaning barn $r r$, and drag beams I I, the hasp $h$ and staple $h^{\prime}$, arranged, as described, on the two beams, and operating in the manner and for the purposes herein described.

No, 84.935.-JOSEPH H. BRINTON, THORNBURG Township, PA.-Cultivators,-December I 5, 1868.

Claim.-I.-A transverse adjusting bar moving in inclined slots, or their equivalents, for the purpose shown.

2.-A yielding pressure applied to the arms or levers $a$, together with a transverse bar moving in inclines, whereby 
(1) regulate the depth the plough in enter the soil, and to it commodate them to any unerenes of the grounel.

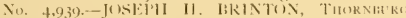

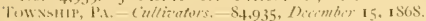
- Reissued funt I1, 1872 .

Claim,-1.-A transwerse adjusting bar, moving in inclined slots, or their equivalent, for the purpone shown.

2.-1 I ieldidg preseure applied to the arms or levers $a$, together 1 ith a transverse bar, moving in inclines, wherelyy to regulate the depth the ploughs enter the soil, and to accommodate them to any unevemness of the ground.

3.- The hollow or $[$-haped shank $x$, provided with suitable apertures for pivot and break-pin, for the purpone set forth.

4.-The hollow or L-shaped shank $x$, pivoted to the plough beams g, substantially as describerl.

5. - The hollow or 4 -shaped shank $x$, provided with the break-pin ze, as shown and described.

6.-The hollow or I-shaped shank $x$, pisoted to the plough-beam 5 , and provided with the lreak-pin $\pi$, as shown and described.

7.-The plough $c$, consisting of the hare s and hollow on [-4haped shank $x$, provided with the break-jin $\pi$, and pis oted to the plough-bean g, substantially as shown and described.

No, 55,001 -GEORGE Y. DWIGHT, ORFioN, IL..-

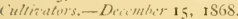

Claim.-1.--The combination of the body platform C, with the draft bar $\mathrm{D}$, the tongue $\mathrm{F}$, and the guiding lever $\mathrm{F}$, in such a manner that, when the said body platform is combined with the bent asle $A$, the said draft bar will lie in the proper relative position for the combination therewith of the parallel beams $(i, i$, and the notchet arch platen $k k$, all sub-tantially in the mamer and for the purpose herein set forth.

2. When the parallel beams $G$; ; are combined with the draft bar $\mathrm{D}$, substantially in the manner herein set forth, the combination therewith of the cultivating yoints $i \quad i$, the notched arch plates $k k$, and the spring catches $l l$, substantially in the manner berein set forth.

No. 85,005.-JAMES HINDS and MAMES (IEE, CUN1LOGUE, It i..-Cultizators.-Derembi' 22, 1868 ,

Claim.-1. - The arrangement of the befts I) $1 \%$, pulleys

F E', and lever $(i$, substantially as and for the purpose specifierl.

2.- The combination, with plough-supporting arms $\mathbf{I}$, pivoted to the beams $\mathrm{A}$, of the adjustable supporting arms $x$, when provided with a loop which slides upon the arms $\mathrm{L}$, substantially as and for the purpose clescribed.

No. 85.189.-DUDLEY W. TRAVIS, ENKIELD, N. Y - Corn Cultizators.-Diembr 22, IS6S.

Claim.-The herein described mode of adjusting the ploughs and hoes, in combination with the pouts or stand. ards $\mathrm{Il}$ and $\mathrm{I}$, bars $\mathrm{F} \mathrm{G}$, and frames $\mathrm{I}$, when the whole is constructed and arranged substantially in the manner shown and described, and for the purpose set forth.

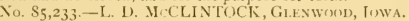
-Culticators.-Dicimbor 22, I868.

Clim.-The combination of the double plows $a$ a handles $d d$, shovels $c ;$ frame $A$, wheel $(C$, lent axles $B$, lass D D, lever $g$, chains $c$, bars $m$, and rent $\mathrm{F}$, all constructed and used subitantially as herein specified.

No, 85,471.-IRA A. P.ALMER, MoNiotTI1, ILI. Cultivators.-Dicimlier 29, 1868

Claim.-1.-The shovel $d$, constructed as descrilied, and for the purpore set forth.

2. - The slotted beam plates $\mathrm{L}$ and $\mathrm{It}$, one of them being c.ooked, and bolt $\mathrm{P}$ and spindle $\mathrm{T}$, arranged sulistantially as described and for the purpose set forth.

3.- The arrangement of doubletree $\mathrm{C}$, bar $\mathrm{W}$, with holes $c e$, and hook $\mathrm{V}$, combined with the frame $\Lambda, E, F$, and tongue $\mathrm{B}$, subst intially as described and for the jurpose set forth.

No. 85.488,-WILIJA.V I. STEW.IRT, RY SHVH.LE, Ixis.-Cultiator:-Dirimber 29, IS6S.

Claim.-1.-The construction and arrangement of the axle $\mathrm{B}$, by which means the front ends of the pluagh or shovel beams are raiset or lowered for the purpose of contrulling the depth to which the aho:els shall enter the earth.
2.-The within-described construction of the coulters II II, for the purpore sut forth.

3.- The arranument of the coulters with reference to the hovek of the cultivator, that is to say, with vertical and longitudinal adjustment with reference thereto, sulstantially as shown and describerl.

No, S5,662,-R. II. IIENRV, MoNMorr, II.L. - Cultimaturs. - Fanum 5,1869 .

Claim.-The adjustable plates $\mathrm{P}$, beam plate $\mathrm{W}$, and guard $\mathrm{X}$, constructed and arranged subitantially as decribed, and combinerl with the frame A, B, C, D, axles T $I I^{*}, \operatorname{armis} \mathrm{F}$, rods $\mathrm{H}$, and lever $\mathrm{J} \mathrm{L}$, substantially as and for the purnose described.

No. 85,675 - GEORGE IT. KRING: FAIRBURY, ILL.Cullieators.- Januarry 5, 1869.

Claim.- I cultivator, having lifting lever $\mathrm{P}$, elbow-lever $s$, and rods $\tau^{\prime}$ and $\ell$, when constructed and operating substantially as herein specified.

No. 85.736 . - ISAIAII B. GIILBERT, Lewisville, 1No-Cultizators-Finumry 12, 1860.

Claim.-1.- The trimverse shaft $I$ and rod $I^{\prime}$, in combination with the arm $K$ and levers $O$, for raising the shovel carriers separately or collectively, subatantially as described.

2.- The combination of the beams I. L', plates M, pivots $m m^{2}$, lugs $m^{1}$. shaft $\mathrm{I}$, arm $\mathrm{K}$, rod $\mathrm{V}$, levers $\mathrm{O}$, pivoted tongue $P$, and lever $Q$, substantially as described, for the purpose specified.

No. 85.812 . - IOHN G. B. G!LL, Chester Court Hows, S. C.-Cibltiaters.- Fanuary 12, 1 S60.

Claim,-1-The combination of the steel guard-plate F and the wonden friction blocks $(\mathrm{r}$, with the bar $\mathrm{E}$, swing har $C$. frame $A$, and beams B, sulostantially as described, for the purpose specified.

No. 86.003.- J. H. COL.EMAN, Columbia, M^.-Cultizators - Famary 19, 1860.

Clain.-1-The arrangrement of the curved coulters it upon the standards $F$ and the front sicle of the shares $G$, as herein show $n$ and described.

2.-The described arrangement of the hinged plongh ex tending above the axle, the beams $\mathrm{E}$, the treadle I, cords $h$, and standard $i x$, wherelyy the ploughs are held down by the pressure of the driver's feet upon the extended beams, and raised simultaneously above the ground by the same pressure applied to the treadle $\mathrm{Ix}$, as herein shown and described.

No. S6.160.-JACOB HUFF, Young AMErica, ILL. Cultizaturs.-Jamuary $26,1860$.

Claim,- The combination of the axle $\mathrm{A}$ with support B the slide $\varsigma$, braces $C$, and tongue $\mathbf{E}$, sulistantially as descriled, and for the purpose set forth.

No. S6,170-THOMAS JACKSON MARTIN, WI1LOW HiLL, JLi..-Cultizators.-January 25, 1860.

Claim,-1.- The arrangement of the plough $\mathrm{F}$ and crank har $\mathrm{H}$, treadle $\mathrm{O}$, armed rock-bar J, arms $1 \mathrm{~L}$, and treadle $K$, in the manner as set forth.

2.-In comlination with the rock-bar $J$ and arms I L the perforaterl bar M and arm N, substantially as described and represented.

3.- The arrangement of the beam $\mathrm{F}$, rock-har $\mathrm{J}$, and plough-standard E, subtantially as described.

No, 86,262.-CARMI WEI.LS, S.INDWICH, ILL. - C vinators.-Janzeari 26, 1860.

Claim,-1.-The combination of the clevises D D, T lever $\mathrm{C}$, axle-beam $\mathrm{A}$, shovel-beams $\mathrm{G} \mathrm{G}_{\mathrm{i}}$, standards $\mathrm{M}$, and shovels $\mathrm{K}$, as and for the purpose herein specified.

2-The combination of the clevises D D, T-lever C, rod $\mathrm{U}$, chains $\mathrm{V} V$, shenve-blocks $\mathrm{T}$, bars $\mathrm{E}^{\prime} \mathrm{E}^{\prime}$, and stirrups $S$, as herein set forth.

3.-The combination of the beams $\mathrm{G}$ G, standards $\mathrm{M}$, levers $P \mathrm{P}$, loop $m$, axle-beam $\mathrm{A}$, and rod $\mathrm{O}$, arrangert to adjust the shovels $K$ in the ground, substantially as set forth.

4.- The combination of the plates $J$, bearings $\mathbf{L}$, and shovels $\mathrm{K}$, the latter arranged to turn on the pivots $a^{\prime}$, as set forth.

No. 86,329.-JOHN C. TOBIAS and WILLIAM N. BATES, EL PASr, I1.L.-Cultizators.-Jamuary 26, 1 S66. Claim.-1.-The slotted bars A and C, constructed as 
described, and with the axle $D$ fastened to one, and the wheel $\mathrm{B}$ attached to the other, for the purpose of raising or lowering the axle, and with it the plow-beams, substantially as and for the purposes herein set forth.

2.-The arrangement of the axle $\mathrm{I}$, tongue $\mathrm{F}$, whifiletree 1 , and bars $K K$, in combination with the rods $c^{\prime} i$ and slotted bloeks E E, for the purpose of having the draught direct on the plou th beam, substantially as herein set forth and described.

No. 86.905-MART1N CAYWOOI) and JOHN CAYW() )D, PEORIA Co., ILL.-Ciltiz'ators.-February I6, 1869 .

Claim.-I.-Benms $n n$, slotted bars $b l b b$, lrace posts $y y$, gange blocks $l l$, slotted guides $m m$, foot levers 00 , and swivel clevises $c c$, all constructed and operated substantially in the manner and for the purpose as hercin set forth.

2.-Beam gauge blocks $k k$, gils $d d$, brace post $j j$, and beams $i$, , in combination with the cranks $b$, and crank boxes $f$, cross bar $a$, lever $g$, and hook $/ 4$, all when constructed, and arranged, and operated in the muner and for the purpose as herein set forth.

3.- Providing the shovel with a draught gauge $\%$, and combining therewith a shifting bluck $u$, for adjusting the shovel, substantially as set forth

No. 87,019.-13. F. YOUNG, Tomon, 1LL-Cultizators-Fibruary 16, I869.

Claim.-1.-Connecting the inner plough standards $K$ to the rear cross-bar $G$ of the pivoted frame $\mathbf{E} F(i$, by the adjustable slotted plates $k^{1}$, and pirot plates or pivot $k^{2}$, substantially as herein shown and described, and for the purpose set forth

2.- The adjustable jointed and slotted shoes $\mathrm{U}$, to which the ploughs are attached, in combination with the plough standards, substantially as herein shown and described, and for the purpose set forth.

No. \$7,151.-WILL1AM DAY, MURRistown, N. J.Cultitiators.-February 23, 1860.

Claim.-The cross head F F, for holding the cultivating tools, when arranged adjustably on and removable from the longitudinal bars B B, substantially as and for the purpose herein shown and described.

No. 87,296.-RICHARD B. ROBBINS, ADRIAN, Mich.-Corn Cultivators.-February 23, 1860.

Claim.- I. - The frames $\mathrm{H} \mathrm{E} \mathrm{I} \mathrm{K} \mathrm{L} \mathrm{and} \mathrm{II}^{\prime} \mathrm{E}^{\prime} \mathrm{I}^{\prime} \mathrm{K}^{\prime} \mathrm{I}^{\prime}$, in combination with their respective links $a$ and $b$, and $a^{\prime}$ and $l^{\prime}$, for the purposes of raising and lowering the teeth, substantially as set forth and described.

2.-The combination of the rods, $r$ and $r^{1}$ with the rames $H E I K I$, and $H^{\prime} E^{\prime} I^{\prime} K^{\prime} L^{\prime}$, or their equivalents, substantially as set forth and dencribed.

3.- The levers $R$ and $R^{\prime}$, in combination with their respective frames $\mathrm{HE} I \mathrm{KL}$ and $\mathrm{II}^{\prime} \mathrm{E}^{\prime} \mathrm{I}^{\prime} \mathrm{K}^{\prime} \mathrm{I}^{\prime}$, substantially as pescribed.

4.- The chains $\mathrm{C} \mathrm{C}^{\prime}$, or their equivalents, for the uses and purposes herein described.

No. 87,192.-GEORGE J. HAYES, IONIA, NICHCultivators. Warch 2, 1869 .

Claim.-I.-The combination of the tongue, axle frame, and cultivator frame when united to each other and the cultivator frame is capable of being raised upward, and swung slightly backward, by a lever and its appliances, operating as herein described and represented.

2.-In combination with a cultivator frame, that is moved backward as it is raised upward, as herein described, a drag, or harrow, attiched thereto, and moving therewith, but capable of being raised or lowered independently of the cultivator, sulsstantially as and for the purpose described.

No. 87,627.--HOR.ACE C. BRI(iG.S, WEST AUBUR,

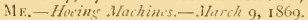

Claim,-1.-The combination of the axle $O$ and wheels $E^{\prime}$ with the frame A B C D E F of the cultivatur, subutantially as herein shown an I described, and for the purpose set forth.

2.- The combination of the arms and supports $Q$, levers $\mathrm{R} r^{\prime}$, and chains $S$, with the axle () and rumners $\mathrm{D}$, sulsstantially as herein shown and described, and for the purpose set forth.
3.- The combination of the foot lever Z, pivoted toothed plate $\mathrm{J}$, toothed har $\mathrm{T}$, arms $\mathrm{V}$, standards $\mathrm{W}$, and ploughs, or hoes $\mathrm{X}$, witl each other, and with the forward cross-bar A of the cultivator frame, subst.ıntially as herein shown and described, and for the purpose set forth.

4.-Forming the standards WV with two separnte and distinct seats, for the plonghs, or hoes, sulsstantially as herein shown and described, and for the purpose set forth.

5.- The draught bar $\mathrm{N}$, constructed in three parts, and operating in conection with the tongue $\mathrm{K}$ and drauht irons $H$, substantially as herein shown and deseribed, and for the purpose set forih.

6.- The combination of the roller $\mathrm{I}^{\prime}$ and detachable arms $A^{\prime}$ with the rear cross bars $B$ and runner $D$ of the cultivator frame, substantially as herein shown and described, and for the purpose set forth.

7.-The combination of the adjustable wedge block I with the forward cruss-bar $\mathrm{A}$ and inclined rear end of the tomule, substantially as herein shown and described, and for the purpose set forth.

No. 87,690.-WHLLAM LOHKER, GRAнAм, Mo.Citltiattur Ploushles.-Marih 9, I860.

Claim. - The combination of the axles $A$, frame $C$, arm $H$ ], vertical shafts $I$, plough beams $F$, and $E$, chains $N$, arms or levers $\mathrm{M}$, short shafts $\mathbf{K}$, and levers $\mathrm{L}$, with each other, as herein shown and described, and for the purpose set forth.

No. S7,824.-WIILIAM F. COULTER, GIDEON COULTER, and JOIIN A. I.ANERY, II.ARDINSRTRG, IND, - Whiel-Cultizators.-Dharch 16, 1869.

Claim.-The spring bar $a$ attached to the rear end of the draught bar, in combination with the notch $b$ in the upper slide of the axle, an and for the purpose described.

No, 87,923,-JAMES C. FRENC11, MINMOUTH, ILL. Cultirators.-Warch 16, 1869 .

Claim.-1. - The construction of the joint piece $a$, as and for the purpose described.

2.- In combination with said joint piece, the plough beam $I$ ) and the upright standard $C$, substantially as shown and desscriberl.

3.-The standari $C$, substantially as shown and described.

4 - The combination and arrangrement of the standard C, cross beams $G$, and axles If IB.

5.- The arrangement of the plough-beams I) D, with reference to the joint-piece $a$, by which said heams may lie carried nearer to or further from the wheels of the machine.

No. 88,311.-JAMES R. 1.ITTL1:, GaMeSHURG, 1L1..Cultizators.-Whreh 30,1860 .

Claim.-1.-The journal-spinclle $C$, uprioht $m$, wheelspindle $\mathrm{B}$, flange $\mathrm{L}$, braces $\mathrm{F}, \mathrm{D}$, and $\mathrm{E}$, arran:ed ublastantially as described, and combined with the axle $\mathrm{A}$, hounds $K$, and drau ht-pole $I$, in the manner and for the purpose set forth.

2.- The upper plate $O$, when provided with the elevations $\mathrm{R} g$, and recess $S$, and oper:ting in combination with the lower plate $\mathrm{P}$, beam $\mathrm{N}$, and bolt $\mathrm{O} \mathrm{O}$ and $\mathrm{Y}$, and clampin plates $\mathrm{W}$ Wr, in the manner set forth, so as to secure the adjustments described.

No. 88,353.- CiEORGE IV. ISRESLLER, LATAYETIE, Iows.-Combined Ilarrozes and Cultizators.-Marth 30, 1860 .

Claim.-I. - The standards F K, hung to the cross-bar E, by means of the V-shaped rods II $\mathrm{N}$, substantially as and for the pur o-e herein shown and described.

2.- The slotted plates $\mathbf{M}$, hinged to the ax!e, and connected with the s:andard $\mathbf{K}$, by mean of the pin or screw $\iota$, in the manner de:cribed.

3.- The slotted hars I, hung to the rear of the axle, to operate in the manner and for the purpose herein set forth and shown.

4. - The harrow $\mathrm{O}$, suspended from the pole $\mathrm{C}$ by the rod $P$, and raised and lowered by the lever ( $)$ and rod $h$, in combination with the adjustable standards $k K$, all operating as described, for the purpose specified. 
Vi), $88,638 .-1$ 13. J.11, ARIINiTuX, IL.L,-Cultizators, Ipril 6,1560

Claim. - 1. The arrangement of the inner heams $\mathrm{E}$, loy means of the enlarged eyes - aut pin $a$, in front, and the strap $d$, connecting the outer beams, so that they are capable of vertical adjustment, amli of being rocked literally, as set forth.

2.- The comlination, with the outer beams D and inner beams E, of the strap l, hingel straps $d$, upright bar $f$, and adjustable link s, arranged as described, for the purpose specified.

No. S8,758.-11. J. WITIT.ES, RO(KFoRI), I1.1.-CWTlisuturs. Ipril 6 , is 69

Claim, The construction, arrangement, and combination of the frane $13 \mathrm{~B} 1 \mathrm{H}^{\prime}, \mathrm{J}^{\prime} \mathrm{J}^{\prime} \mathrm{W}^{\prime}$, swinging plough-supports C C $i$, ploughs a $a$, driver's seat $\mathrm{F}$, foot-rests I I, levers Il H, and dratrght devices I $\mathrm{K}: \mathrm{l}, o a^{\prime}$, the whole constructed and operating sulstantially as and for the purpose specified.

No. 88.868.-JUHN R. II.AND, BU.IINGSTIL.E, IND,Cultiators. - Afril 13,1869 .

Claim, - 1.- The provison, in a cultivator, of the slotted side-berams $C^{\prime} C^{\prime}, c c^{\prime}$, adjustable pivots $s s^{\prime}$, swinging arms $S S^{\prime}$, support $\mathrm{T}$, and seat $\mathrm{U}$, for the object explained.

2.- The combination, as herein described, of the crossbeam $\mathrm{E}$, hangers $\mathrm{F}^{\prime} \mathrm{F}^{\prime}$, coupling devices $1 \mathrm{I}^{\prime} k k^{\prime}$, heams $\mathrm{K}$ $K^{\prime}$, standards $L, L^{\prime}$, handles $N^{\prime} N^{\prime}$, har (), and spring $R$, for permitting of the elevation of the shares $/ l^{\prime}$, for the purpose set forth.

3.- The general combination and arrangement of the slotted cross-beam $\mathrm{E} c c^{\prime}$, hangers $\mathrm{F}^{\prime} \mathrm{F}^{\prime}, f f^{\prime}$, screw-threarled tie-rods $G G^{\prime}, g^{\prime}$, , slotted plate, $11 I^{\prime}, h h^{\prime}, I I^{\prime}$, shiftable braces $I J J^{\prime}$, beams $K^{\prime} K^{\prime}, k^{\prime} K^{\prime}$, tandards $L^{\prime} I^{\prime}$, shares $/ l^{\prime}$ $\mathrm{r}$,ds $\mathrm{Ii}$, handles $\mathrm{N} \mathrm{N}^{\prime}$, perforated hars, $\mathrm{O}^{\prime} \mathrm{O}^{\prime}, o o^{\prime}$, and set screws P P', for the purpose of producing an improved adjusiable cultivator.

No, SS,9I5-JAMES B, SEXTON, PELLA, lowA, aSsignor to himself and J. L. AN1)REWS, same place.Culliatators.-4tril 13 , 1 S60.

Claim-I, - The slotted draunt-lors $\mathbf{~ I}$, constructed and operating in connection with the frame I) E, plough-beams $\mathrm{l}$, and draught-rlevice $\mathrm{N} O \mathrm{P}^{2} \mathrm{O}$, sub-tantially as herein shown and described, and for the purpose set forth.

2. - The bars $\mathrm{N}$, having one or more boles formed in them, hooks $Q$, and loops () , in combination with the draught-bars $\mathrm{Ml}$, and doulle-tree $\mathrm{P}$, substantially as herein shown and described, and for the purpose set forth.

No. SS,940,-JAMES ARIISTRONG, JR, ELMIRA, ItL.-Guard-Altachment for Cultizators.-April I 3,1869 .

Claim.-1.-The vertically-movable standard J of the plant-fender, attached to the cross-beam $\mathrm{C}^{\prime}$ by means of a sliding joint formed liy the slot $n$, p ivot-pin $s$, and adjustable bearing pin $t$, sulstantially as descrilied.

2.- The vertically self-adjustable fender-tandard J, pivoted to the shovel-carrying frame of a cultivator, and connected to laterally-vitrating shovel-standards, L. L, substantially as described.

3.- The slotted extension $k$ on the rear end of a plantfender, $K$, which is connecled by rod $K^{-1}$ to the shovelcarrying frame, in combination with she lower extension $k^{\prime}$ of the standard J, passed loosely through said extension $k$, and adapted for allowing the fender to rise and descend, but keeping it in place centrally between the laterally-mov. able shovel-standards L L, subatantially as described.

4.- The laterally vibrating and laterally ad ustable stand ards L L, in combination with the centrally arranged fender carrying standard $\mathrm{J}$, the extensible brace $\mathrm{P} \mathrm{P}^{\prime}$, and the adjustable connecling rod $\mathrm{R}$, substantially as and for the purpose descrilsed.

5.-A plant-fender $K$, altaclied to a cultivator-frame by means of a front laterally and vertically vibrating suspension rod $\mathrm{K}^{\prime}$, and a rear laterally and vertically vibrating connection, in such manner that while the fenter will swing laterally with the shovels $L^{\prime} L^{\prime}$, it at the same time allowed to rise freely over olstructions in its path, substantialiy as descrilsed.

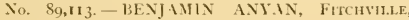
Онго.-Combined Cultivaturs and Planters.-Afril 20 , I 869 .
Claim,-I.-The combination of the statinnary cross-bar (1), foot-lever $S$, and curds or chains $k$, with the central leam $\mathrm{K}$ and movalle side heams $\cap$ of the cultivator, sub. stantially as herein shown and described, and for the purpose set forth.

2. - The combination of the piveted lock-lever $\mathrm{U}$ with the central beam $K$ and movable side beams $O$ of a cultiva tor, substantially as herein shown and described, and for the purirose set forth.

3. - The combination of the cross bar $\mathbf{L}^{\wedge}$ lever $\mathbf{. 1}$ ', cross bar $N^{\prime}$, and guards $\mathrm{P}^{\prime}$, with the spouts $\mathrm{I}^{\prime}$, ploughs $\mathrm{J}^{\prime}$, slide $\mathrm{H}^{\prime}$, hopper $\mathrm{G}^{\prime}$, beam or frame $\mathrm{F}^{\prime}$ and beams, $\mathrm{K}$, substantially is herein shown and describerl, and for the purpose set forth.

4.- The combination of the cross bar V, chains W, cross bar $\mathrm{X}$, lever $\mathrm{Y}^{\top}$, rack bar $\mathrm{A}^{\prime}$, and seat hoard $\mathrm{B}$, with the beams $K$ and forward part of the running gear of a wagon, substantially as herein shown and described, and for the purpose set forth.

5.- The combination of the lrace bars $\mathrm{E}^{\prime}$ with the forward part of the tongue $(i$, substantially as and for the purpose herein set forth and described.

No. \$7,729.- SOLYMAN BELL and GEORGE W. BRONAON, I.A SALLE, CO., JLL.-Corn-Cultivators.May 4, เ 869.

Claim.-1.-The method by which the balf-cylinder shield is attached to the tongue and standards, by spring rod and chains, as above described:

2.- The adjustable collar clevis, by which the beams are attached to the frame.

3.- The mianner of attaching the handles of the machine to the standards and to the frame, by means of the loose staples and bolt and socket.

4.- The whole machine, as a combination of gopher and cultivator, operating as hereinbefore more particularly described.

No. 89,801 -PHILANDER SPRAGUE, Pecatonica, IL1.-Cultizators.-May 4, I 869 .

Claim.-1.-The arrangement of the forked tongue $A$ axles $B$ B, wheets $C$ C, semi-circular braces $D$ and $f$, seat $\mathrm{E}$, and bent rod or bar $g$, with its books $h / h$, substantially as herein set forth.

2.- The arrangement of the forked tongue $A$, plough beams $\mathrm{F} \mathrm{F}$, handles $\mathrm{P} \mathrm{P}$, and adjustable brace $\mathrm{T}$, all constructed and operating substantially as and for the purposes herein set forth.

3.- The arrangement of the plough beams F F, stationary shins I I, pivoted shins $\mathrm{K} \mathrm{K}$, and adjustable cross-bar $\mathrm{M}$, to which a centre shin $\mathrm{N}$ is secured, substantially as herein set forth.

No. 90,1 2.-J. MCILVAIN, Hascork, ILL.-Cultizators.-May I8, is69.

Claim.-I.-The standard and brace $I$, when attached at front and rear as described, for the purpose set forth.

2.- The screw hooks $K$, when arranged as described, for the purpose set forth.

No, 90,20S.-HIRAM VAN METER, MACOME, 1 LI..Cullizators._-1Muy IS, I869.

Claim, $-\mathbf{I}$, The combination of the plough beams I I with a cultivatcr frame, constructed as shown and described, with the plough beams attached to the frame, as set forth.

2 - The sockets ex, arranged as described, upon the cros-har A, whereby the elastic bars D of the seat are adapted to be held upon the frame, with their centres resting upon the boxes $c$ of the axles, as herein set forth and shown.

No. 90,905.--I. H. WILKINSON, Michigan City, IND,-Cultin'ators.-Fune $\mathrm{I}, \mathrm{t} 869$.

Claim. - I. - The rod $G$, in combination with the lever $\mathrm{V}$, sheave block and pulleys $\mathrm{H}$, beams $\mathrm{P} \mathrm{B}$, shovels $\mathrm{L}$, standard $\mathrm{N}$, and catch $\mathrm{R}$, the whole being constructed and arranged subtantially as and for the purpose set forth.

2.- The combination of the loop bolts C, beams B B, shovels $\mathrm{L}$, and cross pieces $\mathrm{D} \mathrm{E}$, the latter having a series of holes through them, for adjusting the beams, sulstantially as herein de-cribed. 
3.--The combination of the frame A A, cross pieces D E, Joop bolts $C$, beams $B$, shove $\mathrm{L}$, and axletree arms $F$, said arms being adjustable on the frame, and constructed as and for the purpose described.

No. 90,921 . - JOHN BRVAN, LEBANON, ILL.-Machines for Ploughing and Breaking Up Ground-June 8, I 869.

Claim.-1.- The pivoted frame or hounds A A, in combination with the plough beams and main frame $J \mathrm{~J}$, as constructed and arranged.

2.- The lever and link $i$ ', in combination with the hounds $A$, and main frame $f$, as shown.

No. $91,084--D A V I D$ F. CARR, EAst UNIoN TuwnSHup, OHIO.-Cultizators. - Fune 8, 1869.

Claim.-I. - The combination, with the axle B, of the beams $\mathrm{C}$, loops $\mathrm{E}$, braees $\mathrm{C}$, and shovels $\mathrm{F}$, when adjusted and arranged substantially as and for the purpose specified.

2.- The lever $\mathrm{M}$ and link $\mathrm{M}^{1}$, in combination with the axle B, and parts above claimed, as and for the purpose set forth.

No. 91,5 f6.-JOHN ROBINSON, PLAINFIELD, arsignor to AARON SNELL and ARTHUR T. I), AUSTIN, WiLl Co,, IlL.-Sulky-Cultizutors.-Junc 22, 1869.

Claim.-I. - The combination of the slotted metal seat $s$, post $v$, and swivel brace $t$, with the shovel beam $d$, arranged, operating, and constructed as and for the purposes set forth.

2.-The general combination of all the parts described and shown, as and for the purposes set forth.

No. 9I,66I.-R. B. PARKS and J. R. PARKS, NEPONSET, ILL.-Cultivators.- - Fune 22, 1869.

Claim.-1.- The suspended beams I 1, with plough or share standards J attachet, in combination with the levers $\mathbf{K}$, conneeted by the rack $\mathrm{N}$ and lever $\mathrm{O}, \mathrm{all}$ arranged and combined to operate in the manner substantially as and for the purpose set forth.

2.- Securing the frame $\mathrm{A}$ to the axle bar $\mathrm{B}$, by means of the clamps C, constructed and arranged as shown, so as to admit of the ready adjustment of the frame $A$, in a more forward or backward direetion, as may be required

3.- The sector rack $\mathrm{N}$ and lever $\mathrm{O}$, in combination with a cultivator, substantially as and for the purposes described.

No. 91,721.-WTLLIAM H. CUMMINGS and IIOR-

ACF, L. CHIL.DS, BARNBborough, Lowa. - Ploughs.June 22, 1860 .

Claim.-1.- The arringement of the bar F, braces $\mathrm{E}$ E, rods $\mathrm{C} \mathrm{C}$, beams $\mathrm{D} \mathrm{D}$, and rods $\mathrm{L}, \mathrm{L}$, all substantially as set forth.

2.-The shields or guards $G$, when used to protect the plough beams, substantially as set forth and described.

3.-The combination of the plough beams $\mathrm{D}$, rods $\mathrm{C}$ and and $L$, shields $G$, braces $E$, and plate $I$, when all are used in the manner and for the purpose set forth.

No, 91, So2.-IV. J. IVELLS, SiNDEY, assignor to himself and H. W. NEAL, TolkDo, OHIo.-Cultivators.Fune 22, 1869 .

Claim.-I. - The construction of the shovels or blades $\mathrm{R} \mathrm{R}^{\prime}$, substantially as and for the purposes set forth.

2. - The arrangement of the shovels $E$ and $E^{\prime}$ and $R$ and $R^{\prime}$, substantially in the manner and for the purpose set forth.

3.- The combination of the ploughs $\mathrm{R} \mathrm{R}^{\prime}$ and $\mathrm{E}^{\prime} \mathrm{E}^{\prime}$. levers I I and I, and ratchet bar $g^{\prime}$, all arranged substantially in the manner set forth.

No, 91,876 - ALEXANDER SHAW, Monmouti, ILI.-Cultizators.- Fune 29, I 860

Claim.-1.- The construction, arrangement, and combination of the frame picce $\mathbf{1 3}$, spindle 11 , pivot $V$, jivot joint $M$, and brace $\mathrm{W}$, as shown and for the purpose described.

2.- In combination with the above devices, the braees $\mathrm{C} \mathrm{D}$, tongue $\mathrm{A}$, plates $\mathrm{L} \mathrm{L}$, and ploughs $\mathrm{K} K$, arranged as shown and for the purpose described.

No. 9I,894.-J A. WOODWARD, S. S. WOODWARD, and THOMAS MASON, SANDWICI, ILL. Cultivators.- 7 uni: $29,1860$.
Claim.-1.-The combination of the elamps Z Z, pins $V$, frame S T U, and beams $J$, as and for the purpose set forth.

2. - The combination of the sockets $f f$, handles $d$, plates $p$, and beams $J$, said plates being arranged to clamp the handles to the beams, as set forth.

3.- The inelined standards $\mathrm{D}$, in combination with segments $F$, ratchets $E$, levers and springs $G \mathbf{H}$, beams $\vec{J}$ chains $t$, clamps $Z$, and frame $\mathrm{S} T \mathrm{~T}$, as shown and speeified.

No. 91,9Si.-IVIL1,1AM SNOOK, Pleasant PLaIn, Iowa.Cultizators.- Fute 29, 1860

Claim.- The combination of the bent yoke $\mathrm{K} L$, bent lever () , curved plates $\mathrm{I}$, and the adjustable eonnecting bars II $\mathrm{N}$ of the cultivator beams, arranged, in their relation to the ploughs, as herein set forth.

No, 92,135-NATITANIEl. WILSON, ST, Lous, Mich.-Sulku-Cultivators.-June 29, 1869.

Claim.-1.- The bars $B$, secured to the frame $A$, as described, and operated by the treadles J, ropes or chains $m$, and pulley $n^{\prime}$, substantially as set forth.

2.-The rock shaft $G$, arms $h$, ropes or ehains $i$, pulleys $K$, lever $H$, and quadrant $I$, in combination with the longitudinal hars $a$ and $B$, provided with standards $C$, and cultivator teeth 5 , operating as and for the purposes described.

3.- The arrangement of the parts A, B, C, D, E, F, G, H, I, I, K, I, $a, b, c, d, e, f, r, h, i, k, m, n$, and $\rho$, or their equivalents, when combined and operating substantially as and for the vurposes herein set forth.

No. 92.350.-D. H. PAUl, DE Wirt, IowA - Cultizators.-July 6, 1860 .

Claim. - The application of reciprocating saws to a cultivator, in the manner subutantially as shown and described, for the purpose of cutting or severing weeds or trash, which may adhere to the plough or share standards, and stripping it from the latter. as set forth.

No. 92,529.-ISALAH IIENTON, SHeLbyvili.F, It.L. - Cultivators.-Juty I3, I860.

Claim.-The combination of the pivoted levers $P$ pivoted cross-bar $R$, and chains $(2$, with each other and with the pivoted bars I and plough beams E, substantially as herein shown and described, and for the purpose set forth.

No. 92,686.-JOHN P. ZELI.ER, SOUTI BENI, IND. - Cultizators.-July 13, 1869.

Claim - I. - The arranoment of the har A, stationary buttons $B$, and movable buttuns $C$, substantiall as and for the purposes set forth.

2. - The arrangement of the bar A, vertical pins $a a$, and beams D $\mathrm{D}$, the latter having the plough beams $\mathbf{E} E$, plotighs $\mathrm{F} \mathrm{F}$, and braces $\mathrm{G} G$, all substantially as shown and deseribed.

3.- The arrangement of the beans $\mathrm{D} \mathrm{D}$, brackets $b \quad b$, bars $H$ II, and chain I, all substantially as shown and described.

4. - The arrangement of the brackets $c c$, bar I, handle $K$, arms $\mathrm{L}, \mathrm{l}$, and ehains $d d$, all substantially as shown and described.

5.- The combination of the har $A$, buttons $B C$, beams D D, ploughs $\mathrm{F} \mathrm{F}$, eonnecting hars 11 , brackets $c c$, bar $\mathrm{I}$, handle $\mathrm{K}$, arms $\mathrm{L}, \mathrm{L}$, and chains $d$, all constructed and arranged as described, on an adjustable carriage, so that said carriage may be used with any other agricultural implement, if properly constructed, suhstantially as lerein set forth.

No. 93,318.-JOH1N I. LINDLY, LEBANON, I1.L.Gans Plowghts.-Ausust 3, 1869.

Claim,-1.- The arrangement of the bars $G\left(G^{\prime}\right.$, with the plough bar $H$, and relative to the frame $A$, and the draught attachment $\mathrm{N}$, substantially as and for the purposes set forth.

2.-The crank bar L, its lever $l^{\prime}$, and straps M, arranged to raise the plough bars II, substantially as set forth.

No. 93,374--IHENRY WADSWORTH, DUXIURY, MAss.-Cultizators. - Ausust 3, 1860 .

Claim.-The cultivator $\mathrm{G}, \mathrm{H}$, connected to the axle $\mathrm{A}$ 
by the single universally turning cye $K$ and vertical slicling belt $C$, adjustable by means of the nut $C^{\prime \prime}$ or its equivalent, and provided with the handles I, or thir equivalents, whereliy it may $\mathrm{l}_{\mathrm{x}}$ manipulated, all substantially in the manner and for the purpose herein set forth.

No. 93.412,-NATHAN BUT'TLER, OTTRRVILL, Mo., assignor to himself and D. S. BUTl.FR, same place.-Ciultivaters.-Aurust 10, 1869.

Claim.-1.- The bolster E, hinged to the axle B, and beveled npen its rear lower edge, substantially as herein shown and described, and for the purpose set forth.

2 - The combination of the rearwardly prujecting arm $\mathrm{I}$, sliding seat $\mathrm{L}$, and foot rest or platform II, with the hinged bolster $\mathrm{E}$ and axle $\mathrm{B}$, substantially as herein shown and described, and for the purpose set forth.

3.- The notched plough standards G, adjustably secured to the hinged bolster $\mathrm{E}$ by means of the detachable loops $\mathrm{H}$, in combination with the said hinged bolster $\mathrm{E}$ and axle $\mathrm{B}$, substantially as heretn shown and described, and for the purpose set forth.

4.- An improved cultivator, formed by the combination of the wheel $\mathrm{A}$, axle $\mathrm{B}$, tongue $\mathrm{C}$, hinged bolster $\mathrm{E}$, arms I, sliding seat L, fuot rest or platform $\mathrm{M}$, and plough standards $G$, with each other subitantially as herein shown and described, and for the purposes set forth.

No. 93,605-WILLJAM EMMONS and DAVII) A. WELLS, SANDwich, II.L.. - Corn-Cultizators,-August 1o, IS69.

Claim - $\mathrm{r}$ - The combination of the frame $\mathrm{A}$, axle $\mathrm{C}$, and pivoted bars D D, all substantially as set forth.

2.- The lever $\mathrm{L}$, in combination with the cams, or their equivalents, when used to elevate both beams at once, sulstantially as specified.

3.- Securing the handles to the beams, lyy means of a thumb screw, so that they can be regulated at will, substantially as set forth

4.-The levers $\mathrm{L}, \mathrm{M}$, and $\mathrm{N}$, rod $\mathrm{O}$, pawl $\mathrm{P}$, and ratchet $H$, when arranged to operate substantially as set forth.

5.-In combination with the above, the beam I, hars $\mathrm{E}$, chains $\mathrm{R}$, frame $\mathrm{A}$, metal plates $\mathrm{D}$, and shoes $\mathrm{H}$, when all are combined, as set forth.

No, 93,611.-DANIEL D. FRANKLIN, FLORA, IL... assignor to himself and J. S. UNDERWOOD, same place. Cultizators. - Ausust 10, 1869.

Claim.-1.-The combination and arrangement of the draught-bar $A^{\prime}$, bent-rods $C^{\prime}$ fastened to the lower ends of the standards E, so as to vibrate freely, and permit the driver on his seat to rock the machine and raise the cultivator teeth, substantially as described.

2.- Hinging the cultivator beams $\mathrm{H}$ and $\mathrm{N}$, and the pivots of the rods ' $C^{\prime}$, in the standards $\mathbf{E}$, so near the axles of the carrying wheels that the machine can vibrate freely on the pivots of the carrying-wheels, while in motion, sulstantially as described.

3.-In combination with the stock and removable share, the lip on the stock, for covering and holdinir the point of the share, substantially as described.

No. 93,651.- HIRAM J. WATTLES, ROCKFORD, ILL. - Cultizators.-August 10, 1869.

Claim. - 1, - The frame $\mathrm{C}$, when constructed substantially as described, for the purpose set forth.

2.-The arms F F, when provided with the pulleys $f f$, and used in connection with the lifting levers $\mathrm{E} \mathrm{E}$, as and for the purpose described.

3.- The slotted wedge $l^{2}$, when used in combination with the bars $h$, as described, for the purpose set forth.

4.- The evener $\mathrm{K}$, having the clevises $k k$, when com-

bined with the draught bars $k^{1} k^{1}$, in the manner and for the purpose set forth.

5.- The cultivator described, consisting substantially of the frame C, lifting devices $\mathbf{E}$ E, beams II, standarils I, and draught devices $\mathrm{K} k$, when combined and used as and for the purpose described.

No. 93.730.-NEAL McKAY, Columera, Mo.- CultiF'ator.Ploughs. - Augyst I 7, I 869 .

Claim.-The combination and arrangement of the rear ploughs D, fastened to the main frame, the inner and front plouglis C, adjustably secured upon the rock shaft B, the hand-lever $\mathrm{G}$, pivot $r$, and chains $\mathrm{F}$ F to the inner ploughs, and the hand-lever II, with its four armed rock shaft, and chains $h h h h$ for lifting the four ploughs, secured by the catch /, with the adjustable seat $\mathrm{K}$.

No. 92,749.-IOIIN J. ROSE, Elmwond, Ill.-Cultivators.-August 17, 1869 .

Claim.-1, - The right-angle hinges $\mathbf{I}, \mathbf{L}$, in combination with the beams E E, ploughs $\mathrm{N}$, shovels $\mathrm{M}$ M, and chains I I', of a riding cultivator, all substantially as and for the purpose shown and described.

2.- The spring $U$, chains $I^{\prime}$, when combined with the cross-beam or axle-heam $\mathrm{G}$ of a cultivator, and the plough beams E, all substantially as shown and described, and for the purpose set forth.

No. 94,067-A. C. BRINSER, MIDDLETOWN, PA.Cultizators.-August $24, \mathbf{1} 869$.

Claim.-I, - The combination of the platform F and G and seat $H$, substantially as shown and described.

2.- The axle $\mathrm{A}^{\mathrm{A}}$ ' in combination with the curved arms $\mathrm{C}$ and $\mathrm{E}$, when constructed substantially as shown and described.

No, 94,106,-RICHARD HANEY and JAMES S,

ESTES, PEorio, ILl.-Cultizators.-August 24, 1869.

Claim.-1.-The axle $l$, with flanges $\ell^{\prime}$ and $z^{\prime}$, substantially as shown and described.

2.- In combination with a plough beam, the plates $e e$, with flanges, bolt $d$, box $b b$, and journals $a d$, substanti-lly as shown, and for the purposes specified.

3. - In combination with an axle $l$, and flange $z^{\prime}$, the box $b b$, journals $a \quad a$, plates $e c$, and bolt $d$, as shown, and for the purposes specified.

4.-In combination with an axle $l$, having flange $t^{\prime}$, and $\operatorname{cap} f$, having flange $v^{\prime}$ encircling and covering the tapering ends of the hub, the wheel $L$, as shown and described.

5-In combination with the bars II M, and adjustable connecting-rods $m^{\prime} m^{\prime}$, the cross beam A, standards B B B $\mathrm{B}$, pole $\mathrm{D}$, with branches $\mathrm{E} \mathrm{E}$ and braces $c c c^{\prime} c^{\prime}$, substantially as shown, and for the purposes specified.

No. 94,456.-ELISHA WALKER and JOSIAH J. PLATT, LA PORTE, IND.-Cultivators,-Ausust 3I, I 869. Claim.-1.-The mode of elevating and lowering the ploughs by the self-acting double eccentric M, substantially as set forth.

2. - The mode of turning the shovels $A$ in or out by the double arljusters N N and single adjusters $O O$, substantially as set forth.

3. - The combination of the tongue $\mathrm{D}$, posts $\mathbf{L} \mathbf{L}$, braces $a$, knuckle joints J J, hinges $\mathrm{E}$ E, bars $b \quad b$, self-acting double eccentric M, double adjusters $\mathrm{N} \mathrm{N}$, and single adjusters $O O^{*}$ respectively, constructed and arranged substantially as set forth.

No, 94.542.- JOB MCNAMEE BAKER, FAYETTEvili.e, TeXAs. - Cultizators.-September 7, 1869.

Clain,-1.- The blades or ploughs E, F, and G, arrang ed and operated substantially as and for the purposes herein shown and described.

2.-A combined cultivating, ridging, planting, and rolling machine, arranged and operating substantially as described.

3.- In combination with a cultivator, the stalk-cutter $\mathrm{S}$, substantially as described.

4. - The method of adjusting the beams $H$, with the blades substantially as described.

5.- The method of operating the slide of the planter, in combination with the rollers $R$, substantiantially as described.

No. 94,623.-EDWARD P. LYNCH and HENRY R. RAFF, DAYENPORT, IowA,-Walking-Cultivators.-Septembir 7,1869

Claim.-I.-The curved frame $\mathrm{A}$ and the adjustable axles $\mathrm{B}$, constructed and arranged as herein described.

2. - The curved cast-iron frame A, with the forked or V shaped tongue $\mathrm{H}$ secured thereto, by means of the flanges or lugs thereon, substantially as described.

3.- The pieces $\mathrm{C}$, formed with the grooves in their sides, and the series of holes for receiving, holding, and permittin the adjustment of the beams $\mathrm{D}$, substantially as described. 
4.-The combination of the piece $\mathbf{C}$, boxes $a$ and $c$, and clip-bolt $b$, with the axle B, all arranged as described.

5.-The shoulder-piece or block I, secured to the axle B, substantially as described.

6.- The shovels $F$, provided with the grooves and recessed block $h$, and secured to the beam by the T-headed bolts $u$ and strap $v$, as set forth.

7.-The piece $n_{*}$ in ; combination with the grooved block $h$, for the purpose of adjusting the inclination of the shovels, substantially as described.

8. - The piece C, cast with its arms $w$ at the front, said arms having holes therein to receive and hold the journals of the boxes $a$ and $i$, as herein described.

No. 94,903.-EDWARD P. LYNCH, DAVENPURT, Inwa.-Cultizators. - Siptember 14, 1869.

Claim.-1.-A walking cultivator, having the central or fifth shovel applied thereto, substantially as described.

2.- The combination of the bars $C$ and the beam $D$, the the latter being curved, as shown, and secured to the former by the bolt $o$ and pin $c$, as set forth.

3.- Securing the beam $n$ to the bar B, by means of the bolt $o$ and clip $a$, with the pun $e$, as described.

4.- Constructing the beams of cultivators of wroughtiron bars, made thicker on their lower edges, as herein shown and described.

No. 95,142,-JAMES 11. ROBINSON, Selma, Ala.Corn and Cotton Cultizutors.-September 21, IS69.

Claim.-1.-Attaching draught-pole by means of two piv. ots, substantially for the purposes described.

2.-The construction and combination of draught-pole $K$, rock-shaft $B$, and hand-operating lever $J$, so as to form a joint, through which a universal leverage may be conducted, by means of a single hand-operating lever, for the purposes substantially as described.

3.- - Mode of arranging the ploughs in front and rear of rods $\mathrm{D}$ and $c$, and having plates of different length, and projecting to the front and rear, the rods passing through them for the purposes described.

4.--Rock-shaft B, arms C, rods D and $c$, arranged to counteract each other under pressure, and to move the ploughs up and down at a uniform angle, for the purposes describd.

5.- The treadles $\boldsymbol{H}$, and their aplication to $\operatorname{rod} c$, for the purposes described.

6.-The combination of the rock-shaft B, arms C, rod D plates $\mathrm{E} \mathrm{E}^{\prime}$, standards $\mathrm{F} \mathrm{F}^{\prime}$, rod $c$, treadle $\mathrm{H}$, and handlever J, substantially as and for the purpose described.

7.-So arranging the ploughs as that they will operate in the ground parallel with or nearly opposite to the axis of the draught-pole and hand hand operating-lever, for the purpose described.

8.- Mode of securing standards by means of hooks and cross-chains, for the purposes described.

No. 95,338.-THOMAS J. HALL, BRyaN TrXas.Cultivators - Septomber $28,1869$.

Claim.-1.- The cultivator-beams A, arranged either singly or in pairs, and suspended, by the adjustable rods $B$, from the levers $\mathbf{C}$, vibrating later.lly, and arranged to be operated by the feet, subsiantially as specified.

2.-The combination of the levers C, transverse beam 1 , and syings 11 , when arranged substantially as specified.

No. 95,352.-ALMON IIUNT, MACOME, ILL.-Cultiz'ators.-Siptember 2S, 1869.

Claim.- The cultivat or herein descrilsed, having frames $\mathrm{C}$, bars $\mathrm{D}$, equalizing-bars $\mathrm{K}$, clamps $\mathrm{P}$, and plates $c$, arranged, with reference to the beams (), as described, con structed and arranged substantially as set forth.

No. 95,453.-SA.MUEl. FISIlER, Higutstown, N. J. - Whetled Cultivaturs and Plowsths.-Octuber 5, 1 S69.

Claim.-In combination with a main axie, a pair of car rying wheels, and a main frame that can be witened or narrowed, and adjustable beams and ploughs thereon, the lubb, pulley, lever, and chain, and their appliances, for raising or lowering, or holding the ploughs or cultivators on the nain frame or axle, substantially as described.

No. 95,520,-SIDNEY A. SABIN, PECATUNiCA, Ill. Cultivators. October 5, I869.

Claim.-1.- The sliding attachment described, by means of which, the lifting chains and the shovel beams are united consisting essentially of the clevises $j$ and irons $\mathbf{k}$, or their equivalents, as or for the purpose clescribed.

2.- The shield $\mathbf{P}$, having the arms $p p$, in combination with the bar $p^{3}$, as and for the purpose described.

3.- The machine described, consisting essentially of the frame B B C D, lifting devices $h h^{1} h^{2} h^{3} \mathrm{I}$, clevis $j$, irons $\mathrm{K}$, beams $\mathrm{L}$, bar $\mathrm{M}$, standards $\mathrm{N}$, and shields $\mathrm{P}$, the whole being combined and arranged as described.

No, 95,762.-JEREMIAH BOHIAN, NEW IIARTFOK D, lowA.-Cultizators.-Octohir 12, 1860.

Claim,-I.- The evener E, pivoted upright B, metallic straps $c$, and sweep F, when cunstructed and arranged substantially as herein described, and for the purpose set forth.

2.- The braces $h$, having their lower ends connected to the shovel beams $\mathrm{H}$, by means of guage-nuts $t$, for adjusting the beams laterally, and their upper ends bookenl or journaled to the frame to allow them to swing, substantially as and for the purpose set forth.

3.- The bent arms 5 , in combination with the block $\mathrm{N}$ ! lever $\mathrm{K}$, and sweep $\mathrm{F}$, when constructed and arranged substantially as herein describerl, for the purpose of spreading the shovels, as set forth.

4. - The lever $\mathrm{K}$, in combination with the sweep $\mathrm{F}$, cross piece $O$, shovel-beams $G$ and $I I$, and cord $k$, when contructer and arranged to operate subitantially as and for the purpuse set forth.

5.-The treadle-hook $\mathrm{L}$, and spring $f$, in crimbination with the lever $K$, cross piece $O$, and sweep $F$, when constructed and arranged sulistantially as herein described, and for the purpose set foith.

6.-- In combination with the sweep $F$, and the devices for operating the shovels, the block 1 , having friction-rollers therein, when constructed and arranged sulustantially as and for the purpose set forth.

7.- The shield $\mathrm{M}$, and slotted braces $\mathrm{P}$, when eonstructed and arranged substantially as and for the purpose set forth.

No. 95,790. OSCAR 1. GAYIORD, PLANFIRLI, 1L1..-Sulky-Cultivators.--Oclober 12, 1869 .

Claim.-The combination of the main frame $a$, diagonal axles $c c$, cross bar $b$, double tree $\mathbf{r}$, straps $2^{2}$, pulleys $3^{3}$, and suspended arms $4^{4}$, arrangerl to operate as and for the purposes set forth

No. 95, S31.-JOHN C. BEARL, MeNDotA, llu.-Cultivators,-October 12, 1869.

Claim - I. - The standards 1 , with sleeves $D^{\prime}$, when constructed and arranged substantially as slown and described, for the purpose set forth.

2.-The axles $\mathrm{C}$, when constructed and arranged scbstantially as shown and described.

3.- The clevises F, when constructed as shown and described, in combination with the plates F', both arranged to operate as and for the purpose set forth.

4.- The combination, with the whiffle-tree, of the thimble whereby the former may be raised or lowered, as set forth.

No. 96,367.-DUDLEI W. TRAVIS, ENFIEI.D, N. Y. -Corn-Cultivators.-Oitober 26, 1869 .-Antedated Oitober $12,1 S 69$.

Claim.-1.-The combination of the adjustalle plonghs Gand $H$ frame D F F', and rods C, substantially as cleseribed.

2.- The arrangement of the lever $\mathrm{L}$, in combination with the ploughs, frame rods, and carriage as set forth.

3.-The construction of the spring $k$, in combination with a carriage plough frame, as set forth.

4.- The combination of the whole, made by the twowheeled carriage $A$, eross-bar $\mathrm{B}$, rods $\mathrm{C}$., longitudinal pieces $\mathrm{D}$, posts $\mathrm{E}$, adjustable ploughs $\mathrm{G}$ and $\mathrm{H}$, seat $\mathrm{I}$, spring $\mathrm{K}$, and lever L, arranged and operating together, substantially as set forth.

No, 96,271.-SILAS C. SCHOFIELD, CHICAGO, ILL. Combined Cultirators and Sicders.-Octubir 26, I S69.-Antedated October I6, I 860.

Claim.-1.-The combination of the main beams $\mathrm{F}$ and 
angle beams II, when constructed and operated substantially as and for the purpose specilied.

2. The elbow-pliates 1 , when constructed substantially as described, and used for the parpose of adjuting the angle of the beams $\mathbf{B}$ and 11 , sulsetantially as specified.

3.-The swivel-phate J, when comstructed and operating substantially as and for the purpose described.

4.- The metalic stall P, when constructed and operating substantially as and for the purposes specified.

5.- The combination of the treadle $T$, chain $R$, and metallic stall $\mathrm{P}$, when arranged and operating sulstantially as set forth.

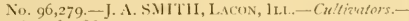
Oitwier 26, IS60.

('laim.-1. - The frames 1) I), when provicled with plates 5.5 , and adjunting holes at the top and lottom, substantially as and for the purpose described.

2.- The combination of the heams $\mathrm{B} B$ with the vertical cylindrical bars $h h$, when said bars are provided with the plate' $(;$ and $F$, the plates being pivoted together substantially as and for the purpose specified.

3.- The double-tree H, provided with pentants $m \mathrm{~m}$, in ccmlination with rock I $I$, or their equivalent, the said rots heing connected with a pulley, /, on double-tree $\mathrm{H}$, in the manner and for the purpose set forth.

No. 96,299.--ELISIIA WALKER and JOSIAII J IIATT, LA Porte, 1ND, - Cultiecators. - Octobit 26, I $\$ 60$.

Claim,-The double-tree A, provided with the stirrupshaped iron frames E E, with the pivoted regulatin bars F $\mathrm{F}$ and the chains $\mathrm{K} K$, when combined and operating upon a cultivator, sulstantially an described and shown.

No. 96,322.-DAIII) li. ITULT, WILKINSUN CUUNTY, Miss. - Combined Cultizaturs and Sied Planters. - November $2,1860$.

Clain.-1.- The curved bars I, in combination with the plow's $\mathrm{F} \mathrm{F}^{\prime}$, and a frame con isting of part $\mathrm{A}^{\prime}$, that are connected together by bolts $\mathbf{I}$ and 2 , when all the parts are constructed, arranged, and operate substantially as herein described, for the purpose set forth.

2.- The above combination, in combination with a trench opening plongh, II, that is provided with an adjustime-lor, J, and with a hopper, $\mathrm{I}$, that is provided with adju-table supplemental sides N, a cylinder that will plant cotton-seed or corn, and an agitating-cylinder above the same, which are driven by a shaft $\mathrm{O}$, and snitable gearing connected therewith, and with the wheel $\mathrm{E}$, when all the parts are constructed and arranged with respect to each other, ancl operate substantially as described, for the purpose set forth.

No. 96,379--WM. T. BAKER, L.MCASTER, TEXASCultizators.-Nin'tmber 2, 1569 .

Claim,- $\mathbf{I}$ - Tne tases $C$, in combination with the frame E, for supporting and guiding the leams and stock of the plough, arranged subatantially is described.

2.- The combination of the sp rings $\mathrm{K}$, rod $\mathrm{J}$, and levers $\mathrm{G}$, arranged as tle-cribed.

3.-The foot piece $J$ and springs $K$, by which the plough may be simultancously thrown from the ground.

No. 4-The clevises (), arranged sulistantially as shown and described, in combinat, $m$ with the stock $m$, of the plough, for regulating the depth of the plough, sulstantially as described.

5.- The conlsination of the rols $F$, having, at either end, adjustable sctew bolts and muts, as shown, with the levers $G$ and beams $D$, all arranged, as c'eseribed, to regulite the depth and angle of inclintion of the several ploughs, in the manner set forth.

6. - In combination with a cultivator, the doubletree A, constructed and arranged substuntially as and for the purposes herein shown and described.

No. $96,382,-$ E. CH.IRI.ES BE.IN and FRANCIS N.

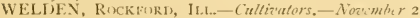
1869.

Claim.-1.-The comlination of the bent metal hars, the axle, the pole, and the braces, to form the main frame of the machine, substantivlly as de-crilsed.

2. - The combination of ad ustable frot rest $\mathrm{R}$ with eye $r$, having the slot $r^{-1}$ and recess $r^{2}$, with the standard $\therefore$, having the projection $s$, as and for the purpose described.

3.- The combination of the flanged bearing block with the recessed bearing plate, as deseribed, for the purpose set forth.

4.-The combination of the flanged bearing block, recessed hearing plate, and hook bolt, with the shovel tream and standard, as described, for the puipose set forth

5.-The band O, provided with the staple-shaped projec tion ${ }^{1} e^{2}$, as and for the purpose described.

6.- The employment of wings or arms, or their equivalents, substantially as described, for the purpose set forth.

No, 96,5:10-H. W. CLAPP, NonthamptoN, Mass.Ho:ms. Wartincs.- Vorember 9, 1869

Claim.-1,- The combination, on a track, of two or more hoes or spades, E. E, arranged for operation by motion deriverl from the wheels of the truck, as herein shown and described.

2.-The combination, with a pair of spades or hoes, operating as described, of a guard or shield $\mathrm{Q}$, moving and acljustable vertically, as describeil.

3.- The combination, with the spacles or hocs, arranged for operation as described, of the vibrating cultivators $\mathrm{V} V$, as specified.

4-The combination, with the spades or hoes, of the cultivators $\mathrm{V} V$ and $\mathrm{V}^{2} \mathrm{~V}^{2}$, as specified.

5.-The combination, with the spales or hoes E E, of the chains $\mathrm{M}$, rollers $\mathrm{N}$, levers $\mathrm{O}$, and spring catches $\mathrm{P}$, as specilied.

6.- The combination of the spales or hoes, cultivators $\mathrm{V} \mathrm{V}, \mathrm{V}^{1} \mathrm{~V}^{-2}$, and $\mathrm{H}^{1}$, all as specified.

No. 96,733 -RICHARD B. ROBBINS, ADRIAN, Mich.-Sulliv-Cutticiators.-Novimber 9, is69.

Clnim,-1.-The arrangement, herein shown and deicribed, of the parts $\mathrm{R}$ and $\mathrm{R}^{\prime}, \mathrm{I}, \mathrm{N}^{\prime} \mathrm{N}^{\prime}, \mathrm{J}$, and 11 , and the bolts $r^{\prime}$, as and for the purposes specified.

2.- The shifting device $c$, used in connection with the chains $c$ and $c^{\prime}$, rollers $/$ and $l^{\prime}$, lides $f$ and $p^{\prime}$, for the purposes set forth and described.

3.- The foot rest $o$ and $o^{\prime}$, in connection with the slides and $f^{\prime}$, in the manner set forth and descrileded.

4.- The st rrups $a$ and $a^{\prime}$, in comnection with the guiding rods $h$ and $h^{\prime}$, chains $i$ and $i^{\prime}$, rollers $v$ and $\imath^{\prime}$, constructed in the manner set forth and described.

5.- The arrangement, herein shown and described, of the rocking doubletree $\mathrm{K}$, chains $d$ and $d^{\prime}$, rollers $v^{\prime}$ and $v^{\prime}$, singletrees $\mathrm{P}$ and $\mathrm{P}^{\prime}$, and the ways $y$, as and for the purpo-es specified.

No. 96,801-A J. GRUSH, SPRINGFIEld, Ili..-CornCullizaters.- Noz'smber 16, is69.

Claim-1.-The tongue or beam A, made in two parts, connected by a detachalle joint, $\mathrm{A}^{\prime}$, and provided with the axles B D, substantially as specified.

2.- The combination, with the plough beams $I^{\prime}$ and the tongue or beam $A$, of the har $M$ and lever $O$.

No. 96,838.-S. G. RAYL, AgrNey City, lowa.Combined Doubde-Shatel and Two-Hlorsc Cullivators.Norember 16, 1860.

Claim.-I.-Connecting the inner shovels $B$ to the fluugh beams A, by a curved standard, $\mathrm{C}$, in such a way that the top of said shovels may be unobstructed, substantially as herein shown and described, and for the purpose set furth.

2.-The shield F, constructed and connected with the plough beams $A$, substantially in the manner herein shown and described, and for the purpose set forth.

3.-Comecting the handles $\mathrm{N}$ and $\mathrm{P}$, either or both, to the plough beams $A$, by a system of detachable braces, substantially as herein shown and described, and for the purposes set forth.

4 -The pivoting rods $Z$, perforated swinging plates 13', clevises $\mathrm{C}^{\prime}$, and bars $\mathrm{D}^{\prime}$, with each other and with the plough beams $A$ and carriage $T$ U V, substantially as herein shown and described, and for the purpose set forth.

5.- The carriage T U V X as herein shown and described, that is to say, in such a way 
that the forward ends or the plough beams A may project in front of the cross beam $L$ and knces $Y$, a and for the purpose set forth.

No. 97.377.-JAMES FERGUSON, HUNTLEY GRove, ILL, - Ciultirators-Dorimbir 30, IS60.

Claim. - I. - The beams $\mathrm{D}^{\prime}$, when provided with joints $d d^{2}$ it front and rear, as describel, for the purpose set forth

2.- The standard $H$, bar $I$, and spring $h^{\prime}$, when constructed substant ally as described, for the purpose set forth.

3.- The standard $H$, bar $I$, and spring $h^{\prime}$, when comlined with the beams $\mathrm{D}^{\prime}$, sulstantially as and for the purprose =et forth.

1.--The machine described, consistins of the frame A $a$ a $a^{\prime}$, wheels $B$ B, pole C, beams $D^{\prime} \mathrm{D}^{\prime}$, shovels $\mathrm{I}$, rock shaft $\mathrm{E}$, band lever $\mathrm{F}$, standard $\mathrm{H}$, bar $\mathrm{I}$, spring $h^{\prime}$, the whole being combined and arranged as clescribed.

No. 97 573.-HIRAII J. IVATILES, RoCKFURD, ILI. - Cirltivetors.-Dicimber 7, I 869 .

Claim.-1.- The frame described, consisting of the longitudinal beams A A, transverse beams B b b, and braces $\mathrm{C} \mathrm{C}$, the whole bein! combined and arrangred as lescribed, for the purpose set forth.

2.-The trace $\mathrm{Il}$, eontructed an descriled, with the half circle $m m^{1}$, and hinge $m^{2}$, for the purpose described.

3.- The machine described, having the frame A B \& $\mathrm{C}$, lifing derices $\mathrm{E}_{t} \cdot \mathrm{G} \mathbf{H}$, beams $\mathrm{J}$, standards $\mathbf{K}$, the whole combined and arranged as described, for the purp -se set forth

No, 9S,112,-JAIIES B, SKINNER, R(ICFOR1), I1.1. -Cultionaters.-Decimber 2I, IS6́g.

Claim.-1.-The combination of caster wheels with a rigid frame, having vertical movement, substantially as described.

2. - The combination of a cultivator frame having vertical movement, with a lever, where said frame is adjusted vertically by said lever, substantially as and for the purpose described.

3.- The combination of a cultivator frame resting upon wheels attached by swinging bars, with lever, when said levers operate to raise or depress the frame, substantially as deseribed.

4.- The cultivator frame described, consisting of the cross beams $\mathrm{B} \mathrm{B}$, shovel beams $\mathrm{C} C$, and cross bars $c c^{1}$, when arranged for adjustment, sulstantially as described, for the purpose set forth.

5.- The ad untable standard $f$, in combination with the levers $\mathbf{F}$ and wheels $\mathbf{A}$, as and for the purpose described.

6.-The levers $\mathrm{F}$, with spring stop devices described, in combination with a standard $f$ and yoke standard $a^{\prime}$, substantially as describerl.

7.- The washer $\mathrm{G}$, when constructed as described and used in connection with the levers $\mathrm{F}$ and the frame, as and for the purpose clescribed.

8.- The machine descrilhed, consi-ting escentially of the

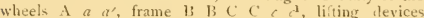
$\mathrm{F} f, \mathrm{H} / \mathrm{h}$, stanclarck $\mathrm{M}$, and shovels $\mathrm{m}$, the whole being combined and arranged as described, for the purpose set forth.

No. 98,326.-JESSE A. WILAON, HAMBurin, IHWA. - Cultizaters. - Decimlire 28, 1860.

Claim,-1. The casting $\mathrm{E}$ and $\mathrm{I}$, constructed and secured to the ench of the beam $C$, substantially as herein shown and described and for the purposes sel forth.

2.- The bows F (; an I K L, con-tructed and arranged ubstantially as herein shown and described, in combination with the castings E I and tongue II, as and for the purpone set forth.

3.- The slide-bar $P O$ and adjustable hows $M$, in combination with the tongue $H$ and beams $C$, sulstantially as herein shown and described and for the purpose set forth.

No. 98,560.-A. L. CHUbB, Grand Rapids, Mich.Cultraters.- Fanmary 4. 1870 .
Claim. - The side bars B B, when cast with recesses on their inner sides, to receive the crost bars or beams $\mathrm{A} \mathrm{A}$, substantially in the manner specifiecl.

No, 98,708 ,- WILLIAM B. RAPER, CaRTHAge, ILL. -Corn-Ploughs.-Jonuary II, IS70.

Clam. - In a corn-plough, the combination and arrangement of the several parts, viz: the ratcheted joints B C C', by which the two sets of wheels and ploughs are adjusted toward or from each other; the downward pointing arms E E', with their double hinging parts $\mathrm{G} \mathrm{G}^{\prime}$, having their series of boles $r w^{\prime \prime}, \mathrm{N} c$; the ratcheted manner of adjusting the plough standards $/ 2 H^{\prime} h^{\prime} H^{\prime}$ up and down on the plough beams F F'; and the doubletree, having dependent parts L I', to bear the smeletrees $\mathrm{II} \mathrm{N}^{\prime}$ and draught rods $N^{\prime}$, reachirg back to the wheel frame $B$ all substantially as set forth.

No. 5,otS.-W WL1,1A.y B. RAPER, Carthage, It.L, assignor to JoIIN IA( $\mathrm{KSO}) \mathrm{N}$, - Cultizuters, $-98,708$. January 11, I870.- Keir-ued fuly 30, 1872 .

Clain.-I.-In a wheel-cultivator the axle beam B, made extensible in the manner described, in combination with pivot arms E E, plough bearns F F, and adjustable connection I I, substnntially as shown and described.

2.-The axle made in three parts, and providerl with the serrated surfaces, and held by any rnitable devices, substantially as shown and described.

3.- In a straddle row cultivator having a raised or arched axle, I claim the slots and bolts, in combination with the serrated surfaces, for the purpose of making the wheels extenuible, substantially as set forth.

No. 98.970.-BENJANIN S. HJERS, PEKIN, ILL.Cidtizators-Fanuary Is, IS7o.

Claim.-1.- The two stright axles B $\mathrm{b}^{\prime}$, independent of each other, in combination with the straps C C, substantially as herein hown and described, and for the purposes set forth.

2.- The two adjusiable, laterally-inclined braces $\$ S$, in combination with the straps or clamps C C', and tongue F, subutantially as shown and describerl, and for the purposes set forth.

3-The sliding lug $\mathrm{J}$, within the the cock-eye $\mathrm{M}$, provided with one or more notches, so as to allow it to pass hy the clevis $H$, substantially as herein shown and described.

4.- The cock-eye $\mathrm{M}$, in combination with the sliding lug J, and rod or link, WV, substantially as and for the purposes set forih.

5--The combination and arrangement of the clevis $\mathrm{H}$ and sliding lug J, provided with holes for pins or bolts, so as to make the plous his rigid to the line of draught substantially as herein shown and dercribet.

No, IOO,490.-WHORA(E CARR, WOOSTER, OHIS,Cultieaturs.-Warde S, 1870

Claim.-1.-The constructing and arranging the two miclulle beam and shovels of a cross row, or series of leams and shovels of a wheel cultivator, in combination with a suitable operating handle or lever, that the foints of said middle stovels nay be turned outward from or inward towarl each other simultaneously, as described, hy a single direct movement of said operating hantle or lever, for the purpose set forth.

2.- The combination of the oscillating heams $F^{\prime \prime} F^{\prime \prime}$, togrgles $11^{1} \mathrm{H}^{1}$, arm $\mathrm{H}^{2}$, either single or jointed, and operating handle $\mathrm{K}$, substantially as specified.

3.- The combination and ars.ungement of the oscillating beams $F^{\prime \prime} F^{\prime \prime}$, togules $H^{1} H^{1}$, arm $H^{2}$, either single or jointed, links $11^{3} \mathrm{H}^{+}$. handle $\mathrm{K}$, and arms $\mathrm{G}^{\prime} \mathrm{G}^{\prime}$, with and without the braces $G$, substantially as and for the purpose specified.

4. - In combination with a turning beam holler, B, forming the arm $\mathrm{H}^{2}$, in two jointed partr, as and for the purpose set forth.

5.- In combination with the turning axle or beam holder $B$, frame $H$, and lever $M$, the foot plate $C$, rod $A^{\prime}$, and arm $A$, sulstantially as described.

6.- The plates $R R$, and pins $R^{\prime} R^{\prime}$, as and for the purpose set forth.

7.-Connecting the middle beams $F^{\prime \prime} \mathrm{F}^{\prime \prime}$, when arranged to swing simultanenusly in contrary directions on horizontal 
axes or bearings, by toggles $11^{1}$, as and for the purpose set forth.

No, 100,500-HOR.ICE ('ARR, WoOsTlR, ()HtO,Cullitators.--Warch 8, is7o.

Claim-1-The combination in a wheel-cultivator of the shovel beam $\mathrm{F}$ " F" arranged to work on perpenelicular axles, toggles $\mathrm{H}^{\prime} \mathrm{H}^{\prime}$, lever $\mathrm{I}$, and connecting link or links " II" H" $H^{\prime \prime}$, when so arran red that the said beam m.ry be turned simultaneously in contrary directions without raising the shovels from the ground, substantially as specified.

2 - Connecting the shovel beams $\mathrm{F}^{\prime \prime} \mathrm{F}^{\prime \prime}$ oscillating on perpendicular axes or pivots by toggles $H^{\prime} 1^{\prime}$ ', so as to give said beams simultaneous movement in contrary directuons without raising the attached shovels from the ground.

3.- The combination in a wheel-cultivator of a turning axle $\mathrm{B}$, rigid shovel beams $\mathrm{F}^{\prime}$, movable shovel beams $\mathrm{F}^{\prime \prime \prime}$, arranged to turn simultaneously on vertical axes in con trary directions, frame $\mathrm{H}$, and lever $\mathrm{N}$, substantially as and for the purpose set forth.

4.-The hollow clips L, or their equivalents, in combination with the loops $f^{\prime \prime}$ and movahle beams $F^{\prime \prime}$, as and for the purpose set forth.

5.-The employment of the loops $f^{\prime \prime}$ as pivots for the leams $\mathrm{F}^{\prime \prime}$, in the manner sel forth.

6.- The spring $K^{\prime}$ in combination with the lever I and beam $\mathrm{F}^{\prime \prime}$, as and for the purpose set forth.

No, IOO,5OI.-HORACE CARR.-WmosTER, ()HO.Cultiators, -Warch 8 is7o.

Claim.-I.-In a wheel-cultivator having an axle or equivalent cross bar or bars sustaining the shovel beams with their shovels, and which axle or cross bar may be so turned on its bearings as to raise or lower the shovels from the ground, as set forth, so arranging or articulating the shovel heams on separate bearings that they may be raised or lowered either singly or in sets of two or more, independently of the movement of said axle or cross har.

2.-The combination and arrangement of the bars I, lever, $F^{\prime} F^{\prime \prime}$, hars $F^{\prime \prime \prime}$, and shovel beam $E^{\prime \prime \prime}$, substantially as and for the purpose set forth.

3.- The combination and arrangement of the clevice ( ${ }^{\prime}$, lever $\mathrm{F}^{\prime \prime}$, connecting rod $\mathrm{G}$, and link $\mathrm{F}$, wiih a single loam $E^{\prime \prime \prime}$, so that said beam may with its shovel be ruised or lowered independently of the rest, sub-tantially as set forth.

4.-In combination with the articulated beam $E^{\prime \prime \prime}$, the hangers E, constructed and arranged substantially as and for the purpose set forth.

5.- In combination with the independently-articulated beams $\mathrm{E}^{\prime \prime}$, and axle $\mathrm{B}$, the lever $\mathrm{D}$, link $\mathrm{L}^{1}$, and arm $\mathrm{L}^{2}$, substantially as and for the purpose specified.

6.- The lock bar $K$, in combination with the arms 1 and beams $E^{\prime \prime \prime}$, for the purpose set forth.

7.- The springs $H$, when arranged as and for the purpose descriled, in combination with the rocking device $\left({ }^{\prime}\right.$, and beams $\mathrm{E}^{\prime \prime \prime}$.

No. I00,720.-MARTIN BRUNER, JR,, FrEMONT,

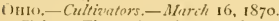

Claim,-The rod $\mathrm{O}$, bent as shown, and pivoted at its ends to the hounds $\mathrm{E}$, and the har $\mathrm{P}$ pivoted thereto and to the beams II, wherehy the furward movement of said rod will elevate, and the reverse movement lower the ploughs, as set forth.

No, 100,812 - IANIES B. SKINNER, RockForu, H.I. - Cultizators, - Warch $15,1870$.

Claim.-1 - The combination of the main frame, the laterally-reciprocating shovel frame, always moving parallel to itself, the traversing roller beneath the tongue, and the supporting rollers upon the axle, all these parts being con structed to operate as set forth.

2.-The combination of the tongue, the guide bracket, and the traversing roller on the shovel frame, all these parts being constructed to operate as set forth.

3.-The combination of the shovel frame, the guide bracket, the guide rails on the axle, the supporting rollers, and the lifting levers, all these parts being constructed to operate an set forth.
N1), 101,216,-(11ARLES BIRD, ACKLFY, IOWA.Cullizators._. Wurch 29, 1870

Claim.-1.-The combination of the ploughs 1), bars $\mathrm{E}$, and screw spindles $\mathbf{E}^{1}$, cross head $\left(\mathbf{a}^{1}\right.$, all arranged to operate substantially as and for the purpose set forth.

2,-The combination of the plows $\mathrm{F}$, swinging beams $G$, cross head $G^{1}$, nuts $\left(i^{2}\right.$, and screw spindles $E^{1}$, all arranged to operate substantially as and for the purpose set forth

No. I01,240.-SOLONIAN H. 1)WIGHT and WIL LAM B. CHAMBERS, INEATUR, IH...-Cultizutors Yark 29, I870.

Claim.-In combination with an clevated truck frame constructed and arranged as described, and supported and carried upon a pair of wheels as herein stated, the pivoted beams $\mathrm{B} \mathrm{B}$, and the cultivator teeth or ploughs, and independently pivoted and suspended guards E connected therewith, and arranged to be drawn by or carried on said elevated frame, as described.

No, I01,380,-C. L. REII, LoutsviL..E, Ky.-Cultivalors.-March 29, 1870 .

Claim.-1.-The bedder E, constructed substantially as shown and described.

2.- The combination of the frame $\mathrm{C}^{\mathrm{w}}$ with the hanger $\mathrm{C}^{\mathrm{l}}$ and bedder $\mathrm{E}$, substantially as set forth.

3.- The arrangement of the hangers $\mathrm{C}^{1}$ and $\mathrm{C}^{2}$, bedder E, and cultivators $F$, when combined with the frame $C$, so that the machine may be converted from a cultivator into a bedder, or vice tersa, as set forth.

No, IO1,536,-GARLAND B. ST. J()HN, KA1.AMAZOO, Mich.-Cultizators,_April 5, 1870 . Antedated April s, 1870 .

Claim-1-The combination of beams $\mathrm{C}^{\circ} \mathrm{C} \mathrm{C}^{*} \mathrm{C}^{\mathrm{*}}$, together with beam $\mathrm{A} A$ and $\mathrm{B} B$, arranged substantially in the manner and for the purposes set forth.

2.-I do not claim a separate drag har with drag teeth inserted to form a combination of harrow and cultivator, but what 1 do claim is the construction and arrangement of ploughs or shovels E E, substantially as hereinbefore specified.

3.- The combination of beams B B, bolts $b b$ and $c c$, together with plates $G \mathrm{G}$, all arranged substantially in the manner and for the purposes set forth.

No, 101,706.-M. C. BLFFIN(;TON, LA HARPE, Ili. Corn Ploughs - thril 12, 1820

Claim.-1.-The doubletree $I$, when pivoted at the ends to bars $q$, which slide in traps $z$, and which carry the single trees on perforated pendants $t$, substantially as and for the purpose herein shown and described.

2.-Making and arranging the universal-binged joint on the ends of the plough beam?, with the several parts and functions as specified and described.

No, IOI, 720,-FR ANK FAR NSIVORTH, FRANKFORT, 1LL.-Cultizators.-April 12, iS7o.

Claim.-1.-The combination of the shovel posts $a$, axle $d$, boxes $e$, chains $n$, pivoted cross bar $i$, and lever $m$, arranged, operating and constructed as and for the purposes set forth.

2.-The main frame $\mathrm{C}$, in combination with the roller $b$, segment $u$, lever $z$, and chains $"$, arranged, operating, and constructed as and for the purposes set forth.

No, 102,201,-CLARK ALVORD, COURTIAND, Wis -Cultivators.-April 26, 1870.

Claim - I.-The axle I combined with the props G; when the latter project upward and forward from the axle, for the purpose of enabling the drag hars, whose ends they support, to be lifted from the ground by turning the axle upon which they rest, as and for tne purpose described.

2.-The axle 1, combined with the upwardly and for wardly projecting props $\mathrm{G}$, tongue $\mathrm{B}$, and drag bars $\mathrm{C}$, when the two latter are each pivoted between the props, as and for the purpose set forth.

3.- The combination and arrangement of stay bars D and lever $\mathrm{E}$ with such axle.

4.- The application of plate L to the drag bar and cultivator teeth, as above shown and described.

5.-The stay bar $\mathrm{D}$, combined with the tongue $\mathrm{B}$ and standard $\mathrm{K}$, in the manner and for the purpose here in shown and describerl. 
6.-The tongue $\mathrm{B}$ and drag bar $\mathrm{C}$, when pivoted upon one and the same rod.

No. 102,631.-NICHOLAS WERTS, MAGNol.1A, II.I. Cultizators.-May $3,1870$.

Claim.-1.-The brackets $G$, vertical rods $D$, with crank levers $n q$, piroted arms $\mathrm{O}$, angular connections $\mathrm{R}$, and braces $\mathrm{H}^{\prime} \mathrm{H}$, as constructed and arranged with beams I, C and $F$, substantially in the manner and for the purpose as herein shown and described.

2.-In combination with the above, the hinged extension $u$ of the arm E, substantially as shown and described.

No, 103,537.-HENRY A. ADAMS, SANDWICH, 1 LI. Cultivators.-Mhy $31,1870$.

Claim.- I.- The combination of the extensions $\mathrm{E}$ with the bent axle arms $\mathrm{D}$ and elevated axletree $\mathrm{A}$, for the purpose specified.

2. - The combination of the thimbles $\mathrm{L}$ and the draught bolts $\mathrm{F}$ with the upper axletree and the lower axle extensions, for the purpone specified.

3.- The adjustable yoke $\mathrm{H}$, in combination with the thimble $\mathrm{L}$, for the purpose specified.

4.- The combination of the plates $\mathrm{J} J$ and the adjustable yoke for attaching the plough beams to the draught bolts, with a flexible connection capable of vertical adjustment, for the purpose specified.

5.-The combination with the axle extensions $\mathrm{E}$ and draught bolts $\mathrm{F}$, of the eye bolts or draught rods $\mathrm{M}$, for the purpose specified.

6.-A tie rod, having its forward end attached to the cross-tree or tongue of the cultivator, and its rear end laterally adjustable, in combination with a laterally adjustable draught bolt, for the purpose specified.

No, I03,918,-HENRI W, OSTROII, GRAND RAPIDS, Mich.-Cultivators, - Fune 7,1870 .

Claim. - I. - The independent cross beam C, arranged adjustably on the :tandards O, substantially as and for the purposes sct forth.

2.- The combination of the sections of plough beams $\mathrm{B} \mathrm{B}^{1} \mathrm{~B}^{2}$, levers $\mathrm{E} \mathrm{E}^{1} \mathrm{E}^{2}$, chains $\mathrm{I}^{\prime}$, catches $\mathrm{G}$ on tongue $\mathrm{K}$, standards (), cross beam C, and chains 1 , all arranged in frame $\mathrm{A}$, to operate as herein described and shown.

No. 104.334-W.INUEL II. MITCHELL, EI. PASU, IL.L-Cultizutors. - Func 14, 1870,

Claim.-1.-In combination with the bent axles D D, herein described, the arljustahle scalloped plates $y$, and eye holts $\approx z$, whereloy the plough beams are attached in such a manner as to have a double vertical adjustment, as specified.

2.- In c mbination with the clamp $s$ and connecting rods $r r$, the eye bolts $z^{\prime}$ and the excavated slotted thimbles $t t$, provided with the spikes or points $i ;$ whereby they are f revented from turning on the wool of the plough beam, as specified.

No. I04,399.-JOSEPH ADAMIS, MANTENo, 1L.L.Cultivators.-June 21, 1870. Antedated June 11, 1870.

Claim,-1.-The crank screws $G$ and nuts $F$, to which the forward ends of the plough beams are jointed, in com bination with the frame work of a cultivator, substantially as herein shown and descritied, and for the purpose set forth.

2.-The right-and-left screw $\mathrm{C}$, provided with a lever or handle, D, in combination with the adjacent ends of the axles 1 , substantially as herein shown and described, and for the purpose set forlh.

3.- An improved cultivator, formed by the combination of the wheels $A$, axler $B$, right-and left screw $C$, provided with a handle or lever, $\mathrm{D}$, plough beams $\mathrm{E}$, jointed to the nuts $\mathrm{l}$, and swiveled crank screws $\mathrm{G} g^{\prime}$, with each other, and with the branched tongue $\mathrm{I}$, substantially as herein shown and described.

No. 105,225-JUNATHAN LEWIS, WAsHINGTON, D. C.-Cultiviators.-July 12, 1870 .

Claim.-The construction and arrangement of the plough standards $H$ II, beams $G\left(i^{\prime}\right.$, levers $L$, coupling rods $L^{\prime}$, and cross bars $\mathrm{M}$, with the hangers $\mathrm{F} \mathrm{F}^{\prime \prime}$, rod 1 , an $l$ adjusting pins $a a$, all as and for the purpose specified.

No. 105,630.-NOAH G. BLAUSER, ETNA, OHI\%.Sulky-Cultinators.-Fuly 26, 1870 .
Claim.-The improved cultivator, consisting of the tongue $\mathrm{C}$, honnds $\mathrm{D}$, axle $\mathrm{B}$, wheels $\mathrm{A}$, triangle $\mathrm{F}$, plough beains $\mathrm{E}$, pivoted adjustable ploughs $\mathrm{G} g^{1} g^{2}$, rollers $\mathrm{Q}$, lever $\mathrm{S}$, chain $\mathrm{R}$, foot levers $\mathrm{O}$, rods $\mathrm{N}$, bar $\mathrm{K}$, standard $\mathrm{N}$, bar $\mathrm{J}$, uprights $\mathrm{H}$, adjustable bars $\mathrm{I}$, and scraper $\mathrm{Y}$, removably attached to the tongue $C$, all constructed and relatively arranged as shown and described.

No, 106,039.-JEFFERSON ESHLEMAN, CANAAN CeNTRE, OHIO, assignor to himself and LEVI E. MILLER, same place.-IItheel-Cultivators.-August 2, 1870.

Claim.- The spring metal link F, constructed of a bow shape, and used in combination with the pivoted tooth arm $\mathrm{H}$ and bent lever $\mathrm{N} k$, on the cultivator axle $\mathrm{A}$, said link serving as a means both of raising the tooth $\mathrm{J}$. from the ground and of holding it down to its work under a spring pressure, substantially as herein set forth.

No. 106.161.-SETH B. HOISINGTON, GAIESBURG, 1LL.-Cultirators.-Ausust 9, 1870.

Claim.-1.-The combination and arrangement of the plate $\mathrm{N}$, with its cross hear $\mathrm{N}^{\prime}$, with beam $\mathbf{U}$, plates $\mathbf{F}$, bolts $\mathrm{G}$ and $\mathrm{H}$, and $\operatorname{rod} \mathrm{C}$, substantially as and for the purpose sf ecified.

2.-The arrangement of bearings $\mathrm{E}$, eye bolt $\mathrm{D}$, axle $\mathrm{A}$, and rod C; substantially as and for the purpose specified.

3.-The combination aud arrangement of beam $U$, hook $W$, and nut $W^{\prime}$, socket $V$, bolt $Y$, and nut $V^{\prime}$, with shank X, substantially as and for the purpose specified.

No. 106,35t-JOHN L. GRAHAM, Bentley STATroN, ILI.-Cultizators.-August I6, 1870

Claim. - The combination and arrangement of the pivoted part $\mathrm{E}$, rod $\mathrm{H}$, crank $\mathrm{l}$, its vertical shaft and lower crank arm $K$, and connecting rod to back end of frame $\mathbf{L}$, sub. stuntially as and for the purpose specified.

No. 106,579.-EDWIN D. HATCH, OCONomowoc, Wis.-Wheel-Cultizators,-August 23, 1870 .

Claim. - The arrangement of the axle $\mathrm{C}$ with the adjustable screws $\mathrm{A}$, frame $\mathrm{D}$, and lever B, substantially as set forth, and for the purpose spec fied.

No. IO6,728-JOHN RO()T, HARTLAND, N. Y.-Cultirators.-August 23,1870 .

Claim,- The combination of the ad ustable frame $\mathrm{C} \mathrm{C} d d^{1}$, draught pole $\mathrm{E}$, jointed brace rods $a$, axle $\mathrm{A}$, guide stirrup J, and operating lever L, all arranged and operating substantially as hercinbefore set forth.

2.- The combination of the laterally adjustable plough beams $\mathrm{D}$, vertically adjustable frame $\mathrm{C} C d^{1}$, connecting har $G$, and lever $F$, arranged and operating as herein shown and descritied.

No. IO6,743.-STERL1NG C. THORNTON, MACOMB, TFX is.-Combined Gang Ploughs and Cultizators._Augrust $23,1570$.

Claim.-1.-The frame A, axle B, radial arms $h$, curved arms $c$, lever $h$, and fulcrum post $i$, said lever and fulcrum post being located on the central line of the frame, and operating to raise both sicles of the lattir equally at the same time, and all the part specitied being arranged with reference to each other, as described.

2.- The lraces $m^{\prime}$, standard $i$, cross bar $n$, and frame $A$, the said cross bar being placed upon tne said frame, and all the part, specified being arranged with reference to each other, as described.

3.- The frame A, standards $i$, rigidly attached to the frame, doubletree $\mathrm{H}$, bars $z \%$, and rods $x$, the latter connecting the doubletree directly to the stantlard $i$, and all the parts sprecified being arrarged with reference to each other, as described.

No. 107,110,-CLARK STINTZ, Clark Colnty, OHIo,--Corn Ploughs and Planters.-September 6, 1870.

Claim.-1.-The combination of draught bar $\mathrm{E}$ with stay plate $\mathrm{P}$, doubletree $\mathrm{M}$, tongue $\mathrm{T}$, bolt $f$, and frame $\mathrm{A}$, when u`ed in a corn plough and planter, substantially as and for the purpose hereinlefore set forth.

2.- The arrangement of the angular foot levers $g g$, stirrups $j j$, suspending bars $\xi^{\prime} r^{\prime}$, and connecting rods $r r$, in connection with frame $\hat{A}$, tongue $\mathrm{T}$, and bolt $f$, substantially as and for the purpose hereinbefore set forth. 
No. $107,357,-W H 1.1 .1 \mathrm{AH}$ (iI1.MIAN, OTT.IWA, I1.L-

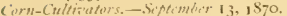

Clain.-The arrangement of the cross loar $\mathrm{A}$, gangs $\mathrm{B}$, flanges 1 ), axle $\mathrm{E}$, hrace $\mathrm{l}$, and tongue $(\mathrm{C}$, when constructed and operating together as rlescribed.

Ni), IOS,260.-VEXEND() P. IIARRIS, GRERSHR(;

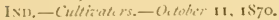

Chim.-1.-The combination of the pole A, cross bar $C$, and axle 13, secured together as described, with the equalizer bar E, chains $d d$ and $w$, and pulle. ¿, all constructed and arranged suhtontially as set forth.

2.-The combination of the rod $G$, with arms $\mathrm{V} V$. having flanges $r r$, lever $\mathrm{W}$, cords or chains $s . s$, windlass $\mathbb{X}$, and rods $t$, with the axle $B$, and culivator heams $11 \mathrm{H}$, ali constructerl and arranged substantially as shown and described, and for the purposes herein set forth.

3.- The combinition of the plough beams H J, adjustable double stocks $S \mathrm{~S}$, and dauble brices $\mathrm{T} T$, and the shovels $\mathrm{L}$, with flanges $\uparrow$, all substantially as set forth.

4.- The arrangement, upon the rear end of the clraught pole $I$ of a cultivator, of the double hinge $y$, for adjusting and holding the seat $\mathrm{R}$, substantially as herein set forth.

5.-The combination, with the beams H H, the arma $\checkmark \mathrm{V}$, with flanges $r r$, and connected to the $\operatorname{rod} \mathrm{G}$, all as shown and described.

6.- The combination of the beams J J, uprights MI M. cross piece $\mathrm{N}$, double $\mathrm{T}$-shaped bar $\mathrm{L} \mathrm{L}$, on the bar $\mathrm{I}$, and swivels $K \mathrm{~K}$, all sulsstantially as and for the purposes herein set forth.

No. IOS,392.-THIOMAS M. REED, (iERMANTOW: () Ho-Cultizentors-Oitoby 18, is7o.

Claim.- The arrangement of ploughs e $e$ with roller J, and their operating mechanism, in combination with the su-pended harrow $H$, substantially as and for the purpose specified.

No. 10S,945-D.NIEL C. STUIER, LANARK, ILL-

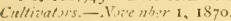

Claim - - I - The combination of the short sliding eyebearing J, long tubuler bearing $\ell$, and retaining screw h, substantially as described.

2.-The short axle extension $\mathrm{P}$, tuhes $t$, braces $c d, c^{2}$ and forked tongue, combined suhstantially as and for the purpose described.

3.-The tuhular eye bearing J. with perforated ears, in combination with the short axle extencions $P$, tulse $t$, plates $G G$, and bean $D$, suhnt intially as described.

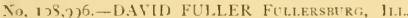
- Attuchment of Cultirator-Frame's to Wisen Axtetres. Viviember $8,1870$.

Claim. - The arran rement in a culivator of the beam $\mathrm{F} \mathrm{F}^{\prime}$, pivoted levers $\mathrm{K}$, foot board $\mathrm{K}^{\prime}$, arljustable seat $\mathrm{L}$. connecting rods $h h^{\prime}$, and clevises $j j^{\prime}$, constructed substan tially in the manner and for the pirpose hereinbefore set forth.

Vi) IOO,129.-HENRY IIOWE, ONEONTA, N, Y.-

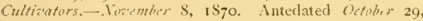
1870.

Claim.-The plos $\mathrm{h}$ heam: $\mathrm{E}$, hung to the main frame of the machine by rearwardly swinging pendants $G^{\prime} G^{\prime}$, in combination with the lever $a$ and chains $c$, so arranged and operatng as to cause the plonglis to rise from the earth on coming in contact with an olsticle, substuntially as shown and described.

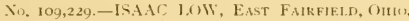

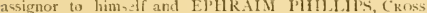
CUT, PA.- Cidticutors, - Virember 15. I870

Claim.-1.-The combination of the levers $x$ and pivoted lonps or connecting rods 1' with the cross beam D and cultivator frames $\mathrm{H}$, substantially as herein shown and described, and for the purpose set forth.

2 - The arrangement of the wheels $\mathrm{A}$, axle $1 \mathrm{k}$, standards $\mathrm{C}$, tongue $\mathrm{E}$, cross beams I) $\mathrm{G}$, braces $\mathrm{F}$, double plough frames 1 , tandaris $K$, braces J 1 , rods .1 , levers $X$, and rods $\mathrm{P}$, constructed as and for the purpose described,
No, 109.363.-13EXJAMIN F, VOUNG, Tw LON, II.t.. - Cultizators- Vorember 15, is7o.

Claim.-The arrangement of the plate $k$, lever $\mathrm{N}$, rocking shaft $\mathrm{I}$, arms $Q \mathrm{Q}$, link $n^{\prime}$, shield $\mathrm{V}$, braces $y$ and IV, parallel motion bar $\mathrm{X} \times$, stirrups $\mathrm{I}, \mathrm{L}$, plough slaudards $\mathrm{K} \mathrm{K}$ and I I, with braces J J, all as shown and set forth.

No, 109.403 -WIL1.1AM FRENCH and JAMES CRAWF(ORI) FREN(H, KEOKUK, IOWA, assignors to WILLIAI] FRENCIl, same place.-Corn-Ploughs.Vie'mber 22, 1570.

Claim.- In a com-plough, the arrangement of the axletree I $\mathrm{B}$, shaft $\mathrm{FF}$, yoke $\mathrm{H}^{\mathrm{H}} \mathrm{H}^{\prime}$, vilbrating-luars $\mathrm{R}$, evener $\mathrm{I}$, draft-rod $\mathrm{V}$, and brace-rod $\mathrm{IV}^{\prime}$, as specified-

No. 109,554-JAMES B. SEXTON, PElla, JUWA.Cultizators - Vizember 22, 1870

Claim.-1.-In a cultivator, the diamond-shaped couplings $c c$, when constucted and arranged subtantially as and for the purpose specified.

2.- In a cultivator, the adjustable and corrugated axleplate $H$, when constructed and arranged as and for the purpose set forth.

3.- In a cultivator, the plate $Z$, pins $u u$, and cap $z$, with the screw-nute, as described, when the several parts are constructed and arranged substantially as and for the purpose specified.

Ni) 109.754.-EINIIN R. POWEl.L, JEFFERSONYILI.E,

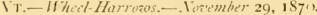

Claim. -1.-The combination, with the sulky-frame A B (. $\mathrm{L}$ and harrow proper $\mathrm{G}$, of the truck $\mathrm{E} F$, hinge-joints $\mathrm{J}$ $\mathrm{K}$, and chains II I M, constructed and arranged substantially as described and represented, for the purpose st forth.

2.-The tuoth g, composed of the cast point $1+6$, steel mould-hoard 2, and bolt 3. constructed and arranged as represented and described, for the purposes set forth.

3.- The axle-tree A, wheels B B, tongue C c, seat D, pulley-bracket ' $\mathrm{N}$ ( $)$, and hand-lever I. I, the whole constituting an improved sulliy-frame, as constructed, combined, and arranged in the manner shown and described, for the purposes set forth.

Vi) II0,046,-FREEMAN C. JEWELL, RAHWAY, N. J.-Cinllizators.-Dicember $13,1870$.

Claim-1-A cultivator-frame, formed of the bars B and upwardly-curved cross-bars $\mathrm{A}$, the arms $\mathrm{C}$ D E, and rods $\mathrm{F}$, when constructed and adjusted together as described.

2. - The beam ( $i$, slotted bars $H$, and the plough-standards, combined with a viluratory frame A B C D E F, to adjust the pitch of the ploughs, as described.

3.-The slotted and bent plough-beams, having their rear slotted parts thickened or flanged, in combination with the rod $\mathrm{F}$, slotted bars $\mathrm{H}$, and the standards of the plough 1 , substantially as herein show'n and described, and for the purpose set forih.

4.- The upper ends of the standard of the ploughs I, constructed substantially as herein shown and described, to adapt them for attachment to the slotted beams G, sulstantially as herein shown and described, and for the purpose set forth.

5.-The anus D E $\mathbf{F}$, crank-arms $\mathbf{J}$, bowed axle $\mathbf{K}$, lever 1, bar $\mathrm{U}$, and catch $\mathrm{N} n^{1} n^{2}$, when all are combined and acljusted tugether, as and for the purpone described.

No. IIo,IO9.-HENRY BEIAIONT, ROMFORD, ENG: 1.AND.-Werlines for Tilling or Cultizating - December 13 , 1870 .

Claim.-1.-An improved cultivating or digging-machine, constructed > uhatantially as described, having a number of strong forks, $f f f f$, fixed in a frame, $d$, which is suspended within another frame, $c$, upon the arms of crank-axles $b b$ of carriage-wheek $a$, arranged so that at each turn of the wheel with the machine moving forward the forks $f f$ are, by mean of the crank-axles, forced into and brought out of the grouml to lreak up the soil.

2.- The digging-forks $f f$, in combination with the suspended frame $d$ and the crank-axles $b b$, arranged and operating as and for the purjose described.

3.- The cultivating-machine, so con-tructed as to allow the ure of interchangealile parts, as described. 
No. 110,133.-TAMES M. HARFER, E1. PASt, I1.1.Ilarrozos.-December 13, IS70.

Claim. - In a wheeled straddle-row cultivator, the harrow attachment herein described, when constructed with a front shovel-plough, $\mathrm{B}$, and side metal bars or plates $a d$, substantially as and for the purpose specified.

No. 110,256.-ISAAC B. MIIION, DUNK1RK, (1HI1.Cultizators.-December 20, 1870 .

Claim.-The arrangement, in a cultivator, of a bi-branched pivoted beam (' ' C' and detachable guides I', as set forth, for the purpose of enabling the fifth plough ' $A^{\prime}$ to be readily removed or lifted up simultaneously with the other ploughs.

No. 110,257 - -ISAAC B. MAHON, DUNKIRK, OHIO,Cultizutors.-December 20, 1870 .- Antedated Detembit' 15,1870 .

Claim.-1.-The combination of clip E and washers $\mathrm{G}$ F with braces D D and wheels B B, as and for the pur pose described.

2.- The curved connecting-har I', perforated as set forth, combined with a pair of pivoted cultivator-beams $1 \mathrm{~J}$, for the purpose of rendering the latter susceptible of adjustment with respect to each other in a vertical direction.

No, Ito, 302,-PETER E. SNITII, SC TLAND NECK, N. C,-Cultivators,-Devember 20, 1870

Claim,-1.-The lifting-arms $M$, sliding upon an in dependent shaft L. combined with the arljustable axle B C, to enable the distance between the cultivators to be grad uated without detaching any of the parts.

2.- The perforated spring-bar R, applied, as described, to an independent rock-shaft, L, the arms $\mathrm{N}$, for the purpose of enabling said arms and shaft to be secured at any desired point of adjustment.

No. 110,548.-JOSEPH H. CARLOW, KIDDER, M[1,Cultivators.-December 27,1870 .

Claim.-I.-The combination and arrangement of the beams $\mathrm{J} \mathbf{K}$, adjustahle hars $I \mathrm{I}$, pin $i^{3}$, strap $\mathrm{L}$, and pin $j^{1}$, allowing the easy adjustment or removal of the beams, sul, stantially as described.

2.- The combination of the beams $\mathrm{J} \mathrm{K}$, upright $\mathrm{N}$, rod $O$, chain or cord $P$, and treadle $R$, as and for the purpose described.

No. IIO,853.-HUGH P. JORDAN, VICTORIA, TEXA4. -Sulky-Cultizators.-January 10, IS71.

Claim.-1.-The frame-work of the cultivator, consi-ting of the bent axle-tree B, bari C, rear cross-bar N, tongue $\mathrm{E}$, and brace-rods $\mathrm{F} O$, said parts being constructed and arranged substantially as herein shown and described, and for the purpose set forth.

2.- The plough-standards $\mathbf{K}$, draft-bars (), plough-standards $\mathrm{R}$, and draft rods or chains $\mathrm{U}$, constructed and arrans. ed in connection with the bars $\mathrm{N} \mathrm{C}$ and axle-tree $\mathrm{B}$, substantially as herein shown and described, and for the pur pose set forth.

3.- The combination of the shaft or roller $\mathrm{X}$, levers $\mathrm{W}$, and connecting-rods $\mathrm{V}$, with the plough-standards $\mathrm{K} \mathrm{R}$ and bars $\mathrm{C}$ of the frame-work of the cultivator, substantially a herein shown and described, and for the purpose set forth.

4.-The combination of the levers Z and connecting-rod $\mathrm{Y}$ with the plough-standards $\mathrm{R}$, and with the cross-bars $A$ attached to the braces $\mathrm{F}$ of the frame-work of the cultivatur, substantially as herein shown and described, and for the purpose set forth

No. 111,037 -GEORGE WALTER BRONGON, OTTAWA, ILL.-Cultizators.-Jantary 17, 1S71.

Claim.-1. - The slide-bars $H$ 11, in combination with the boxes I I, the stems I I, the chains P P, and the plough beams $\mathrm{K} \mathrm{K}$, substantially as and for the purpose described.

2.- The sliding braces $\mathrm{K} R$, in combination with the plough-handles $\mathrm{L} L$ and the plough-bcams $\mathrm{K} K$, subutan tially as described.

No. II1,056.-THOMAS HARDING, LA FAYETTE, IND.-Ploughs. - Fanuary 17, 1871

Claim. - 1.-The axle B, constructed with the cast-iron end pieces $b \quad b$, when said end pieces are provided with sockets $d d$ and flanges $c c$, for the purposen described, and the wooden cross-bar, as set forth.

2.- In a straddle-row cultivator, the draft-pole $A$ and a double crank-axle $\mathrm{B}$, when joined together substantially as described, so that said draft-pole and axle can lie adjusted in height, for the purpose set forth.

3.- The combination of the double crank-axle $\mathbf{B}$, tongue $\mathrm{A}$, jointed thereto by means of the strap $\mathrm{D}$, and the braces E, for the purpose of adjustment, as set forth

No. III, 256.-H. MUKTIN ROSE, Cl.iNTuN, ILL.Cultivutors.-Fanuary $2+187 \mathrm{I}$

Claim. - I. - The combination of the seat and its adjustable arms $C^{\prime}$ with the bifurcated end of the tongue $C$, subtantially as described, for the purpose specified.

2.-The combination of the slotted block i', with the driver's seat $\mathrm{B}^{\prime}$ and the seat-arms C', for the purpose specified.

3.-The ploughs and beams of a wheel-cultivator suspended beneath the axle from the upright frame E, mounted thereon by means of the bent adjustable bars $H$, and adjustable frame I, sulstantially as herein shown-and described.

4.-In combination with the adjustable pendent bars $\mathrm{H}$ and plough-beams, the adjustable frames I, slotted bar J, and adjustable loops $K$, substantially as described, for the purpose specified.

5.- in combination with the adjustable frames 1 , and slotted bar J, the wediges $r$, substantially as described, for the purpose specified.

6.- The beveled recensed hlocks $\mathrm{X}$ and eye-bolts $\mathrm{V}$, contructed as described, and applied to the beams and standards in the manner herein set forth anil shown, for the purpose specified.

7.-The foot-horns I', constructed as described, and adapted for adjustment upon the plough-beams in the mamer set forth, for the purpose specified.

8 . - The jointed adjustable levers $K$ ', constructed as described, and provided with the friction-rollers $m^{\prime}$, in combination with the guide-frames $I$ and plough-beams, substantially as and for the purpose specified.

9.-The plourh-beams, when connected at their forward ends to the drait-pole by means of the pivoted plates y and pivoted block $O$, substantially as described, for the purpose pecilied.

No. 111,432 - -JARVIS CASE, LA FAYRTTE, IND.Cultututars.-Januart 31,1871 .

Claim. - I - A cultivator having the axle $\mathrm{A}$ attached rigidly to the tongue, and provided with the arms $A^{\prime}$ having wheel attached, in conbination with the beams hinged to the ho.ly $\mathrm{A}$ of the axle, and extencling back ward far enough to cause the line of draft extending from their hinged point to the shoveln to fall in rear of the longitudinal plane of the armis $A^{\prime}$, sulistantially as and for the purpose set forth.

2.-The loops E, hinged or clasped to the axle $\mathrm{A}$, in combin ition with the beams having the laterally-pro;ecting arm at its fronl end, whereby the leams can be attached rigilly or lowsely to the loojs and still be at liberty to move vertically, substantially as describeci.

No. III,7S1-MARSHALA,SATTEEY, TAYURVILLr, ILL.-Cullizaturs. - Fitirury It, IS7I.

Claim. - The aslen $\mathrm{B} \mathrm{B}$, each extending out about onethird the clistance between the hubs of the wheels, combinect as descrilned, with a right-angled har, C C, and obtuseangled bar, 13 1), the former fastened to said axles at the outer part and the latter at the iuner part, near the hub, al as and for the purpose set forth.

No. II ,496.-RICHARD B. ROBBINS, ADRIAN, Nicu. - Sulky-Cultizators - Narch 7, I871

Claim.-1he spring $h$, connected with the shank of the side rail of the frame $\mathrm{D}$, and the pendent arm of the crossbar, and in combination therewith, substantially as specified.

No, $112,994,-F R A N C l S$ N. WELIDEN, ROCKFORD, ILL.-Cultivators,-Mareh 21, IS71.

Clain, - 1, - The iron c, bent os descriled, in combination with the beams $\mathrm{E}$, when alt iched to the tonguc at or near the evener as rlescriberl.

2.- The spring bolt $h$, contructed specifically as described, that $\mathrm{i}_{r}$, with its covering plate extending over and ahout the lever, for the touble purpose of preventing the lever from moving laterally, and for protecting the internal bolt mechanism, as describerl.

3.- The combination of the standard F, rack bar I, le:er $\mathrm{H}$, and larace rod $i$, the parts being arranged as de- 
scribed, that is, the rack bar being secured above to the standard, and held below from vertical and lateral movement by the brace rod, without other support, the lever also being hinged to the standard and secured to the rack har as described.

No, $113,019 .-L E R$ IV. CONNER and RI(II.IRI) (i.

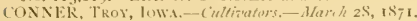

Chim,-1-The axle 1 , constructed as described, and combined with the beam I) and eye bolt $d$, substantially an described, and for the purpose specified.

2.- The arrangement of axle $A$ and tongue 13 , double tree $C^{\prime}$ and rods $c$; with beams I) D, shanks E and F, forks $G G$, and hracen 11 and $F$, substantially as and for the purpose specified

No, 113.511 - IUl

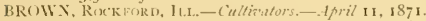

Claim,-1.- The seat $h^{\prime}$, constructerl apecifically as deseribed, in combination with the curving serrated support $/ h$, as set forth.

2.-The combination of the auxiliary frame with the main frame when the former is hinged to the litter forward of the neck yoke, as described.

3. - The aljustable font rest P, when constructed as described, and combined with the supporting beam. as set forth.

4.- The jointed shovel beam M N, provided with means of adjunting and securing the relative position of the part MI $\mathcal{Y}$ without interfering with the free movement of the auxiliary frame relatively to the main frame, as described.

5. - The combination of the seat $h^{\prime}$, adjustable as de scribed, with the adjustable sent arms attached to the main frame, as set forth.

6. - The har $\mathrm{C}$ provided with pulleys $c \epsilon$, rigid pendant $C^{\prime}$ with pulleys $d^{\prime} c^{\prime}$ and stay rod $d$, in combination with the rod $c^{\prime}$ and chain $f$, as described.

No. II 3.520.-AI.MION IHUNT, MICOMB, ILL.-Cultiz'aters.-1pril i I, IS70.

Claim. - 1. A wheel-cultivator composed of frame A A', axles $\mathrm{E}$, bolts $\mathrm{G}$, thimbles $\mathrm{H}$ having studs $h$, beams $\mathrm{D}$, plater I, and bolts I, pole B, and equalizer K I. N, the whole constructed and operating substantially as and for the purposes set forth

2.- The thimbles $H$, constructed as described, and arranged to operate with axles $\mathrm{E}$ and beams $\mathrm{D}$, as and for the purpose set forth.

Xi. II4,232.-JAMES T. TROIVBRIDGE, AKRON, () H(1).-Seeders and Cultivators. - thril 25, IS7 I.

Claim.-1. - The metallic end piece $A$, when cast with a flange $a$, and luzsic on the top to receive the axle 1 ), and with a rocket for the end of the front cross bar $\mathrm{B}$, all constructed and arranged substantially as and for the purpose set forth

2.-The socket $k$, on the arm $g$, for securing the torth $h$, as described.

No. IH 4.42 -OR I ANDO M. POND, INDEPENDENCE, InwA. - Comlined Ploughs and Markers. - Mer 2, 1871 .

Clain-1.-The iron $f$, constructed as deccribed, and attached, by mean of the staple $c$ or other suitable means, for the purpose of holding and adjusting the plough arm I, substantially as herein set forth.

2.- The arrangement of the axle $\mathrm{A}$ b. wheels $\mathrm{C} C$, tongue $\mathrm{D}$, clevise $a n$ arms $\mathrm{E} E$ and $\mathrm{F}^{\prime} \mathrm{E}^{\prime}$, handles $(i)$ bars $d d$, ploughs $H 11$, plough arm - I $\mathrm{I}$, irons $f f$, and clamps $c e$, all contricted and arranged substantially a and for the purnoses herein set forth.

No, I14.767.-JOIN 11. CONLEY, MOINGONA, JWWA. - Cultizators.-ilay 16, IS71

Claim. - The two transerse iron arches D D, fastened together at each end in a common pair of sockets, $\mathrm{C}$ C. and diver,ing nuwarily toward the top, combined, a described, with the axles, as and for the purpose specified.

No. $115,138,-1 . E A N I) E R$ IVALKER, VICTURIA Trxas.-Cultivators.- May 23, $187 \mathrm{I}$.

Claim,- The combination of the pivoted side beams $\mathbf{E}$, to which the forward ploughs $\mathrm{H}$ I are attached, chains J, pulleys $\mathrm{K}$, and piwoted handles $\mathrm{L}$, with each other and with the heam 1 , sulatantially as herein shown and decribed, and for the purpose set forth.

No, 1t5,159.-TIIEOP'llll, I. CAPP, BLOOMNG-

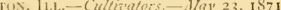

Clnim.-The arrangement of the cross pieces $\mathrm{D} \mathrm{D}^{\prime}$. the lraught pole $\mathrm{E}$, the straps $\mathrm{C} C$ ', the axles $\mathrm{B}$ and the wheels $\Lambda$, when each of said parts is construcled substintially as descriled and shown, as and for the purposes set forth.

No, 115,213 - IIOSES IOIINSON, THRE, RIVERS, VICH., assignor of one-half his right to JOIIN G. OTT, ande place.-Cullicaters and Wheding Machines.-May 23,1871

Claim.- The implement herein dercribed, consisting of the cross head $\mathrm{A}$, beam $\mathrm{B}$, shank $\left(\mathrm{C}\right.$, nuts $C^{2} c^{2}$, blades $\mathrm{D}$, and handles $\mathrm{E}$, when the same are constructed and arranged to operate as and for the purpose set forth.

No. 115.427 . -GUSTALUA D. BROWN, LEBANON, II.L._Corn-C'ultizaters, - May 30, $187 \mathbf{I}$

Claim,-In a cultivator, the arrangrement of standard quides $\mathrm{F} \mathrm{F}^{\prime}$ having slots $f$, plough $\mathrm{E}$, standards $\mathrm{E}$ ' having holes $c$, hand levers $G$, ratchet tandard $s^{2}$, plongh frame I having holes $\rho$, tongue $\mathrm{B}$, hand bar $\mathrm{C}$, segmental bar $\mathrm{C}^{\prime}$, eat bar $\mathrm{D}^{\prime}$, and seat $\mathrm{D}$ made adjustable, when all said parts are constructed to operate as described.

No, I1 5.459.-CONRA1) FURST, CHICAGO, ILL.Cultizators-1/ay 30, 1871

Claim. - 1.- The frame A. constructed as described, and extending hack of the axles, when so combined with the short axles $C$ that the ends of the plough beams may be raised and lowered, substantially an and for the purposes specified.

2,-The adjustable bars J, when combined with the frame and plough beams so as to move with the beams $\mathrm{F}$, snlatantially an deseribed.

No, 115,875.-PHILIT MAIER, MAPLETON, Wis.Cultiaturs.-Fune 13,1871

Claim.-The arrangement of the frame $\mathrm{A}$, axle $\mathrm{C}$, standards B having the self-locking pins $e$, the standards $h$, lever $\mathrm{D}$, hinged strap $j$, and hook $k$, as herein shown and described, for the purpose specified.

No, 117,215 . -JACOB W. SPANGLER, JACKSON Township, PA.-Cultizalors.- Fulj. 18, 1871.

Claim.-The arms I I having their lower extremities constructed with a clouble curve, as shown, in combination with the plough shanks $i j$ constructed with slots and slotted elbows, as described, substantially as and for the purpose specified.

No, 117,279.-NEWTON J. HARRIS, MEREDOSIA, II. - Cullinators. - Julv 25, is71.

Claim,-The frame D, constructed as described and having plough heams $O$ ottacher thereto, in combination with lever $\mathrm{E}$ and perforated bar $\mathrm{H}$, as and for the purpose specified.

No. 117.547.-HENRY P. KYNETT, LISBON, IOWA. - Cultizentors-August I, $187 \mathrm{I}$.

Claim.-1,-In a cultivator, the devices for attaching the front of the beams $t$. the frame, consisting of plates $\mathrm{A}$, with hinges $\mathrm{B}$, screw bolt $c$, and support swivel-standard B, substantially as described.

2.-The devices for raising and lowering the cultivators and allowing them to have the required lateral movements, consisting of the bar $\mathrm{D}$, lever $\mathrm{F} e$, and catch $h$, all constructed and arranged subatantially as described.

No, il 7, 803 - ANTHONY II. MYERS, HERMoN, ILL. - Cultiz'ators.-Ausust S, 1871 .

Claim, $\rightarrow$ The plates $\mathrm{L}$, chain $\mathrm{N}$, and pulley $\mathrm{P}$, when arranged to operate with the doubletree $\mathrm{K}$ and draught pole $\mathrm{A}$, as and for the purpose specified.

Ni), 118.053 -EDIIIN hEESE, EuTAw, Ar.A., assionur to C. M. REESE, same place.-Cullivators.Ausust 1 5, 1871 .

Claim.- The arrangement of the shovel frame $a$, bar or bow $c$, lever $f$, rock shaft $E$, chains $g, g$, and whiftletree $h$ with the frame $\Lambda$ and tongue $F$, as shown and described, to operate as specified.

No, II 8,371.-MIIREYBEAU 1). LAMAR, ATLANTA, GA-Cutton-Cultizators-duryst 22, 1871 , Antedated Aurust II, I $87 \mathrm{I}$.

Claim.-1.-The shifring wing 16 , arms 17 , and cranked 
levers 56, constructed and arranged as clescribed, in combination with ploughs 15 and angular frame 14 , for the purpose set forth.

2.-Cuff 22 , rod $2 \mathbf{I}$, angle knee 20 , curved lever $\mathbf{1 9}$, angular frame 1.4 , and curved rack 6 , ali constructed as described, and arranged relatively one to the other, as set forth,

3.- Wheel 2 provided with an annular row of teeth 44 , pulleys 26 and 27 , haft and pinion 25 , carrying also wheel 51 , arranged relatively one to the other, an and for the purpose specified.

4.-Curved rack 6 , pinion 8 , pawl Io, ratchet 9 , bandle wheel 11 , and slider 7 , arranged relatively to each other and to lever $\mathbf{I} 2$ and pinion 8 , as and for the purposes set forth.

No. IIS,562.-ARN()ID TOMIKINS, PARIS, II.I.Cultizators - Iugust 29. 1871 .

Claim. - The combination of the axle G, guide pieces S., plates $\mathrm{F}$, and side pieces, when operating tugrether as described,

No, 118,567,-NICHOLAS WHITEHALL, NEWTown, JND.-Sulky Cultizutors.-Ausust 29, I87 I

Claim.- The improverl machine formed by the arrangement of the tooth bars $G$ G and L L and foot supports or levers, centre benm I, heams J J and N N, cross pieces H and $\mathrm{M}$, bent axle $\mathrm{C}$, cros piece $\mathrm{D}$, bar $\mathrm{E}$, and bearing bars B B, as shown and described, operating as speci fied.

No. 119,205.-JOHIN A. V]ARS, SHerman, TexA5.Whicl-cultizutors. - September $\mathbf{1} 9, \mathbf{1} 8_{7} \mathbf{1}$.

Claim. The double frame $A$, composed of the framen D I), the interior frames $\mathrm{H}$ II rained and lowered on the cranks $\mathrm{K}$, the caster wheels $\mathrm{C} \mathrm{C}$, and main $w$ heels $\mathrm{B} \mathrm{B}$, all constructed, asranged, and combined substantially as and for the purposes described.

No. I19,750.-DAIII B. EBERLY, PINE VILIAGE, IND.-Cultivators.-Oitolier IO, IS7I.

Claim.-1.-The device formed by the shovel O provided with the spring cap $\mathrm{P}$, the standard $\mathrm{K}$ having a vertical and horizontal prition with an open slot, L, at its front end, pivoted at XI and clamped at $\mathrm{X}$, in combination with the beam II, c m-tructed to operate as hereinbefore described.

2.- The slotted angular arms D D, lnop F, with nuts and screws $d$, slotted braces $G$ G, perpendicular journals $E$ $\mathrm{E}$, and plungh-frames $\mathrm{H} \mathrm{H}$, arranged relatively one to the other, as and for the purpose hereimbefore set forth.

3.- In comlination with the double-pointerl shovel (), the spring-cap $\mathrm{P}$ secured thereto by the rivets $i i$, and screwb.jt $j$, for the uses and purposes hereinbefore set forth.

No. 120,073,-PHIIIP R. JENkiNs, Cotroniti.t., IowA.-Cultirators.-Ocluber 17, 18, I.

Claim.- The arrangement of the frame D E at an elevation above the axle in the rear, and at a deprescion below the same in front, while rigidly supported on the axle at about one-third the distance from the front of aid frame, as and fo: the purpose specified.

No. I 20,435.-PHILH' HEWITT, FARMLAND, IND.Sulky-Cultiraters. - Octobir 31,1871

Claim.-1.-Fenders, formed of spiral-wire conls R, and attached to plates $Q$, on the insicle of the cultivator-plonglis, in and for the purpose specified.

2.- The combination of frame S provided with levers $Y$ $\checkmark$ and having slots thereon, the beams I I provided with levers $U \mathrm{U}$ passing through said slots, and the frame I) having seat $\mathrm{F}$ on the rear thereof, all con-tructed and arranged as and for the purpose specitied.

No. 120,684.-JERONE H. TOMLINSON, HoEst CARrole, Ile.-Cultirators, - Vivermber 7, 1871 .

Claim.-A wheel cultivator having the end-piroted Leam $\mathrm{E}$ E of the ploughs attached by the describerl connecting mechanism to the pivoted axles of wheels $C$ C, as describerl, sis that as the plowman moves the bandles of his plougbs laterally both ploughs and wheels will correspondingly adapt themselves to the sinusities of the rows and avoid cutting up the plants.

No. 120,692,- WILLIAM C. WILSON, BRUNSWICK,

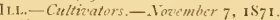

Claim.-1. - The shovel $h$, baving the pins or bolts $k f$ eyed loosely to a strap on the back thereof, in combination with the shoe $]$ provided with the oval slots or boles $m$ and ears with holes $i$ ifor receiving the bolts or pins, sulstantially as described.

2.-In a wheel-cultivator, the construction and arrangement of the axle B with it braces $c c$ and $d d$, holes $c e c c$, tongue $\mathrm{C}$, hounds $g g$, and hooks $n n$, wheels, A A and the beam $\mathrm{F} F$ with extension. $\mathrm{E}, \mathrm{E}$ and shovel-stems $\mathrm{G} \mathrm{H}$, all as thown and described.

No. 120,732.-JOHN FANING and FRIEDRICII LECil.ER, BURI.INGTON, IowA.-Cultitators,-Voe'mber 7,1871 .

Claim.-1.- The semicircular contrivance J, with its ap pendages $n$ and $s$, cunstructed and operating as described. 2.-The combination and arrangement of the axle B C with its perforations, pins, or bolts $c c$, tubular devices $r \quad r$, beams P P, wheels A A, and parts $b$ b, all constructed, arranged, and operating substantially in the manner and for the purposes berein clescribed.

3.- i he combination of the inner and outer perforater arms of the axle $\mathrm{B} \mathrm{C}$, bolts or pins $c c$, and the grooved parts $b b$ of the wheels, for adjusting the height of the axle and at the same time maintaining the proper relation of the beams and sbovels to the ground, as berein set forth.

No. 121,114-ABRANI M. MANNY, LENA, ILL, Cultizators.-Nove'mber 21, I871.

Claim. - I - The combination of the heams E, having bent rods $\mathrm{E}^{\prime}$ pivoted on the under side of the tongues $c$ to bolt $d$, v.brating lever $\mathrm{D}$ having hook $d^{\prime \prime}$ at its rear end, segmental supporting bar $\mathrm{D}^{\prime}$, and chains $b \quad b$, constructed and arranged to operate in the manner described.

2.-The arched adjusting-rod $G$, having auxiliary rod $g^{\prime}$ attached thereto, in combination with the hnok $g$ on tongue $c$, in the mamer and for the purpose descrilsed.

3.- The combination of the inclined handles $\mathrm{H}$, beams $c$, ch:rins $b$, and vibrating lever $D$ having hook $d^{\prime \prime}$, construct ed in the manner and for the purpose of raising and holding the beams at any point vertically, as described.

No. I21,115.-ABRAM M. IIANNS, LENA, ILI.Cultivators.- Vorember 2I, IS7I.

Claim. - The rigid frame of the cultivator, composed of the bent piece $\mathrm{C} C$, cross-girts $c$ and $c^{\prime}$, and curved metal part $\mathrm{C}^{\prime}$ loolted at it forward ends to pieces $\mathrm{C}$, and clamped to the upright pat of the arched axle I) by clamps $a$, in the manner described

Ni). 121,613.-MARQUUS L. (iORHAM, ROCKFrJRD, I1.t. - Cultiz'ntors.-December 5, IS7 I.

Clain.-1.- The comlination of the beams $C$ and crossbrace 1) with the plate $a$ and hammer-strap $b$, constructed in the manner and for the purposes as shown and described. 2.-The combination of the slotted adjusting-plate $o$ and stud ' $\mathrm{l}$ ' having a reces to receive the plough-standard with the standard (), constructed as shown and described.

3.- The combination of the angular beams T bearing upon axle $\mathrm{B}$ with the adju-ting screw-bolt $;$ and beam $\mathrm{C}$, constructed and arranged in the manner and for the purpose shown.

4.-The hangern $\mathrm{E}$ with sockets $t$ connected to vertical sockets $\mathrm{F}$ by stud $d$, arms $\mathrm{I}$, and links $\epsilon$, in combinntion with the lifting-levers $I$ and $\mathrm{L}$ and fulcrum-bracket $\mathrm{K}$, all arranged to operate in the manner described.

5.-The sway-bar $\$$ and rollers ", in combination with the slotted adjustable plates $k$ and beams or drag-bars 11 , constructed and arrangerl in the manner as descrilsed.

6. - The lever 1 . having lip $i$ and button $k$ thereon, in combination with lever $I$ and fulcrum bracket $K$, as described.

7.- The shields W pivoted to the forward ends of beams $H$, and suspended and adiusted by cords $x$ passing through the beams $T$, and by which cords the shields are raised at the will of the operator and independently of the beams $\mathrm{H}$ and of each other, as described.

No 121,670.-THOMPSON $C$. SEBRING, MIIFORD, asimor to BYRON G, STOUT, WALTER D. KING and ALGERNON $\rightarrow$. KJNG, PoNTIAC, Mich-W WhetCultizutors.-Detember 5, I87 I.

Claim.-The metallic hovel standard J, having a vertical groove at its rear end, flattened at the top, bent in a semicircular form, and braced to the frame, and secured to 
the circular shaft $C$ by means of the semicircular bolt $d$, which is passed through an opening in the standard below the shaft and clinched, and by the nut $c$ above the shaft, sulutantially as and for the purposes set forth.

NO. 122,28, - MBRAHAH P. ROIIREK, CIIRISTIAN F. ROIIRLR, and IOIIN II. BLOSE, CLAKKK

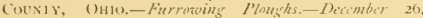
1371 .

Claim.-1.- The arrangement of the pivoted or balanced frame $C$, projecting frame $b$, fout board $b^{\prime}$, slide $i$, slot $i^{\prime}$. and loop $j$, as shown and described, as and for the purpose set forth.

2.- Spring cuch $s$, guide plates $s^{\prime}$ and platos o, arranged and combined with back rail $a^{\prime}$, plough beams $c^{\prime}$, and handles $m$, substantially as shown and descrilied, as and for the purpose hereinbefore set forth.

No, 122,400, OSCAR L. NEISLER, INUIANOLA, lowA.-Cultizators.- January 2, 1872.

Claim.- Passing the front end of my jointed bean $\mathrm{K}$ through one of the open spaces in the frame D and connect. ing the same with the evener $\mathrm{E}$, in the manner described, as a means of preventing the beam from lateral movement and at the same time allowing it free back-and-forth and up-and-down motion.

No, 123,235.-ADOLF F. CARLSON, ATTLA, IND.Cultizutors-Jonuary 30,1872 .

Clain.-1. - The combinat on, in a corn-plowsh, of the longitudinally-bisected box 1 , collar $\mathbf{E}$, arljustahle brace or stay $\operatorname{rod} \mathrm{G}$, and forked jaw $\mathrm{H}$, all constructed and arranired substantially as and for the purposes herein set forth.

2.-The combination of the bent axle A, wheels B B, tongue C, boxes D D, collar; E E, braces G G, jaws H H, plough beams I I, doubletree J, and singletrees L L, all constructed and arranged substantially as and for the purposes herein set forth

No. 123.715 - A. S. MCDERVOTT, OGDEN, IOWACultivators. - Februnry 13, 1872 .

Claim. -1.-The loose 1 urning and sliding collars $k k$, in combination with the independent cranks $g \mathrm{~g}$, chains $t t$ and in lependent laterally-adjustable cultivator leams $C$ $c$, all in the manner and for the purpose clescriberl.

2.-The combination of the piroted plough beams $\mathrm{C} \mathrm{C}$ independently adjustable and braced front guides $G^{\prime} G^{\prime}$, independ intly adjustable rear guicles $\mathrm{G} G \mathrm{G}$, later. ble loose collars $k$, chains $i t$, inclependent cranks $g$, adjusting stop levers $\mathrm{L} f \mathrm{~L} f$, and toothed segments $c c$, all arranged subst.untially in the manner and for the purpose descrilied.

No, 124.014-NILS F. SANDEIJN, NEW YURK, N. Y.-Cultivalors.-February 27,1872 . Antedated Fib ruary 10,1872

Claim,-The arrangement of the wheel L, spindle M, crank $Q$, lever $\mathrm{N}$, touthed bar $\mathrm{R} S \mathrm{~S}$, and notched stutl $\mathrm{T}$, in connection with the frame $A$, as shown and described.

No. 124,320.-TOHN E. BYERS, BU ILER, PA.-Culti vators.- Wurch 5,1872 .

Claim. - The combination of the bars 20 and 22, double tree 23, and chams 14 and 21 , and plouh heams 4 and 5 , substantially as and for the purpose specified.

No, 124,831-JUSEPH T. W. LARRABEE, NEWTOS, IND.-Cultizutors.-Warch 19, 1872.

Claim. - The balance draught pole $\mathrm{F}$, composed of two pivoted or hinged sections and secured to the axle $B$, in combination with the adjustable or variable weight $G$, driver's seat $G^{\prime}$, and $\operatorname{dog} I 1$, or its equivalent, as and for the purpose set forth.

No, 125,087 -NILS E, SANDELIN, MOTT HAVEN, N. Y., assignor to bimself. EDWARD O. JENKINA, NEW YORK, N. Y., and JOHN PAULSON, VASA, NINN. - Cotton Cultizators. - Warch 26, I 872.

Claim.- The combination of the adjusting bars $\mathrm{K} k$ with the gangs F F of weeler and ploughs, the bar $\mathrm{H}$, the lever 1 , the legs or bars $i i$, and the stop or cross bar J, substantially as shown and described.

No, 125,093.-JACOB W. SPANGLER, YorK, PA.Cultivators.- Warch $26,1 \mathrm{~S}_{72} 2$.

Claim.-1.-The slotted sector plates $\mathrm{E}^{1}$ provided with right angled arms $\mathrm{E}^{2}$, in combination with wheels $\mathrm{E}$, axle
A, pivots $c^{\prime}$, bolts $c^{\prime \prime}$, foot treadle $(i$, rock shaft $F$, and links $\mathrm{F}^{\prime}$, sulstantially as describel.

2,- The clips $h$, provided with shoulders, as described, in combination with the slotted rib II' and drag bars H, substantialiy as set forth.

No. 125,271.-ISA.AC: 11. CHAPPELL, LAWRENCE, KAs,-Cultirutors-April 2, 1872 .

Claim.-1.-The cultivator frame composed of the adjustable side beams C' C', connected at their rear ends by the cross bar $\left(i^{\prime}\right.$, and at their front ends by the cross bars $G(i$, where the frame is pivoted to the longitudinal bean $C$, which rest; on the axle $\Lambda$, all sulsstantially as set forth

2. - The bent plough beams H II' pivoted to the adjusta. ble bars $\mathrm{C}^{\prime} \mathrm{C}^{\prime}$, and the slotted guides $\mathrm{I}^{\prime}$, which are extended downward below the rear ends of the beams C', all substantially as set forth.

No. 125,961.-HUGH PAXTON JORDAN, VICTURI, Texas - Cultizators.-April 23, 1862.

Claim.-1.-The plongh standards $\mathrm{K} \mathrm{k}$, connected by hooks $L^{\prime}$ and baving side keepers, combined with pivoted bars $O$, pivoted bars $U$ having foot rests $E^{\prime}$, bars $B^{\prime}{ }^{\prime} \mathrm{N}$ provided with keepers, and lever E', all arranged as described, and applied to the frante of a sulky cultivator, for the purpose set forth.

2. - The band and set screw $C$, in comlination with the draught bars $\mathrm{O}$ of the outer plough, standards $\mathrm{K}$, and with the lower horizontal parts of the axle B, substantially as berein shown and described, and for the puryose set forth.

No. 126,156.-JAME; RUE, Englishtown, N. J.Cultizators - t pril 30,1872 .

Claim.-1.-The plates $\mathrm{A}^{3}$ and their holding means $\mathrm{A}^{4}$, changeable in position, as shown, in combination with the inclined frame pieces $\mathrm{A}^{2}$ and teeth $\mathrm{B}$, and suitable securing means $b b^{\prime}$, and arranged to serve therewith, as and for the purposes herein specified.

2.- The eyes $\mathrm{M}$ and arms or parts $\mathrm{M}^{1} \mathrm{M}^{2}$, connected by the movable or adjustable fastenings $m^{2}$, as shown, in com. bination with the link $\mathrm{K}$ and pole or tongue $\mathrm{E}$, when the latter has liberty to move forward and backward to a limited extent, all arranged and operatıng substantially as and for the purposes herein specified.

3.- The arrangement of the wheels $\mathrm{C}$, and levers $\mathrm{D} \mathrm{D}^{2}$, and notches or holding points $a^{1}$ serving relatively, to the teeth $\mathrm{B}$, frame $\mathrm{A}$, tongue $\mathrm{E}$, stirrup-link $\mathrm{G}$, and adjustable eye $\mathrm{M}$, as and for the purposes herein vet forth.

No, I 26, 828 , WIILIA II H. MURREY, BRODHEAD, Wis, assignor of one-half of his rigbt to SAMUEL N. G( )SLING, same place,-Cultizators-May 14, 1872 .

Cl im. - The combination of the rods $\mathrm{M}$, draft-pole C, axle 1 , staple $m$, seat $L$, bolt $y$, and bent plate $z$, substantially as and for the purpose specified.

No. 127.674.-GEORGE BRADI.ER, RockFokD, ILL, - Cultiziators.- Fune II, IS72.-Antedated Junc 5, 1872 .

Claim.-The plate I having corrugated concave $i$, plate $l^{\prime}$ liaving the corrugated convex surface $i^{1}$, and bolt $i^{4}$, in combination with the plough standards $\mathrm{E}^{\prime}$ and beams of frame $\mathrm{E}$, constructed and arranged as described.

No, 127,935.-JAMES G. STOWE, BHoMINCTOS, 11.L., assignor to "Bloomington Mavufacturtng CoMPANY," same place.-Cultiz'ntors.- - $u n$ 11, 1872 .

Claim,-The combination, with the plough-beams A A, of the L-shaped slutted blocks C C and bolt and screw $x$, all constructed and useil sulstantially as set forth.

No. 128,499.-.GILPIN MOORE, MGLINR, 1LL., assignor to DEERE \& CO., same place,-Cultivators.-July 2, 1872 .

Claim.-1,- The combined frame and axle tree B, composed of the two hows $b b^{\prime}$ and spindles $b^{\prime} b^{\prime}$, when constructed in one piece, in the manner and for the purpose specified.

2.-The coupling or joint-piece composed of the parts $\mathrm{K}$, L., M, and N, constructed substantially as described, and arranged to operate in combination, for the purpose specified.

No. 128,653.-HOWARD L. PIGG, KNobnoster, Mo. assignor to IVILLIAlI 1 . PJG(;, (for the use of MARY F. I'Ififi, same place,-Cittirators,-July 2, 1872. 
Claim - $\boldsymbol{I}$ - The combination of the yoke B connecting the plough-beams, connecting rods or chains $\mathrm{C}$ C', cranked rock-shafts $\mathrm{D} \mathrm{D}^{\prime}$ and supporting-hooks $\mathrm{F} \mathrm{F}^{\prime}$, substantially as and for the purpose specified.

2.-The combination of the yoke $\mathrm{B}$ connecting the plough-beams, connecting rods or chain $\mathrm{C}$ C', cranked rock-shafts $D^{\prime} D^{\prime}$, hooks $F F^{\prime}$, and adjustable arm $G G^{\prime}$, subatantially as and for the purpose specified.

No. 128,701. WILLIAJl P. liROWN, MAt.TA, OHIU. - Cultitatiers. - Ful1 9, IS72.

Claim.- Spring-arms and chains for sustaining the weight of shovel-leams, substantially as described.

No, I2S,069.-WILTIAM W. MARSH and HARRlSON WC INTYRE, SViAMURE, ILL.-Ciultiontors.- $7 u l y$ 16. 1872 .

Claim. - The adjustable foot rests $c$, when constructed and altached to the plough-beams, substantially as and for the purposes specified.

No. 129.420.-DAVII NoRMAN, CRAwFornstille, IND.-Cultiontors.- Fu/v 16, I872.

Chim. - The angular lever $n$, in combination with the aljustable haluncing or equalizing bar $K$, connecting rods I., and the downward projectins arms $\mathrm{C}$ provicled with the forwarl and upward projections $C^{\prime}$, all constructed and arranged substantially $\mathrm{as}$ and for the purposes set forth.

No. I 29,693.-ANDREW THONIPSON, OTrAWA, TLL. - Culfirators. Jul' 23, 1872.

Claim.-1 - The general combination of the following parts with tach other, to wit: the tongue $A$, cross piece $B$, the frame casting $C^{\prime} \mathrm{C}$, the cross heads $\mathrm{E} \mathrm{E}$, the beams $\mathrm{H}$, $H$, and the arljustable slides D D, substantially as and for purposes described.

No. 129,730.-WILLIAM H. (iRIFFITH, LOCK HART, TFXAS., asignor to himself and SFr)KES MII. CENHOMIMER, ane place.-Cultizaters.- Fuly 23 1572 .

Chim. - The combination of the three arliustable uprights $\mathrm{K} \mathrm{M} \mathrm{K}$, cross b,ur $\mathrm{I}$, adjustable lever $\mathrm{V}$, and stand ards $O P$ with each other and with the plough beams $G$, tongue $C$, and axle $B$. substantially as hertin shown and described, and for the purpose set forth.

No. 129,759--JAIIES B. SKINNER, deceased, (CHARIA)T"IE L. SiliNNER, administratrix, Rock. FORD, H.L.-Cultizutars.-July 23, IS72.

Claim. - I. - The beams $\mathbf{F}$, pivoted or hinged at their forward ends to horizontal and arljustable bars or brackets $\mathbf{E}^{3}$, forward and above the axle $\mathrm{A}$, in the manner and for the purpose substantially as described.

2.- The combination of the frame or tongue $\mathrm{C} C$. braces $\mathrm{E} \mathrm{E}^{\prime}, \mathrm{E}^{\prime \prime}$, and $\mathrm{F}^{\circ}$ with the horizontal and adjustable bar or bracket $\mathrm{E}^{3}$, all constructed and arranged in the manner and for the purpose described.

3.-The combination of the horizontal bar or bracket $\mathrm{E}^{3}$, having arljusting holes ' ' therein, with the pivot plates $f$, pivot pin or bolt $f^{\prime}$, and beam F, substantially in the manner described.

4.- The plough stamlards $H$, having the irregular form shown in Figs. 2, 5, and 6, with the ploughs $H^{\prime}$ attacled thereto, and recured to the licam of a cultivator liy means of the faced nut 1 , eye 5 , screw bolt 3, and screw nut 4. substantially in the manner and for the purpose described.

5.-The plough standard H, shoped as above described, and wedge 6 , in combination with the faced nut 1 , eye 5 . screw bolt 3 , and screw nut 4 , substantially as described and shown.

6.-The flinged rose or corrugated plates 1 and 2 , handles $G$, screw bolt 3 , and nut + , in combination with the beams $F$, in the manner substantially as described.

7.-The shields J, draw bars $;$, and bent bar i"', in combination with the adjuntable bent and slotted bar $i$, con-tructed and opernting in the manner substantially as shown and describet.

No, 130,337-HENRV TII.DEN, DAVENPORT, IOWA. - cultiżuturs.-Auszust 6, 1872 .

Claim.-1,-In combination with the plough standards of straddle row cultivators, a harrow attachment for each standard, composed of two or more adjustable toothed beams, 1), substantially as described, for the purpose specified.

2. - The combination of the adjustable rod I with the cultivator and harrow, substantially as described, for the purpose specified.

3.- The harrows, consisting of the parallel beams $D$, two or more, and the adiustable cross bars $\mathrm{E}$, substantially as described, for the purpose specified.

No. 130,393.-MICHAEL STOL.L, CoNesTogA TownSHIP, PA.-Cultizators.-August 13, 1872.

Claim. - The arrangement of the two-armed lever A B, lirace and supporting guide bar: $\mathrm{D}$, and seat $\mathrm{E}$, in combination with the centre beam $C^{\prime}$ with its flanged and perforated terminus $\mathrm{F}$, and hinged connection with the axle $\mathrm{G}$ of the wheels $\mathrm{H}$, all substantially constructed and operated in the manner and for the purpose specified.

No. 130,454-I.AFAYETTE K. TIPTON, EAston, No.-Cinliziators.-August $13, \mathbf{I S}_{72}$.

Claim.-1. - The arrangement of the axles B, braces $\mathrm{M}$, beam $\mathrm{H}$, and frame work C D E F G to adapt the machine to receive the ploughs and afford a free passage for the plants, suhstantially as herein shown and described.

2.-The combination of a screw shank, S, and set screw $\mathrm{U}$ with the plough $\mathrm{T}$ and serew socket formed in the lower end of the plough standard $R$, substantially as herein shown and described, and for the purpose set forth.

Vo. 130,700.-IVILI.IAM H. CUMMINGS, BuoNesBorot'iH, Iuwa.-Cultinators.-Ausust 20, 1872.

Claim. - The combination of the circumferentially grooved metal block $G$, with its flange $b$ placed loosely upon the axle, and the twinted wrought iron brace $D$, with the short axle $a$ and frame A B C, all substantially as set forth.

No. 130,869.-WILLIAM R. ROBINSON, MATrooN, 11.1.-Cultizafors.-August 27, I872.

Claim. The combination of the pivoted step $Q$ and adjustable brace $R$ with the handles $P$ and beam $K$, substintially as herein shown and dencribed, and for the purpose set forth.

No. $131,404-G$ GORGE HENRY LUND, MACFORD, Wis.--Cultivators.-Siftember 17, 1872.

Claim.-I.-The dray bars A, each being independently pivoted at the forward end, and provided with perforations near the centre, so that said bars may le used in sections. having more or less hari in each section, by means of the pin or bolt B, substantially as and for the purpose specified.

2. - The combrnation of the beam $A$, standard $E$, brace $F$, and yauge $D$, the several parts being constructed as described, and arranged so that the gauge may be adjusted high or low, and to or from the shovel or plough, substantially as and for the purpose set forth.

3.-The bar $\mathrm{A}$, chains and links $\mathrm{M} \mathrm{N}$, in combination parts $\mathrm{K} d \leqslant \mathrm{~J}<\boldsymbol{c}$, and lever $\mathrm{L}$, all constructed and arranged substantially as and for the purpose herein described.

No. 131,720.-N1LLLA.I I. THUMPSON, ROCK. VILI.E, INU.-Cultinators.-Septimber 24, I 872.

Clain.-The combination of the bars A A, the bar B provided with the clevines $R R$, the bar $C$, seat $D$, axletree $\mathrm{E}$, keved spindles $\mathrm{F} \mathrm{F}$ providcd with clevises $\mathrm{H} \mathbf{H}$, and the curved braces $T T$, when so constructed and arranged as $t \rightarrow$ be adapted to receive the parts used for marking, cultivating, and breaking, in the manner herein shown and described.

No. 131.909.-ANDREW T. SHERIVOOD, AMADOR, C.u..-Cultinators.-October 1, 1872.

Claim.-The loosely-hinged cultivators $\mathrm{E} \mathrm{E}$, in combination with the seat 1 , timber $l$, and springs $m$, so arranged that the driver's weight can be applied to force the cultivators into the ground, substantially as described.

No. 132,277.-HENRY H. GIBSON, QUINCY, ILI.Cultiontors. - October $\mathbf{1 5}, \mathbf{1} 872$.

Claim.- I.-The blocks $\boldsymbol{H}$ and I provided with the shoulders $c$ and set screw $d$, for the uses and purposes shown and specified.

2.-The combination of the levers $O$, blocks $H$ and $I$, rods $\mathrm{D}$ and $\mathrm{C}$, plough beams $\mathrm{N}$, chains $\mathrm{A}$, crank $\mathrm{P}$, lever $\mathrm{R}$, 


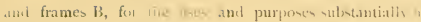
shown and describerl.

No. 132,527.-REUHEN FI.W()()1) and RI('HARI)

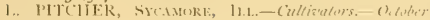
$29,1 i^{2} 2$.

Claim.-1.-The combination of the movable learings with the hars $\mathrm{B}$ of the tongue or frame and the plough heams C, so that the ploughs may be more, back and the machine changed to a walking-cultivator, substantially as described.

2. The pivoted frame $n$ in combination with the beam C. bar 5 , brace $i$, arranged to move on the liolt / of such fr.me, substantially as and for the purpose specified.

3.- The combination of the arm $j$, provided at its outer end with the $\operatorname{arm} k$, arm $r$, friction nut or clutch $m$, and beams $C$, substantially as specified.

4.-The combination of the bar $s$ with the arms $r k j$ and beams $C$, substantially as specified.

5. - The combination of the arms $k, j$, and $r, \operatorname{rod} s, \operatorname{arm} t$, and beam $C$. for making the machine rigid, substantially as dencriberl.

6. - The combination and arrangement of the standard b with the arm $n$, opening $d$, and fricion-nut $c$, sulstantially as and for the purposes dercribed.

No. I32,845.-SAILEL MARTIN, KNoBNestF, Mo.

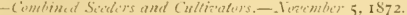

Claim, -1, - The combination in one machine of a harvester, stalk-chopper, cutters, pulverizer, and seed-drills, subutantially as and for the purpose herein specified.

2.-The axle $\mathrm{A}$ and wheels $\mathrm{B}$ in combination with the short shafts $B^{1} B^{1}$ and pulverizers $A^{\prime}$, as and for the purpose set forth.

3.- The bent guide $\mathrm{G}^{\prime}$, chopper $\mathrm{E}^{\prime}$, and shaft $\mathrm{F}^{\prime}$, arranged and operating substantially as and for the purpose herein described.

4.-A series of revolving cutters, (1) arranged lietween the chopper $E^{\prime}$ and puJverizers $A^{1}$, and supported from a rigid frame directly beneath the axle $A$, as and for the purpose herein specified.

5.-The lever $Q^{\prime}$, in combination with the friction-roller b, wheels $\mathrm{R}^{\prime}$, and $\mathrm{B}$, slotted wather $\mathrm{I}^{\prime \prime}$, and chain 'S', constructed and arranged as and for the purpome set forth.

6.- The combination of the chopper $\mathrm{E}^{\prime}$, cutters ${ }^{\circ}{ }^{1}$, and pulverizers $\mathrm{A}^{1}$, and drills $\mathrm{B}^{1}$ when arranged substantially as herein described, and for the purpose set forth.

7. - The chopper E', cutters ( ${ }^{\mathrm{I}}$, pulverizers $\mathrm{A}^{\mathrm{T}}$, in comlination with the drills $\mathrm{B}^{1}$, anil seeding mechauism, substantially as and for the purpose set forth.

8.-The side bars C $C$, extendin r ontsile of the wheels $\mathrm{B} B$ and supported by the extention of the axle $\mathrm{A}$, and combined with the ton wue $\mathrm{E}$ and transwerse birs () 1), substamtially as and for the purpose specified.

9.- The arrangement and construction of the frame, wheel, and axle, as herein descr.bed, to receive the different devices for operation in breaking the ground, planting, and harvesting, substantially as herein described.

No. 133.067-TAIESG. STUWE, BLIUMINGTUN, IL.L., assignor to KER.EI H. FEI.L. same place-Cultizaters.

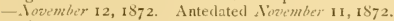

Claim.-1.-The combination of the cup 1, having flanges is $b$ and circumferential bead $c$, with the jaws J J having ears $f f$ and a groove on the inner circumference corresponding with the lead on the cup, substantialily as and for the purposes lierein set forth.

2. - The combination of the shovel, carrying-block $x$, tube $h$, cross-slot $a$, bolt $k$ with bead inside the tube, with the tubular beam $\mathrm{L}$ (or tubular piece $m$ ) with open-end slot $y$, all secured torether by the nut on the exteiror, substantially as set forth.

No. 134,248 - ROBEITT C. BUCKLEY, PEURIA, III.. - Ciullizators.-Dicimber 24, 1872 .

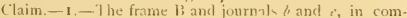
bination with the free axle F, hook-tolt $f$, plater $a$ and $g$, and beam $\mathrm{F}$, suhstantially as and for the purpares herem set forth.

2.- ' the benm $\mathrm{H}$, constructed in one piece and provided with a shovel $l$, and branching arms, each of which being provided with a hook for the purpose of being connected with the axlen E E, substutially herein $\rightarrow$ t forth.

Ni). 134,615.-JAMES SHERRILL, HARR1SBRG,

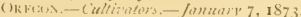

Claim,-1,-The forked or clutch rod 1 , cross-head Icver B', y,ring rod.C', arm II', and catch I', in combination with the seed hox $T$, sear-wheel $\mathrm{W}$, sliding plate $\mathrm{G}$, and roller $\mathrm{Nl}$, substant ally as herein shown and described, aud for the purposes set forth.

2.-The draft-frame $E$, pendent from stationary frame and axle, and having the plough-beams pivoted thereto, as and for the puryose describel.

No, 134,662.-WIL1.1.M G. MALBLRT, COL.tmivs, Nish. C Cultitaturs. - Jamuary 7, 1873 .

Claim.-1.-In combination with the frame A B C, the sliding clevis C'moving in the slots $c$, and the curved tongue $\mathrm{F}$, all constructed and arranged substantially as and for the purpose set forth

2.-The wedges $f f$, in combination with the cultivator stochs $\mathrm{G} G$ and screw-bolts $g, g$, substantially as and for the purpose set forth.

No. 134,940,-GiEORGE WAGGONER, NFw KiNi: STuN, PA, - Cultizators.- - (unuary 14, 1873 .

Claim.-The combination of the tongue $\mathrm{H}$, axle $\mathrm{A}$, frame B E, bar I, shoulder $\mathrm{I}$, and slotted plate L, all arranged as and for the purpose specified.

No. 135.264.-AMOS B. COLI'ER and IOHN PRIEST, AlRANY, ORECin.-Cultizators.-Fanuary 28 , 1873 .

Claim.-1. - The combination, with the cultivator, the truck, and the caster, of the housings, the lever D L, standards $\mathrm{F} \mathrm{K} \mathrm{N}$, the comnecting link () , the pins $P$, and the acljustable collar $Q$, substantially as specified.

2.- The combination of the hook $\rightarrow \mathrm{R}$, rods $T$, and lever $S$ with the (rack and cultivator, sub-tantially as specified.

No. 135,912.-JACOB B. HINCKLEY, NACOGIUCHES Countr, TEXAs, - Cultizutors.-Fihranry I8, 1873.

Claim. - 1. - The beam 1), phutghs $t$ and $\mathrm{E}$ with strin $\phi$ and braces $c$, heams $F$, straps $d$, pivots $f$, and links $c$, sliding bars 5 , bar $\mathrm{K}$, and wheel $/$, for the purposes specified.

2.- - lever $\mathrm{G}$, stanclard $H$, lever $m$, fulcrum-har $n$, pin $O$, slot or groove $p$, and chain $r$, and nutches $s$, in combination with the frame of a wagon or cart, for the purposes specified.

No. 135,064.-[ACOB BEHEL, ROCKFORD, assignor to himself and GEORGE R. RICIJARISON, EARLVILIF, luL.-Cultizators.-Fibruary 18,1873

Claim.-1.-The combination of the axletree B, the converging tongue timbers $\mathrm{C}$, the cross brace $\mathrm{D}$, the bracing pendants $\mathbf{F}$, and the brace rorla $d$, all these members being constructed and operating as set forth.

2.-The combination of the perforated tongue, the elongated slot in the thimble $c$, the forked turning shank $/$, the transverse locking pins $\mathbf{I}$, and the neck yoke $\mathrm{H}$ pivoted on one sile of the axis of the shank, all these members heing constructed and operating as set forth, to raise or lower the neck yolie and tongue.

3.- The combination of the pendants $\mathrm{E}$, the sockets inclined townward and forward, the eye bolts $i$ turning in the sockets, the drag bar, and the plough-standards, all these member, being constructed and operating as set forth, to cause the shovel to traverse a greater arc than the drag bars as set forth.

4.- The combination of the drag har $I$, the long shovel standarl II swiveled thereto, the radius yolit $\mathrm{P}$ swiveled to the standard, the radius link $\mathrm{P}^{\prime}$, and the detent lever $\mathrm{O}$ and rack $\mathrm{N}$, all these members being constructed and operating substantially as set forth.

5.-The combination of the long standards NI, their swivel yokes $R$, and radjus links $p /$ with the rod $O$, all these members being constructed and opetating substantially as set forth, to maintain the proper relation between the stundards, while allowing them free adjustment in all direction.

6.- The combination of the long standards $\mathrm{M}$, the drag bars 1 , the rigielly connected shields $\mathrm{T}$, the draught chain $t$, the link rods $\ell^{1}$, and the pivoted arms $t^{2}$ connecting the hiekl and clrag bar, all these members being constructed and operating substantially as set forth. 
7.-The combination of the socketed rings $l$ on the standards with the rigid draw rods $l^{3}$ inserted therein and secured by frangible pin, these member, leing constructed and operating as set forth, to prevent bending or yielding of the draught connections by back pressure on the standard.

No, 135,997-JAMES MILLS, JollNsTOWN, W1s.Cultizaters.-February is, iS73.

Clim.-The combination of the upright lever: G G, the lower ends working in slotted plates attached to the shovel bars E E, with fulcrum at the axle, and adjustable crossbar $L$ at the top to spread and contract the shovel hars, sulf. stantially as described

No, 136,047.-DAVI1) EDWARDS, MElbol'rNe, VICTokiA.-Cultizators.-Fibruary $\mathbf{1} 8, \mathrm{IS}_{7}$

Claim, - $\mathbf{I}$ - The spindle $\mathrm{H}$, passing down through the longritudinal slot $\mathrm{E}$ in the axle $\mathrm{C}$ and pivoted therein, and having its free end guided in the semi circular slotted bar $F$, as and for the purpone set forth.

2.-The inclined links $\mathrm{K} K$, flap $\times$, and link $\mathrm{L}$, in combination with the spindle $\mathrm{H}$, slotted axle $\mathrm{C}$, and semi-circular sloited bar $\mathrm{F}$, all constructed and arranged as hercin shown.

No. 136,108,-JOHN W. SWICKARD, GAINA, ILI.. assignor of one-half his right to JOHN HOUGH, same place.-Cieltizaters.-Fibruary I $8, \mathbf{1 S}_{73}$.

Claim.-1.- The combination of plates $\mathrm{K}$, bars $h h$, and beams $\mathrm{E} E$ with the pivoted handles N, substantially as anil for the purpose specified

2-The handles N N and yokes M M, when combined and arranged to operate with the journal $b \dot{b}$, plates $\mathrm{K} K$, bar $h /$, and beams $E$, substantially as described, and for the purpose specified.

3.- The guards P P, when combined and arranged to operate with the vertical part $a^{\prime} a^{\prime}$ of the axle $\mathrm{A}$, substantially as described, and for the purpose specified.

No, 136,297.-SINGLETON L. YOLNG, SCOTIVILLE, ] LL.-Cultizators.-Fiduary 25, 1873.

Claim.-1.- The combination of the lever $\mathbf{E}$ having pinion $\mathrm{D}$ on the lower end, and the axle arms $\mathrm{B} \mathrm{B}$ having racks on their inner end; arranged on the axletrees $A$ of a wheel-cultivator, as and for the purpose decribed.

2.-The device B B D E, combined with the guide F pendent from the middle of the axletree, as and for the purpose set forth.

3.- The drught hars $\mathrm{H}$ and adinstable braces 1 combined with and pivoted to beam $\mathrm{A}$, as and for the purpose specified.

Nu, 1 36,409.-BAl.TIS F. BR.1TE, NEW SCOTLAND, N. Y.-Cultivators - Whrih 4, 1873.

Clum.-1.-The picker $m, m$, arr.nnged to revolve between the wings $H \mathrm{H}$, substantially as and for the purpose set forth.

2-The combination of the wheels $\mathrm{C}$ C, pule $\mathrm{B}$, frame A with the suspended beams F F carrying the double mould-boards $G_{i} G$ and heaping wings $H \mathrm{H}$, when all are constructed and arranged subutantially as and for the purpose set forth.

No. 136,477,-WIILIAM WHLLERTON, JACKSUNIILLF, I L1..-Cinltî́tutors.-1/arch 4. 1873

Claim.-The combination of rick bar U, bibranched chain $\mathrm{P} S$, pulley $T$, laterally sliding pulleys $Q Q$, and keeper $V$, all arranged as an I for the purpose described

No. 136,708.-WILLIAM P. DALE, AgrictltukAL Coliteste, PA.-Cultizators. - Warch $11,1873$.

C'aim.-I. - In a cultivator, the canter wheels $\mathrm{B}^{2}$, bracke:s $\mathbf{B}^{t}$, friction rollers $a$ and fifth wheel $\mathrm{B}^{\mathbf{t}}$, sulistantially a, specified.

2.- The draw hinges $J$, as described, connecting the laterally and vertically adjustahle shovel beams $I$ to the transicise bars I', su'stantially as specilied.

3.-The perforated flanged cross piece $\mathrm{F}^{\prime}$, in combination with the perforated longitudinaliy-adjustable beam braces $K$ and adjustable shovel beam, $I$, substantially as and for the purpose set forth.

4. - The bar $d$, arms $d^{\prime \prime} c$, bar $c^{\prime}$, lever $\mathrm{H}$, and rack $\mathrm{H}^{\prime}$, in combination with the frame $\mathrm{D}$ and houmds $\mathrm{B}$, substantially as specified.

No. 137,094.-ORLANDO M. POND, INDEPENDENCE, IowA._Cultiviators._-Warch 25, 1873.

Claim.-1. - The forked hook $a$ with projecting circular prong " to form an adjustable connection between the tongue $\mathrm{D}$ and shovel heams $\mathrm{E}$, substantially as herein set forth.

2.- The combination of the flanged plate $H$, cuncave ratchet piece $\mathrm{I}$, eyebolt $h$, and shaft $i$, with ratchet pinions $k k$, to which the clamps for holding the shovel arm are attached, substantially as and for the purposes herein set forth.

No. 137,478 . HAZEN H. PERKINS, OSCEOLA, IL.L. -Cultizators. - April I, 1873 . Filed Oetoler $\mathbf{1}, 1872$

Clain.-1.-The beam, E E, carrying the shovels or ploughs, and adjustable by means of the slotted plates $b \quad b$, provided with ratchets $d d$, and attached to the axle, in combination with retractile lever $\mathrm{F} \mathrm{F}$, arms $i f$, and brace rods 10 ' 10 ', substantially as set forth.

2.- The adjustable shoes $S^{\prime}$, provided with screw cranks or their equivalent in combination with the shovels 1 . having a casting, $9^{\prime}$, on the back provided with a cross slot to receive the pin of the shoe, substantially as and for the purpose set forth.

3.- The clevis $x \cdot x$, having a pivolal connection with cross bar $\mathrm{N}$ attached to the beam, $\mathrm{E} E$ by braces $2^{\prime} 2^{\prime}$, in combination with the adjustable bar $z$ and cross-bar $y$, substantially as and for the purpose set forth.

No. 137,703,-JA3LS R. J]CDONALD, NEVADA, IowA.-Cultizators.-April S, I 873 . Filed Scptember 14. 1872 .

Claim.-In a cultivator, the combination, with the adjustable pole, the plough beams, and the pivoted brace rixd, of the adjustable axle lent upward at $e$ to connect with the pole, and relatively downward and outward at $h$ to receive the wheels, substantially as specitied.

No, 137,033.-JUHN M. KNUN, RENSSELAER, JND, assignor to himself and IRA C. KELLI, same place.Cultivators. - Afril 15, 1873 . viled dugust 6, I872.

Claim. - I. The combination, with the beam $G$ and standard $G^{\prime}$, of the sarldles $x^{3} y$, hook $x$, stirrup $x^{1}$, and links $x^{2} z$, as described, for the purpase set forth.

2.-The combination of the pivoted beam $G$ with the post 1 , having the spring catch, and the end bar J, as shown and described, for the purpoce set forth

No. $\mathbf{I}_{3} 8,45 \mathbf{1}$-C CHRIST THEDE, ALED, I1.L.-Cultivators.-tpril 29, 1873 . Filed tusust 31,1872 .

Clain.-The combination of the laterally adjustable axle sections $($ and the threaded cross piece $b$ with the slotted pole braces $\mathbf{E}$, draft pole $\mathrm{A}$, and plough frames G carrying the ploughs $\mathrm{J}^{1} \mathrm{I}^{2}$, as shown and described.

No. 139,471.-JOHN P. MIANNY, RICKF()RD, ILL. (inltivators.-Fun: 3,1873 . Filed Narch 21, 1872 .

Claim-I - The combination, in a cultivator, of the bifurcated tongue frame, the vertically-adjustable draw bars $\mathrm{E}$ proted to the horizontally swinging pivoted bracket $E^{\prime}$, and the hinged connecting rod $e$, all these members being constructed and operating substantially as set forth.

2. - The combination of the swing frome $G g$, drag bas $H$, suspension rods $\mathrm{K}$, and radius bars $\mathrm{J}$, sulstantially as set forth.

3.- The combination of the swing frame G $g$, shiclds M, suspension rods $\mathrm{K}$, radius bars $\mathrm{J}$, and drag bars $\mathrm{H}$, substantially as set forth.

4.- The combination of the swing frame $(i s$, radius hars $\mathrm{J}$, drag bars $\mathrm{H}$, suspension rod $\mathrm{K}$, and locking treadle L. substantialiy as set forth.

5.-The combination of the drag bar H, cap $j$, radius har $J$, thimble $j^{2}$, and bolt $j^{3}$, substantially as set forth.

6.- The combination of the drag har $\mathrm{H}$, the friction socket $h^{1}$, the conical hollow plug $h^{2}$, the eye bolt $h^{3}$, and the standard $i$, all these parts being consiructed and operatung as set forth.

7.-The combination of the drag bar $\mathrm{H}$, the crank shaped standard $i$. the socket $i^{2}$, and the shovel $I$, these part $\checkmark$ being constructed as set forth.

No. 139,478.-GEORGE R. RICHARDSON, EARL- 
YHL.F, and JACOB BEHEL, R(xkFOR1), 11...-Culticators.-Juni $3,1 \$ 73$ Filed Vire'mber 9, is 609.

Claim.-I, - The combination of the rocking bail 1), pivoted on the tongue timbers $C$, the inner shovel standards $\mathrm{F}$ swivelcd on the rocking bail, outer shovel standards $\mathrm{E}^{\prime \prime}$, each pirotecl to its respective imer standard at top, and connected with it by a link, b, near the bottom, and draught rods e connecting each standard with the tongue timbers, these members being constructed and operating substantially as set fot th.

2.-The combination of shovel standards $\mathbf{E}$, swiveled on a rocking bail, $\mathrm{D}$, with hand levers $\mathrm{G}$ pivoted to the stand ards and suspended from the main frame by a swivel Jink, $\mathrm{H}$, these members being constructed and operating sub stantially as set forth.

No. 139,085.- JHII.JP F. WELLS, VIIFORD, Мich., assignor to himself and D. WEBSTER WELLS, same place.-Cultizutors.-June 17, 1873. Filed April 12, 1873 .

Claim.-I, - A plough standard, $G$, pivoted to the upper end to bar $C$, and held rigidly in a vertical plane between the bifurcations of a stud, $J$, on the cross bar, as and for the purpose described.

2.- ihe front plate $\mathrm{F}$ upwardly flanged and constructed to receive and retain the tongue and longitudinal bars, in the manner shown and described.

No. 140,353.-REUBEN ELI.W()OD and RICHARD 1. I'ITCHER, SYCAMORE, JLL.-Cultivators.-Fuly I, I873. Filed Dicmbe' 7,1872

Claim.-1.-The combination and arrangement of the beams $(\mathrm{j}$, rods $\mathrm{N}$, and brackets $\mathrm{M}$ with the arms $a$, provided with the slot or holes $c$ and rod $d$, substantially as and for the purposes specified.

2.-The combination and arrangement of the beams G, rods $\mathrm{N}$, brackets $\mathrm{N}$, with the arms $a$, rod $d$, and locking device $e f$, substantially as described.

3.-The swing-bar $\mathrm{K}$, in combination with a beam, $G$, and chains L, substantially as specified.

4.- The combination of the rack with the bracket it by spring $i$ and pin $j$ of the lever, constructed and operating substantially as described.

5.-The foot-rest 1, when provided with projections above and below the plough-beam, in combination with the clamp $n$, so that it can be both vertically and laterally adjusted, substantially as described.

No. I 40,437-IIATTHEW P. SIMPSON, PANA, and JOSEPH P. ELLACO'T T, SHFLBYIILlE, assignors to THE SHelbyVille Nanefacturing; Company, SHelhyville, ILL.—Cultizutors.-July I, IS73. Filed Muy I6, 1873 .

Claim.-I.-The combination of the draw-heads $f$, grooves or recesses $f^{2}$, bars or rods $f^{3}$, and connecting pieces $f^{7}$, substantially as shown and described.

2.-In combination, the draw-head $f$, grooves or recesses $f^{2}$, bars or rods $f^{3}$, connecting piece $f^{2}$, plates $g^{1}$, and convex surfaces $g^{3}$, substantially as specified.
Claim.-1. - The springs $m m m m$, in combination with the swinging frames $\mathrm{D} D$ and pendent arms 0 , for the use and purposes described.

2.- The double cross-head $\mathrm{H}$, in combination with the inner rails of the swinging frames 1) 1), for the uses and purposes described.

3.- The anchor-shaped pendent hooks $c$, in combination with the staples $f$, when used in a lateral-moving cultivator, substantially as described.

4.-The metallic shanks $i$ of the drag bars, passing through the eyes of the pendent arms $\theta$, in combination with adjusting-nuts and spiral springs, subtantially as described.

No, 141,786.-JONATHAN M1. GUSTIN, WILMINr: Ton, OHio.-Cultivators.-August 12, IS73. Filed January $28, \mathbf{I} 873$.

Claim.-1.-The yielding beam-supporters, consisting of the bent plates $\mathrm{Ml}$, swiveled to the beam $\mathrm{E}$, and holding the adjustable screw-rods $\mathrm{N}$ and springs $\mathrm{O}$, substantially as and for the purpose specified.

2.- The yielding beam-supporter, consisting of the bent plate $\mathrm{M}^{\prime}$, hinged to a swiveled horizontal shank, and holding the adjustable screw-rod $\mathrm{N}$ and spring $\mathrm{O}$, substantially as and for the purpose specified.

3.- The adjustalle arched or bent brace $H$, constructed and arranged as shown and described, in combination with axle $\mathrm{A}$, axle-arins $\mathrm{C}$, and clutch-plates $\mathrm{B} \mathrm{B}$, substantially as and for the purpose specified.

4.- The adjustable and removable seat $\mathrm{G} \mathrm{G}^{1}$, loop $\mathrm{G}^{2}$, and rack $G^{3}$ combined, substantially as and for the purpose set forth.

5.- The axle A and axle-arms C, in combination with the clutch-plates $\mathrm{B} \mathrm{B} \mathrm{B}^{\prime}$, bolts $b^{3}$, and the combined walking and riding cultivator berein described.

No. I41,9SS.-NOAH G, BLAUSER, ЕтNA, ОнIO.Corn-Cultivators.-August 19, I873. Filed May I4, 1873 .

Clain. - The combination of the beams $\mathrm{L}$, plates $h / h$, ball $c$, braces $f f$, stirrup $k$, and rod $m$, for making a joint and adjustable connection for the front end of the beams, as is herein set forth.

No. 143.338.-JOHN H. FRANK, Millheim, PA.Cultizators.-September 30, I873. Filed Ausust 9, I 873 .

Claim.-1.-The combination of the frame-bars J J', the single and double pivoted joints, and the screw-bolts $p^{\prime}$ for rendering the drag-bars laterally rigid, therehy adapting the machine to be used as a field-cultivator, as described.

2 - The combination of the frane bars $\mathrm{J} \mathrm{J}^{\prime}$, the donble and single pivoted joint, screw bolts $t^{\prime}$, drag-bars $\mathrm{H} \mathrm{H}^{\prime}$, and shovel-standards $G$, as and for the purpose described.

No, I 43, F 31 - - JAMES F. MATCHET and PERRY IV.

Sll1TH, PARIs, No,-Whecl-Cultivators.-October I4, is73. Filed June 7, is 73 .

Claim.-The double bow $\mathrm{C} \mathrm{C}$, tongue $\mathrm{D}$, cross-bar $\mathrm{E}$, and arms $\mathrm{F}$, all pivoted together and moving freely upon each

Insert after claim 1. pateut No. 145.331. (. Bk.111.) De'tmber 9, 1873 , (parte 227), the following omitted claim 2 - The racks $H$ H, hand levers $G(1$, and loups 5 , in combination with the upriglits $\mathrm{l}$, and slotwed emnecting ba $1^{1}$, arranged and operating sulsstantially as described.

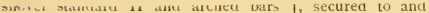
rising above the drag bars $c$, as specified.

No. I 11,462 , RICHARD B. ROBBINS, ADRIAN, Mich.-Cultiarators.-Ausust 5, I873. Filed Derember 20, 1872 .

Claim.-The anchor-shaped pendent hooks $\epsilon$, in combination with the staples $f$, when used in a lateral moving cultivator, substantially as described.

No. 5,676.-RICHARD B. ROBBINS, ADRIAN, HICH. -Cultivators.-I41,462.-August 5, 1873 .- Reissued $D_{i}$ cember 2, 1873. Filed October 13, 1873 .
Clam. In combination with the bent axle B and trame E, the forked slide $G$, screw-bolt $D$, lever and nut $F$, ad justable standards and shovels $G \mathbf{K}$, and subsoilers $\mathbf{L}$, as and for the purpose described.

No. 145,636 -DAVID B. EBERLY, Pine Village, InD.-Cultizators.-December I6, I873. Filed May 31, 1873 .

Claim.-I.-The expansible axle-tree B, consisting of the slotted links $b$, substantially as specified.

2.-The combination, with a drag-beam, D, of the shovelplough and the adjustable weed-cutting knife-blade attach 
ed to the sides of said drag-beam, and extending rearwardly of the sliare, as shown, and for the purpose mentioned. 3.-In a cultivatır, the detachable middle slotted link $b$, in combination with the arch $\mathrm{J}$, substantially as specified.

4.- The fulcrum $p^{\prime}$, with its connection-pin $Z$, in combination with the slotted extension-axle B, substantially as specified.

No. I46,030.--IVIILIAM H. STRONG, Clinton TuWNSHIP, SENECA COUNTs, OH10.- Wheel-Cultivators.December 30, 1873. Filed May 19, 1873.

Clain.-In a wheel-cultivator, the lugs A A, cranked levers D E, bar F, chain $G$, and hooks $I$, arranged and attached in the manner described, and for the purpose hereinbefore set forth.

No. 146,576 . - ISAAC CORY, DALTON, IND.-Cultivators.- Fanuary 20, 1874. Filed Septenber 27, 1873 .

Claim.-I.-The combination, with seat-bar 1 and stirrups $G$, of the clamps $F$ F, to hold both seat and foot-rest adjustably to the frame, in the manner described.

2.- The front bar $\mathrm{K}$, bowed in the center, and the middle bar $\mathrm{H}$, bowed on each side, combined with the side bars $\mathrm{C} \mathrm{C}$, to allow the plonghs to be pivoted in front, the handles to rise uj, and the implements to be moved laterally or vertically, in the nanner described.

No. 146,638.- JA.IES P. BATTEN, UNION PRECINCT, assignor of one-half his right to THUM]AS M. TURNER, Fremont, Nebr.-Fanuary 20, 1874 . Filed Noriember 25,1873 .

Claim.-1.-The equalizer or curved yoke D, chain $d$, and pulley $c$, in combination with rods $g$ and hinges $f$, as and for the purposes set forth.

2.-In combination with the hinged plough-beam and standard, the curved bar $k$, acute angled scraper $\mathrm{F}$, and shovel $G$, constructed and operating as shown and described.

No, 146,822.-HATTHEW GREEN, WALKER STATlon, Mo.-Combined Cultivators, Stalk Cutters, Harrines, and Corn Planters.-Finuary 27, 1874. Filed Siptember 6,1873 .

Claim.-In a wheeled implement, the supporting frame $a b d$, the beams and guide rods $l m$, the arched axle $C^{\prime} C^{\prime}$, combined and adapted, as set forth, for the attachment of a cultivator, stalk cutter, harrow, or corn planter.

No. 147,245.-LYMAN W. DICKERSON, MANLJUS, N. Y.-Quack Diggers and Cultivators.-February 10, I 874. Filed September 20, I873.

Claim.- The segments $F$ and $G$, with teeth $/ l$, in combination with the frame $\mathrm{A}$, ratchets $\mathrm{M}^{\prime} \mathbf{M}^{\prime}$, and ropes $s s$, substantially as and for the purpose hereinbefore set forth.

No. 147,669.-JAMES B. LUCAS, PELlsville, I1.L.Cultizators and Ploughs.-February 17, 1874. Filed Fuly 19, 1873 .

Claim. - The combination of the braces $\mathrm{W}$, couplings $\mathrm{X}$, brace $\mathrm{Y}$, and couplings $\mathrm{Z} \mathrm{\textrm {A } ^ { \prime }}$ with the tongue $\mathrm{C}$, hounds $\mathrm{D}$, bent axle $B$, and braces $F$, substantially as herein show $n$ and described, and for the purpose set forth.

No, 148,261.-BYRON D. TABOR, W1I.SoN, N. Y. assignor to himself and C. D. TABOR, same place.-Cultivators.-March 3, 1874. Filed January 29, 1874.

Claim. - I. - In a cultivator, the arm $G$, with its short axle $\mathrm{D}$, spindle $b$, journals $d$, and stops $e$, in combination with pronged lever $\mathrm{H}$, forming half-boxes $f f$, substantially as and for the purpose set forth.

2.- The combination in a cultivator, of the pronged lever $H$, having half-boxes $f f$, and lug $i$, with stops $e$, rack-bar $\mathrm{I}$, and spring $a$, subitantially as and for the purpose described.

No. $148,78 \mathbf{r}$-JEREMIAH H. TROUT, KINGWOOD, assignor to himself and ISAAC S. CRAMER, SERGEANTSvil, rember $15, \mathrm{IS}_{73}$.

Claim. - The combination of a shovel-standard in two paris, $\mathrm{K} \mathrm{L}$, and jointed to allow an outward lateral movement to the lower part, with a spring on the outside and a lever on the inside, to enable the plow to be operated in the manner described.

No. I 48,839 . - WILLIAM D. MILLER, SPRINGFiELD, Онь.,-Cultivators._-Harch 24, 1874. Filed Oitober 20, 187.3 .
Claim. - 1.-In combination with the bar A, the bar B, braces F F, and tongue D, to form a trussed wheel, framed as set forth.

2,-In a straddle-row cultivator, the plow-beams 11 , constructed and combined with the wheel-frame A B, and clevises $\mathrm{H} \mathrm{H}$, receiving their draft independent of each other and of said wheel-frame, as set forth.

3.- In combination with the slotted bar B and the plowbeam 1 , the adjusting-clevis $\mathrm{H}$, for the purpose substantially as set forth.

4. - In combination with the plow-beams I I, the adjusting-arch M M, with the spreader N, substantially as set forth.

5.-In combination with the arch $\mathrm{M}$, the lever $\mathrm{P}$, and saddle $k$, for the purpose set forth.

No. I49,I 30--EPHRAIM IVES, PLeASANT HILl, IND, Sulky Cultiwators.-March 31, 1874. Filed January 17, 1874 .

Claim.-1.- The combination, with the pivoted bars D, of the centrally-arranged lever $\mathrm{J}$ and connecting-chains 1 , for causing the ploughs $\mathrm{F} \mathrm{G}$ to appraoch each other, and the bent or crank foot-levers $\mathrm{L}$ and chains $\mathrm{K}$, for causing the ploughs to incline outward, and thus widen the space between them, as shown and descriced.

2.-The combination of the slotted bars $\mathrm{P}$, the bolts $\mathrm{Q}$, and the notched lock -bars $\mathrm{R}$ with the bent axle $\mathrm{N}$ and the outer U-shaped hangers $\mathrm{E}$, substantially as herein shown and described.

No. 149,154.-JOHN IV. RABB, LA GRANGe, TEX.Frame for Cultizators, Scrapers, Ëc.-March 3I, 1874 . Filed $\mathcal{F}_{\text {une }} 2 \mathrm{I}, \mathbf{1 8 7 3}$

Claim.-The beam $\mathrm{C}$ having button $\mathrm{H}$, bearings $\mathrm{B}^{\prime}$, and staples $C^{\prime}$, the hound-frame $D$ having spring $S$, and the crank-axle B having stop-pin E, all combined as described, and adapted to be used in connection with various farm implements, subst.mtially as specified.

149,938.--SAHUEL LUNEY, DENISON, IOWA, assignor of two-thirds his right to WILL1AM LUNEY and JAMES LUNEY, same place.-Cultivators.-April 21, 1874 . Filed Harch 26, 1873 .

Claim. - 1.-In combination with the main frame, having the beams $G$ attached thereto, the slotted hand-levers 1 , mounted on the pivots $\mathrm{J}$, and provided with the eyebolts $x$ and the transverse pins $e$, which limit the descent of the beams, but allow them to rise freely and to keep a horizontal position as set forth.

2. - In combination with the hinged bearns $G$, cross-har $h$, and elevated seat $O$, the treadles $\mathrm{H}$, mounted upon the main axle, and connected directly to the beams by the chains $k$, as shown.

150,426.-GILUAN MEEKS, KANEVIL.L. ILL.-Cultivators.-May 5, 1874. Filed September 25, 1872.

Clim.--The movable guiding tongue $\mathbf{b}$, arranged relatively to the split tongue $\mathrm{A}$, and the means D for application of the draft, as shown in combination with the cultivator beam $\mathrm{C} \mathrm{C}$, flexihly attached to the loose end of the movable guiding-tongue $\mathrm{B}$, and acting in connection therewith and the standard $F$, chain $H$, pulley $G$, and lever $E$, as specified.

No. 150,616.-EDMUND D. REYNOLDS and OLIVER B. REYNOLDS, NuRth Bridiewater, Mass. -Wheel-Cultivators.-May 5. I874. Filed Fibruary 14, 1874 .

Claim.-1.-In combination with the pole and axle, made relatively immovable, the plough-frame pivoted on the pole forward of the axle, and having capalility of laternl swing movement, and also to be adapted to be locked forward of the axle, in a fixed position laterally with reference to the pole, by means of a locking pin or bolt, substantially as shown and described.

2.-In combination with the plough-frame made to swing vertically with reference to the pole and axle, the links 4 and lever $p$, substantially as described, for connecting the top of the plough frame to the pole and raising said frame, and for locking the frame (vertically) with reference to the pole and axle.

3.- The sliovel plough or plough blade C, formed, as described, from a flat sheet, of the form shown at B.

No. I5I,530.-AMOS BARKER, NeBraska City, 
Nerraska.-Cultizators and Markers.-June 2, I\$74.

Filed . Warch 14, $1 \mathrm{~S}_{74}$

Claim. - L-The arched bar B with horizontal ends, in combination with coupling blocks $\mathrm{F}$ and bent axles I, adapted for the attachment of wheels II or R, as shown and described, for the purpose specified.

2.- The combination of the lever blocks $\mathrm{J}$ and hook blocks $K$ with the bent exles $I$, wheels $H$, and plough beams $C$, sulstantially as herein shown and descriled

No. 151,789 . - JOIIN NCGEE, DAVID W. MlCGEE, and WILLIA.J I. MCGEE, FAIRLEY, IOWA.-C'altizators.-June 9, 1874 . Filed October 25, 1873 .

Claim.- In a cultivator, the combination, with hanging frames or st.uples $\mathrm{F}$, of vertically-hinged drag-bars $\mathrm{C} \mathrm{D}$, hraces $G$, and laterally-hinged guide-plates 1 , as and for the purpose set forth.

No, 151,839.-HUGH CARGO, Bowling GReen, Ohlo. - Ciultizators.-June 9, 1874 . Filed February 24, is 74

Claim.-1.- The combination, with the frames $\mathrm{A}^{\prime}$ and shovel-beams $\mathrm{C} \mathrm{C}$, of the frames $\mathrm{E} \mathrm{E}$, pivoted to the plates $A^{\prime}$, the $\operatorname{arcs} f$, bell-cranks $F$, and rail (;, for raising the said shovel-beams, substantially as described and shown.

2.-The herein-described adjustable cultivator, wherein the frame $\mathrm{A}^{\prime}$, wheel $\mathrm{B}$, beams $\mathrm{C} C$, clevises $\mathrm{D} \mathrm{D}$, frame plates $\mathrm{E}$ F, bell-cranks F F, and bail $\mathrm{G}$ are constructed and combined substantially as shown and set forth.

No. 152,343.-LEVI JUDSON DAVIS, ELLSWORTH, On10.-Cultizators.-Funi 23, 1874. Filed December 3, 1873.

Claim.-1.-In a wheel-cultivator, the combination of the hinged axle $A$ and shovel-standards rigidly attached thereto with the arm $\mathrm{H}$ and evener $\mathrm{E}$, connected by the draft-rod $G$, and the tongue $\mathrm{B}$, substantially as shown and described.

No. 153,621 -N. J. SKAGGS and L. W. TRUE, TALLADEGA, ALA.-Combined Sulky. Ploughs and Cultivators.July 28, 1874. Filed May 29, 1874 .

Claim.-I.-The combination, with axle-frames $A$, of frames $G$, hinged at one end thereto, and extending, as well as receiving, ploughs on both sides of the axle, as shown and described.

2.- The combination, with plough frames $G$, hinged within axle-frame $A$, of draft-chains attached to a staple on and under the said plough-frames, as and for the purpose specified.

No. 153,751.-WM. M. Coston, Quituan, Mo.Sulky-Cultivators, - August 4, 1 S74. Filed March 28, IS74.

Claim.-The carriage or frame of a sulky-cultivator, composed of the perforated side beams C C, adjustable wheels A A, front connecting bars D D, and rear metall:c plates or bars $\mathrm{K}$, bent at their ends around the side heams of the frame, and having rearwardly-projecting central arm $\mathrm{S}$ for the adjustable attachment of the driver's seat, all the parts being constructed and relatively arranged as herein shown and described.

No. I54,00I.-ABNEK S. BAKER and WN. H. IAN. DON, Kalamazio, Mich.-Gang-Cultitators.-August II, I874. Filed 1/ay 5, 1874 .

Claim, - The combination, with the wheel 1 and slide J, of the slutted lever $\mathrm{K}$, wheel or roller $p$, headed pin $s$, slotted and notched plate $\mathrm{M}$, and standard $\mathrm{L}$, all substantially as and for the purposes herein set forth.

No. 154,OS1,-JOHN L. POLLARD, SCOTt's Hili, Tens.-Cultivators.-Aurust I1, I874. Filed February 28,1874 .

Claim. - The plough-beams G G', pivoted at $i$ to the rear portion of the draught pole $\mathrm{D}$, and connected together at their front ends by a bolt, $b$, the guides $\xi g$, the rod $\mathrm{H}$, and hand-lever $\mathrm{L}$, all constructed, arranged, and operating as described.

No. 154,404.-JOHN LUX, Hopkinton, IOWA.-Cultivators.-August 25, 1874. Filed March 21, 1874.

Claim - In a wheel cultivor, the laterally and longitudirally slotted verticle pendants $H$, in combination with the sliding sheaves and pulleys $i$, substantially as set forth

No. 154,472,-V. K. GEORGE, Geneseo, I I.L.Eveners for Cultivators.-August 25, 1874 . Filed July 7,1874 .

Claim. - In combination with the double-trees D E, ar ranged on each side of the axle and connected by rods $d d$, the depending bars $a$, braces $b \quad b$, and single-trees $G G$, all operating together as and for tle purposes set forth.

No, 154,586, - WILL1AM 1'. DALE, Agricultural Collikie, PA.-Cultivators.-Siptember 1, 1874. Filed Fibruary 21,1874 .

Claim.-1.- In a cultivator, the beams D D pivoted at their front ends to rods $c^{1}$, which pass through slots $e^{2}$ in arms $\mathrm{C}$, in combination with laterally vilurating arms $\mathrm{F}$, and staples $f$, which suspend the rear ends of said beams, substantially as described.

2.- The beams D, hung so as to be movable longitudinally, as described, and having single-trees connected to their front ends, in combination with the chains $k n$, arranged as described.

3.-The guards I I, staples $f f$, and plough heams D D, arranged to be movable, as described, in combination with the laterally and vertically vibrating arms $F$, connected by slots to said staples $f f$, substantially as set forth.

4.- The laterally and vertically vibrating arms $F$, with studls $h$, suspending the rear ends of plough-beams D, in combtnation with the pivoted treadles 5 , and the perforated connecting rod $\mathrm{H}$, substantially as shown and described,

No. 154,666.- V]ARQUIS L. GORHAM, RuckForD, It.L.-Cultivators.-Siptembir 11, 1874. Filed Muy 17, 1872.

Claim.-1.-The combination of the hangers $\mathrm{E}$, recessed disks $\mathrm{F}$, disks $a$, and their necessary holes and studs, with the drag-bars 1, to allow of a vertical motion to the drag bars, as described.

2 , - The suspension rods $d$, regulating springs 5 , and drag-bars $\mathrm{I}$, in combination with hangers $\mathbf{E}$, to which they are attached, substantially as described.

3.-The bent sway-bar $\mathrm{N}$, having right-angled piece $p$, in combination with pin $r$ and axle $B$, as and for the purpose described.

4. - The shields $u$, beams $S$ and $R$, in combination with the drag-bars I, as and for the pnrpose described.

5.- The clamp-block $\mathrm{K}$, having vertical and lateral sockets, with shovels $l$ attached thereto, and eye screw-bolt $n$, in combination with the standards $H$, constructed and operating as described.

NQ. $154,835-A$. F. CARLSON, C. SHIPPS and W CAMRON, AttrCA, IND.-Wheel-Ploughs and Cultivators.-September 8,1874 . Filed March 23, 1874 .

Claim.-1.- The bent and twisted bars $D^{\prime}$ attached to the double-tree D, which has its ends hent downward, forming a convenient attachment, to which to couple the cultivatur-ploughs $\mathrm{G}$ and the eveners $\mathrm{H}$, substantially as herein set forth.

2.- The combination of the bent double-tree D, bent and twisted arms $\mathbf{L}^{\prime}$, hook-couplings $b$, pins or bolts $b^{\prime}$, and the cultivator-ploughs $G$, substantially as and for the purposes herein set forth.

3.- The combination of the cultivator-plough $\mathrm{G}$, bail $e$, rod or bar $e^{\prime}$, lever 1 , and the axle B, provided with a groove on its under and rear side, all substantially as and for the purposes herein set forth.

4.-The combination of the circumferentially-grooved axle $\mathrm{B}$, stirrup $\mathrm{J}$, with hooks formed at its ends, the setscrew's $f f$, adapted to carry bars $J^{\prime} J^{\prime}$, pins $f^{\prime} f^{\prime}$, and breaking-plow $\mathrm{k}$, all substantially as and for the purposes herein set forth.

No, 154,915.-SYLVESTER RUFFNER, CARTHAGE, Онго,-Cultivators.-September 8, 1874 . Filed June 29 , 1874

Claim.-I.-The combination of the pivoted tongue $H$, trigger $\mathrm{K}$, and pivoted handle $\mathrm{P}$, constructed and operating as and for the purpose set forth.

2.- The combination of the pendants $\mathrm{F}^{\prime} \mathrm{F}^{\prime}$, whiffletrees $\mathrm{G}$, and flexible stays $\mathrm{T} T$ with the swinging tongue $\mathrm{H}$ and beam $\mathrm{C}$, as shown and described.

3.- In combination with the beam $\mathrm{C} c$ of a cultivator and the pivoted tongue $\mathbf{H ~} \mathbf{1}$, the draw-bolt $J$, trigger $K$, perforated bar $\mathrm{L}, / \mathrm{N}$, circle plate $\mathrm{M} O \mathrm{O}^{\prime}$, and stops $o \mathrm{o}^{\prime}$, as and for the objects stated.

No. 155,159. - EMANUEL M. KISSELL and MARTIN L. KISSEI.L, SPRINGFIIID, OHO- Mher. 
Cultizatura-September 22, 1874. Filed fanuary 12, $1 \mathrm{~S}_{74}$.

Claim.-1.-A square draft-post, forked to receive the cross-beam in a cultivator, and secured to the latter in such manner as to allow of a vertical as well as lateral adjustment of the same by the clamping devices described, consisting of links $m m$ above and below the cross-beam B, edge plates $n n$, provided with syuare grooves or guides $n$ " for the reception and securing of the post in a perpendicular position, and as guides for the vertical adjustment of the same, block $u$, and set-screw $d$ for fastening it at any point, all arranged in the manner described, as and for the purpose set forth.

2.-A plough-standard having a lateral brace extending across the immer angle of the same, and secured to the beamplate by the same bolt which pivots the standard to the beam-plate and beam, in the manner described.

3.-The flanged rhomboidal beam platen () , provided with ratchet parts $r$ and gains $s^{\prime}$, in combination with beam $C$, brace $b^{\prime}$, and standard $s$, as shown and described, as and for the purpose set forth.

4.-Plate D and parts $s^{\prime} s^{\prime \prime} e^{\prime} e e^{\prime \prime}$, in combination with beam $\mathrm{C}$, brace $b^{\prime}$, and standard $s$, arranged in the nianner shown and described, for the purpose set forth.

5.-The journal $v$ and plates $i^{\prime} i^{\prime}$ and $p$, in combination with the forked draft-post $\mathrm{E}$ and the clamping device, as descrihed, by wlich the same is attached to the cross beam $\mathrm{B}$, in the manuer shown and described, as and for the purpose set forth.

No. 155,419.-A. CANFlEI.D, Garnett, Kansas.Corn-Cultizaters.-September 29, 1874. Filed June 20, I 874 .

Claim.-1.-The vertically-adjustable arched irons $a$, in combination with the tongue $\mathrm{D}$ and seat beam $\mathrm{E}^{\prime}$, substantially as and for the purpose set forth.

2.- The reversible foot or stirrup braces, combined with the shovel beams, substantially as described.

No. 7,513.-A. CANFIELD, DAVENPORT, IOWA.Corn-Cultizalors. - I55,419. - September 29, I 874.-Reissued February 20, 1877. Filed January 16, 1877

Claim. - I. - The pendant bars F, curved as described, and arranged to operate with the plates $\mathrm{C}^{\prime \prime}$, carrying the bolt $f$, bar $\mathrm{C}$, and having the holes $f^{\prime \prime}$, for the adjusiment of the beams $\left(; G^{\prime}\right.$ substantially as described, and for the purpose specified.

2. - The vertically-adjustable arched irons $a$, in combination with the tongne $\mathrm{D}$ and seat beams $\mathrm{E}^{\prime}$, substantially as and for the purpose specified.

3.- The arched plates $a$, secured to the tongue, as described, and having slots $c^{\prime \prime}$ combined with the bar $\mathrm{E}$ and bolts $c^{\prime}$, substantially as and for the purpose specified.

4.- The reversible foot or stirrup braces, combined witl the shovel heams, substantially as and for the purpose specified.

No. 155,717.-EDWVARD 1, ENO, ST. Lours, Mo.Cultizators.-October 6, 1874 . Filed Fuly 14, 1874 .

Claim.-I.-The combination of the bars D and G, tongue $\mathrm{E}$, lever $\mathrm{I}$. and lever frame $\mathrm{K}$, all constructed and operating substantially as set forth.

2. - The combination of the double-ended lever $\mathrm{M}$, link $\mathrm{N}$, and hook $\mathrm{P}$ with the plough beam and axle, all substantially as and for the purpose set forth.

3.-The combination of the plough heams O, clip S S T and round upright $\mathrm{U}$, all sub-tantially as set forth.

No. 155,905.-THEODORE F. VANDECIRIFT and W. VANDEGRIFT, WaBASH, IND,-Wialking-Ploughs. - October 13, 1874 Filed August 25, 1874.

Clain, - 1.- The tongue, composed of sections D $\mathrm{D}^{1}$ jointed together and combined with the pivoted sheath $\mathrm{D}^{2}$ the hand lever $\mathrm{F}$, and its connecting $\operatorname{rod} b$, substantially as described.

No. 155,956,-SAMUEL JONES, LINCOLN, ILL.-Cuttivators.-October 13,1874 . Filed August 28,1874 .

Claim.-1.-The combination of the flanged bent circle $A$, clamp B, axle $b$, and set screw $d$, all constructed subsiantially as and for the purpose herein set forth.

2.- The combination of the two short axles $b b$, each having a wheel, $C$, the sleeves $h h$, one on each side of each wheel, the perforated fianges $i j$, connected to said sleeves, and the couplings $\mathrm{G}$, with perforated flanges $p$, on the ends of the plough beams, all substantially as set forth.

3.- In combination with the two axles $b b$, and wheels $C$ C, the sleeves $h h$ on each side of each wheel, and provided with perforated flanges $i$, the four plongh beams $111 \mathrm{I}$, slotted cross-bars L L, handles P P, and the slotted comnecting bars $\mathrm{R} \mathrm{R}$ for lateral adjustment, all substantially as set forth.

No. 156,2I6.-A. J. GOODRICH, Rock Grove, JlL.Cultivators.-October 27, 1874 . Filed February 7, 1874.

Claim. - The combination of the tongue $\mathrm{A}$ and beams $\mathrm{C}$ $\mathrm{C}$, with the double-tree $H$, the latter being suspended from the tongue and connected with the rear ends of the heams, in the manner and for the purpose specified.

No. 157,603.-JAMES M. HOLI.ADAY, TWYMAN's STORE, VA.-Double Cultizators.-December 8, 1874 Filed Oetober 23,1874 .

Claim.-I.-The combination upon the frame $B$ of the tongue $A$, spring-seated lever $C$, intermediate lever $D$, rack $b$, and catch $c$, all constructed and arranged substantially as and for the purpose described.

2.-The single-pivoted traction-frame $\mathrm{H}$ in combination with the crank-axle $G$ and the adjustable supports $m$, substantially as and for the purpose described.

3. - The comlsination of the studs $n$ of the cultivator with the arched pieces $\mathrm{J}$ and loops /, substantially as and for the purpose described.

4.- The combination of the traction-frame $\mathrm{H}$, the folding section $\mathrm{M}$, the handles $\mathrm{N}$, and the cultivator $\mathrm{O}$, substantially as and for the purpose described.

No. 157,721.-WN. P. NUNGER, BERGEN, N. Y.Cultizuters,-Decumber 15, 1874. Filed June 30, 1873 .

Claim.-The combination, with the cultivator-frame A A, of the series of angular knives C C C, arranged in alternate positions, and lapping each other on the inside, and graduated in depth from front to rear, as and for the purpose specified.

No. 158,709.-R. S. HIGGISN, FATRFIELL, ILI..Cultivators.- Junuary 12, 1875. Filed Ats $115 t 19,1874$.

Claim.-1.-The combination of the pivoted oblique braces 12 , pendants 6 , main frame 1 , beams 7 , and singletrees 11 , substantially as and for the purposes set forth.

2.- The L-shaped bars 27 , constructed and operating as described, in combination with the plough-beams 7 , loops 31 , transtere har 24 , and nuts 2526 , substantially as and for the purposes set forth.

3.-The nuts 2526 and screw protecting sleeves 28 , in combination with the $\mathrm{L}$-shaped bars 27 and transverse bar 24. for adiuting the plough-beams as to their distance asunder.

4.- The combination of the hooks 18 and pivoted bails 19 with the pivoted handles 17 , beams 7 , and draft apparatu- 613 , by means of which the plongh-beams are supported while out of use, without afiecting the application of the draft to the main frame.

No, 158,752 - JOSEPH STOFFORD, Galfgere, Il.t. -Wheel-Cultizators.-Fanuary 12, 1875. Filed August 21, 1874

Claim,-I - In a walking straddle-row cultivator, the combination of the pivoted pole $\mathrm{C}$, rigid axle $\mathrm{A}$, wheels $\mathrm{B}$, and plough heams D D, so that the operator may control the direction of the machine by the plough handles, and permit of the tongue vibrating freely, substantially as and for the purpose specilied.

2.-The suspending rods E E, secured to the forward ends of the plough beams, and projecting forward of the axle, and operating in combination with the brace rods $a^{1} a^{j}$, substantially as and for the purpose specified.

No. 159,500.-EDWIN C111 LDREN, DUNLEITH, ILI. -Cultivators.-Fibruary 9, 1875. Filed October $y$, 1874 .

Claim.-The combination of the fivoted draft-pole C and lever $\mathrm{E}$ with the swing arms J J, provided at their forward ends with rollers $i i$, resting upon the front timber $d^{\prime \prime}$ of the cultivator frame, the said swing arms heing pivoted at the centre beam $d^{\prime}$ and to the plough beam, supporting 
sway ham 11, and connected by a link, $c$, to the diraft pole, subtintially as specified.

Vi1, $150,507-11$ AR()UIS L. (i)RIIAM, Rixktiok1,

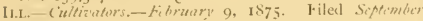
$2 \mathrm{I}, \mathrm{IS} 74$

Claim.-1.-The removable centre heam B, with it plough $b$, hinged to yolie $C$ lyy the swivel joint formerl by eyebolts $c^{\prime}$ and $c^{\prime \prime}$ and attaclied loosely to drag hars $A$ hy the yole $\mathrm{C}$ and eyebolts $c$ combined and operating sul st.ntially as and for the purposes describerl.

2.- The free sway bar 1), with its terminal ends $d$, in combination with the socket $d^{\prime} d^{\prime \prime}$, constructed an de scribed, and adjustable on drag bars $I$ of a cultivator, sub. stantially as and for the purpo-e described.

No, 150.560,-GEO, S. BROWER, G, W. BROWER,

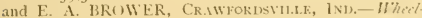

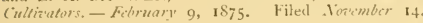
1874.

Claim.-1.-The slotted frame-pieces 13, having curved rear sockets, $\mathrm{E}$, in combination with the sent-bar $1 \%$, shor axles $\mathrm{A}$, and bolts $\mathrm{C}$, as and for the purpore spucified.

2. - The comlination of the yokes I II with the crossbar $I$ and pins L L, arranged as and for the purpose speci. fied.

3.-The comlanation of braces $\mathrm{R}$, stay-rods $\mathrm{T}$, and hang ers $\mathrm{L}$ with rod $\mathrm{Q}$, to support the plough-standards, as set forth.

Yo. I59,680.-EDWIX E. LEACH, CEDAR RAPIDS, Iow:1. - Itheil-cultizuters.-Fibruary 9, I\$75. Filed Octolier 17,1874

Claim.-The combination of the elevated vertically-adjustable part A of the axle-tree, standards C, and combined supporting or draught bars and braces $\mathrm{E} \mathrm{E}^{1} \mathrm{E}^{2}$, substantially as and for the purpose specified.

No. I60,142.- TACOB BEIIEL, RorkFIRI, ItL., as signor of one one-half bis riglt to RALPH EMERSON same pace.-Cultivators. - Fobruary 23, is75. [Filed Janum, 26, I 875

Clain.-I.-The handle E, pivoted to the beam or dragbar $\mathrm{D}$, in combination with the rod or connection $\mathrm{F}$, sub stantially as and for the purpose specified

2. - The combination of the beam or (lrag-bar D, handle $\mathrm{E}$, and rod or connection $\mathrm{F}$ with the ratchet--egment 6 ; and pawl or catch $b$, for ch.nnging and holding the beams in dif ferent positions, substantially as descrilsed.

Vo, $160,210,-$ L L LAWRENCE and $\mathrm{G}_{2}$, S. THOMAS DUBLIN, IXD, assignors to WAYNE ArRICLITURAL. COMPANy, same place.-Cullivators.-Fitirtary 23, IS75. Filed January 2, IS75.

Claim.-1. - The describest combinat on of bed plate $\mathrm{E}$, turn table $\mathrm{G}$, tongue $\mathrm{H}$, bolt $\mathrm{K}$, lever $\mathrm{X}$, and catch $O$, for the purpose herein desiunated.

2.- The tungue $\mathrm{H}$, rigidly secureil to the circular turn-table $(\mathrm{F}$, in combimation with the drop catch () and lever $\mathbf{I}$.

3.-In a wheel-cultivator, the arched axle $\mathrm{B}$, with the offsets $b$ and the frame $\mathrm{D} \mathrm{D}^{\prime}$, in combination with the pivoted tongue $H$, secured to the frame by the turntable E G.

No, I 60,602.--P. F. L.ANDPHERE, MAZON, (MURRIY J'. ()) 11.L., assignor to himself and DELOSS IONES, same place.-Cultizators.-Warih 9, I875. Filed fanuary' 18,1875

Claim, - 1, - The combination of the two tongues 6 , the cross-bars $\mathrm{F}$, connecterl by the bars $f^{2}$, braces $f^{3}$, and stay boit $f^{4}$, the two axles $\mathrm{H}$ connected together by the block $h^{1}$, liar or plate $h^{2}$, braces $h^{3}$, and stay bolt $h^{4}$, the cranliaxle arms I, and the wheels $J$, to adapt the machine for une as a three-horse two row cultivator, or as one or two twohorse single-row cultivators, substantially ae herein shown and descrilied.

2.- The combination of the pivoterl draft-bars $\mathrm{K}$, the ropes or chain, L. the uide pulleys .1 , and the evener $N$, with the crosaluars $F$ and the axles $H$, substintially as herein shown and described.

3.- The combination of the crosu-bar $\mathrm{C}$, having its end parts curved or arched with the two pairs of beams A, subtantially as herein shown and described.

No. I60,621. - ALBERT D. SIMONS, WINDOR, CUNN.

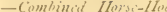

Filed Jammary 25, is 7

Clain, - 1.-The arches hean C, liatus lorizontal arms $\mathrm{B}$, in combination with the guide clamps $(i$, plought $A$, and hoe blades D, subutantially as hereis dencribed.

2.-The arched beams $\left({ }^{\prime}\right.$, with the ploughs and hoes attached as described, and the guide clamps $f_{i}$, in combinintion with the arched support J, rods $L$, braces $\mathrm{M}$, and stud, $\mathrm{N}$, substantially as shown and clescrubed.

3.- The combination of cultivators A D, arched beam $C$, lever $O$, and spring catch $\mathrm{P}$ with the truck frame and tongue, substantially as set forth.

Nis. 161,047.-CH.ARLES II. LLFKIN, IANGD, N. Il-Machines for Dixrins Stonr's, Situmps, Rioots, Eit Warch 23, 1875 . Filed Fitumery 24, 1873 .

Claim. - The combination of the hook or prong B, draw ron $\mathrm{D}$, swivel $\mathrm{G}$, beam $\mathrm{A}$, stay iron 1 , bandles $\mathrm{C} C$, $\operatorname{rod} \mathrm{J}$, braces E E, and brace $\mathrm{F}$, sub-tantially as and for the purpose hereinbefore set forth.

No. 161,102,-W11.LIAM P. DALE, PEnNsYi.vaNiA

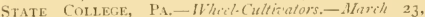
1875. Filed Augurst 29, 1874 .

Claim.-1-In combination with hinged or pivoted shovel-carrying beams D I), the vertically and laterally vibrating arms $\mathrm{F} F$, connected together at their front ends by means of a hand har, $G$, substantially as described.

2.-Beanis D D, connected by joints C C to longitudinally-vibrating arms $\mathrm{E} \mathrm{E}$, having independent bearings on the bounds $\mathrm{C}$, subtantially as described

3.- The supports $S^{\prime} S$ ', pivoted to the seat $S$, and having hooks $s$ son their ends, in c.mbination with plates l l and hounds $\mathrm{C} \mathrm{C}$, as described.

No. I61,592, - WILLIAM CLEMENTS, FiskTiLle, TEX-Combined Gang-Ploughs and Cultizators. - April 6, 1875 . Filed Decomber 23,1874 .

Claim. - The cross-bar MI, allapted to straddle the row, and rising up to form a foot-rest, and fournaled in the frame $\mathrm{I} \mathrm{L}$, in combination with the cultivator-standards $\mathrm{N}$, pivoted at or near their centers to the bar $\mathrm{M}$, and near their upper ends to a cross-bar, $O$, whereby they may be lifted or laterally adjusted, substantially as and for the purposes set forth.

No 161,855.-JO11N N. BASHAW, GENETA LAKE,

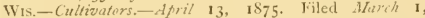
1875

Claim, - 1, - In a cultivator, the combination of the beams $\mathrm{D}, \mathrm{D}^{1}$, and $\mathrm{D}^{2}$, hinged as described, whereby the beams $\mathrm{D}^{2}$ and $\mathrm{D}^{2}$ may be adjusted in relation to each other, and in relation to the beam $\mathrm{D}$, all constructed as and for the purpase set forth.

2.-The split tongue $\mathrm{A}$, hinged beams $\mathrm{D}$ D, each having adjustable beams $D^{1} D^{2}$, in combination with the flexible brace E, chains $n n$, elbow levers $H$, and $\mathrm{T}$-joint $a$, all as and for the purpose set forth.

No. I62,126,-LORENZO IV. TKLE, TALIADEGA, ALA-Sulky-Ploushs.-Afril 13, 1S75. Filed Filmary 27,1875

Claim.- I.- In combination with the beams E, pivoted to cranks $f$, the draft-rods $i$, sloted arms $h$, and links $i$, the rods $e$ passing through slotted standaris $d^{\prime \prime}$ of caster wheels $d$, substantially as described.

2.-Plough standards $\mathrm{D}$, having rounded ends $n$, secured to their beams hy means of studded blocks $p \mathrm{~L}$, clips $r r^{-1}$, and rods $r^{2}$, substantially as described.

3.- - Springs $g$, applied to the ends of plough beams E, as and for the purpose described.

4 - The levers $J$, having lifter: $l l$, on their lower ends, and connected to arms $m$ on cranks $f$, in combination with the plough beams $\mathbf{E}$, pivoted to said cranks, substantially as described.

No. 162,151-CLEHENT 1. CARTER, UNHWN CIIY, IND.-Ploushs_-Afril 20, IS75. Filed Jamuary 12, I 875 .

Claim.-1.-The combination of the wheels $g$, having long stub axles $h$, wilh the frame, having the vertical slotted posts $k$ and guides $i$, and with the cranks $n$, rock shaft $O$, and lever $l$, as shown and described.

2.- The combination of the inner standards $B$, pivoted at their middle to a rigid support, having the arms $f f$ and 


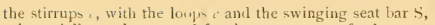
substantially as shown, and for the purposes set forth.

No. 162,273.-A.MOS B. COJ T'ER, ALBANY, OREtit) - Cirltiuters.-April 20, 1875. Filed January 30, 1875 .

Claim.-1.-As an improvement in cultivators, the com bination of the obliquely-arranged plongh frame $\mathrm{A}$, sliding on front king loolt $b$, and by rear guide frames $F$ on the rear axle, with the supporting min beam $\mathrm{D}$, and operating lever $\mathrm{D}^{1} \mathrm{D}^{2}$, and frame comneeting rods, for raising and lowering the ploughs as required, subsantially in the manner ant for the purpose set forth.

2.- The combination of sliding plongh frame A with main leam 1), and pivoted sumporting hoows H operated by spring acted lever H', for locking plough frame in rained pusition, substantially as set furth.

No. I62,700.-El.I SHUPE, MIDutirit.e, Mich.Conltivators.-April 27, 1875 . Filed North 13, 1875

Claim.- I. - The frame A, having a traft-pole, B, and a handle, $C$, secured to it, in combination with the arm $\mathrm{E}$ and foot bat $\mathrm{F}$, pivotally eunnected to said frame, and with segments D J, spring latching arms $\mathrm{K}$, and wheels $\mathrm{N}$, substantially as described.

2.- In combination with the handle $C$ on frame $\Lambda$, the rlotted tandard $G$ and in pin on the foot bar $F$, stibstan tially an and for the purposes descrilsed.

No. 162,761.-JOHN ORLANDO, WEST YARMOUTH, Hass.-Strawhery-Culizators.-.May 4, I875. Filed Fibruary $12,1875$.

Claim.-1. - In combination with a wheeled carriage, A, and frame C, arranged and applied together, as described, a vibratory rake, $\hat{H}$, disk-cutters $F \mathrm{~F}$, a series of plough teeth, $F$, ant euter $G$, all being arranget to operate as explained.

2.-In combination with the wheel-carriage $A$, the viloratory rake, ant the frame $C$, arranged and applied tosther, as specified, the arms $h^{\prime} l o$ and the levers $i m$, pivoted to. gether, and applied all as chown and described.

No. 163,372 -FIITIII D, GURHA.M, HADLEY, ILL. -Cultiactors-Nay is, 1875. Filed April 12, 1875.

Claim. - The foot eultivating shoe dencrilued, consisting of the sole $\mathrm{B}$, shovel $c$, brace $n$, coulter $s$, heel support $a$, and set screw 0 , all constructed, arranged, and operating, as and for the purposes set forth.

N. 164,148.-B. C. COX, Conper Hil. I, Mu.-SulkyCultiziters.-June S, 1875 . Filed January 30, 1875.

Claim. - The half-keeper $k^{\prime}$, pivoted toe bars $O^{\prime}{ }^{\prime}$, and plate, 1 , combined with plough lseams, suistantially as and for the purpuse set furli.

No, 164,960 -ALEXANDER F BATCHELI.ER, Cedir Falis, Iowa,-Corn-Cultizutors-June 29, 1875. Filed April 24,1875 .

Claim.-1.- Longitud nally-adjustable axles $a$, in combination with laterilly and vertically adju-table spindles $G$ hung from the axle $\mathrm{B}$, substantially as rlencribed.

2. - Handler E. adjustably pivoted to frame $\left.1^{\prime}\right)^{\prime}$ and conneeted to the spindles $G$, in comlination with the suspension links $n$, rods $o$, and spring $s$, substantially as described.

3.-In combination with the revolving ploughs $h$, the rolling clearers $p$, and the segment rack $I$, sulustantially as described.

No. 165.13\%-THEODURE F VANIDEGRIFT and WHLL'A II VANDEGIRIFT. WABASI, INI., assignors of one-half their right to $\mathrm{O}$. W: $\mathrm{WIE}$, same plaee.-Cirltivecors.-Fune 29, I875. Filed May 1. 1875.

Claim.-The frame $\mathrm{C}$, proviled with hounds $\|$ ", formed of a single piece, in eombination with the box 1 , reeessed and piroted tongue $\mathrm{E}$, spring lateh $\xi$, and lever $d$, substantially an de cribed, and for the purpose set forth.

No. 166,050.-GERSHON WILKINSON, UUINEY, OH'.-Cultirutors.-Fuly 27, 1875. Filed April 17, I\$75.

Claim.-I. - The combination of the pivoted and ointed standards $K$, the elbow lever $N$, and the springs (), with the curved rear part of the plongh beams 1 , substantially as herein shown and described

2.-The combination of the pivoted and slotted plates
L. with the standards $\mathrm{K}$ and the ploughs $\mathrm{M}$, substantially as herein shown and described.

3.-The combination of the levers or arms $\mathrm{T}$ and the acljustable hook plates $U u^{\prime}$, with the outer adjusting bars $\mathrm{R}$, substantially as herein shown and described.

No. I66,417-6E()RGE W. SCHENCK, GeNEVA LAKE, WIs., assignor to C. E. BRANDUN, same place.IItrel-Cultitutors-Angust $3, \quad$ I 875 . Filed Hay I5, 1875 .

Claim.-In a enltivator, substantially as described, the combination of the levers, $K^{\prime}$ for lifting each set of shovels, buth placed at one side of the frame, one being rigidly secured to a rock shaft, and the other turning independently of said rock shaft, so as to be used separately or to be simultaneously drawn back by one hand, substanstantially as described and shown

No. 166,636.- INIUER SCHRADER, WAI.A.A WALLA, Wash. - Civitiontors.-Aurust 10, 1875 . Filed Fune 7 , 1875

Claim.-The combination, with sliding rod D and swiveled rods $D^{\prime}$, holding front and rear wheets, of the rock shaft $\mathrm{E}$ having arm $e$, the lever $H$ having oblong slot $h$, the rods I J, anl the lever $\mathrm{K}$, all arranged in connection with fiame $A$, as and for the purpose described.

167,226,-IV, MI. COSTON, QuTMAN, Mo,-Cultizator Frames.-August 31,1875 . Filed April 17, 1875.

Claim. - The eombination of the adjustable bearings $H$ and axle $G g^{1}$, provided $\mathrm{w}$ ith a bar, I, to receive the seat, and with supporting hooks $5^{2}$, with the perforated side bars $A$, the crost-bar $B$ C, the tongue D, the braces $E$, and the wheels $\mathrm{F}$, substantially as herein shown and descrilied.

No. 168,105.-11. N. PROUT, WestFIEL1, Mass.Hoing Machines.-Siptember 28, IS75. Filed Fibuary I 3,1875 .

Claim.-1.-The eombination, with spring hoes $\mathrm{F}$, of touble socketed stocks $F$, al, ustable by rods $a$ b $d$ and slicle pieces $d^{\prime} f$, as shown and described.

2. - The lever $E$, pivoted in fromt to the frame and tongue, and adjustable at the rear in slotted guides $h h$. as and for the purpune specified.

No. I 68,537 - JOB SPAlN, Nislit LEWisburg, OH10. - Sulley Cultizators.-Oitubr 5, 1875 . Filed July 24 , I 875

Claim, - The combination, with the eonnected plough heams $\mathrm{I}$, of the rock sha't $h$, with treadles $k$ and handles $N$, rertical shafts $O$, with arms $n p$, and adjustable pins $s$, substantially as and for the purpose set forth.

No. $170.726 .-1 I[$ iH 11. GILCHRIST, SWAN CREEK, assignor of tne-half his right to JOHN J. WWORDEN, Youngstow:, 1L1.-Com Linweris.-Detember 7, 1875 . Filed $/ u l y, 24,1875$

Claim,-The combination of the plate A, bar B, and prongs $C$ with ench other, substantially as herein shown and described, to adapt the device for attachment to the plonghm in's foot, as and for the purpose set forth.

No, $172,775 .-B E N J 4 M I N$ W. REMY and NOAH T. REVY, BRorkinte, IXD; said N().MH T. REMI assignor to said B. W. REMY, and sair B. W. REMY assignor to REBECCA A. REMJ, BENJAMIN M. REMY, NOAH T. REMV, and CATHERINE R. SHIRK. - Whed-Culliwators.-Fimmory 25, 1876. Filed August 26,1875

Claim.-1.- In combination with the tongue $C$ and axles A $\mathrm{A}$, the blocks $\mathrm{F}$, outer arehes $\mathrm{D}$ D, inner arches $\mathrm{D}^{\prime} \mathrm{H}^{\prime}$, and loops $G G$, all substantially an and for the purposes herein set forth.

2.- The plough-beams $J$, formed as deseribed, and eurved upward at their rear ends, as and for the purposes herein set forth.

3.- The combination of the plough-beams J J, curved and perforated as described, the double adjust able standards $\mathrm{P}$, pivoted to the beams, and the brake-pin $x$, all substantially as and for the purposes herein set forth.

No. 173,747.-EI)WARI W1ARD, Lovisville, KY., as ignor to B. F. A VERY, same place.-Whicel-Cultivators. - February 22, 1876. Filed Dicember 13, 1875 .

Claim.-1.-The shovel-beam $\mathrm{K}$ and the pair of shovelstandards L L thereto attached, made of separate pieces of metal, in the forms shown and described, and united by 
screw-bolts // passing through branches of the bcam, and through the bowed portion of the pair of standards, sub. stantially as and for the purposes set forth.

2.-The curved slotted shovel-standards I, and N, has ing beveled or concase seats $n n$, with separate bearings, in combination with the shovel-block $\beta$, having convex tongues $p^{1}$, and the yoke $q$, substantially as described.

3.-The pivot-standard $h$, attached to the socket of the bean, and formed with a central channel and stops, $h^{\prime} h^{\prime}$, in combination with the fender bar 1 , as shown and de scribed.

4.- The arch A, rising from the inner ends of the axle arms, and bowed outwardly and upwardly to support the tongue $\mathrm{I}$ ), in combination with the arched brace (, attached to the front of the axle, and extending firs forward, then upward and backward, and yoked to arch $\mathrm{A}$, and clamped to tongue 1) in rear of said arch, substantially as shown and descrilied.

5.-The double-eyed yoke-clip $a$, in combination with the arches $A$ and $C$, substantially as described.

No. 174,013.-CHARLES J. SEABROOK and IIENRT HEINE, Talladega, Ala. - Combined Seed. Planters and Cullizators. - February 22, 1876 . Filed Janแaว 8, is 76 .

Claim.-The lifting-frame M, constructed as shown, pivoted to the frame $\mathcal{A}$, and capable of being reversed, so as to arrange the ploughs connected thereto in different positions for different kinds of work, as set forth.

No. 174.563.-HARVEY PACKER, S.INIwich, ILI., assignor to the SANDWICH ENTERPRISE Company, same place.-Cultintors.-Warth 7, 1876. Filed . Huszust 2, I 875 .

Claim.-The combination, with the plongh beams $\mathrm{F}$, of the brackets $O$, having outward projecting tubes $O^{\prime} O^{\prime}$, cast therewith, the plough-standaids $\mathrm{M}$, and the bolts and nuts $O^{2}()^{3}$, all constructed substantially as and for the purposes herein set forth.

No, 174,577--ANDREW RUTIEDGE, RockFORD, II.L., assignor of one-balf his right to WM. A. KNOWL. TuN, same place.-Cullizators.-Warch 7, 1876 . Filed Fune 23,1875 .

(laim.-1,-The combination, substantially as before set forth, of the main frame, the hand-lever, the flexible connection, and the shovel-beam, provided with an intermediate bearins, to which the flexible connection is applied.

2.-The combination, substantially as before set forth, of the vibrating evener, the whiffletrees, the clamp pulley blocks, the brackets therefor, and the flexible comnections between the whiffletrees and the evener.

No. 174,686.-JANES C. LEIDV, Galesburg, Tht.Cultivalors._Wurch 14, 1876. Filed Xoxtember 10, 1875.

Claim. - I.-The axle of a straddle-row cultivator, constructed of a single bar of iron, bent so as to form a rectangular frame, with downwardly-projecting parts $a$, hetween which the spindles of the supporting-wheels are secured, substantially as and for the purpose specified.

2. - The pendants $\mathrm{E}$, having spherical heads $\epsilon$, in combination, with the clamp-plates $\mathrm{D}$ and bolt $d$, substantially as and for the purpose specified.

3.-The standard-plates $\mathrm{L}$, placed diagonally on the standards, and combined with the plates $\mathrm{M}$, beams $\mathrm{F}$, standards $\mathrm{J}$, and bolts $\mathrm{N}$, substantially as described, and for the purjose specified.

4. - The combination of the spindle $b$, having bead $b$, with the notched washer $b^{\prime \prime}$, axle-bars $a$, and thimble $b^{2}$, substantially as and for the purpose specified.

5.-The evener $\mathrm{G}$, pendants $g$, rods $h \mathrm{H}$, combined with the beams $\mathrm{F}$, penilants $\mathrm{E}$, and axle $\mathrm{A}$, and tongue $\mathrm{C}$, substantially as and for the purpose specified.

No. 175,077.-OLIVER C. GREEN, DUBi.IN, IND, assignor to CASPEK GREEN and JOHN GREEN, same place.-Which-Cultinators.-Warch 21, I876. Filed Fithruary 15,1876

Claim.-1.-A swinging tongue, D, having its pivot $x$ above the axletree, and perpendicular to the axis of the ground wheels, as berein described, in combination with a main rear draught doubletree, $\mathrm{E}^{2}$, hitch bars $(i$, and singletrees $\mathrm{F}^{2}$, supported in front and outside of the frame and wheek, so as to travel around the wheels without interference when the tongue is turned in either direction.

$2,-1$ swinging tongue, 1 ), having its pirot above the axletree, and perpendicular to the axis of the ground wheels, in combination with a horizontal frame, C, affording extended supports or hearings, $r, r$, beneath the tongue, in front and in rear of the pivot, as herein shown and described, and for the purpose specified.

3.- The combination of the swinging tongue $\mathrm{D}$, the rear draught doubletrees $\mathrm{E}^{2} \mathrm{E}^{3}$, staycd at about right angles thereto, the low hitch bars $G$, pivoted to the ends of one of these donbletrees, and connected to the other by rods $s$, and the ingletrees $\mathrm{F}^{2} \mathrm{~F}^{2}$, attached to the hitch bars, substantially as herein shown and described.

4.-The rocking har $\mathrm{I}$, constructed with a mortise $q$, pivoted between the frame bars $C$, and provided with the gravitating arm $r$, in combination with the pivoted tongue $\mathrm{D}$, as and for the purpose set forth.

No. 175,212,-WILL A. VAN CAMP, METAMORA, IND., assignor of one-half his right to JOSEPH A. VAN CAMP. same place.-Doublic Corn-Plousths. - Warch 2I, 1\$76. Filed Jaauary 22, $1 \$ 76$.

Claim, - 1,- In a cultivator, an arched axle, made in two sections, B B, overlapping each other in the centre and adjustably connected together by clamps $\mathrm{C}$ and set screws $a$, sulsstantially as and for the purposes herein set forth.

2.- The combination of the adjustable axle sections B B, heams A A connected thereto by staples $b \quad b$ and

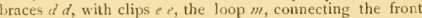
ends of the beams; and the wedge 1 , all substantially as and for the purposes herein set forth.

No. 175,370.-ALEXANDER MEHARRV, PLEASANT HILI, IND, assignor to himself and WILIIAM BROWN, same place.-Draug-tht-Equalizers.-March 29, 1876. Filed $\mathscr{F}_{u} l_{y^{\prime}} \mathbf{1} 7, \mathbf{1} 875$.

Claim.-The combination, with bent axle $\mathrm{A}$ having pulleys F F, and pole $\mathrm{B}$ having pulley $\mathrm{E}$, of the centrallypivoted bar I and connections D G J, arranged as and for the purpose specified.

No. 175,392,-1. P. THONPSON, PHEs.PS, N. Y.Cultivators.-Harch 29, 1876 . Filed fanuary 26 , 1876 .

Claim.-1.-In combination with the primary and secondary frames hinged together in front, the fixed pole, hinged seat bar H, and pivoted standards J, and adjusting segment or bar $\mathrm{N}$, constructed and arranged to operate conjointly, substantially as and for the purposes set forth.

2. - In a combined fallow and crop cultivator, the secondary frame, provided with coupling loops $n$ on the upper and lower side of the foot bar F, and otherwise constructed as shown and described, whereby it may be attached to the primary frame, as shown, for cultivating fallow ground, or attached thereto in an inverted position, so as to receive longer shanked teeth or "hillers," to adapt the same machine for cultivating growing crops.

No. 175,636.-JOHN A. AJAMIS, Battle Creek, Nich.-Cultizators,-April 4, 1876 . Filed December 23, 1875 .

laim.-1. - The combination of the stationary main frame $A$, braces D D, tongue $G$, pivot bolt $i$, and movable cultivator frame $\mathrm{H}$, all substantially as and for the purposes herem set forth.

2. - The notched guide plate $/ /$ attached to the under side of the frame $\mathrm{H}$, in combination with the bars $\mathrm{L}$ and and $L^{\prime}$, as and for the purposes herein set forth.

No. 177.063.-REUBEN El.1,W(x) and RICHARD L. PITCHER, SYCAMORE, JLL. ; said PITCHER assignor to said ELWOOD,-Cultizalors,-May 9, 1876. Filed Vorember $\mathbf{1 7}, 1875$

Claim.-1.-The combination of the levers H, provided with pins $d$ and the spring $b$, with the curved standards $]$, provided with openings $c$ on their sides, substantially as and for the purposes specified.

2.- The bent bar $t$, in combination with the drag bar D, shaft $G$, cylinder $F$, bar 0 , and cross rod $\ell$, substantially as and for the purposes specified.

No. 7,560.-R. ELLWOOD and R. L. PITCHER, SYCAMORE, ILL.; said PITCHER assignor to said ELL. 
WOOD.-Cultivator,-177,063.-May 9, 1876,--Reissued Aarch 20, 1877. Filed February 12, 1877 .

Claim.-1.-The combination of the standards I and cross rod $/$ with the side pressure levers $H$, for keeping the standards in position without additional bolts or braces, substantially as specified.

2.- The combmation of the levers $\mathrm{H}$, provided with pins $d$, and the spring $b$, with the curved standards 1 , provicled with openings $c$ on their sides, substantially as and for the purposen specified.

3.- The bent bar $p$, in combination with the drag bar D, shaft $\mathrm{G}$, cylinder $\mathrm{F}$, bar $o$, and cross rod /, substantially as and for the purpoies speeified.

No. 177,153.-H.H. PERKINS, Oscrola, ILL.Whicel-Cultizators,-May 9, 1879. Filed Siptember 17 1875

Claim.-1. - The combination of the bent roek-hafts $V$, slotted adjustable plates $\mathrm{W}$, stationary hangers $\mathbb{U}$, inwardly extending rods $B^{2}$, treadles $D^{1}$, downwardly-extending rods $Y$, and links $Z$, with the inner and outer ad justable shovel standardu, and the vertically adjutable beam frame, as and for the purpore set forth.

2.- The eombination of the swinging and laterally adjustable collars $Q$, notehed plate $\mathrm{N}$, cap-plate $\mathrm{I}$, pivoted eatch $\mathrm{O}$, and spring $\mathrm{P}$, witls the imner shovel-tandaid, $\mathrm{L}$, transverse screw-shaft $R$, and the beam frame, as and for the purpose set forth.

3.- The combintion of the roller $\mathrm{Mi}^{\prime}$, adjustable front roil $\mathrm{L}$, having perforated hooked rear portion $l^{\prime}$, with the jlant-fender ' $\mathrm{J}^{\prime}$, and its front arms $\mathrm{K}^{\prime}$, as and for the purpose set forth.

4.- The combination of the bent and forked bar R', with the adjustable supporting rorl $\mathrm{N}^{\prime}$ of the guard plates $\mathrm{J}^{\prime}$, and the yoke $\mathrm{E}^{\prime}$, pivoted to the plough-standards I. substantially as herein shown and deseribed.

No. 177,317.-GLALCUS BARCAFAR, STRINGFIELD, OHг.-Cultizaturs.-Hay 16, 1876. Filed Warith 27 1 876 .

Claim.-1.-In a wheel cultivator, the combination of the swinging posts $\mathrm{C}$ with the arebed axle $\mathrm{A} u$, and with the plough beam coupling $\mathrm{D}_{\mathrm{g}}$. substanti.lly as and for the purpose set forth.

2. The double-tree $\mathrm{N}$, swinging rods $u$, with loops $t$, and draft rods $s$, in eumbination with the swinging pests $C$, ball and socket joint $\mathrm{D}_{\mathrm{g}}$, and plough beams $\mathrm{E}$, having a draft longitudinally independent of each other and of the axle, substantially as and for the purpose specified

3--The combination with the plough, connected to the swinging pout- $\mathrm{C}$ by the ball-and-oeket joint, consisting of the sectional boxes $\mathrm{D}$ and the plates $h$, with balls ir of the eross.bar 1 , carrying upon each end hooded sheaves $\mathrm{K}$, and the chains $f$, pivoted levers $L$ and semicircular plate $\mathrm{M}$, with stops $\%$, substantially as and for the purpoie set forth.

No. 177,666.-DAN1AL C. TANNER, KIRTLAND, OHro.-Cultizators.-May 23, 1876. Filed Dicember 27, 1875

Claim.-I.-The combination of the side pieces B B of the frame, constructed as cleserihed, the chains $\mathrm{F}^{\prime}$ and $\mathrm{P}$, the standards I I, and the pendant vibratory arms $E^{\prime}$, the parts being construeted and arranged to operate as shown and described.

2. - The combination of ths standard $\mathbf{H}$, arliustable in the sleeve $G$, with the foot $a$, adju-table in the standard $H$, substantially as and for the purpose described.

3. - In a cultivator, the combination of the standards F and $H$ and the sleeves $G$, for rendering the shares adjustable, substantially as and for the purpose set forth.

4.- The combination of the sway-bar $\mathrm{C}^{\prime}$, piroted to the rear end of the machine, the chains $\mathrm{F}^{\prime}$ and $\mathrm{P}$, the pendant vibratory arms E', whiffletrees $\mathrm{E}^{\prime \prime}$

No. 177,685 .-HARLIN BUTNER, DUNCAN'S BRIDGE, Mo.-Combined Ilarrors and Cultizators.-Hay 23, 1876 . Filed Alarch 13, 1876.

Claim.-The combination of the ploughs $\mathrm{K} \mathbf{L}$ and harrows $\mathrm{M} \mathrm{N} \mathrm{O}$, relatively arranged substantially as and for the purpose specified.
No. 177,853--EMANUEL M. KISSELL and MARIIN KISSELL, SPRINGFIELD, OHIO.-Wheel-Cultiz'ators. - 1/ay, 23, 1876. Filed Jamuary 10, 1876.

Claim.- I.- In combination with draught-post $b$ and rod cof a wheel-cultivator, with its key $\mathrm{V}$, the frame-bars $h$ and and $h^{\prime}$ clevis-plates $f f$, and connecting-bolt $g$, as shown and specitied, for the purpose set forth.

2.-Hook-bars $a$, in combination with draught-post $b$, links / $/$, set screw $s$, and the cross-bar $x$ of a wheel-cultivator, as shown, as and for the purposes set forth.

3.- The suspended draught-bar $d$, provided with a The:id, $c^{\prime}$, for the purpose of allowing of two seprarate points of attachment thereto for the draft rods $c$ and $c^{\prime}$ by their front ends, in oriler to equalize the draught in the manner specified, and for the purposes set forth.

4.-The draught-bar $d$, provided with pivoted cross-head $c^{\prime}$ in eombination with the evener $d^{\prime}$ and rods $c c^{\prime}$ to form separate means of attachment to the wheel-spindle and plough-beam, as shown and described.

No. $7,8,3,-$ E. M. KISSELL and Y. L. KISSELL, SHRINGFIFID, OHH, - Whecl-Cultizuters. - I77.853. Hay 23,1876 . - Reissued August 7, 1877 . - Filed July 18, I8:7.

Claim.-1.-The plough-heam frame composed of the bars $h h^{\prime}$, bolted together at their forward ends, and selfbraced in the rear by the hent angular portion of the bar $h^{\prime}$, substantially as shown, and for the purpose set forth.

2.-In combination with the draught post $\mathrm{E}$ and rod $a$ of a wheel-cultivator, the frame bars $h h^{\prime}$, clevis-plates $f^{\prime}$, and connecting bolt $h^{\prime \prime \prime}$, as show $n$ and speeified.

3.- The combination, with the laterally and vertically ad ustable draught posts $\mathbf{E}$, of the hooked bars $c$, altached thereto, so as to be adjusted laterally with the posts, and always oecupy a relative position with the plough-beam frame, substantially as set forth.

4.-The combination of the hooked bars $c$, posts $\mathrm{F}$, links $e$ set-screws $d$, and the elevated axle of a wheel-cultivator, substantially in the manner and for the purpose speeified.

5.- The suspended dranght bar $f$. provided with a T-head for the purpose of allowing of two separate points of attachment thereto for the draught rods by their front ends, in order to equalize the draught, substantialiy in the manner specified.

6.- The draught-bar $f$, provided with a T-head, in combination with the double-tree and the dranght-1ods, to form separate means of attachment to the wheel-spindle and plough beam, as shown and deseribed.

No. $178,960,-$ ELI W. KUS,ELL and JOHIX N. RUS SE1L, Asntuy, Mo.-Sullip Plourhs and cultizators.Fune 20,1876 . Filed April 10, 1876

Claim.-1.- The combination of the axle $A$, bent sis times at right angler, (twice at one end and fonr times at the other, the wheels B C, the eye-burs $D$, and the board E, with each other, to form the frame work of the machine subtantially as herein shown and described.

2.-The combination, with the axle and the plough-beam of the casting or bearing $\mathrm{K}$, provided with a hook shaped flange $k^{\prime}$, and the adjustable collar or elamp $N$, as shown and deseribed.

5.-The cumbination of the lever $\mathrm{L}$ and chain $\mathrm{M}$ with the bent axle $\mathrm{A}$, the bars $\mathrm{I}$, and the board $\mathrm{E}$, substantially as herein shown and described.

No. 179,133.-STEPHEX PCRDY, KFWANEE, ILL.Culticators.- Fune 27, 1876. Filed Ausust 30, 7875 .

Claim.-I.-The combination of the boxes $\mathrm{H}$ and the pivot block $\mathrm{L}$, formed in two part: each having a trunnion, $l$, and provided with suitable oil passages $l^{2} /^{3}$, with the axles D, constructed to operate substantially as and for the purposes specilied.

2.- The combination, with a pair of eultivator plough beam, pivoted together subst:ntially as deseribed, of the standarts $h h^{\prime} m$ of the piourth beams and journal boxes, and the adjustable or extensible links $\mathrm{N} \mathrm{N}$, consisting, essentially, of two metallie plates having a series of bolt holes formed therein and provided with ears or projections at their extremities, which, when bent over, clasp the two plates together, as described, all arranged and constıucted 
to admit of a vertical and lateral adjustment of the ploughs, substantially as and for the purposes set forth.

No. 179,378 . - LEVI WERTENBERGER, LAKETON, IxD, - Sulky-Ploushs. - Fume 27, 1876. Filed April $\mathbf{1}$, is 76 .

Claim.-In combination with the shovel carrying beams of a sulky-plough, angular levers J, constructed and applied as clescribecl.

No. ISO,271.-WILLIAM N. RIDDLF, CADDU C GRNE, Texas. - Whact.Cultie'dors.-Juil. 25, 1S76. Jiled April 25,1876

Claim.-1.-The combination with pin I, having loop $\mathrm{V}$, of the spring $\mathrm{U}$, arranged to hold the ploughs down to their work, lut yelding sufficiently to allow them to move, as shown and described, for the purpose specified.

2.- The combination of the bow's 11 , the pins $\mathbf{I}$, the arms I $\mathrm{P}$, and the lever $\mathrm{L}$, with the plongh beams $\mathrm{C}$, the tongue $\mathrm{K}$, and the uprights $\mathrm{M}$, attached to the axle $\mathrm{B}$, substantially as herein shown and describer.

3.- The combination of the bent lever $Q$ with the lever L, pivoted to the uprights .1 , and with the pin I of the rear bow $H$, substantially as herein shown and described.

No. ISo,319.-SAMUEL A. BUCHAN AN, JEFTERSON, Wis,-Sulky-Cultizutors.-July' 25, 1876. Filed April 15 , 1876 .

Claim.-1,-The adjustable hinge and coupling, consisting of the tenoned post $\mathrm{G}^{\prime}$ hub $d$, with arm G, and lug $\varepsilon$, and the adjustable pivoted casting $\mathrm{I}$, in combination with the drag bar $\mathrm{H}$ and sway har J, as and for the purposes herein set forth.

2. - The hinge and coupling, consisting of the lug $k$, shaft $n$, with eye $n$, and forked pivoted arm L, in combination with the drag bar $\mathrm{H}$ and lever $\mathbf{K}$, as and for the purposes herein set forth.

3.-The combination of the pivoted plate R, carrying the plough standard, and having its free end inclined, and the slotied plate $\&$ having inclined shoulder $x$ and lip $y$, substantially as and for the purpoșes herein set forth.

No. 1 So,43S.-WILLIAM P. STALCUP, BrooKVILle, IND, assignor to WILLIAM A. LINDSAY and J. WV REYNOLDS, same place.-Cultitators.-August $\mathrm{I}, 1876$ Filed fune 15,1875

Claim.-1.-The combination of the binged axles and rods $\mathrm{D}$ D with the blocks $\mathrm{E}$, as descrilied.

2. - The combination of an axle, hinged at its inner en to a fixed support, with a supporting socket at its outer end, adapted to jermit vertical adjustment, substantially as described.

No. $1 S 0,987$. - G. BRADLEY, RockFor1, IL.., assignor to C.R. CHANDLER, same place-Corn-Cullizators. - fugust 15, 1876. Filed Februnry 14, 1876

Claim.-1.- The rods or bars G G, yoke $G^{\prime}$, pivoted to each other and to the axle $\mathbf{A}$, as described, in combination with the loop $\mathrm{H}$ and showel beams, for controlling said shovel and permitting their free lateral movement, substantially as described.

2.- The concave and convex ribbed plates $j$, in combi nation with the shotel beams and standards, for ad usting the angle of the shovels, substantially as described.

No. $181,069 .-A L 1 . X$. HAMILTON, HARRISSBURg, ARk.-Sulky-Ploughs--August 15, 1S76. Filed May 22, 1876 .

Claim. -1,-The combination of the rods J, the arms L, the shaft $\mathrm{Ml}$, the levern $\mathrm{N}$, and the slotted foot-bonrd $\mathrm{K}$ with the upper end of the plough-standards 1 , and with the bars C D of the frame, substantially as herein show and described.

2.- The combination of the curved and slotted arms $\mathrm{O}$, having notches or a series of teeth, and connected at their rear ends, by a transverse bar, with the braces $P$, the seat $\mathrm{Q}$, the plough-frame, and the plough-raising devices, as and for the purpose set forth.

No. 181,106.-WM. J. ROBERTSON, JASPER Co., Mo, assignor of one-half his right to PIIILI,IP KNIGHT, same place.-Prairie-Sod Cultivators.-August 15,1876 . Filed. Way 13, 1876 .
Claim. - The combination of the double beam I I, constructed as described, the colter $J$, with shoe $K$ and clasp $\mathrm{L}$, all substantially as herein set forth.

No. 1S1,245.-CIEMENT L. CARTER, UNION CITY, Inn.-Cultivators.-August 22, I\$76. Filled May I1, 1876.

Claim.-The rock-shaft $g$, with its cranks $n$, in combination with the connecting-links $m$ and bars $f$, thus uniting the frame . I with the tongue bais $l$, as and for the purpose specified.

No, 1S1,302,-JOHN C. BANNIGAN, DUNLETTH, lli. - Cultin'alors.-August 22, 1S76. Filed Maych 21, 1876.

Claim.-1 - The combination, with single-trees If $\mathrm{Q}$, of the connected rods N P, and lever $\mathrm{O}$, the latter pivoted to axle, as shown and described.

2.-The combination, with tongue and yoke, of the pin S and ring $t^{\prime}$, connected and arranged as and for the purpose set forth.

3.- The combination of the plough-beams, having front ends held by a ball and socket joint, and with each other, by adjustable hars $H$, as and for the purpose specified.

4.- The combination of the pivoted levers J, the swiveled arms $\mathrm{K}$, and the connecting rods $1 \mathrm{~L}$, with the axle $\mathrm{B}$ and the pluugh-beams $F$, sulstantially as herein shown and described

No, 181,494 -DANIEL C. STOVER, FREFPORT, lLI. -Cultinators - August 22, 1876. Filed Murch 4, 1876.

Claim.-1.-The axle or frame and beam D, in combination with the rigid bar E, pivoted at one end, and arranged to slide back and forth upon the axle at the other, for holding the beam up when not in use, and regulating the depth of the ploughs when at work, substantially as and for the purpose set forth.

2.- The combination of the axle or frame, bar E, beam D, and slotted plate $l$, substantially as and for the purposes specified.

No. i 8 , 944-THOMAS J, JONES, Blairsburg, lowa. -Cultivators - September 5, is76. Filed fune 9, is76.

Claim. - The combination of the two beams $d$, united at their front ends by the bow $g$, single-trees $h$, attached to the ends of the bow, lever $i$, shaft $n$, and chains or rods $\ell$, substantially as shown and descrilied.

No. 182,138 . THOMAS R. WALLIS, EgG's PoINT, Miss,--Whec-Cultizutors.-September 12, 1876. Filed Way 22, 1876 .

Claim.-I,-The axle-frames, consisting of eliptical plates $\mathrm{G}$ and connecting-bolts $\mathrm{H}$, combined with the short axles $\mathrm{B}$ and the arch standards C, substantially as herein shown and described.

2.- The bolts $\mathrm{H}$, formed on the arch-standards $\mathrm{C}$, and combined with plates $\dot{G}$, substantially as herein shown and described.

No. 182,443.-WILliaM P. HUBBARD, FARMLAND, InD.- Wheel-Cultivators.-Siptember I9, is76. Filed Alugust 5 , 1876 .

Claim.- The combination of the pivoted tongue G, having the toothed segment-plate $\mathrm{H}$, the circular bed-plate $\mathrm{F}$, the lever 1, provided with toothed plate $i$ and r.tck-bar J, whereby the tongue is deflected, and retained at any desired angle, substantially as decribed and shown.

No. 182,623.- WALES ALDRICH, DAYTUN OHO., assignor to DAYTON MACHINE COMPANY, same place.Whed-Cultitators.-September 26, 1876 . Filed June 23, 1876 .

Claim.-The metal arches $C$ and 1 , of the shape represented, each clasping, respectively, the inner and outer ends of the stub-axles $\mathrm{B}$, and braced by the tongue $\mathrm{E}$ and bars $b$, the whole united substantially as and for the purpose specified.

No. 1 I2,988.-FREDRIC P BEUCI.ER, CHARLESTON, Invs.-Cuitizators.-October 10, 1876 . Filed April 24 , is 876 .

Claim,-r.-The cultivator holder having a lreakingpin connection with a pin above arranged to break, combined with a hook below, which admits of removing the plough, substantially as set forth.

2.- The combination of parts E F, having an elbowshaped space between them, with the wheel-frame C C and wheel-axle E, substantially as set forth. 
3.- The combination of the tongue, the wheels, and the tubular pipes $C^{\prime}$ ', bent and connected, substantially as set forth, to form a cultivator-frame.

4.- The cultivator-plough beams formed of tubes having the jomt-comection in front, and curved down to receive the cultivators, and having the curved portion enlarged, substantially as set forth.

No. 183,004.-LUDlA H. HODGES, TARRANT Co., Texas,- Wheel-Cultivators.-Oitober 10, 1876. Filed Fuly 20, 1875 .

Claim.-1.-The clevis $\mathrm{k}$, having four sides in the forn of a parallelogram, and pivoted eccentrically between the vertical bars E F, as set forth.

2.-The reversible clevis $K$, eccentrically pivnted on the vertical bars $\mathrm{E}$ and $\mathrm{F}$, in combination with the plough beam and frame, whereby the front end of the plough beams are attached and provided with both lateral and vertical adjustment; as specified.

3.-The bent plate.$t$, forming a keeper for the marker and a draught hook, in combination with the draught rod $\mathrm{R}$, chain 6 , beam $\mathrm{B}$, and bar $\mathrm{E}$, as shown and deseribed.

No, 183,25 t.-JACOB HENRY COLE, DANVILle, PA.-Combined Ciultizators and Sulliy-Ploughs.-October $17,1 \$ 76$. Filed Siptember 5, $1 \$ 76$.

Clam.-1. - The combination of the pivoted tongue D, the sliding and rotating shaft $h$, connected to the tongue and to the beans, the lever I, shaft $k$, with arm $k^{\prime}$, and link $i$, substantially as and for the purposes herein set forth.

2.- In a cultivator or sulky-plough, a single shaft, b, sliding and rocking in boxes $a \quad a$, and comected to the plough beams, in combination with two separate and independent lever, whereliy the ploughs may he rained and lowered and moved laterally, substantially as herein set forth.

No, 183,280 -CHAS. A. BENTLEY, CANTON, ILL, assignor of one-half his right to MARTIN HOFFMAN, same place.-Cultivators.-Ortober 17, 1876. Filed .tugust 29,1876 .

Claim.-I.-The frame C, carrying the ploughs $\mathrm{G}$ and 1 , and tongue $\mathrm{D}$, pivoted to the frame $\mathrm{A}$, and arranged to operate with the rock shaft il cranks $m$, and hand lever $m$ ", substintially as and for the purpose specified.

2.- The seat support, constructed as described, of a truss frame, and adjustably seated on the bars C, substantially as and for the purpose specified.

No, I83,639.-ANDREW CANFIELD, DAVENPokT, IowA.-Riding and Walking Cultivators.-Oetober 24, 1876. Filed Ausust 26, I 876 .

Claim, - I. - In a cultivator, the seat suntaining rods $\mathrm{F} \mathrm{F}$, in combination with the double stirrup $G$, having openings $g s$, and perforated plates $\mathrm{H} \mathrm{H}$, substantially as and for the purpose set forth.

2.- In a cultivator, the seat-sustaining rods $\mathrm{F} \mathrm{F}$, double stirrup $\mathrm{G}$, having openings $g .5$, and perforated plates $11 \mathrm{H}$, in combination with the laterally and vertically vibrating shovel beams $\mathbf{L}$, provided with foot rest $Q^{\prime}$, substanti.lly as and for the purpose set forth.

No. 18t,042.-ALMON HUNT, MACoMB, assignor to SMITH C. FEKGUS()N, KEWANE, ILL.-Cultivators.Nor'mber7, 1876 . Filed Warch 8, 1676.

Claim.-1.-The sleeve G, operating as a connecting plate between the detachable pole I and the ploushs D, when the latter are suspended, as set forth.

2.-The sleeve $\mathrm{G}$, having plate $g \mathrm{H}$ on its ends, and stops $/ 2$ operating, in combination with the detachable pole $\mathrm{I}$, axle $\mathrm{A}$, and ploughs $\mathrm{D}$, having hooks $\mathrm{L}$. for engaging studs $\mathrm{K}$, substantially as and for the purpose specified.

3.- The sleeve $G$, having plates $g H$, and stops $h$ between the plates, operating in combination with the sections $\mathrm{A}^{\prime} \mathrm{A}^{\prime}$ of a divided axle to hold them in place and limit their motion, substantially as and for the purpose specified.

No. 184,155 . - ORLANDO HUFFMIAN, $;$ FRIEND, NEBRA 5 , assignor of one-half his right to BAlLEY G. McKINZIE, same place.-Wheel-Cultivators.-November 7, 2876. Filed March 23, 1876 .
Claim.-1.-In combination, the beams $\mathrm{A} \mathrm{A}^{\prime}$, having bifurcation $c$ at their rear ends, the plough standards $C$, having reduced spindles ", and the pivoted cross bars D E, substantially as specified.

2.- In combination with the beams $\mathrm{A} \mathrm{A}^{\prime}$, pivotal bar $\mathrm{D}$, and vibrating standards $\mathrm{C}$, the rotating eyebolt $\mathrm{F}$, handle $\mathrm{G}$, and pivotal rods $\mathrm{H} \mathrm{H}^{\prime}$, substantially as specified.

No. I 84,441 . - WILLIAM B. STURGIS, SHELIYVH.1K, ILL.—Cultivators.-Nowimber 14, 1876 . Filed August 21, 1876 .

Claim.-The tubular or bored compling blocks M, the short crank axles $\mathrm{B}$, the curved bar $\mathrm{C}$, having periorated ends, the set screws $\mathrm{D}$, for securing the axles in any adjustment, the pair of froni braces $1 \mathrm{~J}$ and the rear lirace $\mathrm{K}$, inclined as specified, and the frame $F$, all constructed and arrangert as shown and described.

No. 185,471 - J. C. BANNIGAN, DeNIEITH, II.L.Cultivators.-Decimber 19, 1876. Filed June 17, 1876 .

Claim.-1.- In a cultivator, the combination, with the vertically and horizontally vibrating shovel beams $\mathbf{I}$, of the tripping levers $J$, the angular journal rods $i$, depending from and rotating axially in the rear ends of the bars $C$ C? and affording learings for the said levers, and the pivoted rods $m$, nubstantially as specified.

2.-The levers $F$, pivoted to vihmte vertically on the axletree, in combination with the angular rods $\mathrm{E}$, the evener ' $)^{\prime}$, draught rods $\%$, secured to the lower end of the said lever, and sustained by the vertical arm of the angular roll $\mathrm{E}$, substintially as specified.

3.- In combination, the shovel pomt P, having metallic bridge $p$ and set screw $q$, with enlarged rounding head $i^{\prime}$, and the standard $h$, having a concave recess in its lower end, adapted to recelve the said head, substantially as described.

4.- In combination with the beams $I$ and levers $J$, the rod $m$, connecting the same, and provided with an eye, $n$, upon its npper end, adapted to engage with a proecting spur $i$, upon the ends of bars $\mathrm{C} \mathrm{C}^{\mathbf{l}}$, substantially as specified.

No. 185.932.-J. H. J(NES, ROCkFoRU, HLL, assignor to R. EMERSON and W. A. TALCOTT, same place.Cutizutors.-Fanmary 2, 1\$77. Filed October 5, 1\$76.

Claim,-1.-The combination of the evener, provided with double draught-hooks, the pivot-pin connecting it to the machine, the elongated broad-based tubular sleeve enveloping the pivot-pin and bearing upon the upper surface of the evener, and the strap-iron or brace, these members being constructed and operating as set forth, for the purpose specified.

2.-A down-hanger for the attaciment of the shovelbeam, constructed as described, adajted to be secured at its upper end to the frame of the machine, slotted at its lower end, provided with $\mathrm{V}$-shaped ribs or centrally-raised projections upon the opposite sides or inner walls of its slot, and a cross-prece or pin spanning the slot at its lower end, for the purpose specitied.

3.- The broad-hooked plate, adapted to be secured to the shovel-beam, constructed, as described, with a hook at its under front edge, and having its apper edge curved from the front backward, for the purpose specified.

4.- The combination substantially as hereinbefore set forth, of the slotted internally-ribbed down-hanger, its crosspin and the broad hooked plate secured to the slovel leam, fitting in the slot in the down-hanger, between the vertical centrally projecting ribs thereof, and resting upon the cross-pin, whereby, while allowed to swing sidewine and rock vertically, the beam is prevented from wabbling, as set forth.

5.-The combination of the shovel-beam, hinged at its front end to the machine, a lever for raising and lowering said heam, located upon the machine in rear of the point at which the shovel-beam is binged, and the lifting comnection secured at it lower end to the beam, remote from its front ent, and at is upposite end altached at a point subst.ntially in the vertical plane of the said hinged connection between the beam and frame, to a support operated by the lever, these members being constructed and operating substantially as hereinbefore set forth, whereby the beam, in swinging sidewise, moves substantially in a horizontal plane, and 
the depth at which the shovels are working at the beginning of said movement sideways remains unchanged.

6.- The combination of the down-hanger, the shovel beam hinged thereto, the lifting connection, the thrust-bar, and the lifting lever, these members being constucted and operating substantially as hereinbefore set forth.

7.- The combination of the hinged shovel beams, the lifting levers, their supporting detent-brackets, the thrust bars, the lifting connections between the thrust bars and the shovel beams, the yoke connecting said beams and the curved rods passing around the thrust-bars, secured at their upper ends to the lever-supporting lrackets, and at their lower ench jointed to the yole, these members being constructed and operating substantially as hereinbefore set forth whereby the levers and the yoke are both supported by the detent-brackezs without interfering with the movements of the yoke, levers, or thrust bars.

8.- The combination, as hereinhefore set forth, of the shovel-heam, the bracket, yieldingly attached, by its upper portion, to said beam, and having a serruted face upon its lower pendent portion, which projects below the beam, the grooved and serrated plate, the short shovel-standard and the eyebolt and nut by which the standard is secured in the gruove of said plate ant the serrated face of the plate secured to the corresponding face of the pendent portion of the bracket beneath the beam, whereby a high swung beam may be employed, a saving is effected by reducing both the length and size of the standarl, and the range of adjustment of the standarl is increased, as set forth.

9.-The slip-casting or bracket M, constructed as de scribed, centially perforated for the passage of the shovel standard eyebolt and provided with two inclined arms of corresponding length, radiating from its center and stotted at their outer ends, wherely the casting is adapted to be secured to the beam upon either side, with either arm in advance, in the manner and for the purpose described.

I0.-The combination of the shovel-beams, the stip-cast inge, their inclinad slotted arms, the bolts passing through the slots and beam, their nuts, and the shovel-standards connected with the castings, these members being constructed and operating as set forth, whereby the castings are rendered reversible and interchangeable, adjustment of the inclination of the standards independently of the castings admitted, and injury to the machine avoided.

No. 186,065.-PIIILLIP STUDER, Mechansville, InwA-Cultizaters.-Fanuary 9, 1877. Hiled October I4, 1 S 76 .

Claim.- The combinatton of the bent bar $\mathrm{C}$ and the braces $\mathrm{E} F$ with the tongue $\mathrm{D}$ and the axles $\mathrm{B}$, substantially as herein shown and described.

No. I86,713.-\$. DAHI.BOM, CARPENTERVHLLE, ILL. - Hhitl-Cultizalors.-January 30, 1877. Filed June 12, I $\$ 76$.

Claim.-1.-In a wheeled cultivator, the draught-bars of which extend in front of the axle, the combination of the dranght bars D, cross-bar F, constructed as described, and connected to botb draught-bars, and evener $\mathrm{E}$, attached to and supported by the cross-bar on the forward ends of the draught bars, sulstantially as and for the purpose set forth.

2.- In a wheele! cultivator, the draught bar. $\mathrm{D}$, arranged between the wheel, and extending in front of the axle, in combination with a draught-aupporting bar, connecting to their forward ends, and an upper draught-frame, provided also with a draught-supporting bar arranged above the former, whereby the machine is adapted to high or low draft by changing the evener from one support to the other, substantially as described.

3.- She bent arms L, constructed as described, pivoted together, and adjustably connected together at their upper ends, in combination with the draught hars 1 , connected thereto by swivel-joints, substantially as and for the purpose set forth.

4.-The combination of the clamping-piece I, constructed with a projecting bearing-flange, $i$, eyebolt $h^{\prime}$, standard $H$, and draught bar $\mathrm{D}$, substantially as described.

5.-The combination of the standard $\mathrm{H}$, holding-clamp I, and pivoted stop $K$, substantially as and for the purpose set forth.

No. I $86,780,-A$. K. W()].FE, P'rairie City, Mo.Wheel-Ploust Carriagets.-January 30,1877 . Filed July I, 1876

Claim.-The independent cranked axles $A$, arranged to swing freely upon the tongue $\mathbf{B}$, in combination with the evener $F$, arms $E$, and draft-rork $G$, substantially as shown and clescribed.

No. 1S6,873.-JOS. F. POOLE, MuNknE, W1s., assignor of one-half his right to E. C. GILLETT, same place.Combined Cultivators and Corn Plantors.-Jamury 30, 1877. Filed Decemher 21, 1876,

Claim.-1.- The cultivator-beam berein described, made of two parts, $G G^{\prime}$, hinged together, and provided with the adjustable flanged plate $e$, for regulating the depth at which the plough is to work, as set forth.

2.-The combination of the tongue $\mathrm{C}$, double-tree $\mathrm{D}$, with adjustable stirrups $\mathrm{E} \mathrm{E}$, jointed cultivator-beams $\mathrm{G} \mathrm{G}^{\prime}$, axle-tree $\mathrm{A}$, and guard $\mathrm{H}$, all substantially as and for the purposes herein set forth.

No. $187,043-$ F. M. NEEDHAM, ROCKFORD, ILL.Wheel-Cultivators.-February 6, 1877. Filed November 29, 1876 .

Claim.-1,-The pendants $\mathrm{E}$, with upward-projecting arm fitted to enter the slots formed by the beam $C$, in pairs on each side, and capable of lengthwise adjustment on the heams, in combination with the drag-bars, carrying one or more shovels, for the purpose of balancing the machine in neck-draft, when used either as a riding or as a walking machine.

2.- The levers $F$ aud $F^{\prime}$, baving cam-formed feet, in combination with the pendants, and caps $c$, for the purpose of fixing the pendants in position on the beams $\mathrm{C}$, as hereinbefore set forth.

3.- The combination of the levers $\mathrm{F}$ and $\mathrm{F}^{\prime}$, connectingbar $f$, and sliding pawl $f^{\prime}$, fitted to engage the notched upper portion of the pendants to which the levers are pivoted, to bold the levers in pairs locked, as and for the purpose hereinbefore set forth.

4.- The combination of the pendants and wheels $f^{\prime \prime}$ journaled thereto, and operating as described, for the purpose of reducing the friction in sliding the pendants back and forth on the beams $\mathrm{C}$, as hereinbefore set forth.

5.- The pendants, fitted with the globular enlargement $g^{\prime}$, in combination with the drag-bars $\mathrm{H}$ and loops $g^{\prime \prime}$, these part; constructed and applied as hereinbefore set forth.

6.- The brackets $i$, fitted with spring-bolts $i^{\prime}$, in combination with the drag-hars and suspension-braces and perforated plates $h$ and $h^{\prime}$, to hold the drag-bars in an elevated position, as and for the purpose hereinbefore set forth.

7.- Tbe brackets $i$, fitted with spring-bolts $i^{\prime}$, in com bination with the drag-bars, suspension-braces, and perforated sliding plates $h^{\prime}$, for the purpose of regulating the depth of cultivation, as hereinbefore set forth.

8.- The arched sway-bar P, having arms $p$ hinged thereto, and connected to the suspension-braces $\mathrm{I}$, in a laterallyadjustable manner, by means of eye or hook bolts, and held in an upright position by staple-formed loop $\mathrm{T}$, these parts constructed, arranged, and operating as and for the purpose hereinbefore set forth.

No, 187,235.-R. B. ROBBINS, ADRIAN, Mich.-Cultivators.-February 13, 1877. Filed May 22, 1876 .

Claim.-1.- The jointed rocking $\operatorname{rod} \mathrm{H}$, in combination with the beams or swing-frames $\mathrm{G} G$ ant levers I I, with their connections, substantially as and for the purposes herein set forth.

2.-The combination of the beam $\mathrm{G}$, with projection $m$, and the lever I, with loop $n$, for locking them together, as set forth.

3.- The adjustable rod $R$, having its rear end bent vertically upwaril, and perforated, as shown, in combination with the lug $y$, beam G, spring $w$, and shield S, substantially as shown and described.

4.- The combination of the leg $\mathrm{L}$ and serrated wrist $l$, slotted to receive the leg $\mathrm{L}$, with serrated sleeve l', attached to the tooth or blade, and held in place by a nut on the lower end of the leg, substantially as shown and described, 
all constructed, arranged, and operating to facilitate the ready adjustment of the tooth to any desired angle.

No. 189,266 - IOHN RICIIARDSON, ANCASTER Tuwnshi, IVentworth County, Ontario, Canada.Fallow-Cultivators.-April 3, 1877 . Filed August 1 I, I 876 .

Claim.-1.- In combination with the frame D, adjustably secured to the rear of the cultivator by the rod $\theta$ and pin $c$, the rods $\mathrm{P}$ and nuts $\mathrm{R}$, for adjusting the beight of said frame, and the chain $\mathrm{O}$, and wheel 11 , and its pawl for elevating said frame, substantially as herein set forth.

2.- In combination with the draft-bar $G$, the center-bolt, and rear adjustable bar $O$, the bar $J$, for preventing the frame from drawing obliquely, substantially as set forth.

3.-The combination of the draft-bar $G$, bolted to the tongue, the link $\mathrm{H}$ and hook $\mathrm{I}$, attaclied to the frame $\mathrm{D}$, and the bar $J$, secured to the rod $O$, as and for the purposes set forth.

No. I89,896.-J. M. LONG, Hamiltox, OHIO.-Cultivators. - April 24, 1877 . Filed $M_{2 y} 3 \mathbf{1}, \mathbf{1} 876$.

Claim.-1.- The frame consisting of rigidly-connected parts A B, in combination with flexibly-connected parts C E $D^{\prime} O$ and stay $D$, substantially as and for the purpose described.

2. - The combination of the draft-bar $D^{\prime}$ and stay $D^{\prime}$ with coupling $\mathrm{O}$ and double-tree $\mathrm{E}$, as and for the purpose specified.

3.-The hinged coupling-block $\mathrm{F}$, in combination with pivoted axle-arm supports $\mathrm{C}$, draft-bar $\mathrm{D}^{\prime}$, stay $\mathrm{D}$, double tree $\mathbf{E}$, and plough-beam $\mathbf{H}$, as and for the purpose de scribed.

4. - In combination with the upper branches of pivoted axle-supports $C$ and shaft B, the collar $f$, with its set-screw for laterally adjusting the ploughs and carrying-wheels, in the manner and for the purpose specified.

No. 190,247.-IVM. PlERCE, STUNEHAM, MAss.Strazoberry and ligetable Cultiantors.-May I, $1 \mathrm{~S}_{77}$. $1142 y, \mathbf{1} 876$.

Claim.-1.-The stationary and vibrating blades ancl can-grooved roller, in combination with the belt to pick up, and the hox to contain, the vines severed from the row, substantially as decribed.

2.- In combination, the vibrating vine cutting blades, the cultivator, the toothed belt, and the box or receptacles to contain the vines substantially as described.

No. 190,328.-W. P. HUBB.ARI) and J. W. ROBIN SON, FARMLAND, IND.-Cultivator Attachments.-Hay 1, 1877 . Filed Fanuary 6,1877 .

Claim.-1.-In combination with the extensible lever I and adjustable rack bar $J$, the plate 1 and the tongue and lever gear E G, substantially as descrilsed, and for the purpose set forth.

2.-In a wheel-cultivator, the supporting plate D, with its extension $D^{\prime}$, made in one piece, and attached to the transverse braces of the wooden frame $\mathrm{A}$, in combination with the pivoted tongue $F$, having gear $E$, and the pivoted lever 1 , having gear $G$, whereby the gears are supported by said plate, always held in engagement with each other, and shielded from obstructions from below, substantially as described, and for the purpose set forth.

No 190,972,-E. M. Ki.SSELL and M. L. KISSELL, SPRINGFiei1, OHIt.-Whecl-Cultizators.-May 22, 1877. Filed Nozember $11,1 S_{7}^{6}$.

Claim.-1. - The safety break joint B, pin $c$, slot $d$, gutta-percha blocks $e c$, or their equivalents, shields $f f$, screw bolts $g g$, substantially as described and shown.

2.- Hitch bars E, arched axle C, and brace rods $\mathrm{D}$, in combination with the beams and tongue of a cultivator, constructed and arranged substantially as shown and described.

No, I9I,IOI-NATHAN T BREWSTER and A. D. NEHER, Roseville, CAL.-Cultirators.-May 22, 1877. Filed April I 1, 1877 .

Claim, - 1.- The double seprable frame A A', combined with the detachable blocks $B$ and the cultivator teeth $\mathrm{C}$, having reduced shanks passing through the said hlocks and bars, to be secured above the same, and provided with hraces $D$, substantially as and for the purpose set forth.
2.-The combination, with the double frame $\mathrm{A} \mathrm{A}^{\prime}$, of the detachable blocks $B^{1}$, held by the shank of the cultivator tooth, and the axle of the transporting wheel, arranged in bearings in said blocks, as and for the purpose described.

No. I91,179.-WM. J. ROBERTSON and PHILIP KNIGHT, JASPER CounTx, Mo.-Cultivators.-May 22, 1S77. Filed April 13,1877 .

Claim.-1.-A plough beam $g$, consinting of two parallel plates, the end of one being fastened to the inside of the mould-board, and the other to the inside of the land stce, in combination with the interposed plates $i$ and the plates e, for connecting the beam to the axle, substantially as shown.

2.- The plough beam , 5 , consisting of two parallel plates that are separated by the interponed plates $i$, and which have their front ends turned outward at right angles, so as to receive the clevis $h$, substantially as set forth.

No. 191,347--JOHN JONES, STONEY PoINT, CAL., assignor of two-thirds his right to SIDNEV B. HOLLY and WII. H. MAGOON.-Cultizaters.-May 29, I877. Filed January $1 ;, 1877$.

Claim. - The combination, with the plough frame A B, having its rear end mounted upon the axle $D$, of the heamextenson $\mathrm{F}$, provided with the rack $l$, spindle $g$, driving wheel H, and upward turned standard 1 , and secured to the front of the frame, and lever $O p$ pivoted to standard I and spindle $g$, and connecting rod $J$, which passes back over the frame and unler the driver's seat, and rod $K$ secured to the rear axle, the several parts constructed and arranged to operate together in the manner herein shown and described.

No. 191,606.-AUST1N S. MCDERIJOTT, PraIFIE CREek, (Ileli.erax P. O.,) Iowa.-Cultitaters.-June

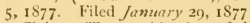

Claim. - The combination of the sockets $C$ ', the cranks $D^{\prime}$, the chains $E^{\prime}$, the levers (', the pivoted stand ards $H^{\prime}$, the keepers and citches $I^{\prime} J^{\prime}$, and the pins and springs $K^{\prime}$ L', with the plough beam J and the axle B, substantially as herein shown and described.

No I0I,660-WILLIE, E. DEWEV; ELKHoR, W1S. - Cultivators. - Fune 5, 1877. Filed April 12, 1877.

Claim.-1 - The combination of the tongue or pole D, the angular or bent castings or arms $H$, laving transverse slots $x$, the drag bors 1 , pivoting bolts $b$, and adjusting holts $d$, all sub-tantially as and for the purposes herein set forth.

2.- The combination of the tongue or pole D, angular slotted arms $H$, pivoted adjustable drag bars 1 , and the split or crotched tongue $\mathrm{E}$, secured to the axle $\mathrm{A}$, and attached above the tongue I to the same by the link $a$, all substantially as and for the purposes herein set forth.

3.- In combination with the tongue or pole I), carrying the drag bars, the hinged lever $O$, carrying the adjustable seat $\mathrm{N}$, the standard $\mathrm{P}$, with hook $/$, and the connecting chain $v$, all substantially as and for the purposes herein set forth.

No I $92,462,-$ JAMES SHERRILL, IJARRISBURG, OREOUN,-Cultiwators.- -7une 26, 1877. Filed March 3, 1877 .

Claim.-I.-The plough standard M, pivoted between and at the ends of elastic bifurcations of beam $\mathbf{E}$, and having a wedge-shaped projecting end beyond the pivot, the bifurcations converging from the top downward to hold the standard end, as shown and described.

2.- The plough beams $\mathrm{E}$, having their forward ends bent sidewise into $U$ form, to receive the cross rod $F$ of the draw frame GH I, substantially as herein shown and described.

3.- The draw frame formed of the cross rod $F$, the curved bar $\mathrm{G}$, the cross bar 11 , and the parallel bars 1 , in combination with the plough heams $E$, the clevis $J$, and the adjustable supporting bars L, substantially as herein shown and desribed.

No. I92,541,-GARRT STORM, PORTLAND, MICH., assignor to himself and IACOB N. BENEDICT, same place.-Cultimators.-June 26, 1877. Filed January 22, 187.5 .

Claim.-The combination, with the axle beam $\mathrm{C}$ and 
bar $F$, of the ruck shaft $H$, brackets $I$, lever $\mathrm{J}$, arms $d d$, and curved link - 1, for raising and lowering the shovel beam and locking the same in either position, sulstantially as described.

No. 192,742.-JA.1ES L. CURRV, OSKA1605A, IoWA.

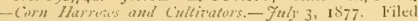
Gomwary 9, 1877

Claim - In a whed corn harrow or cultivator, the combination, with the arns $\mathrm{E}$, depending from the beim $\mathrm{I}$, of the peculiar couplers $A$, composed of the wings $a a^{\prime}$, meeting at an acnte angle, the said wings being obliquely inclinecl toward each other, and being slotted at $b b^{\prime}$, respectively in the line of the direction of their inclination, together with the beam $F$ and the bolts $c$, as and for the purpose specified.

No. 192,800.-L. WERTENHERGER and G. II. AMISS, LAKETON, IND, ; said AMIISS assignor to said

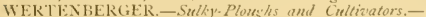
July 3, 1877. Filed $\mathrm{Wur}_{\mathrm{r}} \mathrm{31}, \mathrm{1} 877$

Claim,-1. The combination of pivoted frame $\mathrm{N}$ with levers $\mathrm{M}$, shafts $\mathrm{M}^{1}$, pivoted beams $\mathrm{G}$, and to rgle connections, substantially as and for the purpose set forth.

2.- The combination of pivoted beams $G$ with braces $J$ and $L$, standards $H$, rock shaft $\mathrm{N}^{1}$, and adjustable toggles, suhst intially as and for the purpose set forth.

Vo. 192,922,-HENRT P. KYNETT, LISBON, IOWA. - Ciultizators. - July 10, 1877 . liled June 20, iS77.

Claim.-1, - The devices for connecting the beans to the cultivator, consisting of the combination of sockets 27, pivoted to the front ends of the brams, the round bolts $b$, having heads at the lower ends, the single bearings $c$, having lugs $s$ and semicircular grooves, and fastened by the eyeholts $c^{\prime}$, which evebolts hold in place, also, the connecting bolts $b$, substantially as described.

2.- The cultivator mould $K$, having the upper part of the mould concave and at the upper part of the beveled point straight, substantially as and for the purposes descrilsed.

No. 192,992, -SAMUEL N. HENCH, ICKESBtRt;, assignor of one-hall his right to WALKER A. DROMGOLD, PATTERSUN, I'a.--Cultizators.-Fuly 10, I877. Filed Wirch 10, 1877 .

Clain.-1.- The combination of pivoted adjusting-lever $\mathrm{R}$, having diagonally-opposite lips $r, r$, with locking plate $S$, having notch $s$ and reversed notches $s^{\prime}$, wherelyy said lever is adlapted to raise the cultivator teeth out of engagement with the ground, or to adjust them to any depth required, sub-tantially as and for the purpose set forth.

2.- The combination of drag bars W' with pivot rod W, supplemental drag bar $\mathcal{Y}$, and spring plates Z Z, substantially as and for the purpose stt forth.

No. 193,912.-WALTER G. BARNES, FREHPTRT, 1L..-Corn-Cultizators.-August 7, 1877 . Filed func 19,1877 .

Claim.-1.-As an improvement in cultivators, the combination of the hinged beans $D$, having spring loops $G$, axle $\mathrm{B}$, and tongue or frame $\mathrm{A}$, having hooks $i$, subst.mtially as and for the purpose herein shown and described.

2.- In combination with the beams $\mathrm{D}$ and axle $\mathrm{B}$, the adjustable coupling j.w herein described, consisting of the plates $p p^{\prime}$, having segmental slots $g$, projecting lips $r r^{\prime}$, and diagonal front caps or braces $s s^{\prime}$, constructed and combined to operate subtantially as and for the purpose herein shown and described.

No, 194,146,-T. D. GUTHRIE, JR., G.ILA, IL.1.Cuitizators.-Auszist 14, 1877. Filed Fune 2, 1877 .

Claim. - The combination - $f$ the coupling $A$, rigid beam $\mathrm{B}$, and beam $\mathrm{D}$, with bent standard $\mathrm{F}$, pivoted to the beams, piece I, and brace $\mathrm{C}$, substantially as describul, and for the purpose specified.

No. I94,I50.-SOUIRE I. HINKLE, SARATOGA, IND. -Ridins-Cultivators.-Angust 14, 1877. Filed Junc 4, 1877 .

Claim.-1.-The combination of the arched axle B, arched and bent hars $\mathbf{K}$, the cross bar $\mathrm{L}$, and caster-wheels, as shown and described.

2.-The combination of the bent bars $\mathrm{K}$, seat $\mathrm{N}$, plough beams $U$, with foot rests $y^{\prime \prime}$, levers $A$, and chains $Z$, substantially as and for the purpose specified.

No. 194.366.-JAMES II. PAI.M, Lexinciron, OHo. -Riding-Cultizuturs,-August 21, 1877. Liled January 17,1877

Claim,-I, - The tongue $\mathrm{E}$, provided with the contraction and swell, sulstantially as shown and described

2.- The handle $f$, composed of the paris $i l$, in combination with the flanged quadrant $a$, the lower portion of the handle being provided with a spring, 5 , arranged to project a pin, $i$, beyond the end of the handle, substantially as shown and described.

3.-A cultivator handle pivoted upon its bolt and provided with a spring device to engage it rigidly with its plough beam, whereby the handle is held in working position or released and adjusted at various heights by elevating the handle itself, substantially as set forth.

4.-A cultivator handle, $f$, provided with the spring $s$ and pin $e$, in combination with the flanged quadrant $a$, substantially as set forth.

5.-The lever $x$, pivoted on the centre pin $y$ of the circular ratchet $\imath^{\prime}$, which forms a bearing for the lever upon one side and an engaging ratchet upon the other, and provided with the spring $z$ and stud $w$, substantially as shown and described.

No. 194,570.-DAVID ARCHER, JR., Brier Hill, N. Y.-Adjustable Iflici-Cultivators.-Augutst 28, 1877.Filed fune 30,1877

Claim.-The combination, in a cultivator, of the tongue 1 and standard $G$, having wheel $H$, with the front bar $F$, pivoted between beams A A, and provided with lever J, as and for the purpose specified.

No, I96,SIS.-W. NETTLER, FrankForT, ILL.-

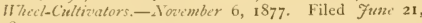
I 877 .

Claim.-The cross-bar e, pivoted at its centre to the top of the adjustable main frame $\mathrm{B}$, in combination with the cross rols $a$ and frame $c$, for the purpose of moving laterally the frame $c$, with its two shovels altached below, having rear push braces with break pins, in the manner and for the purpose set forth.

No, 197,038,-IRWIN MACY and J. C. WATKINS. Harrisbtiri, OREgon, - Whect-Cultivators. - November $1_{3}, 1877$. Filed $\mathcal{F}_{4} / \mathrm{l}_{13}, 1_{77}$,

Claim.-1.- The combination of the inclined or diagonal bar J, macle in two parts or sections, the draw rods 1 , and the braces $T$, with the plough-beam $S$ and the frame-work of the machine, substantially as herein shown and described.

2. - The combination of the adjustable perforated bars $\mathbf{I}$ $\mathrm{N} \mathrm{P}$ with the inclined or diagonal har $\mathrm{J}$, to which the plow beams are attached, and with the frame work of the machine, substantially as herein shown and described.

3.- The combination of the levers $\mathrm{X}$ and catch-bars $\mathrm{Y}$ with the arms IV, the diagonal bar J, and the plongh bcams $S$, substantially as herein shown and descritsed.

No, 197,503,-MORRIS I. UTTER, ROCKFORD, ILL. - Ciullizators.- - Virember 27, 1877 . Filed drugust I4, 1877 .

Claim-1-The combination, with the axle-tree, the converging beams $\mathrm{C}$, secured thereto, and cross-bar $\mathrm{E}$, of the pendant bars $b$, secured to the ends of cross bar $\mathrm{E}$ by brackets, and the brace rods $f$ and $f^{\prime}$, the lrace-rod $f$ being secured to the pendent arm and arm of the axle, while the brace comnects the lower end of the pendent arm with the cross-bars substantially as described.

2.- The join-plates $c$ and $d$, washer $e$, and joint-bolt $c^{\prime}$, these part, constructed, arranged, and operating, as herein described, to produce a donble hinge-joint, reversible and interchangeable, capable of use on either side of the machine, as and for the purpose hereinbefore set forth.

3.- The combination, with the levers M, located in front of the diver's seat, of the supporting chains or linked rods, connected at their foward ends to levers $\mathrm{MI}$, and also to the frame at a point practically in the same vertical plane with the forward ends of the drag-bars, and at their rear ends connected to the longitudinally-adjustable plates $\mathrm{K}$, substantially as described, 
4.- In a standard bracket, the combination of the bedplate $H$, the slotted slip-arm $h$, fitted to receive the shovel standard, screw-bolt $h^{\prime \prime}$, upon which the slip-arm works, swivel-sockets $g$, and eye-bolt $g^{\prime \prime}$, whereby the shovel is allowed to turn back to pass obstructions, as herembefore set forth.

5.- The swivel block $i^{\prime}$, in combination with the shiel and chambered socket, substantially as herein described, to limit the oscillatory movement of the shield, as hereinbefore set forth.

6.- The chambered socket secured to the drag-bar, and made adjustable thereon by means of the screw eye-bolt, as herein described, in combination with the swivel block, secured to curved supporting bar to limit the downward movement of the shield, as hereinbefore set forth.

7.-The rosette-plates herein described, secured to the inner face and rearward-projecting ends of the converging beams, the inner plate made adjustable to raise or lower the stud projecting eccentrically from its inner face, for the purpose of raising and lowering the driver's seat, as and for the purpose hereinbefore set forth.

8.-The adjustable seat plates $\mathrm{P}$, in combination with the curved hars N, pivoted at their forward end to the frame, and the seat $\mathrm{O}$, made longitudinally adjustable on the seatbars, and arranged to turn the seat forward, substantially as set forth.

No. 198,069.-IRA BARBER, L.I PoRTE, INDIANA. -Cultivators,-Dicember 11, 1877 . Filed March 12, 1877 .

Claim.-I - The combination of the axle and the plate I with pivot post $\mathrm{H}$ and cross-bar $\mathrm{G}$, all being constructed, arranged, and combined substantially as shown and de. scribed.

2.-The rigid bar L, attached to the upper frame-work by a pivot-joint, and provided at is lower end with notch $s^{\prime}$ and sever.l pin-holes and a pin, such lower end passing through a slot in the crosu-plate $m$, securep in the plough beams, in combination with sard frame-work and the ploughbeams, substantially as deseribed, whereby the plough may be hitched up when not in use, and may also be adjusted at different positions, so as to regulate the the depth of its cut.

No. 198,563 -ROBORT T. BOWNE, FELISTON, M1) -Cultizators.-December 25, 1877. Filed Vevember 20, 1877 .

Claim.-1.-In a straddle row cultivator. two gangs or groups of drag bars, each provided with a cultivator tooth, coupled together by a link rigidly secured to one group and muvably attached to the other, and operated by a handlever, so that the driver may at will cause said groups to recede from or approach each other, as set forth.

2.- The gangs or groups of drag bars, each prosided with a cultivator tooth, connected together by a link rigidly attached to one group and movably attached to the other, combined with the slotted bell-crank M, connecting rod $O$, and hand-lever $\mathbf{N}$, whereby the driver can shift the relative positions of said groups at will.

3.- The main frame, provided with a seat and separate gangs of cultivator drag bars and their teeth, and a main axle, $\mathrm{C}$, pivoted to said frame, combinerl with the toothed segment $F$ and pinion $G$, geared thereto, and a dout,le foot lever, $H$, attached at its centre to the pinion-spindle, so that the driver, while sitting upon his seat, can rest his feet upon said lever, and thereby control and guicle the apparatus.

No. 195,616.- JAMES HIGGINS;, WEsthifld, N. I. - Cultizators.-Decimber 25, $1 \mathrm{~S}_{77}$. Filed April 2, 1877 .

Claim.-The axle of a wheel cultivator, provided with rigid arms 1 , to which are pivoted the forked drag bars $\mathbf{F}$, the pivot-rod $H$, stay-rod $G$, and pivoted link $J^{\prime}$, in combination with the rock-shaft $K$, having rigid arms J, lever L, and pawl and ratehet $m n$, substantially as described.

No. 198,624.-JOHN S. JOHNSTON and C. A. JOHNSNN, ROCKFoRD, IH.L.-Cultivators.-December 25 , 1877. Filed Octuber 22, 1877 -

Claim.-The combination of the adiustable eye or socket plates $\mathrm{F}$, the connecting bars $\mathrm{G}$, the hars $\mathrm{H}$, and the bar or block $\mathrm{N}$, with the plough beams $\mathrm{A}$ and the axle $\mathrm{I}$, whereby the plough beams are allowed to oscillate laterally and are raised by the driver's weight, substantially as herein sliown and described.

No. 198,752.-HUGH PARKER, OTTAWA, ILL.Gopher or Ridging Attachments for Cultivators.-January I, 1878 . Filed August 14, 1877 .

Claim.-1.- The herein-described gopher or ridging attachment for cultivators, consisting of the adjustable blades C C, bars D D, pivoted brace-hars E H 1, and adjustable bars $\mathrm{G}$, substantially as and for the purpose specified.

2.- The combination, with the blades $C$, of the bars D, provided with the vertical slots $a$, and the slotted brace-bars E H I, substantially as and for the purpose specified.

3.- The combination of the bar $\mathrm{D}$, provicled with the slots $a$ and slotted brace-bars, and the horizontal bars G, provicled with the slots $s$, substantially as and for the purpose specitied.

No. 199,025.-WILLIAM P. BROWN, ZANEsVILI.E, OHto.-Cultizator-Tongues.-January 8, 1878 . Filed Afril 23,1877

Claim.-1.-An adjustable device located upon a cultivator-tongue, and extending rigidly across the same, so as to separate the team without being turned from a horizontal plane, substantially as described.

2.-A separating wheel or disk, combined with the tongue of a cultivator, and arranged to rotate substantially as and for the purpose set forth.

3.- The separating-wheel $\mathrm{B}$, arranged to rotate, and mounted upon a standard fixed to the tongue of the cultivator, as and for the purpose described.

4.-The handles $\mathrm{F}$, having hooks $e^{\prime}$ in combination with the cultivator-tongue, the har $\mathrm{E}$, and crank-shaft $\mathrm{C}$, substantially as and for the purpose described.

No, 199,680,-LOUIS ANTHOINE, EPWORTH, IUWA. - Cultizators.- Fanuary 29, is78. Filed Ortober 30 , 1877

Claim.-The combination, with cross-bar B, of a ploughbean $\mathrm{N}$, connected therewith by the $\mathrm{U}$ - bar $\mathrm{K}$, lug-pivot $\mathrm{L}$, and offetted bar $M$, substantially as and for the purpose specitied

No, I99,701,-MUCKERSIE G. GRAHAM, MONмочтн, ILl.-Cultizators.-January 29, 1878. Filed Oituber 15,1877

Glaim.-1.-In a eultivator, the side frames to which the ploughs are hinged or journaled, combined with one of more bars $\mathrm{B}$, having guides, by which they are connected with the side frames, and whereby the said side frames may be slid or reciprocated upon the bar or bars $B$, to advance or recede either of the side frames while they are held at uniform distances apart, and the bar or bars $\mathrm{B}$ remain at right angles to the line of progresion of the macline and in a horizontal position, substantially as specified.

2.- The ginile pole or tongue $\mathrm{E}$, bolted to the bar $\mathrm{B}$, and arranged to operate with the sliding frames A, ploughs $\mathrm{J} J$, and wheels $F$, without interfering with the sliding or parallel motion of the frames, substantially as and for the purpose specified.

3.-The extensile and contractule yoke C D, arranged to operate with the standards $A^{\prime}$, to which the cultivatorploughs J are attached, substantially as and for the purpose specified.

4.-In combination with an extensible yoke C D, and bar $\mathrm{B}, \mathrm{t} n$ which the tongue $\mathrm{E}$ is bolted, frames $\mathrm{A}$, having ploughs $J$ and wheels $F$ attached thereto, and arranged to operate substantially as described, and for the purpose specified.

5. - The bar or bars B, combined with the bars $a^{\prime \prime}$, on which they slide, and with the standards $A$, ploughs J, and wheels F, substantially as described, and for the purpose specified.

6.- The bars $\mathrm{B} \mathrm{B}^{\prime}$, having adjustable loops $b$ on their ends, combined with the frames $A$, ploughs $J$, and wheels $\mathrm{F}$, substantially as and for the purpoce specified.

7.- The draft-plates $I I$, rigidly attached to the standards $A^{\prime}$, and having extended rear ends $l^{\prime}$, to which the ploughs J are connected, combined with the sliding frames A, wheels $\mathrm{F}$, bars $\mathrm{B}$, and tongue $\mathrm{E}$, substantially as described, and for the purpose specified. 


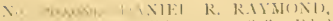

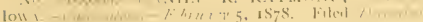
o. Is:;

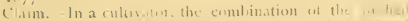

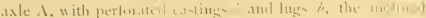

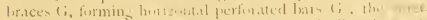

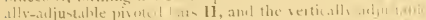

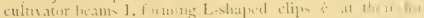

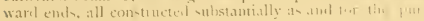
proses herem wet forth

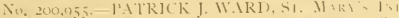

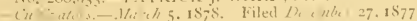

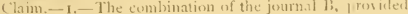
with the upright orm $\not 11$ and the lorizontal am $k^{2}$, the -lecre C. ptosided with the lus ', the curved arm $i^{2}$. and the cur-

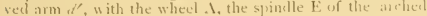
har or axle $F$, and the plongh-licum $D$, sulmandially ats

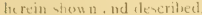

2. The combination of the bent lever 1 ., the in cights $V$, the bent and lutted levers (), the rods, wires or cliam 1', and the hinger arm () with the plowsh-beam, () and the archedlo, or axle $F$, substantially as hercin 4 m. wn and descrilue 1.

3. The emmbination of the lock lilock 1 ani yring latch J $k$ with the arm formed unom the piroterl enl if the weiuhted lever $1 . X$, the plingh heam 1 , ant the plongh tantarel H, as anil for the purpose-pecified.

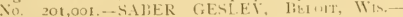

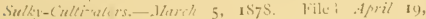
$1 \$ 77$.

Claim-1.-The standaril $i$, having the slotted foot har to on :ts lower end an! the groo.cd lokek or arm $f$ tipun its mpler end, and proviled with the port $k$. pivoted to the fout bar $b$, and slirling in the grooved arm i, sulutantially as lown and tescribed.

2.- The combintion of the standard $S i$ ib and post $k$ with plate E, having thimble soeket, and plough lieau li, as shown and described.

3.- The eombination of the stanilard if $f$ b. soclitt plate E r, brace rods oo, plough beams 13 , hingerl slotted arms s, bent levers $L$, and ratchet plates $R$, all arranged sutrt.intially as shown and deseritied, and for the purpone set furth.

No. 201,136.-1)AVID S. IVAGNER. CARLISLK, PA. -

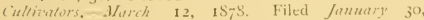
ISts.

Claim.-1, - In a enltivator, the emphination of the louble standard m, durble pointed shovel \%, rods $s$, catches $r$, rots $u$, and spring $\ell$, subutantially an hown.

2. In a cultistor, a double pointed shuvel \% povided with the rods $s$, in cum ination with the spring catches, and doible standards $m$, the part being combined to operate in sueh a manner that the point of the shovel remain in the earth muil it strikes an olstruction, when it sutomatioslly revolves half way around, ame at onee cnter, the earth with its other point, substantially as de -crilsed

3.- The combinatmon of the conneeting rod $/$, pivoted anin lles $c$, loops.. levers $h$, rods $i$, and connecting ilevie s for uniting the leams $j$ to the handles, subatantially ar set forth.

4.-The combination of the revolving shosel, catches to hold it in fo-ition, connecting rods, and yrung, sulset.mtially as shown.

5. - The adju-trlile stop $A$, in enmbinati. $n$ with the standards and the tarned up ent of the beam, sulstan. tially as described.

No, 201,627,-D.ATIS PATTEE, DFs MIONE, lOwA

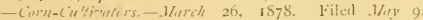
1877

(laim. - 1 - The swinging tirrup) form couplings 5 , in ombination with a cultivator cariage and plough lieam. substantislly as and for the purposes set forth.

2.- In a whed-cultivator, the combination of the car wowe frame $a b$. the avle learers $d d$, the stub axles, liwing erank $m$. the sesmental raeks $r s$, and the stirrul form lean couplings s, substantially as and for the purposes shown and devcribed.

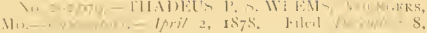
1877

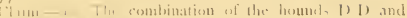

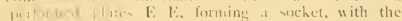

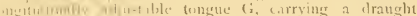

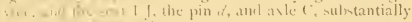
thut wat r riluil.

The a gab mai aljustable perforated clesis 11, prowhil with the leops on combination with the auljustable

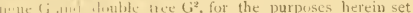
$\{1,11\}$,

Ihe ctun' +1natisti, wath the tongue, of the arljustable

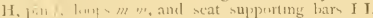
tontially - an l sur the jurposes herein set forth

4-The comaliastum of the plough beams $(O$ and $R$ and the curved 4 totrit iron $\mathrm{V}$, sibstantially an and for the purfusen herein xit Touth.

5.- The cosulasuation of the main clevin $\mathrm{N}$, elevis $W^{\prime}$. mit adjutable am A', carrying the revolving fender $\mathrm{B}^{\prime}$, ulutantially ,24, and for the purposes set forth.

No. 202,112.-FREDERICK (. [EFFIER, AINSwurti, JowA. - Culli,aturs. - Iprit 9, $1 S_{7} \mathrm{~S}$. Filed $D_{i-}$ miler +1577

Clam.-1.-The eombination, with Jever E, working in rear cuard (i and engaging with the intermediate bar D, of the forward vibratory lar $\mathrm{L}$, which connects with the iraupht apparatus, said lever and vibratory bar being pixoted to the fixed bar $F$, and adauted wath reference to the rock shaft $B \rightarrow$, that the vibratiry har may have free sliding bearin upon the fixed har, subutantially as set forth.

2.- The eombination, with the cultivator heams and dranght frames rigitly seeured to each other, of the hook bolts, by which the said heam are adapted to lie laterally adiustable, the dratuht frames having their outer side pieces secured to the respective uprights if the mam frame, while their inner sille pieces are cunneeted by braces to the rigicl cross bar of saikl frame, substantially as deseribed.

3-The combination, with the draught frames $\mathrm{N}$, mide as hown, of the draught bars 11 , pivoted to the ontwardly projecting extremeties of the curvel side pieces \&, substantially as set forth.

No. 202,383.-GEO. W. STIVER, MUNRuE, ITIS-

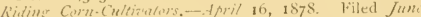
I 5, I $\$ 77$

Grim,-1.-The hand and footever, connected by a chain parving over a pulley direct to each, and of arranged that the foot lever earries the drag lar.

2.-The lever $\mathrm{E}$, provided with the spring $f$ upon ond side of the tanlard $\mathrm{D}$, and the projection : upon the uppo-ite sile, in combination with wheel $\mathrm{F}$, ehain $\mathrm{H}$, and toot lever, substantially as and for the purpose set forth.

Vi, 203,304-DAVII) 1. WELLJIAN, FKAZEE CITY,

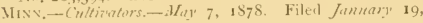
$187 \mathrm{~s}$

Cluim,-In a wheel cultivator, the axle A, having its wheel laterally adjustalile thereon, anit carrying a series of drag bar, G If, arranged on both silles of aid wheels, in combination with the tongue and frame ( J) E, the ele vated cros bar $\mathrm{F}$, the lifting frame $\mathrm{N}$, levers $\mathrm{H}$, guides $j$. aul book $k$, unbstantially as shown and deseribed.

No. $204.412,-$ IOSEPH YOL NG, CLAXTON, MICH.Culviatars-1/oy 28,1878 . Filed Januaty 17,1878 .

Claim.-1.-A eultivator frame to which the ploughs are attached, said frame being piroted at its rear end to sicle beams, or to a frame pivoterl or hinged to the axle, and at its front end to proted levers, whereby the frame may have an oblique forward falling motion and a eorrespondingly oblique backwarl rising motion, substantially as and for the purpuse set forth.

2-The combination, with the cultivator frame $\mathrm{C}$ and side heam, B, con-trueted to operate as speeified, of the seat or seat board, eonnected to saitl frame and beams by pivoted standards $J$ and straps $c^{\prime}$, sulstantially as and for the purpose set forth.

3.- The frame consisting of the parallel bar C, con- 
nected at its lisr end to the pivoted cross piece $\mathrm{D}$ and at it - front end th cross piece $\mathrm{E}$, the latter haviny it bearings in pendant strays $\%$ in combination with the lever $A$. strups $t$, and heams $B$, substantially as and for the purpose lescriberl.

Vi). 205,85u.-WillLiAl S. MOON, PleAsant Grove, GA.-Culticulus-July 9, 1878 . Filed April I5, 1878 .

Claim. - In combination with the side beam 1, provided with the hend $d$, the plough foot $\mathbf{L}$, formed of a metal bar, bent double in the centre, with one arm com each - tule of the side beam, and provided with rearwardly and loswmwarlly curved tops, and connected to the beam at two points, as shown at $h i$, as and for the purposes set forth.

No. 206,040,-FRANClS W. PUSEV, CARTHAGE, Ixw.-Whitl-culliators.-July 16, I878. Filed Fune 4, 1878 .

Claim,-1.-In a wheel plough, the vertical thaft $K$. having a crank, $K^{-3}$ alove, and a crank, $K^{1}$, belox, and a crank axle or hinge, $\mathrm{K}^{2}$, at the reas end af the crank $\mathrm{K}^{\prime}$, combined with the plongh beam $\mathrm{R}$, in the manner and for the purpose set forth and described.

$2,-$ In a wheel-plough, the arms $m m$, having clamps $O O$ and vertical sleeves $I, L$, combined with the arched axle $B$ and crank shafts $K$, in the manner and for the purpose set forth and described.

3.- In a wheel-plou $\mathrm{h}$, the tongue $\mathrm{F}$, with lever $\mathrm{E}$ and comnecting rodk o $a^{\prime}$, combined with the cranks $K^{-3} K^{\top}$ and plough beam $R$, in the manner and for the purpose set forth and described

4.-The rods $\mathbf{K}$, with cranks $\mathrm{K}^{-3}$ and $\mathrm{K}^{1}$, combined with the rear end of the tongue $\mathrm{F}$, in the manner and for the purpose substantılly as set forth and described.

5.- The plough beams $R$, combined with the crank bar $\mathrm{K}^{\mathrm{I}} \mathrm{K} \mathrm{K}^{3}$ and rear end of the tongue $\mathrm{F}$, in the manner and for the purpose subutanially as shown and described.

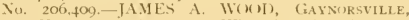

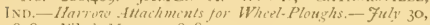
1878. Filed, $1 / a 127,1878$

Claim - The herein described harrow, constructed as shown, and having its beams provided with transverse elongated shots C C, and fastening devices passing through said slots and adajted to be applied to different shaped beam of clouble or other plough, substantially as specified.

No. 206,763.-WALTEK G. BARNES, FREEFORT, 1L.L.-Riding-Cultivalors.-August 6, 1878. Filed Fitrrut? 28,1878 .

Claim.-1. As an improvement in riding-cultivator, the combination of the tongue $A$, having adjustable roveplates $\mathrm{E} \mathrm{E}^{\prime} \mathrm{E} \mathrm{E}^{\prime}$, connecting arms (1) $\mathrm{D}$, and pivoted converging seat bars $C^{\prime}$. carrying the seat $C^{\prime}$, whereby the throw and elevation of the seat may loth he regulated, -ubrantially as and for the purpose herein shown and decribed.

2.-The combination, with the flanged rose plates $\mathbf{E} \mathbf{E}$, of the arm D D, having perforation $f$, bolis s.s, rose plates $E^{\prime} E^{\prime}$, having recesses $h / h$ and thumb nuts $i$, subutantiall as and for the prorpone herein hown and set forth.

3.- The combination of the adiustable arms $\mathbf{1} \mathbf{~}$, fanged werige plates $d$. bolts $t c$ and pivoted converging ,eat arms $C \mathrm{C}$, subitantially as and for the purpose hereiniefine set forth.

4.- The combination of the pivoted cultivator beams $\mathrm{K} \mathrm{K}$, having keepers $\mathrm{P} P$, hinged swa bar $\mathrm{N} N$, per. inated cruss bar (), an il adjustin r loolts $u$, sub-tantially is and for the purfore herein shown anil described.

5.-The combination of the slotted plates $R$, adjustable wit preces $T$, having hearls $S$, and jam nuts $2 \%$. substanially as and for the purpose herein shown and decribed.

No, 206,003-SPENClR R, STANTON, OXFuRD,

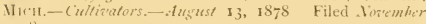
9. 1877 .

Claim,-1.- In a cultivator, the combination of the main frame $\mathrm{A}$, the movable cross bar $\mathrm{K}$, held in guides attacherl to the main frame, the plough feet or standards J, rigidly attached to the cross bar, and the lever L, attached to the bar $k$ and pivoted on the main frame, whereby the bar $K$, with the plough standards, can he moved laterally is either rlirection across the frame, for the purposes herein set forth.

2.-The combination of the frame $A$, crank axle $D$, with arm $b^{2}$, rod $u$, and lever $\boldsymbol{G}$, the laterally-sliding bar $\mathbf{K}$, with plough feet $J \mathrm{~J}$, and lever $\mathrm{L}$, all constructed and arranged to operate substantially as and for the purposes herein set forth.

No, 206,925-CARLOS D. BRADLEY. MACEDONIA, IowA, assignor of one-half his right to THEODORE E. BRYANT, same place.-Cultivators.-August 13, 1878 . Filed April $5,1 \mathrm{~S}_{7} 8$.

Claim.-1.- The combination, with the laterally adjustable plough or shovel beam $O$, of the shaft 1 . provided with arm $(Y$, having a slotted plate or lateral extension, $R$, and threaded and nutted rod $r$, connectung by swivel joint the said beam to the lateral slotted extension $R$ of the shaft arm ' 2 ', substantially as shown and described, for the purpose set forth.

2.-The combination, with the laterally and vertically ad, ustable handle 1 , of the extensible yoke consisting of the rods $k k$ and the collars $l l$, provided with adjusting or holding screws $m \mathrm{~m}$, and correspondingly adjustable or movable shovel heams $\mathbf{K} \mathbf{K}$, to which the yoke $k k$ is swiveled, substantially as shown and described, for the purpose specified.

3.-The combination, with the shovel-beam-securing castings $f f$, lifurcated at their forward ends, and having their fastening bolt provided with rollers or pulleys $e e$, of the diaft-equalizer, consisting of the levers $\mathrm{D} \mathrm{D}$, rods $\mathrm{F} \mathrm{F}$, and $F^{\prime} F^{\prime}$, the rods $F \mathrm{~F}$ connected together by cross tree $c$, chains $d \dot{d}$, and whiffletrees $G G$, substantially as shown and descrihed, for the purpose specified.

No. 206.961.-JAMES E. MUSTARD, Gil.N HAL1., IND.-Which-Cultizaters.-August 13, 1878. Filed March 4. 1878 .

Claim.- The combination of the arched draw-bar $\mathrm{E}$ and fifth-wheel C D with the arched axle B, the plough-beams $G$, and the independent draft-connection I J $\mathrm{K}^{\text {L }} \mathrm{L}$, substantially as hown and described.

No, 207.398.-FRERIC IV. DEGEN, New ATHENS, ILL.-Sulky-Cultisators-August 27, r878. Filed Febэแ⿰ 1, 1878 .

Claim.-I.-The block $J$, swiveled npon the hanger $I$, and having $t w o$ bearing-faces, in combination with the two plough-beams $\mathrm{K} \mathrm{K}$, and with the arm $\mathrm{L}$, having a vertical notched cross-head, and the angular plate or keeper $V$, uhereby two separate plough-beams are attached to one hanger, and allowed independent movement or vertical adjustment with respect to each other, as shown and described.

2.- The combination of the swinging curved arms $J^{\prime} J^{\prime}$, the connecting-bar 1 ', the pivot bolts 1 , and the slotted plate $H^{\prime}$ ' with the pairs of literally-movable plough-beams having guide-plates $\mathbf{K}^{\prime}$, and the supporting frame, as and for the purpone set forth.

No. 208,073.-FRANCIS M. CROPP, Platte County, Mr.-Cultizalors.-Septimbir 17, 1878. Fited February I6, 1878 .

Claim.-The coupling cunsinting of the sleeve $h$, having the perforated rib $i$, the forked arm $k$, U-shaped yoke $m$, and bolt /, combined and arranged substantially as specified. No. 208,320-[OAN1EL KERSCHNER, THOS. S. MONGER, and FRANCIS M. MGNGER, CONNERSFILLE, InI.-Floughs. - Siptember 24. I878. Filed March II, 1878 .

Clain.-I.- The arched axle $B$ and its pins $c$, combined with the clamping-plates $r c$, having recesses $/ \ell$, and pivoter to the adjustahle heam $c$ of the ploughs, and arranged to form an intervening space for the pasarge of the pins $\epsilon$, all snbstantially as set forth.

2.- The combination, with the parallel heams $C \mathrm{C}$, of the plate $D$, ears $i j$, and bar I. bolted to the jlate between the ears, and extended backward and forward to form the standards, $5 ., 5$, substantially as set forth.

3.- The combination of the plate $\mathrm{D}$, ears $i$, and pivoted arms $d$. having enlargements $d^{\prime}$ and bolted to the beams $C$ $\mathrm{C}$, as set forth. 
No. 208,377.-THE(H)()RE T. DANIELS, NHREISU,

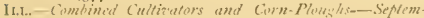
ber 24,1578 . Filed $F_{u} / v 6,1578$.

Claim.-1,- The plough-beam coupling consisting of the bolt or rod \& extendinuthrough the ears of the beams, and the clipe around said bolt, crimped in front of the same and extending forward, in combination with the axlc-plate $\because$ and its bolt, substantially as specificd.

2.- A cultivator having an arched axle, side-heam sections, and detachable centre beam, connected to the arch of said axle by means of a transverse har, the perforated guide-bar $\mathrm{A}^{\prime}$, extending transversely across the rear ends of the beams, and the vertical hanger-rorls $\sigma^{\prime}$, extending through the perforations of said bar into the heam encl-, substintially as specified.

3.-A cultivator having a squared and centrally-archer axle and a section of several beams, connected to cach enil of sicl axle by a single clip engaging a lateral pixot on the axle and a vertical pwot on said clip, a horizontal rod passing through the ears of sairl clip and connecting the forward ends of said beams, in combination with the cross-bar $A^{\prime}$, screw-loolts $y^{\prime}$, and handle $f^{\prime}$, subutantially as specified.

No. 208,921.-CHESTEK NASH, I)AVIS JUNCTION, In..-Cullizators.-Oitobir 15, 1878. Filed Ausust 17, 1878 .

Claim, -1- The combination, with the main frame of a cultivator and slide-ways arranged to project above and below the main frame in front of the axle, of draw bass, each luaving a slide secured to its forward end, said slides provided with bearings or sleeves, which surround the slicleways at points above and below the culcivator-frame, substantially as set forth.

2.-The combination, with stationary slideways attached to the main frame of a cultivator, and arranged to project above and below the main frame, of dring-bars, each having a slide secured to its forward end, said slides provided with bearings or sleeves, which surround the upper and lower portions of the slideways, and are adlapted to be vertically adjusted thereon, and hand-levers attached to the upper ends of the slides and arranged to raise and lower the same, substantially as set forth.

3.-The combination, with the main frame of a cultivator, provided with slideways located in advance of the axle and arranged to project above and below the main frame, of flexible connections having the:ir opposite ends respectively attached to the slides and drag-bars, substantially as set forth.

4.- The combination, with the drig-hars of a cultivator, of shovel-frames piroted to the rear ends thereof, and connected by a pivotal sway-har, whereby the shovel-frames are adapted to have independent vertical movement and a lateral movement in unison with each other, substantially as set forth.

5.- The combination, with the drag-hars and shovelframes pivoted thereto, of a sway-bar, to the opposite encls of which the shovel-frames are adapted to be pivoted in a laterally-adiustable manner, substantially as set forth.

6.- The combination, with the drag-bars and shovelframes pivoted thereto, of a sway-bar composed of two transverse bars, between the opposite ends of which are pivoted the upper ends of the shovel-frames, substantially as set forth.

No. 209,118.-ALBERT GEPPERT, SPRINt; PRAIRIE, Wis.-Wher\%-Cultivators.-October 22, 1878 . Filed March 23, 1878 .

Claim.-The combination, with the tongue $\mathrm{C}$ and heam $\mathrm{D}$, of the casting $\mathrm{F}$, with jaws $d d$, the casting $\mathrm{J}$, with hubs $b$, the swiveled pin $G$, having a flattened eye at its upper end, and the pivoting-bolt $e$, all constructed substantially as and for the purpones herein set forth.

No. 209,210,-DANIEL ARGiERBRIGilT, TRnY, OHIs,-Wheel-Cultivators,OCtuber 22, 1878 . Filed Warch 16,1878 .

Claim.- The box $m$, secured on the axle to cover the inner end of the wheel-hub, and provided with drag $\mathrm{K}$ and arm L, substantially as set forth.

No. 209,224.-HUGH H. CANADAY, FAIRFIELD, Inws.-Ridins-Cultivators. - Octaber 22, 1878 . - Filed December 1, 1877.
Claim.-In a wheel plough, the frame A, having the horizontal side bars, $a$, extending from end to end, the front bar, $\mathrm{B}$, hent downward at each side at $a^{\prime}$, and horizontally at $c$, to receive the clevices $d$, thence upward at the middle to form an arch, $h$, for the tongue, the adjustable wheelclamps $h$ on snid bars, the rear har, $C$, having the seat $G$ and the foot rests $\mathrm{J}$, connecting the rear ends of the ploughbeams and depending therefrom in rear of the shovels, substantially as specified.

No, 209,401.-MOSES JOHNSON, LOCKFORT, N. Y., assignor of one-half his right to MOSE. C. RICHARDSoN, sime place.-Cultirators.-Octob'r 29, 1878. Filed 7 uly 19, $1 S_{7} 8$.

( Jaim. - The cultivator tooth $\mathrm{F}$, made of one sheet of metal, bent nearly at right angles, forming a vertical section $h$, corresponding to the land side of a plough, which inclines rearwardly from the point to the top, and is provided with a rear extension, curved inward toward the furrow, and having a horizontal or share section, $h^{\prime}$, with a cutting-edge running backward obliquely from the point, substantially as shown and lescribed.

No. 209431.-JOHN STIMMELL, Coltmés, OHIo. -What.Cultirators.-Octobir 29, 1878. Filed August 23 1878 .

Clain.-In a wheat-cultivator, the combination of the pivoted cross-bar $\mathrm{D}$, having hinged cultivator beams $\mathrm{F} \mathrm{F}$, provided with the shanks I J, having points U, notched crosspiece $\mathrm{H}$, standards $\mathrm{K}$, having pins $b$, and pivoted handles $\mathrm{M}$, provided with loops $\mathrm{N}$, constructed and operating substantially as and for the purposes set forth.

No, 209.527.-FRANK T. VERHAREN, VINTON, InWA-Corn-Cullivators.-Octobir 29, 1875. Filed August 4,1877 .

Claim-1-As a means for connecting the axle arm C with and giving to the same a certain degree of motion upon the frame bar B, the sleeve $c$, provided with the slot $c^{\prime}$, the the brace bar $\mathrm{E}$, and the screw $\mathrm{F}$, said parts being combined to operate in the manner and for the purpose specified.

2.- In combination with the axle arm $\mathrm{C}$ and ploughbeam 1 , the sleeve $G$, provided with the plate $g^{\prime}$, having vertical openings $g^{\prime \prime}$, the ears $g$, provided with horizontal openings $g^{\prime \prime \prime}$, and the bolts $H$ and $\mathrm{K}$, substantially as and for the purpose set forth.

3.-As an improvement in wheel-cultivators, the pole $\mathrm{A}$, frame bar B, axje-arm C, sleeves $c$, having the slots $c^{\prime}$, ground-wheels D, brace-bars $\mathrm{E}$, screws $\mathrm{F}$, sleeves $\mathrm{G}$, having the ears $s$, plates $g^{\prime}$, and openings $g^{\prime \prime}$ and $g^{\prime \prime}$, ploughbeam $\mathrm{I}$, draw.bar $\mathrm{L}$, bolts $\mathrm{H}$ and $\mathrm{K}$, and hooked bar $\mathrm{N} n$, all constructed and combined to operate in the manner and for the purpose substantially as specified.

No. 209.780.-GEORGE W. STAVER, MonroE, Wis.-Cultivators.-Noz'mber 12, 1878. Filed January $9, \mathbf{1} 878$,

Claim.-The plates I I and sway-bar F, said plates clamping the sway-bar and inclosing the balls $\mathrm{H}$, in combination with plates $\mathrm{G}$, port $\mathrm{E}$, and the beams C, substantially as set forth.

No, 210,073 -WILIIAM T. ADDISON, NewCASTLE, IND.-Cultizators.-Notimber 19, 1878. Filed September 23,1878 .

Claim. - I - In a cultivator, the combination, with its axle or beam, of the cranked arms or bars $\mathrm{C}$, having set or adjusting screws $d$, substantially as and for the purpose specified

2.- The combination, with the beam or axle of a cultivator, of the cranked bar $C$, set-screw $d$, and adjustable rods or braces E, substantially as and for the purpose specitied.

No. 210,861 - WII.I.AM A. KNOWLTON and AN DREW RUTLEDGE, ROCKFORD, ILL.-Cultizators.December $\mathbf{1 7}, \mathbf{1} 878$. Filed Afril $30, \mathbf{1} 878$.

Claim.-1.-A pendant provided with bracing arms adanted to be secured to the side of the tongue beam and to the under side of the cross bar connecting the tongue beams the lower end of said pendant provided with a socket, in combination with a joint bar having a journal, $b^{\prime}$, which turns within the socket on the pendant, the lower end of the joint bar provided with a stud, $b^{\prime \prime}$, and the plate of the 
arag bar journeled on said stud and secured by a bolt, subrantially as set forth.

2.- The evener having end hooks rigidly secured thereto for the attachment of the whiffletrees, in combination with removalile vertical eveners pivoted to the straps of the end hooks, the lower ends of said vertical eveners provided with books to receive the whiffletrees, and draught-links secured at their rear ends to the axle-tree, while their forward ends are attached to the vertical eveners, substantially as set forth.

3.-The comlination, with the herein described tbreepart sbovel-standard, of grooved blocks adapted to receive the forward and rear edges of the side plates of the standard and adapted to receive a shovel on the front side of the forward block, held in place thereon and made vertically adjustable on the standard by a screw bolt or bolts passed from the front through the parts between the side plates of the standard.

4.- The comhination, with the thrce-part shovel-standard herein described, of yrooved blocks adapted to receive the forward and rear edges of the side plates of the standard, the front face of the forward block adauted to receive the convex surface of the shovel block secured to the shovel, and held in place and made adjustable on the standard by means of the screw bolt in the slot of the shovel back yass. ing through the grooved blocks and between the side plates of the shovel standard, substantially as and for the purpose hereinbefore set forth

No. 210,993.-ANDREW CANFIELD, DAVENPORT, Iowa.-Cultivators.-Dicember 17, 187S. Filed Ortober 26, 1878 .

Claim. - The combination of the tubular axle-tree $\mathrm{A}$, the tubular $\mathrm{T}$-couplings $t$, passed over the ends of said tree and secured thereto, and the horizontally and vertically bent tubular arms $B$, the horizontal end screwed into said Tcouplings, and the vertical end having the vibrating collars $c$, adapted to receive the plongh beams E, substantially as specified.

No. 211,646 . -STEPHEN BAII.EV, LEBANUN, ILL.Cultivators.-Janumy 28, 1879. Filed loomber 16 , I 87 S.

Clain.-I. - The combination of the frame B, hanger I), bearings $d d$, beams $C C^{\prime}$, lever I, link $J$, and arm $K$, sub. stantially as described.

2. - The combination of the beams $C \mathrm{C}^{\prime}$, arm $\mathrm{K}$, joint $k$, eye $k^{2}$, link $\mathrm{J}$, and lever $\mathrm{I}$, substantially as described.

3.- The combination of the axle $a$, arm $G$, standard $a^{1}$, beams $\mathrm{C} C$, and eyes $c^{\prime} c^{\prime}$, substantially as described.

4.- The arm G, having the forks $g^{-1}$, jointed together at $g^{2}$, and provided with the nut $g^{4}$, in combination with the beams $\mathrm{C} C^{\prime}$ and eyes $c^{\prime} c^{\prime}$, substantially as describel.

5.-The combination of the axle $a$, bearings $a^{3} a^{3}$, pivoted levers II $H$, clips $h h$, and forked arm $\mathrm{G}$, substantially as decribed.

6. - The combination of the axle $a$, standard $a^{1}$, forked $\operatorname{arm} G$, levers $H \mathrm{H}$, clips $h h$, beams $\mathrm{C}^{\prime} \mathrm{C}^{\prime}$, eyes $c^{\prime} c^{\prime}$, and barin is $a^{3} a^{3}$, substantially as described.

No. 211,785 . -NOAI 1. KEMY, BRonkviLI.E, IND.Whet-Culticators.-Finuary 28, 1879. Fileil Mar 31, I 878 .

Claim.-1,- The extensible crank axles $\mathrm{B}$, having ring grooves $h^{\prime}$, in combin ition with the cylinder $C$, attached to tongue $D$, and the set screws $c^{\prime}$, as and for the purpose described.

2.- The combination of the sectional axle B, cylinder $\mathrm{C}$, tongue $\mathrm{D}$, evener $\mathrm{E}$, hanger $\mathrm{F}$, links $\mathrm{H}$, and brace rods I, substantially as shown and described.

No. 211,792,-PRIOR S. RUSSELL, RIVERSIDE, CAL.-Cultivators.- January 28, 1879. Filed Nowember 9, $187 \mathrm{~S}$.

Claim. - The improvement in cultivators or soil dressers consisting of the non-adjustable central beam, A, mounted upon the stationary and turning pairs of wheels, $C D$, and provided with the hinged adjustable diverging wings $G$, with their operating levers, as shown, said wings being provided with the chisels or teeth $H$ and the diagonally. arranged cutters $R$, substantially as and for the purpose herein described.

No. 212,193.-CHESTER C. CLOVER, OsWEgo, K.IN.-Sulky-Ploughs.-February 11, 1879. Filed March 16,1878

Claim,-Tbe plougb beam J, suspended near its front end by means of the perforated bar $\mathrm{L}$, and suspended at it: rear end by the holder $O$, in combination with an elbow lever, M, the forward end of which works in a slot, e, in the rear end of the plough beam, and tbe locking dog $\mathrm{P}$ and foot lever R, substantially as sbown and described.

No. 212,546,-THEODORE M. FI.ENNIKEN, and ASA HALL, ROCKFORD, IlL, assignors to N. C. THOMPSON, same place.-Cultivators.-February 25, 1879. Filed April 18, I 878 .

Claim.-1.- The combination, witb the drag bar and hanger, of the flaring topped sheath $b$ and the sleeve or holder $b^{\prime}$, the sheath enclosing the sleeve and being supported by trunnions on the latter, and both encircling the hanger, and held thereon by a suitable device, substantially as set forth.

2.- The combination, with the shield, of a hound bolder piece provided with means for supporting the shield in any horizontal plane, and held to the har or other supporting part of the frame by a device whicb permits the bolder to be turned for the insertion or removal or adjustment of the shield.

3.- The shield holder having a longitudinal opening to receive the projecting pin upon the shield and a $\mathrm{U}$-loop at one side of said opening, said loop serving to sustain the shield and to retain the pin in the opening, substantially as set forth.

No. 213.675-THOMAS MEIKI.E, LouISIII.1., KY. -Carriage-Cultivators.-March 25, 1879 . Filed October 25. 1878 .

Claim.- The universal fulcrum $\mathrm{K}$, constructed substantially as described, in combination with the foot lever $H$ and the cultivator beam L, constructed, connected, and operating together as and for the purposes substantially as described.

No. 213.943 -ALEXANDER SANDERS, EL DnRADO, ILL., Wheel.Cultivators._April 1, 1879. Filed Feliruary 8, 1879 .

Clain.-1.-The double gangs of ploughs A $a a^{1} a^{2}$, connected by the saddle $\mathrm{D}$, wbeels $\mathrm{B}^{\prime}$ and guy chains $\mathrm{E}^{\prime}$, combined with a sulky tongue, E, as and for the purpose set forth.

2.- The arched saddle $\mathrm{D}$, main beams $\mathrm{A}$, and double gang of plougbs, in combination with the axle $\mathrm{G}$ and wheels, tongue $\mathrm{E}$, and semicircular hearing $\mathrm{H}$, subst.ntially as and for the purposes set forth.

No. 214,113,-L.EVI DAVIS, IR., BIG Rock, ILL.Cultivaters.--April 8, I879. Filed Nowember 22, 1878 .

Claim.-I.- In a cultivator, the combination, with the sbovel-beams and the shields, of an angular biting lipped casting, $b c c$, the pivot-screw $a$, and the nut $e$, whereby the shank of the shield is clamped upon said lipped-plate casting by the nut in such manner as to be adjusted by the force of the driver's foot, and preserved in its adjustment.

2.- The shield-shank friction-joint, formed by the casting $b \in f$, pivot-screw, and clamp-nut.

3.- The cultivator-shield $\mathrm{B} d$, provided with the toe projection $x$, in combination with the friction or biting lipped casting, the pivot-screw, and the clanip-nut, as and for the purpose set forth.

No. 214,138 -SIDNY B. HOLLY and JOHN JONES, Stony PoINT, Cal.-Cultizators.-April 8, IS79. Filed February 26,1878 .

Claim,-The wheel-hub W, provided with an irregular bore and recess, $\mathrm{X}$, at each end, and having the box $\mathrm{Y}$, made to fit in the irregular bore, in combination with the square journal $Z$, with its sleeve $G$, and the caps $N^{\prime} N^{\prime}$, all combined and arranged substantially as and for the purpose described.

No. 215,385 . - JAlles M. MITCHFLL, PoInt Peter, ARk.-Cultizators.-Way 13, 1879. Filed August 27, I 878 .

Claim.-The combination, in a cultivator, of the $\mathrm{V}$-shaped bar $\mathrm{G}$, slotted axle $\mathrm{B}$, bar $\mathrm{O}$, provided with a 
number of holes, the rod $\mathrm{H}$, the branched bars $\mathrm{I}$, and the cye siraps $\mathrm{N}$, whereby the bars $I$ are held in position on the rod 11, substantially as and for the purpose specified.

No. 215,931.-WHLLIAIJ JONES, MIII. I'OINT, N. Y - Cultizators.-1Kuy 27, 1879. Filed Murch 27, 1879.

Claim.-The combination, with the axle II, having crank at each end, provided with wheels C C, of the link D, having two or more holes at the free end, the brace $\mathbf{E}$, the adjustable lever $F$, the lever $G$, having hook on long arm, the standard 1 , and the chain $H$, all arranged as shown and described.

No. 217,282.-ROBERT S. HARRIS, I) URUQUF, IowA.-Cultizators.- $f_{u l y} S, \mathbf{1} \$ 79$. Filed fune 6 , 18,5

Claim - 1, - In a sulky-cultivator, the shafts or divided tongue $\mathrm{C} \mathrm{C}$, having independent adjustment upon the axle $\mathrm{B}$, and the front connecting arch, D, in combination with the plough beams $E^{\prime} E^{\prime \prime}$, pivoted at their forward ends to the shafts, and provided with handles $\mathrm{G}^{\mathrm{G}^{1}}$, adjustahly connected together, all constructed and operating substantially as shown and described.

2.-In a sulky corn-cultivator, the combination, with the laterally-adjustable shaft $\mathrm{C} \mathrm{C}^{\prime}$, of the plough beam $\mathrm{E}^{\prime} \mathrm{E}^{\prime \prime}$ pivoted at their forward ends to such shafts, and provided with handles $G \mathrm{G}^{1}$, adjustably connected together by the screw rod $\mathrm{G}^{2}$, constructed and arranged substantially as described and shown.

3.- The equally diverging point and land side $c c^{1}$, having outwardly bent lower edge $t^{2}$, in combination with the mould board $d$, situated en:irely above the point and land side, and provided with outwardly curved edge $d^{\prime}$ substantially as described and shown.

4-The downwardly projecting arms carrying foot rests and seat, situated at the rear of the cultivator and on each side of the row, substantially as and for the purpose set forth.

5.-In a corn-cultivator, the combination of the arms $\mathrm{H}^{\prime} \mathrm{H}^{\prime}$, placed subuantially as shown, with the foot rests and seat adjustable upon such arms, for the purposes set forth.

No. 2I7, SI1.-G1LPIN MOORE, MoLINE, lLI., assignor to DEERE \& CO., same place,-Cultizators, - Fuly 22 , 179. Filed February 4, 1879.

Chim.-1.-In a wheel-cultivator, the combination of the axle, one or more ploughs hinged to the axle, and one or more springs, connected at their rear ends to the forward ends of the plough beams, and at their forward ends to the wheel-fr.me in front of the axle, substantially as set forth.

2.-In a cultivator-coupling, the slotted sleeve $\mathrm{E}$, in com bination with boxes $\mathrm{G} 1 \mathrm{I}$, ad, ustably secured to the sleeve by bolts and nuts, substantially as described, and for the purpone specified.

3.-In com ination with the sleeve $\mathrm{E}$ and adjustable boxing G II, the slotted sleeve I, spindle J, and ploughbeam - having bracket $K$, substantially as and for the purpove specified.

4.-The vertically adjustable slotted sleeve $I$, in combination with brackets $K$, plough-beams $\mathrm{D}$, spindle $\mathrm{J}$, with stud $j$, and hoxes $\mathrm{G} \mathrm{H}$, which su-tain the sleeve I and spindle $\mathrm{J}$, substantially as and for the purpose specified.

5.-In combination with the wheel-frame and ploughs, the spindle J, or elongated journal for the plongh-beam, and the spring II, connecting the elongated journal or spindle $J$ and the wheel-frame, substantially as and for purpose specified.

6.-In combination with a cultivator wheel-frame and plough, a spring connected at one end to the wheel-frame and at its other end to the journal-bolt on which the plough beam has lateral motion, so that the plough-sustaining force of the spring will not have a tendency to draw the plounh to one side whenever it is deflected for any purpose, suhstantially as and for the purpose specified.

No. 217,614 . -JACOB WAGNER, JR., CHICAGo, ILL. -Wheel-Cultivators.-July 29, 1879 . Filed fanuary 23 , 1379.

Claim.-1.-The circular coupling plates $\mathrm{C}$ and $\mathrm{E}$, sleeves $g g$, and collar $\mathrm{G}$, in combination with the beam $\mathrm{A}$ and axle $h$, substantially as described, and for the purpose specified.

2.- The coupling-plates $\mathrm{C}$ and $\mathrm{E}$, sleeves $5 g$, collar G, and axle $h$, in combination with the beam $A$, parallel rods $k k$, and vibrating yoke-frame $a d$, substantially as and for the purpose berein described.

No. 2 IS, 274.-JAMES I1. JOHNSON, EDWARDSIILIE, ALA.-Cultizators.-August 5, 1879 . Filed June 2I, IS79.

Claim.-1.-The combination, with the axle A, having bail $C$, and the clamp-plate $b$, resting on the ends of said bail, of the uprights $(i$, extending through the axle and plate, affording bearings to the beam-shaft, and having shoulders $c$ and the clamp-nuts $d$, substantially as specified.

2.-The combination, with the axle $A$, hail $C$, tongue $D$, and the open slotted uprights $\mathrm{G}$ on the axle, of the rockshaft $\mathrm{H}$, journaled in said uprights, the beams $I$, spacing. blocks $e^{\prime}$, the rod $\mathrm{K}$, spacing-blocks $f$, the lever $\mathrm{L}$, pivoted to the beam, the link $l$, vibrating on shaft $K$ and adjustably secured to said lever, and the rack-bar $\eta_{\text {, erected on the }}$ bail, substantially as specified.

No. $218,454-$ RICHARD B. ROBBINS, ADRIAN, Nich.-Cultiators.-August 12, 1879. Filed Verember I8, 1878 .

Claim,-1.-The pendant 30 , consisting of the parts 31 and 32 , the parts 32 having extension 35 , provided with graduating holes, the whole held together by rod 33 and jam nut 34, substantially as and for the purpose set forth.

2.-The combination of casting 44 and arm 41 , the latter bent over the casting, as shown and described, and secured by a wooded safety pin, substantially as shown.

3.- The combination of the perforated angle iron 67 . crossbar 66 , cross head 64 , and rails 37 and 63 , as set forth.

4.- The foot lever 55, consisting of one part 56, having an extension, 58 , and another part, 57 , hinged and adapted to operate in connection with part 56 , substantially as and for the purpose set forth.

5.-The combination of the irons 72 and 73 , serrated and flanged, as described, with the shield 71 , the shield 71, having a free up-and-down motion between the flanges independent of the serrated irons, substantially as set forth.

6.-The combination of the seat bars 75 , angle irons 76 , serrated and slotted, as described, clasp 77 , and bolt $7 \mathrm{~S}$, all constructed and adapted to operate substantially as set forth.

No. 2IS,526.-CAGER HADGRAVE, ClarksVille, ARK.-Cultivators.-Ausust 12, 1879. Filed Fune 2, 1879

Claim.-The combination of the upright rods C, the collars and set screws $\mathrm{H} h^{\prime}$, and the clevises $\mathrm{G}$ and $\mathrm{I}$ with the short axles $\mathrm{B}$, the cross bar $\mathrm{D}$, to which the tongue $\mathrm{E}$ is attached, the plough beams $F$, and the draw chains $J$, substantially as herein shown and described.

No. 218.527.-CAGER HARDGRAVE, ClaRKSVILle, ARK.-Cultizators.-August I 2, I879. Filed December 20,1878 .

Claim,-The combination, in a cullivator, of the bent axles $c$, the rods $c$, the sliding bars $f$, and the screws $i$, provided with the nuts $k l$, with the cross-bar $d$ and the plough beams $m$, substantially as and for the purpose described.

No, 218,561 -OLOF OLSON, RED OAK JUNCTION, IowA., as signor of one-half his right to LOU1S W. JOSEPH, same place.-Cultivators.-Ausust $\mathbf{1 2}, \mathbf{1} 879$. Filed fune 21,1879 .

Claim.-I. - In a cultivator, the two-way sliding blocks $\mathrm{F}$, provided with the set-screws $f$, in combination with the portion of the cultivator-axle $F^{\prime}$ and the shaft $\mathbf{E}$, as and for the purposes substantially as set forth.

2,- In a cultivator, the two-way thimbles $G(i$, provided with the set-screws $g^{3}$, in combination with shafts $G^{\prime} G^{\prime}$, the collars $\mathrm{K}$, provided with set-screws $k$, the double-tree $\mathrm{L}$, and the link $k^{1}$, ring-hooks $k^{2}$, and shafts $\mathrm{E}$, as and for the purposes substantially as set forth.

3.- In a cultivator, the lever $\mathrm{M}$, in combination with the 
bar: $f^{2}$, provided with a series of adjusting holes and the shackles $f^{1}$, and the sliding two-way blocks $\mathrm{F}$, as and for the purposes substuntially as set forth.

No. 219,065.-JOSEPH M. BROWN, FlORENCF, TEX. - Combined Planters and Cultizators.-September 2, 1879 Filed Harch 2, 1878.

Claim.-The combination of the frame $\mathrm{C}$, having slot: $d$ in its front and rear rails $c^{\prime} c$, and a slot $i^{\prime}$, in its side rail $j$, tongue $\mathrm{B}$, extending across the frame, and driver' seat $\mathrm{E}^{\prime}$, both tongue and seat being laterally adjustable to gether on the frame and axle $\mathrm{A}$, with the laterally-adjustable draft-irons $\mathrm{C}^{\prime}$, draft-hars $\mathrm{D}$, rods $f$, elongaterl staple $a$, arranged on the right hand $r$ ail of the frame, plate $b$, block $k$, and adjnstable brace $G$, whereby the implement is convertible and adapted to operate either as a cultivator, a gang. plongh, ar a seed-planter, substantially as described.

No. 2 I9.326.-ISAAC UTTER, ROCKFORD, ILL.Cullizators.-Siptember 2, 1879 . Filed February 8, 1879

Claim.-The combination, with the main frame, the divided crank axle journaled thereto, and capable of independent back-and-forth swinging movement, and the plough beams, of the limiting sloited brackets $b$, the branching cross-bars, and vertical evener bars, pivoted at tbeir upper ends to the main frame, and at their lower end connected with the forward ends of the branching draught rods, substantially as set forth.

No. 219.882 . ANDREW B. TRAVIS, BRANDON, Мich. -Cultivators.-Siptember 23, 1879. Filed April 29, 1879.

Claim - I-In combination with the frame F G, flexibly connected at its forward end, the frame J, rock shaft $p$, handles $\mathrm{L}$, and slotted arm $K$, substantially as and for the purposes herein set forth.

2.-In combination with the frame $F \mathrm{G}$, the track clevis $a^{\prime} a^{\prime}$, chains $t$, with rollers $y^{\prime}$, and a mechanism for raising and lowering said chains, for the purposes herein set forth.

3.- The drag guards $\mathrm{V}$, pivoted to an arm, $\mathrm{T}$, attached to and projecting in front of the tooth $\mathrm{R}$, for the purposes set forth.

4.- The adjustable tooth $\mathrm{R}$, formed with the flanges $i^{\prime}$, and provided with the removalle point $S$ and pivoted drag guards V, substantially as and for the purposes herein set forth.

No. 220,463.-WIIIJAII P. BROWN. ZANFSVIILLE, OH10,-Cultivators.-Oteber 14, I879. Filed Arril 12 , I 879 .

Claim, $-1,-1 n$ a riding and walking-cultivator, the lever $\mathrm{F}$, provided with the spring pawl $f$ and arm $\mathrm{F}^{?}$, in combination with the segment ratchet $\mathrm{F}^{\mathrm{J}}$, the lever $\mathrm{K}$, connecting rod $\mathrm{L}$, toggles $\mathrm{H} \mathrm{H}^{\prime}$, and draught bolt $\mathrm{D}$, as and for the purposes set forth.

2. - The lever $k$, provided with the lug $k^{3}$ and hole $k^{2}$, engaged with the lever $\mathrm{F}^{2}$ by the hook-and-eye joint $k$, in combination with hook bolt $\mathrm{K}$ ', cultivator beam $\mathrm{E}$, and the connecting rod L, substantially as and for the purposes set forth.

3.-In a riding and walking-cultivator, the bracket $\mathrm{C}$, attached to the tongue $\mathrm{B}$ and to the axle $\mathrm{A}$ by the brace $\mathrm{C}^{1}$, and provided with slots $\mathrm{C}^{2}$, in combination with the draught holt $\mathrm{D}$, the sleeve $\mathrm{D}^{1}$, and the adju-table clevis $\mathrm{E}^{\mathrm{y}}$ provided with the set screw $\mathrm{D}^{2}$, substantially as and for the purpoies set forth.

4.- In a ricling and walking-cultivator, the combination of the lever $\mathrm{F}$, the connecting rod $\mathrm{N}^{2}$, the lever $\mathrm{N}$, proviled with the segment gear $\mathrm{X}^{-1}$, the stirrup $\mathrm{MI}$, provided with the rack $\mathrm{I}^{\prime}$, and the Iraught bar $\mathrm{D}$, constructed and operating substantially as and for the purposes set forth.

5-In a riding and walking-cultivator, the combination of the lever F, provided with the spring pawl f and the $\operatorname{arm} \mathrm{F}^{2}$, with the segment rack $\mathrm{F}^{3}$, lever $\mathrm{K}$, connecting rod $\mathrm{L}$, toggles $\mathrm{H} \mathrm{H}^{\prime}$, and draught rod $\mathrm{L}$, and the connecting rod $\mathrm{N}^{2}$, lever $\mathrm{N}$, provided with the stgment gear $\mathrm{N}^{3}$, rack $\mathrm{M}^{\prime}$, and stirrup $\mathrm{NI}$, substantially as and for the purposes set forth.

No, 220,985.-AUGUST NORLING and CIIARLES
A. NORLING, STANFon, Jows - Cultizaton-October 28, 1879 . Filed April 5,1879 .

Clain.--1.-The combination of the divided adinstable axle $\mathrm{C} \mathrm{C}$ with the perforated connecting-bars $\mathrm{B} \mathrm{B}$, the vertically-adjustable arms $m$ on each end of the axle, the four-armed block I, and the cultivator-beam having arms $p$ $p$, all constructed as described, whereby the cultivators can be adjusted out and in and up and down, and can be manipulated in any direction without twisting, substantially as and for the purjoses herein set forth.

2.-The double eccentric $G$, having on each side the points $h i$, at different distances from the pivot, and a certain portion on each side, from $i$ to $x$, on a true circle, in combination with the chains, rods, and double-tree, substantially as and for the purposes herein set forth.

3.-The combination of the jointed beam $\mathrm{H}^{\mathrm{H}}$, link $\mathrm{L}$, spring jaws or snap () $O$, and the rod $P$, with cone $v^{\prime}$ whereby when the joint of the brace is broken the two parts do not separate, but remain together, substantially as and for the purposes herein set forth.

4.-The combination of the bean, the shorel R, pins tw stationary plate $S$, and adjustable plate $\mathrm{V}$, as and for the purposes set forth.

No, 221,058.-GEORGE HAMMANS, GUSPORT, IOWA. - Cultivators.-October 28, 1879. Filed June $16,1879$.

Claim_- I.- The combination, in a three-horse cultivator, $o$ ? the double-tree nade in two parts, F F, pivoted on the poles $\mathrm{G} G$, and their inner ends connected by the link $h$, the arms or rods I I I, and single-trees J J I, all substantially as and for the purposes herein set fortl.

2.-The combination, in a cultivator, of the ploughbeams $\mathrm{A} \mathrm{A}^{3} \mathrm{~A}^{3}$, rods $i$, and triple crank-shaft $k$, and the plough-beams $\mathrm{A}^{\prime} \mathrm{A}^{\prime}$ and $\mathrm{A}^{2} \mathrm{~A}^{2}$, and the divided rods $t, l$, with separate handles L I, having sockets $\tilde{z}^{\prime} \tilde{z}^{\prime}$ for adjusting the divided ruds, whereby the centre beam A, and outside beams $\mathrm{A}^{3} \mathrm{~A}^{3}$, may he raised and lowered independently of the beams $A^{\prime} A^{\prime}$ and $A^{2} A^{2}$, and vice versa, substantially as herein set forth.

No. 221,280.-JONAS DIERDORFF, GosHF, IND,Cultizators - Hovember 4, 1879 . Filed July 8, 1879 .

Clam.-The combination, in a cultivator with an arched axle and tongue, of the draught block $\mathrm{B}$, the bars $\mathrm{A} \mathrm{A}$, hinged thereto in front, and provided with the side loops or clips $a^{\prime}$, at the other end, and the screw $\mathrm{C}$, having nuts $c^{\prime}$, as show $n$ and described, whereby the bar A and block B may be elevated or depressed, to suit the height of the growing crop, without affecring the sleptly or position of the ploughs.

No. 222,391-JAIIES M EIDER, INDIANAPOLIS, Ist).CCultivators.-December 9, 1879. Filed August 30, 1879.

Claim.-1.-The arljustable bracket $\mathrm{O}$, combined with the universal joint $L^{2} L^{\prime}$, spring $K$, cup $J$, rod $I$, and coupling $\mathrm{G}$, as and for the purpose specified.

2.- In combination with the arched axle of a cultivator, the bracket 0 , with arms $g$, the universal joint $L$ L' the spring $\mathrm{K}$, the cup $\mathrm{J}$, the rod 1 , the rod $H$, the serrated lugs $\mathrm{G} \mathrm{G}^{\prime}$, the coupling $\mathrm{F}$, and plough heams $\mathrm{W} \mathrm{W}$, as and for the purpore specified.

3.-In combination with the coupling $\mathrm{F}$ of a shovel beam, the jointed rod $H 1$, spring $K$, universal joint $L L^{\prime}$, and bracket $\mathrm{O}$, as and for the purpose specified.

No. 222,44 , HENRY BLOEDEI, FOND DU LAC, Wis.-Cultivators.-Dicember 9, 1879. Filed Ausust 15, 1879 .

Claim.-1.- The combination, in a cultivator, of the axle mounited on wheels and provided with a rigid tongue, with the $v$-shaped frame having the series of beams $D$ independently hinged thereto, said frame, with its hinged beams, being rigidly suspended underneath the axle, and all being arranged to operate substantialky as shown and described.

2.- In combination with the series of independentlyhinged hars $\mathrm{D}$, arranged in $\mathrm{V}$ form, as shown, the rotating shaft $\mathrm{E}$, provided at its centre with the arms $n$ for raising the central beams equally with the remaining beams which are connected direct to said shaft, as set forth.

3.- In combination with the pendants $m$, having the bars $\mathrm{D}$ hinged thereto, as described, the connecting bars 
or braces $\because$ arranged in the manner shown and dc scribed.

No. 222550.-D.1NIEL UNTHINK, SPICH.AN1, INn.-Cinltitulers.-Dicimber 9, IS79. Filed funi 25. 1579.

Claim.-1.- The combination of the set of three parallel bars, $H$, provided with double jointed couplings $f ; 1$ at the ends of each bar, with the frame J, to which the plough standards $K$ are attached, and with the bars $F \quad F$ anil crauk I), by which they are connected with the axle l;, subtantially as herein shown and rlescribed.

2.- The combination of the notched plates $a^{2} e^{\prime}$ and $e^{3} f^{\prime}$ with the connecting bar $\mathrm{F}$, the crank arm 1), attached to the axle $B$, and the bar $F$, with which the forward ends of the parallel bars $H$ are comnected, substantially a herein shown and described.

3.- The combination of the double notched plate $\mathbf{M} \mathbf{~ I}^{\prime}$ and the notched plates $j^{\prime}$ and $n^{\prime}$ and their bolts $n^{\prime} m^{2}$ with the bandle $\mathrm{N}$ and the frame I, to which the plough standardi $K$ are attached, and with which the rear ends of the parallel bars $H$ are connected, substantially as herein shown aud described.

No. 9,607,-D.ANIEl, UNTHANK, SPICELAND, assignor of one-half his right to FRANCIS A. COFF1N, Richatow, IND, - Cultivators.-222,550, Decemier 9, IS79.-Reissued Warch 15, ISS1. Filed linember 17, I SSo.

Claim.-1.-The combination of the set of three parallel bars, $H$, provided with double-ointed couplings $G$ i it the ends of each bar, with the frame J, to which the plough standards $K$ are attached, and with the bars $F$ F and crank I), by which they are connected with the axle B, substantially as herein show $\mathrm{n}$ and described.

2.- The combination of the notched plates $d^{2} t^{\prime \prime}$ and $e^{3} f^{\prime}$ and their bolts $f^{2} f^{2}$ with the connecting bar $E$, the crank arm $\mathrm{D}$, attached to the axle $\mathrm{B}$, and the bar F, with wbich the forward ends of the parallel bars $H$ are connected, sub. stantially as herein shown and described.

3.-The combination of the double-notched plate $\mathrm{MI} \mathrm{II}^{\prime}$ and the notched plates $j^{2}$ and $n^{\prime}$ and their bolt $n^{\prime} m^{2}$ with the handle $\mathrm{N}$ and the frame I, to which the plongh stanc?ards $K$ are attached, and with which the rear ends of the parallel bars $H$ are connected, substantially as herein shown and described.

4.- The parallel rods $\mathrm{H} \mathrm{H} \mathrm{H}$, having pivotal hearings at each end, and pivoted to the compling blocks $G G G^{\prime}$ I I I', combined with the plough frame I and bar F, with side projecting studs $f^{3} f^{3} f^{2} j^{\prime} j^{\prime} j^{3}$, as and for the purpove specified.

5.- The combination, in a cultivator, of the ploughs 1 , a lateralty and vertically adjustable frame I, to which the pioughs are attachect, the uprigbt $F$, and the parallel rods having double-jointed complings at each end and connecting said frame $J$ and upright $F$, as and for the purpose specified.

6.- In a cultivator, the frame I, in combination with the parallel rods having double-jointed couplings at each end, and attached thereto, wbereby the frame may be adjusted vertically and laterally without changing its vertical position to that of an inclined one, substantially as shown and described.

7.- In a cultivator, the frame $J$. with stud pins $j^{\prime} j^{\prime}$ projecting from one side at the top and lottom of said frame, and also having a stad pin ${ }^{3}$, projecting from its opposite side midway between the ther two studs, combined $w$ ith the coupling blocks I I I', the parallel rods $H$ H $H^{\prime}$, the compling blocks $G G G^{\prime}$, and corresponding atud pins $f^{2} f^{3} y^{2}$ on the upright $F$, as and for the purpose specified.

8 . - In a cultivator, the combination of the upright $F$, having parallel rods II secured thereto by double hinge joints operating at right angles to each other, the notched plate $f$, and the crank connection $\mathrm{E}$, with notched plate i', substantially as shown and described.

9. - The compound crank arm eomposed of the crank I), with notched side plate, $d^{2}$, and the connecting rod $\mathrm{E}$, with notched side plates at each end, as at $e^{\prime} e^{3}$, combined with the bar F and axle B, as and for the purpose specified.
No, 222,576.-W'11.LI.IM (')1'PAGl, VH,W C'UUNTY, Ixil.-Plonghs.-Dicember 16, is79. Filed Seprember 29, 1879.

Claim.-A hectional plough beam or drag bar consisting of the forward part, $\perp$, having a handle rigidly attachec thereto, and the renr curved section, 13, hinged to allow free lateral movements of the plough, substantially as shown and described.

Nu, 222,710.-WIII.JAII S. MOON, PLFASANI

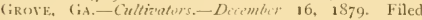
Siptember 26, 1879.

Claim.-1.-In a cultivator, the sulky composed of the arched axle $A$, wheels $B$, tongue $C$, bent bars $D$, L-shaped arms $F$, and braces $D^{\prime}, I^{2}$, and $F^{\prime}$, all constructed substantially as and for the purposes berein set forth.

2-In a cultivator, a plongh beam constructed substantially as described, and reversible, end for end, connected to the sulky and operated by means of a lever, and held rigidly in place by a pawl, substantially as set forth.

3.- The combination of the reversible plough beam $G$, with $V$-shaped foot $\mathrm{II}$ and plough 1 connected thereto, the links $d$, lever $J$, with gravitating $\operatorname{dog} h$, and the rack $K$, with two sets of notches, $x \cdot x^{\prime}$, at varying angles, substantially as and for the purposes herein set forth.

No. 222,767.-EDG.AR A. WRIfiHT, DAVFNPORT, lowa- Whed-Cultizators-Dicmber 16, 1879. Filed Sor'ember 12, 1879 .

Claim.-1.- In combination with a vertically-swinging beam or drag bor, a spring, substuntially an described and shown, arranged to urge the beam downward when in action and urge it upward when it is lifted aboye the operative position.

2.-In combination with a vertically-swinging beam or drag bar, a double acting automatic spring, substantially as described, serving the double purpose of holding the beam down to its work and of assisting to lift it when it is thrown out of action.

3.-In combination with a vertically-swinging beam or drag bar, a spring, substantially as shown, adapted to exert an automatic spring action upward or downward upon the beam, according to the position of the latter.

4.-In a cultivator, the combination of a frame, a vertically-swinging beam or drag bar attached thereto, and an automatic spring, substantially as described, connected with one of said members, and arranged to urge the beam downward while the latter is in an operative position, but not when it is raised above said position.

5.- In a cultivator, the combination of a frame, a vertically-moving beam or drag bar connected thereto, the pulley or equivalent bearing connected to one of said members, and the spring arm connected to the other member and provided with the portion $d$, bent as shown, and adapted to act against the pulley and hold the beam down in an operative position.

6.- In a cultivator, the combination of a main frame, a vertically-noving beam or drag bar connected therewith, and a spring, subutantially as described, unterposed between said parts and acting vertically upon the beam, said spring being constructed and arranged to pass a centre or dead point as the beam moves vertically, and in passing said point cease or change the direction of its action on the beam.

7.-The combination of the frame, the vertically-moving beam, and the vibrating spring having the portion as shown and described, adapted to urge the beam upward after the latter has risen above its operative position, but not urge it upward when it is in said operative position.

8 - The combination of the frame, the vertically-moving beam or drag bar, the roller or equivalent bearing connected to one of said nembers, and a vibrating spring, constructed substantially as described, adjustably secured to the other of said members, as shown, whereby the operative position of the beam and the action of the spring may be varied.

9.-The combination of the frame, the vertically-moving 


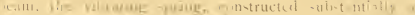

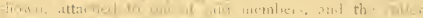

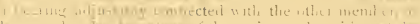

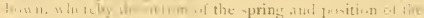
las :

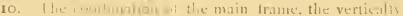

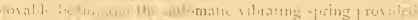

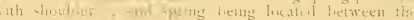

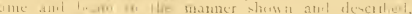

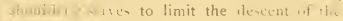

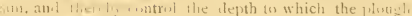
It ex eltst ti.e grumil.

II.- In of theted cuitus.tur, the comlination of an

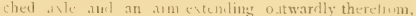
ind adipterl to comperate with and permis the linteral dit-ment of a yring iperating upon the beam, sulstanilly as ileseribeil.

12.-In a cultivator, the combination of a frame. a ertically-swincing beam, a libratms lifting spring or pring arm. aml a roller or equivalent hearing riting in the spring, said parts arransed, subtantially as deII I $^{1}$, >o thit the distance between the roller anl the vid end of the quing clectease as the heam rice

Ni. 222.910.-WII.LIA.II PEXDI.EY, LIIIILI.F, G

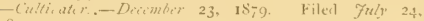
IS70.

Claim.-1. - The combination of the draw bar d, the untched cross bar $C$, provicled with the arms $e^{2} e^{3}$, and the ley $c^{\prime}$, the bent bars or heams $B$, slotted at their forwari mils, and one ut more pairs of hent lar or leams, D F:, liasung their rear ends bent inward, slutted, uxerlapped, . ad seaured by a bolt with each other, in form an adjusta. the frame woik for a cultivator, ulstantially as herein hown and described.

2.-The combination of the arjuntalile hangers or up rights $K$, the levers $\mathrm{M}$, and their adpuable hanger $\mathrm{X}$ : and the levers () with each other and with the wheels and axles $1 \mathrm{~J}$, the arms $: *$ of the cross bur C. and the frame 1) D E, sulatantwlly as herein shown and described.

3.- The jlough frame provided with hanger $K$, bifurcated at the lower ent and fitting on the axle. as shown and descrilied.

Xo. 223.755--JUSHUA PIERIONT. BeSHNFLI, II L., araignor to P'HRPoxT \& TV111F, same place-combinet Rilins and Halkin, Gallizats.-Fanmary 20, 1850. Filed -tusust 15, 1879 .

C'laim,-1.-In combination w ith the main frame A 13 B', haring the plow ths secured thereto by pendants $F$, forward of the axle, the axle C. comstructed vibstantiolly as descrileil, anil futurnaled on the har B, w that it may lie adjusted t. In the wheel. I forward or in rear of the har $B$, sub. mutially as shown and described, amil for the purpose jecitied.

2. - In eomlination with the main frame of a cultivator living the ploumbs secured thercto at their formard ends finwird of the aske by the independrntly-oscillating pen-

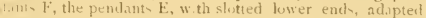
t." receive the ride part-. c'. of the axle, and to act as -tops in alju-ting the axle, substantiatly as and for the purpose specitic

3 - In combination 1 ith the main frame and oscillating axle and f lough- angs huged to ancillatin y pendant forward of the sxle, an ejualizins-bar pivoted beneath the axle and connecteil by link, with the plongh-beans, subat: ntially dencritict. and for the purpose -pecifierl.

4.- In comlin.tion with the main frame of a cultivator If ling the uncillating axle $C, s 0$ thit it mas be arljustud to 11. the whete in foumt ur rear of har 1 , by means of pen21ut- E, and povirled with plougho secured to the main fi me orsi, rd of the asle it their formard ench la mean

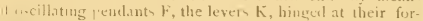
wanl enis to the main frame, and their rear ends connccted with the pluarsh loy chains or cority, for the purposes ypeeifierl.

5-In combination with the main frame having the axle foumal arljustable in front or rear of the pisotal line, and |w.silel with intersentently meillatimg pendant $\mathrm{F}$ forW.an! uf the ave, and to which the forwarl ends of the hingli gangs are attached, the equalizing-bar I, connected

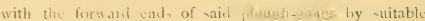

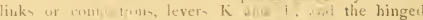

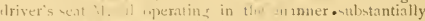
and for thi ungume- -pecitied

No. 22, 4 i,-BENI.MIIX M. ROUT, Mount Joy,

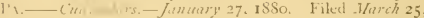
$1 \times 71$.

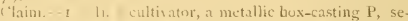
ancel to the +1.1 if the timbers $A$ A', sulustantially as -hown, ant h+ug twn upright $\rho^{\prime}$, which are provided with hol, wont fin $f^{\prime \prime}$, between which the pole M rests, and a pies, I leetween which and the box-casting $\mathrm{P}$ the double-tres 1 / liceil zad necuret lyy bolt $\rho^{6}$. in combination with the yon, if an I finthe-tree, all constructed as shown and reonrit, 1

2.-I In: a ting. I'. of the penliar shape shown and dencli,$t$, texing it upright $f$. and a projection $f^{3}$, cast

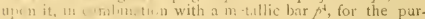

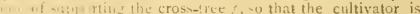
wit d la the $f^{\text {till }}$, hich rest- between the uprights $\beta$ and

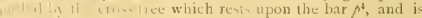
tung and sai $1.1 \%$, substautially in the and lew it purpone set forth.

Inu, lating $P$, consiructed as described, in w1 3 th the frame of a culivator carrying a num1at batilily as and fur the purpose specified.

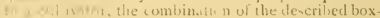

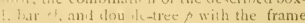
for l: wres the spates. -ubstantially as 116 i

-WII.LI.II W. BL.U) WETT and

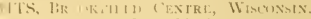

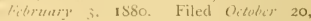

I. - - line combiration, with the wheels and

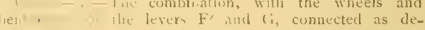
(c) 1

2. Whisaton in a culivitor, of the wheels, bent al. ... Whard II II, and levers $F^{\prime}$ and $G$, as set $6+1$ !

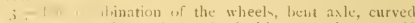
tath hets 1 , and locking mechamsm $h$ $\mathrm{K}$

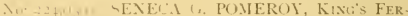

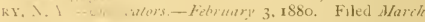
IJ. :

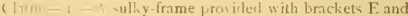
the silluic, the le-tree, combinet with the cultivator-beams F. 1 i. I : - 1 l bracket between the point of draught attachanch and the point of atlachment of the standard M.

2.- The sulky-frame and the cultivator beams $F$. pivoted thercto at a point between the draught attachment and the st.undirl attachment, as ret forth, combined wih the sliding donhl-tiee ahove the formard ends of satd beams and the connecting clinin or rod.

No. $224.074-C H A R L E S$ D. CARTER, ALIFGAN, Mren.-Cintizuters.-Fibnary 3, ISSo. Filed Derember 18. 1879 .

Clairn.-I.- The beams $d$, having the hooks f formed on their front end to catch under and . rumd the axle, in combination with the castings s, seched to the top of the beam and catching over the tof of the axle, sulistantially as shown.

2. - The combination of the axle $c$, rusl $s$, socket, $r$, levers v, and gangs, substantially as yecified.

3.- The combination of the lever $\%$ and adjustable boxes $u$, with the connecting rods at, sulutantially as shown.

4.- The combination of the lever $:$ loxes $z$, provided with the weights or lalls $x$, moving thereon, and ctonnecting rotk at, unbstantially as clescribed.

No. 224.111.-ELGENE SIASSON and El IIIN C.

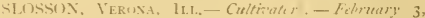
ISSo. Filed April 16, I879.

Clum. 1.-The Araught beams, in comlination with the diverging touth beam $-\vec{F}$, pivoted pusts $\mathrm{E}$. and the bracerods H, sulstantially as de-criber?.

2.- The coltivator iraught heam $\mathrm{N}$, in combination with 


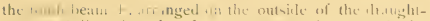
tream an b viscreing therefrom an $x$ evemis torwat, the t:oth-tream J, arranged diagonally actom the rear cut of the drau hit-tieam in a direction oppo-ite to that of the lream $\mathrm{F}$. and the tecth $1 \mathrm{~K}$, alciched to the beams $\mathrm{l} \mathrm{J}$, and arranged thereon substantially as dencribed and shown.
No. 225,304. INTONE STAUFFICIIER, JUDA,

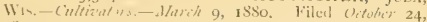
1879 .

Claim.-The ratchet r, having an extension, s, on its rear end to receive the pulley or roller 4 , substantially as iescribed.

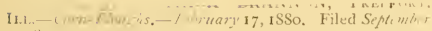
3. 1879 .

Claim.- 1 - The thaft $i$, jumaled in bearings in front of the driver's seat, lhe movable shaft $m$, separated from and connected with the shaft $i$ is its center by the shank of lever $n$ and it each end quadrant $l$, the lever $n$, and hook at, in combination with the connecting roils 1 , and plough leamI, substantrally as set fortli.

2.- The that $i$, journaled in bearings in front of the dtiver's seat in cumbination with the movable shaft $\mathrm{m}$, separated from and connetted with the shaft $i$ at its centre hy the shank of lever $n$ and at each end by the quutrants the lever $n$, hook $w$, rods In, plough-beinos I, and cuspended frame $\mathrm{N}$, substantially as specified.

No. 224,773.-JAUES FOIRBES, MruIR4, X. Y - Cultiators.Februm 24, 3580. Filed Dismler 26. is 79 .

Claim. - The triangular cultivator frame G G $(i$. carrying the ploughs $I$ I $K$ and gange cutter $N$, and provided with the sliding trinsver-e bar E, in combination with the sotted bare is and rotatinis transterse bar $\mathrm{F}$, attached to the frame $A$, aml having hand lever $b$ and curved arms or rods $i$ sub-tantially as and for the purpose specified.

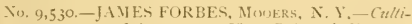

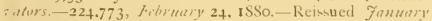
II, ISSI. Filed 7 utr 15, 1 SSo.

Claim.--1.-In cumbination with the slotted metallie

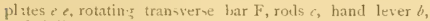
an: l sliding transverse har F, the triangular cultivator frame $G\left(i G^{\prime}\right.$, carrying the ploughis $I J K$ and gauge cutters $X$, the said frame being arranged, as shown and described, sn that its w'le enf travels in advance of its narrow end, a and for the purposes set forth.

2. - The triangular cultivator frame $\left(; \quad ;\left(i^{\prime}\right.\right.$. carrying the ploughs $1 \mathrm{j} \hat{K}$ and gange cutter $X$, and provided with the sliding transvere lar $\mathrm{E}$, in combination wilh the slotted bars $\mathrm{I}$ an'i rotating transverse bar $F$, atlached to the frame $A$, and hand lever $b$, and curved arms or rod $c$, substantially as and for the purpose specified.

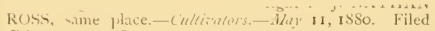
Fitrum 9, isSo.

Claim. - I, - In a com plongh, the draught bir or frame $\mathrm{C}$, loosely pivoted to the side frames, $\mathrm{B}$, by the horizontal pivots $c$, to a point to the rear of the wheel-spindles, and having the point of power attachment in front thereof, while the ploughs are attached to said bar or frame at an intermediate point, all substantially an whown and described, and for the purpose specifierl.

2.- In a corn plowing, the wheels A, frames B, arch D, hound $\mathrm{E}$, tongue $\mathrm{F}$, loosely-pivoted lars or frames $C$, and plough $G$, all arrangerl and operating in combination with each other. substantially as shown and specified.

3.-In combination with the side frames of a corn-plough loasely pivoted on the arch and having the draught bars or frames luosely piroted thereto, a tongue pivoted in the manner shown, said several parts being thus constricted to allow ench of them to occupy varying relations to the others, all substantially as shown and et forth.

No. 227,543-ORLANDO J. KING, ChARITOx, lowA. - Cultitrators.-Mher i1. ISSo. Filed lYarch 20, 1880.

Claim-1.-The combination of the straddling beam $A$ in a cultivator with the stanclard $B$, coupling plate $K$, and the long and short shovel beams, arrangerl as herein de-cr.bed, the said long beams being rigidly secured to the coupling plates, and the short beams being pivoted and comected with levers, substantially as herein shown and set forth.

2.- The combination of the straddling bar A in a cultivator with 2 series of fixed and adjustable beams, arranged to be raised or lowered lyy hand levers e and segment levers $a$, the coupling plates $\mathrm{K}$, holding the forward ends of the heams and piroted hetween the stand. ards $\mathrm{F}$, and shaft d, substantially as, herein shown and set forth.

Xก. 228,659.-(iEf)RGE .I. IIIRK., Fowler, PA.

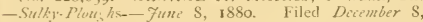
ISSO.

Claim,-In a wheel-cultivatur. the combination of the axle $\mathrm{C}$ and the two pairs of guide hangers $/ t h$ with the wheel spindles $\mathrm{H} \mathrm{H}$, the sliding bar I I, having notches 
4a.

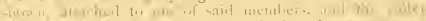

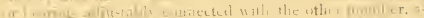

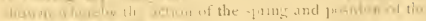

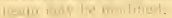

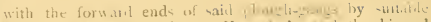

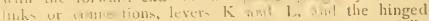

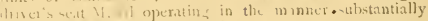

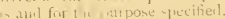

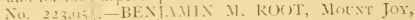
1.

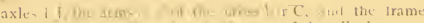

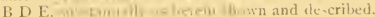

3.- -1 or flugh thase prisvil... with hanger $K$. bifur cated th the lums end and fitun; on the asle. as shown and dentit an.

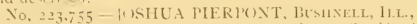

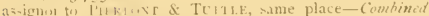

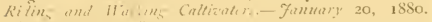
Filed lusut 15 . 15-1).

(la.m-1,-In combination with the main frame A B B'. liasing the plou he sccurel thereto by pendant $F$, forward if the le $^{-}$the axle (" cunstructed stbstantially as describcil. and juturnaled to the lar $B, 4$ that it may be adjusted

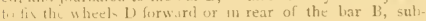
$-1, n t i a l l s$ as thown and describerl, and for the purpose - Int ificit.

- In cumbuntion with the main frame of a cultisntor

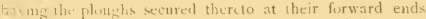
Fomard at the axk by the independently-oscillating pen-

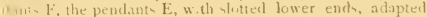
6. w e cive the side part- $c^{\prime}$, of the avle, and to stct as stops 1. . lin-tung the axle, substantially as and for the purpose

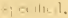

i- In comblination with the main frame and oscillating

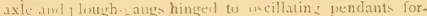
watd w the . Ne, an e palizing loar piroted lieneath the axle

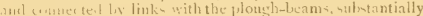

1 cleastivel, anil fiar the parpone ypecified.

4.- In cmanlin tuan with the nain frame of a cultivator

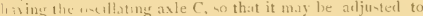
is the wicets 11 tiont or rear of har B, ly mean of pen1. int- F, and sompled with ploughs securerl to the main tr.me for a... of of the asle at their forwat ench by mean

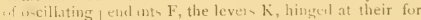
4 . If end to the man frame, amel their rear end- connected sith the ploughis lis chains or curcls. for the furposes speontieit

; - In combination 1 ith the main frame having the axle formil aljustable in front or rear of the pisotal line, and

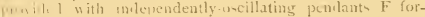
w. I , it the avle, and to which the forwaril ends of the

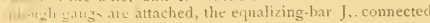

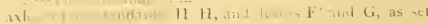
linit

3.-. In Shinatiun of the wheel. lacut asle. curved staibi, | thets 1, and locking mechausm $\mathrm{h}$ k'1:

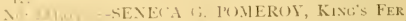

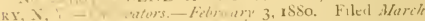
11. Is:

(1in - y - 1 -11ky-frame provileal with brackets $\mathrm{E}$ and the smo tree, comb ned with the cultivator-beams F. ju. 7 and bracket between the point of draught altachen +4 and the point of atachment of the standard MI

2. I he sulky-frame and the cultivator beams F, pivoted thereto a a point between the draught attachment and the standard attuchment, as set forth, combined with the slicling coulate-tee alove the forward ends of sard beam and the comnectinis chain or rod.

Vo 224.074 - CHARL.ES 1. CARTER, ALAEGAN, Mich. - Cultiviors.-Finumy 3, 1SSO. Filed Derember I8, 1879 .

Claim - 1. - The beams d. having the hooks $f$ formed on their front end to wath under and , romd the axle, in comlination with the castings 5 . seculed to the top of the beam ant catching over the tisi of the axle, sulistintially as shown.

2. The combination of the axle $c$ roul s, sockets $r$, levers $v$, and gangs, sub-tantially ar yecitied.

3. The combination of the lesers and adjustable boxes $u$, with the connecting rul $a$, -ulistantially a shown

4.-The combination of the lever $\pi$, boxes $u$, provided with the weights or halls . 1 , moving therens, and connecting rock as sulsatantially as describerl

Vo, 224.11 - EL(iENE $\$$ LOSG $) \mathrm{N}$ and EUTIN $C$.

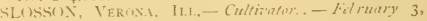
s S50, Filed toril 16, 1870.

Chim - 1. - The Araught heam, in coml ination with the diverging touth beam $\mathrm{F}$, pisuted pusts $\mathrm{E}$, and the bracerods $H, a$, antially as dercriliet.

2.- The cnltivator draught beam $\mathrm{D}$, in combination with 


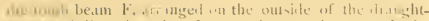
1enot and civerging therefrom as it extenels torward, the t:xoth-beam J, arrange I di.gonally acrose the rear end of the dranzht-heam in a lirection oppo-ite to that of the besm $\mathrm{l}$. anet the teeth $\mid K$, attached to the leams F J, and arranged thereon subtantially an described and shown.

No. 224,139-IIENRI R. BURI)GE, CARE GIR IRI EAt, IJo, : inignor to himself and CHARLES FILRTH,

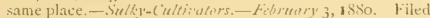
lirember 22, 1879 .

Claim.-1. The combination, with the axle $B$ and half keepers $\mathrm{F}$. of the bars $\mathrm{E}$, pivoted to the axle and adapted to connect with the single trees and the draw bars of the ploughs, as shown and described.

2.- The branclied draught-bar $\mathbb{K}$, piroted to the beam above the plough and connected by a slot with the devia.pin $\mathrm{N}$. in combination wi h the cultivator beams $\mathbf{L}$ and the clevis plate $\mathrm{II}$, a and for the purpose specitied.

3.-In a cultivator, the combunation, with the lraw bar $K$ of the plough heams an! the axle $B$ of the sulky, of the pivoted clranght bars $\mathrm{E}$, sulutantially as berein slown and clescribed, to keep the pluughs at a uniform rlepth when working upon uneven ground, as set forth.

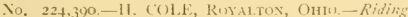
Alindim 'ni for Cultivators-Fibruary Io, 1880. Filed Derember 6, is79.

Claim.-1.-The combination of the bars A, provicleal with the $\mathrm{C}$-bolis $\mathrm{B}$, the crons-loas $\mathrm{C}$, and the cross bars $\mathrm{D}$, the caster-wheels E F, and the alliustable crombar $G$, that carries the driver's seat 11 , subtantially as herein blown and described, to allapt the desice to be attached to a cultivator as set forth.

2. - The combination, with the bars $\mathrm{A}$, the crosahearl $\mathrm{C}$, and the crous-liars 1), of the connecting har $\mathbf{K}$, sub-tantially as herein shown and described, so that the device may be used with a cultivator pruvided with a sulit tongue, as set forth.

No. 224.639.-P.ITRICK BRANNON, FREIFOKT,

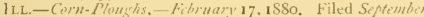
3. 1879 .

Claim. - 1 - The shaft $i$, joumaled in bearings in front of the driver's seat, the umovalile shaft $m$, separated from and connected with the shaft $i$ at its center by the shank of lever $n$ ant : $t$ ench end 'fuadrut $t$, the lever $n$, and hook $z$, in combination with the connecting-rods $L$, and plough beam. 1 , substantially as set forth.

2.- The shaft $i$. journalerl in bearings in fromt of the dtiver's seat in combination will the nuvable shaft $m$, separated from and connected with the shaft $i$ at its centre liy the shank of lever $n$ aml at each end by the quatrants the lever $u$, hook $" \prime$, rods 1 , plough-beams 1 , and 4 , pended frame $\mathrm{X}$, substantially as specified.

No. 224,773.-JAUES FOlRBES, MexiER, N. Y.Cullievtors, - Februt)! 24. 1S80. Filed Dizmler 26, I879.

Claim.-The triangular cultivator frame G G $\mathbf{C}^{\prime}$, carrying the ploughs $1 \mathrm{~J} \mathrm{~K}$ and gauge cutter $\mathrm{N}$, and provited with the sliding transvere lar $\mathrm{E}$, in combination with the slotted bars $\mathrm{D}$ and rotsting transverse har $\mathrm{F}$, attached to the frame $A$, and having hand lever $b$ and curved arms or rads $c$ subatantially as and for the purpose specifiecl.

Xo. 9,530-JA.MES FORBES, Moxers, X. Y.-Culti-

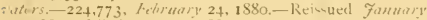
11, 1881. Filed $F_{u / y} 15,1880$

Claim.-1.-In cumbination with the slotted metallic plites e e, rotatin tranviere lar F, rods $c$, hand lever b, an'l sliding tran-verse lar $\mathrm{E}$, the triangular cultivator frame $G G G^{\prime}$, carryung the ploughs $I J K$ and gauge cutters $N$. the sid frame being arranged, as shown and described, st that its $w$ de ent travels on advance of its narrow end, an and for the purpores set forth.

2.- The triangular cultivator frame $G G G^{\prime}$, carrying the ploughs I I $\hat{K}$ and gauge cutter $X$. and provided with the sliding tronsvere lar $\mathrm{E}$, in combination will the slotted thars (D) ani rotating transverse bar $F$, attached to the frame A, and hand lever $b$, and curved arms or rod $c$, substantially as and for the purpose specified.
Xio. 225,304-1.TONE; STAL HFICIIER, II 1H,

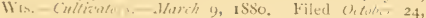
$1 \$ 79$.

Chim.-The ratchet $r$, having an extension, $s$, on its rear end to receive the pulley or roller t, substantially as dercribed.

No. 226,321.-DATI1) M. IOHNSTON, RED B1.UFF, CA1, - Cullientors-April 6, isSo. Filed lonember 21, 1879 .

Clim. - The cultivator $A$, composed of metal bars or sections $"$, having their forwart eluh, $c$, bent downward and forward to receive the blacien $/$, and their rear ends bent into elbow, as shown, and secured to each other by bolts $d d$ and tie pieces $t$, whereby there is formed a rigid frame, the teeth of which are thrown out of line, as set forth.

No. 226,674.-WILLIAM PENDLEI and ANDER S(I) IIOSS, TILKING Rixk. G., assigners of one-third of their right to J. E. STEPHENS, same place.-Whec\%

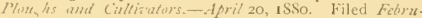
ari 4,1880 .

Clain.-The combination of the frame $f$ with the standards $s$, $\mathrm{C}$-shaped frame $\|$, hangers l, lever $o$, and rack $r$, ubstantially as described.

No. 226-833.-BYRON (: HKADLEY, CHICAGO, ILL. -Cultizators-April 27, 1880 . Filed Auszrst 4, 1879.

Claim.-1.-The combination of the spring $C$, attached to the axle, an descrabed, with the rocking head s, chain D, and heam $B$, whereby the attachment and operation of the spring in made independent of the frame or parts mounted on the elevated portion of the axle, substantially as specified.

2.- The combination of the bent rod or bar $k k^{\prime}$, brace $l$, arms $j j^{\prime}$, and rocking head $*$ with the hooked rod $n$, plite $m$, and spring $\varphi$, constructed and operating substantially as described.

No, 227,383.-JAMES 11. PEIRCE, Blountsille, 1 D., assisnor of one-half of his right to JUNATHAN KOSS, same place.-Cintizators._May 11,1580 . Filed Fibrunty 9 , 1 SSO.

Claim.-1.-In a corn plough, the draught bir or frame C, loosely pivoted to the side frames, B, by the horizontal pivots to a point to the rear of the wheel-spindles, and having the point of power attachment in front thereof, while the ploughs are attached $t$ ) said bar or frame at an intermeliate print, all substantially as thow $n$ and described, and for the purpose specified.

2,- In a corn plaunh, the wheets A, frames B, arch D, hounch $E$, tongue $F$, loosely-pivoted lars or frames $C$, and plough $(i$, all arranged and operating in combination with each other, substantially as shown and specified.

3.- In combination with the side frames of a corn-plough lowely pivoted on the arch and having the draught bars or frames loosely pivoted therelo, a tongue pivoted in the manner shown, said several parts being thus constructed to allow each of them to occupy varsing relations to the others, all substantially as shown and et forth.

No, 227,543-ORLANDO J. KING, CuARITON, Jowa

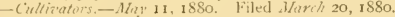

Claim.-1.-The comlinntion of the straddling beam A in a cultivator with the standard 1 , coupling plate $\mathrm{K}$, and the long and short shovel beams, arranged as herein described, the said long beams being rigidly secured to the curpling plates, and the shurt beams being pivoted and comnected with levers, substantially as herein shown and set furth.

2.- The combination of the straddling bar $A$ in a cultivator with a series of fixed and adjustable beams, arranged to be raised or lowered by land levers $c$ and segment levers $a$, the coupling plates $k$, holding the forward ends of the heams and piroted between the standarils $\mathrm{B}$, and shaft $d$, sulstantially as, herein shown and set forth.

No. 228,659 .-GEORRIE M. MIIRKK. FuWLER, PA. - Sulkp-Plourhs- Fun 8, 1 SSo. Filed December 8, 1880 .

Claim.-In a wheel-cultivator, the combination of the axle $C^{\prime}$ and the two pairs of guide hangers $h / h$ with the wheel spindles $\mathrm{H} \mathrm{H}$, the sliding bars $1 \mathrm{l}$, having notches 
F, the lever $\mathrm{K} K$, Jrasing through the bian I, the pawls , $i$, and the frame A 5 , substantially as shown and described.

No. 229,534-JOHX W. IILDSON, WEILINGTOx,

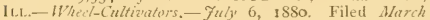
10. ISSO.

Claim.-1.-The sleeve D, cut away for the passage of spring $G$, the latter attached to har $d$ and coiled around and secured to axle A and arm F, constructed and arranged as shown and rencribed.

2.-The combination of the yoke $J$, pronged and serrated plate $\mathrm{L}$, arijustable plough beams $\mathrm{K}$, rud $i$, and collar M, substantially as and for the purposes herein set f.rth.

3.- In combination with two sets of plough beams, the shares $R$ and connecting spring $t$, as and fur the purposes herein set forth.

No. 230,057.-JOHN H. RHA.IV, ANT100H, IND.-

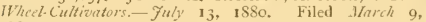
1880.

Claim.-I_- In a wheel-cultivator, the central arch, A. and half arches $B$, in combination with the wheels $D$, connected to the half archs B lyy hine arms $\mathrm{C}$, and the curved plough heams connected to the arch $\mathrm{A}$ by hinge boxes $\mathrm{E}$ and half hinge joints $\mathrm{F}$, substantially as and for purposes set forth.

2.- In a wheel-cultivator, the plough beams hinged to the arch $A$, as shown and described, in combination with the chains $\mathrm{X}$, arch $\mathrm{M}$, and weight $\mathrm{P}$ thereon, substantially as and for the purposes set forth.

3.-In a wheel-cultivator, the plungh heams hinged to the central arch, $A$, by boxes $E$ and joints $F$, as described, in combination with the chains $\mathrm{N}$, weight $\mathrm{P}$, and lever $\mathrm{T}$, substantially as and for the purpose set forth.

4.-In a wheel-cultivator, the double tongue () Q, pivotel or hinged to the arch $\mathrm{A}$, as shown, in combination with the hinged adjustable neck yokes $\mathrm{R} R$ and the front arch, S, substantially as and for the purposes set forth.

No. 9,511-JOHN H. RHAHV, A.TIC:H, JND.Wheel-Culfitutors,-230,057, July I3, I880.-Reissued Dicember 2I, I880. Filed Norimber 6, I880.

Claim.-1.-In a wheel-culivator, the eentral arch, A, and half arches B, in combination with the wheels I), connected to the half arches $B$ by hinge arms $C$, and the curved plough beams connected to the arch $A$ by hinge boxes $\mathrm{E}$ and half-hinge joints $\mathrm{F}$, substantially as and for the purposes set forth.

2.- In a wheel-cultivator, the plough beams hinged to the arch $\mathrm{A}$, an shown and described, in combination with the chains $\mathrm{N}$, arch $\mathrm{M}$, and weight $\mathrm{P}$ thereon, ub-tantially as and for the purposes set forth.

3.- In a wheel-cultivatur the plough beams hinged to the ceniral arch, $A$, by loxes $E$ and joint $F$, as described. in combination with the chains $\mathrm{V}$, weight $\mathrm{P}$, and lever $\mathrm{T}$, substintially as and for the parposes set forth.

4.-In a wheel-cultivator, the double tongue $Q Q$, pivoted or binged to the arch $\mathrm{A}$, as shown, in combination with the hinged adjustable neck yokes $R \mathrm{R}$, ring $\mathrm{V}$, and the front arch, $S$. substantially as and for the purposes set forth.

5.- In a wheel-cultivator, the plough beams hinged to the central arch. A, in comlination with chains F, weight: $\mathrm{P}$, and pulleys $\mathrm{O}$.

6.- In a wheel-cultuvator, the combination of chain $\mathrm{H}$ with pulleys 1 , connected to clevises $\mathrm{X}$, pulleys $\mathrm{I}$, secured to head thocks $W$, pulleys $K$, secured to top end of halfarches $\mathbf{B}$, an 1 pulleys $\mathbf{L}$ at the top of central arch, $\mathrm{A}$.

7.-In a wheel-cultivator, the combination of hinged plough beams, the laalf-arches for supporting the wheel arms, and the draurht-attachment clevises, with a washer between the clevis and the head blocks, whereby the height of the beam may be varied.

No. 230,414 - - TAMES B. GRACEY, RICHMOND, VA - Agriculural tmplements.- $7 u l v 27$, isSo. Filed $D$ i cimber 31, 1879.

Claim.-1. - The slotted bars B B, with plates $a$, in combination with bar $\mathrm{T}$, connected to both front and rear of beams $Q$ by toggle-joints $U$, and operated by lever $V$ whereluy both of saul leams, throughout their length, can be moved to and fro in opposite lateral directions, for the purpose set forth.

2.- The combination of beams $Q$, toggle joints or arms $\mathrm{U}$, perforated sliding bar $\mathrm{T}$, bar $\mathrm{W}$, lever $\mathrm{V}$, and pin $\mathrm{Y}$, all as described.

3.-The mould-hoard, share, and landside, maile in one piece, and combined with standard $O$, provided with arm P, which extends along the landside to strengthen the same, and projects beyond the share, so that a socketed point $\mathrm{H}^{\prime}$, may be fitted thereto, substantially as set forth.

4.-The longitudinal bur $T$, provided with slotted plate $f$, in combination with beams $Q$, provided with plate $d$, perforated arm $\mathrm{L}$, and pins $e$, substantially as and for the purposes set forth.

5.- The perforated arm $\mathrm{U}$, and pins $c$, in combination with longitudinal bar $\mathrm{T}$ and plate $f$, stabstantially as set forth.

No: $231,846$. EZEKIEL D. POWELL, VATES TownSH1P, MCLFAx CotNTy, J1.L.-Cultizators-Ausust 31, ISSo Filed Itay 21, ISSo.

Claim.-1.- In a wheel or straddle-row cultivator, the combination of the two sections of pivoted plough-beams D D, of diff rent lengths, the hortest beam- having angular shares facing outward or in opposite directions, and the ntermediate and longest beams having angular shares facing inward or toward each other, all constructed and relatively arranred to operite substantially as and for the purpose herein shown anil described.

2.- In a corn plough or cultivator, the combination, with pivoted plongh beams and their handles, of the adjustable connecting brace $\mathbf{G}$, having pulley $H$, and the guide and stay chain I, passing over sail pulley and connecred to the beam., subutantially as and for the purpose herein shown and described.

No. 232,871 - IOHN II. BAILEY, ST. Locts, Ho., a-signor to DEERE, MINSUR \& $\mathrm{CO}_{\text {., same place. }}$

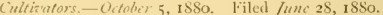

Claim.-The combination of the curved scraper $A$, having the shape shown and describel, with the block $\mathrm{B}$, attached so as to swivel on the boss $c$, and baving the straight slot $e^{2}$ and curved - lot f, receiving. re pectively, the crew holts $i$ and $d$, which control and fix the relative positions of the scraper and block, all sulustanitaily as and for the purpose specinerl.

No. 233,379.-SPENCER R. STANTON, OXFORD, Mich.-Cultiontors.-Octobir 19, rSSo. Filed December 4. 1879.

Claim.-1.-The combination, with the frou frame bar, $A$, and the standards of a cultivator, of the brace rods i, clips $d$, havint two or more hole, for adjunting said rods, the sile braces $f$, and movable clips $e$, sulsitantially as and for the purposes herein set forth.

2.-The flanged casting $R$, having slot $r$, laterally adjustalle, as lescribed, in combination with the vertically-adju-table handle $\mathrm{P}$, as and for the purposes set forth.

No. 233.931 - JA.YIES H. JONES, RorkFORD, 1LL,Combinid Culfituters and Secders. - lizmber 2, IS80. Filed tpril 15, 1880 .

Claim. - I - The combination, with a main frame and a drag bar, of a bracing penclant pivoted to said main frame. to have lateral adjustment in a horizontal plane, said pendant maintaining a constant angle relative to the main frame during said adjustment, substantially as set forth.

2 - The combination, with a drag bar, of a bracing pendant secured to a bracket, which latter bas one portion vertically pivoted to the main frame and another portion adapted to be connected to different horizontal points of sail frame, substantially as set forth.

3.- The combination, with a drag bar, of a bracing pendant secured to a bracket, having it rear portion pivoted to the main frame, and it forward portion provided witlı a curve slot, in which latter fits a bolt adjustably connect. ing the bracket to said main frame, substantially as set forth.

4.- The combination, with a shovel standard, a slip bracket, and a bolt fastening the latter to the outer side of a drag bar, of a handle fitted between the inner side of 
the dray bar wo so ilump, the latter being secured to the drag bar by the - ate bolt which passe's through an itrm of the slip bracket, sulmtantially as set forth.

5. The combination, with a shovel stanclart, a wip bracket having two arms, and bolts fastening the latter to a drag har, of a handle fitted between the etrag har and a clamp, said clamp being secured to the drag bar loy the same bolt which passes through one of said slip arma, the bolt of the other slip arm passing through the handle iinelf, substantially as set forth.

6.- The herein described slip brackets to upport the shovel standards, having their slip arms provided with a recess to receive a pivot waher, substantially as hereinbefore set forth.

7.- The combination, with a shosel stanclard and a whip bracket, of a pivotal washer fittel to the recessed slip arm. substantially as set forth

8. - The combuntion, with an oblong socket secured to a drag bar and having its sides provided with arched grooves, of a bracing pendant having lateral projections which fit in said arched grooves, substantially as set forth.

9.- The combination, with a transwerse ruller extending between the two side clrau bars, wf a slip bracket centrally secured to said roller, and a shovel standard secured in vertical adjustment to the bracket, sub-tantially as set forth.

10.- The combination, with the slip bracket carrying a shovel standard, with shovel thercto attacherl and fixed to the transverse roller, of a lever handle pivoted to the slip bracket and held in position thereto by a salety sli bolt connettion, substantially as and for the purpose hereinbefore set forth.

11.- The herein dencribed centre shovel, consisting of a slip brachet fixed to a transverse roller, a shovel standard, with a shovel fixed thereto, supported in the bracket and made vertically adjustahle thercon, and a lever handle piroted to the slip bracket and held in position thereto by a safety slip bolt connection, substantially as and for the purpose hereinbetore set forth.

12. - The combination, with the drag bars, of the hereindescribed centre shovel having the journal ends of its transvetse roller supported in journal-bearing bracket fixed to the drag bars, substantially as and for the purpose hereinbefore set forth:

13.-The lifting and supporting levers, in combination with their forked fulcrum suppo:ts, the levers hinged thereto by a free staple joint connection, substantially as and for the purpose hereinbefore set forth.

14.- The combination, with a lever fulcrumed on the main frame and a hook depending therefrom and adapted to embrace a tongue beam, of a drag bar and intermediate connection of the latter with the hook, said drag bar being restricted in its lateral swinging movement when raisted by said look engaging with the longue beam, substantially as set forth.

15.-The combination, with a lever fulcrumed on the main frame, a hook adapted to embrace a tongue beam, and intermediate connection between the hook axd dritg bar, of an upright secured to the tongue beam and provided with a longitudinal series of lateral nutches, which provide engagement for the forward extremity of the lever, substantially as set fo:th.

16.- The combination, with lever, fulerumed on the main frame, hooks which embrace the tongue beans, and connections between the houks and drag bar, of upright rack bars secured to the tongue beams and en jaged by the forward arms of the levers, and a spring which connects the rear arms of the levers, substantially as set forth.

17.- The combination, with a seat heam and a vertical arm having a slotted trotly provided with a lateral stucl, of a bolt which secures the arm in vertical adjustment to the drag bar without 1.as-ing thrumgh the seat beam, said arm having its upper extrenity provided with a horizontal flange which provider constant bearing for the edge of the beam, the lateral stud fitting in the side body of said beam, substantially as set forth.

18.-The combination, with a seed hopper having its opposite extremities respectively provited with dischargeopenings, of two independent spouts extending from said openings laterally outward in opposite inclination, sulstantially as set forth.

19.- The herein descrilsed conic scatterers, in combina(ion with the seed conducting spouts made laterally adjustable thereon, sulistantially as and for the purpose hereinbefore set forth.

No. 234.046.-JACOB MANG.AS, LincolN, 1I.L.Sulky-Plumshs.-Nonitmler 2, ISto. Filed August 20, issio.

Clam.-In combination with the sulky-frame A, the castmetal sections $\mathrm{K}$, adjustably secured to the hangers $\mathrm{B}$, the hinged consecting-plates $\mathrm{H}$, secured to the said adjustable sections and perforated to allow lateral adjustment of the plough-beams, the said beams and cross-bar $G$ being slotted, as shown, to pernit adjustability of the side beams and secure said side heams to the central bifurcated beam, all constructed and adapted to operate substantially as and for the purposes specified.

No. 234,973.-LEONARD G. FATH, Hil.tsBorovgir, 11.1._-Ciltisators. - Nor'mber 30, 1880 . Filed Siptem$4 i * 6,1880$.

Claim.-1.-In combination with the uprights of the frame of the cultivator, the sliding blocns mounted thereon and provided with spindles for the wheels, and the levers pivoted thereto, provided with friction-rollers working under segments secuted to the sides of the frame, substantially as specified.

2.-In combination with the frame of a cultivator, the bail for supporting the plough-bean, the said bail being loosely secured in swivel-blocks journaled in bearings in the uprights of the frame, and the lever for operating the said bail, wherehy a longitudinal as well as oscillating movement may be given to the bail, stbutantwally as and for the purposes specified.

No. 235,012,-JNo. T. PAYNE, White STUNe, VA.-

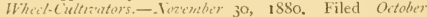
11,1880 .

Claim.-I.-The combination of a frame A, supported upon wheels, the beams 1 , united together by means of perforated plates and secured to the frame by means of the notched bar which extends along under the front edge of the frame, and provided with a suitable elevating device, whereby the beams can be raised above and lowered to the ground, substantially as shown.

2.- The combination of the frame $A$, the notched bars II $\mathrm{U}$, beams I, secured together by the plates $\mathrm{L}$, and provided with the clevises $J$ and supporting devices $V$, an elevating mechanism for raising and lowering the ploughs, and a mechanism for moving them back and forth on the frame, substantially as described.

No. 235,393.-JOHN WV. SWICKARD, GALYA, IL1.., assignor to TIIONAS BROWNLEE, same place.-Cultirators.-Decimber 14, 1880. Filed Fibruary 25, is8o.

Claim,-1- - In a cultivator, an axle or frame having a central part hinged to side parts, so that the side parts may be oscillated without inclining the central part forward or backward, in combination with wheels which support the axle or frame, and to which it-side parts are journaled, so that they may be uscillated, and plough-gangs attached at their front ends to the side parts of the axle or frame, so thit the weight of its central part counter-balances the weight of the plough-beams and assists in rassing their rear ends whle permiting the plough-gangs to have free lateral movement, substantialiy as and for the purpose specified.

2.- The combination, with a cultivator axle or frame having a central pant hinged to side parts, so that the side parts may be oscillated without inclining the central part forward ir hackward, of wheek which support the axleframe, ancl to which is side parts are journuled, so as to permit of oscillating them, and of plough-gangs hinged at their forward ends to said side parts of the axle, so as to permit of lateral movement of the plough-gangs, and otherwise attached thereto so that the central pait o the axle will act as a counter-halance to the plough-gangs, and assist in raising them from the ground, substantially as and for the purpose specified.

3.- In combination with a hinged axle haviug oscillating 
ide parts, substantially as described, journaled to the sup. porting-wheels, and adapted to raise the rear ends of the pluugh gang, which are hinged or connected therewith, substantially as described, the tongue $H$, secured to the central part of the axle and adapted to hold it in upright position, substantially an and for the purpose specified

4.-The combination, with the a.le having oscillating side part journaled to the supporting-wheels, and a cen tral part which acts as a counterpoise to the weight of the plough-gangs, of drait-plates attached to said oscillating side parts of the axle, having series of vertical holes, whereby the draft of the tean may be wilized in forcing the ploughs into the soil, substantially as and for the purpose described.

No. 235,452.-WILLIAM PENDIEY and ANDERSON MUSS, LUDVille, GA.-Whe't-Cultivators.-Dicember I4, I8So. Filed September $1_{3}, 1850$.

Claim.-1.-The combination of the beams $\mathrm{P}$, having their ends turned vertically upward, with the blocks $\mathrm{H} \mathrm{I}$ and operating lever whereby the blocks are tumed upon the axle, substantially as described.

2.-The combin.tion of the block $\mathrm{H}$, placed upon the axle, and having operating levers attached to them, with the blocks L, passed over the ends of the blocks II and made laterally arljustable, substantially as set forth.

No. 235,593-JOHN VAN BUREN, HONEOYE, N. Y. -Whech-Cultizators.-Detember 14, ISSo. Filed August 18, 18 So.

Claim.- In a wheel-cultivator, the combination, with the oblique side bar, C, of the obliquely-grooved side iron, $\mathrm{D}$, engaging the outer edge of said side har, and having the broad cheek flinge $f$ extending parallel with the wheel, spindle $m$, and supporting flange $l$, extending under said side bar and bolted thereto, substantially as specified.

No. 235,692.-JOHN T. MCNORTON, FLORENCE, Texas.-Plough-Carritges.-Dicember 21, 1880 . Filed May $31,1880$.

Claim.-1.- the combin.tion, in a plough-carriage, of the bifurcated arms B, adjustably secured at their upper ends to the ander side of the cross beams A, with capability of movement therealing, hy screw bolts, their lower ends being secured to the wheel axles, as described, and the adjustable braces $a$, substantially a, set forth.

2.-The combination, in a plough-carriage, of the keepers $\mathrm{D}$, having outwardly turned upper ents, and means for securing the vertical, transverse, and lotlgitudinal adjustment of said keepers, consisting of screw eyebolts $\mathbf{I}$ and nuts 2 , securing sajd kecpers to the under side of the cross beams, uprights $c$, bolts 3 , securms said keepers and uprights together, screw threaded rods $i$, bracing the keepers and secured to the rear cruss beam, and yokes $f$, substantially as set forth.

No. 236,243.-CHARLES NIEDERAUER, LA GRANGE, lexis, assignor to himself and HENRY STUDENANN, same place.-Cultizators.-January 4, 1851. Filed June 26, 1850 .

Claim,-I. - The combination, with the hinged plough $a b c$, of the adjustable frame $d$, the adjustable segments $f$, the blocks $\xi$, having slots $i$, the foried lever $h$, the rod $k$, having bearings in the frame, the lever, $h$, connecting, by rods $m$, with said blocks, and the h ndles, having pawl and ratchet, substantially as shown and clescriled.

2. - The combination, with a plough stundard hinged to frame $d$, of the slotted pivoted block $g$, and the segment $f$, adjustably connected therewith, as and for the purpose specified.

No. 236,341.-FLAVIUS J. LAMPTON, HAMMONvit.Le, Kr.-Whet-Cultizalors.-Fanuary 4, iSSi. Filed October $28, \mathbf{1} 880$.

Claim.-1-The combination of the frame $A$, having the holes $\mathrm{H}$, with the $\mathrm{U}$-shapet adjustable frame $\mathrm{I}$ and wheel $\mathrm{D}$, having a shank which projects up through the frames A I, subitantially as shown.

2. - In a wheeled cultivator, the combination of the frame $A$, having the holes $H$, the vertically-adjustable $\mathrm{U}$-shaped frame I, ant wheel D, having a shank which passes up through both frames, with the boxes $F$, provided with the levers $\mathrm{O}$, connecting rod $\mathrm{P}$, levers $\mathrm{R}$, cords or chains $Q$, and the plough beans, substantially as deserilsed.

No. 237,179.-CHRISTOPHER GRATTAN, STOCKTuN, CAL.-Ploughls.-Fibruary I, ISSI. Filed lovembe $\%, 1880$.

Claim.-1.-A gang-plough consisting of the diverging plough frames or beams $A$, with the opposing series of right and left ploughs secured to the two beams, respectively, said frame being jointed or linged at D, in combination with the three pars of wheels $\mathrm{F}, \mathrm{P}$, and $\mathrm{S}$, whereby the front, centre, and rear of the machine are supported independently, substantially as herein clescribed.

2.- The diverging-jointed plough frame $a b$, with its oppositely-placed ploughis and the three pairs of wheels F P S , in combination with the levers I R T, with their retzining racks, whereby the front, centre, and rear of the plough irame may be elevated or depressed, substantially as herein described.

3.-The $\mathrm{V}$-shaped plough frame $a b$, jointed at $\mathrm{D}$, and having its forward portion supported upon the two pairs of wheels F P, and the rear portion provided with the wheels $\mathrm{S}$, in combination with the lever $\mathrm{T}$ and rack $\mathrm{K}$, whereby the rear portion of the frame $b$, with its wheels $\mathbf{S}$, may be elevated from the gruund, substantially as and for the purpose herein described.

No. 237.739.-CHARLES O. GARDINER, SPRINGFIELD, OHIO, assignor to P. P. MAST \& Co., same place. -Cultizators._lebrutury 15, 1881. Filed July 7, 1880.

Claim.-1.-In combination with the wheeled frame and the vertically-swinging beam or drag-bar jointed thereto, the upright arm connected rigidly with the be $m$, the lever jointed at its lower end to the arm and bearing at its upper end loovely against a fixed roll or bearing on the frame, and a spring-connection, sulstantially such as shown, uniting the arm and the lever with each other and tending to throw the beam upward.

2.- In combination with the wheeled-frame and the swinging beam jointed thereto, a rigid arm connected with the beam, a lever pivoted at one end to said arm and resting at its free end against a bearing on the frame, and a spring-connection, substantially such as shown, uniting the arm and the lever, and adjustable to and from their point of connection, substantially as described.

3.- The combination of the frame, the beam having the arm connected rigidly therewith, the lever jointed to the arul and having the shoulder or incline rear one end, the spring connecting the arm and lever, and the roller or bearing on the frame.

4.-In cumbination with the lever $G$, as dereribed and shown, the arm $F$, provicled with the series of notehes, the spring, and the adju-table spring-bearin.

5.- In combination with a wheeled frame and a beam or dras-bar connected thereto, a lifting spring, and an arm provided with an incline or shoulder and adapted to be actunted by the spring, and to sustain the beam in an elevated porition by means of said shoulder, substantially as deccribed and shown.

No. 237,740-CHIARLESO. GARDINER and WILLIAI ( DOWNEY, SPRINiFIELI, OHW, assignors to P. P. MAST \& CO., same place.-Cultivators.-February 15, 1881. Filed fune 28, 1880 .

Claiu.-1.- The cultivator coupling having the rigid arm, with its upper end provided with the series of holes disposed in different vertical and horizontal planes, as described and shown.

2.- The combination of the frame, the heam-coupling having the upright arm formed rigidly thereon, the spiral compresion-spring. and the sliding and swinging rod, havins one end seated lo sely in the frume, and the other end pivoted to the upper end of the coupling-arm by an adjustable pivot, which permits the rod to be moved forward and lackward in relation to the arm.

3.- The combination of the frame, the compling baving the rigid upright arm thereon, the rod and the spring, the spring being arjustable in tenison, and the rod adjustable forward and hackward at its point of connection with the arm, substantially as deseribed.

4. - In combination with the axle, the draft-frame, and the beam operating rod, the Aanged plate $F$, constructed as 
described and shown, with the lip or flange, whereby it is adapted to serve the double purpose of uniting the frame and axle and of holding the rod and it spring.

5. - The combination of the parts $l " c$, the connecting pivot, and the screw $i$, applied to hold the prot, at shown.

No. 238,989 .-L.AFA I ETTE K. TII'TON. MAYSVH.1.1, Mo.-Cultizators. - Warch 15, ISS1. Filed Wirember 29, 18 so.

Claim.-1.-In a cultivator, the combination, with the uprights $\mathrm{D}$ of the carriage-frame and the couplings $S \mathrm{~T} V$ $\mathrm{X} Y$ attached to the plough-beam, of the frame $\mathrm{I}$, having longitudimal slots in its side bars, and the fastening bolts $Q$, substantially as herein shown and described, whereby the forward ends of the plough-beams can be raised and lowered, as set forth.

2.-In a cultivator, the combination, with the adjustable frame $\mathrm{P}$, attached to the uprights D of the carriage-frame, and having lugs $\mathrm{R}$ upon its side bars, and the plough beams $\mathrm{W}$, of the hinging rod or bolt $\mathrm{S}$, the hinged plate $\mathrm{T}$, having perforated cross-hend upon its rear end, the plate $V$, having pin $\mathrm{U}$, the guard plate $\mathrm{I}$, and the fastening bolt $\mathrm{X}$. sul). stantially as herein shown and described, whereb; the plough beams can have a free vertical and lateral movement as set forth.

3.- In a cultivator, the combination, with the axle $\mathrm{B}$ and uprights $\mathrm{D}$ of the carriage - rame and the draft rods $\mathbf{K}$, of a series of hooks L, substantially as herein shown and described, whereby the point of draft attachment can be axl. justed in line with the centre of resistance, as set forth.

No. 24c,571.- JONAS L. BACHMAN, STONY Rl'N, PA.-Cultivators.-April 26, 1881 . Filed December 7, 1850 .

Claim.-I.-A cultivator axle-tree $\mathrm{B}$, having a horizontal right angle bend forward of and next to the wheels, a second bend, also at right angles, and horizontal, to form the bearings for the plough couplings $E$, with vertical right angle bends from said bearings, terminating with final right angle bends at the desired height under the top frame, and provided with bearings $C C$ for the sub-axle $D$, the axletree being continuous thronghout, and the bending similar from both sides, as shown, and for the purpose substantially as described.

2.-The sub-axle D, provided with the double opposite cranks, $\mathrm{D}^{\prime} \mathrm{D}^{\prime}$, and slotted arm $\mathrm{D}^{\prime \prime}$, in combination with the axle tree $\mathrm{B}$ by the bearings $\mathrm{C}$, with the plough-beams $F$ by the connecting rods $d d$, and with the hand lever $D^{\prime \prime \prime}$ by a pin and sliding block working in the slot of the arm $\mathrm{D}^{\prime \prime}$, constructed and arranged for the purpose shown and specified.

3.-The axle B, frame II N, rock-shaft J, arms $K$, lever $\mathrm{L}$, plow-beams $\mathrm{F}$, rods $d$, and sub-axle $\mathrm{D}$, substantially as shown and described.

4-The coupling $\mathbf{E}$, having laterally-bifurcated head, and the bearing boxes $E^{\prime \prime} E^{\prime \prime \prime}$ at front and rear of axle, the back of box E"'l and the wall of the bifurcated head being struck with a radius from the bolt Eiv, in combination with axle $\mathrm{B}$ and plow-beams $\mathrm{F}$, substantially as shown and described.

5.- The hand lever $\mathrm{D}^{\prime \prime \prime}$, having its fulcrum on the axle tree $\mathrm{B}$, in combination with the sub-axle $\mathrm{D}$, the slidin: block working in the arm $D^{\prime \prime}$, and with the quadrant Dr on the top frame, substantially as shown, and for the purpose specified.

6.-The pulverizing double-tined harrows $\mathrm{P}$, constructed and adapted to be used in combination with the shovels H', as specified, and substantially as shown.

No. 241,319.-NELSON DULANEY, LYNNYILLE, ILL.-Sulky-Cultivators.-May 10, I881. Fileu Junuary 5, I88I.

Claim.-I.-In a sulky-cultivator, the combination, with the main frame $F$, of the pivoted seat frame $C D$, the bars $\mathrm{M}$, having stops $\mathrm{N}$, and the adjustable slotted bars $\mathrm{O}$, bent to form stops $\mathrm{P}$, as shown and described.

2.-The standards $\mathbf{W}$, supporting ploughs at their lower ends, connected at the top with hand lever pivoted between the standard connections, and immediately attached to a rocking beam $\mathrm{X}$, to provide means of throwing the plough points toward or from each other, as de. scribed.
No. 241,657 -CIINTUN MLNIJENIIILI., MAR

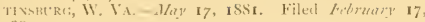
IS8I.

Claim.-In a cultivator, the wheeled frame $\mathrm{A}$, having lugs $a^{3}$ and parallel inclines $\eta^{4}$ at it forward end, in combi. nation with cross rod $a^{2}$, levers $c^{2}, t^{\prime}, c^{2}, e^{3}$, and $c^{\prime}$, shafts $a^{\prime}$, foot pieces $b$, and ploughs $c$, substantially as shown and described.

No, 242,134.-JAMES JOH.ANESON, BELOIT, WIS. Sullir-Cultivitars-May 31, 1881. Filed March 9, 1881 .

Claim.-The standard E, with ball joint thereon, as shown, the device $\mathrm{D}$ and vertical lever $\mathrm{k}$. with ball joint, as shown, the sicle lever, $x$, couplins chain $x^{2}$, the foot lever $g$, and hand lever L, whereby the culivators are manipulated by the hands or feet of the operator from his seat upon the machine, substantially as and for the purprose herein particularly described and shown.

No. 242,478 , -RICHARI) B. R()BBINS, AIRIAN, Micri-Cultivaters.-Gune 7, ISS1. Filed March 29, 1880

Claim,-1.-The lever $R$ ant chain 5 , in combination with beam $\mathrm{T}$, lever $\mathrm{L}$, rack $\mathrm{l}$, and roller $h$, substantially as set forth.

2.- The foot lever $W$, in combination with leser $L$, rack $P$, and lucking bolt $U$, as described.

3.- The lever L, provided with sliding rod U, and operating spring, in combination with rack $l$, lever $V$, and fool lever $I W$, the severai parts operating as described.

4.- The reversible shovel (', constructed with one end wider than the other, and provided with sleeve $5^{\prime}$, slotted as described, for the purposes set forth.

5.- The standard $Z$, in combination with sleeve $A$ ', provided with lug $\%$, and a shovel or tooth provided with sleeve $1 \mathbf{b}^{\prime}$, slotted as described, for the purpose set forth,

6.- The standard iron $\mathrm{Y}$, constructed as described and sesured to the bottom and the side of the rail, in combination with the plough standari, substantially as described.

7.-The combination of a cultivator heam, standard iron $\bar{Y}$, constructed and secured to the beam as described, and the standard $Z$, slotted and beveled along the slot and secured to said iron, as described, for the purpose set forth.

8.-The sleeve 1', provided with one or more slots at both top and bottom, in combination with a dutuble pointed shovel, for the purpuses set forth.

9. - The sleere A, provided with lug $\%$, in combination with the standard $Z$ and slceve $B$, slotted at one or both ends, substantially as described.

NO. 242,497.-EDGAR A. WRIGHT, DAVENPORT, Iow: - Cultitaturs.-Junt 7, I881. Filed, 1/ay 23, 1879 .

Claim.-1.-In a cultivator, the combination of a vertically swinging drag bar or beam nnd a litting spring which act with increasing force or effect on the beam as the latter rises, and vice versa.

2.-In a wheeled cultivator, the combination of a vertically moving beam and a lifting spring, substantially as decribed, wherehy an increasing upward strain in communi. cated to the beam as the latter rises.

3.- The combination of a wheeled frame, a vertically moving beam or drag har attached thereto, and a lifting spring, substantually as described, which exerts a greater train or effect upon the beam when the latter is elevated than when it is depressed.

4.-The combination of a vertically moving beam, a lifting spring, and a shifting or changing bearing or fulcrum, wherelyy the lifting action or effect of the spring upon the beam is increased as the beam is elevated, sulutantially as described and show $\mathrm{n}$.

5.-A vertically movable heam, in combination with a lifting spring, connected therewith by a changeable or shifting bearing. sulstantially as lescribed, whereby the lifting force or eftect of the spring upon the rising beam is maintained notwithstanding the decreasing tension of the spring.

Ni. 242,678 -ISAAC $\rightarrow$. MUSSETTER, OAKLAND, 
(Mis, - Culli, R.,.-Jum, 7, 18S1. Filed Afril 4, 1881

Chim.-In a cultivitor, the combination, with the clip i), of the link $F$, leam ( $i$, bell-crank lever II, rod I, and lever or link $\mathbf{K}$, whereby the print of the heam is moved corre-ponditgly with latcral movement of the handle of sidid beam and a traight line draft secured for the latter in every position, substantially as shown and described.

No. $2+3,0,0$. - T).ANIEL UN'THANK, SPICELAND,

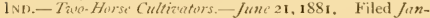
uสry $22,1 S 8 \mathrm{I}$.

(1aim.-1.- In combination with the arch of a cultivator axle, the bar 11 , having a radially-notched plate, $r$, at one side, the sleeve 1 , provided with a longitudinally square bole for the square bar $\mathbf{K}$, and also provided with an arm, $I$, having a hub with radially-notched face to engage with the notched face $r$ of the bar $H$, the clamp L', with the square bar $K$ attached, and clamp $I$, all constructed and arranged to oper,ite substantially as specified.

2.-The rear plouch-frame, $G$, having its lower end, I, cist hollow, an it it ends provided with nutched plates $g y^{3}$, combined with the notched hul $r^{\prime}$, of the ploush-st indari ()$^{4}$, the ratchet $\xi^{2}$, with radial notches on one side and parallei notches un the projecting part as of the other side, and the plough standard (), with slot $O^{\prime}$, with recessed notched parts ()$^{2}$, substantially as specified.

No, $2+3,123$ - CH $\backslash$ RI.ES A. HAG assignor to Furst \& BRADIEY MANUFACTURING CoMI'ANy, same place-Cultioutors.-Fume 21, I881. Filed Notember $25,1879$.

Claim.-1.-The arm or support $\mathbf{A}$, having a pivotal connection at its lower portion with the frame work of the cultivator, and arranged to rock or swing in a vertical plane in combination with a cultivator-beam loosely suspended from said arm or support, and a spring loosely connected at one end with the upper portion of the latter, substantially as and for the purpose described.

2.- The combination of a rocking arm or swinging support,
A, a string or spring-arm, 1 , and their connecting-link $\mathrm{C}$ with the cullivator beam $\mathrm{E}$ and the chain 1), connecting the latter with the rocking arm or swinging support, substan. tially as described.

No. 243,216 . - LAURANCE H, CONNER, GRAND VIEW, TEXAs.-Cultivators.-Jume 21, 1S81. Filed May I4, $158 \mathrm{I}$.

Claim.-1.-In a cultivator or other agricultural implement, the combination of carrying wheels A A, a sectional axle consisting of parts $\mathrm{B} \mathrm{B}^{\prime}$, each of said sections being provided upon its inner surface with cogs or teeth, and moving in suitable guides attached to a bolster carried thereon, and a geared pinion placed between the cogged sections of the axle, the parts being arranged for joint operation, substantially as set forth.

2.-The combination, in a cultivator or other agricultural implement, of the carrying wheels, two movable cogged sections of an axle, a pinion placed hetween said cosged purtions, and a bolster carrying guides for the sections of the axle, and friction rollers for facilitating the movements of the sections of the axle, substantially as set forth.

3.- In combination with the adjustable sections of an axle for a cultivator or other agricultural implement, a geared pinion placed between the geared portions of the sections of the axle, the perforated disk $H$, thaft $\mathrm{E}^{2}$, fog $\mathbf{l}$, and spring $k$, the parts being arranged for joint operation, substantially as described.

No. 243.507-HARVEV IV. CHA MBERLAIN, LNCKPORT, ILL-Cullizators.-Fune $2 \mathrm{~S}, 1 \mathrm{SSt}$. Filed Fibrary 15,1881 .

Claim,-The combination, with the bean $I I$ and a pole $A$, of a coupling, $R$, having the gronve 1 , a post, $S$, provided with the flange $D^{\prime}$, and the sundard $C$, frovided with the slotted lugs $\mathrm{B} B$, bearing $C$, for receiving the end of the post $S$, and thumb screw o, for adjusting said post, substantially as described. 


Ayres, Plate Claim Bosisinger, J. WT.

Bradłey, B. C.

Brannan, P.

Brock, S. $\mathbf{W}$.

Jirown, W. P.

Brown, W. P.

Brown, W. P.

Butterfield, J. S

Carr, N., Jr. and J.

Coons, S. P.

Cronsley, $\mathrm{S}$.

Iryden, W. A.

Dryden, W. A.

Fawcett, G.

Feltman, If

Fox, J.

Friberg, A.

Ginte- I, N.

H.ugue, C. A.
$931 \quad 297$

939298

$942 \quad 299$

$935 \quad 298$

$9+\mathrm{I} \quad 299$

944300

943300

941299

$933 \quad 297$

$940 \quad 299$

937298

$934 \quad 297$

$932 \quad 297$

937298

$\begin{array}{ll}94 \mathbf{I} & 299\end{array}$

938298

$936 \quad 298$

$935 \quad 295$

$9443^{n 0}$
Hartman, C. R.

Hilesabeck, F. I.

Holland, L. M.

Kinsey, C.

Letz, J. P.

Lueth, J.

Luppen, L.

Luppen, I.

Lynch, E. P.

Manly, F. B.

Manly, F. B.

Needham, B. F. and t. II: 9.4229.

Osborn, B. F.

Paradic, J. B.

Perrigo, . L. S

Pierpont, I.

Pitts, J. K.

Platt, W. H

I'orter, M., Jenkins, C. E. and $G . F$.
Potter, H. J.

Plate Claim

$942+300$

$942 \quad 299$

937298

Sanders, J. R. $\quad 938298$

Smith, W. E. $\quad 932297$

Smith, A. $\quad 940 \quad 299$

Stover, D. C. $\quad 934 \quad 297$

Tipton, J. B. $\quad 933 \quad 297$

Underwood, F. J. $\quad 933297$

$$
\begin{array}{llll}
\text { " } & \text { (R.) } 933 \quad 297
\end{array}
$$

Vanluvanee, J. and Smith, H.

$937 \quad 298$

Van sickle, (i. W. and IcConaughy, $\mathrm{C}$.

$940 \quad 299$

Van sickle, $(i$, W. and IcConaughy, C.

943300

Weir, W. S., Jr.

Weir, IV. S.

Whitney, S. $\mathrm{Ml}$.

$\begin{array}{ll}931 & 297\end{array}$

939299

$931 \quad 297$ 


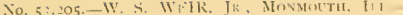
Cultitutars. Hariti $13,1 \sin 6$.

Claim. - The combination with the plate 1), ear. s. mul jurnal $\therefore$ of the grouved hearing plat s $C$ C cylindrical projections $\therefore, \ldots$ plates 1 ; 13 , and serew bolt $i$, all constructed and arranged to operate in the manner and for the purpese cpecitied.

No, 57.562-MICHAKL, PURTIR, C. \&. JFNKINS

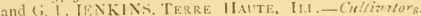

Anitzest 25,1 , 66 .

Claim - the combiration of the adjusable swivel hrack t.ts $a$. plough leams E E, and axle $\mathrm{A}$, arranged and opera ting in the manncr as and for the purpose herein specified

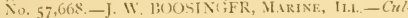
virutars.... Siplimber 4, 1866

('laim..-1 The clevis $D^{\prime}$ and strap $D^{2}$ when cronstruct crt and employed substontially as described and set forth.

2 - The combinution of the nlough beams $D$ with the (kevis [), als., the combination of the said beams with the devices 1. . $a^{\prime} \pi^{3}$ for the purposes and in the manner suthstanti. liy as descrilsed.

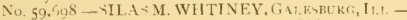
Couplim or Cultionto s._- Votemsier 13, 1866

(Taim.-The adjustable rectangular frame C, eye bolts D and $\mathrm{E}$. and connecting har $\mathrm{B}$, when sasd parts are con-truct ed substantially as herein shown and described, in combin ation with the plongh bean $A$ and axtctree of frame $G$, as and for the purpose set forth

No, 67,07s-IV. E SMITiI, OOUAWka, IL...-Culliintors - Fuly 23, 1867 .

Claim,-The couplings $(i$, composed of two parts, $d d$, counected by a vertical bolt $h$, and having packing $i$ interpuned between them and the pin $t$, and connected to the axle and plough h, ams, substantially as and tor the purpose set firth.

No. 69,697.-JOSHUA PIERPONT, 1.A HARPE, II I., issignor to himself and SIDNEY $\$$. TUTTLE, same place. - Cullivator Conflins. Octoler 8, 1867.

Claim,-1. The turn table clevis, with the head is in umbination wuh the axle arm a both constructed and operaing substantually as and for the purpose herein described

2 - The cumbination cf the clevis and the axle arm $a$ with the wnnecting l,ar $\mathrm{E}$, ar anged and operating as and for the purpose described.

No. $76,634,-1$.EWIS M. HOLLAND, Gai.EsBURG,

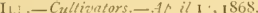

Claim.-Coupl ng the shovel beams $B$ with the axle of the cultivator by means of the screw pivots $b$, with cross pieces $e$ fitting iu the sockets of the plates $a$, substantially in the manner and for the purpose as herein set forth.

No. 85,293.-IV. A. IIRYDLEN, JovMouth, I1.1.. as. signor to himself and JoII N. TURNBULL, same place. - Cultivalor - Divemlic 29, 1868 .

Clain - The metal axle, with a vertical coupling spindle, $F$, cast thercon as a part of the same, substantially as described and for the purpose set forth.

No. 85.412. - FLAVIL: J. UNDERWOOD, ROCk ls: AND, 1.1. , assignor to B D. BUFORD, same placeCullivato s.--Decemher 29, 1858 .

Claim-1-The cult vat $r$ frame, consisting of the bars $A$ and the bent bar $B$, with the axles $C$ attached, the part $A$ being made adjustable, substantially as shown and des ribed.

2.-The manner of attaching the ploughs to the axle $C$, by means of the plates $h$, grouved boxes 5 , and studs ir pins $i$, all constructed and arranged to operate as described.

3.- The shovels F, provided with the boxes b, bolts c, and bar $c$, in combination with the rounded shank $a$ of the plough beam, whereby the shovels are rendered capable of being adjusteil nnd s.cured in place, substantrall: as herein described.

4 -Connecting the handles of the lwo set: of cultivator shares ly means of the lar I, when so arranged as to limit the distance to which said handles my move unet, anil yet leave them free to approach each other, substantially as shown and described.

No, 4,665-FLAVIU, J. UNIEERWOOD, Rock, I>I.AND, II...., assignor to BASIL. D. BUFoRD, same place,-Cultizizlo:5-S5.41?.-Din'm'er 20. i868. Re issued Deremter 12, I 71 .

laim. - 1. - In com ination with the plough heams $\mathrm{F}$. and round axles C. a coupling joint, G, which, encircling the axle, turns around it as a center.

2. - In combination with the elenents last afores id, a j sint upon which the plough leams may swing horizontally as well is have a vertical oscillation.

3. - The studs $i$ upon the axle, in conformation with the plongh beams and grooved loxes $g$, forming part of the joint coupling $(i$.

4.-A series of studs, $i$, arranged along the axle $\mathrm{C}$, in comhination with the plough heams and adjustahle grooved sou ling

5- T' e coupling $\mathrm{G}$, including in its construction the parts A. $\%$, and 1 .

f, - In combination with the hent beams $\mathrm{F}$ and shanks $\mathrm{F}$, the bolts ", boxes, $b$, and plates $c$ for adjustably connecting the shanks and beams.

7. - In combination with the shanks $F$ and a device substantially such as set forth for connecting them, the bent beams 1 , when made round at their lower ends so that the hovels may he adjusted to throw the earth to either side and he raised or lowered to regulate th- de th of plowing.

$S$-In combination with the plough beams $\mathrm{E}$, a frame, $\mathrm{B}$ C. to which the said beams and the wheels are attached, and a franc. $\mathrm{A}$, adjustahly connected with one another so that the frame A can be raised or lowered without affecting the position of the plough herms and ploughs, substantially as set forth.

9 The parts last aforesaid when adjustably connected horizontally in relation to one another, substantially in the manner set forth.

10.- The axles C 1 and bur $B$ when re pectively so constructed that axles may he attached or detached, sul:stantially as set forth

11.- The bar I and plough handles in combination when 5o arranged as to limit the disiance to which the handles may b-separited, I ut leaving them free to be approached at the will of the operatcr.

No. 85,509. - NATHAN CARR, JR, and JOHN CARR,

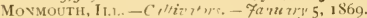

Claim. The plate $\mathrm{E}$, cylinder $\mathrm{M}$, and hook $\mathrm{S}$, with nut $\mathrm{H}$, constructed and arranged as descritied, and combined with spindle $\mathrm{B}$, wrench $\mathrm{T}$, and casting $\mathrm{A}$, the whole being constructed, operated, and arranged in the manner substantrally as described, and for the purpose set forth.

No S7,oSo.-JOHN B. TIPTON, PEor a, ILL. Culti vitnis. $-\mathrm{T}$ fir.ary 16,1869 .

Claim $,-1,-$ In combination with a cultivator, the slotted springs $C$, and the ball and socket joints $F$, constructed and operating sulıstantially as described.

2. - A cnltivator, having hall and socket joints $\mathrm{F}$, springs $\mathrm{C}$, elevated axle, as described, and rest $\mathrm{H}$, constructed, ar ranred, and operating substantially as herein specified.

No. 87,724 -DD. C. STOVER, LANARK, Iis.-Cultivat s. $-11_{1}, h=18,1859$

Claim, - The combination of the pivoted adjustable yoke $\mathrm{D}$ with the bent rod $\mathrm{C}$, bracket $\mathrm{B}$, and carriage $\mathrm{A}$, arranged and operating as described, for the purpose specified.

No. 91,727.-WILliAM A. DRYDEN, Mosmouth, It.L., a.signor to himself and I. M. TURNBUL.L. Cutti 7) 7 tua Foints. - Fune 22, 1869 .

Claim. - The combination and arrangement of the plates Fand $\mathrm{K}$, with their respective projections $\mathrm{H}$, and $s$, and tongue $e$, with the eye bolt $\mathrm{C}$, nut $\mathrm{D}$, grooved juurnal spin dle $\mathrm{A}$, and beam plate I, substantially as described, and for the purpose set forth.

No 94,497 ,-JOHN LUETH, KanKakee, Il. Cul'itrat ris.-Septembir 7, 1560

Claim. -1.-The wedge shaped plate I, provided with grooves $h / h$, in combination with the grooved back plate $n$ shovel $\mathrm{H}$, bolt $m$, and standard $\mathrm{C}^{\prime}$, as set forth.

2. - The reversible stirrups $\mathrm{F}$, provided with pivots $b b^{\circ}$, placed at one side of their center, in combination with the beams $G$, standards $G^{\prime}$, shovels $\mathrm{H}$, depending standards $B$, and vertical parts $B^{\prime}$ of the elevated axle, as and tor the purpose set forth

No. 95505 - - 1. S. PERRIGO, SANDWICH, IIL.-Cul-

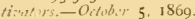


Claim.-1.-The two part clevises Q, piroted to the beams $A^{\prime}$, and to the clips $\mathrm{M}$, and provided with slotted end $T$, for aljunting the dejth which the shovels are to run in the ground, as set forth.

2. The combination of the clevises $Q$, clips $\mathrm{N}$, and standards $K$, as described.

3.-The combination of the clevises Q, standards K, clips $\mathrm{H}$, and rods $\mathrm{B}^{\prime} \mathrm{E}$. as and for the purpose set forth.

4. - The combination of the rods $d_{c}$, standards $V$, shovels $\mathrm{U}$, and $\mathrm{cam} z$, for holling the shovels the required distance apart, as ipecified.

5.- The two part clamp $Y \vec{\zeta}$, in combination with the standard $\mathrm{V}$, bolt and nut $\mathrm{Z} \mathrm{X}$, angular har $\mathrm{O}$, and shovel $\mathrm{U}$, for holding and adjusting saicl shovel, as devcribed.

No. 97,032.-S. W. BROCK, NIANTIC, ILL.-Cultizit tors. - Verctulie' 23, 1869 .

Claim.-The curved slotted strap H, pin or key I, bar F, and adjustable bolts $\mathbf{E}$ with each other and with the slotted plough beams $G$ and slotted standards $C$ attached to the cross beam A, su'tantially as herein shown and described, and for the purpose set forth.

No, 97,073-I. N. G.ATES, BuRNSIDE, IL.L.-Culti-a tors. - Tozember 23, 1869.

Claim.-The knuckle D and adju-table knuckle holder E $c^{\mathrm{l}}$, constructed and operating in connection with the plough beam and truck frame of a cultivator, substantially as herein shown and described, and for the purpose ret forth.

No. 98.604.-JOHN P. LETZ, LACox, ILL-Cultiva. tori, - Jinuary $4,1870$.

Claim.- The plate $d$, provided with the circular head $d^{\prime}$ and orifice $e^{\prime}$, in combination with the rounded recesses and bolts and staples, in the manner and for the purpose described.

No, 100,8 4 - BENJAMIN F. OSIIORN, Nishvil.te, TE.N., asignor to T. H. JoNES d (n., same place,-Cultivators.-Au zust 30,1570 .

Claim.- The arrangement, with respect to the beams A A and bars 1) $\mathrm{E}$ of a cultivator, of flanged vertical stud plates $\mathrm{F} \mathrm{C} \mathrm{Fl}$, grooved joint $\mathrm{K} \mathrm{l}$. M, horizontal stud plate $0 \mathrm{l}$, and bolts $\mathrm{NG}$, to admit of lateral and vertical adjustment, a4 hlown and described.

No. I08,274.-LUPPE LUPPEX, J'EKIX II.L. Shotr Plowshs.-Octaber 11, I87o.

Claim,-1,-The clamp, composed of the plates $G^{1} \quad i^{1}$, which are constructed witl central pins and annular flange: surrounding the same ups their opposing faces, in combination with the axle socket $\mathrm{F}$, to form a coupling, substantial. ly as set forth.

2.-The arrungement, relatively to each other, of the axle socket $F$, clamp $G^{1}\left(i^{1}\right.$, draw liar $\left(i\right.$, socket $G^{2}\left(i^{2}\right.$, and plough beams $\mathrm{G}^{3} \mathrm{G}^{3}$, sub tantially is set forth.

No. 108, 275.- LLPPE LUPPEN, PFKIN, 1LI. - Shun'tPlowshs.-Ovelier 11, is7o.

Claim.-1.-The socket 1 , hasing upon its side one or more projections $D^{\prime}$, subtantially as and for the purpose sct forth.

2.-The combination of the socket 11 , shims $D^{2}$ and $D^{3}$, and beam or draw bar $A$, substantially as and for the purpose set forth.

3.-The combination of the socket $\mathrm{C}$ or beam A, brace $\mathrm{F}$, and rocket $\mathrm{D}$, substantially as and for the purpose set forth.

No. 111,627 - INDREW FRJBERG, MGIINE, IL..Walkins-Cultivaturs. - Feb, unsy 7, 1871

Claim,-1.-The coupling F, composed of the pieces a and $b$, having th" circuinferential cruoves $c$ with tateral space $\therefore$ connecting said grooves, to enable the coupling to be adju.tud laterally and held in position, ar described.

2.-The arlju tal.le shos $\mathrm{H}$, in combination with a shank or biam so curved that the shovel may be adjunted thereon at different inclinations without varying the height of its lowur point, substantially as clescribed.

No. 112,990.-I(1HN VANIUVANEE and HUGH S.MITH, MOLNE, ILL. - Wialinin-Culivators. Warh 21, $18 ; 1$.

Clalm. - The combination of the grooved huls D, made adjustable on the axle $\mathrm{A}$, with the circular $\mathrm{T}$ hear $\mathrm{F}$, secured to the hub by means of the segmental clamps $i$, substantially ar set forth.
No. I24.724.-GAMUEL CROSSLIET, ROCK ISLANI ILI..-Cultivators.-1Warch 19, I872.

Claim.-I.-The clamip B, constructed substantially as and for the purpose set forth.

2.-The boxes $\mathrm{C} \mathrm{C}$, when con-tructed with convex outer urfaces, for the purpose of retaining them within the clamps when in ordinary use, and also for causing them to separate said clamps when the ploughs meet with an unusual obstruction, the parts being arranged substantially as set forth.

3.-The clamps D $D^{1}$, constructed with concave cavities upon their inver surfaces and with slot in their front ends to allow the bolt to paw out through, substantially as and for the purpose set forth.

4.- The combination, in a plough or cultivator, of the two purtions of the clamp (1) $)^{1}$ and the clamping bolts, when one of such bolts is provided with a wooden pin, substantial ly as and for the purpose set forth.

5. - The combination of the clamp $\mathrm{D}^{1}$, the boxes $\mathrm{C}$, the ciamp B, and the axle of a plough or cultwator, substantial ly is and for the purpose set forth.

No. 125.092.-SAILEL, ROCKAFELIOW, NOLINE, IL..., assignor to himself, HE.LAN A. BARNARI), and J. S11.AS LEAS, same place.-Wher7-Cultivators.-Apili 23 , I 872

Claim.-The single coupling (), having the recess E and ho!low tulue $d$, used in connection with the beam $A$, and clamped to the pivoted axle G by the bolt and nut $h f$, all as and for the purposes set forth.

No. 1 26,276.-GEORGE FAITCETT, FARMIXGTON, 1LL. - Cultivators. - April 30, 1872

Claim.-The reversible slctted clevis $E$, having curved arm $a a$, in combination with holt $s$, eye holt $e$, riding bear ing $f$. bridse $s$, cylindrical nipple or bolt guard $k$, and plate h attached to beam C, all constructed and arranged in the mamer and for the purpose $a, 4$ f forth.

No. 128,29;.-JolIN Fol. Oskitoosa, lowi.Ploustls. - Junc 25, 1872

Claim. - The clamping device comm ored of the pont, It,

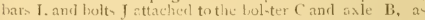
specified, and carrying the plough compling $\mathrm{K}$ I. II N 0 at its lower end, said coupling leing vertically adjustahle, as hown and described, for the purpone specified.

Nu, I20,642-JANES AVRES and MANNING: F

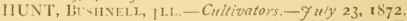

Claim, - The cumbination of the adjustable plates E /. pivotal block $F$, beam $I$ ), nipple $/$, and shaft ( $\mathrm{F}$, substantial ly as and for the purpowe set forth

No, $131.908,-J O H N$ R. SAVDIER-, DIVWXPURT,

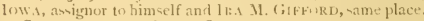
- Cultitators - Oitol, $r 1$, i $8-2$.

Claim, - In combination with the clamping di-co I J, sectional -leeve D, and axle B, the collar cut out to form the part $-\mathrm{NO}$, and having the ear. $\mathrm{PO}, 4 \mathrm{O}$ as to admit of being arranged with and permit the movement of the discs aud axle, as specified.

Ni) I 35,360-JAMES K. PTTTS, MCLEAN, ILL Plough-Ciuplings,-Januar, 28 , is 83 .

Claim.-The plough coupling shown, consisting of the plates $A$ and $A^{\prime}$ provided at their forward ends with the cylindrical opening $C$, and at their rear end with the semispherical bouses $a$ and recess or $\rightarrow$ lat 1 , connected together by the bolt $\mathrm{B}$, and combined with the tongued bar $\mathrm{E}$ and $\mathrm{E}^{\prime}$ by means of the bolt $F$, substantially an and for the purpose pecified.

No. 135,401 - BYRON C. BRADLEY, CHICAG(), ILI. - Cultingters-Felutury 4, 1873

Claim.-1. - The parts $A$ and 1, , con-tructed sub-tantially as shown and described, aud used in comnection with a cul. tivator or lough beam and tanflard, substantially as and for the purpose herein specitied.

2.-The part A B, bean $E$, and stanclard $F$, in combina tion with the piece of washer $\mathrm{D}$ and bolt, the several parts being con-tructed and arianged substantially as and for the purpose described.

No. 137,024.-WHILIAM 11. PLATT, DATTuN, OH1) -Cultizalors. - Marih 18, 1873 .

Claim,-I, - In combination with an axle having recesses $c$, the sleeve $H$ cast in a single piece, and having bolt $n$, sub stantially as specified. 


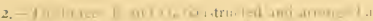

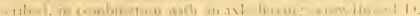

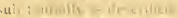

\section{3. - The $10-6,11$,}

1.

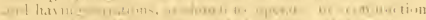

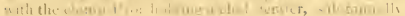
wascabes

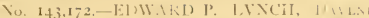

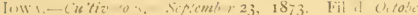
Ic), 187 .

(laiur-1.-The clesis or attachunent for fortening the

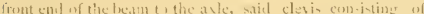
the lar ls witls an upper rigill arm. a, and a lower linuged

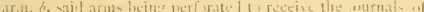

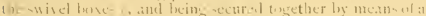

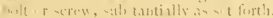

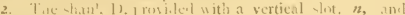

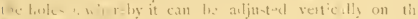

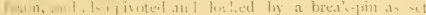
11 .

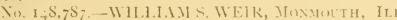

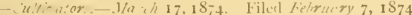

lim.-The prins lult 1, arranged to operate with the

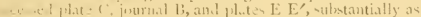

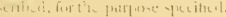

No. 153.704-6. IV. V.IX SICKLE and C. MECON

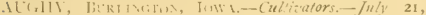

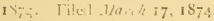

Claian-1.-In a cultivator, frictisn couphings for secur1t. the leams th the aske, commusect of the plate for cmbrac

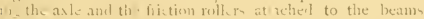

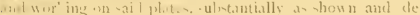
critc 1 .

2-In a culti,atr, the enmbination of fretion crupling

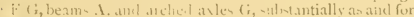

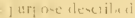

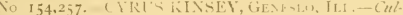

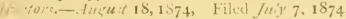

('aim.- - - The combinati m, with the axle i and plow

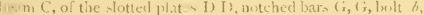
and pin $h$, all solwatat titlly and for the purpose herin set Fint?

2. - The cont instiom of the phates i) D. proxiteil with wit holer ami cuncel lats a asdererilued, the notched bars (i $(i$, loolt $b$, an l jin $h$, ublantially as and for the purporen herein set forth.

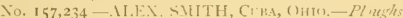

- liv mber 2, 1874 . Hited secht mis 5,1874

Claim.-Tle coml nation if the plougli sleath or atame

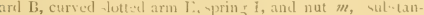
tially as and for the puip w-c litr, in set forth.

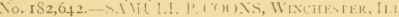

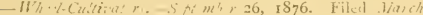
27,187 .

(laim,-1, - The lis: 1), ar r.meal to embrace the -wived pie e $C$, and alju-tally connected therew ith by mean of the arsemlling bolt $c^{\prime}$, and arranesel to connect with th fubular axl- piece $\mathrm{E}$ by $m \therefore n$ of the crew strap $F$, as dencrithet and set forth

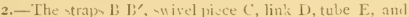
axle $G$, combinct and aransed an and for the purpose set finth.

No, 183.301.-CIHARLES R. HARTMAN, AILISIS,

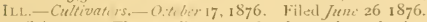

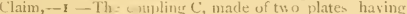
lalf round groosic 11 ar th- front and semi-circular groovenear the rear, in comblination with asle and continuous doulble beam, as an f for the purpone vpecifierl-

2.-Th. curs I har $\mathrm{E}$, pmowled at their lower enels with

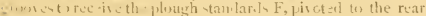

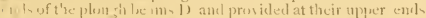

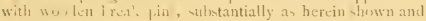
dencribet.

3.-The combintion, with tire asle B and the guicle-

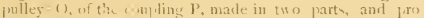
i ef w ith ree. - in ticir buner-urface to receive jin- at

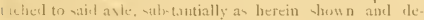
arilied.

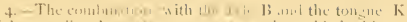

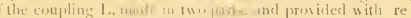

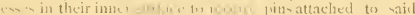

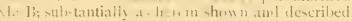

Ni, IS4,960,-IIENRY FEI.TIIAN, I'EKIN, ILL-Cul-

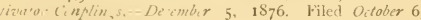
1876

(laim - The herein describes eounling for cultivators, consisting of the tecre I), having one or more leaves or A.ingen probiled with a serien of holes, in combination with the 1.1 in $c$, provi led with the seric of perforated ears vil-tantially as shas n and described.

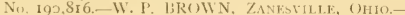

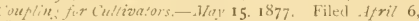
1577

Cham.-1,-The pipe Lox provided with a projection aclapted to (i)-uperate with a spring. "le cight, or the draft, to ancls the - Lil fipe-box agminst or with the weight of the rear cultivater or ploughs, sulstantially an and for the purpose tercribst.

2.- The combination, with the crank axle and the gangs or plotygh of the pipe-box. having arm $\mathrm{Al}$, the spring $\mathrm{X}$, attreched to tice main frame, the head I, 2 nt the stirrup G, or its equivalent, basing lrackets II and pivot bolt b, anc fantured to the pipe box, sulistantially as and for the purpose (1) serili-4

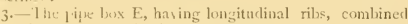

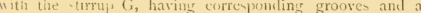
dimping device, subtantially as clencribed

11. I95.979.-IOHN \&. BUTTERFIELD, IJENDON,

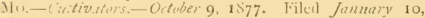
$\mathrm{S}_{77}$

Clain - 1, - The coupling $\epsilon$, componed of the plate $e^{1}$ havin: et.1- $e^{3} e^{3}$, and of the lomer plate $e^{2}$, which is looped soume tic ludt $d$, subtantidly at herein shown and de erilued

2.- The combination of the ploughshare $G$ with the - lottel tray $m$, which emlraces the -tandard, and with the fastenin twalt $n$, inner bearing plate $z \%$. and with the nut which in-unk into a groove in the -tamlarel, all arranged so that the rerew $n$ bear againt the flate $w$, substontially as peciticel

No. 197.032.-FREDK. I. IIIL.ABECK, SHELBY

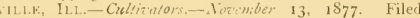
fu: $u$ : 24, 1877 .

Chim. - The combination of $\mathbf{U}$ tar, $\mathrm{E}$ and bent bars $\mathrm{H}$,

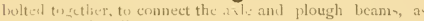
Glown : and texcrilsed.

No. 199 565.-LENI.AMIN F. NEEDHAM and LA B.AN W. NEEDHAM, NiWe ISTLF. IXD.-Whect.Culti

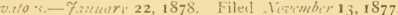

Claim,-1.- The combination of the clamp plates B, bent twice at rivit angter to form luge $d$, with the pivot bolt $C$, (ine wather $f$, and the perforated plough bean, substantially an und frot the purpose dercribed.

2.- The comlination of the asle, having collar $c$, the clamp plater B, laving curved grooves and stot $g$, and bent twice at right angl, to form lug $d$, the pivot bolt $\mathcal{C}$, washer: f. and plough beam D, substantially as and for the purpose denctiliert.

No, 205,787.-PATRICK BR.ANNAN, FREEPURT, TI.1. Cirn Ploughs.-Fitivary 26, 1878 . Filed Octuber 23 I 877

Claim.-The plough beams L. provided upon the upper amil lower surfaces of their front ends with the lips $d$, havins anertur 2 , in combination with the cylindrical sleeve 1 , privided with scalloped lips $a$, projecting rearward from the twi and bottom of sail sleeve, and having apertures $b$, thus protecting the axles $\mathrm{B}$, and affording a free lateral move ment of the plough beams, substantially $a$, shown and set forth.

No, 205,416.-GEORGE W. R.IY, WATSON, Mo.-

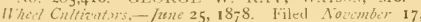
1877

(laim,-I, - In a cultivator, the plough beam having the piven that connect, it to the frame dropped down below the fream, suh-tantially for the purposes herein set forth.

2.-The combination, with a cultivator bsam, of a clevis, or it-efuiralent, having hanger, attached to or projecting 


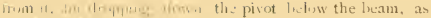
herint if itit

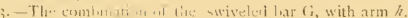

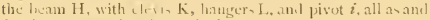
for the purjos a herein set forth.

Ni, 2I6,I45.-WII.I.IAM P. BROIV V, ZANESUILLE, OHun.-Phush and Culfieator Couplings.-Jum: 3, I879. Filed Haw/ $29,1879$.

flaim.-I. - The castins A, hasing three arms, $\mathrm{f}$, to al luw vertical aljustment of the plough heams, and having the semi-circular reces, i), corrusated at $d$, contructed and alapted to seric as iet fisth.

2.- The castims li, having plat $F$ f, arms $G$, having cers tral enlared aperture, 11 , anl slots $i$, combined with the laracket \& ('c and lall, H' j, avet forth.

3.-The taple bult I. combinad with the bracket I am $B$, adapted to chanse th: lince of traft as $4 \mathrm{p}=$ cified.

No. 234,060.-HiNAK I. I'TTTER, ('EXTRALIA, KAN

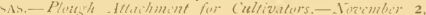
1880. Filed Ausmt 10, 18So.

(laim.-1,-The comlsuntion, with a plourh banm, D,

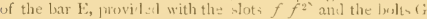
$G^{2}$, pasing throush said slots and through boles in the plough leam, ant fastened by nuts, substantially as h.rein lencribed.

2,- The plough beam $\mathrm{D}$, bar $\mathrm{E}$, bracket $\mathrm{H}$, anil -lotted liar $\mathrm{K}$, in combiuation with the plater $\mathrm{C}$ and banwer $\mathrm{A}$ of a sulky, as shown aucl il-acribud, for the purpone upecised.

Ni), $238,943,-F R$. NK B. M. NLY, M+1.T.I, Oatu.-

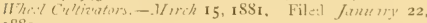
ISSI

Claim.-I.-Box (' and plate D, in combination with plates E E. held together a-direribeil, rod F, spring H, and learimg $(j, s u b$ - antially as speci ied.

2.-In a wheel eultivator, the e inbiation wit ine box $C$, having arin .. of the plate $\mathrm{D}$, having the curved slot $y^{\prime}$

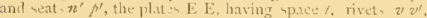
and curved sist $e$, the bolt $\mathrm{Z}$ and $s$, ro: $\mathrm{F}$, spring 11 . and learing $(i,-$ ulstantially as and for the purpones set fort?.

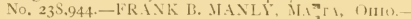
What cullisator. - Wurch 15, 188I. Filed January 22, 1881

Claim.-I.- Swivel plate $\mathrm{M}$. having groove $d^{\prime}$, hole $b^{\prime}$, and shoulder $c^{\circ}$, in combination with plat $E$, having rib $\vec{F}$ and shot $n$, and bolt $R$, substantially an ilescribed.

2.-13ox $\mathrm{B}$, having flange- ce and lot b. in combination with bolt, 1) D and plate E, hasin r lury and holes $w$, substantially andencribed.

3.- In a whe 1 cultivator, the combination of the yo'se $k$ provided with the seat, $t t$, with pot $\mathrm{L}$, having stop pin $l^{2}$, and the swivel plate II, hasing groove 8 . block $\mathrm{N}$, having groove $n^{2}$ and ril, 0 , bolt 2 , and set serew $\mathrm{P}$, nubantially as and for the purpuses set forth.

No. 238,994 (iEORG IE W. VAN SICKLE and CAL.

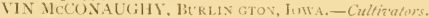

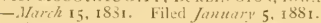

Claim.-1.-A cultivator with if lyeam (') secured to the axle I by hinged conplings A $\mathrm{B}$, whereby, in combination with alinstuble braces $\mathrm{D}$, the tas me C may be rais a aw lowered to till more or less clecyils, a uhatantially as clencribed. 2. - In a cultivator with hince I couplings A B, friction wollers $1 \mathrm{I}$, and friction plates $\mathrm{E}$. talts $\mathrm{F}$, and nuts affixed thereto, whereby the friction roller - may $b \geq$ brought more or les tightly in contact with the friction plat as, substantially a and for the purpose dencribed.

3.- In a cultivator, coupline A B, provided with frictionrollen $\mathrm{H}$ and friction plates $\mathrm{E}$, secured to the main axle $\mathrm{I}$, on which they revolve, sulutantially as and for the purpone described.

No. 239,258 - IOHN B. PARADIS, JMIFN T. IL.L.Couplinte-Cultizators._-Warch 22, 18SI. Filed fune 25 I SSO

Claim.-I.-In a cultivator coupling, the combination. with the axle plate and the clamping plate, of a I vhaped conp. ling bar, having it traight arm secured to the cultivator beam and pivoted near one end of the axle plate, sail lar with it curved extension, moving and guided between the axle and clamping plates, subiantially as described and shown.

2.- The combination of the compling bir $\mathrm{C}$ 'with the axle plate B, yoke I), bloc': E, and removalile clan inz plate $F$, substantially as described, and for the purposs set forth

No. 240,377--WIJLI AM P. BROWN, ZIVFivILI F, OHto.-Culvivatos.-April 19, 1881. Filed Fibmary 12, $1 \$ S_{1}$

Claim. - I. - A ploush beam having in it, front portion a revilient flexible joint, substantially as sp scifierl.

2.-. A plough beam having its front portion - flexihly jointef, und carrying an interacting sprin between prsicction. on the portions of the jointed ploush beam, subut intially a specitied.

3.- The combination, with the coupling vleeve anl it draft heave or pr jecti n, of the reiilient flexible jointed ploush beam, substantially as siaci ieil.

4.- The conbination, with a plows't leam ant it: com ling -leev, hatine a draft heare or pr joctinn, an I a for warl $\mathrm{am}$. C of the li tinz spring, togrle, and tie, suls tantial. ly as specifed.

5.-The combination, with a flexible plough buam, of a coupling leeve having a draft projection at ons cal and spring lifting devices at the other con operating in antugonism to the traft, sulutantinlly as suecitied.

No, 243,122-CHARLE; A. HACiUE, CHIc:Aro, II.1.. assiznor to FURST \& BRADIEY, Manufacturing fiom. pany, same place,-Culliv wor-Couplizys--Jum:21, IS8I Filed live mber 25, IS79.

Claim - I - I couplinu lient or stocict formed from a ingle piecs, having an opeuing to receive a pipe box or thimble, and an end opening for compression, and a slit to facilitate clamping and prevent brenkige, and held in place lsy a clamping bolt, substantially as specified.

2.- A coupling consinting of two heads or sockuts, each formed from a sincle piece with opening for the pipe lox or thimble, and provided with compressing sluts in enable a bolt to clamp each bead or socket on its pipe box ar thimble, subitantially as and for the purpones specifiel. 
A. $1,13,5,11$

Adam, S. T

Airey, R. $C$

Albertion, $C$.

Alenanter. I. E.

Itlen, II. K.

Allis, . 1. ().

Illion, I. II,

Nlloways, ].

Amonets, A. A.

Intirews, J. 11.

Andrews, I. II

Irmistronit, J and G

Armstrong. $J$ and $C$.

Armstiong, $C_{i}$, and J., Jr.

Jrmstrong, (j, amel Vlurchesom, 1). I.

itwood, C:

Atwood, $C$

Itwool, C.

Avery, (i. C.

Bailey. I.

liailey, J. and Jlarshall, (i.

Baird, E. F.

Baker, 11. H.

lakewell, $\mathrm{C}$. N.

ballath, A. II.

Barclay, J, 11, and Sellar, k.

larringer, I. II.

liarr, ().

Bartlett. I. II:

Battell. W.

liaxter, $R$

Beal, 1. IV

Beclielhymer, E. S. and Canadiy, II 11

Beers, E. A.

leers, E, A.

Beers, E. A.

Beklen, C.

licliluke, J.

Benjamin, E. D.

lienson, B. \&

Deyneret, 1), and 1) (umoulin, $\mathrm{C}$

levdan, I.

liergquist, A. F.

berry, II, (), II

lierthisume, L.

Dettentorf, II. P.

bingham, J. and Pond, (). $\mathrm{II}$.

Ijlack, J. E and W IV.

Black, J. F. and W. I. 988 . 324

Black, I. I. and Pates, T. 1176376

Blackstone, IV

Blackwood, J.

13lanchard, A. 1).

liond, J L.

Borchert, H

Borchert, $\mathrm{H}$.

liorland, A. I.

Borland, A. J,

lowen, $\therefore$. B. and $\mathrm{Ab}$. bott, A. II.

Bowman, L. D.

Bowman, R. J.

Bowce, W. I. and Haines, G, W.

Boyd, J. G.

Bradley, B. C.

Bradley, B. C.

J'radley, B, C and Il ague, $C . A$.
I"in) thumes

1951 322

11535

$\begin{array}{ll}1085 & 350 \\ 1087 & 351\end{array}$

$1165 \quad 372$

1108356

tor 5333

$1054 \quad 344$

$10+8 \quad 342$

II $40 \quad 364$

1025336

I049 342

$1071 \quad 347$

Iog6 353

$170 \quad 374$

$988 \quad 324$

$992 \quad 325$

IO5 I 343

1009331

$1130 \quad 361$

$1147 \quad 366$

$1085 \quad 350$

$974 \quad 310$

1016333

$1082 \quad 350$

1214 iS8

1001328

$1172 \quad 374$

$1000 \quad 328$

$995 \quad 326$

1008331

$\cos 33 \mathrm{I}$

$1021 \quad 334$

1117358

$109 \mathrm{I} \quad 352$

$1109 \quad 556$

$1124 \quad 360$

$985 \quad 324$

$\begin{array}{ll}1187 & 379\end{array}$

$1029 \quad 337$

$1104 \quad 355$

$999 \quad 328$

$1163 \quad 371$

$1212 \quad 387$

$1094 \quad 352$

$1197 \quad 382$

II $86 \quad 379$

$1083 \quad 350$

$\begin{array}{ll}1176 & 376 \\ 1082 & 350\end{array}$

1061345

1174 375

I056 344

$1200 \quad 38$;

$\begin{array}{lll}211 & 3 S_{7}\end{array}$

I06I 345

$1068 \quad 3.46$

I067 346

$1123 \quad 360$

1216388

$1042 \quad 341$

$10.46 \quad 342$

I1 $35 \quad 363$

$1187 \quad 379$

$1152 \quad 367$
1192381 lit, * ley, I, C, and llague $C$. 11 .

litalley, 13.

Brewer, I.

Brinckerlofi, C. R.

Drinly, T. F. C.

lirowis, 11.

Brown, J. C, and Slimpert, G. H.

rann, $C$ and Gerth, I

l3rown. WV. J., Hayzlett, J. (i., and seaton,

1). F.

Brown, E. C

Brown, 11.

Brown, L.

Brown, $\mathrm{N1}$

Brown, I.

Brown, I. 11,

Bruner, T.

Bryan, J.

Bryan, S.

Bryan, F.C.

Buckley, R. C.

Buld, E. C .

Burke, 1.

Burlingame, A, H.

Burlinsame, A. H.

Durlingame, A. H.

Burton, N. F.

l'usholl, $\mathrm{W}, \mathrm{K}$

$976 \quad 320$

(R.) $976 \quad 320$

$1139 \quad 364$

Bushell, IV. K. and D. I1 146366

bullitt, H. N.

Bumgarner, $\mathrm{H}$.

Burket, G. and Gaskill, S. II.

Buttom, A. T. and lundy, S. J.

Cahill, l.

Cahill, N. and Norey, A. 1 :

Calill, il

Cahill, 1.

Cahill, 1.

Camphell, J.

Canaday, II, H.

Canalay, H. H

Canadiy, 11. H.

Canaday, I1.11.

Carns, J. C.

Carr, H. C.

Carter, G. R.

Carver, II. E

Casaday, WV. L.

Case, J.

Care, P. I.

Chace, E. A.

Chamberlın, T. B

Chambers, C. F

Chambers, C. F.

Chapman, I.

Chapman, 1 .

Chapman, L.

Chapman, L.

Chapman, I.

Chapman, 1.

Chapman, I.

Chapman, 1.

Chapman, L.

Charles, li, G.

Chearebro. I. E.

Clark, R di.

Clayton, I.

Clayton, J.

Clees. J.

Cischrane, J.

(iole, J. II.

Colton, G. D).

Civlton, (i. 1)

(i)lvin, H. H, and John

Connor, II. J.

Conrath, P.

Comway, C. R.

Coreth, R.

Coreth, R.

Coreth, R.

Cornell, $T$. J.

Cornell, T. J

Corr, C. IV

Cotton, J.

Covell, A. T.

Cox, J. and $s$.

Crane, B. I.

Cravath, M. A.

Cremer, F

Crossley, IV. G.

Crossley, W. G.

Crothers, F. R.

Cruthers, F. H.

Crothers, F. R.

Crump, T. J.

Cruttenden, A. E.

Culver, $\mathrm{H}$.

Cummings, W. H.

Cummins, IV. B.

Cummins, J. R.

Cummins, I. R.

J. K. 1083 350

Cunningham, A. 1044341

Curkendall, G. 112836

Currie, J.

Curtiss, N. S.

Curtiss, M. S.

Curtio, MI. S.

Curtiss, N. S.

and E. IV. 1123360

Curtiss, M. S. 1148 366

Dahl, G J. $\quad 1017333$

Dailey, A. A. 1050 343

J falton, H. N. $\quad 997 \quad 327$

Dalton, H. N. $\quad 1041340$

Daniels, H. L. $\quad 1150 \quad 367$

Daniels. E.S. $\quad 1178376$

Daniels, H. L. $\quad 1220 \quad 389$

Davenpurt, F. S. $\quad 979 \quad 32 \mathrm{I}$

Davenport. F. S.

Davlnport, F. S.

(R.) $998 \quad 327$

$1133 \quad 362$

$\begin{array}{ll}1211 & 387\end{array}$

$1021 \quad 334$

Davison, Gi.

(R.) $1022 \quad 334$

Lavison, J. M. and Spen-

$$
\text { cer, } \mathrm{N} \text {. Jr. }
$$

Davison, $\mathrm{A}$

$1028 \quad 337$

Dawson, C. $\mathrm{H}$.

$1033 \quad 338$

Dick, C. I. and Woehl, N1. 1215 358 
Drake, S. E.

Duane, J. B.

DuBois, $\mathrm{N}$.

Duclos, V.C.

Durant, A. P. and Buckley, D. M.

Durant, A. P.

Duval, G. R.

Eastham, C. L.

Eaton, E. C.

Eaton, E. C.

Ebaugh, H. H

Eberhart, J. WV.

Eckert, J. H.

Eddleman, J. P.

Edgell, J. B., Alexander, J. W. and E. A.

Edwards, C. A.

Edwards, W. L.

Eldred, D.

Elam, J. T., P. and J. A

Elliott, M. A

Elliott, M. A.

Ellis, G. A.

Ellison, A.

Elliston, C. T.

Ellwood, R.

Elmer, N.

Eustice, E. A.

Evans, W.

Fagan, T. B.

Fanning, S. A.

Fargo, C. A.

Farrow, A.

Fay, D. M.

Fay, J.

Fay, J.

Felker, V

Felker, V.

Fenner, R. R.

Ferguson, S. T.

Ferguson, S. T.

Filkins, J. D. and De Puy, W. H.

Fisher, $\mathrm{s}$.

Fisher, D. S.

Fisher, J. B.

Fisher, J. B.

Fisher, J. B.

Flansburgh, P. H.

Fleming, S, W.

Fletcher, J. J. and Sursa, J. W.

Flinn, M.

Florance, J. L.

Flow, J.

Fosgate, D. O.

Fosgate, D. $O$.

Foster, IV

Foster, F. MI.

Foster, F. M.

Fowler, A. A.

Frank, C.

Franklin, B.

Fraser, E. J.

Fraser, E. J.

Freeman, IV. II.

Freeman, A.

Freeman, H M, Lowe, J. and Stevens, J. F.

Freeman, M. J.

Freeman, H. M.

Frubling, W.

Frye, J.

Frye, J.

Frye, J.
Plati Claim

$1150 \quad 367$

$970 \quad 319$

1093352

IO28 337

$98_{3} \quad 322$

$989 \quad 324$

1044342

1006330

I I 3357

I I 6358

1007330

$1159 \quad 369$

$990 \quad 325$

1046342

$997 \quad 327$

1043341

$1138 \quad 363$

971319

1196381

$1055 \quad 344$

$1207 \quad 385$

I 145365

1049342

I098 353

1223390

$\begin{array}{lll}1 & 152 & 367\end{array}$

$1219 \quad 389$

I 23360

1126360

$106734^{6}$

$1036 \quad 339$

IOI 533

I067 346

1104355

$1120 \quad 350$

$975 \quad 320$

985323

I I IO 356

$1151 \quad 367$

1225391

$964 \quad 317$

$973 \quad 310$

$100533^{\circ}$

I I $64 \quad 372$

I $59 \quad 360$

$115636 \mathrm{~S}$

IO46 342

1208386

$1184 \quad 378$

1019334

1 I $40 \quad 36.4$

IIIO 357

I $64 \quad 372$

$1174 \quad 375$

IOI 2332

$1162 \quad 371$

$1200 \quad 383$

I 139364

1122360

I176 376

$973 \quad 319$

975320

$982 \quad 322$

I 068346

$1075 \quad 348$

$1173 \quad 375$

I 159360

I $34 \quad 362$

(R.) $1134 \quad 363$

965
917

$965 \quad 317$

$96831 S$
Fuller, II and Boyd, T.

L. $\mathrm{H}$. and Boyd, T. I.

Funk, W. J.

Funk, D. M.

Gale, A. II.

Giale, A. J.

Gale, A. H.

Gallagher, WV

Gaskill, R. R.

Gaskill, R. R.

Gatlin, W. S. and Hubbard, B. R.

Gay, C. F

Gesley, S.

Gibbert, P. M.

Gilbert, I. R.

Gilbert, 1. R.

Gilbert, I. R.

Gilbert, I. R.

Gilbert, I. R.

Gilloert, I. R.

Gillham, S. I and G. M 1009

Gilham, S. J., Taylor, W.

C. and Stolle, J. W. 1059344

Gilliland, A. L. and $B$.

$$
\mathrm{F} \text {. }
$$

Gilass, J. H.

Glasscock, M

Gileeson, 1. H

Glidden, J. F, and Vaughn, P. W.

Glidden, J. F and Vaughn. P. W.

Goddard, C. F.

Goldthait, E.

Gollyer, II

Goodell, O. E:

Goodwin, J. H. and Woodard, D.

Gore, E. F.

Graham, S

Graves, R. R.

Green, I. B.

Green, 1. B.

Greenfield, J. T.

Greener, G. W

Grimes, J. IV.

Grimshaw, IV. S

Gritamner, F.

Ground, R. B.

Groves, $\mathrm{G}$. A

Grove, M.

Haege, I.

Ilaege, J.

Haege, J.

Hague, C. A

Hague, C. A.

Haight, G. C

Haines, G. IV

Ilale, $\mathrm{A}$.

Hall, T. J.

Hall, T. J.

1lall, O. D.

Hamaker, J.

Hammitt, J. M. and viller, 11. T

Il ammond, A.

II ammond, A.

Hammontree, J. F.

Ifance, R.

Hardin, W. E

Hardy, J.

Harris, J.

Harris, J.

Plate Claim

I $35 \quad 363$

1 1.47366

$1042 \quad 341$

$1146 \quad 365$

11.41364

1225391

I 87379

1019334

989
324

$996 \quad 327$

$1017 \quad 333$

$1038 \quad 339$

$1201 \quad 3^{8} 3$

$9^{8}+\quad 322$

I $090 \quad 351$

$1100 \quad 354$

1131362

$1178 \quad 376$

$1206 \quad 385$

I $84 \quad 379$

$990 \quad 325$

$1059 \quad 345$

I $199 \quad 382$

I043 341

$115^{8} \quad 3^{69}$

$1144 \quad 365$

1209386

$963 \quad 317$

$1210 \quad 386$

$121 \mathrm{~S} \quad 389$

$1144 \quad 365$

1043341

I023 335

1007330

$1079 \quad 349$

1085350

$11853 \mathrm{So}$

I $172 \quad 374$

1122359

1076348

1217388

1078349

1074348

1095353

$974 \quad 320$

$977 \quad 320$

$977 \quad 320$

$\begin{array}{ll}1 & 4967\end{array}$

1224391

108735

$1067 \cdot 346$

$999 \quad 328$

$964 \quad 317$

(R.) $964 \quad 317$

$1035 \quad 338$

(R.) $1035 \quad 338$

$1137 \quad 363$

I1 47366

$1000 \quad 328$

$985 \quad 323$

$991 \quad 325$

$1136 \quad 363$

I IOO 354 
Iacolby, I)

James, 11.1 .

Ianes, J. II., Tucker 11. and Terry, T. 1$)$.

Ial: II. I).

Jefiries, W. I.

Jefferson, 1. E:

Jefferson, T. E

Icfferson, T. E.

Jefferson, T. E.

Jefferson, T. E

Jefferson, T. E.

Jennings, $\mathrm{B}$.

Johnson, P. C:

Judkins, M. D.

Iudson, A. C.

Kay, J.

Keasor, J. 1.

Keasor, J. 1.

Keith, A.

Kelly, L. H.

Kendig, D.

Kennedy, J.

Kenuedy, L. F

Kewin, C.

Keys, I. and IeMier, J. R.

Killan, H, and Valleau, G.

Kimball, G.

lincaid. J. D.

King, G, S.

Kingston, S. 1. and (iore,

Kinkel, C.

Kirkpatrick, S.

Kirkpatric, $\mathrm{S}$.

Kneedler, J. D.

Kneedler, J. A.

Kuehn, WV.

Lane, J.

Lane, J.

Lane, J.

Langsford, Li. P. and Strond, Wr. N.

Laraway, R. K. and J.

Latham, A.

Lathrop, L. B.

Laughlin, I. L.

Laughlin, J. L.

LeBoyteaux, I. H, and

Lee, $\mathrm{J}$. Ashton, C. A.

Lee. J.

Legg, I. T.

Leidy, I. C.

Levee, E.

Lewis, J. B. and Cidall, J. E.

Lewis, I. W

Lewis, J. IV

Likes, Il.

Lindgren, A.

l.ittlefield, C. II.

Litzenberg, B. F.

Litzenberg, P. F.

Lockwood, S. M

Logan, J. B.

Long, J.

McBride, J.

McCall, E. R.

McClènve, II. P.

IcConnell, J. R.

McConnell, T. R.

Mc Connell, J. R.

IcCool, IV. C.
Plate Claim

$995 \quad 327$

$1194 \quad 3^{81}$

R.) $11943 \mathrm{Si}$

$1077 \quad 349$

$1196 \quad 382$

1034338

I $177 \quad 376$

I I 8 I 377

$1179 \quad 377$

1204384

$1226 \quad 391$

$1227 \quad 392$

$1043 \quad 341$

1117358

I $136 \quad 363$

10.41340

I028 336

IOI I 332

IOI8 333

$\begin{array}{ll}987 & 324\end{array}$

I $177 \quad 376$

I II 357

I 147366

$1162 \quad 37$ I

I073 348

I $10735^{6}$

$\begin{array}{ll}963 & 317\end{array}$

$1174 \quad 375$

1009331

I I 3 I 362

966318

$1003 \quad 329$

I 123360

$116337 \mathrm{I}$

IO28 337

I 099354

$978 \quad 321$

$1073 \quad 347$

1167373

I $163 \quad 371$

$1132 \quad 362$

$1003 \quad 329$

$1209 \quad 356$

1005330

$1127 \quad 361$

1224391

$986 \quad 323$

$967 \quad 318$

$967 \quad 318$

1007330

I $154 \quad 368$

IOI5 333

$1025 \quad 336$

"(R.) $1025 \quad 336$

I036 339

I037 339

1059344

I 19538 I

1002329

I I93 381

1217388

$991 \quad 325$

I029 337

1002329

I I49 366

IOS8 $35 \mathrm{I}$

1042341

IO26 336

I054 343

I 08835 I

I069 $34^{6}$
Mcliool, II. C

NcCormick, I. R.

Ilc Cormick, J. K.

Mc 'ormick, J. K.

Mclennan, J. $\mathrm{K}$.

Mc.lahan, II. s.

Mcl'ike, I. M.

McTamahan, $\mathbf{F}$.

Mahou, I. I3.

Manuel, G. IV.

Mlanuel, G. IV.

Jlantuel, D. 1.

Manuel, I. A.

Markillie, T. R.

Markillie, T. R.

Marr, J.

Vars, IV, IV.

Marshall, J. 0.

Mason, $\mathbf{I V}$.

Mason, IV.

Mlason, W.

Mason, H. W.

Mlathews, IV. IV.

Matteson, D. C.

Matteson, D, C.

Jatthews, E. G.

Mead, J. J.

Necham, O. S.

Neclaris, J. A.

Meharry, W. I.

Neikle, T.

Meikle, $\mathrm{T}$.

Meloy, E. and Stanley, A. R.

Melvin, M. A.

Merkel, P.

Merrill, A.

Mickelson, M.

Miller, IV. D. I $196 \quad 382$

Minuse, $\mathrm{H}$.

Moore, I.

Moore, J. G.

Moore, $\mathrm{G}$.

Moore, G.

Noore, $\mathrm{G}$.

Moore, J. II.

Morizan, W. V. and Ilackman, T. W.

Mor:man, J. A.

Mlowrey, C.

Mowrey, C.

Mowrey, C.

Munson, A. K.

Munz, J. F.

Murphy, M

Murry, J

Myers, C.

Myers, C.

Myers, C.

Myers, C.

Nation, R.

Neal, H. IV

Neal, H. W.

Neal, H. W.

Neff, S.

Neff, J. B.

Neff, I. B.

Neff, I. B.

Nelson, IV.

Newlin, W.

Newlin, W.

Newlin, W.

Newman, IV. B. and Wilkinson, T. J.

Newman, IV. B.

Newtun, R.

$1073 \quad 347$

I I 12357

$1149 \quad 366$

$1212 \quad 357$

$107534^{\circ}$

$1156 \quad 368$

$1030 \quad 337$

IOIS 334

I $020 \quad 334$

1077349

1069346

1109356

$972 \quad 319$

$980 \quad 321$

I OSo 349

$1170 \quad 374$

IOI 1332

IO3I 337

I052 343

1072347

$050 \quad 343$

1015333

969315

(R.) 969319

IO21 334

1195381

$11.42 \quad 36.4$

I $168 \quad 373$

$1054 \quad 343$

$1190 \quad 380$

167373

$1218 \quad 389$

I054 343

I 066346

$939 \quad 328$

$1070 \quad 347$

$\begin{array}{ll}\text { IOIO } & 331 \\ \text { IOI } & 332\end{array}$

$1033 \quad 338$

I IOI 354

I IO7 $35^{6}$

I II 357

$1184 \quad 378$

$1208 \quad 386$

I 22 I 389

I 146366

I I $46 \quad 366$

$1217 \quad 389$

I $190 \quad 380$

1195381

1035338

$1056 \quad 344$

$\mathrm{IOS}_{3} 350$

I $100 \quad 354$

I $166 \quad 373$

I 2 I 388

$980 \quad 321$

I $020 \quad 334$

I039 3.40

$1071 \quad 347$

1085350

$119238 \mathrm{I}$

I 19338 I

I $203 \quad 38.7$

Merle C Yaim 
Reeve, HI, E.

Reeves, H. E.

Renfro, R. A.

Reuss, I. L.

Reynerson, I. 11. and

Worrell, J. $\quad 1047 \quad 342$

Reynolds, E. D, and U. B. 1126360

Rice, IV: B.

Richardson, I. W.

Richardson, H.

10So 349

1113357

Richardson. T. and

MeInnis, M.

Richardson, W. M.

Riddle, W, N,

Riggs, D. C.

Riney, T. I.

Robbins, I. H. and S.

Roberts, II.

Robertson, 11. II.

$1120 \quad 359$

II 31362

11 $36 \quad 363$

I008 331

II 191380

$100434^{6}$

991325

$972 \quad 319$

(A. I.) 972319

Robertion, E.

1003355

Robertson, S. M. and

Hamilton, A. A. $\quad 1219 \quad 389$

Robinson, J. G.

Robinson, J. G.

Rockwood, L. O.

Rogers, W. T.

Rogers, J. C.

Rogern, IV. C:

Rourat, it E.

Rooil, E.

Root, J

$973 \quad 319$

$1034 \quad 338$

1105355

$994 \quad 326$

$1006 \quad 330$

$1160 \quad 371$

$1127 \quad 361$

$107+348$

$1031 \quad 337$

1189 3रo

Rowen, N, and Amis, (i, 1161371

Rurldick, IV. A. $\quad 1120 \quad 359$

kunk, J. L. $\quad 978 \quad 321$

Kunk, J. L.

$979 \quad 321$

Runk, 1. L., Brown, J. II. and Morgan, E. N.

Kush, R. I). and E. W. $111735^{\circ}$

Rusell, E. W: $1110 \quad 357$

Ryer, IV. H. $1212 \quad 387$

Sachse, L.

Sampson. ().

Siattley, M.

Sattley, M.

Sattley, $\mathrm{H}$.

Sattley, M

sicheumack, S. S.

richlag, E.

Schmeiser, HI. J.

Scofield, B. 13.

Search, C. F.

Senrs, D. A

Sears, D. A.

Scibel, J.

Seibert, G. and J.

Seibert, $G$, and $I$.

sexton, E.

shepard, I

Sherrill. J.

short, T.

Siegordner, $C^{\circ}$

sikinner, I. 1).

S.inner, J. B.

skinner, H. M.

Slaughter, IV. J

Slosson, E.

Sluwer, B.

1076348

I055 3+1

$979 \quad 321$

$088 \quad 321$

$1075 \quad 34 \mathrm{~S}$

$1114 \quad 358$

$1103 \quad 355$

$\begin{array}{lll}118 & 378\end{array}$

$1134 \quad 362$

$969 \quad 319$

$1175 \quad 375$

$1047 \quad 342$

$1093 \quad 352$

$98+323$

$97+320$

I035 339

$1004 \quad 329$

$1037 \quad 339$

$1169 \quad 374$

$052 \quad 322$

$1165 \quad 372$

$\begin{array}{lll}986 & 323\end{array}$

$991 \quad 325$

$1079 \quad 349$

1115358

1115358

$1023 \quad 335$

(R.) $1023 \quad 335$

(R.) $1023 \quad 335$

1039340

Silusser, B.

$\begin{array}{ll}\text { Simalley, D. A, and J. H. } & 1092 \\ \text { Smith, H. I. } & 352 \\ 1002 & 329\end{array}$
Smith, H. B,

Smith, H. B.

Simith, G. M.

Smith, J. 1 .

Simith, A. and T. S.

Smith, A.

Smith, A. and Watson,

$$
\text { iV. } P \text {. }
$$

Smith. F. F.

Smith, F. P.

Smith. H. C.

Smith, G. H.

Smith, I.

simith, F. F.

simith, F. F

smith, F. J.

simyth. H.

Snow, IV.

snow, C. $\mathrm{P}$

Sparks, 0 .

spencer, J. I.

spencer, N., Jr.

Sprasue, E. I.

Stafford, H. 1'.

Standish, I'. IH.

Stanley, A. R. and En. sign, W. 11 .

Stanley, F.

Stearns, J. L.

Stemegger, $(i$.

Sterling, W.

Stuart, If. C

Stevens, C. I3.

Stevem, (. I:

Sitockstill, S. I. and

Kurtz, H. H).

Sture, D.

Sitone, J.

Sitone, J.

Sitont, S

Summers. R. B. and

Dement, S

Summers, L. M. and IVilin, $\mathrm{N}$.

sursa, J. II:

Sursa, J. IV.

sura, J. IV

Sura. I. IV.

Sutherlen, IV. B.

Sutherland. J. A.

Sutter, J.

Suydam, J. H.

Swallow, J. E.

siweeny, II. I'.

sweet, Z. T.

Tappan, G. S.

Taylor, . . H.

Terry, T. D., Case, A. and Larkin, $C$.

Thompson, J. N, and Kenaily, IV.

Todd, G. II.

Totten, J.

Tozer, $\mathrm{G}$.

Travi, J. E

Trayis, J. E

Trealway, J. IV.

Trenery, N. J. ancl sisley. J. 1

Trumlle, H. F.

Tucher, A. WV.

Tucker, A. II.

Turley, M.

Turley, $\mathrm{II}$
Plale Claim

\begin{tabular}{ll|l}
1039339 & Tustin, J.
\end{tabular}

1062345 [rban, J.

rogs 344 Vail, A.

$993 \quad 326$

$\begin{array}{ll}965 & 317\end{array}$

$1029 \quad 337$

$1024 \quad 335$

$1026 \quad 336$

$1026 \quad 336$

$989 \quad 324$

I $41 \quad 364$

$1166 \quad 372$

$\begin{array}{lll}1213 & 387\end{array}$

$1206 \quad 385$

$1197 \quad 382$

$\begin{array}{ll}986 & 324\end{array}$

$1086 \quad 351$

I $162 \quad 37 \mathrm{I}$

$974 \quad 320$

1007330

I050 343

$1105 \quad 356$

I009 331

$1024 \quad 335$

$1025 \quad 336$

$119 \mathrm{~S} \quad 3 \mathrm{~S} 2$

$1030 \quad 337$

Ii) 6333

I004 352

1191380

$1078 \quad 349$

$1096 \quad 35,3$

1077349

$980 \quad 321$

980 322

$1080 \quad 351$

$906 \quad 327$

$947 \quad 327$

$1188 \quad 380$

1005329

10.46342

I050 343

$1055 \quad 344$

1019334

1105355

$963 \quad 317$

1053343

$1052 \quad 343$

I $07 \mathrm{~S} \quad 349$

$1030 \quad 337$

1216385

$1214 \quad 387$

IOSI 349

$10+1 \quad 340$

1 II 357

$1032 \quad 33^{8}$

I07 347

$984 \quad 322$

$990 \quad 325$

1051343

$1186 \quad 370$

$1224 \quad 390$

$115 \mathrm{~S} \quad 360$

I 89380

$\begin{array}{lll}965 & 317\end{array}$

968 31S

Wade, T. I.

Walker, A.

Walker, R.

Warwick, J.

Wirwick, J.

Vanarsdell, IV. A.

Van De Mark, C.

Van Ciorder, J. 1.

Van Gorder, J. L.

Van Gorder, G. IV

Van Winkle, $\mathrm{G}$.

Volkmann, B.

Volkmann, F.

Walton, E. WV

Walton, E. W

Warren, G. II.

Warren, G. H

Warren, (;. H

Warwick, J. and A. T. $1177 \quad 376$

Watkins, I. T. $1022 \quad 335$

Watson, W. M. $992 \quad 325$

Wiattles, H. J. $\quad$ IOIO $33 \mathbf{I}$

llatt, G. $\quad 99+\quad 326$ 
No. 3.47t-11. 13ROWN, PAY - Marih 9, $15+4$.

Claim.-1.-Constructing the plongh in the manner described, that is to say, constrncting and arranging the projections II and I, npon the monld-board, so that the plough miy be used either side up, a right or left.

2.-1 do not claim combing a number of plough and at taching them to a frame.

No. 8,544-E. GOL,PTIIAJT, FORT IVAYNE, IND,Whicel-Plouglis. - Verember 25, IS 51 .

Claim.-1.-The cutter, $\mathrm{C}$, or its equivalent, to separate the sward for the first furrow at a proper distance from the coulter, acted upon by the dro $1^{1}, a^{3}$ and lever, $\mathrm{C}^{5}$. or their equivalents.

2. -The piece, I)s, fastened to the heel of the mouldhoard in combination with the coulter, $\mathrm{C}^{4}$, to turn wille furrows,

3.- The mode of connecting the tongne and plough, respectively, to the axle, by means of the links and the Joose tenon on the tongue, substantially as described, so.2s to allow the team to walk entirely asifle from the furrow, or direct course of the plongh, in ploughing prairie, mar $h$, or other land with soft under strati, and make the plough rnn smoothly and work well, and so as also to enable the plonghman to take an extraordinarily wide furrow, with one member of the te im walking in the forrow with a common yoke, thus dispensing with the long yoke now commonly nsed for that purpose.

4.- The rope, D, and lever, $\mathrm{D}^{\prime}$, or their equivalents, in combination with the mode of connecting the tongue and plo'igh to the axle, substintially as describerl, for the purposes set forth.

No. 8,8 4.-11. KII.L.AI and G. VAILEAU, ScotTVII.L., N. Y-Wheel-Ploushs. - Mherch 30, 1852.

Claim.-I. - Mounting the tongue or pole, $\mathrm{A}^{2}$, upon the timbers, D, E, an I unit ing the same by an intermediate jointed connect.ng rod, IV, to the horizontal coupling rod, L, which unites the front and rearward ends of the pivoted arms $\mathrm{J}, \mathrm{J}$, of the axles $\mathrm{K}^{2}$, whereby the direction or guiding of the gang of plouglis is regulated by the action of the team itself, in moving in any direction the attendant may require.

2. - Confining the tongue or pole, $\mathrm{A}^{2}$, between the hori zontal plate, $S$, and timber, D, by mean; of a fulcrum bolt, $\mathrm{U}$, for the purpose of allswing the tongue or pole, $\mathrm{A}^{2}$, to vibrate or move right or left with the direction of the team, whereby the rejuired direstion is given to the propelling and upportin: wheels; and whereby the ton rue or pole may be shifted or adjusted in it po-ition to accomodate two or three hotse; an 1 yet mintain its central draught with the ploughs.

No, IO,IOI.-C. K. BRINCKERHOFF, Batavi, N. Y.-Whici-Plows hs. - October II, I $S_{53}$.

Claim-1.-Combinin, with the plough-beam, between the plough and the clevis, two wheer, one on each side of the beam, and of different diameters, the one resting in the furrow and the other on the Jand, for the purposes set forth.

2:- Making the tread of the furrow-wheel narrow, so that it may press lightly against the land, and guaye the width of the furrow-slice, and cast aside any small stones that may roll against the land.

3.-Making the wheels, especially the furrow wheel, atjustable in the clirection of its axis, for the purpose of adapting its position to furrows of different widths.

4.- Iaking the furrow-wheel bevelling outward on the side which presses against the land; also, making the small wheel acjustable vertically with reference to the shaft $\mathrm{B}$, and the large wheel.

No, 291.-C. K. BRINCKERHOFF, BATAVIA, N. Y. -Wheel-Ploughs. - October II, $18_{53}$. Reissued January 30, 1855 .

Claim.-I.-Combining with the plough beam between the plough and the forward end of the clevis, by means of a single shaft, two wheels, one on each side of thc beam, and of different diameters, the one resting in the furrow, and the other on the land, for the purposes set forth and described.
2 - Making the tread of the furrow-wheel narrow, for the purposes described.

3.-Making the furrow-wheel beveling outward on the side which presses against the land as above described and for the purposev hereinhefore set forth.

No, I0,153.-I. D. FIl,KINS and WIILIAM H.

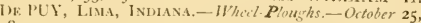
1853 .

Claim,-The combination of the fimler tongue $b^{\prime}$ and stiff tongue $b$ with the running gear, to adipt the gangplongh to being drawn by two teams abreast.

No, 12,791.-T. J. HALl, TAWAKana IILL.S, TExas. - Gandr-Ploushtis.-May I, I855.

Claim.-The arrangement of the plonghs and pivoted beams with adjustable cross-beams, so that the ploughs may have a convenient permanent adjustment, in connection with their self-adjusting property in the flough beam, as set forth and described.

No. 3.7 6. - THOMAS J. HALL, BRyan, Texas,Gang-Ploughts.-Alay I, 1\$55.-12,79I extended seven years. Reissued Vorember 9, I860

Claim,-1,- The arrangement of the ploughs and pivoted beams with the adjustable cross-leams, so that the ploughs may have a convenient permanent ad ustment, in connection with their self-adjusting property in the plough beam, as set forth and described.

2.- Limiting the lateral vibration of the revolving cutter or coulter, that it may not, when out of the gronnd, vibrate so far that it would not recover its true position when again in contact with the ground, substantially as described.

3.-The bent brace $k$, when constructed in the form as described and attached to the frane of the plough in the manner and for the purpose substantially as described.

No. 14.373.-AARON and THOMAS SMITH, TROY, It.1._Wheel-Ploughs, - Murch 4, 1856.

Any number of shares may be used, and the front axle B may, by loosening the nut on the bolt, be adjusted so that the shares will be in Jine with the centre of the axle.

Claim,-Combining the axle $\mathrm{B}$ and wheel $\mathrm{J}$ with the bed piece $A$, when constructed and arranged substantially in the manner and for the purpose set forth.

No. 16,216.-MI. TURLEY, Galesburg, Ill., - WheelPloushs.-Decimber 9, 1856 .

Claim.-The arrangement of the standard, mould-board, and slide cutter $\mathbf{K}$ with regard to each other, and to the other parts of the plough, so that they will operate as set forth.

No. I 6,9I2.-TESSE FRYE, SPRINGFIELD, ILL. - GangPloughs. - Warch $3 \mathrm{~T}, \mathbf{1} 857$.

Claim. - The so hanging of a gang or series of ploughs upon their stock and beam as thit the conductor upon his seat, may, by a system of hand-Jevers and connecting rods substantially such as set forth, adjust said series of ploughs to any desired depth or width of furrow, as set forth.

No, I6,9r3.-J. FRYE, SPRINGField, Il...-IVteelHoughs. - March 31, 1857 .

Claim,-1.-Supporting the after end of the plough-beam $A$, upon a vertical journal at the left hand end of the axle $\mathrm{T}$, when the bearings at the opposite end of said axle are so arranged that the position thereof may he varied and adjusted, sub-tantially in the manner and for the purpose set forth.

2.-Arranging the bearings of the rollers $e \mathrm{e} e f$, and $g g$ r in such a manner that their positions may be varied and adjusted, substantially in the manner and for the purpose set forth.

3.-In combination with the mould-board, composed principally of the series of adjustable rollers as set forth, 1 claim the adjustable triangular plate $w$, for the purpose of making the whole conform to the position in which the furrow slice is to be laid or turned substantially as set forth.

No. 17,591,-J. SUTTER, ST. LOUis, Mo.-WhectPloustis. - Jnne 16, 1857.

Claim.-The comhinition of the ploughs D, with the 
frame $\mathrm{B}$, and pivot $\mathrm{O}$, arranged and operated in the manner and for the purpose set forth.

No. 18,343.-SAMUEL L. K1NGSTON and DAVID GORE, Plainview, 1Ll.-Gang Ploughs,-October 6, I 857 .

Claim.-1.-Attaching the bar $\mathrm{F}$ to the bars $\mathrm{A}$ by means of the lever D and arm G, and having the ends of the bars $\mathrm{K}$ connected by chains $m$ : to arms $n$, connected to a bar $\mathrm{L}$, to which a lever $L^{1}$, is attached, the lever $O$ being attached to one end of the bar A and to the rod $q$ as shown, and the screw rod $\mathrm{V}$ attached to the bar $\mathrm{B}$, and passing through the bar $g$, whereby the shares may be adjusted vertically and laterally, and also raised temporarily when necessary as shown and described.

2.- A mould board, constructed of conical wire rollers $\mathrm{X}^{1} \mathrm{X}^{1}$, arranged as shown, or in an equivalent way, for the purpose of raising and turning the sward, as set forth.

No. 18,397--GEORGE W. HILDRETH, LockPoR'r, N. Y.-Gang Ploughs.-October 13, 1857.

I do not claim the arranging of ploughs in a gang so as to turn several furrows at the same time, nor the carrying it on wheels changeable in height.

Claim.-The axletree having a triple motion, in combin. ation with the centre bolt and bolster plate, constructed and arranged substantially in the manner and for the purposes set forth.

No 4,222.-GEO. W. HIIDRETII, I.OCKPORT, N. Y. -Gang Ploughs._October 13, 1857; reissued December 27,1870 .

Claim.-I. - The combination with the frame A of a gang plough of crank supports, M M', for the main carrying and supporting-wheels, whereby the height of the frame from the ground can be adjusted substantially as described.

2.-A crank axle-tree, for supporting the frame in a gang.plough, provided with a crank upon each end, one of which is adjustable and so secured to the axle-tree that the supporting wheels which turn upon the ends of said crank axle-tree, can be adjusted in the arcs of circles, to run upon the same or different horizontal planes, for the purposes above described.

3.-The combination, with the supporting axle-tree $\mathrm{H}$ in a gang plough, provided with cranks at its ents, one of which is adjustable independently of the other, of a hand lever for turning said axle-tree, for the purposes above described.

4.-The combination in a gang plough of the following elements, viz: A supporting axle-tree, provided with a crank at each end; two supporting wheels, one on each crank; a hand lever for turning the axle-tree and cranks, and a holding device for retaining the axle-tree and cranks in position when adjusted.

5.- The combination, with the frame in a gang plough, of a tongue or draft pole, which can be raised and lowered, and also moved to the right and left, for the purposes stated.

6.-The combination, with the plough frame of a laterally adjustable supporting axle-tree $\mathrm{H}$, for the purposes stated.

7.--The combination, with a crank axle-tree $Q R$, in a gang-plough, of an eye bolt and nut, for retaining the crank and its supporting wheel in any desired adjusted position.

8.-A cast metallic frame, for carrying the gang of ploughs, cirnstructed substantially as above ilescribed.

9.-A combined cast and wrought iron frame for gang ploughs, constructed substantially as shown and described.

10. - The combination, with the cast iron main frame, of a tool-box cast with said frame, substantially as shown and described.

II - The combination, with the frame and axle-tree in a gang-plough, of a metallic-plate connection $J \mathrm{~J}^{\prime}$.

12.- The grooved and tongued plough attaching plates D E, substantially as and for the purposes set forth.

13.- The combination in a gang-plough of a series of plouzhs, having short and long land-sides, substantially as and for the purposes set forth.

No, 18,698,-JOEL. LEE, Galesburg, Ill.-Gang Ploughs. - November 24, 1857 .

Claim.-1.-The peculiar arrangement consisting of the friction wheels $d$, inclined planes $f$, and lever $\mathbf{K}$, for adjusting the plough frame to any required position, as set forth.

2.- The peculiar arrangement consisting of the flange or guard $e$ and pivoted axle $a a^{1}$, for allowing the turning of the front truck to aposition at right angles, or nearly so, to the hind truck, so that the machine may turn a square corner without liability of of lifting the plough shares out of the ground, as set forth.

No. 18,803.-JARVIS CASE, SPRINGFIELD, Jll.Wheel Ploughs.-December 8, 1857 .

Claim,-1.- I Iinging the tongue to the beam of a plough, and extending a lever or lever seat from one to the other, so that the driver mounted on the plough may, by said lever, throw the plough or ploughs out of the ground, as set forth.

2.-Supporting the front of the beam on the centre of an axle $c$, supported in wheels $c c$, so that said beam may be raised or lowered on said axle, but not affected by the passing of said wheels over the rough ground, as set forth and explained.

No. 18,820.-J. LEE, Galrseuk'; Ill.,-Wheel Ploughs. - December 8, 1857 .

Claim.-The combination and arrangement of the two wheels $E$ and $E$, attached to the different sections of the beam, swiveling quarter around in opposite directions, and bracing the ploughs as described, when used in the manner and for the purpose set forth.

No. 19,077.--M. A. CRAVATH, LODA, ILL.-Wheel Ploughs.-January 12, 1858.

Claim.-1.-The method substantially as described, of att.iching the ploughs to the frame whereby they are marle capable of being thrown out of and into action by partial rotation on their axes, as exhibited.

2.- In combination with the above, the described arrangement of the wheels E F G, whereby the chief weight of the implement devolves upon the wheels E F, which run on the level bottom of the furrow.

3.- The described construction and arrangement of the jointed land side beam $\mathrm{A} \mathrm{A}^{\prime}$, in combination with the lever $\mathrm{t}$, and $v$ rack, or equivalent devices, operating substantially as set forth.

No. 19,388.-M. TURLEY, Galesburg, Ill..-Whet Ploughs.-February 16, 1858.

Claim.-1. - The combination of the beams, ploug-shank, lever, and brace or adjusting rod, arranged behind the axle substantially as set forth.

2.- The combination of the wheel B, for holding with the cutter $m$, for cutting the stalks, substantially as described.

3-The combination of the weed gatherer $n$ with the plough or ploughs, when arranged and operating as set forth.

No, 20,342,-JESSE FRY'E, MExDUTA, ILL, - GanjPloughs.-May 25, 1858. Antedated March I8, 1858 .

Claim.-1.- The attachment of the tom ues to the forward and rearward plough-stocks, and the connections between the varions plough stocks, so that whon the team is turned, the plough shall be turned so as to point to wards a common centre, substantially in the manner and for the purpose described.

2.-The connection of the forward furrow wheel with the tongue by means of the curved slotted arm $\mathrm{R}$ and bolt $\mathrm{I}$, in combination with the cranks and connecting rods between the wheel shafts, so that when the team is turned, the forward wheels shall be turned in the same direction, and the rear furrow wheel shall be made to track the forward wheels, substantially in the manner and for the purpose set forth.

3.- Hanging the hinged coulter $t$ to the rear of the front furrow wheel by means of a chain, which, when the team is turned, will raise said coulter out of the furrow, substantially in the manner and for the purpose set forth.

No. 20,647.-DON C. MATlE SON, STOckToN, CA. - Gang-Ploughs.-June 22, 1858 .

Claim.-The arrangement, as described, of the false beam $\mathrm{N}$, goose-neck $\mathrm{G}$, axle $w$, lever $i$, catch $\mathbf{I}$, and the system of ploughs attached to their frame, as set forth; the 


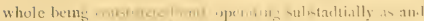
for the purpos - pecine

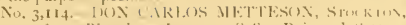

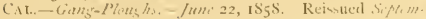
$b_{i}, S, 1 S 08$.

Clim. - The arranecunent, as cleseritued, of the fale

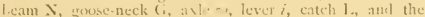
system of ploughs attacheal tos their frame, as set fonth, the whole lreing constructed and operating sulstantially as an! for the purposes specifict.

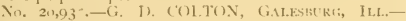

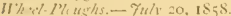

Claim.-1 - Irranging the frame 13, secured to the axle C. as described, with the strap) $n$, cord $m$, and windlass (i, the several parts leing operated in the manner and for the purpose set forth.

2.-This in arrangment with the revolving coulters and a double-pointed besm, all being constructed and operated substantially as descrilied.

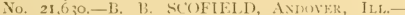

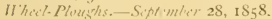

Claim, - The arraugement uad combination of the pivoted b.ir s, vare I) land-side E, standars F, curved rack pinion $G$, and lever $I I$, a and for the purpones shown aud described.

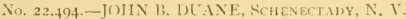
- Cirltizaters-Jonutart 4,1859

Claim.-The arrangement and combination of the frome 1). having wheels 5 , lar $\mathrm{F}$, wheel $\mathrm{G}$, lar $\mathrm{E}$, and frame $\mathrm{A}$, as and for the purpose shown and descrilsed.

No. 22,629.-G. I). COLTUN, GAlEstotkc; ILL.-

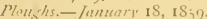

Claim,-Combining and aranging together the beam $\mathrm{H}$, the standard $d$ and $i$, upri ht $a$, lever $E$, axle $\mathrm{B}$, brace $Z$, bar $\mathrm{H}$, and pole $\mathrm{C}$; a il pole feachine forward and resting upon the neck-yolic, in the manner and for the purpose specitied.

No, 23.134 -JUHN II. WHITNEY, BulTus, MAss. - Ploterts. - Marde 1, $18,9$.

Claim.--The arranerment of the hined arms C D, arljustable brace $E$, and standard $\Lambda$, with the wheel $H$ ancl plough beam $G$, the whol: lecing constructed for operating undmiantially as and for the purpene dencribed.

Su, 23,159.-C. H. IHATVON, JACKSUNIILI.E, ILL. Cultirativis- March 8, is 50 .

(laim.-The plough ham D I) arranged as shown in conmectesn with the roller $O$ applierl to the machine, substantially in and for the purpmese set forth.

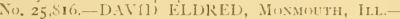
Ploushs - Vituber IS, 1359 .

Claim.-The arrangement, for joint operation, of the share frames II I, axle II, and coulter L, as and for the purpose set forth.

No. 26,587.-T. S. IIEPTINSTALI, MIEntora, It.1.-

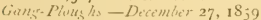

Claim. - The arrangement of the whecls A B B, shaft C and $\mathrm{D} \mathrm{D}$, spindle $\mathrm{E}$, triansle $\mathrm{F}$, rod $\mathrm{G}$, lever pole $\mathrm{II}$, regulator $I$, and rollers $K \mathrm{~K}$, as descilied and for the purpuse set fortls.

Nu. 27,34 - - iEOR(iE, IV. IIUNT, MUscatiNe, lowa.

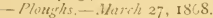

Claim. - I - The arrangement of a vertical coupling and a liustin, jin 1, whi.h has that prortion, which pasese through the beam, roand, and that portion, which passe through the asle, suare, in combin tion with a diagonal alju-ting-bar $\mathrm{P}$, a connecting ro. $\mathrm{N}$, and a vertical lever (), ab-tantially as and for the purpose set forth.

2.-The arrangement of the long slut $\mathrm{W}$ in the axle, with an upper and under sotted sliding plate L L $L^{1}$, and the coupling and adjusing pin $I$, substantially an and for the purpuse - set forth

3.- The arrangement of the beam $\mathrm{A}$, slottecl axle $\mathrm{D}$, coupling pin I, slotted plate $\mathrm{L}$ L1, diamonal connecting rod $\mathrm{V}$, all'ustin s bar $\mathrm{P}$, lever $\mathrm{O}$, driver's stat $\mathrm{C}$, tre ulle $\mathrm{II}$, plough $F$, horizontal rotary land side wheel $G$, and rotary coulter H, in the manner uncl for the purposes set forth.

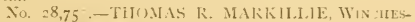
TE" II: - P" , : $-\therefore, 1,1,1$,
Clam,- Dhe mongesang of the plough or ploughs, as conected to the truck, 14 combination with the levers 6 and 1. Whe whole being constructed aud operated in the manner and for the purpose rlescribed.

No, 29,104-DIIENRY H. ROBERTSON, KINGTON,

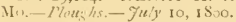

Claim. The arransement of a linged plough F, car riage A $A^{\prime} \mathrm{I}$, vertical adjusting screw $d$, segment guide frame $E$, toothed segmental adlusting hars $i j, \operatorname{cog}$ pinion 4 , pawl 0 , or stop $m$, sulatantially as and for the purpose set forth.

No. 304. - 1. I., to original Letters Patent No, 29,104.Plourhs.

Claim.-The arrangement of a hinged frame, consisting of a strccesion of andes $\mathrm{A} \mathrm{A}^{1} \mathrm{~A}^{2} \mathrm{~A}^{3} \mathrm{~A}^{3} \mathrm{~A}^{5}$, in combina tion with the beams I of an exual number of ploughs, all constructerl anel operating sulutantially as set forth.

No. 29,160,-THOMAS S. IIEPTINSTALL, MeNDuTA, II.1.-Ciang-Ploushs.-July 17, isoo.

Clam,-The peculiar aarangement of the frame $A$, plough $B$, arms $F$, with wheels attached, lever $C$, with castor wheel on its lower end, connecting rod $\mathrm{H}$, lever $a$, curved rack $i$, and pinion $x$, operating by means of crank handle $b$, when the several parts are connected substantially as and for the pur orose specified.

No. $29,8+3$ - - IOSEPLI HARDEV, MuLINF, IL.L., as. imnor to O. CHAMIJERLAIY and WV. II. BABCOCK, ame place.-Gluzrghs.-August 28, 1860 .

Claim.- The arrangement of the axle $B$, plough $\mathrm{G}$, bean H, guile bar I, rack J, sector $\mathrm{K}$, standard $\mathrm{I}$, castor wheel $\mathrm{F}$, arhor E, and frame $A$, all as shown and described, for the purpose set forth.

No. 30, I $36,-E D I V I N$ J. FRAZER, Kansas City, Mu. - Gitom,

Claim - C mecting the plough beam $K$, to the bar $G$, through the meclium of the pendant bar I, provided with the Jide $i$, and bolt $k$, in connection with the clip I, attached to the plough beam K, and provided with the slot $l$, subtantially as ile-crilued.

No, 30,727.-SAMUEI FISHER, WFST WINDSOR, N. J.-Mluste- Vovmlis 27, 1860.

Claim. - The combination of the pivoted beams $\mathrm{G}$ with the pivoted plongh supported by a pin, when arranged to operate in the manner and for the purpose set forth; and this whether the plough be made adjutable, and be raised or lowered, or held by the devices described, or by other accomplishing a similar object by substintially the same means.

No. 30,837--JOHN G. ROBINSON, BIDDEFIRD, ME. -Plorighs, -Dicember t, ISso.

Claim.-The arrangement of the arm $b$, slotted pendant $C$, and axle $\mathrm{A}$, with the plough frame $G$, adjustable bar $\mathrm{J}$, and adjustalule lever $K$, as and for the purposes shown and lescribed.

No, 30,863.-H. H. D.AKER, NEW MARKET, N. J.Plenghis.-Dicimber 11, 1860

Claim.-1.-The mounting of the ploush slares upon Wheels arranged in the manner shown by 13 and $C$, throush the melium of a frome $G$, which slicles vertically within, and in supported and guided by an extenor or principal frame $A$ as thown and described.

2.- Rai-ing the plough $\triangle$ and 2 , vertically at will, by the motion of the bearing wheel $\mathrm{C}$, through the aill of mechanism, substantially as set forth.

3.- The means, subitantially as show $n$ and described, for holling the forward side of the plough frame $G$ higher than the rear side thercof, when in the act of being elevated, in combination with means ubbstantially as shown and described, for holding the said plough frame level when it is fully low ered for the purpone designated.

4.-In combination with the wheels $\mathrm{B}$ an $1 \mathrm{C}$, frame $\mathrm{A}$, ploughs I and 2 , the employment of the spring E, for the parpose devionated.

5.- The cimployment of the adjustable standard $\mathrm{S}$, in combination with the spring $\mathrm{E}$, for atjusting the rigility of the latter, in the momner and for the purpose shown.

6 , - In combination with the aljutable spring $\mathbf{E}$, the employment of the wheel .1 , for the purpose set fortis 
No, 30,892,-(HLIVER SPARKS, SHELINA, Mo,Ploushs-Dirember 11,1 S6o.

Claim.- The two ploughs, arranged one in front of the other, as and for the purposes set forth, in combination with the levers $F G^{1} H$ and $G$, arranged, supported, and operatıng as described.

No. 30,967.-JACOE IIAEGE, SHHoH, II.L.-GansI'Tursths.-December I8, 1860 .

Claim,-1.-The employment or use of vertical pivots passing through the centre of the axle, in combination with chains $c$ and $f$, as and for the purpose descrilsed.

2.-The arrangement of the hinged slotted standards I, in combination with the screw rods $k$, guards $n$, and nuts $m$, and with the adjustable plough shares $\mathrm{D}$, all com-tructed and operating in the manner and for the purpose set forth.

3.- The arrangement of the swinging rods $f^{1}$, in combination with the lever $F$, and bean: $C$, constructed and operating as and for the purpose specified.

4.-The arrangement of the belly strap $I_{\text {, in combina- }}$ tion with the lever F, treadle $\mathrm{H}$, and beams C, constructed and operating substantially in the matner and for the pur pose described.

No. 31,563.-GEORGE SEIBER'T and JOHN SEIBERT, AsHLEY, 11.1.-Iloughs.-Fibuary 26, I\$61.

Claim.-1.-Arranging the piece J with the anle 11 and tongue $x^{\prime}$ in the mamef described, for the purpose specifiect.

2.- The brackets $b \quad b$, set screws $a$, and latch $F$, arranged in the manner described, for the purpose speci. fied.

3.- The slot $P$, the studs $G G^{\prime}$, and berm $A^{\prime}$, when arranged in relation to their respective parts substantially in the manner described, for the purpose specified.

No. 32,129.-ElJWIN J. FRASER, KANSAS, MI3,Ploughs, - dpail 23, 1861.

Claim,-The arrangement of the levers $N$ I $O$ and detents $\mathrm{P} Q$ with each other, and with the slotted bar 1 . rod $\mathrm{M}$, cords $A f$, and plough, in the manner and for the purposes shown and described.

No, 32,231--VALENTINE FEIKER, assignor to himself and RUFUS JONES, CARMr., ME.-Ploushs.April 30, 1861 .

Claim.-The arrangement of the plongh holder, as constructed, of parts N H I F E and I, attached to plough A, with plough governor B, operating as descrilsed and for the purposes set forth

No, 32,311.-TIIOMAS PATTERSON, RUSH, lLLPloughs.-May 14, 18 u.

Claim.-The plough body G, secured to jointed leam $\mathrm{F}$, as described, in combination with straps $d d$ lever $\mathrm{F}$, jointed-bar $h$, chains $\mathrm{K} \mathrm{K}$, and jointed sliding cross tree $\mathrm{D}^{\prime}$, all arranged and combined with the wheels $\mathrm{B} \mathrm{B}^{\prime}$, axle $A$, and draught pole $\mathrm{I}$, as and for the purposes set forth.

No. 32,958.-J. F, and W. L. BLACK, LANCISTER, ItL.-Gany.Ploushs. - july 30, 1861 .

Claim.-The toggle $\mathrm{L}$, with lever $\mathrm{N}$ attached, draught pole F, foot hoard J, driver's seat 1, plough beams C C, and axle $A$, combined and arranged to operate as and for the purpose set forth.

No, 33,568, -N. F. BURTON, PLYMotTh, ILL.Plowshs-October 20, 1861.

Claim.-1.-The combination of the subsoil plough I with the surface plough $\mathrm{I}$, when said ploughs are attached to adjustable beans $\Lambda$, arranged substantially as and for the purpose set forth.

2.- In combination with the subsoil and furrow plourhs $\mathrm{I} \mathrm{M}$, the roller $\mathrm{K}$ attached to the frame $\mathrm{J}$, and arranged to operate conjuintly with the ploughs, as set forth.

3.-The attaching of the axle 1 to the beams $A A^{\prime}$ throus the medium of the bail shaped rod $\mathrm{I}$, in combination with the arm II attached to the axle D, and having its bearing or fulcrum on the rod 1, as described, whereby the depth of the penetration of both shares may be regulated as desired.

No. 2,221.-N. F. BURTON, Galeshuri, Ill.-

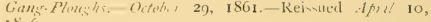
18,6

Claim.-I.-The device for aljuting the leams $A \Lambda^{\prime}$, by means of plate $f$, and clamps $e c$, and bars $g k$, substantially ae set forth, whereby the depth of penetration of the plotigh $\mathrm{M}$ and 1 may be changed at pleasure.

2. - The combination of the subsoil plough $I$, having a long winged mould board, with the surface plough $\mathrm{M}$, arranged as and for the purpose set forth.

3.- The attaching of the axle I) to the beams $\mathrm{A} \mathrm{A}^{\prime}$, through the medium of the ball shaped rod I in combination with the arm $H$, attiched to the axle 1 , and having its bearing or fulcrum on the rod L, as herein described, wherehy the depth of the penetration of both ploughs may be regulated at pleasure, aud they may also be male to run out of the ground when desired.

No. $33,851 .-11$. B. READY, SACRAMINTO, CAl.-

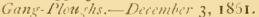

Claim.-1.-The curved beams $A$, when used in connection with a gang plough, or a series of ploughs, connected together by cross bars B B B', constructed and operating as and for the purpose set forth.

2.- The arransement of the arms $G$, wheels $I$, and the lever $\mathrm{J}$. when attached to the right hand arm $\mathrm{G}$, and connected (1) the central beam $A$, as and for the purpose set forth.

No. 2,992.-WILLIAM B. RE.IDY, SACRAMENTO, CA1.,-Gang-Ploushs - Dirimbir 3, 1861--33,851. Reissued June 16, 1868

Claim.-1.-The curved beams A, when used in connection with a gang-plough, or a series of ploughs connected together by cross bars 13 B B', constructed and operating as and for the purposes berein set forth.

2.-The arrangement of the arms $(\dot{B}$, wheels $I$, and lever $J$, when attached to the right hand arms $G$, and connected to the certral beam $A$, as and for the purposes set forth.

No. 37,750.-JACO) 11AEGE, SHHOH, S'I. CLAIR

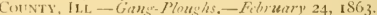

Claim.-1.-The attuching of the plough beam to the :uxle A by mean of the stirrup or loop $\mathrm{Q}$, pin $\mathrm{S}$, and chains $d^{\prime \prime} d^{\prime}$, and bar $\mathrm{T}$, and woodeu pin $e^{\prime}$, in combination with the lever or treadle J, all arranged as shown, wherehy the plongh or ploughs may be readily raised above the surface of the grombl when neccsary, and the beam allowed to become detached from the axle or cauriage when the former comes in contact with any obstruction which may lie in their path.

2. - The rotary cutters $I$, when placed on a screw rod or shaft II, and secured thereon by jamb nut $i$, and said shaft. hung in the arms $(; G$, substintially as and for the purpose specified.

3.-The combintion of the bar Z, cutter $\mathrm{B}^{\prime}$, when applied to the subsoil plou h $\mathrm{X}$, and used in connction with a gang plough for the purpose set forth.

No, 38,161.- LACOB HAEGE, SHH.OI, ST. ClAIR County, Ill-Gans-Plous $h$ s. - Ifril 14, 1563.

Claim.-1.-The combination and arrangement of the pole $G$, axle $E$, vertical rod II', and draught rod I, substantially as shown, to admit of the lateral adjustment of the draught relatively with a gang-plongh, as set forth.

2.-The paticular manner of attaching the pole $G$ to the axle $E$, to wit, by means of the socket $b$ fitted on the axle $\mathrm{E}$, and arranged in such a manner as to receive the pole $\mathrm{G}$, and having a screw e passing vertically through it, and through the oblong slots $f y$ in the axle and pole, whereby the pole $(;$ is firmly secured to the axle $E$, and the former permitted to be readily adjunted when desired

No. 39,483 - II. R. HUES, HaYwak1)'s, Alameda

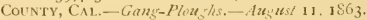

Clam.-The peculiar arrangement, construction, and application of the axle $\mathrm{D}$ and $\mathrm{am} \mathrm{E}$, the slotted oval $a$, and the spring slide and lever $A 13$, for the jurpose berein secified and described.

No. 39,743.- COHN S. PADOIN, LEHANIN, STt. Ct.AIR

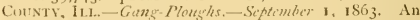
tedated March $1,186_{3}$.

Claim,--1.-The combination of the movable frames, consisting of the sills K R, with the main framc, when they 


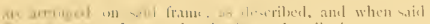

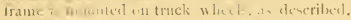

2.-1hir andinition of the musvable and aljustable plough Lenn, 1) with the sill K, when sait heam ar macle to merate in connection with saicl vilk, shlutintially as described.

No, 39.039.-G. W. HUNT, MHSCATINE, J WWA.Ploughis.-Siptimere i5, 1855

Claim.-1--Inelining the plough to suit the inclination of the land, by means and in the manner herein shown and lescribed.

2.-The friction rollers II 1 , in combination with the sliding plate $\mathrm{I}$, fixed plate $\mathrm{C}$, and rod $\%$, for the purpose specified.

3.- The employment or use of the two wheels V V, at the rear or hack cut of the henm 1), when said whecls are thed in combination and in relation with the plough $\mathbf{E}$, and itiver sent $1 \mathrm{~W}$, as set forth.

4.- The arrangement of the $T$, branched at it; lower end to receive the axle $n$ of the whecls ' $" z$, as and for the pur prose set $f$, reth.

Yo. 30.961.-J. L. RLNK, Nishrile., Washington

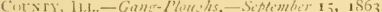

(laim.-The employment of the inclined bolster I), in in cotillumation with the screw $f$, platform $\mathrm{E}$, and heams 11 all heing construeted and arranged to operate substantially as licrein dencribeil for the purposes set forth.

No. 40,62)-WILLIAI KUEHN, LIVEIY, ST, CIAIR Cin NTY, II.L.-Gans-IYoushs.-Noztmber 17, 1853.

Claim-1.- Piwoting or hinging the front ends of the beams $E E^{\prime}$ to the top of the asletrce $A$ of two carriage wheds in such manner th.t a lifting bar $c$, or its equivalent may be applied beneath them to allow the beams to have an unrestrnined swinging movement vertically, and to ema ble them to be operat d by silil har, substantially as de scrilsed.

2.-A driver's seat arnaneed sver the axle $\mathrm{A}$, and attach$\therefore$ ts the bound $C^{\prime}(C$, which are secured riritly to saic ale, in combination with suinging flourh leams E L', ulimtantially as described.

3.-The arrangement and combination of the pivoted

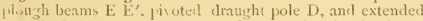
lwumin $\mathrm{C} \mathrm{C}$, with the supporting bar $c$, wherehy the driver 1. enabled to raise the rear ends of the plough beams, by $\mathrm{r}$ - aing upon the rear end of the draught pole, the driver at being suppotted lisy and upon the bounds, substantially is describud.

4.-Applying the leverage power to the hinged beams E $\mathrm{F}^{\prime}$ ' in rear of the axle $\mathrm{A}$, beneath sail beams, hy mean. sub-tantially as described.

5.- The combination of sw inging plough beams $E$ E', linged to the axle $A$, extended hisunds $C^{C} \mathrm{C}$, lifting har $C$ pisoter draught pole $\{$, transverse stop plate $b$, and treadle $\mathrm{k}$, all arranged and operating subatantially as described

Yo, 40,721.-LORENZ WoLF, ST. Luts, Mo,-

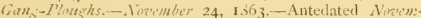
i, 1 il, 1853 .

Claim.-1.- The employment of the standard box $f f^{\prime}$ fot $i$, constructed and arranged in herein described for the purposes set finth.

2.-The within descriled arrongement and combination of tie levers, $n$ with reference to the beam $\mathrm{C}$ and sten or wheel standard / of the improved gang plough, $\llcorner$ ab tantially in the manner and for the purposes set forth.

3.- The use of the rucher iron $/ 4$, formed, constructed, mul arranged to operate substantially in the manner and for the purposes herein set forth

Jo. 41,H9--MARSHALL SATLEJ, TAYLoRSVILLE, 11.1.-Gizns Pluwstes, - Fedruary 2, 1844

Claim.-1.-Attaching the beam $K$ to the frame by means of crank $\$ \mathrm{~S}$, operated by a lever $T$, in the manner explained.

2.-The draught chains $\mathrm{R} R$, attached arljustably to the axle $\mathrm{B}$, and adapted to be drawn tight by fowering the Thloughs to their working position.

No. 41,491.-F.S DAVENPORT, JERSEYVILLE, ILL. -Gang-Plewshs.-Fibruary 9, 1865.

(laim.-1. - The hinger or swinging avletree I) at

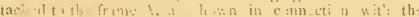

aljutalile: stropm forth.

and 1 is the farpon herein aet

2.-The caster whed II attached to the $\checkmark$ haft (;, which is connected to the slidling har $\mathrm{F}$, having a lever J attaclied, when said parts are used in combination with the swinging axletrec 1), as and for the purpose speeffed.

No, 41,643.-J. L. RLNK, NAshvII.Le, II.L.-Gims-

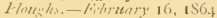

Claim. - 1. - The combination of the pulleys $p \rho$, endless chain $i$, and adjusting lever $(i$, with pivoted plough beans I) $\mathrm{D}^{\prime}$ attached to the tongue $\mathrm{C}^{\prime}$ in front of the axletree, all operatiner sulstantially as deveriberl.

2.-The manner herein dencribed of uniting the two parts of the axle and the hounds, so that when the axle is extended in length or shortened, the hounds will be aljusted to operate therewith, as set forth.

3.-The laterally-adjustal)!e pulley standard $\mathrm{E}$, in combination with the laterally adjustable hounds $\mathrm{C}$, plough heams $D D^{\prime}$, and extensible axletree $B$, substantially as deseriberl.

4.-The combination of the pivoted plough bean $\mathrm{D}$, extensible axletree $\mathrm{B}$, and laterally adjustable hounds $C$, in the manier and for the purpose specified.

5.- The specifier construction of standard boxes $\mathrm{N}$, so that they afford two bearings or sujports $n \|^{\prime}$ while made in one piece $\mathrm{N}$, and otherwise operate, with wedges or setscrews, for the purpose set forth.

No. 41,686,-F. R. CROTIIERS, SPARTA, ILI-GangPlowshs.-February 23, 1864

Claim.-1.-Hinging the axletree to the frame of the machine so that the former will swing forward of its hingeconnection, in combination with the rhrasting connecting rod $\mathrm{N}$, corcl or chnin $/ / 2$, and windlass $p$, all applied and operating sulstantially as ilescribed.

2. - The use of a tiff rod $\mathrm{N}$, in combination with a windlass $f$, an. I a hinged axle $\mathrm{D}$, operating substantially as and for the purposes described.

3.- The manner of autaching the draught pole $\mathrm{P}$ to the plough beams, substantially as and for the purposes deseribed.

No. 42,258.-ROBERT NATION, Chrbanse, II.L, assignor to himself and JAMES N. ORR. $-G$ ans'-I'lom - Ipril $5,1 \mathrm{~S} 64$

Claim - The combination and arrangement in a gangplough of the plough beams I) D, the guirles F F, provided with the slots $a$ a, the axle 11, provided with the slots $s$, the chains $c$ c the roller $\mathrm{R}$, the lever $l$, all constructed and operating as and for the purposes herein delineated and set forth.

No, 43,804-DRATER STONE, PITTSRORD, N. Y.Gang-Plou hs and Sicters.-Lurust 9, 1864.

Claim.- The combination and relative arrangement of the dranght beam A, liagonal plongh beam B, ribbed jointed plite $\mathrm{C}$, tie bolt $\%$, (one end of which is connected to the e.ir c of the washer plate $w^{\prime \prime}$,) with the seed box B, and its appurtenances, all being arranged and operating conjointly in the manner and for the purposes set forth.

No, H,206.-THOMAS R. MARKILLIE, WINCHESTER, ILL.-Gan:-Ploweths.-Siplimber 13, 180.4 .

Claim.-1. - Hinging or pivoting the plottrh beams E E' to the frame beams $13 \mathrm{~B}$, on both sicles of the axle $\mathrm{A}$, by means of arms $g^{\circ} \mathrm{s}^{\prime}$, and arranging the plowgh beans so that they will extend out on each sile of the axletrec to receive the forwarl and rear ploughs, stibtantially as described.

2.- The lever $G$, and arm $h$, and pin $f$, in combunation with the hinged beams E I:', constructed and operattng sulsstantially as and for the purposes described.

3.-The adjustable bracket: $\ell$, arranged on the trame leam $\mathrm{B}$, in combination with the hinged beans E E', subtantially as and for the purposes described.

4.--The ad ustable vertical guide plate $b$, on the axletrec $A$, adapted to receive a slot in the rear end of the pivoted Iraught pole $\mathrm{C}^{\prime}$, substantially as and for the purposes described.

5.- The combinution of bent lever 1 , werforate I ch ac's plat: $)^{\prime}$, .n I anile plate /, with the pivoted draght pole 
$\mathrm{C}^{\prime}$ and frame beams B B, arranged and operating subatantially as and for the purposes described.

No. 44,351.-JOHA STONE, PlatTSBURg, Me.-Gang Plonshs.-Siptember 20, 1864.

Claim.-1.-In combination with the levers $\mathrm{E}$ and ploughs I, the catches F, constructed, arranged, and operating substantially as and for the purposes herein set forth.

2.- The standarel $D^{\prime}$, which support $>$ the seat, in combination with the levers $E$ and catches $F$, the same being arranged substantially as and for the purptses set forth.

No. 44,924.-S. H. AD.AMS, CNLLTERVIL.1. IL..Gang-Ploughs-Dinember S, 1834.

Claim.-1.-Pivoting the forward ends of the plough beams $\mathrm{E}$ E to a slotted lever D, and supporting the rear portions of said beams upon a slotted lever $D^{\prime}$, hoth lever $D$ rnd D- being capable of receiving a lateral or eniwise adjustment, substantially as and for the purposes de scribed.

2.-The combination of the intermediate beam, $G$, lever D, and hidged plough beams E E, with the adjusting lever J, substintially as described.

3.- The laterally and vertically arlju-table levers I) $L$ pivoted to the supporting frame A B, and adapted to form a forward pivot connection and a rear support for the plough beams, substantially as descriluerl

4.-The ventical guides $e \cdot$ applie.l to the laterally adjustable lever $D^{\prime}$, in combination with the pivoted pleugh beams E E ana lever D, sulstantially as de. scribed.

No. 44,969,-JABISH PIERCE, WYANET, ILI.Ploughins-Machines.-Noermber. 8, is64.

Claim.-1.-The combination of the plough $F$ I", clevises $G^{\prime} G^{\prime}$ and axle $D$, with the frame $A$, axle $D^{\prime}$, seat M rot wheels B, substantially as and for the purposen set forth

2.- The combination of the lever $\mathrm{H}$, link J, clevis $\mathrm{J}^{\prime}$ and pin $K$, the whole being employerl in the manner and for the purposes herein specified.

No, 44,971.-GEORGE OUIRIN ant IOREVZ BER. KEI, Smithsun, II.L. - Gang-1loushs. - Vimemtur 8 , 1864 .

Claim.-1.-The combination of the vertically-adjutable bar E, pivoted har F, and laterally-adjustable pivoted connections $\mathrm{G} c$, with the plough beams if 11 , all arranged and operating sulstantially as described.

2.-The combination of the sectur place supports $G$ G; with ploug beams H, which are capable of being expancled or contracted laterally, substantially as described.

3.- Securing the axle of the rear supporting whecl J. to a lever $h$, which is connected to a sector ; by means of a rod $k$, the whole operating substantially as described.

No. 45,427.-LEANDER MILLEK and HERMIANN

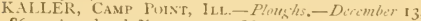
1864. Antedated fanuary 10, 1863.

Claim,-1.-The axle C, provided with the cranks D D, having the wheels E E attached, in connection with the lever $F$ and stop bar $G$, all arranged as and for the purpore herein set forth.

2.- The bar I attached to the bar $a$ of the frame A, as shown, and secured at the desired height by the catch $j$ and notched segment bar I, in connection with the adjuntable plough beam $\mathrm{K}$ attached to the bar I, substantially as and for the purpose herein set forth.

3.- The combination of the acljustable beam $K$, bar I, and adjustable axle $C_{1}$ all arranged as and for the purpose specified.

No. 45,520.-JABISII PIERCE, WYANET, II.1..Wheel-Plonghis.-Dicember 20, 1864.

Claim. - The rod $\mathrm{O}$, links $\mathrm{T}$ and $\mathrm{R}$, in combination with beams $\mathrm{L}$, links $\mathrm{N}$, hounds $\mathrm{B}$, standarels $\mathrm{H}$, lever $\therefore$, when constructed and arranged as herein described.

No, 45,897.-THONAS SIIORT, FuRMtat: ILT. Gizns-Ploughth.-Jimuary 10, 1865

Claim. - The arrangement of the double crank shaperl connecting rod $\left(G\right.$, devices $c c^{\prime}$, links $a^{\prime} a^{\prime}$, beam $E$, lever $\mathrm{H}$, and post I, the whole being employed for joint operation, in the mamner and for the purpose speciflecl.

No. 45,988,-W. H. FREEMAN, BloOMfield, Iowa. Gano-Ploushs.-January 24, 1865.

Claim. - In conbination with the stationary frame A, the hinued plough beam or beams $F$ and levers $G, I$, and $H$, for the purpose of adjusting the height as well as the inclination of the ploughs, substantially in the manner and for the purposes described.

No. 46,137-JoHN C. I'FIEL, ARENzVILLe, Ilt.Gans-Plonghs.-Jinuary 31,1865 .

Claim.-The arrangement of part by which the relative poritions of the plongh beam and the draught pole are maintained after the front of the former has been depressed by the foot of the driver, and cunsisting of the tension chain $K$ an I lever $G$, with its retaining rack $J$, the points of attachment being the flraugl.t pole $\mathrm{B}$ and the frame $\mathrm{A}$, the whole constructed and operated as described and represented.

No. 46,164.-HENRY WEBSTER, BEETUWN, Wis.cims-Ploughth.-January 31 , 1865 .

Claim.-1.- The empluyment or use in a mounted gangplough of an oblique adjustable asle so arranged as to admit of the ready adjustment of the wheek for giving the ploughs more wr less land, substantially as set forth.

2.- The frame II, applied to or connceted with the clraught pole $A$, by means of a joint in connection with the racks ant toothed segments, when applied to gang ploughs, subatantially as set forth.

No 46,412 .-RICHARDSON WILSON, FuWLER, N. Y.-Whiched-Houshs.-Felizery 14, 1865.

Claim.-? he arrangement of the vertical atl, ustable supports D J, with regard the beam E and the axles of the supporting wheeh A II, as and for the purpose herein described and represented.

No. $46,550-$ A. P. DUR.INT and D. Y. BUCKLEY,

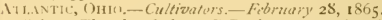

Claim,-The plough frame B D when aranged under the main frame in front of the axletree, and the puwer applied directly thereto, and when attached, adjusted and operated in relation to the main frame, substantially as set forth.

No. 46,903.-I. HOLI.AWAI, Gilrus, Cat.-GansPhoustes.-Bhith 21, 1865

Claim.-The link joint 1 , in combination with the adinstable rods h $i$, lever J, plough frame $\mathrm{H}$, and truck $\mathrm{A}$, constructel and operating in the manner and for the purphe substantially as herein shown and described.

No. 45,974.-IR.A C. PRATT, asisnor to J. II. CAMPBELL, D. MOULERV, E. EMERSON, and $H$.

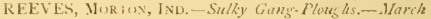
21,1865 .

Claim -1.-Attiching one or more ploughs E, direct to the draught pole $\mathrm{C}$. when the latter is connected to the main frame $A$, and all arranged to operate as and for the purpose set forth.

2.- The oblique bar 1), attached to the rear part of the draught pole $C$, and having a plough $E$ secured to it, and arranged as shown, so as to be capable of bcing adjusted substantially as and for the purpose specified.

3.- The lever II, with cam I attached, arranged and applied to the drausht pole to operate in relation with the axla $a$ of frame $\mathrm{A}$, and for the purponts specified

No, 47,686.- IOHN E. TR.IVIS, assignor to himself and ELON FRANCISC(), GRERIILL., ILL.-GangPloughs.- Mary o, 1865 .

Claim.-1.- The combination of the plough frame B and its attached ploughs wi:h the fived frame $\mathrm{A}$, by means of a fulcrum piece $X$, or other imilar hinged joint, subtuntially in the manner and for the purpose herein set forth.

2.-The employment of the levers $t$ and $t^{\prime}$, with their fulcrums $/$ and $l^{\prime}$, and their comecting links $\ell$ and $\ell^{\prime}$, and their bolt $f$ and $f$, ween combined with the frame $\mathrm{B}$, substantially as and for the purposes set forth.

No. 47,942.-I'HILO II. GILBERT, KEWANEF, ILL. -Gang-Ploushs.-Nay 3o, 18 i5. 
Claim.-1.-The combination and arrangement of the ploigh beams I) 1), the connecting adjustable straps $f f$, and the removable pivoted connection $\mathrm{Z}$, with the tongue $($ ), as and for the purposes herein specified and described.

2.-The combination of the plough beams I) I), the jointed lever I J, the supports $\mathrm{H}$, the lever $\mathrm{F}$, and the standard $\mathrm{E}$, arrane ed and operating substantially as and for the purpose specified and shown.

3.- The combination of the plongh beams $\mathrm{D} \mathrm{D}$, the reciprocating bean $\mathrm{C}$, the rear support $\mathrm{N}$, and the tongue (), piroted to said beams, arranged and operating as and for the purposes shown and set forth.

4.- The combination of the plough beain D D, reciprocating beam $\mathrm{C}$, the axle $\mathrm{A}$, provided with the slots $a$, the bolts $b b$. rack $c$, pinion wheel $d$, and lever $c$, arranged and operating as and for the purposes specified.

Nu. 47,989.-JACOB SEIBEL, MANLIUS, ILl.-Gang. Ploushs.-Mizy 30, 1855.

Claim.- The combination of the seat I, fulcrumed at J, perforated standard $\mathbf{M}$, the spring $\mathbf{K}$, provided with the pin $a$, the lever L, or its equivalent, for operating said spring and pin, the rod $\mathrm{N}$, and plough beams $\mathrm{P}$, arranged and operating substantially as and for thə purposcs herein specified and shown.

No. 4 8,049.-JOIIN C. BROWN and $q$. H. SLIM PERT, PINkNeviti.ie, Ill.-Gang-Ploughs.-Fune 6, 1865 .

Claim.-1.-The arrangement of the hinged adjustable beam L, with a caster wheel $\mathrm{C}$, in the manner and for the purpose herein described.

2.-The use of self-locking levers J J, for raising or depressing the ploughs, applied to the adjustable guides d d', substantially as described.

3.-Connecting the hooked rocking levers I I to the plough beams by means of bent swinging rods, substantially as described.

4. - The lat rally adjustable slotted plates $d d^{\prime}$, applied to the slotted frame $G$, and adapted to serve as guides for the plough beams $\mathrm{F} \mathrm{F}^{\prime}$, and also as bearings for levers which are used to raise and depress said beams, substan tially as described.

5.- Pivoting the forward ends of the plough beams to rocking bars $a a^{\prime}$, which are arranged one in advance of the other, and applying the ploughs to said beams at about equal distances from their respective pivotal connections, substantially as described.

No. 48,387 - VALENTINE FELKER, CANNEL, ME. -Ploughs.-7une 27, 1865.

Claim.-I.-Elbow C, upright D, and level elbow b, combined and arranged to operate substantially as and for the purpose set forth.

2.- Rod $\mathrm{G}$, lever $\mathrm{H}$, truck $g$ and adjustable collar $j$, when arranged and combined to operate substantially as described, whereby the depth of the furrow is not only controlled, but the direction of movement of the truck al ways corresponds to the line of draught.

3.- The arrangement of the plough holder, as constructed of parts C D B and $b$, attached to plough A, with plough governor $\mathrm{GH}$ and $j$, operating as described and for the purposes set forth.

4. - The combination of two ploughs in one gang, when combined and arranged to operate snbstantially as and for the purposes specified.

No. 48,512.-JAMES BREWER, Albany, N. Y.Sulky. Ploushs. - Yuly 4, I865.

Claim.-1.-Making one of the standards E, E, with the plough beam in its proper position, yielding to a certain degree, for the purpose of permitting the plough to pass ob structions which are its line, and which are to hard to cut, substantially as and for the purpose specified.

2. - The combination with the plough beam of the rigid standard $\mathrm{F}$, yielding standard $\mathrm{E}$, screw bolt $o$, and spring $p$, substantially as and for the purposes specified.

3.-Hanging the plough beam of a sulky plough between two standards in such a manner that the operation of the plough is not affected by the passage of the supporting wheel over rough or uneven ground, as and for the purpose speci-

4.- The combination with the plough and its beam G, herein described, of the laterally adjustable caster wheel $H$, when fastened to the rear of the plough beam, substantially as and for the purpose specified.

5.-Connecting the hound in the furrow side to the pole by means of a hinge $s$ for the purpose of making it and the furrow wheel adaptable, as and for the purpose specified.

6--The combination with the foot lever $\mathrm{L}$ and plough bean $G$, when capable of rotation within the stanclards 1 , of the friction rolls $\%$, as and for the purposes specified.

7.-In combination with the plough beam $G$ and tongue $P$ the adjustable breast yoke $Q$, for the purpose of cutting more or less land, as herein described.

No. 48,679.-A. HAMMUND, JACKSONVILLE, ILL.Gang Ploughs.-Fuly i1, I865.

Claim.-1.-The segment rack L, pawl M, and foot lever $O$, all arranged and applied to the plank or timber $\mathrm{D}$, and bean $A$, substantially as and for the purpose specified.

2.- The button $P$, when applied to the plank or timber $\mathrm{D}$, and used in connection with the rack $\mathrm{L}$, pawl M, and foot lever $\mathrm{O}$, for the pnrpose set forth.

No. $48,696 .-$ - J. H. LA BOYTEAUX and C, A. ASHTON, Jacksonnille, IlL. - Gang Floughs. - Fuly II, I865.

Claim.-1.-The adjusting of the axle $\mathrm{A}$, and consequently of the plough beams and ploughs, by means of the lever $j$ connected with the axle through the medium of the chain G, arranged sub-tantially as described, for the purpose of adjusting the ploughs to suit the surface of the ground over which they work

2.-The pivoted plough beams N M, in connection with the bar $S$, lever $T$, and chain $N^{*}$, all arranged to operate in the manner substantially as and for the purpose set forth.

No. 48,846 . - JAMES B. SKINNER, ROCKFORD, II... Gang Ploushs._- Fuly 18. 1865.

Claim.-1.-The combination in a gang plough of one or more ploughs before and one or more ploughs behind the supporting axle where the ploughs are firmly attached to a rigid Irame which is itself adjustable upon and in relation to the axle, substantially as set forth.

2.-The combination of the tongue with the main frame by a hinge and lock, substantially as described to render it rigid or flexible at the will of the driver.

3.-The combination of a clevis with the main frame of a gang plough and the tongue whether rigid or flexible, substantially as described to, work three or more horses abreast and equalize the draught between them.

4.-The attachment of the left supporling wheel of a gang plough to a crank axle to preserve the desired parallelism of the axle to the ground, substantially in the manner set forth.

5-The combination of an adjustable gauge wheel with the rigid main frame of a gang plough, when arranged forward of the ploughs, substantially as and for the purpose set forth.

6. - The combination in a gang plough of a rigid main frame and an adjustable axle with a mechanism for raising and lowering the frame, substantially in the manner described for the purpose set forth.

7.- The combination of the main frame, the axle, and standards by the draught rod and reach or guides, substantially in the manner described for the purpose set forth.

No. 49,087.-C. W. CORR, CARLinville, 1L1..-GangPloushis. - tu ust 1, is65.

Claim.-1.-The crank axles $C$ provided with the hole, or its equivalent, as shown and described.

2.-Receiving the ploughs by means of the clip $b$ and brace $f$, substantially as shown and described.

3.-The combination of the plough standards $a$, stirrups $d$, and lever $\mathrm{N}$, all arranged to operate as and for the purpose set forth.

4.-Attaching the independent crank axle $\mathrm{C}$, one above and one below the main frame, as shown and described.

5.- The stirrup or guide $\mathrm{V}$ in combination with the bolt $p$ and stud $p^{\prime}$, for the purpose of adjusting the tongue laterally, and at the same time permit it to have a vertical movement, as and for the purpose set forth. 
6.-The foot lever $\mathrm{W}$ arranged to operate in connection with the tongue and main frame, with its front end working in the slotted bolt $\mathrm{X}$, as and for the purpose set forth. 7.- The slotted bolt $X^{\prime}$ in combination with the slotted wedge $x$, for the purpose of adjusting the parts, as shown and described.

No. 49,564.-HENRY SMYTII, New LORENZO, CAL. -Gang Ploushlis. - August 22, 1865.

Claim.-The construction of the eccentrical shaft or axle in two parts, so as to be able to raise or lower one wheel without interfering with the other, and the arrangement of the $\operatorname{cog}$ wheel attached to the eccentrical shaft or axle, to raise or lower the body of the plough, torether with the ploughshares, by means of the wheel or endless screw, and their combined arrangement, for manufacturing gang ploughs.

No. $49,8_{33}$.- IRA C. PRATT, assignor to himself and L. F. PRATT, NorTon, ILL.-Sulky-Ploughs.-Siptember $5,18 \div 5$.

Claim.--1.-The plank A, to which the plough beams B are secured, connected with the dranght pole I by joint or eyebolts $f$, and operated or adjusted by the driver on his seat, through the medium of a lever or arm, or their equivalents, substanti.lly as set forth,

2.-The adjusting of the plank $A$, and consequently the plough heams and ploughs, higher or Iower with the axle $\mathrm{D}$, in order to regulate the depth of the penetration of the plourhs by means of the plate $\mathrm{E}$ securcd to one end of the plank, and provided with a series foles $c$ in a vertical line, through any one of which the bolt $b$ passes into the axle at one end, in connection with the slotted plute (; through which the axle passes, and the lever $F$, attached to the plank and bearing on the axle, substantially as and for the purposes set forth.

No. 49,911,- I. S. P.JDON, Summerfield, II.L. Gang-Ploushs. - Siptenber 12, 1865.

Claim. - 1. - The side bar $\mathrm{C}$ C, seat standards D I, slotted axle $\mathrm{A}$, and slotted brace $\mathrm{C}^{\prime}$, in combination with the pivoted plough beams $F F$, and rocking levers $G G$, all arranged and operating substantially as described.

2.-In a wheel-cultivator, proviling for expandin $r$ or contracting plough beams $\mathrm{F} F$, the supporting frame thereof, and the contrivances for elevating or depresuing the said beams, substantially as described.

3.-Supporting the plough beam $\mathrm{F} \mathrm{F}$ in an elevated position by means of levers $G G$, links $d d$, and a spring catch lever $g$, which is pivoted to a post projecting from the draught pole, substintially as described.

4.- Pivoting the plough beams $\mathrm{F}$ to side beams $\mathrm{C} \mathrm{C}$, which are susceptible of being separated or contracted without detaching them from their axle $A$, substantially as described.

5.-The use of slotted standards J J, in combination with the slotted sector plates $j j$, and fartening $k k^{\prime}$, substintially as described.

6.-The clamps $\mathbf{K}$, applied to the standardy $J$, subst un tially as described.

No. 50,828,-ALBERT KEITH, Lision, Ilt..-Sulky. Ploughs. - Novimber 7. 1865

Claim. - The combination of the lever $v$ with the sliding brace $z$, guide standard $z$ and standard M, and the arrangement and combination of the standard 1 , with the arm $K$ and standard M, substautially as set forth.

No. 50,837.-1SAAC F. NUTTING, PALMER, MAss.Whecl-Ploushth.-November $7,1865$.

Claim-- The combination of the head lever E, connec tions $a b \mathrm{~F}$, with a plough $\mathrm{D}$, and axle $\mathrm{B}$, and draught pole $\mathrm{C}$, when mounted on the wheels $\mathrm{A} \mathrm{A}$, sub tantially in the manner and for the purpose clescrib ad.

No. 51,358.-MARSHALL SATTLEY, TAYLORSviILE, ILL. - Gang-Ploushs, - Dicember 5 , IS i5.

Claim.-1.-The frame $\mathrm{J}$, in the described combination, with the axle $\mathrm{A}$, plough beams $M \mathrm{M}$, levers $\mathrm{L} \mathrm{L}$, and upright $g_{3}$, all constructed and operating as described.

2.- The attaching of the draught pole $\mathrm{W}$ to the frame J by means of the slotted plate $\mathrm{X}$ and bolts $m^{\prime} m^{\prime}$, for the purpose of admitting the lateral shiftiner of the pole, and the setting of the ploughs more or less to land, as de scribed.
No, 51,536.-CAROL.1. ATWO()I), 1.EBANON, ItL.Ginus-Ploughs. - Dicimber 19, 1865.

Claim. - The metal bars 11 and I I in connection with the clamp J, all arranged substantially as shown, to admit of the lateral adjustment of the plough beams with the sills $\mathrm{F} \mathrm{F}$, for the purpose set forth.

No. 51,543--J. F. and W. L. BLACK, LANCASTER, 1.L.-Gang-Ploughs.-December 19, 1865

Claim,-1.-The connecting of one of the wheels $C^{\prime}$ to its axle $\Lambda$ by means of the bar $\mathrm{E}$, fitted in the socket $\mathrm{D}$, and connecied by a chain $G$ to a lever $H$, in the manner substantially as described, to admit of the vertical adjustment of the plough', for the purpose specified.

2.- The adjusting of the draught pole M laterally through the medium of the screw $g$, plate $h$, and nut $i$, substantially as and for the purpose set forth.

No. 51,790.-CHARI.ES BELDEN. MUHLRURG, OH10.-Gans-Cultizators.-Jinuary 2, 1866

Claim.-The blades $n$, contructed as shown, with a rib $p$, and arranged in relation to each other diagonally across the machine, in combination with the tandards $m$ and diagonal frame $C$, substantially as and for the purpose set forth.

No. 51,\$75-II. C. SMITH, RIIME FARM, IIL.Gang-Ploushs - January 2, iS66.-Antedated Decembi's 28,1865

Claim. - 1.- The connecting of the plough henms A A to the axle $\mathrm{C}$ by means of the king bolt $\mathrm{I}$, strap $\mathrm{E}$, and plates $\mathrm{F} \mathrm{F}^{\prime}$, all constructet, combined, and arranged in the manner and for the purpose herein set forth.

2.- The plough-beams $\mathrm{A} A$ attached to the axle $\mathrm{C}$ as hown, in combination with the frame $H$, the latter being comectel at its front end to the plough beams by the rod $b$ and its rear end supported lyy the caster wheel I ; the above parts being wed in connection with the corl or chain $c$, pulley $f$, lever $J$, and the strap $K$, or its equivalent, for the purpose specified.

No. 52 IO4,-THOMAS WV(IIFE, GIRARI), ILL.Sulky-Ploushts.-January 16, 1856.

Claim - 1. - The connecting of the front ends of the plough beams ( $\mathrm{G}$ by hinges II, to springs I attached to the framing of the device, in combination with the shafts cap, arms $d$, rods $\mathrm{N}$, and levers $\mathrm{P}$, or an equivalent means for operating the springs, sub-tantially as and for the purpose herein set forth.

2.-The raising and lowering of the plough leams through the merlium of the rods $K K^{\prime \prime}$, cranks $K^{\prime} K^{\prime \prime \prime}$, thafts $L L^{\prime}$, and levers $M M^{\prime}$ all arranged subtantially as describerl.

3.- The ad ustable frame $S$, constructed and applied to the plough beams $G \mathrm{G}$, substantially as and fir the purpose specified.

No. 52,401.-A. P. DURANT, ATI.ANTA, ILL.Gang-Plou; - $h$ s.-February 6, IS66.

Claim.-1.-Uniting the two ploughs $\mathrm{MN}$ to a single beam $\mathrm{G}$, where said beam is arranged between the frame $\mathrm{C}$ $\mathrm{C}^{\prime}$, and hung on a pivot to the front end thereof and forward of the axletree, substantially as shown and described.

2.-The two levers $S S^{\prime}$ when united together in the manner described, and connected to the rear end of the plongh beam $G$, for the purpoie of keeping said team from twisting, or the plough from slewing or "creeling" out of their proper path, and for the purpose of raising them out of the ground, as set forth.

No, 52,555.-ROLANI) R. GASKIL.L, El. PAso, ILI..-

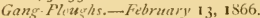

Claim.- Ilinging the tongue $A$ to plough beam $B$, at the middle thereof, or directly above the share II, in combination with brace $\mathrm{L}$, hinge $x$, hars $\mathrm{F} \mathrm{F}$, brace $\mathrm{K}$, and axletree $G$, the several parts being arranged as and for the purpose set forth.

No. 52,633,-JOSEPII WIDMAN and FRENCH MULi.ICA, EL PAso, It.1.-Ploughtis.-Fetruary 13, IS66.

Claim.-1.-The attaching of the plough heam $\mathbf{E}$ to the axle $\mathrm{A}$, through the medium of the hounds $\mathrm{C}^{\mathrm{C}}$, in combination with the draught pole $\mathrm{F}$ and bar $\mathrm{K}$, attached to the plough beam, and all arranged to operate in the nanner substantially as and for the purpose set forth. 


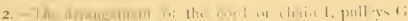

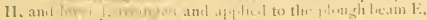

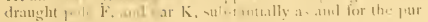
pore - pretilat.

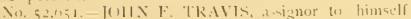

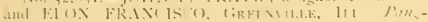

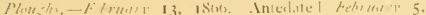
ISots.

Claim, - 1.- The aliding lar $\mathrm{C}$, when uncal in connection with the axle 13 and bol-ter 1 , and regulatimg bolto a $7^{\prime}$, at and for the purpone set forth.

2. The biured braces 1111 , the levers $\mathrm{H}^{\prime \prime} \mathrm{H}^{\prime \prime}$, and pus $\mathrm{F}^{\circ} \mathrm{F}$, for the purpose of attaching the plough frame a. yous plomgh to the lobler thereaf, when such parts are constructed and employed in de-cribed and set forth.

No, 52,990-1. 1. and B. F. (i.11.1.1L.A.NI), J.ITTHE-

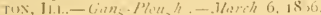

I'laim. 1.- Aitaching the plough beams to the axle 13 ly means of the rock shaft 1 , provited with the arms $t \cdot t$ and lever $c$ : arramed to operate substantially as axd for the purprese set forth.

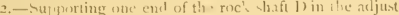
alile bearing $a$, in eombuation with the leser $F$. arranged as awon and dercribed.

3.- The tongre 11, attached to the front end of the plongh beams, in combination with the regment (; ans rocl $m$, pros.

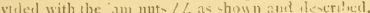

No. 53.+24.-IU)IS H. E(KERI. LHEANON, IL...

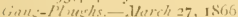

thim. - 1-The arrangenent of the lou, h beam E E,

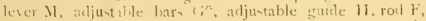
sctew rock $G G_{i}$, in comblination with the tamlasds J, roils

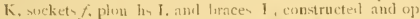
erating in the manner and for the urpore hertin speci fierl.

2.- The comlin tion of the lever $\mathrm{N}$, cro s bar a notched f.l.te $\uparrow$, and frame i, com-lrueted and armageal to merate 4. the manaer and for the purpose he rein specified.

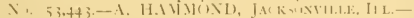

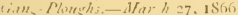

Cliun -1.-Provilin : for adjusting the two supporting wheels $\mathrm{A}$ and $\mathrm{F}$ imultmeouly, by meas of a rack ancl screw, or their e puis alents, nlutantially as described.

2.-Connecting the 1. miside wheel fi to a sprin or yielding lever $G$, subatantialls as tencribed.

3.-Comectin : the rear sapporting wheel I to a ypring or vielcling leser $H$. sulb-tantially as dencrilect.

4.- F'rovicl ng for adjustimi the spr ug : ' of the lever II, $\rightarrow 11$ -

5.- P'isoting the axle bar of the rear supporting wheels $F$ and I to oscill.ting sedmert- vubstantially as ie scribed.

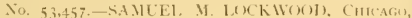

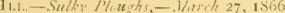

Claim.-1. - The arrangement sulstantinlly as describet of the part $\mathrm{P}$, or it equivalent, in connection with the pole $A$ and the clamp 1 ), or its eyuivalent, substantially as abore de-cribel, by means of which a change of direction is uh, tainerl. substantially as vet forth.

2.-The arrangement of the braces $\mathrm{R}$ and $\mathrm{R}$, in manner -ub-tantially as et forth. with the corn plunghs or their equivalent, o that 1 lue anie can be pointed as one may desire. in order to plough deeper or otherwise, as one may " wh.

3.- The method of rni-ing and lowerin : the ploushs by the arran-ement of the levers I and I, in connection with the lrace, $\mathrm{E}$ and (i, ruming from crom-har to crosubar. as ahove dencribed, or their equivalent, subtantially as above et forth, witl the seat $k$, and in connection with the axlc 1. sub-tintially as ilescrilied, the cross-bar $\mathrm{C}$, with the arms 1 and 1 or thei enivalent, in connection with the hank II and VI, sulstantially an wet forth, ant the cross-piece II, or it- equivalent, sulsatantially as ret forth.

4.- The arrangement of corn plougls in any and all of the ways subrtantially as eet forth. in combination with a frame-work witl wheek, and constructe I substantially as ut forth.

No. 53.749.-MII.TUN RUBEKTS, ST, P.H., MINN,

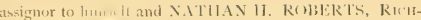

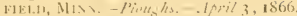

C'lam.-1.-The ittaching of the plough to the axle and wheels, in the mamer substantially as and for the purpose herein eet forth.

2.- The roel I, pivoted to the axle $A$, and presvited with a hook 1 at i.souter end, in combination with the plough ant the wheels aud axle, sulstaniatly as and for the pur pose specified

3.- The whecl 13 , provided with the concave flange $\mathbb{K}$, in combination with the plough $\mathrm{F}$, sutst untilly as and for the purpose ace fortis.

1.- The r. Hlers. $\mathcal{X}$, pliced in the fr.me .1 , having the rodis () () attaclsel, in cumbination with the plough and the wheek and sle, suhntantially an and for the parpose specified

No. 54,029.-IAIIES B. SKINNER, R(sеKFORH, 11.1.

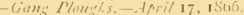

Clam,-1,- The combination of the ploughs in a gang plough, wth the min frame comstructed, arranged and ancratin: sulstantially as describe I when all arranged helind the axle and rendered adja-table, substantially as and for the purpone aet forth.

2.- The combination of the tongue, the man frame and the luching leter, sulstantially as and for the purpose at urth.

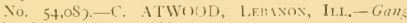
Pliughe-tpril $24,1866$.

Claim,-1,-Forming the forward connection between the be um of the frame $\mathrm{A}^{2}$ of a me:al piate $C$, having slot $a^{\prime}$ in it for the passage of the attaching devices $a$ and $a^{2}$, so that the machuse may be revilily nil unted to any widh.

2. - The adjust.ble tie or brace rods D, or their equivalen's, when used as and for the purpose set forth.

3.- The combination of the shaft $\mathrm{E}$, levers $\mathrm{E}^{\prime}$ and $\mathrm{E}^{2}$,

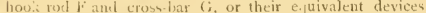
with the plough-beam - of gang ploughs, for the purpuse h.re. in set forth.

4.- The combination of the strap piece $c$ and set screw $c^{\prime}$. with the beam $\mathrm{H}$ and with the brace 11 , is and for the purpose set forth.

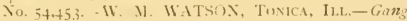
Ploits

Chim.-The combination in a gang plough of the hinged braces and bolts c't'te $e$, or their equivalents, ant side eat and support $n n^{1} \mathrm{~K}$. all arranged s $\mathrm{u}^{1}$ stantially as and for the pupose set forth.

Ni. 54,603,-TH()MAS J. CORNELL, DFCATLR, II.L. - Girns Ploustos.-itar I 5, 1566

Claim.-1.-The combination of the lever NI, and bent arm () for raiving the beams from beneath at a point in the rear of their forward point of attachment, so as to he vibrated upon the said lifting device by a weight applied to the forward ent sulstantially as descrilied.

2.- The combination of the lusk $\mathrm{H}$ attached to the forward ent or the beams and to the carriage, and operating sulstantially as describet.

3.- The comlination of the beam and the curved arm, or its equivalent, which in it-Inetward mutiom operates to keep the beam down umeler the circumst inces described.

4-The mode of attaching the tongue to the carringe, consi-ting of the laterally sliding socket and the guides, arran red and operating as described.

5.- The combination of the links 11 and standards $\mathrm{G}$, whore holes artmit of the vertucal arlju-tment of the links therein.

6.- The arrangement of the foot lever R, the links H and beams 1 , operating as iescribet

No 54.003.-JACOB L. RUNK, JAME- H. IBR()WN,

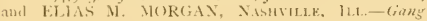

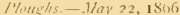

Claim.-1.- The plough heam att :ched to a bulster, the latter leing hinerl or pivoted to the axle or carriage, sulslontially as and for the purpose dencribed.

2.-. Iituching the draught-rod to the lieam in such a manner an to utilize the draught of the team in raisung the plough-from the grombl, when the forward support of the bean is removed.

3.- The combination of the beam $I$ and tongue $G$, or its 


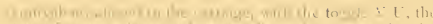

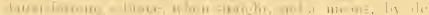

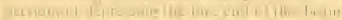

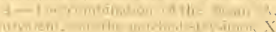

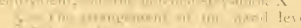

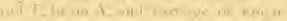
twats

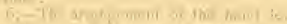

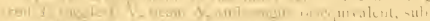

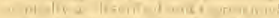

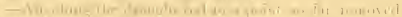

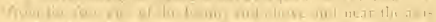

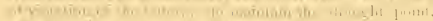

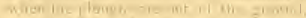

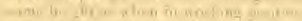

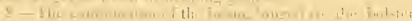

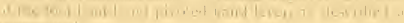

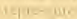

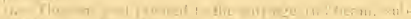

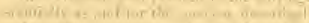

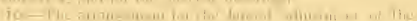

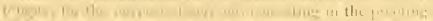

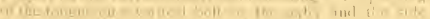

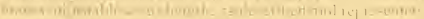

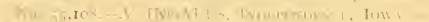

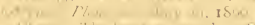

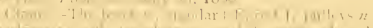

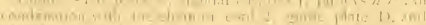

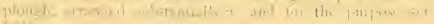
wisio

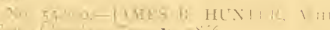

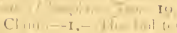

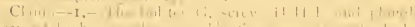

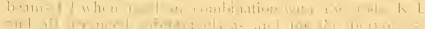
watit

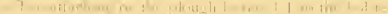

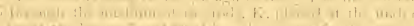

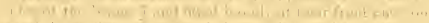

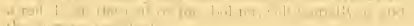

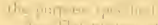

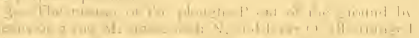

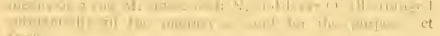
$\ln t 1$

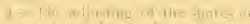

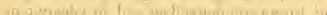

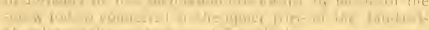

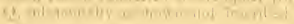

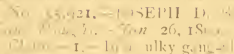

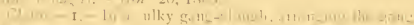

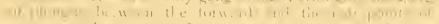
sto

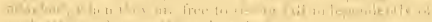

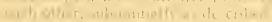

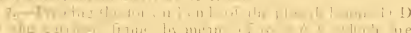

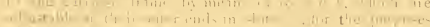

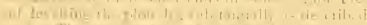

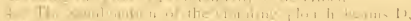

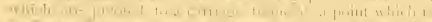

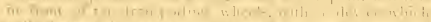

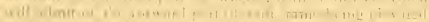

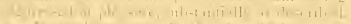

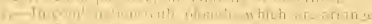

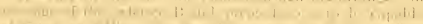

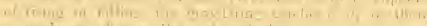

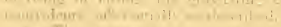

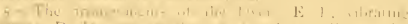

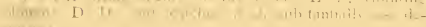

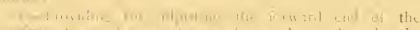

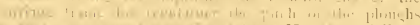

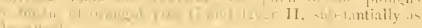
Alowid

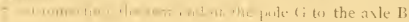

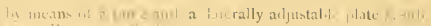

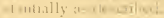

a.- The wit wewh thught rod $\mathrm{K}$ anangerl and applied to the filuegh fownuge 0 as to operate substantially a desculied.

9.- - llac vindmationt of a pole: $G$, which is adjustable at

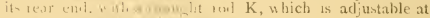

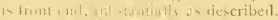

Nu. $1,2, \%$ GLilliE WITT, RICHMOND, VA.-

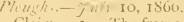

Clim. 1.-The frame $a$, $b i$. cast in one piece, and constructerl as describesl, in combination with the mould lowarl \& landside, and point h, the whole being contuucted and operating in the manner and for the purpose art lorth.

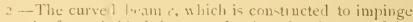
4.13 the frame lichimi the central point of resistance of the antulil thasul, sth tonti,tly as lescribed.

3.- I lu beam $\therefore$, in conbination with the brace $m$ and

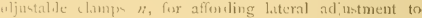

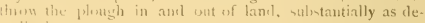
cili -1 .

4. In combluation with the curved beam $r$, the slotted

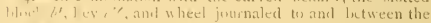
Worth homllew valintantially as descrilued.

5- The wheet if jurnaled to and between the plough

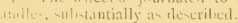

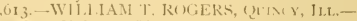
$\therefore-7+k_{1} / 5,-7_{11} l_{1}+1,160$.

(Thum - 1.- The in maner, as hercinberore set forth, of courus tong-ploush or cultivatior heams upou a carriase If $t$ can be user to support either or luth ly mente of the

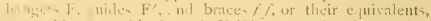

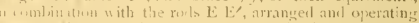

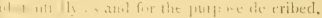

a-The soul lars li, with th:or theves 1. or sn e piva

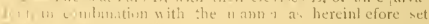

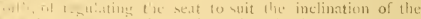

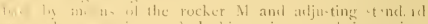

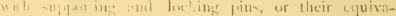
nt-

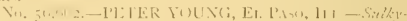
17. $2 .=/ 1+1,24,1$ Sist.

flime I. The coril i anil, sliding rod k, lever $\mathrm{F}$, m. wit arrank col anif eperating as and for the pur$\mathrm{Pit}+\mathrm{t}$ finth.

(m)

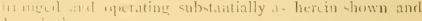

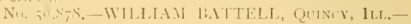

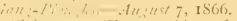

Clan-1-The attacline of the avtes of the whed. 1) 1 in wi the machine to the rear parts of the bars $C$ C. the hunt wis of which ate attached lis hioges at to the romit patt of thr. frome $\mathrm{d}$, in connceion with the ses

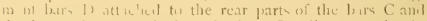

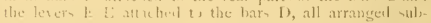
antally an and for the furpore sprecified.

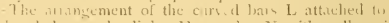
the pingh lies as by links $\mathrm{M}$, gutes $\mathrm{N}$ mith rullers ;

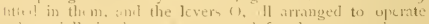
atlictantially in the maner as at.d for the parpose herem in liuth

:- The sesantumtion of the clevises 11 , as sheswn and folde t. to wimit of the arljowment of the plough beams. 4. 'सt font'.

$t$ The thamble . juminleal with set serews $h$, in

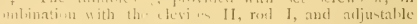

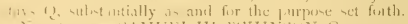

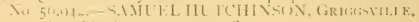

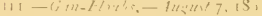

("ain 1 - The clevating or aljusting of the frame $A$ of the machine in a vertical dire tion, in order to regulate the slepth of the penetration of the ploughs, by means of levers II H, grovisted with lower segment ends $a$, and wenred to the sicles of frame $\Lambda$, in combunation wath the prome pims E F, attacherl to frame A, and passing lowely through the asle $\mathrm{D}$, substantially as shown and to a riberl. 


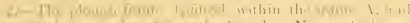

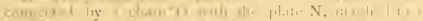

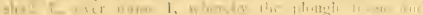

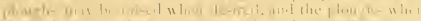

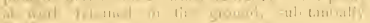

fint

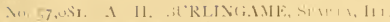

c.

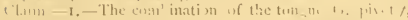

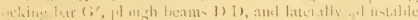

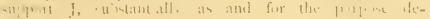
-111 in:al

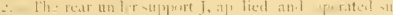

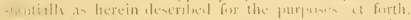

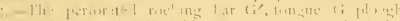

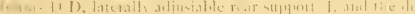

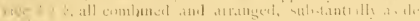

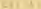

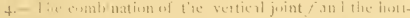

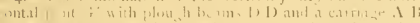

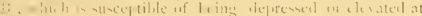

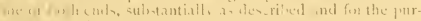
in weet litich.

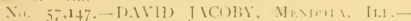

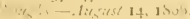

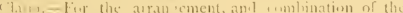

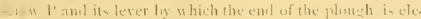

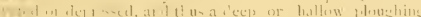

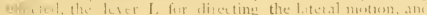
$t$ if insel problle ti for regulatiog the wertical motion of

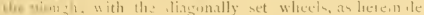
$111,+1$

Nir, 57.SS, - TAMES IV, DRINALIMAIV, DANIEL

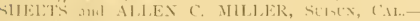

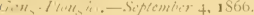

Claim.-1- The peculiar convtriction of the frame in - her to obtain sufficient strength for a mumber of plougha a d lacing the diagenal b.r. $\mathrm{A}^{2} \mathrm{~A}^{3}$ between the par lited $\lim .1 \mathrm{~A}^{\prime}$ and the cross braces $a a^{1}$, substantially as de$+1+i 2 \cdot 1$

2.- The manner of attachment of the plou shs to their rea ective portions of the frame by means of the l, ant loraces

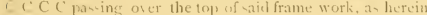

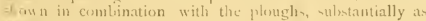
ar $\rightarrow$ rilied.

; The adju-table wheel $\mathrm{E}$ an l seriper $f$, with the

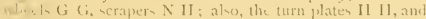

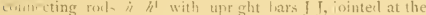
turn whte 11, an esulanaten with the sweep L. sulntantially xalceribed and for the purpone net forth

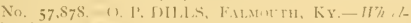

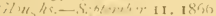

Claim. - The totted atjotit'le lars C F, with

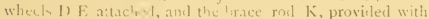
the looy ar eve $t$, all arsangrel and ayplied to a plough, simiantially in the manner as and for the purpose set fortis.

No. $57.587 .-$ ROI AXI) R. (i.1SKILL, MENTriT,

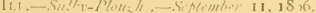

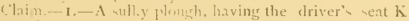
is atrached as to permit it is ascillate fruely, herientally, - 1il tantially a ant for the purposes set forth.

2. The herei before ilifecrilued mech nism for adju tals: unpentine the plough A liy a syatem of lewera ("E ai $\mathrm{F}$, and a chain $\mathrm{F}$, sair soveral warts houg ruspectively

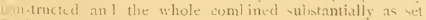
Fintis.

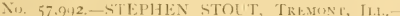

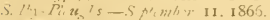

Chi 1.-1.- The attaching of the eraurht pole $\mathrm{K}$ to the

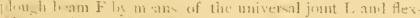

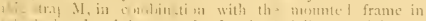

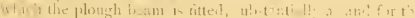
(thithat ynecified.

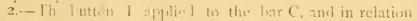

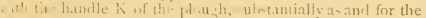
purpose -jecitied.

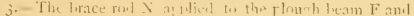

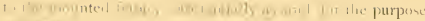

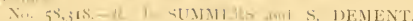

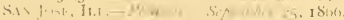

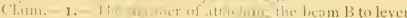

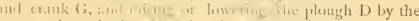

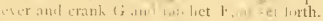

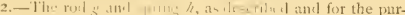
weres net fillo

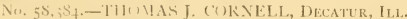

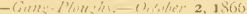

C'lam.-1.- The plinugh andar.l I, juurnated on a hori-

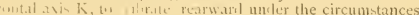
1. acrily, 4 .

2-Ihe cate' (2) in tomlimation with the standard 1, y' 1 at 135 as dererilicel.

i.- The pring R, in combination with the stanctard I, wation s ilueribul.

1. - Ih+ ece 71 rit sesment WV, in combination with the

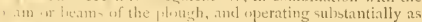
1. $, \mathrm{mil}, 4 \mathrm{l}$.

No. 5 i ; :-H. X. H.MLTON, PACHECO, CAL.-Gang-

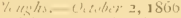

(Thi:s. - 1.-The plough frome F, parallel arms E, beam $11,1.4$ is i, vertical bar $\bar{j}$, and pirm $i t$, combined and operulin. - 1-tantially as described, for the purpose specifi +1.

2.-IIe l-ver J, arms E E, laeam H, and frame F, comtincal ami wperating ablotantially as elescritsed, for the pur120 c. yecticel.

No. 5i, 395,-T. B. EDGELI, J. W. and E, A. ALEX-

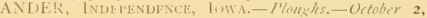
1866

Clam.-1. The constuction of a plough cartage for supporting plutrin, of the avletree A, wheeks B, beam C, cent (', lugam I), pivoted pole $(i$, hand lever 1], and connecting ruxd $s$, subs untially as described.

2.- The pendant E applicil to the beam D of an adjustable plough carriage, which is constructed substantially as flescriberl.

3 - Pivoting a plough to an aljustable beam of a carriage, so: to operate substuntially as set forth.

Nin, $-8,612,-\mathrm{F}$. S. D.IVENIY)RT, JERSEYVILLE, II.L.

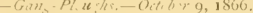

(Thim, I.-The lever P, rod (), an l brake $\mathrm{R}$, arranged and onerating as and for the purpose described.

2 - The himgel board $G$, in connection with the re ver-i le avligs, sulntantully as and for the purpose decerilect

3.- Th- loser (), and quatrant $\mathrm{N}$, for regulating the theyth of the furrom, substantially as and for the purpose yic. ificel

i.- I.Iftums the himel part of the machine by means of the lever or arm I, in connection with the chain I, wheel $K$, ani lever 1 , these parts operating together sulistantially as an I for the purpose described.

5.- llinging the fooboard 11 to the plough frame, as derilied.

6.- - Se-urin the tongue or dranght pole to the footlmarl $M$, in the manner and for the purpose described.

7. - The slicling plough tandard 1', guixle block $0^{*}$, lever $\mathrm{A}$, and nutched seat -1 andarel $\mathrm{C}$, when used to scther and in $\mathrm{c}$ ancetion with the ather parts.

8. - Conmecting the lever L with the tongue or draught $|x|$ - by fantenins it to the funtboard, the whole operating tis thet substantially as and for the purpose set forth.

No. 8,986,-FREDERICK S. DAVENPORT, JERSEY VIH.1, II., a-imar to ROBERT NEWTON.-Gang-

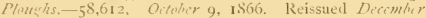
2, 1879. Filed orkex $15,1879$.

Clami.-1.-In a whecl plough, the combination, with a swin: axle ans wround or carrying wheel, of friction clutch mechanism and means for engaging and disensaring the latter with the proutul or carrying wheel, said paits heing comstructed and aciapted to raise the plough by fuching the swing axle to the carrying wheel by friction cluch engagement, and raise the plough beam by the 
drausht or liwwer of the team, unbutintially as et forth

2.- In a wbeel-plough, the combination, with a gromml wheel, a swing axle, and a plough beam connected to the later, of cluch mecbanism connected to the axle and adapted, by engagement with the wheel, to utilize the draught of the team in turning the swing axle into upright position, and thereby mise the plough beam, substantially as set forth.

3.- In a wheel-plough, the combination, with a ground wheel, a swing axle, and a plough heam connecte I to the latter, of a friction clutch connected to the asle and adapted, by contact with the wheel, to turn the anle into upright position, and thereby wise the plongh bea n liy aid of the draught of the team, substantially as set forth.

No. 58.773-J IMES E. CHEASEBRO, BUFAI, N. Y.-Sulky-Plourhs and ITarroses-Oclaber 16, 1866.

Clain,-1.-The combination and attzchment of a plough to a sulky in such manuer that the plough beam thall pass under the axle of the sulliy and project forwarl. and the plough haniles project in rear of the axle, and in convenient gr.ssp of the ploughman as he sits upon his seat, substantially as set forth and described.

2.- The combination of the guide tirrup $l_{i}$ with the slide $(i$, for the purpone of forming a comection of the forward end of the plough beam with a sull:y, sulstantially as set firth.

3 -Connecting the re ir end of the plough to a brace or footboard D, projecting from and in rear of the avle, for the purpose and substantially as described

4.-The driver's seat $\mathrm{A}^{4}$ and foothesard $\mathrm{H}$, projected and supported in rear of the axle, for the purpose and subitantially as set forth.

5.- The combination of a harrow M with a sulky, for the purpose and sub-tantially as described.

No. 5 S,78S-K. I. IOIGE and E. II. WAIKER. GA1.LATIN, Mo.-Gang and Subsoil Ploushs.-OLWbir I6. 1865 .

Claim.-I.-The construction and arrangement of the pole $\mathrm{H}$ in connection with the itandard 1 and axle $\mathrm{B}$, so that it may elevated and lowered, sulstantially as described.

2.-The pole $\mathrm{H}$, when hinged to the crombar of the frame so as to form a lever to raise the ploushs, in comhi nation with the plough beam $\mathrm{E} E$ and jough ' $\mathrm{C}^{\circ}$, wben constructed for the purpores and substantially as lescribed.

No. 59.390.-ALONZO HAL.E. EUREKA, IL..-SulkyPloushis.- lowember 6, I866.

Claim.-I.-The jack chains I $\mathrm{Y}$, connected to the axle $\mathrm{B}$ and lever $\mathrm{R}$, in combination with the plongh berms C C, when constructed and operated subatantially as and for the purposes herein shown and described.

2 - The chains $Y \mathrm{Y}$, in combination with the axle $\mathrm{B}$, lever $\mathrm{R}$, and sector $\mathrm{Q}$, for the purposes herein set fistib.

No. 59,8I3.-D, BEOUERET and E. DENOLLJN, JAMEsTnWN, IL.1. - Gans Poushs. - Vonembir 20, is66.

Clim.-A plough crimposed of a long and a short beam with plough shares $\mathrm{F} \mathrm{F}$, which are operated by levers $G G^{\prime}$, in combination with the unequal crank axle $C$, draught pole $\mathrm{E}$, placed in line with the short heam, and with the cantor wheel J, all constructed and orrating substantially as and for the purpose set forth.

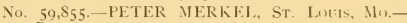
Gans-Ploughs- Viember 20, I866.

Claim.-I.-The combination of the windlass M. shaft 1 , with its arm $u$ and $p$, links $\%$, and plough beams 1 , substantially as described, for the purpone specified.

2.- The adjusting of the plougbi I higher or lower to suit the deptb of furrow required, and also adjusting the wheel $C^{\prime}$, by means of the shaft $C$, provitle I with the pinioms $f f^{\prime}$ and the rack bars F $F$ and slide $d$, provided witb a rac's substantially as and for the prupose set forth.

3.- The fitting and securing of the front ends of the plow beams I I in a cross piece II, componed of two parallel hars $j j$, provided with journals $m$, fitted in the rack bars $F$, substantially as and for the purpone specified.
Xo. 60,095-BRUNe) VOlK IIAN N, NEII loRk, N Y.. assignor to FREDERJCK VOLKMANN, anme place

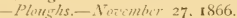

Claim.-1. - The plough frome or plough cart A B C D E F, constructed substantially as deseribed in combination with the plough beam $\mathrm{L}$, for the purpose set forth.

2.-The small balance beam in in combination with the screw chain $u$, the screw $n^{\prime}$, and plough beam I.. substantially au described for the purpose set forth

3.-The screw tree I, in combination with the two horizontal frame pieces $d t^{\prime}$ and the plough heam $\mathrm{L}$. sub-t intially is describerl for the purpose sct forth.

4.- The cart thi't $G$ in combination with the smicircle I) regu'ating corew $\&$ and with the plough frame A B ( D $\mathrm{EF}$, subutantially in the manner and for the purpose deserilueil.

5. - The cart axle $\mathrm{D}^{\mathrm{t}} \mathrm{D}^{\mathrm{t}}$ in combintion with the moveable side piece $\mathrm{F}$ and resulating screw- $C$, $f$ r th: purpose of deepenng the furrow an require !, s batuntally in the manmer lescribe !.

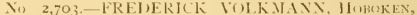

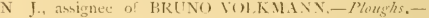
Ninmeer 27, I866. Reiwued Firly 30, 18,7

Clam.- I.- A plow th cart that is male an.l operating substantially as and for the purpose herein shown and thseribed.

2. - The device for rainin and lowerime the front end of the plough bean L, liy means of the -c ew shaft I, (fittel in the axle $t$, and lidin lifoc: $h_{\text {, }}$ ) the nut $i$, and plate $i$, loalance bar $e, \ln i=g$ and $\|$, all made and uperating sulictanti ally as herein shown and deneriled.

3.-The arljustahle link- $n$, when so made by the applica(ion rif a set ccrew $n^{\prime}$, sulsit antially as and for the purpose herein shown ant described.

4.-The draught chain $K$, attached to the under-idc of the plough beam and to the land-ille of the same, or in other word, to the lower left-hand elire of the same, ubut.n. tinlly as and for the purp wh hein shown and de striberl.

5.- The p-rforated axle $\mathrm{D}^{\prime}$, in combination with the frame B A E, and aliding block /, for the purpue of allow: ing the lateral arljustment of the serew shaft $I$, (or its enuivalent.) sulutan(ially as and for the purpons here $\mathrm{B}$ shown and describeil.

6.-The mammer herem shown and de-cribert of adjustahly securins the draught - bar (; to the plougl cart by means of the perforated axle $1 y^{\prime}$, holt $h$, and remicircular front

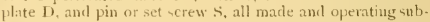
stantially as herem shown and describer

7.- In combination with the leviec for adjusting the plough beam un and clown the wheel 1 of the cart, when to arrangeil that by it adjusment the asle of the cait can be sunk more or lesi, as set fi.rth

8.-Hunging the front end of the plou th benm drectly to the screw shaft I by means of links 85,5 , bulance bar e, and nut $i$, all made anl operting substantially as herein hown and described.

9.- The draught chain $\mathrm{K}$, when secured $t$, the plough in the mamer descriled, in c.mbination with the lateraliy as well as oblipuely arljuvilale draught bar $(i$, is set forth

No. 60,461-IRA W. BHATLETT, (MTEK CREEK. In..-Plow:hs - Dicimber tS, is66.

Claim.-I.-The anle and wheels $\mathbf{E}$; $G^{\prime}$, combined with the ro $1 \mathrm{H}$, and lever $I$, when employed in cunnecion with the heam A, for governing the depth of the plough, as herein set forth.

2. - The combination of the ratchet bar $/$, and set screw $n$, with the toothed coulter bar ]., arran red and owerating as herein set fort

Nis. 60,721 -JAMES M. 1I 1.MMIT'T and HEXRY T.

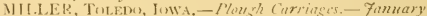
1. 18,7

( 1 aim. - A plough carringe having lar $I)$, spring ( $;$, lever $\mathrm{F}$, sing $\mathrm{E}$, singing leser 11 , ratchet $K$, paw $L$, and handle and spring $\mathrm{M}$, adjusted, comlined, and arranged sulutantially as herein sperifies?

No. 61,030.-I()11 H H.1RRINGER, HIt.LSHOR ,

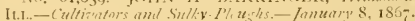




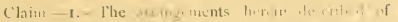
combinet cultivaten an? ulky-plomes operating scparately whon the parts at (ially as herein descrilied.

2. - The arrangement of a shifting phomeh F, come ter

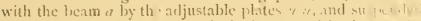

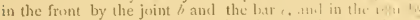

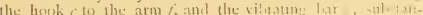
tially arand for the purpoes herein de-cite. .

3-The arrum rement of the shiftin. cultivators

titached wut of line with each other w thie- lient iron leam

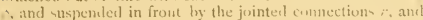
lichind by the books $/$ to the arms $f^{\prime} f *$ " nn the vilorating

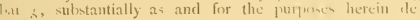
cribed.

4. The arrangement of a suile roul or lever $k$, connecterl with the draught pole $U$, substantially av and for the purpone herein specified.

No. 61.151.-GEORGE BURKET and SAMLEL

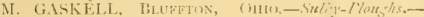
Funutry 15, 1867

Claim, - 1.- The attaching of the rear part of the plough beam by a chain or rofw of to a pulley $d$, on a shaft 11 , on the hounds a $a$ of the draught pole, said hati II having a lever I attached, and all arranged substantially as and for the puryose speciliecl.

2.- The slotted plate $\mathrm{K}$ attached to the platform $\mathrm{D}$, in such a manner that it may le turned forwaril to embrace the plough handle and serve as a bearing or fulcrum for it, and be turned backward free from the plough handle when it is necessary to liberate the latter, subutantially as set forth.

Nis, 51,40S.-J. II. TOULTIIIT, AlmaNy, OREGTN.lim, Ploushs.-Jantiry 22, IS67.

Claim.-1.-The attaching of the plough lenms F F to -iides II II, fitter letween suitable guides ic at the inner ides of the bars A. I, in conn-ction with the foot lever I attached to une of the slitics 11, and the pin K, passing through any of a series of holes in the other slide II, substantitlly as and for the purpore set forth.

2.-The windlass $L$, havans the cold, or chains M M, attached, and the latter connected to the plough beams F F to operate in the manner sulbstantially as anil for the purpose specified.

3.- The windlass $R$ baving a cord or chain $A^{*}$ attached, which is connected to the ploush lieams $F F$, one of the bearings of the windlase being fitted in a slide $S$, and having a pully $\mathrm{U}$ on one end, around which cal a pulley IV, on wheel $\mathrm{D}$, a belt $/ 1$ panes in coml ination with the lever $T$, attached to slide $S$, all bing arran; 4 ll th operatc in the manner substantially as and for the purpoxe set forth.

No. 61,470,-ISRAEL LONG;, ThrRe HAt T⿱一, IXD,Plonthas.-Jinuny 22, 1867 .

Claim.-r.-The adjustable brams F F, occupying prosttions at oppusite siden of the machine and outsile of the wheels, and each adlapted for the attachment of one or more ploughs, substantially as and for the purpose herein specified.

2.-The combination with the ploughs ( $; G^{\prime}$, beam F F, of the collars E E, fitted to turn upon the ends of the axle, and adjuated by me.ns of levers or otherwise, as and fi.r the purpose specifiet.

3.- The combination of the plough benms $\mathrm{E} F$, collars E E, levers $H$, and notched bari I I, all arranged and operating in the manner and for the purpose herein set lirth.

4.- The adjustable donble-trec $K$, in combination with the indeprendent hounds I) $\mathrm{D}^{\prime}$. wherely the drausht may he transferrecl to either vicle of the machine, substantially ac and for th- purpose tlescribed.

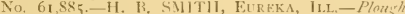
flitarlemiuls. - Fibruary 5, 1867

Claim-1.-The tongue (), attacher to a curret har II on the plongh beam $\mathrm{A}$, hy means of a cliy, $\mathrm{N}$, in such a manner that a universal joint connection will be oltainetl. substantially as and for the purpase sec forth.

2.- The attaching of the plough beam $A$ to the frame D, through the medium of the clip $H$, attached to the frame,

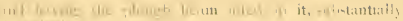

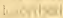

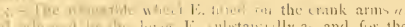

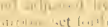

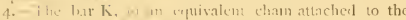

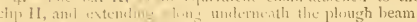

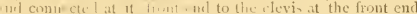
f the plowh leam, whontially as and for the purpose rein $\rightarrow$ ec linth.

No. $12,+30,-$ C. II I 'TTLEFIELT), TURNFR, ME, -

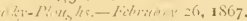

Chim. - The slutwel num guitle o, male last to the cros: har D, and the vibratin. Iring guide s', connected with the avle $B$, in combination wath the rod /h and plough beam $G$, arranged and opertime silustantially as and for the purposes herein ucrerihed.

No. $62,615-0$, r. DILS, Finmouth, Kx, - Sulky-

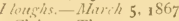

Chim.-The arrangement of the draught pole $\mathbf{E}$ and bars $F($ with the land and furrow whecls $\mathrm{D} K \mathrm{~K}$ respectively attached, the brace rods () P and plough beam A, for the purpose of forming a new and improved sulky-plough, as set forth.

No. 62.641-RANSOM K. IARAWAV and JEROME LARAWAY, BATTLE (KEEK, MICH, - M/mushs, -March 5. 1857 .

Claim. -1.-The manner herein described of attaching the frame $\mathrm{B}^{\prime}$, with wanizlonghs attached, to the frame B attached to driving whecls, and of attaching to the same plough II, as described and set forth.

2. - The manner herein lescribed of raising and lowering the frame $\mathrm{B}^{\prime}$, with plumghs attacherl, or single plongh, liy ineaus of lever C', pawl and ratchet $\mathrm{D}$ and $\mathrm{E}$, and flap " and chain $\mathrm{G}$, in the manner set forth and described.

No, 63.059 -CIIARILES KINKEL, NEW YORK, N. Y., ar-i nor to ALEXANDER WEHLE, same place.-

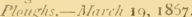

Climin-1.- The general construction of the plough, comvisting of the plough frame $\mathrm{C}$ in connection with the axle $D$, the plough beam $\mathrm{I}$, screw tree $\mathrm{F}$, and shaft II. subutantially as described.

2.- The plough frame $C$, in combination with the screw tree $F$ and universal joint $G$, sulatantially as set forth.

3.- The universal joint $G$ applied to the plough heam $B$ and screw tree F, substantially as described.

- The movable axle $\mathrm{D}$ ia combination with the plough frame $C$, subtuntially as d-scribed.

5. - The application of the improvement to ploughs of the usual corstruction, by means of the cartiron shoe $\mathrm{R}$, substantially as describerl.

No, 61,152,-E. SEXT()N, MrNson, MAss.-GansPlozeshs, - I pril 23, 1867 .

Clain,-1.- The adjustable bars B, provided with the tubular guites or supports $\mathbf{F}$ for -upporting the plonghs, sulstantially at hown.

2.-. In comlination with the lnternlly adjustalsle bars B, the spring rols/and levers $\mathbf{L}$ and $m$, arranged to operate as set forth.

No. 67.358.-HORACE L. PERRY, AURORA, N. Y.Ginn:-Plum:hs,--1tril 30, 1867 .

(laim-1-1-The cast seul plough I), when constructed and used in comlination with the binged plough frame C, main frame $A$, and wheels B B, for the purposes and substantially as herein deicriberl.

2.-The combination and arrangement of the pinion: E E, crank shaft $F$, hinged rack $F_{F}(i$, ratchet whecl $H$, and stop lever $H^{\prime}$, for the purposes and substantially as herein set forth.

No. 64.839.-ELISH. A. CIINSE, RnSEMUND, ILL.Wherl-Plou, $=145 .-M / 71,21$, IS67.

Claim. - A wheel-plou rh having the stationary frame $A$, pivoted frame $F F^{\prime} F^{\prime}$, plough lream $D$ and elevating devices $G G^{\prime} G^{2}$, arranged to opurate uhatantially as and for the purpose described.

No. 64,923,-J. IV. SURSA, SAN LEANDRO, CAL.Gan. IYu, h, - Hay 21, IS67.

Claim:- $\mathbf{I}$.- The combination and arrangement of the haft $c$, the aegment arms $d^{\prime \prime} d^{\prime}$, the axles $s^{\prime \prime}$ of the whecls 
D D, the hand lever $/$, and the rack $k$, for raising and lowering the gang-ploughs A A, substantially as herein described.

2.- The arrangement of the draught pole $\mathbf{F}$, pivoted to the plough beams $\mathrm{B} \mathrm{B}$, and clepressed and elevated by the screw $a$, substantially as and for the purpose set forth.

No. 65,087.-IOSEPH and TAMES INGHAM, SAN Inse, CAL.-Gang-Ploushis.-Miay 28, 1867.

Clain.-I. - The movable pivoted bars $\mathrm{C}^{\prime} \mathrm{C}^{\prime}$ with the egments $\mathrm{D} \mathrm{I}^{\prime}$, wheels $\mathrm{E} \mathrm{E}^{\prime}$, and pinions $\mathrm{F}^{\mathrm{F}} \mathrm{F}^{\prime}$ to raise and lnwer the ploughs, substantially as described.

2.-The two-part axle $\mathrm{G}$ with the vertical connecting necks $\mathrm{K} \mathrm{K}^{\prime}$, to make the plough cut to an equal depth, as le-cribed.

3.- The eyes $L L^{\prime}$, together with the bar $M$ and screw

, for the purpose of regulating the draught, substantially described.

No. 65,094--L. B. LATHROP, SAN Jose, CAL..Ging.Ploushs.-May 28, 1867.

Claim.-1.-The rotary cutters $d$, attached to the wheels , and forming flanges thereon, for the purpose of acting a. land sides for the ploughs, substantially as set forth.

2.- The axle $\mathrm{B}$, when arranged obliquely below the tongue $\Lambda$, and when adjustable by means of the screw bolt $a$ and slotted arm b, substantially as and for the purpose herein shown and described.

3.- The devices for raising and lowering the plonghs, consisting of the screw $\mathrm{K}$, rods $i$ and $h$, and of the axle $\mathrm{B}$, lug $f$ and $g$, bar $\mathbf{F}$, and bolts $c$, respectively, as set forth

4.-The double tongue $\Lambda \mathrm{M}$, in combination with the wheel 1 , supporting the end of the main tonque, and with the hinges $l m n$ and $o f s$, substantially as herein shown and described.

5.-The plough beams $\mathrm{E}$, when bent so as to form offset at the top of the mould-loards, substantially as and for the purpose herein shown and described.

No. 65,IgS.-D). S. FISHER, CenAR SPRING, IND.Ploughs.-May 28, 1867

Clain.-I.-The rising and falling or adjustable plougl bars $\mathrm{E} F$, one or more arranged with a lever or levers $C \mathrm{D}$, and having rotary coulters J attached, all arranged substantially as and for the purpose set forth.

2.- The spring catches $\mathrm{J}^{*}$, one or more, arranged with the bars E F and levers C D, substantially as and for the purpose specified.

3.- Providing the coulter $I^{*}$ with the radial ribs $a$, sulstantially as and for the purpose set forth.

No, 65,709.-F. VALKMANN, HoboKEN, N. J.Ploughts.-Jun: II, I867.

Claim-I.-Securing the upright screw shaft D in the axle $\mathrm{A}$, in the manner set forth, and clamping it by means of a set screw $a^{\prime}$ and clamp E, substantially as herein shown and described.

2.-The link $\mathrm{J}$, when arranged laterally adjustable on the plough beam, substantially as herein shown and decritsed, and for the purpose of changing the draught of the chain I.

3.- The adjustable draught bar $\mathrm{G}$, when secured by a bolt $i$ to the solid axle $A$, and when connected with the draught chain I, sulsstantially as set forth.

4.- Securing the front end of the plough beam to a vertical rod I), which projects from the axle of a cart, substantially as herein shown and described, the said rod not being secured or supported in any frame or other device that is ranged above the axle $A$, and in contact with the same, substantially as set forth, and for the purpose of making the whole cart lighter and of simpler construction.

No, 65,798. - C. L. EASTHAM, RHONE's POINT, ILL. - Gans-Plonesths.-Fune I8, 1867

Claim.-1.- The combination of the axle $A$ and hinged har C. provided with the lever $l$, and having the ploughs ut. -herl thereto, as described, all constructed and arranged to operate substantially as set forth.

2.-The combination of the lever $\mathbf{L}$, connected to the Hough beams and having a fulcrum at or near the axle, with the elbow lever $\mathrm{E}$, pivoted to the tongue, or equivalent 1:2:t, arranged to operate as described.
No, 65,834.-JOHN C. ROGERS, ALDEN, N. Y Sulky-Ploreshs.-June I8, 1867.

Claim.-I.-Connecting a sulky to a plough by means of the link or universal joint $\mathrm{D}^{1}$, or equivalent, for the purpose and substantially as herein described.

2.- The combination and arrangement, with a plough of common construction, of the rack $\mathrm{D}$, link $\mathrm{D}^{\prime}$, pinion $\mathrm{E}$, crank shaft $\mathrm{E}^{\mathbf{l}} \mathrm{F}$, weighted pawl $\mathrm{G}$, and ratchet wheel $\mathrm{G}^{\mathbf{1}}$, all arranged upon a sulky, in the manner and for the purpose substantially as described.

3.-The projection $d^{2}$, or equivalent, formed upon or connected to the lower end of the rack D, in rear of the link or universal joint $\mathrm{D}^{2}$, for the purpose and substantially as described.

4.-The spring rods I I, when constructed and used for the purpose substantially as herein set forth.

5.- The jaws $J$, in combination with the pole of a sulky-plough, for the purpose and substantially as described.

No. 66,039.-JOHN C. PEEIL, ARENZville, Ill. Gang-Plonshs.-Jun' 25, 1867.

Clain.-1.-The lever $a$, having the cam $e$ attached and arranged to operate in combination with the tongue $\mathrm{C}$ and beams $\mathrm{B}$ and $\mathrm{B}^{\prime}$, as shown and described.

2.-Constructing the crank axles $\mathbf{E}$ with a tubular portion to fit on the end of the wooden axle $\mathrm{A}$, as shown and described.

No. 66,155.-JOHN T. LEGG, Lewis County. Mo.Gang-Ploughs.-Fune 25, 1867.

Claim,-1. - The ploughs $\mathrm{A} \mathrm{A}^{\prime}$, beams $c e^{\prime}$, rods $\mathrm{F} \mathrm{F}^{\prime}$ and $G^{\prime} G^{\prime}$, the compound lever $\mathbf{H}^{\prime} \mathbf{H}^{\prime}$, lever handles $\mathrm{K} \mathrm{K}^{\prime}$, and ratchets $\mathrm{M} \mathrm{M}^{\prime}$, arranged, combined and operating for the purpose and in the manner substantially as described.

2.- The lever $n n^{\prime}$ and ratchet $m m^{\prime}$, arranged, combined and operating for the purpose and in the manner described.

3.-The stay chains $\mathrm{P}^{\prime}$, the beams $\mathrm{E} \mathrm{E}^{\prime}$, the tongue $\mathrm{Q}$, the strap $R$, and the stiffening pole $S$, arranged, combined and operating in the manner and for the purpose as heretofore described.

No. 66,477.-HENRY H. EBAUGH, HEREFORD, Mo. - Ploughs--July 9, 1867 .

Claim.-1.- Mounting the supporting wheels B C in swing frames $\mathrm{D} \mathrm{E}$, pivoted to the main frame $\Lambda$, arranged and operating substantially as and for the purpose herein spectied.

2.-The winding pulleys $\mathrm{N} \mathrm{O}$, of different sizes, in combination with the chains, bands, or ropes $n o$, and swing frames D E, substantially as and for the purpose herein set forth.

3.- In combination with the foregoing, the pulleys P R, crank S, and its ratchet and pawl, substantially as and for the purpose herein specified.

4.- The guage wheel I, when arranged and operating with the swing frames D E, as and for the purposes set forth.

5.- The arrangement of the pole or tongue $\mathbf{G}$ in the roller II and guide socket $g^{r}$, as herein specified.

No, 66,583,-ROBERT R. GRAVES, MONTGOMERY, Ai.A.-Gang-tloughs. - Fuly 9, I867.

Claim.-1. - The combination of the draw beam $C$, having the segment spur wheel c' with the vertical shaft L, having the spur wheel $i$, substantially as and for the purpose described.

2.- The combination of the movable frame $F \mathbf{F}$, with the shaft $\mathrm{I}$, wheel $\mathrm{M}$, endless chain $\mathrm{M}^{\prime}$ and wheel $m$, worked by the crank $n^{\prime}$, substantially as and for the purpose specified.

3.- The combination of the rails $\mathbf{K} \mathbf{K}$, springs $k^{\prime} k^{\prime}$, arms $k k$, trucks $f f$ and frame $\mathbf{F} \mathbf{F}$, substantially as and for the purpose described.

4.- The combination of the rod $\mathrm{N}$, spring $p^{\prime}$, lever $\mathrm{P}$ and arms $r r^{\prime}$, substantially as and for the purpose specified.

No. 66,748. - JAMES L. SPENCER, Wellville, VA. Sulky-Plougris and Tobacco-Hiller Atlachment.-July 16 , 1867.

Claim.-1-The combination and arrangement of the 
ploughs $\mathrm{G}_{\mathrm{G}} \mathrm{G}^{1}\left(\mathrm{i}_{2} \mathrm{G}^{3}\right.$, with the arms $\mathrm{NI} \mathrm{H}^{1}$, aml $/ /$, sulstan tially as and for the purpose descrilsed.

2.-The roller $I$, having the short arms $/$ / adjustable in position, and having the handle ${ }^{l}$, sulstantially as and for the purpose described.

3.- The pole $T$, having the shovel $t$, and the blunt arm $t^{\mathrm{t}}$, substantially as and for the purpose specified.

4.-The combination of the gear whecl $\mathrm{P}$, the pinion $g$, the lever $R$, the shaft $Q$, bearing the wheel $S$, and the pivoted pole $\mathrm{T}$, bearing the shovel $t$, and the blunt arm $t^{1}$, sub stantielly as and for the purpose described.

No. 67,351.-D). C. RIGGS, St. Juseph, Mo.-Gum

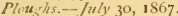

Claim.-I.-In combination with the ploughs $B$, the employment or use of horizontal cutters D $(i$, arranged and applied to operate in the manner substantially as and for the purpose set forth.

2.-The lifting or elevated bar $K$, when arranged in connection with the axle, draft pole and plough beams, to operate in the manner substantially as and for the purpose specified.

3.-The shaft $\mathrm{L}$ on the axle $\mathrm{H}$, provided with the arms $k$ $k \cdot$, and arranged in relation with the elevating bar and plough beams, to operate in the manner as and for the purpose set forth

No, 67,483.-ROBERT BAXTER, FRENCH CAMP, CaL.-Ganis-Ploughs.-Ausust 6, 1857 .

Claim.- The hear picce or flange, in combination with and forming part of the standard, in the manner and for the purpose set forth.

No. 3,244-ROBERT BAXTER, French CAMP, Cal. -Gims-Ploughs - August 6, 1867.-67,483. Reissued Dicimber 29,1868 .

Claim.- A standard for the support of the molil board, or other like part of a plough, formed in one piece with a projecting head, for the attachment of the beam, sulstantiaily as described.

No. 67,501-AlleN T. COVELl, SAN Leandro, CAI.-Gang-Ploughs.-August 6, IS67.

Claim.-1.-Att.rching the beams A A to the pole B between the reaches $a$ a by the rod $C$, so that the ploughs may he made to move np and down swinging on the axle J and rod by operating the lever $\mathrm{G}$, when disengaged, substantially as described.

2.-Attaching the axle $J^{\prime}$ and axle bed $J$, angularly to the frame, the clipps K K, and adjusting blocks $/ l$, substantially as described and for the purposes set forth.

3.- The link; D D, attached to the beams or frame and the rigid arms $\mathrm{E}$ E of the roller operating in them in combination with the beams $\mathrm{A} A$ and pole $\mathrm{B}$, substantially as described.

4.- The construction, arrangement and combination of the heams $\mathrm{A} A$, pole $\mathrm{B}$, reaches $a \quad a$, rod $\mathrm{C}$, axle and axlebed $J$ and $J^{\prime}$, temper blocks $l /$, roller $F$, and arms E E, together with links D D, substantially as described and for the purposes set forth.

No. 67,772,-JAMES D. KINCAID, Buwling GrEeN, M11.-Ploughs.-Ausust I 3, I867.

Claim.-1.-The rock shafts or rollers $\mathrm{C} \mathrm{C}$ and their cranks or elbows ' $c^{\prime}$ the lever $\mathrm{C}^{\prime}$, and the chains $c^{3}$, when combined with the post $D$ of the plough, as and for the purposes herein set forth and described.

2.-The combination and arrangement of the levers $\mathbf{E}$, the chains or rods $\mathrm{F}^{\prime}$, the fulcrum arms $c c$, and the spring catch, substantially as described and set forth.

3.-The attachment of the plough beams to the frame A by means of the device $d d^{1} d^{2}$, substantially as described and set forth.

No. 67,8I4-H. P. STAFFORD, Decatur, Ill.., assignor to himself and M. C. IVYKEL, same place.Gang. Ploushs.-Ausust $1_{3}, 1867$.

Claim -1.-The attaching of the plough beams to the carriage through the medium of the pendant swivel guide M secured to the draught pole $\mathrm{D}$, and the pins $a$ in the sides of the beam $\mathrm{H}$, between which pins the guide is fitted, substantially as and for the purpose specified.

2.- The atraching of the plough beam $\mathrm{H}^{\prime}$ to the beam II by means of the pivot $b$ and the guide $\mathbf{N}$, substantially as and for the purpose set forth.
3.-In combination with the mode of attaching the plough heams to the carriage, as shown, the application of the draught power direct to the plough beams, substantially as set forth as and for the purpose specitied.

4.- The lever 1, having its fulcrum pin $f$ fitted in a swivel $Q$ on the axle $A$ and its rear, and connected by a link $c^{\prime}$ with a grooved roller $d$, which works under an oblong loop or staple () on heam 11 , substantially as and for the purpose specified.

No. $68,065 .-$. . I. and (i. M. (illi.IIAM, CARLISLe, I1.1.-Gans-Plous, - - Au, us 27, IS67.

Claim.-The bars $\mathrm{H} \mathrm{H}$, embracing the heams D D, and operated by the lever $G$, arranged in combination with the frame $A$, in the manner substantially as and for the purposes set forth.

No. 68,277.-G. C. AVERY, CONN'S CREEK, IND.Gans-Ploughts.-August 27, 1867 .

Claim. - The hinged levers D D, vertical bars G $G$, loops $a a$, cords $g, b$, and lever $I I$, the whole combined and operated substantially as and for the purpose herein set forth and described.

No. 68,673.-H. J. WATTLES, ROCKFORD, ILL.Gang-Plousths. - September 10, 1867.

Claim.-1.-The combination and arrangement of the ploughing frame $\mathrm{B} \mathrm{B}$, wheels $\mathrm{H} \mathrm{H}^{\prime}$, caster wheel $\mathrm{F}$, frame support $\mathrm{E}$, chains I J $\mathrm{J}^{\prime}$, with crank $f$, operating substantially as described and for the purpose set forth.

2.-The combination and arrangement of the wheel $\mathrm{H}^{\prime}$ with the slicling support $\mathrm{K}$, groove piece L, segment lever $\mathrm{M}$, spring stop $h$, with stationary segment $k$, when constructed and operating as described.

3.-In combination with the chain support I J J', the arrangement of spring pawl $e, \operatorname{crank} f$, and ratchet wheel $i$, operating substantially as described.

4.-The combination of the stubble turner $\mathrm{N}$ with a ploughing mechanism, as described.

5.-Attaching the team to the ploughing mechanism by the evener $\mathrm{O}$, and the chains $\mathrm{P}$ P being of unequal length, the whole arranged to draw directly upon the ploughs in such manner as to avoid all side draught, substantially as described.

No. 68,7I8,-IORENZO DOMING, OTTOWA, ILLRiding Attachments for Gans-Ploushs. - September ro, IS67.

Claim.-1.-The attaching of the plough to the draught pole $\mathrm{A}$ of the riding nttachment through the medium of the bell crank J, rods I K, and lever M, or their equivalents for raising the front end of the beam, in connection with the suspended rack $\mathrm{R}$, and the bar $\mathrm{P}$, jointed or hinged to the draught sole $\mathrm{A}$, and connected with the plough beam by the stirrup $O$, substantially as and for the purpose specified.

2.-The cam $\$$, on the axis or fulcrum pin of the lever $\mathrm{L}$, in combination with the suspended rack $\mathrm{R}$ and fixed pawl $b$, all arranged substantially as and for the purpose set forth.

3.- The axle B B', projecting from opposite sides of the draught pole $A$ at different points, and braced by the diagonal bar C, when said parts are used as a riding attachment for a tillage plough, substantially as and for the purpose specified.

No. 68,777.-HORATIO MINUSE, MiLAN, OHIO.Carriage-Ploughs.-Siptember to, 1867 .

Claim,-The special arrangement and combination of the herein described plough and carriage, when operated in the manner and for the purpose substantially as set forth.

No. 69,323.-MARSHALL S. CURTISS, BRADFORD, IL1.-Coupling Ploushs and Whecled Carriages. - October 1, 1867 .

Clain - - I - The curved and slotted arm C, its form and manner of adjustment between the ears 1 , combined with the plough beam B, substantially as and for the purpose set forth.

2.- The forward guide $\mathrm{Q}$, combined with the arm sockets $\mathrm{N}$, arranged to allow the forward end of the plough bean $\mathrm{B}$ to have a lateral and vertical motion, substantially as set forth.

3.-The arrangement of the seat $\mathrm{F}$ in front of the crank 
axle $\mathrm{E}$, combined with lew D, the whole being arr.unged in set plough $B$ in the ground, or lifi it out of the ground, as clescribed and set forth.

No, 69,678.-IOIIN I.. KEASOR, L ACONiA, N. H.Self-acting Plowsh Holders.-Ortober 8, 1867 .

Claim.-1.-Attaching one or more ploughs to the side of wayon, sub-tantially as herein shown and described.

2.- The combination of the horizontal bar $C$, vertical bar $\mathrm{E}$, horizontal beam $\mathrm{F}$, and brace bar 11 with each other and with the plough $B$ and wagon $A$, sub-tantially as herein shown and described and for the purpose set forth.

3.-The combination o the pivoted har 1 , chain $k$ or its equivalent, and lever $\mathrm{L}$ with each other and with the plough $B$ and wagon $A$, substantially as herein shown and described and for the purpose set forth.

4.- The combination of the lever plough cleaner $\mathrm{N}$ with the plough $\mathrm{B}$ and wagon $\mathrm{A}$, substantially as herein shown and described and for the purpose set forth.

No. 70,237.-JAMES D. MARSHALL, RENICK, Mo. - Ploughs ant Pianters Conbin d. Oiviber 29, is.j.

Claim.-The carriage $A$, ploughs 1 , vertical posts $a$, swing frame $\mathrm{D}$, and stirrups $d$, when combined and arranged in the manner described.

No, 70,213.-JOSEPHUS MUORE, BLSHNEI.L, ILLPloushs.-October 29, 1867.

Claim.-1.- The combination of the beams $d$ and $c$ the rod $i$ and the spring lever $k$, as and for the purpose de scribed.

2.-The combination of the lever $n$ and handle $t$ with the axles of the wheels $a$ and the main frame $A$, in manner and for purpose specified.

3. - The combination of the elbow lever 2 ' with the spring $w$, and connecting rod $u$, substantially as set forth.

4.-The combination of the elbow lever ' 2 , the spring w', and connecting rod $u$, with the rack plate $s$, and lever $n$, substantially as described.

No, 71,053.-HOR.ACE L. PERRY, AURURA, N. Y. -Ging.Pliughs.-Notintier 19, ISj7.-Improvement on his patent April 30,1867

Claim.-1.-In a gang plough having a main frme $A$. and a plough frame C, substantially as hercin described, hinging the main frame $A$ at one side upon the axle, so that it may be leveled in the manner anel for the purpose set forth.

2.-The rib or flange $O$ formed upon the supporting wheels, substantially as and for the purpore set forth.

No. 71,301.-JAMES HARRIS, SANFA ClARA Cu. CAL.-Gang-Plonghs.-Norembir 25, I 367.

Clain,-1. - The rocking has E, to which the plough are attached, and by which they are zurned over upon the frame.

2.- The elevating lever $F$, the arljustable seat I, the guage screw $J$, the adjusting screws $K K_{2}$, the lever rest $M$, in combination with the resking har $\mathrm{E}$, as descriled, and substantially as set forth.

No. 72,375.-IRENELS DONAI.DSiIN, ToIn10, lowA-Sulkw-Plughs.-Dirembir 17, 1S57.

Claim.-1.- In combination with the plongh and carriage frame, the compound levers $I^{\prime} I^{\prime}$ and casters II $H^{\prime}$ placed in front and rear of the plough for regulating the cut, substantially in the manner set forth.

2. - In combination with the driver's seat $G$, the oscillating arm $\mathrm{L}$, cord $\mathrm{K}$, and adjusting levers I I', arranged sub. stantially as and for the purpose set forth.

No. $72,730$. - WILLIA II FOSTER, GRFENFsEL1), INI. - Cirns-Plowshs.-Dicimbir 31, I867.

Claim.-1.-In combination with the pivoted tongue $C$, the guide straps or bars $\mathrm{L}$, pivoted jaws $\mathrm{M} M$ ', and treadles N $N^{\prime}$ substantially as and for the purpose described.

2. - In combination with the treadles $\mathrm{N} \quad \mathrm{N}^{\prime}$ and pivoted laws $M M^{\prime}$, the spring $O$ and stops $\mathrm{P}^{\prime} \mathrm{P}^{\prime}$, substantially as and for the purpose specified.

3.- The upright lever $\mathrm{K}$, in combination with the frame $\mathrm{E} F \mathrm{f} f$, and foot board $\mathrm{A}^{2} k$, arranged an. 1 adapterl to he veserater substantially as and for the purpose net forth.

Ni. 72,9SI.-WIILIAM (i. CROSSLEY, SHELIS lit'RG, WIs.-Combind Sulky Plowstes and Cultizutors.-

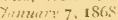

Claim.-1.-The arrangement and combination of the lxam $C$, rod $i$, spring catch $y$, and lever $h$, for regulating the position of plough $\mathrm{E}$, substantially as and for the purpose set forth.

2.- The comlination of rod $S$, having a lever $S^{\prime}$, with arms ()$Q$, ellows $T, T$, loops $P$, and shanks M I, arranged to raine and lower shovels of $f f$, and hold them in position as described, in conjunction with bars 0 ), as set forth.

3.- The loops $\mathrm{K} \mathrm{H}$, in combination with a movable brace $G$, having the plate $J$ arranged so as to fit either loop, as and for the purpose sit forth.

No 4928 . - WII.LI.II G. CROSSILEY, APPLE RIVER, I1.1.., assignor to BLACK, IRVINE \& C(O)-IIhertPloughs. -72,981, Jumary 7, 1868 . Keissued Jume 4, 1872 .

Claim.-1,-The combination, with a sulky having a rigid pole, of a plough beam $F$, rigidly attuehed to the sulky frame by a catch, 1I, at the front end of the beams, and by a hinge $g$, at about the centre of a curvature of the plough-casting, substantially as specified.

2.- The beam $l$, hinged and held in position as described, in combination with the rod $i$ and spring catch $\mathbf{H}$, the parts being arranged as shown and described.

3.-The combination of the shaft $\mathrm{E}$, having lever $\mathrm{E}$, with the ellows $c$, arms $d^{3} \mathrm{D} \mathrm{D}^{\prime}$, and shanks $l^{1} d^{2}$, substantially as specilicel.

4.- The loops $\mathrm{K} \mathrm{K}^{2}$, in combination with a moveable brace $K^{3}$, having the plate 1 , to fit either of said loops, suls atantially as specified.

No. 73,143 -JOSEl'H WARIVIC K, SIRINGWRGUGII,

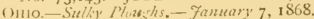

Claim.-1.- The device for lowering and raising the plough beam, consisting of the plates st and $i$, the former bein' slotted, pivoted as described, adjusted by means of the set screwi $k$, and operated by means of the lever $G$ and bow rack $\mathrm{H}$, substantially as clescribed.

2. The screw shank s of the sheath $k$, and nut $t$, in combination with the standard 1 , attached to the lant side $\mathrm{L}$ by means of the bolt $\mathrm{f}$, for the purpose of lowering the plough point, substantually as described.

3. The mould-board I J, with its part J hent around the sheath and secured to the same, substantially as and for the purpose described.

4. - The share M, with its bent part $\mathrm{N}$ connected to the land sicle L, and with the lattet forming the point, atached and constructed substantially as describerl.

5.- A plough with separate mould-boards and share, both attiched to the sheats in sach a manner that no bolt or rivet is used on their surface, sulsstantially as clescrilied.

No, 73,173.-JO11N W. Dx) L D, FuRkesville, lewA. - Cultivatus-_anuary 7, IS68.

Claim.-1. - the combunation of the frame C. strugthening braces 1 , and diagonal plough leam $E$, to which the standards $F$ of the plonghs $G$ are attached, with each other, the sajel parts binur constructed and arranged sub-tantially as herein shown and described, and for the purpose set forth.

2.-Connecting the axle $\mathrm{B}$ to the tongue 1 of the frame $\mathrm{C}$ by the inclined barn $\mathrm{J}$, and jointed or link connection $\mathrm{K}$. substantially as bercin shown and describeil.

3.- The combination of the cross bar M and adjustable chains $L$ with the inclined hars J and frame C, substantially as herein shown and described, and for the purpose set forth.

4. - The combination of the lever $\mathrm{N}$, chain $\mathrm{P}$, and bail or bar $R$, with the frame ( and axle $B$, substantially as herein shown and tescribed, and for the purpose set forth.

5.-The combination of the levers $S$ and $T$ with the frame $\mathrm{C}$, axle $\mathrm{B}$, and inclined bar J, sulstantially as herein shown and described, and for the purpose set forth.

No. 73,480 - SETH WAY, LAIORTE, IND.-GongPlonshs.- Janumy $21,1858$.

Claim.-1.-The mode of supporting the weight by the tongue 1 , and of elevatins and lowering the ploughs D D by the axle $B$, lever $C$, windlass $P$, and catch $J$, respectively, constructed and arranged substantially as set fortb. 
2. - Whe combination of the axle 13 , lever $(\mathrm{r}$, windlase $\mathrm{F}$, tongue I, and exualizalion doubletree 11, reypectively, cunstructed and armanged substantially as set forth.

No. 73.607.-DAVI1) W. HUGlles, (HANer, It.t.Ilowshs.- Finmary 2 I, 1 S68.

Claim.-1. - The placing of the ploughs at the outer sides of the wheels 13 B, substantially in the manner is and for the purpose set forth.

2.- Having the ploughs or shares I I placed in reverse oblique poitions for the purpose of dirpensing with a lankiside, to avoid friction and iranght, and to keep the implement in line with the line of clraught, as set forth.

No. 73,707.-A. FARROW, CARROI.TUWy, ILL.Ganus-Ploushs.-Fanuary 28, 1868 .

Claim.-1,- The combination and arrangement of the lever $\mathrm{C}$, link $c$, and traction connections $b b^{\mathrm{t}}$, herein shown and rlescribed.

2.-The lever $\mathrm{C}^{\mathrm{l}}$, arm $\mathrm{C}^{2}$, sector $\mathrm{C}^{3}$, rack $\mathrm{C}^{4}$, and plough beam li, when combined and oprerated substantially in the manner and or the purpose herein shown and de scribed.

No. 74,238.-W. W. MATIIEWS, VAtfs Cety, 1LL.Gans-Ploughs.-Felinuary i I, IS6S.

Claim-1, - The braces $a d$, draught lars b b, standarils $c \&$ constructerl and in combisation snb-tantially as shown, for the uses and purposes hereis set forth.

2.- The method of ra:sing, lowering, and securing the front end of plough beam by means of the levers $c$ and $\mathrm{K}$, pin $r$, clevises $h h$, draught har $i, \operatorname{cog}$ wheels $m$ and $n n$, with their friction roller, flanges, the lock $\rho$, crank lever $f$, and treadle $\%$, or by any means substantially the same, all iu combination and as shown, for the uses and purposes herein set forth.

No, 74,268,-A, Q. AlLIS, DAYToN, OHю.-SulkyPlows - Fis.-Filuary it, 1568 .

('laim.-1.-The serrated link B, or its equivalent, for the purposes and substantially as herein described.

2.- The lever and bar D, or its equivalent, used for the purpose substantialiy as herein set forth.

3.- The combisation and arrangement of the guide bars $F$ and the catch and lever $G$, for the purpose and sulastantially as herein set forth.

4.- The combination of the several parts, for the purpose and substantially as herein set forth.

No. 74.554-DLIAS LEVEE, WEST POINT, IOWA.Sulky.Ploushs.-Firuary 18, 1S6S.

Claim.-1.- The combination of the sliding guard or guide hats $\mathrm{J}$ and $\mathrm{K}$ with the plough heam $\mathrm{A}$ and with the tongue $\mathrm{F}$ or frame of the sulky, substantially as herein shown and de-cribed, and for the purpose set forth.

2.-The comlination of the adjustable har $\mathrm{R}$, adjustable bent lever $\mathrm{S}$, and bar or handle $\mathrm{U}$ with each other, and with the plough beam $A$ and support $T$, attachel to the tongue $\mathrm{F}$ or frame of the sulky, substantially as and for the purpose set forth.

3.- The combination of the crank journal $5^{1}$. slotted support $s^{2}$, wheel I, and axle, substantially as described and for the purpose specified.

No. 75,069.-GEORGE STEINEGGER, HIGHLAND, ILL._-Gan-Plomsth. - Warch 3, 1868 .

Claim. - The swinging beams $\mathrm{B} \mathrm{B}^{\prime}$, whes lifted by the lever b and link h, subatantially as shown and described, in combination with the litteral braces $/$, eye plates $i$, and bolt $k$, or their equivalent, all as and for the purpose set forth.

No. 75,268,-CHARLES HESS, I.YoN, CiTY, luWs.-

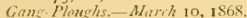

Claim.-1.-The slot $\mathrm{T}$ is the head piece, and axle to adjust the tongue.

2.-The iron beams, when treed in a gang-plough.

3.- The combination and arrangement of the parts, when con-tructed and neel as ahove set forth.

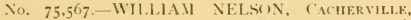
CA1.., assignor to himself, C. E. MG KRE, and $\Lambda$. I PR.ASTER.-Ging. Ploughs,-Wurch I7, IS68.

Claim,- I. - The attaching of the plough beam $\mathrm{N} N$ to the axle $\mathrm{A}$ by means of the boxes $\mathrm{L} \mathrm{L}$, constructed substantially as shown, in combination with the frame $C$, to
Which the dranght pole 11 is attacled, said frame being connected to the axle $A$, as shown, and all arranged to oprerate in the manner substantially as and for the purpose set forth.

2.-The notched segment bar $G$, in combination with the lever $\mathrm{H}$ and arm $\mathrm{J}$, comected by the chain $\mathrm{I}$, and attiched respectively to the draught pole $\mathrm{I}$ ) and the axle $\mathrm{A}$. and all arranged to operate in the manner substantially as and for the purpose specified.

3.- The yokes or frames $O$, provided with the screws $f$ and attached to the lower plates $b$ of the hoxes L I, with the plough beams $\mathrm{N}$ passing through them, substantially as and for the purpose set forth.

No, 75.832.-C. N. BAKEWEI,L, NORMAL, ILL.Sulky-Plowshs and Harrous-March 24, I868.

Claim.-I.-Broadly attaching the same draught to both the plough heams and carriage, by divided tugs, in such manner that ench draught is independent of the other, as herein specified.

2.-The combination of the framc $\Lambda$, supported upon wheels B, driver's seat E, and lever F and chains $\mathrm{G}$ and $\mathrm{H}$, for suspending adjustably a plough or harrow, substantially in the manner set forth.

3.- The combination of the chains $(i$ and II, for suspending the plough or harrow, and lateral chains $\mathrm{I}^{\prime}$, attached to the frame, substantially as and for the purpose set forth.

No. 75,871-GEORGE J. DA1HL, STOCKToN, CAL.Gans-Ploughs.-Minrch 24, IS6S.

Claim.-1. - A plough stantlard, constructed substantially as shown and describecl.

2. - The orifices $n u$ of the offiet $m$, as and for the pur pose set forth.

3.- The tenon hooks $n^{\prime} n^{\prime}$ of the adjustable landside $m^{\prime}$, as and for the purpose set forth.

4.- The head piece $h$ of the standard D, constructed as described, and made with the central opening $i$, as and for the purpose set forth.

5.-The adjustable landside $m^{\prime}$, in combination with the standard D, arranged in the manner described.

6.-The scraper $c$, in combination with the caster wheel $d, a$ asd for the purpose set forth.

7.-A series of ploughs, constructel and operating as sct forth, in connection with a frame of the kind decribed.

No. 75.S95.-WILIIAM S. GATILIN and BENJA. MIN R. HUBDARD, GReEN Tor, No,-Cans Ploughs. - March 24, 1858 .

Claim-1. - The construction and arrangement of the draw bar b, the links $C$, the levers $C^{\prime}$, and the racks $C_{2}$, with reference to the frame $A^{\prime}$ and the plough beams $\mathrm{B}$.

2.- The device, D, $\mathrm{D}^{1}, \mathrm{I}^{2}, \mathrm{D}^{3}$, and $d$, for lifting the ploughs up out of the grouni, substantially as described and set forth.

No. 75.901.-W. E. HARDIN, Bowlung Green, Mo. Phy

Claim.-1.- The lifter $\mathrm{D} d^{1} \mathrm{D}^{1} \mathrm{D}^{2}$, when constructed and operated as described and set forth.

2-The adiustabie axle $A^{\prime} a$, when constructed and employed in the manner shown and described.

No. 75.925.-JOHN L. KEASOR, LACINIA, N. H.Gang-Plonshs.-Warch 24, 1868.

Claim, -1. The combination of the vertical standards II, eye holts or keeners $n^{\prime}$, vertical hars $\mathrm{N}$, hortzontal bars $O$, and keepers R S with each other, with the ploughs $G$ or II, and with the longitudinal hars F, substantially as herein shown and described, and for the purpose set forth.

2.- In combination with the shaft $\mathrm{U}$, arranged as shown and described, the cams $V$, chains $T$, and horizontal bars $F$, all contructed and uperating as described, whereby the ploughs $G$ II are rassed and lowered.

3.- The construction, combination, and arrangement of the adiustable lever $W$ with the shaft $U$, for the purpose of operating said shaft, substantially as herein shown and descrilsed.

4.- The combination of the draught chains $J$ with the bolster $\mathrm{E}$ and forward ends of the plongh beams $g^{\prime}$ or $h^{\prime}$, substautially as herein shown and descrilyed.

5.- The combination of the chains $J$ with the forward 
ends of the plough leams $j^{\prime}$ or $h^{\prime}$, and with the Iongitudinal bars 1 , substantially as herein slown and descrilsed.

No. 75,94r.-ISAAC B. MAIION, DUNKIRK, OHLW. - Cnltizaters mul Gang-Ploughs.-1March 24, 1868.

Claim,-1.-Constructing the frame $A$ of a simple bar, bent so as to form three sides of a quadrangle, and braced by the bars $\mathrm{F}$ applied to the frame and axle, substantially in the mamner as and for the purpone set forth.

2.- The construction of the plough beams $K \mathrm{~K}^{\prime}$ arranged with ancl applied to the $m$ in frame $A$ to operate in the manner as and for the purpome herein set forth.

3.- The har $\mathrm{W}$, applied to the beams $\mathrm{K} \mathrm{K}^{\prime}$, sulstantially as and for the purpose specified.

4.- The oblique draught or brace rods $\mathrm{Y}^{\prime} \mathrm{I}^{\prime}$, applied to the carriage and to the plough beams, substantially in the manner as and for the purpose set forth.

5.-The beam (), attached to the draught pole, and con nected with the plough beams, in the manner substantially as and for the purpose herein set forth.

No. 76,28 . - GEOROE F. WII.LEY, LACONIA, N. II. Plou-h-Carriages.-Warch $3 \mathbf{I}, \mathbf{1} 868$.

Claim.-The construction of the carriage A A A, with the plough $\mathrm{P}$ and attachments, combined and adjusted as shown in the drawings.

No, 76,447.- W. F. HIGGINS and JEROME PERRY, WATSonville, CAL. - Gang-IPoushs.-April 7, 1 S6S.

Claim.-1.-The combination of the inclined beams I and $\mathrm{K}$, braces or supporting bars $\mathrm{J}$ and $\mathrm{L}$, adjustable pivoted $\mathrm{M}$, and pivoted bars $\mathrm{H}$, with each other, and with the plough frame $F$, sulky or wagon frame A, ancl axle B, substantially as herein shown and described, and for the purpose set forth.

2.- The combination of the lever $\mathrm{P}$, connecting bar $\mathrm{O}$, and arm $\mathrm{N}$, with each other with the axle $\mathrm{B}$ and frame. work of the sulky or wagon, substantially as herein shown and described, and for the purpose set forth.

No. 76,735.-MATTHEW FIINN, ST. Luis, M1,Gang Plonghs.-April 14, 1868 .

Claim.-1.-The sliding blocks $c$, connecting rods $c^{1}$, and sectors $r^{2}$, when arranged and employed sulistantially as herein shown and described, for the purpose of transmitting the draught from the axle to the ploughs.

2. - The secturs or sector $\mathrm{D}$, pinion $d$, and beams 13', when combined and arranged as herein shown and described.

3.- The hook $d^{2}$, and lever $d^{3}$, when combined with the beam $\mathrm{B}^{\prime}$ and rector $\mathrm{D}$, as described and shown.

No. $76,845,-13$. W. SUTHERI.EN, FREFSOL, MiNN -Sulkv-Ploug/s. - April 14, 1868.

Claim.-1.-The combination of the axle E, stmdards B B, and plough $\mathrm{A}$, working loosely between the standards, so as to admit of a plough of any construction being suspended by the chain $c^{\prime} c^{\prime}$, and drawn by the chain $c^{\prime \prime \prime}$, substantially as and for the purpose ypecified.

2.- The frame 1 , in combination with the pully G and lever L, substintially as and for the purpose described.

3.-The combination of the lever $L$, frame I, pulley $G$, chains $c c^{\prime}$, and plough $A$, substantially as and for the purpose specifierl.

No. 77,272 -WILI.IAM GALLAGHER, SHULI.SBURG, Wis.-Ploushis.-April 28, 1868 .

Claim. - 1.- The combination of the vertical bar $\mathrm{E}$ with the axle $B$ and forward end of the plough beam F, substantially as herein shown and describet, and for the purpose set forth.

2.- The combination of the lever $\mathbf{K}$ with the plongh beams $\mathrm{F}$ and vertical arms or lars $\mathrm{E}$, substantially as herein shown and described, and for the purpose set forth.

3.- The combination of the lraces $O$ with the axle 13 and plough heams $F$, substantially as herein shown and described, and for the purpose set forth.

No, 77,617.-LEAVITT IIUNT, WEATHERSFIEL.D, VT -Sulky-Ploushs.-May 5, 1868.

Clam.-1.-The hinged beam $\mathrm{D}$, and the plough beam E, provided with and connected by the oval axle $c$, and the chain $i$, or it equivalent, substantially as described and set forth.

2.- The combination of the iron lever $l$ with the bar $k$ and the beam 1, substantially as and for the purposes set forth.

3.- Providing the beam $\mathrm{E}$ and the pole $\mathrm{C}$ with the slots $\mathrm{S}$ and $d$, to act in conjunction, the reby giving the plough some longitudinal play, when the beam $\mathrm{E}$ is connected to the whiffiletree or bolt $t$, by the chain $\mathrm{F}$, or it equivalent, substantially as described and for the purposes specified.

No. 78,111 - GEORGE W. MANUEL, SAN Francisco, CAL.-Gans-Ploughs.-Way 19, 1868 .

Claim.-1.-The arrangement of the crank arms $d \in f$, under the hounds or bars, and in relation thereto, as and for the purpones set forth.

2.- In a gang-plough, having a series of ploughs, arranged on bars or hounds parallel to each other, placing the one plough on the bar $g$, ontsicle of the wheel $a$, and in front of the axle, as and for the purposes recited.

3.- The combination of the extended crank arms $d$ and $\iota$, with the lever $l$ ancl curved bar $\theta$, as and for the purposes herein set forth.

4.-The crank screw $r$ and plates $s$ and $t$, for elevating and depressing the tongue, as described.

No. $78,390,-H$. WALKEK NEAL, SIDNEY, OHo.Ploushs.-May 26, 1868.

Claim.-1.-The lever E, when pivoted upon the main axle, as set forth, for raising and lowering the wheel $\mathrm{A}$.

2.- The combination of the levers $\mathrm{E}$ and $\mathrm{E}$, notehed flange $e^{2}$, and spring $c^{3}$, for the purjose of holding the wheel $\Lambda^{\prime}$ in desired osition.

3.- The cumbination of the tongue 1 , lever $G$, clevis $H$, and plough beam C, arranged and operating as and for the purpose set forth

No. 7 S, 464.-DON CARIOS MATTESON, STOCKTON, CAL.-Gang-Plonghs. - Funt 2, 1868.

Claim,-1.-The bars E F, altached to the front ends of the beams A $\mathrm{B}$, with the perforated draught bar $\mathrm{G}$ attached thercto, substantially as and for the purpose specified.

2.- The attaching of caster wheel $\mathrm{J}$ to a single arbor, $\mathrm{K}$, proviled with a scraper, $f$, sulbstantially as and for the purpose set forth.

No. 78,785 - CHARLES BROWN and LEONIDAS GERTII, I'EOR1A, II.1,-Plourths,_-7une 9, 1868

Claim.-A combined ploughing and cultivating machine, having levers $\mathrm{I}$ and $\mathrm{F}$, with ratchets thereto, rod $\mathrm{C}$, chains $D$, knives $\mathrm{C}$, frames $\mathrm{H}, \mathrm{P}$, and $\mathrm{O}$, and swinging bar $\mathrm{M}$, constructed, arranged, and operating substantially as sjecified.

No, 78,856,-LEONARI) IV. BEAL, DIXon, [1.1., assignor to himself and A. D. INREW, same place.Ploughs, - Fune' 16, 1868 .

Claim,-1.-A plough plate A, constructed substantially as described, so as to lispense with a landside and separate point, and operating as specified and described.

2.- The plough plate $A$, when constructed in the curved form symmetrically before and behind its point of attach. ment to its standard, so as to operate and be reversilble, substantially as described and shown.

3.- The combination of one or more ploughs, A, constructed substtanially as described, with a frame $C$, and wheels W, substantially as set forth.

4.- Securing the axle $\mathrm{E}$ to the frame $\left({ }^{*}\right.$ in such a manner as to be adjusted at pleasure, to vary its direction across the frame, substantially as herein set forth and described.

No, 79,639.-GUSTAVUS A. DAVISON, SAN LEANDRo, CAL. - Gans-Plonshss,-7uly 7, is68.

Claim.-1.-Regulating the level of the machme by the device $O O^{\prime}$, and set screw $\mathrm{P}$, or their equivalents, substantially as sut forth.

2.- The rigid arms II $\mathrm{H}^{\prime}$ and G, attached to the axle, and connecting the lever or sweep $J$, either directly to the arm 6 , or by the link 1, substantially as and for the purpose scribed.

No. $3,669 .-$ GUSTAVUS $\Lambda$. DAVISON, SAN LEAN- 


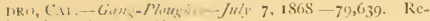
issued Octuier 12, 1569 .

Claim-1.- Regulating the lever of the machine by the device $(1)$, and set screw I', or their equivalents, sulstantially as set forth.

2.-The rigid arms $11,11^{\prime}$, and $\mathrm{G}$, attacherl to the axle, and connecting the lever or sweep J, either dircetly to the arm G, or by the link 1, substantially as and for the purpose specificel.

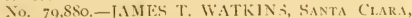
CAt..-Ciang-Ploushs.-Ju/y 14, 1868 .

Claim. - 1.-The ploughs 1111 , in combination with the blocks E E', the holding screws I 1 , liy which the plough are adjusted, and the wediges $a n$, constructed and arranged sulstantially as descrihed.

2. - The blocks E E', mounted upon the axles $\mathrm{C} \mathrm{C}^{\prime}$, and the bent arms I J', with the set screws $K \mathrm{~K}^{\prime}$, for regulating the depth of the furrows, sulst intially as described.

3. - The beut arm $\mathrm{N}$, and connecting rod $\mathrm{O}$, with the handle $\mathrm{N}$ and the entch $\mathrm{r}$. for discngaging the ploughs, substantially as described.

4. - The hent axle $R$, with the nut $R^{\prime}$ and the screw $S$, for raising and deprinsing the furrow wheel, substantially as dencribed.

No. 79.917.-JOHN F, PORTER and $\triangle \mathrm{LONZO}$ NORTON, TIPHitTe, PA.-Gins-Ploughs.-Fuly' ${ }_{4}$ I 868 .

Claim.-I.- Tho hinged coulter I, attached to the plough, and operating as described.

2.- A plough so constructer and operating that the draught is mainly or wholly upon the point, as herein set forth.

3.- The combination of the hinged standarcls $k k^{\prime}$ with the plough $\mathrm{D}$, substantially as described

4.- The combination of the rack $n$, socket S, cam $o$, lever $\hat{s}$, standard $\mathbf{K}$, and plough $\mathrm{D}$, substantially as described, and for the purnose set forth.

No. So,039.-GEORGE WIIARTON, JERsEYvIL..E,

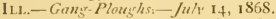

Claim.-1.-Constructing the axle of two parts, II I, connected by a joint, $c$, in combination with the two levers $J J^{\prime}$, all arranged and applied sulutantially in the manner as and for the purpose set forth.

2.- The foot lever $M$, connected with one of the beams $A$ and to the prist $h$ of the axle, as shown, in combination with the shaft $\mathrm{Lx}$, secured to the axle, and having the front ends of the beam $A$ fitted loosely to it, all arranged to oper ate substantially as and for the purpose specified

3.- The trealle platform $\mathrm{D}$, draught pole $\mathrm{E}$, and the lever $\mathrm{F}$, connected to the draught pole by chain b, all combined and arranged substantially as and for the purpose set forth.

No. So,405.-SMllTH GRAllA.M, FinniMORE, WIs, -

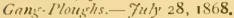

Claim. - The hinged frame beams $g^{\prime} \delta^{\prime}$, bar $i$, lever $k$, link $j$, and metal strip or bar $s$, all combined and arranged sulstantially as and for the purpose described.

No. So,427-BENJAMIN SLUSSER, SIDNEY, OHO. - Sulky-Ploughs - Fuly 2S, IS68

(laim.-1.-The combination of the lever 1, having the shoulder $n$, with the crank $c$, having the projection $m$, and supporting the standard to which the plow is attached, when the several parts are connected and arranged so as to oper. ate together, substantially in the manner and for the purpose specified.

2. - The combination of the crank $c$, standards $g c$, seat G, rod II, and hinged po-t $I$, substintinlly as and for the purpose described.

3.-Supporting the plough upon two standards, E F, bent in the form and attached to the rear side of the plough in the mamer descrilued.

No, 6,563. -HENIIMIN SIUSSER, SIDNEY, OHO, assignar to NORMAN DU BOIS and 1. F. K(U)R.Sulky-1 low hs. - $80,427,7 u / y$ 2S, 1858. Reissued Julv 7,1875 . Filed ipril 17,1857

Claim.-I.-The comlination of the crank-axle $S S^{\prime} I$ and jointed bent lever $\mathrm{L} n$, for the purpose of raising the plough, and permitting it to rise automatically out of the ground, substantially as and for the purpose set forth.
2. - The combination of the unank-axle S S S' I' of a sulky plough, with the beams or frame of the plough loosely pivoted thereto, to permit the plough to risc automatically out of the grount, substantially as and for the purpose described.

No, 7.973,- IEENIAMIN SLUSSFR, SIDNEv, (HIO, assignor, by mesne assignments, to F. 13. $11 \mathrm{UNT}$, J. B.

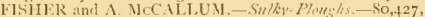
$f_{u l y}, 2 S, 1868$. Reissue $6,563, J u l y, 27,1875$. Reissued

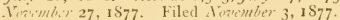

Claim.-I.-In a sulky.plough, the combination of a crank-axle and plough heam, or frame of the plough, the latter being hinged or loosely pivoted to the former, so as to permit the plough to rise and fall, subutantially as and for the purpose specified.

2.-In a sulky plough, the combination of a crank-ixle, plough-beam and lever, the latter operating to raise and fower the plough when required, but without interfering with its independent movement substantially as set forth.

3-In a sulky plough, the plough supported by means of a heam, hent as described, and a crankiaxle mounted on whicels, the beam being pivoted to the crank, so as to move therewith, substantially as and for the purpose specified.

4. - The seat $G_{\text {, }}$ supported on standards pivoted to the axle, as described, and comnected with the draft pole by means of the rod $H$ and hinged post $I$, so that the sent wil! always be maintained in proper position, sulstantially as set forth.

5.-In a sulky-plough having a crank-axle and a vertically-adjustable plough attacherl to the crank so as to move with it, a driver's seat arranged and combined therewith, and which maintains its vertical position without being af fected by the movement of the crank and plough, substantially as and for the purpose specified.

No, 8O,521.-ANDREW WVATKER, ClAREMONT, N. H. -Gons-Plowehs.-July 28, 1868.

Claim.-1. - A stationary frame, with adjustable plough beams underneath, pivoted to the main frame at the rear end and silpended by the ratchet $\mathrm{E}$.

2.-In combination, the gear wheel C, gear circle D, lever $F$, and spring catch $h$, in combination with the ratchet $\mathrm{E}$, for the purpose of adjusting the depth of the furrow, and locking or suspending the ploughs at any given point, the whole arranged, constructed, and combined, and used in combination with and for the purpose set forth.

No. So, ${ }_{3} 8$. - INDRE.W SMITH and WII.LIAM P. W ITSON, PURTIAND, OREGON, assignors to WILITAM P. WATS(IN and T. J. CARTER,-Gans-Ploushs.iustrist II, I8 is

Claim.-1.- The combination of the rod $K$, plate $J$, through which the rod $k$ screws, and which is attached to the hinge joint $I$, hingre plate $I$, plough beams F F, and stan-larils and ploughs $\mathrm{f}$ II, substantially as described.

2.- The combination of the hinged heams $\mathrm{F} \mathrm{F}, \operatorname{cord} c$, rollers $\mathrm{M}$ and $\mathrm{N}$, ratchet $\mu$. paw $p$, and foot lever $r$, sulstantially as described.

3.- Attaching the rear end of the tongue to the axle by means of a clevis, $t$, and a series of holes arranged as described, hy which the draught can he adjusted, sthintantially as ahove set forth.

Mo, S1,571,-ALEX ANDER VAll, HENRY, ILL.Plonshs.-Ausut 25, $1 \mathrm{~S} 6 \mathrm{~S}$.

Clain.-I.-The heam C, supporting the plotigh 1 , and rigidly secured to the axle $\Lambda$, in combination with the iriver's seat $S$, the hinged hounds $E E^{\prime}$, and tongue $\mathrm{F}$, substantially as and for the purpose herein set forth.

2.-The slide $K$, arranged to operate in connection with the beam, hounds, and tongue, substantially as and for the purpose descrilied.

3.- The hinged hounds $\mathrm{E} \mathrm{E}$, in combination with a plou h suspended from a heam, rigidly secured to the axle, substantially as described.

4. - The combination of the beam $\mathrm{C}$, plough $\mathrm{D}$, hinged hound $\mathrm{E} \mathrm{E}^{\prime}$, tongue $\mathrm{F}$, lever $\mathrm{I}$, axle $\mathrm{A}$, and driver's seat $\mathrm{S}$, substantially as and for the purpose described.

No Si,700.-P. H. STANDish, Martinez, CiL., as- 
signor to himself and OLIVER C. COFFIN-GamPlourtss.-Siptember I, is68.

Claim,-I,-The wheel E, lever M, with pawl I and foot pawl N, and manner of arrangement thereof.

2. - The tongue-adjusting rod $\mathrm{J}$, clevis $\mathrm{R}$, plate $\mathrm{P} /$, as arranged, and secured to the bed or beam $\mathrm{B}$.

3.- The construction and arrangement of the hed $\mathrm{B}$, and the manner of attaching the standards thereto, in combination with the tongue-nd usting rod $\mathrm{J}$, clevis $\mathrm{R}$, and plate $\Gamma l$, as shown and described.

4.-The crink-shaped standards, with slotted end and set screw, substantially as set forth.

No. 8I,70I-A, R. STANLEY and HENRY IV ENSIGN, Shullsburg, WIs.-Sulky-Ploughs.-September I, 1868 .

Claim.-I.-The pivoted plough beam N, spring catch (O) and eccentric, $\mathrm{H}$, arranged to operate in the manner substantially as and for the purpose set forth.

2.-The combination of the lever $\mathrm{G}$ attached to the eccentric II, the shaft $F$, pinion $E^{\prime}$, rack $D$, and spring catch $O$ fitting over the end of the plough beam $\mathrm{N}$, substantially as described for the purposes specified.

No. 81,724,-JANES H. ANDREWS, BENICIA, CAL. -Gang-Ploughs.-Siptimber I, 1868

Claim.-I. - Pivoting the pole $\mathrm{C}$ to the hounds D D by a rod, E, and linking the rear end of the pole to the arm $G$, of the shaft $F$, or equivalent device for raising and lowering the ploughs without lifting other parts of the frame, substantially as described.

2.-The double-jointed frame 1 , having an apron, $J$, attached and arranged to operate in the manner substantially as and for the purpose set forth.

3.- The manner of connecting the ploughs to the frame by the clips $\mathrm{M}$ M. slots $\mathrm{N} \mathrm{N}$, with bolts and nuts, substantially as described.

No, 8I.799.-J. B. L.EWIS and I. E. UD.AI.1, CoNCORD, IL..-Sulky-Ploughs.-September I, 1858.

Claim.-1.-The flanges $G$, eccentrics 1 , wrist pins $J$, and pins $\mathbf{L}$, when constructed, arranged and operating substantially as herein described, and for the purposes set forth.

2.-The compound lever M, when constructed, arrangerl, and operating substantially as herein descrihed, for the purpose specified.

3.-The combination and arrangement of the abovenamed parts with the frame $A$, axle $B$, bolt 11 , seat $C$, traction wheels $\mathrm{K}$, plough beam $\mathrm{D}$, plough $\mathrm{E}$, and quadrent $\mathrm{N}$, substantially as and for the purposes specified.

No, 3,336.-J. B. LEWIS and J. E. UDALL, CONCORI, ILL.-Syelky-Ploushts.-8I,799, September I, I86S. Reissued March 23, 1860 .

Claim.-I.-The flanges G, eccentrics $\mathrm{I}$, bolts $\mathrm{H}$, wrist pins J, and pins $L$, when constructed, arranged, and operating substantially as and for the purposes berein clescribed and shown.

2.-The compound lever $\mathbf{M}$, when constructed and operating substantially as and for the purposes described.

3.-The arrangement of the above named parts with the frame $A$, axle $B$, seat $C$, traction wheels $K$, washers $F$, plough beam $\mathrm{D}$, plough $\mathrm{E}$, and quadrunt $\mathrm{N}$, when combined and operating substantially as herein set forth.

No. 82,140.-J. R. McCONnEll, Marengo, Iowa.Sulky-Plowsth.s.-September 15, IS68.

Claim,-1.-The construction and arrangement of the pivoted draught pole $\mathbf{K}$, adjustable side bar $\mathbf{E}$, beam $\mathrm{A}$, and lever $\mathrm{L}$, as herein described, for the purpose specified.

2.- The adjustable right angular bar E, seed bar 1, adjustalle bar J, brace $\mathrm{G}$, and lever $\mathrm{I}$, in combination with the beam $\Lambda$, pivoted draught pole $K$, and plough $C$, all arranged as described, for the purpose specified.

3.- The adjustable right angular bar E, adapted to support the seat and bar II I, the bar I, brace G, and pivoted dranght pole $\mathrm{K}$, as herein described, for the purpose specified.
No, S2,165,-FREDERICK 1 , SMITII, PETALUMA,

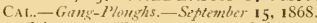

Claim, - 1 - The arrangement of the devices and means berein recited for raising and lowering the frame and ploughs.

2.- The hars, $w$ ith spaces on the end of the beam, and on the tongne, with the bolts and nuts for the adjustment of the land wheel axle, and the caster wheel's arm, as herein set forth.

No. 82,166.-F. P. SMith, Petaluma, Cal.-GangPloughs. - September 15, IS68.

Claim.-The combination of the several means and devices herein set forth, for raising and lowering the ploughs.

No. 82,223.-CHARLES L. IIORN, JR, and LEONARD MANCY, ST. MORGAN, Il.1, assignors to LEONARD MANCY.-Gang-Ploughs.-September 15, IS68,

Claim.-1. - The frame $\mathrm{A} \mathrm{A}^{1} \mathrm{~A}^{2}$, the wheels $\mathrm{B}$ and $\mathrm{B}^{1}$, adjustable arms $b b^{1}$, post $B^{2}$, and brace $B^{3}$, when combined and arranged as herein shown and described.

2. - The plough beams $C$, their posts $C^{1}$, and the frame beam $A_{2}$, when constructed sulstantially as herein shown and described, for the purpose set forth.

3.-The beaus $\mathrm{C}$, post $\mathrm{D}$, and seat $\mathrm{D}^{\mathrm{y}}$, when constructed and arranged as herein shown and described.

4.- The arrangement of the beams C, rod E, and lever $\mathrm{E}^{\prime}$, in the manner and for the purpose herein described and set forth.

No. 82,24I.-NELSON B. NORTON, BURLINGTON,

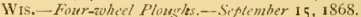

Claim. 1.- The arrangement of the lever 1 , jaws 1 , and metallic strap $\mathrm{K}$, with the plough beam $\mathrm{F}$, frame $\mathrm{C}$. post or standaril I, straps $\mathrm{I}$, and catch $h$, when constructed and used as and for the purpose set forth.

2.-The adjustable rod $g$, in combination with the frame $C$, and plough beam $F$, when arranged as and for the purpose specified.

No, 83,036.-TAMES CAMI'BELL, NEW Town, IL.. -Ploughs, - Octuber I3, I868.

Claim,-1,- The partially-revolving square beam $B$, carrying ploughs or shovels, secured to the plough frame at an acute angle to the line of the draught, constructed and operating substantially as and in the manner set forth.

2.- In combination with the above, the stirrups F F, lever $\mathrm{D}$, notched bar $\mathrm{E}$, hrace chains $\mathrm{M}$ M, cross piece $\mathrm{P}$, and the angle axles $\mathrm{N} \mathrm{N}$, the whole arranged and operating sulictantially as set forth.

No, 83,283.-H. R. HUIE, Haywarn's, CAL.-GangPloughs, Oitober 20, 1868.

Claim.-I.- Securing the arm $e$ of the axle $f$ to the axletree $a$ by means of the eye bolt $i$, as shown and described.

2. - The crank lolt $q$, in combination with the eye bolt $r$, for adjusting the tongue, as berein set forth.

3.- The arrangement and construction of the plate $l$, ears $m$, and boxes $n$, which allows of their heing cast as one piece, as berein described.

No. $S_{3,404}$ - JOHNSON ORR and IIENRY H. MARTIN, OXFORD, OHIO,-Convertible Plourhs and Cultis'ctors.-October $27, \mathrm{I} 868$.

Claim.-1.-The corabination and arrangement, substantially as described, of the frame $\mathrm{A} \mathrm{C}, c c^{\prime}$, swinging hangers $\mathrm{D} d$ and $\mathrm{D}^{\prime} d^{\prime}$, adjustable bars $\mathrm{E} c$ and $\mathrm{E}^{\prime} c^{\prime}$, nuts $\mathrm{G}^{\prime} \mathrm{G}^{\prime}$, ring bolts $F f$ and $F^{\prime} f^{\prime}$, pins $H$, apertures $i$, plongh beans $\mathrm{J} \mathrm{J}^{\prime}$, pivoted sheths $\mathrm{K}^{\prime} k$, ties $\mathrm{M}$, pins $\mathrm{N}$, handles $\mathrm{O}$, braces $R$ r and $R^{\prime} r^{\prime}$, and catch $S$, for the olject stated.

2.-The construction of the brace $T$, with depressed portions $t i$, to serve as steps, and an elevated central portion, $t^{\prime}$, to which the seat $\mathrm{P}$ is attached, all as herein described.

No. 83,507 . - JAMES KAY, SALEM, 1ND, - WheelPloughls.-Oetober 27, 1868 .

Claim.-I.-A two-wheel single riding plough, having the plough $\mathrm{E}$ and its standard $\mathrm{C}^{\prime}$ secured to a hinged frame $\mathrm{C}$, as described, in combination with lateral, front, and rear braces arranged for sustaining said standard, substantially as described. 


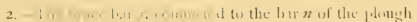

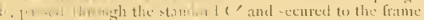
(C) vertantw lls is disetiluet.

3.- It cembantion of levers or tratles $c f$ with a

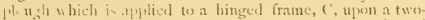
ith el carriage, asu of which levers or treatles is adapterl for rat inur the plons sh and its frame, while the other is at!ajte.l for deprewing said parts, sulutantially its de scrilied.

4.-The lnace $s$, econnected to the Iracket $a^{\prime \prime}$, and the ist molarils $c^{\prime}$, stlostantially as and for the purposes de-1 it edl.

5.-The adjunting serew rothec $c$, al p'iesl to the hingal frame (', and suppotiag this frame upen the asle $A^{\prime}$ of a sinfle riclime plongh, sulstantially as and for the parpose ilereriliet?

6.-In a machine which is emstructed as described, the

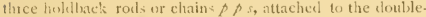
tre-, - - blusantially as and for the purposes described.

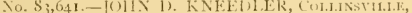

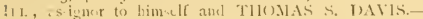

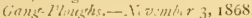

(laim. - live frame $A$ aucl vil rating frame $A^{1}$, the spring $a^{1}$. loon $a^{2}$, ane treadle $a^{3}$, all operited and combinet sulstintially as a sut forth.

Xo. $s_{3} 698,-J A S P E R$ N. D.ATISON and NAA.HAN

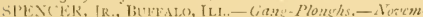
bie 3. 1568 .

Ciam.-1.- The combination of the ploughs, the loams, the cd ustable f lat fom, the lever E and the tonsue so arranged that the tougue shall be llexible when the flough are at work, aul only stiff when used to carry the ploughs above th: ground, the dey the of the cut being indepentlently regulat ted, sulistaitially in the manner set forth.

2. - The comlination of the plou ghe, the ferms, the plat form and axle, with tire braces $N$ and slidiug stat $U$, arang ed to operate subtantially as and for the purpose set futh,

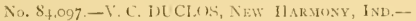

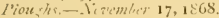

Claim.-1.- The arrangement of the notched utanclares J I. arm $\mathrm{K}$, and pin $d$, for the purpose of regulating the plough, sulp:tantially as herein set forth.

2.-The combination of the hounds $\mathrm{C}$ C, hinged bean $\mathrm{F}$, am $\mathrm{K}$, standaris J J, and lever $\mathrm{L}$, all constructed anil operating sulvtantially es and for the puyjoses hercin st forth.

N. 84.52.-EJW:IRD 1). WENIAMIN, OLI TOWN,

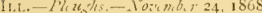

(him - 1-The combination of the whitiletrces with the ploug!, when the same are constructed and arranged in connection therewitl, in the manner herein shown and de scrilicel.

2. - The levers 1) I', piroted to the ends of the axletrec, and bearing whecl axles $\mathrm{E} E$ at the enels of their sho:t arms, ambl having their long arms connected ly the adjustable sway lat $\mathrm{G}$, lic whole arranged and operatisg sul:tantially as lerein set forth and specified.

3.-The folling frame $\mathrm{K}$, arranged and operating at de -cullud, and for the purpome sp-cifeel.

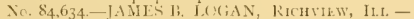

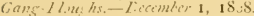

Clim. - The cenal ination and arrangement of the bams 11 , wingins $l$ emms $O$ and $G$, the hanger $F$, and lever $E$, the arrangement being sueh that the ploughs are drawn by the levers (), which are : ttached ti) the forward end of the lew. er thesesf, sulutantially as shown and described.

No. 84652 - ANI REW SAITH. IURTI.INT, OREG GN, a i nor to T. I. CARTER and W. P. WATSON, same

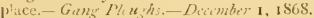

Cla $\mathrm{m},-\mathrm{t}$ - - The eombia tion of the lever (), having the offoct $o$, with the ratchet $\Gamma$, rocl $R$, having the touth or shou'der $r$, and lever $T$, the whole oprerating sub-t.mitilly as an ! for the purpone descrilied.

2.- The arrangement of sucl frame, when constrneted as herein temeril ed, in conl ination with a downward lent axic I), the low strap i, the braces $1 \mathrm{II}$, the dratught pole (;, and the wheels $\mathrm{F}$ l:

3. - The arrangement af the clevi $\mathrm{K}$, larace, $11 \mathrm{Il}$ ', king lanlt C. er mo loar A', and axle I), the axle heing lochinel the

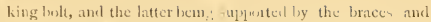
the cros har, ah tantially as herein described.

4. - The linees $n$ and ${ }^{\prime}$, attached at their kower ends, re. spectively, to the moldboat and stamlard, and at their upper ends provided with serew threadr, upens wlich are fitted, above and below the plough heam, through which the lraces pas, acljustims serew nuts, substantially is and for the pur pose speciliet.

No. 84.748. -FRINCIS MUTARNIIIAN, SANTI

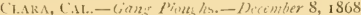

Claim.-1.-The frame or ground work of the gang plough.

2.- The combination and arrangement of the beam $k, t n$ which the ploughs are fastonerl, the boam to which said plough beam is fartened hy hinges, the semi-circular hinges, as constructed, and the maner of fatening the plough in the beam, all as shown.

3.-The screw slicles $A$, in combination with the frame.

4.- The combination and arrangement of the beam $\mathrm{L}$, to which the lever in fastencel, the po:t on which it works, the chain, the pulley on which it works, the evener, and the suard, ail as clescribed.

5.- The spuare block I) under the axletree, for regulating the amount of land, in combination with the evener.

6.-The construction, comlination, and arrangement of the several 1 arts, the slown and dercriled.

No. 8,970,-J. L. GTL.IR.S., MAIOMET, IL..pionsits-Dicember 15,1868

Claim.-ihe combination of the axletree $A$, wheels $Q$ and R, guide stanilards $\mathrm{L}$, upright $\mathrm{H}$, lever $\mathrm{G}$, chain $\mathrm{I}$, and brace $J$, with the axljustable plough beams $D$ and E, all arranged av set forth for the purpose specilied.

No. S5,496, - TIBLOTHY U. WEBB, SPRINTFIELD, IL.1.-Cinn - Vloushs. - Decembir 29, 1858 .

Claim. - In combination with a frame, $\mathrm{A}$, the spreader and bearer, for the furpose of uniting and working as a gang a series of single ploughis, E E, constructed, arranged, and operating substantially in the manner and for the purposes described.

No. 85,621,-Z. T. SWEET, EUgENE CITY, (3REGON.Gams Ploushs. - Jiritury 5, 1860 .

Claim.-1.-The conbination of the cam spring H, rock haft 1 , foot fiece $j$ and staple $h x$, with the side bars $a n$, block $h$, catch $i$, and beams $G$, all arranged and operating as descrilsed, for the purpose specified.

2. - The arrangement of the rack $d x$, and the angular lever I) with the slotted guide plate $d$ upon the axle, and the slide cupon the arm $b$ of the whed $B$, wherely the weiglit of the cultivator loolds the lever locked in any desired jusition, as lierein shown and describerl.

No. $85,768,-$ JOHN Ro(T, HARTLAND, N. Y.-Sulky Plous hs:-Fanuary 12,1 S69.

Clam.-The combination and arrangement, with a plough, of the whecl $\mathrm{E} G$, axle $C$, and arm $\mathrm{F}$, subtantially as set forth.

No. 85.838 -WILIIAM MA.SON, INDEPENDFNCT,

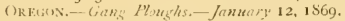

('laim.-1.-In a gang plough, the hent axle herein de crilied, con isting or the part-1) $\mathrm{W}^{\prime}$, the part $\mathrm{D}^{\prime}$ being bent at riglt angles, and having one of its arms fitted in a socket on the end of the part D, the former being made adjustable relat.vely with the latter, by means of nut $n$, and set serew $t$, at, and for the purpose specitiel.

2.-In comblination with the frames $\mathrm{E} F$, crank axle D IJ', crank shaft $J J^{\prime}$, and ploughs $(i)(i$, the levers I $K$, connect ing rod $\mathrm{Nl}$, and treadle $\mathrm{N}$, in and for the purpose specified. 3.- The crrangenent and combination of the lever $\mathrm{K}$ I. $\mathrm{N}$, rotl $\mathrm{A}$, sturs $a a a$, and erank shaft I) $\mathrm{D}^{\prime} \mathrm{J}$, when sairl parts are constructed to operate in the manner speciliesl. 4.- The lever $\mathrm{N}$, when provided with a liange $r$, and adju-tiagr screw s, sulbstantially an specificet.

No. S6,231.-WIILIAD II. ISAACS, TERRE HANTE,

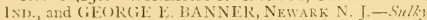

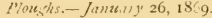

Claim. - The contruction, combination, and arrangement of the ploughs $k$, arms $h$, with suckets $\therefore$ as constructed, and attached by fivots to ontide of frame, levers $j$, connect ing rods $i$, levers $d^{1} d^{2}$, lhaing sping lever $f$ attached, semicircle, and fram an, ar convtucterl. 
No, $86,370-1$, F. CRUTTENDEN, CANISARAGiA, N. Y.-Pliusth Allathments. - Fibruary 2, 1869.

Claim.-1.-The arm B, supporting the guiding wheel $\mathrm{D}$ adjustably, and attached to the plongh beam, in the manner describerl.

2.-The combination with the arm B of the vertical slicle $\mathrm{F}$, suphorting the guiling wheel, and the spring actuated bell crank, all sulutantially as and for the purpose specificel.

No, $86,472,-$ JOSEPll TUTTEN, AHAM, ILL.-Gang Pliushs. - Fibiur, 2, 1869 .

Claim.-The combination of the wheel $A$, axle $B$, bars $(\mathrm{C}$ and $\mathrm{D}$, end bars $\mathrm{E}$ and $\mathrm{F}$, constructed as described, bar (i, castings $\mathrm{H}$, pivoted canter arms 1 , wheels J K, and dranght bar L, with each other, subtantially as herein shown and describerl, and for the porposes set forth.

No, 86,608 - T. TUSTIN, IORTLAND, OREGON.Gan I'lus.'ls.-Fobruary 2, 1869.

(lim. - The lever A B C I $E$, the links $G$ and $F$, (in which may be rotated the bent axle K.) the bent axle K, and the latch $\mathrm{I}$, when used in the manner descrilsed, and for the purposes set forth.

No. 87,284 - (). (1Sighen, Trumansetro, N. Y.-

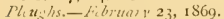

Claim-1.-1'roviding the tomgue $G$ with a lever, 11 . having a spring $g$, and passing through the slotted and notehed plate f, for the purpose of raising or lowering the tomgue, and looklin $r$ it in any prition desired, substantially as shown and described.

2. - The arangement of the plate $h$, cogged sliding liox $h$, with its axle $c$, cogged cam F, and handle $d$, all constructed and opcrating substantially as and for the purposes herein set forth.

3.- The atrangement, on a plough carriage, of the slotteil plate $h$, slicling plate $k$, and luop $m$, for the purgose of holding the plough beam, substantially as shown and described.

4.-The arrangenent of the lever 1 , am 11 , aml spring bar $r$, for the purpose of stuadying the plough, subtantially as herin set forth.

No. 87.398 ,-J()SEPI] CI.EES, DAREYYIL.F, OHH,Ploush Yiruks - Ilarih 2, 1869.

Clain. - 1. - A plough tnck, haring the axle contructed in two parts, and artanged to adjuse either part vertically, without changing the other, substantially as specified.

2.-The part 1 of the axle, corrying the guiding wheel, arranged to be adjusted horizontally and vertically, indepentently of the other part of the sait axle, sulstantially as specitied.

3.-The part $\mathrm{C}$ of the axle, carrying the small wheel, bent at right angles, and arranged for adjustment in the plate A, sulstautially as specilied.

4.- The comlunation, with the parts $(\mathrm{C}$ and $\mathrm{D}$ ) of the axle, of the arm E, culstantially as specilied.

5. - The combination, with the prart $\mathrm{D}$ and $\mathrm{C}$, of the arms

E and 1 , substantially as specified.

No. $57,6+1 .-111 K .1 .1$ CULVER, DANSTHA., N. Y.Plone hs, -Marill o, I 867 .

Claim.-The combination and arrangement of the bar $c$, pendant $s$, chain $1 \mathrm{~B}$, amt handle $E$, with a single or ganesploush, as herein clescriled, for the uses and parposes speci. lietl.

Ni). 87,677-JOIIN R. JACKSON, PI.AHAтеHE:

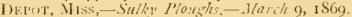

Claim.-1.-The bsams ( C, levers D I), tooth plated uprights $a, a$, in combination with the adjustable and reversible ploughs $\mathrm{E}^{2} \mathrm{E}^{2}$, when the whole is comstructed and arranged substantially an described, as and for the purpose speciliet.

2. - The dotachable center plough $\mathrm{E}^{*}, \mathrm{E}$, nnd $\mathrm{E}^{1}$, with lover ()$^{\prime}$ and upricht $h^{\prime}$, as constructed, when the same is so arronged as to be used in combination with the two sicle plouglss $\mathrm{I}^{2} \mathrm{E}$, substat.tially as described, as and for the purpore specified.

No. 87,865,-JOIIN G. MlOORE, Kingston, OrIo.Tiu ki for Plousths - North 16, I 869 .

Claim.-1, - The combination with a truck, of the shoul der strap 11 , sub-tantially as and for the purpone described.

2. - The combination with the slafts 1 and the soke D, of the hooks F I, and stirrup; sulutantially as and for the parpose leverilsed.
3.-The arrangement of the yole $D$, is le $A$, am the clips E, all sulm tantially an and for the purpose thescrilow

No, 88,28.-ARTEMAS DAVISON, SAN LFANERO,

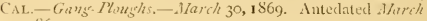
20,1869 .

(laim. - I - In coml ination with the arms D I)' and axes $a a^{\prime}$, on the har $C^{\prime}$, the clutch, con-isting of the jaws F and ( $i$ on the wheel and axle, respectively, subtantially as and for the yarpose describet.

2.- The jin or arm $H$, and the spring $\mathrm{H}$, with the lever $\mathrm{E}$, or equivalent device, for engaging and disengaging the clutch, sul w intially as dercribad

3.-The rack 1 , constructed with the lip $\mathrm{K}$ tugctlier with the holding projection 1 , on the lever $\mathrm{E}$, for retaining the jaws $F$ and 6 in centact until the plouglis are rained, sulstantially as clescribed.

4. - The totted arm 1), with it set screws $c$, to raisc and lower the axle $a$, and aclju-t the ploughs, subsiantially as and for the murpose herein described.

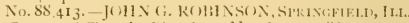

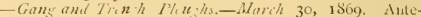
dated. Fitsch 23,1860

Claim.- I.- The comlination of the amertar lever $\Lambda$, rntehet $C$, and spring 13, with the itman $^{1)}$ and wiling axletree arm $\mathrm{E}$, in the manner descilixd, and for the purposes net forth.

2.-The combination of the vertical coupling $\mathrm{F}$, and pisot $\mathrm{M}$, and hoi icontal har $1 \mathrm{l}$, with the verical lever ( $i$, rateliet 1 . and sprinu $K$, in the manner described, and for the puryones set fortt:

No, 88.486 - WI. L. IEFFRIES, LANCASTEK, ()HIO,-

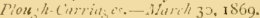

Claim. - The ratcht a and s, when contructed, combined, and operating sub-tantially as and for the purposes yoci. fierl.

No, S\$.998,-GEURt:E WH.ARTOX, TBRSEYIILE,

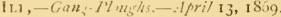

Clam. - The parts describel, consinting subtantially of the lever $c^{\prime}$, arm C, link $D$, and catch E, whon arranget and operating substantially an described and for the purpose sct forth.

No. So, I44-THoMIAS T. H.ILA, Bryan, Trxas,Canir-Jioll hs, - thil $20,1569$.

Claim.-1,-The comlination of the up and down arljuxable totted cross bar 1), hasing the perfornted plate $f$, with the plough leams $\mathrm{E}$, pince, and pivet al levers ( $i$, all arrang ed and operating substantially as and for the purpose herein shown and described.

2.-The levers fi, pivoted to the up and down arljustable cross bar 1 ), connected at their front end with the plough beams, and asljusted with thic rear end on a cros har, $k$, all arranged and operating substantially as clescribed, for the puppose of oscillating the plough beam-, an specified.

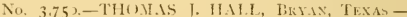

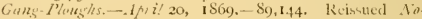
R'ember 30 , 1 Síg.

Claim.-1.- The combination of the up and down adjuable slotted cros bar 1), having the perfurat ad plate /, with the plough beams E, pins $c$, and pivoted levers $($, all arrang ecl and operating sulmtantially is aud for the purpose herein shown and described.

2.- The levers $(i$, pivoted to the up and down adjustablo cross har 1 ), comected at the front tnels with the / fungl beans, and actjusted with their renr encls on a crom line, $k$. all arrunger and operatiug snlstantially as de-crihed, for the purpose of oscillating the plough beam, as yecilied.

3.- The brace or luridle 1 , when conserneted and artang ed with rolation tes the plesugh beam and revolvin $g$ cutter if. to supjort and - trengthen the-tock $(1$, in the manner sul-tantially an descrilsed.

No. $897 \mathrm{~S}$-MILRICT: MLRPHY, VACAIULF, CAI.

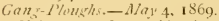

Claim.-1.-In combination with the arm or lever C, rig. idly fixed upon the crank for raising the plongh frame, the adju-table comection of the crank fi. to the axle, ly a poly. gonal pun and corresponding eye, sulutantially as ant for the jurpose et forth.

2.-The hw convexed thare 1 , having the ene nded point 


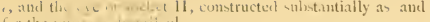
for the pets ine of cisined.

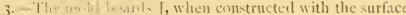
curved, an derated, amit having the convexed edge $d$, sub. tantially a, hetardetribet.

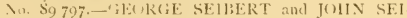

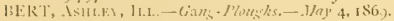

Claim, -1. - The staples fi and $\mathrm{G}$, when arrangel and oprating sul stantially as and for the purpones describert.

2.- The hook $h$ and perforated bar $n$, when combined wit! the plot:gla licrein described, and or erating as and for the purperie's mentioned.

No. 20.175,-J. W. I.EWIS, OREGOS CTTY, OREGON.-

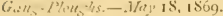

Claim - i.- The frome A aud dranght pole $\mathrm{E}$, with the nlatem (1) for the driver' fect, and the seat $F$, in combinatim with the toggle $I$, lever I, an I the rack $I x$, all con struated and arranged uhtantially as and for the purpose yeecificel.

2.- The piveted bar J, guicles I' I.x, pin $d$, lever $\mathrm{N}$, car ring the eatch () $e$, the chain as, ancl pulley $f$, in eombina tion with the axle L, wubstantially an clescribed, for the pur por y yecitisel.

Ni, 93,237.-GEUR(iE R, CARTER, NEW YUUR, N.

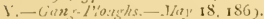

Clam.-1.- In combination with the plough heam or beam frame, the tilting caniage frame, stbstantially as de sentoct.

2. With the tilting carriage frame and the plotgh frame piruted to the front cual the thicrof, the long seat extending from the axle to the rear of the carriage frame, substantially as ahown and desciloet.

3.-A gang ploush, having the plough beams or loam frame pivuterl to the front end of the carriage frame, when the latter is arranged to tip relatively to the draught pole, sulstantially as liuwn anel describe.l.

No. 90,831 -(1)RVIO) X. FARG(), Sogtet, C.1.

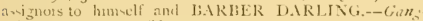

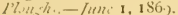

Clam.-1.-The bent platev D 1), attached to the outer frame, av deneribed, the vertical st serew's 1$)^{\prime}$ I)', which buar upon the said plates, for raising or lowering the plongh heam- sulutantially as set forth.

2. - The vertical was $<\mathrm{E}$ E, friction roller $\mathrm{E}^{\prime} \mathrm{E}^{\prime}$. opera. timg in the said way, abol the transerse bar F, to which the rollers are connected, sub-tantially as and for the pup we set forth.

3.- Comnecting the two crank axles H II by the rod $\mathrm{K}^{\prime}$, 6) that lioth of the sitil axler may be operated by the uptight lever, $L, L^{\prime}$, substantially an and for the purpose specified.

4.- The set serews J I, oparating in the heam of the plough frume, and linked to the arma I 1 of the axles, in combination with the sail axles, ats and for the purpose set forth.

5.-In conbination with the levers L L', operating in the

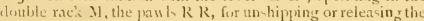
levers alternately from the nutches $l^{2 /}$ ubstantially as and for the purpare specitied.

6. - The front end crom heam of the outer frame, for att:achment of the neap, or polc, axke, and crank axle of the Irivins whech, in combination with the crank axle $S^{\prime}$ and semicircular rack $C^{2}$, the whole comstructed and arranged to pperate sulr-tatially ar yecilicd.

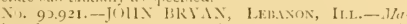

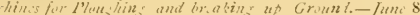
IS69.

(laim.-1. - The piroted frame or lound . I . I, in comhinati on with the plough benm and main frame I I, as con irtacter and arranged.

2.- The lever aml link $i i^{\prime}$, in combination with the hounds I . A, and moin frame J. as shown.

No. 91 6.3.-J. W. I.EWIS, OKEGOX (ITY, OREGOX.Gan, Plous:- -June 22, 156).

Claim -1 - The hointing lever $f$; of a gang-plough, arranged for uperation, in connection with the hand lever II, for raiving the plou girs, su'stantially as herein deseribed.

2. - The cursed extremitic or arms $f f$, in combination vith the hand lever II, and hoisting lever $(i$, sub-tantially

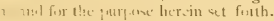

3.-The swinging frame, ane roller $e^{\prime}$, in combination with the beam $E$ and lever $G$, substantially as and for the purpore herein set forth.

Nu. 91.973-Joslail Slllil'AR1), Newrort, MF.Cu'tivatois.-Jun 29, 1569.

Claim.-1 - The combinatum of the two small ploughs A. lars B, supports 1 , wheels $($, ecntral bar $\mathrm{F}$, and ecutral plougla ( $i$, having finger formeel unon the rear elges of it rimgs, with each other, sulastantially its herein shown and descrilsed, and for the purpose set forth.

2.- The fivoted tilting beam II, pivoted lever K, and staples $h^{1} / h^{2}$, arranged upon the frame $1 ; \mathrm{E}$. F, bearing the whecls $C$, as herein clescribed, for the purpose specified.

Ni) 92,016-LUKE C11.11'MIN, COLLINSWLLF, Cusx, nssignor to himself and Cullins ComllAY,

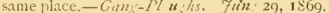

(laim,-1.-The combination of the frame of the gangplongl, with the crankel axle and wheels, by means of a rider, slotted as described, the whole constructed to operate substantially as before set forth.

2.-The tider s, slotted subtantially as described, for the purpose described.

3. - the whecl lever $/$, jointed in the manner described, to the crank arm $j$, and pivoted at its lower extremity to the axle of the furrow wheel $a$.

4.- The combination of the jointed wheel lever, the crank arm $j$, and the rack $1 / 7$, the whole constructed to opcratc substantially as before ret forth.

5 - The post,$r z$, nttiched, the former to the frame $d$, in the manner descrilied, and the latter to the asle of the land wheel, in the manner described, connected at the top lyy the jointed cross bar ().

6.- The combination of the frame of the gang-plough, the cranked axle s', the lifting frame, the differentinl pulleys, and the chain therefor, the whole constructed to operate sub-tantially as before set forth.

7.- The combination of the frame of the gang-plough, the ricler, the cranked axle, the lifting frime, the seat, the jointed wheel lever, the hand lever, and racks, the whole constructed to operate sub:tantially as set fortl.

No. $92019 .-F . R$. CKOTIIEKS, STARTA, ILL.-GansI'T. u chs...June 29, 1869 .

Clain.-I.-The adjuviment plates 1 , and brackets $K$, arranged to permit a lateral and vertical axljustment of the plough beams L. I\%, sthatantially as set fortls.

2 - The beam $~ L$, and $L^{\prime}$, and the brace $N$, and link $O$, when arranged adjutalsly, sulwantially as and for the purposes set forth

3.- The foot lever $\mathrm{P}$, its attachment \%, and chains $\mathrm{O}$ acting to raive the beam, $L$, and $L^{\prime}$, and combined with the detent $K$, for holding the ploughs out of ground, substantially as ret forth,

4.-The axle A, and the adju-table sub-axle C, and frame G, when combined with the lexm. L and $L^{\prime}$, by attach. ment devices, allowing each of saicl beams an independent vertical adjustment, sul-tantially ar et forth.

No. 92, 099-IVILLIAMII, RICE, OAKLAND, ()REGON. - Gan:-Pl u:h-Jun: 29, 1869.

Claim.-The temper holes $A$. in combination with the uprights $\mathrm{B}$. hinges (i, plates $\mathrm{D}$, slot $\mathrm{E}$, plate $\mathrm{F}$, uprights for rollers $f$, screw 11 , lever $b$, leverage $c$, hinges $d d$, chain $d$ wheel $f$, all subatantially as set forth and described.

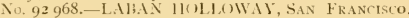
(AL-Gi,n I'louw/is-July, 27, 1869 .

Claim,-1.- The muable arm- C C, pivoted to the sides of the frame, and the treatle lever $\$$ attached to the pole, so that by their vinultaneous movements the plough frame can be raised and lowered, sulstantially in described.

2.- The totterl stops $\mathrm{H}$ at each sile of the driver's sent, amil the trap or bar I, heneath the frame, sulstantially as and for the parposes set fortli.

No. 93.077-CHARL.E. F. (IAY, ALIAAY, ()REGON

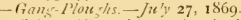

Claim - The cultivator herein described having beam $\Lambda$, rodh $d$, levers $\mathrm{D},(i$, and $\mathrm{I}$, ratchet $\mathrm{H}$, chain $h$, curved arm $n$ and attachment $\mathrm{Y}$, constructed and aranged substintially as spccified.

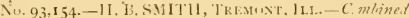

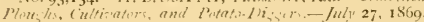


Claim.-1, The ombination of the tongue 1 , roller $\mathrm{K}$, bar $\mathbf{N}$, devis or cleses (), frame $E$, lever $A^{\prime}$, and catch-bar $b^{\prime}$, with each other, sulatantially as herein shown and described, and for the purpose set forth.

2.-The hinged bir $\mathrm{V}$, and pentent swinging bar $T$, when an ranged with relation to the frame E and the plough-beans, as herein described, for the purpose specibed.

3.- The c mbination of the roller $X$, catch-lever $\mathrm{IV}$, and stirmp rod $Z$, with the frame $\mathbf{E}$, sulatantially as herein shown and discribed, and for the purpose set forth.

4.- The combination of the lever $\mathrm{D}$, to which the spindle of the furrow-wheel $C$ is attached, lever $G$, kecper $I$, and lever-pawl If, with each other and with the frame 1 , substantially as hercin shown and described, and for the purpose set forth.

No. 93,35S,-IENTIMIN SLUSSER, SiDNEY, OHю. - Sulky-1'wugh. - its wst 3, 1869.

Claim.-I. - In conncction with such crank-axle, the ligg 1 , constructed and arranged as for the purposes set foith.

2. - In connzction with such axle, the movable plate or rest $\mathrm{C}$, capable of shifting position so as to remain hurizontal, whether the erank be miscel or lowered, substatially as and for the purposes set foith.

3.- The combination and arrangement of the plough-beam $p$, axle $A$, patt $($, having the straps $c c$, and brace 13 , all constructed to operate substantially as and for the purposes specific d.

4. - The weighted trearlle $\mathrm{N}$, in combinntion with the lever $M$, rack $K$, catch $o$, and crank $a a^{1} a^{\prime}$, all constructed $t$, operate substantially as and for the purposes described.

5.--The jointed tongne $T$, in combination with the slottcil plate $t$, cross bar $V$, and arm $e$, all operating sulstintially as sud for the purpones indientel.

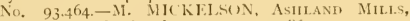

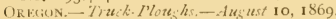

Claim.-1.- The arrangement, together with the tongue and the frame, of the pirot bolt I), yoke $\mathrm{E}$, and set serews $\mathrm{F}$, all subitantially as specilied.

2.-The combination, with the frame and axle, of the lent rod 1I, lever I, and levers $\mathrm{II}$ (), when arranged sub. stantially as specified.

3.- The axle, constructed in two parts, hinged together, anl otherwise arranged as specified, for governing the plane of the truck, as describet.

No. $93.5+9-11$. W. NEAI, SimNer, OUIo, assignor to

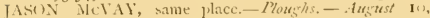
I 869.

Claim-I-In combination with the swinging heam $\mathrm{E}$, lever $h '$, operating sulistantially as and for the purpose speci. fict.

2.-The foot lever $g^{\prime}$, pulley $\mathrm{G}$, chain 11 , and swingingbeam $\mathrm{F}$, all combined to operate sulatantially as aind for the purpose specified.

3.-The combination of foot lever $h^{\prime}$, with pivoted pawl $h$ thercto, ratchet wheds $e^{\prime} f^{\prime}$, pulley $f$, and pawl $e^{2}$, sula stantially as and for the purpose set forth.

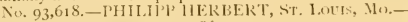

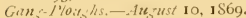

Claim. - I.-The axle bar $a$, trec-journal $\mathrm{J}$, and sector and and pawl tevices for connecting the wheel $A^{2}$ with the axle $A$, sulntantially as set forth.

2.-The front-berard $F^{\prime}$, jivot $s$, link $h$, and pole $G$, connected adjuntally loy the slot $f$ and set screw's $f^{\prime}$, subtantially as set forth.

3.-The stanclard I, lever I., lar 1:2, fulcrum K, links l, and crosuloar l', arranged in comlination with the plough beams 11 , ubetantially as set forth.

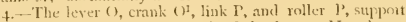
ing and opcrating the front end of the beam. M, subutantially as con-tructed and arranged.

5-The plowrh- $\mathrm{N}$, standaris $n$, pin $=n^{3}$, arms $n^{i}$, and pivot $n^{2}$, when opernting sub-tantially as ut forth.

No. 93.689 -1'ITEK CUNR.ATII, JRII:LGH, ILI. - Ginu-1'lewsh.-Ausust i 7, 18 '

Claim.-1.-The tajo and holts $f$, beam $F$, and guicle $\mathrm{E}$, when constructed and operating substantially in the manner and for the purpores set forth.

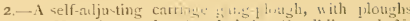
1', lever II, spring catches is and chains $\mathrm{G}$, sliding rods $\mathrm{N}$, and grooved loxes (), levers $L$ and $M$, and tajm and herit , f, beam $\mathrm{F}$, and guides $\mathrm{E}$, constructed and operating substintially in the mamer anil for the puipases sct forth.

No.93.994-1.EAVITT HLNT, WEATHERSFIELI?. VT. - Mous hs, - iwsust 24, IS50.

Claim.-1.- The combination, substantially as herein deserilsed, with the hinged plough beam and -ulky frame. of a stiff or rigid smuge lar to regulate the dejth of furrow, and to cause the plough point to bite or enter the ground at the instant the machine is moved forward.

2.-The combination, with the plomgh beam, of arms hinged to the sulky frame, and connected with the beam, and with the lever for elevating the same, as hercin desciled, so that saicl arms shall serve besth to stiffen or brace, and, in comection with the lever, to raise or depress tine plough.

3-The combination, with the slotter jlumbh b-am and whintctret, helet in a slot in the sulky frame or pole, anel connected with the beam isy a dratght chain or coivivalent device, of the hinged hracing arms, the lever for actuating the same, and the rigid or stiff gauge lar substantially as and for the purposes set forth.

4.- The coul ination and arrangement, ubtantially as herein s ceitical, of the plough leam with the hand lever for raismg or lowerine the same, and an ansiliary foet lever, in dependent of, and having no connection with, the hand lever but comected w ith the b am, and aclated to act in cr njunction with the band lever when required.

5. - The comlination, wh the hand lever and sermental rnck, of the slicing catch bar and levice for of eriting the sami, said bar leing beld to the lever aud feried so an to stracldle the rack, an and for the furposes shown and ret fortl.

6.-The combination, with the forward part of the luam of a plough of otherwine ordinary or sutable contruction, of a pendent arm, carryins the roller, and pivest al or linged to the plongh beam, and a curved and slottesl branch arm connected with lsoth the plough leam and the roller arm, in the mamer and for the pup nes substantially as clescrilued.

No. 9449 I.-FR.INK A. IIII.L, MARVSIILK, CAL.-

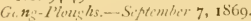

(Jam - - In comlination with the extemled arms I) of the crank, and comncting bar. $I$, the licnt shaft $G$, turning in lowen $\mathrm{F} \mathrm{F}$, said shait being rotated by a swers, $K$, subutantially as and for the pupuse above de scribed.

2.-The wrought-iron vertical standare /, dovetailed into the landside of the plough, substantially as and for the purpus: above described.

3. - Securing the timbers $\mathrm{F}$ and pole $\mathrm{P}$ to the cross bar $\mathrm{C}$. by mcans of the iron bar s and bolts $i$, so that they may lie adjustable, substantially as set furth.

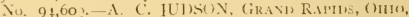
assignor to himself and E. (). IL 1$) \mathrm{S}( \pm \mathrm{N}$, same place. l'oughs.-Sipt:mlier 7, 1 60 .

Cltim.-The arrangemeni of the leam in two parls 1 ), stock E, lolt $F$, block $\{i$, wheel 1), draw lates $K$. clevis $\mathrm{L}$, and bearing plates $\mathrm{I}$, all subatatially as syeci fied.

No, 95220 -IIURACE R. IILIE, IIAYWAKIs, arimor to I.EXNARI) I.. TREATIIELI, and (ileokrit k.

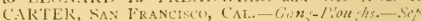
tember 24, I $\& 60$.

Claim.-I.-Attaching the rear end of the plough beam I) to the rear end of the pleugh frame, liy means of a link, II, substantially as herein decibed.

2.-The metal plate $C$, or equivalent device, secured to the axle $\mathrm{B}$ and pole $\mathrm{I}$ ), in the manner alove descritud, for the purposic set furth.

No. $95437-11$. N. DAITON, PACH1:Co, CA1.Spline for Gims-llow.

Claim. - The combination of a coileal or other young with the axle and frame of a gang-plumbl: substantially an herein shown and describerl, and for the purpene net forth.

No. $95539,-1$. N. THOMPSON and WILI.JAM

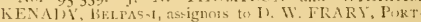

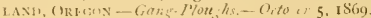


Claim. - The levers $A$ and $B$, the swivel joint 1), nut and crew E, link F, fulcrum G, beam II, and hook I, tugether with the acljusting keys J, or their equivilents, substantially as described, and for the purpose set forth.

No. 95 997--WHLLI.II J. FLNK, PORT1.AND, ORE

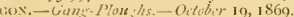

(laim.- The combination of the rock shaft II, the eye piece $\mathrm{F}$, links $\mathrm{C}$ and $\mathrm{D}$, clevis $\mathrm{E}$, roller $\mathrm{I}$, incline $\mathrm{I}$, and check $\mathrm{I}$, on tongue $\mathrm{k}$, when applied to a gang-plough as dexeribed and for the purposes set forth.

No. 96.334-HENRS P. NCCLEATE, ToMALES,

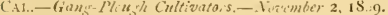

Claim.-The frame A, constructed substantially in the manner described, with parallel braces I3 B B, diagonal strap J. thr surg which the ends of the standards pass, and the draught rod 1 , attached to the rear cross beam $B$, as sijecified, for the purpose set forth.

No. 96 593.-JAIES B. HUNTER, AsHLEY, ILl.-

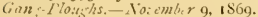

(laim. - 1. - The slotted plat is $F$ and draught rod $G$, in comlination with the plough beams If $\mathrm{E}$, stubstantially as herein shown and described, and for the purpose set forth

2. - The aljistable frame $\mathrm{C} c^{2} c^{2}$, in combination with the axle B, plough be:m D, and tongue M, substantially a.s herein shown and described, and for the purpose set fortls.

3.-The combination of the bent crank lever L with the frame $\mathrm{C}$ and plough beam $\mathrm{D}$, substantially as herein shown and described, and for the purpose set forth.

4.- The combination of the draught rod $O$ with the tongue $\mathrm{X}$, donble tree $\mathrm{N}$, and plough beam $\mathrm{D}$, substantially in the manner herein set forth and described.

No. 96,875. W WORDEN J. BOYCE and GEORGE IV.

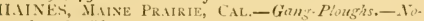
T.tmb.r. 16, 1860 .

Claim.-1.- The machine described, consisting essentially of the frame $a b$, tongue $c$, adjusting devices $c ; i k$, wheels $n$, and lever $p$, the whole being combined and ar ranged for the purpose set forth.

2. - The slicling stirrup $e$, moving in straps or ways $f f$ at the top of the frame, and held in place by a pin, 5 , or their exuivalent , substantially as set forth.

3.-The lifting bar $i$, with it: movalsle fulcrum $k$, on the plate $h^{\prime}$, so that by its link comection with the end of the tongue the draughit pole can be thrown to the right or left, or the end raised and lowered, substantially as set fortir,

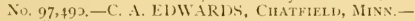

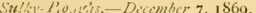

Claim.- The levers $\mathrm{A}$ and $\mathrm{B}, \mathrm{posts} \mathrm{C}, \mathrm{C}$, and $\mathrm{D}$, post $\mathrm{E}$, iron rod $\mathrm{F}$, bed timber $\mathrm{G}$, axle $\mathcal{l}$, plough heam $\mathrm{J}$, and chain or rope $\mathrm{Y}$, all comstructed, combined, and arranged as set forth.

Ni. $97,500,-D E N X I S$ 1I. GLEESON, SAY LEANDR(), CAL, assignor to himself and I)ENNIS G.INNUN, same

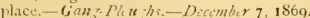

Claim.-The combination and arrangement of the parts of my gang-plough, as herein described, this combination and arrangement cons tins in attuching the draurbt pole E, rigidly to the non-extensible axle of the carrying whecls, the plough leam being lumg on the fulcrum holt D, which pasies through the forwarl stun lard of the driver's seat and the draught pole in advance of the axle, and which plough heams ar: opsatted by a roller shaft and attachments, as shown, the whole of the part $\div$ being combined and arranged $t$ sother. in manner substantially as dencribed, and for the purpssect as set forth

So. 97,646.-BYRON JENNINGS, GILRoY, CAI., assiznor to himself and IIENRY W' IBRIGicis, same

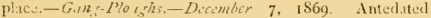
D. combir 1,1869 .

C'ain,-1.- - The combination, with the $\operatorname{arm}$ s $h$, on the sliaft $c$, of the plates $d$, provided with holes i, for making their connection adjustable, sulstantially as and for the purpose set forth.

2. - The curved arm E, attached to the shaft C, slicling lar $;$, and guide $h$, substantially as and for the purpone le-cribel.
3.-The lent lever $1 ;$, with it slotted inclined lug $i$ together with the bent pin or staple n, substantially as described.

No, 98 370,-EMERSON E. GORE, P'HANIX, OREcon.-Cians-Plonshs.-Diccmbir $28,1869$.

Claim.-1.-The combination of the stops $R^{\prime} R^{\prime}$ with the frames $A$ and $I^{\prime}$, and arms $V^{\prime}$ and $F^{\prime}$, whereloy the latter are retained in an inclined position, and the plough: therehy prevented from rising or falling, substantially as and for the purpose : pacified.

2.- The links $\mathrm{D}^{\prime} \mathrm{F}^{\prime}$, connecting the frame $\mathrm{A} \Lambda^{\prime}$, the lind links being slotted, for the purpose of allowing the plonglis to be raived in an inclined direction, as specified.

3.-The hoisting lever $\mathrm{M}^{\prime}$, link $\mathrm{K}^{\prime}$, and crank $\mathrm{I}^{\prime}$, in combination with the links $\left(V^{\prime} \mathrm{F}^{\prime}\right.$, and frames $\Lambda \Lambda^{\prime}$, of a gang-plough, as spccified.

4.- The spring catch $\mathrm{O}^{\prime}$, pivoted to the frame $\mathrm{A}$, for the purpose of locking the frame $A^{\prime}$ in it elevated position, as specified.

5. - The frame $A$, supported on the front axle by the rods $C$, and on the swiveled caster wheel $O$, substantially as described, so that it can be raised or lowered at will, to adjust the position of either plough, or of both, sub-tantially as specified.

6.-The levers D, connected separately with the axle and with the frame $\Lambda$, for raising or lowering the latter, as specified.

7.-The lever $\mathrm{I}^{\mathrm{r}}$, connected with the swiveled shank $\mathrm{N}$ of the caster wheel $\mathrm{O}$, and pivoted to a jointed arm $\mathrm{Q}$, that projects from the frame $A$, to adjust the latter, sulsstantially as herein shown and descrilsed.

8 - The combination, with the frame $A$ and axle $B$, of the jointed rod H, adjustable rod I, and jointed rod J, subtantially as speciffed.

No, 98.569.-1RTHUR CUNNINGHAM, CINCINNat1, Onlo.-Ploushing aft. Herrowing Machines.Jamuary 4,1870 .

Claim.-1.-The connection of the plough beam to the truck, by means of the projecting beam $\mathrm{D}$ and draw rod $\mathrm{E}^{\prime}$, the latter baing provided with the adjuntable block $F$, substantially as specified.

2. - The combination with the plotgh beam and platform, of the lever $\mathrm{NK}$, rod $\mathrm{M}$, and chain I, substantially as specified.

3.-The combination, with the plongh handles and platform, of the beam $T$, perforated bars $R$, and de tachable rod $Q$, when arranged substantially as specihie. I.

4- - The combination, with the truck and plungh, of the vertically adjutable guicle $W$, substantially as specifierl.

5. - The combination, with the gnide, arranged as describs d, of the lever $K$, rod $\mathcal{Y}$, lever $Z$, and foot piece $Z^{2}$ sub-tantially as specified.

6.-The combintion. with the truck and plongh, of the harrow, substantially as specificel.

7.- The combination of the harrow, suspending rod $\mathrm{X}^{\prime}$ clearing plate $\mathrm{V}^{\mathrm{I}}$, lever $\mathrm{Y}^{2}$, rod $\mathrm{V}^{\mathcal{H}}$, and nutehed post $\mathrm{I}^{\mathrm{j}}$, all arranged substantially as specilied.

8.-The combination, with the plough and beam V, of the chain $U$, substantially as specified

Nu. 99.379. - SAMUEL IVELCII, BE1.PASS1, OREGUN.

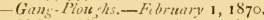

Claim.-The construction, combination, and arrangement of the axle $\Lambda$, hounds $N$, post $G$, with friction roller, sliding groove $\mathrm{F}$, plough frame $\mathrm{E}$, lever $\mathrm{B}$, joint bolt $K$, lever (, post 1 , and fulcrum 1$)$, as shown and describesl.

No. 99.538.-JOFX COX and SOLOMION COX,

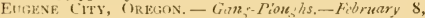
I 870 .

Claim.-1.-The bars $f$ ir $h$, when combined with the upright bar E and plough beams I) I), substantially in the manner and for the purpose herein shown and described.

2.-The ratchet wheel / and loose lever II, when used in combination with the paw $n$, and with the ropes or chains $m$, ulutautially ar hurein shown and described. 
No, $100.3 S_{3}$, GEORGE R. DUVAL, SALEM, OREgon. -Gang-Plo:whs. - March s, is7o

Claim.- The hinged and adjustable axle $\mathrm{C}$ and the lever $G$, with the part connected therewith, that is to say, the chain $\mathrm{J}$, bain $n$ and $o$, tongue $\mathrm{E}$, and brake $m$, in combination with a gang-plough, arranged and operating subatantially an described.

No. Ioo,696.-LEWIS T. IVEBSTER, NorthFIELD, Mlass.-Ploushs.-March 8, 1870 .

Claim.-1.-The compound bifurcated tongue and beams A $A^{\prime} A^{\prime \prime}$, when constructed a herein set forth.

2. - The drausht rod $\mathrm{O}$, in combination with the shaft $\mathrm{C}$ and adjustable collar $\mathrm{N}$, as specified.

3.-The guide 1 , constructed and arranged as de scribed.

4.-The arms $\mathrm{D}$ and $\mathrm{D}^{\prime}$, in combination with the wheels $\mathrm{B}$ and $\mathrm{I}^{\prime}$, and their respactive axles, and lifting device $\mathrm{C}^{\prime}$ F G I, when arranged as specified.

No, ICO,SOO-A. E. PORTER and A. L. PORTER, Limo L.F, IIL.-Riding Altachmen's for I'lous ths.March 15, is 70 .

Claim.-1.-The riding attachment for ploughs hereinlefore describad, compused of the standard A, with pin or bolt $b$, axletree $I\}$ with seat $(i$, and arc of holes $d$, wheel $D$, and hraces $\mathrm{C}$ and $\mathrm{E}$, the said several parts being constructed, arranged, combined, and operated substantially as and for the purposes hereinbefore described.

2.- The lever $F$ with its roller 1 , in combination with the plourh proper I $\mathbf{1 1}$, provided with the described riding attachment A B G 1 E E C, substantially as and for the pur puses descrilucd.

No, IOI.035.-JACOB PRICE, SAN LEANDRo, CAL.Gans-Ploughs,-Narih 22, is7o.

(laim. - 1 . - The lever $\mathrm{F}$, constructed as describesl, and having the foot board $\mathrm{G}$ attached to their forward enck, in combunation with the axle $D^{1} \mathrm{D}^{2}$, and plough beams $\mathrm{B}$, substantially as herein shown and described, and for the purpose set forth.

2. - The combination of the rack bar J, brace bar $\mathbf{K}$, and and spring lever catch L M, with the foot board $\mathrm{G}$, levers F, bzams $\mathrm{B}$, and tongue $\mathrm{C}$, subtantially as herein shown and described, and for the purposes set forth.

No. 101,435-JOHN H. COLE, VACaville, CAL.Sulku Ploushis.-April 5, is 70.

Claim,- The ploughin sulky above described, consisting of the wheels $A$ upon a stitable axle, the tongue $\mathrm{I}$, the qualrant (, the rock shaft $I$ ), the rork arms $\mathrm{E}$, the clevis plate $\mathrm{F}$, the king bolt $\mathrm{G}$, the lever $\mathrm{H}$, the frame I, the socket $\mathrm{K}$, the swivel brace $\mathrm{L}$, in connection with one or more suitable plonghs, and provided with a driver's seat, when the several parts are constructed as described, and combined and arranged to operate as and for the purpose set forth.

No, IO1,539.-JAMES W'. SURSA, SAN LEANDRO,

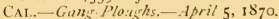

Claim.- In combination with the axle $\mathbf{E}$, lever $\mathbf{L}$, ploughs $\mathrm{S}$, and frame of the plough, the colter $u$, all arranged substantially as and for the purpose specified.

No. IOI,574.-JOIING. BOND, Decater, Texas, assignor to himself and Al.L.EN BAILEV, same place.Sully. Ploushs. - Ipril 5, is7o.

Claim. - The lever $\mathrm{H}$, fulcrumed at $d$, the standards $\mathrm{F}$ and $\mathrm{F}^{\prime}$, beam $\mathrm{E}$, and gnides $\mathrm{C}$, all arranged and operating sulntantially as aud for ahe purposes set forth.

No. 1O2,8O1.-I'ETER H. FLANSBURGH, IlAYWARD', ('Al..-Gans Plowshs.-1Yay 10, 1870.

('laim, - I - The ploughs 1) $\mathrm{w}^{\prime}$ ' in a gang, moved up and down by the standards E E', forming racks, as shown, the segments $F^{\prime} F^{\prime}$, the levers $G^{\prime} G^{\prime}$, or an equivalent device, operating substuntially as and for the purpose hercin described.

2. - The braces $b b^{\prime}$, attached to the ploughs at one end, and operating to throw the ploughs out of the ground in raining, substantially as herein decribed, in comlination with the lifting device above climed.

No. I03.855.-JA.l]ES P. EDDI.EMAN, PIIOT POINT, Trxas. - Combined Sowers, Planters, Cultizators, Scrapers,

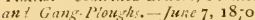

Claim.- I. - The combination of the seed box H, recessed roller $\mathrm{I}$, and band J, with the wheels A, spindlo $\mathrm{B}$. "I rights
C, levers E, frame D, and pivoted frame $S$, to which the plouglas are attached, substantially as herein shown and descriled, and for the purpose set forth.

2.-The combination of the hoppers $\mathbf{K}$, dropping slicles $\mathrm{L}$, cross bar $\mathrm{M}$, how or bent bar $\mathrm{N}$, springs $\mathrm{O}$, plough standards $Q$, and conductor spouts $R$, with each other and with the frame 1 , levers $E$, uprights $C$, spindles $B$, and wheels $A$, substantially as herein shown and described, and for the purpose set forth.

3.-The combination of the turn or breaking ploughs $\mathrm{U} V$ $\mathrm{W}$, and lever $\mathrm{F}^{\prime}$, with the pivotel frame $\mathrm{S}$, frame $\mathrm{i}$, levers $\mathrm{E}$, uprights $\mathrm{C}$, spindles $\mathrm{B}$, and wheel $\mathrm{A}$, substantially as herein shown and clescribed, and for the purpose sct forth.

4.-The combination of the onter cultivator ploughs A' $\mathrm{B}^{\prime}$, inner cultivator ploughs $\mathrm{C}^{\prime}$ ' $\mathrm{D}^{\prime}$, and lever $\mathrm{E}^{\prime}$, with the pivoted frame $S$, lever $\mathrm{F}^{\prime}$, frame $\mathrm{D}$, levers $\mathrm{E}$, uprights $\mathrm{C}$, spindle $; \mathrm{B}$, and wheels $A$, substantially as herein shown and described, and for the purpose set forth.

No. 105.528.-ELISHA WV. IV.ILTON, S.IN LEANDRO, CAI.-Gizng-Plough -July 19, 1870 .

Claim.- The device for elevating and lowering the plough frame, consisting of the sletted plates $\mathbf{E}$, the plates $e$, and the cams $G$, with their arms fand rods $g$, said rods leing atattached to the arm $h$ of the shaft $H$, and the whole operated loy the sweep 1 , substantially as described.

No. $105600,-D E I, 1, A$ A SEARS, ROCKFOKD, 1LL.Gans-l'inghs.-Julv 19, is 70

Claim.-1.-The combination of the curving stanclarils $C$, having the seat thereon. with stmelards $6 \mathrm{H}$, rack and pinions 1, and rlog I. as and for the purpose describecl.

2. - The $\mathrm{crmlination}$ of lever $\mathrm{N}$ with the bearing plate $n$, constructed as described, for the purjose sit forth.

3.- The combination and arrangement of the axle $\Lambda$, with the wheels $a \quad a$, brace $\mathrm{B}$, standards $\mathrm{C}$, tongue $\mathrm{D}$, , seam $\mathrm{E}$, plough frame $\mathrm{F}$, tandards $; \mathrm{H}$, rach and fiuton $\mathrm{I}$, dog $\mathrm{J}$, brace N, and lever $\mathrm{N}$, as describ-d, for the purpose set forth. No, 105 849 -JAMES H. REYNERS()N and $](111 \mathrm{~N}$ WORREL, ChAYTON, IND,-Sal'y A tachment to Pio $\mathrm{s}_{\mathrm{s}} \mathrm{h}$. $-J w / v 26$, I 570 .

Clam.-1.-The lever $d$ and staple $c$, when arranged as described, in combination with the plough and sulky, hercin shown and specified.

2. - The lever 11, with it s slot $s$ and the stop $\%$, in combimation with the plough and sulky herein show n and specified.

3. - The clevis $m$ and bolt $n$, in combination with the arms $g$ gand the sulky plungh, as described.

No, 105,879--JOIIN ALLOWNAS' DECATUR, T1.I., assignor to himself and WV. CUMMINGS, same place.-

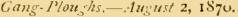

Claim. - The arrangement, witl relation to the bams $F$ $F$, shaft $O$, and axle $A$, of the pisoted pemlant $\mathrm{N}$, and arm O, adjutably connected at their lower or outer ends, as and for the purpose specified.

No. IC6 O33-JAMES L. V.IN (IORI)ER, SIDNEY

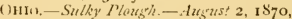

Claim.-1, The comlimation of lever $\mathbb{K}$, loop $d$ hook $c$, catch $h$, and slicling bar $(i$, substantially as and for the pur pose described.

2.-The axle $A$, wheels $B$ B, frame $C$, sliding hars $G_{i} G$, plough beams $11 \mathrm{II}$, loops $d i$, cranks $f$, levers $\mathrm{K} K$, and hooks $h h$, all con-tructed and arranged to operate substan. tially as and for the purposes berein set forth.

No. 106,548,-11ENRV C. CARR, BoRDENTOWN, N.

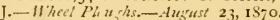

Claim.-1.- The arrangement of the leams 1 , made ad. iuntable by means of a series of holes, $b \quad b$, whaft $\mathrm{B}^{1}$, and crosa beam $C$, substantially as set forth.

2.- The arrangement of the beams 13, rock shaft $E$, arms $\mathrm{E}^{1}$, and adjustable rollers $\mathrm{E}^{2}$, substantially as set forth.

No. 106 799.-ABRAII El.LISON, MLRYsvil..F, CA1. - Gang-Pio:ths. - August 30 , is 70.

Chaim.- The combination, with the bent arms or lars 1 , piroted at one end, and holding the axles $p$ of the lever $k$, provided with the curved Iotted aum or link I, and held ly a rack, or equivalent device, subtantially as and for the purpose spectied.

No. 106 982,-JAMES H. ANITREWS. BEXICIA, CAl. -Girn, Plinestis, - Sipreml, 6 , IS7o. 
Claim.-The combination, with the levers $F$, comected to the plough-frame by links $\mathrm{G}$, of the levers 11 , provided with friction rollers $c$, and held by a rack, J, or other equiva. lent device, subst.untially as and for the purpose herein set forth.

No, 107,052-13ENJAM1N R. HUBBARD, IIIILS-

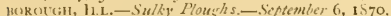

Claim.- The construction and arrangement of the metallic support 13 , the tongue $F$, and the wire or chain attach. ment $\mathrm{W}$, substantially in the manner and for the purpose descrilsed.

N). 107.228.-ALBERT A. DAILEV, WH.soN, N. Y. - Porghts. - Sipt:mber 13,1870 .

Claim.-The combination of the curved or inclined axle $\mathrm{I}^{\prime}$, slotted piroted arm $\mathrm{N}^{\prime}$, and gauge plate $\mathrm{l}^{\prime}$, with each other and with the plough-beam $A$, substantially as herein shown and clescribed, and for the purpose set forth.

No. 107,560.-JAMLA W. SUR.A, SAN likANersco, Cil.-Gint.Plough Beims.-Siptemlier 20, 1870.

Claim.- I. - The long beam B, short bean $\mathrm{C}$, and brace I), combined with the tongue $A$, as and for the purpose described.

2.-The arrangement of angular brace $\mathrm{D}$, and angle clip $\mathrm{E} \mathbf{F}$, as and for the purpose described.

No, 107,829 -NAAllAN SI'ENCLR, IR., EMGL Point, ILL- Lanj-Ploushs.-Sef ember 27, is jo.

Claim.-1.-In a gang plough, the vibrating platform C, in combination with draft bean or plank $\mathrm{E}$, bolt standards $e^{\prime}$, and adjusting nuts, substantially as set forth.

2.-The combination of the adjustable-draft beam $\mathrm{E}$, disk coniters II, standards $\mathrm{H}^{\prime}$, and draft rods I substantially as set forth.

3.- The combination of the coulters $\mathbf{H}$, standards $\mathbf{H}^{\mathbf{}}$, connecting rod $\mathrm{H}^{2}$, and draft rods $\mathrm{l}$, substantially as set forth.

No. $10793^{8}$. -IIENRY W. MASON, HAGERSTOWN,

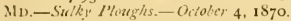

Clain. - The bar $i$, provided with the slotted flanges $t$, the plough beam $h$. the plates $b$, provided with the lugs $e$ and the pin $f$, arranged together as described.

Do. IOS,214,-IAIIES W. TREAIMWY, CROWS PoNT ChNRE, N. Y., assignor to OLIVEK A. WHITTL MORE, DENTFR, COLORADO,_Gang-Ploushs.-Oetolier II, 1870

Claim.-1.-The combination of the beams D, ploughs (i, arljustable gauge-wheels $I$, pivoted draft hars J, upright E, pivoted guard bars $\mathrm{K}$, and perforated bar $\mathrm{L}$, with each other, and with the frame $B$, axle tree $A$ and wheels $C$, substantially as herein shown and described, and for the pur. pose set forth.

2 - The cam levers $\mathrm{N} n^{\prime}$, ropes or chains $\mathrm{O}$, and $\mathrm{U}$, and $S$, crank drum $V$, drum $T$, and roller $R$, with the plongh beams D, all arranged substantially as shown and described, whereby said beams may be singly or collectively elevated.

No, $\log _{31 \mathrm{H}}$ - C.IKELI, ATW(x), LEBANoN, IL..-

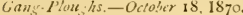

Claim.-1.-The combination of the levers $e$, bolts $d^{\prime}$ $d^{l}$, ruck-valifts $g g$, bolt $-/ /$ with the plough standlards, constructed to operate in the manner and for the purpose sub. stantially as clescribed.

2. - The slotted plates $\mathrm{C} C$, $w$ ith bolt or bolts $a^{\prime}$, for ad justing the dralt right or left, substantially as and for the purpose hereinbefore set foith.

No. 108516. JCSEPH L. PURCELL, THOMHSON, II.L. - Gan -Plout hs, - October 18, I\$7o.

Claim. - The arrangement, in a gang plough, of the slott. d plat orin W, clamps J, serew rod $\mathrm{K}$, beams $\mathrm{B}$, rod $\mathrm{g} \mathrm{N}$,

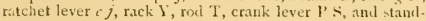
ards () $O$, as and for the purpose set forth.

No. 108,724 - WILLIAII NEWLIN, ATTICA, IND.-

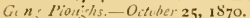

Clain.-1,-In combination with the axle $A$, the clevises II 11 , connected by the strap joint $s e e$, and securing the plough heams I I, all sul stantially as set forth.

2. -The combination of the bent axle $\mathrm{A}$, tongue $\mathrm{D}$, lear. ing har C, cogged staple $\mathrm{C}_{\text {, }}$ and bar L, with slips $\boldsymbol{n}$ and set scrums 00 , all as show $n$ and described.

3.- In combination with the strap joint clevises II II, the plingh heams 1 1, the front endr of which are curved an de- scribed, and provided with the lugs $i i$, substantially as and for the purposes herein set forth.

4. The spring ring $\mathbf{k}$, for comnceting the rear ends of the plough beams, substintially as and for the purposes hercin set forth.

5.-The arrangement of the shaft, with its lwarings in the tongue $D$ and har $f$, the lever $l$ and chains or rods $k$, substantially as shown and described and for the purposes set fortli.

6. - The stay or sicle rods $m m$, connecting the plough beams with the axle, substantially as and for the purposes herein set forth.

No. 109.048 . -JANES O. IOTTER, RoUSEVILLE, PA. - Device fer Operating Plous/2s. - November 8, 1870.

Claim.- In axle $C$, bent to form the central recess D, combined with a plough and beam hung under it, and movable npwardly into it, as rlescribed.

No, 109,136.-WILLIAM MASON, INDEPENDENCE,

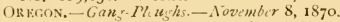

Claim.-The tongue A, extension $\mathrm{A}^{\prime \prime \prime}$, crank arms B and $a$, and axle $\Lambda^{\prime}$, constructed, arranged, and combined with the plough beams C C, and system of levers and connecting rods, as shown and described, and for the purpose sp ecitied.

No. IC9.684. -JOHN E. SWALLOW, HAGERSTOWN, MD.-Whetl-Ploushs.-Nov mber 29, is7o.

Claim.-1.- The coupling $G$, comecting the tongue and forward end of the plough beam, and constructed with segmental racks $G^{2}$, in combination with the pinions $I I H$ substantially as set forth.

2.-The slotted plough beam D $d^{1}$, in combination with the guide t:urs $\mathrm{C}^{2} c$, sliding bolt $\mathrm{D}^{1}$, provicled with a sleeve, $D^{2} d$, and means substantially such as described, to operate upon the sliding bolt to raise and lower the rear end of the plough heam.

No. 110,281.-TIIONAS PEPILEK, IIIGHTSTOWN, N. J.-Ganr-Pourhs.-Dicember 20, is7o.

Claim.-The gang-plongh, composed of the square axle $A$, adjustable box $C$, caps $e$, movable pendants $D D$, the double joints or jaws $\mathbf{E} \mathbf{E}$, constructed for the purpose herein set forth.

No. 110,356. -JAMES HARRIS, SAN FRANCISCO, CA1.-Cank-Plough/s.-Ditember 20, 1870.

Claim. - The asle E, recessed as dexcribed, in combination with the timbers A B, extended cross pieces $\mathrm{D} \mathrm{D}^{\prime}$, and pins $a$, for adjusting the plough frame, seat, and the level of the ploughs, substantially as above described.

No. $110,401 .-J O H N$ H. SUID.AM, ATwater, Mins. - Wheet-1luushs.-Ditmber 25, 1870 .

Claim.-The within described attachment for ploughs, consisting of the wheel 1 , axle $G$, elongated seat $J$, brace $K$, slotted knee $H$, and clamp $a$, all constructed and used substuntially as set forth.

No. 111,226.-JOHN k. MCCONNELL, MARENGO, lowA.-Gans.Plourhs.-Fanuary 24, 1871. Antedated Jumuary is, 1871

Claim.-The arrangement in a gang-plongh, and with respect to a wheel, $I$, and shaft 11 , of the wheel $L$, and the shaft $\mathrm{J}$, adjust.ible in the apertured standards $h^{1} \mathrm{~K}$, as shown and described, and for the purpose specified.

No, II, 228. -JAMES A. ME])ARIS, SULIIVAN, IND. -Combind Gang-1'Wushs and Cultivators,-January 24 , I 87 I

Claim.-1.-The arrangement of the axle A with cranks

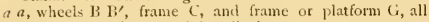
substantially as slown and described.

2.- The arrangement of the frame G, side blocks I I, cultivator ploughs $J$ and $J^{\prime}$, plongh $K$, and subsoilers $L$, all as shown and described.

3.-The arrangement, with the frame or platform G, of the hinged cultivator ploughs $\mathrm{J} \mathrm{J}^{\prime}$, rod $h$, foot lever $f$, rods $i$, false doubletree $\mathrm{N}$, doubletree (), and singletrees $\mathrm{P} P$, substantially as show'n and described.

No. 111,366.-EDW.ARI) NEIMY and ABRAM R. STANLEY, SHUh.sistre, Wts.-Swlky.Ploughts.-Janua)y 31,1871

Claim.-In a combination with the plough beam, the sulky framc, and the king bult $(i$, the levers $j k$, chain and pulley $i$, and rod $k$, arranged to lift the front and rear ends 
of the plough beam, substantially as described for the purpose specilied.

No, $111,799-$ AS. H Al.LISON, CharlotTRSV1L1.E, IND.-Sirlky Altachnent for Breaking-Ploughs. - Fibruary 14,1871 .

Claim.-The tream $I$, in comlination with the rear lifting device $F, d, h$, and $f$, clevis 1 , rack $I 1$, clamp $b$, and lever 1 , as and for the purpose set forth.

No. 111 .911.-FRANC'IS CREMER, ELMWOOD, ILL. -l'luths.-Fitruary 21,1871 .

Claim.-1.- The combination of the suspended adjustable beams $G(i$, cross has 11 , swiveled vertical screw 1 , upright plate $C \cdot d$, and guicles $e f$, with the axle B of a wheel plongh, to achnit of a vertical adjustment of the shovels $l$. as described.

2.-The up-and-down axljustable cros, bar II, supporting the vertical plough leams, subtantially as and for the purpase herein shown and described.

3.- The comisnation, with a wheel plough, of the chain L and pulleys / / /, arranged and described, to equalize the draught.

No. 112,079.-1)RESTES SAMPSON, PRTERSHUR(;,

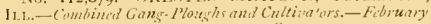
21, IS71. Antedated Fibrary 20, 1871.

Claum. - The combination of the main frame $\mathrm{B}$, mounted on wheels $a$, ancl provided with the seat $\mathrm{C}$, with the auxiliary frame I) having the adjustable tongue ( $i$ attached, anel alizpted to earry either ploughs or cultivators, whereby the inuplement is fitted to ba uxed either as a gang-plough or a cultivator, as set forth.

No, I 2,394-JAMES WV. SURSA, SIN LEANIURO,

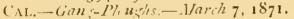

(laim.- The axles $($ and 1$)$, arms $l$ and $G$, and link II, in combination with a single lever, 1, when constructed to regulat: the depth of the furrow without lenving the seat, substantially as describet.

Ni). 112.434 - - III, () A. ELLIOTT, STRATFORD IluLLow, N. 11.-Swlky Plowghs._March 7, 1871 .

(laim. - 1.-The arm ], projecting laterally beyond the plough, and following in the rear thereof, for the purpose of preventing the sod from falling back into the furrow.

2.-The application of the downwardly projecting and rearwarlly curved arm $P^{\prime}$ to the cros; bar E of a plough frame for the purpose of balancing the machine and enabling the plough to rm with uniform stadines.

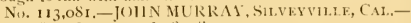

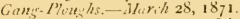

Claim.- The arrangement of the frame $\mathrm{A}$, bars $\mathrm{C}$, axle $\mathrm{E}$, lever $\mathrm{K}$, bulance-baan 11 , connecting rod $\mathrm{G}$, and link $\mathrm{I}$, as describerl, for the purpose set fonth.

No. 113,234.-JOIIN WORRELL and JAMES RY:

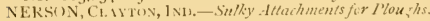
- Warh 28,1871 .

Claim.-In a sulky attachment for ploughs, the combination of the bent lever ( $;$ and adjustalsle bar $\mathrm{F}$ with the foot lever $\mathrm{L}$, shaft $f$, forized arm $X$, and clamp $s t$, subatantially a: specifizl, as an improvement upon our patent of July 26,1870 .

No, 113,235 - JOLN WORRELL and JAMES RV-

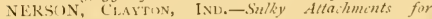
Piou, $/ 25$ - Warih 28.1871 .

Claim.-1.- ln a sulky for ploughs, the axle herein described, having the double bend $k z$, subsrantially as speci fiecl.

2.- In a snliky attachment for ploughs, in combination with the square axle bent in $U$ shape and pivoted, as described, the bent arm $c$, eam hook $c$, and stop $f$, substantially as specified.

No, 113,39 3. - TOEL, I. BOND, M ARSHAL.L TOWN, IOWA. Gans and Sibsuil-13 usis. - Ipril 4. 1871 .

Clam.-1.-The arrangement of the beams A $A^{\prime}$ crosse bar II, bent brace J, plates $\left(i i^{\prime}\right.$, clamps $a$ a' and bolt and nut $d$, and the ploush bars $C^{\prime} C^{\prime}$, all substantially as shown and described, and for the purposes herein set forth.

2.- The arrangement with the frame beams $A A^{\prime}$ of the adjustable rods $\mathbf{K}^{\prime}$, frame $\mathbf{I}$, bar $e$, loop $f$, seed drill lox $\mathrm{N}$, and gauge wheel $\mathrm{M}$, all constru ted and operating sub. stantially ar set forth.

Nis. 113,627 - -1.KE CIIAMMN, COL1NSTILA.
ConN., assignor to himself and THE COLlins CoMmans:Gans /1/utth hs. - 1/ ril 11,1871 .

Claim.-1.-In a gang plough, the combination of the parts $j$ and $j^{\prime}$ and the clamp $t$ with the wheel $i$, the whole constructerl, arringed, and operated substantially as and for the purposics set foith.

2.- The combination of the frame $a$, cranked axle $c$, jointed lever $j j^{\prime}$ clamp $n$, and wheels $c$ and $f$, as part of a gang plough, the whole contructed, aramged and operated substantially as and for the purpores set forth.

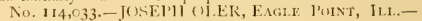
Gan-IMous -1 pril $25.187 \mathrm{I}$

Claim.-1.-In combination with the latcrally adju-table ploughs boam-, the laterally-aljustable coulters, substantially as set forth.

2.- The combination of the platform C, the mowalle tongue $\mathrm{E}$, the double or reversible ratchet standards $\mathrm{F}^{2}$, sector lever $\mathrm{F}^{\mathrm{T}}$, and the tongue loops $\mathrm{F} \mathrm{F}$, subtantially as st forth.

3.-The comlination, in a gang-1 lough, of yole $\mathrm{N}$, coulter block $m^{\mathrm{l}}$, forked standard $m$, and coulter $\mathrm{N}$.

No. 115.057.-1BENAIA11 C. 110) T, lute ATKINSUN.

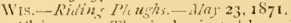

(laim.-1.-The single pivotel lever D, slotted disk $\Lambda$, and whee $(;$, all comlined is described, for the purjuse specifiest.

2. - Whe bracket $\mathrm{K}$, Iub 11 , and haft $\mathrm{B}$, all combined as describul, for the purpoie specified.

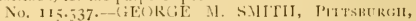

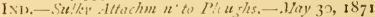

Claim.-The reverible slides $(;$, adjut 2 ble spindle $F$, and tramierse bar 13, cleft at each end, and providexl with the aljusting sectors $H$, constructed, combined, and arranged sul-tantially as and for the purpone specified.

No. $115.63 \%-$ IVILI,1AN 1;. QUICK, BEt.LEIII.F, 11.1.-Gians-Ploughs.-Jien: $6,1 \mathrm{~S}_{71}$.

Claim.-The combination and arrungement of the seat frame E, fout board $\mathrm{E}^{\mathrm{t}}$, movable frame $G$ connected to plough beam- 1), lever shaft 11, carrying hook rod 1, with friction voller $1^{2}$, subtantially as and for the purpose specified.

No, $11 ;, 085 .-W H I L I M$ PARRISH, INYTON, (ORE-

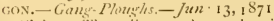

(laim. - The sulky att.ichment herein described, connected ansecilied, in combination with the yole (; eater wheel 1 , arms $1: F$, and lever $F^{\prime}$, subitutially as and for the pup pre set forth.

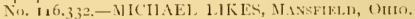

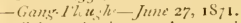

Claim.-An improved gang.ploush, formed by the ar-

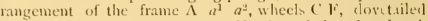
block 1 ) $d^{\prime \prime}$, lever ( 5 , tongue 11 , pivoted har 1 , jlough beam I, ploughs $K$, standards I., gaure wheel $\mathrm{M}$, slotted tandard $N$, lever () , swiveled but $P$, and seat $(?$ with each other, said parts being con-trueted and operatmg substantially as herein shown and describul, and for the purjoses set forth.

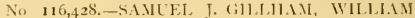
C. TAYLCK, am JAMES W: ST()I.LE, V'ANIMLA, I1.1., assizuors to and (ill.LIJ.MI and T.IYIf)R.-Gang1\%orshs.-Fun 27, 1871.

(laim.-1. - The aljustatle hinge-connection $c s^{2} y^{4}$, between the fore ents of tire beams and the frame, in combination witht he guicle yokes II $I^{2}$, comnecterl to the axlehar lyy adjustible socket bolts $h$, substantially as and for the purpose set forth.

2.- The aljustable brace connections $\mathrm{K} k \mathrm{k}$. / II NO/h, in comlination with the lrem $G$, standard $I$, and axle $C$, sub-t.antially as s-t forth.

N.) 116,956 . - IVILLAA.N $11 \mathrm{AV}$ and TIIOMAS R.

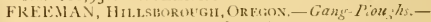
futy $11, i S_{7} 1 .-$ Antedated fuly $4,1 \delta_{7} 1$.

Claim.-1.-The franc $\mathrm{F}$ having the plourhs (i attacher, in combination with the axle A having the arms $f$ attached, the frame and axle being connected by the hinged rod or stirrup I, subtuntially as clescribed.

2.-The axle $A$, having the plates e secured to eneh end, in coml ination with the bent ams $C$ baving the lever $E$ and catch a rigidly attaclaed th reto, said arme leing pivoted one 
to the upper and the other to the lower sille of the axle, sub. st untially as set forth.

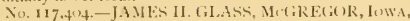

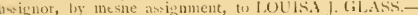
Gim, $-1,0 i t_{3} / h s .-J u l_{1} 25,187 t$.

Claim.-1.- The lax $\mathrm{C}$, operated as described, and serv ing as a protection for the serew and studs $d^{\prime \prime}$, in comlination with the sanged plate $\mathrm{D}$, constructed and arranged substani.illy as specilied.

2.-The $\log ()$, in combin tion with the chain M, shackle

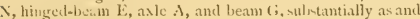
for the purpose set forth.

No. $117,707 .-1$ LWIS 1 . WEliSTER, NorTHFild,

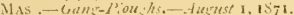

Claim.-1.- The circular revolving leveled furrow guide $a$, as herein shown and described, in combination with the adjustablc arm b and brace $f$, as recited.

2.- The arrangenent of the draft rod $h$ in relation to the axle or shaft and beanr, as and for tie purpose st $t$ forth.

3.-The arrangement of the adjustable springs $m$ and $n$ in rel tion to the ploughs, as leseribed.

No.117,711.-S.MUEL A. IIORTIIEN, TIIMSUN,

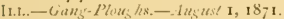

Claim. - 1 he curved bar $\mathrm{M}$, axle 1, cams 1 , lever $\mathrm{N}$, and wigment $\mathrm{R}$, for the purpose of operating the plough-beams $\mathrm{B}$, i 1 tre maner and for the uses and purposes shown and de. scribed.

No. $117,734-A$ NLEW J. H()K1AN1), CHARLESTON, IowA.- - It he. I Pivegris.-1us u.t 8, 1871

Claim.-1.- The slotted bar $h$ and bar $J$, combined as descriled, "with the leam $E$ to adjust the plough laterally at the poins for taking more or less land.

2. - lihe commution of the axle $\mathrm{A}$, whed $\mathrm{B}$, tongue $\mathrm{C}$, and brace $D$, forming one part, with the rock-shaft $(i$, seat $I$, aud rod $h$, forming the second pait, and with the plough be:m $\mathrm{E}$ and lever $I I$ of the thire part, all arranged substanually as lerein shown and tescrilierl.

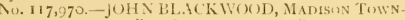

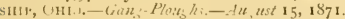

Claim.-1.- The reversilile clews lilochs ?, in combination "ith the axle 13 , plough heams $(x$, aud elevis or straps K. substantially as herein shown and tescribed, and for the jurpose set forth.

2.- The arrangement of the wheels $A$, double crank axle 1), lever $\mathrm{C}$, each bar $i^{\prime}$, forwand frame $\mathrm{D}$, tonguc $\mathrm{E}$, aljustaJile slotted gauge plate $F$, ploughs $G \mathrm{H}$, inclined and cross braces or bults 1, reversible clevis blocks $J$, clevises or straps K, rear frame 1, caster wheel $\mathrm{M}$, chain N, pulley (), brack(t, I, capsan $Q$, bracket $R$, hand wheel $S$, ratchet wheel $T$, sf ring pawl $\mathrm{U}$, and driver's seat $\mathrm{F}, \mathrm{W}$, with ench other, subtantilliy as hercin shown and described, and for the jurposies set forth

No. I\$S.563.-TAMES I. VAN GORDER, SINNEY,

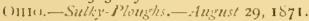

Clam.-I.-The combination of the cranked axle $\lambda \Lambda^{1}$, the coupling if $F^{\prime}$ or it e quivalent, lever 1 , and the ploughhean with plough attuched, substantially as describet.

2. - In combination with the elements of the preceding elause, the pivoted font-piece $]^{x}$, and hinged lateh $k$, which is linket to the foot-picee, substantially as and for the purpose set torth.

3. - The combination of the vertical part $A^{1}$ of the cranked axle, coupling $F I^{\prime \prime}$, plougls-beam $E$, and lever $(i$, the shurt arm of which is linked to the plough-beam for turmug it horivontally, sulstatially as and for the purpose set forth.

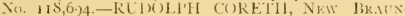

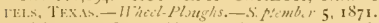

(Taim.-1. - In combination with a gang-plow frame $B$, pivoted in another, $\dot{C}$, the meclimuism, consinting of bent levers $\mathrm{V}$, pin. $\mathrm{II}$, spring $\mathrm{X}$, toes $\mathrm{X}$, sloft $Z$, and leveri $\mathrm{A}$ ', all arranget as and for the purpose described.

2.- The frame work II /', lyars I J $\mathbf{L}$, cross-bur $\mathrm{K}$, and catch-lever $\mathrm{R}$, in combination with the frame $\mathrm{C}$, to which the revolving lough-\{rame $\mathrm{B} \&$ is juvotexl, ancl crank-axle $\mathrm{F}$, sub. stantially as herein shown and descriljed, and for the pur jusc set furth.

3. - The bent bars $\mathrm{M}$, pivoted cross-bar $O a^{\prime}$, spring $O$, an. slottal atandard $P$, in combination with the double cranka. I. I', trame $t^{\prime}$, and the teeth formed upon the lower patt, of the forward arms of the fianc. 11, ulatantially as herein shown and described, and for the purpose set forth.

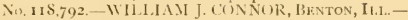

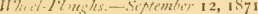

Claim.-1.- The lotted and pivoted plough standarel 13, in combination with the rol $f$ and hand-whed nut of for aljusting the pitch of the plough, substantially as describel.

2.- The leam A recenved, as slescritsed, to reccive the tandards $B$ of the plourlin, and furnished with screw-bolts and nuts which allow the ploughs to he adju-ted laterally aud serve to firmly sustain them in position, substantially ar describud.

3.-- The slotted and vertically adjustable standards $C^{\prime} C^{\prime}$, wheel $E$, beam $A$, ploughs $B$, and swinging-seat 11 , arranged sub: tantially as described.

No. II9,I92.-IIOET, B. S.MITH, TREMONT, ILL.Give-l'wu:hs-Siftembir 19, 1871 .

Clain. - I - In three horse ploughs, the beams M M, combined with draft bar and block () l' baving long upper double-tree clevis $\theta^{2}$ and short lower middle-horse singletree clevi, $v^{2}$, for the purpose of enabling the midkle horse to walk in the furrow, one side horse on the land, and the other on the ploughed ground.

2 - The vilmatory guard V pivnted to the axle and aptied to the beams, as specifiesl.

No I19 04 - IVARRE M. ITTTS, HOLIFN, Mo.

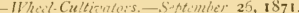

(laim.-I. - The detrchable feet () constructed and secured to the standards $P$, sulstantially in the manner hercin hown and described, to receive the scraper plates Si, as set forth.

2.- The flanges $\mathrm{U}$, formed upon the sides of the bases of the feet () to receive the cutler plates $r$, substantially as herein shown and described, and for the purpose set forth

No. $120,384,-$ IS. M. HUIE and El.SHA ('AR') SAN liraNiseo, CAL.-Gany-Pheshs,-Oitwer 31, 1871 .

Claim.- The combination, in a wheel gang-plough, of the frame H II, cross-timber $\mathrm{I}$, pole I, whecli B E, plate M with their guiding-prongs $n n$, shaft 0 , bar $\%$, plate $\%$, lever $s$, and link $v$, arranged and operating as described.

No. $120.560 .-T O H N$ WVORKEIL and JAMES II. RIDERSON, CiAIfON, INs,-Sulky Altarlumints to Phughs.-Octoler 31, I87 1

Clam.- The curved rack 11 and hinge $F$, in combina tion with the fever $\mathrm{I}^{\prime}$, bean $\mathrm{E}$, har I), and arms $\mathrm{C}$ (', when constructed and arranged substantially as and for the purpore specified.

Nis, 127,572 -I.EKL CIAPMAN, COI.INSIII.I: ConN, assignor to himself and THE CHI.INS COMHANY

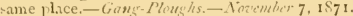

('laim-1. - The beam $a$, made reversible and provirled with sets of ploughs both before and behind the point of sus penvion, sulstantially as clescribed.

2.- The reversible leam a combined with the swivel / sliding block $\rho^{1}$, and stankarel $d$, and male rotary by mean of the worm-gear $c$ and worm, 1 , subutantially as described.

3 -. The parts an claimed in the immediately preceding clanse, combined with the lifting-jack described, sub tantially is described.

4. - The standart $t$ having a reversible beam $a$ hung therein, and made oscillatory siclewise mpon the main axle. by means of the heil-plate f pivoted to the axle-plate $f^{\prime}$, ani and the worm $f$ and worm-teeth $f$, substantially ats toscrilied.

5.- In combination with a reversible plough-heam $a$, the rauge-wheol $m$, attiched arljustably thereto, utubtantially as ilescriberl.

6.- - 1 plough-lueam $a$, made reverible by mechanism substantially as described male adjustable vertically and sidewise by mechauism sub-tantially as tescribed, and the whole hung on a main axle 5 , permanently runk below the level of the centers of the supporting-wheels, subutantially as de scribel.

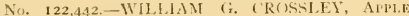

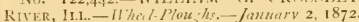

Chim.- The combination of the centrally-adju-table guicles II X with the depending laterally-atjustable -tandard J J said -tanclard hoing arrunged to hold the forward encls of the beam. (' I) in position when clevated, and leaving the 
same free when the ploughs are elevated, as set forth and shown.

Ni. 123.1.4.-WIII.IAI IT. PARRISH and JOIIN

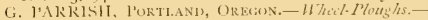
Jantrary $30,1872$.

Clain.-1.-In a sulky-plough, we claim the combina. tion and arrangement of the link NI, pivoted to the hind part of the plourgh-beam, the lever I, pivoted to the link $\mathrm{Il}$, the spring $k^{\prime \prime}$, the post $\mathrm{II}$, and the ratchet-Lar $\mathrm{G}, \mathrm{as}$ and fur the purpose - pecified.

2. - In combination with the mould-board of a sulky. blounh, we elaim the alditional plate or heet $\$$, constructed and arranged as descilibel, to assist in supporting the plough, and in allowing it to be tumed around.

No. 123,204.-JO11N H. ROIBIBSS and SAMLEL

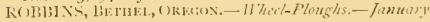
$30,18_{72}$.

('laim.-The adjustable front yoke $\mathrm{F}$ and pin $f$, and the lever-frame $\left(; s^{2}\right.$, having hook $5^{3}$, combined with beam (1) $1^{1}()^{2}$, hasing chain $g^{1}$, all arranged as and for the pur. pore descrilsed.

No, $123330,-$ I.LKL: CIAPJAN, COH.NSTH.IF,

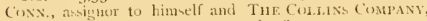

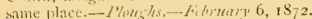

Claim.-I, - The frame $d d^{1} d^{2}$, provicled with the jour nals rigilly attached thereto, in combination with the rotary plough bean $a$. provided with the right and left plough $b$ is subtantially as deserileet.

2. - The rotating stomdard $e^{3}$, provided with wheel or crank and handle $e^{2} c^{t}$, arranged to be operated by the driver, in combination with the boaring $f$ and rotating fough-beam $a$, sulkstantially as and for the purpose set forth.

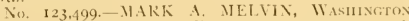

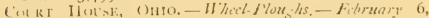
${ }_{1} \mathrm{~S}_{7}$.

Clam.-The fiexible connection device formed by the link $l$ and taples $f l$, in combination with the perforated bar $h$, attached to the frame, the elevis $d$ of thic plongh, ancl the adjusting device $i m n o p q r$, all arrangecl as herein shown and decribed, and for the pup.se specified.

No, 123.505.-CII.IR1.ES N. OWEN, SALEM, (IIIO)-

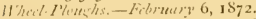

Claim.-1,-The combination of a yoke or bracket, $C$, having a vertical viluration, a hanger $\mathrm{E} \mathrm{E}^{2}$, arljustalic in an are of a circle, and a vertical pivot, $f$, to which the plonghl.enm is attached, sulsstantinlly as described.

2.- In a sulhy-plough, the combination, with the yoke $C$. to wlich the plough-betam is attached, of a hant-lever, conged sector $c r^{-1}$, and a foot-lever, operating as set forth, to lift the plough from the ground.

3.- In combination with the yoke $C$, and the hand-lever and fort-lever, operating as set forth, the sop fi, ratchet. whecl $c^{2}$, and weighted paw $c^{3}$. for locking the ptongh in an eleviated position, substantially as set forth.

4 -In combination with tungue $\left[3^{2}\right.$, beam I), and dropiron 1$)^{\prime}$, the adjustable stop $d^{\prime}$, substantially as described.

No. 123.616.-WH1.1.M D. CLIJIIS, 1 Enx, lowA.

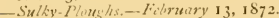

Claim.-1-The arrangement of the tongue A. curred bar l, har or frame $C$, round or bar $c^{\prime}$, vertical frame 1 , wat $l^{2}$, axles 1 , wheels $(i$, keeper $L$, connecting har $\mathrm{N}$, lever () , ellow-lever $l$, connecting-rod $Q$, paw $k$, notched lar $\$$ with the plough-beam J, substantially as and for the 1'urpone hercin slown and descrilsed.

2.-The comlination of the pin $\mathrm{T}$, flanged friction-roller U $u$, curved bar $\mathrm{V}$, catch-bar $\mathrm{W}$ a', spring $\mathrm{X}$, comectingrod $Y$, lever $Z$, lever () and its devices, segmental rack $S$. and frame C with the plough-heam J, substantially as shown and dencribed, for the purpose specified.

No. 123.869 . - R.I.K. G. CIIARLES, G.1.Fsneri, 1.1.- (inne. Ploush h. - Februm 20, 1872.

Cham.-1.-The beams 1), adjutably piroted to the rod II ly plates $I$ and blocks $J$, in eombination with plates $G$

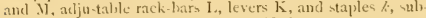
-tantially as and for the purpone upecified.

2.-The axle-tree 1. 1, make in two sections and placed mor alwe the ether, as hown, the uper one hasing an axle for one wheel and the lower one an axle for the oprosite wheel, in combination with the arehes $\mathrm{N} N$ and screws P l', when saicl arches are both firmly bolted to the lower axle-tree and the serews swiveled to the upper one, as blown and described.

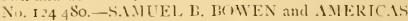

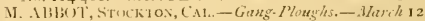
1872.

( Taim.-The bent or crank axle A, having rigid standaris $d d$ secured to it at right angles with said cranc, in combina tion with the plough-bsams I) I), when the said beams are pircted to the jointed links $F$ F and are secured to the under side of the pole or tongue $E$, and operated by the lever 11 rigitly attached to the crank-axle, substantually in the mamer herein shown and described.

No. 124.571.-Gilolige W. HAINE., MAINE PRARIF,

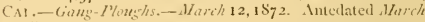
7. 1572

Claim.-1,-The oparating device for elevating and

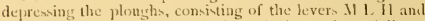
the link I $\mathrm{N}$, or an equivalent device, sulstantially as de`crilud.

2.-The seat E, supported directly upon the axle I) an shown, and leveled ly means of the shotted tandard $C$ and clamprosew, as clescribed.

3.-. The arm, l' $\mathrm{l}$ and the double sibrating lever $k$, together with the draught-rud ti and the operating-lever, as sheserilued and sot fertli.

4.-I claim a yang-plough laving, in combination, the seat, smponted as shown, together with the hercin-deserilsed device for giving a vertical and a side or curving moveme1t.

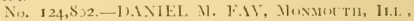
awinor of une half his right to A. S. Mctikl:lW, same

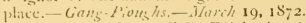

Chim, - The beam E E E' E' having hroad plates $(i$, in

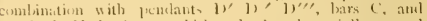
standards 11 having mould-boarls $h$, sulutantially as and for the purpowe ypecified.

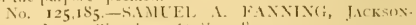

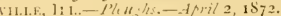

Chim.-1,- The roller 1 , arrimed an lestribed, in the rear and to one side of the turn-jilums $(i,>0$ as to julverize the furrow-slice as suon an turned over.

2.-The bar $\mathrm{N}$. piroted to the beel of plosugh $(;$, and notched so as to finten orer a bar on the rear of the plongly. frame, as and for the purime dererilsed.

No, 125,287 , - INI)REW FREEMIX, IIOMFR, IT.T.-

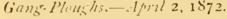

(lam.-The combination, in a gang or sulky pleugh, of

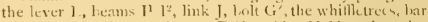

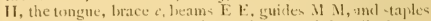
or loom $k \mathrm{~K}$, all substautially as shown and described.

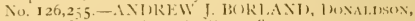
Iow - II hid IH w

Clam.-1-The irace penclast o, comlined with the $n x l e p$, plate $n$, bar $m^{\prime}$, and lever $m$, as specified.

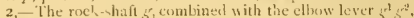
straj $s^{3}$, comnecting-rod $\xi^{4}$, lever $k$, ansl plate $d$, as set forth. 3.- The plate $d$ having an imer series of hole, $d^{\prime}$, and combinal with the rod $h$, strap ${ }^{2}$, and the land-pin as 'pecitied.

No, 126447 -JOSEIII CQCIIRANL, INDIANOIA,

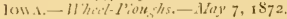

Claim.-The rear frame $\mathrm{D}$, pivotert to the front frame $\mathrm{F}$, supperted liy the adju-table wheel $\mathrm{N}^{2}$, and having the seat I, with levers A C armenged to be operates by the driver, as and for the purpose set forth.

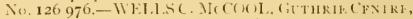

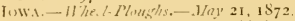

C'him.-The entualier F, provided with a clevis, fr, and

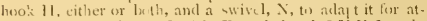

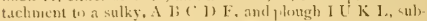
tantially a hercin shown and dencrobsl, and for the purpouse set fonth.

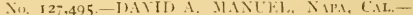
cans-P'oust..-June 4, $1 S_{72}$.

Clim. - The combination of the iream. $C^{+} C^{\prime}$, coster-wheel

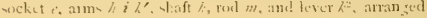


lescritud, for the purpoue of aning and lowering the 1. linughe.

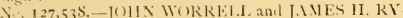

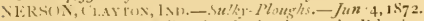
(laim,-1,--1n a sulky-p)losigli, the lent axle li having the vertisal arms $e^{\prime}$ of utue jual lengthe, of which $i^{2}$ is slotte 1 at $d^{2}$, in coml ination with the frame $f$ for supporting the plough-heam, sulutantially as and for the purpones specified. 2.- The combination, with the bent axle 1 having the shtted arm $:$, and supporting the linged adjust.s le frame (i, of the sliwesnal braces $\mathrm{E} \mathrm{E}^{\prime}$, setted at $\mathrm{F}$ for the purpose of a jurtment, and at:ay teal for use with either a left or right haud ulousth, ublstantially as suecilied.

3. -The arlju-table stamelarel 1, having piroted to its lower enil the cyetwolt $T$, and provisled with the frot plate $K$, sub:tantially as and for the purpore specilied.

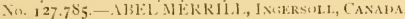
- in! *ito". -Jun 11,1872 .

(Caim.-1. - The plenghs 1) E F G, esnstructed substantially an herwin shown and described, to adajt them for at inchin int directly to the side of the beam, as and for the purpoie set forth.

2. - I gang of ploughri, 1), arranged in the diagonal bean ( combincul, als decribed, with une or more plates, H, arranged on the eiraft-bom .1 , nnd entering the ground to crumteract strain agein:t the line of draft.

3. - The combination of the long taple or bar N, lever (), wheel I', and adjutalsle suppont $Q$ w 1 ith the front beam liof the fram A B C , subtantially as herein shown and describe 1, and for the purpoie set forth.

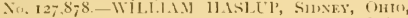

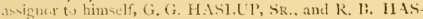

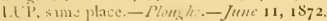

Clam,-1.-The combination of the tongre A, plates B B with firnt a and esp. ( $\mathrm{C}$ to form a jout between the tongue and thesulky, sulintantially an berein sct forth.

2.- The plate 1) and font-lever E, arranged with the top plate 1 and top-ex, C sulstantially as and for the purpore hercin set forth.

3-- In combination with the plough-heam, the brace $\mathrm{k}$, macle aclinutabe in the buttum-cap (?, and fastened by the et serew: $n$, subatantially a- hercinset forth.

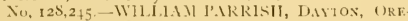
licos.-(iin, Plous'

(laim,-1.-1he cater E, benm (i, adjustable serew C, lever $K$, aml cros lar $a$, contruteded, combinecl, and arrang al in a flourh, - uldatantially as axd for the purpene specifict.

2. - In a gang-plongh having two or more beams with cas ter and lever attichment - as dencribed, the sotted connect ing-bar $C$; stoted bem h, and pivot-pin $($, constructed and arranged sulstantially as an 1 for the purpose syecified.

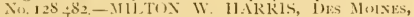

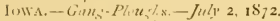

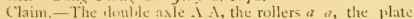
F F, the king-bolt h, the frame fream I) 1), made combined, and operiatei in a gang-plough substantially as described, and for the purposes ypecitied

No. I 28529 - CILY TOZER, JACKsos, Mo,-H7heel.

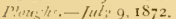

(laim.-The trane . I B C I), combined with the furrow whed 1 , pirot al lax 11 , and land-whed $1 \%$, an and for the purpusic descrilsed.

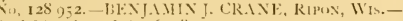

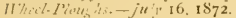

(lam. - The hem it provited with the cloulle plates 1, the axle 11 , the aljustalile sup p.rting-loar $(;$, the crank-shaft i firetsl to the support (i, the font lover 1 , all combined and operating together as and for the jur o o es described.

Nis. 129,161.-H. W, NF.IL, WELI,II1.1., l'A., as

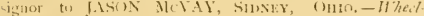
I: $u, 2:-j u_{1}^{\prime}+16,1572$

(7.im. - The frame lormed ly the parts $h, 5,0$, when pis cutcl te the rear extendion of the tongue $k$, sis an to vibrate hrck and fonh. in combination with the bean $G$, lever 1 , an $1 \mathrm{rod} / 4$, the several parts being arranged subtantially as anil for the purpose set finth.

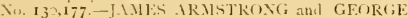

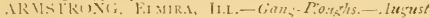
$6,18 \% 2$
Chim,-1. The pole or tongue Eirigilly fixed to a vertically-adjuctable axle-tree, 1 , plough-beams 1, I), which are binged ou top of sitel tree and which extend in front anel rear thereof, in combination with the locking-lever $F$, roxl lever $s^{\prime}$, lever,$^{-1}$, and link $s^{*}$, substantially as described.

2. - The fout-stancls $V^{\prime}$ on plough-beams I) 1), which are hinged to the axle-tree .1 , in combination with a pole, $\mathrm{F}$, which is rigilly secured to said tree, and with the lifting. lever $k$, rod 3 , lever $g^{1}$, and link $g^{2}$, substantially as described.

3. - The touthed segment $/ 11$ macle fa-t on the axle-tree $A$, and the grooved and pivoted guiding-plate is receiving the rear edge of the segment $b^{1}$, and hasing the axle $a$ secured to it, in comlination with the locking-lever $f$ pivoted to segment $\ell^{\prime}$, and having a cam $c$, on it lower end, which acts on the upper elge of the saial guicle-plate $b$, substantially as and for the purpone described.

No. 130,256. ROliER' WILKEK, SAVANNA, Wo.

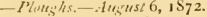

Claim.-The combination of the tongute b, lever $i$, lwalt $l$, catch $h$, and frame 1 C, arranged as specitled.

No. 131,063.-WI1.LIAM MASON, MoNmUUTH, URE-

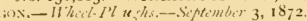

Claim.-The combination of the U-bracket $\mathrm{K}$, the lever $\mathrm{L}$, lever $\mathrm{Ml}$, and canter-wheel I' $\mathrm{Q}$ with the frame C, plough. beam $\mathrm{Il}$, and tongue $(i$, ublatantially as hercin shown and described, and for the purpuse set forth.

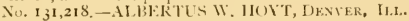
-Gang Plouths.-Sipt mber 10, 1872

Claim,-The arrangement of the levers $\mathrm{N}$, rock-shaft $Q$, arms $\mathbf{k}$, and lever $\mathrm{S}$, with respect to the plough-Leams $\mathbf{K}$, upriglit: $($; and beam 11 , substantially as herein shown and described, anil for the purpose set forth.

No.131,961. - WELLS C. NCCOOL, GUTHRIE CEXTRE, lows.-P'otesis.-October 8, 1872.

Claim.-1.-The obloug clevis b h, with swivels in the ends and a vertical boit through the front end. when combined and operated with a plough and a ridling attachment, in the manner and for the purposes described.

2.- The skeleton heel I) 1), combined with a plough, sub. stantially as tescribed, and for the purposes specified.

No, 132772 . CHARLES N. ()WEN, SALE, OHJO,-

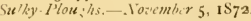

Claim.-1.-In a sulky-plourh the combination, with the forward end of the plough-beam, of a foot-lever arranged within reach of the driver's feet for vibratiug said plunghbeam in a horizontal plane indepentently of the carriage to cause the plough to run to or from land, subutantially as described.

2.-In a sulky-plough, 1 claim the combination of the yoke ()$\left.^{2} 1\right)^{4}$, the laterally-acljustable hanger $(i$, the plough, and its connectimg devices for pivoting and arjusting saic plouglis to the hanger 6 , all substantially as described.

3.- The combination of ratchet-cegment $c$, the pawl $e^{\mathrm{a}}$, anc the weighted lever or lalance $c^{2}$ with the cogged wheel $\mathbf{E}^{2}$, cogged segment $\mathrm{E}$, the yoke, and oprerating devices, substantially as described.

4-- The combination of the hanger $(i$, the pivoted angular plate 11 , and set-serew $5^{\prime}$ for adjunting the position of the l:mi-ide, substantially as described.

5.-In eombination with the drop-iron or treadle $\mathrm{MI} \mathrm{N}^{\prime}$, the adjustable slieling stop $m^{\prime}$, substantially as describerl,

6. - The combination of the adjustable bracket C C', to which the yoke $10^{2} 13^{3}$ is piroted, with the angular stub-axles I) $\mathrm{B}^{\prime}$, having the open space between their imner ends to permit the free vertically adjustment of the plough-beam, sulestantially as clescribecl.

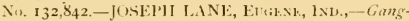

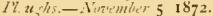

Claim. - I.-The han $\mathrm{T}$ connected to the bars $\mathrm{K}$ by a rule-joint, $s$, an described, whereby the wheel, (1) l' mav operate to support the tongue and also be suypendes hy mean of the hook $\mathrm{V}$, as set forth.

2.-The plougls provided with heams E and levers II, and pivoted to the hanger, $F$, an specilied.

3.- The beam $\mathrm{C}$ provided with notches $\mathrm{G}$, and the plongh beam arranged to rest therein, substantially as specified.

4.- The combination, with the plosugh pivoterl in the 
manner h-cribed, of the rods $\mathrm{M}$ and shifting evener $\mathrm{K}$, ub-tantially as specified.

5.-The combination of the notcherl diagonal bean $C$, hangers $\mathrm{F}$, ploughs 1 ), beams $\mathrm{E}$, and levers $\mathrm{F}$, substantially an specifferl.

No. 132,910.-CIIARLES KEW1N, SAN Francisco,

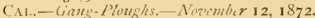

Claim.-1.-The cranked axle $B$ with its rigid arms $j j$, in combination with the lever-bar $\mathrm{K}$ with its arm/and the operating lever (), the two levers being so combined as to froside a compound lever for raising and lowering the ploughs and frame, substantially as above descrilsel.

2 - The sent E supported by the losely connected standarcla $f$, and supported by the adjutable lirace or link $g$, substantially as and for the purpose above described.

3.- In combination with the alove-tescribel compond lever, 1 claim the weight $\$$, substantially as and for the pur puse above described.

Nu. 133,206,-N]ARSITALLS. ('URTISS, liR.ADFUR1),

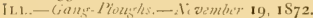

(laim, - 1.- The plough, having a free lateral motion with respect to the wheels and axle $A$ by meansof the rode, arranger to orcillate within the eye of the clevindolt $f$ of the photgh, in comlination 1 ith slots or guicles $d d$, lingeel plat. form 1 anel himgel iron 1, hasing transerse arms is arranget to acillate in slots or guicles $/ l$ of the leams $(i)$, stibtimtially as set forth.

2.- The vertical rod $F$ with foot-board $h$, transverse hori zontal har $a$ sleris-bult $f$, ancl slots or guides $d d$, in combi nation w ith platform li having a binget connection with axk $A$, sw as to effect the raining or lowering of the $p$ ints of the jloughs by means of the driver's foot, substantially as ret forth.

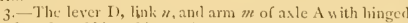
platform lis and hinged iron 1, in combuation with the noteherl parallet guinles $f q$ and beams $(i$, in order to throw or turn the axle ferwanl so as to elevate the beams and piloughs out of the sil, wlien deviret, sulstantially as set forth.

No, 134,121.-JU11N WORRII.I, CI.IYTON, IN1, -

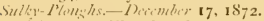

Claim,-I, - The slotter alju-table axle-arms (', holding the wheels 1 , and having their inner encts enlarged and provided with the set-screws 1), in combination with the lient axle-tree 1 , substantially as specifiet.

2.- The lever 1, pivoted to the plough-beam E, and connected to the bent rod J rumning lengthwise of the tongue $F$, and through the sent-silpint 1 , and having the eye $k$ ancl arm or handle $\mathrm{N}$, sul stantially as specilied.

Ni) 134,316.-ERASTLS RUOD, DARIEN, WIS, Ploms Ls. - P)

(laim. - The comlination of the frame $\Lambda$, hinged boards B I., watcherl plates $F \mathrm{~F}$, standarels $\mathrm{I}^{\prime}$ and $\mathrm{F}^{\prime}$, slutted lever 1 , wheel, L 1, and ne or more ploughs, F. M, all contructed and arranged sub tantially as set forth.

No. 134,540.—CIIIRCIE A. GROVES, VAST C1.ARKson, N. Y.-Ginger Monshs.-Jmun? 7, 1873

Clam.-1-The branch-arm $i$ of the plough (i guirled in the stanclard 11, as and for the purpuse sut forth.

2 - The ploughs $(;$ proviled with the shanks $g$ an liranch $i$ and pivoted to the bars $a$ a of the frame $A$, in comlination with the rock-shaft $K$, arm $m$, guide-standaris II, fulley $K$, and corl or chain 1 , all constructed and arranget is and for the purpose described.

No. 134,878,-HAKI. (NW A]. FREFMAN, JOIIN

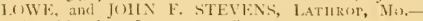

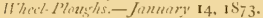

Clam,-1.-The comlination of the rigid frame $\mathrm{K}$. I $\mathrm{N}$ and piwoted draught bars $\mathrm{J}, 1 ., 0$, and $1 \%$, with ench other and with the tongue 1 ) of the machine, substantially as hercin shown and described, and for the purpose set forth.

2.- The comlination of the armed plate $\mathrm{F}, \operatorname{ros} \mathrm{G}$, hent har 11, and short bar $T$, with the tongue 11 and pivoted draught-1 ars I, I, (), and ]', sub-tantially ar hercin shown and clescillect, for connecting the plough-heams $\mathrm{K}$ with nicl draught-barn, as act forth.

Nir. 135 357-SAMUEL, E. P.IRR, SMrTHบH.t.F, It.1.

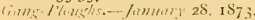

Clam. - The lxent asl. B, havine dot $\alpha$, in combination with the frame $\Lambda a^{\prime} b^{\prime} c^{\prime}$, vertical post $d$, adjustable tongue $F$, and joint $C$, constructed and arranged so that the beams of a gang-plongh or stalk-cutter can be readily attached, sulstantially in the manner as herein shown ancl set forth.

No. 135594 - MARSIIAI,L S.ITTLEY, TAYIOR

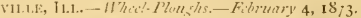

Claim. - I. - In combination with the frame of the ma chine and with the pivoted plough-beam, the tongue I pivoted in front of its rear end, the lever $k$ provided with the arms $k$ and $x$, and the connection 1 , substantinlly as and for the purpere shown.

2.-The herwinbeforedescribed machine, consivting of the axle $A$, gromi-wheel. 1 , rails $C$ and '', ploush-beam $\mathrm{E}$, clevis $\mathrm{l}$, plough $\mathrm{G}$, stamlaris 11 and $\mathrm{H}]^{\prime}$, polc 1 , lever $K$ and $k$, detent $K^{\prime}$, connection $\mathbf{L}$, and quxtrant $\mathrm{J}$, when sail part are constructed and combined to operate sulstanti.lly as and for the purpose specitied.

No. 135,654-J()II. K. MeLENNAN, EI.Mir., I1.I.

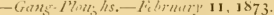

Claim.-1.-The bent slotterl lever; 1) D, with their acl. justing-fletents $(;)$, or erpivalert, attached to the axle li, as comstrtacted in combination with their horizontal latrs $k$. attaclsed to the plosigh leams A A, stabtantially as describul.

2.-The plough-leami I A, when conatruetel as described, and carrying the axle-taple- $i i$, and pivoted at the front to the hecl of the temrue, and connecterl with the fiv. oteal foot board 1 ; stimip/ /, comecting the latter to the hed of the ton rus; the lever 1, ami connecting-bar $r$, iroted to the ford-uand E, combincel and artanged to oprote in conjunctom with the levers 1) b and supporting-rosls is $k$ of the plourh-1x:am-, a rlestribed.

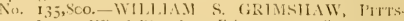

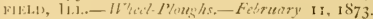

(laim.-1.-The combination of the mowalsle Irame I) 1) with the axle-tree 15, sicl frame having the rock-shaft 1 , to which the plough-frem is fartened, sulstantially as (lcscriberl.

2. - The rod $P$ attinehed to the rock- bnat E and the plongh heam, and acting as an adju-table lrace and guile to the plough.

3.-The fort-lever $k$, in it combination with the axle-tree 1) and the frame if 1), acting as a convenient and efficient device for lowering the ploush.

4.- The comblination of the movable frime [t ]), the roul 1 , and the foot-lever $\mathrm{K}$ acting together, substantially as deseribed, snd for the pur osen hervin set forth.

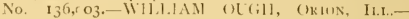
Sully-110u,

Claim.- The plate ( $i$, pivoted to the plowgh-frame i), receising-w hes an a pin, s, and povided with a lever, 11 , in combination with arc-iletted and metched b late $j$, and leck mechanism $i / \mathrm{m}$, sulstantially as and for the purpose deseritaerl.

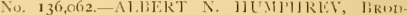

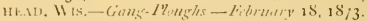

Cham.-1.- The comlination and arrangement of the pivoted inner frame (carrying the plowerh 1 , and trauswere royl $\mathrm{I}^{2}$, the outer draft-fram - ]; havin + the slotted segmental plates $13^{1}$ and levers $\mathrm{E}$, substantially an specilicel.

2. The plate S secural to the axle $A$, and plate i' securce to the frame 1 , in comlinstion with the evener(), double-tree (), and single-treci l' l' R, subutantially as déscribed.

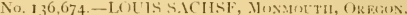

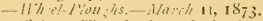

(lam.-The whech () k. having axles $\mathrm{N} 0$, combected by crank arm l', and prosided with sur.whech s ' 1 and lever $\mathrm{U}$, in combination with the plough-frame $\Lambda$, as ant for the purpose de-cribet.

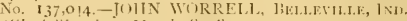

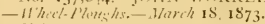

Claim.-1,-The ave A having the arm, B 1'? projecting vertically flewnwarl, one lent at a light angle and ex-

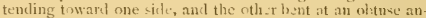
gle anil extenting downward and towarl the rear, vulutamtially as bown and deseribed.

2.- The cumbination of the lever $k$ and notched bar $\mathrm{t}$. 
jointed pole $\mathrm{I}$, connecting-bar G, and plough-beam R, substantially as slown and deseribed.

3.-The combination with the jointed pole and lever, of the clbow-lever II, radial hinge-brace It if $\mathrm{F}$, plough-beam and connecting devices 1 and $G$, substantially, as specified.

No, 137,611-JOAB H. JANES, IIARVEY TUCKER and TILGIIMI.IN I), TERRY, K NomNosTER, Mo,- WheelPloughts. - April \&, 1873. Filed kibruary 27, 1873 .

Claim - I. - The arrangement of the axle $\mathrm{A}$, beam $\mathrm{C}$ with caster-wheel $\mathrm{D}$ and seat $\mathrm{E}$, tongue $\mathrm{K}$, and plough-frame $\mathrm{G}$, all substantially as shown and described, and for the pur. poses hercin set forth.

2.-The arrangement upon one axle, $A$, of the ploughframe $(;$, and drum or roller L, substantially as and for the purposes herein set forth.

No. 137,697.-GEORGE W. MANUEI., NAPA, CAL.Gans. Plumehs.-April 8, 1873. Filed Sip'ember 20,1873 .

Claim.- In a gang-plough, of substantially the described construction, the lever $m$, adapted to slide in notches of its rack, in combination with the lever $m^{\prime}$, allapted to be moved forward and baekward, and the conneeting part, arranged as described, for the purpose set forth.

No, 1 37,870.—STEPHEN L.STOCKSTII.L, MEIWAY, OHIO, and HENRY D. KUTZ, HARRISHURG, PA.Plonghs. - April 15, 1873. Filed September 7, 1872.

Claim.-The plough-beam, provided with perforated ears $a b$, and the pin $b$ formed on the end of the axte $C$, the sleeve $e$, and set-screw $d$, all arranged as shown and described, for the purpose of allowing vertical adjustment of the axle, as specified.

No, 137,915-RICHARD B. GROUND, EDWARDS. VIL.LE, assignor of one-half of his right to CHANCY $G$. S.AUNDERS, assignor, by mesne assignments, to NELSON 1). SWEENEY, MARINE, ILL.-Iloughs.-April 15,1873 . Filed June 27, 1872 .

Claim.-A plough in combination with the sulky attachment A F, clamp composed of the bolts $a b$ and slotted plate $c c^{\prime}$, slotted lever $\mathrm{B} b^{\prime}$, lock-lever E, elevated bar 1 , and perforated are $\mathrm{C}$, all the parts being constructed and arranged subst.nntially as and for the purpose specified.

No. 137.975.-WILLIAM P. SWEENY, MARINE, ILL. -Whith-Ploushs. -April 15, $18_{73}$. Filed Septembir 27, 1872.

Claim.--The beam of a wheel-plough in combination with easter-wheel A, lever B, a locking-latch attached to the lever, and a fixed notched are $C^{\prime} c^{\prime}$, all arranged and operating substantially in the manner and for the purpose specitied.

No, 138,329.-FRED. H.ASBROOK, STOKes' MoUnd, Mo.-Whet-Plonghs.-April 29, 1873 . Filed August 13, 1872.

Claim.-The combination of the bar or rod $\mathrm{A}$, box $\mathrm{C}$, block $G$, chain $F$, and lever $E$, substantially as and for the purpose specifical.

No. 139 032. - CHARLES B. STEVENS, DOXNHISON, Iow.1. - Whiel.Plonghs.-May 20, 1873 . Filed January 16,1873 .

Claim.-The frame A B, supporting-wheets $\mathrm{E} F$ and sliding seat $\mathrm{L}$, in combinatian with pivoted plough $\mathrm{N}$, the seat bing arranged so that the driver may throw his weight on the rear of the frame to assist in raising the plough, all subatantially as described and for the purposes set torth.

No. 139,059-ISAAC B. GREEN, GHLESTE, 11.I.Wheel-1'loughs.-May 20, 1873. Filed March 15, 1873 .

Claim. - The pendent standard $K$ and guide () , arranged under the axle, in combination with a two-barred plough beam, as and for the purpose described.

No. 140.480.-NARSHALL.S. CURTISS, BRADFORD, ILL._-Gans-Plowshs.-July 1, 1\$73. Filed Nivember I3, 1872 .

Chaim. - The plate B provided with teeth or cogs $k$, and pivoted to axle $A$, in combination with lever $B \mathrm{~B}$, and trans. verse arms $f f$ of $\operatorname{rod} b$ having transverse arms $d$ arrauged in guicles $e$ of beams C C, the whole constructed to operate substantially as set forth.

No. 140,505,-DAVID W. 11 UGHES, MExtco, Mo,Sulky-I'loughls. - July I, $18_{73}$. Filed $O_{i} t_{0} b^{\prime}{ }^{\prime} \mathbf{1 2}, 18_{72}$.

(lium, - 1_- In a wheel plough, the transverse bar 1), con structed and arrangerl and used to support the driver's seat $\mathrm{E}^{\prime}$ and tongue $\mathrm{C}$, in the minner subatantially as descrihed.

2.-The bar $\mathrm{H}^{\prime}$, braces I, beam A, ploughs-beam $\mathrm{F}^{\prime}$, lev. er $K$, aud chain $Z$, combined substintially as and for the purpose set forth.

No. 141,551,-HENRV M. SKINNER, RڤKHORD, 1L1.., assignor to CHESTER C. BRLliGisand ABRA1IAN 1. ENOCiI,-Whecl-Ploughtis.-July I, 1873. Filed March 29,1873 .

Claim.-1.-The self tulting plough-beam and hinged tongue, in combination with the tilting loeking lever 1 , operating substantially as deseribed.

2.-The combination of evener II with the forward end of the tilting plough-beam, and with the pivoted tongue, by means of the chain $\mathrm{N}$, as and for the purpose describerl.

3.-The angular stub axle-plate $\mathrm{A}^{\prime}$, made adjustable on the axle-bar as and for the purpose set forth.

4.- The adjustable conlter-standard $R$, in eombination with the adjustable supporting-plates s provided with slots with knife-edge pivot-bearings s' formed on them, as described.

No. 141,073,-JOHN C. PEARL, MENDOTA, ILI.What-Plonghs. - Ju'y 22, 1873. Filed Fibruary 21, 1873 .

Claim,-1.- The combination of the suspension-rod $\mathrm{H}^{3}$, which swivels in a sliding coupling attached to the frame of the carriage, and the plough-beam $\mathrm{E}$, which is loosely sustained in the fork of the suspension-rod by a bolt passing underneath it, substantially as and for the purpose specified.

2.-The berein described coupling for suspending a plough-heam, composed of the parts $\mathrm{II}, \mathrm{H}^{3}, \mathrm{H}^{2}$, and $1 \mathrm{l}^{3}$, constructed and connected, substantially as set forth.

3.-The combination of the platform I, elongated soeket $G$ fixed thereto, angular draft and suspension $\operatorname{rod} F F^{1}$, and laterally-adjustable plough-beam E, all constructed and connected substantially as specified.

No. 14I,S8r.-JAMEA MARR, SIMCOE, CANADA.Ploushs.-Aurnst 19, 1873. Filed March 14, 1873.

Clain.-1.-The combined axle and lever $a$, constructed in one piece, bent and arranged as described, and attached to the beam $A$ by the hanger $b$, in combination with the whecl $1)$ and rack $b$, as bereinbefore specified.

2.-In a self-holding plough, the upright $e$, carrying the holding-wheel $\mathbf{E}$ and attached to the stotted arm $f$, substantially as and for the purpose described.

No. 141,951.-LIONEL. IV. RICIIARDSON, Roscof, It.L.-Whie'-Ploushs.-Ausust 19, 1873 . Filed May 31, 1873.

Claim.-1. The combination of the sleeves $F$, pivoted rods $G$, clamp $H ~ I$, and draught-rod $K$, with the arched or bent axle A and plough-beam $\mathrm{J}$, substantially as herein shown and clescribed.

2.-The combination of the bent lever $Q$ and swivel connecting-rod $R$ with the arched or bent axte $A$, and the clamp H I, pivoted connecting rods $\mathcal{G}$, and sleeves $F$, substantially as herein shown and dencribed.

No. 142,08 4 -RUDOLl'li CORET1I, WEST BFI.I.E. vil.t. I11.-Gang.Plowg/hs.-August 26, 1873 . Filed Juni $2 \mathrm{I}, 1873$.

Claim.-1.- The standard-rack $F \quad F$, mounted on the cranked axle $\mathbf{B}^{1}$, applied to the standards $\mathbf{E} \mathbf{E}$ on frame $A \mathrm{~A}$, and having combined with them the pawts $f f$ and the devices for operating these pawls, subatantially as described.

2.-The steps $s$, applied to a rack-rod, $r$, having a handlever, $G$, on it, in combination with the revolving frame, carrying one or more ploughs, ${ }^{\prime}$, and a cranked axle, B', suspended in front out of the way of said frame, substantially as deseribed.

3.-The standards E, perforated and provicled with adjustable stop-pins $p$, in combination with the standard racks and their pawls, and with lifting-ares $d^{\prime}$ on a turning plough-frame, substantially as described.

No, 142964 -TII.CIIHAN 1). TERKV, ALONZO CASE, and CHARLES LAKKIN, KNomNustER, Mo.Which-Plowghs. - Siptember 16, I873. Filed April 5, 1873 .

Claim.-I.- The eumbination, with the tongue A, axle B, and wheel $\mathrm{C} C$, of the har $(i$, hinged at its front end to 
the tongue and supporting the seat $\mathrm{E}$, and the har $G^{\prime}$ pivoted to the rear end of the bar $G$, and having the plough $\mathrm{H}$ and coulter $\mathrm{J}$ atlached to it, all substantially as herein set forth.

2.-The Iever $\mathrm{J}^{\prime}$, with arm $h$ and studs $i i^{\prime}$, and bars G $\left(G^{\prime}\right.$, staple $f^{\prime}$, and support $k$, the several parts being constructed and arranged as and for the pupuse specified.

3.-The wheel 1), constructed as described, with the outer and inner cutting-rims $d e$, substantially as and for the purposes herein set forth.

4.- In combination with a plough arranged on one side of the centre, as shown, the double tree $K$, equalizing-bar $\mathrm{L}$, single-trees $\mathbf{M}$, rollers $y z$, and chain $x$, all arranged and operating substantially as and for the purposes herein set forth.

No. 143.147--JOIIN D. HARRISON, MIDDLETOWN,

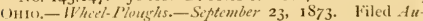
gust 2,1872

Claim.-1.-The combination of arm $l$, link $j$, lever $m$, pawl $k$, and short arm $i$ with studs $n i^{\prime}$, crank $i^{\prime}$, and ratchet whecl $h$, substantially as and for the purpose described.

2. The combination of the frame $a b c c$ with the journaled double crank $e$ and adjustable tongue $d$, substantially as described, for the purposes specified.

No. $143434 .-11$ ENRY M. BULLITT, Louisviller, Kr:-Ploug hitimiages.-October 7, 1873 . Filed Juni 28 , 1873 .

Claim.-The uprights C, provided with axles B at their lower ends, and connecterltorgetherat top by an axle, D, upon which depends a hanger, $\mathbf{K}$, in combination with the stirrup $I, L, M$, brace-rods $G\left(i\right.$, and adjnsting-holes $H{ }^{\prime}$ ' and plough-beam $\mathrm{F}$, constructed and arranged as and for the pur ose set foith.

No, 143,660,-WILLIAM BLACKSTONE, SHEIBY, Cirver, HiL.-Mloughs-Ostobir $7,1 \mathrm{~S}_{73}$. Filed Ju/y 28 , 1873 .

('aim.-1,-Kock-shaft and lever B, with its stotted arm $B^{\prime}$, in $\mathrm{crml}$ ination with the plough-beam and rear conncet ing-hook, as and for the purpose describer.

2.- Lever No. 6 and connection P, in combination with lever No. 5 , with joint $\mathrm{s}$, and the plough-beam, as and for the purpose described.

3.- The combination of the plongh-beam, the rock-shaft, and lever $B$, levcrs 5 and 6 , with their connecting joints $a$ no slots, and ratehuts 9 and $k$, as and for the purpose described.

No. 144 453.-FRED HASBOOK, STOKES' MOUND,

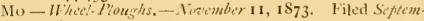
bir 6,1873 .

Claim. - The combination of rocking bar $\mathrm{I}$ and rod $\mathrm{K}$ with bifurcated tongue A $\mathbf{B}$ and beam $\mathbf{L}$, as and for the purpose syecified.

No. 145.0\$3.-ANDKEW H. BALLAGII, BuWENS BURG, asignor to bimself and MARTIF Me NTTT, MOUNi StATIN, IL1..-Riding AHaim:n! for Pioush:-De':m. ber 2,1873 . Filed func 21,1873 .

Claim.- The triangular frame A, caster-wheel $]$, beam $[$, and draft-rod $\mathbf{F}$, combined in a riding-plough, as and for the purpose tlescribed.

No, 145.147-IACOB l3INGHAM and ORL.ANDO M IONI), WATERL(x), IoW.1.-Wheci-Ploushs, - December $2,18_{73}$. Filed Octiber 30,1873 .

Claim.-In a plough-carriage, the axle $A$, having the ad justable screw lifting device $a b d$ at one end, and the plate and box $a^{\prime}$ with set-screw $b^{\prime}$ at the other end, of the axle, in comlination with the plough-beam $D$ and staple $c$, sliding on axle-arm $\mathrm{B}^{\prime}$, and the plough-bzam $\mathrm{H}^{\prime}$, adjustable by slotted guides on the axle, substantially in the manner and for the purpose herein set forth.

No, 145,361.-CIIRISTIAN MVERS, MARvsville, CAL.., assignot to himself and FR.A NCIS J. SCHAEFFER,

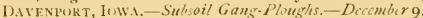
1873. Filed Auszis! 16, 1873 .

Claim. - The combination of detachable share G, having hoo's $e^{\prime}$ and rear extemsion of point II, with under side $C^{\prime}$ and land-sicle $\mathbf{H}^{\prime}$, by means of slot $e^{\prime}$, apertures $f f^{\prime}$, and wedge-piece $;$, for the purpose sct forth.

Vo. 146562 -ROHERT C. AIREV. HIGHLAXD, ILI.

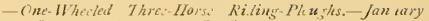
$20,18_{74}$. Filed Nozinb, $\mathrm{S}_{1} \mathrm{I}_{73}$.

Claim.-1.-The combination, with the hinged ploughleam $\mathrm{G}$, hinged are-Lar $\mathrm{M}$, lever $\mathrm{K}$, and locking device $\mathrm{N}$ $\mathrm{O}$, of the horizontal lever $\mathrm{P}$, rod $\mathrm{R}$, and adjustable keeper $\mathrm{O}$, as shown and described.

2. - The combination of the slotted beam $\mathrm{E}$, arranged diagonally with beam $\mathrm{U}$ and axle $($, adju-table keeper $\mathrm{O}$, hinged plough-beam $\mathrm{G}$, hinged arc-bar $\mathrm{N}$, lever $\mathrm{K}$, and locking device $\mathrm{N} O$, as shown and described.

No. 146,507. - ILIISUN G. CUMMINS and JOIIN R. CUMMINS, McKINNEY, TEx.-Gans-Phushs.-Junuary 27, 1874 . Filed May 24, 1873 .

Claim.-The comlination, with the hinged plough-beam or frame $\mathrm{F}$ and the tongue () , of the king-bolt II extended upward, as shown, the lever $\mathrm{I}$ hinged thereto, and the connecting-link $Q$, all as shown and described, whereby the saisl lever can be swung over onto the king-boit and the parts locked, as and for the purpose specilied.

No. 145,939.- IVII.1.1AII NEWLIN, ATTICA, IND,Gang-1'loughs.-January 27, 1 $\$_{74}$. Filed July 3, IS73.

Claim.-1.- The combination in a gang-plough, of the axle $A$, box $G$, slotted box $H$, set-screw $y^{\prime}$, and whecls $C$ C , all substantially as and for the purposes sct forth.

2.-The comlination, in a two-wheeled gang-plough, of the tonarue 1;, secured to the outsile of the axle, the bar 1), beams $a a^{\prime}$, with plougls $b b^{\prime}$, the moring bar $h$ and its brace $i$, and the braces $k$ and $t$, all constructed and operater sub tantially ats and for the purposes set forth.

No. 146987 . - LUE CHAPMAN, COLINSUII\%, Cons., assignor to himself and TIIE C'llLins Conpany, same place. -Dobule-Furrew Pioughs. - Fibrury 3, is;4. Filed $/ u^{\prime}+28,1873$.

('laim,-1.-The forked lever $d$, carrying the wheel o bztween the plough, and having a spring-adjusting device, in combination with the frame $a$ and the jlough, all constructed, arranget, and de-igned for operation sul stantially as slywn and described.

2.- The combination of the double-siled rack s, the lever $d$, the hollow harrel $i$, the two $i^{+}$tons $i^{1} i^{1}$ resting $14.0 n$ the spring within the barrel, the whole arranged, constructed, and designed for operation and use subtantially as deseribed.

No, 147.063--SOLOMION NEFF, CUeA, I I..-Whed Ploushs.-Firuary 3, 1874. Filed Ausust 3o, i 873.

Claim.-1.-The frame $C$, with forwardly-projecting arms $\mathrm{F}$ and braces $\mathrm{G}$, vertically adjustable through slots in the short axles 13 , in comlination with the plough-beans 1 ), carried upon the axle-frame, and pivoted to the front projecting aim. F, all as and for the purpore described.

2.- The comlination, with tongue $\mathrm{K}$, of clevis $\|$, having several perforations, anel the cross-bolt of extensiou $\mathrm{F} / \mathrm{f}$, tu which the tonisue is loosely connecter by an eyeloolt, anil arljutable to regulate the wilth of cut, in the manner set forth.

No. 147,156.-ROBERT NEWTON, JERSEYHII.

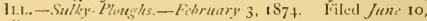
${ }_{1} \delta_{72}$.

An improvement upon the patent grauted F. S. DAVresPokT, ()etsher 9, I 666 .

Claim, - In a wheel-plough, the comlination of the adjustable hinge with the foot-board 13 , beam $A$, and axle, as dercribed.

No, 147.320,-ISAAC B. GREFN, (ill.FSPIF, 11.1.-

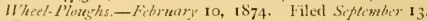
$18_{73}$.

Claim.-The combination of the two detachable and exchangeable double-bar plough beams $\mathrm{E}$, and their attached ploughs, with the puides $\mathrm{N}$, slotted stmelards $\mathrm{F}$, bars or shaft $\mathrm{I}$, lever; $\mathrm{J}$, sliding blocks $\mathbf{L}$, and braces $\mathbf{M}$, and with the frame $c$, substantially as herein slown and described.

No. 147.741 - -ELAKON B. B.AIKD, PLOTON1, II.L., assignor of on -half of his right to RUSSELL C. B.IIRI),

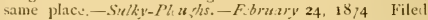
Nici'mber 25,1873

Claim-Che push-trar II, piroted to the rear of the plough-beam $A$ and to the avle B, ly meani of which bar the sulky frame is driven, and a backwaril movement given 
to the plough when the latter is raised, in combination with the stirruj) (i, levers $K$ and $P$ ' $T$, and chain $L$, substantially as syecilied.

No. 147,582,-JOHIN LRBAN, BELTON, TrXAs.Combinal Ploushs, Planters and Callionters. - February $2.4,1874$. Filed Siptember $20,1873$.

Claim.- The combination, with the two parallel beams 1.1 , of the adjuxtable cross-beams $I^{\prime}$ and the sile beams $\mathrm{K} S$, adjustable in the beams P, as described, to form a frame adapted to he used with a planter, ploughs, or enltivators.

N., 148,149.-WILLIAM SNOW, WAVERIY, IHI.-

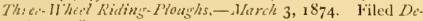
cetm/er $1,1 S_{73}$.

Claim.-1.-In a wheel-plough, the combination, with whecls A $\mathrm{I}$ and tongue J, having swiveled cross-bar $\mathrm{H}$, of the swiveled tandards 13, having the wheel-journals, and the arms $\mathrm{F} \mathrm{F}$, comected by rods $\mathrm{G}$, as and for the purpose described.

2-The combination, with the truck-frame and plough heam, of swiveled standard $\mathrm{E}$, having arm $\mathrm{O}$ and the jour nal on which rear wheel turus, the rod $\mathrm{N}$, and the standar. 1), having arm M, and vibrated from the tongue, as and for the purpose set forth.

3.- The combination of the lever $\mathrm{F}^{\prime}$, the armed shaft $\mathrm{E}$ $1^{\prime}\left(i^{\prime}\right.$, elevi; $C^{\prime}$, link $11^{\prime}$, rod $1^{\prime}$, armed shaft $K^{\prime} J^{\prime} \mathrm{I}^{\prime}$, and bar $\mathrm{N}^{\prime}$, with the plough-beam $\mathrm{B}^{\prime}$ and frame-work $\mathrm{C}$, substantially as hercin shown and described.

Ne, 148,398 , - CALV1N ALBERTSON, DALTON, IND. - breaking-Ploush.-Warch 10. I\$74. Filed fanuiry 31,1874

Clain.-The sulhy-frame $\mathrm{B} \quad \mathrm{B}^{\prime}$ and tongue $\mathrm{A}$, in combi nation with braccs 1), fivcted both on the spindles and plough-beam, rods $b$, and spindles $a a$, when constructed and arranged as and for the purpose herein specified.

No. ${ }_{7} \mathrm{~S}_{47} \mathrm{~S}$ - - CIEORGE C. IIAIGHT, NEWARK, WIS.

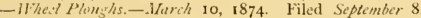
1873 .

Claim.-1.-The comlination, with the wheels $\mathrm{C} \mathrm{C}$, of the axle composed of the long arm $\mathrm{A}$, with its inner ends a bent upward, the short $\operatorname{arm} \mathrm{A}^{\prime}$, with its inner end $a^{\prime}$ bent upward, and the two upward-lent ends $a a^{\prime}$, secured togrether by the stirrup-clamp lis and its nuts, all as shown in Fig. 3 for the plirfose set forth.

2.- The combination of the axle $\mathrm{A} \mathrm{A'}$, wheels (' C

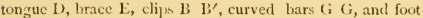
lever J, all constructed and arranged substantially as and for the purposes herein set forth.

3.- The combination of the axle $\mathrm{A} \mathrm{A}^{\prime}$, wheels $\mathrm{C}^{\prime} \mathrm{C}$, tongue D, brace E, clips B $\mathrm{B}^{\prime}$, curved bars $\mathrm{G}$ G, foot lever J, stirrups $\mathrm{X} O$, and beam $\mathrm{L}$, all constructed and arranged sub. stantially as and for the purposes herein set forth.

No, 148,58 ;-GEURGE W. VAN GORDER, WARKLN, OHu,.-Sulky-Ploughth and Ilarruzes.-Mar:h I7, 1874 . riled De.entior $17,1 S_{73}$.

Claim. - The framc A D, having the wheel-spindles at tached near to the center of the ends, and the harrow or plough attached to one side, in confsination with the lever

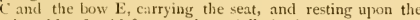
other side of said frame, substantially in the manner as deseribed, and for the purpose set forth.

No 149,140.-JOIIN R. HCCONNEL, WATERIOO,

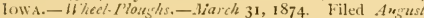
9. 1873 .

Claim.-1.-1n combination with the slotted adjustable axle-arm $F$ and rigid arm II, carrying the wheels $G$, the triangular frame formed of the front plongh-beam $A$, the dis gonal b.1r $\mathrm{C}$, carrying the draft-bar $\mathrm{K}$, and axle $\mathrm{D}$, alt constructed and arranged as shown and described, for the purpose specilied,

2.-The combination of the rear plough-beam B, lever 'T U, draft-bar K, vertical guide-hars L, to adjust laterally both plough-beam and lever, axle 1 , and b ir $\mathrm{H}$, all constructed and arranged as shown and described.

Nis. 150,034.-JOHN D. HARKISON, MIDDLETOWN, ()1Ho, assiguor to one-fourth his right to P. P. LA TOUR RET T1, same place-_Sulky-Plou; hs. -April 21, IS74. I iled Oiaber 3,1873

Claim.-I.-The flough-sulky framc hercin descriled, comsi-ting of two sicle picces, each composed of three lars, $A, b$, and $C$, pivoted togrether at their front ends, the bars, A $\mathrm{A}$ having spindles for the drivint whecls $\mathrm{K} \mathrm{K}$, the lars I3 I connected by cross-bars I) I $)^{1}$ I $)^{2}$, and the bars $\mathrm{C} \mathrm{C}$ connected by a shaft to which the plough is attached, all com. bined substantially as hercin set forth.

2. - In combination with the plough-sulky frame herein deseribed, the shaft $\mathrm{J}$ with arms $n n$, connccting-hars $m m$, and the sleeve $f$ with lever I, arm $n^{\prime}$, and connecting-bar $m^{\prime}$, all substantially as and for the purposes set forth.

No. I50.425.-EIJVIN R. MCCAl, , WATERLon, Iuws.-Whert-Plough Altachments.-May 5, 1874. Filed Febura,y 12, 1874

(lain.-1.-The combination of the draft-beam H, with its adjusting device $h$, connected with the plough-beams J J' and their link attachments $j{ }^{\prime}$ with the diagonal timber 1 , the connecting chains $k$, arms $n$, and hand-lever $L$, operating in the manuer described.

2.-The combination of the frame $\Lambda$, standards $F$ and $G$, draft-beam 11 , plough-beams $J J^{\prime}$, ploughs $K K^{\prime}$, lever $L$, connecting-links $i i$, chains $k k$, and the adjusting device $h$, substantially as herein shown and described.

No, 150,702 ,- HENRY OLDENDORPH and JOHN OL.DENDGRPH, MILLSTADT, II.L.-Gang-Plough/h.May 12, IS74. Filed Fitiruary 26, 1874 .

Clain,-I.-The pivoted axle-arm F, provided with rack bar $f$, formed part of said arm, as and for the purpose set forth.

2.--The combination of the pivoted axle-arm F, its rack $f$, pinion $f^{1}$, with compound lever $\mathrm{C}$, having branch arms $c$ $c^{2}$, as and for the purpose set forth.

3. - The combination of the foot-treadle $f^{5}$, crank-shaft $f^{4}$, chain $f^{3}$, spring-pawl lever $f^{2}$, pinion $f^{1}$, compound lever $\mathrm{C}$, hand-lever $\mathbf{G}$, lock-plate $g^{\prime}$, pivoted axle-arm $\mathrm{F}$, with rack $f$, to operate as and for the purpose set forth.

4 - The combination of compound lever $\mathrm{C}$, conststing of branch arms $c c^{2}$, chain $d$, pulley $d^{\prime}$, hand-lever E, its springpawl lever $e^{2}$ ratchet-plate $e^{1}$, all constructed to operate as and for the purpose set forih.

No. 150,727,-JAMES STONE, BOND COUNTY, 1LL,Gang-Ploughs.-May 12, 1874 . Filed Aturch 21, 1873 .

Claim, -1.-The ploughs arranged obliquely upon curved bcams 13, of graduated length, and connected, at their rear ends, ly rod $\mathrm{C}$ and sleeves $\mathrm{D} \mathrm{D}$, in combination with double loops $\mathrm{E}$, revolving cutters $\mathrm{F}$, frame $\mathrm{A}$, and rod $\mathrm{G}$, substantially as shown and described.

2.-The plough-beams and their connections, in combination with the posts $\mathrm{L}$, branched cross-bar MI, brake-lever $\mathrm{N}$, and ratehet $\mathrm{O}$, all arranged substantially as shown, and for the purpose set forth.

No. 151,054-JOHN B. RALSTON and MATT11EW IIAKVET, ROCKFORD, ILL. -IVheel-Ploughs.-DLay 19, 1874. Filed Decimber 3,1873 .

Claim,-1.- The clamp I, provided with the stud $i^{3}$, in combination with the box $\mathbf{E}^{2}$, connected to the frame by pivoted links, for allowing the jlough both a latcral and vertical movement, as described.

2. - The combination, witls the clamp composed of plates $i i^{1}$, as described, of the vertical pin $i^{3}$, box $\mathbf{E}^{2}$, and link $\mathbf{E}$, all arranged and operating substantially as described.

3.-The clamp $L^{2}$, double-pivoted link $l$, arm $L^{2}$, and cross-bar $\mathrm{L}$, in combination with the plough-beam, having a vertical pivotal connection with the frame for turning the plough to or from the land, as described.

4. - The combination of the forked or Y-shaped tongue frame, axle $\mathrm{B}$, arm $\mathrm{K}$, and cross-bar $\mathrm{L}$, with its arm $\mathrm{L}^{1}$, all arranged for supporting and guiding the plongh, in the manner described.

No. 15t,144-ISAAC k. GILBEKT, CHAmpaIGN, IL1.-Whed-Ploushs.-Way 19, 1874 . Filed Merch 19, 1874

Claim,-1.-The rock-shaft $f^{3}$, having the elbow-lever $f^{\prime}$ and the arm $f^{3}$ rigidly attached, and adapted to raise the plough by means of hand-lever $I$ and its connccting-chains, and to depress it by means of foot-lever J and the connecting-chains $f^{4}$

2. - The comlination of the licam $A$, cross-bar $\mathrm{B}$, tongue $(\text {, arms 1) } 1)^{1}$, aljutalule whech E $\mathbb{L}^{\prime}$, and adjustable seat 
H, all constructed substantially as and for the purposes herein set forth.

3.- The combination of the foot-lever $\mathrm{J}$, chain $f^{4}$, arm $f^{3}$, shaft $f^{2}$, elbow-lever $f^{1}$, rod $f$, and a plough, $G$, substantially as and for the purposes herein set forth.

4.- The comlrination, with the plough $\mathrm{G}$, of the shaft $\mathrm{m}^{1}$, rod $m^{3}$, with nuts $x x$, lever $m^{4}$, and sleeve $m^{5}$, all substantially as and for the purposes herein set forth.

No. 151,125.-GIDEON J. OVERSHINEK, HOLI.ISTER, CAL_-Gang-Ploughs.-May 26, 1874 . Filed April 16,1873 .

Claim.-In a gang plough, the combination of the springs I I and lever G, for lifting the frame $A$ and ploughs $B$, constructed and operating substantially as set forth.

No. $151,649,-$ EDWIN A. BEERS, SYCAMORE, Ill., assignor of one-half his right to E. T. NYE, same place.Gang-Ploughs.-June 2, 1874. Filed February 25, 1874.

Claim. -1 - - In the combination with the plough-beams $S$ and $S$ and laternlly adjustable blocks $P$ and $P$, provided with the slots $p^{\prime}$ and $p^{\prime}$, the tongued and slotted blocks $Q, \eta$, and $q^{\prime}$, and the clevises $\mathrm{R}$ and $\mathrm{R}$, substantially as and for the purpose shown,

2.-A plough-beam swiveled at its front end within a suitable attachment, and locked in position therein by means of a set-screw, substantially as and for the purpose set forth.

3.-In combination with the plough-beam $\mathrm{S}$, hinged at its front end, the bar 1'? said leam, jointed at its longitudinal center, and provided at it - rear end with a longitudinal slot, $b^{\prime}$, which embraces the pin (', substantially as and for the purpose shown and described.

No. 152,018,-1)AVID A. SUALLEY, and JAMES $H$. SHALLEY, BUNKER HILL, ILL.-Sulky-Ploughs and Cultiatators.-Jun. 16, 1574. Filed January 29, 1874.

Claim.-1.-The combination of the metel piece $\mathrm{W}$, hav ing rigid arms $\mathrm{X} \mathrm{X}$, and the crank-shaft $\mathrm{Q}$, having toothed disks $\mathrm{S}$, with the lever $\mathrm{K}$ and spring-stop $\mathrm{T}$, as and for the purpose described,

2. - The combination, with bar $f$, of toothed disk $\mathrm{H}$, hav ing front extemsion with hole or slot, and the pendent strap C, as and for purpose specified.

3.-The combination, with the plough, of the adjustable cutter or rudder $k$, connecting-rod, and locking-cam, as and for the purpose specified.

4. - The combination of axle $\mathrm{B}$, having crank $\mathrm{D}$, handlever $\mathrm{E}$, and disk $\mathrm{G}$, the toothed segment 11 , having side loop $h^{\prime}$, aud the pendent arm 1 of the main axle, all conjoined by a single bolt, as and for the purpose spzcified.

No. $152,45^{8}$. - ALIBERT H. BURLINGAIIE, SPARTA, 11. L..-Gang. Ploughs.-June 30, 1874. Filed May 2, 1874 .

Claim,-1.-The tubular axle fastened to the ploughframe and having connecting screws or pins, the solid revolying crank-arms liaving grooves in their circumference, the adjusting-levers, and the notched stop-hars, all combined substantially as and for the purpose herein described.

2.-The bars $\mathrm{M}, \mathrm{M}^{1}$, and $\mathrm{M}^{2}$, constructed as described, in combination with the ploughs and laterally-adjustable pendant of the frame and axle, as and for the purpose herein descrilsed.

3.- The combination of the oblique lifting-chain $\mathrm{IT}$, the bars $\mathrm{II} \mathrm{I}^{1} \mathrm{M}^{2}$, provided with a lifting extension, and the in. dependently-hinged plough , substantially as described.

No. 152,464.-FINLEY R. CROTHERS, STARTA, 11.1.-Ganj-Plowsh.-Fune 30, 1874 . Filed March 14, 1874 .

Claim.-The clamp $F$, having a broad slot on its under side and adjustably secured to the cross-beam by set-screw $G$, in combination with the double bracket $E$, having hooklirace 11, and right-angled flauges adapted to spring and catch in the slotted clamps, as shown and described, for the purpose specified.

No, 152,507.-JUHN H. PAYTUN, RANTOt L, lLL.Riding-Ploushs.-June 30, 1874. Filed Warch 28, 1874

Clim -1. The combination of the adjustable gaugebeam $\mathrm{T}$, and the adjusting bolt i $\mathrm{V} \mathrm{V}$, with the plough-beam $\mathrm{N}$, substantially as herein shown and deseribed.

2 -The combination of the bow or staple $I^{\prime}$, the perfor- ated block $L^{\prime}$ with the rack-axle $C$, and with the standard $\mathrm{I}^{\prime}$ of the rotary cutter $\mathrm{H}^{\prime}$, substantially as berein shown and lescribed.

No. 152.731.-NORMAN DU BOLS, GRERNILLr, Он10.-Sulky. Ploughs.-July 7, 1874 . Filed Warch ${ }_{13}$, 1874 .

Claim.-1.-The combination and arrangement of the channeled arc $\mathrm{P}$, chain $\mathrm{II}$, and lever $\mathbf{E}$, having the curved foot $Q$ and pawl $R$, with pin S, substantially as shown and described for the purposes specified.

2.- The toothed arc $\mathrm{T}$ and lever $\mathrm{D}$, having stud $b$ attached to the hound $K$, in combination with the arm $F^{\prime}$, at tached to the axle $\mathrm{C}$, and with are $\mathrm{P}$, chain $\mathrm{ML}$, and lever $\mathrm{E}$, substantially as shown and described.

No. 152,771.-DELOS A. SEARS, ROCKFORD, LLL.Sully Ploughs.-July 7, 1874. Filed March 15, 1873 .

Claim.- I. - The combination of the wheels, the axle, the frame-beam pivoted on the brace-rods, the seat-standards hinged to the axle and serving as guiles to the frame-beam, the segment-gears $G$, mounted on a rock-shaft in the framebeam, gearing into racks on the seat-standards, and controlled by the hand-lever, and sector-rack on the frame-beam all these members being constructed and operating in comhination, substantially as described, to raise, lower, and adjust the frame-beam independently of the axle and without tipping the ploughs, as set forth.

2. -The combination of the wheels, the axle, the laterally sw inging plough-heam, the vertically-adjustable frame-horm, and the tongue hinged thercto, to play freely vertically, or to be locked tigidly, when desired, all these members being constructed and operating in combination, as set forth.

3.- The combination of the rolling coulter its raclius-arms, quadrant-flange, and hook-bolt, these members being constructed and operating in combination, substantially as sct forth, to render the coulter laterally adiustable.

No. 153,037.-WM. O. M. BEKRY, SAN Fra.icisco, CAL.-Gang.Ploughs.-July 14, 1874 . Filed Mizy 12, 1874 .

Claim.- In combination with the plough-beams $\mathrm{H} \mathrm{H}^{\prime}$ with their connecting rod $n$, the vertical rod $L$ and tube $K$, with its horizontal tude $u$, crank-lever $O$, and connecting. rod $p$, substantially as and for the purpose above described.

No, 153.256.-GEORGE W. HUNT, MUscatine Co., Iowa.-Camiage-Plougths.-July 21, 1874 Filed Febru a)y 17,1874 .

Claim.-1.- In combination with the gallows C C, tongue $\mathrm{B}$, and beam $\mathrm{A}$, constructed and arraiged as herein described, the adjustal,le connecting gauge-bolt $\mathbf{E}$, with lever $\mathrm{J}$ and chain $f$, as and for the purpose set forth.

2.- In combination with the plough-beam $\mathrm{A}$, mounted as described, the hinged bar $\mathrm{P}$ and adjustable axle $\mathrm{O}$, provided with wheel N, constructed and arranged as described, and for the purpose set forth.

3.- In combination with the plough-b:am $A$, axle-staud ard (), and wheel $\mathrm{I}$, the upright hand-lever L, gauge lar $\mathrm{U}$, axle or bar $\mathrm{P}$, and brace $h$, constructed and arranged as herein descrilsed, and for the purpose set forth.

4.-A carriage-plongh, consisting of the fore wheels D I, gallows $\mathrm{C} C$, t tongue $\mathrm{B}$, connecting adjustable gauge-bolt $\mathbf{E}$, plough-beams $\mathrm{A}$ and $\mathrm{V}$, wheel $\mathrm{II}$, and adjutalile wheel $\mathrm{N}$, all constructed and arranged substantially as herein describerl.

154.293.-WLLLIANI STARILING, LA I'RAIRIE, II.L.

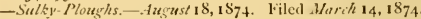

Claim, - 1.- The crank-bar $\mathrm{K}$, combined with the plou, $\mathrm{h}$ beam $\mathrm{N}$, lever $\mathrm{L}$, and axle $\mathrm{A}$, as and for the purjose st forth, so that the horses are made to raise the plough out of the ground.

2.-The combination of the jointed lever $\mathrm{U} V$ and stop W, with the brace J, tongue I, and plough-heam N, sulsstantially as lerein shown and described.

3.- The qualrant $T$, provided with the long keeper $t^{2}$, the open keeper $t^{2}$, and the two bolts $t^{3} t^{4}$, in combination with the standard $\&$ of a rotary cutter, for connecting said cutter adjustably to a plough-beam, substantially as herein shown and clescribed.

No, 154,306,-T. WEA VER, II ARRISIuRg, PA.-Sulky Athashimints for Ploughls....Aug $t \mathbf{1} 8,1874$. Liled June 26,1873 . 


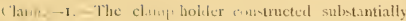
wh h. I w w forth, in combination with the plough-leam j and the alliy attachanent proper, for the purpore set forth. 2. - The major clip ' $n^{\prime} n^{\prime} c^{\prime}$, provided $w$ ith the arm $\mathrm{R}$ $R^{\prime}$, in comblination with the stays $F^{\prime} F^{\prime}$ of ihe trendle 11 ,

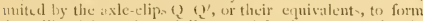
the rolline joint, sulmtatially as and for the purpose herein ut firth.

3.- The say $\mathrm{F} \mathrm{I}^{\prime}$, pivoted to the treadle $1 \mathrm{I}^{\prime}$ at $y^{\prime} y^{\prime}$, and clamped aclju-tably by the lineline crews at $Z^{\prime} Z^{\prime}$, in eomloi-

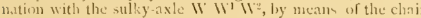
l' l", or its e puiva!cut, when the fore and aft shifting of the axic $i$, therely eflecterl, sulstantially in the manner an and for the parj we hersin set forth.

4-The groove $S^{1}$ and sht $S^{\prime}$ in the major clip, in com. cination with the vertical jamb $O$ of the arehed frame $\mathrm{E} E$ :' secured torgether by the bolt and nut $d d^{\prime}$, or their esuixit. lent-f for the purpose herein sne forth.

5.- In co mbination with segment $\mathrm{E} \mathrm{E'}$, having detents i) and guard 1$)^{\prime}$, the slott d lever A N and plunger $b^{\text {"2 }}$, having h w'iced lit $r r^{\prime}$, to reach throm sh alid slotted lever, and hole it atju-tal and applied to the segment, suls-tumtially in the mannor ilescribed.

6. - The arrangement of the pivits $\mathrm{I}^{+}, \mathrm{W}^{1}, \mathrm{~V}$, nul $\mathrm{V}^{1}$ to form the triangle or quadrante in canting the plough beam, sul stantisilly is herein sct forth.

7. - The combination of the lever $A \mathrm{~N}$, rod or trap $\mathrm{V}^{2}$, frame $\mathrm{E} \mathrm{E}^{\prime}$, and asle IV $\mathrm{WW}^{\prime}$ W', three parts operating conjuintly to cuntrol the beam J, whintantially as sct forth.

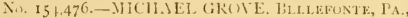

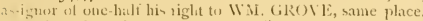

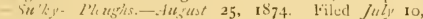
1874 .

Claim.-In a sulky-plough the crank-axle A, bent up at

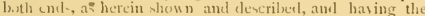
plater 1) 1) allju tably attached thercter, in combination with tive ralixl ams ( C of the short axles of the whed I) I3, constructed and arranged substantially as set forth.

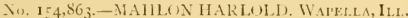

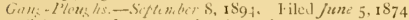

Claim. - - - In a gang-plough, having two separate and in lependent ploughs, the arrangement of the firoted ane arju-table plough-lean. Eand $E^{\prime}$, one on the inside and the uther on the out vile of the wheel $\mathrm{B}$, one in front and the sther in the renr of the axle, the wheel Is being directly in rear of nut on a line with the inner edge of the front plough, an set firth.

2.-The combination of the axle A, spindle $a$, whec 1 ,

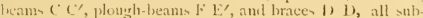
taritially as and for the purposes berein set forth.

3,- The combination of the plough-beam $\mathrm{E}$, beam $\mathrm{C}$, |xel 4, com tim $k$, brace $m$, and standari il, all constructed sub. - butially as and for the jurposes herein sct forth.

4.-The supporting-piece $d$, in combination 1 ith the tandard II :und share J, for the purposes herein set fonth.

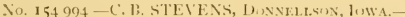

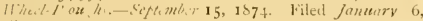
$18 ;: ;$

Claim-1.-The crimlination of levers $\mathrm{K}$ \$', frame $\mathrm{C}$, with rack 1 , sotted pisot-holder k, plough M. holder o,

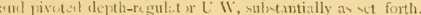

2- The coml ination of the plongh $\mathrm{M}$, franc $\mathrm{C}$, with it

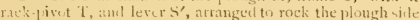
wixe and bosh it at any inclination, aut to lift it when re 'puircel, suh-tantially as act forth.

No, 155,C40.-SIENCEK 13. I'EU(ill, SILFM IXI).-

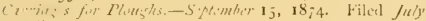
14. 1874

Claim.-In an agricultural imploment, the combination of

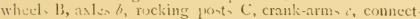
in $-r \cdots, E$, and lever $k$, silstantially as and for the por lis.endecriberl.

NO, $155.134-J A M E S$ ARMSTRONG and GEORGR

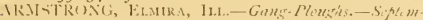

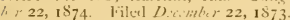

(laim,-I,-The coml ination of the notehed plate D,

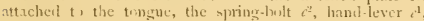

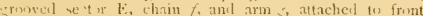

of plough-frume, for clesung the plouyhs from the ground, sulstanti.1ly as shown and deacrib icl.

2. - The casting M, provided with slots s s and notehed segment 2 , substantially as shown and described, for the attachuent and ready adjutment of the conlter by means of levern.

3.- In combination with the plate $M$, comstructed as cleserilued, the coulter l', pivoted bar ( $)$, and hand-lever $R$, all arranged and oferiting sulutantially as thown and de. cribect.

No. I55.4IS,-N1ENRY BLMGNKNER, HHCATUR,

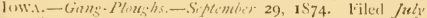
II, 1874 .

Clatim.-1.-The combination of wheels $\Lambda$ P, axles a C, stand:ard $b$, tangue $I$, standard $F$, arms $d t$, draught-bar (; brace II, and levers F I K, constructed and adajted to be used as rigl:t-hand or left-hand plough devices, substantially as described.

2.- In combination with whecls A $\mathrm{B}$, axles a $\mathrm{C}$, standard $b$, lever $F$, draught-bar $\left(i\right.$, and lrace $1 \mathrm{I}$, the arms $d^{2} \mathrm{c}^{2}$, tandard and wheel $\mathbb{L}^{2} l^{2}$, and levers $\mathbb{1}^{2} \mathrm{~K}^{2}$, constructed and adipted to be operated with oxen, sulatimtially as deseribed.

3.-The combination with axles a C, standard b, brace $d$, lever $F$, and lever-are $L$, draught har $(i$, and brace II, constincted and adapted to carry either tongue 1), stanclard $E$, armind $e$, and lever I $K$, to operate the ploughs with hores, or to carry stamlard and wheel $E^{2} b^{2}$, arms $d^{2} c c^{\prime \prime}$, and levers $I^{2} K^{2}$, to operate the plough $\rightarrow$ ith oxen, substantially as descrilied.

4- The combination of wheels A B, axle C, standard ". brace $\iota^{\prime}$, lever $F$, and lever-arc $L$, adapted to carry either tongue $\mathrm{I}$, arms $d$; standard $\mathrm{E}$, and lever $\mathbf{I}$, to operate a single plough with hores, or to carry arms $d^{2} e^{2} e^{2}$, standard and wheel $\mathrm{E}^{2} l^{2}$, and lever $T^{2}$, to operat a single plough with oxen, substantially as described.

No. 155,825 - T. E. C. 13RINIX, L.utisvilit, KY.Whet-Plowshs.-Octeber 13, 1874. Filed July 28, 1874 .

Claim.-1.- ln combination with a plough, the carriage, composed of the wheck i) $\mathrm{D}^{\prime}$, slotted uprights $\mathrm{E} \mathrm{E}^{\prime}$, verti cally-adjustable bar $\mathrm{C}$, with hanger $13 \mathrm{~B}^{1} \mathrm{~B}^{1} \mathrm{~B}^{3}$ and braces $F^{\prime}$ ir, and the vortically-adjustable wheel $G$, hehind the mould-lond of the plough, all substantially as anel for the pup se specifiel.

2. In cumbination with the beam of a plough, stsponded from a carriage such as describect, the seat $\mathrm{F}$ and foot-supports $b$ b, sulstantially as and for the purpose speci. ticul.

No. 155.871.-ROHERT N. HOWES, WILLIAM A. IN)RR, and J()SHUA B. WEBSTER, STOCKTON, C AL-

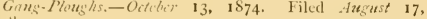
1374

Claim.-I-In combination with the standard $\mathrm{I}$ and caster-whed $u^{\prime}$, the side plate $y^{1}$, forming a support for the whecl and a seat for the scraper $y^{2}$, as sct forth.

2. - The adju-table traught-har $\mathrm{M}$, provided with the attachment-holus s and having the hent ends \%, which are aljintable in the guicles $r$, in combination with the timbers B C and brace $f^{\prime}$, all constructed and operating substantially ar above clescribed.

No. 156.128. - WA]. I. BROWN, I. (i. HAYZIETT, and BEXJ. F. SEATON, MARLN, IowA. - Gans-Pioughs. - Or obir 23, 1874. Hiled Flan:27, 1574 .

Claim,- I. - The combination of lever H, tongue J, curved brace $a$, and beam, E E', all arranged as deserilsed.

2.-The combination, in a sulky-plough, of the lever 11 $1)$, am $f$, rod $Q$, lotted screw $h$, bail $\mathrm{P}$, clamps $e$, standarils $l i s$, and plough-lexms $13 \mathrm{R}$, all arranged as and for the purpose sut forth.

Ni. 156,554-C11 S. T. ELLISTON, CINTON, Mo. - I'loes

Chim.-1. The comlination, with the axle A and tongue [), of the hent bar $G$, with upriglit lar $\mathrm{K}$ and plough-bean 11, all constructed subutantially as and for the purpose herein set forth.

2.- The combination of the roller $a$ and the morticel plisugh-loam 11 with the bar K, pansing through slot - in plough-beam and tonguc, ani frame ( $i$, subst.utially as shown anul tescriluerl. 
3.- The combination of the colter $\mathrm{N}$, hinged bar $\mathrm{O}$, linged pont 1 , and adju-table stirrups $S . S$, sub.tantially as and for the purposes herein set forth.

No, 156 924.-I. 13. HERMAN, BIAIR, NEIBR, - Whict. Ploushis:- Povember 17,1874 . Filed August 10, 1874

(laim.-1.-The combination of the lever $s$ and catch but $T$ with the two parts of the plough-beam $O$, substantially in herein shown and described.

2.-The combination of the slide $\mathrm{W}$, sliding bar V, ant and lock-lever $\mathrm{X}$, with the catch-arm T, lever S, and plough beam (), substutially as herein shown and described.

No. $157,119 .-E$ 1)ERWENT, JR, RO.KR(1RD, II.L. acignor to THOS. I)ERIIENT \& SONS, same place.-

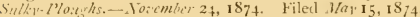

Claim.-1.-The combination of the cranked axle $\mathrm{A}$, hav. ing two paraild vertical portions, $a$, supported on two carry in - wheele, the crom-head 1 , fitted to slicle vertically on the two vertical portions $a$ of the axle, and plough-heam 1 , to which the plough $i$, attached by bill-and-socket joint, as and for the purpose set forth.

2.- The cranked axle $A$, cross-head $P$, plate and ball joint 1 , and plougt beam $\mathrm{I}$, in combination with the raising and lowering devices, an elescribed, and for the purpose set forth.

No. 157,372.-CH.IRIES F. CIIAMBERS, IIUTSUN

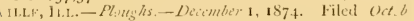
10,1874

ilaim.-1.-A A ulky-plough, whose plough propr, A C ('1), in pivoted in the bifure ited tongue E, and the point of whine plough-beam 1) in capable of being secured in the cam-yoke 1 J.

2.- The plough proper A B C D, whose bəan is bifurcat ed to receise a furrow-whed, $\mathrm{l}$, operating in rear of the share, and is contained in and pivoted to the lifurcated tomy⿺ $\mathrm{l}$.

3. - In a sulky-plou rh, the combination of the tongue $\mathrm{E}$ an. I heam I), each bifurcat al to reseive the furrow-wheel $\mathrm{F}$, with the extenion asle ( $^{\prime}$, and the harrow $\mathrm{K} S \mathrm{~S}$, on the furrow si.ke, ar and for the purposes sct forth.

I 57 8+2.-JNO. A. KNEED].ER, (IIANT, I'A. Sulky. Plorsh

Claim - The combuntion of crakk K, double crun': L contrecting-rod $\mathrm{M}$, aml lever $\mathrm{N}$ with hinged tongue $\mathrm{E}$, rigid bar $C$, and axle $B$, as and for the purnose deraibed.

No. 158,045. - WIIL1.1M 1)16 KIE, (iII.ESPE, JIL.-

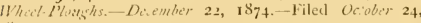
1874 .

Claim.-1.-The combination of the brackets (), atjustable pivoted arms $\mathrm{P}$, and acljust ille collars () with the plourh. leam J an I the croms rock J of the frame A P, substantially as herein shown and lescribed.

2.-The combination of the lever R, the lever-pawl S, and the notched bar $T$ with the plough-beam $J$, the forward pivotal arm 1 , and the forwaril crom-rod $B$ of the frame $A$ 1i, sub-tuti.lly as herein thown and describal.

3. - The branched spring standard $13^{\prime}$, in combination with the ros $1, \mathrm{~B}$ of the frame $A \mathrm{~B}$, for supporting the driver's stat $\mathrm{A}^{\prime}$, ant making it adjustable laterally, substantially as hercis how $n$ and described.

I5S o6g.-ROVAl. HINCE, PECATON:C, I1...-Gons.

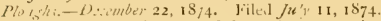

Clum. - The combination of the stationary wood axle 11 with perforated ent, the L-shaped notched plate N, protect ing said end, the angular axle-arm I I' J', with leverocket l, ri ridly attacheal thereto, the annular groove $\mathrm{Y}$ it the axle-arm $\mathrm{I}$, and the detachable $\mathrm{V}$-haped bolt $\mathrm{K}$, passins ar.unal the axle arm an I through the wood axle, all sub-tantially an and for the purpones set forth.

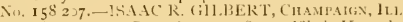

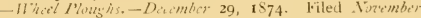
$5,187 \div$.

('lain.-1.-The extended syindle $\left(i^{2}\right.$, proviled with antric pias $i$ iat it, end, in combination with the braces II If' and ploush-beam $P$, as and for the purposes herein ret forth.

2.- The lever $F^{2}$, with its ratchet devices $f h$, rod $\mathrm{I}$ atticinal $t$, the lever, the spindl $: G$, and arm $K$, laving a wetet, all combineal ub tont ally as and for the purpone at fitts
3.-The bracen II II', bolted or secured rigidly to the ploush-beam, and pivoted to either end of spindle $\mathrm{G}^{2}$, for the purpose of holeling the plough-beam in place.

Vo. I 8 2:3 - II RSIIAL1, S. CURT1SS, EARLVILIE, It. . - Gans. IVoush.-December 29, 1574 . Filed May 27, $18_{74}$.

Claim.-I.-The adjustable draught-beam F, pivoted centrally to the cross-lar $6 b$, attached to the head of the longh-beams $G 11$, in combination with the cross-rod $i$, arranged in the slotted guilich s.5. and regulator $h$, construcled to operate substantiolly $a_{n}$ set forth.

2. - The rotary cutters $\mathrm{K} \mathrm{K}$, having their standards provided with the lngs $q$, in comlination with the arlustable socket plates $r$ and $r r$, pivited to the beam $(i$, plate $r, r$ having a recess or depression, s, constructed sub tantially as set forth.

3-The construction and arrangement of the beams (i $\mathrm{H}$, coulter socket $\sim r r$, coulters $\mathrm{K} \mathrm{K}$, with lugs $\%$, crossbars b i b b. carrying the forwari coulter, and to which the beam $\mathrm{F}$ in pivoted, cross-bar $a$ a, pin $z$, and plate $y$. or heel of draught-beam $\mathrm{F}$, sulhatantially as clescriberl.

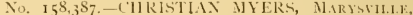

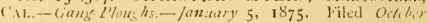
20, 1874

Claim.-In a gang-plough, the fixed axle C, provided with the aticulat'd crmi-jurnals 1), connect al by lin's E to the ends of the double-crants rocing shaft $I I$, provided

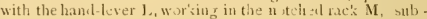
stantially in and for tixe purpones liereinlefore set forth.

Nu. I58735-- l'ETERSON I'RAIIL and FRANCIS

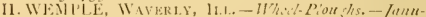
art. 12, 1875 . Filed deo'er 31, 1874.

Claim, - 1-The loove arm f, pivoted on axle 6 , and swiveled to rigil arm $\mathrm{K}$, as and for the purpone described.

2.-Th: combination of the arm $\mathrm{M}$, lever $\mathrm{N}$, lever-catch (), lever-1aw I', and notched bar (2, with the axle G, the arme I $\mathrm{K}$, au d the plough-beam $\mathrm{A}$, substatially as herein shown and deweriled.

3.- The arrangement of the transportins-whed $\mathrm{F} 11$, in connection with the plough-lucan 1 and plough $b, t$, enable both of said wheels to run iu furrows, substuntially as herein shown and decribed.

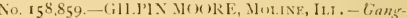

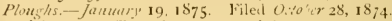

Claim.-1. - The asle constructed in two partr, the bent or arched inner ents of which overlap and are pivoted to each other, the fixe. 1 jrortion $A$ carrying the ratchet 4 har, and the movalle fortion ${ }^{\prime}$ ' carrying the flough-heams ind mechanism for rains, lowerint, and adjutins the ploughs, stebtantially as and for the purpose set lorth.

2.-The hand-icrer 1: contructed av describerl, with a foot on its lower ent, and arranged to operate with the lugs (b) on the hub of the supportin'r-whe', at:d with the ratehet-liar E, scctional axle $A A^{4}$, and plough-beam- 1) 1), subat.utially as Jescribed, and for the purpuace specitied.

3. - The rach-Lar $\mathrm{l}$, contructed as de cribed, with a diverging arm $f$, arranged to operate with the band-lever l: lugh $b$, sectional axle $\Lambda^{\prime} .1$, and plowih-beams (1) 1), sul)tautiatly as and for the purpone specifierl.

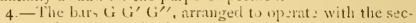
tional axle $A A^{\prime}$ and plomsh-beams i) b, sul,-tuntially as dencribed, and for the purpose specitied.

5.- The combination of $\mathrm{h}=$ tongue 1 , pionted plate $t$, and fixed plate J, the tongue secured to the plite $d$, so as to oncillate vertically and made adju-talse laterally, sul.-tantial y as and for the purpose set forth.

No. 159,642.-JAJ1E C. C.AR X4, M11.LRook, I1.1.-

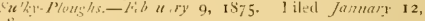
1875

Claim- - The comlination, with the frame $A$, arched asle 1 , plough-bean $k$, ant $p$, le $K$, constructel a describet, of the leve: I, "eatch $m$, perforated guile $n$, am lever $($, all constructed and operatins at shown and dencribed.

No. 159779 - CARKETT V.IN WIXK1.E, A WON, JI.L.

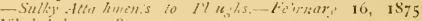
Filed $j u l: 22,18 / 4$.

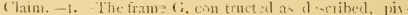

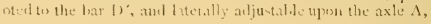




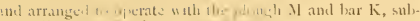
t.utially as and for the purpore foctiont.

2. The bus li, adjustally attachud to the bars a, and conblined with the axle .1 and bar 1$)^{\prime}$, for adjuting the plough-frame and atteching cultivat or-sulsatantially as deserilsed, and for the parpose specitiet.

3.-The draft-pole E, removably and rever ibly attuchesl to the bar i)' and axle A, and ar ranged twojerate with the said part-and with the cultivator-ploughs $l^{\prime}$ and frame $G$, interethan reably, suls.mintially as deseribed, and for the purpose speciliet.

4. The hand-lever $\mathbb{K}$, rac's $;$, $K^{\prime}$, and $K^{\prime}$, bar $\mathrm{J}$, sleeve 1 , an 1 ploush $\mathbf{M}$, in conbination with the pivoted frame 6 , axle .1, and har 1$)^{\prime}$, substantially as and for the purpose yecificil.

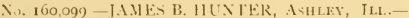

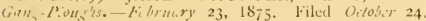
is; 4 .

(Ttim.- The combination of the fixed $U$ bar $G$, the slot1 . I vitically-aljustable forward stambard $\mathbb{K}$, and slotted rear standard $J$, with the axle $F$, the plongh-beams $A B_{\text {, and }}$ the tongac I, $\mathrm{a}$ - herein shown and discrib :1.

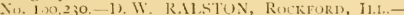

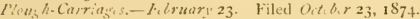

Claim.-1. - The arm or lever $\mathrm{C}^{2}$, comnected with the swiveled ploush-beam, as described, and proticied with the hand-lever (" and trealle ("), wherely the driver is enabled to raise the plough by the aid either of his hand or his feet, ur luth, as described.

2-The clamp which connects the plough-bean with the vertical swivel and bail, composed of the slotted angular plat: $\mathrm{F}$ and the angular bolt $\mathrm{F}^{-1}$, substantially as and for the purpuse set forth.

3.-The furrow-wheel stub-axle crank $K$, mounted upon the crouk-axle $A^{2}$, and hiving the eccentrically-stotted plate $A$ rigilly connected to it, in combination with the lever L, povidel with a pin for actuating the axle $k$, arranged and operating as tescribed.

No. 16,28$),-W I L L 1 A M$ 1\%, oUICK, ST, lous, Mo.

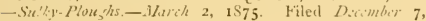
I 874 .

Claim,-1 - The plough-beam C, arranged in relation with the axle at in herein shown aud described, an! hinged loy its brace $c$ to the frame $\mathrm{B}$ and sub-beam $\mathrm{D}^{\prime}$ in the manner and for the purpose set forth.

2.- The combination of the adjusable frame $k$, its braces $13^{\prime} \mathrm{b}^{2}$, levers $b^{1} a^{2}$, rods $b^{\prime}$, and axle $a$, as herein shown and described, to operate 25 and for the purpose set forth.

Nis. $1,2 \mathrm{~S}_{\text {, }}$ S. S. SCHEUMACK, VICTOKA, TEXAS. - Giants-Ploushis-Wirth 23, 1 \$75. Filed Derember 12, $1 \mathrm{~S}_{74}$

Claim.-The plough-frame $\mathrm{A} \mathrm{A}^{\prime} \mathrm{E}$, and saddle 11 , having aiju-ting han sers $/ h \hat{h}$, and pivoted lraces $I 1$, combined wit. the axle $K$, as and for the purpose specified.

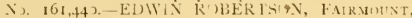

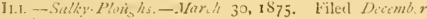
5. $15 ; 4$.

Claim. - The straight and stiff plongh-heam $G$, in combi nation with the diagonal brace $G^{1}$, buth pivoted and vertically adjurable by the mean and for the purpoie described.

No. 161,645-JAlllis T. WElLL, CorT Cotwry,

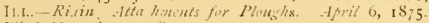

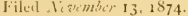

Clum.-1.-Bloci $c^{\prime}$, in combination with lever D', roul $c^{\prime}$, anl upright $l^{*}$, sulntantially as and for the purpose set forti.

2.- Tevers 1$)^{\prime}$ and $O$, upright $d^{\prime}, \operatorname{rod} c^{\prime}$, and block $c^{\prime}$, in combination with pieces $C^{\prime} C^{\prime}, 13 b^{\prime}, b b^{\prime}$, all constructed and arranget to operate suld-tintially as and for the purpose net folth.

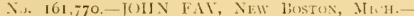
Swiky-l'ousls-ipril 6, IS75. Filed January 22, 1875.

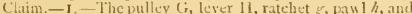
chain. I 1', in combination with the $t$ ngue and plough. lisam of a sulky-plough, cubtaritially as and for the purpose set futth.

2.- Th: combination of the bolt $a$, swivel $b$, guile-bar

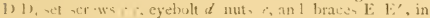

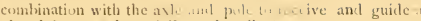
plough-beam, subatantially as clercibet.

No. 162,015.-BENTIMINS. BLNSON, BA1.TIMURE, M11, Ipril 1 3,1875 . Filed fanuary $16,1875$.

Clam.-1. - The combination, with a plough, of an in clined wheel, provided with a circumferential groove that receives and runs upon the projecting edge of the mplowet ground, substantially as and for the purpose described.

2. - The combination, with the plough-liem A and the axle 13, of the inclined grooved wheel $\mathrm{E}$, for the purpose of regulating the furruw, substantially as described.

3.- The combination, with a plough, having a detachable hecl picce, of the rear wheel $\mathrm{r}$, inclined to the rerticle plane and constructed on described, with a circumferential groove for the purpose of lightening the draft and rendering the plough self guiding, substantially as dercribed.

No, 9.5+9-BENJ. S. BENSON, B.LLTIMORE, MD., a4signor to HENKY A. SESMU(R, aaid SEYMOLR as

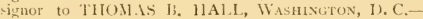

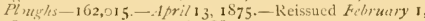
I8j. Filed Norimbir 16, is8o.

Clnim.-1.-In a plough -upported by carrying-wheels, the combination, with a supporting-axle, of supporting or carryin I wheels comecterl with the opposite ends of sail axle anil located on opposite sides of the plough, one of said whecls being inclined and arlapted to bear against the verti. cal wall of the unploughed ground, sulstantially as set forth.

2. - In a plough supported by carrying-wheels, the combiuation, with a supporting-axle, of supporting or carrying wheels connecterl with the opposite cnds of said axle and located on oprosite sides of the plough, one of said whecl being inclined and laterally adjustable and ulapted to bear against the vertical wall of the unploughed ground, sulstun. tiilly as set forth.

3.- The combination, with a plough, of an inclined wheel provided with a circumferential groove that receives and runs upon the projecting eslge of the unploughed ground, substantially as and for the purpose set forth.

4.-The combination, with the plough-bean $A$ and the axli 13 , of the inclined granved wheel $E$, for the purpose of regulating the furtow, suls tantially as clescribed.

No. 162,C94. - THOS. .I. NICHOL, SHARTA, IL..Gan.Plowstis.-Ipril 13, I875. Filed Oclober 24, 1874

Chaim - i. - The combination, with crank-axles $\mathrm{k}$, of the bent bar C, ling plates I), and bolts E, as and for the purpose deneribed.

2.- The co:nbin atioa, with the wivele:l plough-beam holiters or blocks N, of blocks $O$ and braces 1 , having a lateral adjustment, as and for the purpone sut forth.

No. t62.115-J. A. SUTHERLAND, E1.mwoom, IL..

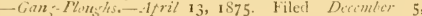
1874 .

Claim.-1,-In a four-whecl gang plough the axle-trecs B ( , having standards $d$, provided with pins $d$, in combinathon with bolsters $\mathrm{T}$ is and adjustable plough-frame $\mathrm{G}$, constructed to operate uhistantially as and for the purpere set forth.

2.- The combination of the adjustable plough-frame $G$, carrying the ploughs $1 \mathrm{~J}$, and coulters $1 \mathrm{~K}$, seat-frame (), bolster, 1 ' bolt-rod, $\mathrm{E} F$, yprings $f f$, itmalards $a$, pins $d$, and axle-tree li C, substantially as and for the purpose set forth.

No. 162,254.-i.ORING o. RO(KWOOD, OTTAWA,

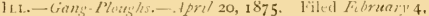
1875 .

Claim-1-1-The illiptical lever-frame E, recured in a vertical position unon the axle $\mathrm{A}$, and adjuntable unon it by the slicle $K$ and the collars I 1 , sibutantially ar and for the purpose set forth.

2.-The illiptical frame $\mathrm{E}$, in combination with the lever J, the lever I), and the lever $\mathrm{X}$, in the manner and for the purposes set forth.

3.-The illiptical frame $\mathrm{E}$, in combination with the plotgh-beams il $\mathrm{N}$, the slotted plates $\mathrm{N} \mathrm{N}$, the gaug -picce or clevi, $R$, the balauce-lever (2, the sway rod $S$, the sleeve $F$, and the brace rod $T$, in the manner and for the purpose set foith.

4.- The solid clamp O, having the ench cut away to $\mathrm{rc}$

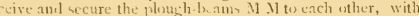




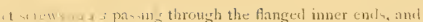

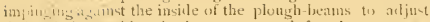
thein 1. lative pmition, in the manner and for the purpuses set forth.

No. 162,709.-E. J. SURAGUE, CASADAGA, N. Y.Cian:-Plourhi-tpril 27, 1875 . Filed fammary 2, 1875.

Clime-1.-The combination, with the loops F laterally acljutalule on axle $G$, and the stpporting-lusts $J$, of the aljustins scraw S, substantially as specilicl.

2.- In a gang-plough the combination, sulutantially as chesibed, of the clip-loups $\mathrm{F}$, extencling rearwally from the axle $(i$, the sottet loop $r$ secureal upon the front end of the plough-frames, the adjustably-connecting links 1 , and the vertically-adjustable screw $\mathrm{E}$, all operating substantially as asd for the purpone set forth.

No, 162942 -ORNAN OSBORN, TRUMANSBtRu,

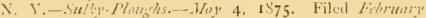
4,1875 .

Claim.-1.-The swinging frame, ensisting of the slese $f$, arms If 1 , and curved arm $I$, in combination with the plourh-beam $K$, pisoted to the arn $[$, and held by the loop $a$, all suls-tantially as herein set forth.

2.- The combination of the two-handled lever $\mathrm{P}$, having

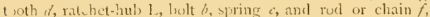
with the swinging frame $($; $1 \mathrm{~J}$, having losp $a$, and the filerurh-heam $K$, all substantially as and for the purposes hercin ec forth.

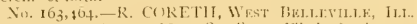

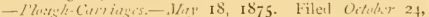
$1 \mathrm{~S} 74$.

Clam.-1.-The combination of the lever 1, having a link, $L$, with the carriage-frame $B$, having the ploush-frame $A$ attached to it, and with the haring or hanger $i$ of the axle $C_{\text {, sub }}$, antially as and for the puryose set forth.

2.-The comlination of the alju-table self-fartoning

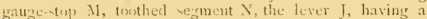
lin's, L, the carritse-frame B, hasing plough-frame A attached to it, and the bearing-hanger $E$ of the axle, substantially an descrilucel.

3.- The link 1. of the kever J, attached to the guiding lice of the haniser or becring $\mathrm{E}$ of the axle, nas to thip through sairl jiece, and thus give a bonger adju-tment than in reyuired for the movement of the lever at the time when the plough-frame is revolving, substantially ar and for the 1 thr onc describerl.

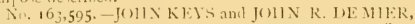

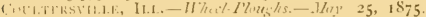
Vilet Eitw'un! 2 ), 1875 .

Clam.-1. The arched axle $A$, con-trueted with the yindle a b, in comblinatum with the shout comb-axlen C, confined hosily therean ly $u$ ut,$c$, in the manuer and for the jurpose herin stencriluel.

2 - The inle-bar J, pinted to the siden of the archerl axle, and conmected at their front cud by a pivated yoles, J', in comlination with to har $K$, hell-erink $k$ erer 1 , and a

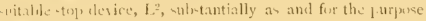

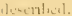

3. The perforated swive ling yoke $\mathbf{K}^{\prime}$ on the pivoted a de tha . I , in combination with the tmmin sleeve () $g$ on the wi ratius bux l, wherds the fromt and reat of the bean are ijput and allowed morement in a vertical plane.

4 - The c mbination, with the arched axle $A$, fun ane $G$, and phutgh II 11', of the $r$ ar and front - uy nding supports 1 I I'K an! the I-ver, I aml II, substantially in the man mir and fis the parpone duncribed.

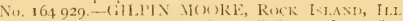

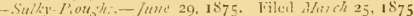

Claim. - 1, - In coml ination with a phatgh-leam sut sar rying 1 late, the werlge-sajesl 1-rojections, 1, inclines in

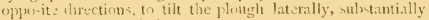
an shumen and pecilied.

2. - In a sulky-lotugh, the crank-axle C, having the arm (s arranged and piveted to the arch or frame $l$, and con nected with and snypoting the axi of the whed $K R$, eceatrically, sulutantially in the mamer and for the purgones il in:rilecil.

3 - The plate 6 , having the projection $a \quad a a^{\prime} a^{\prime}$ and inclines I, and hingeel to the arme $r c^{-1}$ of the crank-axke C,

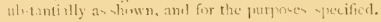

4 -The combination, with the han B, wif the plate $(;$ puniled with inclines I and prejectioss $a a^{\prime}=$ ubstantially ar and for the purpore sit forth.

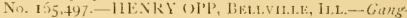
P'wa, hs.-July $1_{3}, 1875$. Filed .1.,y $1,18_{75}$

Clam.- I - The combination of the holts $\mathrm{E}$, the eyeplat in $F$, and the bars $G$, having crus-heads ujon their forward ends and shont transverse sots in thcir widened rear entis, wth the cros-lars 1$)$ of the frame ( 1 ), and with the plomgh-beam If, substantially as hercin shown and described.

2.- The combination of the chain $T$, the nawl $L$, and the matchet bar $l$, with the complex lever it $N$ () $v^{\prime}$ i) $k$, ancl the frame $\left({ }^{\circ}\right)$, subentially as herein shown and descrilsed.

3-The comlination of the lugged plate $X$, the stamdard

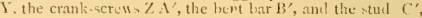
with the frame ( 1$)$, and the tonguc 13 , sulutantially an herein shown and rlecriberl.

No. 165653 - IIILIIAM K. AH.IEX, KANSAS CITY,

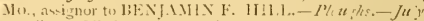
20, 1875 . Filed otiter $23 \quad 1874$

(laim.-1.- The fiame A, c.rrying me or more ploughthares B, fivoted to the axle $C$, the crombar $E$, spinu-far $F$, and the pisoted hand-lever $\mathrm{K}$, whereby the frane in cap. able of having cither a horizontal, vertical, or tilting motion, ulutantially as an! for the porpose sct forth.

2.- The $\mathrm{c}$ mbinat on of the nichlle beam ( of the frame $A$, ams the upright har $K$, extenling alose and below the saicl beam, and provideal with hole, as and for the purpere yrecitied.

3.- The lever $G^{\prime}$, the hra'ie-lever 11 ', the latch $N^{\prime}$, with

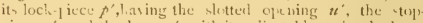

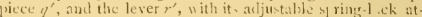
tachmesit $t^{\prime}$ located in front of the axle-haft $i$, cuml ined, arrangerl, and of crating as and for the purpeses pecilicil.

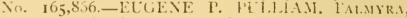

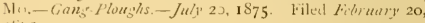
1. 75 .

Claim.-The combination of the series of gan $z \cdot p$ lough beam 14 , rigid rar bur 11 , pisoted fr.mt bor 1., and hlott al sudict-irm $E$, as shuwn and descritud, to enable the alt tucle of all tie beams on le imaltancourly regulated, in the manner at foith.

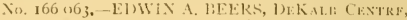
11.1.-Gans-1"Wughe-juj 27,1875 liled Juni 17 , 1875

Claim.-I - In comlination with the jointed loars II and $W$, the sha't S, proviled witi the ams $y$ and 1 , and fout-lever $\mathrm{p}^{\prime}$, and c sonsetel $t$, or with aid trax by menn of the rod $Z$ and $\%$, sulatantially as and for the purpene specitical.

2.- In combination with the plongh-tream $\mathrm{N}$ and $\mathrm{N}$, the

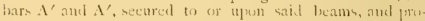

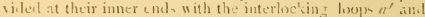
$a^{\prime}$, sul, $t$ untially as an.l for the purpose show 1.

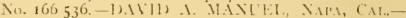

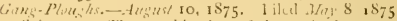

Chim. - I - The comlination of the man beam $A$ and crank-axle li swinging thereon with the governin rear shaft

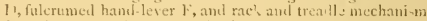
for rai-ing and lowering wheel, and resulditing the th of pluta he, - ub-tantially as set finth.

2.- The comlination of the rear crant-axle and sha' 1,',

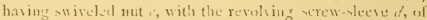

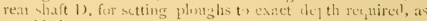
yrecitivel.

3.-The main fream $A$, in comilnation with firot

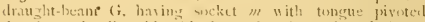
therein, and aljustable sil. lir.ec / to throw draugh-lram out of line of dranght and plengh- to or from the lane, a net forth.

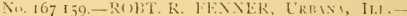

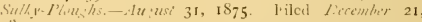
$1 \mathrm{~S} ; 4$.

Claim.-I - The lever D, poviled with fulcrum-irum d $t^{1}$, in coml ination $w$ ith the fuleram put.

2.- The enmetination of the followsug element the beam

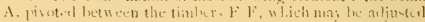


to any desirable point upon the axle $G$, the lever 1), provided with fulcrum-irons $d d^{\mathrm{l}}$, and the fulcrum-post $\mathrm{T}$.

3.- The combination of the followiug elements; the lever 0 , pivot 4 lo one of the timbers $\mathrm{E}$, timbers $\mathrm{L}: \mathrm{E}$, plough-beam $A$, lever 1 . cross-bar 5 , and tongue $P^{2}$, as shown and described.

No, 167.474 .-ELI W. RLSSEI.I, AsHI.FY, Mo.Sulky-l'ou,h-.-Siptimticr 7, 1875 . Filed Jun: 19, 1875 .

(laim-The combination of the adjustable beam $G$, the pivoted curved bar J, the rigid arm $K$, and the lever $L$ with the frame A I3 and the plough II I, substantially as hercin shown and described.

No. 167,857.-JAS. Flow, Pli.ot Poixt, Thx.-

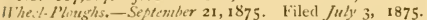

('laim.-In a wheel-plongh, the frame A B E, arranged with one sitle longitudinally adjustable ujon the axle $G$, in combination with the two sets of ngid guides $\mathrm{K} N$ and slotthd plough-beam J, whereby the plough is gauged to take more or less land. substantially as shown and clescribed.

Nu, I68.595.-S. F. WOODWORTH, RockroRm, ILI.* -Salky-Ploughs. -October 11, IS75. Filed Aug'st 2, $\mathrm{IS}_{7} 2$.

Claim.-1.-The crank-formed lever axle-arm E, composed of arms $c e^{\prime} c^{\prime \prime}$, brace $d$, and lever $c$, in combination with the internally-toothed segment ratchet $G$, as for the purpose sct forth.

2.-The combination of the anglc-lever J, segment-toothed ratchet $b$, link $k$, screw-clamping device $h$, and clirved guidebar 11 , for the purpose of rai-ing and lowering the plongh, and holdling it in position, substantially as shown and described.

3.- The toncuc $\mathbf{K}$, hinged to the plough-bcam between the axle and the clevis, substantially as deseribed, in combination with the guide $p$ lite $Q$, secured to the rear end of the tongue, to work in the grooved curved guideway $p$, secured to the clamping device $h$, the upward-projecting radial arm of clevi; $\mathrm{L}$, titlud to slide in loop $r$ on, tongue $K$, all these members being constructed and arminged to operate substantially as described, for the perjose of holding the tongue rigid with the plough-beam laterally, and to permit of a frec independent vertical movcment, as described and show $n$.

4.-The lever $\mathrm{M}$ and link $s$, in combination with the tongue $\mathrm{K}$ and clevis $\mathrm{L}$, for the purpose of tilting the plough on the axle, and holding it in the tilted position, substantially as described.

5.-The coulter $\mathbf{W}$, yoke $w$, clevis $y$, bars $v$, tube $z$, and yoke $i$, in comt ination with the axle and plough-beams ad. ju-table thereon, as described.

No, 163,646.-DANIEL KENDIG, NAPA CiTY, CAI. - Gang-Ploughs. - October 11, 1875. Filed July 28, is $; 5$

Claim--The semicircle or rack $\mathrm{B}$, in combination with the lever $C$, having the sliding Loves $D$ and $F$, and their connecting-arm $\mathrm{E}$, and the pawl $\mathrm{G}$, rod $\mathbf{I I}$, and operating lever 1 , the whole con-tructed substantially as and for the purpose herein described.

No. I69 313.-G. M. TOI)I, WATERLOO, lowa.Pioush Litichmints.-Octohr 26, I\$75. Filed Octobir 1, 1574

('lai $n,-1,-$ In a sulky-plough, the angular draw-bar $b b$, suspendel below the frame by the long bolts and sleeves $c i$, and braces $f f$ an: $a$ a, as set forth.

2.- The combination of the draw-bar $b \quad b$ and braces $a$ a with the sulky-frame, and with the plough-beams $c c$, and the adju-talle connecting-bars $g g$, substantially as shown and described.

No. 170,262.-FRANK A. HILL. SAN LEANDRO, C.Al.-Gung-Plunghs.-November 23,1875 Filed Aurtust 19,1875 .

Claim.-1-The standards F F, which support the shaft 1), ant to which the beams II M are secured, having the slot, h, throurh which the axle $A$ passes, in combination with the cranks $\mathrm{K} K$, connecting-bars I I, shaft $\mathrm{D}$, and lever $\mathrm{L}$, substantially as and for the purpose set forth.

2.-The lever 1 , crank-shaft D, link $c$, and crank-axle $A d^{c} c$, in combination with the slotted standards $\mathrm{F} \mathrm{F}$, cranks $\mathrm{K}$, links I, and plough-beams $\mathrm{II} \mathrm{M}$, all constructed an:I arranged substantially as and for the purpose described.
No. 7,204.-FRANK A. HILL, SAN I.ANDRo, CAL.Gang-Ploughs.-170,262, Nivember 23, 1875. Reissued $\mathrm{Ju}_{1}, 4,1876$. Filed . Way $23,1876$.

Claim.-I.-The standards $\mathrm{F} F$, which support the shaft D, and to which the beams II M are securred, having the slots $h$, through which the axle $A$ passes, in combination with the cranks $\mathrm{K} \mathrm{K}$. connecting-bars I I, shaft D, and lever 1 , sub tantially as and for the purpose set forth.

2,- The lever I, crank-shaft D, link $\iota$, and crank-axle A $d c$, in combination with the slotted standards F F, cranks $\mathrm{K}$, links $\mathbf{1}$, and plough-beams $\mathrm{MI} \mathbf{M}$, all constructed and arranged substantially as and for the purpose described,

3.-The vertically-grooved block or casting $\mathrm{P}$, perforated as described, and arranged to be adjusted laterally between the beams $\mathrm{II} \mathrm{M}$, in combination with the pole $\mathrm{O}$ and journaled plate $\mathrm{N}$, substantially as and for the purposes describad.

No. 170,487 -GEORGE MOOR, LAFAYETTE, OREGON. Sulky-P/i $u_{5}$ ks. - Noziember 30,1875 . Filed June 18, 1875 .

Claim.-1.- In a sulky-plough, the branched and curved plough-beam $\mathrm{E}$, having the slots $\mathrm{J}^{\prime} \mathrm{L}$, in combination with the rods $J$ and $K$ and the sleeve or spreader 1 , substantially as shown and described.

2.-In combination with the axle and frame, the branched beam E, curved hangers 1 , pivoted bar $F$, arms $C$, and rigid lever $A$, whereby the plough is held or raised in a horizontal or level position, substantially as shown and described.

No. 171,205.-JOHN WORRELl, Crayton, IND.Ploughs.-December 14, 1875. Filed liovember 27, 1875 .

Claim.-The plates $c c$, secured to the plough-beam 0 by means of staples and nuts $d$, and having pivoted between them the oscillating bar $e$, in combination with adjustable bearings $f$, arched har $\mathrm{D}$, and arms $\mathrm{E}$, pivoted to the vertical portions $a a^{l}$ of an arched axle, 13 , substantially as described.

No. 171,299.-J. R. MCCORMICK, GEORgetown, Trx.-Gans-Ploughs.-Decembir 21, 1875. Filed Oclober 9, $1 \mathrm{~S}_{75}$.

Claim.-1.- In a gang-plough, the beams E, pivoted to the rod $a$, in combination with the bifurcated connections $\mathrm{G}$, adjustable on rod $d$, links $\mathrm{J}$, adjustable arms $\mathrm{J}^{\prime}$, and lever $\mathrm{K}$, snbstantially as describerl.

2.-In combination with the front adjusting devices described, the links $l$, adjustable arms $l^{1}$ on shaft $I^{2}$, arm $g$, connecting-rod $g^{1}$, and adjusting-lever $s^{r^{2}}$, substantially as specified.

No. 171,427.-H. RLCHARDSON, JANESVILLE, IVIS. -Sulky Ploughs.-December 21, 1875. Filed Noventer 3,1875 .

Claim.-1.-The adjustable rod C, running from the axle A to the plate $\mathrm{B}$, and having the plough-coupling $\mathrm{D}$ placed thereon, substantially as and for the purposes herein set forth.

2.- The plate $\mathrm{E}$, carrying the spindle attachment $\mathrm{G}$, and made movalile on the axle, in combination with the adjusting bolts, plate $H$, and axle $A$, substantially as shown and described.

No. 172,025.-F. H. ISAACS, NEWARK, N. J.-Sulky Ploushts.-Jinuary 11, 1876. Filed October 14, 1875.

Claim.-1.-The ploughs $A$, by the lifters $B$, lung to the rovolving shafts $\mathrm{C}$, and the flange-stops $d$, in combination with the frame $\mathrm{D}$, substantially as and for the purposes specified.

2.-The ploughs standing at an oblique angle in the lifters, and provided with the scale-gauges $\mathrm{S}$, to graduate the width and depth of cut, and hung, one on the outsicle and the other on the inside of the frame, substantially as set forth, and for the purposes specified.

3. - The combination of the lever $H$, operating in the semicircle $\mathrm{l}$, rods $\mathrm{G}$, cranks $f f$, rock-shafts $c c$, arms $\mathrm{B}$, and ploughs $\mathrm{A}$, whereby both ploughs are operated by one lever, substantially as and for the purposes set forth.

4.- The ploughs $A$, lifters $B$, shafts $C$, and weight $M$, in combination with the lever $H$ and connecting-rods and cranks $G f$, arranged substantially as shown and described, and for the purposes set forth.

No. 172, 103.-ENOCH C. EATON, PinckNevilile, I1.L.-Gan Ploushs.-Janutry 18, 1876. Filed Oitobir $2,1 S_{75}$. 
Claim.-1.-The couplings F, the levers G, and the $\mathrm{U}$-bars $\mathrm{H}$, in combination with the frame $\mathrm{C}$ and the plough-beams $\mathrm{I}$, substantially as herein shown and described,

2. - The combination of the guides $\mathrm{L}$, the ratchets $\mathrm{M}$, the lever-pawls $\mathrm{N}$, the bent levers $\mathrm{O}$, and the links $P$, with the levers $G$, and the frame $C$, substantially as herein shown and described.

No, 172,825-PIIHLONAS PATTYSON, PLEASANT

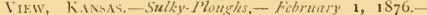
Filed Oetobe' 26, 1875 .

Claim.-The bars $\mathrm{E}$, having perforated ears $\mathrm{E}^{\prime}$, the swiv eled post $c$, with its elevis device $c$, and the friction-pulley $e^{\prime \prime} ;$ in combination with the angular lever $\mathrm{F}$, or its exuiv alent, and with the plough-beam and frame, all constructed substantially as shown and describel.

No. 173,138 .-MARSIIALL SATTLEV, TAYLOR-

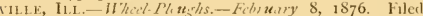
Noticinticr 8,1874 .

Claim.-1.-In a ricling.plough, the combination of the main frame $\mathrm{A}$ \& $h i$, with the vertical bars $e e$, rectangular frame $j$, and diagonal braces $k$ i, substantially as described.

2.- The diagronal traces $k \mathrm{k}$, slides $l /$, pivoted har $m$ and pixoted draft-bars $f /$, in combination with the plough beam l', and perpendicular bars $e$, substantially as de scriberl.

3.-The comlination of the bell-crank lever $n$, pivoted draft-bar $f$, plough-beam 13 , pivoted bar $m$, slides $l$ l, and diagonal frace $k \cdot k$, substantially as descrilsed.

No, $173,264,-$ KAMUEL IBRTAN, TWIN GROVE, Wis.

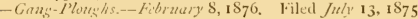

Claim,-1.- The plough-standarels 1 , extending up thromigh the julough-frame, and pivoted to the top of the stand arels $f_{i} 11$ aliove said frame, substantially and for the pupose described.

2.-The spring-clasps $\mathrm{J}$, combined with the benms $d$. long spring metal plough-standards 1 , and standards $G$ H, sulstantially as and for the purpose described.

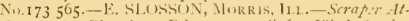

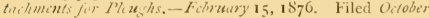
$23,18_{75}$

Clain.-1 - The combination, with scraper plate $A$ and standard $\mathrm{C}$, of the connecting-plates $\mathrm{B}$ B, rigidly fastened to the former, and pivoted to the latter, as and for the pturpose described.

2.- The combination of plates $\mathrm{A} \mathrm{B}$ aud standard $\mathrm{C}$, the former pivoted to and projecting lehind the latter, with a cress-pin, 1 , and wedge $\mathrm{E}$, to adjint pitch of scrapers, as set forth.

3.- The combination, with scrapers $\mathrm{A}$, attached to pivoted plates 13 , of standards $C^{\prime}\left({ }^{\prime}\right.$, cross-lar $H$, and braced 1 , all fourty connected, ns and for the purpose specified.

N), 171.679.-W. I. SLALGIITEK, GREENHE D, ILI.

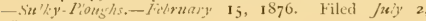
$18-5$.

Claim. - I - The combination of the plane $\mathrm{F}^{\prime}$, pulleylever II, yokes ( and I), and l lough E I, subtantially as leserilued-

2.-The combination of the plane I, pulley-lever 11, yolkes C and $\mathrm{D}$, and plough E 1 , substantially as described.

3 - In a ploug h, the lever II, proviled with the pulley G, in combination $\mathrm{with}$ the planes $\mathrm{F}^{\prime}$, and $\mathrm{J}$, substantially as describ:t.

No. 174343 - S.ANL. T, ADAMS. MEINA, OHIn,-

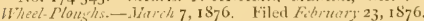
Claim, - I - The carriage-frame $\ell$, luaving the crooked axie Is rigitily, but aljustalily, sectred to it, and having the draft-pole 1 ) pitoted to it front rod $a$, in combination with the lever $E$, its toothed segment $G$, the lever $K$, and its anti friction rollet b, subutantially as described.

2.- The conlination of the clasp 1 , provided with the stauclard f, clio is, wa-her h, and collars $y$, with the rear rod $n^{\prime}$ of the drait-frame (; subrtantially as descrilsel, and for the purpese set forth.

Niv, 174416 - ENOCII C. EATON, PINCKNEYIILF,

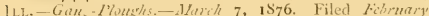
14,$18 ; 6$.

Claim,-1.-The combination of the post A. brace 1 ,

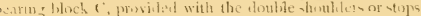

$C^{\prime}$, and the lever $\mathrm{D}$, provided with the hooks E, to adapt the device for attachment to the frame of a gaug-plough for raising the ploughs, substantially as herein shown and described.

2-The combination of the biock $\mathrm{H}$, provided with the slot $h^{1}$ and hook $h^{2}$, and the clamping-screw 1 , with the axle ( $r$ and the frame $F$ of a gang-plongh, substantially as here in shown and described.

No, 174.473,-LEROY CAHILL, KAIAMAOOO, MICH. - Whool-1\%ughs.-March 7, 1876, Filed March 2, 1876. C'aim.-I.-The combination of the frame, convisting of the perforated hars A D and C C, sejarated by the side bars $\mathrm{B}$ l3, as described, the perfornted tongue $S$, and pins $z$ $z$, wherelyy the tongue may be shifter from the centre to the side, and a'ice i'ersa, all constructed substantially as set forth.

2.-The combination of the platform $\mathrm{E}$, with slot $a$ and foot-rest, the seat $G$, double-spring suprom, II $1 \mathrm{H}$, and bolts b b, to adjust the seat back and forth, as berein set forth.

3.-The combination of the hangers $\mathbf{I}^{\prime} \mathbf{I}^{\prime}$, crank-axle I, with perforated disk $\mathrm{L}$. bolt $h$, nnd nut $i$, as and for the purposes herein set fortin.

4.- The combination of the frame A I) C C, having shifting tongne, and with extonded bar 13 at one side, the the hangers $m \mathrm{~m}$, hail $\mathrm{M}$, having extended arm, the link $\mathrm{N}$, pipoter to the front end of the bail, and to the lever (), which is pivoted to the formard part of the extended bar I?, nll constructed substantially as and for the purposes hercin set forth.

No. 175.870-RAI.PII D. RUSII and EPIIR.IIU IV.

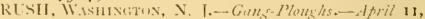
1876. Filed Janutry 24,1876

Claim,-1.-The comlination, with a slotted ploughbeam, of phench, having a standarel provilcal with holes $e^{2} c^{2}$, the pin $\mathrm{E}$, pivot $\mathrm{E}^{\mathrm{j}}$, and adjustable link $\mathrm{E}^{2}$, substa11tially as ret forth.

2. - The comlination of the whech $\mathrm{A} A$, the axle $\mathrm{B}$, the plough bean C. the removalble beam C', and the benm ("), provided with two slots, $c^{2} c^{3}$, whereby the jloughs may be arranged for ploughing corn, or as a gang-plough, at the oftion of operator, substantially as set forth.

No, 175-937-EINGAKD S. BECKELHIIIER and IIUGII II. CAN.IDAY, FAIRHEII, IW.I- Cims-

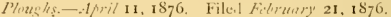

('lam.-The combination of the hent levers $\mathrm{R}, \mathrm{O}, \mathrm{P}$, and $\mathrm{N}$, and the chains ( ) and M, with the plough-lxams ( $i$, the coupling-bar $T$, and the carrige $A$ if C sulutantially as herein shown and described.

No. 175,921,-EIDIUVD C. BR(IVN, ANTELYE, CAL.

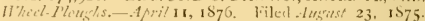
(Claim,- In combination with a plongr, having the pole Gisecured to a journaled plate $f$, and it rear end engaged with a slicling cating, $('$, the lever $I I$ am l plate I, with it: holen $t /$ and $m$ and the horiontal racks $/$ and $I$, subutantially na and for the purpose descriled.

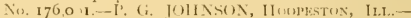
Ilousts. April 11, 1876. Filed Therth 4, 1876.

Claim.- The combination, with the flough-lxam and the b.nt lever ( $i$, pivoted to the frame anul provided with an arm, I1, estending upward, as hown, of the rutating slecve $s$, the clamping cyeloolts $c$, nnd plate $f$, all as and for the purpose ineciliect.

No, $176350,-$ WILL1AN W: PLSEY, C1BA, I11.. as-

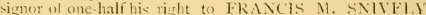

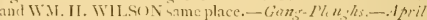

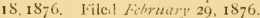

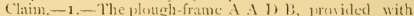
stantards I I, cross piece II, carrying the adjustrble wheel frame II II $\mathrm{L}$, screw $K$, and wheel $E$, suhntuntially as and for the purpores descrilsed.

2-The com! ination, with the plough-frame of the plourls. beame () (), pisteted at their fromt ends upon the crems-rod l?, the adjustable lints V, leveri ?, and horizont al locking-de tents if, as and for the purpores clescribed.

3.-The tongue U, hasing the hed/, and pivistet upon the

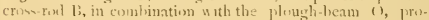
viteal with the simur $u$ and the lever (1) Jecting upon the 
Fioss the II of the frame, whereby the ploughs are held thove the ground, as shown and deseribed.

4. - The combination, with the lever () () and the plough beams () (), lat rally adjustable upon the pivat-rods $13 \mathrm{k}$, of the elevated frame I II $i$ hand cross-brace $k$, as and for the purposes dercribed.

5.-The slotted recessed cles is or pivotal recess o 0 and lide of holt $\beta$, substantially ats and for the purposes deveriber.

Nis. $176.595-M() R T 1 M E K($ CIIILL and AMOS F.

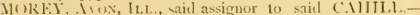

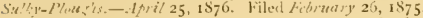

Claim.-1,-The skeleton frame A A, comprosecl of a tongue with arms hranching to the rear, having the hang $r$ 5 and circle-plates ob in combination with the levers $C$ C, catended to furm crank-axles $c e$ and spring-catches 1) D, uib.tantially as shown and deseriber.

2.- The combination of frame .1 . A hangers $y^{5}, 5$, levers $C$ C. and circle-plates b b adapted to carry the rectangular frame 11. -upporting a plough-beam, or the double-jointed couplings $i$ attached to cultivator heams, constructed and arranged to eperate substmitilly as and for the purpose set forth.

No, 176.836.-W. I. CASIIDAY, NEW CARLISLE,

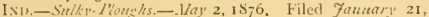
$18-6$.

Claim.-1-The skeleton axle $\mathrm{C}$, united $\mathrm{l}$, the vertical prots $i c$, and having a fixed wheel-spindle at one end, and at the other end a spindle capable of oblique vertical acljument, wherelyy the whed is adjusted to stand vertically, or at an inclinet angle from the other, substantially as shown and described.

2.-The skeleton axle-tree $C$, provicled with the guidebraces $c c$, in combination with the slotted plates $e c$ sliding thereon, aut with the plough-beam or beams $\Lambda$, wherchy the plonghs are adjusted to any desirable depth and width of furrow, sub-tautially as shown and described.

3. - The combination of the beam or beams 1 , plates $i c$

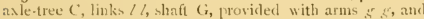
lever H, wherely the saicl axle-tree in operaterl, subiatially in the mambr hereinbefore descibed, for the purposes set forth.

4,-The block $d^{\prime}$ swiveled vettically upon the axle $a$, and held at any aljustment thereon by set-screw $s$, in combina tion with the whecl-ypindle $d^{1}$ placed at right-angles there with, the two adjustably connected by the ratchet-divis, wherely the wheel I) ${ }^{2}$ may be adjusted to various angles to the axle, substantially as shown and described.

5.- - In a sulky-plough, the wheel $\left[\mathrm{z}^{2}\right.$ provided with an angular pointed rim, $r$, in combination with the frame $C$ C having the acljustalle spindle and axle $a$, an.l the wheel sy indle $d^{1}$, substantially as shown and described.

i. 7.9+3-IVILLIAM L.. ('ISIII), NEW CAR-

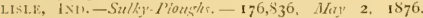

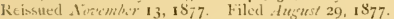

Claim.-I-A sulky-plough, one of the wheck of which iv adjustable to an inclined position from the vertical sulstatially as and for the purposes described.

2 - The skeleton axle $\mathrm{C}$, united to the frame or axle poper by the ponts $c i$, and hasing a fixed wheel-spindle at une end and at the other end a spindle capable of oblitue arlju-tment, whereby the wheel is adjusted to stand vertical or at an inclined angle from the other, -uhatantially as show $n$ and deacribed.

3.- The -keluton axle-tree $C$, provides with guide-l races c, in combination with the slotted plates ic elidiner thereon, and with the plotigh-beam or beams $A \wedge$, wherely the pl sugh are adjustalile to any de-irable dejth and width of furmw, substantially as and for the purjose described.

4 - The combintion of the beam or beam . 1 A, latew

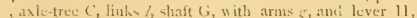
whereby the sais plough is oprerated, sub-tantially in the manuer and for the purpone set fosth.

5.- The libek $d^{2}$, swiveled upon the axle $a$ and held at any point of aljustment thereon lyy set-xcrews s, in comlination with the whect-ypindle $d^{\prime}$, placed at iggt angle: ther with, the two adjustably connected loy ratchet disks, wherely the wheel 1$)^{2}$ may he adjuted to rarious angles to

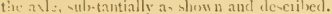

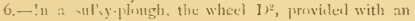

angular pointed rim, $r$, in combination $w$ ith the frane $C$, having the aljutable spindle and axle $a$, and the wheelspindle $d^{1}$, suldatantially as shown and decribed.

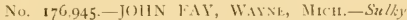

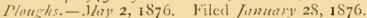

Claim.-I.--In a sulky-plongh, the combination with the frame () and bean ( of the axles b, having arms adjustalie in either ent of the said lseam, the brace-rocls J J, and the plates $/ i$, sulstantially as described and slown.

2.-The combination of the guide $\mathbf{E}$, haterally adjustable at the upper encl, with the crankesl shaft $b$ and lever $c$, substantially as described and shown.

3. - The combination with the frame $D$ and beam $C$ of the vertically-adjustable axles $\mathrm{B}$, the gang of ploughs $\mathrm{G}^{\prime}\left(\mathrm{i}^{\prime}\right.$, the lever II, and the clains I $I^{1} I^{2} I^{3}$, all subiantially as described and shown.

No. 177.078, - TIIUMAS RICIIAKIJUN and MAL CUIM MCINNES, FERGits, (ANAD.1-Gan Plaus/ls. - May 9, 1876. lilied Aurch 13, 1876 .

Claim.-1.-The frame of a gang-plough, composer of the rails $\mathrm{A}, \mathrm{B}$, and $\mathrm{J}$ and brace $\mathrm{K}$, in combination with the clevin-block $T$ ' and the plough-standard $\mathrm{E}, \mathrm{F}$, and $\mathrm{G}$, having shonlders and flat shanks, as shown and described.

2.- The bell-crank 1', having holes $f$ pierced in one of its arms, as shown, and connected to the cranked axle 1 . hy the rod $K$ and lever $S$, in combination with the $\operatorname{rod} Q$, quadrant 0 , hand-lever $\mathrm{N}$, and cranked axle $\mathrm{M}$, arranged and opernted subutantially as and for the purpose specified.

No, $177,562,-W$. A. KUDDICK, CARTHAGF, Mก.What-Ploumls. - May 16, 1576. Filed Jarch 21, 1876 .

Claim.- The V frame li C, vetically adjustable casterwhecl $\mathrm{l}$, vertically adjustable wheel $\mathrm{E}$, and the vertically adjutable tougue $F$, combined and arranged with the plough, substautially an specified.

No. 177.975--TOSEPH WARWICK, FRANKLIN, OHI, assignor of two-tivirds his right to MIOSES SNITII and

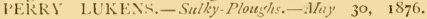
Filed Oriober 9, I 875

Claim.- The sotted hinged frane $\mathrm{F}$, in combination with the inclined self-adjunting yole $d$, to which the plough is connected, subtantialiy as and for the purpose described.

No. ${ }^{3} 7^{8} 523$ - WILLTAM HENRY, TRFNTON, Mo, as ignor of one half his right to GE()R(il: W. NOOliERLY, same place. - Sulky. I'lusghs. - June 13, 1876. Filed Jan-

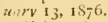

Claim.-1n a sulky attachment for plough, the combina. tion of the cranked axle $A$, strengthening keeps or clutches $\therefore$, tongue $G$, and lever 1 , whereby the pitch of the axle $A$ nay be adjusted at the will of the operator, substantially as and for the purpose hereinluefore set forth.

No, 178,524 -WILLTAM HENRT, TRENTon, Ilo. assignor of one-half his right to GE()RGE W. NO(J)ERLY. same place.-Sulky. Plough h. - June $\mathbf{1}_{3}, 1 S_{7} 6$. Hiled Diwimber 17,1875 .

Claim.-In a sulky attachnent for ploughs, the combination of the double axle-tree $k \mathrm{k}$, luving -et-screws $x$, with the downwarilly-projecting cating (', having lots $y$, by which it position relative to axle $\mathrm{K} L \mathrm{~L}$ may be adjusted, substantially as and for the purpose hereinlefere set forth.

No. 178558 . - IOHIN D. RAI.STUN, KOCKWRD. IU.L. assignorto himself and II. H.ARVEI, prome place.-

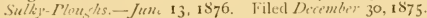

Claim, - 1 - The combination of base-plate 13 and clauping-plates C, corrugated, unlutantially as descrilsed, and clampling holts /, operating to clamp the plough-bean sidewise, and to adapt it to plough-berms difiering in whitsls and to plough cutting furrow's of lifferent widths, suhstantially as hereinbefore sct forth.

2. - The has-plate 1; and side climping-plates $C$, corrugated, sub-tantially as described, clamping-bolt $>l$, and clamping-liar $\mathrm{E}$, in combination with the box $\mathrm{A}$, swiveled theretu liy king-bolt connection, substantially as and for the purpose bere inbefore set forth.

No. 179,014.-IU11N W. GR1MES, AIPLTOS CITV.

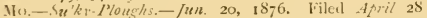
1376

(laim.- The slotted elraft-bar 1), jis oted to the pendant 4 of the frame 13, in enmhination with the plough-fream $c$. 
and mechanism $a$ d e f $C$, for adjusting the same vertically, as shown and described.

No. 179,094 -ANSON T. BUTTON and SAJUEL J. LUNDY, UXBridge, CANaDA, - Gang-Ploughs, - June 27, is 86 . Filed . Horch 7,1876 .

('laim.-1.-In a plough, the shares $\mathrm{B}$, having the arns $b$ and $b^{\prime}$, the former extending upwarl perpendicularly from and on a line with, and directly over the land-side of the share, and the latter extending laterally from the base of the former on the land-side of the share, whereby when the beam $\mathrm{A}$ is secured in the sent thus constituted on the share, the land-side of the share will be on a line with the furrow sicle of the beam, as described, and for the purposes specified.

2.-In a gang-plough, the combination of the guide-wheel C on axle $c$, carried by swivel-arm $c^{\prime}$, the bar $\mathrm{D}$, with its female screw $d^{1}$, the slotted upright bracket $\mathrm{F}$, male screw $e^{1}$, crank $c^{2}$, and cam-lever $d^{2}$, all arranged to operate as and for the purpose specilied.

3.-In a gang-plough, the slip draw-clevis $\mathrm{F}$, having the key $f$, with its rearward-opening slot $f^{\prime}$, the chain $g^{2}$, bolt $f^{-3}$ and nut $f^{4}$, arranged to op rate for the purpose specified,

No. 179,291.-CHAS, FRA.NK, FRERHUR;, I11..-Combined Plourths and Cultizutors.-June 27, 1876 . Filed Wurch 6, i875).

Claim.-1. - The inclined shoulders $f^{\prime}$, formed upon the outer sides of the rear parts of the side bars of the frame $\mathrm{F}$, to receive the arms of the lifting - bar $\mathrm{P}$, snbstantially as hercin shown and clescribed.

2. The combination of the hook-bolts $\mathrm{II}^{\prime}$ with the tongue $L^{\prime}$ and the cross-bars of the frame F, for securing the said tongue to saicl frame adjustably, substantially as herein shown and described.

3.- The combinat on of the hook-lever $\mathrm{B}^{\prime}$ and the flanged pulley or roller $A^{\prime}$ with the frame $\mathrm{F}^{\prime}$ and with the liftingbar $\mathrm{f}$, with which the plough-beams arc connected, substantially as hercin shown and described.

No, 179,545.-WIIIIAM EVANS, MULINE, IIL.assignor to the Mol.iNe l'Lough CoNPAxY, same place.Wheel-13lus hs.-July 4, 1876 . Filed April 15, 1876 .

Claim.- The combination, in a sulky-plough, of the two crank-shaft, $\mathrm{E}$ and $\mathrm{F}$, with the pulley's $o$ and $n$ and the chain $\mathrm{S}$, or it equivalent, all arranged to operate substantially as and for the purjuse set forth.

No, 179761 - - L. D. BOWWAN, BEDFORD, TENN.Sulky-Ilougris. - July 11, 1576. Filed April 1, 1876 .

Claim,-In a g.ıng-plongh, an apperatus for elevating or depresing the ploughs, consting of the combination of the rock-shalt $c$, hand-lever $\mathrm{J}$, notched rim $\mathrm{k}$, link $i$, ratchet wheel $\mathrm{H}$. and pawl 1. l, sulotautially as described.

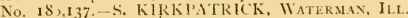
-Gans-Plousths-July 25, 1876 . Filed Mity 26, 1875

Claim.-1.- The combination of the hatger $\mathrm{F}$, pivoted to the ton:sue-frame, and provided with an aulju-ting-slot, tightening-bolt for fastening the hanger, and plough-lyeam $G$ suppoited in the banger, all constructed and operating as de scribed, for the purpose of arljuting the rear end of the plough-beam laterally, sulstantially as set forth.

2.- The combina ion of the plough-beam $G$, fivoted coul ter plate Z, and curved coulter standard, all constructed and opcrating as described, for the purpose of holding the coul ter-stamdard to the plough-leam, and adjusting it thereon, sulust.untially as set forth.

No. $18,46+$-MARSIIALLS.CURTISS and EDGAR W. CURTISS, BRADFORI, ILL., assignors of one-third their right to J. B. DOYLE, same place,-Gang-Ph $\boldsymbol{u}+\mathrm{t} / \mathrm{s}$. Ausust 1, 1876. Filed December 29, 1875 .

Claim 1-The lifting link 1 , provided with the pivot jiu $g$, connecting with the arc-headed bar $\mathrm{E}$ and slot $u$, con necting with the pin $j$ of the lever $\mathrm{H}$, in combination with the arc-beaded lever $E$ and the lifting-lever $H$, substantially and $a$ ifor the purpose described.

2.-The lifting. link $\mathrm{F}$, provided with a slot $u$ and pivot g, the arc-headed bar $\mathrm{E}$, its bearing-slot $/$, and the liftin' lever 11 and it; detent-jaw $h$, substantially arranged as described.

3.-The plough-beam $K$, provided with the loop $t$, in comlination wilh the lifting-bar $v$, and with the slotter link F, archeaded b.ar E, keeper l, lever H, pins $j$, and with the frame, sulstanti llly as shown and lescribed.
4.-The combination, with the coulter-stem $p$ and its sta1.le, of the set-screw $q$, as and for the purpose described.

No. 180,624.- WILLIAM B. NEWMAN and TILl)EN J. WILKINSON, WARRENSHURG, Mo.-Ploughs.-Auyust 1, 1876 . Filed May 13, I $\delta 76$

Claim.-The combination of the plough-beam E with standards $f f$ and guide-toop J, the pivoted tongue $\mathrm{H}$, straps $i h$ forked lever $K$, and ratchet and pawl $k i$, as and for the purpose set forth.

No, 181,20 , JOSEPH II. HAYNE, DALI.AS, TEXAS.

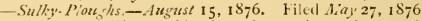

Claim.-1, - The combinnticn of operating and suspeuding lever 1 , with stirrup $K$, spring $O$, and plough-beam $G$, substantially as st forth.

2.-The combination of iraft-rod $\mathrm{P}$, plough-leam G, guide-loop $k$, and p rforated link $h$, substantially as described, and for the jurpose set forth.

No, 181,931-EWWIN A. BEERS, IH KILI CENTRE, II.L.-Gan'-Plonghs. -Seplember 5, 1876 . Filed junc 2, 1876 .

Claim.-1.-In combination with the bar W, the pole $\mathrm{V}$, provided at its rear end $\mathrm{w}$ ith the forked plate V', which is pivoted upon stid har, and the adjustable collars $w$ and $w$ placed around the latter, ant bearing against the forked eats of said plate, substantially as aud for the purpose specificel.

2. - In coml ination with the $m$ in franes, the axle tite $C$, provicled with the crank portion $c$, journaled within the plates $\mathrm{B}$ and $\mathrm{l}^{\prime}$, and having secured upon one end a radial anm, $\mathrm{D}$, that cont lins the axle-arm $d$ of the ground-whecl $\mathrm{E}$, substantially as and for the purpose shown.

3.- The axle-tree $\left(C\right.$, the arm I) $d$, the main frame $A, A^{\prime}$, $\mathrm{B}$, and $\mathrm{L}^{\prime}$, and the plow-fiame $\mathrm{L}, \mathrm{L}, \mathrm{M}, \mathrm{N}, \mathrm{N},($ ), and $\mathrm{k}$, constructed and combined in the manner and for the jur ose set forth.

4.- The plow-frames, consi ting of the leams $\mathrm{L}, \mathrm{L}$, and $\mathrm{Ml}$, cross-bars $\mathrm{N}$ and $\mathrm{N}$, di-k $\mathrm{Q}$, plate $K$, and fivotal bolt, all combined to operate subsatitially as and for the furjese shown and described.

5.- In combination with the plow-frame, hinged to or upon the double-crmak axle-tree $c$, the quaciant \%, having the radial slut $t$ and shoulder $l^{\prime}$, the lever $U$, and the bar U', substantially as and for the purpose specificd.

6. - In combination w ith the man frame, the carter-beam I, pivoted at it front end to said frame, forward of the axle, supposted at it, rear end, in rear of the flow's, ly a carter. wheel $k$, and having at such end inde pendent laternl motion, substantially as and for the purpose shomn.

No. 182,248 - IV. A. VANARSIILL, NCAFEF, KY,Sulki-Pluaghs.-Siftember 12, I876. liklcd Jantaily 22, 1876

(laim.-1- The combination of the axle-tree $\mathrm{b}$, slotted 1.-slraped iron $\mathrm{E}$, wheel-stindle $d$, with collar $\epsilon$, box $\mathrm{G}$, with rod $h$ and nut $f$, substatitially as and for the puryose hercin set forth.

No. I82,569.-THOMAS B. FAGAN, VAN WRRT,

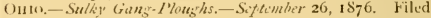
Ausust $7,1876$.

Claim.- In a sulky garg-plough, the combinition of the axle secured obliquely to the tongue, and of curved and slotted guide-bars attacbed thereto, with the swinging ploughbeams, substatially in the mamer and for the | urpose set forth.

No, I\$2.735.-EDNILNO b. REINOLIS and ()I.I.

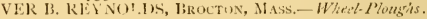
- September 26, 1876 . Hiled Murch 13, 1S76.

Clam.-I. In a litting device for ploughs, the toggles $m$ $m^{\prime}$ and bar $A$, in combination with the bars 99 , sulstantially as and for the purpose set forth.

2. - The toggles $m m^{\prime}$ and bar $\mathrm{A}^{\prime}$, in comlination vith the bars 99 arms 1010 , and shaft $\mathrm{I}$, substatially as and for the purpose sct forth.

3.- 'he slotted arms $c e$ and beams $f g$. provided with bifurcated cncls, in combination with the bars 1212 arms $e^{\prime \prime} e^{\prime \prime}$, and shaft E, subutantially as and for the purpose set forth.

No, $182, S_{20}-$ E. T. HUNTER, IIAIISVII.LE, II.I.Wher\%-Plu ush.-Oitober $3,1: 76$. Filed ju'y 22, is 76 .

Claim.-1.-The comlination of the axle $(;$, provided with the cranks $y^{2}$, the lever $O$, the be ol-rod $d^{\prime}$, thit netched 
bar $\mathrm{P}$, and the cotpling $\mathrm{QR}$ with the bars 11 , the wheels $F$, and an ordinary plougl, substantially as herein shown and described.

2.- The combination of the reversible board I, provided with the slotted currugated plates $\mathbf{K}$, and the tongue J, proviled with the corrugated plates $\mathrm{L} \mathrm{L}^{\prime}$, with the bars $\mathrm{H}$, at taclied to the axle $G, s^{1} 5^{2}$, substantially as herein shown and deseribed.

Nu. $18,178,-J O H N$ L. LAUGHLIN, PERU, ILL.Sulky-Plowghs.-Ociolier 10, 1876. Fited June 23, 1876.

Claim. - 1.- The combination of the U-shaped frame $F$ and the plungh hung to the central portion $d$ of the same, with the pivoted lever H, from opposite ends of which the arms $c^{\prime} c$ of the said frame are suspended, substantially as deseribed.

2.-The combination of the lever $\mathrm{H}$, hung to the frame $A$ of the plough, with blocks $\mathrm{G}$, connected to said lever and adapted for the reception of the side bars of the plough-carry. in Irame $^{\mathrm{F}}$, as set torth.

No. IS $8_{3}, 213 .-1 / A R I E$ E. RONAT, ROCHEILL, ILL.Pions s/s.-Oitober 10, 1876. Filed July 17, 1876 .

Claim.-1.-The combination of the plough-beams A A, the plough-standarls and monld-boards L M, pivotel thereto, with the chains $\mathrm{P}$, sheaves 0 , and windlass $(2$, for throwing the plotghs in and out of working position, in the manner described.

2.- The combination of the axle C C, plough-beams A A, cross-bars B B, main cross-beam E E, standards F F, and adjusting screws 1 , substantially as and for the purpose set forth.

3.- The combination of the axle $\mathrm{C} \mathrm{C}$, detaehed axle-section $C^{\prime}$ guiding-standard $\mathrm{F}$, and adjusting-screws $\mathrm{D}$ and $\mathrm{H}$, and as for the purpore set forth.

4. The combination of the plough-beams A A, cross-bars B B, and draft-chains $\mathrm{P}$ attached thereto, as and for the purpuse set forth.

5.- The combination of the axle (' C, carrying-wheels $G$, $G, G^{\prime}$, and $F$, the gauge-wheels $\$ S$, with the ploughs $A$ L II, as for the purposes set forth.

6.-The combination of the pivoted ploughs L M, beams $A$, short beams $L^{\prime}$, lugs $l^{\prime}$, and locking-bar $\mathrm{K}$, as and for the purpose set forth.

7.-The combination of the pivoted ploughs L M, chains $\mathrm{P} P$, win.llass $\mathrm{Q}$, locking rock-shaft $\mathrm{W}$, arms $\mathrm{X}$, and pins $x$, as and for the purposes set forth.

8.- The combination, with a gang-plough, constructed to operate substantially as herein set forth, of the plat orm $\mathrm{U}$, driver s seat $V$, and operating-arms $q \mathbf{R}^{\prime}$ s, projeeting above said platform, within reach of the driver, substantially as her in set forth.

No. 183254 - -GEORGE CURKENIJALL, DAVEN-

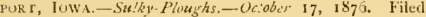
Mity. 24, 1876

Claim.-1.- The axle A, having a central crank, $a$, and side eranks $a^{\prime} a^{\prime \prime}$, and the horizontal parts $A^{\prime} A^{\prime \prime}$, arranged to uperate with one or more ploughs, L, attached to the centrat portion of the axle, and with arch C, substantially as de seribed, and for the purpose specified.

2.- The axle $A$, having centrat erank $a$ and side crank $a^{\prime}$ rigidly connected thereto, and sicle crank $a^{\prime \prime}$ adjustably attached thereto, for operation witit one or more ploughs, L, areh $\mathrm{C}$, and wheels $\mathrm{II}^{\mathrm{B}} \mathrm{B}^{\prime}$, substantially as described, and for the purpose specilied.

3.- Ihe lever $\mathrm{J}$, arranged to operate with the cranks $a a^{\prime}$, aren C, plough 1, wheels B B', and crank $a^{\prime \prime}$, sub:tantially as and for the purpose set forth.

4.- The lever $\mathbb{K}$ and the adjustable crank $a^{\prime \prime}$ combined witn the axle $\mathrm{A}$, having cranks $a a^{\prime}$, substantially as and for the purpuss specified.

5.- Levar, $\mathrm{J}$ and $\mathrm{K}$, attached respectively to the axles $a$, $a^{\prime}$, and $u^{\prime \prime}$, and arranged to both operate upon the same segment-bar H, as and for the purpose set forth.

6.- The braess $\mathrm{N1}$, attached at their forward ends to the axle $\mathrm{A}$, and at their rear ends to the beams $\mathrm{L}^{\prime}$ by a pivotal bolt, $m$, a zd a bolt, $m^{\prime}$, through a slot, $m^{\prime \prime}$, substantially as and for the purpose specified.

7- Th: arch $\mathrm{C}$ and tongue $\mathrm{G}$, combined with the triple crank-axle $A$, plow 1 , and wheels $I^{\prime} B^{\prime}$, substantially as and for the purpose specified.

8 . - Th areh $i$ and ton ue $f$, combined with the triple crank-axle $A$, plough 1 , wheels $B^{\prime} B^{\prime}$, drivers seat 1 , levers J $K$, and segment 11 , subitantially as and for the purpose specilied.

No. 183,610.-S. F. WELCH, OTrAWA, ILI.-Whed Ploushs.-Ociober 24, is 8 . Filed June 15, 1876 .

(laim.-1.- The perforated leveling arms $n^{\prime} n^{2}$ of the lifting-frame $i i^{3} n n n^{2} n^{2}$, in eombination with said frame, and with the lugs $c^{2} e^{2}$ of the rear elip-plate $d^{2}$, and with said plate, subntantially as described, and for the purpose specified.

2.-The slotted elip-plates $d$ and $d^{2}$, in combination with elamps $/$ and $m m$, and with the plough-beam B substantially as deseribed, and for the purpose speeified.

3.- The special arrangement and combination of levers $\mathrm{F}$ and $\mathrm{A}$, paw $\mathrm{l}, o$ and $o^{2}$, notched segments $\mathrm{N}$ and $\mathrm{D}$, conneeting-bars $c$ and $\mathrm{H}$, the lifting-frame and elip-plates $d$ and $d^{2}$, substantially as deseribed, and for the purpose specified.

No. I\$ 3.794.-LUKE CHAPMAN, Collinsville, Con NECTICUT, assignor to the COLLINS COMPANX, same place. -Gany-Ploughs.-October 31, 1876. Filed Fibruary $10,1876$.

Claim.-The wheel $c$, hung on the arm $d$, the lever $c$, and toothed quadrant-arm $\theta$, all rigidly secured together, in comhination with the rigil arm $g$, pawl $h$, and shaft $a$, all constructed and arranged for operation substantially as deseribed.

No. 184,425.-JOHN B. RALSTON, ROCKFORD, ILL. - Gans-Ploushs. - November 14, 1876. Filed Fun: 23, 1876 .

Claim.-I. - The beams A and D, with ploughs thereto attaehed, connected by a hinge joint, substantially as de scribed, permitting of an independent lateral swinging movement of the ploughs, and made vertically adjustable relatively with each other, and adapted to wheeled-sulky attachments to be comnected thereto by means of the usual connection, substantially in the manner and for the purpose hereinb fore set forth.

2. - The brace-rod $m$, constructed with adjusting screw nuts, as described, in combination with the bracket $\mathrm{C}$, and plough-beam D, for the purpose of raising or lowering the rear end of the plough thereto attached, to adjust it to the proper working depth and holding it rertically rigid relatively with the plough to which it is attached, as and for the purpose hereinbefore set forth.

3. - The bed-block $h$, and cap $i$, with arms $k$, in combination with the brace $m$, and plough-beam 1 , having a plough thereto attached, for the purpose of leveling the plough $\mathbf{E}$ latterly, substrntially as and for the purpose hereinbefore set forth.

4.- In combination with the plough-beams $A$ and $D$, hav ing ploughs thereto attached, the clasping-lever $F$, pivoted thereto and fitted with loops to embrace the beams for the purpose of connecting or disconnecting the plonghs, substantially as and for the purpose hereinbefore set forth.

No. IS4 499.-NIERCER BROWN, ST. JOSFPH, ILL.Sulky-Plourtis. - Vivember 21, 1876. Filed July 1, 1876 .

Claim - i.- The frame-work formed of the bent axle B, the tongue $\mathrm{C}$, the forward braces $\mathrm{I} \mathrm{F}$, and the rear braces F, G, constructed and comlined with each other substantially as herein shown and deseribed.

2. - The combination of the adjustable hook-rods $\mathbf{L}$ with the forward end of the plough-beam $H$, and with the for wardly-projecting ends of the rear braces $\mathrm{E} \mathrm{G}$, substantially as herein shown and described.

3.- The combination of the plough H I $\mathrm{K}$, hung by pivoted acljustable rodv to the elevating mechanism, with the leveling devices, consisting of the cross-rod $W$, rock-shaft $\mathrm{V}$ and lever $\mathrm{L}$, and with the ad ustable draft-hraces $\mathrm{L}, \mathrm{L}$, to take more or less land, all construeted substantially as shown and described.

No. 184.57 \%. JOHN BAILES, BELLEVILLE, ILLINOIS, assignor to the Pump AND Skein Company, same place, Riding Atlacksent for Plowshs.-Nov'cmber 21, 1876. Filed $1 / a_{y^{\prime}} 27,1876$

Claim.-The combination, with the carter-wheel L M of, the soeket-piece 1 , connected to the frame $\mathrm{C}$ by parallel rods or arms $e^{\prime} k$, preserving the verticality of the socket; substantially as set forth. 
No. $18_{+} 5^{8}$.-ALBERT H. BURL1NGAME, SPARTA, J LL. - Whech-Plou, ths. - Novimber 21, 1876. Filed Octobir 2), 1876 .

Claim-1.-The wheeled frame C, as describerl, in combination with the lever $\mathrm{F}$, having a lifting-chain $f$, the ploughbeam $\mathrm{G}$, baving a draft-clevis, $\zeta$, and links $K$, and the lever M, substantially as set forth.

2.- The wheeled frame $\mathrm{C}$, as described, in combination with the lever $\mathrm{M}$, having a link, $\mathrm{N}$, the plongh-bam $\mathrm{G}$, having a draft-clevis $g$, and links $\mathrm{K}$, substantially as set forth.

No. 18 \&,6ro.-ISAAC R. GILBERT, Loursvil.1.7, Kv. -Whicl-Ploushs. - Vorember 21, 1876. Filed October 31, I 876 .

Claim.-1.-The combination of the plain half-circle R, provided with the stop-lug, as described, the movable locknotch $Z$, adapted to be fastened at any point on the circle by a sat-screw, and the lever I, all as and for the purposes herein set forth.

2. - The combination of the horizontal socket $B B^{\prime}$, socket or box $\mathrm{A}$, and the platform supporting the beam $\mathrm{P}$, all in one solici arch, $b^{2}$, sulstantially as berein set forth.

3.- The combination of the $\operatorname{arch} b^{2}$, socket $\mathrm{B}^{\prime}$, with adjustable plug having eccentric pin on its inner enl, and the crank-shaft II, with arm placed on said pin substantially as and for the purposes set forth.

4.- The rag-wheel on the wheel W, the pawl $K$, provided with spring and extended lug, the brace $J$, with inclined lng end, and their connections with the lever $\mathrm{L}$ and latch $\mathrm{M}$, substantially as for the purposes herein set forth.

No. $184,629 .-G$. S. K1NG, Minne.tpt).IS, MINv.Plousth-thachments. - Vovimbir 21, 1875 . Filed Siptimbet $3 \circ, 1876$.

Claim.-1.-The combination, witl a plongh-beam, of attaching-plate $A$ with segmental geared levers $B$ and $C$ and gauge-whet 1 , subst.untially as set forth.

2.- In a plough, the combination of fixed standard $A^{2}$ with pivoted standard $\mathrm{E}$, connecting rod $\mathrm{F}$, plate $\mathrm{A}$, and lever l, substantially as set forth.

3.-In a plough, the combination, with geared lever $B$ ard gauge-whed I, of an actunting geared lever, $C$, adauted to be operated both by hand and by foot, substantially as set forth.

4.- The combination of tubular standard $\mathrm{E}$ with rod $\mathrm{G}$, cap.ble of rotation therein, gauge-wheel I secured to the lower end of said rod, connecting-rot F, fixed standird $\AA^{1}$, and segmentally-geared levers 1 C C , substantially as sct forth.

No, 184655 -WILLIAM M. RICHARDSON, ROS COE, lLL., assignor of one-half of his right to $\mathrm{F}$. IV.

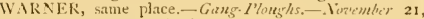
187 . Filed Aurust 26,1876 .

Claim.-The gang-plough herein described, consiting of the bent longituclinal hars $\mathrm{A} \mathrm{A}^{\prime}$, connected by the bars $\mathrm{C} 1$, all marle in one piece, and standaris $l^{*} F^{\prime}$, having upper extensions $f$ and lower extenions $f^{2} f^{3}$ bolted to the landsides $G G$ of ploughs, substantially as described, and for the purpose set forth.

No. I8:,297.-IIANNIB.IL, 11. COLVIN and ISAAC R. J()HNS: iN, WINFIEL,D, lowA.-Ploushs. De:ember 12 1876. Filed October 12,1876 .

Clim.-1.-The combination of the rigid frames A D, the plough-beam II, pivoted frame 1 , rod $i$, dotible-crank MI, rod $m$, and lever $N$, substantially as and for the purposes berein set forth.

2 -The combination of the frames A D, connectel rollers $\left(; i^{\prime}\right.$, arm $f^{\prime} l$, adjustable connection $11^{2}$, sliding connec tion, J, plough-beam $\mathrm{H}$, and lever $\mathrm{K}$, substantially as and for the purp sses lierein set forth.

No. 185,338 . - S. P. LAN( WAX IHA HIF, TEXA i. -Sulky Attachments for. Piourhs. D.cemir 12, 1876. Filed Aurusi 21, 1876.

(lim.-I.-The perforated bar 13, slicling on vertical $\mathrm{b}$ :nd; of short axles, and the shoe $\mathrm{B}^{\prime}$, connected therewith by two bolt-, in combination with the two rods 1 ) $\mathrm{D}$, passing through fixed parforated plate $C^{\prime}$, and operat d by the lifurcat al lever E, as and for the purpose speci ied.

No. I8;493,-LUKE CIIATMAN, COIIINGVILLF,

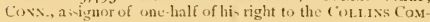

PAvy, same place._Gans-Ploushs.-December 19, 1876. Filed April 14,1875 .

Claim.-1. - The main shaft $e$, centrally enlarged and shouldered, as described, combined with the plough-frame through the medium of the journal-boxes $f f$ and the $U$-bolts $s$, substantially in the manner and for the purpose set forth.

2. - The wedging brake or clamp $m$, in combination with the jointed lever $i$, the arms or levers $h h^{2}$, axle $e$, and wheel $k$, substantially as and for the purpose described.

3.- The combination of the arms $p$ and $/ h^{3}$, the lever $s$, the rod $\epsilon$, and the frame of the machine, substantially in the manner and for the purpose set forth.

4 -The combination of the arm $h$, the shaft $e$, the perforated disk $u$, pins $v$, and side bar $a$, substantially in the manner and for the purpose set forth.

5.- The seat-standard $x$, in combination with the crosspiece $w$, side picces $a b$, axle $c$, and brace $x^{2}$, arranged as shown, wherehy the said standard and axle are mutually supporting, substantially as specified.

No, 185,601 -E. W. WILTON, Collinsvill.e, CaL. -Gang-Phushs.-December 19, is76. Filed May 16: 1876 .

Claim.-1.-1n combination with the ploughtheam I), supported above the axle $A$ and pole $C$, and operated by the cam $\mathrm{E}$ and lever $\mathrm{F}$, the inclined links $g$ s, substantially as and for the $1: u_{1}$ ose described.

2.- The combination of tonzue $\mathrm{C}$ and slotted plate I, rigidly bolted to each otizer, one end of the plate lings pivoted to the axle-tree, and the cther enl inoved by the lever I, thus giving the plongh more or less land, as desired.

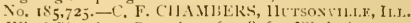
-Whet-Ploughs.-Dicember 26, I876. Filed funi 20, 1876.

Claim.-1.- In combination with the fivoted plough $\Lambda$, having the handle $\mathrm{U}$ and catch $\mathrm{V}$, and the gouse-neck if, the adju-tahle and releasable cam-yoise $\mathrm{X}$, connected with lever 1, capalble of engagement in rack 2 , in the manncr set forth.

2. - The combination of the perforated plates 8,13 and 14 , rods 9,11 , and 12 , and single-tiee 10 , for rigulating the width of furrow and the amount of draft, as explinined.

No. 185,729.-CIIARLAS R. CONWAY, MIIWAY, Wis., assignor to JANLE. CONWAY, same place,_ziliy. Ploxphs.-Decimitier $=6,1875$. Filed Oileber 23, 1870 .

Clam.-The combination with the frotit can-lever N, con nected by corl 0 with the rear of plough-Leam, of a tongue, C, pasing beyond the axle, and therc curving uj uarilly, hangers J K, and pulleys $\mathrm{I}, \mathrm{Q}$, all arranged as showu and described, for the pup ose specilicd.

No, IS; $821,-1$. S. DAIENYORT, JERSEYVIL1.K, 11.1..-What-I'lumsths-_inuary 2, 1877. Filed Octibr $28,1 S_{7} 6$.

Clam. - The axle-arm $d$, pixoted upon the suspension-bar C, so as to admit of angular adjutment with reference $t+3$ the opposite axle, and sccured in po-ition relative thercto by the locking device described, or it .eyuivalent, so that loth axl.s may be simultancously actuated for cither raising or lowering the plough fy the sin le land-kver E, the comiliuation and operation of sail part, buing stubstantilly as aus for the purgone horiu set forth.

Ni. $185972,-11$. I. SCHMLISER, BURLINGION, assignor of one-hatf of his right to J. SCHNLELEK, Drs

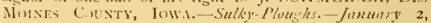
1877. Filed Oclubir 20, 1876 .

Claim.-The conbination of the frames $a b c c$ and the adju-t:ale plate $d$, subst untially as describul.

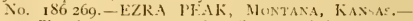

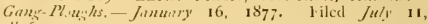
1876 .

Claim.-The combination of notched wheels $A$ with the frume $C$ of a gang-plough, substantially as hercin shown and described.

No. 1S6,335-WILIIAM FRU1]1.1NG, SAN JOSF, CaL.-Cians.Ploughs, - January I6, I877. Filed Derimler $6,18,6$.

Claim.- I.-The forwarl fane $a$, provicled with the whe ls $A \Lambda$, seat $1:$, and lever $E$, in combination with the piou h-frome C, proted so described, and frovisled with the rate $F$ and lever $G$, all constructed to operate : ubstantially as and for the purpose set forth. 
2.-The plough consisting of the parts $a$ and $C$, constructed as described, in eombination with the swinging harrow $\mathrm{H}$ and lever $\mathrm{K}$, all constructed to operate substantially as and for the purpose sct forth.

No, 7,931.-W11,1.I.II FRU111.ING, Sis JosF, CA1. -Gilms-I'lonsis,-IS6,335, Jamutry 16, 1877. Reissued Oc:ob. 30, 1877 . Filed (letobir 2, 1877 .

Claim.-1. - The combination of the frame $a$, rigidly attached to the axle, with triangular plough-carrying frame $\mathcal{C}$ and bent lever $\mathrm{F}$, pivoted directly to and arranged to lift the plough-frame frum the front, all sulstantially as shown and described.

2. The forwarl frame $a$, provicled with the wheels A A, seat $\mathrm{B}$, and lever $\mathrm{E}$, in combination with the plough-frame $C$, pivoted as described, and provided with the rake $\mathrm{F}$ and lever $(i$, all con-tructed to operate substantially as and for the purpose set forth.

3.- The plongh consisting of the parts $a$ and $C$, constructed as described, in combination with the swinging harrow $\mathbf{H}$ and lever $\mathbf{K}$, all constructed to operate substantially as and for the purpore set forth.

Vo. 186 40).-BYRiN C. BR ADLEY, CincAgo, II.1.Axle's fir Swbiv anl Gany-lloughs.-Januar 23, 1877. Filed SeA mir $7,1 S_{75}$.

Claim.-1.-The grooved plate $A$ and plate C, provided with a journal upon it suter side to receive a wheel, and with a groove or grooves upon its inner side to receive the pin $b$. in combination with the angle plate $B$, substantially as and for the purpose specified.

2.-The combination of the plates A B C with the groove $a$, pin $b$, crank $d$, and ratchet $e$, substantially as sei forth.

No. i 86673 - - H. FLLLER and T. L. BOY D, FRANK1.1x, ()Hwo.-Sulky-Plours/8. - January 30, 1870. Filed IVay $12,1876$.

Chaim.-I.-The combination of the plough-beam D, provided with the standard $\mathbf{E}$ and friction whecls $a b$, and the frume A, provide 1 with the standard B and chaft-stud $F$, subutantially as and for the purpo ie berein specified.

2.-The combination and arrangement of the plongh-standard E, upright I, I ops. II I, and suspending and elevating mechanism 6 L II N, substaintially in the manner and for the purposes described.

No. $186,567 .-W$. B. NEWMAN, PitTsvili.t, Mo.Sulky-Iloughs.-Janu-uy 30, 1S77. Filed September 2, 1875 .

Claim.-1.- The combination of adjusting lever $\mathrm{C}$ with the draft-tonguc, the pisoted plough-beam, and the bars $\sigma^{\prime}$, whereby said lever is adajted to adjust the draft-tonguc vertically, and the plough-beam and plough laterally, sub santially as set forth.

2.-The combination of lever () with pivoted plate $Q$ and and $\operatorname{loop} R$, having rock $r$, and with plates 00 , rod $p$, and sermental rack ()$^{2}$, substantially as and for the purpose sct forth.

No. $157,032,-M$. S. MCMAHAN, SAV JHAE, CM..Cosher Gians-Ploush:-Fibru,ry 6, 1577. Filed Dixin bi: $4.1 \mathrm{~S}_{75}$

Claim.-1.-The combination of the frame b, rockin npon the axle with triangulur plough-carrying frame II 1, and Il and with the bent lever $1 E$, the latter arranged to lift the plough-frame from the front or to hold it down when at work, all substanti.lly as shown and described.

2. - The spirally curved rever-ible plough-share $A$, having an angular slot npon it, edge, in combination with the standard 13, lent and notched at its lower end, and with the key C, arranged to hold either end of the share in proper working position, as shown and described.

N., 187,132 -JACKSON F. 11.MIMONTREE, HAR R:S iNH.LF, Mo.-Sully-lYousts.-Fibruary 6, IS77. Fi.e.l / $412 i^{7} 17,1876$

Claim.-In combination with a plough-benm, $\mathrm{i}$, thic double clevis $\mathrm{K}$ C attached to the loop $\mathrm{N}$ and to the lever I, subutantially as flescribed.

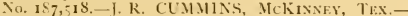

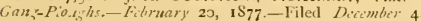
1876.

Clain.-In a gang-plough, the crank-axles $(i$, provicled with a mortive upon their front and rear sides, in comtin. tin with the removable levers II and notchcal segment I, whereby the levers maybe inserted in either side of the crank-aslss, and locked in the ratchet, adjusting the wheel as to height, ancleausing them to run in front or rear of the main axle, substantially as and for the purpose specified.

No. 187,563.-WMI. N. RIDIDE, CADDo Grove, Tex. -Srlky-Pl(ustis.-Fibruary 20, 1877. Filed Dicember 4, 1876

Claim. - I - In a wheel-plough, the main beam A, extcneled rigidly forward to form the tonguc, in combination with the adjustable plough-beam $\mathrm{B}$, and adjuntable wheel $\mathrm{S}$, pivoted behint the plough to the rear end of the tongue, substantially as and for the purpose specified.

2.- The combination of the keepers G E I, with the plough-beam $\mathrm{B}$, the double-trec $I I$, and the tongue $A$, sub. stantially as herein shown and described.

3.-The combination of the pivoted axle $\mathrm{O}$, the connecting $\operatorname{rod} P$, the pivoted lever $O$, and the catch-bar $R$, with the tongue $\mathrm{A}$, and the wheel $\mathrm{N}$, substantially as herein shown and described.

No. 188,247.-MARK D, IUDKINS, USAKIS, MINY.-

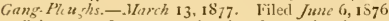

Claim.-1.-In a gang.plough, of two ploughs or more, the combination of the crank axle $\mathrm{A}$, side bars $\mathrm{C} \mathrm{C}$, having corner-pieces $b b$, the rear eross-bar $\mathrm{D}$, with bolts $d d$ ancl nut i $c e$, and the swiveled frame $G$, with the wheel E, all substantially as and for the purposes herein set forth.

2.-The combination of the crank-axle $A$ with the lever $\mathrm{Ml}$, the plougb-beams II having notches $\mathrm{X}$ near their rear ends, and the crank-rod J, substantially and for the purposes herein set forth.

No. $188,586 .-H . H$. CANAIAY, FAIRF1ELD, IOWA.Gans-Ploustls.--Narch 20, 1877 . Filed February 17, $\mathrm{t} \mathrm{S}_{77}$.

Claim.-The conibination of the vertically-vibrating frame $G$, and the beam-frame $F F^{\prime} f^{\prime}$, having staples $H$, with shaft D, arms b b, ehains E, levers $c \circ i i^{\prime}$, and chain $l^{\prime}$, sulstantially as specified.

No. ISS,797.-O. D. HALL, FrEEPORT, ILL.-SulkyPloughlis.-Mharch 27, 1877. Filed Fibruary. 8, 1877 .

Claim.-1.-The latch or tritgrer t, adapted to be operated by the feet in combination with the draw-rocl and chain $\mathrm{G} \mathrm{G}$, for applying the power of the team to the raising of the plough, and for holding the plough off the ground, substantially as described and represented

2.-In combination with the draw-rod and pulley, the branch lever l, for the purpores substantially as described and represent $=\mathrm{d}$.

3.- The combination of the draw-rod, pulley, and chain with the lever $\mathrm{F}$, lateh $f$, and plough.beam $\mathrm{C}$, substantially as and for the purpose describet and represented.

No, $188,856,-11$. E. CARVER, MARION, lows, assignor of one half of his right to A. J. BOARDIIAN, same place.-Sul'ky-Plous/ls._-Jurch 27, 1877 . Filed Lity 25,1876

Claim.-An attachment for sulky-ploughs, consisting of a frame contructed of parallel beams $\mathrm{B}^{1} \mathrm{~B}^{2} \mathrm{~B}^{3} \mathrm{~B}^{4}$, arranged in pairs on each side of the tongue, and united by cross. ieces $\mathrm{B}^{3} \mathrm{~T}^{\mathrm{6}}$, e.ach pair or set earrying brackets $\mathrm{F}^{2} \mathrm{~F}^{2} \mathrm{~F}^{3} \mathrm{~T}$ for the sup ort of the stub-axle; earrying the wheels, substantially as and for the purpose herein shown and specifiecl.

No. 19?,0I6.-WMI. I.. EIWARIDS, ElLISON, ILL. Plourhs, - 1/ril 24, 1877. Filed Vuambir 16, 1 S76.

Claim.-The combination, in a wheel-plough, of the squareaxlo $A$, the beam $(i$, supported on top of the same, and held thereto by the clip b, and the brace 11 , connected to the beam, and having a square loop to pass around the axie, thereby providing for lateral acliu-tment of the heam on the axle, all constructed substantially as and for the purposes herein set forth.

No. 193,450.-GE(), H. WILSEN, DAVENPURT, IOWA

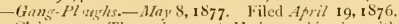

Claim.-1. - The spring-entch 11 , in combination with the caster-wheel C, substantially as specified,

2.-In combination with the frame $A$, a caster-wheel that is allowed to swing freely around, and that can be locketl rigitly in position for the purpose set forth, sub-tantially as specifie.1.

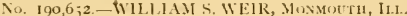


-Sulky-Ploughs.-May 8, 1877 . Filed January 18,1877 . Claim.-1.-In combination with the axle $A$ and yoke $H$, to which the plough is secured, the double-elbow lever $\mathrm{L}$, link $O$, lever $N$, and link $P$, the lever $N$ being pivoted to the axle, and the whole arranged in close proximity thereto, substantially as and for the purpose specified.

2. The bolt $\mathrm{F}$, having a detent, $f^{\prime \prime}$, arranged to operate with the sliding plate $D^{\prime}$, constructed as described, and with the perforated plate $a^{\prime \prime}$, substantially as and for the purpose specified.

No. 190,737.-W. K. BUSHNELL, Burlington, Iown. -Silky Attachmen's for Plougks.-MIay 15, 1877.-Filed Warch 2., 1877.

Claim.-The combination of the parallel slotted uprights $\mathrm{H}$, the three bolts $\mathrm{K} I \mathrm{~K}$, the slotted plates J, and the keeper $a^{1}$, with the wheels and axle $F(i$, and the plough-beam $A$, substantially as herein shown and described.

No. 19I,3+2.-FRANK A. HILL, SAN LEANDRo, CA1..-Sulhy-Ploughs.-May 29, 1877. Filed March I, 1877 .

Claim.-1.-The combination, in a wheel-plough, of the wheels $\mathrm{E} \mathrm{E}^{\prime}$, oppositely-inclined crank-axles $\mathrm{D} \mathrm{D}^{\prime}$, extension-arms $F F^{\prime}$, supplement shafts $G G^{\prime}$, reversely-operated levers $1 \mathrm{~J}$, and racks $\mathrm{V} \mathrm{V}^{1}$, the several parts constructed and arranged to operate in the manner substantially as herein shown and described.

2.-In combunation with the beam $\mathrm{B}$, diagonal brace and axle $\mathrm{A}$, of the sectional beam $\mathrm{C}$, having both parts secured by the bolts of the brace $b$, adlapting the frame to the use of one or two ploughs, substantially as herein shown and described.

3.-The mould-board $\mathbf{X}$ and land-sicle, formed in one piece, and provided with the block $Y$ and extended brace $Z$, in combination with the share $\mathrm{V}^{2}$, with its grooved projection $q$, the two parts being secured by a bolt and key or wedge, $i$, substantially as and for the purpose described.

No, 191,588.-WILliAM HENRY TRENTON, Mo. assignor of one-half his right to GEORGE IV. MOIBERLY, same place.-Sulky-Ploughs.-June 5, 1877. Filed February 19,1877 .

Claim.- - The combination of frame A B C, having bearings $a$ $b c$, long axle $\mathrm{F}$ having lever $\mathrm{H}^{\prime}$, and bails or keepers $1 \mathrm{~K}$ rigidly attached thereto, swinging plough-beam $K^{\prime}$, and pivoted brace I, substantially as and for the purpose herein shown and specified.

No. 191,667.-AI.BERT A. FOWLER, Pl.ANo, TEX.Sulky-Plou,hs, - June 5, 1877. liled Afril 13, 1877.

Claim.-1.- The constination of a jointed frame, pivoted to the arch $C$ of the plough, the beams B, studs $i$, and slotted guides $k$, is shown and described.

2.-The combination of the plough-beams, the pivot-studs, the vertically-slotted guides, the pivoted parts H I of the vihrating frame, laving the parallel slots $l$, all as shown and described.

No. 192,142.-A. A. AMUNETT, WRIGITSBOROUGH, TEX., assignor to himself and JAS. E. WEL.LS, same place. - Whet-Ploughs.-June 19, is77. Filed April 23, 1877.

Claim.-The combination of the bars $B$ and their crons bar $\mathrm{E}$ and bo!ts $\mathrm{C} \mathrm{D} \mathrm{F}$, the crosi-rod $\mathrm{G}$, and the eyeholts $\mathrm{H}$ with the plough-beam $A$ and the wheels and axle J I, subst untially as herein shown and described.

No, 192,279.-IOHN E. PURTER, CHIROKEE STAtion, Kansas.-Sulky. Ploughs.-June 19, 1877. Filed Nay 12,1877

(laim-1.-In a sulky-plough, the axle forming the straight arm (i, crank-arm $\left(i^{1}\right.$, and centre crank $G^{2}$, in combination with the wheels $\mathbf{E}$, arm $a$ with chain $b$ connecting with the plongh-beam, and the lever 11 , whereby the plough is raised or lowered and the wheel, adjunted with one operation of the same lever as set forth.

2.-The combination of the pivoted lever II', "ith guide $i$, the sliding rod $h$, forked at its lower end, and the plough-beam $K$, substantially as and for the purpose described.

Nu. 193,152,-J. L. FLORANCE, P1.ANr, TEXAs.-

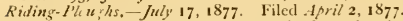

Claim. -1.-The combination, with the frame 1), pivoted to the cranked axle $C^{\prime} c^{\prime}$, and liaving apentured cross-lna, of the superposed beam $\mathrm{E}$, having bolts $\epsilon^{\prime}$, as and for the purpose described.

2.-The combination of the hook-arms $\mathrm{O}$ with the hinged frame D, and with the crank $c^{\prime}$ of the axle $C$, substantially as herein shown and descrilued.

No. 193,226. - THOMAS J. CRUMP, BUENA VISTA, TEX.-Gang-Ploughs.-July 17, 1877 . Filed Ahizy 19, 1877 .

Claim,-1.-An improved gang-plough, consisting of the plough $\mathrm{A} \mathrm{A}^{1} \mathrm{~A}^{2} \mathrm{~A}^{3}$, front bar or frame $\mathrm{B}^{1}$, auxiliary frame $\mathrm{B}^{2}$, rear or carriage frame $\mathbf{B}$, pivoted seat $\dot{C}$, elevating device E, backing device 11 I/, and central coulter 1), the several part seing constructed, arranged, and combined to operate substantially as specifiecl.

2.-The combination of the ploughs $\mathrm{A}^{2} \mathrm{~A}^{3}$ and auxiliary frame $\mathrm{B}^{2}$, with the main frame or bar $\mathrm{B}^{1}$, and rear carriageframe $\mathrm{B}$, substantially as described.

No. 193,899.- (EEO, H. SIIITH, ROCKFORD, IH.L. Sulky-Ploushs.-Autust 7, 1877.-Filed June 7, 1877 .

Claim.-1.-The herein described screw-gear $n l$, toothed rack $d$, socket $\mathrm{I}$, and shaft $\mathrm{H}$, having anmular grooves $c$ and swiveled trumion-plates at its lower end, in combination with a plough-beam, for the purpose of raising and lowering the plough theruto attached, to regulate its working depth and hold it suspended for transportation, as hereinbefore sut forth.

2.-In combination with a plough-beam having a plough thercto attached, the clamping-plates ", shaft II, touthed rack $d$, and socktt $\mathrm{I}$, to admit of a vertical rocking movement and a lateral oscillatory or swinging movensent of the plough, as and for the purpose hereinbefore set forth.

3.- The socket 1 , with slotted bed-plate $f$, fitted with shaft $\mathrm{H}$, capable of an oscillatory and a vertical movement in the socket, with plough ther to attached, pivied to the becl-plate $h$, in combination with the axle-tree, to incline the socket from a vertical position to either side to level the the plough, as hereinbefore set forth.

No. 193,041-ANSEL II. (iAI.E, FREFPORT, 11.L.Sulky-Ploughs.-August 7,1577 , Filed June 20, 1877 .

Claim.-1.-The combination of the plough-beam Bivivoted bar: $G$, slicling draft-lar $E$, and frame-bars $A$, substantially as described and shown.

2.- The combination of plough-locam B, hars $\mathrm{G}$, guide $\mathrm{L}$, latch M, spring 8, aud draft-bar L, substantially as shown and described.

3.-The sliding clamp F, carrying the draft-bar E, pivoted connecting-bars $\mathrm{G}$, rock-shaft $\mathrm{N}$, with arm 1 , lever $1 \mathrm{I}$, and bar $\mathrm{K}$, in comlination with plough-beam $\mathrm{B}$ and frame-bar: $A$, substantially as shown and described.

No. 193,98;.-J. F. MEAD, DKKALB, I1.1..-P'li $u_{3}^{x / l s .-~}$ Austut 7,1877 . Filed $7_{u n e} 28,1877$

Claim.-The combination of the axle $A$, having the for ward-1 rojecting arms $c^{\prime} c^{\prime}$, the plough-beain $\mathrm{E}$, pivoted to axle arms $c^{\prime} c^{\prime}$, and the elbow-lever $F$, lined to the axlc and linked to the rear end of the plough-beam, substantially as slown and described.

No. $194.029-\mathrm{T}$. BRUNER, RICHFIELD, MIXN-Augrust 14, 1877. Filed Sipiember 16, 1876

Claim.- In combination with the frame $\Lambda$, laving openings at its front and rear, the plough-beans comm ctecl, as shown, as:d provided with the perforated plates $b$ and bolt $c$, as and for the purpose set fort'?.

No. 194.072.-11. H. CANAD 11, FAIRFiel. I JWA.Sulky. Ploushts. - Ausut 14, 1877 . Filed Juse jo, 1877.

Claim.-The combination, with a sulliy-carriage, the vertically vibrating frame $G$, and the plough-bean $\mathrm{l}$, of the adjustable clamp-plotes $\mathrm{F}^{-1} \mathrm{~F}^{2}$ and the clamp-:taples loosely stracklling the end bar of said frame, subnt.mtially as speciticel.

No. 194,167. SAMUEI, PENNOCK, ITHACA, N. Y. -Pluwh-Sulkies.-Ausuit 14, 1877 . Filed Junc 18, 1877 .

Claim.-1.-The combination, with round bar G, supprorted under frame $A$, of the turning and stiding sleese $\mathrm{H}$, provided with longitudinal cos $l$ and teeth $g$, and having arm I, attuched to the plough-heam, as and for the purpose dencribed.

2.-The combination, with the sleeve II, having rack and longitudinal cong, of the pisoted sector $h$, having lever 
$t$, and the lever $K$, having toothed sector $m$, as and for the purpose specitied.

No. 19t,258. WIII.AAM T. ORR, KEWANk, 11.1., assignor to JOSEPH ORR, same place.-Sulk\% I'loushs.Ausus/ 14, 1877. Fïled December 2, 1876 .

Claim.-1.- The vibrating arm $\vec{l}$, journaled in front of the axle-tree, and laving both vertical and horizontal mo:ement, adapted for use substantially as specified.

2. - In combination with the vertically-vibrating beam having a curved serrated rod, $\mathrm{N}$, and the vertically-vibrating arm 1 , to the end of which the said bcam is pivoted, the connecting-rod $j$, vibrating knee-crank $\mathrm{G}^{\prime}$, lever $\mathrm{H}$, having staple 0 , a pawl, $f$, and a mechanism for actuating the sam 3, substantially as specified.

3.-The a:m 1, having universal movement relative to the axle-tree, in combination with a vertically and hornzontally vibrating beam and a rot for sustaining its front end, as set forth.

4 -The rot $\mathrm{I}$, pivoted to the axle, and having a vertical ere, $l$, in it free ent, in combination with the $T$-ihaped bolt $m$, having tubular arm $n$ and an attaching-nut, $z$, the forked front end of a plourh-beam, and a bolt passing through eyes in the fork, registering with the bore of the bolt $m$, subatantially a, specified.

5.- The eyualizer, consiting of the walking-beam P, having arms $w w^{\prime}$ of unzqual lengths, the rods $x x^{\prime}$, con necting the clouble-tree and single-tree, respectively, with the said arms, and the regulating-rod $y$, connecting-rods $x x^{\prime}$, combined and arranged substantially as specified.

No. $194619 .-R$. A. RENFRO, Rockivel., TEXas.S.thy-Plouy hi.-A Ausust 28,1877 , Hiled June 11, 1877 .

(laim,- the combination with crank-axle, frame, and beam, of the tirruis $\mathrm{E}$, learings $\mathrm{F}$, clips $\mathrm{G}$, rock $\mathrm{H}$, armed shat I, pivoted rod J, and lever $\mathrm{K}$, as and for the purpos: specifierl.

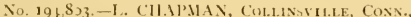
ansignor of one-half his right to the Conliss Compans, same place.-Wheel-I'l ustlis.-Siptembir 4, 1877 . Filed December 33,$18 ; 6$.

Claim - I- ln a wheel-plough, the combination of the plough-beam $i$, sleeve $i$, embracing and rotating on the main axle $a$, and the lever $k$, adapted to be operated by the driver's foot, all arranged as described.

2.-In combination, the plough-beam $i$ and lever $k$, piv. oterl on axle $a$, and the pawil $m$, located with reference to the fuot-lever, so that hoth lever and pawl may be operated by t're driver's foot, sub t intially as hown and described.

3. -In a wheel-pluagh, the combination of the foct-lever $l$, and the pivot al hand-lever $r$, also jointed to the footlever, for raising and lowering the plough, subutantially as show $\mathrm{n}$ and described.

o. 1950د-JOHN H. GOODWIN and DAVII

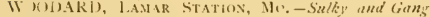
Plou,hs-Sep ember 11. 1877. Filed Filruary 3, is77.

Clam.-1.-A, an improvement in gang.plougis, the conbination of the pivoted plongh-lreams $B$ and hinged heam brac $=F$ with the connectimg chains, pulley frame, and adjusting or tnk lever mechanim, sulstantially an and for the purpose set forth.

2 - The coml ination of the pivoted plough-henms $\mathrm{B}$ and hinged laraces $f$ with the connecting chaiur $a a^{1}$, jointed pulley frame 1), and crank lever mechani $\rightarrow m$ to raie plourhi int.s upright porition with pulley frame after work, sulutantantially as set forth.

Ne. 195.119.-JOS. F. (ILIDI)EN and PHINEAS WI.

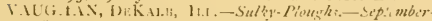
11. 1877 . Filed terst is, 1877 .

('tain.,1,-in a suliy-ploush, the furrow-whecl placed up on a spinlle suppost d directly in the rear end of the 13) uth-bem, and in an arm attached to the plough, sul Limidilly as set fortis.

2,--The combination of the axle $\mathrm{C}$, adju-table bar $\mathbf{I}$. pivet al arms $\mathrm{I} x$, and tongue $\mathrm{Al}$, as sct forth.

3. $-1 h=\mathrm{c}$ mbination of the tongue $\mathrm{Il} \mathrm{N}$, elbow-lever $\mathrm{P}$ li, .5 , wit's 4 lot $x$, and the plough-beam with adjustable clip $k$, having projecting $f$ in $i$, sutstantially as and for the purposer ut foith.

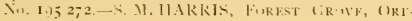

(iox.-Hhe\%-Ploush.-Sepiembr 18,1877

Filed Way 28 , 1877

("laim.-The combination, with the crank-axles J arrang ed in bearing, supported on cross-lar B, of the rack lever I. and spring-pan ls $\mathrm{N}$, as shown and described.

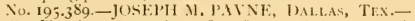
Sulky-Plouplis.-Siplember 18, 1877. Filed July 28, 1877 .

(Jaim.-I - In a sulky-plough, the combination, with the plough and frame, of the pivoted connecting-bars $\mathrm{D}^{\mathrm{D}} \mathrm{D}^{\prime}$, having holes $x$ in their inner end for adjusting the plough at different divtances from the wheels, suhstantiantly as herein set forth.

2.-In a sulky-plough, the combination of the pivoted connecting-bars I) $W^{\prime}$, with adjusting-holes at their inner ends, and a plough, with its lieam at their outer ends, and the in lependeut levers $J J^{2}$, with pawls and ratchct segments $K$ $\mathrm{K}^{2}$, substantially as and for the purpose set forth.

No. 19549 t.-GEORGE A. EI.LIS, PHILAdeI.phiA, PA., as:igner of one-half of his right to T. L. RICART,

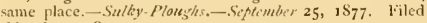
Wiarih 20, 1877 .

Clain. - 1 - In combination with the bars D D, arms $d^{2}$, and standards $d^{3}$, the levers $E$, rod $d$, and sping $E^{\prime}$, substantially as shown and described.

2.-In comlination with the frame $\mathrm{A}$ and axle $\mathrm{C}$, the crank $i$ having openings for the journal-axles, and slots $c^{1}$, and being secured to saicl frame and axle, respectively, by means of holts $c^{2}$ and screws $c^{3}$, substantially as shown and described.

3.- The ploughshare $\mathrm{F}$, hung upon the beam or bar $\mathrm{F}^{\prime}$, substantially as described, so as to slicle or move Jongitndinally thereon.

4.-In comlination with the share $F$, beam $F^{\prime}$, and standards $f f$, the buffer-spring $\mathbf{l}$, for the purpose describer.

5. - In combination with the beam $\mathrm{F}^{\prime}$, arranged at a right ande with the axis of the wheel $(\%$, the ploughshare $F$, supended from saicl beam by the standark $f f$, and arranged to swing upon said beam, sulmtantially as descrihed and shown.

6.-In combination with the beam $\mathrm{F}^{\prime}$, ploughshare $\mathrm{F}$, and stantlards $f f$ turning on the beam, the ellow-lever II and connecting-rod $\mathrm{N}$, said connecting-rod being arranged, substantially as dencribed, so as to permit free lateral movement of the share, for the purpose set forth.

7.- In combination with the rolling or slicling platform $G$ and axle $C$, having a rack, $c^{5}$, the crank-shaft $l^{1}$ and pinion $i^{2}$, substantially as shown and set forth.

8. - in combination with the transverne-bar $\mathrm{A}^{2}$ and plat form $\mathrm{G}$, the sliding or rolling carriage, composed of the plate $\mathrm{P}^{2},-\operatorname{trap} \mathrm{P}^{1}$, and ioller (2. substantially as thown and described.

9. - In combination with the carriage $\mathrm{P}$ and platform (; the vertically-adjustable bracket $R$, sulntantially a, bhown and described.

10,- The combination, with the bracket $\mathrm{K}$ and platform G, of the ecceratric crank $S^{\prime}$ and lever $S^{\prime}$, arranged and operating, sulstantially as shown and described, to raise and lower the point of the plough-share $\mathrm{F}$

No. 194,458,-1).ANIEI. II. FUNK, 11ARRISETRG, (ORE

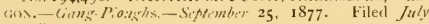
30, 1877 .

Claim.-1.-The combination of the forwardly-projecting bar (, the rarwar lly-projecting bar $\mathrm{D})$, the cross-bar $\mathrm{E}$, the swival-screw $F$, and the lead-har $(;$ with each other and "ith the wheel, and arle A 11 for connecting the ploughbeams with said wheels and axle sub-tantially as herein hlow $n$ and described.

2. - The comlination of the strap $H$, the pivoted blocks 1, and froted bars J witis the lead-bar ( $;$ and with the beanm $K$, to enable the pitch of the plough to he tempora. rily changed without changing the po-ition of the led-har $(i$, -ulistantially as herein sown and de-cribed.

3. - The comlination of the that $\mathrm{X}$, the chaim $\mathrm{It}$ and $\mathrm{I}^{\text {? }}$ and the lever and catch-plate () R and the plongh $b=a m s ~ K$, the pivoted hars I, and the leall-har $G$, substantially as herein hown and described.

4.-The coml instion of the shait and pulleys $L^{\circ} T$. the 
chains S and $\mathrm{W}$, and the lever and catch-plate $\mathrm{X} \mathrm{V}$ with the plough-beams $K$, the frame C D E, and the axle B, substantially as herein shown and described.

No. 195.977.-WM. K. BUSHNELL and DAVID BUSH NELL, BURLINGTON, Wis.-Sulky Atlachmeuts for Pltugh. - October 9, 1877. Filed July 26, 1877 .

Claim.-The adjustable plates forming the rear side of slots in uprights $\mathrm{H}$, the hinged and slotted keeper, with the headless bolt with flange in the centre, the forcing-lever and slotted plate above the foot-board, and the adjustable pole, all in combination as specified.

No. 197,159.-CHARLES MOWREY, STOCKTON, CAI.. -Gang.Plouglus. - Vow'mber 13, 1877 . Filed Ausust 4, 1877 .

Claim.-1.- The bent arm, $H$, supporting the front of the frame $\mathrm{A}$, and journaled in the links or arms $\mathrm{M}$, which project from the shaft $\mathrm{N}$, said shaft turning in boxes upon the bolster $O$, and provided with the lever $P$, so that the plough-frame A may be raised and lowered, substantially as herein described.

2.-The levers $\mathrm{P}$ and 1 , with their operative devices, as shown, in combination with the sliding guide $T$ and connecting rods $\mathrm{S}$ and $\mathrm{U}$, substantially as and for the purpose herein described.

No, 197.16\%,-CHARLES MOWREY, STOCKTON, CAI. -Gang-Plizushs.-Nivimber 13, 1877 . Filed Murils 23, 1877 .

Claim.-1,-The plough-beams A, having the shaft E and arms $\mathrm{F}$, connecting them with the axle, in combination with the arms J, united by the links $K$ to the axle $H$, and the operating lever 1 , whereby the ploughs are allowed to enter the ground or caused to rive out of it, substantially as lierein described.

2. - In combination $\mathrm{w}$ ith the beams $\mathrm{A}$, connected with the axle $H$ by the haft $\mathrm{E}$, arms $\mathrm{F}$, the links $\mathrm{K}$, arms $I$, and operating lever 1 , the wheel, with its crank arm (2, mounted upon the axle $\mathrm{H}$, sulstantially as herein described.

3.-Th? rack $\mathrm{X}$ and the boxe, $\mathrm{D}$, formed in one carting, and so fitted to the frame A A as to support each other and the frume, substantially as herein dencribed.

4. - The box $W$, fitted to the shaft $E$ so as to $b$ : moved from side to side, in combination with the lever W', tongue $\mathrm{T}$, and screw $\mathrm{V}$, said box being constructed to receive the end of the tongue, and to form journal hoxes, within which the crank-screw V turns, and elevates or depresses the pole, substantially as herein described.

No, 19738 - -JANIS KENNEDY, MINNFSOTA CITY, MInN.-K'iding-I'leughts. - Lotember 20, 1877 . Filed October 13,1873 .

Claim,-1,-In combination with a plough, the sulky attachment, consisting of the slotted beams D $D$, axle $a$, wheels $\mathbf{E}$ E', adjustable seat $\mathbf{C}^{\prime}$, swiveled hook $\mathbf{I}$, and bar II, all substantially as and for the purposes set forth.

2.- The rod 1 , with arms $h h$, forked at their lower ends, forming clamps, and provided with bolt $i$, in combination with the handles of a plough, substantially as and for the purposes set forth.

No. 198,017.-JOHN HAMAKER, WHTtE CloUn, IowA.-Sulky-Plowglss-December 11, 1877 . Filed . Vo vember 6,1877 .

Claim,-The bail $l$, having the journals 5 , in combination with the plough $n$, lever 6 , aud chain 7 , substantially as described.

No, 198,068.-JOHN BAILEY and GEORGE MAKSHALL, Brilevil.I.E, li.l.-Riding Attachmen's for Pliushs. - Deicmber 11, 1877. Filed March 21, 1877 .

Claim.-1.- In a one-wheel-plough attachment, the cross har $C$, rigidly secured to the plough-beam by means of a broad becring-plate, (", and contructed with an arm C"', adajted to form a support for a seat and a frot-rest, and a stud or spindle, $c$, forming a bearing for a crank-lever, which carries the wheel, as and for the purposes set forth.

2. - The lever $K$ and arm I, attached to or near the har $C$, in coml ination with the $\operatorname{cog}$-segments $k$ and $l$, substantially as and for the purpose set forth.

3.- The bar $C$, rigidly attached to the beam $B$, in combination with the wheel $F$, bell crank lever $\Gamma$, y ring catch $(;$, or equivalent, and notched quadrant or rack $F$, substantially as and for the purpose set forth.

No. I98,100.-HENRY FUII.ER and THOMAS 1. BoYi), Franki.1n, OH10.-Sulky.Ploughs,-December 11 , 1877. Fileri June 5,1877 .

Claim. - The frame consi ting of the plates B, guides $b$. and tongue $\mathrm{A}$, in combination with the pirot provided with grooved rolls $c$, upon which the plough-leam (' works, sub tantially as described.

No, 195,190,-MARSHAI.T. S. CURTISS, BRADIORD, Is.1., as ignor of two-thirds of his riglt to JA.MES B. DOYLE and HAKMON PHENIX, same place.-GansPloughs.-December 18, 1877 . Filed $J u^{\prime} y 3,1877$.

Claim.-1.-A beam-adjuting lever as a connection between the plough-beam and its draught-bar 13 or transverse hitching-bar, said lever fivcted at its forward end to said dratight-lsar, and behine? saidl har again fivoted to the plough-beam, and having a detent at the rear, for the purpose of the lateral adjustment of the head of saicl heam in taking more or less width of land in ploughing, subetantially as and for the purposes described.

2.-The combination of the lever $\mathbf{F}$ with the ploughleam $\mathrm{A}$ and a transverse draught bar, adapted to suing the front end of the plough-beam laterally, sui stantially as and for the purposes described.

3.-The coml ination of the lever $\mathrm{F}$, to mose the joughbeam hoirontally, with the detent -1 ar $\mathrm{Nl}$ and the draugh tbar or leader 13, subtantially as and for the purjoses de. scribed.

4. - The comlination of the lever $\mathrm{F}$, bar $\mathrm{B}$, detent $\mathrm{l}$ ar $\mathrm{C}$, and staple $h$, or detent of beam E, suh: tantially as and foi the purposes described.

5-The draugl:t-bar or beam-supj orter $\mathrm{b}$, fiveted to the pirotal braces $C$ and to the forward end of lever $F$, sub. stantially as aud for the purposen dlescribed.

6.- The conbination, with the $\mathrm{b}$ am $\mathrm{A}$, frosided with lever $\mathrm{F}$, and connected to liar $\mathbf{b}$, eperated by the netcherl detent-bar $(j$, of the lifter 1 , with it - litles $k$, an $\mathrm{K}$, com necting-rod $\mathrm{I}$, and lever $\mathrm{H}$, attached to the torgue, : $u 1$-tantially as described.

Nir. 198,193-CHARIES DOMSCHKE, AU TIX,

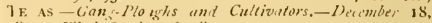
1877. Filed $O_{i} b_{i}, 16,1877$.

Clain.- The combined gang-plough and cultivatur-frane $\Lambda$, hasing a peiforated front crom-liar and perforated rear cross-b.r, the elbow-lever, $B$ li, carrying the adjutalle what, $C$ C , laterally-moving tongne $G$, and laterallymovalile brackuts $y s$, all adapted to receive ploughshares or cultivators that are attached to the uncler side of the frame A, substantially as specifiecl.

No, $198932,-J O S E P H$ M. PAYNE, DALLAS, TFXAS, -Plizshs.-Jamuary 1, 18,8. Filed Jamary i3, 1877.

Claim-1.-In a one-wheel plough, the combination of the crons bar $\mathrm{H}$, having the ratchet $\mathrm{H}^{\prime}$, and being rigidly secured to the plough-beam, with the bell-crank lever $F$, carrying the wlieel 6 upon its shorter arm, and the sy indle crank $f$, journaled to the cross-har, substantially as described, and for the purpose set forth.

No. 199,382,-JOHN WCBRIDE, I)F MUIVE, IOWA. - Janua $\%$ 8, 1878 . Filed Warch i 7, is 77 .

(laim.-1,-In combination with the plough-heam and hinged axle, the lever $B$, having the combined rack and feniler 1 , and lever $\mathrm{B} s$, rovided with the :pring-latch $z, \sim n b$ stantially as and for the purposes shown and described.

2. - The acljustal,le and jointed fulcrum $t$, adaj ted to sup. port the lever $\mathrm{B}^{2}$, and to clamp the coulter $w x$ to the ploughbe.im, substantially as shown and described.

3.-The vertical lever 13 , having the comlined rack and fencler $y$ and the gravitating latch $h$, the hinged axle $(;$ car rying the wheel $\mathrm{I}$ and rack, $s$, the jointed fulcrum $t$ clamping the coulter $w^{\prime} x$, the horizontal lever $1{ }^{2}$, faving a sping latch at it rear end, and carrying a caster-wheel at its front end, and the hinged and adjust.hile brac: $m$, when arranged and coml.ined to operate substintially as and for the purposes shown and descrihed.

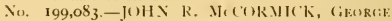
Tow:, Trxas-Jimuary \&, 1878 Filed J1, $n \cdot 30,1877$.

Claim.-1. - The conbination. with the plough-hes m frame

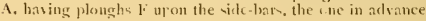


of the other, and axle C, having the double crank F, of the transporting-wheel I)' arranged on said axle, and working hetween the side-bars a $a^{\prime}$, upon solid ground between the furrows of saicl beam-frame, substantially as specified.

2. - The combin.tion, with the avle $C$, having the double crank $l \therefore$ of the transposting-wheet $1 \%$, journaled upon the outer bend of said crank, working between the sitle beams a $a^{\prime}$ of the plongh-heam frame, and the connecting-rods $r r^{\prime}$. pivoted, respectively, to the said side-lars, and to the end and inner bend of said crank, sulstantially as specified.

No. 199153 - CHARLES A. HACiL'E, CHICACic) It.

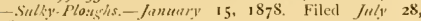
1877.

Claim.-1.-The indepemlent sindes, carrying the landwheel $A^{\prime}$, anil connected with the machine hy arms $F$ E, in combination with lever $(i$ and rack $d$, for vertically raising or lowering that portion of the frame and crank next to the land-wheel, for the purpose of leveling the plough trans. versely, and it the same time keeping the axles of the wheels in the same vertical plane, substantially as specitied.

2.-The spinclle carring the land-wheel, crank B, frame ( (" I), arms F F, hinged to each other at $f$, the arm F being secured by the spindle s, and the arm $\mathrm{E}$ being hinged to the crank $\mathbf{B}$, in combination with devices for raising and lowering the end of the frame and axle next to the land-wheel, substantially as specified.

3.-The spindle s, carrying the land-wheel, in combination with the cramk $\mathrm{B}$, frame $\left(\mathcal{C}^{-2} \mathrm{~J}\right)$, rack $d$, arms $\mathrm{F}$ E, lever ( $i$, and rector $i$, all constructed and operating substantially as described.

Vo. 199,4t3.-CORNEAI.ILS I. IACKSON, MIII.ERS Bt kt: 1t.1.-Whect.Ploughs.-January 22, 1878 . Filed ip. il 23,1877 .

(laim,-1.-The combination of the V-lever D, clank axle H, l-trap I, and spring I with the plough-leams and wheel, an and for the purpose described.

2. -The standard $k$, made with a lateral offiset or bend, and provided with a slotted top plate, the curverl brace $k^{s}$, the handle-seat $k^{4}$, and the arm $k^{3}$, in combination with the heam, the mould-looard, and the share of a plough, sulxtan. tially as herein show'n and descrilsed.

Vo. 199,622,-HU)RA('E I. DANIEI.S, REDW'UOD

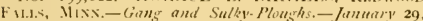
IS78. Filed Hoiember 3,1877 .

Claim.- The bent frame 1 , having braces $\alpha$, clevises $f$, and clips b, and the sulky frame, in combination with the beams $\left(\mathrm{i}\right.$, draurlit-bar $\mathrm{I}$, and operating lever, $11 \mathrm{H}^{\prime}$, constructet and arranged substantially as and for the purpose set forth.

o. 199.626.-SA.ILEI, E. IRAKE, CANTUX, ILL., ans inor of one-half his risht to (iF()RGE il. PI.ATT, same

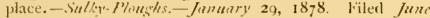
3), 18,77 .

Claim.-1 - In axle constructed, substantially as fle scribal, of a wron ght -iron bar having vertical site and horiz nut il portion $a a^{\prime} a^{\prime}$, and cast-metal plates $B \mathrm{~b}$, having flang is $b b^{\prime \prime}$ and circle dists, for the purpose specified.

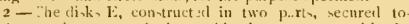
gathar, a vown, at $e^{\prime} e^{\prime}$, cumbinz.l to operate with the disks (; substantially ar described, and for the purpose ypecitied.

3. - The dotted angle plates $I^{\prime \prime \prime}$ and bolt $i$, arranged to op: rate with the vottel saddle 1', yoke 1, and plough heam J, subt unti.llly as and for the purjoses specified.

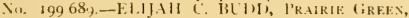

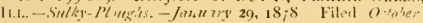
6 is 7

(I) - The combination, with plongh-heam (i, pivoted to frante 1), of the looscly-swinging voke 1), attaehed to plough beam by a loup that slicles thereon, an vbown and dencriberl, for the fup pus specihed.

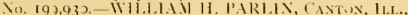

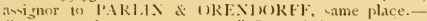

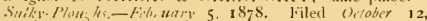
I $S_{77}$.

Claim.-1.-1n a ulky-plough, an axle $A$, having a 1) sub.:--cran's at, tu which the plon rh is attached, and a crank "' . carrying the land icle wheel, waid crank diverging $(\mathrm{l})$. li vely irom the whect-yinile, ar how 13 and deacribed, whereby the we iaht of the driver and frame is utilized in rai-ing the plough from the ground, substantially as and for the purpose specified.

2.-The axle $A$ having central double crank $a$, to which the plough is attached, the obli pue crank $a^{\prime \prime \prime}$ at one end, and a fixed crank (; unon the other end, to which a crank. I, is journaled, and on which the furrow wheel 1', is carried, substantially as and for the purpose specified.

3.-The crank axle $A$, constructed as described, and combined $w$ th the cranks $G$ and $I$, levers $I 1$ and $J$, rack-hars $I$ $\mathrm{F}^{\prime}$, arch $\mathrm{C}^{\prime}$, plough $\mathrm{K}$, and wheels $\mathrm{I}$, $\mathrm{B}^{\prime}$, subutantially as de scribed, and for the purpose specified.

4. - The axle $\mathrm{A}$, having double crank $a$ and crank $G$ in the relative radial positions described, arranged to operate with the crank $\mathrm{I}$, arch $\mathrm{C}$, and plough $\mathrm{K}$, substantially as described, and for the purpose specified.

No. 200,038., SAll T. FERGUSON, MiNxiapolis, MINN.-Wullky. I'loughs.-Felnzuary 5, 1878. Filed January

8,1876 .

Claim.-1.-The independent crank-arms $C^{\circ}$ and $C^{\circ}$, hav ing clifferent lengths of crank or radius, combined with the running-wheels and the platform, and extencled past each other in parallel position, to form a stiff support for said plat form, as described.

2. - the crank arms made of bent tubular section $a$ and $b$, of different diameter, secured the one within the other, with the joint in the radial portion, substantially as described.

3.- The plough.pivoted to it supporting frame, as described, so as to suing over the platform in a reversed position, in combination with a laterally adjustable seat, sub stantially as and for the purpose described.

4.-The comlination, with an adjustable lifting-frame, substantially as described, of a plough having its beam pivested to said frame in the rear of it s draft connection, so as to swing over the platform in a reversed position, as and for the purpose set forth.

5.-The totted and anjustahle gauge-bar 1, located upon the lever 11, and provided with a foot or stop, in combina. tion with the platform, the lever, and the plough, for the purposen of adjusting the latter as to clepth, as set forth.

No, 200,249-BIRON (. BRADI.EY and CHARLES

A. HAfile, ('HeAgo, H.L.-Sulky. Ploughs - February 12,1878 . Filed $J u_{1}^{\prime} 28,1877$.

Claimz-1. - In a sulky or gang-plough, a plough hinged upon a crank, in combination with a lever permanently se cured to the crank, and a rack or other equivalent device connected with the plough-beam, for the purpose of raising and lowering the plough independently of the frame, ancl loching the plough when in use, $\rightarrow$ that it cannot turn on the crank, substantially as specitied.

2.-A plough-beam hinged to a crank, B, in combination with the frame ( 1 ), supporting a reat, tongne $\mathrm{ll}$, stop 0 , lever $\mathrm{L}$, and rack J, -uldrtantially as and for the purpose set forth.

3. - The sleeve $h$ provided $w$ ith spur $i$, to fit a correspond ing recess in the spindle-arm, and having the hole that receives the spindle diagonal to or not concentric with the cir cumferetice of the leeve, whereby the sleeve is prevented from turning upon the :pindle, and the pitch or gather of the wheel in regulated, unlstantially as specified.

o. 2005 2.-KOBERT C. BUCKI.EY, PEURIA, 11.I.

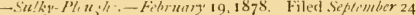
1877

(laim,-1.- The bar or platform $\mathrm{F}$, one end hinged to the under sidle of the axle tree, and it- other connected with a lever, by mean of which and it, connection with the plough-beam the ponition of the plough with relation to the sulky frame is aljunted, unlutantially as ancl for the purpone specitied.

2 - The combina ion of the inclined axle-tree $c$, hinged platform $\mathbf{F}$, and lever $(;$ w th the hail 1 , unloxtantially an and for the purpone upecified.

3.- The combination of the inclined axle-tree $\mathrm{C}$, hinged platform $F$, bail l and lever $K$, suh-tantially as and for the purpones specifiel.

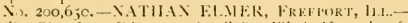

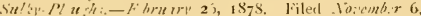
1877

inim, - 1.-The combinat on, with the plough tandaril, 
of a diverging plough beam constructed with downwardlyprojecting rear end, between the plates of which the standard $i$, pivoted, the lower rear portion of said beam serving as a stop to limit the movement of the plough standard, sulustantially as clescribed.

2.-The combination, with a plough standard, of a diverging plough-beam constructed with downwardly-projecting rear end, between the plates of which the standard is piv oted, the lower rear portion of said beam provided with a set-screw for adjusting the position of the plough, sulsstantially as described.

3.-The combination, with a vertically-adjastable main frame, of the diverging plough-heam, braced at it - forward end by a cross-bar, and having the plough-standard pivoted between the plates of its rear end, said beam constructed with a downward rear projection, which serves as a stop to limit the movement of the plough, substantially as described.

4--The combination, with the diverging bars of the plcugb-beam and cross-bar located between said bars, of a vertical conlter-shaft, provided with a crank on its lower end, towhich is fivoted the yoke of a rolling conlter, and a screw-eycbolt engaging with the cross-bar and conltershaft, whereby the rolling coulter may be acljuted either vertically or latterly, substantially as and for the purpose described.

5-The rock-haft journaled in the main frame, and provided at ene end with a hand-lever, $i$, and at the otherend with a curved arm, $i^{\prime}$, in combination with the locking and lifting lever $(i$, which is piroted to the seat-supporl, link, connectinc the rear end of the lifting-lever with the plough bear, and curved link $i$ ", connecting the lever $G$ with the curved arm $i^{\prime}$, substantially as described.

6. - The combination, with the curved arm $i^{\prime}$, rock-shaft 11 , lever ( $;$, and curved link $i "$, of the draw-bar, con-tructed and ananged substantially as described, whereby the power of the $t=a m$ may le employed to raise the lock and plougl, sub tantially as described.

7.-The combination with the rock-shaft provided with the hand-lever and curved arm, the lifting-lever $(i$, and curved link $i$ ", of the draw-bar, constructed and arranged substantially as described, whereby the joint action of the operator and team may be employed to raise and lock the pl,w su:pended, substantially as described.

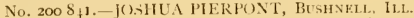
-Sulky-Ploushs.-Warch 5, 1878. Filed June 9, 1877 .

Clim.-1.-In a sully-plough in which the ploughbeam is connected to the axle by means of a piroted yoke projectin r rearward from the axle or frams, the combination of a pivied yoke projecting forward from the axle or frame, and connected to the plough-bzam by menus of a link or lever, s', as to permit the plough to rise and lower by the o.cillation of the yokes, substantially as and for the purposes : pecitied.

2.-In combination with a plough connected to the axle by a rear yoke, a forward yoke, link, and lever, 1, by means of which the plough may be raised from the soil with its point end first, substantially as described, and for the purpose specified.

3.-The lever $\mathbf{K}$, arranged to operate with the yokes $\mathrm{G}$ $H$, lever 1 , axte $A$, and wheels $C$, substantially as dencribed, and for the purpose specified.

No. 23,025 -JAMES C. LEIDY, Galeshers, 1hl.Sulky. Plus ths. Wharch 5, is 8 s. Filed Octobir 12, 1877 .

Claim.-1. - The bar $1 \mathrm{I}^{\prime}$, arranged to operate with the r s c's-shaft I, independent cranks $j k^{\prime}$, connecting-rods $j^{\prime \prime}$ $\mathrm{L}$, and sulky A B, substantially as and for the purpose specified.

2.-The levers $k$ and $I 1$ and their respective cranks or arims $k^{\prime} j$, and links $j^{\prime \prime} L$, combined with the plough $\mathrm{D}$, hinged to the sulky-frame, so at to have lateral oscillation, substanti.lly as and for the purpone specified.

3. - The combination of the laterally-hinged plough with two cran's or arm: $j k$, to which the plough is connected, $\rightarrow)$ that the one crank, $j$, may be oscillated to incline the plough, while the other, $\lambda^{\prime}$, aids in retaining it in position, subrantially as and for the purpose specitied.

4. - In combination with the frame A, the yole $\mathbf{E}$, havinz entis ${ }^{\prime}$, bent ar curved an descrilsed, to facilit ate placing and removal in the frame $A$, substantially as and for the purpose specified.

No. 251,097 . -JOHN CURRIE, LoNION, ONTARI, CANADA.-Gang. Plough Frames,-March 12, 1878 . Filed fugust 8, 1877 .

Claim.-The herein described gang-plongh frame, consinting of the single wrought-iron bar $\mathrm{A}$, bent as shown, in combination with the brace $\mathrm{B}$, top and tottom plates $c c^{\prime}$, and the standaris $\mathrm{D} \mathrm{D}^{1} \mathrm{D}^{2}$, secured to the bar and brace, as specified.

No. 201,227.-THOMAS B. CHAMBERIIN, CLARIN1B, luw.1.-Sulky-Plow, ths.-Wurch 12, 1878. Filed Jul 2,1877 .

Claim.-1.-An attachment to sulky-ploughs for sustaining the plough in profer wolking fosition, contiting of two bearing-plates pivoted together, one being secured to the axle or frame, and the other to the plough-beam, substantially as set forth, said plates having the devices, substantially as de. scribed, to lock the plough in porition or allow its limited or unlimited latcral oscillation.

2.-An attachunent to whecl-ploughs conisting of two bearing plates pivoted together, substanially as described, one or both plates being beveled or made convex, so that the carriage-frame may have a rocking motion, and may ocil. late without affecting the position of the plough, subutantially as set forth.

No 201,576.-THOMAS I. WADE, STH. 50, KAviAS, assionor of one-half his rirht to THEO. A. MC(C)RDICK. - Piou, hs. -Natch 19, is/3. Filed dusust 24, 1877 .

Claim-1.-In combination wit/ the plons-carriage herciubefore described, the lever E, link 1t, arms I I, and slide $\mathrm{K}$, all aranged to carry the plongh and lokel it in forition when ploughing, sulstant ally as described.

2.-The combinition of the crom-piace $\mathcal{C}$, adjustably ar ranged on the ton sue $\mathrm{A}$, uxd arm - I J, adjuntably connected together, with lever E, link $\mathrm{H}$, and si.le $\mathrm{k}$, as and for the purjose sct forth.

Vo. $=01,670,-I I O R A C E$ L. HEIVIT'T, AI.Tox, H1.., assignor of one-half his right to 1.EWIS M, RUMISEY and

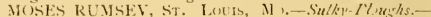
Warch 26, 1878. Filed Fanmary 14, 178 .

Claim.-1.-The arched axle $E$, in conbination with the car ting 1$), p$, rforated plate (;, axle-crank (; lever $F$, and spring catch lever 11 , all constructed an d arranged to operate subsatially as described.

2.- The arched axle $\mathrm{F}$, having knee $\mathrm{E}^{2}$, in combination wit's the comer-bracket, 1, having pirot-pins i', the saic comer-bracket, constructed to embrace and strengthen the axle at the linees $\mathrm{K}^{2}$, and serve as a pivotal connection for the frame J, all subtantially as and for the purpose set forth.

No. 201694.-IOHA M. MCPIKE, ST. IIFLFNA,

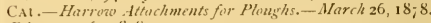
Festuary 16,1878

Claim.-1.- The harrow consiting of the single touth bearing-beam $\mathrm{E}$, supported from the plough-leam $b_{j}$ means of the spring-a rms $\mathbf{B} \quad \mathrm{G}$ and the vitical tandards $\mathrm{D}$, substantially as berein described.

2-The ingle-beam harrow $\mathrm{E}$, with its vertical standar 1 s 1), guided and :mpported by the spring-arms B $(i$, and f rovided witls the adjusting collars and screws $\mathrm{F}$, substantially as berein described.

No, 201,765.-JAY BOSTWICK FISHER, 1)AVFpOrT, Iowa, Sulky-Ploughs,-Narh 26, $18 ; 8$. Filed Fibruary 2,1878 .

('laim - 1.-A plough having a moukd-board constructed, sulstantially as described, with the past, 0()$^{\prime}()^{\prime \prime}$, so as to turn over the furrow-slice smoothly and crenly without breaking, substantially as is forth.

2. - In combination with a plough having a mould-hoard constructed sulmtantially as described, the concave revolsing mould-hoard, T, arranged to acrap : smooth and fill up the crevice or joint between the furrow, substantially as set fortis.

3.- In combination with a plough, $\mathrm{X}$, constructed suh. stantially as described, and with the revolving moaldboard ' $\mathrm{T}$, a seeding device, $\mathrm{U}$, con-isting of the simles wheel $\mathrm{V}$, rod $\mathrm{V}^{\prime}$, spring $\mathrm{r}^{\prime \prime}$, an! seed-cup stiles WI W', 
constructed and operating substantially as and for the pur junce 1' ciliesl.

4.-The combinition in a plough, of the monld-troard (1) i' ( )', plates $P$ P", proint $Q$, punt $n$, and heam $(i$, -nb-t.untially as and for the purpose specitied.

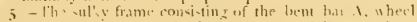

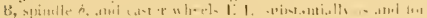

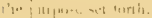

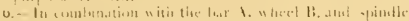
the slutted plate $L$, which permis of the whed ti-ing: without affecting the working position of the plongh, substuati.illy as set forth.

7.-1n combination with the bar $\mathrm{I}$, wheel $\mathrm{B}$ and spindle $b$, and plate $C$, the spring $c$ operating $-u b s t a n t i a l l y$ as and for the purpos specified.

s.- The combination of the plate $C$, bar .1 , spinclle $b$, and yring i wth the lever ', and '", shbatantially an and for the purpose specitied.

9. - The plough-post $n$ and plough-beam 6 , contiucted, and-scribed, of two plates, one passing through between the doubled portion of the pot and the other overlapping it. an described, in combinmtion witb the adju-ting-screw. unbstantially an and for the purpose specified.

Io. - In combination with the frame $A$ and plough-bean

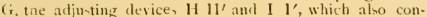
stitut : the mann for hinging the beam to the frame, substantially as set ferth.

Ii. - The combination of the coulter $K$ and circular-sw cutter $\mathrm{K}^{\prime}$, geared to rether. $\rightarrow$ an to operate sub-tantially as and for the purpose -pecified.

12. - The lever J, having the forward-bent portion $j^{\prime}$, operating in combination with the frame $A$ and devices II $\mathrm{H}^{\prime}$ and $\mathrm{I}^{\mathrm{I}^{\prime}}$ to raixe and lower the plough, and with tie rox $j$ to limit it forward swinging movement, sul. -t.untially an set furth.

1:- The combination of the plate 11 and alju-table (ap-plate 1l', having bifurcated journal-hearing orms, sul. tantially as and for the purpease specified.

14.-The revolving coulter $K$, constructed with arcshaped knives or indentatims. and so as to leave flat propelling point, arranged at right angles to the cutting-edges, suli-tantially as set forth.

15.- The strat id rol $R$, pivoted sleeve $r$ ', and spring panl $\rightarrow$, in combination with plate,$"$, and with the frame 1 and plough, whotant ally an and for the purpone specifiecl.

16. - In combination with a perforated plate, 11, ancl adjuvtable cap $\mathrm{ll}^{\prime}$, apring-pin $h^{\prime}$, for the purpose of adjunt. meut, vub-tantially as set forth.

17. The lever $Z$. in combination with the frame $A$ and alju table tevice, $H^{\prime}$ and $\mathrm{I}^{\prime}$, for the purpose of adju-ting the lateral movement of the beam while the point remainin it, proper 10 -ition, sub-tantialls as set forth.

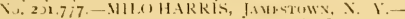

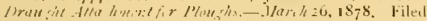
Heriti I, $1875^{\circ}$

(laim.-1.-1 Iratht attichment to operate in front of it plenti-beam, coms ting of the truck $\mathbb{E}$, the perforated and

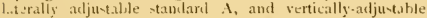
pule b, constructed and arrauged substantially as shown and ilescrilsed.

2.-The combination of tunck $E$, - toudari $A$, pole $B$, taree 1), aut plourh-beam \&; all combined and :urranred -ulst mitially an -hown and de-cribed.

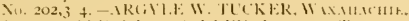

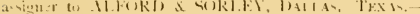

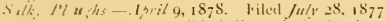

Clam.-1. The reverible bail or clesin f, pivoted on the ensl of the asie $A$, allapted for the reception of plough-

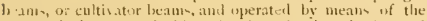

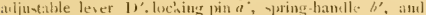
p.ritrateal vegment $\mathbf{E}$. - ubstutially as and for the purposen it- rein ret finth.

2. - In a sulky plongh and cultivator, the frame t.. contrut $t$ d of a -ingle roil, bent sub-tantially in the maner shuwn and de-cribed, and forming the etat-upperting arm. av well a $t^{t}:$ parallel pait $t^{\prime} d^{ \pm}$, to which the adjuntable

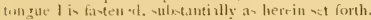

3.- 1 h. combination of the rever-ible clesi- 1, with it operating-lever $1 \gamma^{\prime}$, the plough-txam $\mathrm{I}$., clamp $h^{\prime} h^{\prime}$ and cuffo or clips $m, m$, with the fins or luge " on the clevis. untorantially as and for the punposen hercin set forth.

4.- The bent or curved axle, prosided with a rigis cranh or arm at each end, projecting in oppo-ite directions in comlination with a lexk-leser. wherely one whect i- mined ans

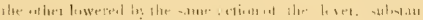

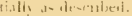

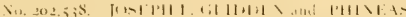

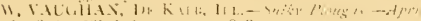
16, 1878 . Filed fin:ary 19, 18,8

Claim,-1,-In a one-wheel sulky plough, an axle $A$ having at the end opposite the wheel a pin or rod $a$, extending downwird at right angles with the axle, and at it lower end supporterl is an angular bracket $b$, in combination with a swiveled frame, $(i$, and a plumgh, wntr-tantially as and for the purposen set listh.

2.-The swiveled frame $(i$, the lower end of which is at tached to the landside of a plough, aud hasing the brace 1 ecureil to the plough-beam, and extending rearward to form one of the hearing for the wheel $J$ of the plough, sub. stantially as dencribed, and for the purposen wet forth.

3 - The combinatim of the axle A, with clongated screw rod at the end, the arm $k \mathrm{k}$, nut $k k$, tongue $i$, and brace II, withscren-rod and nuts $m$, whereby the tongue can be adju-ted on or of the land, for the purposes set forth.

o. 202,615. WM. H. WHITTI.ESEY and CIIAS.

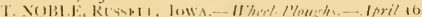
1878 . Filed Janury $17,18_{7} 8$

(Ciam.-1.-The combiation, with the independent foot lever F. I: and plough-baam " ", of the tranverse slotteil plates i $c$ or other equivalent wechanism, to attacb the free rear end of ratil lever to the plomgh-beam and allow the latter to vide thereon, wherebs the plowsh-heam mav hase free lougitudinal novement when being rased, and the plough may be leveled, substantially as shown and dencribed.

2. - The foot-levers 1: provided with spring-pawls and ratchet $i, i /$, in combination with the parallel plates $c c$. be tween which slite the free rear ends of the levers $\mathbf{E} \mathbf{E}$ and plough-lieam ("), substantially an and for the purpose set forth.

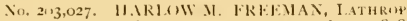

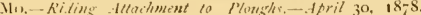
Filed fiebruary 21, 18,8.

Claim-I- The combination of the crank $\mathrm{D}$, the axle $\mathrm{E}$. the pivoted block $(;$, and the lever I with the plough-beam $I$, the wheel $F$, and the frame 11 , ubb-tantially as herein vhown and described.

2.- The combuation of the notched har 4 , the connect ing-bar $\mathrm{T}$, the catch-lever $\mathrm{L}$, the latch $\mathrm{V}$, and the spring II with the axle f:and the frame II, unbotantially as herein shown and described.

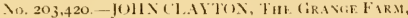

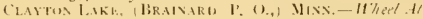

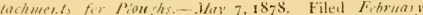
27,1878

(taim. - The head-btock $\mathrm{A}$, baving a bole formed thrungl its upper part to reccive a plough-beam, and grooves ans slot- formed in it, lower part, aucl provided with the plate 1 and the screw 11 for clamping the plough. beam, and with the bols $1:$ and the bearing If for the wheel waft or axlen. -ubsantially an bercin shown and described.

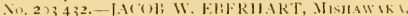

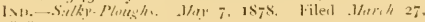
1878

flam.-1. - The arched asle -1, prosided with the hearinge a $a$ at each ent, threngh which the cranh- li li pas. the lesers 11 1), connciteal tis the inner ends of said crank and the stirrup $l$, all contructed whetatially as and for the purpme hercin ut forth.

2. - The combination of the aninging stirrup $\%$ plongh beam $(i$, stotted angular plates $b \quad h$, clip $d$, and adjustable collar $f \%$, ulmantially an and for the purposer herein at fotth.

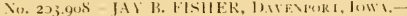

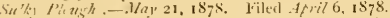

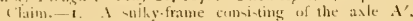

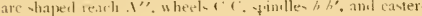


guide-wheel B, constructed substantially as and for the purpose specified.

2.-A caster guide-wheel, B, having projections $a$ and knife-cutting edges between them, substantially as and for the purpose specified.

3.- The caster guide-wheel, $\mathrm{B}$, having projections $a$, and cutting-edges between them, and having the upright standard $i^{\prime \prime \prime \prime}$ fastened to the rear end of the lengthwise plate $i^{\prime \prime \prime \prime}$, having wings $a^{\prime}$ and slot $i^{\prime \prime}$ between the said standards $i^{\prime \prime \prime \prime}$, and having the vertical journal-shaft $a^{\prime \prime \prime \prime}$, on which the caster guide-wheel B operates, secured to the front end of said plate $i^{\prime \prime \prime \prime \prime \prime}$, in order to form a long bearing-crank shoulder $a^{\prime \prime}$, and strong lockage at the rear end, formed and operating substantially as and for the purpose specified.

4--The caster guide-wheel $\mathrm{B}$, having projections $a$, and cutting-edges hetween them, and having the upright standarrls $i$ " " fastened to the rear end of the lengthwise plate $i^{\prime \prime \prime \prime \prime \prime}$, having wings $a^{\prime}$ and slot $i^{\prime \prime}$ batween the said standards, and having the vertical journal-shaft $a^{\prime \prime \prime \prime}$, on which the caster gruicle-wheel turns, secured to the front end of said plate $i^{\prime \prime \prime \prime \prime}$, in combination with the bearing-box $a^{\prime \prime \prime}$ and lock-pin $i^{\prime}$, pivoted to the lever $\mathrm{F}$, all operating together for the purpose of cutting a straight furrow across the field, substantially as shown, and for the purpose specified.

5.-The combination of an arc-shaped reach $A^{\prime \prime}$, with the seat 1 . convolute-spring support $\epsilon$, foot-rest 4 , clasp-band $\iota^{\prime}$, bolted so as to be adjusted back and forth, and arm. bearing band $f$, bolted to the seat-spring $e$, to hold and adjust the top $1 Y^{\prime}$ substantially as and for the purpo,e specified.

6 - The combination of the arm-bearing band $f$ with the seat 1 , elbow-steeve $f^{\prime}$, jointed stem $f^{\prime \prime \prime \prime}$, adjustable rod. band $g^{\prime \prime}$, adju-table arm-rods $g$, plate $g^{\prime}$, plate $h$, and collar-block $h^{\prime \prime \prime}$, substantially as and for the purpose specified.

7.-The combination of the top $\mathrm{D}^{\prime}$, consisting of the elbow-sleeve $t^{7}$, jointed stem $f^{\prime \prime \prime}$, adjustable rod-band $f^{\prime \prime \prime}$, plate $r^{\prime}$, plat $=h$, rim-rods $h^{\prime}$, circular-rod $h^{\prime \prime}$, and collar blocks ' $h^{\prime \prime \prime}$, all constructed substantially as and for the purpose specified.

8.- Lever ()$^{\prime}$, having an elbow-support bearing, $u^{\prime} \prime \prime \prime$ provided with hinged arms $u^{\prime \prime \prime}$, which have the other end pivoted to the sleeve of cup $\boldsymbol{u}^{\prime}$, to allow the friction-spring () to rise and lower with the plough, and plate $u^{\prime \prime \prime \prime}$, binged to the lever ()$^{\prime}$, for it fulcrum adjustment, sulstantially as and for the purpose specified.

9.-The coil-spring $U$, having cup-caps $u u^{\prime}$, sleevebearing $u^{\prime \prime}$, and bent or double-rod $u^{\prime \prime \prime \prime \prime \prime}$, substantially as and for the purpose specified.

Io.- The combination of the friction coil-spring $O$, having cup-caps $u u^{\prime}$, sleeve-bearing $u^{\prime \prime}$, and bent or double-rod $u^{\prime \prime \prime \prime \prime \prime, ~ w i t h ~ t h e ~ p o s t ~} Q^{\prime}$, lever $O^{\prime}$, rod $O^{\prime \prime}$, and rack $\sigma^{\prime \prime \prime \prime}$, substantially as and for the purpose specified.

11. - The combination of rod $O^{\prime \prime}$ with the axle-lever $O^{\prime}$ having plate $u^{\prime \prime \prime}$ and journal shaft $a^{\prime \prime \prime \prime}$, substantially as and for the purpose specified.

I2.- The combination of the furrow-guide support $\mathbf{N}$, having it, lower end divided, as shown, and uyper end perforated, with the bar $N^{\prime}$ and plough $P$, to operate subttantially as described, for the purpose set forth.

13. - In a sulky-plough, the combination of an adjustable bar $N^{\prime}$, with the axle, furrow-guide support $N$, and jourml-shaft $a^{\prime \prime \prime \prime}$, substantially as and for the purpose speci fied.

14.-The lever $G$, with its respective elbow $j$, bolted to the bar $j^{\prime \prime}$, which is hinged with it to the axle or frame of the sulky, and bearing bifurcated end $j^{\prime}$, substantially as and for the purpose specified.

15.-The arms $k$, having a bearing-collar, $k$, anel collar bow $m$, comutructed sub.tantially as and for the purpose specitied.

16.- The combination of the yoke I, having journal end and journal-pin $l$. with the arms $1^{\prime}$, knee plate $l^{\prime \prime}$. and arm.$k$, substantially as and for the purpose speci ficil.

17.- The combination of the arms $k$, having the collar b.w $m$, with the ellow-lever J', to lock the central lateral movement of the plough-beam, semi circular bar $j^{\prime \prime}$, and rod $i^{\prime \prime \prime}$, substantially as and for the purpose specified.

18. - The perforat tubular cogy-bearing brace $w$, provided with a bearing-rim, $z c^{\prime}$, and connecting-pin $z w^{\prime \prime \prime}$, constructed substantially as and tor the purpose specified.

19.- The combination of the perforated tubular cogbaaring brace $w$, proviled with a bearing-rim, $w^{\prime}$, and connecting-pin $w^{\prime \prime \prime}$, with the double beam $Q$, one bar having cog-pins, arms $I^{\prime}$, and knec-plate $I^{\prime \prime}$, having the knee-pan $n$, to operate substantially as and for the purpose specified.

20.- In a sulky-plough, the combination of the operating device $H$, consisting of the arms $l$, yoke $I$, arms $1^{\prime}$, knee-plate 1 ', and levers J J', with the double heam $Q$, having the $\operatorname{cog}$-brace $w$, and lever $\mathrm{G}$, having hifurcated end $j^{\prime}$, the ellow $j$, bolted to the bar $j^{\prime \prime}$, having bar $j^{\prime \prime \prime \prime}$, and axle or frame of the sulky-plough, substantially as and for the purpose specified.

21. - The lever $G$, having the elbow $j$, bolted to the har $j^{\prime \prime}$, having hinged ends $j^{\prime \prime}$ and bifurcated end $j^{\prime}$, in comb $i$ nation with the frame $A$ or axle and journal-bearing collar neck $k^{\prime}$, substantially as and for the purpose specified.

22. - The combination of the hinged lever J. having ellow-arms $o$ and handles $o^{\prime}$, with the knec-plate 1 ', elbow-lever $I^{\prime}$, and seat $I$, to regulate the lateral movement of the plough, sulstantially as and for the furpose specified.

23.- In combination, the elbow-lever $\mathrm{J}^{\prime}$ with the spring collar-bow $m$ and knee-plate $1 "$, for the purpose of locking the lat:ral movement of the plough, subatantially as and for the purpone specified.

24. -The lever-rack $K$, having the spring collar-bows $p$, macle more than semi circular in form, in order to clasp aud hold the lever, substantially av shown for the purpose set forth.

25-The combination of the lever-rack $\mathbb{k}$, having the spring collar-bows $p$, with the arc-shaped reach and lever $G$, suhstantially as and for the purpore speciied.

26. - In combination, the sleeve-rubler $p^{\prime}$ with the rack $K$ and lever $(i$, for the purpose of securing a safe and firm vibrating hold of the lever in the collar-bow, with easy adjustment, substantially as and for the purpose specified.

27. - In combination, the lap-spring sleeve $t^{\prime}$ with the lever $\mathbf{M}$ an I rac's $K$, for the purpone of socuring an up-an 1 . down movement of lever $\mathrm{H}$ in the coltar-bows $f$, when rising and lowering the plough, and lateral movement, substantially as and for the purpose specified.

28. - In combination, the hinged lever M, made adjuntable up and down by the lap-spring sleeve $t^{\prime}$, to correspond with the vertical motion of the plough by the lever $G$, operating substantially as and for the purpose specified.

29.-In combination, the furrow-cutter 1, consivting of the disk-blade mould-boards $s^{\prime}$, divided, as shown, with cutting-edges the whole length of each blade, and dish. ing from the centre of the mould-boarks to the end of blades, circular blade-scrapers $s$, as shown, having two blades on each sleeve, secured to the axle between the said mould-boards, to remove obstruction from between the divisions of the blarles, and frame $r$, having axle $r^{\prime}$ and arms $r "$, with the plough-beam (), mould-board $\mathrm{T}$, and share $s$, for the purpose of dividing the furrow. slice as it passes over the said mould-board and share, substatially as and for the purpose specified.

30. - The land-side reversible plate $R$, made wedgeshaped from the ends to the centre, to be used end for end upside down, having a rib-shoe, $x$, constructed substantially as and for the purpose specilied.

31. - The combination of the reversible land-side plate $R$, made wedge-shaped from the ends to the centre, and having a rib-shoe, $x^{\prime \prime}$, with the pont (Q made substantially as and for the purpose specified.

32.- In a plough, the combination of an adjustable double-tream $\left(\hat{\text {, fot }} Q^{\prime}\right.$, land-side revervible plate $K$, mould-boards $T$, and rever,ible hare $S$, subtantially as and for the purpore specitient. 
No. 234,C91-WII.LACE ('. ROIXIERS, PAPHLIHON,

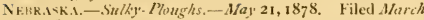
$16 \quad 1 \leqslant 78$

Claim.-1.-1n a plough-sulky, the frame comisting of the bars A A, vertical lars $13 B^{\prime}$, spindles, and wheels, in com. binati in with tongue $\mathrm{E}$ and braces $\left(; \mathrm{G}^{1}\left(i^{2}\right.\right.$, sulstantially as and for the purposes set forth.

2. - The combination of the hars A A, forked plate or bar 1 , with roller $i$, plough-beam $\mathrm{J}$, and the $\operatorname{dog} f$, taking into netches on one of the bars $A$, substantially as and for the purproses set forth.

3.-The combination, with the forked plate I and plough Jyeam $\mathrm{J}$, of the plates $h / h$, rod $f$, pivoted stirrup $\mathrm{L}$, the quadrant II, formed with the catch $m$, and a laterally adjustable device, all substantially as and for the purposes set forth.

No, 204,517,-EIDWARI) WIARI) and GEOR(iE C.

AVERY, locisvil. K, KY, assignors to B. F. AVERV \& S()NS, same place.-Sulky-Phughs. - Jun 4 , I878. Filed April 29,1878

Clain.-1.-The double-crank-axle frame, consisting of the arms C (' and E E', which form angles at or about the center of the wheels of the plough, the front and rear connecting-bars $\mathrm{F}^{\prime}$ and $\mathrm{F}^{\prime}$, and the short axles $\mathrm{B}$ and $\mathrm{B}^{\prime}$, one of which is adjustable, sail frame being adafted for having the plough proper hung upon it rear bar and the tongue-support to rest and rock upon its front har, substantially as and for the purpose described.

2. -Th: adjustable arle-arm $\mathrm{B}^{\prime}$, having the clasping or slotted slide attached to it, and connected to the divergent perforated arm $\mathrm{E}^{\prime}$ of the double-crank-axle frame, as shown so that when the plough proper is raised and the arm is nearly horicontal the slide with axle and wheel are capable of moving backward until the axle $\mathrm{B}^{\prime}$ coincides with the axle $B$, sulstantially as and for the purpose described.

3.-The rocking double-crank-axle frame having a brace or supfort, $c$, attached to it, in combination with the link $\mathrm{m}^{1}$, lever II, rocking frame $\mathrm{C}_{\mathrm{i}} \mathrm{i}^{\prime}$, and driver's seat, wherehy facilitues for raiving the plusgls are afforded, and the weight of the driver, when on the seat, assists to lift the plough, substantially as described.

4. - The combination of the short axles, one of which is adjustalsle, an slescribed, double-crank-axle frame having arms which form angles at or about the center of the supporting-wheels, and the rocking support or seat-frame $i^{\prime}\left(i^{\prime}\right.$, substantially as and for the purposes described.

5.-The combination of the tubular bracket. $\mathrm{J}$, attached to the leam of the plough and to the rear bar of the double crank-axle frame, the tubular stop $J^{\prime}$ on said bar and between the tubes of the brackets, the sct-screw $j^{\prime}$, and the hraces $k$, substantially ar and for the purposes descibed.

No, 204612 - NELSCX ROWEX and GARRT

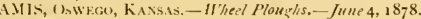
Filed Marh 30,1878

(laim.-The combination of the stirrup $\mathrm{H}$, with plough connected thereto, the rod or link $m$, lever $c$, rod or link $b$, slicle (, and wheel D, all con-tructed and arranged substanrially as and for the purposes sct forth.

No. $204893 .-F R A N C 1 S$ M. FOSTER, MUXTGOMERY CutNTy, asignor of ore-half his riglt to W. A. PEFFER. (i)FFETILI.F, KaNsas.-Sulky-flous/is,-Juni 18, 1878 Filed $f / r i, 25,187 i$.

('laim.-1.- In a sulky plough, the comlination of the axle $\mathrm{A}$, rigid arms B 1 , plough beam $C$, pivot d between sai $f$ arms and provide $l$ with egment-gear $b$ and elbow-lever $K$, h.sing seared segment $t$, subvtantially as shown and de scilibed.

2.-The axle A, arm- B B, lever $\mathrm{h}$, provided with seg ment-gear $a$ and rack $f$, in combination, with piroted plough-beam $C$, having segment-gear b and cav-r-wheel $d$, sulke intially as hown and describerl.

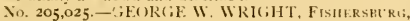
1xi, - Sulky.I'l u, hi,-Jun: i8, I878, Filed thril 15 , 18,5

(laim-1.-In axle com tructed $w$ ith its wheel-spindles on diferent sides of and parallel with it-elf, in combination wit. a frame-work loo-ely mounted thereon, so that said frame work may always retain it; level independently of the pro-ition of the whecls, nb-tantially an her, in hown and reci.ied
2.-In combination with the axle, substantially as de scribed, and a frame-work loosely mounted thereon, a later ally-acljustable driver's seat, by which an accurate balance is maintained, subvantially as herein shown and specified.

No, 205,397,-I.ESTER 13, KENNES, CHARLTIT, Мнн.-Pules for Agricultural Implements,- June 25, 1878. Filed April 15,1878 .

Claim.-The combination of the pole $\mathrm{A} \mathrm{B}$, macle in two parts, jointed together at $a$, the frame $\mathrm{C}$, caster-wheel $\mathrm{D}$, clevis $F$, clips $G G^{\prime}$, and link $H$, all constructed substantially as and for the purposes herein set forth.

No. 205,509.-CHARLES P. SNOII, FREEPORT, ILI., assignor of one-half his right to HIRAM BRIGIIT, same place.-Plous $/ 2 s .-f u l y y^{\prime}, 1878$. Filed February 28,1878 .

Claim,-1,-The segmental gearing $t k$, lever $x$, and rack $\mathrm{E}$, in combination with the sleeve $h$, lips $i$, plough-beam $l$, and bar $m$, substantially as set forth.

2.-As a means for allowing the lateral movement of the plough-beam /, the curved bar $m$, hinged at each end on the axle $\mathbf{B}$, and provided on its under surface with the lips $\boldsymbol{n}$, and on its upper surface with the foot-lever $p$, in combination with the sleeve $h$, having lips $i$, between which the ploughbeam is pivoted, substantially as set forth.

No. 205.752.-J()HN 1.ANE, CHICA(i), ILL., assignor of one-half his right to the CHICACo P'LOLGH MaNLFACTURING: Company, same place.-Sulky-I'lourths.-July 9, 1878 . Filed January 15, 1878

Claim.-1.- The lever H, rod $d^{3}$, and carrier D, arranged and operating as shown, with rod-link $e$, extension $b^{1}$, and support $C$, all arranged and operating sulnstautially as shown, and for the purposes set forth.

2.-The leaver $H$. carrying the lock-lever $h^{6}$, with segment $G$, connected therewith, as shown, and operating with rod $d^{3}$ and carrier I), also with rod-link $e$, foot-roll $z c^{\prime}$, extension $b^{\prime}$, and support $\ell^{\prime}$, all arranged and combined substan. tially as shown, and for the purpose set forth.

3.- The carrier D, bent and formed as shown, and the ends of the arms pivoted on the pivot-centers $d d$, and ex. tended forward ol the axle to near the forward end of the plough-beam, where its forward end rests on top of the plough-lieam, and rod $d^{3}$, the lever $\mathrm{H}$, all arranged and operating ubstantially as shown, and for the purposes set forth.

4.- The lever $H$, rod-link e, extension $b^{1}$, and support $C$, arranged as slown, and having the foot-roll $w$ attached to the rod-link $e$, and all arranged and operating substantially as shown, and for the purpose set forth.

5.- The rod-link $c$, connecting the short arm $h^{1}$ of the lever $H$ and extension $b$, and the top end of rod-link $c$, extending and supporting the foot-roll $w$, as shown, all arranged and operating substantially as shown, and for the purpose set forth.

No. 205,827.-ISA.AC BERD.AN, CHATFIEI.D, MINS. -Sulkits for thoughs.-July 9, 1878, lifiled llav 22, $18 ; 8$.

(laim.-The combination, with the frame $a$, tongue $a^{2}$, and axle $b$, extended and formed into a crank, $e$, on the outer side of the wheel $b^{\prime}$, of the plate $e^{\prime}$, having slots $e^{\prime \prime}$, adju-ting arm $c$, provided with horizontal pils $c$, beam $d$, attached by suitable clevines, to plate $e^{\prime}$, so that its forwari end has a free vertical movement, and chain $f$; all arranged sulutantially as and for the purpose set forth.

No. 255,874 - SMILEY KIKKPATRICK, WATERMAX,

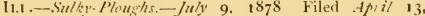
1878 .

Claim,-The crank-shaft k, provided with the lifting footlever $\mathrm{K}$, and a depressing foot-lever $\mathrm{M}$, both attached to said shaft, in combination with the rock-shaft $h$, provided with the lifting foot-lever II, the plough-heam $\mathrm{F}$, comnected at its rear and frost ends to the shafts, respectively, as specified, and the catch-springs $1 \mathrm{~N}$, sulutantially as and for the purpose set forth.

No. - 06,732.-R. S. IllliGiN.S, NFuga, I1.t.-K'iding Pliu, /ts, - August 6, 1878. Filed Dicemb r 29, 1877

Claim.-1.-The combination, with the beam A, standard $\mathrm{B}$, and share $(\mathcal{C}$, of the land-side $\mathrm{D}$, constructed with a vertical arm $d$, forming a hearing for the furrow-wheel, and the rod or bar $d^{\prime}$, for hracing sai $I$ arm to the heam and tanelard. sulnt.metially an-hown and described. 
2.- The combination of beam A, provided with plate 9 , having notches $\%$, the crank-axle $G$, the lever $K$, the loar $I$, fulcrumed to the bent lever $\mathbf{K}$, and constructed with a hook $l$, adapted to engage in said notches, and the supportingwheels $\mathbf{E}$ atd $H$, all aranged substantially as shown and described, for careening the plough in the furrow

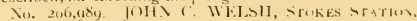

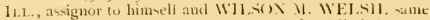
julace-Sulky-Plonghs.-Amgnst 13. 1875. Filed Jume 4. $18_{7} 8$.

Claim.-The lever-plate $m$, swinging and provided with fuot-piece luelow its fulcrum in combination with the tongue d and Jever $k$, having pin $l$, as and for the purpose specified.

No, 207.598, - JAY B, FISHER, I)AIFNP(ORT, JWWA -

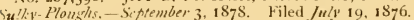

Claim.- I - I tubular axle having a slot, $a^{2}$, constructed substantially as and for the purpore specified.

2 - The crank-spindle 1 ), having the grooves $d$ and $d^{\prime}$. to operate submantially an and for the purpose specified.

3 - The combination of the crank-spindle $D$, having the grooves $d$ and $d^{1}$, with the tubular axle $A$, having slot $a^{2}$, screw $d^{2}$, and wheel to adjust the spindle $I$, substantially as and for the purpones specified.

4.- In combination, the crank-spindle 1 , having the urooves $d$ and $d^{\prime \prime}$, with the tubular axle-.l, screw $d^{2}$, wheel, and sami-circular rim E, for the purpsoz of leveling the sulky-frame, sulstantially as and for the purpose specified.

5 - In a sulky-plough, the combination of the lever $\mathrm{F}$ with the tubular axle $A$, having the slot $a^{2}$, and semi-circular lim $\mathrm{E}$, to operate substantially as and for the purpose specified.

6. - The bifurcated lock-lever $\mathrm{M}$, having the neck $m$, arm. $m^{1}$, and endis $m^{\prime}$, substantially as and for the purpone specilie. $i$.

7.-In combination, the lifurcated lock-lever $\mathbf{M}$, having the neck $m$, arm $m^{1}$, and ench $m^{2}$. with the lever 1 , semicircular rim $\mathrm{F}$, and the bifurcated arms $f$, to operate substantially as and for the purpose specified.

8.-In combination, the lifurcated lock-lever M, having the neck $m$, arm $m^{1}$, and ends $m^{2}$, with the lever $F$, samicircular rim $\mathrm{E}$, bifurcated arms $f$, and spring-lever $\$$, for the purpose of lockage, substantially as and for the purpose specified.

9 - The combination of the bifurcated arms $f$ with the lever $\mathrm{F}$, semi-circular rim $\mathrm{E}$, bifurcated lock-lever $\mathrm{M}$, and roke $U$, sub-tantially as and for the purpose specified.

I0. - In combination, the springr-lever $\mathrm{I}$ with the lever $f$ and hifurcated lock-lever $\mathbf{1 1}$, sulistantially as and for the jurpe se specitied.

11.-The yoke 1 , hasing a wivel bearng neck ", pro jecting rearwarl, for the purjuse of freeing the plough from obntacles by throwing the sulky-frame forward, substantially as and for the purpose yecitied.

12. - The combination of the yoke $\theta$, having a swivel bearing neck, $o$, with the bifurcated arms $f$ and bifurcated arms $P$, having a swivel-neck, $\rho$, and knee pin- $\rho^{2}$, sub-tantially as and fur the purpose specitied.

13.- In combination with the tubular axle A, having slot $a^{2}$, and plougls-beam, the operating device comisting of levers $\mathrm{F}$ and $\mathrm{X}$, bifurcated arms $f$, bifurcated lock-lever $\mathrm{M}$, senu-circular rim $\mathrm{E}$, yoke $(1$, bifurcated arms $P$, and kneepan- $\rho^{2}$, which also constitute the means for hingiag the tubular axle to the plough:-heam, sulutantially as and for the purpose precified.

14. - The combination of the hifurcated arms I' with the knee-pans $f^{2}$, plough-beam, and yoke $(1$, having the neck $o$, to operat: sulistantially as and for the purpose specitierl.

15.-The combination of the tubular asle A. having sluts $a^{2}$, with the spindle 1, , pin $a^{1}$, and wheel, subutantially as and for the purpose specified.

16. In comlination, the tubular axle $\mathrm{A}$, having slot $a^{2}$. with the spiadle $1, j^{\text {in }} a^{1}$, whel, and staple $\therefore$, having slot $b$, whith permits of the rising of the whecl-up, in the manner sulmtantially as described, without affecting the working position of the plough, substantially an and for the purpose specified.

17. - In combination with the tubular axle A, hasing sut $a^{2}$, spindle 3 , pin $a^{1}$, wheel, and taple $c$, having slot $b$, the

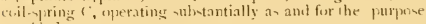
vecitied.
IS. - The combinatis of the taple $c$, having the slit $i$, with the $t$ ul ular axle A. substatially as and for the purpone yeciticet.

19.-In cumbination, the staple $r$, hasing the slot 1", with the tubular asle $A$, spindle 13 , jin $b^{\prime}$, and coil-spring $C^{\prime}$, suhstintially as and for the purpone yecifiect.

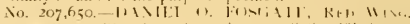

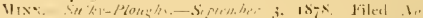
a, mber 26,1877 .

(laim.-1. - The combination of frame $A$, axles 1 , - tandard 1 , tongue supoit 1$)^{\prime}$, and tongue $\mathrm{E}$ in a sulky-ph ugh, as shown and described.

2.-The frame $\mathrm{A}$, having the central hemi, $\ell$, in comlination with the plough-leam passing through said hend and supported at the front of frame, subutantially as shown and de=cribed.

No. 2J7.674:--DEN NIS W. PAI.MEK, I)EI KUIT, MU.

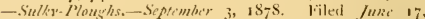
$1 S 78$.

Claim.-1.- The combination, with sulky and plough:heam, of the tongue $E$, having central flots $i c$, the lraces $J \mathrm{~K} \mathrm{II}$, the pirsted bars 1 . 1 . having jaws $h \mathrm{~m}$, and the link-connected levers, subtantially as shown and described.

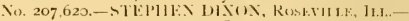

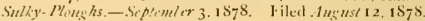

Clam.-I.-In a whed-plough, the taud side lar of the plongh, com-tumeted sulatatially as describer', and with a lower harpened edge to facilitat it, entrance into the ail when rained and lowesed by slight elevations under the land vide wheel, an and for the jur o-e pucitied.

2. - The land-side bar $\mathrm{F}^{\prime \prime}$ of a flough convulucted with a lower happened colge, athatatially as deraibed, and for the purju 4 yrecitied.

3.- In a wheel-plough, the brace $(i$, attochest st ome $\mathrm{cm}$ to the pliagh and at the other end to the whed-trame, in comlination with the plotgh, having the rear lower jeition

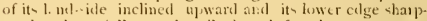
ened, sulstantially as descril ed, and for the faijone set forth.

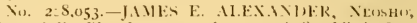

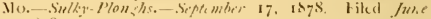
$7,358$.

('laim, - In a sulkv-l.luugh, the slutten arm $i$, hung loosely upon the axle 6 , in coml ination with the plate $b$, camsing the jeurnal for the wheel s, sub-tantially as aud for the jur. lic s: st f forth.

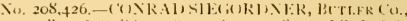

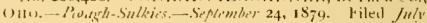
$2,1 S_{7} \mathrm{~S}$.

Claim.-1.- In a sulkyplongh, the comlination, with the main frame and plough beam, of the sul-frame 1 , the guide chain $a$, the lifting-lever and chain $\mathrm{I}()$, and the ad. justable non-lifting depresor $T$ ' $\mathrm{S}$, sulutantiantlly as buwn and yecified.

2. - The axle D, sub-frame I, articulating joint I, twi-ting. lever $\left(\right.$, radius bar II, connecting-roul $t_{i}$, and aljusting-lever $\mathrm{F}$, all combineal subiantially as ypecilicel.

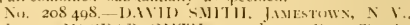

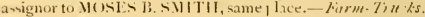
- Oitobir 1, 18,8 . Filed $/ u^{\prime}, 21,18,8$

Claim. The conl ination, with axle $A$, formed with the

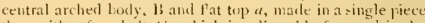
therewith, of eyetiolt $l$, wlich is adju-tably fa-tened it the selies of holes b, pasing transverely through saicl arched body, and in prosicled with lese link $1 \%$, tugicther with han.mer-trap, $\mathrm{E}$, projecting rearwarlly over said Pat top, snd formed with hook extremity e, subtantially as st ferti.

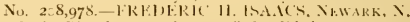

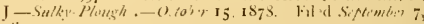
1577

(laim.-1.-The lever (; having the cut-otid $A$ and 13 , in combination with the connectiog-rod $(i$, crank $f$, law $1-1$ i, and notehed ugment 1 , wherely the lever is lucked to the drising-wheel and the plough rained or lustred by the for ward mosement of the machine, stumantially as whow $n$ and describer?.

2.- The combination of the lever $($, having the cut-affis I

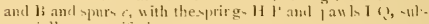
-rantially av-pecitied. 
3.- The combinatton of the ratchet $\mathrm{K}$ and gear-wheel 1 ., rigid upon the drivin $r$-wheel or axle, with the ratchet $k$, gear-wheel S, lever C, cut-offs A B, pawls I $Q$, springs H P, lu:s $n r$, and notched segment $\mathrm{D}$, substantially as set forth.

No. 209,067.-CHRISTIAN MIYERS, NAPA CITY, CAI. -Ploughs, - October 15, 1878 . Filed August 29, 1878.

Claim. - 1.- In a plough, the combination, with the axle D, provided with the arms $\mathrm{A} A$, having spindles $\mathrm{B} \mathrm{B}$ and studs C C, and the plough-beams E E, of the rod $G$, for connecting said beams at their forward ends, racks $\mathrm{H} \mathrm{H}$, having the lower right-angled portions $h h$ secured to said rod $\mathrm{G}$, curved spring-levers $K K$, liaving detents $L \mathrm{~L}$, and the perforated arms II N, the several parts constructed and relatively arranged to operate substantially in the manner herein shown and described.

2. - In a plough, the slip-share $P$, having tongue $Q$ and lug $\mathrm{U}$, the frog $S$ and fixed portion $\mathrm{T}$, having groove $\mathrm{R}$ anc slot $\mathrm{V}$, in combination with sliding portion $\mathrm{W}^{\prime}$ of land-side $\mathrm{W}$, having stud $a$, and bolt and nut $\mathrm{X} Y$, constructed and operating substantially as and for the purposes set forth.

No. 209.175 -JOH N LANE, HYDE PARK, lLL. -Sulky Plow $h s_{0}-O$ tiber 22,1878 . Filed Fune 13,1878 .

Claim.-1 - In a sulky-plough, the frame consisting of arch $\mathrm{B}$, foot-rail $\mathrm{C}$, tongue-brace $\mathrm{C}^{\prime}$, and elbow $\mathrm{E}$, combined with the axle $\mathrm{A}$ and tongue $\mathrm{I}$, all arranged and bolted or riveted together as shown, and operating substantially as and for the purpose set forth.

2 - The combination of the bent axle A, the arch B, the latter adjustably attached to the former by means of the bolts $b$, substantially as shown, the crank-axle $A^{\prime}$, the segment sleeve $a^{3}$, and the lever $a^{4}$, substantially as and for the purpose set forth.

3.- The rod-brace $\mathrm{F}$, havirg an eye at one end and a nut and screw-thread at the other end, combined with the arch $\mathrm{B}$, elbow $\mathrm{E}$, and tongue $\mathrm{D}$, all arranged substantially as and for the purpase set forth.

4.- The hanger $\mathrm{M}$, having slotted eye $m$ and grooves $v$, all substantially as shown, and for the purpose set forth

5.-The foot-lift $\mathrm{L}$, locked in position by the lever $\mathrm{R}$, lock-lever $r$, and link $L^{\prime}$, and the yoke J, hinged to the footlift 1 , by the bolts at $/$, and limited by the stop-hook $h^{1}$, and the yoke J, pivoting on the pins $h$ and arch $B$, and the plough-beam $K$, connected to the yoke $J$ by means of the saddle $\mathrm{P}$ and hangers $\mathrm{V}$, having slotted eyes $m$, all arranged and opsrating subst untially as shown, whereby the depth of ploughing is controlled and the plough kept in its steacly forwar l progress while the land-wheel is passing over ridges and furrows and the tongue is swaying laterally, as set forth.

6. - The combination of the bail-yoke J, having both limbi $j j^{\prime}$ extending forward of the axle, and the extensions havin $;$ two perforations, $l /$, and having a stop-hook, $h^{1}$, formed offiret at the bottom of the extreme forward end, all as shown with the fout-lift $L$, connected therewith, substantially as shown, whereby they are made rigid or flexibly connected, as shown, and with the $\operatorname{arch} \mathrm{B}$, the axle $\mathrm{A}$, and the plough heam $K$, all sulsitantially as and for the purpose set forth.

7.-The foot-lift $\mathrm{L}$, bent slape, having two arms and a closed end, and rear end of the arms $o o^{\prime}$ connected with the extensions $j j^{\prime}$ of the bail-yoke $\mathrm{J}$, and provided for both rifil and flexible connection, as shown, and the forward part of the arm 00 , bent upward, supporting the closed end an a foot-board rest, as specified, in combination with the bail yoke I, constructed substantially as shown, and with the arch B, the axle $A$, and beam $K$, all substantially as and for the purpose set forth.

8.-The combination of the plourh W, the beam $\mathrm{K}$, the latter hent curved and supporting plough $\mathrm{W}$. as shown, the slicing-plough IW', consisting of a share only, without turning mould-board, in advance of and above the cuttingline of plough $\mathrm{W}$, the beam $\mathrm{K}^{\prime}$, bent eurved and supporting slicinz-plough $\mathrm{W}^{\prime}$, and connected to the heam $\mathrm{K}$, and the revolving-clisk coulter $\mathrm{X}$, arranged to cut perpendicularly down by the side of and in advance of the slicing plough IV' to the depth of ploughing of the plough W, substantially as and for the purpose set forth and shown.

9.-The combination of the slicing-plongh $\mathrm{W}$, consi-tin of a share having an extending high breast, as shown, and for the purpose shown, and withoul a turning mould-board, plough W, having a turning mould-board, the plough W', arranged in advance of and above the cutting line of the plough $\mathrm{W}$, and the disk-revolving coulter $\mathrm{X}$, the latter ar ranged to cut down by the side. of and in advance of plough W' to the depth of ploughing of plough W, subutantially as and for the purposes set forth.

No. 209.283.-THOMAS MEIKLE, LOUISVILLE, KY. -Sulky-Ploushs.-October 22, 1878 . Filed August 31, 1878 .

Claim.-In combination, the U-shaped grooved standard $F$ and the stiding box $G^{2}$, with the plough $D$ attached out side of the wheel, as and for the purposes substantially as described.

No. 209,512.-CHAUNCY G. PRICE and JAMES M. MERRITT, TAma County, Iowa. - Sulky-Ploushs.October 29, 1878. Filed February 28, 1878 .

Claim.-1. - The combination, with a crank-axle macke with the two right-angular arms formed thereon, of the lever which is fulcrumed on the axle-spindle, and adapted to engage respectively with the outer extremeties of said arms by suitable bolt-connection, substantially as set forth.

2. - The combination, with a crank-axle provided with the two arms formed right-angularly on opposite sides thereof, of the lever, fulcrumed on the axle-spindle, and adapted to be engagred by bolt-connection with either one of the arms, said lever being made with the spring-ratchet, which engages with the segmental rack, substantially as set forth.

3.-The combination, with a crank-axle made with the two right-angular arms projecting respectively from opposite sides thereof, of the lever adapted to engage with the outer extremeties of the arms, said lever being made with a bifurcated lower end, which loosely embraces the axlespindle, and adapts the lever to be operated when connected respectively with either one of said angular arms, substantially as set forth.

4.- The adjustable clamp composed of the U-shaped side pieces, $l$, and tie-rods $l^{\prime}$, in combination with a plough. beam and bail and clamping-collars, whereby any width of beam may be secured either above or below the bail, substantially as set forth.

No. 209,688.-EDIVARD T. HUNTER, HALLSVILle, ILL.-Sulky Breaking-Ploughs.-November 5, 1878. Filed Septimber 9,1878 .

Clain,-1.-The combination, with the crank-axle D, of the disk $\mathrm{F}$, the pivoted angle plate $(;$, the spindle $\mathrm{H}$, the wheel I, the sliding plate J, the pivoted-rod $K$, and the lever $\mathrm{L}$, as and for the purpose specified.

2. The combination of the block $\mathrm{F}^{\prime}$, convexed and corrugated upon its upper side, with the lower block, E, concaved and corrugated upon its lower side, the four bolts $\mathrm{H}^{\prime}$, and the bottom plate, I' for connecting the plongh-beam adjustably with the axle $\mathrm{D}$, substantially as herein shown and described.

3. - The combination of the adjustable pin $\mathrm{J}^{\prime}$ with the bent axle I), provided with holes to receive it, and the blocks $\mathrm{E}^{\prime}$, provided with a ring-groove in their grooved faces, substantially as herein shown and described.

No, 210,137 -OLIVER S. MECHAM, Champaign, I1.L. - Wheel-Ploushs. - Vowember 19, 1878 . Filed August 17,1878 .

Clain.- The arrangement, in a wheel-plough, of the rectangular frame $c$, having seat-frame $l$ rigidly secured to the inside thereof, the axle $a$, provided with lever $m$ and four bearings, as described, and having the plough-beam pivoted to the central bent portion thereof, the slotted frame $f$, secured to the frame $c$, and having one of the end hearings of the axle in its lower end, the rack-bar $f$, wheel $r$, and lever $s$ all constructed and arranged to operate as described.

No. 210,147.-GEORGE P. PRICE, Carlisle Sta. TION, OHb.-Plough-Sulky anl Cultizatur. - Novemb'r 19, 1878 . Filed Oitiber 12, $1 S_{7} 8$

Claim.-In a plo agh-sulky, the combination of the frame $\mathrm{F}$, composed of the arms $f^{1} f^{1}$ and the short arms $f^{2} f^{2}$, provided with the removable frame $r^{\prime}$, the short arms $j^{2} f^{2}$ being adapted to be sprung into and removed from holes in the frames I) D, in combination therewith, and with the frame $\mathrm{E}$, composed of the arms $\mathbf{E}^{\prime} c e^{l} e^{2}$, and $z$, removably connected to a clamping-frame upon the plough-bean near 
its end, and adapted to be operated by suitable levers, as $\mathrm{G}$ $J$, for the purpose of permitting the plough-beam to be removed and replaced by cultivators, as set forth.

N J. 210,425.-DAVII W. HUGHES, BUTIER COUNTY, (OH 10.-Riding Plowghs,-December 3,1878 , Filed Febru. ary 9,1878

Claim.-1.-The combination, with an axle of a ridingplough sulky, of a side-frame consisting of the angular bar $E$, having a vertical and horizontal branch, and the bar $F$, having a horizontal and inclined branch, converged to form a plate for a pivoted tongue in front, substantially as specified.

2.-In combination with a sulky-plough frame and a plough outside of the wheels, the angular arm H, pivoted to the axle, the arm-brace $g$ attached to the plough-beam and coupled therewith, and the lever $\mathrm{J}^{\prime}$, fulcrumed on said axle and connected with said arm, substantially as specified.

3 -The combination, with a plough and its carriage, of the vibrating brace $\mathrm{H}^{\prime}$, the connecting-rod $\mathrm{J}$, and a lever $\mathrm{K}$, as and for the purpose specified.

No. 210,559 - JAMES SHERRILL, HARRISBURg, OREGON.-Gany Cultivators and Seeders.-December 3, 1878 . Filed $J \boldsymbol{u} / \mathrm{y}: \mathbf{2 7}, \mathbf{1 8 7 8}$

Claim.-1.-In a gang-cultivator, the combination, with a diagonal cross-bar, to which the forward extremeties of the plough-beams are secured, and which is adapted to move the ploughs collectively to or from the land, of levers and connecting mechanism adapted to vary and maintain said har in any desired vertical adjustment, substantially as set forth.

2.- The combination, with a diagonal cross-bar, to which the forward and downwarlly-curved extremeties of the plough-heams are secured, and a second diagonal cross-bar, to which the rear arched portions of said beams are loosely connected, so as to have free vibratory movement in a lateral direction, of a lever which engages with said front diagonal cross-har and operates the same in a rocking motion, whereby said plough-beams are thrown to or from the land, substantially as set forth

3.-In a gang-cultivator, the combination of the two diag onal cross-bars, to which, respectively, the forward and rear bodies of the plough-beams are connected, said bars being adapted to be independently varied in adjustment to or from the ground, and said forward cross-bar being adapted to be laterally moved or rocked, substantially as set forth.

4.-A gang-cultivator constructed with a bar, to which the plough-beams are secured, and which is capable of moving the ploughs laterally to or from the land, in combination with with mechanism adapted, respectively, to vary the degree of the angular inclination of the plough-points to the ground, and to bodily raise or lower the ploughs relative to the lat ter, substantially as set forth.

5.- The combination, with the front diagonal cross-bar, having depending clamp-pieces on its under side, to which the plough-beans are pivoted, of the upright lever, provided with a spring-clamp, and the horizontal locking-bar, having notchen with which the side projection of said lever engages, sub-tantially as set forth.

6.- The comlination, with the front diagonal cross-bar, to which the plough-beams are indirectly pivotcd, of the levers attached to the top frame, and the connecting. links secured to opposite ends of the cross-bar, sajd levers being adapted to engage with rock-bars, substantially as set forth.

7.-The comlination, with the front diagonal cross-bar, to which the plough-beams are indirectly pivoted, so as to have independent vertical movement, of the central draft-clevis, connecting by rods with the axile-tree and said diagonal cross-bar, the latter being provided with rod-connecting clevises, which are longitudinally adjustable thereon, substantially as set forth.

8.- The combination, with the top frame, having loop engagement with the axle-tree at its forward end, and provided with a caster-wheel at its rear end, of the rear diagonal cross-bar, supporting the plough-beams by loops, and connected with the top frame lib bell-crank levers, which latter are operated by a hand lever and intermediate connecting links, said hand-lever engaging with a rock-bar, substantially as set forth.

No. 210,830.-GEORGE ARMSTRONG and ROBERT ARISTRUNi, executor of IAMES ARAISTRUNG, IR., deceased, ElMIRA, ILL.; said ROBERT ARMSTRONG assignor to said GEORGE ARMSTRONG. - Gan Plows hs.-December 17, 1878 . Filed February 25, 1878 .

Claim.-In a gang.plough, the combination of the perforated cross-bar $\mathbf{C}$, the adjustably-pivoted draw-bar $\mathbf{B}$, the perforated movable $\mathrm{D}$, pivoted lever $\mathrm{G}$, and segmental rack $K$, all substantially as and for the purpose herein set forth.

No. 210,867 -WILLIAM W. MARSH, SYCAMORE, IL..-Sulky.Ploughs.-December 17, 1878. Filed April 16,1878 .

Claim.-I - The frame formed from a single piece, and having a vertical portion, $\mathrm{B}^{\prime}$, provided with a head to re ceive the sliding head for operating the land-wheel, and a vertical portion $\mathrm{B}^{\prime \prime}$, provided with an opening $\mathrm{C}$, all substantially as and for the purpose specified.

2.-The frame formed from a single piece, having the vertical portions $B^{\prime} B^{\prime \prime}$ to receive the spindles for the wheels, and provided with the opening $\mathrm{C}$ and the recess or shoulder $D$ for attaching the tongue-support, substantially as specified.

3.-The reversible head $\mathrm{W}$, provided with hub $g^{\prime}$ and pins $e^{\prime} e^{\prime}$, and carrying the spindle $\mathrm{D}^{\prime}$, in combination with a supporting-head and devices for enabling the spindle to be reversed when worn, substantially as specified.

4.- The pivoted plate $P$, provided with the ears $n$ and with the projections $i$, which form spaces $j$ between them, in combination with the bail or swinging frame $Q$, the rod $o$, and the plougl-beam, substantially as and for the purposes herein set forth.

No, 210,992,-HUGH B. CANADAV, FAIRFIEI.D, lowa.-Ploughs.-December 17, 1878. Filed Nozember 9,1878 .

Claim.-The combination, with the platform $\mathbf{A}$, having depending hangers $\mathrm{E}$, the vertically-vibrating bail $\mathrm{F}$, pivoted thereto, and the beam $G$, coupled to said bail at its front end, of the swinging bail $\mathrm{H}$, it; operating-lever $\mathbf{l}$, the ratchet $\mathrm{J}$, and the clevis-bail $K$, vibrating on the bail $\mathbf{H}$ and coupled to the beam, substantially as specified.

No. 211, CO7.-GEORGE W. GREENER, LONG POINT, ILL.-Sulky.Ploughs.-December 17,1878 . Filed June Io, 1878

Claim.-The axle $a$, having the U-shaped bend at or near its center, the said bund being made to support the seat, and just wide enough to act as a guide for the plough-beam, and to receive the roller over which the clevating chain passes, substantially as shown.

No. 211.372.-ORLANDO BARR, ElgIN, Ill., assignor of one-half his right to GEORGE P. LORD, same place.-Sulky Gans-Ploughs.-Janut'y 14, 1879. Filed February 21, 1878 .

Claim.-1.- In a sulky for ploughs, the main axle A, constructed with double bonds, whereby a central closed stinup adapted to receive and guide the front end of a plow-beam is provided, substantially as described.

2.- The main axle A, bent as set forth to form a closed stirrup, in combination with the plough-beam $\mathbb{E}$, arranged within the stirrup, which serves as a guide and sulpont thereto, substantially as described.

3.-In a sulky.plough, the main axle bent as set forth to form a closed : tirrup, in combination with the plough-beam, arranged with a loose joint within said stirrup, which serves as a guide and suppost thereto, whereby the axle may be tilted at either end without affecting the fosition of the ploughs, substantially as described.

4. - The main axle $\mathrm{A}$, provided with the stirrup $a$, in combination with the clamps $F$, provided with lugs $f$, which in. close the sides of said stirrup to make a loose joint, and the plough-beam E, substantially as clescribed.

5.-The clamping-irons $\mathrm{F}$, having their outer surfaces convex, and provided with lugs or projections $f$, substantially as described.

6.-The plough-beam $\mathbf{E}$ and clamp $F$, arranged to move in the axle-stirrup $a$, in combination with the link-rod $G$, provided with a slot $g$, coupled to the clamp F, and the lever II, substantially as described.

No. 211 425.-JACOB PRICE, SAN LEANDRO, CA1.Sulky-Plowh - Janu wy 14, 1879 . Filed September 12, is 8 S. 
Claim.-1.-In a sulky-plough, the combination of the axle $($, having the fixcd crank $D$ and the loose spur-whecl $H$, with the loose journal-crank $D^{\prime}$, the spindle-shaft $F$, pinion $(i$, and brake 1 , as and for the purpose specified.

2.-In a sulky-plough, the combination of the rigid ploughframe $\lambda A^{\prime} 1$, the double-crank axle, the pinion $G$, spur wheel $\mathrm{H}$, brake $\mathrm{I}$, and levers $\mathrm{K} \mathrm{N}$, substantially as shown and described.

3.-The combination of the double-crank axle, the gear wheels G H, corrugated brake I J, foot-lever K, locking lever $\mathrm{N}$, and segment $\mathrm{M}$, with adjustable stop, substantially as shown and deseribed.

No. $211,626 .-M A X$ J. FREEMAN, Walla Walia, W. T.-Sulky-Ploughs.-Jantury 28, 1879 . Filed October 21,1878 .

Claim. - 1.-The bed-plates B $\mathrm{B}^{\prime}$, the transverse shaft $b^{\prime}$ the pisot $b$, the foot-lever $\mathrm{F}^{\prime}$, main axle $a$, wheels $\mathrm{A} \mathrm{A}^{1}$ hand-lever $F$, the upright frame $C$, supporting the ploughbeans carrying ploughs, all said parts being combined, constructed, and arranged to operate substantially as set forth.

2. - In a gang-plough, the combination of the eccentric having cam-arm, the plough-beam having oval yoke-bar, the chain-connection of cam-ann with foot-stanchion, the handlever to operate said eccentric, the guicle-frame, all said part being constructed and arranged as shown and described to operate the plonghs for vertical adjustment, as and for the purposes set forth.

3.- In a gang-plough, the plough-beams carrying ploughs, the oval yoke-bar, the eccentric having cam-arm the chainconnection of cam-arm with foot-stanchion, the hand-lever to operate said eccentric, the guide-frame having its lower end secured to a transverse shaft, the plough-truck having bed-plate part, to contain said shaft, all said parts being combined, constructed, and arranged as shown and deseribed, to operate in the manner, and for the purposes set forth.

4.- The hand lever $\mathbf{H}$, the segment-bar $h$, the collars $g g$, the arms $g^{1} g^{2}$, and the connecting rod $g^{3}$, in combination with the plough-beams carrying ploughs, the standards of which pass through said collars, by means whereof the lateral adjustment of the ploughs is achieved, in the manner and for the purposes set forth.

No, 211,662 - FRANKLIN B. HUNT, RichwoND, IND.-Sulky-Ploughs.-January 28, 1879 . Filed March 27,1878

Claim.-1.-In a wheel or sulky plough, the combination, with the plough-beam, of a circular vibrating leveling block, through which the plough-beam passes, subsantially as set forth.

2.- In a wheel or sulky plough, the combination, with the plough-beam, of the laterally-vibrating leveling block, through which the plough beam passes, and the longitudinal ly-vibrating bearing blocks, connected directly to the crank axle, substantially as set forth.

3-In a wheel or sulky-plough, the combination, with the plough-beam and adju-table crank-axle, of the pivoted bear ing-blocks $\mathrm{F} \mathrm{F}$ and circular leveling-block $\mathrm{E}$, forming a direct connection between said plough-beam and crank-axle, substantially as set forth.

4.- In a wheel or sulky-plough, the combination of the seat-arch, the stationary furrow-wheel axle, and the crankaxle, said furrow-wheel axle arranged below the line of the crank-axle, and both directly connected to and by said seat arch, and each operating independent of the other substantially as herein shown and described.

5.- The combination, with the plough-beam, of the slot ted circular leveling-block E, provided with lugs for the reception of pins orbolts, to secure the plough-beam thereto, substantially as specified.

6. The combination of the slotted circular leveling-block $\mathrm{E}$ and the adjustable pivoted blocks $\mathrm{F} F$, provided with in terior bearing for supporting said leveling-block, substantially as specified.

7.- The combination of the seat-arch provided with the lug $\mathrm{N}$ and the slotted seat or foot-rest suspended thereon, and the bolts or screws for adjustably securing the seat or foot-rest in any desired position, substantially as specified.

$8-$ In a wheel or sulky-plough, the combination, with the plough-beam and seat-arch, of the leveling and pivoted bearing block and crank and furruw-wheel axles, directly at tached to said seat-arch, one above the line of the other substantially as herein shown and described.

9. - The seat-arch provided with two extended socketed bearings, P P, cast with and forming a part of the seat-arch, as and for the purpose herein shown and described.

10.- The quadrant attached to the seat-arch in rear and to the tongue-bearing in front, in combination with the lever and the segment $\mathrm{K}$, pivoted to the lug $I^{\prime}$, attached to the seat-arch, substantially as specified.

II. - The seat-arch provided with the bearings for the crank and furrow-wheel axles, tongue, segment $\mathrm{K}$, and quadrant $\mathrm{M}$, substantially as specified.

12.- The seat-arch provided with the bearings for the crank and furrow-wheel axles, quadrant M, and double bearings for the tongue, cast as integral parts of said seat-arch, substantially as set forth.

13.-The pivoting-blocks F F, attached to the crank-axle, in combination with bolts or serews, by means of which the leveling-block E, attached to the plough-beam, is clamped and held in position when adjusted, sulsstantially as set forth.

14.- In combination with the crank-axle and segment I, a detachable segment, $K$, whereby the plough may be permitted to play automatically, substantially as shown and described.

No, 211 666.-LEROV BROWN, WaitsBurg, W T.Sulky-Plou, ths.-January 28, 1879 . Filed June 13, 1878 .

Clain.-The plate I, bolted adjustably to the frame E, in combination with the tongue $\mathrm{K}$, the lever $\mathrm{L}$, and the hinged pin $\mathrm{N}$ as and for the purpose described.

No. 211,724 .-DANIEL O. FOSGATE, ROCHESTER, MiNv.-Sulky-Ploughs.-January 28, 1879 . Filed November 15,1578 .

Claim.-The combination of the centrally pivoted tongue embracing and sliding on the post J, the curved bar $\mathrm{O}$, having notehes formed in its convex slide, the sliding loolt $\mathrm{P}$, and the pivoted lever $Q$ with the horizontal har $K$, brace $L$, frame $\mathrm{F}$, and axle $\mathrm{A}$, whereby the tongue may be fixed or freely vibrate in a vertical plane, substantially as shown and described.

No. 211,968,-ALBERT D. BLANCHARD, HuTCHInson, Kansas.-Whel-Ploughs.-February 4, 1879. Filed June 20, 1878 .

Claim.- t.- The combination of the eccentric $d$, lever $e$, and ratchet $c$ with the slotted lever $a$, catch $n$, stanclard $b$, plough-beam $h$, and frame, substantially as shown and described.

2.- The eccentric $d$, made rigid upon the lower end of the lever $e$, and provided with the ratchet-plate $c$, having a slot, $s$, and being actuated by the spring-cateh $f$, substantially as shown and described.

No. 212,234 -GEORGE KIMBALL, LAWRENCE, KANsas. - Wheel-Ploteghs,-February 11,1879 . Filed Decem. ber 30,1878

Claim.-The frame A, having the plough connected to its outer side so as to run just in front of the small wheel $U$ by means of a pivot-plate, $R$, the front end of the frame being made to catch in the clasp or elip $\mathrm{U}$, secured to the plough so as to limit the distance which the plough will turn substantially as described.

No. 212.34I,-JAMES R. WHITNEV, MAGNOLIA, Wis.-Sulky-Ploughs.-February is, i879. Filed Oc'obe' 23, 1877 .

Claim.-The combination, in a sulky-plough, of the beam formed of two bars, $a d$, standing edgewise, having the rear ends bolted to the axle and their forward ends curved, as shown, the standard-socket $B$, arranged between and boited to said hars, and the shank of the plough adjustable vertically in saicl socket, all construeted and operating as described.

No. 212,750.-CASPER F. SEARCH, CHICAGO, II.L.. assignor of one-half interest to JOHN C. COONILE, same place.-Sulk1-Ploushs, - February 25, I879. Filed September 25,18

Claim.-1.- The combination, in an adjusting device, of a crank-axle journaled in swinging bearings, a spur-wheel mounted on the said axle, and a rack engaging the caid wheel, substantially as specified.

2.-The combination of the swinging hearing $\mathrm{B}$, the 
axle $\mathrm{D}$, carrying a crank-arm, the wheel $\mathrm{C}$, mounted on the said axle, and the rack $G$, all operating together substantially as specified, in connection with an adjustinglever and a bolt or catch.

No, 21 2,919.-BENJAMIN FRANKLIN, JAMESTOWN N. Y.-Ploughs and Farm Trucks,-March 4, 1879. Filed December 4,1878 .

Claim.-1.-The combination, in a farm truck, of the draft-pole $\mathbf{A}$ and $\mathrm{U}$-shaped clevis $\mathbf{F}$, having slots $f$, and adapted to embrace and slide vertically upon the rear end of the draft-pole, the draft-rod I, pivoted to said draft-pole, extending rearwardly through said clevis, and provided with look $k$, substantially as specified.

2.-The combination, in a farm-truck, of the draft-pole A, curved sectional frame B, forming journals $c^{\prime}$ for the axle $C$, carrying the adjustable wheels $D$, the $U$-shaped clevis $\mathbf{F}$, provided with adjusting slots $f$, engaging bolt $c$ on the rear end of said pole, and the longitudinal draft-rod I, passing through said clevis, connected to the draft-pole, and provided with a loop, $k$, whereby a plough or other farm implement may be attached, as specified.

No. 213,178 - JOHN R. CUMAINS, MCKINNEY, Texas.-Attachments for Ploughs.- March 11, 1879 Filed Dicember $2 \mathrm{r}, 1878$.

Claim.-The combination, with a ploug-beam, A, and a circle-plate, $\mathrm{B}$, provided with transverse rib $a$, and having said beam clamped thereto, of the bearing-plate $C$, having transverse sleeve $d$ extending beyond the edges thereof, an axle, $\mathrm{D}$, extending through said sleeve, a pivot-bolt, $f$, con necting the circle and bearing plates, and adjustable collars $d^{\prime}$, substantially as specified.

No. 213,614-JOSEPH BLACK and T. PATER, Al TON, IIL., assignors to IIAPGOOD \& CO., ST. LoUis, Mo,-Sulky-Ploushs,_-March 25, 2879 . Filed Februury 13, 1878 .

Claim.-1.-The foot-rail C, consisting of a bent bar, U-sheped, and the end of one of the arms extending bent upw:arl, forming the seat $c$, for supporting the tongue, and both arms attached to the arched axle $\mathbf{A}$, all substantially a showu, in combination with the arched axle $\mathrm{A}$, tongue $\mathrm{D}$, and brace $\mathbf{E}$, all constructed to operate as described.

2.-The brace E, provided with flanges $f f^{\prime}$, embracing the sides of the tongue, and with seat $c^{\prime}$, in combination with the tongue $\mathrm{D}$, foot-rail $\mathrm{C}$, and arched axle $\mathrm{A}$, all constructed to operate as described.

3.- The sulky-plough frame consisting of the arched axle $A$, tongue $D$, and foot-rail ( $i$, provided with one arm extending bent upward, forming the seat $c$, and both arms attached to the axle, and brace $\mathbf{E}$, provided with flanges $f f^{\prime}$, all constructed and arranged to operate as shown.

4.-The combination of the beam $K$, adjusting-rod $I$, bai $J$, provided with extension $\mathrm{P}^{2}$, link $\mathrm{P}^{3}$, and lever $\mathrm{S}$, provided with means for adjustable stoppages, segment $\mathrm{R}$, tongue $\mathrm{D}$, and arched axle $\mathrm{A}$, all constructed to operate substantially as shown.

No, 213.623 -JOHN ClAYTON, Clayton Grange FARM, ( BralNARD P. O.,) MinN. - Gang-Ploughls.-March 25. 1879. Filed Decembir 10,1878

Claim.-1.-The arms A A, provided with the slots D, and pivoted at their centers, and through the said slots to the under side of the beam, and at the ends to the sicle beams, B B, substantially as herein shown and described, and for the purpose described.

2.-The flanged side beams, B B, attached to the ends of the arms A A, and provided with slots, by means of which, and bolts and screws, the hangers $\mathrm{C}^{\prime} \mathrm{C}^{\prime}$ and the posts $\mathrm{B}^{\prime} \mathrm{B}^{\prime}$ may be adjusted and secured at any desired inclination, substantially as herein shown and described.

3.-The side brackets, substantially as shown and described, on the clevis end of the beam, for preventing the rods from being pulled out of upright position by the action of the lever.

No. 213.717 -TOSEPH WARWICK and AI.FRED T. WARWICK, FRANKIIN, assignors of one-half their right to SARAH CIEAVER, WEST CARROLLTON, OHIO.Pluzhth-Sulkies.-March 25. 1879 . Filed March 30, 1878 .

Claim.-1.- The combination, with the seat, of the sup porting crosa-bar provilerl on one of its vertical sides with a pivot or lug, upon which said seat is pivoted, substantially as shown and described.

2.-The combination, with the seat-support, of the seatpivoted thereto and adlapted to he rocked or vibrated laterally thereon, substantially as shown, and for the purpose set forth.

3.- The combination, in a whecl-plough, of the laterallyvibrating plough-beam and the pivoted seat, adapted to vilorate or rock laterally upon a horizontal axis, substantially as and for the purpose described.

4 - The combination of the loosely-slicling stirrup J, casting $\mathbf{K}$, with tube $k$ and recess $x$, the adjustable levelingplate $\mathbf{I}$, and the bolts $h$, plate $m$, and nuts $i$, all substantially as and for the purposes herein set forth.

5.-The combination of the stirrup J, which slides loosely through the pivoted tubes $d d^{\prime}$, and the elbow-lever $\mathrm{N}$, with eye $n$, substantially as and for the purposes herein set forth.

No. $213.9 ; 6$. - LENUEL M. KELI.Y, LITCHFIEID, KY.-Gang-Ploughs.-April I, 1879. Filed December 7,1878 .

Claim.-The combination of the tongue and axle frame, having $\operatorname{rod} d$, with eyes $p h$, the plongh-beams $0 o$, connected at the rear by a laterally-adjustable lift-frame, and in front with the eye $p$ of tongue-frame, and the lever $i$, arranged as shown and described.

No, 214,396. - THONAS E. JEFFERSON, BOSTON, MAss.-Sulky-Ploushs.-April 15, 1879 . Filed October 28,1878 .

Claim.-I.-In a plough, the chais or its equivalent $k$, arranged as shown, for the purpose of securing the mouldboard frmly in place to the fulcrum $g$, around which it swings, sulstantially as set forth, by which the ordinary support from the land-side is dispensed with.

2.-A wheel-plough having two supporting-whecls in the same transverse line, one of which is arranged to run in a land-stde furrow and the other in an open furrow previonsly formed, and one or more ploughs having the long mould. board or mould-boards adapted to extend back and sidewine sufficiently to embrace the entire space between the wheek, and to invert the soil behind the furrow side wheel, subst mtially as described.

3.- In combination with the swinging mould-board $H / 4$ and its stationary frame $a$, the stationary knife or cutter $i$, as and for the purpose set forth and de-cribed.

No 214 440.-IUSEPH M. PAVNE, BoONVILI.E, Mo.Sulky-Ploushs. - April 15, 1879. Filed October 23, 1878

Chaim.-The plate $O$, having bearings $N$ N, bolts $T \cdot T$, and plate $S$, in comlination with the slotted rack $R$, strad. dling the bolts $\mathrm{T} T$, and having eye $Q$, caster-wheel $l$, having shank $\mathrm{M}$, swiveled in the bearings $\mathrm{N} N \mathrm{Q}$, and the segment-lever W V, for operating the rack, the whole arranged and operating substantially as described, for the purpose set forth.

No, 215,268,-EDWIN \&. DANIEI, RUTI:R, MoSully-Plousths. - M/ay 13, 1879. Filed February 11, 1879.

Claim.-1.-The combination, with rock-shaft L, provicl. ed with a rearwardly-extending arm, $\mathrm{Il}$, and forwardly-ex tending slotted arm $\mathrm{K}$, and lever $\mathrm{l}$, provided with a stud $i$, working in the slot $k$ in arm $\mathrm{K}$. of the plough-beam $\mathrm{N}$ and chains S. , substantially as described, for the purpose set forth.

2.- The combination, with the sulky-frame, having de pending brackets or hangers $\mathrm{R} R$, crank-shaft $Q$, and rockshaft $\mathrm{L}$. provided with arms $\mathrm{M} \mathrm{K}$ and lever $\mathrm{I}$, of the plough bean $\mathrm{N}$ and chains $\mathrm{S} S \mathrm{~S}$, substantially as described, for the purpose herein set forth.

No 215,346 , - ISAAC R, GILBERT, LoUISVIILE, $\mathrm{kY}$. -Sulky-Pli w- hs.-May 13, 1879. Filed March 13, 18;9.

Claim.-1.-The flanged bracket I, removably attached to the clbow-lever $K$, as and for the purposes herein set forth.

2.-The movable arm $M$ and rock-shaft $h^{\prime}$, in combina. tion with plough-team $A$ and tubular bearings $B^{\prime} B^{\prime}$, substantially as and for the purpose set forth.

3.-The lever $O$, combined with the elbow-lever $P$, spring-pawl $p$, and roller $r$, substantially as lierein set forth. 4.- In a sulky-plough, the arrangement of devices, sul)stantially as herein described, whereby the spring-pawl that engase; with the rack and the pawl that engage, with the 
1.itchet wheel on the hub may be operated simultaneously for raiving the plough from the ground.

5.-The foot-lever $S$, provided with the projections $s$, , in combination with the roller $r$ and spring pawl $\rho$, substan. tially as and for the purposes hercin set forth.

6.- The combination of the foot-leser $\mathrm{S}$, slotted link $\mathrm{V}$, lifting-1naw $\mathrm{W}$, and ratchet-wheel $\mathrm{V}$, substantially as and for the purposes herein set forth.

No. 215.918 - MILO HARRIS, JAMESTOWN, N. Y..Fiarm Tirucks or Dranshlat Atuchments for Plousths or Har. renes.-1hay 27, 1879 . Filed Nozember 9, 1878.

Claum,-1, - In farm-trucks, the cast standard 1), having cap $\mathrm{E}$ and mortise $h$ formed thereon, in combination with spring $g$ and seat $(i$, constructed in the manner substantially as shown and described.

2 - In combination with a plough attached to a farm truck by a loose joint, the plough-holder $\mathrm{P}$, having wheel or wheels $U$ and adjusting-chain $K$, substantially as shown and described.

3 - The combination, in a farm-truck, of the main axle C, the adjustable arm-spindle $c$, and the cast standard I), having cap $\mathbf{E}$ and mortive $h$, with the gain at the bottom, and projection for attaching the braces $\mathbf{L}$, substantially as shown and described.

No. 215 929.-THOMIAS E. JEFFERSON, BOSTnN,

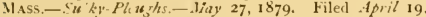
1879

(laim.-1.-In a sulky-plough, two or more ploughs ar ranged abreast of each other, and having mould-boards or s!ares of approximately equal length opposite each other, and having between their inclined opposite surfaces an unobstructed space, in order that the slice or turne 1 earth of the land-i le share or mould-board may be thrown and inverted into the furrow formed by the furrow-side plow, substant ally as described.

2. The combination, with the ploughs, of the beveled bea ing wheels $b b^{\prime}$ and the coulter-bearing whee's $d c$ whereby the lateral strain is resisted at both ends of the plough, and the same caused to run straight, subtantially as described.

3. - The combination of the two rear bearing-wheels, $b b^{\prime}$, and the self-locking levers $" \|^{\prime}$, for the purpose of elevating the ploughs, substantially as set forth.

4.-The combination, with the pivoted or fulcrumed ploughs, of the rigid adjustable braces or stays $v v^{\prime}$, connected to the rear cnd of the mould-board $S \mathrm{~S}$, whereby the mould-Loard may be adjusted in either direction and firm ly held in position, substantially as described.

5.- The combination of the adjustable braces $v v^{\prime}$ with the double hearings and fulcrumed in the bifurcated levers $u u^{\prime}$ for the purpose set forth.

6. - The bearings and fulcrum in levers $\boldsymbol{u} \boldsymbol{u}^{\prime}$, as constructed with hanging l.rackets $n n n n$ from the main axle 0 , as and for the puryose set forth.

7.- (ne or more revolving disks, $x$, arranged at the rear end of the nould-toard, for the purpose of pulverizing and invertiug the soil, sub-tantially as described.

8. - The combination of one or more ploughs, $S$ S', movable on fulcra $m m^{\prime}$, with braces or stays 1616 and $z^{\prime} z^{\prime}$, as and for the purpose set forth.

9.- The combination of the notched arms or levers 1989 rocking wheels 99 on shaft 8 , main shaft $o$, and levers $u u^{\prime}$, as and for the puipose set forth.

1).-In combination with rocking-ploughs $\$$, locking-le ver $u$, and sliding horizontal notched link, 19, as and for the purpose set forth.

II.-The combination or sliding-pole $\mathbf{1 2}$, pole-shaft 8 , and disks 99 , as and for the purpose set forth.

12,- The combination of the pole 12, spring 15 , pole-shaft 8 , disks 9 9, and notched levers or links 19 19, as set forth. $1:-$ - The wheel $e$, having frojecting trom its periphery The continuous amnular cutting and bearing rim, having a sharp edge and concave faces, substantially as and for the purpose set fortl.

14 - The herein described self-adjusting elastic seat I, with it, adjustable foot-rest 3 on the foot-bar 2 , ear 4 , bolt 5 , 5 ming 6 , and st $n$ lard 7 , as and for the purpose set forth.

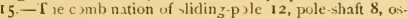
cil'ating clisk=9 9. link 19. and elf-locking lever $u u^{\prime}$ with rear bearing furrow wheels $b b$, for the purpose of elevating the ploughs, substantially as set forth.

I6.- The plough having the upward-projecting bifucated standard fulcrumed to and embracing backet i $r$ support $n n$, projecting downward from the frame, substantially as described, and for the purpose set forth.

No, 216,375. - IIERCER BROWN, VERMHLION Grove, II.L.,-Sulky-Plough Attachments.-June 10, 1879. Filed April 7,1879 .

Claim.-1.-In a sulky plough, the axle A, having the nght angular bend $k$ at one end and the obtuse-angular bend $b$ at the other, in combination with a slide, E, working on the latter bend, and actuated by a lever mechanism to tip or tilt the plough, substantially as specified.

2.- In a sulky-plough, the sub-frame consisting of the bail $H$, the sliding cross-rod $G^{\prime}$, the axle $A$, having incline $b$ at one end, the slide on said incline, a lever mechanism raising or lowering said slide, and a plough-beam suspended from said bail, substantially as specified

No. 216,415 - THONAS E. JEFFERSON, BOSTON, MAss, -Sulky-Ploughs. - June 10, 18;9. Filed Buy 17 1879

Claim_-1.-The axle B, anti-friction pulley $\mathrm{C}$, arms $\mathrm{C}^{\mathrm{T}}$ and friction-roller $\mathrm{C}^{2}$, combined with the knife-arm $\mathrm{D}^{1}$ pivoted at $d^{1}$, to give upward stroke to the knife, as and for the purpose set forth.

2. The knife-arm $\mathrm{D}^{1} \mathrm{D}$, having knife $\mathrm{D}^{2}$, as shown, combined with the eccentrics $\mathrm{C}^{1} \mathrm{C}^{2}$ and cutting guides $d^{2}$, as set forth.

3-- The curved bars E, carrying the ploughs, combined with the adjustable frame $\mathrm{F}$, as set forth.

4.-The adjustable frame $F$, combined with the operating thumb-nut $f^{\prime}$, and with springs $f^{2}$ above and below, as specified.

5.-The adjustable harrow composed of the shaft $\mathrm{T}$ and dinks $T^{2}$, combined with the slot $t^{\prime}$ in the frame $T^{1}$ and proper securing devices, whereby the said harrow may be adjucted independent of the mould-board, as specifierl.

6.-A double-slotted sliding tongue, combined with a double-tree and an intervening spring, $\mathrm{J}$, as and for the purpose specified.

7.-The sliding slotted tongue and double-tree and spring $\mathrm{J}$, combined with an elbow-lever, $\mathrm{H}$, and chain $\mathrm{I}$, for rais ing the points of the ploughs out of the ground, by the draught, as specified.

8.-The tongue, draught-chain $\mathrm{I}$, and ellow-lever $\mathrm{H}^{\prime}$, combined with a self-adjusting king-bolt, $K$, pawl $\mathrm{K}^{1}$, and notches $K^{2}$, as set forth.

9. - The self-adjusting king bolt $\mathrm{K}$, pawl $\mathrm{K}^{-1}$, and notched tongue $\mathrm{K}^{2}$, combined with pedal $\mathrm{L}, \mathrm{l}$, elbow-lever $\mathrm{H}^{\prime}$, and chain 1 , connecting with draught, as set forth

Io.- In a sulky-plough, the combination of the slotted hollow hing-bolt $K$, pawl $K^{1}$, pedal-lever $\mathrm{L}$, and draught, as specilied.

11.-The spring draught-bar $\mathbf{M}^{4}$, combined with the king-bolt $K$, frame $\mathbf{M} \mathbf{M}^{1}$, and draught, as and for the purposes set forth.

12.-The elbow-lever $\mathbf{H}^{\prime}$ II, having pulleys $\mathrm{g}^{\prime}$, and the draught and connecting-chain, with the plough-frames $G$, with jaws $G^{1}$, as and for the purpose set forth.

13.-The elbow-lever $I^{\prime} H$ and plough-frames $G^{\prime} G^{1} y^{\prime}$, combined with the rod 11 , nut 13 , and spring 12 , which overbalances the soil, as and for the purposes set forth.

14.-The sping 12, rod 11, and adjusting-nut 13, to counterbalance the soil upon the ploughs, combined with the plough-frames and the main frame $A$, as set forth.

15. - The cushions $h^{+}$on bar $\lambda$ of the elbow-lever $\mathrm{H}^{\prime}$, to allow and modify a yielding lateral motion to the front end of ploughs, as specified.

16.-The spring 12 and connections 11 and 13 on the elbow $H^{\prime}$ and frame, in combination with the cushions $h^{4}$ on the bar 11 , to regulate and modify the perpendicular and lateral motion of the front of the ploughs. as speci fied.

17. - The combination of the draught-spring J, spring $\mathbf{~} 2$, and cuslions $h^{4}$, with their connections, to prevent concusion from the front of the ploughs coming in contact with reci ting culv-tances, as wet fortl 
18.-A furrow side wheel attached to or journaled in an oscillating standard, ant? adapted to automatically adjust itself with its connections, as and for the purpose set forth.

19.-The standard $\mathrm{X}$, carrying furrow-wheel 25 , pivoted loosely at $Z s$, and adapted to swing in a modified degree in a curved slot, $x$, as set forth.

20.- The combination of the standare $\mathrm{X}$, furrow-wheel 25 , curved slot $x$, and pulleys $w z$ with the arm W of the frame, and arm $Y$, as specified.

21.- The pivoted frames $\mathbf{E}$ and pivoted levers $\mathbf{G}^{2}$, comprising the plough-supporting-frame, as set forth.

22. - The springs $f^{2} f^{2}$ and frame $\mathrm{E}$, combined with the rear poition of the plough-frame $\mathrm{E} \mathrm{G}^{1}$, to cushion the ploughs vertically in either direction, as specified.

23. - The frame $E$, pivoted to the cross-bar $A^{1}$ of the frame $A$, and the frame $G^{1}$, pivoted at $G$ to the frame $E$, adapted to support the ploughs, and having a double pivoted joint, as shown.

24. - The vertical bar $\mathrm{F}^{1}$, nut $f^{\prime}$, and frame $\mathrm{F}$, combined with the springs $f^{2}$ above and below the nut $f^{\prime}$, and with the plough-frame E, as set forth.

25. - The bifurcated frames $G^{1} 28$, pivoted to the horizontal shaft $G$, combined with the ploughs, and with the bar $H$, to afford a firm support to the ploughs, as specitied

26. - The combination of the springs $f^{2} f^{2}$ and the cushion $k^{4}$ with the plough-frame and frame $\mathrm{A}$, to cushion the ploughframes both laterally and verically, as shown and described.

27.- In combination with the plough having a belt or endless-chain mould-board, the seecler and planter $V$, having automatic feed-bar $z$, combined with the harrow $T T^{2}$ and connecting-tubes $\gamma^{\prime}$, as set forth.

28. - The point $R$, held upon the share $R^{1}$ by the point $\mathrm{R}^{3}$ and the securing-wedge $\mathrm{K}^{2} \mathrm{R}^{4}$, as and for the purpose set forth.

2.9. - A reversible adjustable flexible coulter, $\mathrm{N}$, inclined as shown, combined with the frame $G^{2} G^{2}$ and plough, as set forth.

30.-A plough mold-board consisting of one or more triveling belt, or endless aprons, running over a forward approximately horizontal roll and a rear vertical roll adapted to receive the soil from the thare near the point and elevate, carry, disintegrate, and invert the same, as specified.

3T. - The harrows $T \mathrm{~T}^{2}$, inclined as shown, combined with one or more carrying-belts, as shown, for the purpose specified.

32. - One or more cleaners $S^{\prime}$ as shown, combined with the belt $\mathrm{P}^{\prime}$ and rollers $\mathrm{S}$, and adapted to automatically clean both at the same time, as specified.

33.- One or more cleaners situated in rear of belts, and adapted to clean the harrows $\mathrm{T}$ and out vide of belt at same time, as set forth.

34. - The chain formed of the metal plates P', having sharpened edges and end loops, and endless chains passing through said loops, as and for the purposes set forth.

35.-The roller 14, having slots 15,19 , and 25 , combines with flanged cap 16,18 and cup-cap 21 , as set forth.

36. - The cup-cap 21 , combined with cap or cover $\mathbf{2 3}$, cut away at $23^{+}$, and with the covering securing-cap 24 , adapted to surve, with the roller 14 , as set forth.

37. - In a plough, the combination of the self-lubricating roll 14 described with one or more traveling belts, as specified.

No. 216,442-EDWIN WV. NEWTON, FRANKLIN Grove, IlL. -Sulkv-Ploushs.-June 10, 1879. Filled Jinu.try 9,1879 .

Claim.-1.- The two-part sulky frame joined in front by the pivot-bult $\mathrm{D}$ and at the back end by a curved guide-bar, $\mathrm{P}$, one part carrying the driver and the other the plough, substantially as shown and described.

2.-The combination of the curved guide-bar $\mathrm{P}$ with the connecting-bar $Q$ and the lever $\mathrm{N}$, fitted with a set of holes arranged in a curved line, for the purpose of leveling the sulky-frame, all substantially as shown and described.

3.- The combination of the short lever-arm with the long and highly inclined braces T ' $T$ ', for the purpose of causing the point of the plough to rise inuch faster than the beel when coming out of, and drop much farter than the heel when going into, the ground, substantially as shown and de scribed.

4.-The combination of the prolonged open beam, the bolt $\mathrm{S}$, and the lever $\mathrm{N}$, to let the plough turn horizontally and auljust itself to the line of draft in turning, substantially as shown and described.

No. 216,714.-GIDEON E. WOLCOTT, DE KaI.B, IL1.-Kiding-Ploughs.-June 17, 1879. Filed Decimbur 5,1878 .

(laim.-1.-The plough-carriage formed of the rear or long axle $\mathrm{L}$, having an offset formed upon it, and having the journal at its furrow end inclined clownward, and the bar $\mathrm{F}$, the forward or short axle, $\mathrm{F}$, hinged to the forward end of the bar E, and having its journal inclined downward, the brace-bar $\mathrm{X}$, the upright land-side wheel $\mathrm{A}$, and the two inclined furrow wheels $\mathbf{B}$ C, substantially as herein shown and describéd.

2.- The draw-bar $K$, pivoted to the holt that hinges the forward end of the bar $\mathrm{E}$ and the inner end of the forwar or short axle, F, to each other, and having its rear part bent outward and provided with a hook, $k^{\prime}$, to hook upon the said axle $F$, substantially as herein shown and described.

No. 217,036 - SAlIUEL. E. WO(O)S and ARTHUR H. WHEWELL, LEEDS, COUNTY WV YURK, ENGLAND, - Asricultural Implements.-July 1, 1879. Filed ficbruary 20,1879. Patented in England, Deicmsir $1 ; 1876$.

Claim.-I-The combination of the plougi-beam 3 with the short front link, 5, and longer rear-liuk, $5 a$, and with the two brackets 22 , in which said links are always free to vibrate, and with the lifting device 6 , by which both ends of the plongh-beam are simultaneously raised or lowered, all substantially as herein shown and dencribed.

2. - The combination, in an agricultural implement, of lever 18, draw-bars 2121 , cross-bar 11, carriage 11a, guide-rotls 1919 , connecting rods 1212 , cranks, 1313 , vertical shafts 14 14, and brackets 15 15. as and for the purposes herein set forth.

3.- The combination, in an agricultural implement, of lever 18, draw-bars 2121 , and trame lock-pieces 2222 with pivoted plough-beam; 3 , substantially as described.

4.-The combination, in an agricultural implement, of the balancing beam 7 , chains $6 \quad 6$, and frames or bars 33 , substantially a ctescribed.

No, 217,491.-EINWARD SCHLAG, CHCAGo, 11.L.Agricultu al Implem nts.-July 15, 1879. Filed Jan.ary I0, 1879 .

Cham.-1,-The rotary plungh or cultivator D, made in the form of a spiral or scren of only one convolution, and provided with the cutter $1{ }^{\prime}$, substantially as shown and described.

2. - The combination, with the frame $\mathbf{A}$, of a series of rotary ploughi, $\mathrm{D}$, each inade in the form of a spiral or screw of only one convolution, arranged olsi juely, and provited with the cutter $1{ }^{\prime}$, sulstantially as shown and described.

3.-The combination, with the frame A,trucks J, fames, a vertical spindle $z$, and crank $m$, of the driving wheels 13 I', pulleys (", and ploughs 1), subotantially an and for the purpose specitied.

4.-The roller $P$, and guide-wheel I, journaled upon the shaft $i$, in combination with the vertical sliding fram $j$, ruel $k$, and lever $l$, subtantially as shown and described.

No. 217,893-JESSHE H. MO()RE, ALEm, III..Sulk v-Ploushs.-July 29, i\$ 79 . Filed Septemier 4,1878

Claim. - I. - The axle formed with a serien of righ-angled bends, forming the cross-portions $\mathrm{C}$ E $\mathrm{D}$ and the longitudual sections $F_{i}(i$, in combination with the seat-support $b$ upon the micldle section of the axle, wherehy the weight of the driver is equalized, and offers no resistance in raising the plough, as and for the purpose specitied.

2.- The bent axle, as shown and described, in combina tion with the furrow-wheel $\mathrm{A}$ and it, spindle-arm $\mathrm{L}$, provided with a bearing for the axle at each end, to adjust the wheel straight from the axle or to provicle a crank. as shown and specitied.

3 - The seat support $b$, having a loose bearing upon the axle, in combination with the bar $\mathrm{V}$, loop $\mathrm{W}$, cross-bar $\mathrm{T}$, and bent axle, substantially as shown and dexcribed.

No. 218.250 . - IOIIX J. FI.E.TCIIER and JAIES W. 


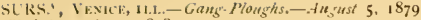
Filet loiember 4,1878 .

( laim.- I.-The axle B, having eranks of unequal length and provided with the arms $\mathrm{B}^{3}$, in comlination with the plough-frame having the cross-bar $\mathbf{E}$, with ears c', and lever $\mathrm{F}$, substantially as shown and deseribed.

2-The combination of the solid body $C$, rigid plough beam 1 , and the removable plough-beam $\mathrm{M}$, the latter being adapted to be entirely removed from the body to form a sinrle plough, sairl beams, when in use, being seeured together by the inelined brace-bar $O$, and to the sides of the solid body by through-bolts $\mathrm{N}^{\prime}$, as shown and described.

No. 218.516 . -1SAAC R. GILBERT, LOUISVII.1. $k$ r. -Sulky.Ploughs. - Angust 12, 1879. Filed Marih 13, 1879.

Claim.-1.-The curved raek-bar G, provided with the clip or bracket $b$ on it, inner side, for the purpose of fitting over the end of the arched axle, and bracing the rack-bar both lengthwise and transversely, substantially as set forth.

$2,-$ The combination of the arched axle $\mathrm{A}$ with the curved gurle 11 , raek 1 , and arm $f$, when said guide, rack, and arm are cast in one pieec, substantially in the manner and for the purpose set forth.

3.-The eombination of the $I$-shaped lever $K$, eurved guide 11 , link $i$, pivoted lever $\mathrm{J}$, and spindle $a^{\prime}$, all arranged for joint operation substantially as described.

4.- The comlination of the plough-beam P, plates R, with lugs $r r$, the automatic adjusting seat $s$, and the elip $t$, with bilts z', sul.stantially as and for the purposes herein set forth.

5.-The elevis composed of the plates $S . S$ and $T$ and open tulie $\mathbf{V}$, and the laterally-adjustable coupling $\mathbf{W}$, provided with the tubular extension $x$, substantially as and for the pur poses hercin st forth.

Yo. 218,734 - TlHOMAS T. HARRLSON, AUBREY, Kavsas, - Su'kw-Ploughs,-Ausust 19 1879. Filed May 24. 1879 .

Claim.-The sulky formed by the eombination of the wheels $A$, the swiveled erank-axles $B$, the frame $C$, the short side bars, $\mathrm{D}$, the eross-bar $\mathrm{E}$, and the piroted tonmue $k$ with each other, to adapt it to receive a breaking-plough or cultivating-ploughs, substantially as herein shown and deseribed.

No. 218,840 -NEISON J. TRENERY and JOHN I.

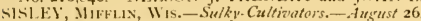
1879. Filed Oetober 2, 1878 .

Claim.-The comhination of the uprights $a$ and cross-lor $b$ and $j$ with a plough and sulky-eultivator, means being provided for the adjustable attachment of the part to the axle and lifting-chains of the cultivator and to the heam of the plough, all substantially as described, and for the purpese set fottl.

Vo. 218856 , MURTIMER CAHILI, STERI.IXe, II.I. -Sullin. Ploughs._-1urust 26, 18,9. Filed Dicumber 9 1878 .

Claim,-1. - The clamp D, eapable of lateral adjustment upon the crank $e$, said elamp having the horizontal seetion $t^{\prime \prime}$ and vetical seeve $c^{2}$, collar $g$, and set-screw $f$, in combi nation with a clamping device for holding the plough-lseam seeured to a bolt passing through the vertical sleeve $c^{2}$, sulstantially as and for the purpose described.

2. - The ratchet wheel $n$, eonneeted to the pivotal horizontal erank $e$ by link $m$, working in combination with lever $\mathrm{F}$, slotted plates $\mathrm{O}$, and stop $\mathrm{H}$, all eonstrueted to operate substantially a and for the purpose set forth.

3.-The combination, with the elamp 1), formed with husizontal section $c^{1}$, virtieal sleeve $c^{2}$, and the collar is, with set-crew $\%$, of the pisotal bolt $h$, angle-iron 1 , plates $i k$, and set-serews $j$, substantially as and for the purpose set forth.

No. 219381 - WILLIA.M P. BETTENIOORF, PERE, 11.1.-Ciultizators and Ploushs. - Sepiember 9, 1879. Filed Necumber 14 18, 8

Claim.-1.-A crank-operating lever having interacting latches or levers, one connected 1 ith the detent of said lever upon the usual ratcheted arc of a plough or cultivator, the wher connected with a detent aranged to lock the crankaxle to the wheel when it is required to raine the plough or cultivator hovels simultaneously with the liberation of the main lever from its ratcheted arc, and a forward motion of said lever for the purpose of obviating two distinct movements in different directions in the process of depressing the crank-axle and engaging the wheel with the crank to assist the motion, substantially as and for the purpose cleseribed.

2.- The combination, with a erank-axle, of a curved arm for automatically releasing the clutch-bolt, an intermediate arm or lever, a main lever provided with two spring-latehes and conneeting rods, and a curved ratchet, sub-tantially as and for the purposes set forth.

3.-The combination, with lever $\mathrm{E}$, of lever $\mathrm{F}$, having an engagement on the cam or arm $g$ of the follow lever or latch $\mathrm{F}^{\prime}$, so as to operate the rods $e^{\prime} f$ of respective latches simultaneously, substantially as and for the purposes specifie 1.

4.-The combination, with a crank-axlc, of the clutchbolt $d$, curved releasing-arm $k$, lever $G$, and operating-lever $\mathrm{E}$, provided with two hand-levers or latehes and connectingrods, substantially as shown and described.

5.- The cam-headed top or arm $k$ on arch B, in combination with the arm $w$ of erank G, for reversing or withdrawning the bolt $d$ at the end of the forward stroke of lever $\mathrm{E}$, subutantially as described.

6. - The combination and arrangement, with crank $C$, arc $\mathrm{H}$, and lever $\mathrm{E}$, of latches $\mathrm{F}^{\prime} \mathrm{F}$, rods $f c$, lever $\mathrm{i}$, bolt $d$, ratehet $m$, and sop $k$, substantially as and for the purposes deseribed.

No. 219467 -REUBEX $11 \mathrm{ART}$ and MILFORD P. NICHOI.SON, SANTA MARIA, CAL.-Siplember 9, 1879. Filed $M a y$ 2o, is 79.

Claim.-1.-1n a gang-plough, the diagonal plank or plough-beam $\mathrm{F}$, having slots $a$ a near its ends, in combination with the beams ( 1 ), to which it is bolted, whereby said benm is suspended and adapted to be adjusted at both ends forward or backward, to adjust the plough toward or from the land, sut stantially as herein shown and deseribed.

2. - The links $\mathrm{K} \mathrm{K}$, conneeted with the outside of the beams ( 1 ) at the front, and the standard $O$, secured to the rear end of the beam $\mathbf{D}$, in combination with the lever $\mathrm{M}$ and the bifurcated lever L L, whereby the beams C D are supported and ae unted from three points out of line, and are prevented from tilting to one side, substantially as herein clescribed.

3.-The beams C I), with their tubes or sleeves I, moving upon the guides $I 1$, said tubes projecting above the plonghbeam, so as to enter depressions in the axle B and steady the ploughs, substantially as herein deseribed.

No. 219.565.-JOSEPH BELDLKE, SAX FRANCISCO, Cal.-Gang-Ploughs,-Siptember 16, 1879 . Filed Fibratry $18,1879$.

Claim.-1.- The plough-beams 6 ; 1 of a gang-plough, connected by the rear angular brace $j$, with its - lit-and-pin fastening, and loving the bridge-shaped hraces $k$, a aid beams and braces being eonneeted by a crank-rod, L, and the forward ends of the beams being con. ed is ith arnus C D, of unequal length, substantially as ancl for the purpóse deseribed.

2.-The axle $\mathrm{A}$, with its arms (' $D$ of unequal length, in combination with the plough-beans $\mathrm{G}, 1$, which are loosely connected at th $=$ rear ends, substantially as and for the purpose deseribed.

No. 219.709-ANSEL 11AVES GALE, FREHORT,

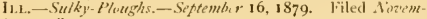
her $\mathbf{1}, 1877$.

Claim.-1.-The combination of the iron frame $a a^{\prime}$, the stationary side plates, $b h$, holted thereto, and the adjustable onter plates, $e$ e, turning upon rigid studs $b^{\prime \prime \prime}$, projecting from the faces of the inner plates, $e^{\circ} c^{\prime}$, as described.

2.-The combination, with the iron frame $a a^{\prime}$ of the inuer plate-, $b b$, fixed thereto, the outer plates, $e^{\prime} e$, carrying the wheel-spindles $u t$, and turning on rigirl studs $b^{\prime \prime} " b^{\prime \prime \prime}$, the fastening-bolts $a^{\prime \prime}$, and clips $k r$. substantially as and for the purpose set forth.

No. $219.799 .-B Y R O N$ C. BRADLFY, CHCAGO, 11.L. -Sulky. Plousths. - September 23. 1879 . Filed July 14 , 1879 .

Chim.-I.-In a sulky-plough, the lever E, in combination with a friction.bank, $b$, and a shoulder or stop, $h$, all so eonstructed that the lever E can lie used to apply the fic- 
tion-band to the hub, and also for raising the plongh by the action of the operator alone, substantially as specified.

2.-In a sulky-plough, the lever $\mathrm{E}$, in combination with the friction-band $b$, shoulder or stop $h$, and rack $G$, sulstantially as and for the purposes specified.

3.- In a sulky-plough, the lever $\mathrm{E}$, in combination with the casting F, provided with a shoulder or stop, $h$, substantially as specified.

No. $219800,-B Y R O N$ C. BRADLEY and CHARLES A. HAGiUE, ChICAgo, Ili.,-Sulky-Ploughs.-Seplember 23, 1879 . Filed April 28, 1879 .

Claim.-1.-In a sulky-plough, the friction-band $c$ and a connecting bar or piece, $i$, in combination with the crankaxle and one of the hubs, or an extension thereof, for the purpose of raising the plough out of the ground, substantially as specified.

2.-In a sulky-plough, the friction-band $c$ and connecting piece $i$, and the levers of $g$ and bar $h$, in combination with the axle $\mathrm{B}$ and one of the hubs, or an extension thereof, substantially as and for the purposes specified.

No. 219,935--JUHN T. GREENFIELD, UNionToWN, $\mathrm{K} \mathrm{x}_{\mathrm{t}}$-Ploughs. - Septcmber 23, 1879 . Filed April 29, I879.

Claim.- The combination of the beam $A$, having a curved and grooved standard, $\mathrm{B}$, the axle $\mathrm{G}$, provided with the toothed slide $\mathrm{C}$, the quadrant-lever $\mathrm{F}$, the curved lever $\mathrm{J}$ sliding in guides $h$ and carrying the gauge-wheel $K$, and the hinged frame I, all arranged substantially as shown and described.

No. 219997 - - 1.AWRENCEM. SUMIMERS and MORDECAl IWILSON, Nurborne, Yo.-Sulky-Plourhs.Sept mber 23, 1879. Filed January 22, 1879 .

Claim.-In a sulky-plough, a main wooden frame, $A$, recessed to receive the plough-beam, and provided with a strip $a$, around the recess, and with short axles bolted to the said frame, in combination with the slotted plates held to the main frame by bolts, and adjustable vertically, said slotted plates carrying the crank shaft $\mathcal{C}$, journaled in bearings on thcir lower ends, all the parts being constructed and arranged as and for the purpose set forth.

No. 220436 ,-ALBERT C. ROSENCRANZ, EVANSville, INn,-Wheel-Ploughs,-Ociaber 7, is 79 Filed August 30,1879 .

Claim,-I.- The side-wheel, $r$, having it supporting standard passed through the socket of a swinging plate or bar and pivoted to the adjustable lever $t$, whereby the wheel may be adjusted to level the plough and to regulate the side draf, upon liill-sides, sul stantially as set forth.

2. - The combination of the wheel $r$ with the standard $r^{\prime}$, piroted plate $s$, lever $t$, bar Q, rack-bar $s^{2} w$, and spring catch upon the lever $t$, substantially as set forth.

No. 223,446 . -ARGVLE W. TUCKER, WAXAHACHIE, assignct to CEORGE F. Al.FOKD, IALIAS, TEXAs,Pioughis. - O iober 7, 1879. Filed Juiy 18, 18;9.

Clam - I - The combination of the arched axle E, with optosite crank-spindles $b$, reversely adjusted by lever $I^{2}$, and wheels $F$, with rollers $i$ in their hubs, substantially as and for t'ze purposes herein set forth.

2. - I he cumbination of the arched axle $\mathrm{E}$, rocked by the lever $\mathrm{I}^{2}$, the two inclependent bails or clevises $\mathrm{G} \mathrm{H}$, lever I $1^{1}$, and rack-bars $\mathrm{L} \mathrm{L}^{1}$, all constructed and arranged substantially as and for the purposes herein set forth.

3.-The comlination, with a sulky-frame, of one or more plough-beams, J, front clevis, G, with clips g, rear clevis, H, with plates $h m$ and boits $z$, and the operating-levers $\mathrm{I}^{1} \mathrm{I}^{2}$ substantially as and for the purposes herein set forth,

No. 225,633.-WHLL1A.I J. MEHARRV, STATE LINE, IND., (SHFIDON, IL.L, P. O.)-Sulky-Ploushs.-October 14. 1879 . Filed February 20, 1879.

Claim.-1.- The sulky-frame $\mathrm{CED}$, the axle F, having a crat $k$, $f^{\prime}$, upon its land-side end, the larger furrow. wheel, $G$, and the smaller land-whet $I, I$, in combination with the lever I, cranks $K$, rigid arms I, and plough-beam $A$, whereby the plough is raised and the land-wheet lowered at one :troke of the lever, as specified.

2. - The combination, with asle $F$, plough $\mathrm{H}$, and beam $A$, of the arins $T$, crinl-arms $K$, and lever $\mathbf{L}$, as and for the purpose specified.
3.-The combination of the two rigid arms J, the two crank-arms $\mathrm{K}$, the hand-lever $\mathrm{L}$, and the foot-lever $\mathrm{M}$ with the plough A $\mathrm{H}$ and the axle $\mathrm{F}$ of the sulky, substantially as herein shown and described.

No. 220,643.-WILLIAM NEWLIN, ATrica, Ind.Itheel-Ploughs.-October 14, 1879. Filed January 14, 1879.

Claim.-1.-In a wheel-plough, the jointed axle B C, in combination with the hubbed chutch $\mathrm{J}$, having recess $x$, and the crank $\mathrm{J}$, with hig $i$, substantially as and for the purposes herein set forth.

2.-The combination of the axle B, crank E, pivoted thereon and having one arm slotted longitudinally, the bowl $f$, and wheel-spindle $e$, adjustable in the slot in the crankarm, and a lever, dog, and a rack for holding the crank in different positions, substantially as set forth.

3.- In combination with a two-wheeled plough having the plough-beam suspended below the axle, the slotted bent bar $\| 1$, provided with the flanges $m m$ and adjustable foot-rest $\mathrm{O}$, and the plongh-beam $\mathrm{N}$, with its forward cnd arranged between the foot-rest $O$ and flange $m$, substantially as and for the purposes herein set forth.

4.- The combination of the bent axle $B$ and clutch I with the movable lock-lever $\mathrm{I}^{\prime \prime}$, having a slotterl connection with the clutch, whereby said axle has a limited free movement, substantially as specified.

5-The combinction, with the crank $B$ and plough-beam $\mathrm{N}$, of the hanger $t$, pivoted to the crank asd loosely connected with the beam, and braces $p$, pivoted at both ends, sub-tantially as specified.

No, 220,70I-PHILO L. CASE. IES MoINEs, IOWA: -Sully-I"loughs.-Octebir 21, 1879 Filed May' 27, $18 ; 9$

Claim.-1.-In a sulky-plough, the bowed carriage-axle $\mathrm{A}$, having branches $\mathrm{B} \mathrm{B}$, the cross-bar $\mathrm{D}$, the revolving po-t, E, and the vertically-adjutalle hubs $f$, formed with wheel-spindles, whereby the wheels are turned by the t mane independent of the frame, arranged and combined substantially as shown and describ_d, to operate in the mamner set forth.

2 - The rack $h$, having a hub, $i$, in combination with the post $\mathrm{E}$, the hub $f$, carrying the wheel $(i$, and the operating mechanisin $k / m$, sulut intially as shown and described, for the purposes specified.

3.- The igid carriage axle and frame A B B C C D, the revolving po-t $\mathbf{E}$, the adjustable vertical hubs $f$, carryingwheels (i, the pivoted pole P, and the piroted cross-bar R, having arms s, flexibly comnected with it; ends, arranged and comlined substantially as shown and described, to operate in the manner set forth, for the pur s s specifed.

No. 221,597-ADEN K. MUNSON, MARYSTIILF, Kansas, - Sulky-Piourhs. - Voember 11, is79. Filed Jume I I, 1879

(laim.-1. A plough-frame having the slotted hangers 5 . in comlination with the slotted yoke $h$ and shacklë $\pi$, hinving trunvion $l$, as show' and describer.

2.- The comlination of the lough-frame $c f$, slotted hanger $s$, yoke $h$, shackle $i$, arljust. ble notched plate $p$, link $m$, and lever $n$, as and for the parpone set forth.

3.- The combination of the plongh-tean k, draft-rods $t$, shitted hangers $g$, slotted yoke $h$, shachle $i$, connections $r r^{\prime}$, rock-shaft $q$, lever $z^{2}$, and bent cross-bar 5 , as and for the purpose specified.

No, 2>2,-34.-THOMAs L. RINEY, I.AHDONIA, Mo. - Iher Ploughs.-Dicember 9, 18;9. I iled Ju y 8, 1879.

Claim.-1u a sulky-plough, the combination of the crankhar $b$, having the exten-ion or lug $b^{2}$, projecting forward of its beaings on axles $a^{2}$, the lever $h$, fulcrumed on the part of the crank $b$ forward of its center of motion, and the brace $h^{2}$, connecting the lever $\mathrm{u}$ ith the crank in the rear of said center of motion, substantially as and for the purposes set forth.

No. 223.186.-HENRY C. STUAKT, WARRFNTON, Mo.- Sulky-L'toughs.-December 30, 1879. Filed October 28,1879 .

Claim.-1,-The combination of the axle A, with arms $A^{\prime}$, having in eye in its ond, the vertical frame $\mathcal{C}$, with side rod, $b$, the brace $a$, lever $\mathrm{D}$, and chain $e$, sub-tat,tially as and for the purpones hercin -et furth. 
2. - The combination of the vertical adjustable frame $C$, kecpers $h h$, upright I, with plough-beam attached thereto, and the lever I), as and for the purposes herein set forth. 223,881.-IS.A.AC BURKE, SACRAMENTO, CAL.-Sulky. Plon:hi-January 27, 1880 . Filed January 31, 1879.

Claim.-1,-The combination of the axle C, constructed as described, the guide-standard $K$, guage-standard $G$, and frame .I, substantially as and for the purposes set forth.

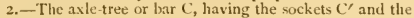
boxes $\mathrm{F}$ formed with or upon it, to reccive the standards $\mathrm{G}$ and $K$, so that the ploughs are guided and the pressure is applied to them directly through the line of the axle, substantially as and for the purpose herein described.

No. $223,8_{33}$-GEORGE ARMSTRONG, ElMIRA, and I) U.NCAN L. IIURCHESON, WEATHERSFIELD, ILL.; said WURCHESON assignor to said ARMSTRONG. - GancPhurhs-Janu 2 ry 27, 1880 . Filed February 8, 1878 .

Claim.- In a gang-plough, the pulley $\mathrm{C} D$, in combination with the bar B, lever $F$, and rod $\mathrm{H}$, substantially as and for the purpose specified.

No. 224 934- -JOSEPI B. NEFF, CUBA, assignor to REUBE. ELWOOD, SYCAMORE, It.t.-Sulky-Plough. - February 3, 188j. Filed Decemlier 16, 187S.

Chim.-1. - The combinatton of the brackets $c$, attached to the plugh-beam with the rols $a$ and adjustable collars $d$, for allowing the bracket; a limited free play on the rods, substantially as described.

2. - The combination of the brackets $c$, rods $a$, and adjustable collars $d$ with the collar $b$ and rock-shaft $C$, substantially as set forth.

3.- The plate $k$, having the ears $l$, in combination with the beam $D$ and bar or rod $O$, substantially as described.

4 - The extended bar $n$, for supporting an evener indepen lently of its clevis-support, con-tructed and applied substantially a specitied.

5. - The cumbination of the bent axle or frame $A$, arms $\mathrm{N}$, rod $\mathrm{O}$, adjusting-b.r $\mathrm{P}$, and bar $\mathrm{F}$ with the cranked or bent rock-shaft $C$. lever, $J$, one or more rods, $a$, one or more Lrackets, c, and plourh-beam D, all constructed and operating substantially as specified.

No. $22403 \%$-TOSEPII B. NEFF, CUBA, assignor to

REUBEN ELWUOD, SYCAMURE, ILL.-Sulky-Plotghs. -Fibruary 3, 188 . Filed December 16, 1878.

Claim. In combination with the pivoted toncrue $\mathrm{F}$, the adjunt:able inverted stirrup $e$, and slotted bracket $a$, the pivotal bolt $d$, serrated plate $b$, and bolt $c$, substantially as shown and described.

No. 224.095.-BENJAMIN F. LITZENBERG, Rus-

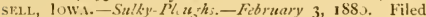
December 1 2, 1879

Claim, - The herein-described improved sulky-frame, consinting of the reversible sides $\mathrm{A} \mathrm{A}$, axle $\mathrm{D}$, crank-axle $\mathrm{F}$, having lever $\mathrm{M}$, foot-bar or bail $\mathrm{L}$, and spindles $\mathrm{H} \mathrm{H}$, all con-tructed, combined, and operating substantially as and for the purpoie set forth.

X. 224 is8. - WILLIA.I A. JA.MES, Sr. Louts, Mo. -Salky-1'lou; - Fs.-February 3, IS8o. Filed December 4. 1879 .

Claim.-In a sulky-plough, the combination, with the crink $C$ of the axle $B$ and the bean $D$ of a plough, of the bent bar $G$, proviled wit's stops $H$, the angle-iron,$~ l$, adjustinr-bolts, and the adju-tin-braces $L$, substantially as herein shown and described, so that the plough may have the adju-tmsnts as set forth.

Nu. 95 I. - WILLIAM A. JAMES, ST, Lovis, Mo.Sulky-Plough. -224,188, Fibruary 3. 1880.-Reissued De:ember I I880. Filed Noventber I, I88s.

Claim.-I. - In a sulky-plongh, the combination, with the crank $C^{\prime}$ of the axle-arms $B^{\prime} B^{\prime}$ and the beam $D$ of a plough, of the bent bar $\mathrm{G}$, provisled with stops $\mathrm{H}$, the angle-irons $\mathrm{J}$, adjuting-tolt, and the adjusting-braces 1 , substantially as $\mathrm{h}$ rein shown and described, so that the plough may have the adju.tments as set forth.

2.- - 'he combination of axle B B' C, arched seat-support $\mathrm{H}$, and arm R, attached to the purt $\mathrm{B}$ of the axle and hinged to the support $\Gamma$, sub-tantially as and for the purpose set forth.

3.- The combination, in a sulky plough, of lever $\mathrm{V}$, notched segment $c$, crank-axle B $B^{\prime}\left(C^{\prime}\right.$, arched seat-support
$\mathrm{P}$, and arm $\mathrm{R}$, constructed and relatively arranged substantially as set forth.

4.-The combination of axle-crank $\mathrm{C}$, briclge-bar $\mathrm{G}$, and angle-irons $I$, adjusting bolts and nuts $\mathrm{J} K \mathrm{~N}$, bars $\mathrm{L}$, and plough-beam with eye-lugs $\mathrm{M}$, for the purpose set forth.

5. - The combination of bridge-bar $\mathrm{G}$, with slotted ends to embrace the axle, and blocks $O$, constructed to fit the slotted ends and bear against the under side of the axle, for the parpose set forth.

6.-The combination of axle-crank C, bridge-bar $\mathrm{G}$, stops $\mathrm{H}$, and angle-irons 1 , substantially as and for the purpose set forth.

No. 224,195.-AU(;UST LINDGREN, NoLINE, ILL.Sulky-Plou,hs.-February 3, 1880 . Filed June 28, 1879.

Claim. - 1. - In a sulky-plough, the combination, with a hand-lever $\mathrm{O}$, having toothed segment at lower end, of the bar E, pivoted near its forward end to the bar F, provided with the furrow-wheel axle $\mathrm{H}$, and having the toothed segment M, the axis of the furrow-wheel being distinct from that of the segment and in the rear thereof, as shown and described, whereby the furrow-wheel and segment are lifted together.

2.-The combination of the connecting-bar V, the crank $\mathrm{IV}$, and the sleeve $\mathrm{X}$ with the bent bar $\mathrm{E}$, the block $\mathrm{G}$ of bar $F$, the catch-plate $C^{\prime}$, the lever $Y$, and the slide $L$, that carries the axle of the land-side wheel, as shown and described.

No, 224,455.-ELBRIDGE G. MATTHEIVS, LA SANK, MinN.-Ploughs.-February Io, iSSo. Filed Warch I, 1879 .

Clain.-1.-In a plough, the combination of the crank axle $\mathrm{C}$, having the perforated disk $\mathrm{D}$, with the slidingarm M, substantially as and for the purposes set forth.

2.- In a plough, the crank-axle $\mathrm{C}$, having the perlorated disk $\mathrm{D}$, with the sliding arm, in combination with the ploughis $\mathrm{L} \mathrm{L}^{\prime}$, secured to the racks $\mathrm{F}$, working in ways in the block $\mathbf{E}$, and the pinions $\mathrm{G} G$ upon the shaft $\mathrm{J}$, carrying the perforated disks $\mathrm{H} \mathrm{I}$, and the hooked rods $\mathrm{K}$, substantially as and for the purposes set forth.

No, 224,713.-JAKUB F. IIUNZ, Delaware, Ohio. -Sulky-Ploughs. - February 17, i88o. Filed December 3 , 1879 .

Claim,-1.-The combination, with the arch $a^{2}$ and the brace or frame $a^{4}$, having the series of holes $i$ in its lower end, of the swing-brace $h^{\prime}$, having its upper end pivoted near the upper end of the inner side of the vertical arm $a^{2}$, the head-block $h$, journaled in the lower end of the brace $h^{\prime}$ and in one of holes $i$ of frame $a^{4}$, and yoke or bail $d$, substantially as set forth.

2.- In a sulky for ploughs and cultivators, the combina tion of the side bars, $a$, the arch $a^{2}$, the braces or frames $a^{4}$, having their ends secured to the bars $a a$ in front and rear of the vertical arm $a^{3}$ of the arch $a^{2}$, and having their lower or bow ends secured to the lower ends of the vertical arms $a^{3}$, the yokes $c$ and $d$, one of which is journaled to the lower end of the brace $a^{4}$ in front of the vertical axial plane of the wheel, and the other journaled to said brace in rear of said axial plane, and the rotating head-blocks $h h$, all arranged to operate substantially as set forth.

No. 224,820-JOEL ELAM, THOMAS P. ELAM, and JOHN A. ELAM, Greenvili.e, Il.l.-Sulky-Ploughs. - Fibruary 24, 1880 . Filed April 25, 1879.

Claim.-The combination of the axle $\mathrm{A}$, having downwardly-projecting arms B C, placed at an angle of abont sixty or sixty-five degrees to each other, tongue $\mathrm{J}$, brace $\mathrm{K}$, connecting the tongue with the rearward-extending arm $B$, bail L, hinged upon the spindle of arm B, plough M N, pivoted upon the forward end of said b.ill, furrow-wheel E, and adjutable transporting-wheel $\mathrm{H}$, all arranged and operating sulstantially as and for the purpose set forth.

No. 225,105-FRANKLIN C. BRYAN, WINONA, Minv,-Sulky-Ploughs.-Warch 2. 1880 . Filed January 6,188 .

Claim.-In a reversible sulky-plough, the combination of the frame $A$ and independent crank-axles $E E^{\prime}$, having separate operating levers $l$, with the right and left plourhs $G^{\prime} G^{\prime}$ and their beams $F^{\prime} F^{\prime}$, independent plough-supporting cranks $\mathbb{K} K^{\prime}$, having separate operating-levers 1 , and suita- 
ble catches for said levers, all arranged substantially as specified.

No. 225.138.-WM. D. IAPS, IWATERTOWN, MINN, Sulky Plou, rhs. - Warch 2, is8o. Filed Decimber 29, I 879. Claim.-1.-In combination with the frame $A$ and rod B, the I-shaped bars H H, cap-piece with slotted arm 1 , and the adjustable seat $\mathrm{J}$, as and for the purposes herein set forth.

2. - The combination, with the pole $\mathrm{L}$, of the movable collar with the slotted arm $m$ and the tongue-holder $M$, all contructed substantially as and for the purposes herein set forth.

3.- The combination of the shaft P, arm $w$, lugs $x k$, spring $d^{\prime}$, cogged swinging arm $\mathrm{S}$, pinion $a^{\prime}$, crank-shaft $\mathrm{V}$, and foot-lever $\mathrm{W}$, substantially as and for the purposes herein set forth.

No. 225,156 . WILIIAM D. MILLER, SPRINGFIEID, OHIO.-Whed Pti.ushs, - Warch 2, 18 o. Filed October 7,1879 .

Claim.-1, - In a wheel-plongh, the bail H, supporting the front end of the plough-beam $K$, fitted rigilly to the square journal of the crank-axles, and having an indejerdent lifting-lever, J, whereby the axles are turned to level the frame and the front end of the plough-beam lifted by the same stroke of the lever.

2.-The hail (i, provided with a swivel coupling for at tachment of the plough-beam $\mathrm{K}$, combined with the bail $\mathrm{H}$, provided with the rod $e$, to form a long loop or slot, in which the plough-beam may move laterally.

3. - An adjutable swivel-coupling for the bail and ploughbeam, composed of the slotted plate $\mathrm{Nl}$, with it lugs $i$, and the plate $\mathrm{N}$, mounted upon horizontal pivots, combined with the saddle-plate $O$, mounted upon said plate $\mathrm{N}$, with a vertical axin, and provided with tie-bolt $t t$, tie-plate $d$, with upturned lugs at its ends, and coupling-bolt 5 , sub-tantially as set forth.

4.- In combination, in a sulky-plongh, a frame mounted upon wheels, two bails whereby the plough is comnected to the sulky-frame, and a plough the land-side whereof $i$ arched from the front along it, lower edge, so that it docs not bear upon the bottom of the furrow except at it point, for the purpose set forth.

No. 225207 - - LOUIS BERTHIAUME, ST. I'AUL,

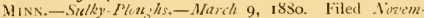
ber* $29,1579$.

Claim.-1-The combination of the conlter-shaft $\mathrm{K}^{2}$ and collar $t^{3}$, provided with lugs $t^{5} t^{5}$, adapted to fit in slot 4 in the plate $t^{2}$, to allow lateral play of the collar, with the beam I3, stotted clamping-plates $t^{\prime} t^{2}$, cheek-plates $t^{\prime} p^{2}$, and bolt $t^{4} r^{\prime}, t^{2}$, substantially as described, and for the purpose set forth.

2.- The combination, with the right-angled frame $\mathrm{I}^{\prime}$, having the standard $\mathrm{K}^{\prime}$ bolted thertto, of the vertical hait $\mathrm{R}^{2}$, proviled with the cross-pi ace $\mathrm{R}^{6}$ and spring $\mathrm{i}^{\prime}$, rod $\mathrm{R}^{5}$, foot-lever $\mathrm{R}^{3}$, and leam $\mathrm{B}$, substantially as described, and for the purpose set forth.

3.- The combination, with a plough having a short land. side and a stand.rril vertically and angularly adjustable in a clamp attiched to the plourh-beam, of the beam 1 , attached to the pivoted bail $I^{\prime}$ by a swivel-clamp, and the sulky frume and tongue, subnt intially as described, and for the purpose set forth.

No. $225 \cdot 5 ; 8$. -FREIRIC I. SMITH, CHICAGO, 11. . -Su'ky Ploughs, - Warch 16, isso. Filed December 5, 1879 .

Claim.-1.-The combination of the vertical inclined bracket with screw $c^{\prime}$ with the adjustable lever fulcrumblock $r$, adapted to move up or down on said screw, the connecting rod 5 , clamp 6 , and the plough $A$, as and for the purpose set forth.

2.-The combination, with the hand-lever $a$, having the arm-extension; $a^{2}$ and $a^{\prime \prime}$, and the adjustable rack-frame $a^{\prime}$, of the adjutuble fulcrum $c$, the vertical inclined screw $c^{\prime}$, the connsting-rod 5, clamp 6, and the plough A, substantially as and for the purpose descibed.

3.- The combination, with a rectangular lever consinting of arms 8 and 9, and having the foot-lever 11 integral therewith, of the are 10 , perforated in the manner shown and adajtal to secure the arm 9 in different positions. as herein described, the vertical arm 12, the horizontal connection 13, shaft 14, connecting-rod 15, clamp 16, and the ptough $A$, substantially as and for the purpose herein described.

4.-In a sulky attachment for ploughs, the comlination of the following element;, consisting of the hand-lever $a$, having extensions $a^{2}$ and $a^{3}$, the adjustable part $c$, the vertical inclined screw $c^{\prime}$, connecting-rod 5 , clamp 6 , the rectangular lever consisting of arms 8 and 9 , the arc 10, vertical arm i2, horizontal arm 13, shaft 14, connecting. rod 15 , clamp 16, and the plongh $A$, all constructed and arranged as herein shown and described.

No, 22, 668,-GEORGE H. WARREN, TAMA CITY, Iowa. -Sinlky-Ploughs. - Warch 16, 1880. Filed Deccmber 18,1879 .

Claim,-I.-In a sulky-plough, the combination of the pivoted bail $\mathrm{F}$ with arm $\mathrm{H}$, the braces I 1 , roller $d$, and camlever $J$, all constructed and arranged to operate subutantially as and for the purposes herein set forth.

2.-The combination, with the wheel-slides I) I, having rack-bars $b$ b, of the scgmental racks $\mathrm{K} \mathrm{K}$, connecting-rod or rods $i$, and single lever $L$, whereby the wheels may be adju-ted simultaneously, one up and the other down, sulstantially as and for the purposes herein set forth.

3.-The combination of the bait $\mathrm{F}$, plough-beam $\mathrm{N}$, and the double-clampst, having each side made in two pars, substantially asshown and described, and for the puiposes set forth.

No, 225.744-LLKE CHAPMAN, COLANSTIIIE, CoNN., assignor of one-half of his right to the Cirl.LINs Cim. PANY, same place.-Whel-Ploughs, - March 23, 1883. Filed December 6, is 79 .

Claim.-1.-1n a wheeled plough, the combination of the wheeled carriage, a wheel-bridge adaptable to both wheels, and a plough home by the wheel-bridge outride and on either side the wheels, sub-tatially as stown and de. scribed.

2.-In a wheeled plough, the combination of the wheeled carriage, the $\mathrm{T}$-joint, the wheel-bridge, and the plough borue outsitle the wheels, subtantially as shown and described.

3.-In a wheeled plough, the comlination of the wheeled-carriage, the wheel-briclge, the p.rti-divk pivotally hung to the wheed-bridge, and the plough pivotally liung to the parti-di-k, substantially as shown and described.

4.- In a wheeled plough, the combination of the wheeled carriage, the whel-bridge, the parti-dist' pivot tlly hun to the wheel-brilge, the plongh pivotally hung to the parti-disk, the lever for operating the patti-disk and the pawl-and-ratchet gear for retaining the parii disk in adjustment, sulstantially as hlown and described.

5.- The combination of the plough-beam $t$, with its stand ard, mould-Loard, and share, the frame $r$, screws $" ~ "$, and the sleve $\rho$, bearing the trumions $\rho f$, all substatially as hown and described.

6. - In a wheeled plongh, the combination of the wheeleal carriage, the wheel-bridge, the larti-disk pivotally hung to the wheel-brilge, the crank pin $n$, the sleeve $o$, wit:1 it trunnions $p t$, the frame $r$, and the plough-beam $t$, with it; standari, mould-tword, and share, all substanti.lly, as shown and described.

No, $225769 .-$ FRANCIS STANIEV, ToRONTo, ON-

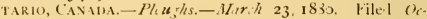
t. bir 17,1879 .

('lain.- The plonghshare B, pivoted on the holt 1 ) to the frame $\Lambda$, the conlter $F$, and coulter-bar $\mathrm{E}$, attached to the ploughshare $\mathbf{B}$, and working in the guide-bar $\mathrm{E}^{\prime}$, in combination with the links ( ) and lever (), pivoted to the pillar l', the whole arranged substantially as and for the purpoue specificd.

No, 226,027-BVRON C. BRADIEV, CHICA(\%), 11.1.. -Sulky-l'loushs, - Warch 30, 185o, Filed June 1 7, 1878.

Claim. - The combination of the lar $\mathrm{B}$, having turneddown arm $c$, the reversible bracket $c$, the tongue 11,4 b. stantially as and for the purposes herein set forth.

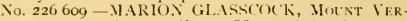

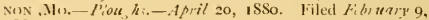
I SSo.

('laim,-I.-In a whe'-plough, the curved braces $(C$, 
pisoted to the horicontal ends of the arehed axle $\mathrm{A}$, and hav ing the end bearings, $c c$, arranged to clamp the plongh luam, substantially as shown and described.

2.- The combination of the arched axle $\mathrm{A}$, the benringblocks $13 \mathrm{l}$, the curved braces $C^{\prime} C$, with bearings $c i$, and bols $b$, the foot-lever $d$, and the plough-beam 1 , the ploughbeam and bracen made removable to adapt for the attacls. $m \geq n t$ of cultivator-beams, sulmtantially as shown and des.r.bed.

No, 226,705-1.EROY BR(III, WAITSBURG, W. T.Sulky Plongths. - Ipril 20, 1883, Filed Septimber 18, IS79.

Claim.-1.-The combination of the pivoted bar l' and the sliding-keeper $y^{2}$ with the bar $\mathrm{G}$, the axle $\mathrm{C}$, and the cross-head $u^{\prime}$, provided with a number of holes and formed won the rear end of the bar $\mathrm{U}$, which passes around the off whetl $\mathrm{A}$, and with which the plough beam $\mathrm{L}$ is connected sub-tantially as herein shown and described.

2.- The combination of the lever $\mathrm{A}^{\prime}$ and the connectinghar $Z$ with the rear end of the bar $E$, the pivoted bar $Y$, the sliding keeper $y^{2}$, and the bar $\mathrm{U}$, which passes around the of wheel $\mathrm{A}$, and with which the plough-beam 1 . is connected, substantially as herein shown and described.

No. 2-6.739.-FRANC1. II. FOSTER, CoFfEYTLLE, KANsAs, awignor to himnelf and ELISHA GiALUP, same

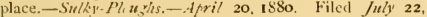
I 879 .

Clain.-I-The combination of the lever $\mathbf{~}_{i}$, provided with the cam Q, the curved ratchet-bar 1, with the crankaxle $\mathrm{F}$, the tongue $\mathrm{L}$, the arms $\mathrm{C}$, and the cross-bar $\mathrm{D}$, sub. st.untially as herein shown and described.

2. - The combination of the cam $Q$ with the movable cran'i-axle $\mathrm{F}$, the arms $\mathrm{C}$, the ton rue 1 , the plough-beam $\mathrm{M}$, an 1 the lever ( $i$, subst intially as herein shown and described.

No, 227,723.-11ENRY BOREHERT, AURORA, NIss.

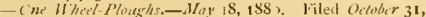
1879 .

Claim.-1.-The combination of seat-bar D, hinged framc 11 , and screw-rod 1 with the beam B of plough $\mathrm{A}$, subntantially as and for the purposes set forth.

2.- In a one-wheel-plough, the combination of the plough $A$ and fram $2 H$, hinged to the seat-heam $D$, and adjutable by rorl l, with adjustable wheel (;) substantially as shown anil decribed.

No. 228, 6;6.-WIILIAH B. (2UICK, WYANDOTTE, KANsAs, axirnor to REUBEN IV. FISHBOKN and IIENRI HAIVER, same place, one-third to each. - SulkyPio:yghs.-Jume 8, 1830 . Filed April 20, 1880.

(linm,-I - In a sulky-plough, the combination of platform 1), axle A, male with a forwardly-extending bail or tongue $\mathrm{B}$, and spindle $\mathrm{F}$, drive-wheel $\mathrm{G}$, journaled upon said spindle and provided with the concentric clutch $Q$, groovel wheel 0 , sliding upon the axle and prosided with the concentric clutch $\mathrm{P}$, connecting-chain $\mathrm{V}$, rock-shaft $\mathrm{W}$, prosided with the arms $\times \mathrm{Z}$. connecting-link $\mathrm{A}^{\prime}$, and hinged plough-beam $\mathrm{B}^{\prime}$, subutantially as and for the purpose herein shown and specitied.

2. - In combination with the hinged and vertically-adjust. able plough-beain $\mathrm{B}^{\prime}$, link $\mathrm{A}^{\prime}$, and rock-haft $\mathrm{W}$, having arm $-Z \mathrm{X}$, for operating the same, the sliding holt or lockbar $b$, with it, operating mechanism, composed of the rockshaft $~^{\prime}{ }^{\prime}$, having arms $a a^{\prime}$ and spring $d$, substantially as and for the purpose her:in shown and described.

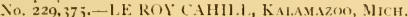
-Su'kp-Piou, h. (arriage's. -June 29, 1883. Filed April 2, 188 .

Claim.-1. - In a sulky-plough carriage, the device herein described, con-isting of the socket or collar 1 , disk 1$)^{\prime}$, and semi-tulse $1 y^{2}$, and provided with means for adjusting the lever thereon.

3.-The combination, with a crank-axle, of the device 1) 1$)^{\prime}()^{\prime}$, having the part $1 y^{\prime}$ corrugated, as described, the corrugated washer 1 , lever $G$, and bolt and nut, sulutantially $\mathrm{a} ; \mathrm{h}$ herein set forth.

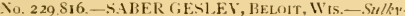

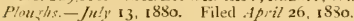

Claim.-1 - The avle B, having one long angle or crank, to whic's the plough $\mathrm{K}$ is attached, and a shorter ingle or crink carrying the land-side wheel, the axle li being bont and con-tricted un on: piecs, in the form shown and de- scribed, whereby, in this peculiar form of construction and arrangement of the axle, the plough may be rained and the land-wheel lowered by slightly rotating the axle by means of the lever F, substantially as shown as herein particularly specified.

2.-The box and clip $\mathrm{H}$, having the downwardly-project ing arm, in combination with the bar $(;$, lever $F$, and ratchet E, substantially as and for the purpose set forth

3.-The plough and beam $K$, with the axle $B$ and wheels $\mathrm{A}$, to the long angle or crank of which axle the ploughbeam $\mathrm{K}$ is journaled and secured by mears of the box and clip $\mathrm{H}$, in combination with the wedge $i$, downwardly-projecting arm of the box and clip $\mathrm{H}$, bar $\mathrm{G}$, lever $\mathrm{F}$, and ratchet $\mathrm{E}$, substantially as and for the purpose hereinhefore particularly described.

No. 229 822.-REUBEN HOl.GATE, NePONSET, ItL, - Gang-Plourhs.-July 13, 1880 . Filed Aurust 16, 1879

Claim.-1.-In combination with a telescopic axle, $A^{\prime}$ $\mathrm{A}^{\prime \prime}$, and ploughs, a telescopic bar, $\mathrm{A}^{\prime \prime \prime}$, adapted to be raised and lowered to allow the ploughs to rise and lower and to adjust their depth of ploughing, as and for the purpose specified.

2. - In comlination with the telescopic bars $A^{\prime} A^{\prime \prime}$ and the plonghs, the har $A^{\prime \prime \prime}$, adjutably secured to the bar $\mathrm{A}^{\prime} \mathrm{A}^{\prime \prime}$ by yoke 11 and slicling plate $c^{\prime}$, substantially as and for the purpose specified.

4.- In combination with the bars $\mathrm{A}^{\prime} \mathrm{A}^{\prime \prime}$ and adjustable har $\mathrm{A}^{\prime \prime \prime}$, the hollow shaft $\mathrm{E}$, having pinions $f f$, and end $a^{\prime}$ of the bar $A^{\prime \prime}$, having pinion $f^{\prime}$, sulstantially as and for the purpose specified.

4.- The clutched sleeve I and cord $i^{\prime \prime}$, in combination with the clutched end $a^{\prime}$ of the bar $A^{\prime \prime}$, and with pinion $f^{\prime \prime}$, and thaft $\mathrm{E}$, having pinions $f f^{\prime}$, and shaft $d^{\prime}$, having pinion $\mathrm{F}$, substantially as described, and for the purpose specified.

5-ln comlination with the hinged hars $\mathrm{P} \mathrm{P}^{\prime} p^{\prime} p^{\prime \prime}$, fixed block p $^{\prime \prime \prime \prime}$, and plonghs $\mathrm{L}$ and () , the link $\mathrm{P}^{\prime \prime}$, sub. stantially as and for the purpose specified.

6.- In combination with a plate $K^{\prime}$, hinged to the shaft $k$, the yoke $K^{\prime \prime}$, and beam /, connected substantially as and for the purpose specified.

7.- In combination with the shaft $\mathrm{K}$, yoke $\mathrm{K}$," beam l, and plate $K^{\prime}$, the standard $k^{\prime}$, and the cord $w^{\prime \prime}$, for adjust. ing derth of ploughing, substantially as and for the purpose specitied.

8 - The lever $\mathrm{ll}$, bolt $\mathrm{m}^{\prime}$, and cord $\mathrm{m}^{\prime \prime}$. in combination with the har A"', block J, and shaft $\mathrm{K}$, to which the plough 1 . is attached, substantially as and for the purpose specified.

9.-The lever $M$ and pawl $m^{\prime \prime \prime}$, in combination with the sleeve $\mathrm{N}$, having notched disk $n$, and with the shaft $\mathrm{K}$, sub. stantially as and for the purpose specified.

10.- The detent $n^{\prime}$, in combination with the sleeve $N$,

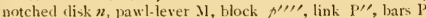
$p^{\prime \prime} p^{\prime} p^{\prime \prime}$, and plough $O$, as and for the purpose described

II. - The draft-bar, $S^{\prime} \mathrm{s}^{\prime \prime}$, hinged to the block J ant plough-heam $\sigma^{\prime}$, respectively, in combination with plough 1. (), bar $\mathrm{R}$, and equalizer-bar $S$, substantially as and for the purpone specified.

12.-The rods $\mathrm{Q}$, in combination with plough beam ( $)$ and adjustable bar $A^{\prime \prime \prime}$ of a gang-plough, as and for the purpose specified.

13.- In a gang plough, oscillating draft-hars $S^{\prime} . S^{\prime \prime}$, in combination with a draft-bar, $S$, and with a plough, L, fixed to the wheel-frame, and a plough, 0 , connected with the plough 1. sulstantially as and for the purpose specified.

14-- In a gang-plough, a plough, $L$, hinged to the axle or wheel-frame, and a plough, (), connected with the plough $I$ by hinged connections ${ }^{\prime \prime}{ }^{\prime \prime} p^{\prime} p^{\prime \prime}$, so as to permit the plough so approach each other in turning at the end of furrow: substantially an and for the purpose specified.

No. 230,014.-JUH.N I. HOKE, SOUTH BEND, 1XD,Sulky-Ploughs. -Ju/y 13, 1880. Filed Aprit 16, I8So. (laim.-1.-The combination of beam $\mathrm{B}^{3}$, bracket 1),

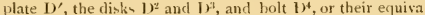
lent, the clevis $1 \mathrm{E}^{\prime}$, the locking-slide $\mathrm{F}$, arm $\mathrm{F}^{2}$, and the tongue of the machine, the parts being constructed and arranged for jcint operation, -ubstantially as set forth, whereby the plough can he tumed around by the direct draft of the team. 
2.-In combination with the beam of a plough, a braclict, $\mathrm{D}$, and adjustable plate $\mathrm{D}^{\prime}$, a lever $\mathrm{D}^{\mathrm{t}}$, and link $\mathrm{D}^{\mathrm{T}}$, the pasts being arranged for operation substantially as described, whereby they may be made to give the proper dip or position to the point of the plough and to regulate the same with reference to harel and soft ground, as described.

3.- The combination of the adjustable plate $\mathrm{D}^{\prime}$, having a grouve in its upper surface, the disk $\mathrm{D}^{2}$, having a projection upon its under surface, and the bolt $\mathrm{D}^{4}$, whereby the width of the furrow cut by the plough can be regulated by a transverse movement of the disk upon the plate described.

No. 230,042,-JOSEPH B. NEFF, BushNELL, Il.t.Sulky-Ploushs.-July 13, 1880. Filed January 20, 1880. Claim.-1.-In combination with the wheel and axle of a plough, a toggle-joint having one of its bars provided with a rack-bar, arranged to operate with its other bar provided with a pawl, by means of which the toggle-hars may be locked at different angles to or in a straight line with each other, substantially as and for the purpose herein shown and set forth.

2.-In combination with the wheel and axle of a plough, a toggle-joint having one of its bars provided with a rack-lar, arranged to operate with its other bar extended to form a liand-lever, and provicled with a pawl, by means of which the togrle-bars may be locked in different relative pocitions, snbstantially as described, and for the purpose specified.

3.- In combination with the axle or frame of a wheel plough and a sliding plate which carries the whet, a togglejoint having one of its bars provided with a rack-bar arranged to operate with its other bar extended to form a hand lever, and proviled with a pawl, by means of which the togglehars may be locked in cliferent relative position:, to adjust the heirbt of the slicling plate and wheel relatively with the axle, subatiutially as anil for the purpose spzcitied.

4.- In combination with a wheel-plough frame and plough, the vertically and haterally adjustable stop $\mathbf{I}$, arranged so as to tilt or turn to one side, substantially as and for the purpose specitied.

No. 230,192.-IIENRY A. OINSTED, OAKLANn, CAL.-Gans-Ploushth.-July 20, I8So. Filed Miny in, 1880

Claim.-In combination with the plough-beams G, carry in the ploughs $\mathrm{G}^{\prime}$, sail beam; bein $r$ hinged, pivoted, or otherwive loosely connected to the wheeled frame, the slites $F$, guides $E$, and lever $H$, and the rear guile, $J$, and lever $L$, wher by both forward and rear ends of the ploughs are correspondingly elevated from the ground, substantially as and for the purpose herein described.

No. 230,335-- LOU1S W: l'UWELI, MEXIA, TEx.-

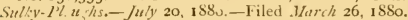

Clim. - The combination of the slotted axle $\mathrm{A}$, adjust? ble lianger C D, and diagonal braces $\mathrm{E}$ with the slotted beam $\mathrm{F}$, adjustable haners $11 \mathrm{I}$, and braces $\mathrm{K}$, adapted for the athe hment of beams of various sizes, as described.

No. $20,+19 .-$ TIIOUAS E. JEFFERSON, DusTon,

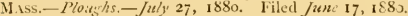

Clain.-1.- The combination, with a main frame, $A$, o a ploush having the mould-board attached to it, of an auxiliary frame, $C$, having forw: $r$ rd extensions to which the plongh-beam is attached, and rear cxtensions to which the furrow-side wheel is applied, said auxiliary frame boing hinged intermediate its ends to the main frame, substantially as and for the purpose clescribed.

2.-In combination with a plough or ploughs, one or more harrowing or cultivating devices, as at $\mathrm{B}$, or thei ejuivalenti, for relieving said plough or ploughs from pies: $u$ :e and friction on their land-sides, and harrowing or cultivating the 1 ughed soil simultaneously with the operation of ploughing, substantially as sct forth.

3.-Cuting wheels or diskis, or the equivalent thereof, as at B, of relatively large and small diameters or size, in combination with a plough, whereby the ploughed soil is uniformly harrowed or cultivated, and also the pressure and riction on the land-side of the plough are avoided, substanthaily as set forth.

4-In combination with a plough, the obliquely-set contrivance $\mathrm{B}$, for relieving a plough of pressurc on its lanclside, and a land-side le.2ring wheel, $\mathrm{A}^{\prime}$, sulsistantially as and for the furpose described.
5.-In combination with a plough, the contrivance or device, as at $\mathrm{B}$, for relieving a plough of pressure on its landide, the forward grooved wheel, $\mathrm{A}^{2}$, and landsidebearing.wheel A', substantially as described.

6. - In a plough, the furrow-side bearing-wheel $\mathrm{D}$, applied to an auxiliary frame, $C$, having a plough attached to it, in cumbination with clisks or wheels, as at $\mathrm{B}$, applied to a main frame, A, whereby the frames are supported on the furrow side by the disks or equivalent contrivance while ploughing and harrowing are going on, and by the furrow-irle wheel when the said operations cease and the plough and disks are raised out of the soil, sub-tantially as described.

7.-The mould board $\mathrm{N}$, having edged wheels $f$ extending up through its curved surface above the place where ordinary horizontal cutters have been applied, and in rear of and to one side of the place where an orlinary coultercutter has been applied, said edged cutters serving for reducing friction, and also enabling the plongh to cut narrow slices and hold them while they are being turned over, subtavitially as sel forth.

8. - The mould-hoard $\mathrm{N}$, provided with lapping extensions $g$, notches $g^{7}$ and $g^{4}$, and lugs $g^{3}$ and $g^{9}$, in combination with the share $\mathrm{N}^{\prime}$, provided with a slotted $\operatorname{arm}, h h^{2}$, lapping extensions $g$, and a thickened portion $h^{\prime}$, and with the point $\mathrm{N}^{2}$, provided with lapping extensions $g$, thickened extension $g^{\prime}$, and a screw-threaded loar, $y^{2}$, passed through the lug $s^{*}$ of the mould-board, substatially as deccribed.

9.-An edged conlter, Q, provided with l:terally-yielding blucks or cushions $m$ at its centre or hub, in combination with a plough, whereby it is allowed to yield laterally inclependently of the plough when it mects unjiclding ofstructions, substantially as described.

10.-A rolling coulter having an automatic back and upward movement and provided with a relief-syring, substantially as and for the purpose described.

11.-In combination with a plough, an edged coulter provided with siclding devices for relieving it of strain in both itsupward and backward and it, lateral movements, suls:tantially as described.

12.-A plongh having its front bearing-whel hanger extended upward to form support, which are forward of the centre of the axial stem J of said hanger, substantially as and for the purpose describel.

13.-In a plough, the forward-beariug-whecl, $\mathrm{A}^{2}$, having

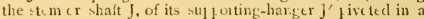
lat $r$. lly adjustable bearing, $j^{2}$, and extended upward beyond saicl learing to form sulpuits $q$ for a pivet, $q^{\prime}$ of a draft tongue or pole, $\mathbb{K}$, forward of the ccitre of the vertical asis of said stem $\mathrm{J}$, and for a gucling-friction-roller, $q^{3}$, to rest in, in combin.tiun with a tongue or dralt-pole $\mathrm{K}$, which is provided w ith grooved pulleys $l^{2}$, and is piroted to said stem or shait $J$, whereby the longne and draft-chains $l^{\prime}$ and $l^{7}$ are allowed movements in vertical and horizontal planes with. out lialility of bincling, substantially as described.

14. - In a plough, the part or section $h^{\prime}$ of the tongue or pole K, provided with a toothed wheel or wheels, $\mathbf{L}$, or the eiguivalent thereof, and a drum, $l$, and with a plain suppouting and guiding wheel, $L^{\prime}$, sulatutially as and for the purpose described.

15.- - In a plough, the combination, with the tongue or pole K, of the toctlied wheel or whets I., crum l, plain supporting and gtuiding-wheel $L^{\prime}$, or its equivaleut, pulleys $l^{2}$, roller $q^{3}$, draft-chains $l^{\prime \prime} l^{4}$, windlass-drums $l^{3}$ and $l^{3}$, ratchet wheel or wheds $l^{4}$, and pawl $l^{k}$, substantially as and for the purpose described.

16.- The turning stem or shaft $J$, of the hanger of the front supporting wheel, $\mathrm{A}^{2}$, provided with a guiding frictionroller $q^{3}$, in combination with a hingcd claaft pole or tongue, $k$, provided with guidc-pulleys, l' forward ol the axis of said stem or shaft J, sub tantially as described.

17.- The combination of the part of section $k^{\prime}$ of the draftpole $K$, provided with guided and supported wheel or wheels $\mathrm{L}$, and the outer tubular part, $k$, of said toncue $\mathrm{Cr}$ pole, provicled with a rack $L^{2}$, or its eyuivalent, for said whed or wheels to gear with, subtantially as described.

18.- The combination of the past $l^{\prime}$ or of the draft tongue or pole k, provided with a grided or supported wheel or wheels, $\mathrm{L}$, and the outer tulbular part, $k$, of said tongue $K$, provided with a rack, I. ${ }^{2}$, a windlass mechanism, and a 
plough whereby the draft of the team can be employed in a very effective way for raising the plough, and the loc: movement of the team for lowering the same, sub-tantially as clescribed.

19 - :11 a plough, the coml ina ion of the adju-table gnagetop l', with the extensitste tongue $K$ and a windlass mech. ani-m, wherely the dejth to which the plongh is automatici lly lowered is controlled, sulstantially as described.

20.- In a plough, the gange-ntop a plied to the windlassshalt 1$)^{\prime}$, in conlination with the plough frame and hinged plough, substantially as de-cribed.

2I. - In a plough, the combination of the stem $J$ of the front wheel, $A^{2}$. latcrally-adjutable bearing-hlock $\mathrm{J}^{2}$, and the pole or tongue $K$, wliereby the center draft of the plough and its appliances may be regulated, substantially a: set foith.

22. - in a plongh, the spring-seat 1 , comprising the rear w.r.t-extended stiy-bar $p^{\prime}$, spring $p^{3}$, pendent rod $p^{\prime}$, stand ard $p^{2}$, spring $p^{\prime}$, and guiding-zye $p^{4}$, substantially as and for the fupose described.

23. - I remonable Lox for journal-bearings having screw threarls on it out $r$ surface for insertion into a hanger or frame, in coml ination with the revolsing shatts or axles and the friction-roller, sulstantially as shown and described.

24. - The combination of the seed-plasting mechanism, as a $\mathrm{E}$. E', with the nain frame, nuxiliary frame, obli que disks or wheel-, as at $\mathrm{B}$, or an equivalent contrivance for reliesing the plough from pressure and friction on its land side and also harrowing or cultivating the soil, and a plongh for turning over the soil, substantially as described.

Ni, 230477 -HORICE E. REEVEL, FORT 1)OMF, INW., assignor to GEORGE B.SHER.MAN, same place.Sulky-Ploushs.-July 27, ISs:. Filed fidruntry 10, 188 o.

Claim.-1.-In a sulky-plough, the combination, with the plough-beam $\mathrm{N}$, having its forward end bent upward, and and the bearings $\mathrm{L}$, of the connecting-bar $\mathrm{T}$ and the lever $\mathrm{L}$, pivoted upon said bearing, substantially as herein shown and described, whereby these parts all rock upon the axle, as spacified.

2.-In a sulky plough, the combination, with the lever $\mathrm{U}$ and inclined bar $d$, of the slotted and notched plate $f$, having its forward end beveled, the wooden pin $i$, and stop pin $j$, substantially as berein shown and described, wherehy the plough is allowed to swing back should it strike an obstruction, as set forth.

No, 230,528.-ROSIVELL YI. CLARK, ICPHERSON, Kaxsas. - It heel-Ploughs.-Ju/y 27, 1880. Filed A/ril 27 , ISSo.

(laim.-1.- The combination, with the frame of the plough, of a wheel, B, behind the plough, having it, axis in a stationary bearing, and a wheel, $\mathrm{B}^{2}$, turning on a short asipivoted at one sicie of the frame, to permit said wheel to be brought at right angles to the frame at one sicle thereof, substantially as set forth.

2.- The bifurcated push-rod or brace 1 , in comlination with the frame $\mathrm{A}$, plough $\mathrm{C} c$, and the adjusting derice, substantially as described, for moving the plough-beam vertically, substantially as $\mathrm{s}$ t forth.

3-The combination of the hand lever $G$, rock-shaft $F$, sleeve $\mathrm{E}$, and connecting devices with the plough $($; , having a beam, c, extending loosely into said sleeve, substantially as herein set forth.

4.- In a wheel-plough, the comhination, with the frame, of a plongh and push-rod arranged substantially as shown, wherely the plough may be propelled from the rear, substantially as set forth.

5.- The combination of the frame, plough, and a puch-rod I, arranged to propel the plough from the rear, the said plough being pivoted to said rod to vibrate from side to side, and adjustable, as set forth.

No. 230,760 -ISAAC R. GILBERT, LOUSVH.LE, KY - Which.Ploughs. -Augrtst 3, I 880. Filed April 26, 1879.

Claim.-1. - The combination of the slide C, having s.in. dle $c$ and rack-har $D$ attached thereto, with axle $A$, slotted arm $g$, L-sbaped lever E, and spring-pawl $a$, all con-tructed and arranged to operate substantially as and fur the purposes set forth.

2. - The combination, in a sulky-plough, of axl. $\mathrm{A}$, plate $\mathrm{B}$, and slicle ( with rack-har 1 , 1,-shared lever $\mathrm{E}$, thotted arm ", an 1 spindle $e$, all con truct of and arronged substantially an and for the purpos deseribed.

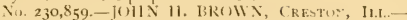

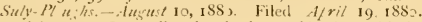

( laim. - I, - In a sulky plough, the coml in tio.s, with the plough and beam $\mathrm{A}$, of the clamp ing-rod 5 the clamps 6 and 7 , the oxcillating box 8 , and the jointed lever 9, sub tantially as and for the purpose described.

2.-In a sulky plough, the combination, with the plough $\mathrm{A}$, of the rod 5 the uscillating box 8 , the lever 9 , provided with the fivoted joint II, the box 10 , attached to the frame $\mathrm{L}$, the oscillating box $\mathbf{I}_{2}$, and the angular rock-shaft $\mathbf{1}_{3}$, substantially as herein shown and described.

3-In a vulky-plough, the combination or the following elemert $;$, consisting of the plough proper and the beam $A$, the clamping-rod 5 , the clamps 6 and 7 , the orcillating $10 \mathrm{x}$ 8 , the jointed lever 9 , the boxes 11 and $\mathbf{1} 2$, the angular rock shat 13 , the fulcrum-block 16 , the clamp 17 , and the operating-lever 14, all comstructed and arranged as herein shown and described.

No, 230,9:2.-FRANCIS F. SUITII, AYRORA, ILI., assignor of one-half of his right to JOHN M. LOC KW()()I),

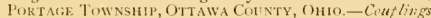
for Sulliy nith rther Pliutis-Austest 10, 1880 . Filed J. nuarj, 28,1880 .

Claim.-1. - The coupling C, composed of the two plates $b b^{\prime}$, united togcther, as described, and having the rear central be aring at $c$ and a front stop at $c$, whereby the shaft or axle is coupled to the lough and yet allowed free lateral and longitudinal motion and the plough-beam and coupling are allowed free vertical oscillation, while tilting of the shaft or axle and plough independently of each other is preverted substantially as set forth.

2. - The coupling $C$, composed of the plates $b b^{\prime}$, united together, as described, and having the rear central bearing, $c$, and a front stop, $\epsilon^{\prime}$, in combination with the axle or shalt $\mathrm{A}$, collars D 1,', aud plough-beam B, substantially as shown and set forth.

3.- The combination of the coupling device $\mathrm{C}$, axle $\mathrm{A}$ of a sulky or carriage, a plough-bean, $\mathrm{B}$, stop-pin holes $i i$, top- fins $j j$, and adjutable collars D J)', substantially as dencribed.

No, 231,193--JOHN L. REUSS, CASTRONILLE, TEXAS. - IIthel-Ploughs.-August 1 7, 1880 . Filed June 2, 1880.

('laim.-1.- The combination of the bent axle A, arms B $\mathrm{B}^{\prime}$ of the axle, guicle $c$, sheath $b^{2}$, link $\mathrm{F}^{\prime}$, having angular bend at it: lower end, ellow-lever $\mathrm{F}$, and segmental rack $\mathrm{E}$, all substantially in the manner shown and described.

2.-The combination of the tongue $\mathrm{H}$, plow-beam $\mathrm{C}$, rigid to the carriage-axle $\mathrm{A}$, lever $\mathrm{I}$, and link $m$, the tongue being pivoted to the plough forward of the axle, and the link $m$ to the tongue between the axle $\mathrm{A}$ and the pivot 5, all sub. stantially as and for the purpuse herein described.

3.-The combination of the double-armed crank-shaft $n^{\prime}$ and it adjusting lever $\mathrm{K} w$ ith the plates $h^{\prime} h^{2}$ and the pote or tongue 11 , pivoted, as at $r g^{2}$, to the rigid forwardly-ex tended end of the plow-beam $C$, subtantially as and for the purpose described.

No. 231,210-MUGH H. CANA[AY, FAIRTIEL1), IowA. - Sulkp-Moushs.-Ausust 17, 1880. Filed Jun 26, 188,

(laim.-I-The combination of the combined rock shaft and bail $G / h$, having rigid arms $k n$, and the hand-lever $J$, by means of a link, l, substantially as shown and describerl, for the purpose specified.

2.- The combination of the rock-shaft and bail $\mathrm{G} / h$, hav ing rigid arms $k$ and $n$, the lever J and link $l$, and the stub. axle $c d$, having a rigid standard, $f$, for the purposes speci. fied.

3.- The straight axle $\mathrm{A}$, the carriage-frame $\mathrm{B} \mathrm{B}$, the stubaxle $\mathrm{C} d$, having a standard $f$, the combined rock-shaft and lock-bail $G h$, having rigid arms $h$ and $n$, the hand-lever J, the connecting-link $l$, and the rack $m$, arranged and combined sulu-tantially as thom and described, for the purposes specified.

No. 231.218.-MILO A. ELLIOTT, STRATFORd HoILow, N. I1.-Thusths.-Aurnst 17, 1880. Filed Marih 17. 1883 .

Claim. $-\mathbf{r},-$ In a piough, the comlin.tion with the $\mathrm{V}$. 
ship 2 arm $\mathrm{O}$, connected to the plow-beams by rods $\mathrm{H} \mathrm{I}$, of the pole $\mathrm{B}$ and the auxiliary tongue $l$, carrying the doubletree $m$, and the pivoted hook $n$, substmtiajly as and for the purposes set forth.

2.-In a plough, the combination of the plow-beams G, pivoted a shown, with the pivoted hook $n$, shaft $H$, lever $L$. and pole an 1 tongue B /, substantially as and for the purpoies set forth.

No. 23r,302,-SAMUEL IV. FLEMING, DUNKIRK, OHIO, asignor of one-half of his right to JAMES RUSH, s.me place - Plough-Timiks.-Augut 17, 1885. Filed Wizy 6,1880

Claim.-In a plongh-truck, the combination, with the axle $\mathrm{B}$ thereof and the bean $\mathrm{D}$, secured by braces $\mathrm{E}$, of the rearward and upward eurved truck-post $C$, clevis $G$, rod $G^{\prime}$, and loop-bolt II, having tightening-handle I, construeted and operating substantially as and for the purposes ret forth.

No. 232,052.-WIILIAI V. MORGAN and THOMIAS W. HACKMIN, ALLERTON lowA.-Sullyy-PloughsScp'cumbir 7, ISSo. Filed February 19, is8).

Claim.-1,-In a sulky-plongh, the beam-clamp constructed subitantially as berein shown and deseribed, consisting of the hook-bolt () , the flanged plate $Q$, and the nut $\mathrm{R}$, whereby the plow-beam $\mathrm{P}$ will be held securely, as set forth.

2.- In a sulky-plourh, the combination, with the bent axle $\mathrm{B}$, of the buil $\mathrm{K}$, the arm4 $\mathrm{N}$, the cross-bar $\mathrm{M}$, the socket-

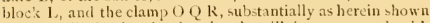
and describsd, whereby the plough will be connected with the carringe adjustably, as set forth.

No. 232.258.-THUMAS T. H.IRRISON, AUBREY, Kavs 15. -Su'ky.Ploushs.-September 14, 1883. Filed Fun: 17,18 : 0 .

Claim.-1 - The spindles B, axles D, having vertical end post , $\mathrm{C}$, the arched bar $\mathrm{E}$, having end holes, the plate $\mathrm{H}$, crank-screw J, and cross-beam F, combined, as and for the purpose described.

2.-The braces Q, plate R, l,op S, pin V, bent lever W, and plow-beam $T$, combined to adjustably support the front en 1 of plow-beam, $\mathrm{a}$; shown and described.

No. 232,345 - (IIARI.ES F. GODD.ARI), WE-TMitcheLl, lowa-Ploughs. - Sephmber 21, i88o. Filed Warch is, 1879

Claim. - The curved plough-bean A, provicled with the slot $a$, in eombination with the slotted rear arm, $F$, adjust :bl: spindle I), front wheel, (; and rear wheel E, arranged so that the line of support between the wheels may pass the middl $=$ of the plough, whereby it is supported from downward and lateral pressure wit jout the aid of a l.mel-ide t ongue, or t ir I wheet, subatantially as shown and describer?

No. 2325 5. - IRANKIIN B. HUNT, RICHMOND,

IND, asti ruor of one-half of his right to D. B. ROBBIN.t-

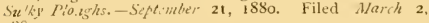
1880.

Claim,-1.-In combination with the pendant or plongl beam-supporting pivoting device $T$ ' $T^{\prime}$ attached to the crank, the bar t., alio secured to the side arms of the crank, and the adjusia' $]$ slotted plate $\mathrm{E}^{\prime}$, as and for the purpose specified.

2 - The pendant or plough-beam-supporting device T T', combined with the swivel $\mathrm{X}$, said swivel provided with a we. I te-shaped hole, $i$, for the plough-beam to move ohli juely in, an 1 also proviled with a lug, $h^{2}$, and a set-serew, $h^{3}$, at ons sile and a notehed luj, $h^{\prime}$, at the other side, substantially a described, for the purpose specihed.

3 -Treswival devica $\mathbf{X}$, provided with the wedge-shaped hole $i$, for the plough-beam to receive an obli jue adjust$m$ sut in, and also provided with the lug $h^{2}$ and set-serew $h^{3}$ at one sile and a notched lng, $h^{\prime}$, at the other side, substantially as slown, for the purpose, specitied.

$4-\ln c$ mbination with the plough-beam $\mathrm{D}$, the oblique adjusting device componed of the hollow case $\mathrm{S}^{2}$, having, a laz $h$, on one side $t$, en ra re in the notched lug $h^{\prime}$ of the swivel device, the screw-shaft $R^{\prime}$, nut $V$, and the handwheel $c$, as and for the purpose specified.

5. - n a sulky-plough, the oblique adjusting device V R'. counl in ed with the oscillating or rotatmg adjusting derice $\mathrm{X}$ for the plouth-beam, the pendant ' $\mathrm{T}$ ' $\mathrm{T}$, the crank, $1 \mathrm{I}$ ', and a ljustable block $\mathrm{E}^{\prime}$, as and for the purpose specified.

6. - In a sulky-plough, the beam $\mathrm{D}$, provided with the d eve $S^{\prime}$, combined with the oblique adju ting device $\mathrm{com}$ - posed of the hollow case $S^{2}$, having a lug, $h$, on one side to engage in the notched lug $h^{\prime}$ of the swivel device, the scriw shaft $K^{\prime}$, nut $V$, and hand-wheel $r$, the swivel $\mathrm{X}$, and the pendant ' T T', as and for the purpo:e specified.

7. - In a sulky-plough, the seat-arch W, provided with the sockets $\mathrm{M}$ and $\mathrm{U}$, having their lower edges projecting on both sicles to form a strong support for the tongue and permit the mechavism to be reversed to adapt it to a right or left hand plough, sub tantially as described.

8.- li a sulky-plough, the seat-arch $\mathrm{W}$, provided at one sicle with a brackit. $\mathrm{J}^{2}$, combined with the donble-ended stud $\mathrm{N}^{\prime} \mathrm{N}^{2}$, the removable quadrant $\mathrm{J}$, and lever $\mathrm{H} \mathrm{G}$, substantially as ciescribed, for the purpose specified.

9.-In a sulky-plough, the quadrant $\mathrm{J}$, having retainets for the lever $H$ on one sicle of the arch and a down. ward-projecting arm, $\mathrm{J}^{3}$, provided with a hcle, $a^{2}$, and a nutch, $a^{3}$, at its lower end, substantially as shuwn, for the purpose specified.

Io. - In combination with the curved scat-spring $\mathrm{K}$, the spring $\mathbf{K}^{\prime}$, having its downward-curved end operating on the upper edgz of the arch $\mathrm{W}$, as described, for the purpose specified.

1I. - In combintion with the horizont al longitudinal pirot $m$, the pivot-plate $l$, the pivot-plite $j$, the stud-Lolt $n$, and the seat-springs $K$ and $K^{\prime}$, substantially as described.

12.-In a sulky-plough, the combination of the ploughbenm-suppuring clevices ' $T$ ' $T$ ', the of lique adjusting devices $S^{\prime \prime} R^{\prime} \gamma c$, the vertical adjustung-crank I I I', and the lateral adjusting slotted plate $E^{\prime}$, as and for the purpes z specified.

13.-In a sulky-plough, the scat arch W, having a etitral seat mounted on a sping, $K$, and supported laterally by the spuing $K^{\prime}$, comlined with the central forward-pojicting arm $O$, having a slot in its cuter end, and the foot.rest 1', sul.stantially a, described.

No. 232,515-ADOLPHUS 1.ATHAM, TIPPECANOFTww. Inn-Pronglt-Trucks.-September 21, 1880 . Filed Febrary 16,188 .

Claim.-In a plough-truck for supforting a plough, the compound wheel D (, the wheel 1) runuing on the arm of the truck-frame, and being f-rovided with a thimlle-arm, $E$, on which the wheel $(\mathrm{i}$; placed, so that $\mathrm{l}$ cth $\mathrm{whec}$ ls may have an independent movement or rotation, or Loth may rotate together, in comlinstion with a single wheel on the eprosite arm of the truck, as specified.

No. 2,28 ; - THOMIS PONELL, STOCKTON, CAL.

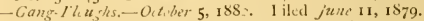

Clim. - In a gang-plough and harrow combined, the comlination, with the obli jue beam A, comnected to the ide pasalled bars or beams, C 1), and hasing the anguler level-arm $\mathrm{I}^{\prime} \mathrm{H}$, of the harrow $Q$, having it igl tan led bars $y$ yinged or pircted to the beam $A$, and haviug the operating-leicr $x x$, as and for the parpose st forth.

No. 232,87 -SH,ASH. WO()H.RIDGE, VI:NICE, II.I. -Cangr-Ploughs.-Oitaber 5, 1880. Jiled Iebriari' I4 1 so.

Claim.-I. - The frame $A$, pivoted to the axle at $n^{\prime}$, and provided with the hanger $n$ and lever 1 , in combination with the diagonal rock-haft $\mathrm{D}$, with $1 \mathrm{j}_{\mathrm{j}}$ icl arms $\mathrm{E}, 5$, lever $G$, and connecting-links, and plough-Leams $b^{\prime} l^{\prime}$, substantially as hhown and described.

2.- The frame $A$, in comlination with two or more independestly-rivoted plough-beams, $13 \mathrm{~B}^{\prime}$, of unecual length, said beams being fivoted to the inner silles of the leamm $a^{\prime}$ $a^{2}$ of the frame, aad confined by ublorg loops, as at $c$ and $d$, and oceupying a position alove the axle, and also being connected with a diagonal rock shaft 1 , and to a hand-lever $G$, ly devices F E and $g . g$, substantially in the manner and for the purpose discribed.

No. 233, 83.-HENRY GOLYER, WHTE HAI, ItL.-Prushs.-Octeber I 2, I880. Filed Jute 19, I8So.

Claim.-I. - In a sul'ky-plough, t' e co nl.ination, with the plough-beam, of the angular lever and chain, both comnected ther to, and slotted standard secured upon the bar A, sil?stantially a, and for the purpose specified.

2. - In a wheel flongh, the standard $H$, aclapted to hold the plosgh-beam between its vertical parallel arms, and I aving it low er end fivoted to the axle, the lever 1, pivited to 
th $*$ standard $H$, the claim $m$, and link $l$, arranged to operate su'stantially as and for the purpose set forth.

3.- In a wheel-plough having a slotted standari, 11, the a ljtstahle clamp $P^{\prime}$, composed of plates $i j^{\prime}$ and bolts $j^{2}$, the plate ${ }^{\prime}$ heing furnished with bearings $k$, and a lug, $j^{3}$, and the friction-rullers $k^{\circ}$, arranged in pairs to bear agains the ront and rear edges of the side bars of the standard, sub$s$ antially as set forth.

No. 233,276-SAMLEL PETERS, (Kow: PUINT, 11.I., asignor to (iEORGE SAYFORD, same place.Pl ush-Trucks. - October 12, ISSo. Filed Siptombir I3. 15 so.

Claim.-in a plough truck, the combination, with the axle, of the standard $\mathrm{D}$, provided upon its front edge with open notches $d d$, the slip-link F, closed at both ends and provicler at its rear end with a screw threaded seat, $f$, and the evebolt $(;$, screw-threaded to fit the seat $f$, and adapted ts engagc with the standard $D$ at one end and to receive the plough-clevis at the other end, $g^{\prime}$, substantially as set fort'?

No. 233,7 22, -IIENRY BORCIIERT, AURORA, MINN. -One Whict-Plonshs.-Oiribir 26, 1880 . Filed June 23, 180 .

Claim.-1.-1n a one-wheel-plough, the combination of heam or bar $\mathrm{E}$, having boxes $e$ and shaft or rod $c^{\prime}$, with lever $\mathrm{H}$, fixed to one encl of said rod, and tongue $\mathrm{G}$, fixed to the other end of said rod, and plough-beam $a$, substantially ar and for the purposes set forth.

2.- The combination of plough $\mathrm{A}$, axle $\mathrm{B}$, wheel $\mathrm{C}$, and foot-board $\mathrm{D}$ with b am or har $\mathrm{E}$, boxes $e$, and shaft or rod $c^{\prime}$, and tongue $\mathrm{G}$, jointed thereby at or near the forward end of tonge $a$, and lever $H$, hinzed to the bean $E$ about on a line with the rear cnd of $G$ and forward end of tongue $a$, substantially as and for the purposes set forth.

No. 234,176.-FREDERICK $\$$, D.IVENPORT, JER SEYvil.t.e, li... - Wheel-Ptoushs, - Vivimber 9, isSo. Filed $/ u ! y, 9,1 \cdot S_{3}$.

Claim.-1.- In a wheel-plough having an axle adapted to turn and thereby raise the plough from the ground, the combination, $w$ it's the axle provided with a rixid arm, a platform, journaled on the axle, and a plough-beam mounted on the platform, of draft mechanism directly connected to the axle-arm and a locking device which detachably secures to gether the platform and the axle-arm, said locking device being connected to the platform at a point forward of the asle-arm and adajted to transmit the draft to the axle in a line passing through the latter, substantially as set forth.

2 - In a wheel- lough having an axle allapted to turn and thereby raise the plough from the grounl, the combination, with said axle provided with a rigid arm, a platform journaled on tie axle, and a plough-beam mounted on the platform, of a pawl firoted on the latter for engaging or disengaging with axle-arm, a longitudinally-slicling draft-rod, and a connecting device between the latter and the axle-arm, substantially a, set forth.

3. - In a wheel plough having an axle adapted to turn and thereby raise the plough from the ground, the combination with said axle provided with a rigid arm, a platform jourmaled on the axle, and a plotigh beam mounted upon the platiorm, of a spring-pressed foot-pawl piroted on the platform ard engaging with notches formed on the arm, a longiturlinally-sliding draft-bar, and a link connecting the latter with the axlc-irm, substantally as set forth.

234,32S. - CHAKLTON PATTERSON and HER.IAN

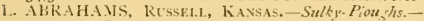
Do:vimber 9 1883. Filed Ju'y 2, is8o.

(laim. - The arch $\mathrm{A}$, having the rack $\mathrm{M}$, the parallel bars I), provided with bearings, and the vertical bar, C, forming a slot or guide, in combination with the axle-arm $\mathrm{D}$, having the cross-head $F$, the curved link $G$, and the elbow-lever $H$, ubstanially as shown and destribed.

No. $234615-W L L L A M H$. RYER, LA CRosse, Wis, asignor to himself and ALBERT HIRSHHEl

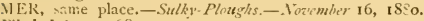
Filed $J u l y, 19,1 \& 80$.

Claim. - The combination, with the arched cross-bar $A$, having the trunnions $m$, of thie U'-shaped cross-bar $n$, connecting usth lever $r$ and extending backward to support the plou $h$, the plate $p$, and half-tuhe $\%$, the rod $S$, laving spiral spring $u$, and the frame having lug $t$, substantially as and for the purpose specified.

No. $234.68_{3}$-J ()H. R. HCCORMICK, Georgetow: TExas. - Sulky. Ploughs, - liovember 23, 18si). Filer May $25,1880$.

Claim.-The combination, with the crank-axle and tongue, of the angular guide-braces $\mathrm{D} \mathrm{D}$, diagonal l,race $\mathrm{E}$, and the adjustahle collars $G G$, substantially as and for the purposes set forth.

No. 234.743-AXEL F. BERGQVIST, FAIRFIELD, lowA, assignor to himself and DAVID LOCKE, same place.-Sulky-Ploughs.-November 23, I88o. Filed Sett'mber 4,188 s.

Claim.-I.- The combination, with the bail having a crank-extension, $g$, and the wheel $\mathrm{B}^{\prime}$, carried by a rockshaft, C, having cranks $i$ and $l$, of a lever, F, comnected above its fulcrum with the crank $i$ by a link, $h$, passing over the axle, and connected below its fulcrum and below the axle with the crank of the hail by link-bar $f$, substantially as shown and described.

2.-The combination, with the bail and the plough-beam, of the clip-plate $m$, fastened to the beam, and the swingingplate $n$, connected at its middle to the bail and jointed to the clip-plate, and a chain, $o$, connecting the upper end of plate $n$ with the forward end of the clip-plate, substantially as shown and described.

3.- The combination, with the axle and the bail, of the $\mathrm{U}$-shaped frame I), bent over and extended down below the axle in the rear thereof, and provided with bearings for the bail, and the braces $c$, passing beneath the axle and connecting the side bars of the frame $D$ with its rear and pendant encls, as shown and described.

No. 235,175.-FRANCIS F. SMIITH, AurorA, II.L.Suiky-Ploughs.-Decomber 7, 1880. Filed May 22, 1880 .

Claim.-1.-The combination, with the supporting-bar A and crank-shaft $k^{\prime}$, of sector $k^{5}$, having a bracket, $k^{3}$, which linds against the side and edges of the supporting-bar $\mathrm{A}$, subtantially as and for the purpose described.

2.-The combination of the lever II, toggle-lever $m \mathrm{~m}^{\prime}$, sector $k^{3}$, having a bracket, $k^{3}$, and the crank-shaft $h^{\prime}$, and supporting-bar A, substantially as and for the purpose described.

3.-The combination of the sectors $k^{4} k^{5}$, having brackets $k^{2} k^{3}$, in combination with the slicle $\mathrm{B}$, having a brackel, $b^{3}$, the axles $\mathrm{A}^{\prime} \mathrm{A}^{2}$ of the sulky-carriage, set out of line with one another, and the crank-shaft $k^{\prime}$, having its anns in line with each other, stubstantially as and for the purpose described.

4.-The combination, with the supporting-bar $\mathrm{A}$ and crank-shaft $k^{\prime}$, of sector $k^{4}$ on the landside of the carriage, provided with a bracket $k^{2}$, which serves both as a set guage for the sector and as an extended support for one end of the crank-shaft, a lever, link, and a slide, B, the parts being arranged to limit the extreme up and down movement of ti.e slide, substantially as described.

5-The spring check-roller J, suspended upon a suppoiting-frame, provided with stops, in combination with the plough-beam $K^{\prime}$. whereby a sping-roller and a laterally vibrating plough-beam are adapted for operating together in a sulky-plough, substantially as and for the purpose described.

No. 235,205,-I.E ROY CAHHLL, KaI.AMaZOo, MtCH. - Sulky-Ploughs. - Decimber 7, 1880. Filed Afril 28, 1870.

Claim.-1.-The combination of the axle I, crank or arm $J$, provided with the ratchet disk $d$, the lever $I$, provided with similar disk $d^{\prime}$, and the rack-bar $\mathrm{M}$, as and for the purpose set forth.

2.-The combination of the pole $\mathrm{E}$, having slot $x$, or its equivalent, the eye-bolt $f$, plate $\mathrm{R}$, rod $\mathrm{S}$, and thumb-nut $t$, whereby an up-and-clown and a backward-and-forwarcl adjustment of the rod $S$ is secured, as and for the purposes herein set forth.

3.- The swiveled crank-hook $m$ and shouldered casting $n$, in combination with the bail $\mathrm{N}$, for the purposes set forth.

o. $235313 .-$ SALEEL H. TAYLOR, KANSAS CITI,

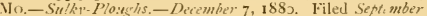
30, 1883 . 
Claim -1,-The combination. with the wheel A, axle B, yoke $\mathrm{C}$, and plough-beam $\mathrm{G}$, of the bars $\mathrm{H}$, provided with the slots $i$, for preventing lateral deviation of the plough, substantially as herein described.

2. - The combination of the bars $H$, provided with the foot-board or cross-bar $\mathbf{K}$, and the axle $\mathbf{B}$ and plough-beam G, for raising the plough from the ground, substantially as herein described.

No. 235,490,-J. W. BARCLAY, ABERDEEN, and ROBERT SEllAir, Huntly, COUNTy of ABerdenn, Scothand.-Combined Ploughs and Diggers.-December 14, I85\%. Filed Aurzest 11, IS80. Patented in England July 24,1876

Claim.-1.-The combination, in a plough, of a share, a segmentary monld-board, and one or more interposed horizontal, or substantially horizontal, blades or tines twisted obliquely to the line of draught, the lower side having a cutting-edge, and the blades or tines separated from each other and from the share and mould-board by intervening spaces, sub-tantially as and for the purpose specified.

2.-In a gang-plongh, a shaft having a crank-axle and carrying-wheel at one end, and a crank-arm, link, and shoe at the opposite end, in combination with a lever for operating the shaft, and a chain and screw-rod for controlling the lever, substantially as and for the purpose specified.

3.-A gang plough having a crank-lever and conveying wheels or shoes for raiting the plonghs out of the furrows, and an independent pivoted guide-wheel, the shaft of whic b has a limited vertical novement in the collar by which it is attached to the frame, substantially as and for the purposes described.

No. 235,767 - W W. HEMIIE, Michigan VAlley, Kivsas,-Sulky-Plousths. - December 21, 1850. Filed Aluzust 7 , i SSo.

(laim.- In a sulky-plough, the combination of the axle A, the lever, $\mathrm{N}$, hinge $\mathrm{O}$, $\mathrm{U}$-shaped holder $\mathrm{P}$, in which the plough-beam $Q$ is clamped by means of the bolts 2 , the supporting-rod $\mathrm{S}$, and hrace $\mathrm{R}$, the $\mathrm{b}$ am being adjustable laterally uron the axle, substantially as shown.

No. 235 , S90.-CHRISTIAN MIERS, SAN FRANCISCO, CAL.-Gans-Ploushs.-December 28, 1880 . Filed October 2, 1850 .

Claim. - I - In combination with the side bars or beams,

A A, cf a plough-rrame, the plate B, having turned-up end ir flanges for securing the beams to it, and having the thimble $\mathrm{C}$, to receive the pin or holt of the draught-pole, substantially as herein described, to operate as st forth.

2.-The $L$-shaped standard $G$, having the fulcrum for the lever $\mathrm{M}$, and the upright har J, having the segment $k$. both inited together, substantially as dercribed, and secured to the side bar or beam, A, of a gang-plough, subtantially as descriled, for the purpuses set forth.

No. 236,146,-CHARLES I. DIC $K$ and MICHAEL WOEIIL, Cokvous, IND,-Pliterhs, Janieary 4, i88t Fil.d Sepiember 20, is8o.

(laim-1,-In a sulky-plough, the combination, with the ver i cal frame B ( I), provided with the short axle $C^{\prime}$, of the forwardly-projecting upwardly-curved arm 1)', having is stort horizontal extension, provided with an upwardly extended and forwardly-curved and perforaterl rack-arm $\mathrm{F}$, short axle $\mathrm{G}$, liaving short vertical arm $\mathrm{H}$, provided with flanges $I^{\prime} I^{\prime}$ at its lower and upper ends, forwardly extended pivoted arm: I, latching-lever $K$, and detent $\mathrm{N}$, the several part, constructed and relatively arranged to oferate substantially in the manner herein shown and described.

2.- In a sulky-plough, the vertical sliding frame $\mathrm{N}$, having the bearings $\mathrm{O}$, the shaft $\mathrm{P}$, carrying loop $\mathrm{P}^{\prime}$, and the pivoted forked arm $\mathrm{T}^{\prime}$, carrying the loop $\mathrm{U}$, in combination with the pivoted latching-lever $S$, vertical arm $R$, horizontal arm $\mathrm{R}^{2}$, stirrup $\mathrm{R}^{3}$, and tongue $\mathrm{V}$, constructed and operating substantially as and for the purposes set forth.

No $236,157-$ ROZANDER S. HIGGiNS, NEOGA, IL, -Sulky-1'lou, hs - January 4, IS8I, Filed October 251880 .

Claim-- I - The combination of hinged arm E, standare $\mathrm{H}$, the furrow-wheel $\mathrm{F}$, and set screw $\mathrm{K}$, as and for the purpose at forth.
2.--The combination, with the hinged arm $\mathrm{E}$ and furrowwheel, of the strap-plate J, having lug $j^{\prime}$, and set-screw $K$, as and for the purpose set forth.

3.-The combination of the vertical bar 11, foot-lever 1 . hinged arm $\mathrm{E}$, furrow-wheel $\mathrm{F}$, and plough-standard, as and for the purpose set forth.

4. - The scraper 1 , having horizontal portion $l$, hinged on the top of the plough-beam $a$, formed with lateral extension $l^{\prime}$, and provided with set-screw $\mathrm{Ml}$, in combination with the furruw-wheel $\mathrm{F}$, as set forth

No, 236,193. - GEORGE S. TAPPAN, PALMYRA, NiBRAsKA. -Sulky. Plonghs.-Janumy 4, I881. Filed fune 21, 1880 .

C'laim,-The combination, in a sulky plough, of the block $\mathrm{D}$, hinged tongue $\mathrm{E}$, frame $\mathrm{A} \mathrm{B} \mathrm{C}$, having bail ' $\mathrm{T}$, hinged frame $\mathrm{L}$, having stem $\mathrm{V}$, lever $\mathrm{Q}$, connectin-rods $\mathrm{S} \mathrm{W}$, and the plough, the beam of which is provided with a transversely-perforated bail or bracket, by which it is pivoted upon the stem $\mathrm{V}$ of the frame $\mathrm{U}$, substantially as and for the purpose herein shown and specified.

No. 236,536.-ROBERT J. BOWMAN. ALEXANDRIA, LA.-Gang-Ploushs, Planters and Cultizators.- Jinuary I I, I881. Filed fuly 9, I830.

Clain.-1,-In a combined gang-plough, planter, and cultivator, the comlination, with the frame $\mathrm{A}$, the ploughbeams $\mathbf{K}$, and the gear-wheels $\mathrm{V}$, of the cross-bean $\mathrm{P}$, the connecting-bars $j$, the pivoted equal-arned levers $h$, and the curved rack-bars 5 , substantially as herin shown and described, whereby the rear ends of the plough-beams will be raised at the same time and by the same movement as the forward ends, as set forth.

2.- In a combined gang-plough, planter, and cultivator, the combination, with the frame $\mathrm{A}$ and the shaft $\mathrm{V}$, that carries the gear-wheels $\mathrm{V}$, of the coiled spring $c$, the sleeve $d$, the pawl $c$, and the rachet-wheel $f$, substantially as herein show an and described, whereby the weight of the beams and their attachments are balanced, and the ploughman relieved from the said weight when adjusting the machine, as set forth.

3.-In a combined gang-plough, plauter, and cultivator, the combination, ith the plougn-beams $K$ and the forwarl crombeam, $\mathrm{N}$, of the right-angled clevis $\mathrm{L}$, the two eyebolts $\mathrm{XI}$, and the grooved or flanged wrshers (), substantially as herein shown and described, whereby the plongh-heams are adjustably and firmly connected with the forward crossbeam, as set forth.

4.- In a combined gang-plough, planter, and cultivator, the comlination with the plongh-beams $k$ and the rear cross-heam, 1', of the plates (1), having aperture, and the wedlye-keys R, sulistantially a herein shown and described, wh rely the plough-beams are connected with the rear cross-be:m adjustably and firmly, as set forth.

5.-In a combined gang-plough, planter and cultivator, the combination, with the connecting-bars $j$ and the rear cross-beam, I', of the clevis $l$, the eyebolt or plate $m$, the fianged or grooved plates or washers $n$, and the wedue. keys $\theta$, sutstantially as herein shown and described, whereby the cross-beam is held from lungitudinal movement, as set forth.

No. 236.574 -FRITZ GIRTANNER, Big StTunE Citr,

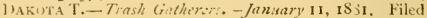
Ausust $31,1: 80$

Claim.-1.-The trash gatherer $\mathrm{X}$, having its upper portion twiste I obli juely to its lodly portion, then outwardly, downwardly, and backwardly, substantially as shown and described.

2.-The plough $\mathrm{W}$, in combination with a trash gatherer fastened to the face of the plough-standard and having it: upper portion twisted toward the mould-board side of the plough, said upper portion being twisted obliquely to the body purtion, which is secured to the forward face of the plough-:tandard, then outwardly, downwardly, and backwardly, st:bstantially as set forth.

No. 236,601,-BENJAMIN F, LITZENBERG, RUs. SELL, IoWA.-Sulky-Ph. us hs.-January II, IS81. Filed June 23,168 ,

C :im.-In a sulky-plough, the frame or side pieces, A A, having four equidistant adjusting-p rforations, B J , E F, in comlination with crose-lar ; , bail $C$, and w hecl-spindles 
I 1, whereby said plougli can be changed to a cultivator, or in locit $\mathrm{n}$; one spindle higher than the uther, or to a right or leit liand plough, without reversing or shifting said side piecen, $\mathrm{A} \mathrm{A}$, in the manner herein shown and described.

No. 236,907. - Cl1ARLES MOWREL, STOCKTON, Cul.-Sialíy. Pious hs.-January 25, 1881. Filed Sepecmb.r 2+. 188 ).

Claim,-1.-The combination of the plough-beam $\mathrm{A}^{\prime}$, the swivel-suppott $D^{\prime}$, secured to the shaft $D$, the sliding support (", sccured to the forward shaft, J, and means for moving the : ame laterally, substantially as set forth.

2. - The combination of the plough-beam $A^{\prime}$, the swivelsupport $\mathrm{D}^{\prime}$, the sliding swivel-suppost $\mathrm{C}^{\prime}$, secured to the sh.it I by plates $a b$, and sleeve $E^{\prime}$, and crank-screw ( ${ }^{\prime}$, sul stantially as described.

3.-The hinged tongu $1 \mathrm{I}^{\prime}$, in combination with lever $\mathrm{N}$, arm $\mathrm{Il}^{\prime}$, wod $\mathrm{L}^{\prime}$, braces $\mathrm{I}^{\prime}$ and $\mathrm{I}^{\prime}$, and a rest for the rear end of the tongue, substantially as described.

4. - The combination of movable frame $A$ and plough l ean $\Lambda^{\prime}$, lever $\mathrm{N}$, shafts $\mathrm{J}$ and $\mathrm{I}$, and connecting-cranks, hingel tongue $\mathrm{H}^{\prime}$, arm $\mathrm{H}^{\prime}$, and rod $L^{\prime}$, substantially as described.

No. 237,oro.-OLIVER E. (OOODELI, BANGOR, Mlich. - Poush-Carriages. - Janu.ry 25, $185 \mathrm{~s}$. Filed April $\mathrm{I}, 1879$.

Claim.- In a plough-carriage, the bail $\mathrm{J}$, reversibly secured within the frame $A$, substantially as described, in combination with the lever $\mathrm{L}$, arm $\mathrm{K}$, and link $\mathrm{N}$, as and for the purposes set forth and shown.

No. 237,765.-THOMAS MEIKLE, Louisville, Kx. -Sidky-Ploustis.-Fehruary 15, 1881. Filed Decembir 6,188 .

Claim.-I.-In a sulky-plough, the combination of the axle $\mathrm{A}$, vertical frame or standard 1 , the double bars $\mathrm{C}^{2} \mathrm{C}^{3}$, wheel 1 , and caster-wheels $G^{\prime} G^{\prime}$ substantially as shown and de-cribed.

2.- The combination of the triangular frame $\mathrm{C} \mathrm{C}^{\prime} \mathrm{C}^{2} \mathrm{C}^{+3}$ having the vertical standard $D$, forming a guide for the plougb-clamp and slide, the bell-crank lever $\mathrm{L}$, link $O$, and plough-beam $\mathrm{P}$, substantially as shown and described.

No. 237,824 - WILLIAM H. CUMMINGS, BOONFSBorotgh, lowa.-Sulky-Ploughs.-Fibruary 15, $188_{1}$ Filed October 23, 1880 .

Claim.-The combination, in a sulky-plough, of a leverframe fulcrumed to the axle and carrying the plough at its lower end and the seat at the other, with the upright pivoted to the foot-supfort and the frame of the machine, and suitable levers and devices for operating the lever-frame, substantially as and for the purposes specified.

No, 237,842,-EDWARL A. EUSTICE, GREENVALF, It.L.-Sulgr-Ploughs.-Febrany 15, ISSI. Filed Octobir 13,1585 .

Claim.-1.-The combination, with the wheel-spindle hav ing the vertical arm $\mathrm{D}$, and the link and lever $\mathrm{H} \mathrm{G}$, of the anguular flanged bar $\mathrm{E}$, its vertical part forming a groove for the spindle-arm, and a rack to secure the wheel in vertical adjustment, and its horizontal part slctted and seated upon axlc B, whereby the axle may be extended, substantially as shown and described.

2.- The combination of the grooved and flanged bar M, bolted to axle, the bars $\mathrm{N}$, having flanges to rest against said bar . I, and slotted extension-plates $O$, bolted to the plongh-beam and forming a slide to lift the beam $\mathrm{P}$, and the bolt Q, all substantially as shown and described. 3.- The plough-standard $c$, having a rear hole to receive bolt $d$, a curved front slot, $e$, the corrugations $f$, the toothed washer $g h$, and the bolt $i$, as and for the purpose described.

No. $235,053 .-S A M U E L$ M. ROBERTSON and $A U$ GUSTUS A. HAMILTUN, LYNNYILle, IOWA-Sulky. Plows

Claim.-In a sulky-plough- the combination of beam 1), frames $\mathrm{C}$, lever $\mathrm{K}$, link $l$, arm $i$, and $\mathrm{U}$-shaped frame J, having bifurcated ends, as shown and described, for attachment to the frames $\mathrm{C}$, as set forth.

No. 238,766 . - HORACE I. DANIELS, REDWoOn Fa1.Ls, MixN.-Suly-Ploushs,-March 15, 1881. Filed June 9,1880 .

Claim.-The lever $b$, of curved form, and pivoted at its center and provided with the foot-rests $x x^{\prime}$, in combination with the plough-beam I, carrying plough I, hail $\mathrm{F}$, and lever $(i$, constructed and operating substantially as and for the pupo ic set forth.

No, 238,8 8.-KNECA (. Sl'OMER()), KiNG'S FIRRY, N. 1:-Sulky. Ploughts, - March 15, 1881. Fild December 2, 1880 .

Claim.-1.-In a sulky-plough, the combination, with a vertically-adjustable bar or plate having the spindle secured thercto, said plate or bar hasing a rack formed on its rear side, of a spring-pressed locking-plate located in horizontal grooves in the the guide-way and adapted to engage the tetth of said rack, a bell-crank lever pivoted at one end to the locking-plate, and a rod attached to the other end of the bell-crank lever and extending forward and adapted to be operated by the foot of the driver, substantially as set forth.

2.- In a sulky-plough, the combination, with a pirotal bracket located over the axle of diverging hangers $M$, secured at one end to the bracket and rigid with the plough beam, and a hanger, $\mathrm{S}$, secured at one end to the plonghbeam and having its opposite end attached to one of the hangers $\mathrm{II}$, and a bell-crauk lever for raising and lowering the plougl, substantially as set forth.

3.-In a sulky-plough, the combination, with the pivotal plate or bracket $\mathbf{N}$, of the cliverging hangers $M$, sccured at one end to said plate or bracket, and at their lower ends rigidlysecured to the plough-beam, a hanger, S, secured at one end to the plough beam and at its upper end to the plate or bracket $\mathrm{N}$, and a bell-crank lever aud chain for raising and lowering the plough, sulstantially as set forth.

No, 238,993-C - HARLEL VAN IUE MARK, HILLSDALE, Micir.-R'iding-Ploughs-March 15, 1881. Filed Siplember 14,1880 .

Claim.-1.-In a riding plough, a centrally-pivoted tilting frame having the 1 ough supported by the rear end, and the driver's seat supported wholly by the forward end thereof, and adajted to tilt independently of the tongue and main frame of the machine, whereby the weight of the driver is utilized to counterbalance and raise the plough, substantially as and for the purpose herein specified.

2.-In combination with the tilting frame G H H I and the plotigh $\mathbf{K}$, stupported by the rear end thereof, the standard $\mathrm{F}$ of the driver's seat, arranged to be adjusted forward and backward on the said tilting frame wbile the pivots of the latter remain substantially in the vertical plane of the axle-support, substantially as and for the purpose hcrein specified.

3 - In combination with the centrally-pivoted tilting frame $G$ H H I, the plough $K$, suspended from the rear end thereof by means of a suspending-lever, L, pivoted to the said frame so as to impat a lateral angular adjustment to the plough, substantialiy as and for the purpose herein specified.

4.-The block or hanger $d$, having the round bearing $c^{\prime}$ and vertically-oblong bearing $t$, for receiving the pivot $t$ ' of the plough-suspending lever $\mathrm{L}$, in combination with the tilting frame, substantially as and for the purpose herein specified.

No. 239,249,-FRANK A. HILL, SAN LEANDRo, CAL.

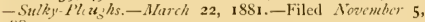
188 3.

Claim.-The axle C, having the arms I) $\mathrm{D}^{\prime}$, and lockinglever 1 , in combination with the bolster $B$, carrying-beams $A A^{\prime}$, and also pivoted on said arms, and with the lever $\mathrm{F}$, bell-crank E, conrecting-link G, and wheel $\mathrm{K}$, all as and for the purpose set forth

No. 239,530.-JOHN A. MORSMAN, Centralia, II.L.-Sitky-Ploushs.-Nurch 29 188I. Filed fonunry 4. $188 \mathrm{I}$.

Claim.-1.-The combination, in a sulky-plough, of the plough-beam, with the frame $A^{\prime}$ and links $C^{\prime}$ for supporting it, the lever $\mathrm{L}^{\prime}$, connecting with said link and fulcrumed upon the nain frame, the link $F^{\prime}$ connecting with the forward end of said lever, which is extended in advance of it' fulcrum, and the counter-balance $\mathrm{M}^{\prime}$, said members being constructed and adapted for operation, substantially as described.

2.-The combination, in a sulky-plough, of the plough. beam, suppoited at a point between its forward end and the ploughshare, with the pivoted lever $1{ }^{\prime}$, fulcrumed upon the 
main frame, a link connecting said lever with the forward end of the plough-beam, a notehed arm, $G^{\prime}$, eonnected with the forward end of the lever by a link, the pawl $k^{\prime}$, for engaging the notehes of said arm, and the counter-balance $M^{\prime}$, all constructed substantially as described.

3.-The combination, in a sulky-plough, of the main Irame with the pivoted lever $S$, the rod or link $\mathbf{V}$, comneeting the rear end of said lever with the plough-lieam, the counter-lialance $\mathbf{M}^{\prime}$ at the forward end of the lever, the notched arm $G^{\prime}$, the lever $D^{\prime}$, carrying a pawl adapted to engage the notehes of said notehed arm, the link $\mathrm{F}^{\prime}$, the forward end of the lever $\mathrm{D}^{\prime}$, with the lever $\mathrm{S}$ and with the notched arm, and a link connecting the lever carrying the pawl with the forward end of the plough-beam, substantially as described.

4.- The combination, in a sulky-plough, of the frame A and the cross-bar $\mathrm{H}$ with the plough-beam $\mathrm{W}$, its support ing-frame $\mathrm{A}^{\prime}$, hung upon the swinging frame $\mathrm{B}^{\prime}$, the rod or link $\mathrm{V}$, the adjustable segment $\mathrm{U}$, pivoted lever $\mathrm{S}$, link $\mathrm{F}^{\prime}$, notehed arm $G^{\prime}$, pivoted lever $D^{\prime}$, carrying a pawl, $K$, the counter-balance $\mathrm{M}^{\prime}$, and the link $\mathrm{C}^{\prime}$, connecting the lever earrying the pawl with the forward end of the plough-heam, said memlers being constructed and organized for operation sulstantially as described.

No. $239,5^{8} 7$ - JOHN IV. WTTT, GRENOIA, KANSAS. -Sulky-Ploughs.-Warch 29, 1881. Filed November 26, Is8o.

Claim,-The combination, with the arched axle B, plough-heam $\mathrm{E}$, and lever $\mathbf{I}$, of an angle-bar, having its vertieal arm attached to the top of the axle, extencling downward parallel to and below said axle, bent twice at right angles and secured to the spindle-arm to form a beamguide, adjustahle to either side for a right or left plough, substantially as deseribed.

No. 240,207.- GORliE H. WARREN, HAMPTON, IowA,_C:amps for Sulky. Ploughs.-April 12, 1881. Filed August 14, 1882.

Claim.-1.-A clamp for securing the plongh-beam to the bail of a sulky-plough, the same consisting of two jaws pro vided with shoulders to form a seat for the beam, the said jaws being slotted at their upper and lower ends, the uppe ends having an adjustable clamping-bolt, and the lower ends adjustable clamping-bloeks and a clamping-bolt, whereby the jaws may be elamped upon the beam and bail, sub stantially as herein specified.

2. - In combination with the clamping-jaws, adapted to embrace the plough-beam and bail, the adjustable clamping blocks, corrugated as described, and the corrugations on the outer faces of the jaws, with the clamping-bolts, by means of which the jaws are elamped to the beam and bail, substan tially as and for the purposes speeified.

No, 247290.-GEORGE II. WARREN, HAMPTON, lowA.-Sulky-Plough Attachments.-April 19, 1881. Filed August 20,1880 .

Claum.-1. - In combination with the foot-lever of a sulkyplough, the angle-lever $\mathrm{I}$, pivoted in a slot in one arm, $\mathrm{K}$ of the same, and provided with bearings at opposite ends, by which it may be operated to lock and unlock the said foot lever, substantially as specified.

2.- The combination, with the foot-rest A, construeted with reesses $\mathrm{C} \mathrm{H}$, the foot-lever $\mathrm{K}$, pivoted therein, and having an angle-clutcling lever $d \mathbf{M I}$, fulerumed in a reces in the upper arm thereol, the other arm being connected with the forward end of a plough-beam by a pitman, L, ar ranged as set forth.

No. 240,925 - HORACE E. REEVES, ForT DODGE, IowA, assignor to GEORGE B. SHERMAN, same place. -Sulky.Ploughs.-Warch 3, 1881. Filed October 19, 1885

Claim,-I.-The combination of the hollow sleeves or casings $\mathrm{B} \mathrm{B}$, the notched plates $\mathrm{F}$, rigilly attached thereto and the double-crank axle $\mathrm{C}$, substantiully as deseribed.

2.-The yoke $\mathrm{H}$, provided with the swivel $\mathrm{G}$, screw-pin $\mathrm{S}$, and tail nut $i$, in combination with the plough-beam $D$, sul?stantially as described.

3. - The combination of the lever $\mathrm{S}$, vertical spring-eateh , jointed straight arm $\mathrm{T}$, eurved arm $\mathrm{U}$, and plough-beam D, sulsstantially as described.

4.- The eomhination of the jointed bar or arm $T$, lever $S$, curved arm $\mathrm{U}$, and break-pins $f$ and $t^{\prime}$, whereby, in meeting an obtruction, the plough and bzam are made free to rise clear from the ground, and, if necessary, as high as the driver's seat.

5.-The combination of lever $\mathrm{S}$, arm $\mathrm{T}$, curved arm $\mathrm{U}$, clamp V, and plough-beam D, substantially as descrilsed.

6.-The combination of the yoke $\mathrm{H}$, supporting-frame $\mathrm{L}$ II N N, and sleeves $\mathrm{B}$ B', the latter provided with the bosses $p p$, to which the rear end of the supporting-frams in secured.

No, 241,103.-HENRY IVEBER, IR., GRand MEanow, Minx.-Plough-Sulkies.-May 3, 1S81. Filed February 19, 1881 .

Clain. - 1. - The combination, with axle, seat, and arms $\mathrm{M}$, of the brace $\mathrm{G}$, provided with a bearing for said axle, ant the collar $\mathrm{H}$, provided with a projection, I, as and for the purpose specified.

2.-In a plough-sulky, the combination, with the axle I), the tongue-braee $\mathrm{G}$, and the driver's seat, $\mathrm{K}$ of the arms $\mathrm{M}$, the hinged rods $\mathrm{L}$, and the inclined bar $\mathrm{O}$, substantially as hercin shown and described, whereby the driver's weight is made to balanee the weight of the plough, as sut forth.

3. - In a plough-sulky, the combination, with the lever U, the axle 1 , and the crank-axle $\mathrm{C}$, of the arm $\mathrm{Y}$, substantially as herein shown and described, wherel,y the er $a n k$-axle $C$ is locked in place when both cranks are in vertical po.itions, as set forth.

No. 241,848.-REUBEN ELLIWOUD, SYCAMORF, ILL. -Sulky-Pioitghs. - May 24, 1881. - Filed January 10, 18 ○.

Claim.-1.-In a sulky-plough, the arehed Irame C, prosicled with the forwardly-projecting extensions $\mathrm{C}^{\prime}$, and carry ing a crant, from which the plough-beam is suspended, in combination with the connection for the forward end of the plough-beam, formed by passing the eross-rod through the elevis and connecting its ends to the forward extensions of the arehed frame, substantially as deseribed, whereby when the plough is loeked the forward eonneetion beeomes rigid, substantially as descrilied.

2.-In comlination with the plongh-crank and ploughbeam, the soeket $g$, arranged on the crank, and provided with the rearward extension $s^{\prime}$ and the stirrup $h$, pivcted at its ends to the rearward extension $r^{\prime}$ and to the plotgh beam respectively, substantially as describerl, whereby the ploughbeam ean swing vertically and forwardly and rearwardly, as set forth.

No, 242,320.-FRANK A. HILL, SAN LEANDRO, CAL. -Side-Hill Plousts, - May $3 \mathbf{1}$, is8i. Filed Octeter is, isso.

Claim,-1. - In eombination, the b=2ms B B', cross-pieces $a b$, eonnccted to the tongue, the whole forming the frame which support the ploughs, sairl frame bing pioted to the straight axle $\mathrm{A}$ on one side and moving in guide $f$ on the other side, the $\operatorname{rod} k$, and the hand-lever, substantially as deseribed.

2.- In eombination with the plongh-share having the inclined reeess $s$ and projection $p$, the detached portion $m$, with curresponding recess $o$ and projection $n$, and the fatening-bolts.

No, 242,431.-JOHN CATTON, WEST JERSEY, I1.1.Plough-Tiu-ks.-June 7, 18si. Filed Dicimber 2, isso. Claim.-A sulky-plough provided with an adjuntable plate $\mathrm{C}$, provicled with soeket; $\mathrm{E} \mathrm{E}$, in combination with segment s G, attached to the plate C, and laterally-arljustrlble erank axles F F, provided with levers $H$, and bolts or stops $\mathbf{I}$, working upon said segments, substantially as and for the purpose specified.

No. 2424 9.-HENRY E. TRUMBLE, KAIAMAZOo, MICH., asignor of one half to $G$. EDWIN DUNBAR, same plaee.-Riding Sulkies for Pli usilis-Jun: 7, 1881. Filed Ausust 10, 1880.

Claim,-1-The frame with its perpendicular and oh liquely-angled loops, and the recesses or ways, the lever having the obliquely-angled slotted extension, and its ratehut secured to the side of the forward loop of the frame, the bail-rod haviug its ends loosely loented in said ways of the frame and slots of the angled extension of saicl lever, the hail having the rear plough clamp or holter locat cd thereon, 
all in combination, substantially as tescribed and shown, for the objects set forth.

2--The bail-bar supporting the rear clamp, the encls of aid bail located loth in the ways of the loopecl frame and the slot of the angled extension of the lever, the lever having the honk-rod and adjusting-chain, saicl chain connectung with the bail near where the clamp is located all in combination substantially as described.

3.-In a jiling-sulky for ploughs, the frame having the ways or recess shown, the nut with it- eye or loop end adjustably localed in said way and supporting and securing together the clutch-joint, and also adjustably rotaining in its eye the angled extension of the wheel axle, all constructed and combined substantially as specified and shown, for the object set forth.

4. - In a sulky-plongh, the bail-bar having either end loosely located both in the ways of the looped frame and in the slot of the lifting-lever, all substantially as described and shown.

No. 243.125.-CHARLES A. HAGUE, CHCAgn, lLI., as-irnor to FitRs \& BRADLEY M IANUFACTURING COMPANY, same place.-Sulky-Pli usths,-June 21, IS31. Fiteci Octo ber 13,1579 .

Claim. - I. - In a sulky-plough having a frame or arch, 13, mounted on wheels and a single indepentent crank or bail, $A$, carrying a plough-beam, $G$, and a plough, a pivoted comnection for the plough-bean to the crank, which will carry the beam in the arc of a circle on a line passing through or near the centre of the axial supports for the frame or arch, substantially as described.

2.-In a sulky-plough, the frame or arch $\mathrm{B}$, horizontal supports or arms $\mathrm{C}$, and crank or bail $\Lambda$, carrying the plough-loam $G$, in combination with the lever $K$, directly attaclied to one end of the crank or bail, substantially as specified.

3.- In a sulky-plough, the combination of the arch or frame mounted on wheels, the tongue rigilly connected with the arch or frame, the crank having a connection with the plough.beam which carries the plough in the arc of a circle on a line passing through or near the centre of the axial supports, the rack rigidly attached to one side of the tongue, and a hand-lever rigidly attached to the crank and arranged to engage the rack, all substantially as described, for the purpose sct forth.

No. 243,140.-JOHN L. LAUGHLIN, RAciNe, Wis, - Wheel-Pioushs.-June 21, 1881. Filed April 7, 1880

Claim.-1.-The arm $a^{\prime \prime \prime}$, journaled on the cnd of the axle $\mathrm{A}$, and carrying the wheel $\mathrm{B}^{\prime}$ at its lower end and lever $\mathrm{C}$ at its upper end, in combination with the axle $A$ and plough and yoke $\mathrm{F}$, which is journaled to the axle and connected with the arm $a^{\prime \prime \prime}$ by a link, L, substantially as and for the purpose specified.

2.- In combination with the axle $\mathrm{A}$ and yoke $\mathrm{F}$, hinget to the axle, and to which the plough is attached, the arm $a^{\prime \prime \prime}$, journaled on the axle A, and the lever M, provided with a $\log , m^{\prime}$, adapted to engage with the notched bub of the wheel $B^{\prime}$, and thereby oscillate the arm $a^{\prime \prime \prime}$ and yoke $\mathrm{F}$, which is connected therewith by a link, $\mathrm{L}$, and raise the plough by the draught of the team, substantially as and for the purpose specified.

3.- In combination with the arm $a^{\prime \prime \prime}$, journaled on the end of the axle $\mathrm{A}$, the levers $\mathrm{C}$ and $\mathrm{M}$, connected by a slotted arm, $c$, substantially as described, and for the purpose specified.

4.- In combination with the arm $a^{\prime \prime \prime}$, journaled on the axle $\Lambda$, and levers $C$ and $M$, which may be uscillated together, and are adapted to raise the ploughs by the draught of the team, the rack-bar $k$, having a cam-projection k'", on its front end, substantially as and for the purpose set forth.

5-In a wheel or sulky-plough, the combination of the arched axle $A$, having a slot $f^{\prime \prime}$, in one of its vertical sides, the yoke $F$, journaled at one end to the vertical sile part of the axle and its other end seated in the slot $f^{\prime \prime}$ in the axle, link $j$, arm J, rock-shaft $H$, and lever $H^{\prime}$, substantially as and for the purpose herein shown and described.

No. 243.236. - SAM. T. FERGUSON, MINNEAPOL1S, Mixx.-Sulky. Ploughs.-June 21, 1981.-Filed Mur.h 5 , 1851 .
Claim.-1.-The combination, with the plough, the laail (C) having upwardly-extended and slottud arm $\mathrm{F}$, and the link of the haxl-lever, of a serew-stem, $(i$, projecting upwarlly through the said arm into range of reach from the driver's seat, and a wut comnected to the link and surrounding sail screw, substantially as shown and described.

2,- The combination, with the link $\mathrm{E}$ and the hand-lever $\mathrm{D}$, of the foot-lever 11 and a separate link, $d$, connecting the foot-lever to the link of the hand-lever, and extending abswe the fulcrum of the hand-lever, as shown and described.

No. $243,242$. -ALGUSTUS J. GidLl, AliLon, Mich. -Sulky-Ploughth.-Jun: 21, ISSI. Filed February 17, 1881

Claim.-In combination with the frame A, pivoted bail D, and hanger $\mathrm{E}$, having arms $a$, to which the levers $\mathrm{F} \mathrm{G}$ are pivoted, the pivoted lever $F$, connected at one end with the bail $\mathrm{D}$, and having at its other end a roller working in the curved slot $d$ of the lever $\mathrm{G}$, substantially as and for the purpose described.

No. 243,676 . - THOMAS E. JEFFERSON, BOSTON, MAss. - Sulky-Ploughs.-June 28, 1881. - Filed May 21, $188 \mathrm{I}$

Claim.-1,-The main frame, constructed, preferably, of metal, having the extension $a a$ and the shorter extension $a^{2}$ $a^{2}$, united to the firt by the paut $a^{\prime}$, and having also the front projecting bar, to which the tongue of the machine is adapted to be attached, substantially as clescribed.

2. - The combination, with the main frame, of the rotary axle, having its bearings in the lower end of the extension $a$ $a$ and in the inner part of the extension $a^{2} a^{2}$, the fixed axle, secured to the outer part of the extension $a^{2} a^{2}$, and the supporting whcels, one secured to the rotating axle and the other mounted loosely upon the fixed axle, substantially as described.

3.-The means for suspending the plough, consisting of the short curved arm adapted to be secured to the suspending shaft, and having side flanges, the link articulated to the flanges of the said curved arm and adapted to work between the same, and one or more other links for forming the connection botween the first link and the plough, substantially as described.

4 -The combination of the suspending cross-shaft, the flanged curved arm secured thereto, the links forming the connection between the arm and the plough, with the plough and means for rotating the shaft, whereby, when the shaft is rotated, the point of suspension of the plough is gradually removed farther from the axis of the shaft, so as, to cause the plou,h to be raised out of the soil slowly at first, but faster as the lifting operation proceeds, substantially as described.

5.- The combination, with the suspending cross-shaft, of the curved arm having an opening through it for the accommodation of the shaft larger than the diameter of the latter and the bolt for holding the arm on the shaft, whereby the arm is allowed to tilt to permit the plough to swing laterally slightly in either direction, subtantiaily as described.

6.-The combination of the cross-shaft, the plough sins pended therefrom by a flexible connection, with meaus for driving said sbaft from the rotating axle, so as to raise the plough by the power of the team, substantially as described.

7.-The combination of the cruss-shaft, the plough-suspending devices, and the plough with the fixed pulley on the cross-shaft, the loose pulley on the rotating-axle, the endless chain, and means for throwing the loose pulley into and out of engagement at will with a clutch on the rotating axle, sub:tantially as described.

8 . - The combination, with the pulley on the end of the plough-suspending shaft, of the lever $\mathrm{D}$, having the laterallyprojecting pin, the spring for bearing against snid pin to force the lever outward, and the stationary shouldered locking plate, with which said lever automatically engages when the plough is raisecl, substantially as described.

9.-The combination, withe loose pulley on the revolving axle, of the ctop on the frame, adapted to automatically engage with the stud on the pulley when the plough is lifted to its highest point, so as to throw the said pulley out of engagement with the clutch on the revolving axle, substantially as described.

rc.- The comlination, with the fixed pulley on the sus- 
pending cross-shaft and the loose pulley on the revolving axle, and their connecting-chain, of means, substantially as described, for automatically disengaging the loose pulley from the revolving clutch when the plough is elevated, and other means, substantially as described, for automatically locking the cross-shaft from backward rotation at the time when or immediately after such disengagement of the loose pulley takes place.

II.-The combination, with the main frame and a plough flexibly suspended therefrom so as to be capable of vertical movement, of a rocking frame pivoted to or hung upon the main frame, and having chains or their equivalents extending to the standard of the plough and to the plough-beam, substantially as shown, whereby, when the plough meets an obstruction, its point is automatically caused to rise and its rear portion to descend so as to clear the same, substantially as described.

I 2, - The combination, with the main frame and a plough suspended therefrom so as to be capable of a slight lateral movement, of a rocking frame pivoted to or hung upon the main frame, and having chains or their equivalents extending to the plough-standarel and to the plough-beam, substantially as shown, whereby the plough is caused to automatically pass around an obstacle without throwing the main frame and wheels out of their course, and to be afterward brought back again into normal position, substantially as described.

13. - The combination, with the main frame and a plough suspended therefrom so as to be capable of both a vertical and a lateral movement, of the rocking frame and the chains connecting it to the plough, substantially as described.

14.- The main frame of the machine and the plough suspended therefrom, in combination with the revolving axle, arranged to receive the side draft or side thrust of the machine upon it inner end, at or near the center of the macline substantially as described.

15.-In a sulky-plough, the combination of a main frame, a plough suspended therefrom and adapted to be raised by power derived from the team, with one or more of the supporting-wheels, having a peripheral flange or flanges thereon, and adapted to resist the side pressure of the plough, and thus increase the traction or lifting-power of said wheels, substantially as described.

I6.- The combination, with a plough, of a coulter consisting of a concavo-convex disk arranged on a substantially horizontal axis obliquely to the line of draft, and adapted to automatically yield readily to rocks or other obstructions with which it comes in contact, substantially as described.

17. - The combination of the concavo-convex blade of the coulter with the inclined arm in which the blade is mount ed, the vertical arm to which the inclined arm is articulated, the horizontal arm above the plough-beam, the stationary metal straps, and the nuts and bolts, or their equivalent;, for adjusting the blade to the desired angle with respect to the line of draft, substantially as described.

18,--The combination, with the plough, of one or more revolving disks arranged at the rear of the mould-board, and having openings through them to permit of the passage of the soil for the purpose of securing more thorough pulverization of the latter, and also to render said disks self-cleaning, substantially as described.

19.-The combination, suhstantially as described, of the mould-board of the plough, the plate $\mathrm{R}$, having the loop or socket, and the part $P$, carrying the disk or disks, and rendered adjustable in and out and forward and backward by means of the adjusting-bolts, substantially as described.

20.- The plate $\mathrm{R}$, having the loop or socket, and baving segmental slots and bolts, whereby to adjust it so as to cause the part $\mathrm{P}$ and its disks to be moved up or down, substantially as described.

21. - The combination, with a main frame and a plough suspended therefrom, of a series of oblique rotary disks placed directly opposite the mould-bosrd and upon the ploughed furrows, for dividing and harrowing the turneo soil, and for the further purpose of resisting the tendancy of the side thrust of the plough to twist around the frame and tongue and exert a side pressure upon the team, substantially as described.

22. - The combination, with the main frame, the plough suspended therefrom, and the supporting-wheels, one of which has a peripheral flange. of a series of obli puelypositioned rotary disks arranged abreast the plougli, and operating in connection with the flanged wheel to opl ose in direct line the side pressure of the plough, substantially as described.

23.-The oblique harrowing-disks mounted in arns which are hung upon diagonal axes, substantially as described.

24. - The oblique harrowing-disks mounted in arms hung upon diagonal axes and kejt down to their work by means of springs or their equivalent, substantially as described.

25.- The combination of the heads $\mathrm{V} \mathrm{V}$, clampad to their shaft, and having tars $v^{\prime} v^{\prime}$, and guide-loops $v^{\text {if }}$, with the arms $\tau^{2}$, curved arm $v^{3}$, and springs $v^{7}$, substantially as described.

26. - In a sulky-plough, the combination, with the series of obliquely-arranged harrowing-disks, of the $10: k \cdot$ shaft mounted in the extension of the main frame, and upon which the supports of said disks are mounted, and the hand-lever projecting within reach of the driver from his seat, whereby the said series of disks are adapted to loe raised or lowered at will, substantially as described.

27. - The combination, with the main frame and its supporting-wheels, of the suspended plough having the har rowing-disks 0 at the rear of its mould-board for harrowing the soil as it is being lurned to prepare it for the reception of the seed, the seed and furtilizer-sewing derices mounted upon the frame botween the plough and the supportingwheel on the furrow side, and deriving motion from the rotating axle, and the series of obli jue harrowing-rlisks for further harrowing the soil and covering the seed, all arranged and opernted substantially as dencribed.

28. - The combination, with the main frame of the machine, the plough, and the oblique harrowiny-disks, of seed and fettilizer sowing mechanisms arran'red upon the main frame, and the levers $x^{\prime} x^{3}$, under the control of the driver from his seat, for throwing into or out of operation at will either or both of said mechanisms, substantially as described.

29. - In a wheeled plough, the combination of a main frame and supporting-wheels, a plough suspended from the main frame by a flexible connection, and chains or their equivalent for connectias the bean of the plough directly or indirectly to said main frame, as described, whereby, by the application of the draught to the plough-leam, the proper position of the plough in the ground is automatically preserved, sulsstantially as dencribed.

30. - The gear-whecl $r^{4}$, mounted loosely upon the hul of the fixed disk $i^{5}$, and having a segmental slot, in combimation with the lateral fin or stud on the sai.l disk, and the spring $y^{3}$, for the purpose of preventing breakage of the teeth of the gears when thrown into engagement while the machine is running, sulsiantially as described.

No. 213,570. -THOUA I E. JEFFER T.N, B:SiTON,

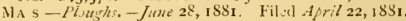

Claim.-1.-A mould-board having its rear portion cut away, as slown, to exteml the length or curvature of the mould-board and more efficiently invert the furrow with the same or less amount of metal, forming fingers, which also serve to pulverize or di-integrate the furrow with approx imately the same draft-power, as specified.

2.-A cut-away mould-board having holding-sockets and set-screws, or their equivalents, combined with cutting. knives secured thereto at any desired point of extension, and adapted to serve the double purpose of extending the curvature of the mould-board, to insure the turning of the furrow, and to cut the tenacious soil or sod, as specified.

3.-A cut-away motld-board having holding means, and provided with independent teeth of concavo-convex form in transverse section, and each adjustably secured thercto by a set-screw or the like, as and for the purposes set forth.

4.-The coulter-plough $\mathrm{H}$, having continuous cutting. edge $h h^{\prime}$ and arms $h^{2}$, combined with the sockets $h^{3}$ and set-screws $/ h^{4}$, said sockets and screw's upon the landside in rear of the line of travel, as shown and set forth.

5.- The ploughshare $\mathrm{A}^{\prime}$, cut away upon its forwar surface at $a^{\prime}$ in combination with the jointer 11, provided with dovetailed flange $h^{6}$, as and for the purposes specified. 


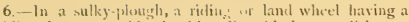
holdingtharife, conbined with aclju-table harrow-disks, as and for the purpones set forth.

7.-1 sulky for ploughs having a single idling-wheel upon the land-side and liarrow disks upon the furrow-side, s.id disks being capable of leing converted into transporting-whecls at will, as herein specitied.

8. - In a sulky-plough the harrow-disks operated antomatically $t$ serve as pulverizers or transporting means as the plotgh is in or out of service, as specitied.

9.-A sulky-plough in combination with harrow disks operated automatically to serve together in action, said disks serving as bearing-wheels when not in service, combined with operating means, substantially as set forth.

to.- The combination of the plough $\mathrm{A} \mathrm{A}^{\prime}$ and harrow disks $d^{4} d^{s}$ with the crank-lever ( $\left({ }^{\prime 2}\right.$, lever $\mathrm{D}$, roch-shaft $\mathrm{D}^{\prime}$, and bevel-gears, or equivalent means, for simultaneously placing the disks and plough in and out of operation, as set forth.

I1 - In a sulky-plough, the loose loop 13 , combined with the elbow-crank lever $\vec{C}$, spring-rod $f f^{\prime}$, and rack-bar $\mathrm{E} \mathrm{E}^{\prime}$, and plough-beam $\mathrm{A}$, as and for the purposes set forth.

1 2. - In a sulky-plough, the combination of the wheel and plough-beam with the springs $c^{\prime} e^{\prime}$, or their equivalents, upon the rol $\mathrm{E}$, acting with $\mathrm{a}$ constant force in reverse directions to allow either the plough or wheel to ride over obstructions without disturbing the other or affecting the line of travel, as specified.

13. - In a sulky-plough, the combination of the beam A and wheel with the bail $B$ and the springs $b \quad b$, or their equivalent;, acting in reveric horsontal directiuns ts allow lateral play to the bum without disturling the line of travel or affecting the wheel as the plough pasies ob truction, as set forth.

14. - In a sulky-plough, the combination of the be:m A, wheel $\mathrm{X}, r$, bail $\mathrm{B}$, and rod $\mathrm{E}$ with the springs $e^{\prime}$ h, or their equivalent; as and for the purposes set forth.

15.-The vertical rateheted ro.l i, having collars i, combined with the frame C', the plough, the ciorriare, and the duplex springs, and with the mean for regulatins the depth of the furrow, as specified.

16.- The combination of the draft-bar $\mathrm{N}$, or its equivalent, having suitable draft attachment, with the plough and the sulky-frame, by means of which construct.ou the plough is forced into the soil by reason of the draft, as specitied.

17.-The combination of the braces $m$, connecting the draft mechanism M $o$ and the plough-beam, with the sulkyframe, whereby a vertical parallel relation between the said part $m$ and frame is alway's maintained, and the draft exert a constant influence, both up and down, to hold the plough in its most operative position, as herein specified.

I8.- In a sulky-plough, the combination of the harrow disks $d^{n}$ with the pulverizing-fingers upon the mould-board, each being so inclined from the plane of the line of travel that the side pressure of either will approximately counteract the opprosite side pressure of the other, as herein specilied.

19. - A revolving coulter swiveled to a frame or beam and held in contact with the soil by the constant force of a spring, in combination with the plough-beam, wherely lateral and vertical play i. afforeded to the coulter, sub-tan tially as and for the purposes set forth.

20. - In a ploughshare, the clovetailed spaces 2 , lip-spaces $\mathbf{I}$, and arms.3, combined with an intermediate point having correymonding connection, and the whole adapted to serve as and for the purposes set forth.

2I. - The share $A^{\prime}$, having spaces 12 and arms 3 , dovetailed or otherwise, combined with an intermediate point 4 and a toe-point, 7, and with connecting devices 5, 6, 8, 9, 10 , and 11 , and holking means 12 , as and for the purpose's set forth.

22.- In a plough, a revolving coulter, swiveled or jointed to the plough by compound joints, and provided with a spring, in combination with the plongli-heam, whereby the coulter will accommodate itself to the sweep of the plough in turning without wrenching the coulter while in the ground, and will be held in constant contact with the soil by the force of the spring, as specified.

23.-A lever, $\mathrm{D}$, and connections $\mathrm{D}^{\prime} d^{\prime \prime} d^{\prime}$, combined with lever $C^{4}$, and harrow-disks $d^{4}$, and adapted to throw said disks into service as harrows or transporting means at will, as and for the purposes set forth.

24. - The toe-point 7, having cut-away portions 8 and 10, and am 9, with beveled edges, combined with a share or intermediate point having corresponding recess, substantially as shown and set forth.

25.-The toe-point 7 , having cut-away portions 8 ro and beveled arm 9, combined with the share $A^{\prime}$ or point 4 , and with lateral set-screw $\mathbf{1 7}$, operating through loop or fugs I $\mathbf{I}$, as and for the purposes set forth.

26. - The combination of the frame $\mathrm{C}$ with the bail or loop $\mathrm{B}$, suspended therefrom, and side springs, b, or their equivalents, and with the beam $\mathrm{A}$, as and for the purposes set forth.

27. - In a plough, a mosld-board having sockets or other holding devices at its rear end, in combination with adjusta. ble and removable extensions, as $14 \mathrm{~V}$, and susceptibte of being elongated, contracted, or removed to insure the inversion of the furrow, whatever the depth, as specified

28. - The revolving coulter, combined with the beam, and attached thereto by a compound swivel, as shown in Fig. 5, and for the purposes set forth.

29.- In a sulky-plough, the bearing-wheel $\mathrm{X}$, having flange $x$, aclapted to serve as a coulter to the furrow being turned, as a means for resisting side pressure, and as a riding means, as shown in Fig. 25, and also adapted to serve as a marker and coulter for the succeeding furrow, a ricting means, and a weans for resinting side pressure while traversing the land, as shown in Fig. 24 , substantially as herein set forth.

30. - In combination with the plougli-beam, the revolving coulter, attached thereto by the compound swivel-joints $a^{\prime} i z^{2}$, and provided with a spring or springs, substantially as shown and described.

31.-The combination of the draft mechanism, the rod $\mathrm{E}$, and springs with the beam A, whereby both the springs and draft serve to hold the plough in its most effective position by a constant force, and to return it thereto after divplacement, as specified. 

. 

. 



1 
